\title{
The HayWired Earthquake Scenario—Engineering Implications
}

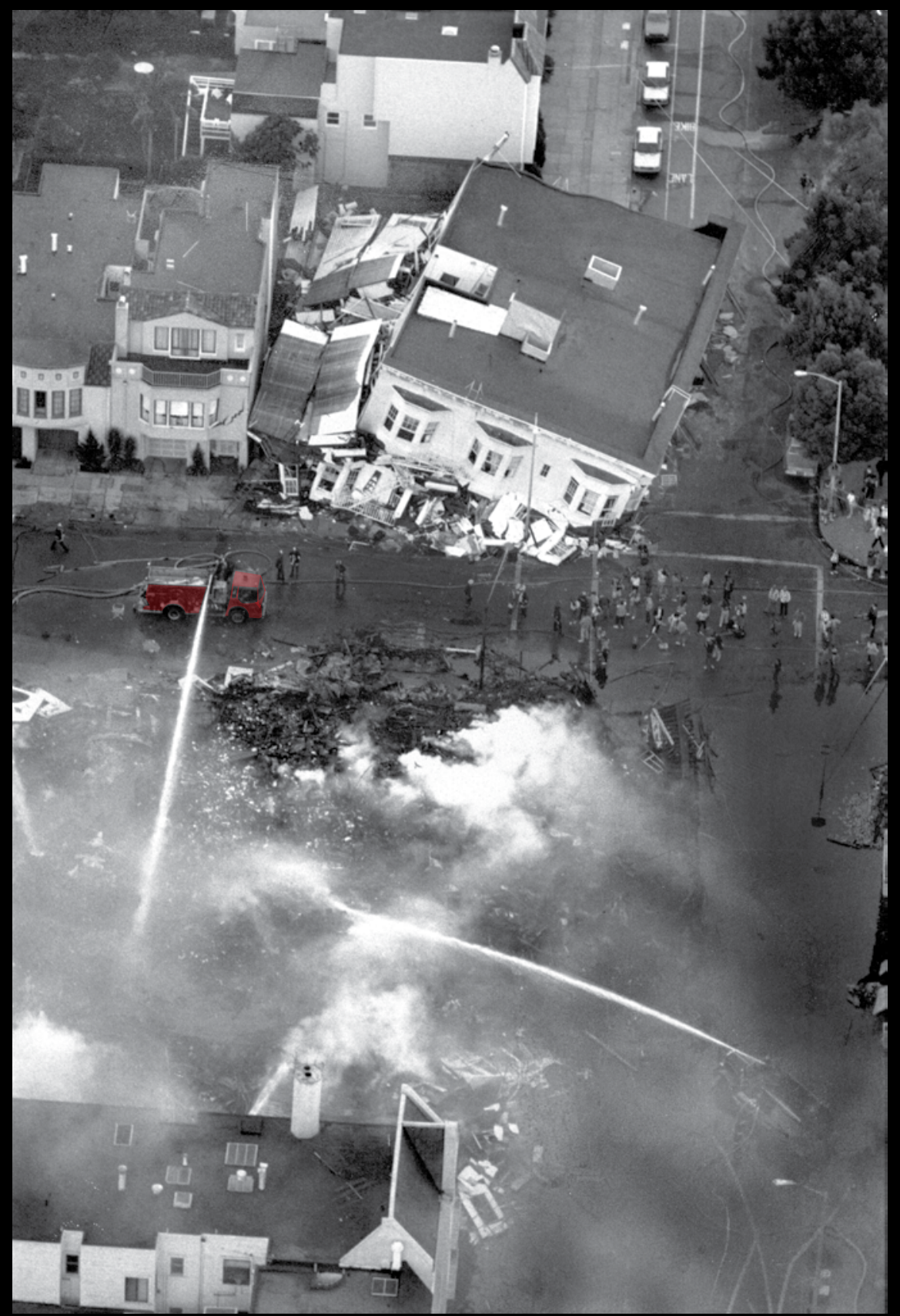

Scientific Investigations Report 2017-5013-I-0

Version 1.1, April 2022

U.S. Department of the Interior

U.S. Geological Survey 
Cover. This oblique aerial photograph captures a moment during which San Francisco, California, firefighters are extinguishing a fire that occurred shortly after an apartment building collapsed and burned to the ground as a result of the moment-magnitude-6.9 Loma Prieta earthquake of 1989. Another apartment building across the street has fallen into the intersection of Beach and Divisadero Streets, bursting out the walls of the weak first story as the structure buckled and collapsed. The damage (building collapses, damage to gas pipelines and other utilities, and fire) in the city's Marina District shown here was caused by amplified ground shaking and liquefaction (soils becoming liquid-like during shaking).

Since 1989, these and five other collapsed buildings in San Francisco's Marina District have been replaced or rebuilt, other buildings' soft first stories have been braced and strengthened, and flexible-conduit gas lines have replaced old, brittle rigid gas lines throughout the neighborhood. Such risk-reduction measures, intended to prevent building collapse and to curtail fire following earthquake, have not yet been taken in many other areas surrounding San Francisco Bay that have been identified as being susceptible to liquefaction. (Photograph copyright Deanne Fitzmaurice/San Francisco Chronicle/Polaris, used with permission.) 


\section{The HayWired Earthquake Scenario- Engineering Implications}

Edited by Shane T. Detweiler and Anne M. Wein

Scientific Investigations Report 2017-5013-I-0

Version 1.1, April 2022 


\title{
U.S. Department of the Interior RYAN K. ZINKE, Secretary
}

\section{U.S. Geological Survey William H. Werkheiser, Deputy Director exercising the authority of the Director}

\author{
U.S. Geological Survey, Reston, Virginia \\ First release: 2018 \\ Revised: April 2022 (ver. 1.1)
}

For more information on the USGS - the Federal source for science about the Earth, its natural and living resources, natural hazards, and the environment-visit https://www.usgs.gov or call 1-888-ASK-USGS (1-888-275-8747).

For an overview of USGS information products, including maps, imagery, and publications, visit https://store.usgs.gov.

Any use of trade, firm, or product names is for descriptive purposes only and does not imply endorsement by the U.S. Government.

Although this information product, for the most part, is in the public domain, it also may contain copyrighted materials as noted in the text. Permission to reproduce copyrighted items must be secured from the copyright owner. 


\section{Foreword}

The 1906 Great San Francisco earthquake (magnitude 7.8) and the 1989 Loma Prieta earthquake (magnitude 6.9) each motivated residents of the San Francisco Bay region to build countermeasures to earthquakes into the fabric of the region. Since Loma Prieta, bay-region communities, governments, and utilities have invested tens of billions of dollars in seismic upgrades and retrofits and replacements of older buildings and infrastructure. Innovation and state-of-the-art engineering, informed by science, including novel seismic-hazard assessments, have been applied to the challenge of increasing seismic resilience throughout the bay region. However, as long as people live and work in seismically vulnerable buildings or rely on seismically vulnerable transportation and utilities, more work remains to be done.

With that in mind, the U.S. Geological Survey (USGS) and its partners developed the HayWired scenario as a tool to enable further actions that can change the outcome when the next major earthquake strikes. By illuminating the likely impacts to the present-day built environment, well-constructed scenarios can and have spurred officials and citizens to take steps that change the outcomes the scenario describes, whether used to guide more realistic response and recovery exercises or to launch mitigation measures that will reduce future risk.

The HayWired scenario is the latest in a series of like-minded efforts to bring a special focus onto potential impacts when the Hayward Fault again ruptures through the east side of the San Francisco Bay region as it last did in 1868. Cities in the east bay along the Richmond, Oakland, and Fremont corridor would be hit hardest by earthquake ground shaking, surface fault rupture, aftershocks, and fault afterslip, but the impacts would reach throughout the bay region and far beyond. The HayWired scenario name reflects our increased reliance on the Internet and telecommunications and also alludes to the interconnectedness of infrastructure, society, and our economy. How would this earthquake scenario, striking close to Silicon Valley, impact our interconnected world in ways and at a scale we have not experienced in any previous domestic earthquake?

The area of present-day Contra Costa, Alameda, and Santa Clara Counties contended with a magnitude-6.8 earthquake in 1868 on the Hayward Fault. Although sparsely populated then, about 30 people were killed and extensive property damage resulted. The question of what an earthquake like that would do today has been examined before and is now revisited in the HayWired scenario. Scientists have documented a series of prehistoric earthquakes on the Hayward Fault and are confident that the threat of a future earthquake, like that modeled in the HayWired scenario, is real and could happen at any time. The team assembled to build this scenario has brought innovative new approaches to examining the natural hazards, impacts, and consequences of such an event. Such an earthquake would also be accompanied by widespread liquefaction and landslides, which are treated in greater detail than ever before. The team also considers how the now prototype ShakeAlert earthquake early warning system could provide useful public alerts and automatic actions.

Scientific Investigations Report 2017-5013 and accompanying data releases are the products of an effort led by the USGS, but this body of work was created through the combined efforts of a large team including partners who have come together to form the HayWired Coalition (see chapter A). Use of the HayWired scenario has already begun. More than a full year of intensive partner engagement, beginning in April 2017, is being directed toward producing the most in-depth look ever at the impacts and consequences of a large earthquake on the Hayward Fault. With the HayWired scenario, our hope is to encourage and support the active ongoing engagement of the entire community of the San Francisco Bay region by providing the scientific, engineering, and economic and social science inputs for use in exercises and planning well into the future.

\section{David Applegate}

Associate Director for Natural Hazards, exercising the authority of the Deputy Director U.S. Geological Survey 



\section{HayWired Review Panel}

The HayWired Review Panel, a group whose expertise spans the scope of the HayWired scenario, assessed the overarching goals of the project along with the scientific approach and oversaw the reviews of each individual chapter in this volume. The panel consisted of Jack Boatwright (U.S. Geological Survey, USGS), Arrietta Chakos (Urban Resilience Strategies), Mary Comerio (University of California, Berkeley), Douglas Dreger (University of California, Berkeley), Erol Kalkan (USGS), Roberts McMullin (East Bay Municipal Utility District), Andrew Michael (chair, USGS), David Schwartz (USGS), and Mary Lou Zoback (Build Change, Stanford University).

\section{HayWired Coalition Partners}

\author{
Alameda County Mayors' Conference \\ Alameda County Sheriff's Office, Office of Emergency Services \\ American Red Cross \\ Art Center College of Design \\ ARUP-Design and Engineering Consultants \\ Association of Bay Area Governments-Metropolitan \\ Transportation Commission \\ Aurecon \\ Bay Area Center for Regional Disaster Resilience \\ Bay Area Council \\ Bay Area Rapid Transit Authority \\ Bay Area Urban Area Security Initiative \\ Bay Planning Coalition \\ Boston University \\ Business Recovery Managers Association \\ California Business, Consumer Services, and Housing Agency \\ California Department of Public Health \\ California Department of Transportation \\ California Earthquake Authority \\ California Earthquake Clearinghouse \\ California Geological Survey \\ California Governor's Office of Business and \\ Economic Development \\ California Governor's Office of Emergency Services \\ California Independent Oil Marketers Association \\ California ISO \\ California Public Utilities Commission \\ California Resiliency Alliance \\ California Seismic Safety Commission \\ Carnegie Melon University Silicon Valley \\ City and County of San Francisco \\ City of Berkeley \\ City of Fremont \\ City of Hayward \\ City of Oakland
}

City of Oakland, Fire Department

City of San Francisco, Department of Emergency

Management

City of Walnut Creek

Contra Costa County Mayors' Conference

Earthquake Country Alliance

Earthquake Engineering Research Institute

East Bay Municipal Utility District

Federal Emergency Management Agency

Joint Venture Silicon Valley

Laurie Johnson Consulting|Research

March Studios

Marin Economic Consulting

MMI Engineering

Office of the Mayor, City and County of San Francisco

Pacific Earthquake Engineering Research Center

Pacific Gas and Electric

Palo Alto University

Price School of Public Policy and Center for Risk and

Economic Analysis of Terrorism Events, University of

Southern California

Rockefeller Foundation-100 Resilient Cities

San Jose Water Company

Southern California Earthquake Center

SPA Risk LLC

SPUR

Strategic Economics

Structural Engineers Association of Northern California

The Brashear Group LLC

University of California Berkeley Seismological Laboratory

University of Colorado Boulder

University of Southern California

U.S. Department of Homeland Security

U.S. Geological Survey

Wells Fargo 



\section{Contents}

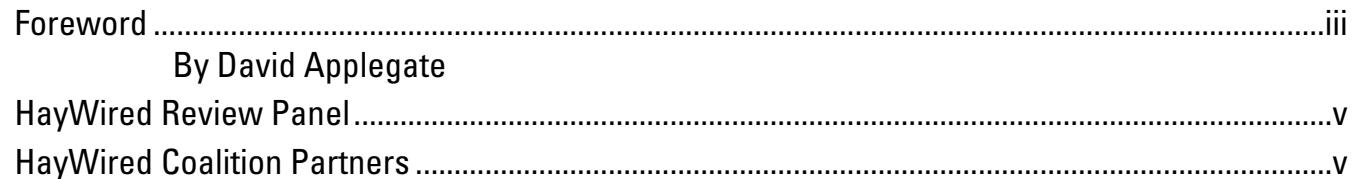

\section{Chapters}

I. Overview of the HayWired Scenario Engineering-Implications Volume ....................................1

By Keith A. Porter

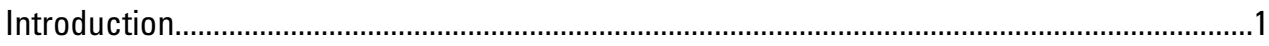

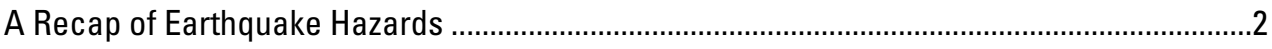

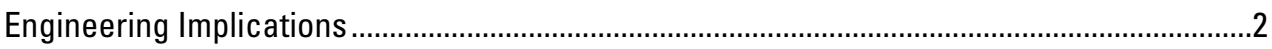

Hazus-MH Analysis ...........................................................................................

Societal Consequences of Current Code Performance Objectives ...................................

A Survey of Public Preferences for the Seismic Performance of New Buildings............5

Earthquake Urban Search and Rescue........................................................................5

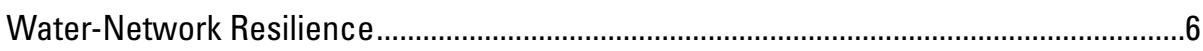

Repair Costs and Downtime of High-Rise Buildings ....................................................

Fire Following Earthquake ........................................................................................

Benefit of Combining Earthquake Early Warning with Drop, Cover, and Hold On ...........9

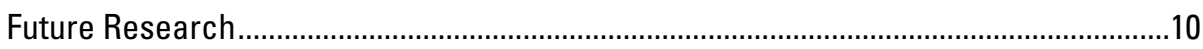

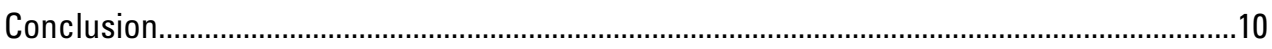

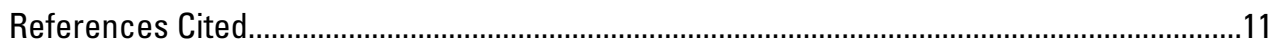

J. HayWired Scenario-Hazus Analyses of the Mainshock and Aftershocks .............................13

By Hope A. Seligson, Anne M. Wein, and Jamie L. Jones

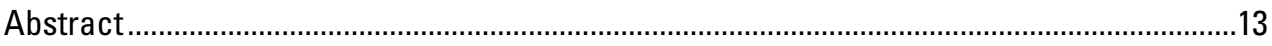

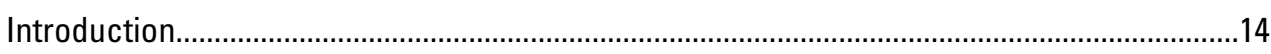

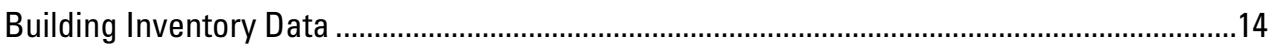

Hazus Results—HayWired Mainshock.............................................................................

HayWired Liquefaction Implementation in Hazus ...........................................................18

HayWired Landslide implementation in Hazus ..............................................................19

HayWired Mainshock Hazus Results ............................................................................22

Liquefaction Modeling in Selected HayWired Aftershocks ..................................................27

Ground Shaking Results for the HayWired Earthquake Sequence ........................................27

Unreinforced Masonry Construction....................................................................................

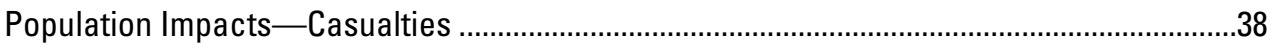

Population Impacts—Displacement and Shelter Requirements.........................................38

Combining Losses in the Mainshock and Aftershocks .......................................................41

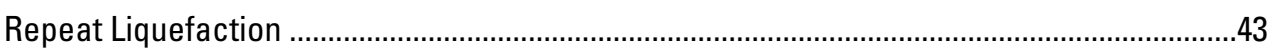

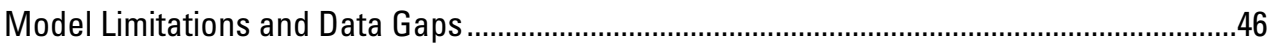

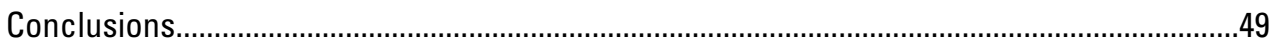




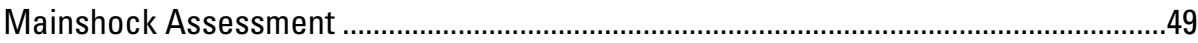

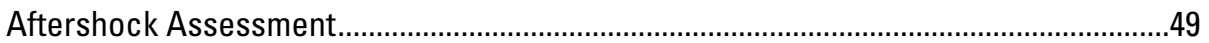

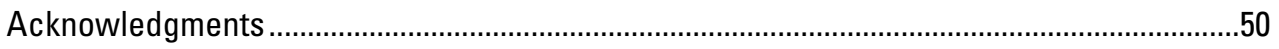

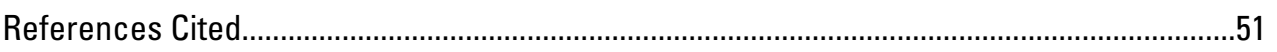

Appendix. Calculation of Shelter Parameters for the 2008 Southern California ShakeOut

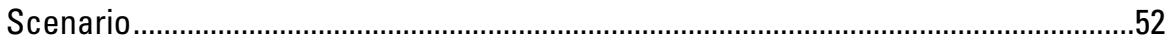

By Kimberley Shoaf

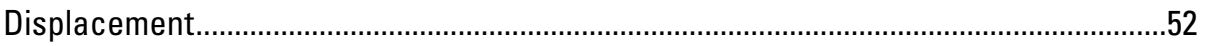

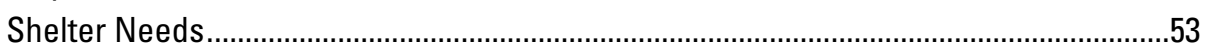

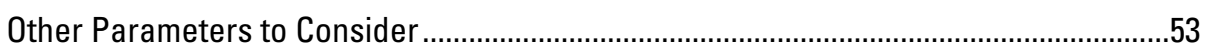

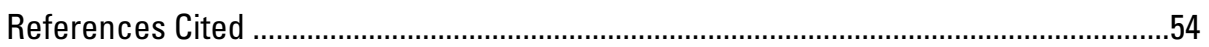

K. Societal Consequences of Current Building Code Performance Objectives for Earthquakes ....57 By Keith A. Porter

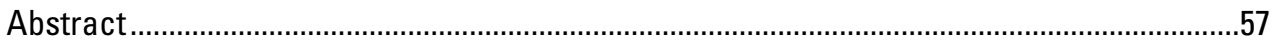

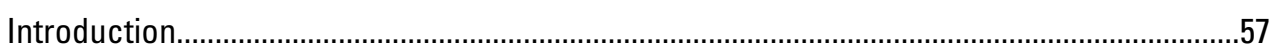

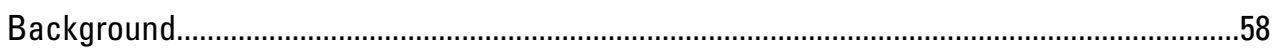

Implications of Seismic Performance Objectives for the HayWired Scenario ........................60

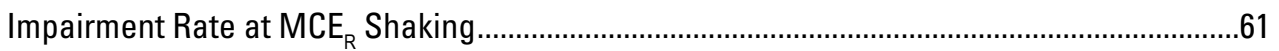

Validation Using Data from the August 2014 Napa Earthquake............................................63

Impairment Rate at Other Levels of Shaking.....................................................................63

Fraction and Number of Impaired Buildings at the Societal Level.......................................66

Options for Improving Building-Stock Performance ..............................................................66

Building Impairment Resulting from Ground Failure ............................................................69

Public Expectations for the Seismic Performance of New Buildings .....................................70

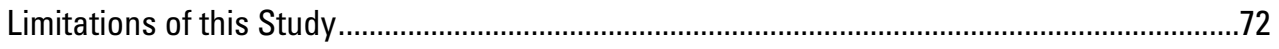

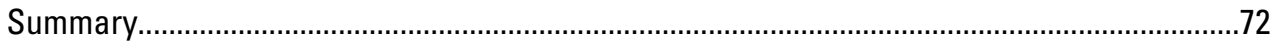

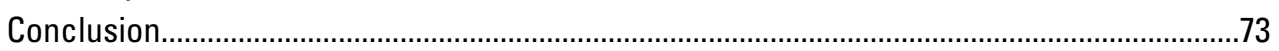

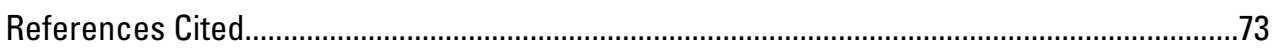

L. Not Safe Enough-A Survey of Public Preferences for the Seismic Performance of New

Buildings in California and the New Madrid Seismic Zone ................................................79

By Keith A. Porter

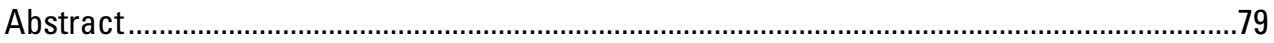

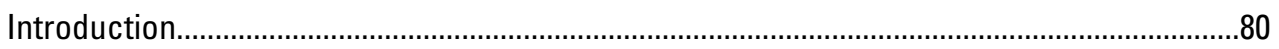

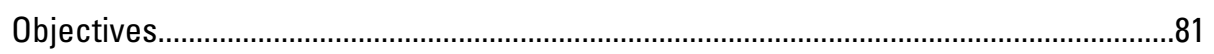

Survey Approach ................................................................................................

Respondent Population and Sampling Procedure ……………………………….........83

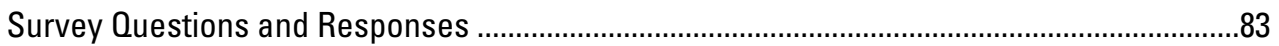

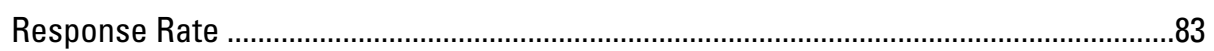

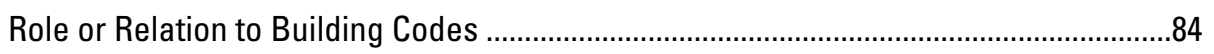

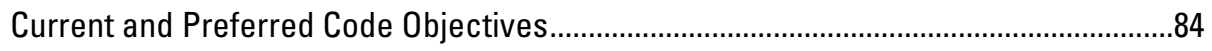

Preferred Performance Measure ................................................................................86

Acceptable Cost for Better Performance ...................................................................87

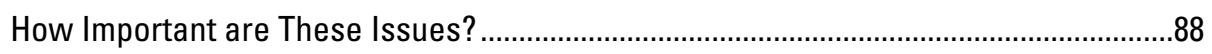

Respondent Demographics...............................................................................

Are Respondents Representative of the Population? .........................................................91

Are Some Groups Willing to Pay More for Better Seismic Performance? .............................93 


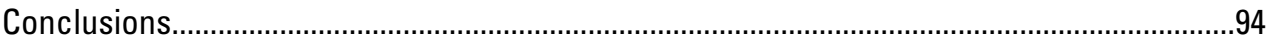

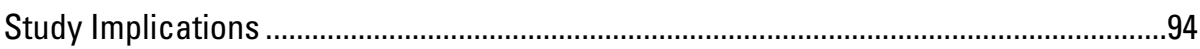

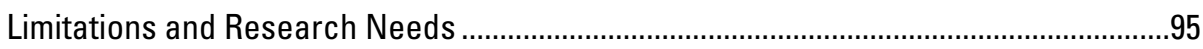

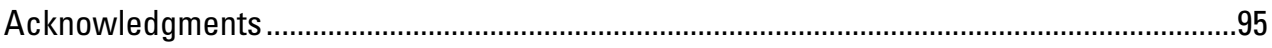

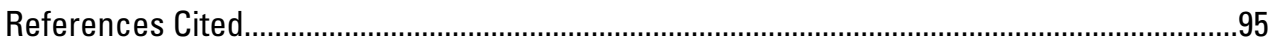

M. An Earthquake Urban Search and Rescue Model and its Application to the HayWired Scenario.. 99 By Keith A. Porter

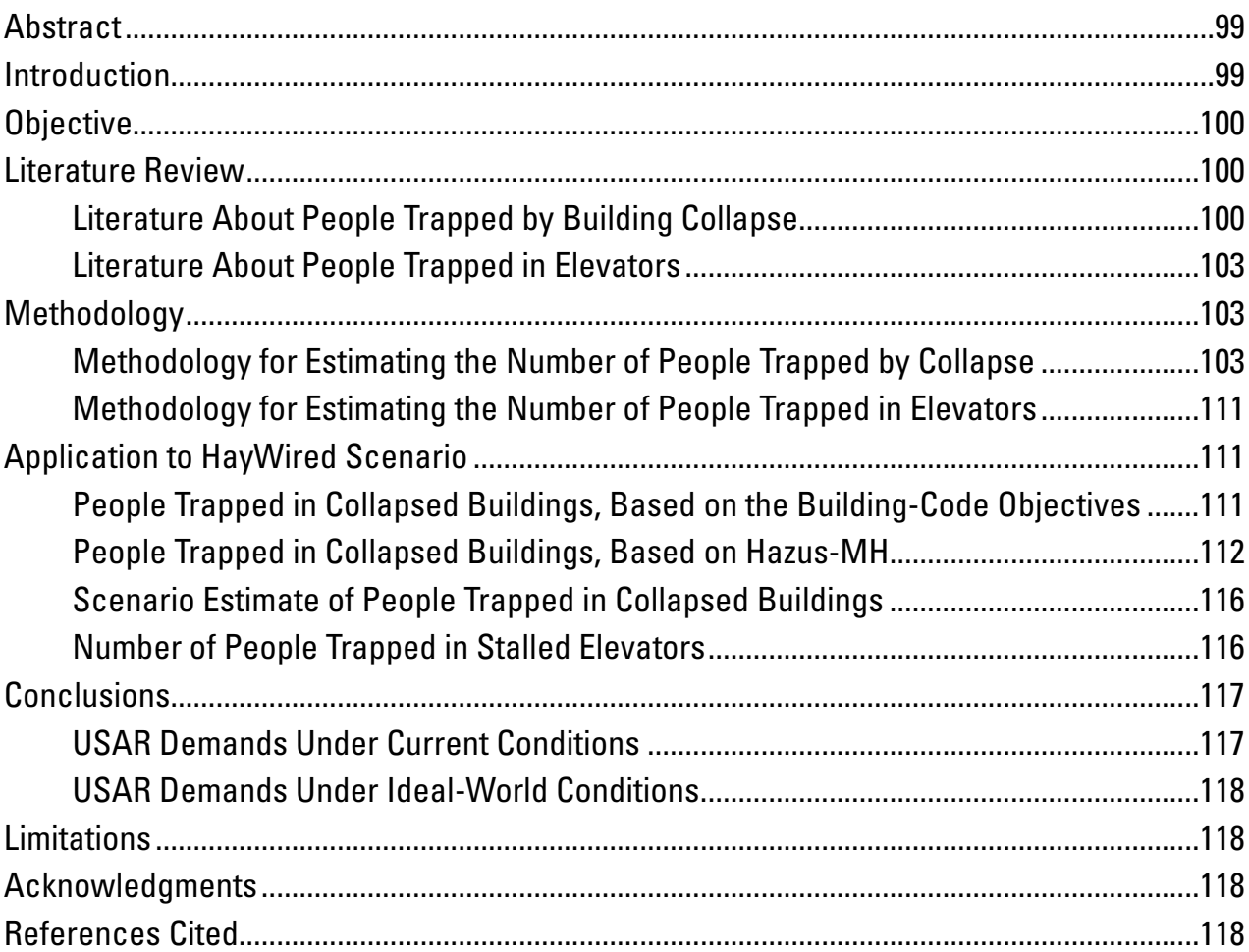

Appendixes 1 through 12-National Information Service for Earthquake Engineering e-Library Images of Building Collapse in California, 1965-2014 ..................................120

Appendix 1. Santa Rosa (1969) Collapse Images.........................................................120

Appendix 2. San Fernando (1971) Collapse Images ..................................................122

Appendix 3. Imperial Valley (1979) Collapse Images.....................................................141

Appendix 4. Westmorland (1981) Collapse Images .......................................................143

Appendix 5. Coalinga (1983) Collapse Images ............................................................144

Appendix 6. Morgan Hill (1984) Collapse Images .........................................................152

Appendix 7. Whittier Narrows (1987) Collapse Images ..................................................154

Appendix 8. Loma Prieta (1989) Collapse Images.........................................................159

Appendix 9. Northridge (1994) Collapse Images.............................................................173

Appendix 10. San Simeon (2003) Collapse Images.........................................................189

Appendix 11. South Napa (2014) Collapse Images ........................................................191

Appendix 12. Earthquakes With No Available Collapse Images...................................192

N. A New Model of Water-Network Resilience, with Application to the HayWired Scenario...195

By Keith A. Porter

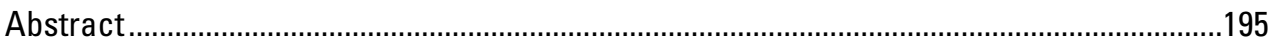

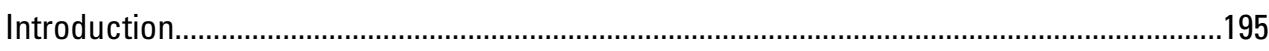

How Water Supply is Important in an Earthquake ..................................................195 


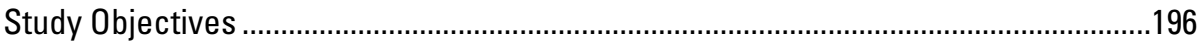

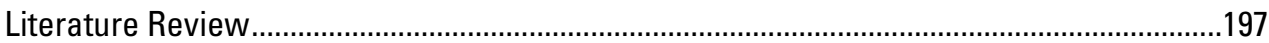

A Panel Approach to Estimating Water-Supply Impacts ...........................................197

Analytical Approaches to Estimating Water Supply Impacts .........................................197

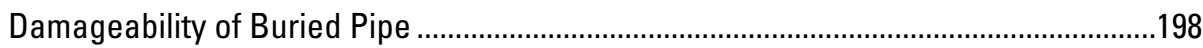

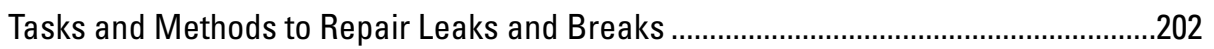

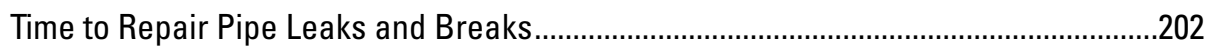

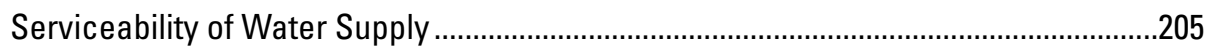

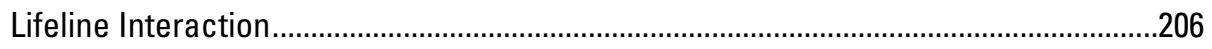

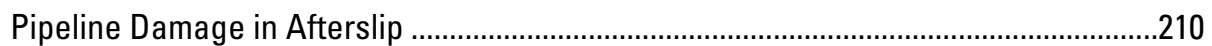

Measuring Loss of Resilience .............................................................................211

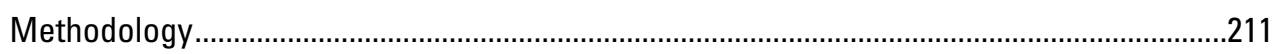

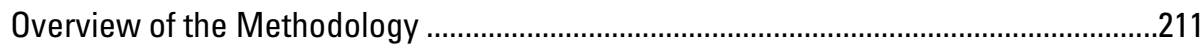

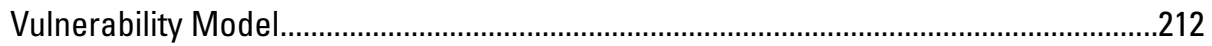

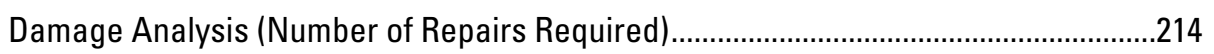

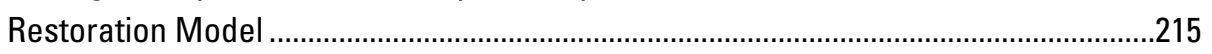

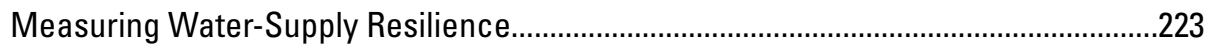

Optional Stochastic Simulation Methodology …………………….............................223

Accounting for Afterslip and Aftershocks .................................................................225

Adjusting Hazus-MH's Lifeline Restoration Model.......................................................226

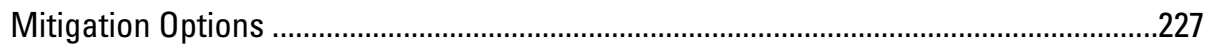

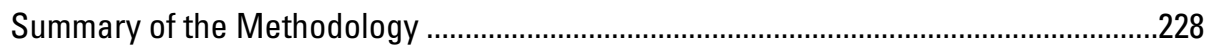

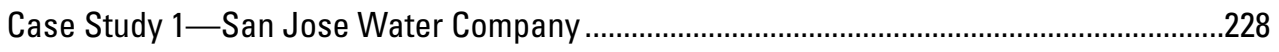

San Jose Water Company Asset Definition .................................................................229

San Jose Water Company Hazard Analysis ................................................................229

San Jose Water Company Damage Analysis.............................................................230

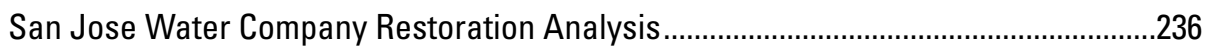

Validation of San Jose Water Company Restoration Analysis .....................................240

Effect of Lifeline Interaction and Consumable Limits ..................................................242

Case Study 2-East Bay Municipal Utility District...........................................................22

East Bay Municipal Utility District Asset Definition .....................................................242

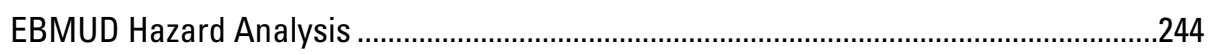

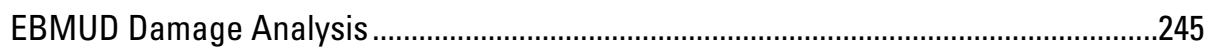

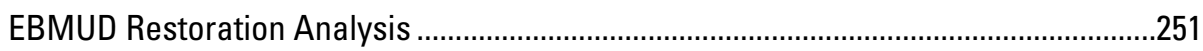

Validation of EBMUD Damage and Recovery Estimates...............................................254

Effect of Lifeline Interaction and Consumable Limits on EBMUD .................................255

Performance of Other Water Utilities Based on Hazus-MH..................................................255

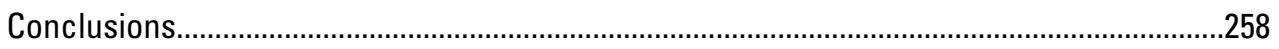

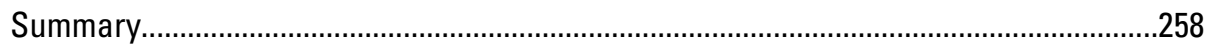

Innovations Introduced Here ..........................................................................258

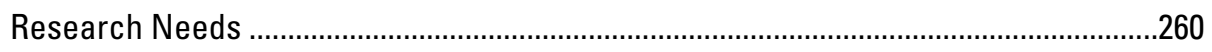

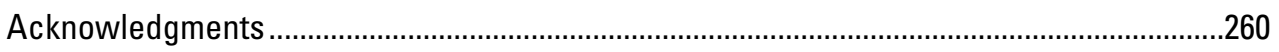

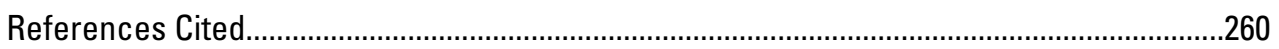


0. Case Studies of Tall-Building Structural Analyses and Downtime and Loss Assessment for the HayWired Earthquake Scenario Mainshock

By Ibrahim M. Almuti, Carlos Molina-Hutt, Michael W. Mieler, Nicole A. Paul, and Chad R. Fusco

Abstract

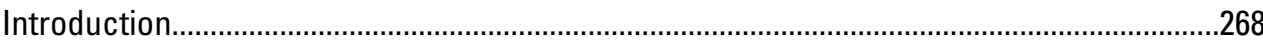

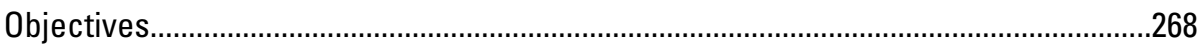

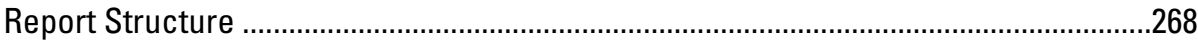

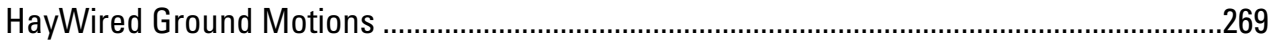

Description of Archetype Buildings, Design, and Analysis Assumptions ..............................272

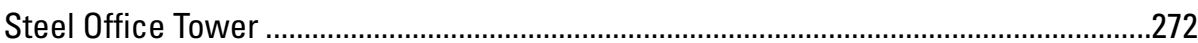

Reinforced-Concrete Residential Tower......................................................................276

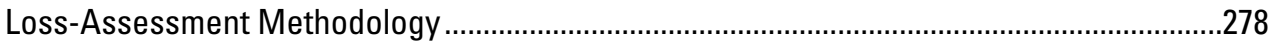

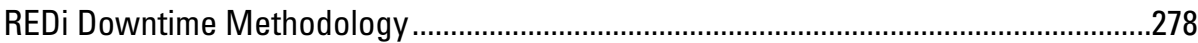

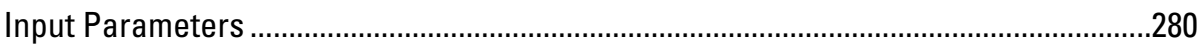

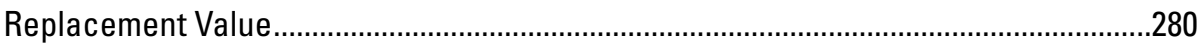

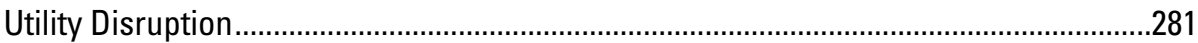

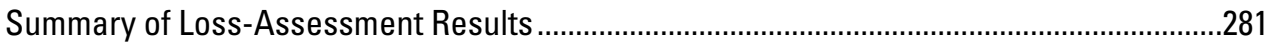

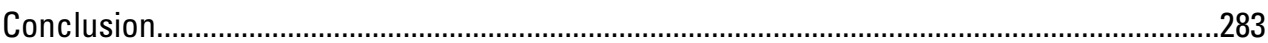

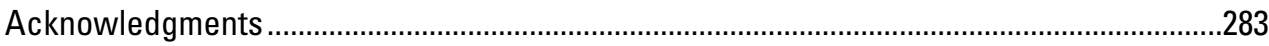

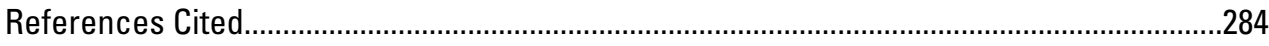

Appendix 1. Building Structural and Nonstructural Components ........................................285

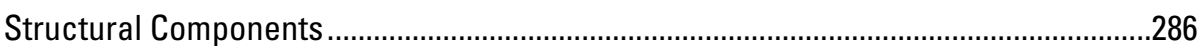

Nonstructural Components .............................................................................................291

Appendix 2. S-SF-B-43-40-Story Steel-Frame Building in San Francisco (Baseline

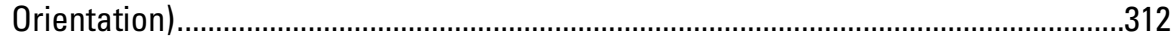

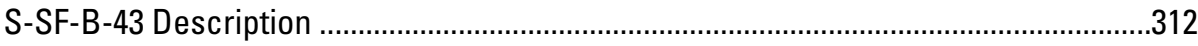

Engineering-Demand Parameters .................................................................................312

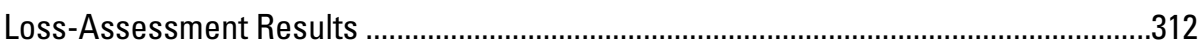

Appendix 3. S-SF-R-43-40-Story Steel-Frame Building in San Francisco (Rotated

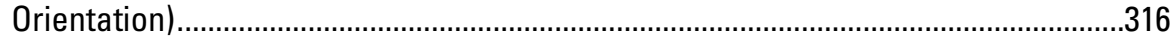

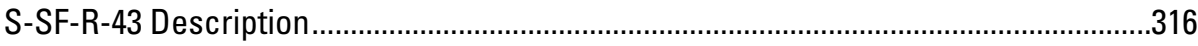

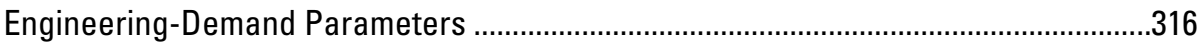

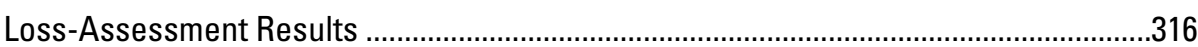

Appendix 4. S-SF-B-20-20-Story Steel-Frame Building in San Francisco (Baseline

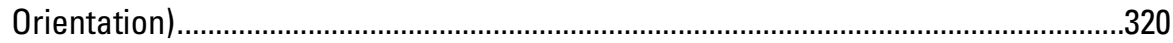

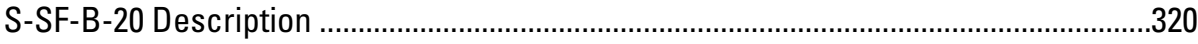

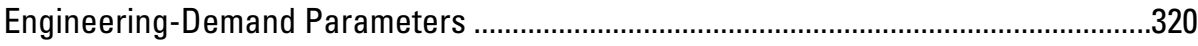

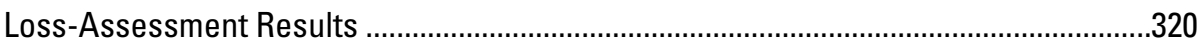

Appendix 5. S-SF-R-20-20-Story Steel-Frame Building in San Francisco (Rotated

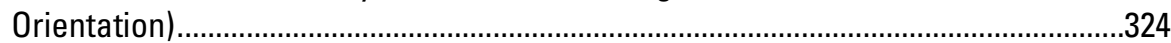

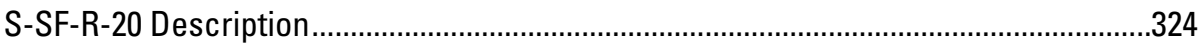

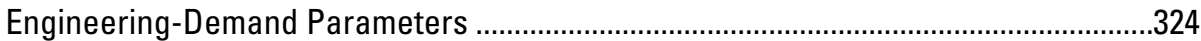

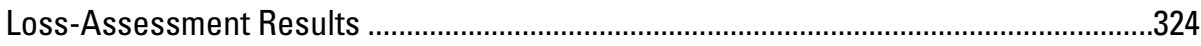


Appendix 6. S-OK-B-20-20-Story Steel-Frame Building in Oakland

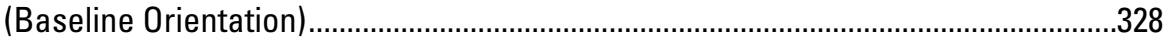

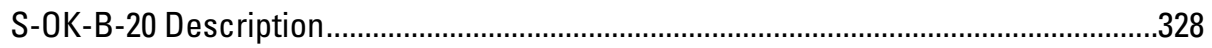

Engineering-Demand Parameters .............................................................................328

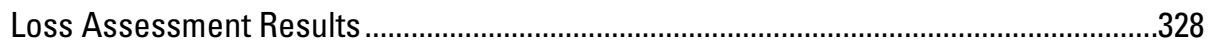

Appendix 7. S-OK-R-20-20-Story Steel-Frame Building in Oakland

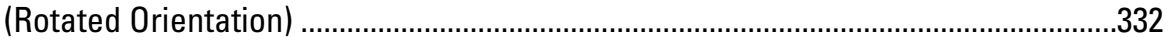

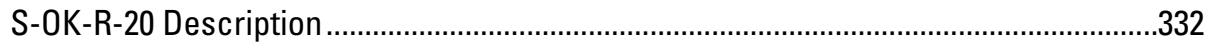

Engineering-Demand Parameters ..........................................................................332

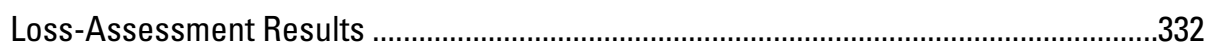

Appendix 8. C-SF-B-46-42-Story Reinforced-Concrete Building in San Francisco (Baseline

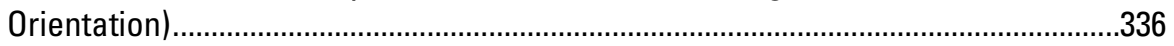

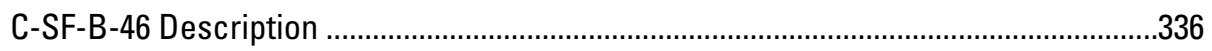

Engineering-Demand Parameters …………………..................................................36

Loss-Assessment Results ....................................................................................339

Appendix 9. C-SF-R-46-42-Story Reinforced-Concrete Building in San Francisco (Rotated

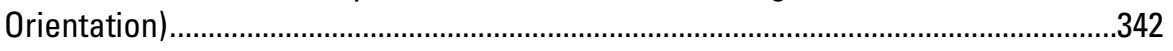

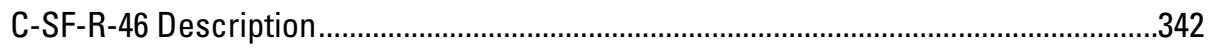

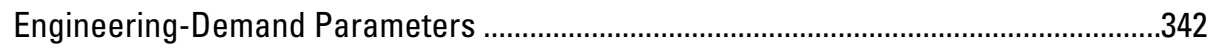

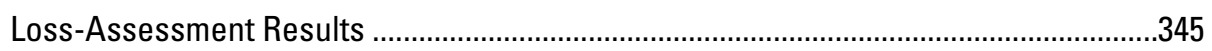

Appendix 10. C-OK-B-46-42-Story Reinforced-Concrete Building in Oakland (Baseline

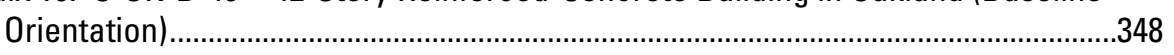

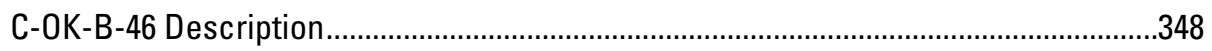

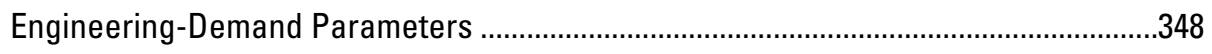

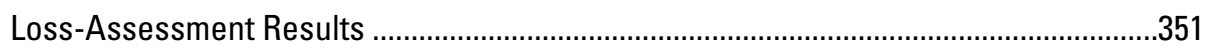

Appendix 11. C-OK-R-46-42-Story Reinforced-Concrete Building in Oakland (Rotated

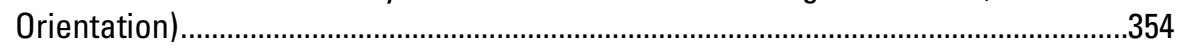

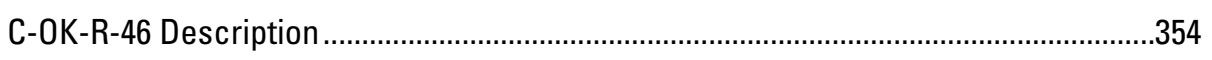

Engineering-Demand Parameters ..........................................................................354

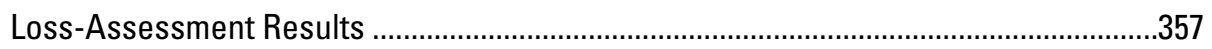

Appendix 12. Inventory of Existing Tall-Building Stock in San Francisco ............................360

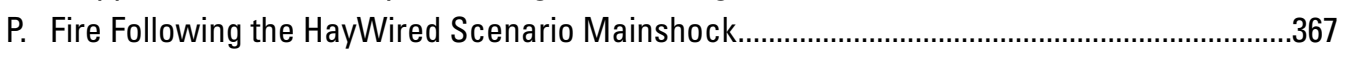

By Charles Scawthorn

Abstract

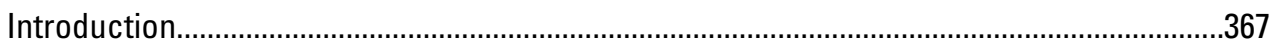

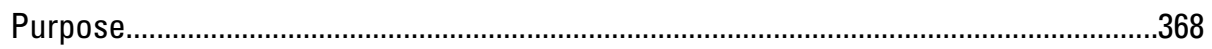

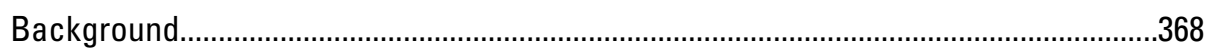

Scenario Earthquake and Prevailing Conditions ................................................................368

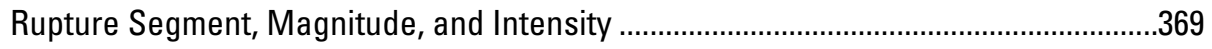

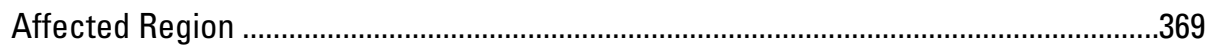

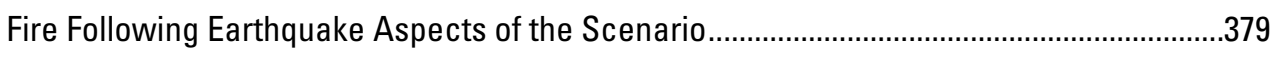

Modeling of Fire Following Earthquake ....................................................................379

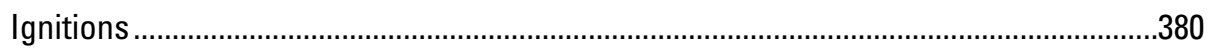

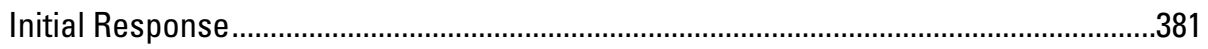

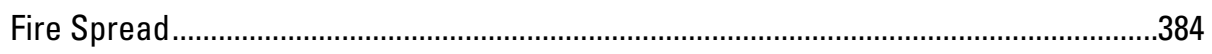

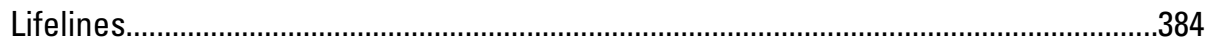


Regional and State Response ....................................................................................39

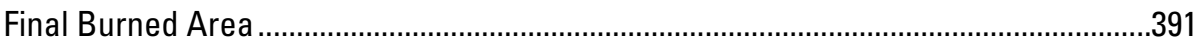

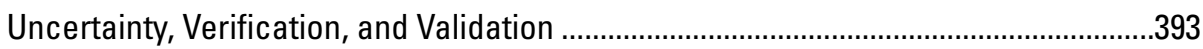

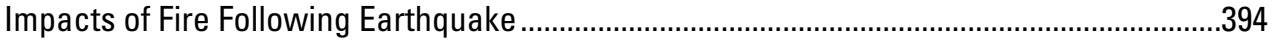

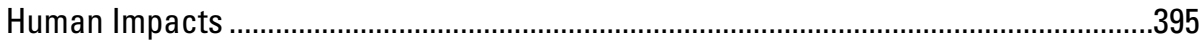

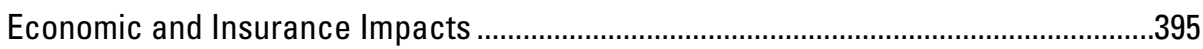

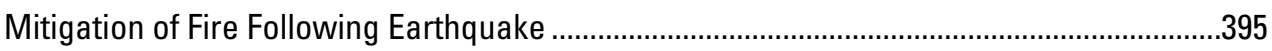

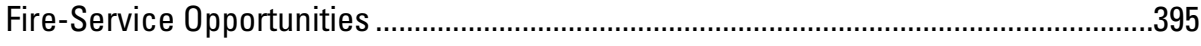

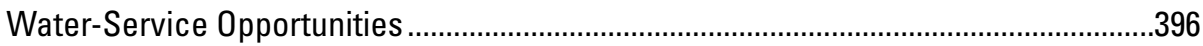

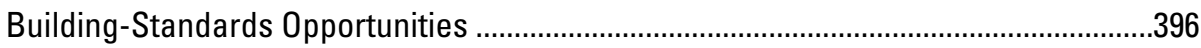

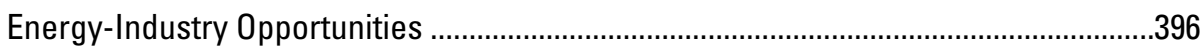

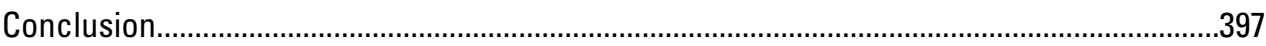

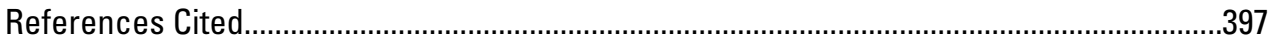

0. How Many Injuries Can Be Avoided in the HayWired Scenario Through Earthquake Early

Warning and Drop, Cover, and Hold On? ........................................................................

By Keith A. Porter and Jamie L. Jones

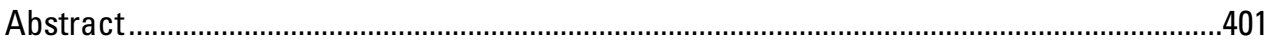

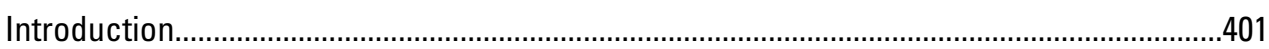

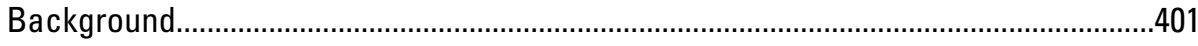

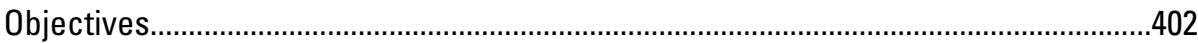

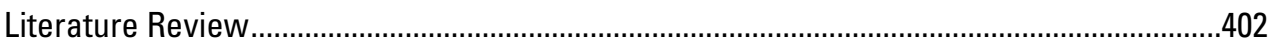

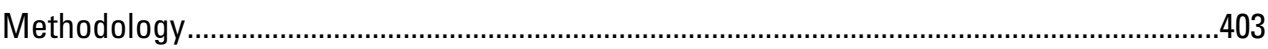

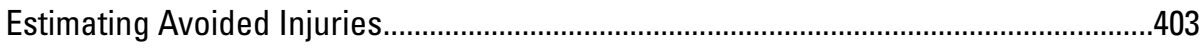

Estimating the Acceptable Cost to Avoid Injuries ........................................................404

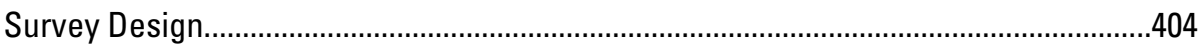

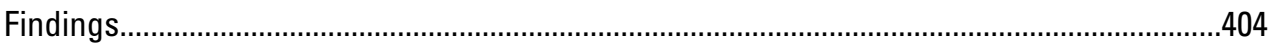

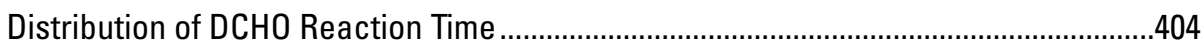

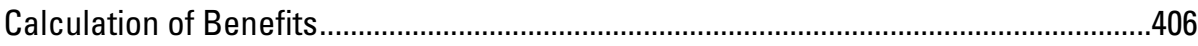

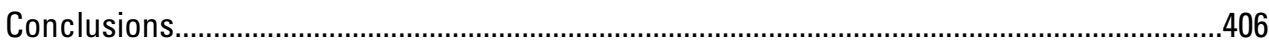

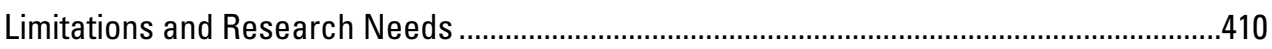

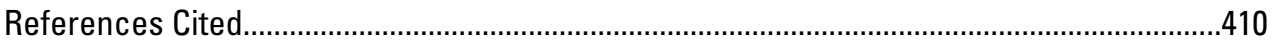

Appendix 1. Survey of DCHO Reaction Times ................................................................412

Appendix 2. HayWired Mainshock Earthquake Early Warning Time Calculation..................427

By Elizabeth S. Cochran, Anne M. Wein, Erin R. Burkett, Douglas D. Given, and Keith Porter

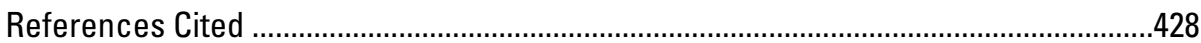




\section{Conversion Factors}

U.S. customary units to International System of Units

\begin{tabular}{|c|c|c|}
\hline Multiply & By & To obtain \\
\hline \multicolumn{3}{|c|}{ Length } \\
\hline inch (in.) & 2.54 & centimeter $(\mathrm{cm})$ \\
\hline inch (in.) & 25.4 & millimeter (mm) \\
\hline foot $(\mathrm{ft})$ & 0.3048 & meter $(\mathrm{m})$ \\
\hline mile (mi) & 1.609 & kilometer $(\mathrm{km})$ \\
\hline \multicolumn{3}{|c|}{ Area } \\
\hline acre & 947 & square meter $\left(\mathrm{m}^{2}\right)$ \\
\hline acre & 0.4047 & hectare (ha) \\
\hline acre & 0.004047 & square kilometer $\left(\mathrm{km}^{2}\right)$ \\
\hline square foot $\left(\mathrm{ft}^{2}\right)$ & 0.09290 & square meter $\left(\mathrm{m}^{2}\right)$ \\
\hline square mile $\left(\mathrm{mi}^{2}\right)$ & 2.590 & square kilometer $\left(\mathrm{km}^{2}\right)$ \\
\hline \multicolumn{3}{|c|}{ Volume } \\
\hline gallon (gal) & 3.785 & liter $(\mathrm{L})$ \\
\hline \multicolumn{3}{|c|}{ Pressure } \\
\hline pound per square inch $\left(\mathrm{lb} / \mathrm{in}^{2}\right)$ & 6.895 & kilopascal (kPa) \\
\hline kilopounds per square inch $\left(\mathrm{lb} / \mathrm{in}^{2}\right)$ & 6.895 & megapascal (MPa) \\
\hline \multicolumn{3}{|c|}{ Cohesion } \\
\hline pound per square foot $\left(\mathrm{lb} / \mathrm{ft}^{2}\right)$ & 0.04788 & kilopascal $(\mathrm{kPa})$ \\
\hline \multicolumn{3}{|c|}{ Velocity } \\
\hline mile per $\mathrm{hr}(\mathrm{mi} / \mathrm{hr})$ & 1.60934 & kilometer per hour $(\mathrm{km} / \mathrm{hr})$ \\
\hline \multicolumn{3}{|c|}{ Angle } \\
\hline degree $\left({ }^{\circ}\right)$ & 0.0174533 & radian $(\mathrm{rad})$ \\
\hline
\end{tabular}

International System of Units to U.S. customary units

\begin{tabular}{|c|c|c|}
\hline Multiply & By & To obtain \\
\hline \multicolumn{3}{|c|}{ Length } \\
\hline centimeter $(\mathrm{cm})$ & 0.3937 & inch (in.) \\
\hline millimeter $(\mathrm{mm})$ & 0.03937 & inch (in.) \\
\hline meter $(\mathrm{m})$ & 3.281 & foot $(\mathrm{ft})$ \\
\hline kilometer $(\mathrm{km})$ & 0.6214 & mile (mi) \\
\hline \multicolumn{3}{|c|}{ Area } \\
\hline square meter $\left(\mathrm{m}^{2}\right)$ & 0.0002471 & acre \\
\hline hectare (ha) & 2.471 & acre \\
\hline square kilometer $\left(\mathrm{km}^{2}\right)$ & 247.1 & acre \\
\hline square meter $\left(\mathrm{m}^{2}\right)$ & 10.76 & square foot $\left(\mathrm{ft}^{2}\right)$ \\
\hline square kilometer $\left(\mathrm{km}^{2}\right)$ & 0.3861 & square mile $\left(\mathrm{mi}^{2}\right)$ \\
\hline \multicolumn{3}{|c|}{ Volume } \\
\hline liter $(\mathrm{L})$ & 0.2642 & gallon (gal) \\
\hline \multicolumn{3}{|c|}{ Pressure } \\
\hline kilopascal $(\mathrm{kPa})$ & 0.1450377 & pound per square inch $\left(\mathrm{lb} / \mathrm{in}^{2}\right)$ \\
\hline megapascal (MPa) & 0.1450377 & kilopounds per square inch $\left(\mathrm{lb} / \mathrm{in}^{2}\right)$ \\
\hline
\end{tabular}




\begin{tabular}{lll}
\hline \multicolumn{1}{c}{ Multiply } & \multicolumn{1}{c}{ By } & \multicolumn{1}{c}{ To obtain } \\
\hline centimeter per second $(\mathrm{cm} / \mathrm{s})$ & \multicolumn{1}{c}{ Velocity } & \\
centimeter per second $(\mathrm{cm} / \mathrm{s})$ & 0.3937 & inch per second $(\mathrm{in} . / \mathrm{s})$ \\
meter per second $(\mathrm{m} / \mathrm{s})$ & 0.0223694 & mile per hour $(\mathrm{mi} / \mathrm{hr})$ \\
meter per second $(\mathrm{m} / \mathrm{s})$ & 3.281 & foot per second $(\mathrm{ft} / \mathrm{s})$ \\
\hline kilometer per hour $(\mathrm{km} / \mathrm{hr})$ & 2.23694 & mile per hour $(\mathrm{mi} / \mathrm{hr})$ \\
\hline & 0.621371 & mile per hour $(\mathrm{mi} / \mathrm{hr})$ \\
\hline radian $(\mathrm{rad})$ & \multicolumn{1}{c}{ Angle } & \\
\hline
\end{tabular}

\section{Datum}

Vertical coordinate information is referenced to the North American Vertical Datum of 1988 (NAVD 88).

Horizontal coordinate information is referenced to the North American Datum of 1983 (NAD 83).

\section{Abbreviations and Acronyms}

1D

one dimensional

$2 \mathrm{D}$

two dimensional

$3 D$

three dimensional

ABAG

Association of Bay Area Governments

AIS

abbreviated injury scale

ASCE

American Society of Civil Engineers

ATC

Applied Technology Council

BAREPP

Bay Area Regional Earthquake Preparedness Project

BART

Bay Area Rapid Transit

BORP

Building Occupancy Resumption Program

BSSC

Building Seismic Safety Council

Cal OES

California Governor's Office of Emergency Services

Caltrans

California Department of Transportation

CalWARN

California Water/Wastewater Agency Response Network

CAPSS

Citizens Advisory Panel on Seismic Safety or Community Action Plan for Seismic Safety

CDC

Centers for Disease Control and Prevention

CERT

community emergency response team

CGS

California Geological Survey

CPT

cone penetration test

CUREE

Consortium of Universities for Research in Earthquake Engineering 


\begin{tabular}{|c|c|}
\hline DBE & design-basis earthquake \\
\hline DCHO & drop, cover, and hold on \\
\hline DDR & demand-to-design ratio \\
\hline $\mathrm{DDR}_{1}$ & 1-second DDR \\
\hline $\mathrm{DDR}_{\mathrm{s}}$ & short-period DDR \\
\hline DEM & digital elevation model \\
\hline EBMUD & East Bay Municipal Utility District \\
\hline EDP & engineering-demand parameter \\
\hline EERI & Earthquake Engineering Research Institute \\
\hline EEW & Earthquake early warning \\
\hline EQE & EOE International \\
\hline ESIP & Earthquake Safety Improvements Program \\
\hline ETAS & epidemic type aftershock sequence \\
\hline$F_{\mathrm{A}}$ & amplification factor \\
\hline FEMA & Federal Emergency Management Agency \\
\hline$F_{v}$ & site coefficient \\
\hline$g$ & acceleration due to gravity \\
\hline GMPE & ground-motion prediction equation \\
\hline GMPGV & geometric mean of the peak ground velocity \\
\hline $\mathrm{hr}$ & hour \\
\hline IBC & International Building Code \\
\hline ICC & International Code Council \\
\hline IDR & interstory drift \\
\hline$l_{\mathrm{e}}$ & seismic importance factor \\
\hline IRB & institution review board \\
\hline LA BOMA & Los Angeles Building Owners and Managers Association \\
\hline LADWP & Los Angeles Department of Water and Power \\
\hline LLEQE & Life Line Earthquake Engineering software \\
\hline LPI & liquefaction potential index \\
\hline LRFD & load- and resistance-factor design \\
\hline M & magnitude \\
\hline $\mathrm{Ma}$ & mega-annum or millions of years ago \\
\hline MCE & maximum considered earthquake \\
\hline $\mathrm{MCE}_{\mathrm{R}}$ & risk-adjusted maximum considered earthquake \\
\hline & mechanical, electrical, and plumbing \\
\hline
\end{tabular}




\begin{tabular}{|c|c|}
\hline MMI & Modified Mercalli Intensity \\
\hline MRF & moment-resisting frame \\
\hline MSA & metropolitan statistical area \\
\hline$M_{\mathrm{w}}$ & moment magnitude \\
\hline NAD83 & North American Datum of 1983 \\
\hline NED & National Elevation Dataset \\
\hline NEHRP & National Earthquake Hazards Reduction Program \\
\hline NGA-West2 & Next Generation Attenuation Relationships for Western United States \\
\hline NIBS & National Institute of Building Sciences \\
\hline NISEE & National Information Service for Earthquake Engineering \\
\hline NIST & National Institute of Standards and Technology \\
\hline NISTIR & National Institute of Standards and Technology Interagency Reports \\
\hline NLRHA & nonlinear response-history analysis \\
\hline NMSZ & New Madrid Seismic Zone \\
\hline NRC & National Research Council \\
\hline$P$ & probability \\
\hline PACT & Performance Assessment Calculation Tool \\
\hline PBEE & performance-based earthquake engineering \\
\hline PBEE-2 & second generation Performance-based earthquake engineering \\
\hline PDT & Pacific Daylight Time \\
\hline PEER & Pacific Earthquake Engineering Research Center \\
\hline PG\&E & Pacific Gas and Electric Company \\
\hline PGA & peak ground acceleration \\
\hline PGD & permanent ground displacement \\
\hline PGV & peak ground velocity \\
\hline PHS & U.S. Public Health Service \\
\hline PSA or pSa & pseudo-spectral acceleration \\
\hline PSA03 & short-period (0.3-second) pseudo-spectral-acceleration response \\
\hline PSA10 & long-period (1-second) pseudo-spectral-acceleration response \\
\hline PST & Pacific Standard Time \\
\hline PVC & polyvinyl chloride \\
\hline PWSS & portable water-supply system \\
\hline$R^{2}$ & coefficient of determination \\
\hline REDiTM & Resilience-based Earthquake Design Initiative for the Next Generation of Buildings \\
\hline RIDR & residual interstory drift \\
\hline
\end{tabular}




\begin{tabular}{ll} 
SA & spectral acceleration \\
$S_{\text {a }}$ & spectral-acceleration response \\
SAFRR & USGS Science Application for Risk Reduction project \\
SCEC & Southern California Earthquake Center \\
SDC & seismic-design categories \\
SEAOC & Structural Engineers Association of California \\
SEAONC & Structural Engineers Association of Northern California \\
SEI & Structural Engineering Institute \\
SHZ & seismic hazard zone \\
SIP & seismic improvement programs \\
SJWC & San Jose Water Company \\
SLE & serviceability-level earthquakes \\
$S_{\text {M1 }}$ & 1 -second spectral response acceleration parameter \\
$S_{\text {MS }}$ & short-period spectral acceleration response parameter \\
SPUR & San Francisco Bay Area Planning and Urban Research Association \\
$S_{S}$ & short-period spectral acceleration response at MCER shaking \\
$T$ & period \\
UCERF3 & Uniform California Earthquake Rupture Forecast, version 3 \\
UPS & uninterruptible power supply \\
URM & unreinforced masonry \\
USAR & urban search and rescue team \\
USD & U.S. Dollars \\
USGS & U.S. Geological Survey \\
$V_{\text {S30 }}$ & time-averaged shear-wave velocity to a depth of 30 meters \\
WGS84 & World Geodetic Survey 1984 \\
$\rho$ & correlation coefficient \\
& standard normal cumulative distribution function \\
\hline &
\end{tabular}






\title{
Chapter I
}

\section{Overview of the HayWired Scenario Engineering- Implications Volume}

\author{
By Keith A. Porter ${ }^{1}$
}

\section{Introduction}

The HayWired scenario is a hypothetical yet scientifically realistic depiction of an earthquake sequence that begins with a moment magnitude $\left(M_{\mathrm{w}}\right) 7.0$ earthquake (mainshock) occurring on April 18, 2018, at 4:18 p.m. on the Hayward Fault in the east bay part of the San Francisco Bay area, California. The hypothetical mainshock has its epicenter in Oakland, and strong ground shaking from the scenario causes a wide range of severe impacts throughout the greater bay region. In the mainshock, the Hayward Fault is ruptured along its length for 83 kilometers (about 52 miles), an event significant enough to touch the lives of everyone who lives or works in the region.

The HayWired Earthquake Scenario-Engineering Implications is the second volume of U.S. Geological Survey (USGS) Scientific Investigations Report (SIR) 2017-5013, which is planned to be published as three volumes. The previous volume of this work (SIR 2017-5013-A-H; Detweiler and Wein, 2017) described a $M_{\mathrm{w}} 7.0$ mainshock on the Hayward Fault, along with an aftershock sequence and other geologic hazards. This volume (SIR 2017-5013-I-Q) presents engineering impacts that could result from the effects of the HayWired scenario. Together with environmental, social, and economic impacts (including impacts to telecommunications and the internet) that are planned to be described in a third volume, these works describe the HayWired scenario, which was developed by USGS and its partners.

The engineering-related implications of the $M_{\mathrm{w}} 7.0$ HayWired scenario mainshock and aftershocks for the San Francisco Bay region discussed in this volume are based on:

1. An analysis using the Federal Emergency Management Agency's (FEMA) Hazus-MH computer program (Federal Emergency Management Agency, 2012a) that suggests 800 deaths and 16,000 nonfatal injuries (from the shaking hazard alone) could occur, as well as property and direct business interruption losses of more than $\$ 82$ billion (for shaking, liquefaction, and landslide hazards).

\footnotetext{
${ }^{1}$ University of Colorado Boulder.
}

2. A study of the societal consequences of the International Building Code's seismic-performance objectives for new buildings. The scenario indicates that, even for new buildings, the code protects life well but is not robust enough to ensure that hundreds of thousands of code-compliant buildings are not red-tagged (rendered unsafe to enter or occupy) or yellow-tagged (safe only for limited use). As a consequence, even if they were all new, code-compliant buildings, a significant fraction of the San Francisco Bay region's buildings - perhaps 1 in 4 could have no or restricted occupancy. A moreresilient building stock is achievable for an additional 1 to 3 percent of construction cost and could allow 95 percent of homes and workplaces to be occupied following a powerful earthquake.

3. The first survey of public preferences for the tradeoff between cost and building resilience, showing that most people expect, prefer, and would be willing to pay for greater resilience of the building stock.

4. A new model of urban search and rescue, indicating that (1) more than 22,000 people in the region could require fire departments to free them from stalled elevators and (2) more than 2,400 people could require rescue from collapsed buildings.

5. A new, nonproprietary model of water-network resilience that accounts for the entire earthquake sequence, lifeline (for example, transportation infrastructure and buried utilities) interaction, resource limitations, and service restoration over time. This water-network resilience model shows that the average east bay resident could lose water service for 6 weeks (some for as long as 6 months). Two options to help improve these outcomes are evaluated.

6. A state-of-the-art performance-based earthquakeengineering study showing that an earthquake like the HayWired mainshock could cause damage sufficient to render older regular steel-frame high-rise office buildings and new regular reinforced-concrete 
residential buildings in downtown Oakland and San Francisco unusable for as long as 10 months.

7. A study of fire following earthquake showing that the HayWired mainshock could cause about 450 large fires in counties nearest the fault rupture, burning buildingfloor area equivalent to that of more than 52,000 singlefamily dwellings. Such fires would kill hundreds of people and cause property (building and content) losses approaching $\$ 30$ billion. A first joint exercise of portable firefighting water-supply systems was also conducted by fire agencies in the San Francisco Bay region.

8. An analysis of the benefits of combining earthquake early warning (EEW) and drop, cover, and hold on (DCHO) actions, including the first study of the time it takes people to complete DCHO. Combining EEW and $\mathrm{DCHO}$ could prevent as many as 1,500 nonfatal injuries out of 18,000 estimated nonfatal injuries (from shaking and liquefaction hazards combined) in the HayWired scenario, a benefit valued at about $\$ 300$ million.

\section{A Recap of Earthquake Hazards}

The HayWired Earthquake Scenario-Earthquake Hazards volume (Detweiler and Wein, 2017) sets the stage for this volume on the engineering implications of the scenario. The Hayward Fault is arguably the most urbanized active fault in the United States. Therefore, it offers an informative case study of the effects of a large urban earthquake on a modern U.S. metropolitan region. The earthquake-hazards volume described the hypothetical $M_{\mathrm{w}} 7.0$ HayWired scenario mainshock, with additional descriptions of the cascading hazards of fault rupture, aftershocks (subsequent earthquakes), afterslip (subsequent movement on a fault), landslides, and liquefaction (soils becoming liquid-like during shaking).

The earthquake hazards volume also describes a largely physics-based model of ground motion for the HayWired mainshock. The model uses physical modeling of wave propagation but with a kinematic (motion-based) rupture model. This model of ground motion shows that damaging shaking (Modified Mercalli Intensity VI or higher) in the scenario occurs over a region of approximately 50,000 square kilometers (about 19,000 square miles) - 170 kilometers $(\mathrm{km})$ (about 105 miles) west to east (from the Pacific Coast to the Sierra Nevada) and $300 \mathrm{~km}$ (about 185 miles) north to south, including almost all the urbanized area of the nine counties bordering San Francisco Bay, as well as Santa Cruz County to the south. The differences between this largely physicsbased model and conventional ground-motion prediction equations were examined, and an explanation was provided of why the physics-based model was used to avoid a systematic underestimate of damage and loss for the HayWired scenario.
The modeled scenario earthquake sequence causes as much as 2 meters (about 6.5 feet) of fault offset either in the form of coseismic slip (fault slip during the mainshock) or afterslip. The aftershock sequence includes 16 aftershocks of $M_{\mathrm{w}} 5.0$ or larger that occur over 2 years and as far as $50 \mathrm{~km}$ (about 30 miles) from the Hayward Fault; several of the aftershocks cause local damaging ground shaking that is stronger than in the mainshock. Earthquake-induced liquefaction and landslides, caused by the mainshock, further threaten people, property, and lifeline infrastructure in every county in the San Francisco Bay region.

\section{Engineering Implications}

The HayWired Earthquake Scenario-Engineering Implications volume (this volume) examines how the HayWired scenario earthquake sequence would affect buildings, watersupply pipelines, and other infrastructure. Many researchers have estimated the engineering impacts of similar earthquakes on the Hayward Fault, and several previous studies of San Francisco Bay region earthquakes were discussed in chapter A (Hudnut and others, 2017). The engineering implications volume is not meant to be an exhaustive study of a Hayward Fault earthquake like the ShakeOut scenario (Jones and others, 2008), which examined a hypothetical $M_{\mathrm{w}} 7.8$ earthquake on the San Andreas Fault in southern California and presented a Hazus-MH analysis along with an examination of 18 special engineering topics. This volume ignores some important, but already well-studied, topics such as soft-story buildings and nonductile-concrete buildings. It sacrifices breadth for innovation to explore some engineering and infrastructure aspects of a San Francisco Bay region earthquake that others have not yet examined, either for a Hayward Fault earthquake or indeed for any earthquake.

\section{Hazus-MH Analysis}

Chapter J (Seligson and others, this volume) estimates the spectrum of damage and loss the San Francisco Bay region would experience in the HayWired scenario mainshock using FEMA's public risk-analysis software, Hazus-MH (Federal Emergency Management Agency, 2012a). The Hazus-MH analysis uses detailed estimates of liquefaction and landslide probability that are customized using estimates of shaking from the HayWired mainshock. It uses a map of developed area to better constrain the effects of the liquefaction and landslide hazards on the built environment than would typical Hazus analyses. For example, landslide damage is estimated at several probability levels to quantify a range of possible impacts to pockets of developed areas in large census tracts in the San Francisco Bay region. Hazus-MH analysis is done for each of the 16 modeled aftershocks of magnitude 5.0 or greater. The analyses estimate cumulative damage from aftershocks, explore the vulnerability of unreinforced masonry and tilt-up buildings to aftershocks, highlight geographic areas where aftershocks produce greater damage than does the HayWired mainshock, and show repeat 
damage from liquefaction. The HayWired earthquake sequence could cause 800 deaths and about 16,000 nonfatal injuries from the shaking hazard alone. If there were even a single collapse of a high-rise building, it could greatly increase the casualty figures. Direct losses related to damaged building stock are more than $\$ 82$ billion, not including losses from fire following earthquake, over the entire scenario earthquake sequence, with very little of it insured. These losses, estimated using Hazus-MH, include about:

- $\$ 53$ billion in building repair costs,

- $\$ 17$ billion in damage to contents and inventory, and

- $\$ 12$ billion in direct business interruption (that is, business interruption losses and additional expenses suffered by building occupants because of damage to their buildings).

Most of these estimated losses in the HayWired scenario are attributable to shaking damage (about 86 percent), the rest are attributable to liquefaction and landslides. Of the losses due to earthquake ground shaking, about 80 percent is attributable to the $M_{\mathrm{w}} 7.0$ mainshock, 12 percent to three aftershocks of $M_{\mathrm{w}} 6.0$ to 6.4 , and 8 percent to 13 aftershocks of $M_{\mathrm{w}} 5.0$ to 5.9. Figure 1 shows that building damage from the mainshock and aftershocks, as a percentage of replacement value, is highest (greater than 10 percent) and most prevalent in Alameda County, followed by Contra Costa and Santa Clara Counties. It also shows widespread damage throughout the bay region of at least 0.5 percent of building replacement costs.

\section{Societal Consequences of Current Code Performance Objectives}

The Hazus-MH analysis for the HayWired scenario examines what happens to the existing building stock in the San Francisco Bay region in a powerful earthquake. Many previous studies have examined the potential effects of earthquakes on buildings (for

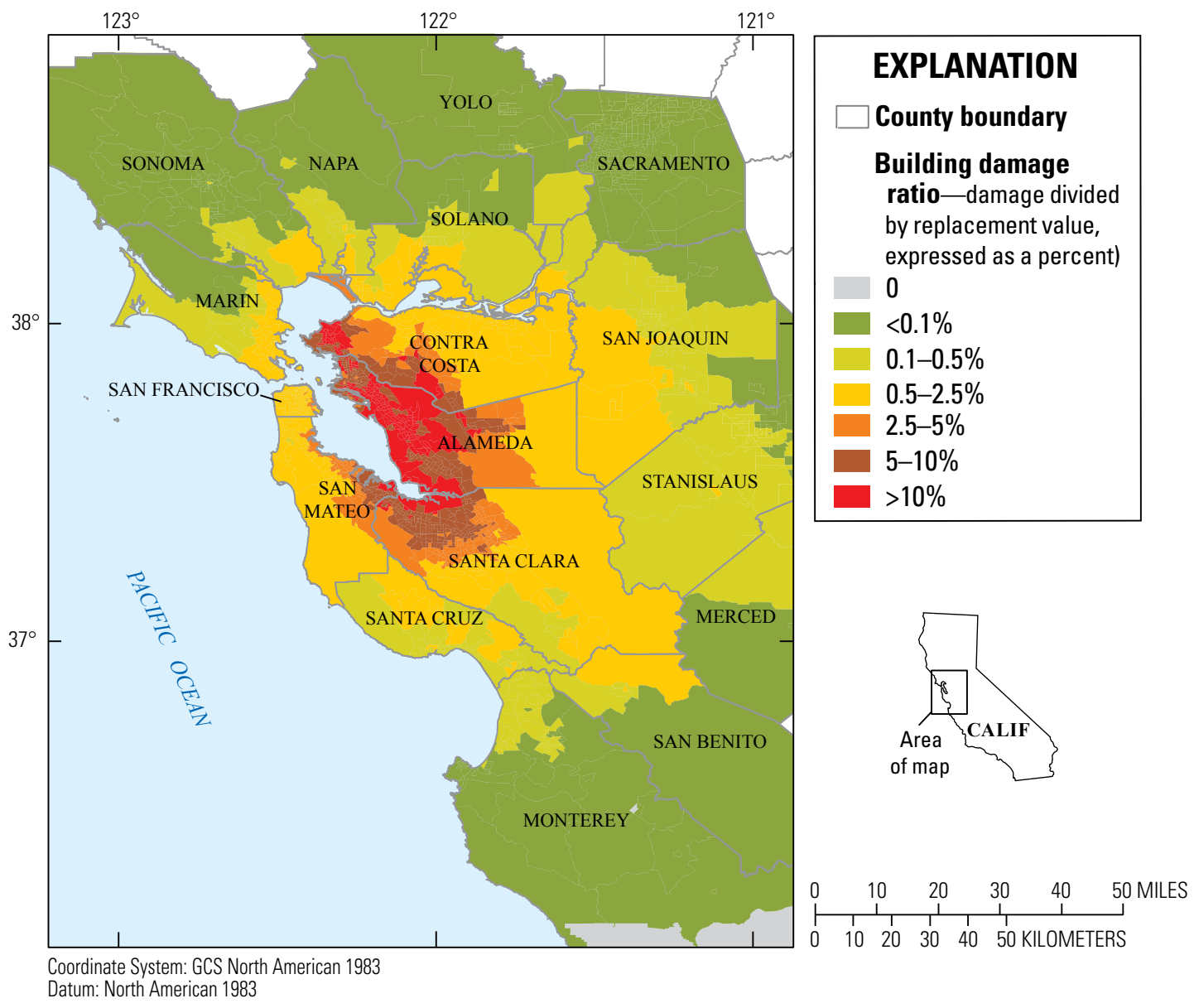

Figure 1. Map of the San Francisco Bay region, California, showing estimated building-damage ratios (repair cost as a percent of building replacement cost) for the hypothetical magnitude-7.0 mainshock and aftershocks of the HayWired earthquake scenario on the Hayward Fault. The building-damage ratio was calculated using the public risk-analysis software Hazus-MH (Federal Emergency Management Agency, 2012a) and considered shaking, liquefaction (soils becoming liquid-like during shaking), and landslide hazards. \%, percent. (From Seligson and others, this volume.) 
example, Jones and others, 2008). The sometimes shockingly large estimates of building damage tend to draw attention to certain existing building types that contribute disproportionately to the overall damaged building stock, such as older unreinforcedmasonry buildings, nonductile concrete buildings, or older weldedsteel moment-frame buildings. In chapter K (Porter, Societal Consequences, this volume), I use this disaster-planning scenario for a new purpose - as a lens through which to view the intended performance of new buildings.

The International Building Code (IBC), on which the California Building Code is based, aims to protect life safety by ensuring that fewer than 1 percent of buildings collapse because of earthquake shaking during their 50 -year design life. However, earthquakes do not randomly affect individual buildings in the way traffic accidents affect people, one or a few at a time. Large urban earthquakes strike millions of people and hundreds of thousands of buildings simultaneously, so when a powerful urban earthquake strikes a region, 1 percent of buildings throughout the region could collapse simultaneously. The remaining buildings do not survive unscathed. Many are damaged to the point that they cannot be used, or even economically repaired, after the earthquake.

Chapter K uses survey data from the $M_{\mathrm{w}} 6.91989$ Loma Prieta and $M_{\mathrm{w}} 6.71994$ Northridge, California, earthquakes to show that, for every collapsed building, approximately 60 are damaged to the point that they are unsafe to enter or occupy (red tag) or have their use restricted to a part of the building or to limited duration (yellow tag). Many more buildings experience damage costing tens of thousands of dollars, often exceeding the owners' financial resources to repair. Again, these results follow indirectly from the IBC's explicit performance objectives for new buildings, which means that, with the code's current performance objectives, the State's existing building stock in 50 years (the year 2067) or even 100 years (the year 2117), for example, will still pose a serious threat to its economic well-being and the lives, livelihoods, and financial stability of the individual people who own, live, or work in those buildings. Figure 2 is a map showing the impairment of existing buildings in the San Francisco Bay region after the HayWired mainshock, even if they all complied
Figure 2. Map of the San Francisco Bay region, California, showing impairment of existing buildings, if they all complied with current building codes, for the magnitude-7.0 mainshock of the HayWired earthquake scenario on the Hayward Fault. Impaired buildings include those that collapsed, are unsafe to occupy, or have restricted use. Warmer colors show areas with the greatest number of impaired buildings. Even if all buildings in the bay region complied with current building codes, 0.4 percent could collapse, 5 percent could be unsafe to occupy, and 19 percent could have restricted use. For only a small percentage cost increase, more resilient buildings constructed to more stringent building codes could allow 95 percent of the bay region's population to remain in their homes and workplaces following such an earthquake. (From Porter, Societal Consequences, this volume.)
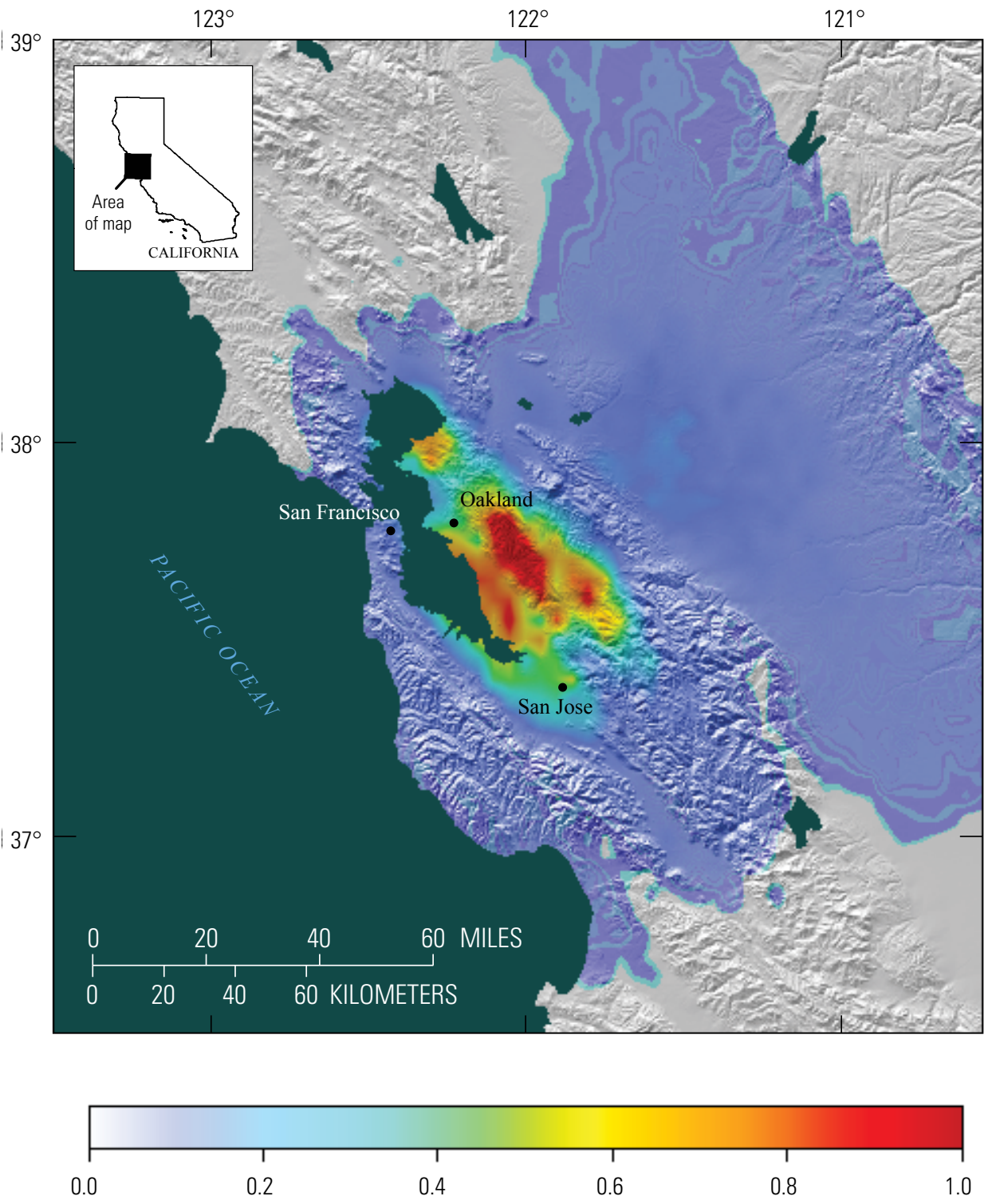

Fraction of impaired buildings 
with current building codes. Chapter $\mathrm{K}$ also shows how stronger buildings, costing about 1 to 3 percent more to build (less than the cost to reroof most buildings) would suffer about 75 percent less damage in terms of collapse, red-tagging, and yellow-tagging in an earthquake like that modeled in the HayWired scenario.

\section{A Survey of Public Preferences for the Seismic Performance of New Buildings}

The IBC strikes a balance for new buildings between better performance and less expense, but what does the public prefer? Chapter L (Porter, Not Safe Enough, this volume) reports on the first survey of the public's expectations and preferences for the seismic performance of new buildings. It turns out that the current building code appears to aim for something different than the public prefers. A survey of 800 people (400 Californians and 400 people from the Memphis, Tennessee, and St. Louis, Missouri, metropolitan statistical areas near the New Madrid Seismic Zone in the Central United States) shows that the majority expect new buildings generally to be habitable or functional after large earthquakes, not merely safe. Survey respondents expressed a willingness to pay at least an additional 1 percent in construction costs to achieve their preferred degree of postearthquake performance (fig. 3). The willingness to pay more for better performance crosses geographic, wealth, and educational boundaries - people from the Central United States express almost the same preferences as do Californians, people from lower income households express almost the same preferences as those from higher income households, and level of education does not seem to affect these preferences.

\section{Earthquake Urban Search and Rescue}

How does building collapse in an earthquake affect demands on urban search and rescue (USAR) teams? Collapse here is defined as the loss of vertical load-carrying capacity in at least part of a building's structural system, which may or may not trap building occupants or passersby. Chapter M (Porter, Earthquake Urban Search and Rescue Model, this volume) estimates the number of people trapped in collapsed buildings in earthquakes, using a new model that draws on an examination of photographs of building collapses in California earthquakes of the past 5 decades. This examination suggests that, when a California building experiences at least some collapse in an earthquake, an average of 25 percent of its occupiable area collapses in such a way that occupants could be trapped under debris. It seems realistic that an earthquake like the HayWired scenario mainshock could trap about 2,500 people in 5,000 collapsed buildings. (There are more collapses than occupants, because not every building collapse traps people.)

Chapter $\mathrm{M}$ also examines the question of how many people would require rescue from stalled elevators in a San Francisco Bay region earthquake like the HayWired scenario mainshock. The ShakeOut scenario hinted that many people could be trapped in stalled elevators when electric power is lost throughout a metropolitan region (Schiff, 2008), but it did not quantify the problem.
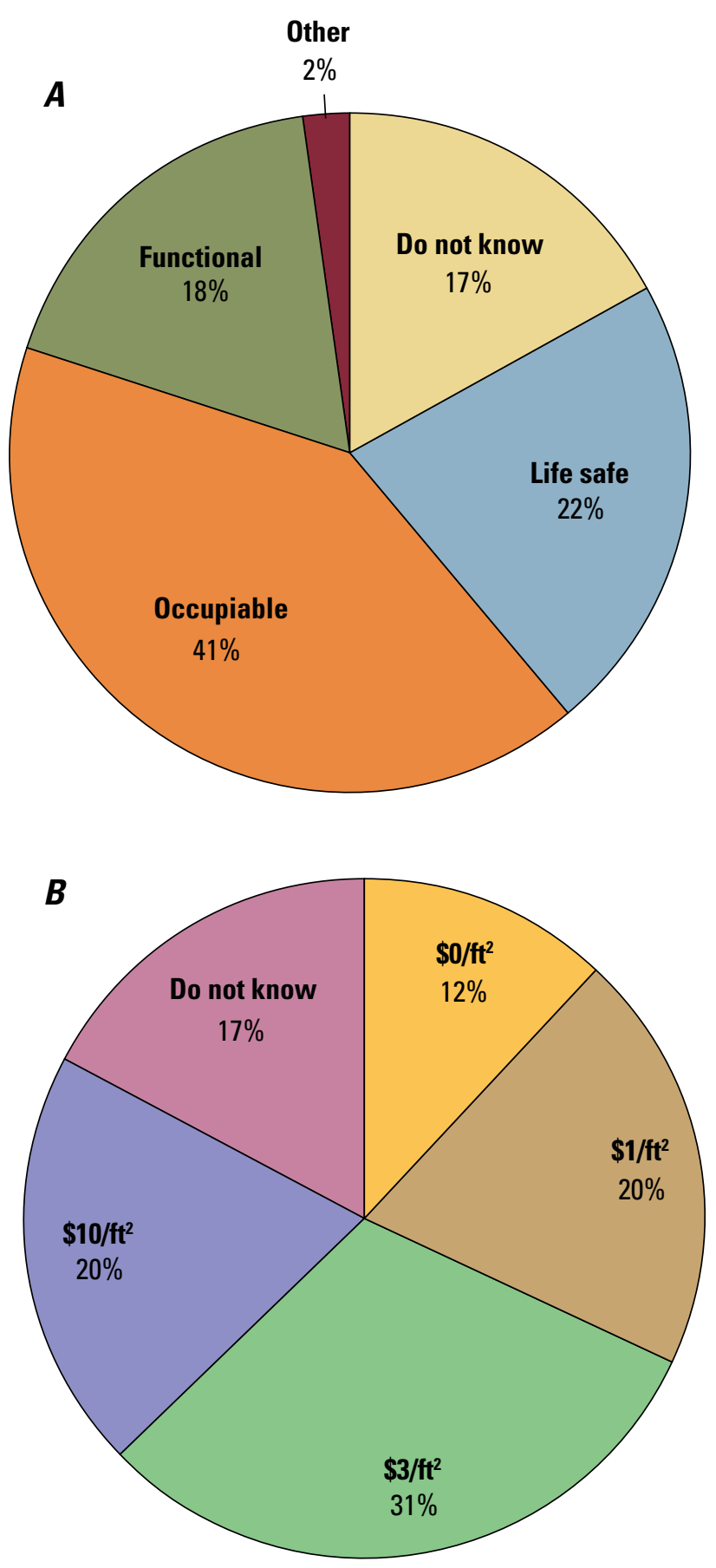

Figure 3. Pie charts showing public preferences for the seismic performance of new buildings from a survey of 800 people $(400$ Californians and 400 people from the Memphis, Tennessee, and St. Louis, Missouri, metropolitan statistical areas near the New Madrid Seismic Zone in the Central United States). Most people surveyed thought that (A) new buildings should remain occupiable or functional after a large earthquake and (B) building buyers would be willing to pay as much as an additional $\$ 3.00$ or more per square foot $\left(\mathrm{ft}^{2}\right)$ to achieve this preferred outcome. \%, percentage of respondents. (Modified from Porter, Not Safe Enough, this volume.) 
Chapter M uses data about the age distribution of bay-region buildings along with the history of elevator emergency-power requirements to show that about 25,000 elevators in the bay region lack emergency power to operate briefly after an earthquake, even to travel to the nearest floor and open doors to let passengers escape. It is reasonable to assume that an earthquake like the HayWired mainshock will cause electric power to go out across the region as utility operators act to protect generators and transmission stability, causing many buildings to lose power before shaking reaches them. Elevator earthquake-safety devices (seismic switches or so-called ring-and-string devices) will therefore not be triggered. As a result, it seems possible that more than 22,000 people could be trapped in approximately 4,600 stalled elevators, requiring USAR personnel - generally firefighters - to free them (fig. 4). The job of extricating more than 22,000 people from 4,600 stalled elevators, along with about 2,400 people from 5,000 collapsed buildings, would fall to the approximately 19,000 firefighters who work in the San Francisco Bay region, at the same time as those firefighters are fighting fires.

\section{Water-Network Resilience}

Many authors have studied the effects of earthquakes on water-supply systems. Chapter N (Porter, Water-Network Resilience, this volume) offers a new water-network resilience model with a unique combination of features. It deals with lifeline interaction by directly modeling how individual repairs are

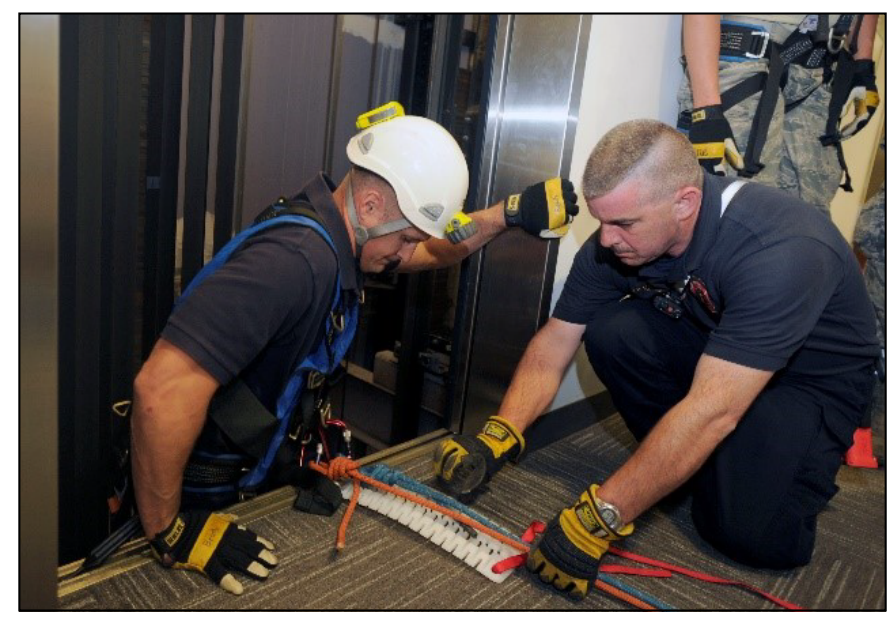

Figure 4. Photograph of firefighters practicing rescue techniques to free people trapped in stalled elevators. Firefighters tend to provide the vast majority of urban search and rescue expertise. After an earthquake like the hypothetical magnitude-7.0 mainshock of the HayWired earthquake scenario on the Hayward Fault in California's San Francisco Bay region, they would be called on to extricate thousands of people trapped in stalled elevators and collapsed buildings at a time when they are also called on to fight fires. (U.S. Air Force photograph by Senior Airman Preston Webb; see Porter, Earthquake Urban Search and Rescue Model, this volume.) slowed by limitations in other lifelines and by human and other resource limitations. It quantifies damage and restoration over an entire earthquake sequence - that is, considering damage in the mainshock, aftershocks, and afterslip. It offers an empirical model of water-service restoration as a function of the number of pipeline repairs performed (as opposed to more rigorous, but computationally demanding, hydraulic analysis). It can be used by water-agency staff with a spreadsheet and geographic information system (GIS), rather than requiring a consultant with proprietary software. It can be implemented either deterministically or stochastically, meaning that a sophisticated user can quantify uncertainty but is not required to do so. It does not require hydraulic analysis of the damaged water-supply system or the system as repairs proceed, although that simplification necessarily limits insight into how water pressure would vary throughout the system. The model offers a procedure to adjust Hazus-MH estimates of restoration to account for an earthquake sequence and lifeline interaction and corrects for Hazus' default assumptions about the number of available repair crews during a disaster.

The new water-network resilience model is used to estimate damage and restoration to counties served by two water networks in the San Francisco Bay region for the HayWired scenario earthquake sequence (fig. 5) - those of the San Jose Water Company (SJWC) and of the East Bay Municipal Utility District (EBMUD). The more seriously damaged of the two networks would likely be EBMUD because of its proximity to the Hayward Fault. In the scenario, EBMUD's 4,162 miles $(6,698 \mathrm{~km})$ of pipe suffer about 1,800 breaks and 3,900 leaks during the earthquake sequence, equivalent to 1.4 repairs per mile of pipe (about 0.85 repairs per kilometer of pipe). More than half of water-pipeline damage results directly from ground shaking (60 percent); the remaining damage occurs from liquefaction ( 29 percent), landslides ( 3 percent), and coseismic slip (4 percent) and afterslip on the fault (4 percent). In the HayWired scenario, the average EBMUD customer would be without water for 6 weeks, some for as many as 6 months. EBMUD customers suffer a total of 19 million lost service days (each day of lost water supply to a service connection). That loss can be reduced by half if current efforts to replace old, brittle pipe are completed before the next large bay-region earthquake occurs, because such pipe is more susceptible to earthquake damage, and replacing it would reduce damage and therefore restoration time. Also, about 200,000 lost service days could be saved by decreasing or eliminating EBMUD's dependence on commercial fuel supplies. In the scenario, SJWC suffers less damage-1,000 pipe repairs, of which about 70 percent are water leaks, the rest breaks - and customers would suffer approximately 1 million lost service-days. A utility can reduce its reliance on commercial fuel supplies in a disaster by installing fuel-storage tanks in its service centers or by otherwise ensuring that repair crews have access to fuel. Implementing such a fuel plan would reduce SJWC's losses by about 25 percent. If SJWC completes replacement of all brittle cast-iron and asbestos-cement pipe (about 25 years at current replacement rates) before an earthquake occurs, losses would be reduced by about half. 


\section{Repair Costs and Downtime of High-Rise Buildings}

New earthquake-engineering procedures have emerged since the ShakeOut scenario (Jones and others, 2008) that allow one to estimate repair costs and duration of loss of function for individual, particular buildings. High-rise buildings like the one shown in figure 6 are a particular concern for the engineering community, because a single building can house more than 1,000 people and dozens of businesses, making such buildings potential threats to lives and livelihoods in the San Francisco Bay region should they be damaged in an earthquake. In chapter O (Almufti and others, this volume), second-generation, performance-based earthquake-engineering procedures are applied to 10 example

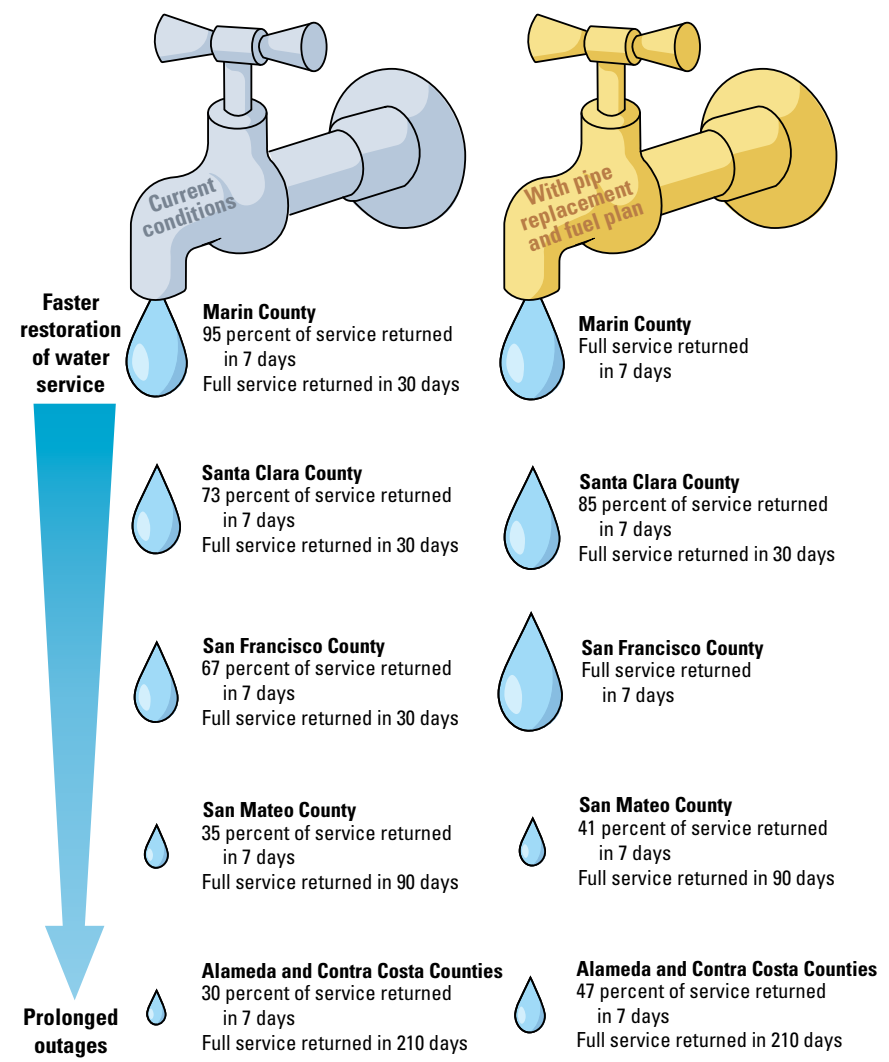

Figure 5. This illustration shows water-service restoration times for counties in California's San Francisco Bay region following the hypothetical moment-magnitude-7.0 mainshock of the HayWired earthquake scenario. The image at left shows current conditions, and the image at right shows how water-service restoration times could be substantially improved if water utilities replaced all brittle pipe in their systems and had a fuel-management plan and emergency generators with fuel at all pumping stations. (From Hudnut and others, 2018, https://doi.org/10.3133/fs20183016, using data in Porter, Water-Network Resilience, this volume.) buildings. These examples show that an earthquake like the $M_{\mathrm{w}} 7.0$ mainshock of the HayWired scenario could damage a pre-1994 (Northridge earthquake) welded-steel moment-frame office tower in downtown Oakland or San Francisco such that it would require 6 to 13 months to reoccupy and cost 7 to 21 percent of its replacement cost to repair, mostly because of nonstructural damage. Even a modern reinforced-concrete high-rise residential building could require 4 to 7 months of repairs before it could be reoccupied and cost 3 to 6 percent of its replacement cost to repair damaged nonstructural elements. Collapse of such high-rise buildings appears to be unlikely in downtown Oakland and San Francisco in an earthquake like the HayWired mainshock. However, this is not to say that other kinds of high-rise buildings could not collapse in these or other locations in the bay region.

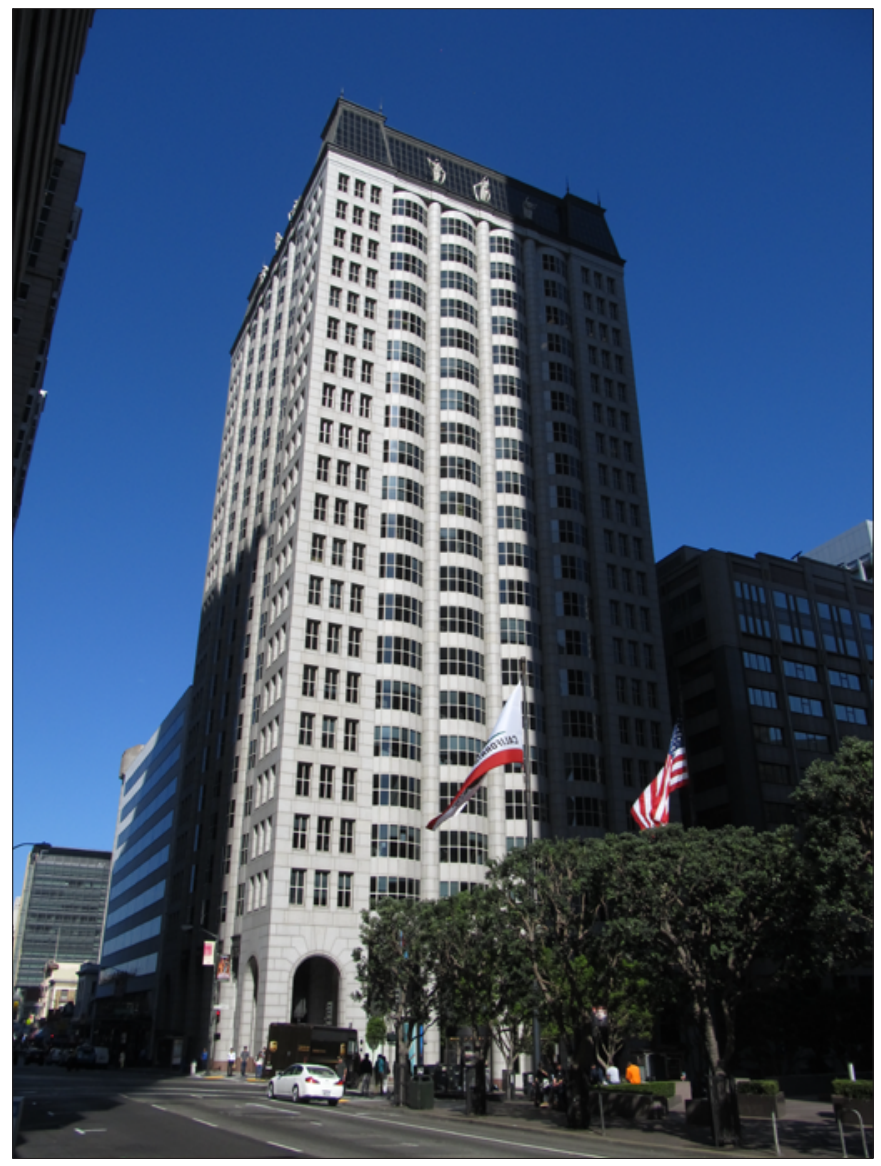

Figure 6. Photograph of a San Francisco Bay area, California, high-rise building. High-rise buildings account for roughly 3 percent of the total building square footage in the bay area, and each of these buildings can house more than 1,000 people and dozens of businesses. However, total collapse of such a building appears to be unlikely in downtown Oakland or San Francisco in an earthquake like the hypothetical magnitude-7.0 mainshock of the HayWired earthquake scenario on the Hayward Fault. (Photograph by Ken Lund, Creative Commons 3.0, https://www.flickr.com/photos/ kenlund/10753946294; see Almufti and others, this volume.) 


\section{Fire Following Earthquake}

In chapter P (Scawthorn, this volume), a standard model of fire following earthquake is applied to the HayWired scenario. The HayWired mainshock could produce about 670 ignitions requiring the response of a fire engine, 90 percent of which would occur in Alameda, Contra Costa, and Santa Clara Counties. Approximately 450 of these fires would not be immediately contained such that large fires would be likely to merge into numerous conflagrations destroying tens of city blocks. The fires would burn approximately 79 million square feet (about 7.3 million square meters) of building floor area, equivalent to more than 52,000 single-family dwellings. These fires would kill hundreds of people and cause property (building and content) losses approaching $\$ 30$ billion.
The property losses are almost fully insured. Fire following earthquake in the HayWired scenario would produce one of the largest single-loss events in the history of the insurance industry.

Other potential economic impacts from fire following earthquake include the loss of perhaps $\$ 1$ billion in local tax revenues. A number of opportunities exist for mitigating this problem, including greatly enhancing the postearthquake supply of water for firefighting; the mandatory use of automated gas shut-off valves, or seismic shut-off meters, in densely built areas; and the use of portable water-supply systems. Toward that end, the first joint exercise of fire agencies in the San Francisco Bay area to practice the use of portable water-supply systems was conducted as part of HayWired (fig. 7).

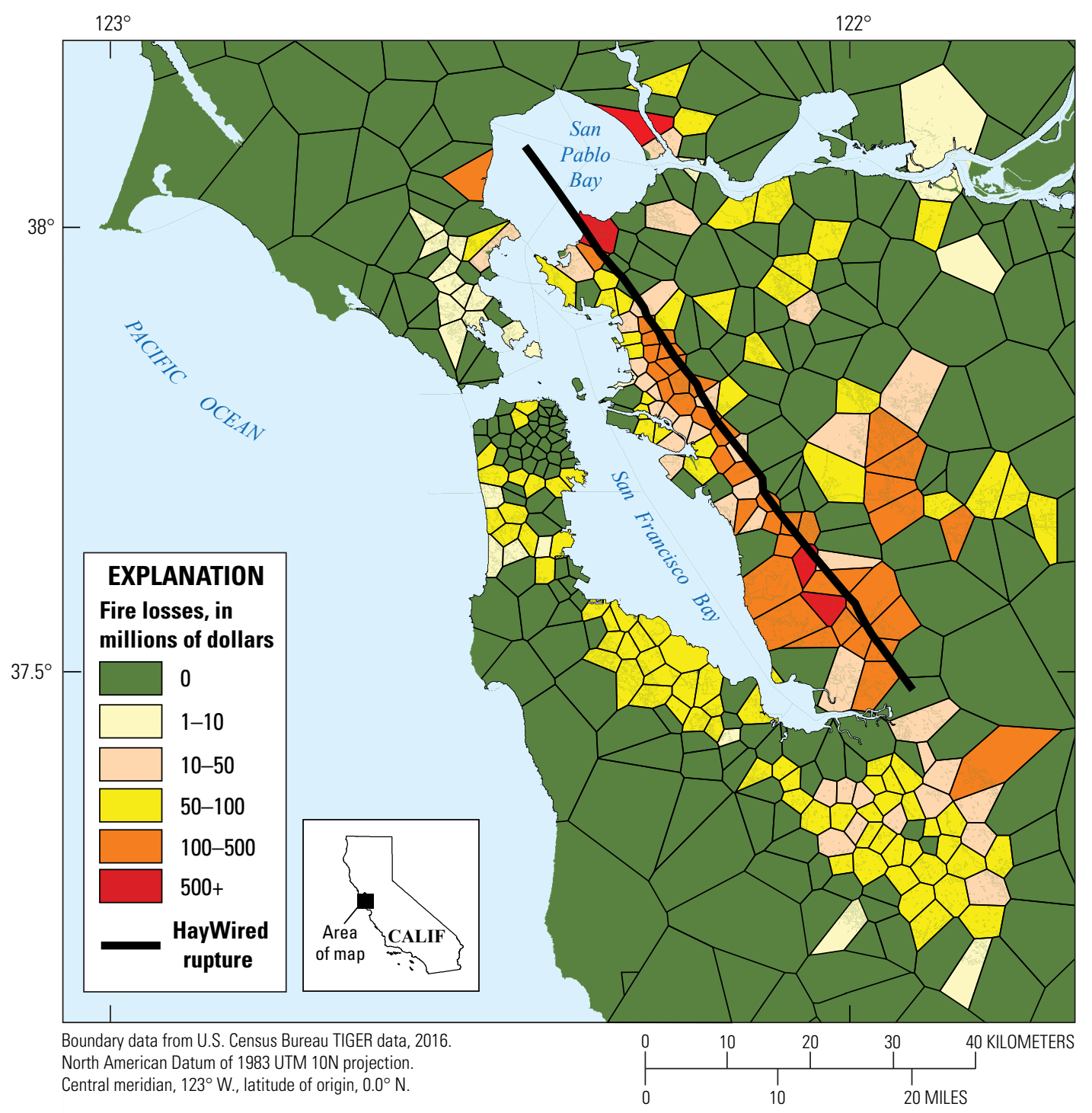

Figure 7. This map of California's San Francisco Bay region shows areas burned as a result of fires caused by the hypothetical magnitude-7.0 mainshock of the HayWired earthquake scenario on the Hayward Fault. Warmer colors show areas with greater losses in millions of dollars. Areas (polygons) shown are based on distance to the closest fire station. The black line shows the length of the fault rupture in the scenario. (From Scawthorn, this volume.) 


\section{Benefit of Combining Earthquake Early Warning with Drop, Cover, and Hold On}

Since the advent of ShakeOut exercises following the publication of The ShakeOut Scenario (Jones and others, 2008), every year millions of people worldwide practice drop, cover, and hold on (DCHO) earthquake self-protective actions (https:// www.shakeout.org/). During the same period, earthquake early warning (EEW) systems have become available (for example, the Android phone and iPhone app Yurekuru Call in Japan) to warn people about earthquakes in the seconds before strong motion arrives. Chapter Q (Porter and Jones, this volume) offers a new study of the potential benefits of combining EEW and DCHO. It expresses those benefits in terms of avoided injuries and the acceptable cost to avoid those injuries. A survey was made of 500 people who first took DCHO training and then reported how long it took them to complete the actions. Using these new data and estimates of the advanced warning (as much as 25 seconds) that EEW would provide San Francisco Bay region residents in the event of an earthquake like the HayWired mainshock, it is shown that combining EEW and DCHO could prevent as many as 1,500 nonfatal injuries out of 18,000 estimated nonfatal injuries (from shaking and liquefaction hazards) in the HayWired scenario (fig. 8). Using U.S. Government standard figures for the acceptable cost to avoid future statistical injuries, the combination of EEW and DCHO in a powerful bay region earthquake would be a benefit valued at approximately $\$ 300$ million.

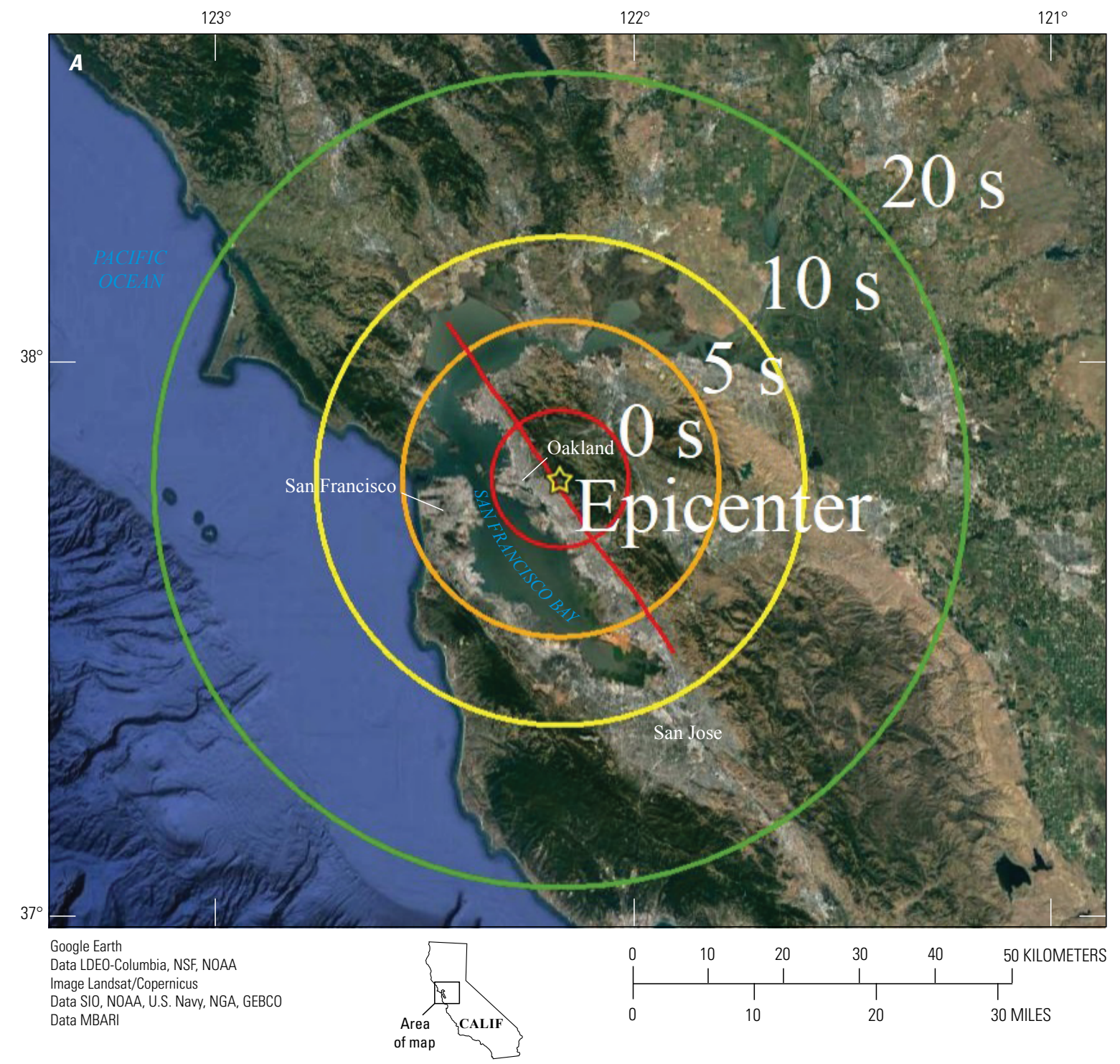

Figure 8. In the hypothetical magnitude-7.0 mainshock of the HayWired earthquake scenario on the Hayward Fault in California's San Francisco Bay region, combining earthquake early warning (EEW) and drop, cover, and hold on (DCHO) practices could result in as many as 1,500 nonfatal injuries being prevented out of 18,000 estimated nonfatal injuries, a benefit valued at about $\$ 300$ million. $A$, Satellite image showing EEW times in seconds (s) for the HayWired mainshock. The red line, shows the length of the fault rupture in the scenario, and the epicenter (star) is beneath the City of Oakland. (Satellite image from Google Earth.) B, Illustration showing how to DCHO (courtesy of ShakeOut.org). 
$\boldsymbol{B}$
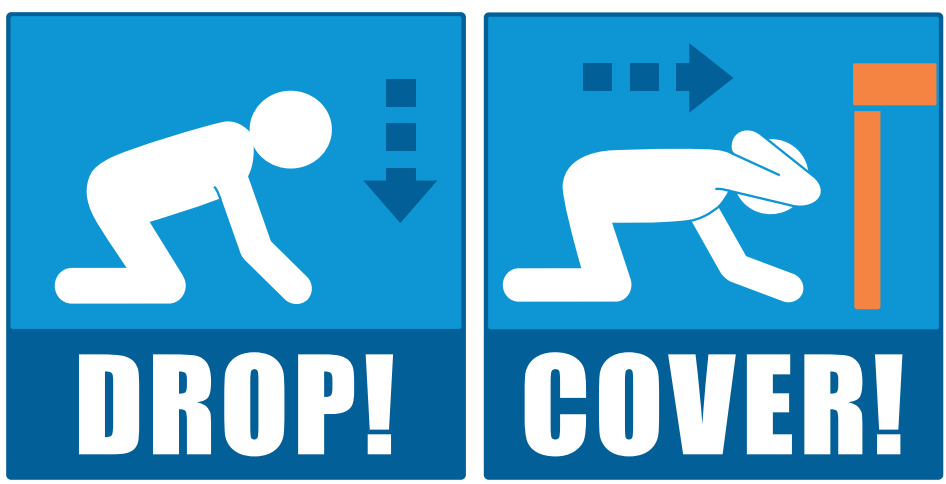

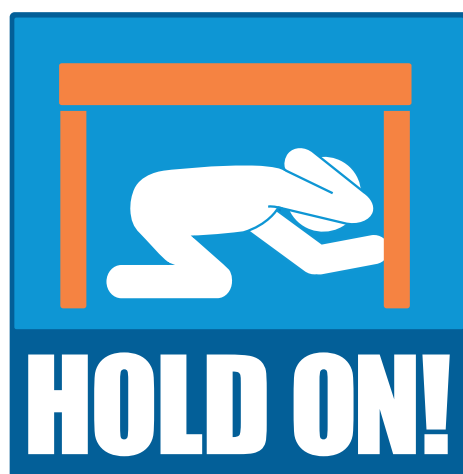

Figure 8.-Continued

\section{Future Research}

The developers of the HayWired earthquake scenario did not intend or expect to examine every engineering-related issue (or other important topic) arising from a large Hayward Fault earthquake, partly because of all the previous work on the subject. However, several outstanding engineering issues remain unexplored and would be worth examining. A few of these include:

1. The cost of performing Applied Technology Council (ATC) ATC-20 post-earthquake safety evaluations.-The 1994 Northridge earthquake resulted in ATC-20 earthquake safety-inspection (Applied Technology Council, 2005) of 100,000 buildings. The HayWired mainshock is a larger earthquake than the one in Northridge and takes place in a more densely populated urban area, suggesting that many more ATC-20 evaluations would be required. California has approximately 6,000 certified evaluators, another 4,000 live elsewhere in the United States (Jim Barnes, California Governor's Office of Emergency Services, oral commun., September 29, 2017). Most have other day jobs. They would only be briefly available to volunteer to perform ATC-20 evaluations. It might take weeks or more to complete the required ATC-20 evaluations. During that time, many occupants would be displaced from their buildings while awaiting evaluations. What would be the cost of delayed ATC-20 evaluations, and how much time and economic value might be saved through automation, such as using FEMA's Rapid Observation of Vulnerability and Estimation of Risk (ROVER) software (Federal Emergency Management Agency, 2013)?

2. Effectiveness of DCHO to avoid injuries during shaking.-People believe DCHO to be effective, but how effective, and how can we be sure? Nobody has ever tested the effectiveness of DCHO self-protective actions. The question matters for several reasons, some of which include judging the costs versus benefits of further reducing nonstructural hazards, and estimating needs for emergency medical care. There is very little informa- tion to answer any of these questions, partly because no research program seems to currently focus on understanding human injuries in earthquakes.

3. Cost effectiveness of seismic gas-shutoff valves.- It seems intuitive that seismic gas-shutoff valves would reduce the risk of fires, but they introduce costs - upfront construction costs and costs of reopening the valves after an earthquake. Under what conditions are the costs justified? The answer is not self-evident.

4. Modeling electric-utility-service damage and restoration.-Electric-service impairment and subsequent restoration depends on electric network stability as much as it does on physical damage to generation facilities, transmission and distribution lines, substations, and neighborhood and pole-mounted transformers. It would be desirable to construct a model akin to the water-network resilience model introduced here, which does not require proprietary software. Such a model of electricutility resilience would need to be able to estimate damage and restoration time, while accounting for lifeline interaction, human and other resource limitations, and the engineering characteristics of the various components just listed, without requiring sensitive data from the electric-service provider.

\section{Conclusion}

This chapter and the volume it summarizes describe realistic engineering implications of a large earthquake on what may be the most urbanized active fault in the United States - the Hayward Fault. It is not intended to represent a best case, a worst case, or an average case, merely one that is worth planning for. It shows how such an earthquake could cause more than $\$ 82$ billion in property loss and direct business interruption losses over the modeled earthquake sequence, plus another $\$ 30$ billion in property (building and content) losses resulting from fires after the mainshock. 
Because it aims at depth rather than breadth, this volume mostly omits a number of important topics that have been addressed well elsewhere; for example:

- What to do about high-risk existing buildings is not addressed. Interested readers can refer to the San Francisco Community Action Plan for Seismic Safety (CAPSS) and Earthquake Safety Improvement Program (ESIP) (see http://sfgov.org/esip/program/) or to the City of Santa Monica's comprehensive seismic retrofit program (see https://www.smgov.net/Departments/PCD/Programs/Seismic-Retrofit/) for valuable guidance on that topic.

- Very little is discussed about dealing with nonstructural building components. The interested reader can see FEMA's E-74 document (Federal Emergency Management Agency, 2012b).

- There is little discussion about electricity and gas. The interested reader can refer to Pacific Gas and Electric Company's web pages on residential and business earthquake preparedness (https://www.pge.com/en US/safety/emergency-preparedness/natural-disaster/ earthquakes/earthquakes.page).

The HayWired scenario's developers hope that the information here and in other HayWired volumes will inform the reader's decisions about how to prepare for a large earthquake, whether by strengthening infrastructure to better resist earthquakes or through improved planning to recover more quickly despite damage. Ideally, the HayWired scenario volumes will help readers collectively improve their own and their community's resilience in future disasters.

Work that straddles the boundary between engineering and social and economic consequences is planned to be described in a third HayWired volume. Beyond that, a group of government and other organizations called the HayWired Coalition (see chapter A, Hudnut and others, 2017; and Hudnut and others, 2018) intends to build on the work presented here through a series of planning and preparedness activities. As HayWired volumes are published, they will be made available at https://doi.org/10.3133/sir20175013.

\section{References Cited}

Applied Technology Council, 2005, ATC-20-1—Field handbook - Procedures for postearthquake safety evaluation of buildings: Redwood City, Calif., Applied Technology Council, $144 \mathrm{p}$.
Detweiler, S.T., and Wein, A.M., eds., 2017, The HayWired earthquake scenario-Earthquake hazards: U.S. Geological Survey Scientific Investigations Report 2017-5013-A-H, 126 p., accessed September 13, 2017, at https://doi.org/10.3133/ sir20175013v1.

Federal Emergency Management Agency, 2012a, Hazus multihazard loss estimation methodology, earthquake model, Hazus ${ }^{\circledR}-\mathrm{MH} 2.1$ technical manual: Federal Emergency Management Agency, Mitigation Division, 718 p., accessed September 13, 2017, at https://www.fema.gov/media-librarydata/20130726-1820-25045-6286/hzmh2_1_eq_tm.pdf.

Federal Emergency Management Agency, 2012b, Reducing the risks of nonstructural earthquake damage - A practical guide: Federal Emergency Management Agency, FEMA E-74, 885 p., accessed September 13, 2017, at https://www.fema.gov/fema-e74-reducing-risks-nonstructural-earthquake-damage.

Federal Emergency Management Agency, 2013, ROVER, end-to-end mobile software for managing seismic risk: Federal Emergency Management Agency flyer, 1 p., accessed September 13, 2017, at https://www.fema.gov/media-library/ assets/documents/21350.

Hudnut, K.W., Wein, A.M., Cox, D.A., Perry, S.C., Porter, K.A, Johnson, L.A., and Strauss, J.A., 2017, The HayWired scenario- How can the San Francisco Bay region bounce back from or avert an earthquake disaster in an interconnected world?, chap. A of Detweiler, S.T., and Wein, A.M., eds., The HayWired earthquake scenario-Earthquake hazards: U.S. Geological Survey Scientific Investigations Report 20175013-A-H, 126 p., accessed September 13, 2017, at https://doi. org/10.3133/sir20175013v1.

Hudnut, K.W., Wein, A.M., Cox, D.A., Porter, K.A., Johnson, L.A., Perry, S.C., Bruce, J.L., and LaPointe, D., 2018, The HayWired earthquake scenario-We can outsmart disaster: U.S. Geological Survey Fact Sheet 2018-3016, 6 p., https://doi. org/10.3133/fs20183016.

Jones, L.M., Bernknopf, R., Cox, D., Goltz, J., Hudnut, K., Mileti, D., Perry, S., Ponti, D., Porter, K., Reichle, M., Seligson, H., Shoaf, K., Treiman, J., and Wein, A., 2008, The ShakeOut scenario: U.S. Geological Survey Open-File Report 2008-1150 and California Geological Survey Preliminary Report 25, 312 p. and appendixes, accessed September 13, 2017, at https://pubs. usgs.gov/of/2008/1150/.

Schiff, A., 2008, The ShakeOut scenario supplemental study - Elevators: Denver, Colo., SPA Risk LLC, accessed September 13, 2017, at http://www.sparisk.com/pubs/ ShakeOutScenarioElevatorsSchiff.pdf. 



\title{
Chapter J
}

\section{HayWired Scenario-Hazus Analyses of the Mainshock and Aftershocks}

\author{
By Hope A. Seligson, ${ }^{1}$ Anne M. Wein, ${ }^{2}$ and Jamie L. Jones ${ }^{2}$
}

\section{Abstract}

The HayWired scenario examines a hypothetical earthquake (mainshock) with a moment magnitude $\left(M_{\mathrm{w}}\right)$ of 7.0 occurring on April 18, 2018, at 4:18 p.m. on the Hayward Fault in the east bay part of California's San Francisco Bay area. Analyses of building damages and direct economic losses from the HayWired mainshock and its aftershocks have been conducted using Hazus, the Federal Emergency Management Agency's (FEMA) multi-hazard geographic information system-based loss estimation methodology and software. The initial Hazus analysis of the HayWired scenario mainshock (Aagaard and others, 2017) - the baseline default run - was conducted by FEMA using Hazus-MH 2.1 with improved inventory data originally developed for the 100th Anniversary Earthquake Conference commemorating the 1906 San Francisco earthquake. In this study, the mainshock was further analyzed using custom HayWired landslide probability and displacement estimates and custom HayWired liquefaction probability estimates. The baseline default Hazus shaking and liquefaction run was also revised to use the same groundwater depth data as used in the U.S. Geological Survey (USGS) analysis of liquefaction probability.

The aftershock sequence (a catalog of earthquakes each with a date/time, magnitude, location, and depth) was simulated by the USGS using aftershock statistics. Hazus analyses of 16 aftershock events of magnitude 5 or greater were performed using the same improved inventory databases as the initial analysis of the mainshock. This chapter (1) describes the results of the initial and revised Hazus analyses of the mainshock (considering shaking, liquefaction, and landslide hazards) and aftershocks (considering shaking and Hazus default liquefaction in selected events), (2) assesses the potential impact of liquefaction and repeated liquefaction,

\footnotetext{
${ }^{1}$ Seligson Consulting, initial efforts conducted while with MMI Engineering.

${ }^{2}$ U.S. Geological Survey.
}

(3) reviews expected performance of unreinforced masonry construction in the various events, (4) compares population displacement and shelter estimates using default parameters and custom parameters developed for the Southern California ShakeOut scenario, (5) compares various approaches for combining losses in the mainshock and aftershocks, and (6) identifies knowledge gaps and study limitations.

The results of the mainshock assessment yield building losses of $\$ 35.2$ billion (in 2005 dollars, estimated as $\$ 43.3$ billion in 2016 dollars): $\$ 30.3$ billion (in 2005 dollars, $\$ 37.3$ billion in 2016 dollars) in damage from shaking, $\$ 4.6$ billion (in 2005 dollars, $\$ 5.7$ billion in 2016 dollars) in damage from liquefaction, and $\$ 300$ million (in 2005 dollars, $\$ 360$ million in 2016 dollars) in damage from landslide. Over the entire earthquake sequence, the total direct economic loss can be approximated as $\$ 67.0$ billion (in 2005 dollars, $\$ 82.6$ billion in 2016 dollars). This includes the following:

- $\$ 43.3$ billion (in 2005 dollars, $\$ 53.3$ billion in 2016 dollars) in building damage for the mainshock and all aftershocks, using USGS-modeled liquefaction and landslide hazard and probability data for the mainshock, where available, and the Hazus default liquefaction modeling approach for other areas in the mainshock as well as for three aftershocks (M5.98 Mountain View, M6.4 Cupertino, and M5.42 Oakland). The remainder of aftershocks were modeled for shaking only.

- $\$ 13.8$ billion (in 2005 dollars, $\$ 17.0$ billion in 2016 dollars) in damage to contents and commercial inventories, estimated using the Hazus default liquefaction modeling approach for the mainshock and the three aftershocks identified above, and considering only ground-shaking hazards for the remainder of events.

- $\$ 10.0$ billion (in 2005 dollars, $\$ 12.3$ billion in 2016 dollars) in building damage-related income losses (for example, relocation costs, lost rent, and so on), modeled in the same manner as contents and inventory damage. 
About 80 percent of the losses from the earthquake sequence are from the $M_{\mathrm{w}} 7.0$ mainshock, 12 percent from the three largest aftershocks of $M_{\mathrm{w}} 6.0$ to 6.4 , and 8 percent from the 13 aftershocks of $M_{\mathrm{w}}$ 5.0 to 5.9. Displaced household assessments range from tens of households for the smallest aftershocks, to hundreds of households for the largest aftershocks, to tens of thousands of households $(77,000$ 153,000 ) for the mainshock (based on the 2000 U.S. Census).

\section{Introduction}

The HayWired scenario examines a hypothetical earthquake (mainshock) with a moment magnitude $\left(M_{\mathrm{w}}\right)$ of 7.0 occurring on April 18, 2018, at 4:18 p.m. on the in the east bay part of California's San Francisco Bay area. The rupture of the Hayward Fault starts under the city of Oakland, with fault slip progressing north into San Pablo Bay and south to the city of Fremont (Aagaard and others, 2017). The mainshock shaking data (U.S. Geological Survey [USGS], 2014), simulated using a three-dimensional model (Aagaard and others, 2017), were used directly in the Federal Emergency Management Agency's (FEMA) damage and loss modeling tool, Hazus (FEMA, 2012). The shaking data for the HayWired mainshock were also used to derive data for (1) liquefaction probability (Jones and others, 2017) and (2) landslide probability and displacement (McCrink and Perez, 2017).

The HayWired aftershock sequence has thousands of aftershocks and is described in Wein and others (2017). The larger aftershocks (magnitude $[M]>5$ ) in the sequence simulated for the $M_{\mathrm{w}} 7.0$ HayWired mainshock are identified in table 1 . The sequence includes two $M>6$ events (one in Palo Alto and one in Cupertino) and spans 2 years. The locations of the 16 aftershocks are shown in figure 1. The regional ground-shaking data for these aftershocks (USGS, 2015) were also used directly in Hazus.

\section{Building Inventory Data}

The initial Hazus analysis conducted for the HayWired scenario mainshock was executed using Hazus-MH 2.1 by FEMA personnel (Doug Bausch of FEMA Region VIII) using the custom ground motion data for the HayWired scenario mainshock (USGS, 2014) and enhanced Hazus building inventory data originally developed in 2005-2006 as part of a modeling effort for the 100th Anniversary Earthquake Conference Commemorating the 1906 San Francisco Earthquake (Kircher and others, 2006). The Hazus database improvements include retrofitted building models for unreinforced masonry (URM), non-ductile concrete, and softstory wood frame ${ }^{1}$ structures; replacement cost escalation factors to better reflect actual building inventory values; and enhanced mapping schemes (relationships by building occupancy class that describe the percentage distribution of square footage among various structural types or model building types (MBTs), as referred to within Hazus). A total of 22 custom mapping schemes were applied at the census-tract level across the bay area, reflecting differing building age and height patterns, as well as building density; a separate set of schemes were applied to San Francisco and Alameda Counties to reflect urban core

\footnotetext{
${ }^{1}$ Within Hazus, non-ductile concrete is generally represented by "pre-code" design level concrete moment frame (model building type $\mathrm{C} 1$ ) and concrete frame with URM infill wall (C3) buildings. Pre-code precast concrete frame buildings with concrete shear walls (PC2) may also be considered non-ductile. Soft-story wood frame is similarly represented by pre-code wood frame (W1 and W2) buildings.
}

Table 1. Sequence of aftershocks of magnitude 5 or greater of the HayWired earthquake scenario, San Francisco Bay region, California.

[Data from U.S. Geological Survey (2014). Date format is month/day/year. Day is relative to the day the HayWired mainshock event occurred, with April 18, 2018, counted as day 1. Latitude is in decimal degrees north; longitude is in decimal degrees west. Depth is how far below the Earth's surface the aftershock hypocenter is located. No., event number; PDT, Pacific Daylight Time; km, kilometers; Mag., magnitude; Short name, short event name]

\begin{tabular}{|c|c|c|c|c|c|c|c|c|c|}
\hline No. & Date & Day & Time (PDT) & Latitude & Longitude & Location & Depth (km) & Mag. & Short name \\
\hline 1 & $4 / 18 / 2018$ & 1 & 4:49 p.m. & 37.6008 & 122.0172 & Union City & 2.60 & 5.23 & UC523 \\
\hline 2 & $4 / 19 / 2018$ & 2 & $4: 16$ a.m. & 37.9630 & 122.3473 & San Pablo & 2.60 & 5.04 & SP504 \\
\hline 3 & $4 / 29 / 2018$ & 12 & 11:13 p.m. & 38.1916 & 122.1483 & Fairfield & 11.05 & 5.58 & FF558 \\
\hline 5 & $5 / 20 / 2018$ & 33 & 8:37 a.m. & 37.7561 & 122.1508 & Oakland & 8.45 & 5.42 & OK542 \\
\hline 6 & $5 / 28 / 2018$ & 41 & 4:47 a.m. & 37.3867 & 122.1780 & Palo Alto & 15.97 & 6.20 & PA62 \\
\hline 9 & $5 / 28 / 2018$ & 41 & 11:53 p.m. & 37.4099 & 122.1184 & Palo Alto & 8.36 & 5.69 & PA569 \\
\hline 10 & $6 / 23 / 2018$ & 67 & 8:27 p.m. & 37.4391 & 122.1511 & Palo Alto & 2.85 & 5.22 & PA522 \\
\hline 11 & $7 / 01 / 2018$ & 75 & 11:19 a.m. & 37.4435 & 122.1561 & Palo Alto & 8.69 & 5.26 & PA526 \\
\hline 12 & $9 / 30 / 2018$ & 166 & 8:16 p.m. & 37.4386 & 122.0770 & Mountain View & 11.29 & 5.98 & MV598 \\
\hline 13 & $10 / 01 / 2018$ & 167 & 12:33 a.m. & 37.3068 & 122.0592 & Cupertino & 14.45 & 6.40 & CU64 \\
\hline
\end{tabular}




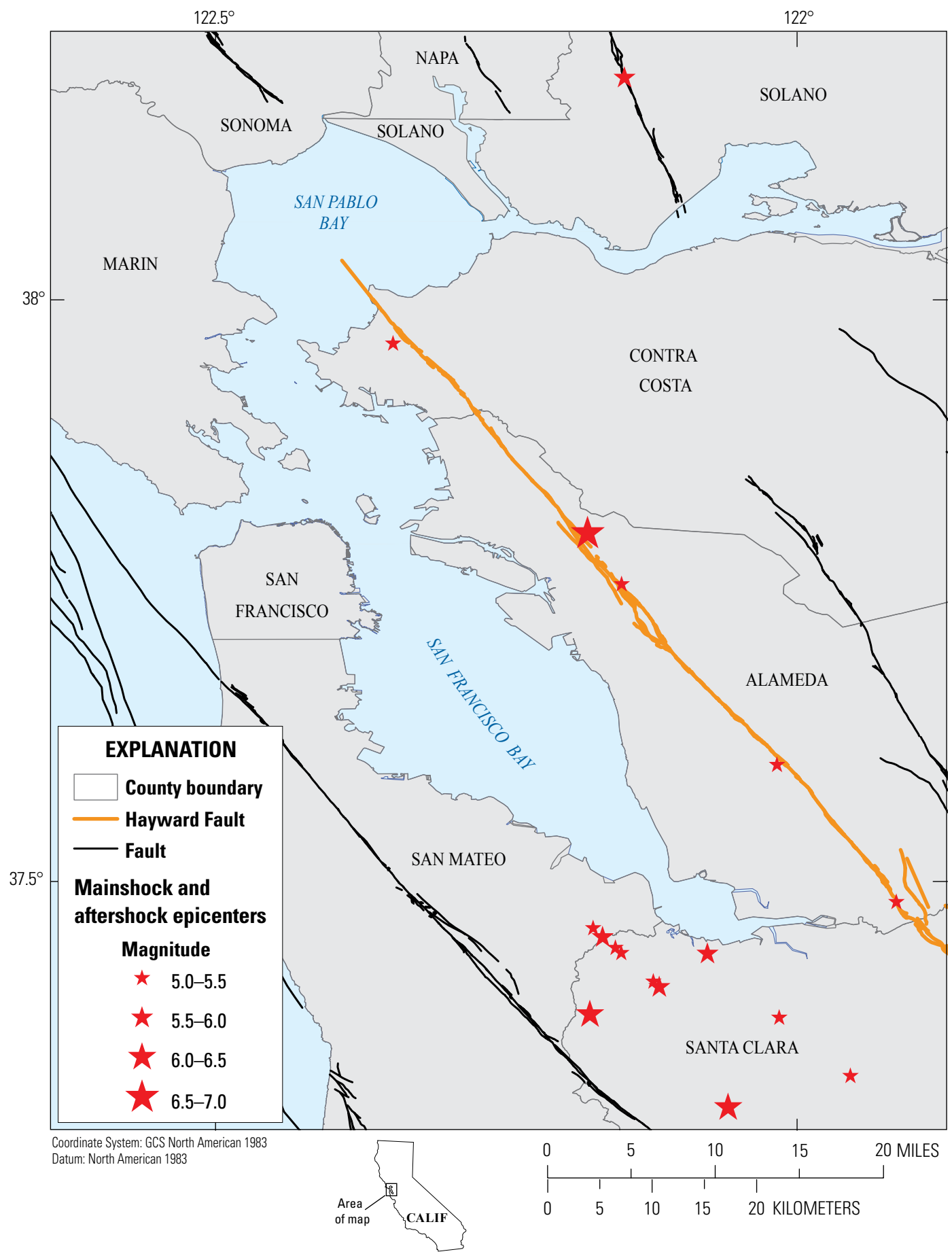

Figure 1. Map showing epicenters of the mainshock (largest red star) and aftershocks of magnitude 5 or greater of the hypothetical HayWired earthquake scenario in the San Francisco Bay region, California.

areas with concentrations of mid-rise and high-rise construction. These schemes are considered a substantial improvement over the Hazus default mapping schemes, wherein all construction is assumed to be low-rise.

Hazus analyses using the custom HayWired liquefaction and landslide data, as well as the aftershock shaking data, were done using the same improved building inventory as that for the initial mainshock Hazus run. Summaries of the improved building inventory data are provided in tables 2,3 , and 4 , by county name, by occupancy, and by structural type, respectively. Note that totals may not match exactly as a result of rounding. Exposure values (and resulting estimated losses) for the Hazus custom bay area inventory data are in 2005 dollars. These values can be approximately escalated to 2016 dollars using Consumer Price Index (CPI) ratios (see https://www.bls.gov/cpi/ data.htm); the U.S. CPI 2016:2005 ratio is approximately 1.23. 
Table 2. Improved building inventory data by county used for the Hazus analyses of the HayWired earthquake scenario mainshock and aftershock sequence, San Francisco Bay region, California.

[Exposure value reported in 2005 dollars; U.S. Consumer Price Index 2016:2005 ratio is approximately 1.23]

\begin{tabular}{lrrr}
\hline \multicolumn{1}{c}{ County } & Building count & \multicolumn{1}{c}{$\begin{array}{c}\text { Building square footage } \\
\text { (thousands of square feet) }\end{array}$} & $\begin{array}{c}\text { Total exposure value } \\
\text { (thousands of dollars) }\end{array}$ \\
\hline Alameda & 413,505 & $1,134,537$ & $155,699,818$ \\
Contra Costa & 321,281 & 717,509 & $102,806,780$ \\
Marin & 93,195 & 237,269 & $36,050,257$ \\
Merced & 56,678 & 117,942 & $12,901,176$ \\
Monterey & 109,838 & 271,611 & $33,772,799$ \\
Napa & 45,053 & 111,729 & $14,579,197$ \\
Sacramento & 378,791 & 890,201 & $110,561,701$ \\
San Benito & 16,279 & 32,842 & $4,135,710$ \\
\hline San Francisco & 172,931 & 671,672 & $100,178,548$ \\
San Joaquin & 159,215 & 358,055 & $42,755,589$ \\
San Mateo & 219,815 & 557,525 & $84,301,336$ \\
Santa Clara & 495,282 & $1,263,479$ & $183,312,185$ \\
Santa Cruz & 90,140 & 208,512 & $28,382,925$ \\
Solano & 120,823 & 265,812 & $34,820,221$ \\
Sonoma & 169,235 & 385,085 & $50,857,518$ \\
Stanislaus & 130,688 & 287,260 & $33,827,997$ \\
Yolo & 46,049 & 120,019 & $14,478,828$ \\
\hline Total & $3,038,798$ & $7,631,059$ & $1,043,422,585$ \\
\hline
\end{tabular}

Table 3. Improved building inventory data by occupancy class used for the Hazus analyses of the HayWired earthquake scenario mainshock and aftershock sequence.

[Exposure value reported in 2005 dollars; U.S. Consumer Price Index 2016:2005 ratio is approximately 1.23]

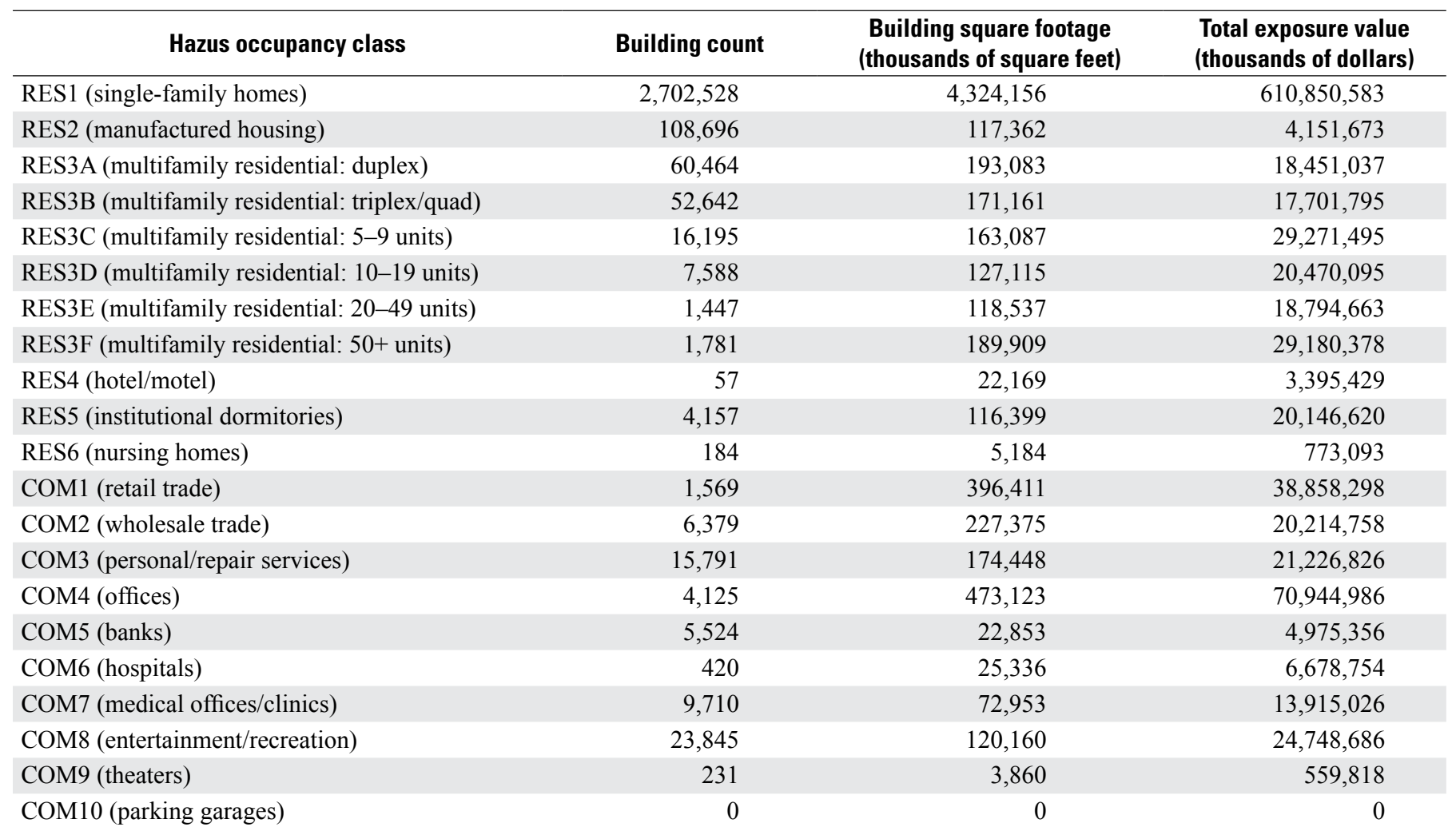


Table 3.-Continued

\begin{tabular}{lrrr}
\hline \multicolumn{1}{c}{ Hazus occupancy class } & Building count & $\begin{array}{r}\text { Building square footage } \\
\text { (thousands of square feet) }\end{array}$ & $\begin{array}{r}\text { Total exposure value } \\
\text { (thousands of dollars) }\end{array}$ \\
\hline IND1 (heavy industrial) & 3,154 & 104,632 & $10,793,540$ \\
IND2 (light industrial) & 2,992 & 107,895 & $9,631,660$ \\
IND3 (food/drugs/chemical) & 903 & 49,298 & $8,382,266$ \\
IND4 (metals/minerals processing) & 99 & 6,115 & $1,035,700$ \\
IND5 (high technology) & 628 & 30,336 & $5,166,822$ \\
IND6 (construction) & 1,478 & 82,533 & $7,333,744$ \\
AGR1 (agriculture) & 611 & $3,068,518$ \\
REL1 (churches) & 2,654 & $10,457,728$ \\
GOV1 (government/general services) & 2,326 & 64,015 & $3,279,910$ \\
GOV2 (government/emergency response) & 231 & 26,109 & 547,978 \\
EDU1 (education/grade schools) & 44 & 2,826 & $5,277,262$ \\
EDU2 (education/colleges and universities) & 345 & 38,997 & $3,138,088$ \\
\multicolumn{1}{c}{ Total } & $3,038,798$ & 18,668 & $1,043,422,585$ \\
\hline
\end{tabular}

Table 4. Improved building inventory data by model building type used for the Hazus analyses of the HayWired earthquake scenario mainshock and aftershock sequence.

[Exposure value reported in 2005 dollars; U.S. Consumer Price Index 2016:2005 ratio is approximately 1.23. $\mathrm{ft}^{2}$, square feet; CIP, cast in place; PC, precast; RM, reinforced masonry; URM, unreinforced masonry; w/, with; conc., concrete]

\begin{tabular}{|c|c|c|c|}
\hline Hazus model building type & Building count & $\begin{array}{l}\text { Building square footage } \\
\text { (thousands of square feet) }\end{array}$ & $\begin{array}{l}\text { Total exposure value } \\
\text { (thousands of dollars) }\end{array}$ \\
\hline W1 (wood, light frame, $\leq 5,000 \mathrm{ft}^{2}$ ) & $2,734,372$ & $4,540,623$ & $634,173,432$ \\
\hline W2 (wood, commercial and industrial, $>5,000 \mathrm{ft}^{2}$ ) & 22,888 & 602,193 & $87,505,195$ \\
\hline S1M (steel moment frame, mid-rise) & 4,747 & 68,584 & $9,587,560$ \\
\hline S1H (steel moment frame, high-rise) & 9,109 & 109,743 & $16,598,964$ \\
\hline $\mathrm{S} 2 \mathrm{H}$ (steel braced frame, high-rise) & 2,565 & 33,002 & $5,042,406$ \\
\hline S3 (steel light frame) & 3,779 & 76,168 & $8,909,731$ \\
\hline S4L (steel frame w/ CIP concrete shear walls, low-rise) & 2,529 & 46,719 & $6,328,477$ \\
\hline S4M (steel frame w/ CIP Concrete shear walls, mid-rise) & 2,936 & 33,876 & $5,096,293$ \\
\hline $\mathrm{C} 1 \mathrm{H}$ (concrete moment frame, high-rise) & 2,865 & 30,933 & $4,649,490$ \\
\hline C2L (concrete shear wall, low-rise) & 13,796 & 270,262 & $36,497,177$ \\
\hline $\mathrm{C} 2 \mathrm{M}$ (concrete shear wall, mid-rise) & 9,991 & 127,918 & $17,573,591$ \\
\hline $\mathrm{C} 2 \mathrm{H}$ (concrete shear wall, high-rise) & 5,087 & 49,514 & $7,368,727$ \\
\hline C3L (concrete frame w/ URM infill walls, low-rise) & 3,424 & 46,946 & $6,464,956$ \\
\hline C3M (concrete frame w/ URM infill walls, mid-rise) & 3,466 & 53,021 & $6,354,659$ \\
\hline $\mathrm{C} 3 \mathrm{H}$ (concrete frame w/ URM infill walls, high-rise) & 1,890 & 18,651 & $2,799,477$ \\
\hline PC1 (PC concrete tilt-up walls) & 5,370 & 182,812 & $20,193,977$ \\
\hline PC2L (PC concrete frames w/ conc. shear walls, low-rise) & 1,060 & 30,568 & $3,620,206$ \\
\hline
\end{tabular}


Table 4.-Continued

\begin{tabular}{lccc}
\hline \multicolumn{1}{c}{ Hazus model building type } & Building count & $\begin{array}{c}\text { Building square footage } \\
\text { (thousands of square feet) }\end{array}$ & $\begin{array}{c}\text { Total exposure value } \\
\text { (thousands of dollars) }\end{array}$ \\
\hline $\begin{array}{l}\text { RM1L (RM bearing walls w/ wood or metal deck diaphragms, } \\
\text { low-rise) }\end{array}$ & 46,314 & 396,562 & $54,177,952$ \\
$\begin{array}{l}\text { RM1M (RM bearing walls w/ wood or metal deck diaphragms, } \\
\text { mid-rise) }\end{array}$ & 5,094 & 72,129 & $9,448,147$ \\
RM2L (RM bearing walls w/ PC conc. diaphragms, low-rise) & 1,747 & 39,094 & $5,205,624$ \\
RM2M (RM bearing walls w/ PC conc. diaphragms, mid-rise) & 1,255 & 19,765 & $2,592,305$ \\
RM2H (RM bearing walls w/ PC conc. diaphragms, high-rise) & 382 & 3,772 & 559,241 \\
URML (URM bearing walls, low-rise) & 10,965 & 148,408 & $19,899,424$ \\
URMM (URM bearing walls, mid-rise) & 3,919 & 31,261 & $4,262,510$ \\
MH (mobile homes) & 111,702 & 146,792 & $7,801,366$ \\
\hline Total & $3,038,798$ & $7,631,056$ & $1,043,422,168$ \\
\hline
\end{tabular}

\section{Hazus Results-HayWired Mainshock}

The initial HayWired scenario mainshock was analyzed using regional liquefaction susceptibility data developed by the USGS and others (Knudsen and others, 2000; as shown in fig. 2), in conjunction with the Hazus default approach for computing liquefaction displacements and probabilities of occurrence and the default assumption of uniform shallow groundwater conditions, to produce a baseline "default" Hazus run.

As part of the HayWired earthquake scenario hazard studies, more detailed liquefaction probability calculations were performed for the mainshock in Alameda and Santa Clara Counties (Jones and others, 2017). Likewise, more detailed landslide probability and displacement calculations were performed for the mainshock for the bay area (McCrink and Perez, 2017). As a result of the focused liquefaction study, the baseline Hazus default run was modified to reflect a dual groundwater depth assumption ( 16 feet in western Santa Clara County, 5 feet elsewhere) consistent with the more detailed study.

Implementing the HayWired mainshock liquefaction and landslide data in Hazus required unconventional implementations of Hazus. Descriptions of these implementations precede the discussion of HayWired mainshock loss results in the following sections.

\section{HayWired Liquefaction Implementation in Hazus}

Liquefaction probabilities were derived for most of Santa Clara and Alameda counties for the HayWired mainshock based on a method by Holzer and others $(2008,2010,2011)$ (see Jones and others, 2017). The liquefaction probabilities were provided for 50-meter (m) pixels throughout the coverage area.

The implementation of these data in Hazus required creating census tract-based liquefaction probability data. National Land Cover Data (NLCD; Homer and others, 2015) were used to identify pixels located in developed areas (identified as low-, medium- or high-intensity development), as shown in figure 3. Census tract-level liquefaction probabilities were then calculated as the average across pixels with nonzero liquefaction probability in developed areas such that (1) liquefaction probabilities in undeveloped areas would not influence results, and (2) resulting loss estimates for the census tract were assumed uniform in the census tract (consistent with the Hazus methodology) and could then be scaled down in proportion to how much of the developed area had a non-zero probability of liquefaction.

Further, because the Holzer and others method does not provide liquefaction displacement values, Hazus-estimated displacements were required. Within Hazus, liquefactioninduced spread and settlement displacement estimates, as well as liquefaction probability estimates, require the input of maps of ground motion, liquefaction susceptibility and groundwater depth. For consistency with the liquefaction probability calculations, the liquefaction susceptibility data input into Hazus was modified from the basic "point-in-polygon" centroidal value for each census tract to a weighted (by probability) average of the liquefaction susceptibility class in non-zero liquefaction probability areas for each census tract. The liquefaction susceptibility map (used in the Hazus displacement calculations) and the Holzer and others method are both based on the same Quaternary geologic map. In addition to the change in liquefaction susceptibility input, the assumed uniform shallow depth to groundwater ( 5 feet) was modified to better reflect groundwater contour data provided by the California Geological Survey and used in the liquefaction probability assessment (Jones and others, 2017); in western Santa Clara County, groundwater depths of 16 feet have been assumed.

Because the custom probability data were only available for part of the study area, Hazus-estimated liquefaction probabilities were required for the remainder of the study region. This necessitated (1) a Hazus run that incorporated the custom (weighted) liquefaction susceptibility to produce appropriate displacements in the custom liquefaction study area, and (2) a second Hazus run incorporating the custom liquefaction probability data (overwriting the Hazus-estimated probabilities directly in Hazus' SQL tables) and interrupting Hazus' computational flow to avoid overwriting the various 


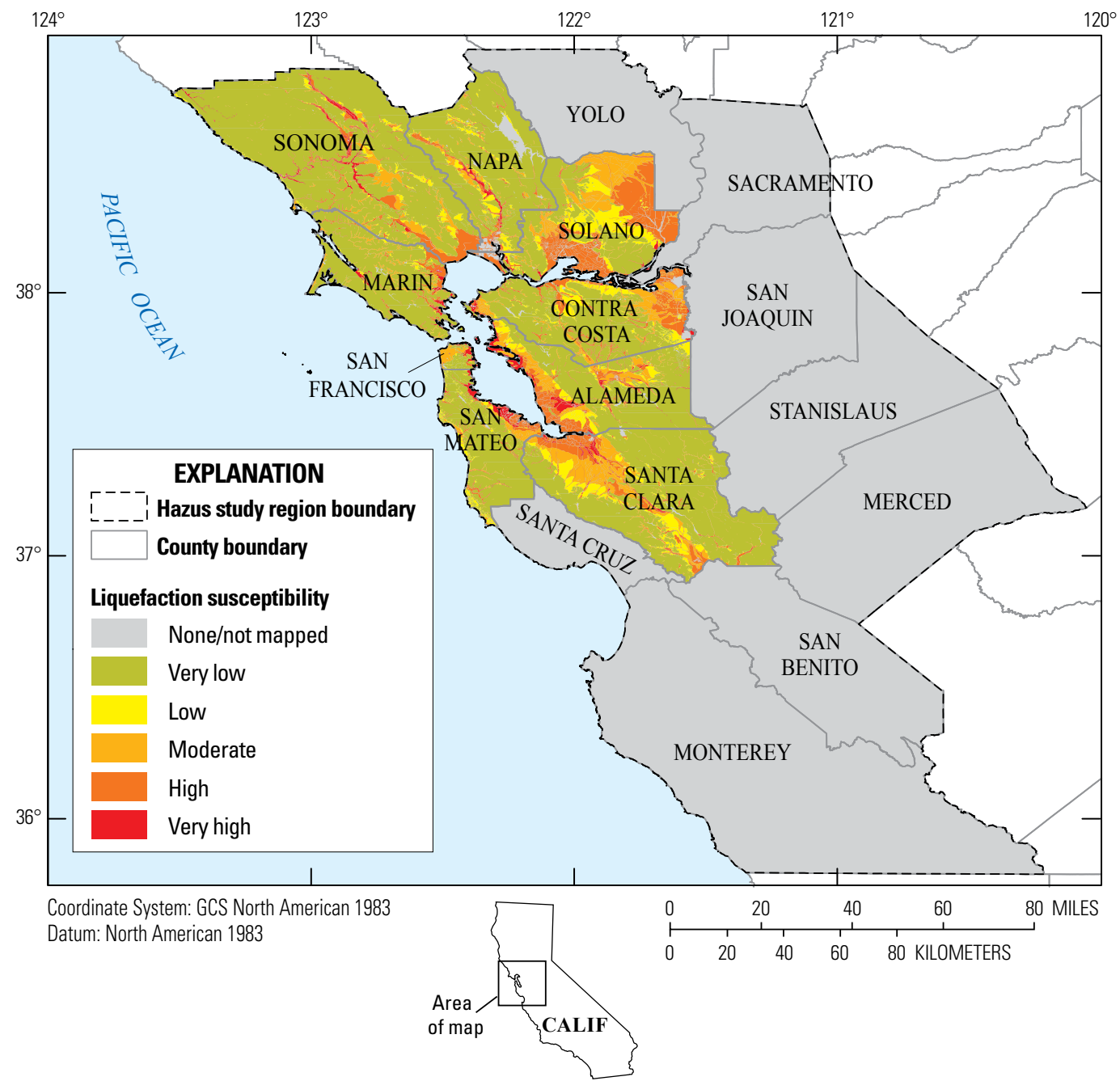

Figure 2. Map showing liquefaction susceptibility in the San Francisco Bay region, California. Data developed by the U.S. Geological Survey (based on Knudsen and others, 2000).

liquefaction hazard data tables. The building damage results produced by this second run were then manually scaled down by the proportion of development exposed to nonzero liquefaction probabilities to arrive at final losses for the developed areas. It should be noted that as a result of conducting part of the analysis outside of Hazus, the availability of Hazus results normally derived from the modified outputs became limited. That is, although we have estimated building damage and associated economic loss using the custom liquefaction probability, dependent impact estimates, such as casualties and shelter, are not available for the customized liquefaction assessment.

\section{HayWired Landslide implementation in Hazus}

Landslide displacement and probability data were provided for the HayWired mainshock for 10-m pixels in nine bay area Counties (McCrink and Perez, 2017): Alameda, Contra Costa, Marin, Napa, San Francisco, San Mateo, Santa Clara, Solano, and Sonoma. The landslide probabilities are derived from the displacements, and are categorized as given in table 5.

Because the landslide hazard is so localized, census tractlevel representations did not adequately capture the highly variable and concentrated nature of the hazard. Accordingly, an alternate approach was taken whereby multiple Hazus runs were conducted, assuming various displacement/probability combinations, and the census tract results were weighted according to the pixel level data, outside of Hazus, as described below.

Six Hazus runs were conducted, each assuming uniform landslide displacement and probability values for a given category, as shown in table 5. These runs yielded loss results for each midpoint displacement and probability value, by census tract. The Hazus inventory was assumed to be uniformly distributed across each census tract (and contributing pixel) within the developed area, as defined by NLCD (Homer and others, 2015), discussed above. (Developed pixels with landslide displacements in Alameda, Marin and Santa Clara counties are shown in fig. 4.) The number of developed pixels in each displacement/probability range were counted for each census tract. The losses for the pixels in each bin were then obtained by multiplying the census 


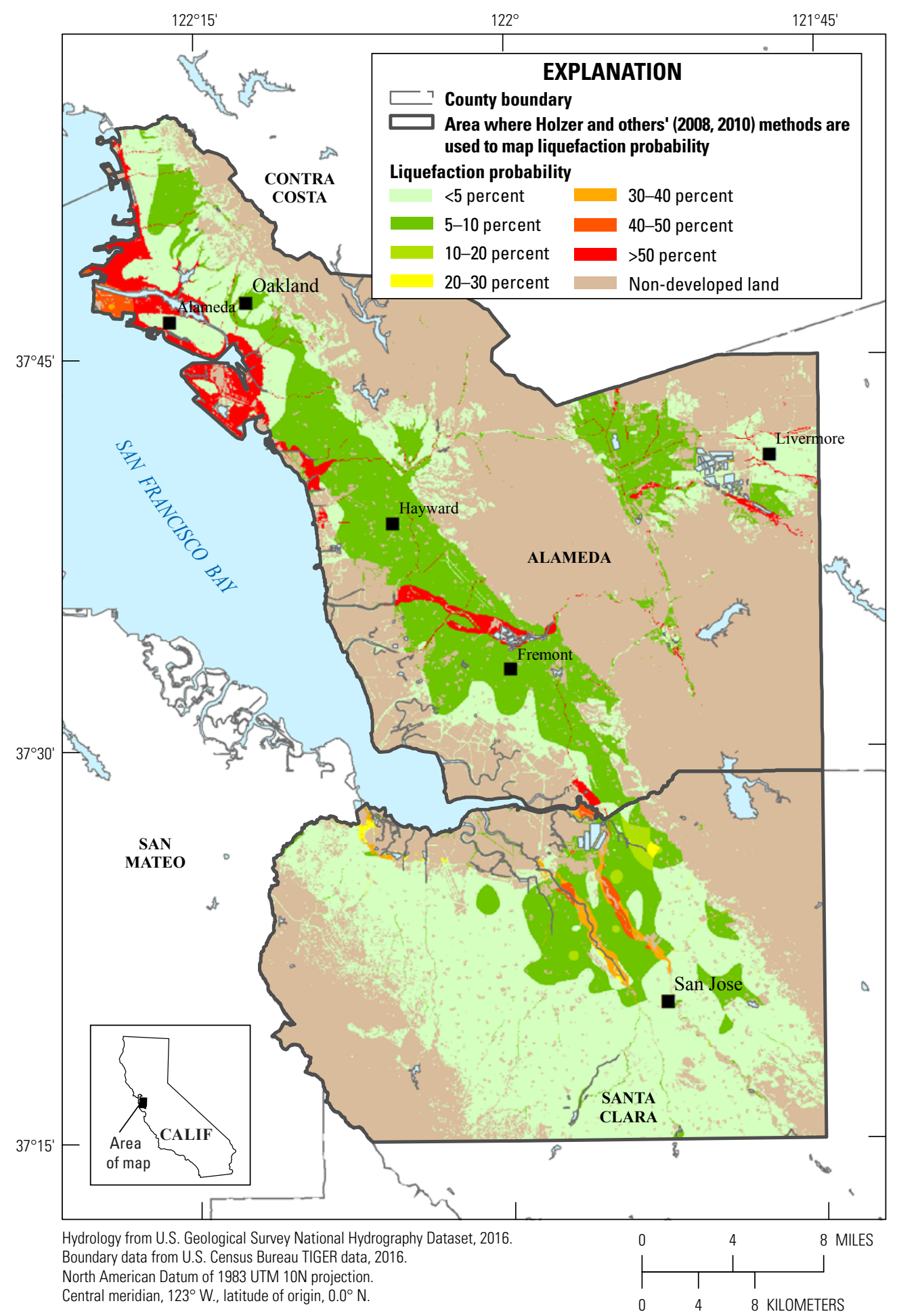

Figure 3. Map showing liquefaction probabilities for the HayWired earthquake scenario mainshock computed using the Holzer and others $(2008,2010)$ method in developed areas of Alameda and Santa Clara Counties, California (data modified from Jones and others, 2017). 
Table 5. Landslide displacement categories and associated probability ranges for the HayWired earthquake scenario mainshock.

[Data modified from McCrink and Perez, 2017. cm, centimeters; L, low, M, medium, H, high, VH, very high]

\begin{tabular}{cccccc}
\hline $\begin{array}{c}\text { Displacement } \\
\text { range } \\
\text { (cm) }\end{array}$ & $\begin{array}{c}\text { Displacement } \\
\text { range } \\
\text { (inches) }\end{array}$ & $\begin{array}{c}\text { Assumed landslide } \\
\text { displacement } \\
\text { (inches) }\end{array}$ & $\begin{array}{c}\text { Landslide } \\
\text { probability } \\
\text { category }\end{array}$ & $\begin{array}{c}\text { Probability } \\
\text { range }\end{array}$ & $\begin{array}{c}\text { Assumed } \\
\text { probability }\end{array}$ \\
\hline $0-1$ & $0.0-0.4$ & 0.2 & $\mathrm{~L}$ & $0.0-0.016$ & 0.008 \\
$1-5$ & $0.4-2.0$ & 1.2 & $\mathrm{M}$ & $0.016-0.15$ & 0.08 \\
$5-15$ & $2.0-6.0$ & 4.0 & $\mathrm{H}$ & $0.15-0.323$ & 0.237 \\
$15-30$ & $6.0-12.0$ & 9.0 & $\mathrm{VH}$ & $0.323-0.335$ & 0.329 \\
$30-100$ & $12.0-39.0$ & 25.5 & $\mathrm{VH}$ & 0.335 & 0.335 \\
$100+$ & $39.0-196$ & 117.5 & $\mathrm{VH}$ & 0.335 & 0.335 \\
\hline
\end{tabular}

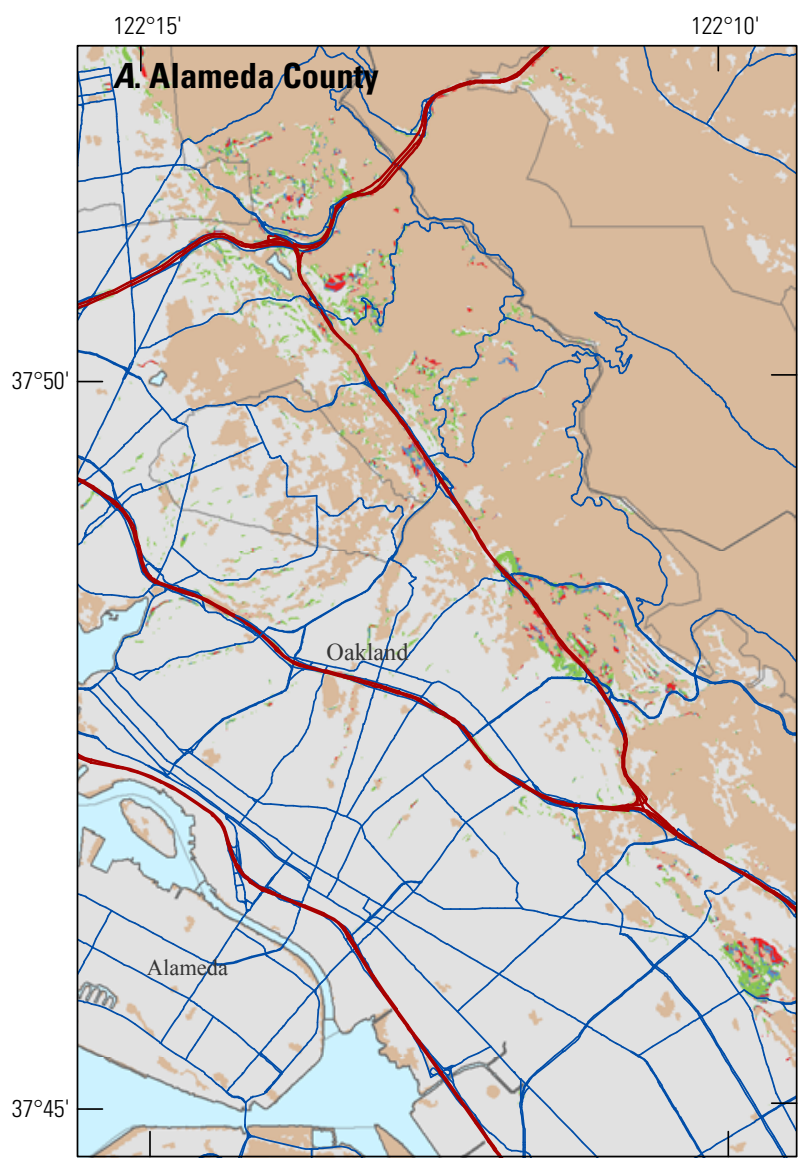

Non-developed land from Multi-Resolution Land Characteristics Consortium National Land Cover Dataset, 2015.

Hydrology from U.S. Geological Survey National Hydrography Dataset, 2016

Boundary data from U.S. Census Bureau TIGER data, 2016.

North American Datum of 1983 UTM 10N projection.

Central meridian, $123^{\circ} \mathrm{W}$., latitude of origin, $0.0^{\circ} \mathrm{N}$
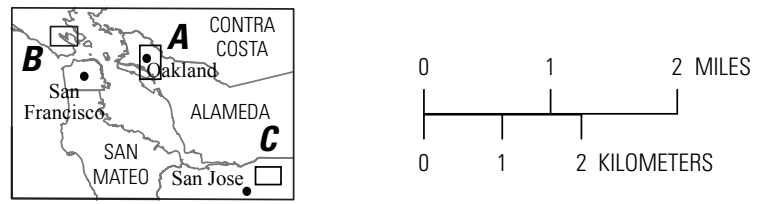

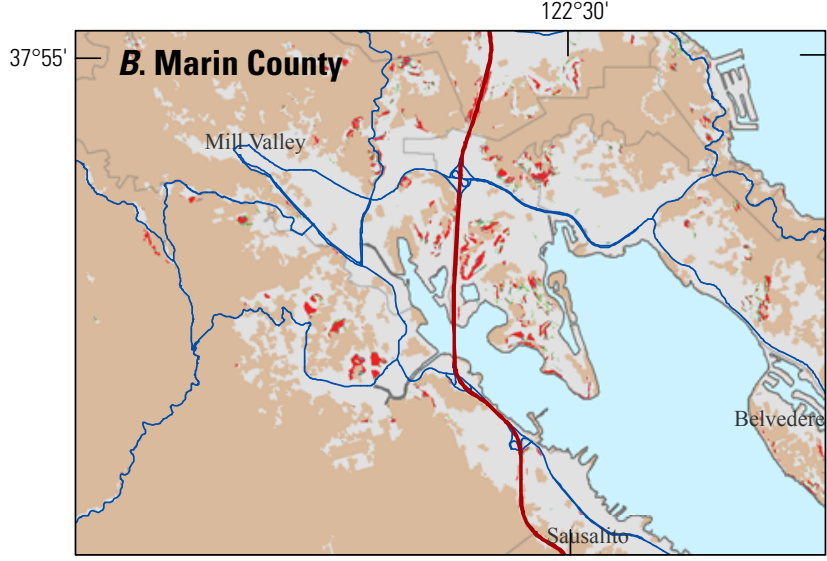

$121^{\circ} 50^{\prime}$

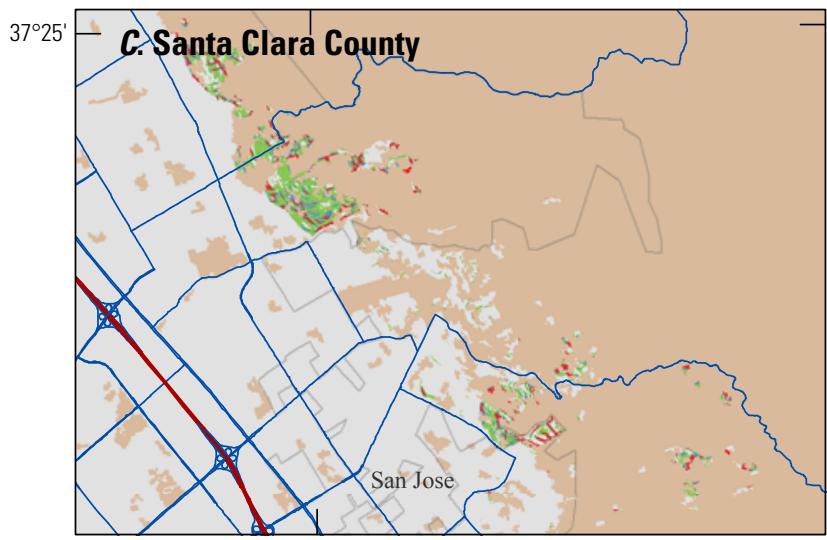

EXPLANATION

Landslide probability on developed land (corresponding displacement, in centimeters [cm])

0-2 percent $\quad(0-1 \mathrm{~cm})$

$2-15$ percent $\quad(1-5 \mathrm{~cm})$

15-32 percent $(5-15 \mathrm{~cm})$

$>32$ percent $(>15 \mathrm{~cm})$

Major highways

Secondary roads

Figure 4. Map showing custom landslide probabilities for the HayWired earthquake scenario mainshock in developed areas of parts of Alameda $(A)$, Marin $(B)$, and Santa Clara Counties $(C)$, California (data modified from McCrink and Perez, 2017). 
tract-level Hazus result for the bin by the number of pixels in the bin, divided by the total number of pixels in the developed area of the census tract. The landslide losses were then summed for each census tract. This method removed the influence of higher displacement estimates in undeveloped areas, assuming uniform distribution of building construction (consistent with the Hazus methodology). It should be noted, however, that the landslide data only pertain to landslide initiation, and do not capture damages downstream of landslides in other pixels.

As with the custom liquefaction data implementation, because we are conducting part of the landslide analysis outside of Hazus, the availability of Hazus results normally derived from the modified outputs become limited.

\section{HayWired Mainshock Hazus Results}

The final mainshock Hazus analyses may be summarized as follows:

- Shaking only

- Shaking and default liquefaction, with modified groundwater depth assumption (modified baseline default run)

- Shaking, custom liquefaction, and custom landslide (custom runs, combined)

A summary of the liquefaction and landslide data available by county is provided in table 6 . As shown, no liquefaction or landslide data were available for the seven outlying counties (Merced, Monterey, Sacramento, San Benito, San Joaquin, Stanislaus and Yolo). Figure 5 displays the geographic distribution of hazards ultimately contributing to building damage for each census tract. It should be noted that the custom liquefaction data did not cover all census tracts in Alameda and Santa Clara Counties (see figs. 3, 5); default liquefaction results were used in census tracts not covered by the custom data.

Building damage estimates for the three versions of the HayWired scenario mainshock, as described above, are summarized in tables 7, 8, and 9 respectively, by county and Hazus building damage state. It should be noted that the data in tables 7 and 8 are taken directly from Hazus, whereas the data in table 9 are approximately derived from resulting distributions of building square footage by damage state, multiplied by Hazus' damage state mean percentage loss assumptions and building exposure values. Best estimates of loss from shaking and default liquefaction have been taken directly from Hazus (tables 7, 8); best estimates of loss from the custom liquefaction and landslide analyses are taken from the approximate results derived from the square footage distributions (table 9). (Estimates of shaking and default liquefaction contributing to the values in table 9 may not exactly match those in table 8 ; differences between estimates taken directly from Hazus and those derived using the approximate square footage damage state distribution average 4 percent at the county level.) Table 10 provides the resultant county-level best estimates of building damage by hazard.
Table 6. Availability of liquefaction and landslide data for counties in the San Francisco Bay region, California.

[Y, yes. Shading indicates counties with no liquefaction or landslide data available]

\begin{tabular}{lccc}
\hline \multicolumn{1}{c}{ County } & $\begin{array}{c}\text { Liquefaction } \\
\text { (default approach) }\end{array}$ & $\begin{array}{c}\text { Liquefaction } \\
\text { (custom approach) }\end{array}$ & Landslide \\
\hline Alameda & $\mathrm{Y}^{1}$ & $\mathrm{Y}$ & $\mathrm{Y}$ \\
Contra Costa & $\mathrm{Y}$ & $\mathrm{Y}$ \\
Marin & $\mathrm{Y}$ & $\mathrm{Y}$ \\
Merced & & \\
Monterey & $\mathrm{Y}$ & \\
Napa & & $\mathrm{Y}$ \\
Sacramento & & \\
San Benito & $\mathrm{Y}$ & \\
San Francisco & & $\mathrm{Y}$ \\
San Joaquin & $\mathrm{Y}$ & \\
San Mateo & $\mathrm{Y}$ & $\mathrm{Y}$ \\
Santa Clara & & $\mathrm{Y}$ & $\mathrm{Y}$ \\
Santa Cruz & $\mathrm{Y}$ & $\mathrm{Y}$ \\
Solano & $\mathrm{Y}$ & $\mathrm{Y}$ \\
Sonoma & & \\
Stanislaus & & \\
Yolo & & \\
\hline
\end{tabular}

${ }^{1}$ Default liquefaction results were used for census tracts in Alameda and Santa Clara Counties not covered by the custom liquefaction data.

As noted above, exposure values and losses estimated using the custom bay area Hazus inventory data are in 2005 dollars. These values may be approximately escalated to 2016 dollars using the net CPI ratio of 1.23. Reported and tabulated dollar values have been stated in the native 2005 dollars to facilitate review and ease comparison.

As shown in the tables, the combined best estimate for liquefaction adds more than $\$ 4.6$ billion to the building damage in this event (see table 10). Most of the losses caused by liquefaction occur in Alameda County (\$3.1 billion), San Mateo County ( $\$ 510$ million), and Contra Costa County ( $\$ 460$ million). Figure $6 A$ shows the geographical distribution of Hazus building damage ratio estimates caused by shaking, while figure $6 B$ shows the distribution of building damage ratios for liquefaction, estimated using the Hazus default liquefaction modeling approach and adjusted groundwater depths.

The difference between default and custom liquefaction damage in Alameda and Santa Clara Counties reflect the differences in the liquefaction probability and estimated displacements at the census tract level. The default and custom probabilities are compared in Jones and others, 2017. The use of custom liquefaction probability data modestly increases liquefaction building damage estimates in Alameda County, impacting a broader area than the default approach, but substantially decreases damage estimates in Santa Clara County. The lower custom liquefaction probability estimates for Santa Clara County and southwest Alameda County are reflected in the lower damage ratios in the same areas in figure $6 B$ and $C$. 


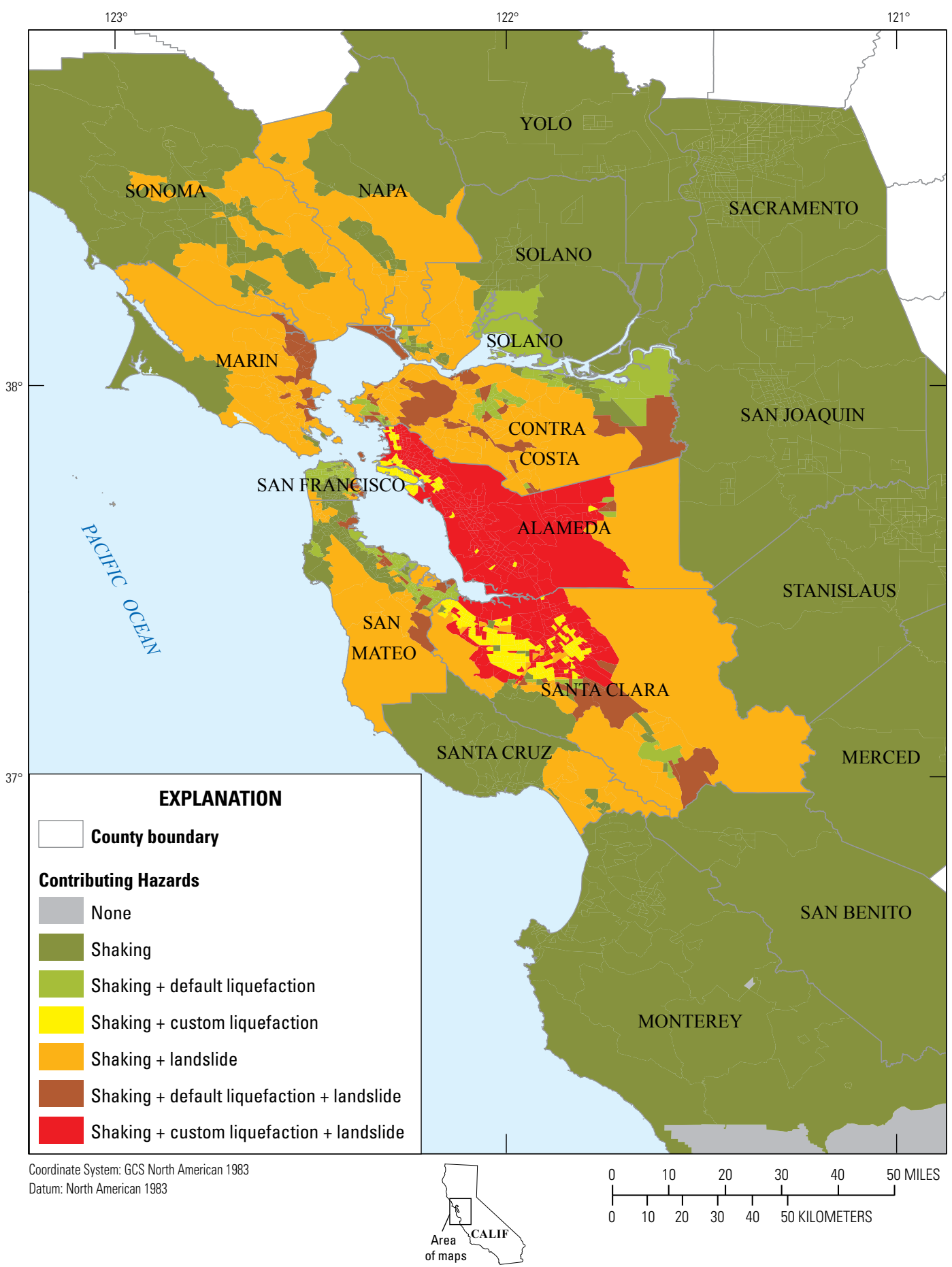

Figure 5. Map of hazards caused by the HayWired earthquake scenario mainshock contributing to building damage estimated for census tracts in the San Francisco Bay region, California. 
Table 7. Building damage resulting from ground shaking caused by the HayWired earthquake scenario mainshock in counties of the San Francisco Bay region, California, estimated using Hazus.

[Data from Hazus (Federal Emergency Management Agency, 2012). Damage reported in 2005 dollars; U.S. Consumer Price Index 2016:2005 ratio is approximately 1.23]

\begin{tabular}{lrrrrr}
\hline \multirow{2}{*}{ County } & \multicolumn{1}{c}{ Slight } & Moderate & Extensive & Complete & Total \\
\cline { 2 - 5 } & \multicolumn{5}{c}{ (thousands of dollars) } \\
\hline Alameda & $1,192,789$ & $4,739,455$ & $4,254,356$ & $6,063,511$ & $16,250,111$ \\
Contra Costa & 742,250 & $1,867,978$ & $1,200,315$ & $1,560,538$ & $5,371,081$ \\
Marin & 133,432 & 126,505 & 20,149 & 1,843 & 281,929 \\
Merced & 4,987 & 1,800 & 118 & 2 & 6,907 \\
Monterey & 16,421 & 6,486 & 443 & 2 & 23,351 \\
Napa & 18,538 & 10,327 & 1,027 & 33 & 29,926 \\
\hline Sacramento & 12,409 & 3,450 & 176 & 5 & 16,040 \\
San Benito & 8,435 & 6,852 & 1,985 & 1,387 & 18,658 \\
\hline San Francisco & 585,608 & 842,303 & 183,617 & 25,099 & $1,636,626$ \\
San Joaquin & 96,226 & 61,923 & 6,610 & 339 & 165,099 \\
\hline San Mateo & 527,695 & 778,106 & 193,827 & 29,036 & $1,528,665$ \\
Santa Clara & $1,272,221$ & $2,314,206$ & 810,956 & 245,904 & $4,643,287$ \\
Santa Cruz & 53,518 & 31,126 & 3,179 & 137 & 87,960 \\
Solano & 86,575 & 67,398 & 9,408 & 782 & 164,163 \\
Sonoma & 20,810 & 7,291 & 475 & 6 & 28,582 \\
Stanislaus & 35,564 & 16,351 & 1,387 & 24 & 53,327 \\
Yolo & 5,069 & 1,514 & 84 & 0 & 6,667 \\
\hline Total & $4,812,547$ & $10,883,071$ & $6,688,112$ & $7,928,648$ & $30,312,379$ \\
\hline
\end{tabular}

Table 8. Building damage resulting from ground shaking and default liquefaction caused by the HayWired earthquake scenario mainshock in counties of the San Francisco Bay region, California, estimated using Hazus. [Data from Hazus (Federal Emergency Management Agency, 2012). Damage reported in 2005 dollars; U.S. Consumer Price Index 2016:2005 ratio is approximately 1.23]

\begin{tabular}{|c|c|c|c|c|c|}
\hline \multirow{2}{*}{ County } & Slight & Moderate & Extensive & Complete & Total \\
\hline & \multicolumn{5}{|c|}{ (thousands of dollars) } \\
\hline Alameda & $1,134,931$ & $4,623,506$ & $6,094,483$ & $7,248,794$ & $19,101,714$ \\
\hline Contra Costa & 733,337 & $1,857,355$ & $1,496,618$ & $1,741,030$ & $5,828,340$ \\
\hline Marin & 132,990 & 127,445 & 44,173 & 16,077 & 320,686 \\
\hline Merced $^{1}$ & 4,987 & 1,800 & 118 & 2 & 6,907 \\
\hline Monterey $^{1}$ & 16,421 & 6,486 & 443 & 2 & 23,351 \\
\hline Napa & 18,538 & 10,327 & 1,027 & 33 & 29,926 \\
\hline Sacramento $^{1}$ & 12,409 & 3,450 & 176 & 5 & 16,040 \\
\hline San Benito $^{1}$ & 8,435 & 6,852 & 1,985 & 1,387 & 18,658 \\
\hline San Francisco & 582,164 & 846,023 & 332,753 & 116,177 & $1,877,116$ \\
\hline San Joaquin ${ }^{1}$ & 96,226 & 61,923 & 6,610 & 339 & 165,099 \\
\hline San Mateo & 518,759 & 780,983 & 520,077 & 222,057 & $2,041,877$ \\
\hline Santa Clara ${ }^{2}$ & $1,253,336$ & $2,307,609$ & $1,440,357$ & 636,429 & $5,637,731$ \\
\hline Santa Cruz ${ }^{1}$ & 53,518 & 31,126 & 3,179 & 137 & 87,960 \\
\hline Solano & 86,393 & 67,688 & 18,389 & 6,104 & 178,575 \\
\hline Sonoma & 20,810 & 7,291 & 475 & 6 & 28,582 \\
\hline Stanislaus $^{1}$ & 35,564 & 16,351 & 1,387 & 24 & 53,327 \\
\hline Yolo* & 5,069 & 1,514 & 84 & 0 & 6,667 \\
\hline Total & $4,713,887$ & $10,757,729$ & $9,962,334$ & $9,988,603$ & $35,422,556$ \\
\hline
\end{tabular}

${ }^{1}$ Counties outside the areas of mapped liquefaction susceptibility.

${ }^{2}$ Estimates reflect the dual groundwater depth assumption (16 feet in western Santa Clara County, 5 feet elsewhere) made for consistency with the custom liquefaction study 
Table 9. Approximate building damage resulting from ground shaking, custom liquefaction, and landslide caused by the HayWired earthquake scenario mainshock in counties of the San Francisco Bay region, California.

[Damage reported in 2005 dollars; U.S. Consumer Price Index 2016:2005 ratio is approximately 1.23]

\begin{tabular}{lrrrrr}
\hline \multirow{2}{*}{ County } & \multicolumn{1}{c}{ Slight } & Moderate & \multicolumn{1}{c}{ Extensive } & Complete & \multicolumn{1}{c}{ Total } \\
\cline { 2 - 6 } (thousands of dollars) \\
\hline Alameda & $1,134,930$ & $4,567,748$ & $6,805,683$ & $7,654,758$ & $20,163,118$ \\
Contra Costa & 746,639 & $1,808,999$ & $1,661,298$ & $1,787,929$ & $6,004,865$ \\
Marin & 130,835 & 117,380 & 102,445 & 50,314 & 400,973 \\
Merced & 4,930 & 1,696 & 140 & 2 & 6,768 \\
\hline Monterey & 15,883 & 6,078 & 486 & 2 & 22,449 \\
\hline Napa & 17,625 & 9,258 & 1,313 & 168 & 28,364 \\
\hline Sacramento & 11,651 & 3,138 & 193 & 4 & 14,986 \\
\hline San Benito & 8,516 & 6,791 & 2,485 & 1,427 & 19,219 \\
\hline San Francisco & 596,005 & 896,174 & 373,868 & 118,965 & $1,985,012$ \\
\hline San Joaquin & 95,074 & 58,211 & 7,898 & 318 & 161,500 \\
\hline San Mateo & 525,836 & 767,512 & 545,032 & 225,213 & $2,063,593$ \\
Santa Clara & $1,283,936$ & $2,318,778$ & $1,163,761$ & 370,790 & $5,137,265$ \\
\hline Santa Cruz & 52,599 & 29,281 & 4,590 & 622 & 87,093 \\
\hline Solano & 85,753 & 63,439 & 21,460 & 6,955 & 177,607 \\
\hline Sonoma & 19,652 & 6,414 & 3,461 & 1,846 & 31,372 \\
\hline Stanislaus & 34,412 & 15,045 & 1,561 & 20 & 51,037 \\
\hline Yolo & 4,695 & 1,326 & 85 & 0 & 6,106 \\
\hline \multicolumn{1}{c}{ Total } & $4,768,971$ & $10,677,268$ & $10,695,759$ & $10,219,333$ & $36,361,327$ \\
\hline
\end{tabular}

Table 10. Total building damage from the HayWired earthquake scenario mainshock in counties of the San Francisco Bay region, California.

[Damage reported in 2005 dollars; U.S. Consumer Price Index 2016:2005 ratio is approximately 1.23 . cm/s, centimeters per second; PGV, peak ground velocity. Shading indicates no estimated damage from liquefaction or landslide]

\begin{tabular}{|c|c|c|c|c|c|c|}
\hline County & Shaking & $\begin{array}{c}\text { Default } \\
\text { liquefaction }\end{array}$ & $\begin{array}{c}\text { Custom } \\
\text { liquefaction }^{2}\end{array}$ & $\begin{array}{c}\text { Combined } \\
\text { best estimate } \\
\text { liquefaction }\end{array}$ & $\begin{array}{c}\text { Landslide } \\
\text { (within 20-cm/s } \\
\text { PGV limit) }\end{array}$ & $\begin{array}{c}\text { Combined } \\
\text { best estimate } \\
\text { building damage }\end{array}$ \\
\hline & \multicolumn{6}{|c|}{ (millions of dollars) } \\
\hline Alameda & 16,250 & 2,852 & 3,057 & 3,081 & 147 & 19,478 \\
\hline Contra Costa & 5,371 & 457 & & 457 & 14 & 5,842 \\
\hline Marin & 282 & 39 & & 39 & 84 & 405 \\
\hline Merced & 7 & & & & & 7 \\
\hline Monterey & 23 & & & & & 23 \\
\hline Napa & 30 & 0 & & 0 & 0.4 & 30 \\
\hline Sacramento & 16 & & & & & 16 \\
\hline San Benito & 19 & & & & & 19 \\
\hline San Francisco & 1,637 & 240 & & 240 & 9 & 1,886 \\
\hline San Joaquin & 165 & & & & & 165 \\
\hline San Mateo & 1,529 & 513 & & 513 & 9 & 2,051 \\
\hline Santa Clara & 4,643 & 994 & 264 & 291 & 21 & 4,955 \\
\hline Santa Cruz & 88 & & & & 1 & 89 \\
\hline Solano & 164 & 14 & & 14 & 2 & 180 \\
\hline Sonoma & 29 & 0 & & & 5 & 34 \\
\hline Stanislaus & 53 & & & & & 53 \\
\hline Yolo & 7 & & & & & 7 \\
\hline Total & 30,313 & 5,109 & 3,321 & 4,635 & 292 & 35,240 \\
\hline
\end{tabular}




\section{A. Shaking}

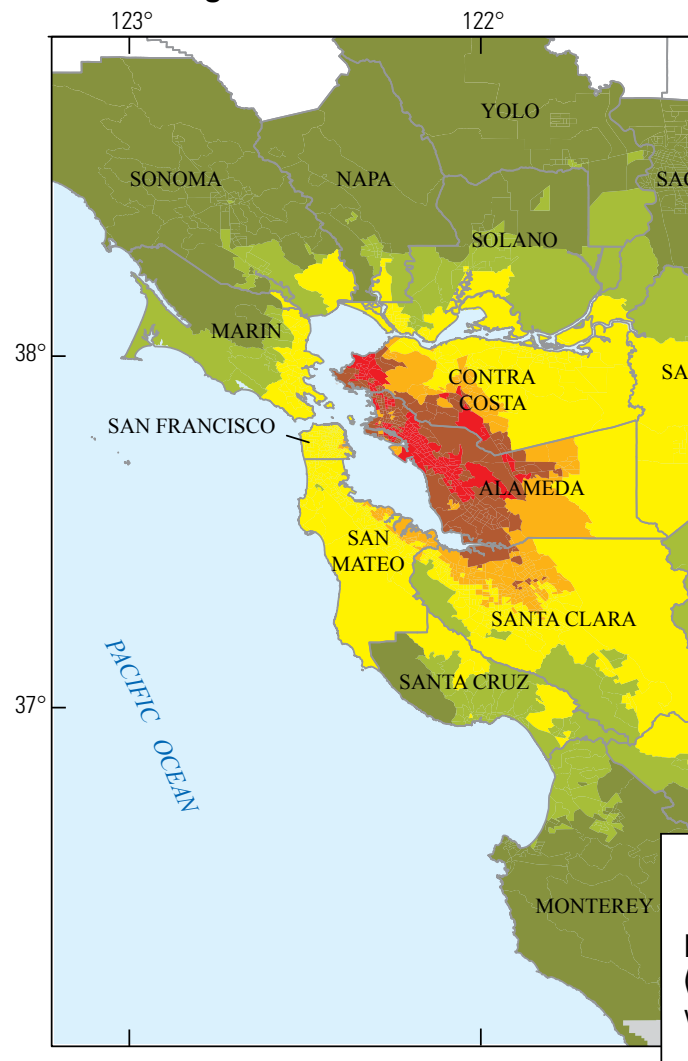

C. Custom liquefaction

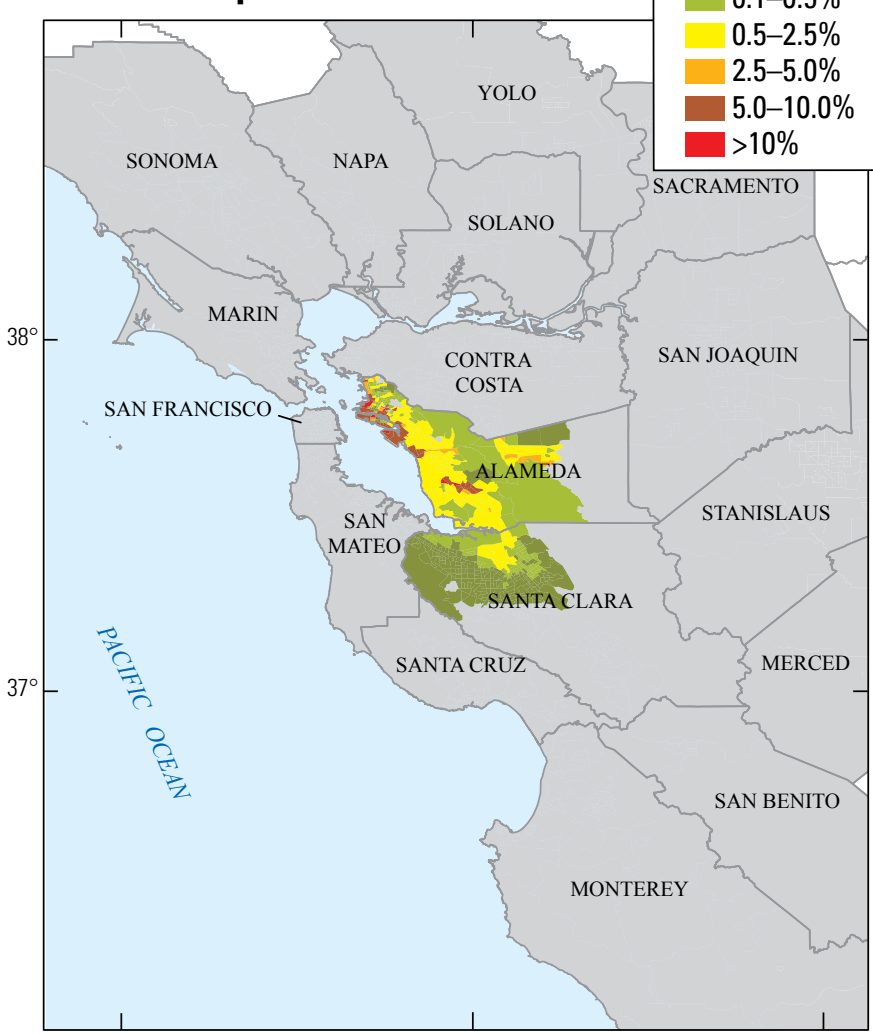

Coordinate System: GCS North American 1983 Datum: North American 1983

\section{EXPLANATION}

SAN BENITO

$\checkmark$ County boundary

Building damage ratio

(damage divided by replacement

value, expressed as a percent)

0

Figure 6. Maps showing building damage ratio by causative hazard for the HayWired earthquake scenario mainshock, San Francisco Bay region, California, estimated using Hazus (FEMA, 2012). $A$, Shaking only. $B$, Default liquefaction (applied where liquefaction computed using the Holzer and others [2008, 2010] method was not available). C, Liquefaction computed using the Holzer and others $(2008,2010)$ method. D, Landslide. 
Landslide building damage, as estimated using the custom landslide hazard data, totals \$291 million in the nine counties in which it was modeled, and is most substantial in Alameda County ( $\$ 147$ million) and Marin County (\$84 million). Census tract damage ratios resulting from landslide (fig. $6 D$ ) are generally modest, peaking at just 3.3 percent versus 17.1 percent for custom liquefaction and 45.6 percent for shaking. Figure 7 provides the best estimate census tract damage ratio map, combining damage from shaking, liquefaction (using custom data where available, default data elsewhere), and landslide.

McCrink and Perez (2017) report slope failure displacements and probabilities in areas of peak ground velocity of 20 centimeters per second $(\mathrm{cm} / \mathrm{s})$ and larger; their approach has more uncertainty in areas below that threshold. Results reported above are those within the $20 \mathrm{~cm} / \mathrm{s}$ contour. Beyond the $20 \mathrm{~cm} / \mathrm{s}$ contour, an additional $\$ 145$ million in damage could be expected, including \$41 million in Marin, \$27 million in each of San Francisco and Santa Clara counties, \$20 million in San Mateo and \$17 million in Sonoma counties.

As a reference point for comparison, the losses from the Loma Prieta earthquake were tallied by Holzer (1994) as $\$ 5.8$ billion from shaking, $\$ 97$ million from liquefaction and $\$ 30$ million from landslides. Loma Prieta earthquake landslide losses were 0.5 percent of shaking losses compared to 1 percent (or 1.5 percent for the whole area) estimated for the HayWired earthquake scenario. Loma Prieta liquefaction losses were 1.5 percent of shaking losses, compared to 15 percent estimated for the HayWired earthquake scenario. The higher liquefaction losses for the HayWired earthquake scenario are attributed to the developed areas affected by liquefaction in close proximity to the fault in Alameda County.

In addition to the summary data provided here, detailed results were generated for use by other HayWired researchers, including the following:

- The distribution of square footage across the various Hazus damage states by Hazus occupancy class and census tract, for the combined liquefaction and landslide mainshock assessment

- Estimated economic loss associated with building damage, by occupancy and county, for the combined liquefaction and landslide mainshock assessment

\section{Liquefaction Modeling in Selected HayWired Aftershocks}

Because the custom liquefaction data were only available in Alameda and Santa Clara Counties, and not available for the other counties potentially subject to liquefaction (Marin, Sonoma, Napa, Solano, Contra Costa, San Mateo, and San Francisco) and because custom liquefaction and landslide hazard data were only developed for the mainshock, it was decided that the focus of the comparative studies of building damage in the various aftershocks would primarily be damage resulting from ground shaking alone. However, to allow for selected comparisons of loss resulting from liquefaction and repeated liquefaction, several of the aftershocks were analyzed both for shaking only and for shaking and default liquefaction, including the M5.98 Mountain View, M6.4 Cupertino, and M5.42 Oakland aftershocks. A comparison of damage estimates for the mainshock and three selected aftershocks, with and without liquefaction assessed using the Hazus default approach and the original uniform depth to groundwater assumption, is provided in table 11. As noted above, in the mainshock, liquefaction is estimated to add approximately $\$ 5.1$ billion in building damage (an additional 17 percent), whereas in the selected aftershocks, liquefaction adds between $\$ 78$ million (an additional 15 percent) in the M5.42 Oakland aftershock and \$218 million (an additional 9 percent) in the M6.4 Cupertino aftershock.

\section{Ground Shaking Results for the HayWired Earthquake Sequence}

Economic loss resulting from building damage caused by ground shaking has been estimated for each aftershock, as was done for the mainshock. Because Hazus is not able to estimate additional damage to damaged buildings, the mainshock and aftershocks have been modeled as independent events. That is, for each event, the building inventory is assumed to be in an undamaged state at the time of the earthquake; previous damage resulting from the mainshock or preceding aftershocks is not considered. The results of the Hazus analyses are summarized in table 12.

As shown in table 12, damage in each of the aftershocks is at least an order of magnitude smaller than that of the mainshock. The aftershocks that result in the largest economic losses from regional building damage are the M6.4 Cupertino ( $\$ 2.48$ billion in building damage), M6.2 Palo Alto ( $\$ 1.37$ billion in building damage), M5.98 Mountain View (\$890 million in building damage), and M5.42 Oakland ( $\$ 510$ million in building damage) events. The total direct economic losses resulting from these aftershocks are \$3.81 billion (M6.4 Cupertino), \$2.11 billion (M6.2 Palo Alto), \$1.38 billion (M5.98 Mountain View), and $\$ 780$ million (M5.42 Oakland). For comparison, FEMA's initial estimate of expected damage and loss in the 2014 M6.0 South Napa earthquake (including liquefaction), generated using the same inventory data as that used to model the HayWired earthquake scenario and its aftershocks, totaled $\$ 347$ million in building damage and $\$ 575$ million in total direct economic losses related to building damage (Doug Bausch, written commun., Federal Emergency Management Agency, 2014). The expected damage in the South Napa event is smaller than the four largest HayWired aftershocks, but larger than the remaining 12 aftershocks. In terms of building damage ratio (defined in Hazus as the ratio of repair to replacement cost), the South Napa earthquake simulation had an overall building damage ratio of 


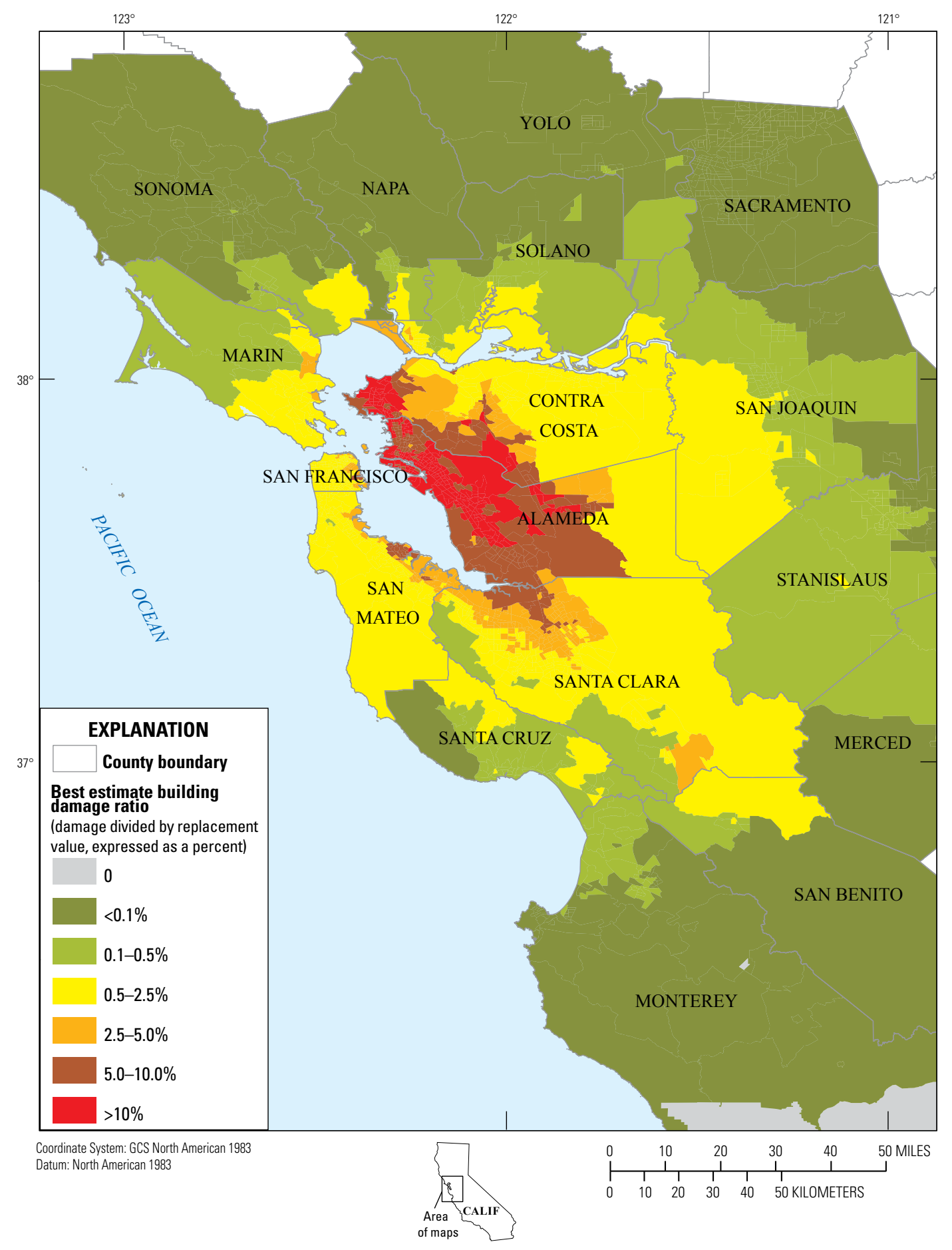

Figure 7. Map showing best estimate building damage ratio for the HayWired earthquake scenario mainshock, San Francisco Bay region, California, considering liquefaction computed using the Holzer and others $(2008,2010)$ method and landslide data, where available (Jones and others, 2017; McCrink and Perez, 2017). 
Table 11. Direct economic losses from the HayWired earthquake scenario mainshock and selected aftershocks, with and without default liquefaction, San Francisco Bay region, California, estimated using Hazus.

[Data from Hazus (Federal Emergency Management Agency, 2012). See table 1 for explanation of aftershock short names and magnitudes. Damage reported in 2005 dollars; U.S. Consumer Price Index 2016:2005 ratio is approximately 1.23. liq., liquefaction. Shading indicates net loss from the liquefaction hazard]

\begin{tabular}{|c|c|c|c|c|c|c|c|c|}
\hline HayWired scenario event & $\begin{array}{c}\text { Structural } \\
\text { damage }\end{array}$ & $\begin{array}{c}\text { Non- } \\
\text { structural } \\
\text { damage }\end{array}$ & $\begin{array}{c}\text { Total } \\
\text { building } \\
\text { damage }^{1}\end{array}$ & $\begin{array}{c}\text { Building } \\
\text { damage } \\
\text { ratio }^{2} \\
\text { (percent) }\end{array}$ & $\begin{array}{l}\text { Content } \\
\text { damage }\end{array}$ & $\begin{array}{c}\text { Inventory } \\
\text { loss }\end{array}$ & $\begin{array}{c}\text { Building } \\
\text { damage-related } \\
\text { income loss }\end{array}$ & $\begin{array}{l}\text { Total direct } \\
\text { economic } \\
\text { loss }\end{array}$ \\
\hline Mainshock shaking only & $5,817.2$ & $24,495.2$ & $30,312.4$ & 2.91 & $8,003.0$ & 305.6 & $8,012.7$ & $46,633.7$ \\
\hline Mainshock shaking + liq. & $7,037.5$ & $28,419.5$ & $35,457.0$ & 3.40 & $9,232.8$ & 376.8 & $9,059.4$ & $54,126.0$ \\
\hline Mainshock liq. loss & $1,220.3$ & $3,924.3$ & $5,144.6$ & 0.49 & $1,229.8$ & 71.2 & $1,046.7$ & $7,492.3$ \\
\hline CU64 shaking + liq. & 382.9 & $2,313.5$ & $2,696.4$ & 0.26 & 948.0 & 40.0 & 455.6 & $4,139.9$ \\
\hline CU64 liq. loss & 49.6 & 168.3 & 217.9 & 0.02 & 59.7 & 4.1 & 50.4 & 332.0 \\
\hline MV598 shaking & 81.1 & 813.2 & 894.3 & 0.09 & 382.4 & 22.3 & 82.4 & $1,381.4$ \\
\hline MV598 shaking + liq. & 104.5 & 892.7 & 997.2 & 0.10 & 410.0 & 24.1 & 105.6 & $1,536.9$ \\
\hline MV598 liq. loss & 23.4 & 79.5 & 102.9 & 0.01 & 27.6 & 1.8 & 23.2 & 155.5 \\
\hline
\end{tabular}

${ }^{1}$ Total of structural and nonstructural damage.

${ }^{2}$ Ratio of repair to replacement cost, calculated as the total estimated building damage divided by the total building replacement value (as defined in Hazus).

Table 12. Direct economic losses from ground shaking caused by the HayWired earthquake scenario mainshock and aftershock sequence, San Francisco Bay region, California, estimated using Hazus.

[Data from Hazus (Federal Emergency Management Agency, 2012). See table 1 for explanation of aftershock short names and magnitudes. Damage reported in 2005 dollars; U.S. Consumer Price Index 2016:2005 ratio is approximately 1.23]

\begin{tabular}{|c|c|c|c|c|c|c|c|c|}
\hline \multirow[t]{2}{*}{ HayWired scenario event } & $\begin{array}{c}\text { Structural } \\
\text { damage }\end{array}$ & $\begin{array}{c}\text { Non- } \\
\text { structural } \\
\text { damage }\end{array}$ & $\begin{array}{c}\text { Total } \\
\text { building } \\
\text { damage }^{1}\end{array}$ & \multirow{2}{*}{$\begin{array}{c}\text { Building } \\
\text { damage } \\
\text { ratio }^{2} \\
\text { (percent) }\end{array}$} & $\begin{array}{l}\text { Content } \\
\text { damage }\end{array}$ & $\begin{array}{l}\text { Inventory } \\
\text { loss }\end{array}$ & $\begin{array}{c}\text { Building } \\
\text { damage-related } \\
\text { income loss }\end{array}$ & $\begin{array}{c}\text { Total direct } \\
\text { economic } \\
\text { loss }\end{array}$ \\
\hline & \multicolumn{3}{|c|}{ (millions of dollars) } & & \multicolumn{4}{|c|}{ (millions of dollars) } \\
\hline UC523 & 14.9 & 333.5 & 348.4 & 0.03 & 176.2 & 12.4 & 8.2 & 545.2 \\
\hline SP504 & 5.6 & 100.7 & 106.3 & 0.01 & 50.4 & 1.3 & 3.7 & 161.7 \\
\hline OK542 & 32.6 & 476.8 & 509.4 & 0.05 & 237.3 & 9.3 & 24.0 & 780.0 \\
\hline PA62 & 159.9 & $1,207.6$ & $1,367.5$ & 0.13 & 525.4 & 23.6 & 193.7 & $2,110.2$ \\
\hline MP552 & 8.4 & 142.9 & 151.3 & 0.01 & 71.2 & 2.6 & 6.9 & 232.1 \\
\hline AT511 & 9.2 & 129.5 & 138.8 & 0.01 & 59.1 & 2.5 & 6.0 & 206.4 \\
\hline PA569 & 27.3 & 326.6 & 353.8 & 0.03 & 157.1 & 7.1 & 25.7 & 543.9 \\
\hline CU64 & 333.3 & $2,145.2$ & $2,478.5$ & 0.24 & 888.3 & 35.9 & 405.2 & $3,807.9$ \\
\hline SV535 & 32.7 & 255.8 & 288.5 & 0.03 & 102.2 & 6.1 & 23.9 & 420.7 \\
\hline SC509 & 14.6 & 210.3 & 224.8 & 0.02 & 101.6 & 5.1 & 10.2 & 341.8 \\
\hline PA501 & 6.1 & 65.6 & 71.7 & 0.01 & 27.1 & 1.3 & 3.9 & 104.0 \\
\hline
\end{tabular}

${ }^{1}$ Total of structural and nonstructural damage.

${ }^{2}$ Ratio of repair to replacement cost, calculated as the total estimated building damage divided by the total building replacement value (as defined in Hazus). 
0.16 percent, similar to the M6.2 Palo Alto aftershock's damage ratio of 0.13 percent.

Regional building damage patterns, in terms of census tract level building damage ratios (total estimated building damage for each census tract divided by total building replacement value), are mapped in figures 8-11. As shown, the aftershocks with the largest losses also show the broadest damage ratio patterns and the highest maximum damage ratios.

Building damage is summarized by structural system or Hazus' MBTs (see table 4 for definitions), grouped across building height classes, in tables 13 and 14; table 13 provides building damage in terms of economic losses (in millions of dollars), and table 14 provides the results in terms of building damage ratio. Although wood frame construction (MBT W1 and W2) makes up the bulk of the exposure (69 percent of exposure, see also table 4), damage to this type of construction makes up a smaller percentage of the losses ( 47 percent in the mainshock, and between 45 and 56 percent in the aftershocks). Conversely, the more vulnerable building types represent larger proportions of loss than exposure, including URM ( 2 percent of exposure, 6 percent of loss in the mainshock, and as much as 8 percent in the M5.42 Oakland aftershock), concrete frame with URM infill walls (MBT C3 - 1 percent of exposure, 5 percent of loss in the mainshock, and 2-3 percent of loss in the aftershocks), and steel frame with URM infill walls (MBT S5-1 percent of exposure, 5 percent of loss in the mainshock, and 2-4 percent of loss in the aftershocks). This vulnerability is further demonstrated by the damage ratios tabulated in table 14; S5, C3, and URM are among the MBTs with the largest net damage ratios in the mainshock $(14,10$, and 7 percent, respectively), along with mobile homes (MH—9 percent) and light steel frame (S3 - 9 percent). Damage ratios in the aftershocks are generally two orders of magnitude smaller than those of the mainshock, except for the larger aftershocks (M6.2 Palo Alto, M5.98 Mountain View, and M6.4 Cupertino), where the ratios tend to be just one order of magnitude smaller than the mainshock. Concentrations of vulnerable building types may also result in higher damage ratios from a nearby aftershock, such as (1) precast concrete tilt-up wall structures (PC1) with a higher damage ratio in the M5.23 Union City aftershock than the other M5 aftershocks and (2) S3, S5, and URM damage in the M5.42 Oakland aftershock. Building exposure (in thousands of dollars) for tilt-up structures (PC1) and low-rise URM is mapped in figure 12, highlighting the concentrations of these vulnerable buildings near the epicenters of the M5.23 Union City and M5.42 Oakland aftershocks.

\section{Unreinforced Masonry Construction}

It should be noted that the MBT damage ratios given in table 14 represent net damage across the entire 17-county study area and include damage for all MBT subclasses (that is, subclasses by height and seismic design level); localized damage and damage ratios for MBT subclasses may be substantially different. For example, for all URM construction (URML and URMM), the net damage ratio in the mainshock is 7 percent, but census tract damage ratios for pre-code (unretrofitted), low-rise URM (URML) range from 0 to 94 percent. Damage to this subclass of URM building represents 60 percent of the URM damage but just 24 percent of the building square footage. Census tract damage ratio maps for pre-code URML construction for the mainshock and three of the more damaging aftershocks (M6.4 Cupertino, M6.2 Palo Alto, and M5.42 Oakland) are provided in figure 13. In the mainshock, pre-code URML damage ratios in Alameda and Contra Costa Counties are substantial, with 51 percent of census tracts in these two counties having damage ratios exceeding 50 percent. Total loss for pre-code URML in the mainshock is $\$ 885$ million, whereas losses in the selected aftershocks are \$20.5 million (M6.4 Cupertino), \$15.7 million (M6.2 Palo Alto), and \$17.4 million (M5.42 Oakland) - 2.3, 1.8, and 2.0 percent of the mainshock loss, respectively. Damage ratios in the selected aftershocks are lower than the mainshock (all are less than 25 percent), and damage is more localized. A small pocket of census tracts has damage ratios between 15 and 25 percent in Santa Clara County in the M6.4 Cupertino aftershock, and a smaller pocket of tracts with damage ratios between 5 and 10 percent are on the border of Santa Clara and San Mateo Counties in the M6.2 Palo Alto aftershock, and census tract damage ratios do not exceed 5 percent in the M5.42 Oakland aftershock.

As noted previously, Hazus is not able to estimate additional damage to damaged buildings; each analysis conducted for this study is independent and assumes that the inventory is in an undamaged condition before the earthquake. Given that the aftershocks may, in reality, cause damage in areas already substantially damaged, it is instructive to examine the URM damage results more closely. To assess whether adding the aftershock damage to the mainshock damage would result in overestimating damage to substantially damaged structures, individual census tract level results in the mainshock and the aftershocks were reviewed.

At the most basic level, the sum of losses in multiple events should not exceed the value of the exposed inventory, assuming no repair between events. For pre-code URML, building damage in the mainshock represents 18.5 percent of exposure, with a maximum census tract damage ratio of 93.8 percent. After adding the damage from all aftershocks, the total building damage ratio is 20.4 percent, with a maximum census tract damage of 96.4 percent. Fortunately, for the simulated aftershock sequence, census tracts with the largest damage to pre-code URML buildings in the aftershocks are not the same as those tracts with substantial damage in the mainshock. At the census tract level, the sum of economic losses from building damage to pre-code URML in the HayWired mainshock and all of its aftershocks does not exceed the building's exposure value. 
A. M5.23 Union City

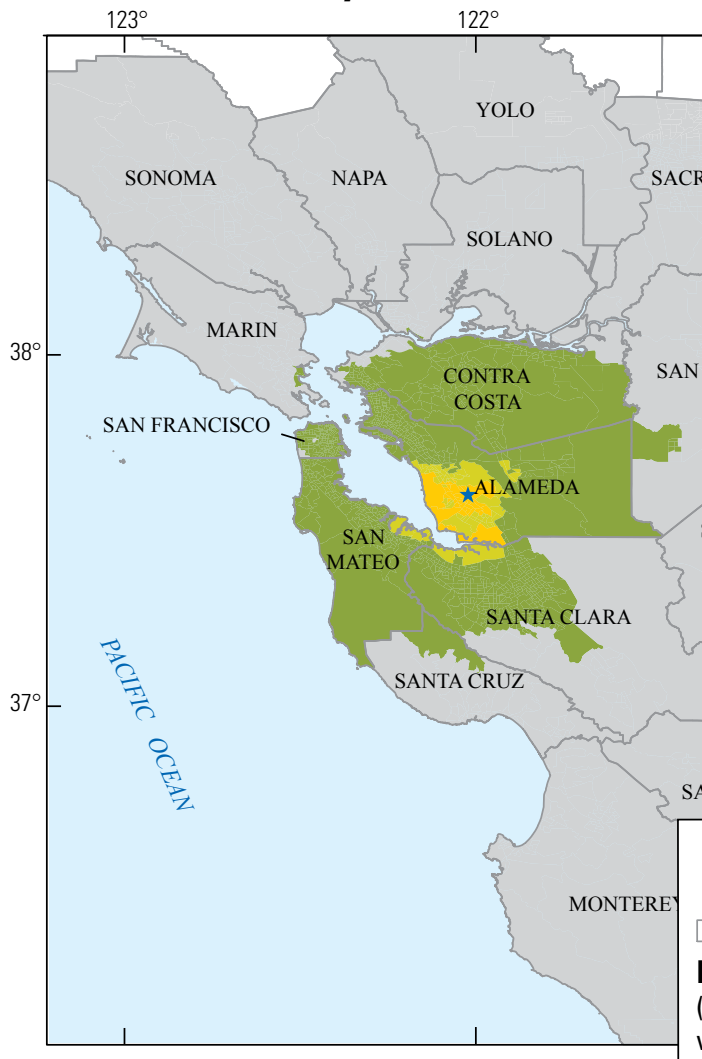

C. M5.58 Fairfield

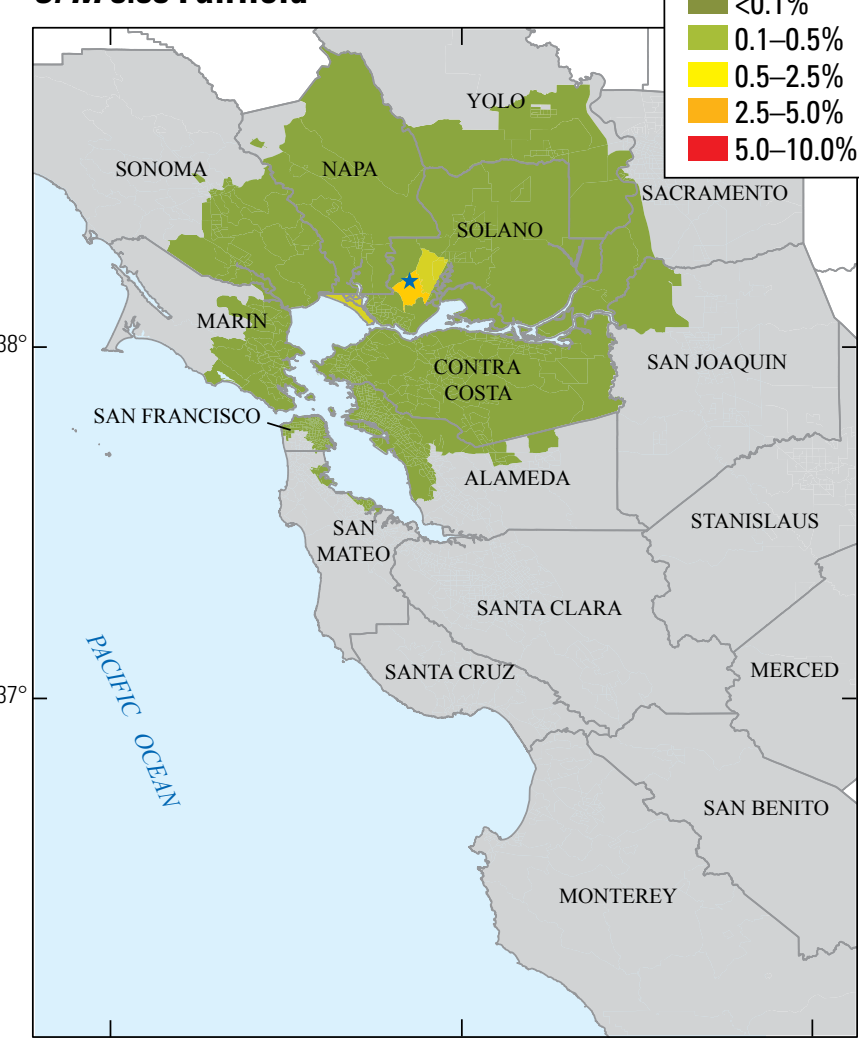

Coordinate System: GCS North American 1983 Datum: North American 1983
B. M5.04 San Pablo

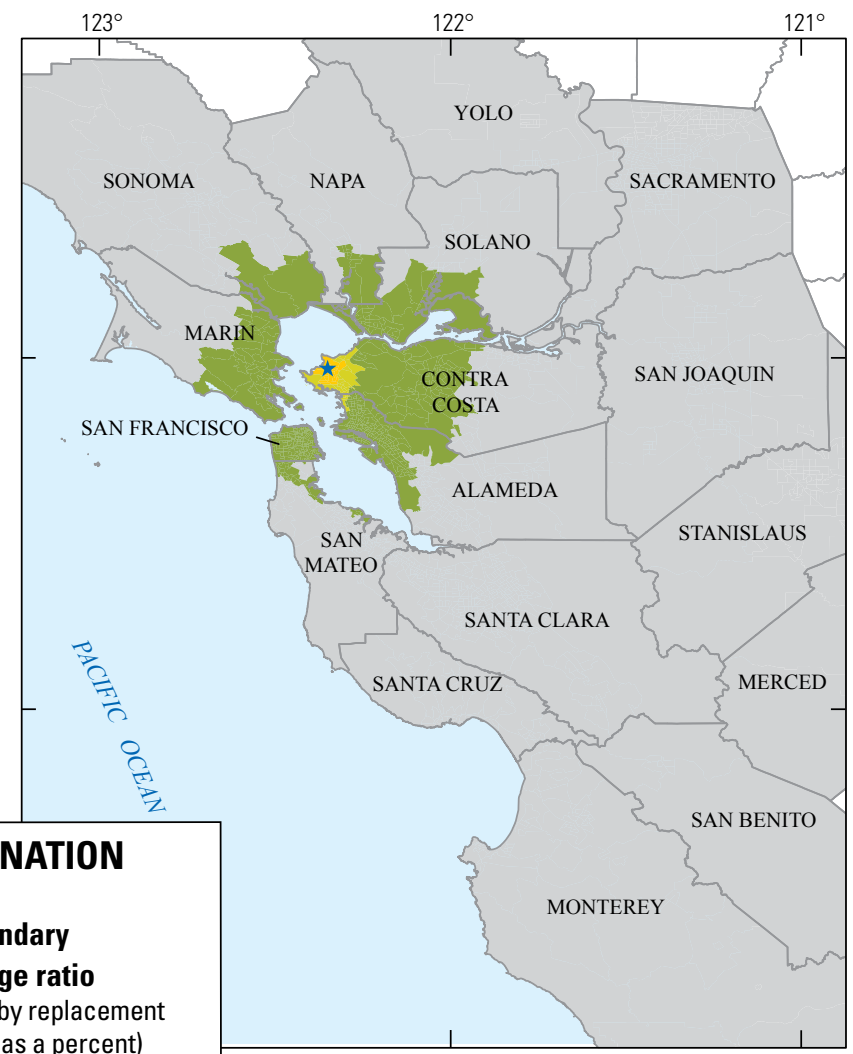

D. M5.10 Fremont

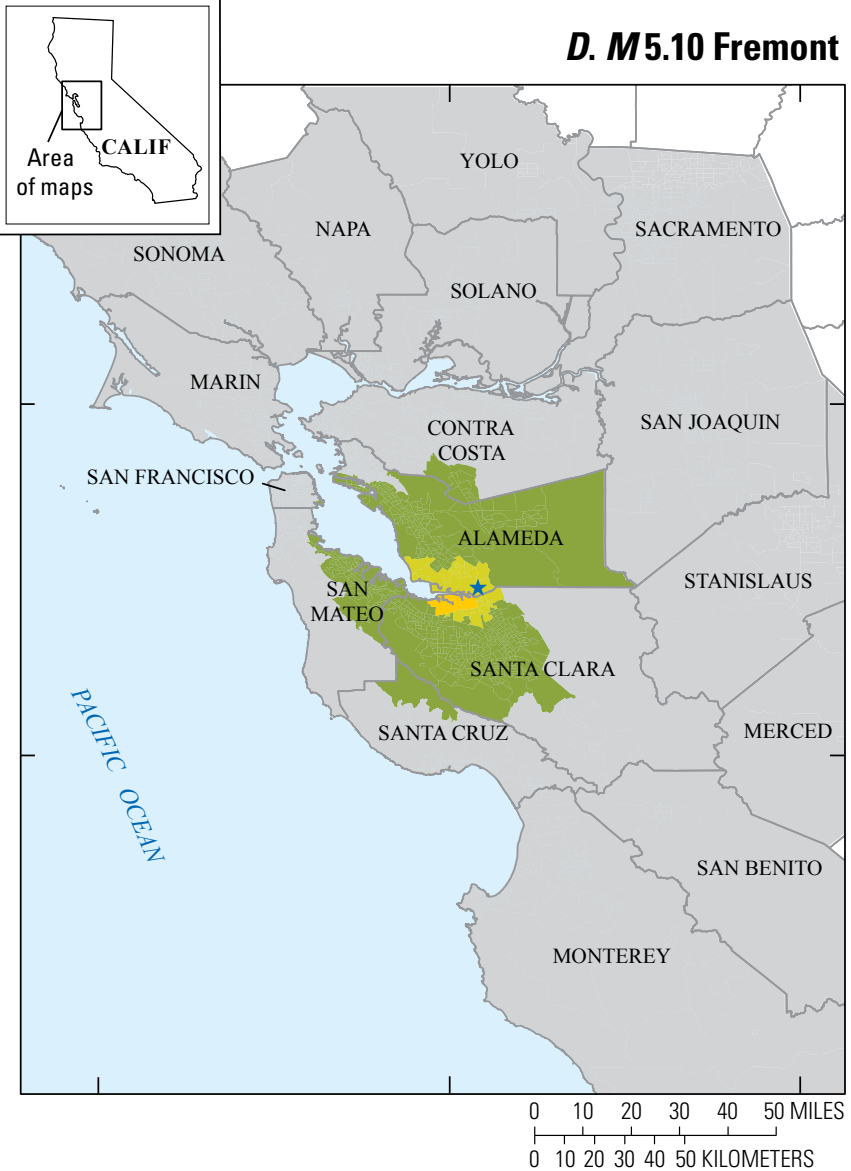

Figure 8. Maps showing building damage ratio for HayWired earthquake scenario aftershocks 1-4 (table 1), San Francisco Bay region, California, estimated using Hazus (FEMA, 2012): $A$, magnitude ( $M$ ) 5.23 Union City; B, M5.04 San Pablo; $C, M 5.58$ Fairfield; and $D, M 5.10$ Fremont. 


\section{A. M5.42 Oakland}

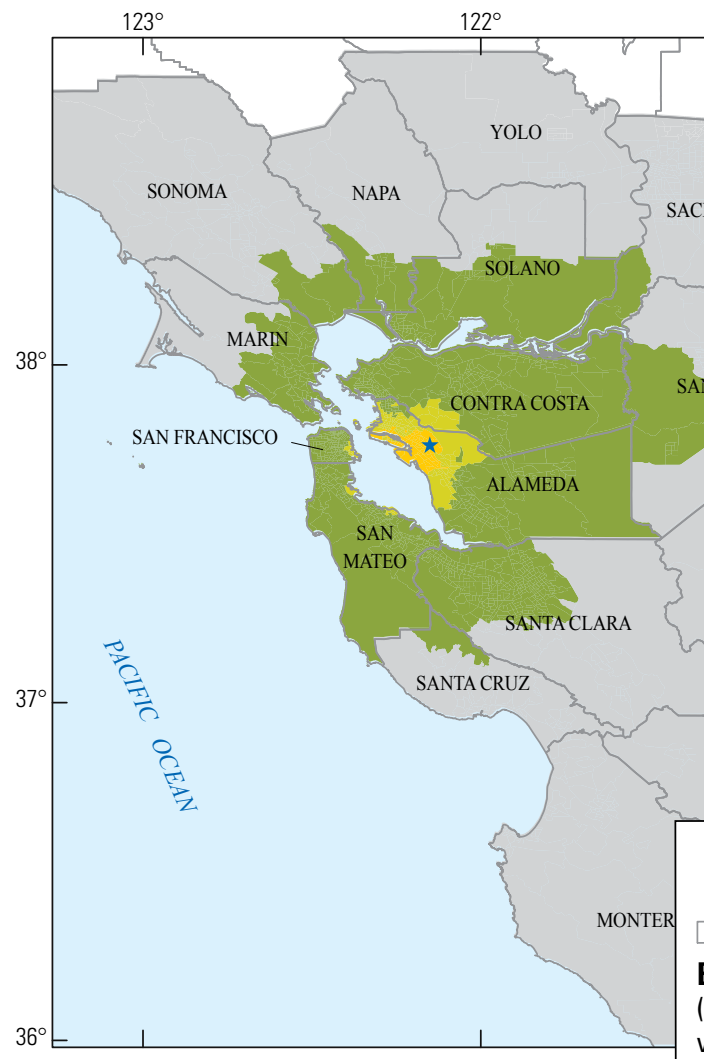

\section{M5.52 Menlo Park}

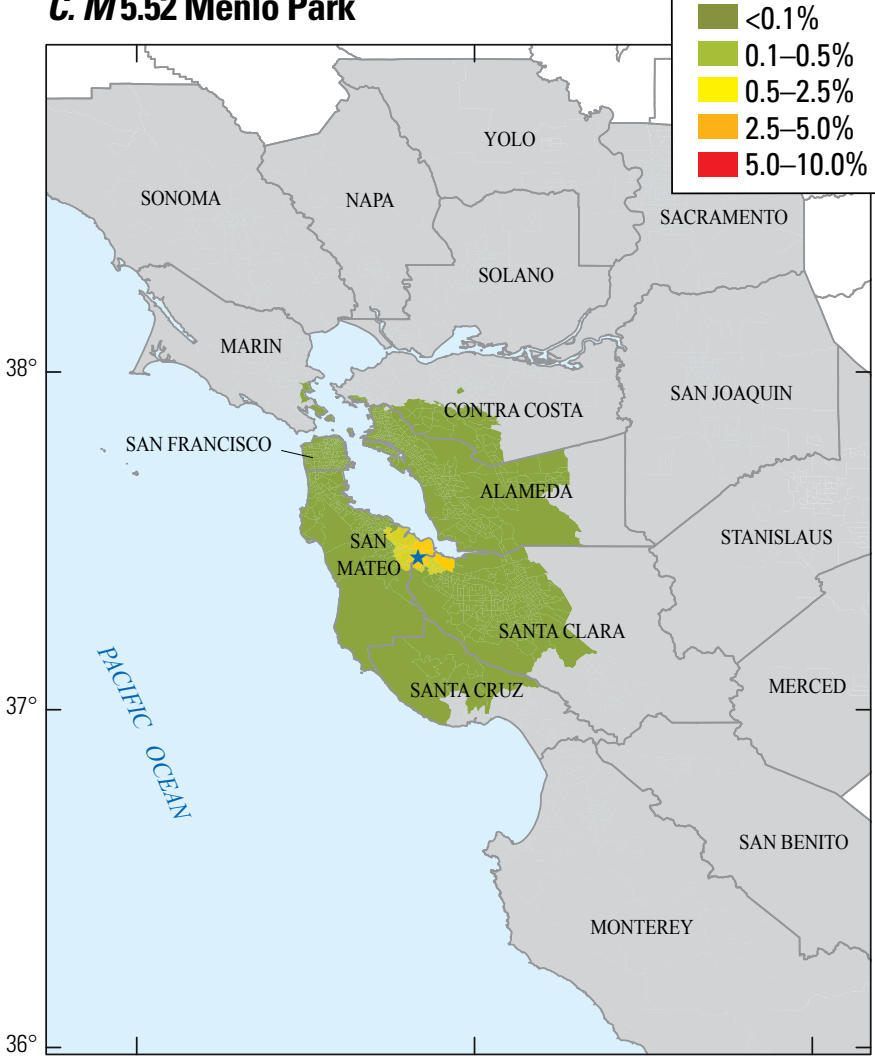

Coordinate System: GCS North American 1983 Datum: North American 1983
B. M6.2 Palo Alto

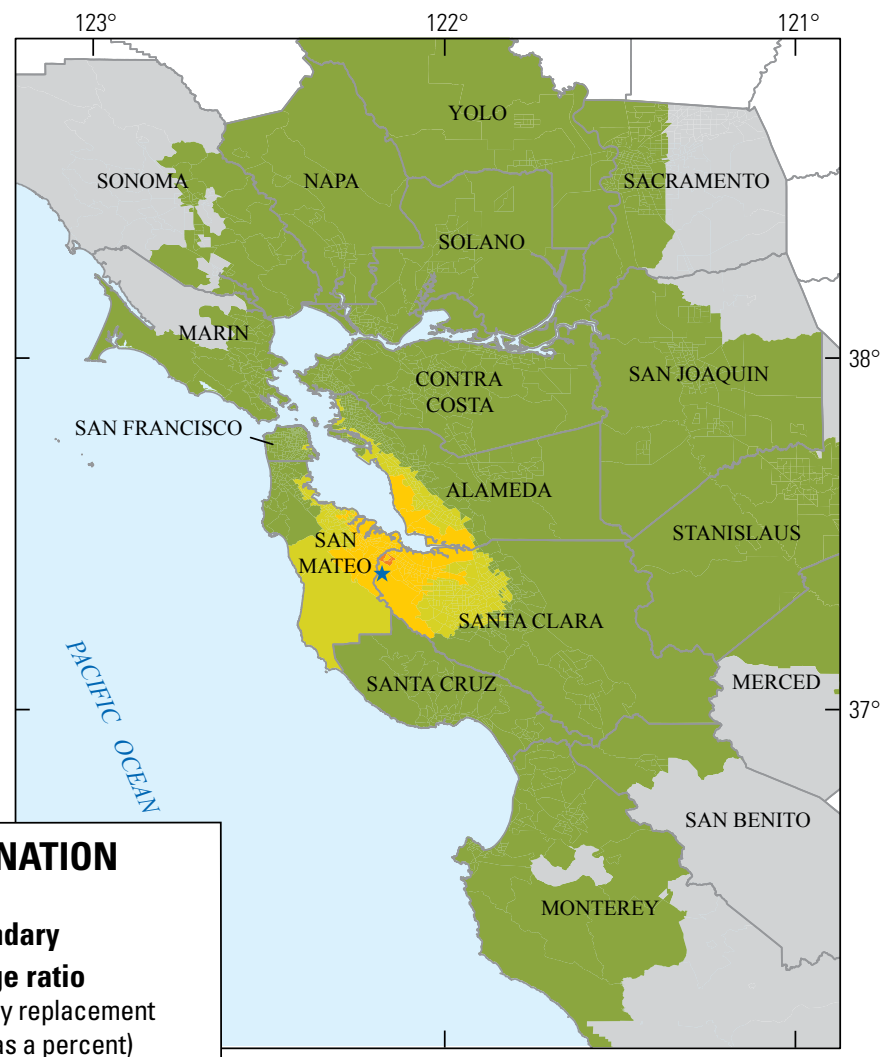

D. M5.11 Atherton

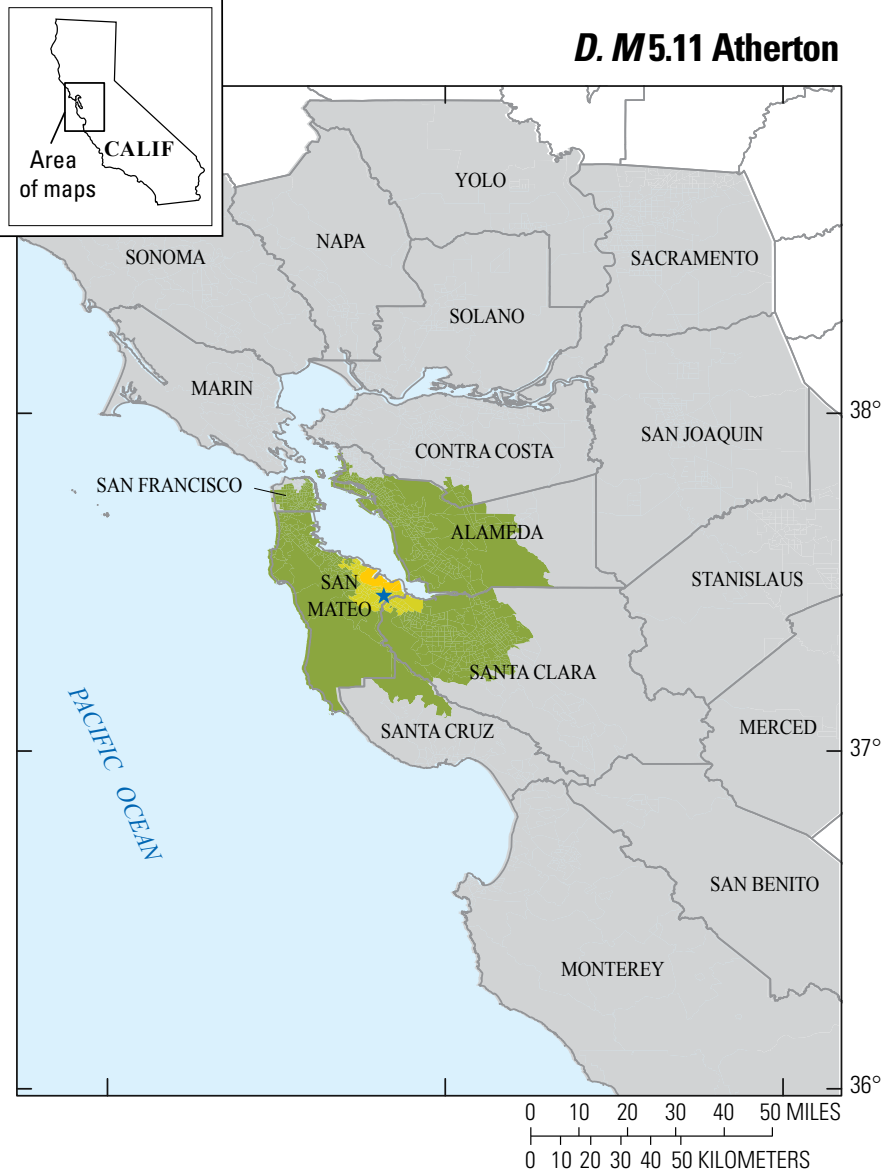

Figure 9. Maps showing building damage ratio for HayWired earthquake scenario aftershocks 5-8 (table 1), San Francisco Bay region, California, estimated using Hazus (FEMA, 2012): $A$, magnitude (M) 5.42 Oakland; $B, M 6.2$ Palo Alto; $C, M 5.52$ Menlo Park; and $D$, M5.11 Atherton. 
A. M5.69 Palo Alto

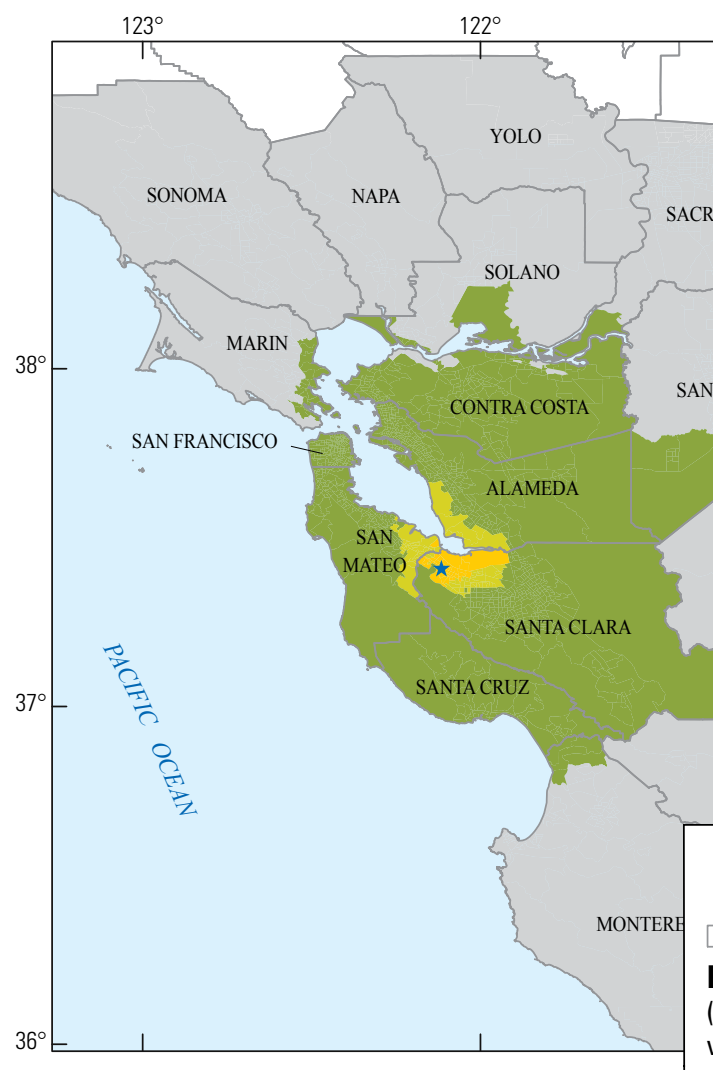

\section{M5.26 Palo Alto}

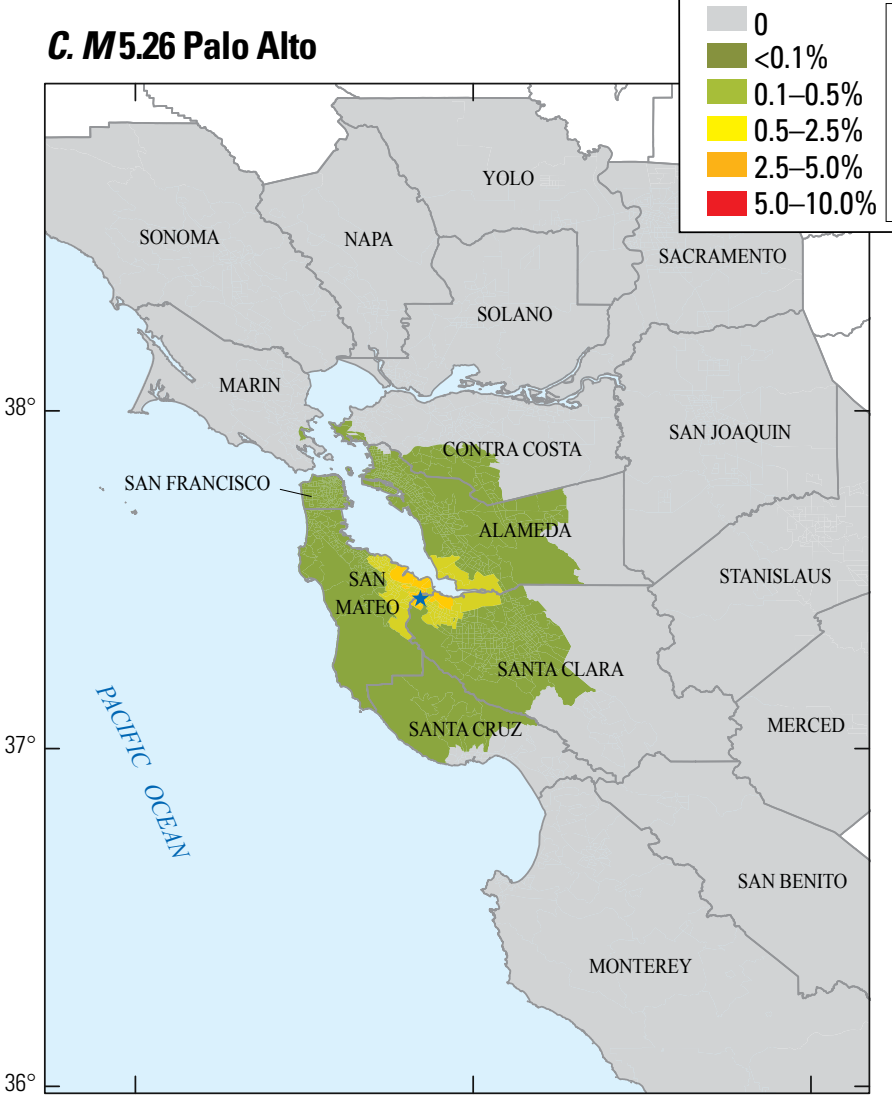

Coordinate System: GCS North American 1983 Datum: North American 1983

\section{B. M5.22 Palo Alto}

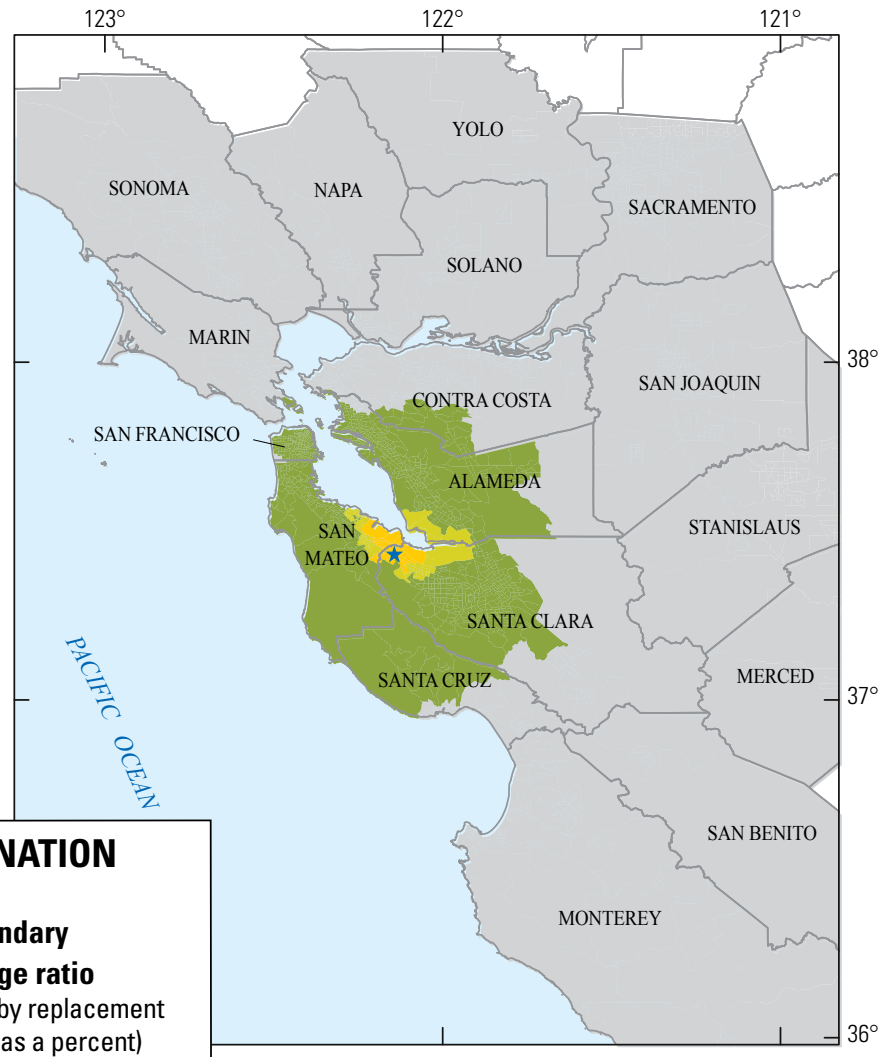

D. M5.98 Mountain View

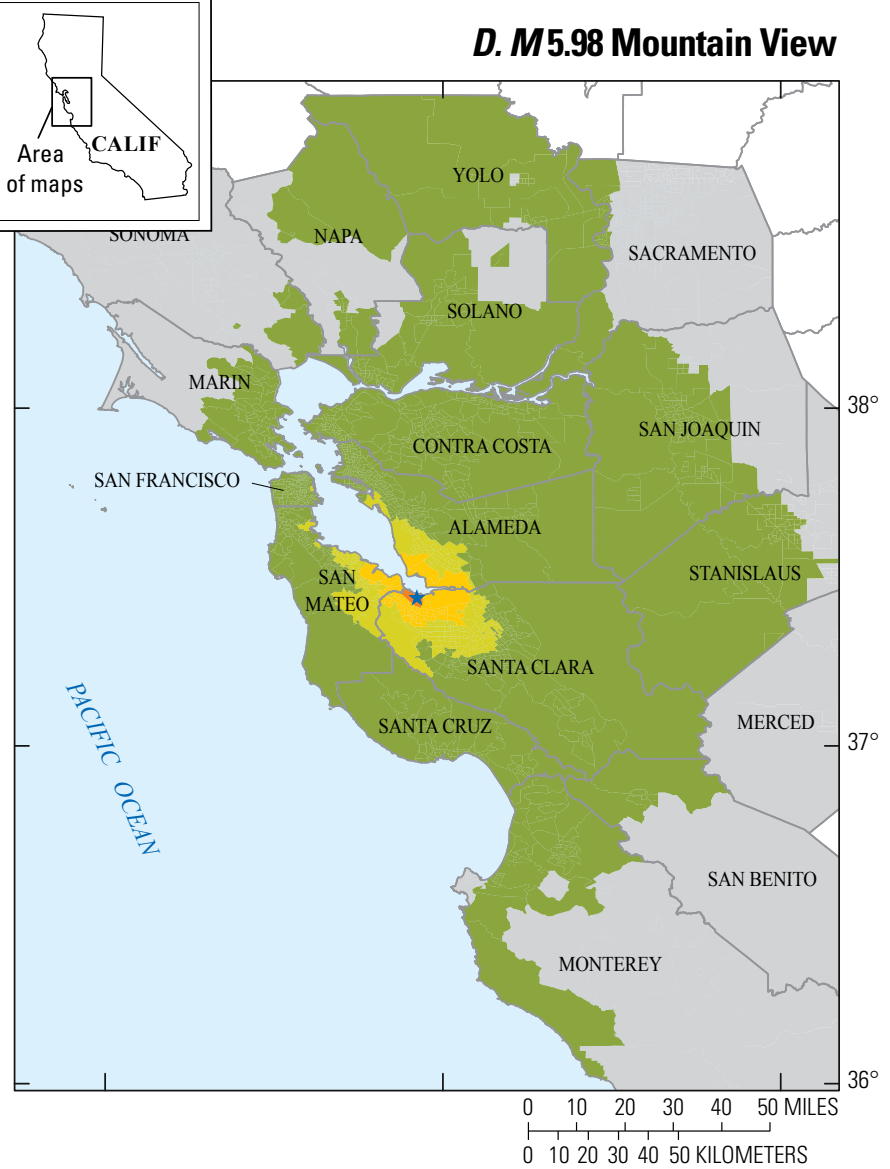

Figure 10. Maps showing building damage ratio for HayWired earthquake scenario aftershocks 9-12 (table 1), San Francisco Bay region, California, estimated using Hazus (FEMA, 2012): $A$, magnitude (M) 5.69 Palo Alto; B, M5.22 Palo Alto; $C, M 5.26$ Palo Alto; and D, M5.98 Mountain View. 


\section{A. M6.4 Cupertino}
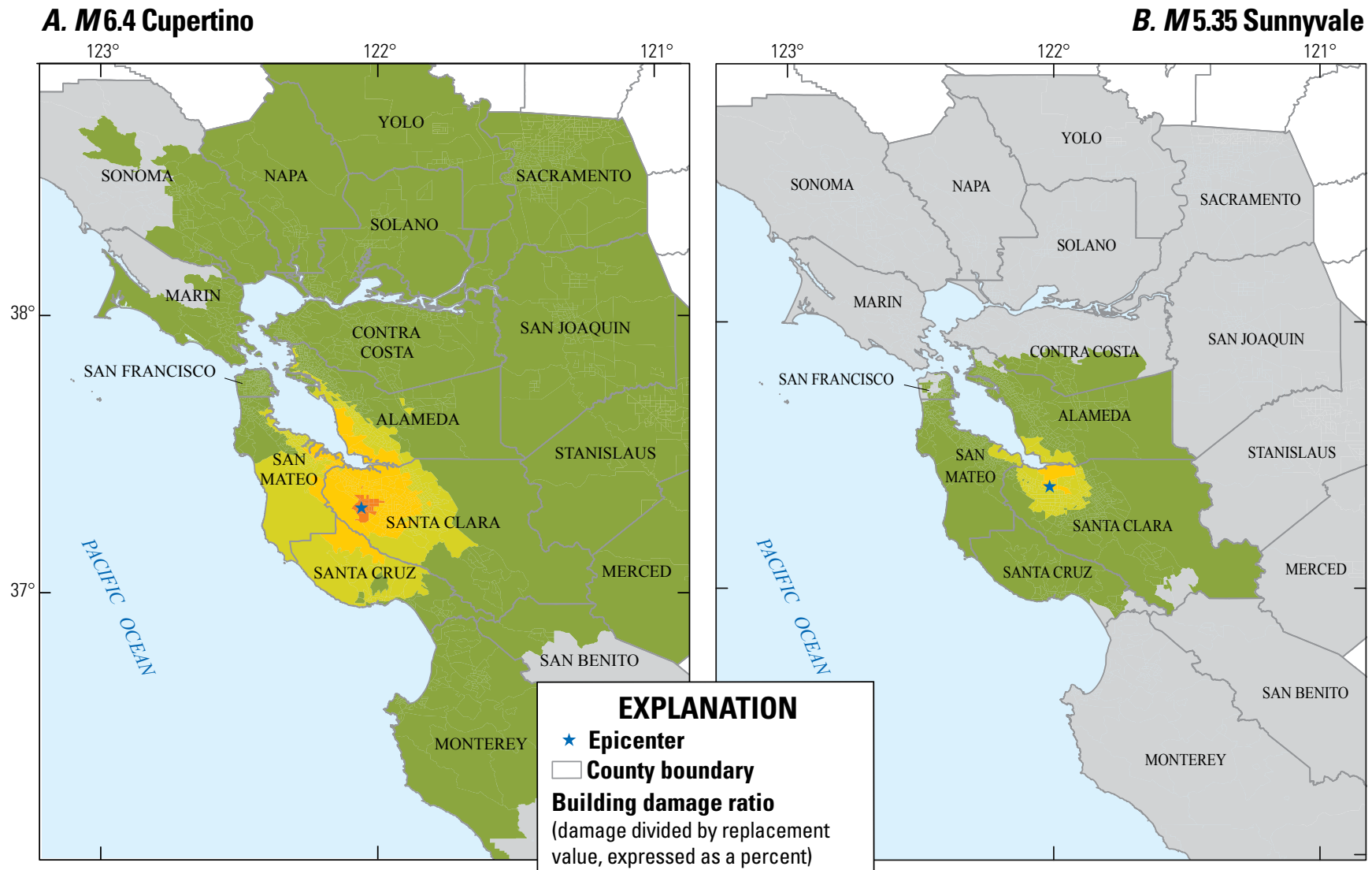

SAN BENITO

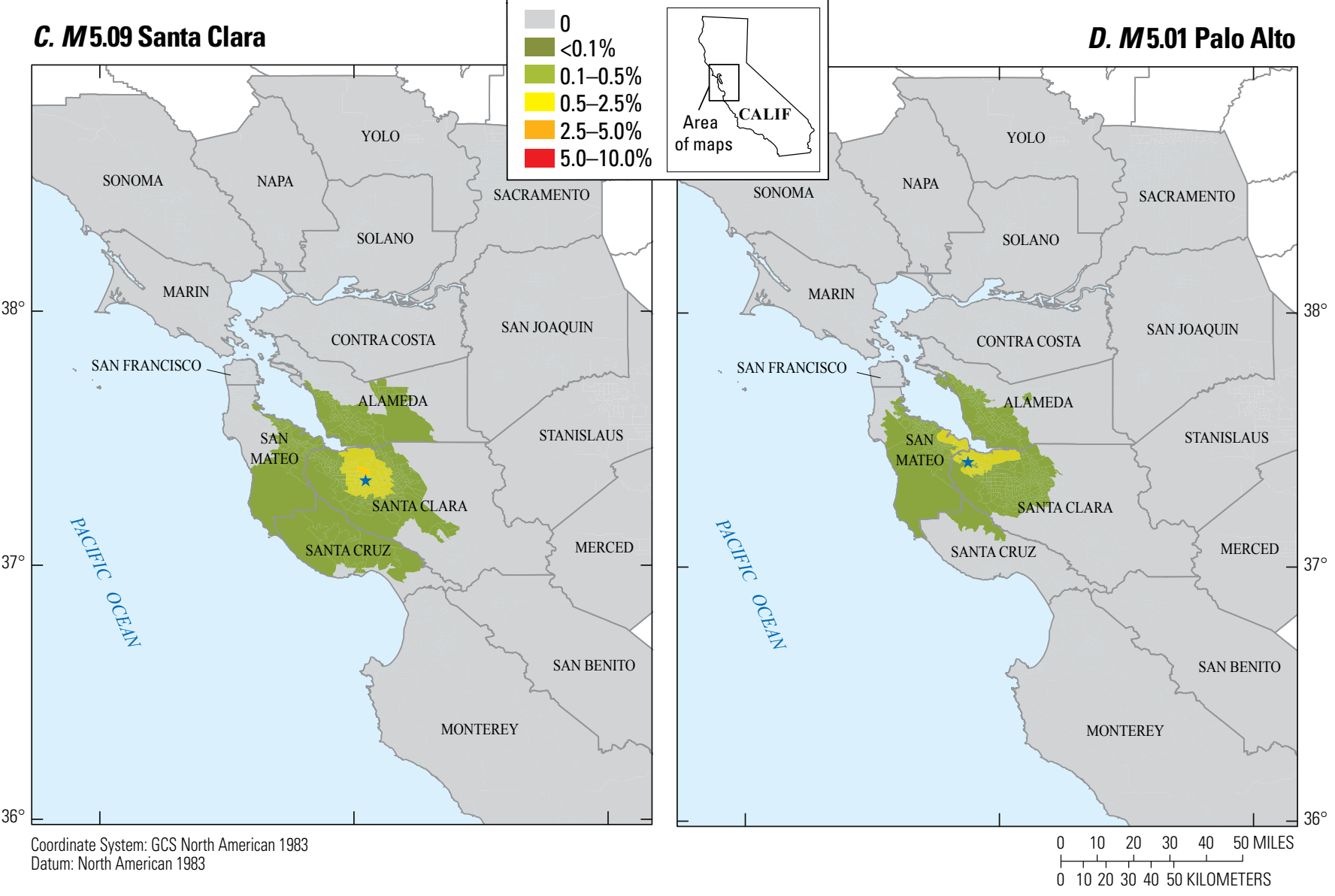

\section{EXPLANATION}

\section{$\star$ Epicenter}

County boundary

Building damage ratio

(damage divided by replacement value, expressed as a percent)

Figure 11. Maps showing building damage ratio for HayWired earthquake scenario aftershocks 13-16 (table 1), San Francisco Bay region, California, estimated using Hazus (FEMA, 2012): A, magnitude (M) 6.4 Cupertino; B, M5.35 Sunnyvale; C, M5.09 Santa Clara; and D, M5.01 Palo Alto. 
Table 13. Building damage by model building type from ground shaking caused by the HayWired earthquake scenario mainshock and aftershock sequence, San Francisco Bay region, California, estimated using Hazus.

[Data from Hazus (Federal Emergency Management Agency, 2012). See table 4 for definitions of Hazus model building types (MBT). See table 1 for explanation of aftershock short names and magnitudes. Damage in 2005 dollars; U.S. Consumer Price Index 2016:2005 ratio is approximately 1.23]

\begin{tabular}{|c|c|c|c|c|c|c|c|c|c|c|c|c|c|c|c|c|c|}
\hline \multirow[b]{2}{*}{ MBT } & \multicolumn{17}{|c|}{ Building damage (millions of dollars) } \\
\hline & 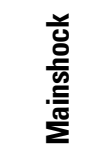 & 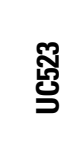 & 莺 & 嵒 & 은 & 蒙 & đั & 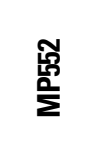 & $\overline{\overline{8}}$ & 总 & ส্ํำ & 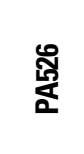 & 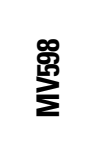 & 总 & 嵑 & $\begin{array}{l}\text { 员 } \\
\text { 号 }\end{array}$ & 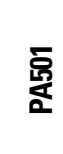 \\
\hline $\mathrm{C} 1$ & 636 & 3.6 & 0.9 & 0.2 & 1.1 & 3.7 & 26.7 & 1.8 & 1.3 & 5.7 & 3.5 & 2.9 & 15.8 & 53.9 & 4.6 & 2.7 & 0.7 \\
\hline $\mathrm{C} 2$ & 2,095 & 29.1 & 9.0 & 2.2 & 10.8 & 35.1 & 127.7 & 15.5 & 14.0 & 35.8 & 34.6 & 25.6 & 89.5 & 207.7 & 28.9 & 25.5 & 7.7 \\
\hline $\mathrm{C} 3$ & 1,580 & 5.3 & 3.0 & 0.6 & 1.8 & 13.9 & 41.7 & 4.2 & 3.6 & 8.9 & 7.9 & 6.2 & 22.3 & 67.5 & 6.2 & 5.7 & 1.7 \\
\hline MH & 667 & 5.8 & 1.7 & 0.5 & 2.5 & 5.6 & 18.1 & 2.0 & 2.1 & 5.6 & 4.1 & 3.5 & 14.8 & 34.1 & 5.5 & 4.1 & 1.5 \\
\hline $\mathrm{PC} 1$ & 788 & 25.8 & 2.4 & 1.2 & 9.8 & 16.0 & 57.1 & 5.5 & 6.0 & 17.4 & 15.4 & 12.4 & 54.2 & 97.4 & 21.0 & 14.6 & 4.0 \\
\hline $\mathrm{PC} 2$ & 158 & 3.2 & 0.5 & 0.2 & 1.3 & 2.0 & 9.8 & 0.8 & 0.9 & 2.7 & 2.3 & 1.8 & 8.2 & 18.1 & 2.9 & 2.1 & 0.5 \\
\hline RM1 & 1,814 & 30.1 & 7.2 & 1.8 & 9.6 & 30.8 & 103.6 & 12.9 & 11.6 & 30.0 & 31.8 & 22.1 & 76.9 & 175.9 & 24.3 & 20.9 & 6.1 \\
\hline RM2 & 271 & 4.7 & 1.1 & 0.3 & 1.5 & 5.1 & 17.4 & 1.9 & 1.8 & 5.0 & 4.6 & 3.5 & 12.9 & 29.6 & 4.5 & 3.5 & 1.0 \\
\hline S1 & 2,257 & 16.3 & 3.3 & 1.0 & 5.2 & 17.9 & 105.3 & 7.3 & 5.3 & 21.9 & 14.2 & 10.8 & 63.3 & 185.0 & 14.4 & 9.7 & 2.6 \\
\hline S2 & 973 & 17.1 & 2.8 & 0.7 & 6.1 & 14.4 & 57.6 & 5.3 & 4.6 & 15.5 & 13.0 & 10.1 & 43.3 & 98.6 & 13.2 & 9.6 & 2.7 \\
\hline S3 & 843 & 9.9 & 2.2 & 0.6 & 3.2 & 12.9 & 33.9 & 3.6 & 3.6 & 8.6 & 7.7 & 6.3 & 24.2 & 51.8 & 7.9 & 5.9 & 2.1 \\
\hline S4 & 514 & 4.9 & 1.4 & 0.3 & 1.7 & 6.1 & 22.5 & 2.3 & 2.0 & 5.7 & 5.3 & 3.9 & 14.8 & 39.6 & 4.6 & 3.8 & 1.0 \\
\hline S5 & 1,561 & 6.3 & 2.9 & 0.6 & 2.0 & 20.2 & 32.5 & 4.2 & 3.6 & 7.7 & 8.6 & 5.9 & 19.9 & 42.2 & 4.1 & 3.9 & 1.6 \\
\hline URM & 1,793 & 10.0 & 4.8 & 0.6 & 2.3 & 41.1 & 35.6 & 4.2 & 4.4 & 8.3 & 9.3 & 7.3 & 21.7 & 47.2 & 6.5 & 5.1 & 2.1 \\
\hline W1 & 11,329 & 135.7 & 51.2 & 9.5 & 36.6 & 229.1 & 534.6 & 61.6 & 58.6 & 135.0 & 145.4 & 104.2 & 311.7 & $1,102.0$ & 112.4 & 83.7 & 29.0 \\
\hline W2 & 3,034 & 40.6 & 11.7 & 2.1 & 10.7 & 55.5 & 143.3 & 18.1 & 15.5 & 40.1 & 43.9 & 29.1 & 100.5 & 227.8 & 27.6 & 23.9 & 7.4 \\
\hline Total & 30,312 & 348.4 & 106.3 & 22.6 & 106.3 & 509.4 & $1,367.5$ & 151.3 & 138.8 & 353.8 & 351.7 & 255.7 & 894.3 & $2,478.5$ & 288.5 & 224.8 & 71.7 \\
\hline
\end{tabular}

Table 14. Building damage ratio by model building type from ground shaking caused by the HayWired earthquake scenario mainshock and aftershock sequence, San Francisco Bay region, California, estimated using Hazus.

[Data from Hazus (Federal Emergency Management Agency, 2012). See table 4 for definitions of Hazus model building types (MBT). See table 1 for explanation of aftershock short names and magnitudes]

Building damage ratio ${ }^{1}$ (percent)

\begin{tabular}{|c|c|c|c|c|c|c|c|c|c|c|c|c|c|c|c|c|c|}
\hline MBT & 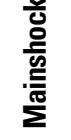 & 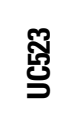 & 贶 & 嵒 & 음 & 鿷 & $\frac{\widetilde{Q}}{\alpha}$ & $\begin{array}{l}\text { 蕰 } \\
\frac{1}{\Sigma}\end{array}$ & $\overline{\overline{5}}$ & 曽 & ส্ড় & 茗 & 嵒 & 芯 & 怨 & 总 & $\frac{\bar{d}}{\alpha}$ \\
\hline $\mathrm{C} 1$ & 5 & 0.03 & 0.01 & 0.00 & 0.01 & 0.03 & 0.20 & 0.01 & 0.01 & 0.04 & 0.03 & 0.02 & 0.12 & 0.41 & 0.03 & 0.02 & 0.01 \\
\hline $\mathrm{C} 2$ & 3 & 0.05 & 0.01 & 0.00 & 0.02 & 0.06 & 0.21 & 0.03 & 0.02 & 0.06 & 0.06 & 0.04 & 0.15 & 0.34 & 0.05 & 0.04 & 0.01 \\
\hline C3 & 10 & 0.03 & 0.02 & 0.00 & 0.01 & 0.09 & 0.27 & 0.03 & 0.02 & 0.06 & 0.05 & 0.04 & 0.14 & 0.43 & 0.04 & 0.04 & 0.01 \\
\hline $\mathrm{MH}$ & 9 & 0.07 & 0.02 & 0.01 & 0.03 & 0.07 & 0.23 & 0.03 & 0.03 & 0.07 & 0.05 & 0.05 & 0.19 & 0.44 & 0.07 & 0.05 & 0.02 \\
\hline PC1 & 4 & 0.13 & 0.01 & 0.01 & 0.05 & 0.08 & 0.28 & 0.03 & 0.03 & 0.09 & 0.08 & 0.06 & 0.27 & 0.48 & 0.10 & 0.07 & 0.02 \\
\hline PC2 & 3 & 0.06 & 0.01 & 0.00 & 0.02 & 0.04 & 0.17 & 0.01 & 0.02 & 0.05 & 0.04 & 0.03 & 0.15 & 0.32 & 0.05 & 0.04 & 0.01 \\
\hline RM1 & 3 & 0.05 & 0.01 & 0.00 & 0.02 & 0.05 & 0.16 & 0.02 & 0.02 & 0.05 & 0.05 & 0.03 & 0.12 & 0.28 & 0.04 & 0.03 & 0.01 \\
\hline RM2 & 3 & 0.06 & 0.01 & 0.00 & 0.02 & 0.06 & 0.21 & 0.02 & 0.02 & 0.06 & 0.05 & 0.04 & 0.15 & 0.35 & 0.05 & 0.04 & 0.01 \\
\hline S1 & 5 & 0.04 & 0.01 & 0.00 & 0.01 & 0.04 & 0.2 & 0.02 & 0.01 & 0.05 & 0.03 & 0.03 & 0.15 & 0.43 & 0.03 & 0.02 & 0.01 \\
\hline S2 & 4 & 0.07 & 0.01 & 0.00 & 0.03 & 0.06 & 0.24 & 0.02 & 0.02 & 0.07 & 0.05 & 0.04 & 0.18 & 0.42 & 0.06 & 0.04 & 0.01 \\
\hline S3 & 9 & 0.11 & 0.02 & 0.01 & 0.04 & 0.14 & 0.38 & 0.04 & 0.04 & 0.10 & 0.09 & 0.07 & 0.27 & 0.58 & 0.09 & 0.07 & 0.02 \\
\hline S4 & 3 & 0.03 & 0.01 & 0.00 & 0.01 & 0.04 & 0.15 & 0.02 & 0.01 & 0.04 & 0.04 & 0.03 & 0.10 & 0.27 & 0.03 & 0.03 & 0.01 \\
\hline S5 & 14 & 0.06 & 0.03 & 0.01 & 0.02 & 0.18 & 0.29 & 0.04 & 0.03 & 0.07 & 0.08 & 0.05 & 0.18 & 0.37 & 0.04 & 0.03 & 0.01 \\
\hline URM & 7 & 0.04 & 0.02 & 0.00 & 0.01 & 0.17 & 0.15 & 0.02 & 0.02 & 0.03 & 0.04 & 0.03 & 0.09 & 0.20 & 0.03 & 0.02 & 0.01 \\
\hline W1 & 2 & 0.02 & 0.01 & 0.00 & 0.01 & 0.04 & 0.08 & 0.01 & 0.01 & 0.02 & 0.02 & 0.02 & 0.05 & 0.17 & 0.02 & 0.01 & 0.00 \\
\hline W2 & 3 & 0.05 & 0.01 & 0.00 & 0.01 & 0.06 & 0.16 & 0.02 & 0.02 & 0.05 & 0.05 & 0.03 & 0.11 & 0.26 & 0.03 & 0.03 & 0.01 \\
\hline
\end{tabular}

${ }^{1}$ Ratio of repair to replacement cost, calculated as the total estimated building damage divided by the total building replacement value (as defined in Hazus). 


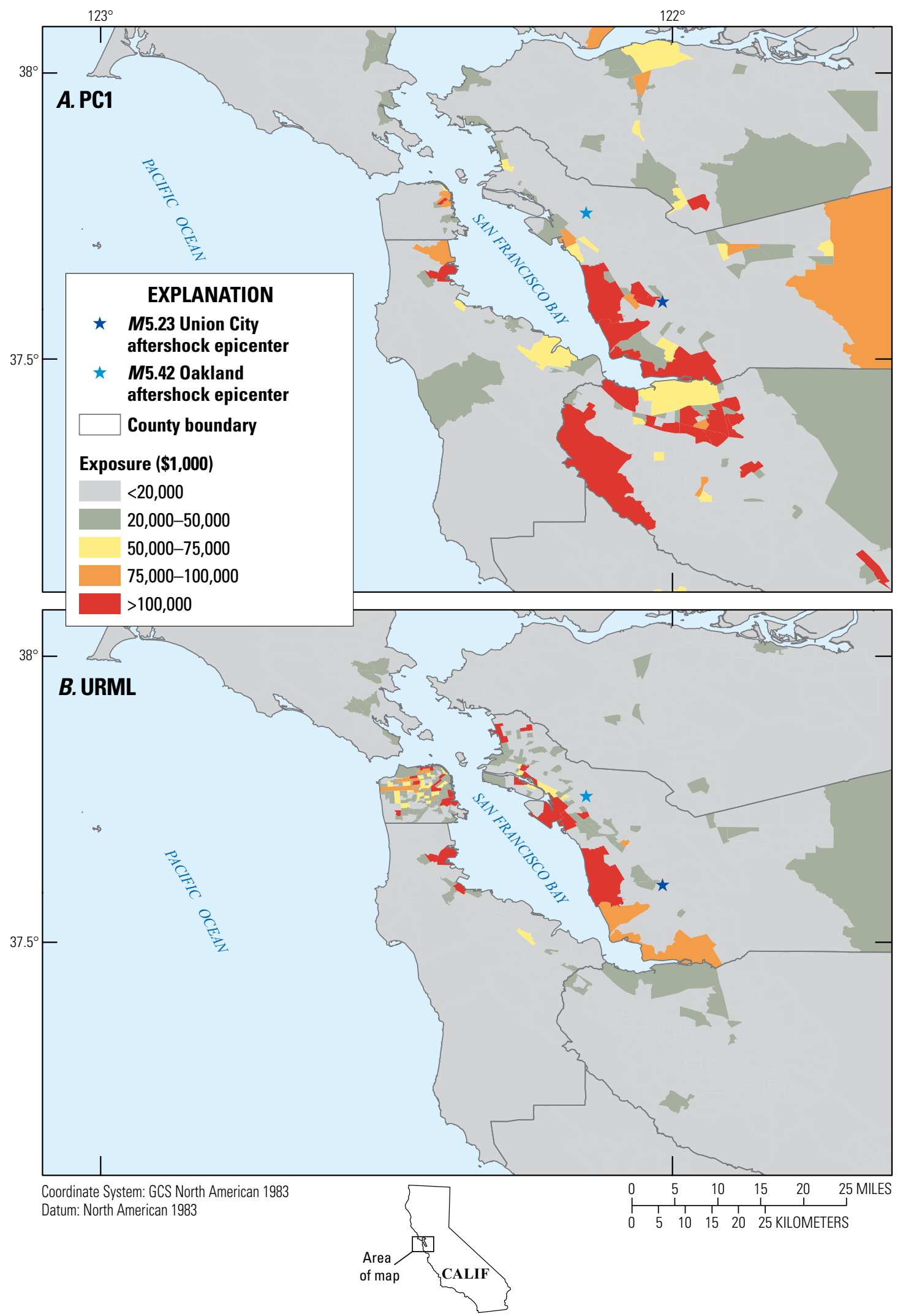

Figure 12. Maps showing building exposure value in census tracts in the vicinity of two HayWired earthquake scenario aftershocks, San Francisco Bay region, California. A, Precast concrete tilt-up wall buildings (PC1). B, Low-rise unreinforced masonry buildings (URML). Values are in 2005 dollars; U.S. Consumer Price Index 2016:2005 ratio is approximately 1.23. $M$, magnitude. 


\section{A. Mainshock}

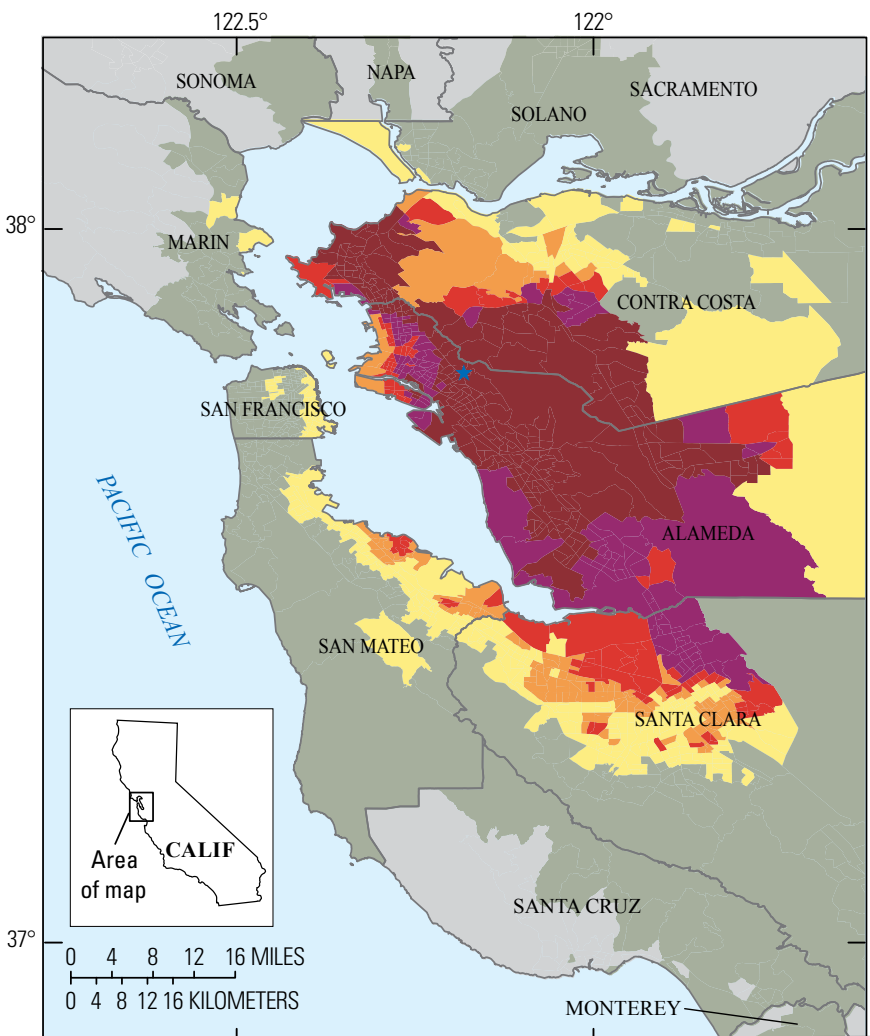

B. M6.4 Cupertino

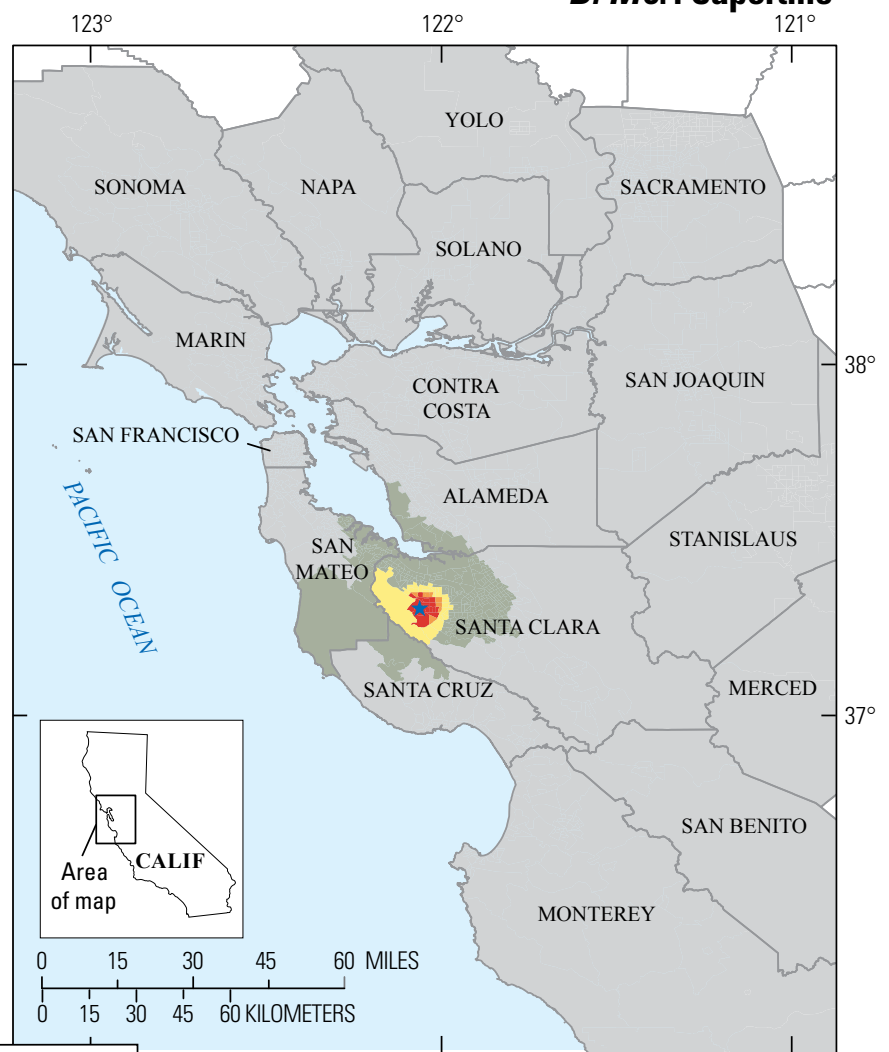

\section{M6.2 Palo Alto}

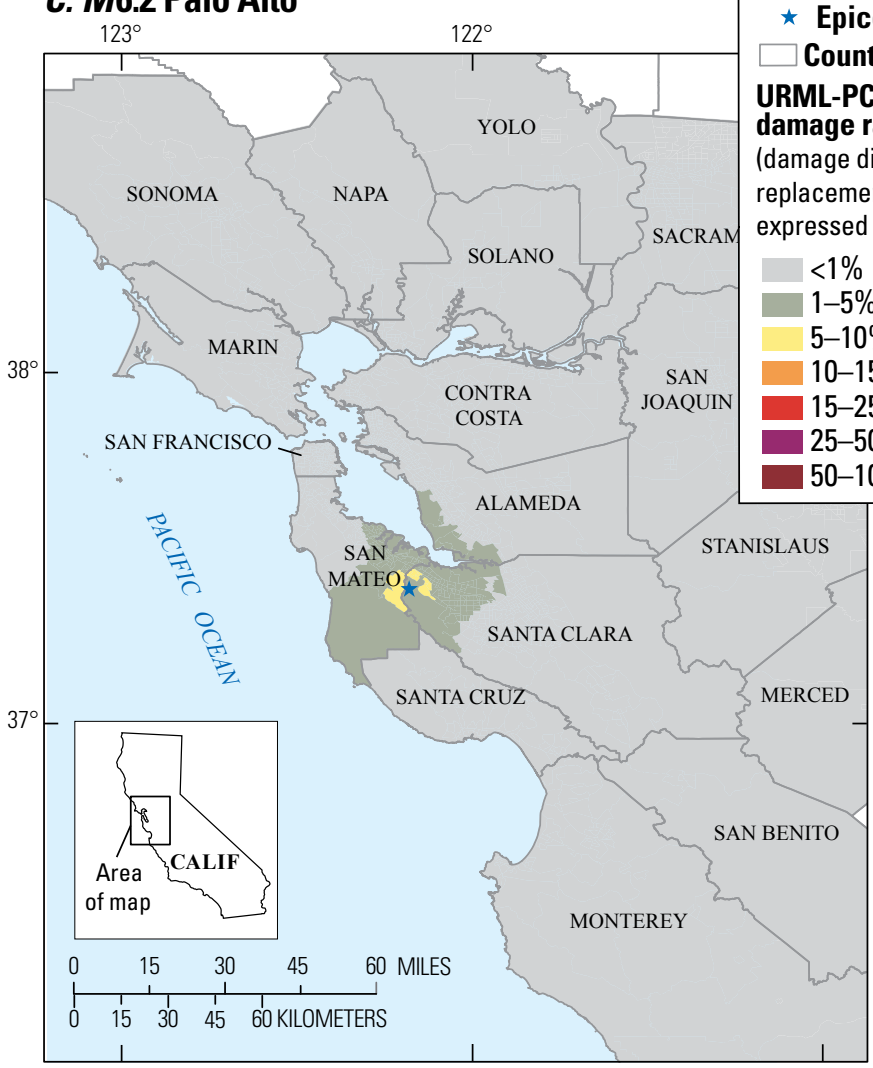

\section{EXPLANATION}

* Epicenter

County boundary

RML-PC building

mage divided by

$<1 \%$

$1-5 \%$

$5-10 \%$

$10-15 \%$

$15-25 \%$

$-50 \%$

-100\%
D. M5.42 Oakland

\section{$122^{\circ}$}

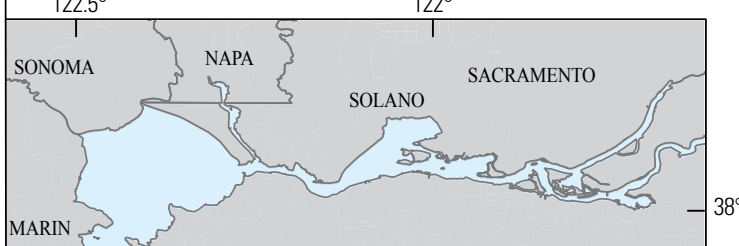

Coordinate System: GCS North American 1983

Datum: North American 1983

Figure 13. Maps showing building damage ratio for pre-code low-rise unreinforced masonry (URML-PC) for the HayWired earthquake scenario mainshock and selected aftershocks, San Francisco Bay region, California, estimated using Hazus (FEMA, 2012): $A$, Mainshock; $B$, magnitude (M) 6.4 Cupertino aftershock; $C, M 6.2$ Palo Alto aftershock; and $D, M 5.42$ Oakland aftershock. 


\section{Population Impacts-Casualties}

The Hazus methodology estimates indoor and outdoor casualties by MBT as a function of each building's damage state. Casualties are estimated at four severity levels as follows (FEMA, 2012):

- Severity level 1-“Injuries requiring basic medical aid that could be administered by paraprofessionals. These types of injuries would require bandages or observation. Some examples are: a sprain, a severe cut requiring stitches, a minor burn (first degree or second degree on a small part of the body), or a bump on the head without loss of consciousness. Injuries of lesser severity that could be self treated are not estimated by Hazus."

- Severity level 2-“Injuries requiring a greater degree of medical care and use of medical technology such as $\mathrm{x}$-rays or surgery, but not expected to progress to a life threatening status. Some examples are third degree burns or second degree burns over large parts of the body, a bump on the head that causes loss of consciousness, fractured bone, dehydration or exposure."

- Severity level 3-“Injuries that pose an immediate life threatening condition if not treated adequately and expeditiously. Some examples are: uncontrolled bleeding, punctured organ, other internal injuries, spinal cord injuries, or crush syndrome."
- Severity level 4 - “Instantaneously killed or mortally injured."

The breakdown of Hazus-estimated casualties by severity level for the mainshock and each aftershock, for each time of day modeled (day, 2 p.m.; night, 2 a.m.; and commute, 5 p.m.), is provided in table 15. The HayWired scenario mainshock has been modeled as a daytime event occurring at 4:18 p.m.; occurrence times for the aftershocks were given in table 1 . Results in table 15 have been shaded for the time of day closest to the modeled occurrence times for each event. Casualties in the aftershocks are as much as three orders of magnitude smaller than those in the mainshock. Expected casualties in most aftershocks are minor (primarily severity level 1 with some severity level 2), with the exception of the M6.2 Palo Alto and M6.4 Cupertino aftershocks, which also result in a few serious injuries (Severity Level 3) or deaths (Severity Level 4).

\section{Population Impacts-Displacement and Shelter Requirements}

The Hazus shelter model allows users to estimate the number of displaced households caused by residential building damage and resulting habitability, and the number of people seeking public short-term shelter. The number of displaced households is derived from the estimated distribution of singlefamily homes and multifamily residential buildings across the

Table 15. Casualties from ground shaking caused by the HayWired earthquake scenario mainshock and aftershock sequence, San Francisco Bay region, California, estimated using Hazus.

[Data from Hazus (Federal Emergency Management Agency, 2012). See "Population Impacts: Casualties" section for definitions of casualty severity levels. Shading indicates simulated time of occurrence for each event. See table 1 for explanation of aftershock short names and magnitudes]

\section{Number of casualties}

Time of day Casualty severity $\quad$ 言

\begin{tabular}{lcrrrrrrrrrrrrrrrrrrrrr}
\hline Day (2 p.m.) & Level 1 & 12,263 & 13 & 6 & 1 & 6 & 31 & 168 & 9 & 9 & 28 & 13 & 17 & 89 & 323 & 32 & 15 & 6 \\
& Level 2 & 3,007 & 0 & 0 & 0 & 0 & 1 & 13 & 0 & 0 & 1 & 1 & 1 & 6 & 28 & 1 & 0 & 0 \\
& Level 3 & 461 & 0 & 0 & 0 & 0 & 0 & 1 & 0 & 0 & 0 & 0 & 0 & 0 & 2 & 0 & 0 & 0 \\
& Level 4 & 837 & 0 & 0 & 0 & 0 & 0 & 1 & 0 & 0 & 0 & 0 & 0 & 0 & 2 & 0 & 0 & 0 \\
\hline & Total & 16,568 & 13 & 6 & 1 & 6 & 32 & 183 & 9 & 9 & 29 & 14 & 18 & 95 & 355 & 33 & 15 & 6 \\
\hline Night (2 a.m.) & Level 1 & 7,827 & 14 & 7 & 1 & 5 & 36 & 146 & 8 & 8 & 28 & 12 & 15 & 76 & 327 & 33 & 14 & 5 \\
& Level 2 & 1,512 & 0 & 0 & 0 & 0 & 1 & 9 & 0 & 0 & 1 & 0 & 0 & 3 & 22 & 1 & 0 & 0 \\
& Level 3 & 179 & 0 & 0 & 0 & 0 & 0 & 0 & 0 & 0 & 0 & 0 & 0 & 0 & 1 & 0 & 0 & 0 \\
& Level 4 & 340 & 0 & 0 & 0 & 0 & 0 & 0 & 0 & 0 & 0 & 0 & 0 & 0 & 1 & 0 & 0 & 0 \\
\hline Commute (5 p.m.) & Total & 9,858 & 14 & 7 & 1 & 5 & 37 & 155 & 8 & 8 & 29 & 12 & 15 & 79 & 351 & 34 & 14 & 5 \\
& Level 1 & 10,600 & 12 & 5 & 1 & 5 & 29 & 151 & 7 & 8 & 25 & 12 & 14 & 79 & 309 & 30 & 13 & 5 \\
& Level 2 & 2,966 & 0 & 0 & 0 & 0 & 1 & 17 & 0 & 0 & 2 & 0 & 1 & 8 & 37 & 2 & 0 & 0 \\
& Level 3 & 1,300 & 0 & 0 & 0 & 0 & 0 & 10 & 0 & 0 & 1 & 0 & 0 & 6 & 22 & 3 & 0 & 0 \\
& Level 4 & 834 & 0 & 0 & 0 & 0 & 0 & 3 & 0 & 0 & 0 & 0 & 0 & 1 & 6 & 0 & 0 & 0 \\
\hline & Total & 15,700 & 12 & 5 & 1 & 5 & 30 & 181 & 7 & 8 & 28 & 12 & 15 & 94 & 374 & 35 & 13 & 5 \\
\hline
\end{tabular}


Hazus building damage states combined with weighting factors (or displacement probabilities) for households residing in buildings in each of the various damage states, given in table 16 . The Hazus model for the number of people seeking publiclyprovided, short-term shelter recognizes that only a portion of displaced households will actually use public shelter resources; the model uses population data and weighting factors, which reflect the income, ethnicity, ownership, and age of the residents in the displaced households to estimate the fraction expected to seek public shelter (for additional details, refer to chapter 14 of the Hazus Technical Manual; FEMA, 2012.). It should be noted, however, that the default values for the age and ownership weighting factors are set to zero, effectively removing these factors from consideration, as shown in table 17.

Table 18 provides the Hazus estimates of displaced households and people seeking shelter for the HayWired scenario mainshock and each of the aftershocks. These results reflect the shelter impacts related to ground shaking only (liquefaction is not included) and were estimated using the Hazus default shelter model parameters. Expected household displacement in the aftershocks is generally minimal, except in the four larger events.

Custom shelter parameters were developed for the ShakeOut scenario (Jones and others, 2008), based on available population survey data from the 1994 Northridge and other California earthquakes (Seligson, 2008), as described in the appendix. The default Hazus parameters and the modified parameters used in the ShakeOut analysis are provided in table 19. Adjustments included modifying the parameters for the percentage of households seeking shelter based on building damage state to include some shelter-seeking behavior for occupants of moderately damaged residential structures (normally set to zero in the Hazus default) and modifications

Table 16. Default damage state factors for the Hazus population displacement model.

\begin{tabular}{llr}
\hline $\begin{array}{c}\text { Model } \\
\text { parameter }\end{array}$ & \multicolumn{1}{c}{ Description } & $\begin{array}{c}\text { Default } \\
\text { value }\end{array}$ \\
\hline $\mathrm{W}_{\mathrm{SFM}}$ & Displacement weight for single-family homes in the moderate damage state & 0.0 \\
$\mathrm{~W}_{\mathrm{SFE}}$ & Displacement weight for single-family homes in the extensive damage state & 0.0 \\
$\mathrm{~W}_{\mathrm{SFC}}$ & Displacement weight for single-family homes in the complete damage state & 1.0 \\
$\mathrm{~W}_{\mathrm{MFM}}$ & Displacement weight for multifamily residences in the moderate damage state & 0.0 \\
$\mathrm{~W}_{\mathrm{MFE}}$ & Displacement weight for multifamily residences in the extensive damage state & 0.9 \\
$\mathrm{~W}_{\mathrm{MFC}}$ & Displacement weight for multifamily residences in the complete damage state & 1.0 \\
\hline
\end{tabular}

Table 17. Default weighting and modification factors for the Hazus short-term shelter model.

\begin{tabular}{llc}
\hline \multicolumn{1}{c}{$\begin{array}{c}\text { Model } \\
\text { parameter }\end{array}$} & \multicolumn{1}{c}{ Description } & $\begin{array}{c}\text { Default } \\
\text { value }\end{array}$ \\
\hline $\mathrm{AW}$ & Age weighting factor & 0 \\
$\mathrm{EW}$ & Ethnicity weighting factor & 0.27 \\
$\mathrm{IW}$ & Income weighting factor & 0.73 \\
$\mathrm{OW}$ & Ownership weighting factor & 0 \\
$\mathrm{AM}_{1}$ & Modification factor for percentage of population under 16 years old & 0.4 \\
$\mathrm{AM}_{2}$ & Modification factor for percentage of population between 16 and 65 years old & 0.4 \\
$\mathrm{AM}_{3}$ & Modification factor for percentage of population over 65 years old & 0.4 \\
$\mathrm{EM}_{1}$ & Modification factor for ethnicity: White households & 0.24 \\
$\mathrm{EM}_{2}$ & Modification factor for ethnicity: Black households & 0.48 \\
$\mathrm{EM}_{3}$ & Modification factor for ethnicity: Hispanic households & 0.47 \\
$\mathrm{EM}_{4}$ & Modification factor for ethnicity: Asian households & 0.26 \\
$\mathrm{EM}_{5}$ & Modification factor for ethnicity: Native American households & 0.26 \\
$\mathrm{IM}_{1}$ & Modification factor for household income $<\$ 10,000$ & 0.62 \\
$\mathrm{IM}_{2}$ & Modification factor for household income $\$ 10,000-\$ 15,000$ & 0.42 \\
$\mathrm{IM}_{3}$ & Modification factor for household income $\$ 15,000-\$ 25,000$ & 0.29 \\
$\mathrm{IM}_{4}$ & Modification factor for household income $\$ 25,000-\$ 35,000$ & 0.22 \\
$\mathrm{IM}_{5}$ & Modification factor for household income $>\$ 35,000$ & 0.13 \\
$\mathrm{OM}_{1}$ & Modification factor for percentage of households that are owner occupied & 0.4 \\
$\mathrm{OM}_{2}$ & Modification factor for percentage of households that are renter occupied & 0.4 \\
\hline
\end{tabular}


Table 18. Displaced households and shelter demands from ground shaking caused by the HayWired earthquake scenario mainshock and aftershock sequence, estimated using Hazus.

[Data from Hazus (Federal Emergency Management Agency, 2012). See table 1 for explanation of aftershock short names and magnitudes]

\begin{tabular}{lrr}
\hline HayWired scenario event & Displaced households & $\begin{array}{c}\text { People seeking short- } \\
\text { term shelter }\end{array}$ \\
\hline Mainshock & 64,410 & 47,009 \\
UC523 & 2 & 1 \\
SP504 & 2 & 2 \\
FF558 & 0 & 0 \\
FR510 & 0 & 0 \\
OK542 & 19 & 17 \\
PA62 & 741 & 408 \\
MP552 & 3 & 2 \\
AT511 & 2 & 1 \\
PA569 & 46 & 24 \\
PA522 & 3 & 2 \\
PA526 & 5 & 3 \\
MV598 & 152 & 83 \\
CU64 & 1,880 & 1,080 \\
SV535 & 18 & 11 \\
SC509 & 3 & 2 \\
PA501 & 1 & 0 \\
\hline
\end{tabular}

Table 19. Hazus shelter model default and custom parameter values developed for the ShakeOut scenario (see appendix).

[Hazus, Federal Emergency Management Agency (2012)]

\begin{tabular}{|c|c|c|c|}
\hline $\begin{array}{c}\text { Model } \\
\text { parameter }\end{array}$ & Description & $\begin{array}{c}\text { Hazus } \\
\text { default } \\
\text { value }\end{array}$ & $\begin{array}{c}\text { Custom } \\
\text { ShakeOut } \\
\text { value }\end{array}$ \\
\hline $\mathrm{W}_{\mathrm{SFM}}$ & Displacement weight for single-family homes in the Moderate damage state & 0.0 & 0.2 \\
\hline $\mathrm{W}_{\mathrm{SFE}}$ & Displacement weight for single-family homes in the Extensive damage state & 0.0 & 0.4 \\
\hline $\mathrm{W}_{\mathrm{SFC}}$ & Displacement weight for single-family homes in the Complete damage state & 1.0 & 1.0 \\
\hline $\mathrm{W}_{\mathrm{MFM}}$ & Displacement weight for multifamily residences in the Moderate damage state & 0.0 & 0.4 \\
\hline $\mathrm{W}_{\mathrm{MFE}}$ & Displacement weight for multifamily residences in the Extensive damage state & 0.9 & 0.65 \\
\hline $\mathrm{W}_{\mathrm{MFC}}$ & Displacement weight for multifamily residences in the Complete damage state & 1.0 & 1.0 \\
\hline AW & Age weighting factor & 0 & No change \\
\hline EW & Ethnicity weighting factor & 0.27 & No change \\
\hline IW & Income weighting factor & 0.73 & No change \\
\hline OW & Ownership weighting factor & 0 & No change \\
\hline $\mathrm{EM}_{1}$ & Modification factor for ethnicity: White households & 0.24 & 0.1 \\
\hline $\mathrm{EM}_{2}$ & Modification factor for ethnicity: Black households & 0.48 & 0.2 \\
\hline $\mathrm{EM}_{3}$ & Modification factor for ethnicity: Hispanic households & 0.47 & 0.2 \\
\hline $\mathrm{EM}_{4}$ & Modification factor for ethnicity: Asian households & 0.26 & 0.1 \\
\hline $\mathrm{EM}_{5}$ & Modification factor for ethnicity: Native American households & 0.26 & 0.1 \\
\hline $\mathrm{IM}_{1}$ & Modification factor for household income $<\$ 10,000$ & 0.62 & 0.3 \\
\hline $\mathrm{IM}_{2}$ & Modification factor for household income $\$ 10,000-\$ 15,000$ & 0.42 & 0.3 \\
\hline $\mathrm{IM}_{3}$ & Modification factor for household income $\$ 15,000-\$ 25,000$ & 0.29 & 0.14 \\
\hline $\mathrm{IM}_{4}$ & Modification factor for household income $\$ 25,000-\$ 35,000$ & 0.22 & 0.08 \\
\hline $\mathrm{IM}_{5}$ & Modification factor for household income $>\$ 35,000$ & 0.13 & 0.05 \\
\hline
\end{tabular}


Table 20. Displaced households and short-term shelter requirements for the HayWired earthquake scenario mainshock, including liquefaction, in counties of the San Francisco Bay region, California, estimated using Hazus with default and custom ShakeOut shelter parameters.

[Data from Hazus (Federal Emergency Management Agency, 2012)]

\begin{tabular}{|c|c|c|c|c|}
\hline \multirow[b]{2}{*}{ County } & \multicolumn{2}{|c|}{ Hazus default shelter parameters } & \multicolumn{2}{|c|}{ Custom ShakeOut shelter parameters } \\
\hline & $\begin{array}{c}\text { Displaced } \\
\text { households }\end{array}$ & $\begin{array}{l}\text { People seeking } \\
\text { short-term shelter }\end{array}$ & $\begin{array}{l}\text { Displaced } \\
\text { households }\end{array}$ & $\begin{array}{l}\text { People seeking short- } \\
\text { term shelter }\end{array}$ \\
\hline Alameda & 51,975 & 38,430 & 87,629 & 28,922 \\
\hline Contra Costa & 12,483 & 8,641 & 21,856 & 6,623 \\
\hline Marin & 128 & 121 & 513 & 155 \\
\hline Merced & 0 & 0 & 5 & 2 \\
\hline Monterey & 1 & 1 & 25 & 12 \\
\hline Napa & 1 & 1 & 29 & 9 \\
\hline Sacramento & 0 & 0 & 9 & 3 \\
\hline San Benito & 32 & 29 & 54 & 23 \\
\hline San Francisco & 2,251 & 1,265 & 11,741 & 2,986 \\
\hline San Joaquin & 11 & 9 & 218 & 87 \\
\hline San Mateo & 1,908 & 1,104 & 6,167 & 1,640 \\
\hline Santa Clara & 7,649 & 5,641 & 24,179 & 7,408 \\
\hline Santa Cruz & 9 & 13 & 89 & 48 \\
\hline Solano & 52 & 39 & 310 & 110 \\
\hline Sonoma & 0 & 0 & 14 & 4 \\
\hline Stanislaus & 1 & 1 & 39 & 16 \\
\hline Yolo & 0 & 0 & 4 & 2 \\
\hline Total & 76,501 & 55,295 & 152,881 & 48,050 \\
\hline
\end{tabular}

to the income and ethnicity factors considered by the model. It should be noted that, based on the default shelter category weights (table 17), income is a more important indicator of shelter-seeking behavior than ethnicity (that is, IW is larger than EW), and those with lower incomes are more likely to seek shelter than those with higher incomes $\left(\mathrm{IM}_{1}>\mathrm{IM}_{2}>\mathrm{IM}_{3}\right)$. The modifications made for the ShakeOut analysis were based on data from recent California earthquakes and resulted in reductions in the proportions of the population expected to seek shelter at all income levels. A comparison of the displacement and shelter estimates for the HayWired scenario mainshock and those estimated using the custom ShakeOut shelter parameters is provided in table 20; both of these analyses include the impacts of liquefaction. The net result of applying the custom ShakeOut shelter parameters was an increase in the estimated number of displaced households from 76,500 to more than 150,000 and a slight decrease in the number of people seeking shelter from 55,000 to 48,000 .

\section{Combining Losses in the Mainshock and Aftershocks}

Two approaches have been used to bound the estimate of potential additional losses suffered as a result of ground

Table 21. Combined losses from ground shaking caused by the HayWired earthquake scenario mainshock and aftershocks, estimated using Hazus.

[Data from Hazus (Federal Emergency Management Agency, 2012). Loss reported in 2005 dollars; U.S. Consumer Price Index 2016:2005 ratio is approximately 1.23 ]

\begin{tabular}{lccc}
\hline \multicolumn{1}{c}{ Combined event } & $\begin{array}{c}\text { Building } \\
\text { damage }\end{array}$ & $\begin{array}{c}\text { Total direct } \\
\text { economic loss }\end{array}$ & $\begin{array}{c}\text { Net building } \\
\text { damage ratio } \\
\text { (percent) }\end{array}$ \\
\cline { 2 - 3 } Mainshock & \multicolumn{2}{c}{ (millions of dollars) } & 2.9 \\
Maximum aftershock & $30,312.4$ & $46,633.7$ & 0.3 \\
All aftershocks & $3,478.7$ & $5,380.8$ & 0.7 \\
Lower Bound 1: mainshock + maximum aftershock & $7,669.4$ & $11,767.1$ & 3.2 \\
Lower Bound 2: maximum individual event & $33,791.0$ & $52,014.5$ & 2.9 \\
Upper Bound: mainshock + all aftershocks & $30,551.1$ & $47,015.4$ & 3.6 \\
\hline
\end{tabular}




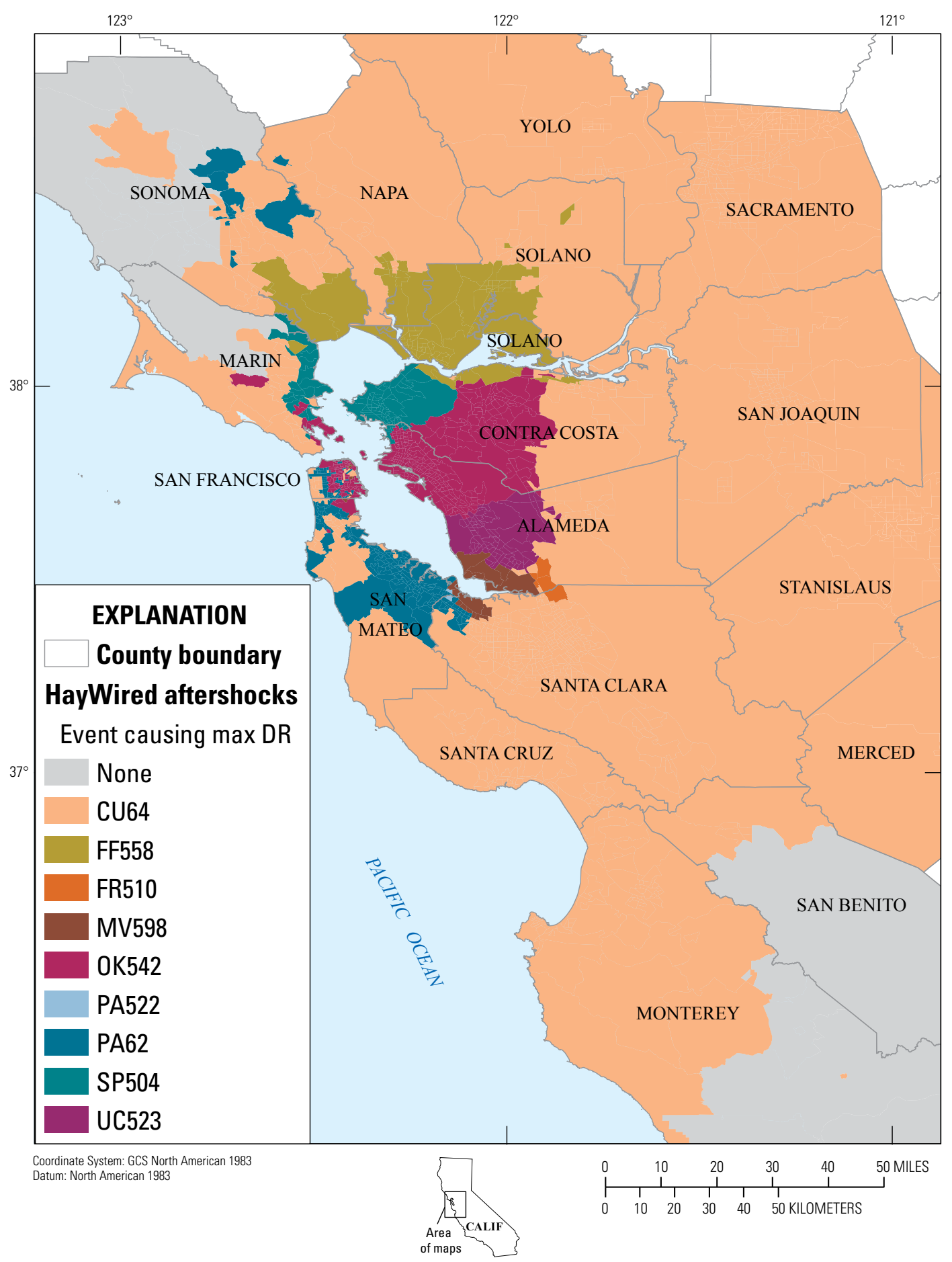

Figure 14. Map showing the HayWired earthquake scenario aftershock causing the maximum building damage ratio (max DR) by census tract, the San Francisco Bay region, California. See table 1 for explanation of aftershock short names and magnitudes. 
shaking in the aftershock sequence; a lower bound estimate for each census tract has been developed as the sum of the mainshock shaking losses and shaking losses from the aftershock causing the maximum damage for that census tract, and an upper bound estimate has been developed as the sum of shaking losses in the mainshock and all of the aftershocks. The aftershocks generating the maximum building damage in each census tract are identified in figure 14. For most census tracts, the largest aftershock (the M6.4 Cupertino) causes the largest building damage ratio. Other events causing maximum damage ratios for selected census tracts include the $M 5.58$ Fairfield, M5.10 Freemont, M5.98 Mountain View, M5.42 Oakland, M5.22 and M6.2 Palo Alto, M5.04 San Pablo, and M5.23 Union City aftershocks. In some cases, a more distant aftershock causes larger damage ratios than a nearby aftershock, as can be seen in parts of Sonoma County, where the M6.2 Palo Alto aftershock generates higher damage ratios than closer aftershocks. However, the damage ratios in Sonoma County are less than 0.1 percent for all aftershocks (figs. 8-11).

The upper and lower bound estimates of total loss in HayWired scenario events are summarized in table 21. Shaking damage in the modeled aftershock sequence adds between $\$ 3.5$ billion (maximum aftershock) and $\$ 7.7$ billion (all aftershocks) to the building damage total — an additional 11 to 25 percent, respectively.

As an alternate to the lower bound estimate calculated above, one could use the maximum loss in all events (that is, the maximum shaking loss occurring in either the mainshock or any of the aftershocks). For most census tracts, this maximum shaking loss occurs in the mainshock, but 49 census tracts (out of 2,122 in the 17-county study area) suffer larger shaking losses in one of the aftershocks, including 12 census tracts where the M6.2 Palo Alto aftershock dominates the losses, 35 tracts where the M6.4 Cupertino event generates the largest building damage, and 2 census tracts where the M5.58 Fairfield event generates the largest building damage ratio; these tracts are mapped in figure 15 , and the resulting losses are provided in table 21 as Lower Bound 2. This alternate lower bound assumes that no other earthquake adds any damage to the maximum damage from one earthquake in each census tract and is lower than the initial version; total building damage is $\$ 30.6$ billion versus $\$ 33.8$ billion in the initial lower bound estimate.

The various resulting census tract level building damage ratio maps are shown in figures 16 and 17, in the same order as presented in table 21 . Figure 16 presents the census tract shaking damage ratio map for the HayWired mainshock, the maximum aftershock, the sum of all aftershocks, and the sum of the mainshock and the maximum aftershock (Lower Bound 1). Figure 17 provides the final two shaking damage ratio maps for the maximum of mainshock and aftershock (Lower Bound 2) and the mainshock plus all aftershocks (Upper Bound).

\section{Repeat Liquefaction}

To examine losses resulting from repeated liquefaction in subsequent events, liquefaction impacts within Alameda County (evaluated using the Hazus default liquefaction approach and uniform depth to groundwater assumption) were reviewed at the census tract level for the mainshock and the M5.42 Oakland aftershock. Alameda County was selected for its proximity to the epicenter of the mainshock and the epicenter of the Oakland aftershock, as well as the presence of highly liquefiable soils (see fig. 2). Maps of expected liquefaction/ lateral spread displacements as estimated by Hazus using its default methodology, considering liquefaction susceptibility, depth to groundwater (assumed shallow), and probability of liquefaction, are provided in figure 18. As shown, many of the bay-front census tracts are estimated to have substantial expected lateral spread in the mainshock, with some additional smaller movements in the M5.42 Oakland aftershock.

As has been noted, Hazus is not able to estimate additional damage to damaged buildings; each of the current analyses is independent and assumes that the inventory is in an undamaged condition before the earthquake. Although this may underestimate cumulative damage, it is still instructive to examine the potential impact of repeated liquefaction in liquefaction prone areas.

In Alameda County, 264 tracts are subject to liquefactioninduced lateral spread displacements in the mainshock; 131 of these tracts are subject to additional lateral spread displacements in the M5.42 Oakland aftershock. Shaking and liquefaction losses in these 131 tracts are summarized in table 22. Even though liquefaction is less widespread in the aftershock, and expected liquefaction damage is minimal compared to the mainshock ( $\$ 77$ million versus $\$ 1.45$ billion), liquefaction damage is predicted by Hazus even in events with magnitudes less than 6 . And in these smaller events, liquefaction has the potential to represent a larger proportion of the overall damage; in these 131 tracts, building damage caused by liquefaction represents 21 percent of the total building damage caused by shaking and liquefaction in the mainshock but increases to 26 percent in the aftershock. 


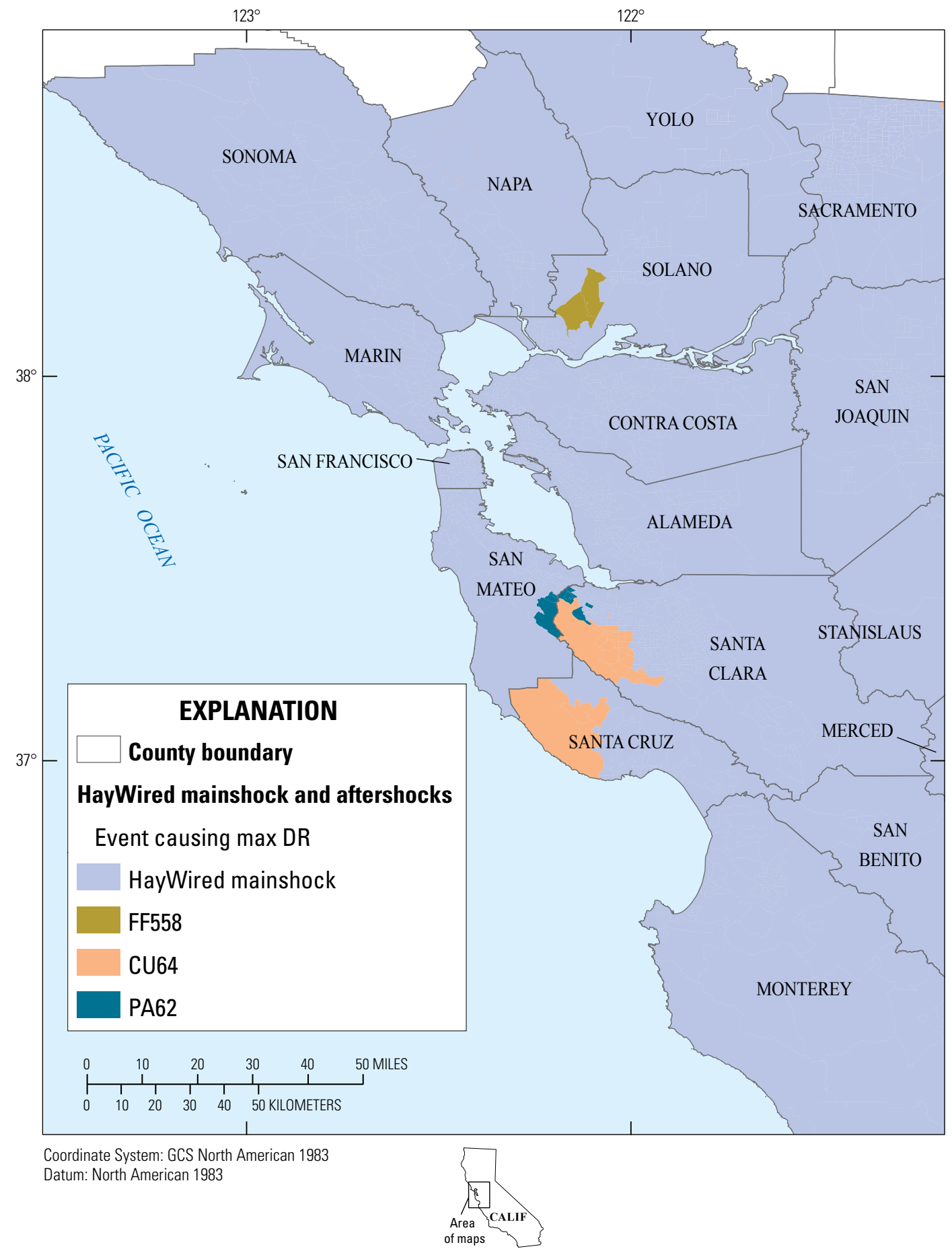

Figure 15. Map showing the HayWired earthquake scenario mainshock or aftershock causing the maximum building damage ratio (max DR) by census tract, San Francisco Bay region, California. See table 1 for explanation of aftershock short names and magnitudes. 
A. Mainshock

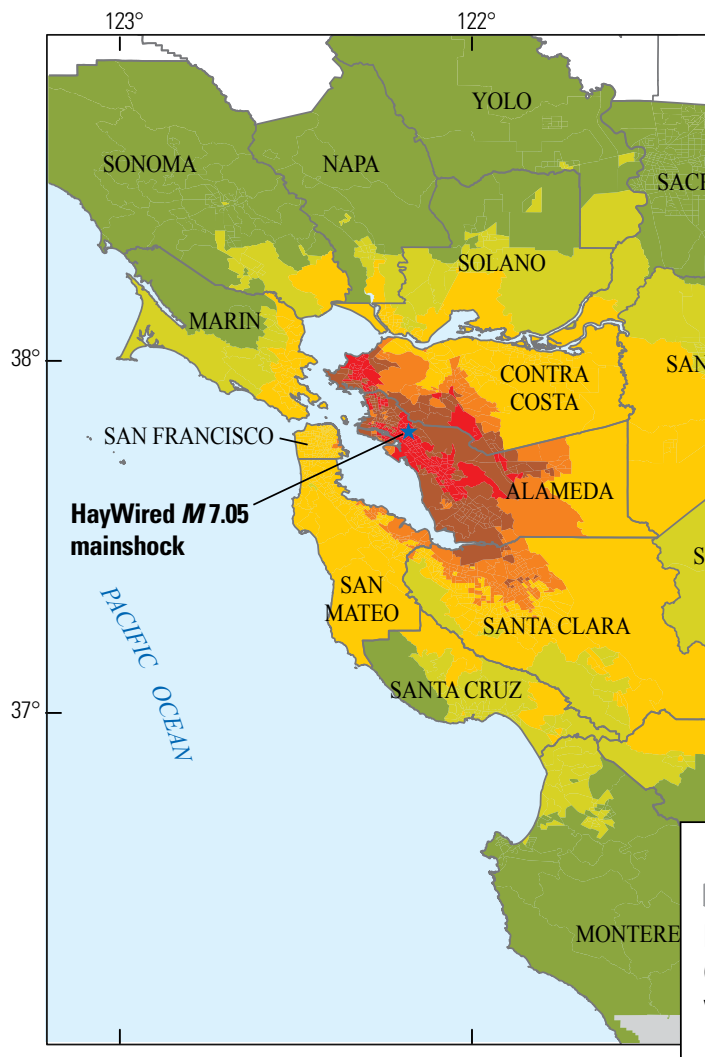

C. Cumulative aftershock

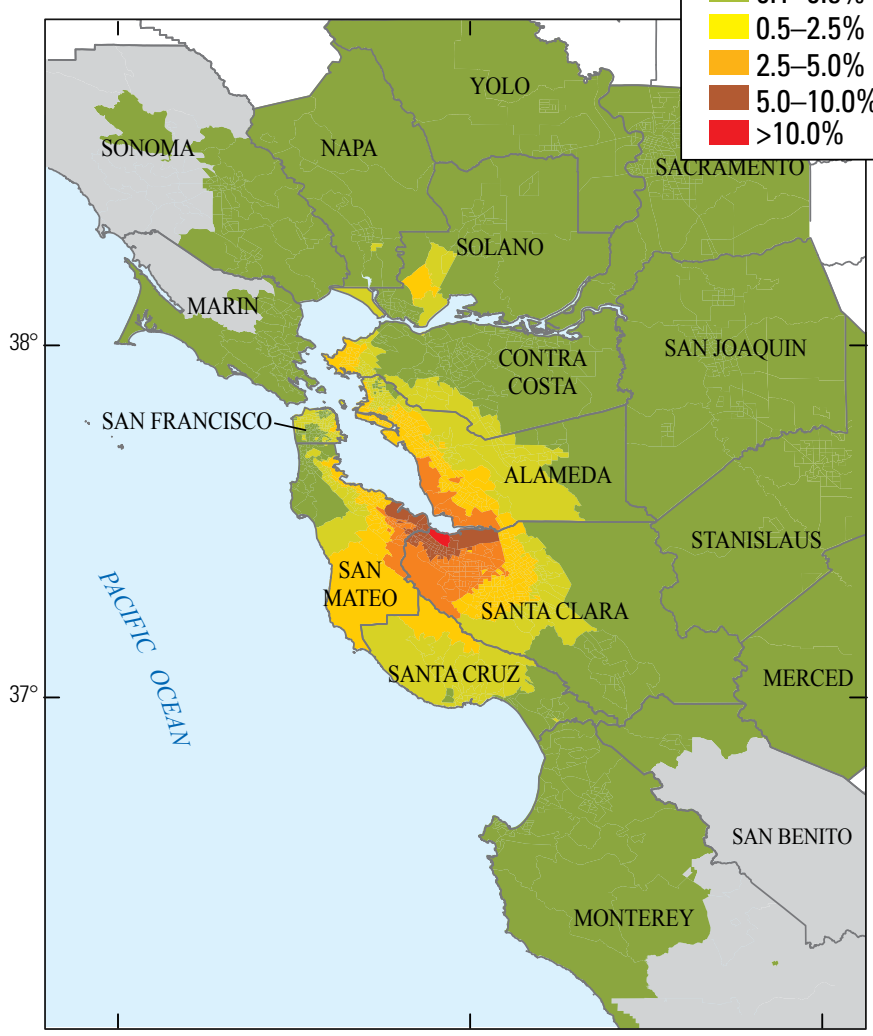

Coordinate System: GCS North American 1983 Datum: North American 1983
B. Maximum aftershock

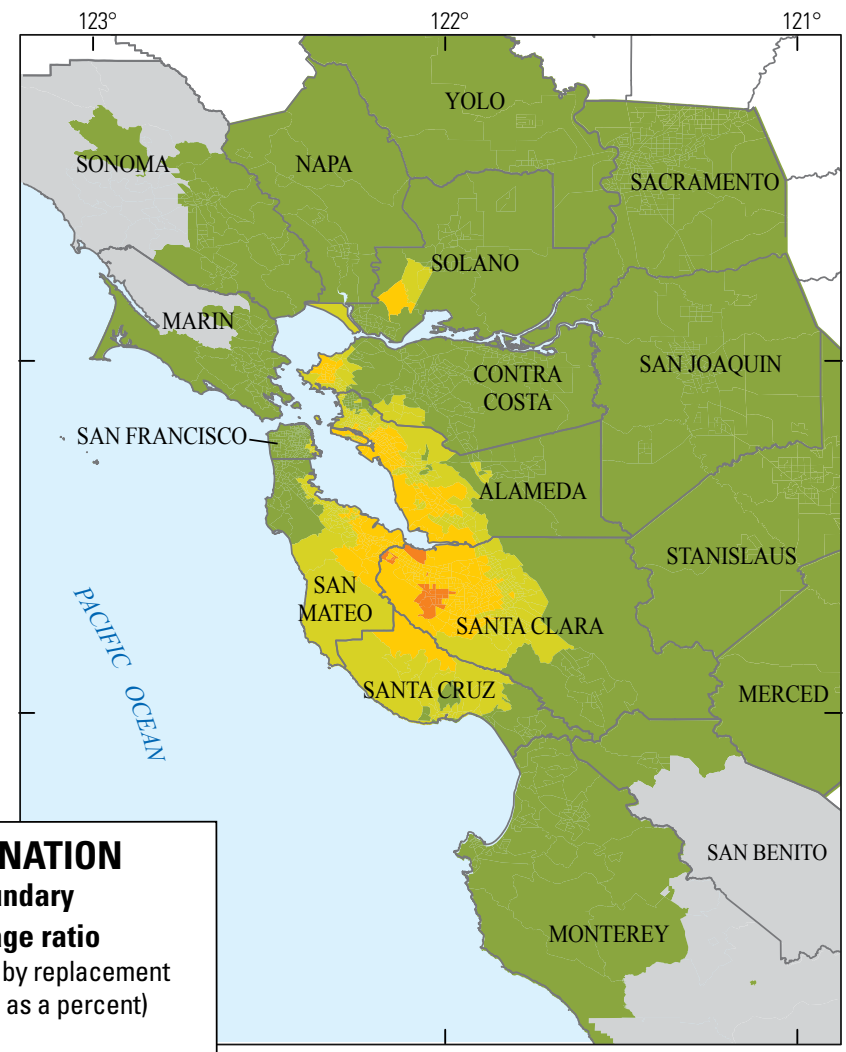

D. Mainshock + maximum aftershock
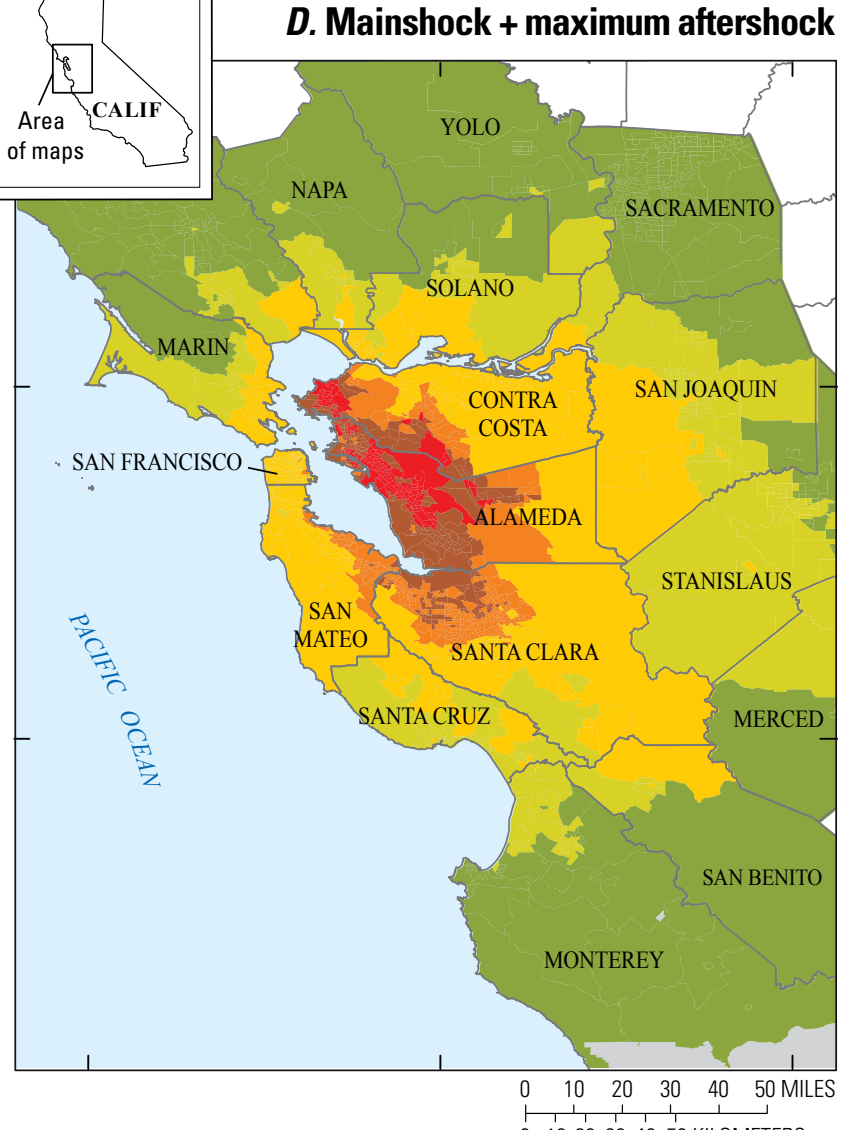

Figure 16. Maps showing building damage ratio from ground shaking caused by the HayWired earthquake scenario mainshock and aftershocks, San Francisco Bay region, California. $A$, Mainshock building damage ratio; $B$, Maximum aftershock building damage ratio; $C$, Cumulative aftershock building damage ratio; and $D$, Mainshock plus maximum aftershock building damage ratio (lower bound 1 ). 


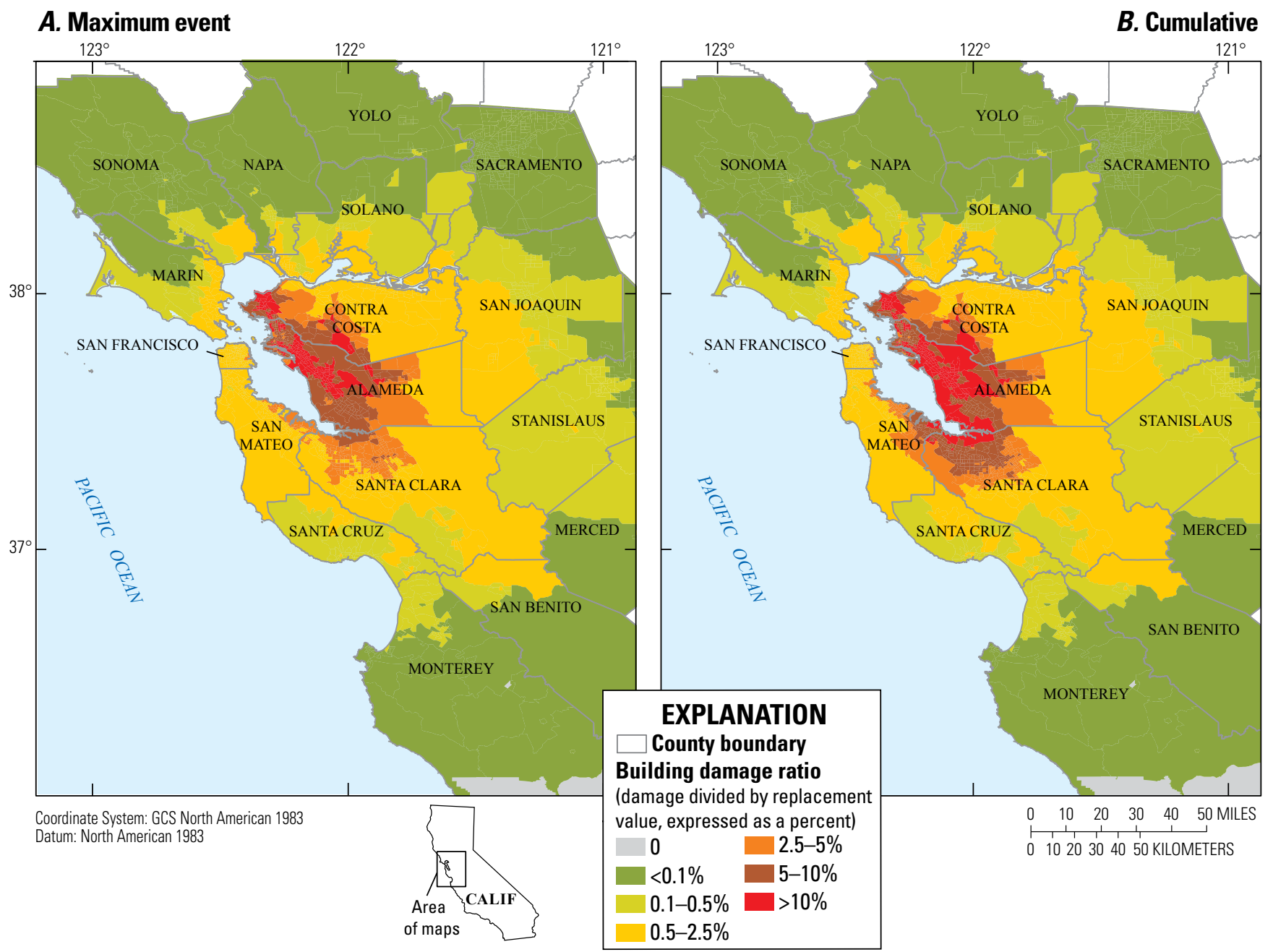

Figure 17. Maps of building damage ratio from ground shaking caused by the HayWired earthquake scenario mainshock and aftershocks, San Francisco Bay region, California. A, Maximum individual event building damage ratio (lower bound 2).

$B$, Cumulative (mainshock plus all aftershocks) building damage ratio (upper bound).

\section{Model Limitations and Data Gaps}

Hazus was developed by FEMA to "produce loss estimates for use by Federal, State, regional and local governments in planning for earthquake risk mitigation, emergency preparedness, response and recovery" (FEMA, 2012). At the time of its development in the early 1990s, its methods were considered state of the art; little has changed in the underlying earthquake methodology since its original development. With time, other more comprehensive analytical methodologies have been developed by the earthquake engineering community, such as Performance Based Earthquake Engineering (see, for example, Applied Technology Council, 2006). Nevertheless, the Hazus framework still provides the only publicly available software and methodology that allows for regional earthquake analysis anywhere in the United States using pre-packaged (default) building inventory data. Studies directly comparing the results of the various approaches have yet to be conducted.

It should be noted that although the inventory data used in the HayWired analyses were enhanced with improved mapping schemes and escalated replacement values, other exposure data (building square footage and building counts) were Hazus defaults based on 2000 census data for residential occupancies and 2006 Dun \& Bradstreet data for non-residential occupancies. With the release of Hazus 2.2 in January of 2015, updated Hazus inventory data reflecting 2010 census data for residential occupancies are now available. Because these new data are based on revised census geographies, they are, unfortunately, currently incompatible with the improved mapping schemes developed for the San Francisco Bay region based on the 2000 census geometries. In the future, to avoid obsolescence of the improved San Francisco Bay region mapping schemes, an evaluation and conversion to the 2010 census geographies will need to be performed. 


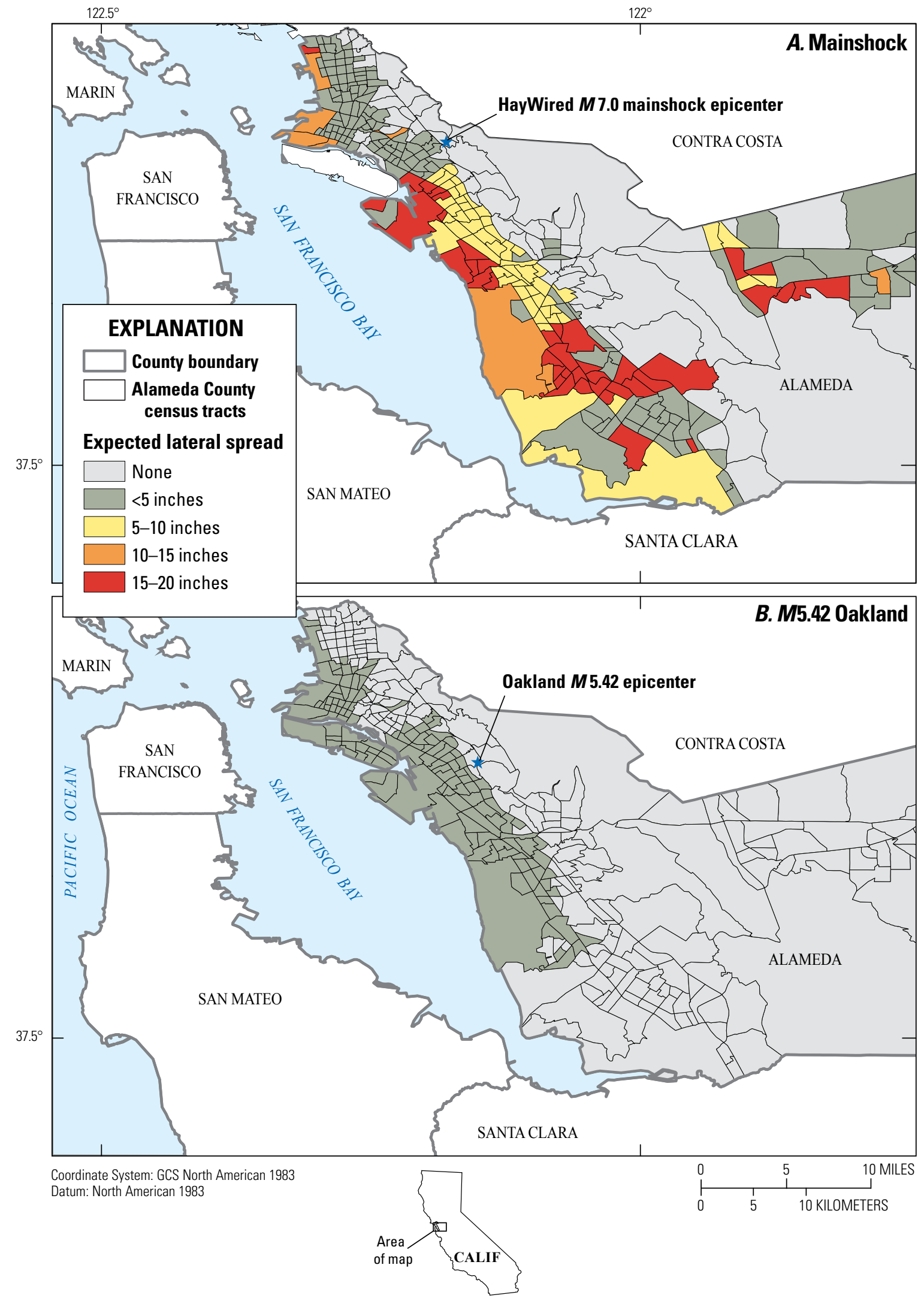

Figure 18. Maps showing expected liquefaction-induced lateral spread displacements by census tract in Alameda County, California, estimated using the Hazus (FEMA, 2012) default approach. A, Spread from mainshock. $B$, Spread from magnitude $(M) 5.42$ Oakland aftershock. 
Table 22. Liquefaction-induced building damage for 131 census tracts in Alameda County, California, suffering lateral spread displacements from the HayWired earthquake scenario mainshock and Oakland M5.42 aftershock, estimated using Hazus.

[Data from Hazus (Federal Emergency Management Agency, 2012). See table 1 for explanation of aftershock short names and magnitudes. Damage reported in 2005 dollars; U.S. Consumer Price Index 2016:2005 ratio is approximately 1.23]

\begin{tabular}{lcc}
\hline \multicolumn{1}{c}{ HayWired scenario event } & $\begin{array}{c}\text { Building damage } \\
\text { (millions of dollars) }\end{array}$ & $\begin{array}{c}\text { Building damage ratio } \\
\text { (percent) }\end{array}$ \\
\hline Mainshock, shaking only & 6,802 & 12.7 \\
Mainshock, shaking and liquefaction & 8,254 & 15.4 \\
Mainshock, liquefaction & 1,452 & 2.7 \\
OK542, shaking only & 293 & 0.55 \\
OK542, shaking and liquefaction & 369 & 0.69 \\
OK542, liquefaction & 77 & 0.14 \\
\hline
\end{tabular}

The current study uses Hazus to assess damage and loss in 17 earthquake events ranging from M5.0 to M7.0. Hazus' known limitations include increased uncertainty for small events, wherein empirical data from past events may be lacking. As stated in the Hazus Earthquake Technical Manual, “....the losses from small magnitude earthquakes $(<M 6.0)$ centered within an extensive urban region appear to be overestimated" (FEMA, 2012).

When Hazus was initially developed, it was expected that ground motions would be computed within the software using standard attenuation functions and reflecting their associated uncertainty; fragility function medians and betas (the uncertainty term) were developed accordingly. Following Hazus' initial release, the use of real-time USGS ShakeMaps was facilitated to support emergency response, bypassing Hazus' ground motion generation capabilities. A subsequent study (Kircher, 2002) indicated that the use of recorded ground motions (that is, an actual event ShakeMap) should be accompanied by reduced fragility function betas, reflecting the reduction in ground motion uncertainty for an actual event. The implementation of this recommendation within the Hazus framework was focused on the emergency response motivation; reduced betas are used whenever a ShakeMap is imported. Unfortunately, this does not reflect the reality that damaging real earthquake events are rare, and many ShakeMaps used with Hazus are scenario ShakeMaps, which do not have the benefit of reduced ground motion uncertainty. In the current study, it may be appropriate to treat the high-quality simulated HayWired mainshock ground motions as having a similar level of uncertainty as a real event (that is, reduced betas are appropriate), but the aftershock ShakeMaps should, in theory, be treated as estimated ground motions with the original (not reduced) betas. In practice, Hazus is not designed to allow the typical user to easily make such a choice; all imported ShakeMaps are treated with the reduced betas, regardless of whether they are actual events or hypothetical scenario events. ${ }^{2}$ If all scenario ShakeMaps could be developed with the same

\footnotetext{
${ }^{2}$ It should be noted that since October 2016 and the release of Hazus 3.2, Hazus now includes a mechanism to import ShakeMap XML grid data and recognizes the difference between "scenario" and "actual" events and applies the appropriate fragility curve betas.
}

level of sophistication as the HayWired mainshock and the southern California ShakeOut scenario, this issue would be moot, suggesting the need for less expensive simulation methods for high-quality ShakeMaps. Because the aftershocks evaluated in this study are treated with the reduced fragility curve betas, we would expect their losses to be underestimated (perhaps counterbalancing the overestimation expected for small magnitude events). The actual level of underestimation would require testing to quantify, but to put it into perspective, Kircher (2002) found a reduction of one-third in economic losses for the M6.7 Northridge earthquake when using the reduced fragility curve betas.

It was challenging to use finer resolution data for liquefaction and landslide hazards, which can vary considerably in a census tract, in the Hazus construct. We developed creative ways to leverage the Hazus damage estimation methodology in areas where the hazards affect the built environment. However, the liquefaction probability method (Jones and others, 2017) left us with an additional challenge, in that liquefaction-induced displacement estimates were not provided. In the future, both probability and displacement liquefaction hazard estimates would be needed.

As noted previously, Hazus is not able to estimate additional damage to damaged buildings, making our quantification of losses from the full earthquake sequence incomplete. To consider cumulative damage in the Hazus context, it would likely require the development of new vulnerability functions (that is, capacity curves for damaged buildings of various construction types and damage states), as well as removal of inventory data for already damaged buildings.

Finally, Hazus does not directly produce certain metrics that would be valuable to emergency response planning and preparedness, including the predicted post-earthquake building safety tag, casualty estimates useful for medical response planning, and urban search and rescue (USAR) needs. However, several aftermarket approaches have been developed to fill these gaps. FEMA has developed and implemented spreadsheet-based approaches for estimating the number and type of USAR teams and personnel required from Hazus damage state distribution data by construction type. This tool uses a simplified assignment of safety tag from damage state. Public health researchers 
have studied casualty data collected from the 1994 Northridge earthquake and have recommended modification factors to extrapolate injuries requiring trauma care, injuries requiring Emergency Medical Services (EMS) transport, and emergency department visits from Hazus casualty severity level estimates (Shoaf and Seligson, 2011).

\section{Conclusions}

\section{Mainshock Assessment}

In the HayWired scenario mainshock, the "best estimate" of building damage totaled $\$ 35.2$ billion (in 2005 dollars, $\$ 43.3$ billion in 2016 dollars), with $\$ 30.3$ billion (in 2005 dollars, $\$ 37.3$ billion in 2016 dollars) resulting from shaking, $\$ 4.6$ billion (in 2005 dollars, $\$ 5.7$ billion in 2016 dollars) from liquefaction, and $\$ 300$ million (in 2005 dollars, approximately $\$ 360$ million in 2016 dollars) from landslides.

This estimate is a full order of magnitude greater than FEMA's initial Hazus estimate of \$350 million (also in 2005 dollars) in building damage resulting from the 2014 Napa earthquake, suggesting that a HayWired mainshock event would cause substantial regional damage and disruption. It should be mentioned that the $\$ 35$ billion HayWired (and $\$ 350$ million Napa) estimate is for direct building damage alone (in other words, for structural and nonstructural damage to the region's buildings) and does not include content damage, or building damagerelated direct economic losses (such as lost rent or the cost of relocation), nor does it include damage to the region's utilities and transportation infrastructure.

Strong ground shaking in the HayWired mainshock causes the bulk of the estimated damage to the regional building stock, with liquefaction adding 16 percent to the building damage estimates in Alameda and Santa Clara Counties when using custom probability data and 14 percent to building damage in the six counties modeled using the Hazus default liquefaction approach (Contra Costa, Marin, Napa, San Francisco, San Mateo, Solano, and Sonoma). Landslide-related building damage adds just 1 percent to building damage in the same eight counties.

The utilization of pixel-level liquefaction and landslide data for the mainshock presented substantial challenges to implementation within Hazus, which is not ideally designed to accept input data at this level of refinement. As a result of having to combine Hazus results with pixel data outside of Hazus, the ability to estimate derivative losses was lost. Although the current version of Hazus (Hazus 4.0) has made some improvements in data utilization (for example, allowing import of a ShakeMap XML grid and averaging ground motions across census tracts rather than taking a simple centroidal value), these features were not available in the Hazus version used for the HayWired studies (Hazus 2.1, for reasons described in the previous section). The approach taken here would likely be difficult for the typical Hazus user to implement. In particular, interrupting various Hazus computations, as was done in the custom liquefaction assessment, is not commonly done, and generally not recommended. Further, the level of effort required to complete the landslide assessment may not be justified by the result; in the current assessment, landslide added just 1 percent to the overall building damage loss, relative to shaking losses, in counties where landslide was modeled. In future studies, users should evaluate how important it is to include landslide damage; one compromise approach would be to limit the assessment to areas of high landslide susceptibility in the regions with the strongest ground shaking (for example, limiting the current landslide assessment to Alameda County would have captured 50 percent of the estimated landslide losses). To consider landslide hazards at a greater level of detail, earthquake damage estimation tools that can accept finer resolution hazard data would be needed (for example, the Hazus earthquake model could be reconfigured to operate at the census block level, as the Hazus flood tool currently operates).

\section{Aftershock Assessment}

Although most of the simulated aftershocks are expected to cause only minor damage, several are large enough to create localized damage and losses larger than those of the 2014 M6.0 South Napa earthquake. For an area still responding to or recovering from the larger HayWired mainshock, these damaging aftershocks would place additional burdens on potentially limited resources.

As has been noted, Hazus does not model damage to damaged buildings, but the Hazus results may be used to estimate lower and upper bound cumulative losses. Lower bound building damage from shaking alone (estimated as the maximum loss of any single event in the HayWired sequence) exceed $\$ 30.6$ billion, whereas upper bound estimates of building losses (estimated as the sum of loss in the mainshock and all aftershocks) are just less than $\$ 38$ billion.

While the upper and lower bound estimates described above address building damage resulting from shaking only, there are also a number of other metrics of interest that may be approximately combined across events. Over the entire earthquake sequence, the total direct economic loss can be approximated as $\$ 67.0$ billion (in 2005 dollars, $\$ 82.6$ billion in \$2016), including:

- $\$ 43.3$ billion (in 2005 dollars, \$53.3 billion in 2016 dollars) in building damage for the mainshock and all aftershocks, using USGS-modeled liquefaction and landslide hazard and probability data for the mainshock, where available, and the Hazus default liquefaction modeling approach for other areas in the mainshock as well as for three aftershocks (M5.98 Mountain View, M6.4 Cupertino, and M5.42 Oakland). The remainder of aftershocks were modeled for shaking only.

- $\$ 13.8$ billion (in 2005 dollars, $\$ 17.0$ billion in 2016 dollars) in damage to contents and commercial inventories, estimated using the Hazus default liquefaction modeling approach for the mainshock and the three aftershocks 
identified above, and considering only ground-shaking hazards for the remainder of events.

- $\$ 10.0$ billion (in 2005 dollars, $\$ 12.3$ billion in 2016 dollars) in building damage-related income losses (for example, relocation costs, lost rent, and so on), modeled in the same manner as contents and inventory damage.

The $M_{\mathrm{w}} 7.0$ mainshock is responsible for about 80 percent of the losses from the earthquake sequence, 12 percent from three largest aftershocks of $M_{\mathrm{w}} 6.0$ to 6.4 , and 8 percent from the 13 aftershocks of $M_{\mathrm{w}} 5.0$ to 5.9. Displaced household assessments range from tens of households for the smallest aftershocks to hundreds of households for the largest aftershocks to tens of thousands of households $(77,000-153,000)$ for the mainshock, based on the 2000 U.S. Census.

The Hazus analyses of the HayWired earthquake scenario and the set of simulated aftershocks have clarified the relationship between this large event and its aftershocks:

- In the HayWired scenario mainshock, liquefaction (modeled in the counties for which liquefaction susceptibility has been mapped and assessed using the Hazus default liquefaction approach) represents 17 percent of the total building damage (more than $\$ 5$ billion). In the selected aftershocks for which liquefaction was modeled, liquefaction represents between 9 percent (M6.4 Cupertino aftershock) and 15 percent (M5.42 Oakland aftershock) of the total building damage. As shown by a review of repeat liquefaction in the M5.42 Oakland aftershock, additional liquefaction could occur even in the smaller aftershocks and has the potential to represent a larger proportion of the overall damage in these aftershock events.

- For shaking only, damage ratios in the aftershocks are two orders of magnitude smaller than those of the mainshock, except for the larger aftershocks (M6.2 Palo Alto, M5.98 Mountain View, and M6.4 Cupertino) which have damage ratios one order of magnitude smaller than the mainshock.

- Damage ratios may increase when concentrations of potentially vulnerable building types are located near an aftershock's epicenter, for example, tilt-up and URM buildings in the M5.23 Union City and M5.42 Oakland aftershocks.

- For the simulated aftershock sequence, census tracts with the largest damage to pre-code low-rise URM buildings are not the same as those tracts with substantial damage in the mainshock. At the census tract level, the sum of economic losses from building damage to pre-code low- rise URM in the HayWired event and all of its aftershocks did not exceed the building exposure value. This supports the proposed approach of aggregating losses across the set of simulated events, without the risk of estimating losses in excess of exposed value.

- The total number of casualties in the aftershocks is as much as three orders of magnitude smaller than those in the mainshock. Expected casualties in most aftershocks are minor (primarily casualty Severity Level 1 with some Severity Level 2), and only two events (M6.2 Palo Alto, and M6.4 Cupertino) are expected to cause any serious injuries (Severity Level 3) or deaths (Severity Level 4).

- Although population displacement resulting from ground shaking alone is substantial in the mainshock (displaced households exceeds 64,000), expected displacement in the aftershocks is generally minimal, except in the four larger aftershock events for which estimates of displaced households range from 50 (M5.69 Palo Alto) to 1,900 (M6.4 Cupertino). When custom shelter model parameters developed for the ShakeOut scenario are applied to the HayWired mainshock, including liquefaction, displacement estimates increase from 76,500 to 152,900 , but the number of people seeking publicly provided shortterm shelter decreases from 55,000 to 48,000 .

\section{Acknowledgments}

Karen Felzer (U.S. Geological Survey [USGS] Earthquake Science Center) simulated the aftershock sequence, and Tim MacDonald (USGS Earthquake Science Center) generated the aftershock ShakeMaps. Andrew Michael (USGS Earthquake Science Center) offered useful suggestions on creating Hazus inputs from the USGS ground failure estimations. Doug Bausch (Federal Emergency Management Agency [FEMA], at the time) set up the Hazus modeling environment for the San Francisco Bay area, executed the initial Hazus run for the HayWired mainshock, and reviewed this chapter. Sean McGowan (USGS Geologic Hazards Science Center [at time, since moved to FEMA]) and Jesse Rozzelle (FEMA) also provided expert reviews of this chapter. Kim Shoaf (Division of Public Health, University of Utah) supplied the customized population and shelter parameters and documentation in the appendix. Keith Porter (University of Colorado) provided input on the model and data limitations. This Hazus analysis was funded by Science Application for Risk Reduction (SAFRR) and Land Change Science. 


\section{References Cited}

Aagaard, B.T., Boatwright, J.L., Jones, J.L., MacDonald T.G., Porter, K.A., Wein, A.M., 2017, HayWired scenario mainshock ground motions, chap. C of Detweiler, S.T., and Wein, A.M., eds., The HayWired earthquake scenarioEarthquake hazards: U.S. Geological Survey Scientific Investigations Report 2017-5013-A-H, 126 p., https://doi. org/10.3133/sir20175013v1.

Applied Technology Council, 2006, Next-generation performance-based seismic design guidelines; Program plan for new and existing buildings: prepared for the Federal Emergency Management Agency, FEMA-445, 131 p.

Federal Emergency Management Agency, 2012, Hazus multihazard loss estimation methodology, earthquake model, Hazus ${ }^{\circledR}-M H ~ 2.1$ technical manual: Federal Emergency Management Agency, Mitigation Division, 718 p. accessed July 18, 2017, at http://www.fema.gov/media-librarydata/20130726-1820-25045-6286/hzmh2_1_eq_tm.pdf.

Holzer, T.L, 1994, Loma Prieta damage largely attributed to enhanced ground shaking: Eos, Transactions American Geophysical Union, v. 75, no. 26, p. 299-301.

Holzer, T.L., Noce, T.E., and Bennett, M.J., 2008, Liquefaction hazard maps for three earthquake scenarios for the communities of San Jose, Campbell, Cupertino, Los Altos, Los Gatos, Milpitas, Mountain View, Palo Alto, Santa Clara, Saratoga, and Sunnyvale, northern Santa Clara County, California: U.S. Geological Survey Open-File Report 2008-1270, 29 p., 3 plates, and database http://pubs. usgs.gov/of/2008/1270/.

Holzer, T.L., Noce, T.E., and Bennett, M.J., 2010, Predicted liquefaction in the greater Oakland area and northern Santa Clara Valley during a repeat of the 1868 Hayward Fault (M6.7-7.0) earthquake: Proceedings of the Third Conference on Earthquake Hazards in the Eastern San Francisco Bay Area October 22-24, 2008.

Holzer, T.L., Noce, T.E., and Bennett, M.J., 2011, Liquefaction probability curves for surficial geologic deposits: Environmental and Engineering Geoscience, v. 17, no. 1, p. 1-21.

Homer, C.G., Dewitz, J.A., Yang, L., Jin, S., Danielson, P., Xian, G., Coulston, J., Herold, N.D., Wickham, J.D., and Megown, K., 2015, Completion of the 2011 National Land Cover Database for the conterminous United StatesRepresenting a decade of land cover change information: Photogrammetric Engineering and Remote Sensing, v. 81, no. 5, p. 345-354, accessed December 15, 2016, at http://www.asprs.org/a/publications/pers/2015journals/ PERS_May_2015/HTML/files/assets/basic-html/index. html\#345/z\#noFlash.
Jones, L.M., Bernknopf, R., Cox, D., Goltz, J., Hudnut, K., Mileti, D., Perry, S., Ponti, D., Porter, K., Reichle, M., Seligson, H., Shoaf, K., Treiman, J., and Wein, A., 2008, The ShakeOut Scenario: U.S. Geological Survey OpenFile Report 2008-1150 and California Geological Survey Preliminary Report 25, $312 \mathrm{p}$. and appendixes, accessed April 12, 2017, at https://pubs.usgs.gov/of/2008/1150/.

Jones, J.L., Knudsen, K.L., Wein, A.M., 2017, HayWired scenario mainshock-Liquefaction probability mapping, chap. E of Detweiler, S.T., and Wein, A.M., eds., The HayWired earthquake scenario-Earthquake hazards: U.S. Geological Survey Scientific Investigations Report 20175013-A-H, 126 p., https://doi.org/10.3133/sir20175013v1.

Kircher, C.A., 2002, Development of new fragility function betas for use with ShakeMaps [unpublished report]: prepared for the National Institute of Building Sciences (NIBS) and the Federal Emergency Management Agency (FEMA), $28 \mathrm{p}$.

Kircher, C.A., Seligson, H.A., Bouabid, J., and Morrow, G.C., 2006, When the big one strikes again - estimated losses due to a repeat of the 1906 San Francisco earthquake: Earthquake Spectra, v. 22, no. S2, p. 297-339.

Knudsen, K.L., Sowers, J.M., Witter, R.C., Wentworth, C.M., Helley, E.J., Nicholson, R.S., Wright, H.M., Brown, K.M., 2000, Preliminary maps of quaternary deposits and liquefaction susceptibility, nine-county San Francisco Bay region, California - A digital database: U.S. Geological Survey Open-File Report 00-444, accessed at http://pubs. usgs.gov/of/2000/of00-444/.

McCrink, T.P., Perez, F.G., 2017, HayWired scenario mainshock-Earthquake-induced landslide hazards, chap. F of Detweiler, S.T., and Wein, A.M., eds., The HayWired earthquake scenario-Earthquake hazards: U.S. Geological Survey Scientific Investigations Report 2017-5013-A-H, 126 p., https://doi.org/10.3133/sir20175013v1.

Seligson, H.A., 2008, The ShakeOut scenario supplemental study-Hazus enhancements and implementation for the ShakeOut scenario earthquake: Denver, Colo., SPA Risk LLC, $9 \mathrm{p}$.

Shoaf, K.I., and Seligson, H.A., 2011, Estimating casualties for the southern California ShakeOut, chap. 9 of Spence, R., So, E., and Scawthorn, C., eds., Human casualties in earthquakes - progress in modelling and mitigation: Springer, Advances in natural and technological hazards research, v. 29, p. 125-137.

U.S. Geological Survey, 2014, Earthquake planning scenario-ShakeMap for HayWired M7.05-scenario: U.S. Geological Survey webpage, accessed on May 23, 2017, at https://earthquake.usgs.gov/scenarios/eventpage/ ushaywiredm7.05_se\#shakemap. 
U.S. Geological Survey, 2015, HayWired Aftershock Planning Scenarios: U.S. Geological Survey Earthquake Hazards Program website, accessed May 13, 2017, at http://escweb.wr.usgs.gov/share/shake2/haywired/ archive/scenario.html.
Wein, A.M., Felzer, K.R., Jones, J.L., and Porter, K.A., 2017, HayWired scenario aftershock sequence, chap. G of Detweiler, S.T., and Wein, A.M., eds., The HayWired earthquake scenario-Earthquake hazards: U.S. Geological Survey Scientific Investigations Report 2017-5013-A-H, 126 p., https://doi.org/10.3133/sir20175013v1.

\title{
Appendix. Calculation of Shelter Parameters for the 2008 Southern California ShakeOut Scenario
}

\author{
By Kimberley Shoaf ${ }^{1}$
}

For the HayWired earthquake scenario, shelter parameters for use in Hazus (Federal Emergency Management Agency, 2012) were those estimated for the 2008 Southern California ShakeOut scenario (Jones and others, 2008) using data from two surveys which were conducted by Bourque and others following the 1989 Loma Prieta earthquake and the 1994 Northridge earthquake (Bourque and others, 2002; Shoaf and Bourque, 1999). In both of these surveys, residents of the impacted counties were asked about their experiences in the earthquakes, including questions about damage to their homes, injuries, and being displaced from their homes. Respondents were asked the following: "As a result of the earthquake, did you evacuate your home, or leave it for any period of time because of damage, possible damage, or how you were feeling?" If they had left their home, they were asked, "Why did you evacuate your home?" and given the opportunity to identify as many of the possible reasons for leaving as applied to their situation. These reasons for evacuation included the following: "Own decision because of structural damage," "Suggested by an official," "No drinking water," "Gas leaks," "No electrical power," "Invitation from a friend or relative," "Too upset to stay," "Afraid of further damage," "Because of a prediction of the next earthquake or aftershock," or "Other." In the Northridge questionnaire, respondents were also given the choice of selecting "Building manager advised." They were also asked where they stayed after leaving their home. These

\footnotetext{
${ }^{1}$ University of Utah.
}

are the data that were used to modify the Hazus parameters for displacement and shelter needs for the 2008 Southern California ShakeOut scenario.

In all, approximately 16 percent of the population were displaced from their homes in the Northridge earthquake and 22 percent in the Loma Prieta earthquake. Hazus estimates for shelter needs include two different components - estimates of displacement based on building damage states and shelter needs modified by a variety of individual and population demographic characteristics. Using both the Northridge and the Loma Prieta earthquake datasets, we modified both the displacement parameters and the shelter needs parameters.

\section{Displacement}

In Hazus, displacement is calculated based on the number of buildings in different damage states. The original parameters in Hazus assumed that everyone in both single and multifamily dwellings in the Complete damage state would be displaced. We concurred with that estimate. In the standard scheme, Hazus also estimates that 90 percent of those in the Extensive damage state in multifamily dwellings would be displaced, but that for all others, there would be no displacement. Based on crosstab analysis of displacement by tagging (red, yellow, green, no tag, no inspection) and by single versus multifamily dwelling, we revised the estimates for those in the Extensive and Moderate damage states. We recognize that tagging is not a perfect match for damage states, 
but with some smoothing, we equated red tag with Complete damage, yellow tag with Extensive damage, and green tag with Moderate damage. These results translated into new estimates for displacement for the other damage states, as given in table 23.

\section{Shelter Needs}

Hazus allows for changes to the shelter needs model by applying both weighting factors and modification factors for certain demographic characteristics of the population. These characteristics include age, ethnicity, household income, and ownership. Logistic regression analyses were conducted for both the Northridge and the Loma Prieta earthquake survey data to estimate the relative importance of these characteristics. Unfortunately, only a very small number of respondents in either earthquake stayed in a formal shelter. Because of the small numbers, we were unable to use "Staying in a shelter" as the outcome variable in the regression analysis. We therefore used "Displaced" as the outcome variable. The results of the regression analyses on the two earthquakes were remarkably comparable. For both earthquakes, the only demographic characteristics that had a significant impact on displacement were ethnicity and income, with income having more impact than ethnicity. The overall Weighting Factor for ethnicity was not changed. However, as a result of the analysis, we revised the individual ethnicity modification factors to reflect less variation, with Whites, Asians, and Native Americans having a relative weight of 0.1 and Blacks and Hispanics having a relative weight of 0.2 , as summarized in table 24.

Because most of the variance in displacement was explained by income, we did not change the overall weighting factor for income. However, the income modification factors were reduced
Table 23. Hazus displacement model damage state factors as modified for the 2008 Southern California ShakeOut scenario.

[For more information on the ShakeOut scenario, see Jones and others (2008)]

\begin{tabular}{lccc}
\hline \multicolumn{1}{c}{ Dwelling type } & $\begin{array}{c}\text { Damage } \\
\text { state }\end{array}$ & $\begin{array}{c}\text { Old } \\
\text { parameter }\end{array}$ & $\begin{array}{c}\text { Revised } \\
\text { parameter }\end{array}$ \\
\hline Multifamily dwelling & Complete & 1.0 & 1.0 \\
Multifamily dwelling & Extensive & 0.9 & 0.65 \\
Multifamily dwelling & Moderate & 0.0 & 0.4 \\
Single-family dwelling & Complete & 1.0 & 1.0 \\
Single-family dwelling & Extensive & 0.0 & 0.4 \\
Single-family dwelling & Moderate & 0.0 & 0.2 \\
\hline
\end{tabular}

as follows: incomes below $\$ 10,000$ and $\$ 10,000-\$ 15,000$ were weighted equally at 0.3 ; incomes of $\$ 15,000-\$ 25,000$ were weighted at 0.14 ; incomes of $\$ 25,000-\$ 35,000$ were weighted at 0.08 ; and incomes above $\$ 35,000$ were weighted at 0.05 .

\section{Other Parameters to Consider}

Hazus uses only damage states of buildings to model displacement. In both the Northridge and the Loma Prieta earthquakes, utility outage was a better predictor of displacement than damage to one's home. The odds ratio of being "displaced due to damage to one's home" in the Loma Prieta earthquake was 1.9. The comparable odds ratio was 2.7 for "electricity outage" and 2.4 for "water outage." Somewhere between 20 and 50 percent of those with utility outage will be displaced from their homes. Clearly, this overlaps with damaged homes, but many without damage will be unable to stay in their homes simply because they do not have the needed utilities. Including a parameter for utility outage would improve the estimates for shelter needs in

Table 24. Hazus shelter needs model weighting and modification factors as modified for the 2008 Southern California ShakeOut scenario.

[For more information on the ShakeOut scenario, see Jones and others (2008)]

\begin{tabular}{lcc}
\hline \multicolumn{1}{c}{ Weighting and modification factors } & Old parameter & Revised parameter \\
\hline Ethnicity weighting factor & 0.27 & No change \\
Income weighting factor & 0.73 & No change \\
Modification factor for ethnicity: White households & 0.24 & 0.1 \\
Modification factor for ethnicity: Black households & 0.48 & 0.2 \\
Modification factor for ethnicity: Hispanic households & 0.47 & 0.2 \\
Modification factor for ethnicity: Asian households & 0.26 & 0.1 \\
Modification factor for ethnicity: Native American households & 0.26 & 0.1 \\
Modification factor for household income $<\$ 10,000$ & 0.62 & 0.3 \\
Modification factor for household income $\$ 10,000-\$ 15,000$ & 0.42 & 0.3 \\
Modification factor for household income $\$ 15,000-\$ 25,000$ & 0.29 & 0.14 \\
Modification factor for household income $\$ 25,000-\$ 35,000$ & 0.22 & 0.08 \\
Modification factor for household income $>\$ 35,000$ & 0.13 & 0.05 \\
\hline
\end{tabular}


future modeling. Given that utility outage is highly correlated with building damage, utilizing the lower bound parameter of 20 percent would be appropriate. A final estimate of displacement would be 120 percent of the Hazus estimate.

\section{References Cited}

Bourque, L.B., Siegel, J.M., and Shoaf, K.I., 2002, Psychological distress following urban earthquakes in California: Prehospital and Disaster Medicine, v. 17, no. 2, p. 81-90, accessed October 2, 2012, at http://journals.cambridge.org/download.php?file=/ PDM/PDM17_02/S1049023X00000224a.pdf\&code=2bc1e69b 4f70ad90559d97c60a9e146d.
Jones, L.M., Bernknopf, R., Cox, D., Goltz, J., Hudnut, K., Mileti, D., Perry, S., Ponti, D., Porter, K., Reichle, M., Seligson, H., Shoaf, K., Treiman, J., and Wein, A., 2008, The ShakeOut Scenario: U.S. Geological Survey Open-File Report 2008-1150 and California Geological Survey Preliminary Report 25, 312 p. and appendixes, accessed April 12, 2017, at https://pubs.usgs.gov/of/2008/1150/.

Shoaf, K.I, and Bourque, L.B., 1999, Correlates of damage to residences following the Northridge earthquake, as reported in a population-based survey of Los Angeles County residents: Earthquake Spectra, v. 15, no. 1, p. 145-172, accessed at http://cat.inist.fr/?aModele $=$ afficheN\&cps $\mathrm{idt}=1768150$. 




\title{
Chapter K
}

\section{Societal Consequences of Current Building Code Performance Objectives for Earthquakes}

\author{
By Keith A. Porter
}

\section{Abstract}

When discussing how to reduce future building impairment during earthquakes, structural engineers tend to focus on the existing building stock. However, today's new buildings are tomorrow's existing buildings, and tomorrow's building stock will not be risk free. The leading model building code in the United States, the International Building Code (IBC), aims to protect the safety of life by providing that a newly engineered building will have no more than a 1-percent probability of collapse in the coming 50 years. However, what about damage short of collapse? Red-tagged (rendered unsafe to enter or occupy) and yellow-tagged (safe only for limited use) buildings can significantly impact the performance of the building stock as a whole in the months or years after a large, but not exceedingly rare, earthquake, such as that simulated in the HayWired earthquake scenario. The HayWired scenario examines a hypothetical earthquake with a moment magnitude $\left(M_{\mathrm{w}}\right)$ of 7.0 occurring on April 18, 2018, at 4:18 p.m. on the Hayward Fault in the east bay part of California's San Francisco Bay area. I explore the implications of the current building-code objectives for future large earthquakes by asking this question: If the existing building stock were replaced with one that entirely complies with current code requirements, what would be the consequences in the Big One? If recent studies for the Building Seismic Safety Council, Federal Emergency Management Agency, and the National Institute of Standards and Technology are correct about the collapse fragility of engineered buildings, a magnitude $(M) 7$ earthquake on the Hayward Fault could result in the collapse of 8,000 buildings and nearly 500,000 buildings could be impaired - red- or yellow-tagged - leaving businesses and households with no or restricted use of the buildings they occupy. Low vacancy rates for space in the San Francisco Bay area would likely lead to the loss of a large number of residents and businesses for the region. However, there are simple and relatively inexpensive alternatives. If cities required all new buildings to be constructed with an importance factor of 1.5 (a relatively simple local modification to the IBC), construction costs would be about 1 to 3 percent higher overall and could reduce building impairment by 75 percent, keeping several thousand residents in their homes and thousands of businesses in operation in the event of a $M 7$ earthquake. Additionally, preliminary surveys suggest that the public's expectations for building performance may be higher than current code objectives - that is, the public wants buildings to be habitable after a disaster, beyond having a low probability of collapse. The surveys also indicate that the public would be willing to pay 1-3 percent more in construction cost (about $0.5-1.5$ percent more in purchase price) for buildings that meet this objective.

\section{Introduction}

When discussing how to reduce future earthquake losses, structural engineers tend to focus on the existing building stock, especially buildings that are fragile and numerous. Among these are unreinforced masonry (URM) buildings (see, for example, Hess [2008] on URM buildings in the 2008 ShakeOut scenario - a hypothetical moment magnitude, $M_{\mathrm{w}}$, 7.8 earthquake on the San Andreas Fault in southern California), nonductile concrete moment-resisting frame buildings (see, for example, Taciroglu and Khalili-Tehrani [2008] in the ShakeOut scenario), and large soft-story wood-frame buildings (see, for example, Porter and Cobeen [2012] on San Francisco's recent effort to manage risk from this building type).

However, today's new buildings are the existing buildings of tomorrow, and the building stock of tomorrow will not be risk free. It is not intended to be. This chapter explores the implications of the current leading building code in the United States for future natural disasters - the International Building Code (IBC). It asks the questions: Where will the current code lead, if its current performance objectives are all met? If the existing building stock were replaced today with one that complies with current seismic design requirements, what would be the consequences? What are some options for cities that adopt building codes and engineers who write them, if those consequences are unsatisfactory?

Seismic performance of buildings can be expressed in terms of building collapse, post-earthquake safety, functionality, economic loss, and other measures. This chapter focuses on collapse and other safety impairment in the sense of the 
Applied Technology Council's (ATC) ATC-20 post-earthquake safety inspections. Buildings are red-tagged if they are deemed unsafe to enter or occupy and yellow-tagged if they are deemed safe for restricted use (ATC, 2005). The ATC-20 tagging process is an imperfect and sometimes inconsistent indicator of building safety, but nonetheless dominates cities' efforts to determine whether buildings are safe to enter and occupy after earthquakes and to control the use of damaged buildings.

This chapter is part of the HayWired earthquake scenario, which examines a hypothetical earthquake of $M_{\mathrm{w}} 7.0$ occurring on April 18, 2018, at 4:18 p.m. on the Hayward Fault in the east bay part of California's San Francisco Bay area. The simulated earthquake causes Modified Mercalli Intensities of VI-X in the region, with very strong shaking along the fault in the densely populated east bay. In a later volume, the HayWired scenario will address the economic consequences of building damage.

The reader may be aware that some of the content in this chapter appears in Porter (2016a). This chapter builds on the findings of Porter (2016a) and introduces new material, including a discussion on the number of impaired buildings in the HayWired scenario, cities' options for reducing damage in a code-compliant building stock, what-if loss and cost estimates if bay area cities were to require all ordinary buildings to be designed with an importance factor of 1.5 , and new research to elicit public understanding and preferences for the performance of a code-compliant building stock.

\section{Background}

First, I review some of the important steps that led to the seismic design requirements in current building codes. Since approximately 1980, engineers have designed California's buildings to achieve a quantified safety objective - that is, to ensure that the probability of life-threatening damage to any particular structural element or connection is less than a specified maximum value, given the occurrence of a fairly rare and severe level of shaking. The procedure for doing so is called load- and resistance-factor design (LRFD). LRFD was developed in the 1970s and early 1980s. Ellingwood and others (1980) offer one of the seminal works on LRFD, raising LRFD to the status of building-code requirements. In that work, the authors provide design parameters that would ensure a probability of life-threatening damage of no greater than approximately 4 percent given design-level shaking. At that time, design-level shaking was defined with a 10-percent exceedance probability in 50 years, which equates to a mean recurrence interval of 475 years. That 4 percent figure applies individually to each component in a building, including the beam, column, shearwall, brace, and connection, rather than to the building as a whole.

In the 1990s, a procedure called performance-based earthquake engineering (PBEE) was developed to manage the seismic performance of existing individual buildings as a whole system, on the basis of four whole-building performance levels: operational, immediate occupancy, life safety, and collapse prevention. See, for example, ATC (1997) for more information.

From the early 1970s through the 2000s, researchers working with the Massachusetts Institute of Technology, URS/ John A. Blume and Associates, the Consortium of Universities for Research in Earthquake Engineering (CUREE), the Pacific Earthquake Engineering Research Center (PEER), and the ATC developed another approach to PBEE that quantifies the seismic performance of individual buildings in terms of repair costs, life-safety impacts, and loss of functionality - in other words, dollars, deaths, and downtime. In this study, I refer to the procedure as second-generation performance-based earthquake engineering (PBEE-2). See, for example, Czarnecki (1973), Kustu and others (1982), Beck and others (1999), Porter and Kiremidjian (2001), Porter (2003), Aslani and Miranda (2006), and ATC (2012) for more information.

In the late 2000s, researchers and practitioners working with the Federal Emergency Management Agency (FEMA) and the National Institute of Building Sciences quantified the likely seismic performance of code-compliant buildings in terms of the probability that a building would collapse when subjected to very rare shaking (the maximum considered earthquake, MCE). See ATC (2009) and National Earthquake Hazards Reduction Program (NEHRP) Consultants Joint Venture (2012) for more information. These authors recommend using the estimated collapse probability as an acceptable probability of collapse for new buildings, suggesting that "the probability of collapse due to MCE ground motions ... be limited to 10 percent ... A limit of twice that value, or 20 percent, is suggested ... for evaluating the acceptability of potential 'outliers' ..." (ATC, 2009). The skeptical reader might take issue with the ATC (2009) recommendation because it suggests formulating a performance objective only after performance data have already been gathered and examined. However, the ATC authors' objective was to ensure that new structural systems would achieve a level of reliability consistent with older ones, using collapse probability as the consistent reliability objective. The process is similar to the way that developers aimed to ensure that new design under LRFD would be consistent with the safety of designs performed using allowable stress design, the precursor to LFRD.

Also in the late $2000 \mathrm{~s}$, some of the same researchers were developing a new basis for building design in which the performance objective was to achieve a uniform probability of collapse in a given time period. In particular, Luco and others (2007) offer a procedure for defining a so-called risk-adjusted maximum considered earthquake $\left(\mathrm{MCE}_{\mathrm{R}}\right)$ motion such that, if a new building satisfied LRFD design requirements at shaking based on $\mathrm{MCE}_{\mathrm{R}}$ motion, then the collapse probability in $\mathrm{MCE}_{\mathrm{R}}$ motion is limited to 10 percent and, more to the point, the long-term collapse risk is limited to 1 percent in 50 years (considering all ground motion levels that could occur in those 50 


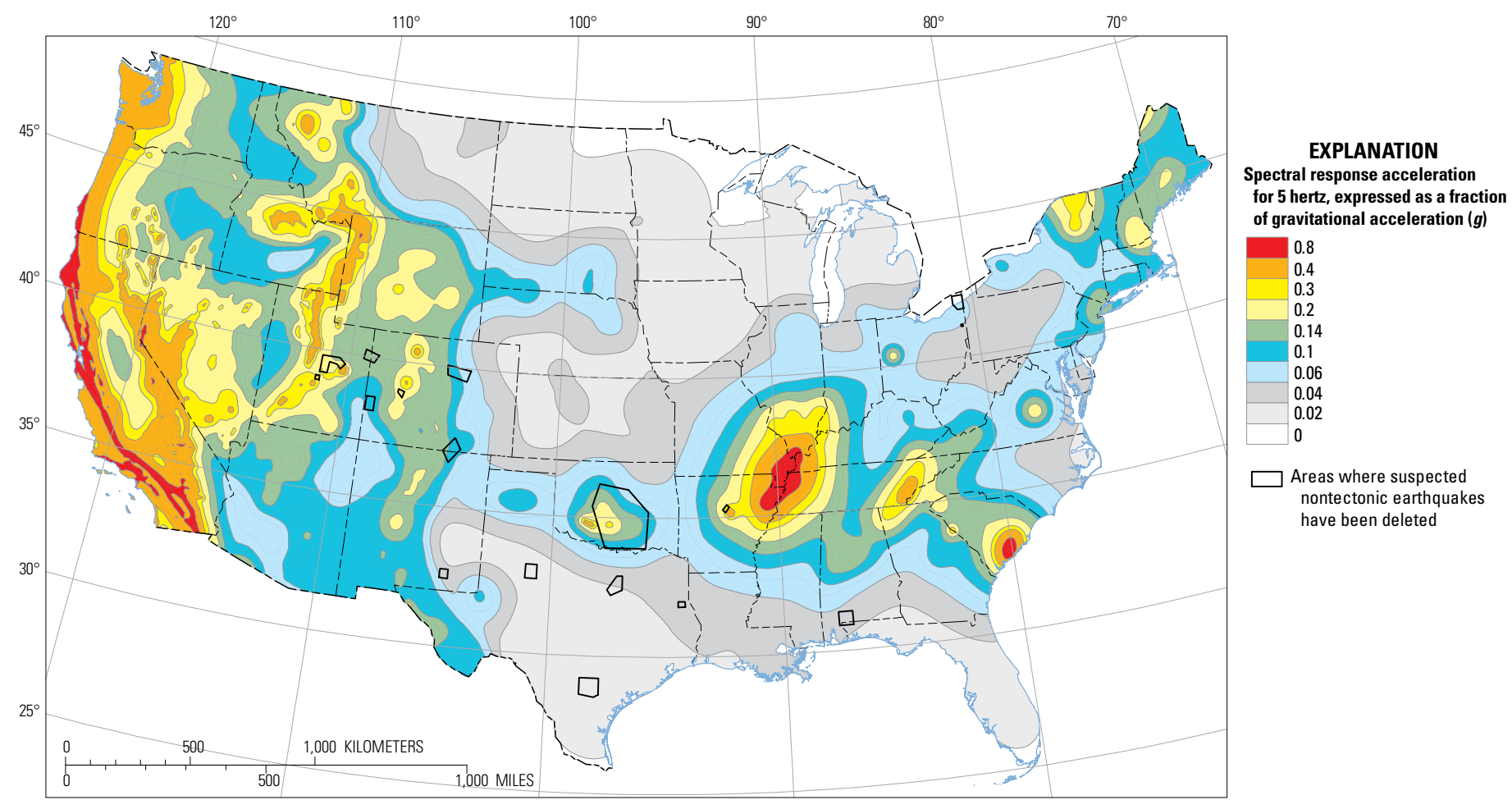

Figure 1. Map of risk-adjusted maximum considered earthquake $\left(\mathrm{MCE}_{\mathrm{R}}\right.$ ) shaking for the contiguous United States (modified from Petersen and others, 2014).

years and their estimated recurrence frequency). To illustrate this concept, a recent map showing $\mathrm{MCE}_{\mathrm{R}}$ ground motion for short-period construction is shown in figure 1 . What is meant by "based on $\mathrm{MCE}_{\mathrm{R}}$ motion" is that design acceleration is the product of the mapped $\mathrm{MCE}_{\mathrm{R}}$ motion multiplied by a factor of $2 / 3$, a factor to account for site amplification, a factor to take advantage of ductility, and, in some cases, a factor to reflect greater building importance. Risk-adjusted design has been incorporated into U.S. seismic design guidelines (American Society of Civil Engineers [ASCE], 2010) and the IBC (International Code Council [ICC], 2012). Though they are not both codes, they will hereafter collectively be referred to as "the code," because ASCE-7 is adopted by reference in the 2012 IBC.

To be clear, the primary performance objective of the most recent U.S. seismic design code requirements is to ensure that new engineered buildings have no more than a 1-percent collapse probability over 50 years. There are secondary objectives as well. The 2015 NEHRP Recommended Seismic Provisions state that ordinary buildings in earthquakes will "Avoid serious injury and life loss due to structural collapse, failure of nonstructural components or systems, and release of hazardous materials . . . and reduce structural and nonstructural repair costs where practicable to do so." The mention of reducing nonstructural repair costs refers to construction requirements that are believed to cost-effectively limit damage, such as bracing large suspended ceilings, as shown in figure 2 . However, only the collapse probability is quantified. Note that the code does not aim to ensure buildings are usable or even repairable after an earthquake, but rather that occupants can safely exit a building after designlevel shaking. Engineers sometimes refer to this objective as "life-safety performance," acknowledging that some buildings are designed stronger (for example, those housing hazardous or essential facilities).

The code appears to achieve its life-safety performance objective. Table 1 compares some of the leading threats to life in the United States with the modeled earthquake lifesafety risk of continuous 24 hours a day, 7 days a week (24/7) occupancy of a building designed to meet the current building code. The number of deaths in new buildings during earthquakes assumes that the average new building somewhat exceeds the minimum safety requirement, exhibiting a 0.6 percent probability of collapse in 50 years instead of 1 percent. It also assumes that collapse affects 25 percent of the building area, as described in Porter (Urban Search and Rescue, this volume), and that 10 percent of occupants located in collapsed building areas die as a result of the collapse (FEMA, 2012a). Deaths in uncollapsed parts of the building are omitted from this calculation. Thus, the mortality rate can be estimated as $0.006 / 50$ years $\times 0.25 \times 0.10=3 \times 10^{-6} /$ year, or 0.3 per 100,000 people per year. The figure would apply to $24 / 7$ occupancy of buildings that comply with the 2012 IBC - that is, in buildings with earthquake loads (as opposed to wind loads) that govern the strength of the lateral force resisting system. 
Table 1. Mortality rates due to building collapse during earthquakes compared with other causes of death in the United States.

\begin{tabular}{lcc}
\hline \multicolumn{1}{c}{ Peril } & Deaths per 100,000 people per year & Where and when \\
\hline Heart disease & 194 & United States 2010 (Heron, 2013) \\
All accidents & 39 & United States 2010 (Heron, 2013) \\
Occupational fatality, roofers & 32 & United States 2011 (Bureau of Labor Statistics, 2013) \\
Auto accidents & 11 & United States 2009 (U.S. Census Bureau, 2012) \\
Firearms & 10 & United States 2010 (Heron, 2013) \\
New building collapse during earthquakes & 0.3 & 24/7 occupancy, wherever earthquake loads govern \\
& & the strength of the lateral force resisting system \\
Earthquakes past $~$ & 0.007 & California 1964-2014 (Wikipedia [2017], drawing on \\
& & a variety of sources)
\end{tabular}

\section{Implications of Seismic Performance Objectives for the HayWired Scenario}

The foregoing brief history discussion of seismic performance objectives raises some interesting questions that can be explored with the HayWired scenario.

1. Quantitative building-code objectives are expressed in terms of collapse risk during a 50-year building design life, considering all possible levels of shaking and their likelihood of occurrence. What about other modes of building impairment, namely red- and yellow-tagging? As used here, a red tag refers to a placard attached to an earthquake-damaged building that declares the building unsafe to enter or occupy. A yellow tag declares the building to be damaged such that its use is restricted. Restrictions might prevent the use of part of the building or they might allow only brief occupancy (for example, to remove possessions). See figure 3.

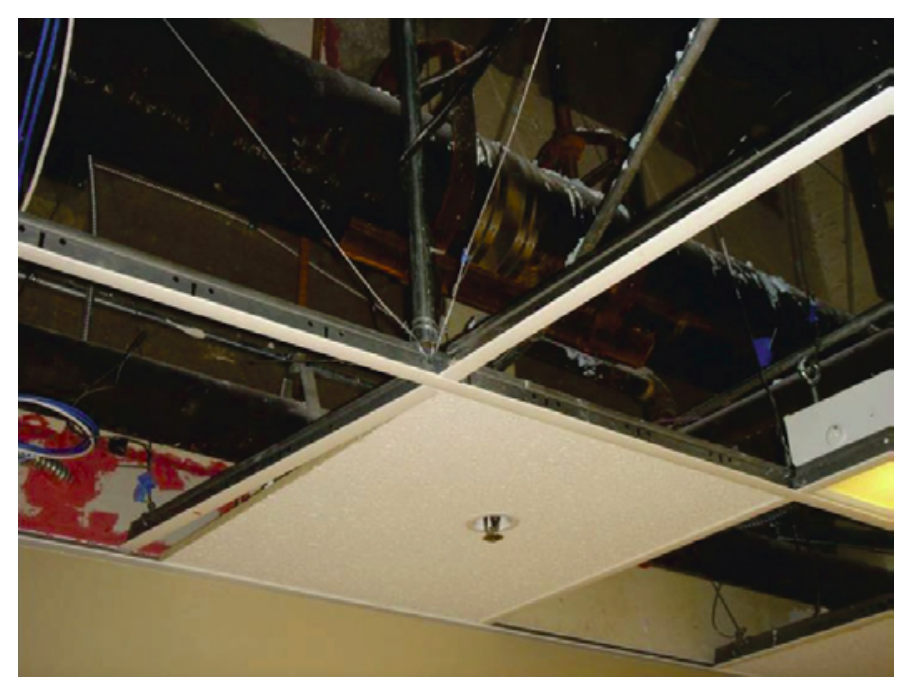

Figure 2. Photograph showing examples of building-code requirements to limit nonstructural repair costs. Note the diagonal wires and vertical post (called a compression post) that support the suspended ceiling. (Photograph from Federal Emergency Management Agency, 2012a.)
2. Quantitative code objectives are also expressed in terms of collapse probability in $\mathrm{MCE}_{\mathrm{R}}$ shaking. However, in a large earthquake, like that in the HayWired scenario, only a small geographic area might experience $\mathrm{MCE}_{\mathrm{R}}$ shaking or greater. What happens at lower levels of shaking?

3. Quantitative code objectives are expressed in terms of collapse probability for a single building. What happens at the societal level, for example, in terms of the fraction or number of impaired buildings in the epicentral region?

4. Suppose a city or a state, such as California, adopted the IBC but decided to modify it to require stronger buildings. What would be the result in terms of the fraction or number of impaired buildings in the epicentral region? Stiffness also matters for building performance, especially repair cost and duration, but I focus here on strength, which more strongly affects collapse and red tagging. See Multihazard Mitigation Council (2017) for a discussion on the effects of greater stiffness as well as strength.

The answers to these questions can inform the public's understanding and expectations for code-compliant buildings and the understanding of their elected officials who adopt model building codes like the IBC. The remainder of this report seeks to answer questions $1-4$.

After an earthquake, red- and yellow-tagged buildings can be impaired for months. Comerio (2006), who studied building restoration after the 1994 Northridge earthquake, wrote that:

Initial inspections of more than 440,000 units listed 7,000 single-family homes, 2,000 mobile homes, and 49,000 multifamily units [as] red- and yellowtagged. Three years after the event, when insurance claims were tallied, it became clear that moderate damage to single-family homes was under-counted in the post-event inspections, as more than 195,000 homeowners made insurance claims, for an average of $\$ 30,000$ to $\$ 40,000 \ldots$. About 40 percent of homeowners began repairs within one year. . For 
the remainder, it took two to three years to resolve the insurance claim, and repairs were likely to be delayed until the insurance funding was available. The time needed for repairs of large apartment and condominium buildings was often longer.

Comerio's (2006) findings imply that even a yellow-tagged building may be unavailable for months or more after the mainshock earthquake. In light of Comerio's observation that 58,000 housing units were red- or yellow-tagged, but 195,000 homeowners made insurance claims averaging $\$ 30,000$ to $\$ 40,000$, it seems that more than 3 times the number of collapsed, red-tagged, and yellow-tagged buildings may be at least moderately damaged - that is, with repair costs around $\$ 30,000$ to $\$ 40,000$. Whereas this study focuses on impairedthat is, collapsed, red-tagged, and yellow-tagged - buildings, it is important to keep in mind that many more buildings may be adversely affected by earthquake shaking.

\section{Impairment Rate at $\mathrm{MCE}_{\mathrm{R}}$ Shaking}

To quantify impairment rates of buildings at $\mathrm{MCE}_{\mathrm{R}}$ shaking, I begin with some observations. Figure 4 summarizes the results of incremental dynamic analyses of a large number of sample buildings (NEHRP Consultants Joint Venture, 2012). The figure shows the fraction of nonlinear dynamic analyses at $\mathrm{MCE}_{\mathrm{R}}$-level spectral acceleration response in which the building is estimated to have collapsed, as a function of the building's estimated fundamental period of vibration ("design period" in the figure). In private conversation, the lead author expressed the opinion that many of the sample buildings ought to be excluded from this analysis, especially the circled data points and all of the data for buildings with design period less than 0.5 seconds (C. Kircher, oral commun., May 8, 2014). The former should be excluded because they would not comply with the current building code, the latter because he believes the structural analyses incorrectly associated a threshold level of peak transient drift ratio with collapse. Excluding these and taking the average of the remaining data suggests the average probability of collapse is 6 percent at $\mathrm{MCE}_{\mathrm{R}}$ shaking.

In addition to collapsed buildings, how many buildings are red- or yellow-tagged in $\mathrm{MCE}_{\mathrm{R}}$ shaking? Unfortunately, there are no analytical studies of red and yellow tagging comparable to the studies of collapse by ATC (2009) and NEHRP Consultants Joint Venture (2012). Table 2 lists evidence for the ratio of red tags to collapses, where both are known - an admittedly limited dataset. The data suggest approximately 13 buildings are red-tagged for every collapsed building. Table 3 shows evidence for 3.8 yellow tags per red tag. Let $r$ denote the ratio of impaired buildings to collapsed buildings. With 13 red tags per collapse and 3.8 yellow tags per red tag, $r=63$ impaired buildings for each collapsed building $(1+13+13 \times 3.8=63.4)$, including the collapsed building. The data in tables 2 and 3 do not reflect a code-compliant stock and they do not account for variability with shaking intensity. However, using this empirical evidence is preferable to using Hazus-MH software (FEMA, 2012b) or another forward analytical model, because engineers generally prefer to rely on empirical evidence over analytical results. Remember, I am only using evidence from past earthquakes to estimate ratios of red tags to collapse and yellow tags to red tags, not rate of collapse.

Table 4 summarizes the implications of these findings for the building stock in a small area that experienced $\mathrm{MCE}_{\mathrm{R}}$ shaking. The values in table 4 rely solely on the building code's explicit objective (10 percent collapse probability conditioned on $\mathrm{MCE}_{\mathrm{R}}$ shaking), reduced to provide a best estimate rather than an upper limit ( 6 percent rather than 10 percent), and that the ratio of red and yellow tags to collapses of new buildings would be the same as has been observed for the 1989 Loma Prieta and 1994 Northridge earthquakes.
$\boldsymbol{A}$

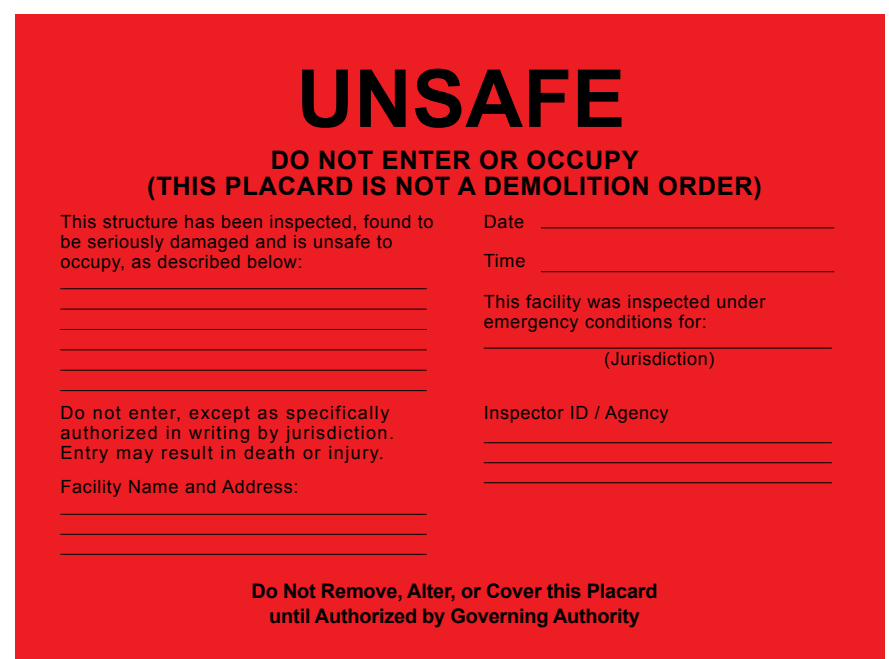

B
RESTRICTED USE

Caution: This structure has been inspected and found to be damaged as described below:

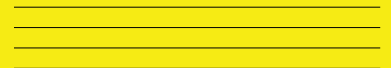

Entry, occupancy, and lawful use are restricted as indicated below:

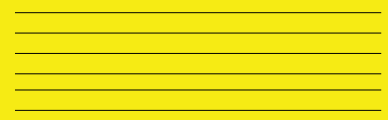

Facility Name and Address:
Date Time (Caution: Aftershocks since inspection may increase damage and risk.)

This facility was inspected under emergency conditions for: (Jurisdiction) Inspector ID / Agency

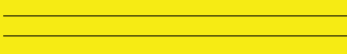

Do Not Remove, Alter, or Cover this Placard until Authorized by Governing Authority

Figure 3. Images of $(A)$ red and $(B)$ yellow tags used to indicate the level of impairment to an earthquake-damaged building (images from Applied Technology Council, 2005). 

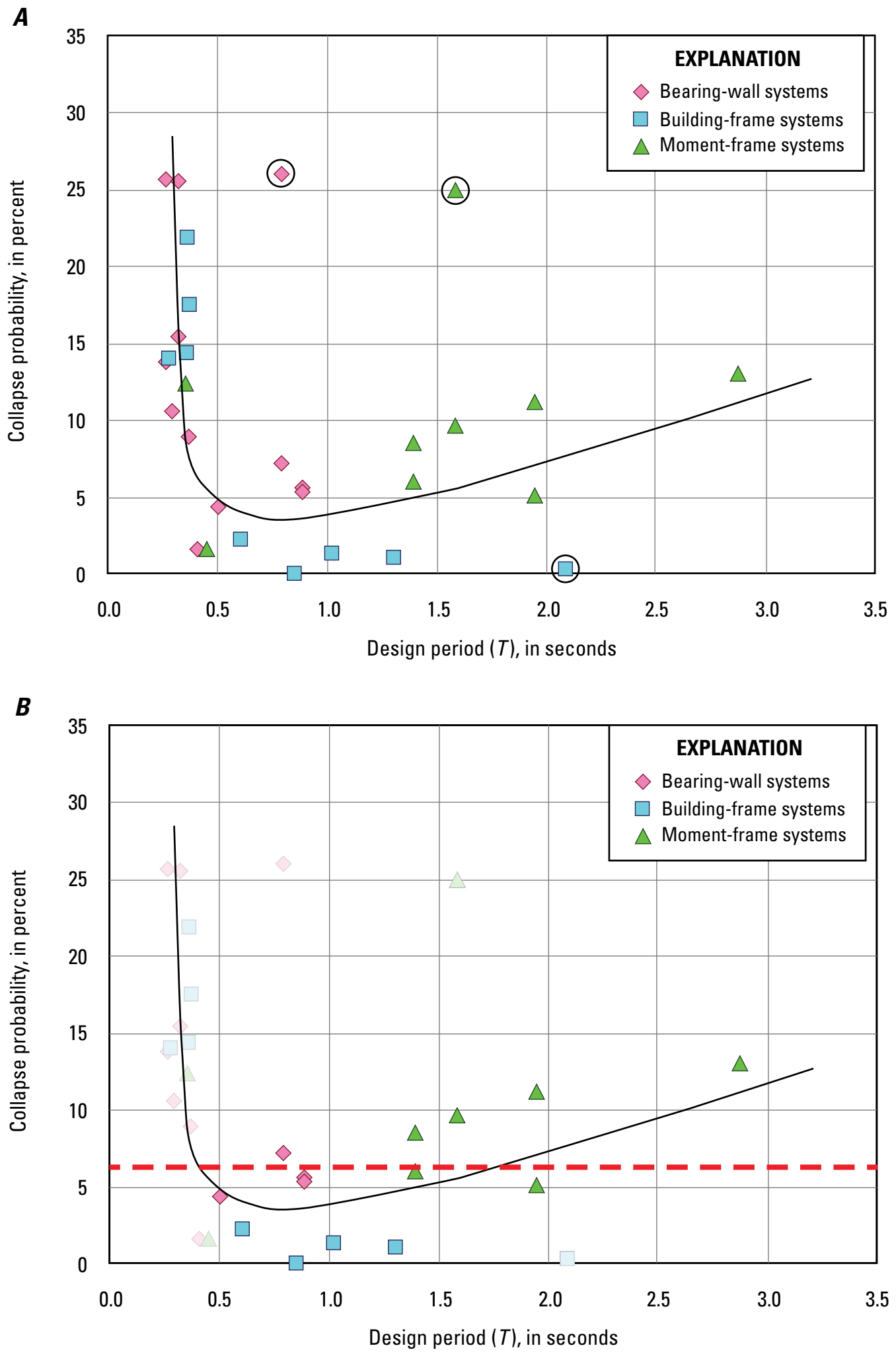

Figure 4. Graphs showing collapse probability conditioned on risk-adjusted maximum considered earthquake $\left(\mathrm{MCE}_{\mathrm{R}}\right)$ shaking versus design period for buildings examined by NEHRP Consultants Joint Venture (2012). The buildings were subjected to multiple nonlinear dynamic structural analyses at a level of motion associated with $\mathrm{MCE}_{\mathrm{R}}$ shaking. $A$, Graph showing all buildings examined by NEHRP Consultants Joint Venture (2012). B, Graph excluding the buildings that the lead author of NEHRP Consultants Joint Venture (2012) thought should be excluded from the analysis, because they would not comply with current code or did not correctly associate peak transient drift ratio with collapse (C. Kircher, oral commun., May 8, 2014). The remaining data define an average collapse probability of 6 percent for all design periods considered (dashed red line). (Images modified from NEHRP Consultants Joint Venture, 2012.) 
Table 2. Red tags and building collapses in select California earthquakes.

[NIST, National Institute of Standards and Technology; SEAONC, Structural Engineers Association of Northern California; EQE, EQE International; Cal OES, California Governor's Office of Emergency Services, Geographic Information Systems Group]

\begin{tabular}{cccc}
\hline Earthquake & Red tags & Collapse & Reference \\
\hline $\begin{array}{c}\text { 1989 Loma Prieta, } \\
\text { San Francisco } \\
\text { Marina District }\end{array}$ & 110 & 7 & $\begin{array}{r}\text { NIST (1990), Harris } \\
\text { and others (1990) }\end{array}$ \\
$\begin{array}{c}\text { 1989 Loma Prieta, } \\
\text { City of Santa Cruz }\end{array}$ & 100 & 40 & $\begin{array}{c}\text { SEAONC (1990), } \\
\text { Fradkin (1999) }\end{array}$ \\
1994 Northridge ${ }^{2}$ & 2,157 & 133 & $\begin{array}{c}\text { EQE and Cal OES } \\
(1995)\end{array}$ \\
\hline Total & 2,367 & 180 & Ratio=13:1 \\
\hline
\end{tabular}

${ }^{1}$ One hundred red tags is an estimate; 300 red tags county wide, factored by number of structures in city versus county, and reduced by number of collapses to avoid double counting.

${ }^{2}$ One hundred thirty-three collapsed buildings is taken from the ATC-20 form data in an unpublished database described by EQE and Cal OES (1995); red tags reduced by number of collapses to avoid double counting.

Table 3. Yellow and red tags in select California earthquakes.

[SEAONC, Structural Engineers Association of Northern California; EQE, EQE International; Cal OES, California Governor's Office of Emergency Services, Geographic Information Systems Group]

\begin{tabular}{llll}
\hline \multicolumn{1}{c}{ Earthquake } & Yellow tags & Red tags & \multicolumn{1}{c}{ Reference } \\
\hline 1989 Loma Prieta & 3,330 & 1,114 & SEAONC (1990) \\
1994 Northridge & 9,445 & 2,290 & $\begin{array}{c}\text { EQE and Cal } \\
\text { OES (1995) }\end{array}$ \\
\hline Total & 12,775 & 3,404 & Ratio=3.8:1 \\
\hline
\end{tabular}

Table 4. Performance of new buildings in a small area subjected to risk-adjusted maximum considered earthquake $\left(\mathrm{MCE}_{\mathrm{R}}\right)$ shaking.

\begin{tabular}{lcc}
\hline \multicolumn{1}{c}{ Building condition } & Percent/ratio & Fraction of stock \\
\hline Collapsed & 6 percent of stock & 6 percent \\
Red-tagged and not & 13 red tags per col- & 78 percent \\
collapsed & lapse & \\
Yellow-tagged & $\begin{array}{c}3.8 \text { yellow tags per } \\
\text { red tag }\end{array}$ & $\begin{array}{c}\text { Most of the re- } \\
\text { maining stock }\end{array}$ \\
\hline
\end{tabular}

\section{Validation Using Data from the August 2014 Napa Earthquake}

Data acquired from the City of Napa, California, after the completion of this analysis can be compared with the data in tables 2 and 3. As of October 21, 2014, the City of Napa recorded 1,767 yellow tags and 175 red tags (F. Turner, California Seismic Safety Commission, written commun., March 10, 2015). Damage descriptions acquired from the City of Napa in a separate database (K. Wallis, GIS Coordinator for City of Napa, written commun., March 12, 2015) suggest 34 structures appear to meet the definition of collapse. According to FEMA P-154 (ATC, 2015), building collapse means that any part of the gravity system experienced dynamic instability leading to the loss of load-bearing capacity. The dynamic instability leads to severe structural deformation of a potentially life-threatening nature, especially falling of all or portions of a structure. Note that, as used here, partial building collapse means that the dynamic instability occurs only in a portion of the building.

The 34 collapses are included among the yellow and red tags, such that the ratio of impaired buildings to collapses is $(1,767+175) / 34=57: 1$. The ratio of yellow to red is higher in the 2014 Napa earthquake than in the Loma Prieta and Northridge earthquakes and the ratio of red tags to collapse is lower. These two ratios counteract each other to result in a ratio of impaired buildings to collapses (57:1) that closely approximates those from the Loma Prieta and Northridge earthquakes $(63: 1)$.

\section{Impairment Rate at Other Levels of Shaking}

Until now, I have considered the impairment rates of a code-compliant building stock that is shaken to exactly $\mathrm{MCE}_{R}$ shaking. Impairment can be estimated at other levels of shaking as well. It is probably higher at higher levels of shaking, and lower at lower levels of shaking. Because the strength of new buildings varies from place to place depending largely on $\mathrm{MCE}_{\mathrm{R}}$, I define new measures of shaking called demandto-design ratio (DDR), with two varieties: $\mathrm{DDR}_{\mathrm{S}}$ and $\mathrm{DDR}_{1}$ defined as follows.

- $\mathrm{DDR}_{\mathrm{S}}$ is the 5-percent damped spectral acceleration response at a period of 0.2 seconds in a particular earthquake at a particular location divided by $S_{\mathrm{MS}}$ the $\mathrm{MCE}_{\mathrm{R}} 5$-percent damped spectral acceleration response parameter at short periods adjusted for site class effects, as defined in American Society of Civil Engineers/Structural Engineering Institute (ASCE/ SEI) 7-10 section 11.4.3. Note that the subscript in $\mathrm{DDR}_{\mathrm{S}}$ indicates short period, similar to that in $S_{\mathrm{MS}}$. 
- $\mathrm{DDR}_{1}$ is the 5-percent damped spectral acceleration response at a period of 1.0 second in a particular earthquake at a particular location divided by $S_{\mathrm{M} 1}$ the $\mathrm{MCE}_{\mathrm{R}}$ 5-percent damped spectral acceleration response parameter at a period of 1 second adjusted for site class effects as defined in ASCE/SEI 7-10 section 11.4.3. The subscript in $\mathrm{DDR}_{1}$ and $S_{\mathrm{M} 1}$ refers to the period length.

One can map $\mathrm{DDR}_{\mathrm{S}}$ for a given earthquake scenario by normalizing the ground-motion map with respect to ASCE/ SEI 7's MCE ${ }_{R}$ ground motion parameter map for a 5-percent damped, 0.2-second spectral acceleration response, adjusted for site class $S_{\mathrm{MS}}$. The result for the HayWired scenario mainshock - at least for the study area modeled by Aagaard and others (2010) - is shown in figure 5.

I further idealize the collapse capacity of all code-compliant buildings as a lognormally distributed random variable measured in terms of $\mathrm{DDR}_{\mathrm{S}}$ or $\mathrm{DDR}_{1}$. I will use $\mathrm{DDR}_{\mathrm{S}}$ when considering the performance of buildings with period less than the corner period, which corresponds to the intersection of the constant-acceleration and constant-velocity parts of the ASCE/SEI 7 design spectrum and is equal to $S_{\mathrm{Ml}} / S_{\mathrm{MS}}$. I will use $\mathrm{DDR}_{1}$ when the period is at or above the corner period. More qualitatively, $\mathrm{DDR}_{\mathrm{S}}$ provides a better measure for lowrise buildings (less than 3 or 4 stories, or so), whereas $\mathrm{DDR}_{1}$ is the better measure for taller buildings. Taller buildings are actually designed based on $S_{\mathrm{MI}} / T$, where $T$ is the building's estimated small-amplitude fundamental period of vibration. If I were to define DDR for these taller buildings as the spectral acceleration $\left(S_{\mathrm{a}}\right)$ response at their fundamental period of vibration, that is, $S_{\mathrm{a}}(T)$, I could then estimate $S_{\mathrm{a}}(T)=S_{\mathrm{a}}(1$ second $) / T$, normalize by $S_{\mathrm{MI}} / T$, and the period $T$ would cancel out of the numerator and denominator, leaving $\mathrm{DDR}_{1}$ as already defined. At the upper limit, I ignore those buildings that are so tall that their fundamental period of vibration lies on the constant-displacement portion of the response spectrum. They tend to have lateral strength governed by wind loads rather than earthquake
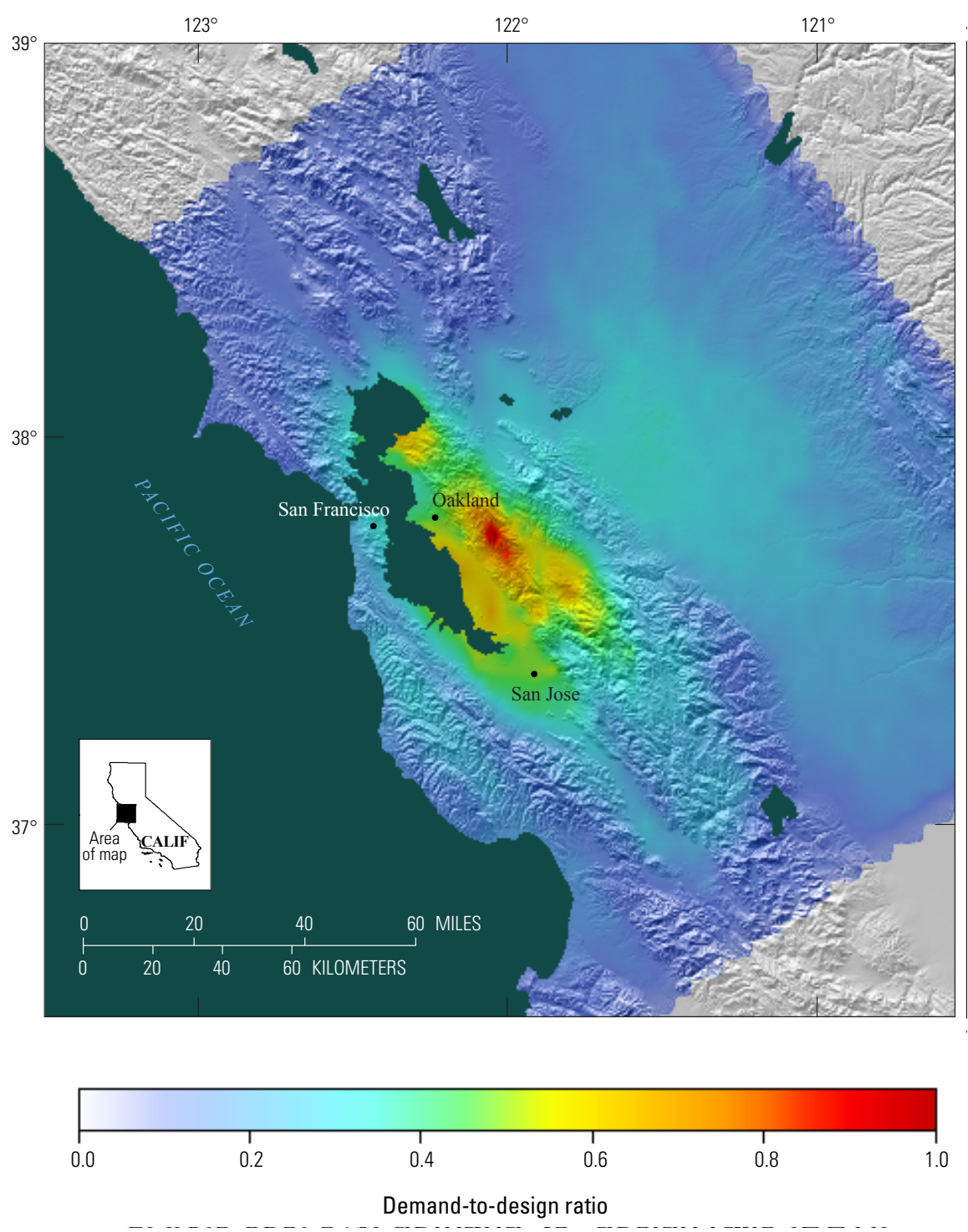

Figure 5. Map of the San Francisco Bay region, California, showing demand-todesign ratio for the moment-magnitude-7.0 mainshock of the HayWired earthquake scenario, calculated for a 5-percent damped, 0.2-second spectral acceleration. (Map created using OpenSHA Generic Mapping Tools Map Plotter; Field and others, 2003.) 
loads, so the formulation developed here would grossly overestimate collapse of these buildings.

By "lognormally distributed" it is meant that this work idealizes the collapse capacity of a building (the level of shaking that the building can tolerate without collapsing) as having a cumulative distribution function of the form:

$$
P[X \leq x]=P_{\mathrm{c}}(x)=\Phi\left(\frac{\ln (x / q)}{b}\right),
$$

where

$$
\begin{aligned}
& \mathrm{P}[\mathrm{A}] \text { denotes the probability that statement } \mathrm{A} \text { is } \\
& \text { true, } \\
& X \quad \text { denotes the uncertain collapse capacity of a } \\
& \text { building measured in terms of } \mathrm{DDR}_{\mathrm{S}} \text { or } \\
& \mathrm{DDR}_{1} \text {, } \\
& x \quad \text { is a particular value of } X \text {, } \\
& P_{\mathrm{c}}(x) \quad \text { denotes the probability that the building will } \\
& \text { collapse when subjected to shaking of } x \text {, } \\
& \Phi(z) \quad \text { denotes the standard normal cumulative } \\
& \text { distribution function evaluated at } z \text {, } \\
& q \text { is the median value of } X \text {, and } \\
& b \quad \text { is the standard deviation of } \ln (X) \text {. }
\end{aligned}
$$

Equation 1 represents a fragility function, which here means a relation between a measure of environmental excitation on the x-axis (here, DDR) and the occurrence probability of an undesirable outcome on the y-axis (here, collapse).

Since the undesirable outcome is building collapse, equation 1 represents a collapse fragility function. Equation 1 is in a form that is commonly used by many PBEE-2, loss estimation, and probabilistic seismic risk analysis studies to estimate damage to structures and components, including collapse. It is not that collapse capacity of buildings and building components are actually lognormally distributed, but rather that the lognormal often fits observed performance data reasonably well, is convenient, has the advantage of decades of tradition, and has support in information theory. The mention of information theory refers to the fact that the lognormal distribution is the maximum-entropy distribution - the one that assumes the least information - for a positively valued random variable with fixed median and logarithmic standard deviation.

To return to the problem of impairment rate at levels of shaking other than at $\mathrm{MCE}_{\mathrm{R}}$, equation 1 requires two parameters, $q$ and $b$. Luco and others (2007) examine a range of values of $b$, from 0.6 to 1.0 , and settled on $b=0.8$ as their best estimate. This value of $b$ was subsequently used in developing the ASCE/SEI 7-10 maps of $\mathrm{MCE}_{\mathrm{R}}$ and is also applied here. With the knowledge that the collapse probability, $P_{\mathrm{c}}$, is $P_{\mathrm{c}}(1.0)=0.06$ (as calculated in fig. 4), one can calculate $q$ as:

$$
q=1.0 \times \exp \left(-b \times \Phi^{-1}(0.06)\right),
$$

which leads to $q=3.47$. That is, the median collapse DDR is 3.47 , which means the median collapse capacity is 3.47 times $\mathrm{MCE}_{\mathrm{R}}$ shaking, whether measured in terms of $S_{\mathrm{MS}}$ or $S_{\mathrm{M} 1}$.
Now, the collapse probability of an arbitrary, code-compliant, engineered building can be modeled using equation 1 with $q=3.47$ and $b=0.8$. The collapse probability therefore is:

$$
P_{\mathrm{c}}(x)=\Phi\left(\frac{\ln (x / 3.47)}{0.8}\right) .
$$

As shown in figure 6, one can use this equation to estimate that at $\mathrm{DDR}=0.5$, the collapse probability is 0.008 , meaning that 0.8 percent of buildings are estimated to collapse at half of $\mathrm{MCE}_{\mathrm{R}}$ shaking.

When one uses a lognormal fragility function for probabilistic seismic risk analysis and fixes a point on the curve near $x=0.1$ or 0.2 with a credible $y$-value, the long-term failure rate tends to be fairly insensitive to the value of $b$ (Kennedy and Short, 1994; Porter, 2017). That means that selecting a different value of $b$ than the one suggested by Luco and others (2007) should make little difference, within a reasonable range. A lower value of $b$ will tend to decrease the estimated number of failures at low values of $x$ and increase the number of high values of $x$, with little change to the total. A similar statement can be made about selecting a higher value of $b$.

Applying the same ratios of red tags to collapses and yellow to red tags determined in the previous sections, one can further estimate that under the model used for collapses by ASCE/SEI 7-10, approximately half of buildings shaken at half the $\mathrm{MCE}_{\mathrm{R}}$ will be impaired (fig. 7).

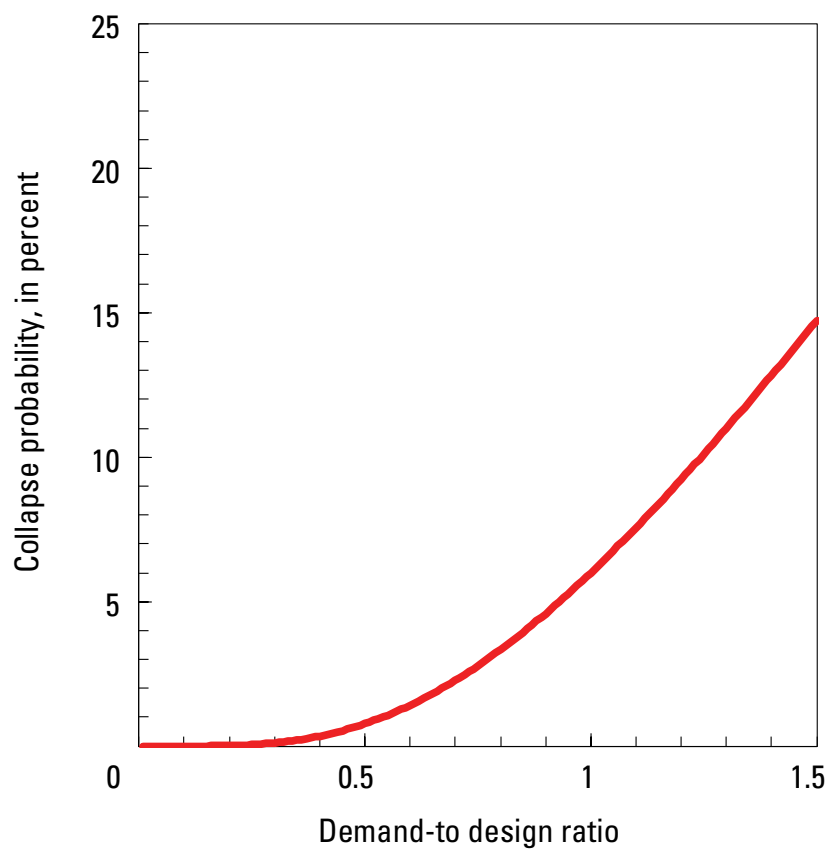

Figure 6. Graph showing the cumulative distribution function of building collapse probability for a range of demand-to-design ratio (DDR) values. When DDR is 0.5 - that is, half of the risk-adjusted maximum considered earthquake $\left(\mathrm{MCE}_{\mathrm{R}}\right)$ shaking - the probability of collapse is about 0.8 percent. 


\section{Fraction and Number of Impaired Buildings at the Societal Level}

More generally, the impairment rate $\left(P_{\mathrm{i}}\right)$ can be estimated as a function of DDR - denoted by $P_{\mathrm{i}}(x)$ - using equation 4 . To do so, simply multiply equation 3 for collapse probability by the ratio of impaired buildings to collapsed buildings:

$$
P_{\mathrm{i}}(x)=63.4 \times \Phi\left(\frac{\ln (x / 3.47)}{0.8}\right) \leq 1.0,
$$

Using the map of DDR (fig. 5), one can map impairment rate spatially, as shown in figure 8 . The figure only shows impairment results from the shaking model; it does not reflect impairment owing to ground failure, including liquefaction, landslide, and surface faulting, which would collectively tend to increase impairment rates by some unknown, but probably smaller, degree. One can then overlay the impairment rate on a map of the estimated building stock to estimate the number of impaired buildings in a scenario like HayWired. To overlay this information, scale the impairment rate by the estimated building stock:

$$
N_{\mathrm{i}}=\sum_{j=1}^{n} P_{\mathrm{i}}\left(x_{j}\right) \times B_{j}
$$

where

$$
\begin{gathered}
N_{\mathrm{i}} \quad \begin{array}{c}
\text { denotes the number of impaired buildings, } \\
j
\end{array} \\
\text { is an index to locations in the inventory of } \\
\text { building stock (such as census blocks), } \\
n \quad \text { is the number of locations in the inventory, } \\
x_{j} \quad \begin{array}{c}
\text { denotes the shaking in location } j \text { expressed in } \\
\text { terms of DDR, and }
\end{array} \\
B_{j} \quad \text { denotes the number of buildings in location } j .
\end{gathered}
$$
Evaluating equation 5 at the level of census tracts and using FEMA's enhanced building inventory, I find that shaking in the HayWired scenario would impair approximately 495,000 buildings. Table 5 lists the estimated number of shakinginduced impairment to buildings. In this scenario, using an average of three people per building (homes, workplaces, or other buildings), up to 1.5 million people could be displaced from those buildings for months or more while the buildings were repaired or replaced.

\section{Options for Improving Building-Stock Performance}

Cities and states tend to have limited options for modifying the provisions of model building codes like the IBC. They tend to lack the necessary resources to do anything other than accept or reject the code. However, there is one code parameter called the seismic importance factor (denoted by $I_{\mathrm{e}}$ in ASCE/SEI 7-10) that one can think of as a volume dial to uniformly increase the design strength of ordinary buildings in a community by a constant factor. The City of Moore,
Oklahoma, for example, recovering from a catastrophic tornado, recently required that new buildings be designed to resist windspeeds 50 percent higher than that required by the $\mathrm{IBC}$ - that is, $135 \mathrm{miles}$ per hour ( $\mathrm{mi} / \mathrm{hr}$ ) rather than $90 \mathrm{mi} / \mathrm{hr}$ (City of Moore, 2014). Because wind pressure is proportional to the square of velocity, the 50-percent increase in design windspeed equates to a 125-percent increase in design strength (because $1.5^{2}=2.25$ ), which means that the City of Moore was effectively adopting a wind importance factor of 2.25 for ordinary buildings. For reference, buildings along much of the U.S. Gulf and Atlantic Coasts are required to resist windspeeds in excess of $140 \mathrm{mi} / \mathrm{hr}$, so the City of Moore was not requiring unprecedented or even particularly uncommon design strength.

Suppose all San Francisco Bay area buildings were suddenly replaced with new ones built with $I_{\mathrm{e}}=1.5$ - that is, 50 percent stronger than the current code minimum. (Structural engineering readers should not infer that this hypothetical situation suggests that all buildings are designed as Risk Category IV under ASCE/SEI 7-10, with the attendant additional requirements. The situation considered here is that the State of California or every jurisdiction adopts the IBC with the exception that ASCE/SEI 7-10 table 1.5-2 is altered so that $I_{\mathrm{e}}=1.5$ for all risk categories.)

Similar to the case in the City of Moore, adopting a seismic importance factor of $I_{\mathrm{e}}=1.5$ would not impose extraordinary or particularly expensive requirements on the design of new buildings, at least for much of California. Consider the map of short-period $\mathrm{MCE}_{\mathrm{R}}$ shaking in figure 9. The contours show the mapped short-period (0.2 second) $\mathrm{MCE}_{\mathrm{R}}$ shaking

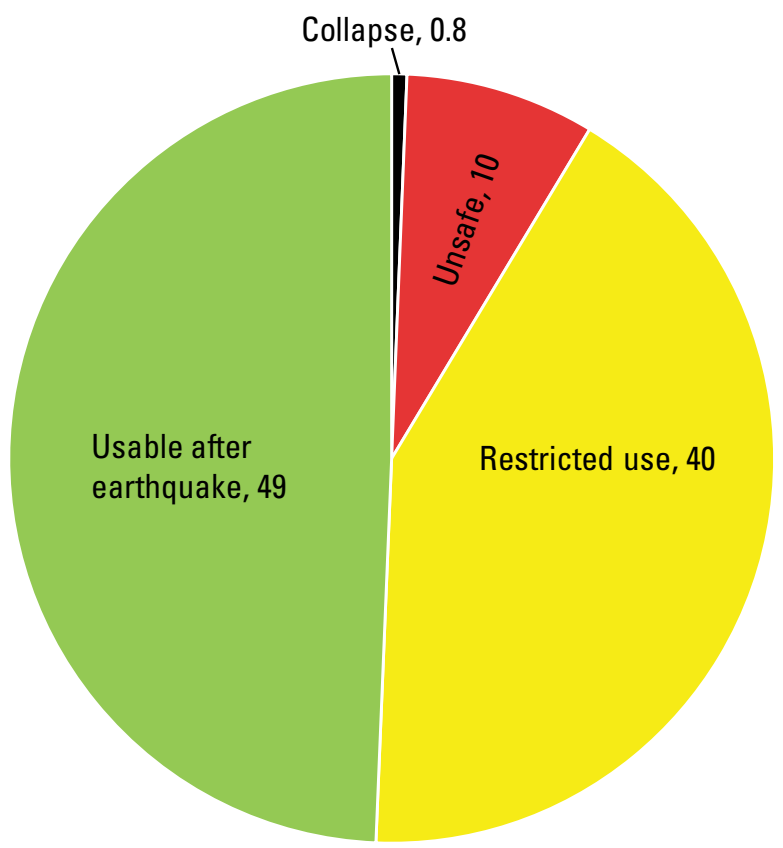

Figure 7. Pie diagram showing the impairment rate, in percent, of buildings at one half the risk-adjusted maximum considered earthquake $\left(\mathrm{MCE}_{\mathrm{R}}\right)$ shaking. Buildings that are considered impaired are either collapsed, red-tagged, or yellow-tagged. 
on rock, denoted by $S_{\mathrm{S}}$ in ASCE/SEI 7-10 and measured in percent of gravitational acceleration $(g)$. For mapped values of 100 or greater (1.0 $\mathrm{g}$ or greater), the amplification factor to account for site conditions (denoted by $F_{\mathrm{a}}$ in ASCE/SEI 7-10) is approximately 1.0 , so the map also shows $S_{\mathrm{MS}}$, the $\mathrm{MCE}_{\mathrm{R}}$ shaking accounting for site conditions other than rock. After accounting for common site conditions, $S_{\mathrm{MS}}$ in Sacramento, California, is approximately $0.8 \mathrm{~g}$, whereas in San Francisco $S_{\mathrm{MS}}$ varies between 1.5 and $2.3 \mathrm{~g}$. This means that if a lowrise building in western San Francisco were built with an importance factor of $I_{\mathrm{e}}=1.0$, picked up, and moved bodily to Sacramento, the building would satisfy seismic design requirements for a building with $I_{\mathrm{e}}$ of almost 3.0 in Sacramento. If the same building were instead picked up and moved bodily only 5 miles east inside of San Francisco, it would satisfy seismic design requirements for a building with $I_{\mathrm{e}}=1.5$. Similarly, an ordinary building constructed in Concord, California, with $I_{\mathrm{e}}=1.0\left(S_{\mathrm{MS}}=2.25 \mathrm{~g}\right)$ and moved 35 miles south near the San Jose International Airport $\left(S_{\mathrm{MS}}=1.5 \mathrm{~g}\right)$ would satisfy design requirements for $I_{\mathrm{e}}=1.5$. Buildings are built in both locations
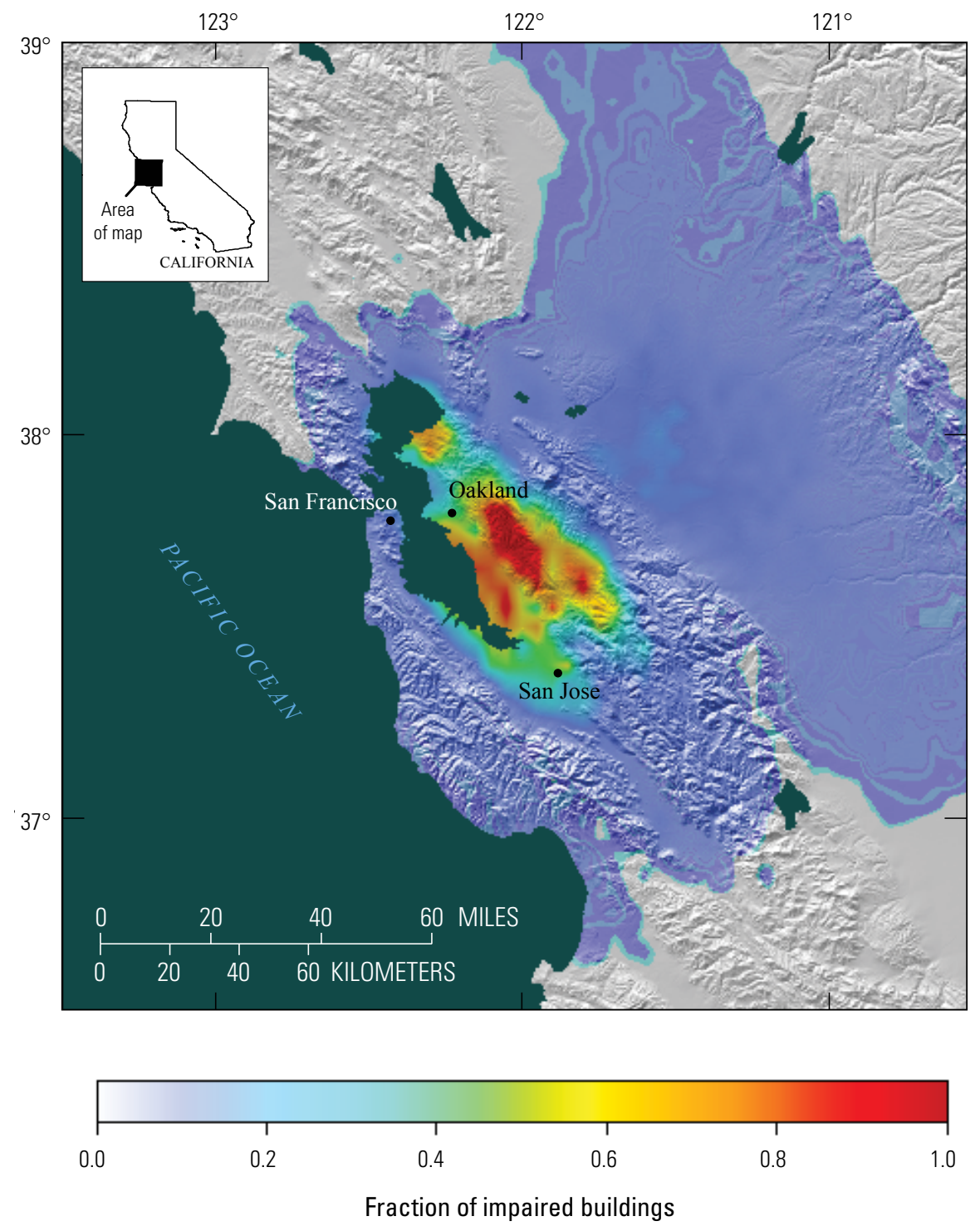

Table 5. Shaking-related building impairment estimates for a hypothetical moment-magnitude-7.0 earthquake occurring on the Hayward Fault in the east bay part of the San Francisco Bay area, like that modeled in the HayWired earthquake scenario.

\begin{tabular}{lc}
\hline \multicolumn{1}{c}{ Building condition } & Estimated number of buildings \\
\hline Collapse & 8,000 \\
Red-tagged & 101,000 \\
Yellow-tagged & 386,000 \\
\hline Total & 495,000 \\
\hline
\end{tabular}

Figure 8. Map of the San Francisco Bay region, California, showing impairment of existing buildings, if they all complied with current building codes, for the momentmagnitude-7.0 mainshock of the HayWired earthquake scenario. Building impairment includes collapsed, red-tagged, and yellowtagged buildings. (Map created using OpenSHA Generic Mapping Tools Map Plotter; Field and others, 2003.) 


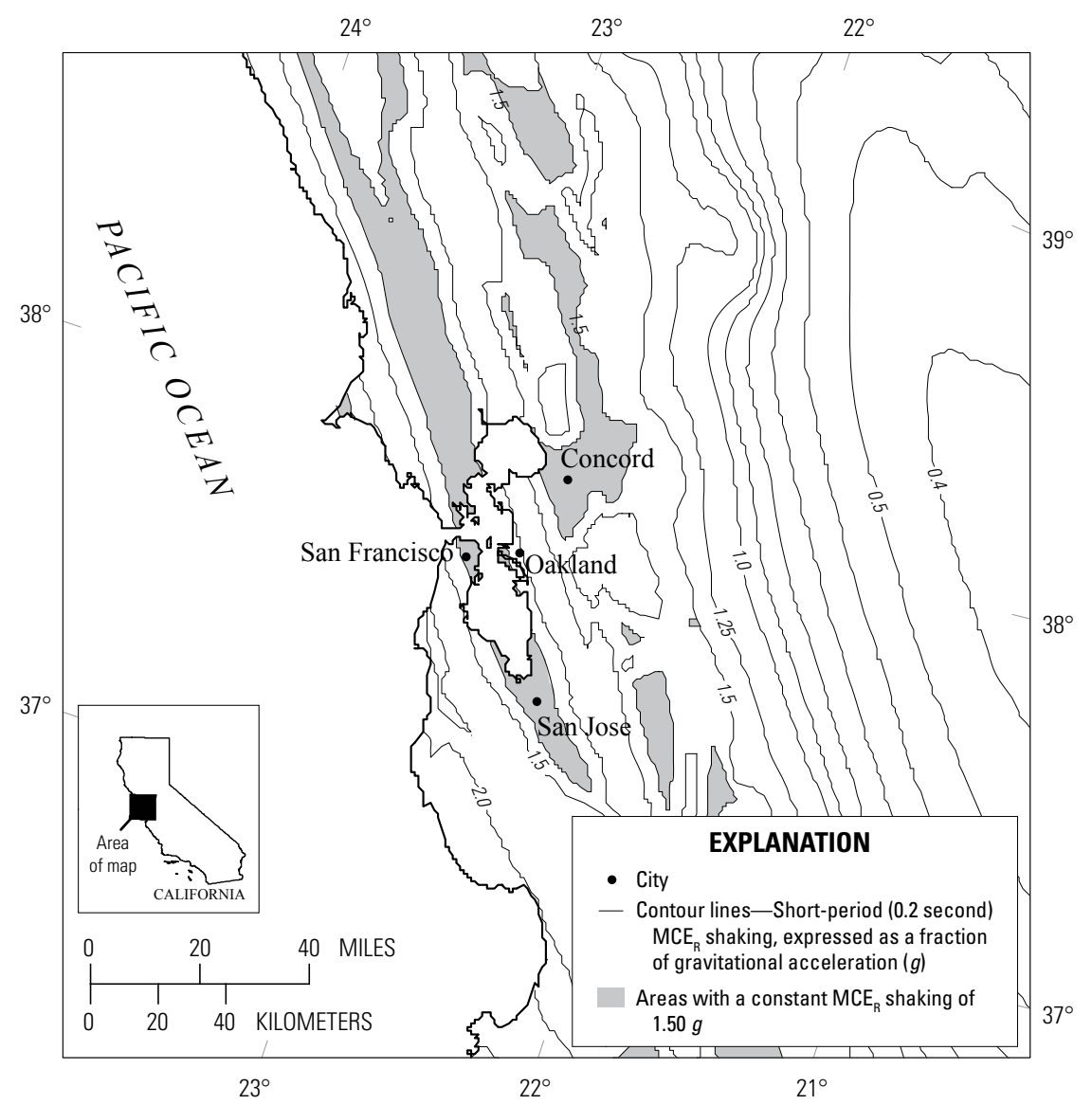

Figure 9. Map of risk-adjusted maximum considered earthquake $\left(\mathrm{MCE}_{\mathrm{R}}\right)$ shaking in the San Francisco Bay region, California. Map shows contours of maximum-direction, short-period (0.2 second) spectral response acceleration with 5-percent critical damping on sites with 760 meters per second average shear wave velocity in the top 30 meters of soil. Contours on the map are expressed as a fraction of gravitational acceleration $(g)$. Contours are shown in increments of 0.1 below $1.0 \mathrm{~g}$ and in increments of 0.25 above $1.0 \mathrm{~g}$. (Map modified from Building Seismic Safety Council, 2015.) all the time, practically and cost effectively, which means that imposing a design requirement that ordinary buildings be designed for $I_{\mathrm{e}}=1.5$ would be practical and not particularly expensive throughout much of the San Francisco Bay area, indeed in much, if not all, of California.

Informal discussion between the author and four California engineers suggests that designing to $I_{\mathrm{e}}=1.5$ would increase construction costs on the order of 1-3 percent (D. Bonneville, Degenkolb Engineers, oral commun., January 2015; E. Reis, U.S. Resiliency Council, oral commun., April 2014; J. Harris, J. R. Harris and Company, oral commun., August 2015; and R. Mayes, Simpson, Gumpertz and Heger, Inc., oral commun., January 2015). The estimate is further supported by NEHRP Consultants Joint Venture (2013), whose authors find that to redesign six particular buildings in Memphis, Tennessee, so that they comply with the 2012 IBC rather than the 1999 Southern Building Code, their strength would increase on average by 60 percent and their construction cost would increase between 0 and 1.0 percent. Olshansky and others (1998) found a similar estimated marginal cost to increase from no seismic design to code minimum. Furthermore, the estimated cost to achieve an immediate occupancy performance level rather than life safety for one of the index buildings of the CUREE-Caltech Woodframe Project is similarly marginal (Porter and others, 2006).

If the previous arguments do not convince the skeptical reader, I offer one more. A square-foot cost manual, such as RSMeans (2011), shows that approximately 67 percent of construction cost of a typical new building is spent on the architectural, mechanical, electrical, and plumbing assemblies, approximately 17 percent on overhead and profit, and of the remaining 16 percent that represents structural cost, approximately half is spent on labor. Most of the remaining 8 percent (mostly structural material cost) is spent on the gravity-resisting system: the foundation, floor slabs, columns, and beams. Of the small remaining portion that is spent on materials for the earthquake load resisting system (perhaps 2 percent), it could be increased by 50 percent to achieve a 1 -percent overall construction cost increase (the purchase price increase would be less if land value is considered). However, strength does not increase linearly with quantity of material. Quantity need not double or even increase by half to achieve a 50 percent stronger building. Strength can increase with the square or a higher power of material. For example, a W44 $\times 230$ wide-flange steel shape is about 63 percent stronger than a W30×191 shape, but weighs (and therefore costs) only about 20 percent more without requiring any additional labor to install. In this particular case, strength increases with more than the square of cost $\left(1.20^{2.6}=1.63\right)$. More extreme cases can be cited.

In California, a marginal construction cost increase of 1-3 percent would translate to a smaller marginal development cost increase because land can constitute more than half the value of a building and its value is unaffected by $I_{\mathrm{e}}$. Suppose the entire 1-3 percent cost increase was passed on to buyers 
and not absorbed by a reduction in the value of land and that land accounted for half the value of the property (it is often much more). The increase in purchase price might range between 0.5 and 1.5 percent - that is, on the order of 1 percent. In Porter (Not Safe Enough, this volume), I will examine whether the public is willing to pay this increased purchase price.

What would be the consequences in terms of building impairment in the HayWired scenario mainshock if the State of California or every San Francisco Bay area city adopted the IBC but required that all new ordinary buildings be designed with an importance factor $I_{\mathrm{e}}=1.5$ ? One can calculate the effect on collapse probability by retaining the assumption that collapse probability is reasonably approximated with a lognormal cumulative distribution function, retaining the assumption that the standard deviation of the natural logarithm of collapse capacity is approximately 0.8 , and multiplying the median collapse capacity by a factor of 1.5 (fig. 10). Assuming the ratios of red tags to collapses and yellow tags to red tags (3.8:1 and 13:1, respectively) still hold, then the map of impairment rate would be that shown in figure 11. Again, results are faily insensitive to parameter $b$.

Evaluating equation 5 at the level of census tracts and assuming $I_{\mathrm{e}}=1.5$ results in the estimate that shaking in the HayWired scenario mainshock would impair about 75 percent fewer buildings than when $I_{\mathrm{e}}=1.0$-impairing 130,000 buildings total, rather than 495,000 . Table 6 shows a side-by-side comparison of building impairment under $I_{\mathrm{e}}=1.0$ and $I_{\mathrm{e}}=1.5$ conditions. Recall that the cost of this reduction in impairment might realistically result in a marginal increase in purchase price of $0.5-1.5$ percent. To put it another way, it may increase the monthly mortgage for a new $\$ 500,000$ house in Concord,

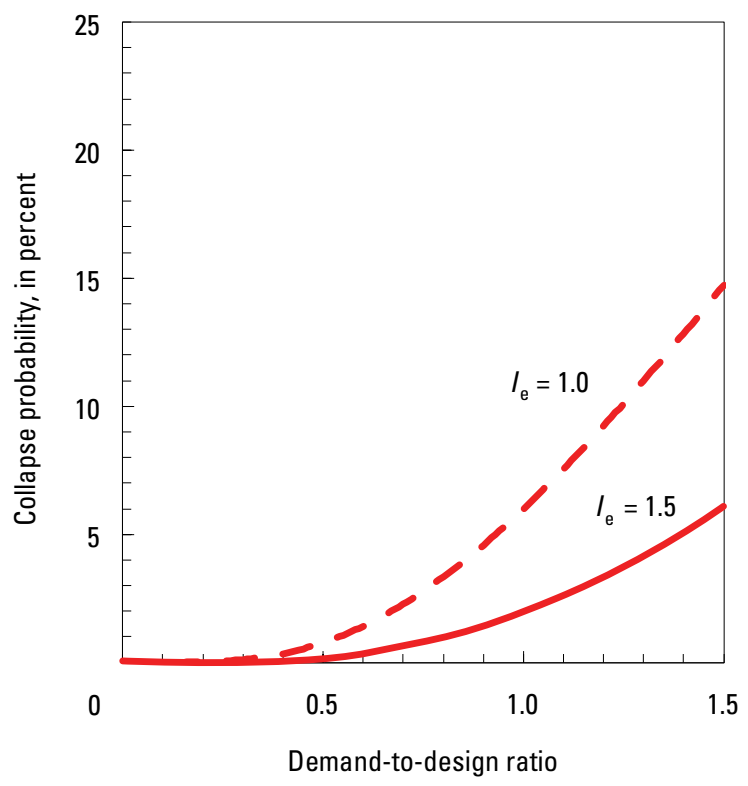

Figure 10. Graph showing collapse probability as a function of demand-to-design ratio for an importance factor $\left(/ /_{\mathrm{e}}\right)$ of 1.0 and 1.5. Note the significant drop in collapse probability for buildings with a higher value of $I_{\mathrm{e}}$.
California, for example, from $\$ 3,400$ to $\$ 3,430$. The values in table 6, however, do not include buildings that are moderately damaged. Recall that Comerio (2006) found that moderately damaged housing units numbered three times as many as collapsed, red-tagged, or yellow-tagged buildings after the 1994 Northridge earthquake.

I consider the $I_{\mathrm{e}}=1.0$ case that the HayWired mainshock would impair 500,000 buildings if all buildings behaved like new ones. The San Francisco Bay area contains approximately 2 million buildings, so 500,000 represents about 25 percent of buildings in the area. What happens to the people who live or work in those buildings? Vacancy rates in recent years are estimated to be approximately 0.5 percent of single-family dwellings, 3 percent of residential rental units (U.S. Census Bureau, [n.d.]), and 12-15 percent of San Francisco office space (Wells Fargo Securities, 2014). These rates are far too low to accommodate the displaced homes and businesses, and may force people to move out of the area.

With a building stock designed to $I_{\mathrm{e}}=1.5$, an estimated 130,000 buildings, or approximately 6 percent of the building stock, would be impaired in the HayWired mainshock. Though that number still exceeds the vacant stock, it is approximately within the bounds called for by the San Francisco Planning and Urban Research (SPUR) Shelter-in-Place Task Force (2012), an urban-planning policy document that recommends housing in San Francisco be resilient enough that 95 percent of the population could shelter in place. With doubling up and other emergency accommodations, this scenario would be more bearable than the alternative $I_{\mathrm{e}}=1.0$ case.

\section{Building Impairment Resulting from Ground Failure}

The building impairment estimates thus far discussed do not account for ground failure - liquefaction, landslide, or surface faulting. The effect of surface faulting can be estimated by assuming that every building whose footprint crosses a fault rupture where there is offset at the surface would be impaired. In the HayWired scenario, surface rupture would result in damage to approximately 500 existing buildings, adding about 0.1 percent to the total impairment quantity if all buildings were designed to $I_{\mathrm{e}}=1.0$, or 0.4 percent if all buildings were designed to $I_{\mathrm{e}}=1.5$. However, the damage to the code-compliant building stock would probably be much lower, for reasons explained next.

The 1972 Alquist-Priolo Fault Zoning Act (California Department of Conservation, [n.d.]) requires that local agencies regulate most development projects within about 50 feet of an active fault, such as the Hayward Fault. Projects include all land divisions and most buildings. The act generally serves to prevent new construction on top of a known active fault. Single-family wood-frame and steel-frame dwellings as high as two stories that are not part of a development of four or more units are exempt. Cities are free to impose greater 
restrictions, such as including the exempt buildings. If every city were to extend the restrictions of the 1972 Alquist-Priolo Fault Zoning Act to all buildings, and all buildings in the San Francisco Bay area were compliant, then there would be no buildings damaged by fault rupture.

More recently, ASCE/SEI 7-10 section 11.8 requires a geotechnical investigation and report for most new ordinary California buildings. The report includes an evaluation of the potential for slope instability, liquefaction, total and differential settlement, and surface displacement owing to faulting or seismically induced lateral spreading or flow. The report must contain recommendations for foundation designs or other measures to mitigate the effects of these hazards. Although section 11.8 does not preclude damage as a result of ground failure, it does tend to prevent it. One can conclude that earthquake damage owing to ground failure in code-compliant buildings will be minor, probably overshadowed by uncertainty in damage resulting from shaking.

The 2015 NEHRP Provisions Update Committee Chair points out that "Our seismic codes don't do much to address liquefaction damage. . We are doing more in the current cycle." (D. Bonneville, written commun., March 2015). Because this chapter addresses the hypothetical situation where all buildings are replaced with new ones, I also imagine that liquefaction damage is largely prevented by current developments.

\section{Public Expectations for the Seismic Performance of New Buildings}

It appears likely that the public is unaware that a codecompliant building stock could perform as described in table 5 , largely because the public has no involvement in the codewriting process. I now review that process.

Seismic design provisions have been present in model U.S. building codes since 1927 and have almost continuously evolved with new editions of the building codes. (Again, recommended provisions, standards, and model building codes
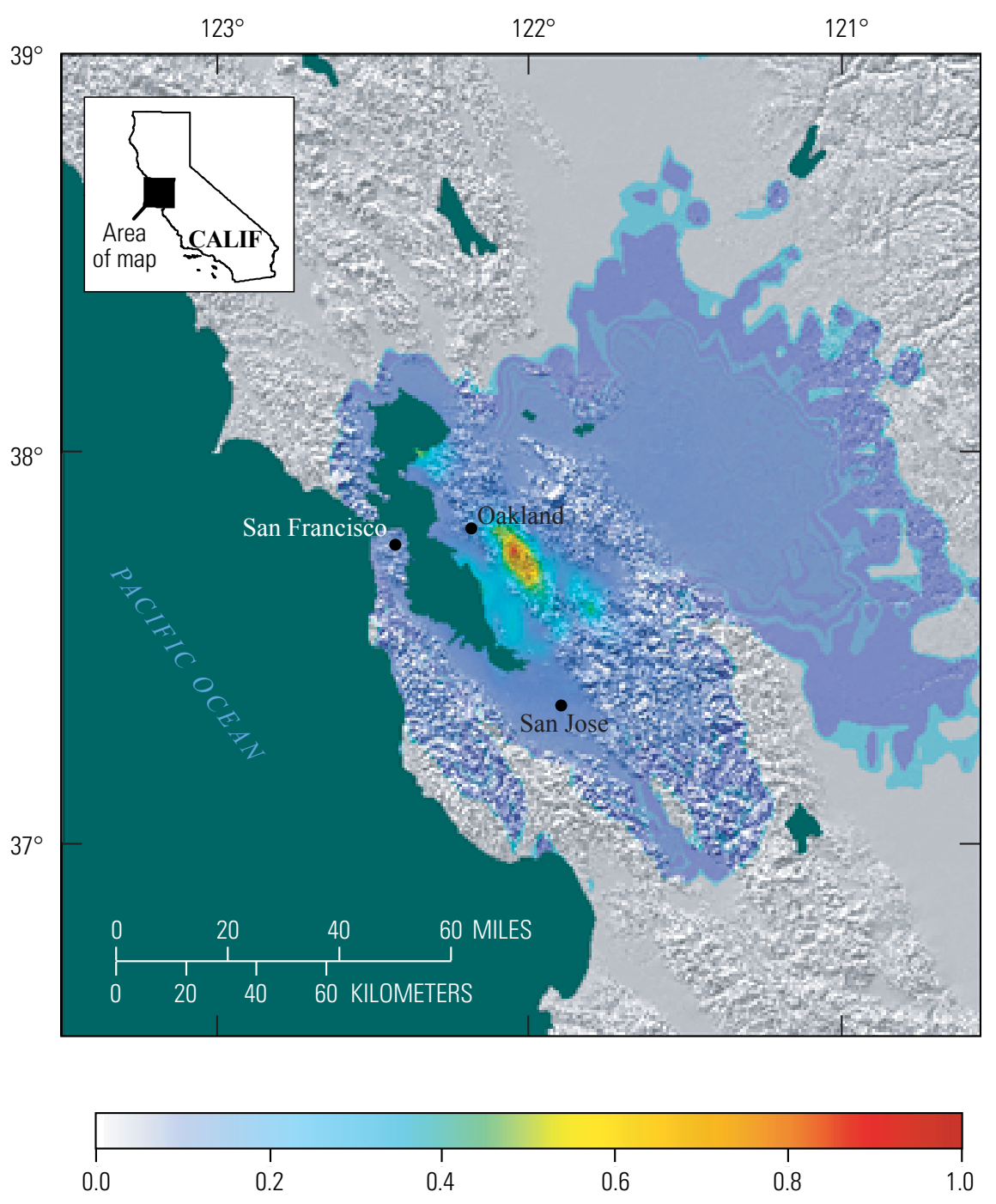

Fraction of impaired buildings
Figure 11. Map of the San Francisco Bay region, California, showing estimated building impairment for the momentmagnitude-7.0 mainshock of the HayWired earthquake scenario if buildings were designed with a seismic importance factor $\left(I_{\mathrm{e}}\right)$ of 1.5. Estimated building impairment includes collapsed, red-tagged, and yellow-tagged buildings. (Map created using OpenSHA Generic Mapping Tools Map Plotter; Field and others, 2003.) 
Table 6. Shaking-related building impairment for the momentmagnitude-7.0 mainshock of the HayWired earthquake scenario.

$\left[I_{\mathrm{e}}\right.$, seismic importance factor; numbers are rounded to the nearest 1,000 for simplicity]

\begin{tabular}{lcc}
\hline Building condition & Buildings with $\boldsymbol{I}_{\mathrm{e}}=\mathbf{1 . 0}$ & Buildings with $\boldsymbol{I}_{\mathrm{e}}=\mathbf{1 . 5}$ \\
\hline Collapse & 8,000 & 2,000 \\
Red-tagged & 101,000 & 27,000 \\
Yellow-tagged & 386,000 & 101,000 \\
\hline Total & 495,000 & 130,000 \\
\hline
\end{tabular}

are collectively and loosely referred to here as codes.) Code writers are required by engineering codes of ethics - such as that of the ASCE (2006) - to "hold paramount the health, safety and welfare of the public," and there is little doubt that that mandate constantly informs the code-writing process. However, code writers have expended little effort to elicit from the public its preferences for the seismic performance of new buildings or its preferred tradeoffs of safety and construction cost. Discussions of acceptable seismic performance have been largely carried out within the structural engineering community. A philosopher of engineering ethics, Davis (2015), has recently concluded that the ASCE Code of Ethics implicitly requires that those discussions include a reasonable effort to involve members of the public and that civil engineers among the code writers are obligated to consider the public's expressed preferences in the code. Several engineering ethicists strongly agree with Davis' (2015) findings (see Porter, 2016b).

As previously mentioned, U.S. building codes aim to protect life safety and limit property damage. The explicit intent of the 2009 IBC, for example, is to "establish minimum requirements to safeguard the public health, safety, and general welfare ..." and includes "safety to life and property" among its goals (ICC, 2009). The NEHRP Provisions (Building Seismic Safety Council [BSSC], 2009) aim "to avoid structural collapse in very rare, extreme ground shaking" and "to provide reasonable control of damage to structural and nonstructural systems that could lead to injury and economic or functionality losses for more moderate and frequent ground shaking." Note the inclusion of protecting the general welfare and avoiding property loss along with protecting life safety, suggesting that the authors did not feel legally constrained to only protect life safety. The NEHRP Provisions could, if its authors choose, change the requirements to control economic loss as well as to protect life.

For earthquake loads in particular, authors of modern codes have assumed it is impractical or uneconomical to achieve seismic resistance much greater than what is implicit in prior codes. (Here, seismic resistance refers generally to the capacity of buildings to resist damage or loss of functionality in earthquakes.) This implies that the authors believe the public would be unwilling to pay for safer buildings, such as those that would remain functional after very strong shaking. ASCE 7 (ASCE, 2010) and, by adoption, the IBC (ICC, 2012) measure seismic acceptability on a per-building basis, which implies that per-building or per-person risk is the best (or at least the most practical) measure of risk.

To say that it is uneconomical to provide greater seismic resistance is roughly equivalent to saying that people would be unwilling to pay for it ("economical" being a subjective judgment, not necessarily measured in terms of, say, benefitcost ratio). Is that true? In some sources (ASCE, 2010; ICC, 2012) and in others that underlie current code requirements for new buildings, there is no examination of the public's willingness to pay. Building owners and tenants have generally not been asked to express their preferences and are typically absent from the committees that establish codes. The authors of National Bureau of Standards Special Publication 577 (Ellingwood and others, 1980) expressed the idea that the A58 standards committee (precursor to ASCE 7) represented "those substantially concerned with its [the standard's] scope and provisions." Although committee members included "a broadspectrum group of professionals from the research community, building code groups, industry, professional organizations and trade associations," it did not include representatives of building owners or tenants.

The authors of a FEMA-sponsored workshop on communicating earthquake risk interviewed a small group of primarily commercial real-estate professionals about their preferred measures of seismic performance (ATC, 2002). The authors expressed the belief that "this workshop represents one of the first significant attempts to obtain input on issues of acceptable levels of seismic risk used as a basis for design, from other than the technical community ...," although they acknowledged that "several important stakeholder groups, notably residential and institutional building owners, and retailers were not represented at all." Only very recently did the National Institute of Building Sciences (NIBS, 2012)—NIBS is the parent body that led the development of BSSC (2009), a foundational document for the IBC - carry out its first survey to "get a baseline read about what Americans know or don't know about building codes." The survey was at a fairly high level and did not inquire about the public's understanding and preferences for the seismic performance of new buildings. The point is that the public is generally not consulted about their preferences for the seismic performance of the buildings on which their lives and livelihoods rely. It would be easier, perhaps necessary, for engineers to support judgments about what is economical if the public were asked what they would be willing to pay for greater seismic resistance.

It is necessary to define "the public" for purposes of this discussion. Here, I adopt the definition described by Davis and Porter (2016), "the public should be understood as including all those anywhere whose lack of information, technical knowledge, ability, or conditions for adequate deliberation renders them more or less vulnerable to the power that engineers wield on behalf of client or employer. The public is a collection or aggregate rather than an organized body. Unlike an electorate or corporation, it has interests but no decision procedure - no will of its own. The public is an abstraction 
(much like a set in mathematics). In the present context, however, the public does not include engineers, building officials, or members of the building industry, because these groups largely control the code."

Davis (2015) recently showed that the ASCE Code of Ethics requires that (1) the public has a role in establishing preferred tradeoffs among health, safety, and welfare; (2) engineers have an ethical obligation to ask about those preferences (within limits of reasonable effort); (3) engineers have an ethical obligation to respond to that information; and (4) the public, as used here, does not include builders, developers, or structural engineers.

To study public expectations as part of the HayWired scenario, I surveyed the public to ask a series of questions (Porter, Not Safe Enough, this volume):

- What do you believe to be the performance objectives most new buildings are intended to meet in a large earthquake?

- What do you think the building code should provide?

- What do you believe are the building performance measures of greatest interest to your community?

- What do you consider to be a reasonable tradeoff between safer buildings and higher initial construction cost?

- How important do you believe the issue is?

- What would be the best way to explore the issue further with local government or community?

The survey seeks information about the public's and local officials' understanding of and preferences for the seismic performance of new buildings that comply with the most modern building codes. In Porter (Not Safe Enough, this volume), I carried out a population-based survey of 400 members of the public within each of two regions: statewide throughout California and the two largest metropolitan statistical areas closest to the New Madrid Seismic Zone, namely Saint Louis, Missouri, and Memphis, Tennessee. The survey shows that the majority of respondents prefer better performance from new buildings than the results presented here for code-compliant buildings. Most prefer that buildings should be habitable or functional after a large earthquake. Survey respondents believe the public would be willing to pay 1 to 3 percent more in construction costs to achieve a higher level of seismic performance.

\section{Limitations of this Study}

There are many uncertainties in studies such as this and it may be that some parameters used here are unintentionally overly conservative. Perhaps the estimated 6-percent collapse rate at $\mathrm{MCE}_{\mathrm{R}}$ shaking drawn from the FEMA and NIST analyses (ATC, 2009, and NEHRP Consultants Joint Venture,
2012) is unrepresentative of real buildings and the true average collapse rate at $\mathrm{MCE}_{\mathrm{R}}$ shaking among new, engineered buildings will be much lower. For example, those studies only considered hypothetical frame buildings and, on the recommendation of the lead author of the two studies, the 6-percent figure reflects a subset of those hypothetical buildings - those with period greater than 0.5 seconds. Guidelines developed for the Global Earthquake Model present procedures for selecting samples of the general building stock so that the sample is representative of the building stock as a whole (Porter and others, 2014). A study similar to ATC (2009) and NEHRP Consultants Joint Venture (2012), but using a representative sample following the Global Earthquake Model procedures, could test the validity of the 6-percent figure for the general building population.

Perhaps the logarithmic standard deviation of 0.8 used by Luco and others (2007) to calculate $\mathrm{MCE}_{\mathrm{R}}$ is too high. The figure could be tested using the representative sample method described above (although long-term collapse rates and numbers of collapsed buildings in a single earthquake should be fairly insensitive to the exact value of the logarithmic standard deviation, as explained above). Perhaps the 63:1 ratio of redand yellow-tagged to collapsed buildings in the Loma Prieta and Northridge earthquakes and the 57:1 ratio in the Napa earthquake overestimate what would happen in future California earthquakes among code-compliant buildings. Procedures presented in ATC (2012) could be used to better estimate the ratio of red tags to collapses. ATC-20 tagging data from the 2014 Napa earthquake, 1994 Northridge earthquake, and 1989 Loma Prieta earthquakes could be analyzed further to develop analytical models for yellow tagging.

Future studies could test the possibility that one or more of the parameters derived here do not represent reality and result in impairment estimates that are much greater than would happen in a real earthquake. However, until better estimates are available, the estimates presented here provide insight into the unintended consequences of current building code performance objectives on large-scale building impairment during a large, but not exceedingly rare, earthquake.

\section{Summary}

The IBC attempts to ensure the safety of life in new, engineered buildings that are subject to earthquake shaking. Current building-code goals include no more than a 1-percent collapse probability in 50 years and no more than 10-percent collapse probability during $\mathrm{MCE}_{\mathrm{R}}$ shaking. However, the code does not control lesser degrees of impairment, such as red and yellow tagging, nor does it control the overall number of impaired buildings in a large, but not exceedingly rare, earthquake, such as the mainshock modeled in the HayWired scenario.

This study shows that in three California earthquakes, approximately 60 times as many buildings have been red- or yellow-tagged as have collapsed. In one earthquake, three 
times as many again experienced at least moderate damage - evidenced by insurance claims averaging $\$ 30,000$ to $\$ 40,000$ - without collapsing or being red- or yellow-tagged. This chapter also shows that FEMA and NIST research supporting the upper-bound goal of no more than 10-percent collapse probability results in an average 6-percent collapse probability during $\mathrm{MCE}_{\mathrm{R}}$ shaking. This work proposes a collapse fragility function for new, engineered buildings whose input parameter is the ratio of shaking at the building site to the siteclass-adjusted $\mathrm{MCE}_{\mathrm{R}}$; the ratio is referred to as the demandto-design ratio (DDR). The impairment fragility function takes the form of a lognormal cumulative distribution function multiplied by the ratio of total impaired buildings to collapsed buildings (63) with an upper bound of 1.0. The logarithmic standard deviation of the fragility function can be applied from the work of Luco and others (2007) that proposed establishing $\mathrm{MCE}_{\mathrm{R}}$. The median of the collapse fragility function follows directly from the observation that 6 percent of new, engineered buildings are expected to collapse in $\mathrm{MCE}_{\mathrm{R}}$ shaking, with a logarithmic standard deviation.

Using the map of ground motion in the HayWired scenario mainshock (fig. 5) and ASCE/SEI 7-10's map of $\mathrm{MCE}_{\mathrm{R}}$ shaking, adjusted to account for site amplification, this study calculates shaking in the HayWired scenario mainshock in terms of DDR. The DDR is evaluated for each location in FEMA's 2010 enhanced building inventory for California to estimate the number of buildings exposed to ground shaking in the HayWired mainshock for various levels of DDR. Using the impairment fragility function derived here, one can estimate the number of buildings impaired in the HayWired scenario, assuming that all of the buildings behaved as if they were new, code-compliant buildings. The result is an estimate that approximately 500,000 buildings would collapse, be redtagged, or be yellow-tagged. As many as 1.5 million people could be displaced from those buildings for months or more while the buildings are repaired or replaced. There are too few vacant buildings in the San Francisco Bay area to accommodate this many displaced people, suggesting that many would be forced to leave the San Francisco Bay area for at least several months, and possibly permanently.

One possible option for states or cities to reduce future building impairment is to adopt the IBC with the modification that all risk category I, II, or III buildings must be designed with a seismic importance factor $\left(I_{\mathrm{e}}\right)$ greater than 1.0. In the hypothetical case that all San Francisco Bay area cities require design to $I_{\mathrm{e}}=1.5$, the total number of impaired buildings in the HayWired mainshock would be reduced by approximately 75 percent, to 130,000 impaired buildings. The estimated 500,000 impaired buildings under current code objectives fails the 95-percent shelter-in-place performance objective of a San Francisco Bay area urban planning organization, SPUR, but the reduced impairment with $I_{\mathrm{e}}=1.5$ (130,000 buildings) meets SPUR's objective. The estimates presented here-500,000 impaired buildings under current code and 130,000 impaired buildings under the what-if scenario-follow solely from current code objectives, the research that established $\mathrm{MCE}_{\mathrm{R}}$, the evidence of collapse, red tags, and yellow tags in California's recent earthquake history, and FEMA's 2010 enhanced building inventory.

The construction cost to build new buildings with $I_{\mathrm{e}}=1.5$ has been approximately estimated here to be $1-3$ percent greater than under the current code, or about a 1 percent greater purchase price considering land value. Such a marginal cost seems entirely practical. Seismic design procedures in ASCE/SEI 7-10 already require buildings on one side of San Francisco to be designed with 50 percent greater strength than buildings on the other side. As another example, the City of Moore, Oklahoma, now requires buildings to be designed with 125 percent greater strength than before the devastating 2013 Moore tornado occurred.

A survey to elicit the public's understanding, expectations, and preferences for the code's seismic performance objectives was undertaken as part of the HayWired earthquake scenario (Porter, Not Safe Enough, this volume). It shows that the majority of the public prefers better performancethat buildings should be habitable or functional after a large earthquake. Survey respondents believe the public would be willing to pay 1 to 3 percent more in construction costs to achieve a higher level of seismic performance. Some argue that civil engineers have an ethical obligation to elicit the public's preferences in drafting seismic design requirements (Davis, 2015), suggesting that surveys such as those undertaken as a part of the HayWired scenario may help inform the next generation of building-code objectives in seismically active areas.

\section{Conclusion}

Current code objectives seem to unintentionally produce a high degree of building impairment in a large, but not exceedingly rare, earthquake, such as the $M_{\mathrm{w}} 7.0$ mainshock of the HayWired scenario. The impairment, in terms of collapsed, red-tagged, or yellow-tagged buildings, would displace a large number of residents from the San Francisco Bay region. The building-code objectives appear, based on a large survey of Californians and people living in the Saint Louis, Missouri, and Memphis, Tennessee, metropolitan statistical areas, to be substantially below what the public may prefer and may be willing to pay for.

\section{References Cited}

Aagaard, B.T., Graves, R.W., Rodgers, A., Brocher, T.M., Simpson, R.W., Dreger, D., Petersson, N.A., Larsen, S.C., Ma, S., and Jachens, R.C., 2010, Ground-motion modeling of Hayward Fault scenario earthquakes, part II-Simulation of long-period and broadband ground motions: Bulletin of the Seismological Society of America, v. 100, no. 6, p. 2945-2977. 
American Society of Civil Engineers [ASCE], 2006, Code of ethics: Reston, Va., American Society of Civil Engineers web page, accessed January 28, 2015, at https://www.asce. org/codeofethics/.

American Society of Civil Engineers [ASCE], 2010, Minimum design loads for buildings and other structures: Reston, Va., Structural Engineering Institute, ASCE/SEI 7-10, $608 \mathrm{p}$.

Applied Technology Council [ATC], preparer, 1997, NEHRP guidelines for the seismic rehabilitation of buildings: Washington D.C., Federal Emergency Management Agency publication 273, prepared for the Building Seismic Safety Council, 386 p., accessed May 21, 2015, at https://www. wbdg.org/ccb/DHS/ARCHIVES/fema273.pdf.

Applied Technology Council [ATC], 2002, ATC-58-1—Proceedings of FEMA-sponsored workshop on communicating earthquake risk: Redwood City, Calif., Applied Technology Council, $74 \mathrm{p}$.

Applied Technology Council [ATC], 2005, ATC-20-1—Field handbook - Procedures for postearthquake safety evaluation of buildings: Redwood City, Calif., Applied Technology Council, $144 \mathrm{p}$.

Applied Technology Council [ATC], preparer, 2009, Quantification of building seismic performance factors: Washington D.C., Federal Emergency Management Agency publication P-695, 421 p., accessed May 21, 2015, at https://www. fema.gov/media-library-data/20130726-1716-25045-9655/ femap695.pdf.

Applied Technology Council [ATC], preparer, 2012, Seismic performance assessment of buildings-Methodology: Washington D.C., Federal Emergency Management Agency publication P-58-1, v. 1, 319 p., accessed May 21, 2015, at https:/www.fema.gov/media-library-data/13964950198480c9252aac91dd1854dc378feb9e69216/FEMAP-58Volume1508.pdf.

Applied Technology Council [ATC], preparer, 2015, Rapid visual screening of buildings for potential seismic hazards - A handbook (3d ed.): Washington D.C., Federal Emergency Management Agency publication P-154, 388 p., accessed May 21, 2015, at https://www.fema.gov/medialibrary-data/1426210695633-d9a280e72b32872161efab26a602283b/FEMAP-154508.pdf.

Aslani, H., and Miranda, E., 2006, Delivering improved information on seismic performance through loss disaggregation, in Proceedings of the 8th U.S. National Conference on Earthquake Engineering: Earthquake Engineering Research Institute, $10 \mathrm{p}$.
Beck, J.L., Kiremidjian, A., Wilkie, S., Mason, A., Salmon, T., Goltz, J., Olson, R., Workman, J., Irfanoglu, A., and Porter, K., 1999, Decision support tools for earthquake recovery of businesses - Final report: Richmond, Calif., Consortium of Universities for Research in Earthquake EngineeringKajima Joint Research Program, Phase III, 146 p.

Building Seismic Safety Council [BSSC], preparer, 2009, NEHRP recommended seismic provisions for new buildings and other structures: Washington D.C., Federal Emergency Management Agency publication P-750, 388 p., accessed May 21, 2015, at https://www.fema.gov/media-librarydata/20130726-1730-25045-1580/femap750.pdf.

Building Seismic Safety Council [BSSC], preparer, 2015, NEHRP recommended seismic provisions for new buildings and other structures: Washington D.C., Federal Emergency Management Agency publication P-1050, $515 \mathrm{p}$.

Bureau of Labor Statistics, 2013, National census of fatal occupational injuries in 2012 (preliminary results): U.S. Department of Labor publication USDL-13-1699, 14 p.

California Department of Conservation, [n.d.], California public resources code, division 2, chapter 7.5, Earthquake fault zoning: California Department of Conservation web page, accessed February 3, 2015, at https://www.conservation. ca.gov/cgs/codes/prc/Pages/chap-7-5.aspx.

City of Moore, 2014, City adopts new building codes, first in the Nation: City of Moore web page, accessed November 25, 2014, at https://www.cityofmoore.com/node/2111.

Comerio, M.C., 2006, Estimating downtime in loss modeling: Earthquake Spectra, v. 22, no. 2, p. 349-365.

Czarnecki, R.M., 1973, Earthquake damage to tall buildings: Cambridge, Mass., Massachusetts Institute of Technology, Structures Publication 359, 125 p.

Davis, M., 2015, What part should the public have in writing engineering standards?, in Security and Disaster Preparedness Symposium - Codes and Governance in the Built Environment, National Institute of Building Sciences Third Annual Conference and Expo: National Institute of Building Sciences, accessed March 1, 2015, at https://www.nibs.org/ store/ViewProduct.aspx?id=4108575.

Davis, M., and Porter, K., 2016, The public's role in seismic design provisions, Earthquake Spectra, v. 32, no. 3, p. 1345-1361, https://doi.org/10.1193/081715EQS127M.

Ellingwood, B., Galambos, T.V., MacGregor, J.G., and Cornell, C.A., 1980, Development of a probability-based load criterion for American National Standard A58: Washington D.C., National Bureau of Standards Special Publication 577, $222 \mathrm{p}$. 
EQE International and the Geographic Information Systems Group of the California Governor's Office of Emergency Services [EQE and Cal OES], 1995, The Northridge earthquake of January 17, 1994-Report of data collection and analysis; Part A, Damage and inventory data: Irvine, Calif., EQE International, project number 36386.02, 322 p.

Federal Emergency Management Agency [FEMA], 2012a, Reducing the risks of nonstructural earthquake damage - A practical guide: Federal Emergency Management Agency, FEMA E-74, accessed June 1, 2014, at https://www.fema. gov/earthquake-publications/fema-e-74-reducing-risksnonstructural-earthquake-damage.

Federal Emergency Management Agency [FEMA], 2012b, Hazus multi-hazard loss estimation methodology, earthquake model, Hazus ${ }^{\circledR}-\mathrm{MH} 2.1$ technical manual: Federal Emergency Management Agency, Mitigation Division, 718 p.

Field, E.H., Jordan, T.H., and Cornell, C.A., 2003, OpenSHA, a developing community-modeling environment for seismic hazard analysis: Seismological Research Letters, v. 74, no. 4, p. 406-419.

Fradkin, P.L., 1999, Magnitude 8-Earthquakes and life along the San Andreas Fault: University of California Press, 348 p.

Harris, S.K., Scawthorn, C., and Egan, J.A., 1990, Damage in the Marina District of San Francisco in the October 17, 1989 Loma Prieta Earthquake, in Proceedings of the 8th Japan Earthquake Engineering Symposium: Tokyo, Japan Earthquake Engineering Symposium.

Heron, M., 2013, Deaths_-Leading causes for 2010: National Vital Statistics Reports, v. 62, no. 6, 97 p.

Hess, R.L., 2008, The ShakeOut scenario supplemental study - Unreinforced masonry (URM) Buildings: Denver, Colo., SPA Risk LLC, 15 p., accessed October 26, 2010, at https://www.sparisk.com/pubs/ShakeOutScenarioURMHess. pdf.

International Code Council [ICC], 2009, International Building Code: Country Club Hills, Ill., International Code Council, 716 p.

International Code Council [ICC], 2012, International Building Code: Country Club Hills, Ill., International Code Council, $722 \mathrm{p}$.

Kennedy R.P., and Short, S.A., 1994, Basis for seismic provisions of DOE-STD-1020: Lawrence Livermore National Laboratory and Brookhaven National Laboratory Technical Report UCRL-CR-111478 and BNL-52418, 65 p., https:// doi.org/10.2172/10146835.

Kustu, O., Miller, D.D., and Brokken, S.T., 1982, Development of damage functions for highrise building components for the U.S. Department of Energy: San Francisco, Calif., URS/John A. Blume \& Associates, 46 p.
Luco, N., Ellingwood, B.R., Hamburger, R.O., Hooper, J.D., Kimball, J.K., and Kircher, C.A., 2007, Risk-targeted versus current seismic design maps for the conterminous United States, in Proceedings of the 2007 Convention of the Structural Engineers Association of California: Sacramento, Structural Engineers Association of California, p. 163-175.

Multihazard Mitigation Council, 2017, Natural hazard mitigation saves - 2017 interim report: Washington, D.C., National Institute of Building Sciences, 344 p., accessed April 3, 2018, at https://www.nibs.org/page/mitigationsaves/.

National Institute of Building Sciences [NIBS], 2012, Results from a survey of Americans on building codes and building safety: Washington D.C., National Institute of Building Sciences, $13 \mathrm{p}$.

National Institute of Standards and Technology [NIST], 1990, Performance of structures during the Loma Prieta Earthquake of October 17, 1989: National Institute of Standards and Technology, NIST SP-778, 212 p.

NEHRP Consultants Joint Venture, 2012, Tentative framework for development of advanced seismic design criteria for new buildings: National Institute of Standards and Technology, NIST GCR 12-917-20, 302 p., accessed May 21, 2015, at https://www.nehrp.gov/pdf/nistgcr12-917-20.pdf.

NEHRP Consultants Joint Venture, 2013, Cost analyses and benefit studies for earthquake-resistant construction in Memphis, Tennessee: National Institute of Standards and Technology, NIST GCR 14-917-26, 249 p., accessed May 21, 2015, at https://www.nist.gov/customcf/getpdf. cfm?pubid $=915569$.

Olshansky, R.B., Bancroft, R., and Glick, C., 1998, Promoting the adoption and enforcement of seismic building codes - A guidebook for State earthquake and mitigation managers: Washington D.C., Federal Emergency Management Agency publication $313,211 \mathrm{p}$.

Petersen, M.D., Moschetti, M.P., Powers, P.M., Mueller, C.S., Haller, K.M., Frankel, A.D., Zeng, Y., Rezaeian, S., Harmsen, S.C., Boyd, O.S., Field, N., Chen, R., Rukstales, K.S., Luco, N., Wheeler, R.L., Williams, R.A., and Olsen, A.H., 2014, Documentation for the 2014 update of the United States national seismic hazard maps: U.S. Geological Survey Open-File Report 2014-1091, 255 p., https://dx.doi. org/10.3133/ofr20141091.

Porter, K.A., 2003, An overview of PEER's performancebased earthquake engineering methodology, in Proceedings of the Ninth International Conference on Applications of Statistics and Probability in Civil Engineering: Civil Engineering Risk and Reliability Association, p. 973-980, accessed June 1, 2014, at https://spot.colorado. edu/ porterka/Porter-2003-PEER-Overview.pdf. 
Porter, K.A., 2016a, Safe enough?-A building code to protect our cities as well as our lives: Earthquake Spectra, v. 32, no. 2, p. 677-695, https://dx.doi.org/10.1193/112213EQS286M.

Porter, K.A., 2016b, Not safe enough—The case for resilient seismic design: Structural Engineers Association of California 2016 Convention, Maui, Hawaii, October 12-15, 2016, 10 p., accessed April 3, 2018, at http:/www.sparisk.com/ pubs/Porter-2016-SEAOC-Resilience.pdf.

Porter, K.A., 2017, When addressing epistemic uncertainty in a lognormal fragility function, how should one adjust the median?, in World Conference on Earthquake Engineering, 16th, Santiago, Chile, 2017, Proceedings: International Association for Earthquake Engineering, no. 2617.

Porter, K.A., and Cobeen, K., 2012, Informing a retrofit ordinance-A soft-story case study, in Proceedings of the 2012 Structures Congress: Reston, Va., American Society of Civil Engineers.

Porter, K., Farokhnia, K., Vamvatksikos, D., and Cho, I., 2014, Analytical derivation of seismic vulnerability functions for highrise buildings: Global Vulnerability Consortium, 136 p., accessed January 1, 2015, at https://www.nexus.globalquakemodel.org/gem-vulnerability/posts/.

Porter, K.A., and Kiremidjian, A.S., 2001, Assembly-based vulnerability of buildings and its uses in seismic performance evaluation and risk-management decision-making: Stanford, Calif., Stanford University, John A. Blume Earthquake Engineering and Research Center report 139, Ph.D. dissertation, 196 p., available at https://www.sparisk.com/ pubs/Porter-2001-ABV-thesis.pdf.

Porter, K.A., Scawthorn, C.R., and Beck, J.L., 2006, Costeffectiveness of stronger woodframe buildings: Earthquake Spectra, v. 22, no. 1, p. 239-266, https://dx.doi. org/10.1193/1.2162567.
RSMeans Co., Inc., 2011, Square Foot Costs 2012 (33d ed.): Kingston, Mass., RSMeans, Inc., 505 p.

Structural Engineers Association of Northern California [SEAONC], 1990, Posting of buildings after the Loma Prieta Earthquake: San Francisco, Calif., Structural Engineers Association of Northern California, $32 \mathrm{p}$.

SPUR Shelter-in-Place Task Force, 2012, Safe enough to stay: San Francisco, Calif., San Francisco Planning and Urban Research, 44 p.

Taciroglu, E., and Khalili-Tehrani, P., 2008, M7.8 Southern San Andreas Fault Earthquake Scenario-Non-ductile Reinforced Concrete Building Stock: Denver, Colo., SPA Risk LLC, accessed October 26, 2010, at https://arazprojects.com/wp-content/uploads/concrete_buildings. pdf.

U.S. Census Bureau, 2012, Table 1103, motor vehicle accidents_-Number and deaths, 1990-2009: Washington D.C., U.S. Census Bureau, accessed May 21, 2015, at https://www.census.gov/compendia/statab/2012/ tables/12s1103.pdf.

U.S. Census Bureau, [n.d.], Quarterly vacancy and homeownership rates by State and MSA: Washington D.C., U.S. Census Bureau, accessed May 21, 2015, at https:// www.census.gov/housing/hvs/data/rates.html.

Wells Fargo Securities, 2014, San Francisco Bay area real estate outlook: Wells Fargo Securities Economic Group Special Commentary, May 6, 2014, accessed May 21, 2015, at https://www.realclearmarkets.com/ docs/2014/05/San\%20Francisco\%20Real\%20Estate\%20 Outlook_05062014.pdf.

Wikipedia, 2017, List of earthquakes in California, accessed December 5, 2017, at https://en.wikipedia.org/ wiki/List_of_earthquakes_in_California. 




\title{
Chapter L
}

\section{Not Safe Enough-A Survey of Public Preferences for the Seismic Performance of New Buildings in California and the New Madrid Seismic Zone}

\author{
By Keith A. Porter ${ }^{1}$
}

\section{Abstract}

Earlier disaster planning scenarios developed by the U.S. Geological Survey (USGS), especially the ShakeOut earthquake scenario, suggest the public is unaware of the lifesafety performance objective in U.S. seismic-design standards and may want better building performance. As part of the USGS HayWired earthquake scenario, I (through the University of Colorado Boulder) undertook an effort to explore this hypothesis by performing a public survey in California and near the New Madrid Seismic Zone in the Central United States. The HayWired scenario examines a hypothetical earthquake with a moment magnitude $\left(M_{\mathrm{w}}\right)$ of 7.0 occurring on April 18, 2018, at 4:18 p.m. on the Hayward Fault in the east bay part of the San Francisco Bay area. The survey was designed to determine (1) whether the public understands the current life-safety objective of the building code's seismic-design requirements, (2) what the public prefers in terms of the performance of the building stock in a large earthquake, (3) whether the public would be willing to pay the costs for stronger buildings, and (4) how important the public finds the issue of the seismic performance of buildings. The survey found that, without major regional differences, respondents:

1. Are largely unaware of the life-safety seismic performance objective of American Society of Civil Engineers ASCE/SEI 7 and the International Building Code;

2. Are more interested in controlling total number of deaths and injuries in a large earthquake than in controlling per-building collapse probability;

3. Are also interested in more than the total number of casualties, specifically that buildings should remain functional or habitable after a large earthquake (the "Big One" in the language of the survey), and prefer better performance than the code is intended to deliver for new buildings;
4. Expect better seismic performance than ASCE/SEI 7 intends to provide;

5. By a large majority, are willing to pay for greater seismic safety, with the modal response (the most common response) being $\$ 3.00$ per square foot additional construction cost to achieve such a higher level of performance;

6. Believe the degree of seismic performance of buildings is important or very importantthe response of approximately 80 percent of respondents - even in the Central United States where earthquakes happen much less frequently than in California; and

7. Tend to be somewhat more commonly of European descent, wealthier, and more educated than the general public, but regression analyses found no strong trends in either region relating education to acceptable cost for better performance or relating household income to acceptable cost for better performance;

Key implications of the survey indicate that:

1. There is a potential need for writers of seismicdesign criteria in ASCE/SEI 7 to revisit the seismicperformance objectives for new buildings, considering the public's apparent preferences for better performance;

2. There is a need for better communication with the public about the building code's performance objectives for new buildings;

3. Practical options for stronger buildings are needed that an elected official can select in case they, like respondents here, want more from new buildings than the life-safety performance objective delivers; 
4. More narrowly, the study has some implications for the HayWired scenario. First, the HayWired study of the potential outcomes of designing stronger buildings addresses a real, measured public preference among Californians;

5. Elected officials in the San Francisco Bay area might be interested in hearing about public preferences for the seismic performance of new buildings; and

6. Those same elected officials might be interested in hearing about the costs and benefits of higher design requirements, in light of this study and the damage estimated by the HayWired scenario in general.

\section{Introduction}

This work deals with public preferences for the seismic performance of new buildings. Before addressing what the public might want, I first briefly discuss what the building code presently provides. ASCE/SEI 7-10 (American Society of Civil Engineers, 2010) recommends minimum design loads for buildings and other structures, including seismicdesign requirements. The 2012 International Building Code (IBC; International Code Council, 2012) adopts ASCE/SEI $7-10$ by reference, and the majority of communities adopt the IBC, sometimes with minor modifications. Thus, ASCE/ SEI 7 tends to control how buildings perform in earthquakes. Oversimplifying somewhat, ASCE/SEI 7 helps to ensure new buildings are designed so less than 1 percent will collapse in earthquakes during the first 50 years of their existence, called their design life. As discussed in Porter (2016), studies by the Federal Emergency Management Agency (FEMA) and National Institute of Standards (NIST) imply that "fewer than 1 percent" means, on an expected-value basis, about 0.6 percent of buildings will collapse during their design life. ASCE/SEI 7 provides various other requirements to control repair costs, but essentially the 0.6 -percent goal ensures a reasonable degree of life safety and is commonly referred to as the building code life-safety performance objective.

In Porter (Societal Consequences, this volume), I showed that the current building code's life-safety seismic performance objective has a serious unintended consequence - that a magnitude 7.0 earthquake on the Hayward Fault with an Oakland epicenter can impair hundreds of thousands of buildings, potentially displacing a million people or more. This earthquake is the mainshock of the U.S. Geological Survey's (USGS) HayWired scenario, which examines a hypothetical earthquake with a moment magnitude (Mw ) of 7.0 occurring on April 18, 2018, at 4:18 p.m. on the Hayward Fault in the east bay part of the San Francisco Bay area.

In the opinion of a USGS scientist who deals regularly with local governments, and based largely on her experience during the development of the ShakeOut earthquake scenario (Jones and others, 2008), city councils and mayors "absolutely do not know" how a code-compliant building stock designed to meet the life-safety objective will perform in a large earthquake, and are unsatisfied when they do learn of it (Lucile Jones, USGS, oral commun., November 19, 2013). The seismic-design requirements adopted by the building code are written with little input from the public.

The 1927 Uniform Building Code (International Conference of Building Officials, 1927) provided the earliest seismic-design provisions in a model building code and was based on the experience and judgment of 60 building officials. In the subsequent 90 years, professional engineers and structural engineers (for the most part) have driven the development of seismic-design provisions. Developers of load- and resistance-factor design once called for a professionwide debate among structural engineers on the proper seismic reliability of new buildings (Ellingwood and others, 1980), but there is no record that such a debate ever took place, let alone a discussion with the public.

Of course, state legislatures and city councils adopt or adapt model buildings codes such as the IBC on behalf of their community. By adopting these codes, there is a measure of consent by community officials. Suppose State and local officials' ignorance of the life-safety objective only points to a failure to communicate on the part of engineers, code officials, or other building professionals. Better communication could conceivably address that problem. Imagine then an effort by structural engineers and others to explain what the building code does and does not provide. If such an effort were undertaken, then when a city or State adopts a model building code, one could say that well-informed city and State governments that adopt the IBC would be giving informed consent on behalf of the public to the risk imposed by the code?

Davis (1991), a philosopher of engineering ethics, argues that if one cannot practically formulate and choose an alternative to a risk, one cannot give informed consent. Whether or not policymakers understand the code's life-safety objectives, most cities and many States lack the resources to formulate an alternative to a model code and, therefore, cannot give informed consent. Those cities and States that cannot formulate and choose an alternative - the elected leaders and their constituents - represent "the public" in the sense meant by the American Society of Civil Engineers' (2006) Canon 1 of its Code of Ethics, which holds that "Engineers shall hold paramount the safety, health and welfare of the public ..." Being a member of the public in that sense has consequencesDavis (2015) has recently shown that the American Society of Civil Engineers' Code of Ethics implicitly requires engineers to consult the public's preferences when writing building standards for earthquakes. He excludes from "the public" the people who write the building code, such as engineers, building officials, and people who work in the building trades. In this work, I detail what may be the first effort to elicit the public's preferences for the seismic performance of new buildings through a large, rigorous population survey. I conducted the survey (through the University of Colorado Boulder) as part of the HayWired scenario. See Davis and Porter (2016) for 
a summary of the survey, along with a discussion of who comprises the public in the present context and the ethics of consulting the public when establishing performance objectives for model building codes.

\section{Objectives}

This report addresses the question, what does the public expect and prefer from new code-compliant buildings in a big earthquake? Would the public be willing to pay to achieve their desired performance objective? It addresses these questions through population surveys in two high-hazard earthquakeprone regions. "High hazard" here means at least seismic-design category D as defined by ASCE/SEI 7-10 (American Society of Civil Engineers, 2010; fig. 1). The study employs a randomsample survey of adults 18 years or older living in two highseismic-hazard geographic regions.

There are many ways to perform a survey; this study uses a web-based survey for efficiency. Web-based surveys have advantages and pitfalls, as discussed by Dillman and others (1998). Potential pitfalls include coverage error (the chance that some groups have no chance of selection), sampling error (differences between responses of a sample and those of the entire population), measurement error (resulting from poorly worded questions), and nonresponse error (the difference between responses received and ones that would have been received from people who declined to respond). Dillman and others (1998) offer a number of recommendations to overcome these pitfalls, as discussed later.

The survey covers two geographic areas to probe for regional differences in public preferences. Those regional differences might reflect different degrees of recent experience with earthquakes, different wealth, or other regional issues.

The two selected geographic regions for the web-based survey discussed in this report are California, virtually all of which is in seismic-design category D or above, and a part of the New Madrid Seismic Zone in the Central United States. In particular, respondents to represent people in the New Madrid Seismic Zone were recruited from residents of the St. Louis, Missouri, and Memphis, Tennessee, metropolitan statistical areas (MSAs), both of which qualify as high-seismic-hazard areas as defined here.

An earlier preliminary survey of 66 Californians suggested the public was largely unaware of the building

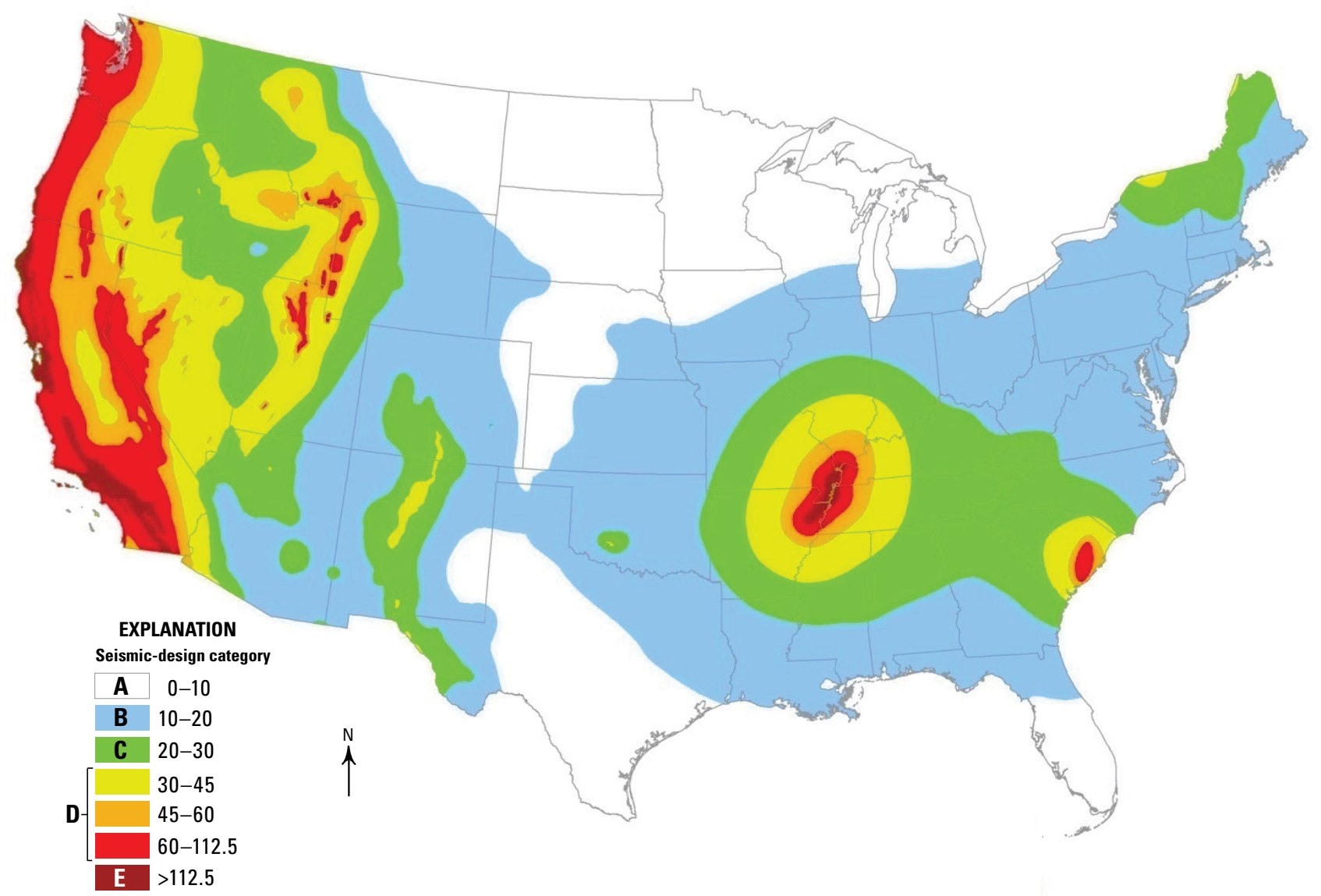

Figure 1. Map of the contiguous United States showing risk-adjusted maximum considered earthquake $\left(\mathrm{MCE}_{\mathrm{R}}\right)$ motion 1-second spectral response acceleration parameter $\left(\mathrm{S}_{\mathrm{M} 1}\right)$ in percent of acceleration due to gravity $(g)$ for seismic-design categories (SDC) A-E. Note that most of California and the New Madrid Seismic Zone in the Central United States-the areas examined in the web-based survey discussed in this report—are in seismic-design category D. (Map from Building Seismic Safety Council, 2009.) 
code's seismic performance objectives for new, codecompliant buildings; the public generally wanted more than life-safety performance from ordinary buildings, and that they would be willing to pay $\$ 3.00$ to $\$ 10.00$ per square foot more for a code-compliant building stock, in which the population could shelter in place after a large earthquake. The preliminary survey constituted a so-called convenience sample because the respondents could be conveniently accessed rather than because they represented a random sample. The preliminary survey also tested the survey instrument; meaning that I personally administered the survey several times and respondents were encouraged to ask questions. None of the questions they asked suggested the survey was unclear. Furthermore, Dr. Liesel Ritchie, a sociologist with expertise in surveys, reviewed the questions and expressed the opinion that the language was clear. Data from the preliminary survey are not included here, to ensure the convenience sample is not mixed with the random sample. See Porter and Davis (2015) for details of the preliminary survey.

At least one other survey has attempted to ascertain the public's confidence in the safety of existing buildings (International Association of Plumbing and Mechanical Officials and others, 2012). Those authors found, "The majority of Americans understands that building codes exist to keep us safe. However, beyond that basic fact their knowledge and appreciation of building codes appears weak. ... Americans are generally confident that the structures where they live and work have adequate safeguards given the types of natural hazards in their areas." The Urban Institute's (1991) study of the public's willingness to pay for life safety informed later decisions about acceptable cost to avoid statistical injuries and fatalities, such as can be found in Federal Highway Administration (1994). The present report may represent the first population survey to elicit the public's understanding of how the code measures seismic performance, its quantitative objective (that is, numerically, how safe are new buildings), the public's preferences for seismic performance, and its willingness to pay for performance in excess of current code requirements. This study is intended primarily to address willingness to pay for seismic safety of new buildings, a new risk context domain to which one can compare findings in other domains. The survey can also be compared with other methods to assess willingness to pay.

Because a public university, the University of Colorado Boulder, performed the survey it satisfies regulations designed to implement ethical principles and preserve the public trust. The 1966 U.S. Public Health Service (PHS) policy, "Clinical research and investigation involving human beings," requires an institution review board (IRB) to independently review research (Office of the Surgeon General, 1966). The 1974 PHS policy 45 CFR 46 specifies requirements for institutional assurances, IRB review, informed consent and ethical conduct. In 1991, 17 Federal agencies issued uniform regulations under the title "Common Rule." The survey discussed here was approved by the University of Colorado's IRB in light of these requirements.

\section{Survey Approach}

The survey was administered using an online survey company, SurveyMonkey.com, because of the ease, speed, and low cost of web surveys compared with alternatives such as randomdigit dialing. The survey aimed to elicit at least 400 responses from adults 18 years and older throughout the State of California and 400 adults in the Memphis and St. Louis MSAs. As shown later, it had 413 individual responses in California and 401 individual responses in Memphis and St Louis. All mentions of those two cities refer to the MSA, rather than the incorporated city. Because building professions have a significant role in establishing seismicdesign requirements, they do not qualify as "the public" in the present context, and so are excluded for the survey. The excluded professions include construction, structural design, architecture, building trades, building officials, and building inspectors.

The sample size of 400 was chosen for each region because, for a population in excess of 10,000,000 people, a sample size of 400 provides a \pm 5 -percent margin of error with 95 -percent confidence. That is, responses to survey questions in each region are expected to be within 5 percent of what the population as a whole would say, with 95-percent confidence. Considering both regions together, the margin is approximately \pm 3.4 percent. (The accuracy of the estimates depends on how representative the sample is of the population; this question is addressed later.)

The large sample size helps to overcome the potential for coverage error. As shown later, responses were received from all major demographic groups (considering gender, income, education, age, race, and ethnicity). Sampling error is inevitable when one cannot survey the entire population, but the large sample size limits the potential error. Measurement error was minimized through the preliminary survey, as previously discussed. Nonresponse error was addressed by keeping the survey brief. As will be shown later, the high response rate limits nonresponse error.

The survey was administered by a survey company according to a human-subjects research protocol approved by the University of Colorado Boulder's IRB on July 2, 2015. Survey responses were collected in July 2015.

The survey asked the following general questions:

1. Do any of the following apply to you? (Asking if respondent belongs to any of the excluded building professions that have a relation to existing building codes)

2. Respondent's role or relation to building codes? (If disqualified from further answering the survey by answering yes to question 1)

3. Performance objectives that most new buildings are intended to meet in a large earthquake?

4. What should the building code provide?

5. Preferred measure of seismic performance?

6. Acceptable cost to increase seismic performance?

7. How important are the issues raised by the survey? 
8. Age?

9. Gender?

10. Race or ethnicity?

11. Education?

12. Household income?

Individual survey responses were aggregated in the form of pie diagrams. Respondents took on average 6 minutes to complete the survey.

\section{Respondent Population and Sampling Procedure}

The survey aimed to sample at least 400 adults in California and 400 adults in the combination of the Memphis and St. Louis metropolitan statistical areas, excluding adults involved in a buildings profession. SurveyMonkey.com offers this explanation of its sampling procedure:

We take great care to ensure that we have a diverse group of members who are interested in sharing their opinions with you.

When a panelist joins our community of respondents and becomes a SurveyMonkey Contribute member, they fill out a profile. This profile contains demographic questions (gender, age, region, etc.) as well as some other targeting characteristics you might care about (cell phone usage, job type, and more).

\section{Incentive Structure}

Each time a SurveyMonkey Contribute member completes an eligible survey, SurveyMonkey makes a contribution to a charity of the member's choice, and the member can choose to enter a sweepstakes.

\section{Recruitment}

We recruit Contribute members from a diverse population of $45+$ million people who take SurveyMonkey surveys every month. For example, after completing a survey, respondents are redirected to a page that may feature an advertisement for SurveyMonkey Contribute.

SurveyMonkey Contribute panelists come from the United States, the United Kingdom, and Australia. You choose the country you'd like your respondents to come from. If you need respondents from other countries, please contact us.

Although we recruit panelists ages 13 and up, we have the ability to target respondents by age and can target 18 and older.

\section{Sampling Procedure}

We email invitations to respondents who match your targeting criteria. Our system selects a random group from the SurveyMonkey Contribute member base who match the demographic targeting criteria you requested.

We use a standard template email notification to notify respondents that they have a new survey to take. It's not possible to customize the invitation email sent by SurveyMonkey Contribute.

\section{Targeting Criteria}

We target members based on the information they provide to us in their profile.

The more variables or criteria you target, the more it constricts the population we can use to build your sample. A more constricted sample may slow down the pace at which your survey can complete — or even make it impossible for us to run your survey at all.

\section{Balancing}

If you send your survey to a general audience, your results are generally representative of the population you're surveying. We automatically balance results according to census data for age and gender, whereas location tends to balance out naturally. Balancing precision and granularity improves as the number of responses increases.

When you choose specific targeting criteria, your results are no longer representative of the general population because you're purposefully focusing on a particular subset of the population.

(SurveyMonkey, 2015)

\section{Survey Questions and Responses}

The survey asked 12 questions to determine the public's preferences for the seismic performance of new buildings. The initial survey question asks whether the respondent is employed in the building industry. Employment in that industry disqualifies the respondent from answering further questions. Incomplete responses are all the people who were invited to take the survey but who declined to begin it $(\mathrm{N}$. Teckman, written commun., July 14, 2015).

\section{Response Rate}

The survey was sent to a total of 1,506 potential participants. The response rate was quite high- 60 percent of those eligible in California and 56 percent of those eligible in St. Louis and 
Memphis. Here, response rate refers to the ratio of "completed" to the sum of "completed" and "incomplete" responses for example, $413 /(413+278)=60$ percent. The pie diagrams in figure 2 show the number of people disqualified, number of completed responses, and number of incomplete responses to the following question:

1. Do any of the following apply to you? (Check all that apply.)

- Employed in the construction industry?

- Employed in the structural design industry?

- Employed in the architecture industry?

- Employed in the building-trades industry?

- Employed as a building official or building inspector?

- None of these apply?

\section{Role or Relation to Building Codes}

Figure 3 shows the number and percentage of responses from people disqualified to the following question:

2. What is your role or relation to building codes?

Please mark all your roles that apply?

- Local elected official?

- Local government staff who advise local officials on building codes?

- Building owner?

- Building tenant (renter)?

- Other (please specify)?

(Detailed information about respondent demographics is discussed below in Respondent Demographics.)

Figure 4 shows the relation of respondents to building codes. (Responses to this and all subsequent questions reflect only completed responses, for example, from respondents who were qualified for and completed the survey.)

\section{Current and Preferred Code Objectives}

Figure 5 shows the percentage of responses to the following question:

3. Although local codes vary, which of these performance objectives do you think most new buildings are intended to meet in a large earthquake? That is, what do you think the current code actually says, not what should it say. Please mark only one answer.

- New buildings will generally be functional after an earthquake, and will require minimal repairs.
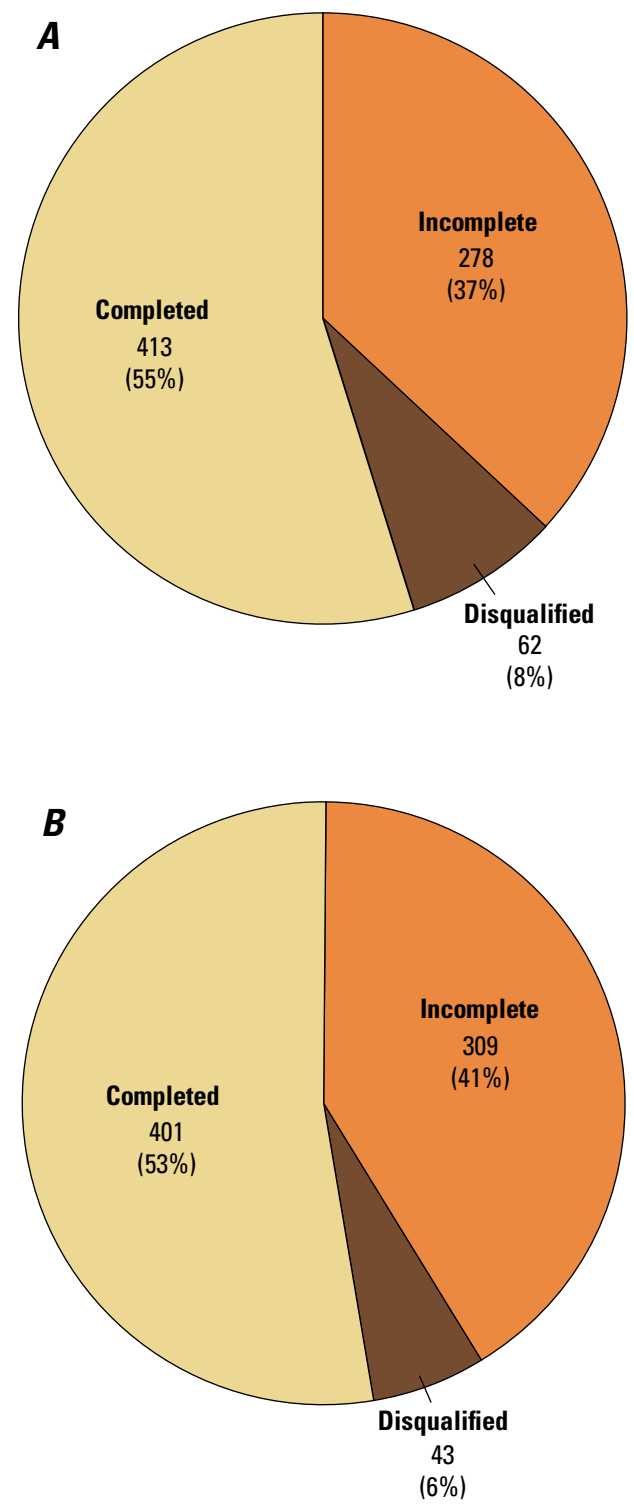

Figure 2. Pie diagrams for survey of the public's preferences for the seismic performance of new buildings showing response rate in $(A)$ California and $(B)$ in the St. Louis, Missouri, and Memphis, Tennessee, metropolitan statistical areas. Completed, those completing the survey; Incomplete, those who were invited to take the survey but who declined to begin it; disqualified, those disqualified from the survey. Number and percentage (\%) of respondents are shown.

- New buildings will generally be occupiable after an earthquake. Although they might require some repairs to be fully functional, the occupants will be able to remain in the building during the repairs.

- New buildings are safe enough that occupants won't be killed, but are not generally intended to be occupiable after the earthquake. That is, a person will be able to exit a building safely, but not necessarily be able to go back in.

- I don't know. 

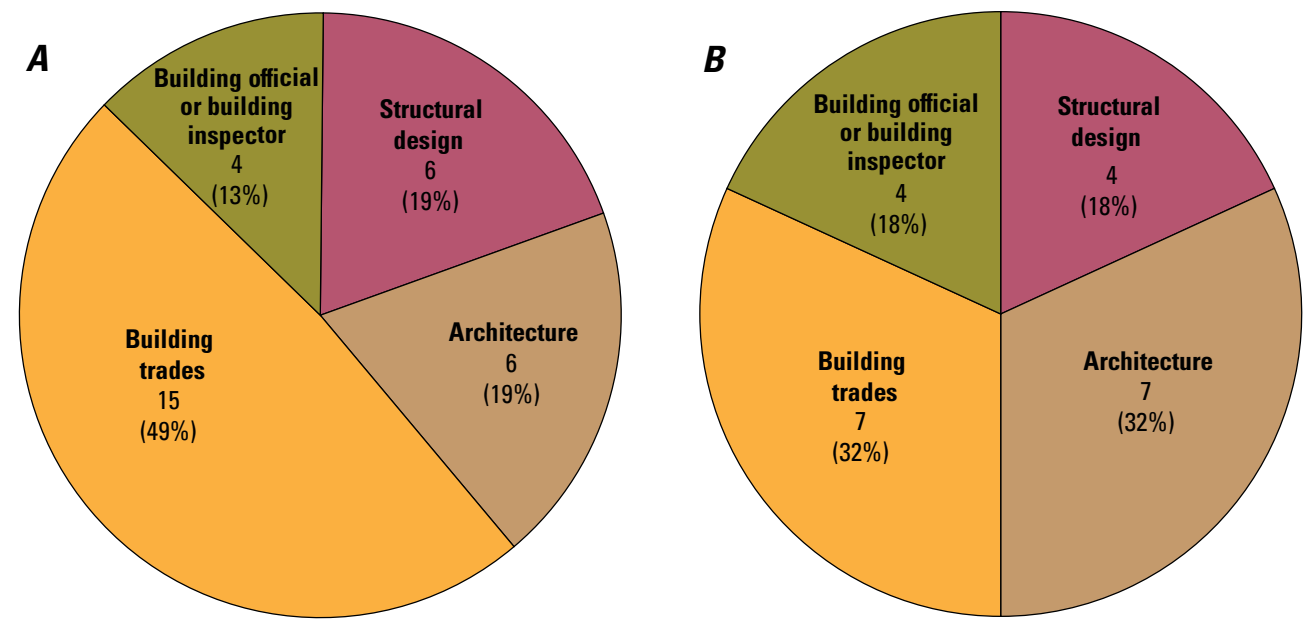

Figure 3. Pie diagrams for survey of the public's preferences for the seismic performance of new buildings showing relation to building codes for people disqualified from participating in the survey in $(A)$ California and $(B)$ in the St. Louis, Missouri, and Memphis, Tennessee, metropolitan statistical areas. Number and percentage (\%) of respondents are shown.
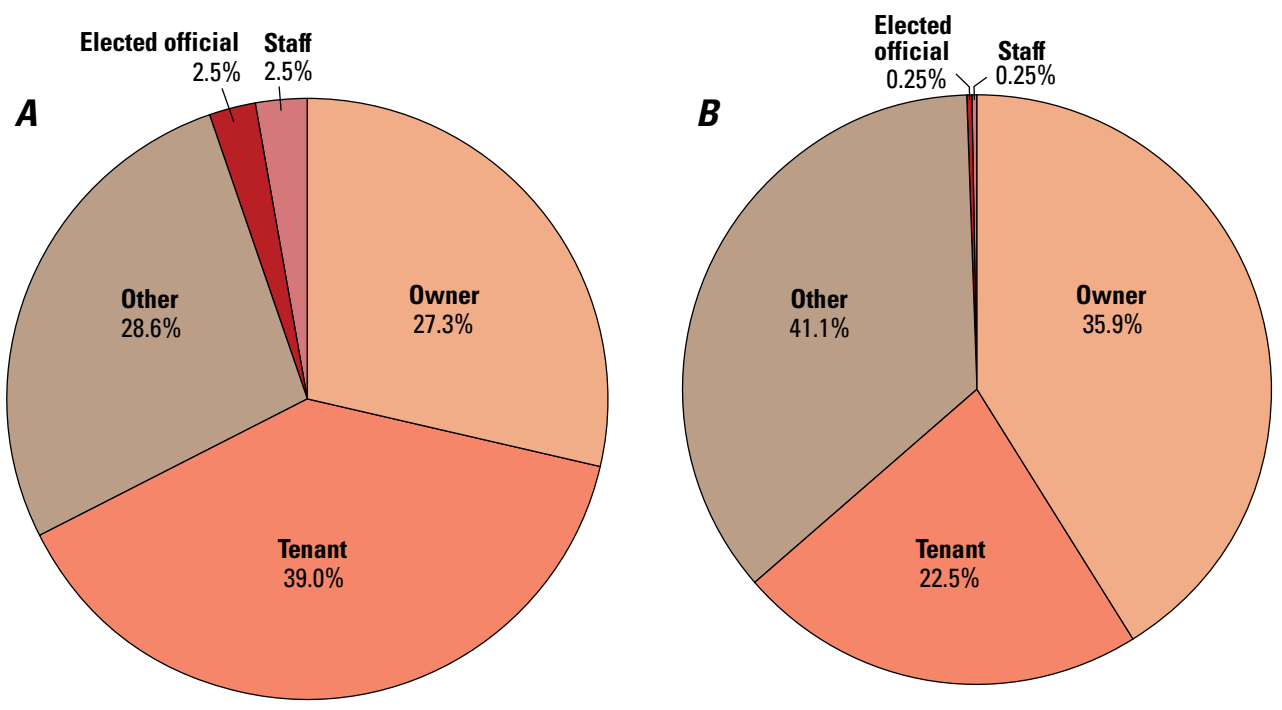

Figure 4. Pie diagrams for survey of the public's preferences for the seismic performance of new buildings showing relation to building codes in $(A)$ California and $(B)$ in the St. Louis, Missouri, and Memphis, Tennessee, metropolitan statistical areas. Percentage (\%) of respondents is shown.
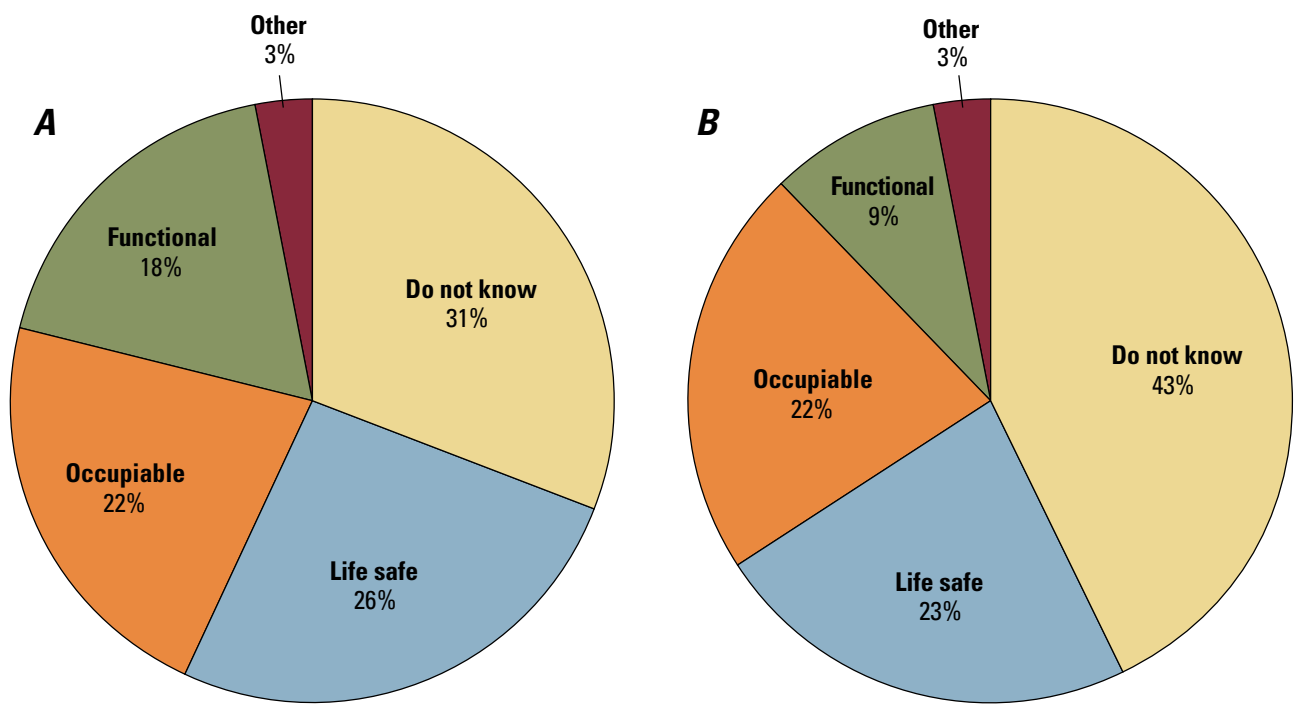

Figure 5. Pie diagrams for survey of the public's preferences for the seismic performance of new buildings showing responses to "Which of these performance objectives do you think most new buildings are intended to meet in a large earthquake?" in $(A)$ California and $(B)$ in the St. Louis, Missouri, and Memphis, Tennessee, metropolitan statistical areas. Percentage (\%) of respondents is shown. 
Figure 6 shows the percentage of responses to the following question:

4. What should the building code provide? That is, if someone builds a new building in your community and it meets buildingcode requirements for seismic safety, which one of these would you most prefer the code to ensure? In some of the responses below I use the term "the Big One," by which I mean an earthquake that might be considered a once-in-a-lifetime event. Please mark only one answer.

- New buildings should generally be functional after the Big One, possibly requiring minimal repairs.

- New buildings should generally be occupiable after the Big One. Although they might require some repairs to be fully functional, the occupants should be able to remain in the building during the repairs.

- New buildings should be safe enough that occupants won't be killed, but need not be occupiable after the Big One.
That is, a person should be able to exit a building safely, but not necessarily be able to go back in.

- I don't know.

\section{Preferred Performance Measure}

Figure 7 shows the percentage of responses to the following question:

5. Which of these building performance measures do you think is of greatest interest to your community? That is, if the building code controlled only one of these measures, which one should it control? Again, "the Big One" here means an earthquake that might be considered a once-in-alifetime event. Please mark only one answer.

- The chance that any given building will collapse in the Big One. ("Per-building collapse probability" in fig. 7.)
Figure 6. Pie diagrams for survey of the public's preferences for the seismic performance of new buildings showing responses to "If someone builds a new building in your community and it meets building-code requirements for seismic safety, which one of these would you most prefer the code to ensure?" for people in $(A)$ California and $(B)$ in the St. Louis, Missouri, and Memphis, Tennessee, metropolitan statistical areas. Percentage (\%) of respondents is shown.

Figure 7. Pie diagrams for survey of the public's preferences for the seismic performance of new buildings showing responses to "Which of these building performance measures do you think is of greatest interest to your community?" in $(A)$ California and $(B)$ in the St. Louis, Missouri, and Memphis, Tennessee, metropolitan statistical areas. Percentage (\%) of respondents is shown.
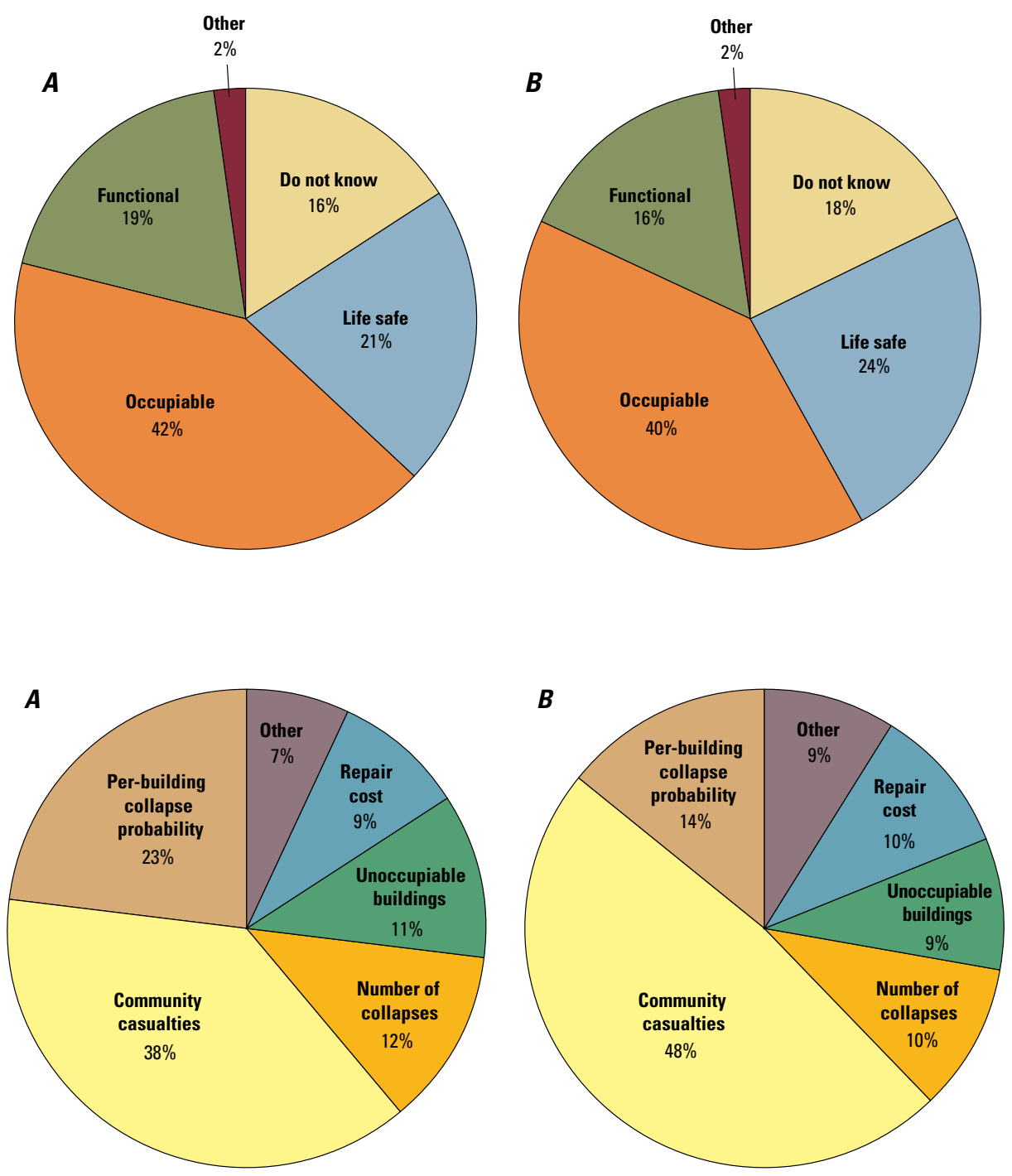
- The total number of people killed or injured by building damage in your community in the Big One. ("Community casualties" in fig. 7.)

- The total number of buildings in your community that might collapse in the Big One. ("Number of collapses" in fig. 7.)

- The number of buildings that would not be occupiable after the Big One. ("Unoccupiable buildings" in fig. 7.)

- The total cost to repair damaged buildings in your community in the Big One.

- Something else or some combination of these (please specify).

Responses to this question beg for some interpretation. The responses suggest respondents are more interested in controlling total number of deaths and injuries in a large earthquake than in controlling per-building collapse probability. Note well that the two measures are not the same. Although building collapse drives deaths and injuries in earthquakes, the per-building probability is blind to the number of simultaneous collapses. A large remote earthquake can subject a small town to very strong motion and produce high collapse probability among that small number of buildings. A large earthquake in a metropolitan area can subject a large number of buildings to the same level of motion and the same collapse probability. ASCE/SEI 7 does not distinguish between the two cases, but the public does.

The public cares very much about the total simultaneous numbers. In one of the most cited studies on public risk perception, Slovic and others (1981) show that the leading factor affecting the public's perception of risk is "associated with lack of control, fatal consequences, high catastrophic potential, reactions of dread, inequitable distribution of risks and benefits (including transfer of risks to future generations), and the belief that the risks are increasing and not easily reducible." They refer to factor 1 as dread risk. This phenomenon partially explains why Americans tolerate more than 32,000 deaths per year as a result of automobile accidents and more than 11,000 annual firearm homicides (both of which cause at most only a few deaths at a time), but found the 2,996 (nearly simultaneous) deaths in the September 11, 2001, attacks on the United States traumatic enough to launch two wars that ultimately cost more than \$1 trillion (Daggett, 2010).

\section{Acceptable Cost for Better Performance}

Figure 8 shows the percentage of responses to the following question:

6. This question is intended to obtain information about the tradeoffs between safer buildings and higher initial construction cost (not retrofit cost). Suppose that in the Big One (a oncein-a-lifetime earthquake), up to 1 out of every 5 buildings in your community would collapse or require major repairs, taking a year or more to repair before they could be reoccupied. Also suppose that you could change the building code so that it would reduce that fraction to 1 in 100 buildings or less, but at the cost of higher initial construction costs. What additional cost do you think building buyers should be willing to pay to achieve that end? Please mark only one answer.

- The current risk is already tolerable. No additional cost seems justified.

- Maybe \$1 per square foot, which would increase the monthly mortgage for the purchase of a new, typical California house from about $\$ 2,000$ per month to about $\$ 2,010$ per month. [In St Louis and Memphis, instead of “...California... \$2,000...\$2,010...." the question says “...St Louis... \$750... \$758....”]

- Maybe \$3 per square foot, which would increase the monthly mortgage for the purchase of a new, typical California house from about $\$ 2,000$ per month to about $\$ 2,030$ per month. [In St Louis and Memphis, instead of “...California... \$2,000...\$2,030...." the question says “...St Louis... \$750... \$770....”]
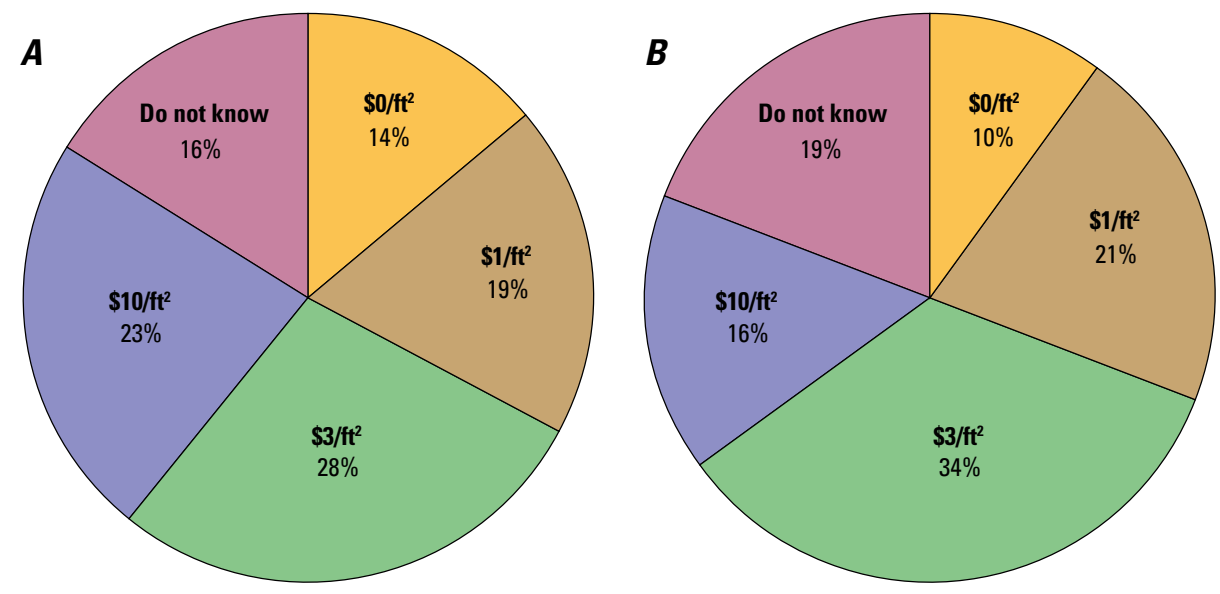

Figure 8. Pie diagrams for survey of the public's preferences for the seismic performance of new buildings showing responses to "What additional cost do you think building buyers should be willing to pay to achieve that end [acceptable tradeoff between safer buildings and higher initial construction cost?]" for people in (A) California and $(B)$ in the St. Louis, Missouri, and Memphis, Tennessee, metropolitan statistical areas. Percentage (\%) of respondents is shown. 
- Maybe \$10 per square foot, which would increase the monthly mortgage for the purchase of a new, typical California house from about $\$ 2,000$ per month to about $\$ 2,100$ per month. [In St Louis and Memphis, instead of “...California... \$2,000...\$2,100...." the question says “...St Louis... \$750... \$824....”]

- I don't know, or you would have to measure the cost some other way (please specify).

\section{How Important are These Issues?}

Figure 9 shows the percentage of responses to the following question:

7. How important are these issues? Please mark only one answer.

- Very important

- Important

- Not very important

- Unimportant

\section{Respondent Demographics}

Figure 10 shows the percentage of responses to the following question:

8. Age?

$\bullet<18$

$\cdot 18-29$

- $30-44$

- $45-59$

- $60+$

Figure 11 shows the percentage of responses to the following question:

9. Gender?

- Female

- Male

Figure 12 shows the percentage of responses to the following question:

10. Which of the following best describes your race or ethnicity? (Check all that apply.)
- White/Caucasian

- African American

- Hispanic

- Asian

- Native American

- Pacific Islander

- Other

Figure 13 shows the percentage of responses to the following question:

11. What is the highest level of education you have received?

- Less than high school

- High school/GED

- Some college

- 2-year college degree

- 4-year college degree

- Masters degree

- Doctoral degree

- Professional degree (JD, MD)

Figure 14 shows the percentage of responses to the following question:

12. How much total combined money did all members of your HOUSEHOLD earn last year?

- $\$ 0$ to $\$ 9,999$

- $\$ 10,000$ to $\$ 24,999$

- $\$ 25,000$ to $\$ 49,999$

- $\$ 50,000$ to $\$ 74,999$

- $\$ 75,000$ to $\$ 99,999$

- $\$ 100,000$ to $\$ 124,999$

- $\$ 125,000$ to $\$ 149,999$

- $\$ 150,000$ to $\$ 174,999$

- $\$ 175,000$ to $\$ 199,999$

- $\$ 200,000$ and up

- Prefer not to answer 

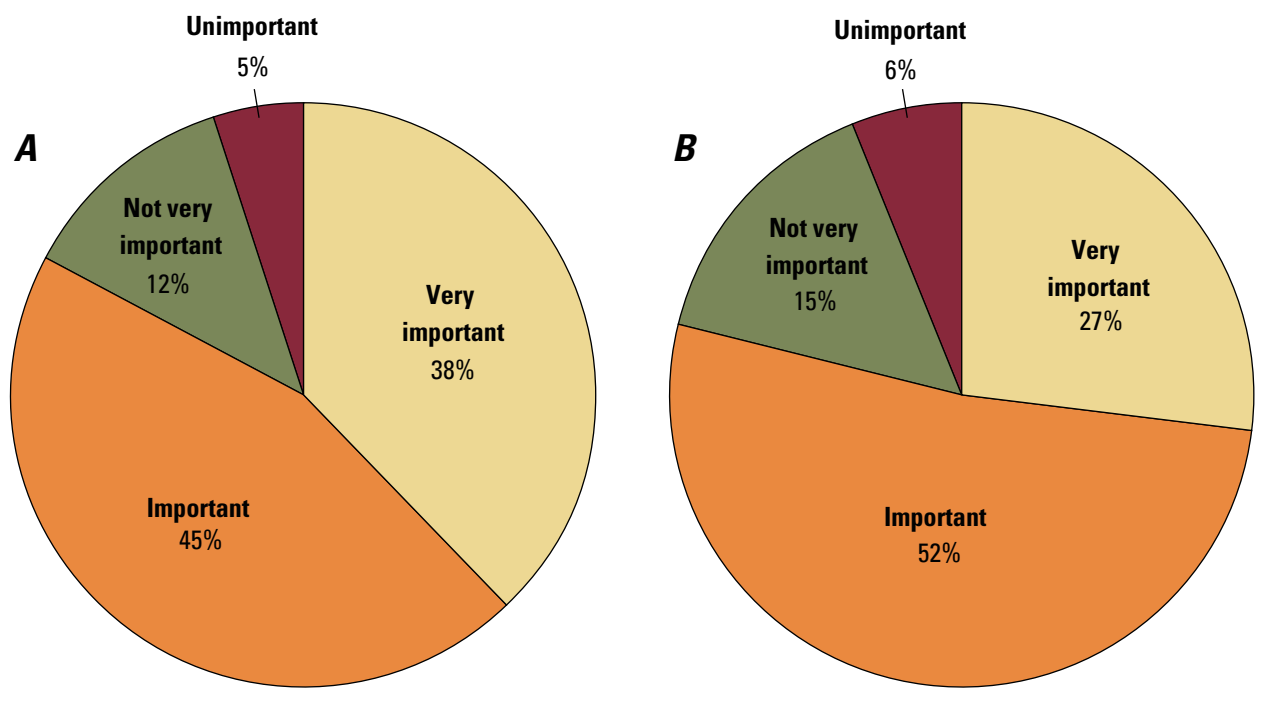

Figure 9. Pie diagrams for survey of the public's preferences for the seismic performance of new buildings showing responses to "How important are these issues?" for people in $(A)$ California and $(B)$ in the St. Louis, Missouri, and Memphis, Tennessee, metropolitan statistical areas. Percentage $(\%)$ of respondents is shown.
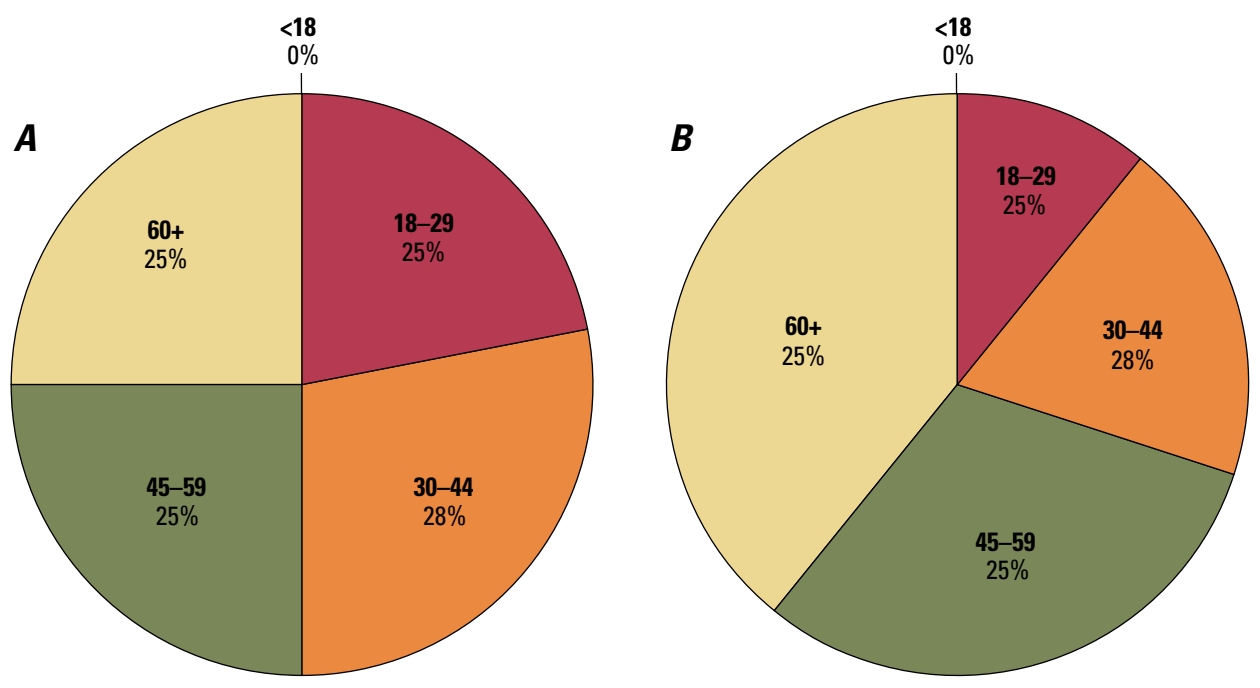

Figure 10. Pie diagrams for survey of the public's preferences for the seismic performance of new buildings showing responses to "[What is your] Age?" for people in $(A)$ California and $(B)$ in the St. Louis, Missouri, and Memphis, Tennessee, metropolitan statistical areas. Percentage (\%) of respondents is shown.
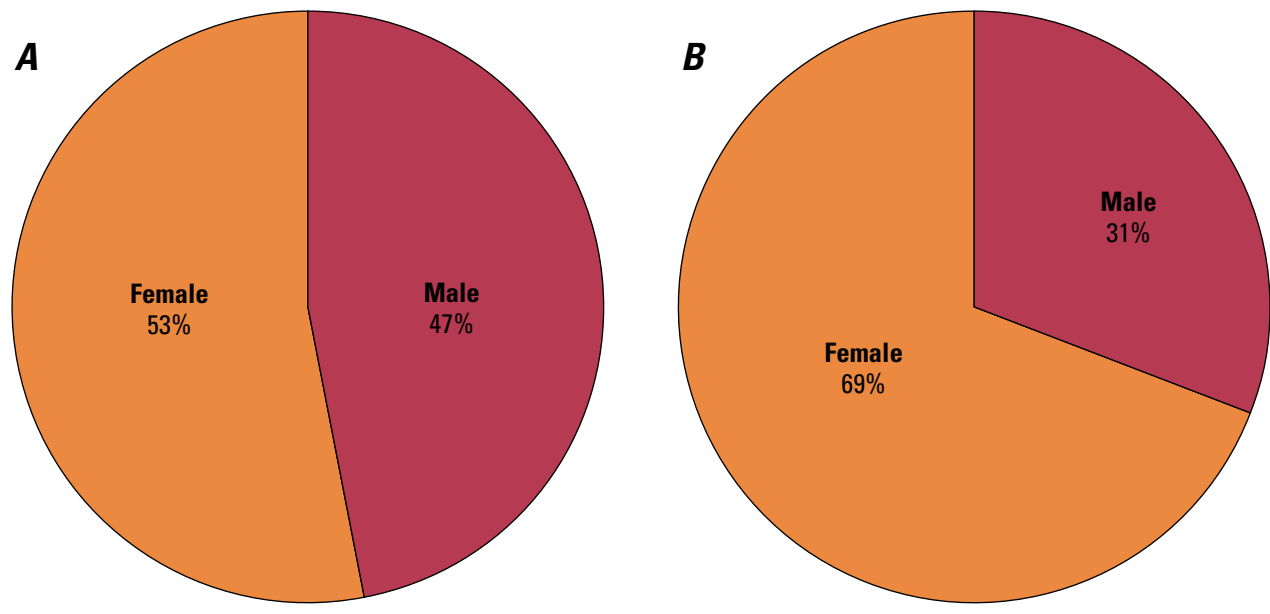

Figure 11. Pie diagrams for survey of the public's preferences for the seismic performance of new buildings showing responses to "[What is your] Gender?" for people in $(A)$ California and $(B)$ in the St. Louis, Missouri, and Memphis, Tennessee, metropolitan statistical areas. Percentage (\%) of respondents is shown. 

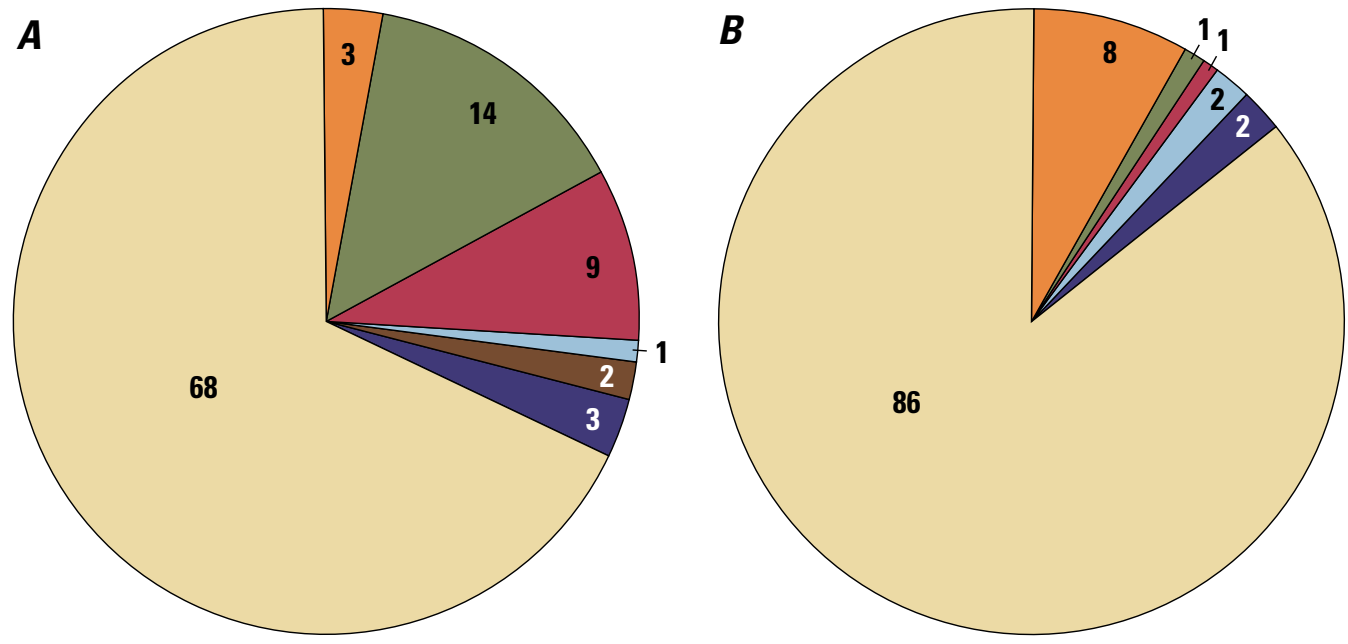

\section{EXPLANATION}

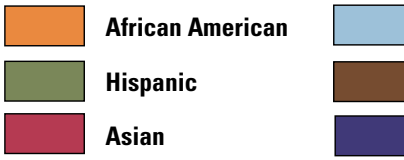

Native American $\square$ Caucasian

Pacific Islander

Other

Figure 12. Pie diagrams for survey of the public's preferences for the seismic performance of new buildings showing responses to "Which of the following best describes your race or ethnicity?" for people in $(A)$ California and $(B)$ in the St. Louis, Missouri, and Memphis, Tennessee, metropolitan statistical areas. Bold numbers show percentage of respondents.
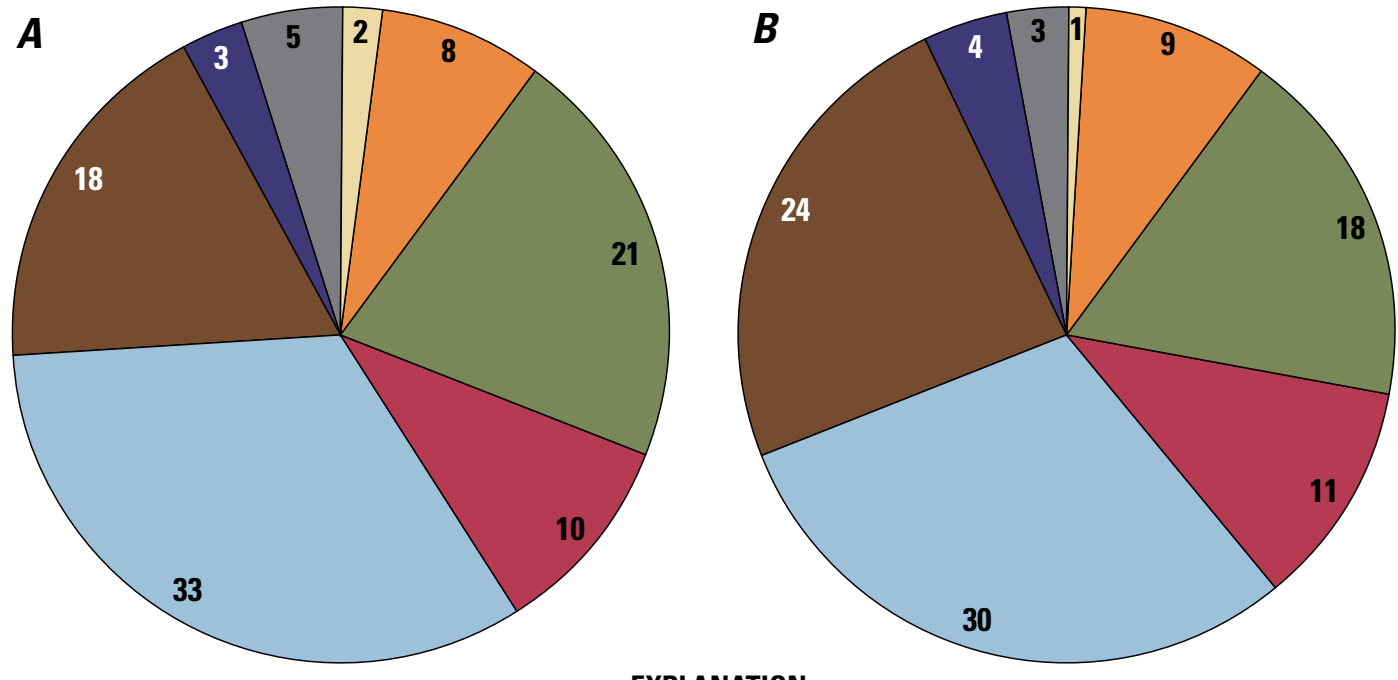

\section{EXPLANATION}

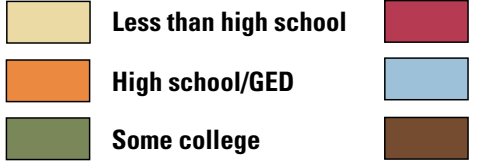

2-year degree

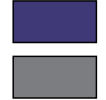

$\mathrm{PhD}$ degree

4-year degree

JD, MD degree

Masters degree

Figure 13. Pie diagrams for survey of the public's preferences for the seismic performance of new buildings showing responses to "What is the highest level of education you have received?" for people in $(A)$ California and $(B)$ in the St. Louis, Missouri, and Memphis, Tennessee, metropolitan statistical areas. Bold numbers show percentage of respondents. HS/GED, high school degree or General Educational Development certificate; JD, doctor of jurisprudence; MD, doctor of medicine. 

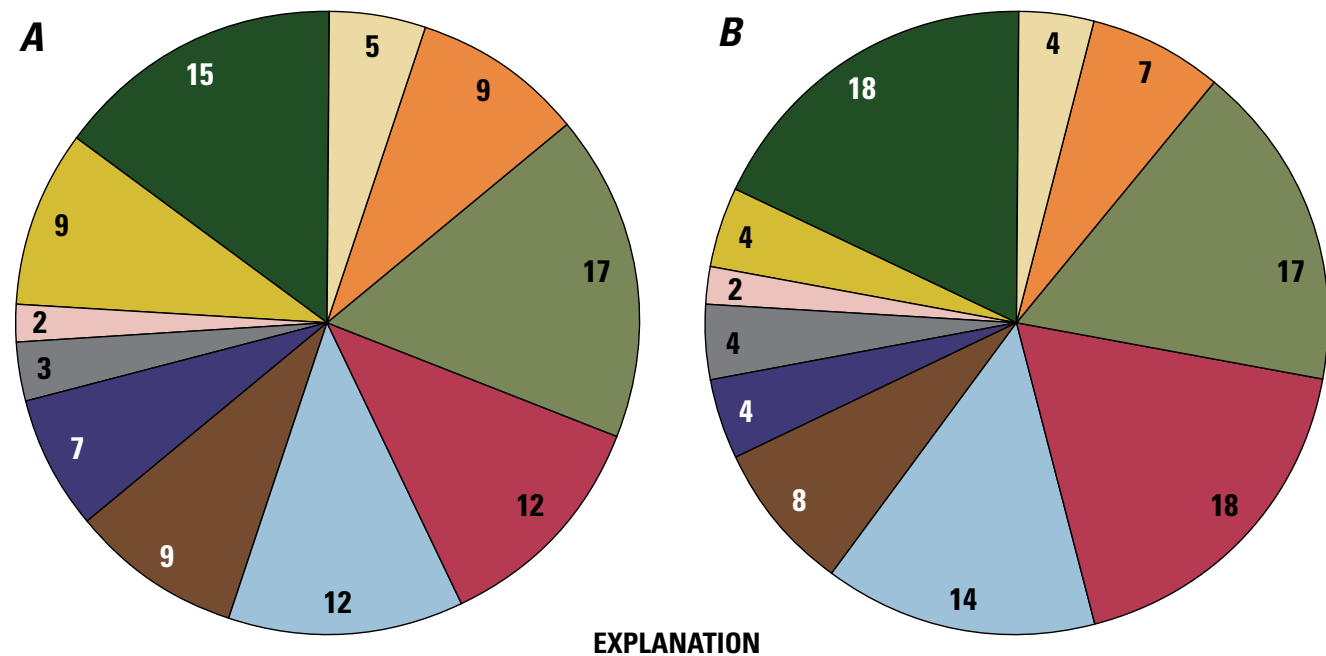

\section{EXPLANATION}
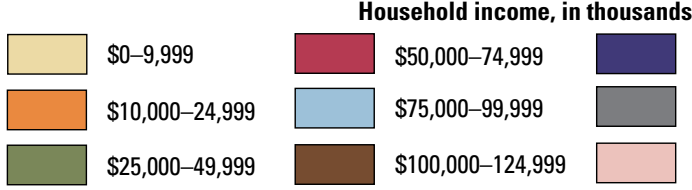

$\$ 125,000-149,999$

$\$ 150,000-174,999$

$\$ 150,000-174,999$

Figure 14. Pie diagrams for survey of the public's preferences for the seismic performance of new buildings showing responses to "How much total combined money did all members of your HOUSEHOLD earn last year?" for people in (A) California and (B) in the St. Louis, Missouri, and Memphis, Tennessee, metropolitan statistical areas. Bold numbers show percentage of respondents.

\section{Are Respondents Representative of the Population?}

This section addresses differences between the demographics of survey respondents and the population of their state or community. If one is to draw any conclusions about what American adults think based on what these respondents said, one must ask how representative respondents are of the larger group. According to SurveyMonkey (2015), respondents "represent a diverse group of people and are reflective of the general population. However, as with most online sampling, respondents have Internet access and voluntarily joined a program to take surveys." Most of the U.S. population regularly uses the internet -87 percent according to the Pew Research Center (2014). However, not all volunteer to take SurveyMonkey surveys. Respondents receive an incentive to take surveys. "Each time a SurveyMonkey Contribute member completes an eligible survey, SurveyMonkey makes a [ $\$ 0.50]$ contribution to a charity of the member's choice, and the member can choose to enter a sweepstakes."

I quantify how representative the survey seems to be. The demographics of the survey do deviate from those of the population as a whole. More women than men responded to the survey in both regions. Responses included 496 women and 317 men, or a 3:2 ratio rather than the approximately $1: 1$ ratio in the general public (fig. 15A). Respondents were also generally wealthier than the population (fig. 15B). California income data are taken from U.S. Census Bureau's (2015) American Community Survey for California households in 2013. Median household income data for Memphis and St. Louis MSAs in 2010 were taken from U.S. Conference of Mayors (2012).

Respondents in both regions report more education than the population as a whole (fig. 16). Educational attainment of Californians is as of 2009 from U.S. Census Bureau (2012). Memphis MSA data are for 2014 from Memphis Chamber of Commerce (2015). Data for St. Louis are for 2012 from University of Missouri St. Louis, Public Policy Research Center (2014).

More respondents are of European (white/Caucasian) descent than the population as a whole (fig. 17). Race and ethnicity data are taken from U.S. Census Bureau (2011).

Survey respondents seem to be more likely to be of European descent than the general population in either region. They are somewhat wealthier and have more education than the general population. These differences may produce a difference between survey participants' responses and those of the general population. The next section tests that hypothesis. 

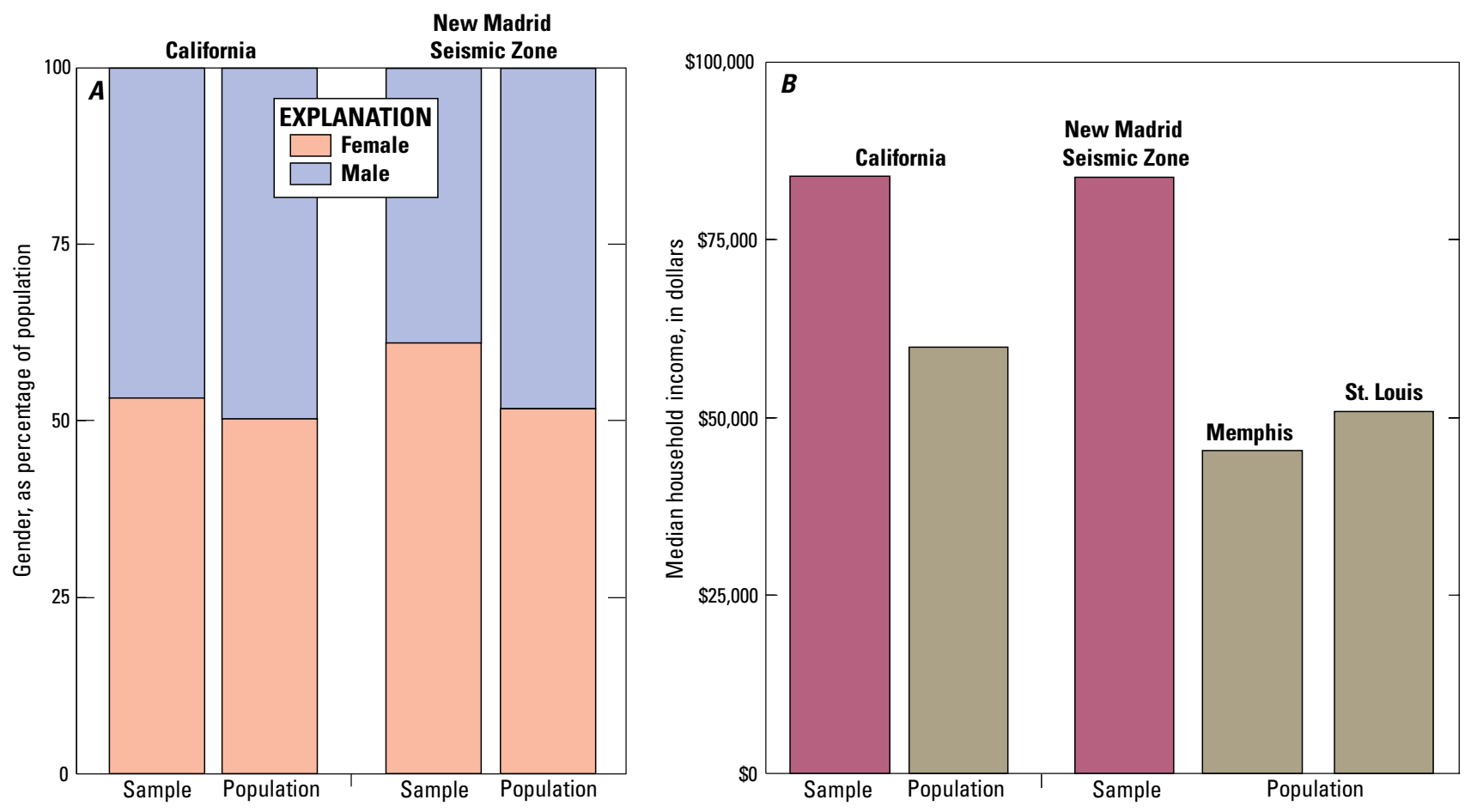

Figure 15. Histograms of respondent $(A)$ gender and $(B)$ median household income for survey of the public's preferences for the seismic performance of new buildings in the California and St. Louis, Missouri, and Memphis, Tennessee, metropolitan statistical areas (MSA).

Figure 16. Histogram of respondent education attainment for survey of the public's preferences for the seismic performance of new buildings in the California and St. Louis, Missouri, and Memphis, Tennessee, metropolitan statistical areas (MSA) as compared to relevant populations 25 years and older. $\%$, percent; HS/GED, high school degree or General Educational Development certificate; BS, bachelor's degree; MS, master's degree; CA, California; NMSZ, New Madrid Seismic Zone; <, less than.

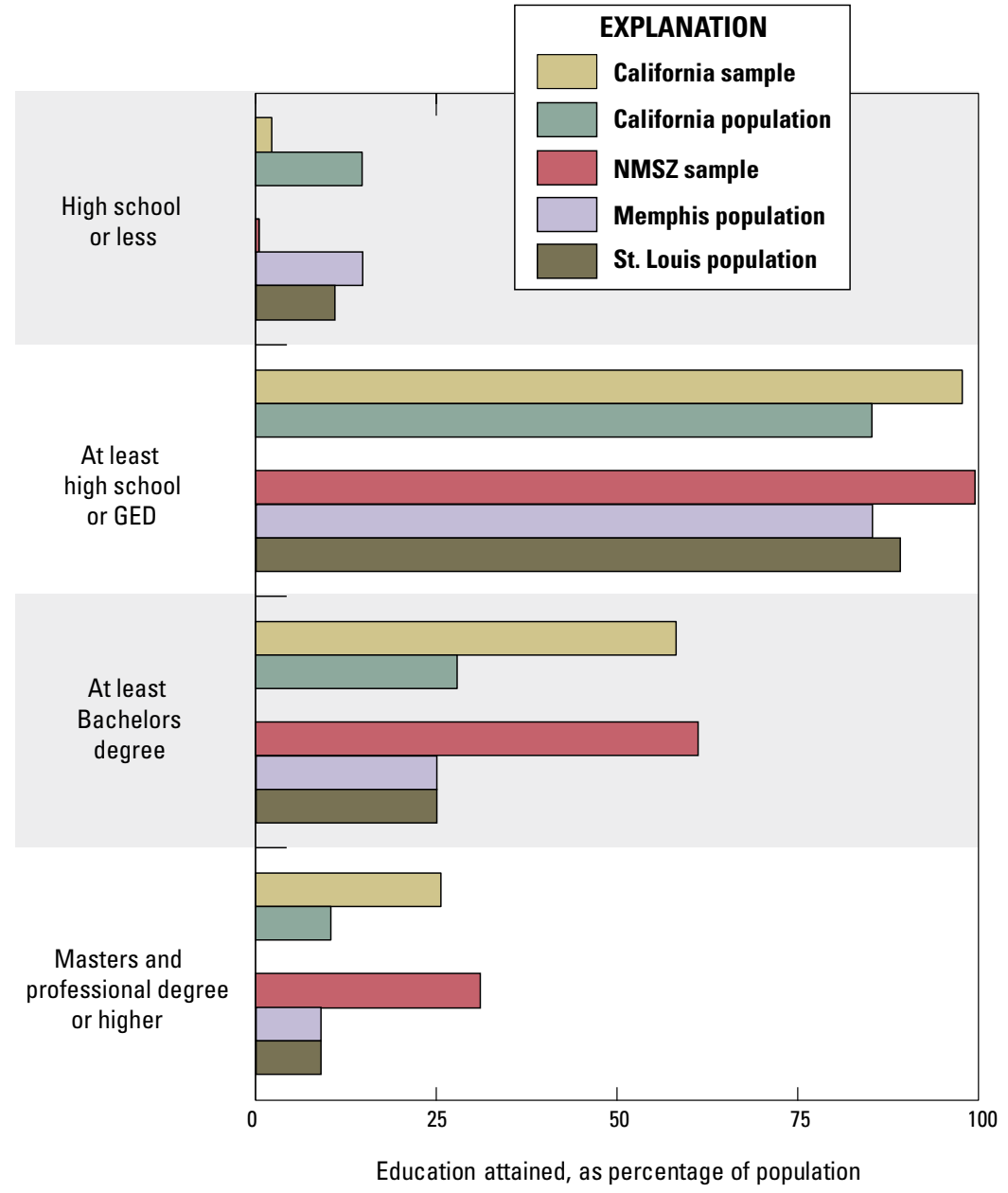

Education attained, as percentage of population 


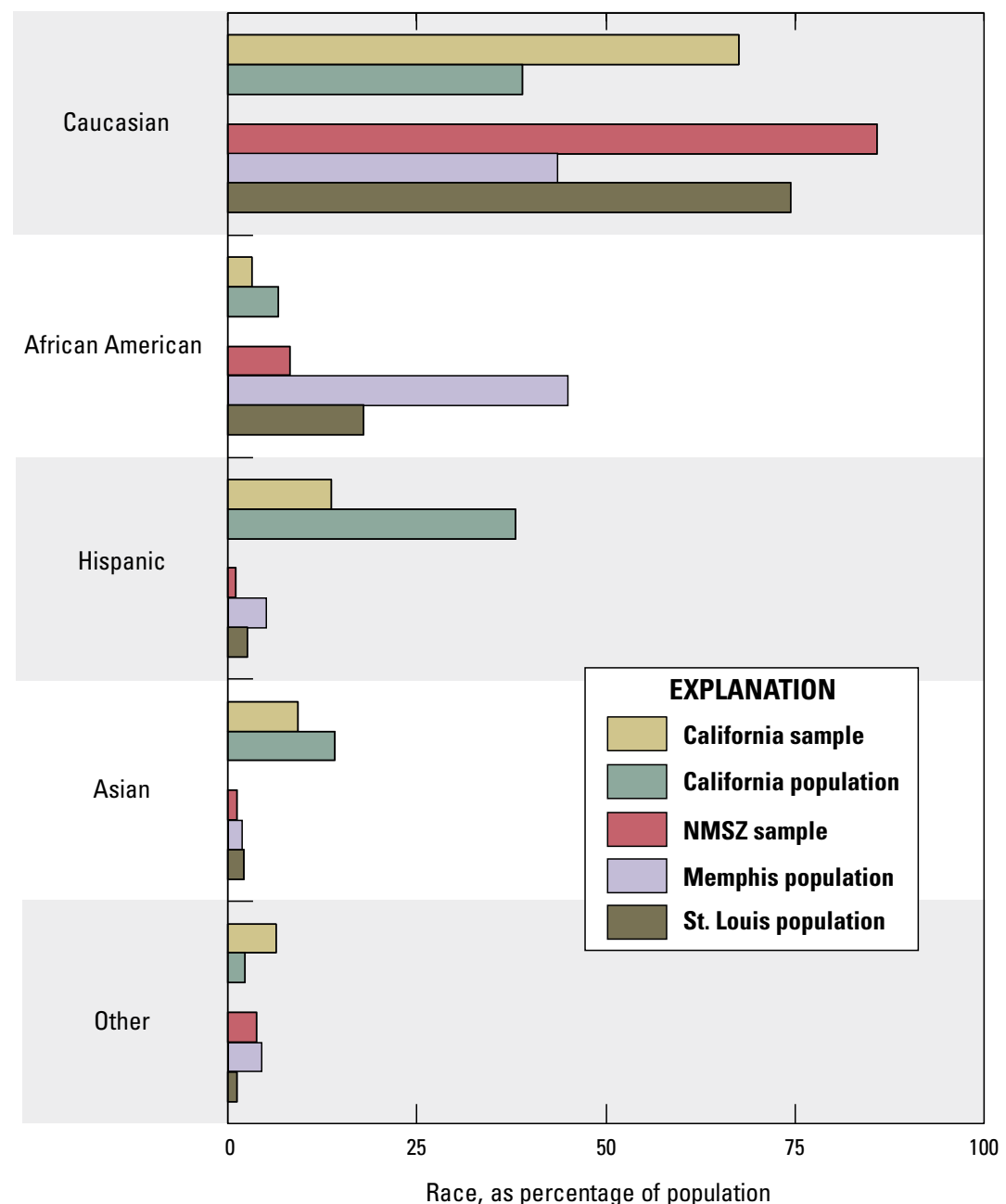

Figure 17. Histogram of respondent race or ethnicity for survey of the public's preferences for the seismic performance of new buildings in the California and St. Louis, Missouri, and Memphis, Tennessee, metropolitan statistical areas (MSA) as compared to relevant populations. \%, percent; NMSZ, New Madrid Seismic Zone.

\section{Are Some Groups Willing to Pay More for Better Seismic Performance?}

This section examines whether some groups are more willing to pay for better seismic performance than others. Better seismic performance is measured here in terms of building impairment. Suppose that people also equate better seismic performance with more life safety. In such a case, one could compare these survey results with expectations from other methods to estimate willingness to pay for safety. There is a rich literature addressing people's willingness to pay for safety; I consider just a few sources and compare what one may predict from them with observations from the present survey.

Needleman (1982) examines several methods to value life safety, including lifetime earning potential (the human capital approach), questionnaires to ascertain people's willingness to pay to reduce their own risk, observed willingness to pay to reduce risk, and observed willingness to take on additional risk for extra pay. He found that the last method produced the most reliable estimates of people's valuation of small changes in their own risk, and the upper bound, the value of avoiding a fatality, is equivalent to 20 times average annual income.
In Porter (2002), I briefly review various methods to estimate willingness to pay for more safety in earthquakes, adding to Needleman's list the application of Stanford-style decision analysis, such as proposed by Howard $(1980,1989)$. In that work I show that, if people behaved as predicted by decision analysis, they should be more willing to pay for life safety in direct proportion to their annual consumption (roughly equivalent to household income), which is consistent with Needleman's finding. I also show that under Howard's decision-analysis framework, older people should be less willing to pay for life safety than younger people, and men should be less willing to pay for life safety than women.

Based on these works, one might suspect that the survey results would exhibit a relation between household income and willingness to pay for better performance or between age and willingness to pay. If either were true, the survey would exhibit a sampling error - a difference between survey responses and the opinions of the broader population. However, a regression analysis of the data from the present survey found no strong trend relating household income and willingness to pay for better building performance. Nor do the survey responses show a relation between education, age, or gender and willingness to pay. 
The coefficient of determination $\left(R^{2}\right)$, between individual respondents' household income and acceptable cost for better performance was 0.010 among 350 Californians who provided both quantities. It was 0.0001 among 303 people from St. Louis and Memphis who provided both quantities. Regression analysis to relate acceptable cost and age in years similarly exhibited low coefficients of determination- 0.001 in St. Louis and Memphis, 0.002 in California. Men and women were approximately equally willing to pay for better seismic performance - in St. Louis and Memphis, women were willing to pay 13 percent more on average than men, but in California, men were willing to pay 6 percent more than women.

One might also suppose that years of secondary and postsecondary education would correlate with acceptable cost for better performance. Among 413 Californians who answered both questions, $R^{2}=0.020$, and among 170 people from St Louis and Memphis who provided both quantities, $R^{2}=0.022$. Nor does one derive higher coefficients of determination from nonlinear regression, fitting polynomials of second, third, or fourth order. (Actually the $R^{2}$ values do rise slightly, but the rise has more to do with overfitting than with more information.)

All these coefficients of determination are too low to reject the null hypothesis at the 5-percent significance level, where the null hypothesis is that the correlation coefficient $(\rho)$ is in fact zero. Put another way, there appears to be no strong relation between education and acceptable cost for better performance, between household income and acceptable cost for better performance, or between respondent age and acceptable cost for better performance.

\section{Conclusions}

As part of the HayWired scenario's study of the unintended consequences of the building code's seismic performance objective, I undertook a public survey in two highly seismically active regions of the United States - one of California adults and another of adults in two metropolitan areas near the New Madrid Seismic Zone in the Central United States, namely the Memphis and St. Louis MSAs. Sample sizes in both regions (413 adults in California and 401 near the New Madrid Seismic Zone) ensure that the results reflect the opinions of the public with \pm 5 -percent margin of error with 95-percent confidence, at least insofar as respondents resemble the public.

The purpose of the survey was to determine whether the public understands the current life-safety objective of the building code's seismic-design requirements; what the public prefers in terms of the performance of the building stock in a large earthquake; whether the public would be willing to pay the cost of stronger buildings; and how important the public finds the issue of the seismic performance of buildings. The survey found that respondents in both regions:

1. Are largely unaware of the life-safety seismic performance objective of ASCE/SEI 7 and the International Building Code;
2. Are more interested in controlling total number of deaths and injuries in a large earthquake than in controlling perbuilding collapse probability;

3. Are also interested in more than the total number of casualties, specifically that buildings should remain functional or habitable after a large earthquake (the "Big One" in the language of the survey), and prefer better performance than the code is intended to deliver for new buildings;

4. Expect better seismic performance than ASCE/SEI 7 intends to provide;

5. By a large majority, are willing to pay for greater seismic safety, with the modal response (the most common response) being $\$ 3$ per square foot additional construction cost to achieve such a higher level of performance;

6. Believe that the degree of seismic performance of buildings is important or very important - the response of approximately 80 percent of respondents, even in the Central United States where earthquakes happen much less frequently than in California;

7. Are more commonly of European descent, wealthier, and more educated than the general public, but regression analyses found no strong trends in either region relating education to acceptable cost for better performance or relating household income to acceptable cost for better performance.

\section{Study Implications}

The survey implies several needs:

1. The Building Seismic Safety Council, which originates many innovations of ASCE/SEI 7, could revisit the performance objectives that underlie the seismic-design criteria of ASCE/SEI 7, considering (among other issues) the public's preferences as elicited here.

2. Structural engineers could communicate better with elected officials who adopt building codes if they want to reduce the public's apparent misunderstanding of the code's performance objectives for new buildings. Engineers might, for example, create brief (1 page or so) documents about the community-level outcomes of the "Big One," written in plain English, and targeted to elected officials, building owners, urban planning organizations, and other stakeholders among the public (as meant here). Such documents could perhaps be included in an appendix to ASCE/SEI 7, or distributed by other means such as by the National Institute of Building Sciences to the United States Conference of Mayors, and the Building Owners and Managers Association International. 
3. Practical options are needed that elected officials can select in case they find the code's outcomes unacceptable. For example, an appendix of ASCE/SEI 7 or of the International Building Code could explain the costs and benefits of higher design requirements and offer optional adoption language to increase required design strength. The optional language might locally modify the code to require all ordinary buildings (called "risk category II" in ASCE/SEI 7-10) to be designed with a seismic importance factor of 1.5 .

More narrowly, the study has some implications for the HayWired scenario. It suggests that:

1. The HayWired scenario study of the potential outcomes of designing stronger buildings (Porter, Societal Consequences, this volume) addresses a real, measured public preference for more resilient buildings among Californians.

2. Elected officials in the San Francisco Bay area might be interested in hearing about public preferences for the seismic performance of new buildings.

3. Those same elected officials might be interested in hearing about the costs and benefits of higher design requirements in light of this study and the damage estimated by HayWired in general.

\section{Limitations and Research Needs}

Respondents spanned the domain of age, gender, race and ethnicity, educational attainment, and income of both regions, so there are no significant unrepresented groups. However, this survey only examined two regions. It may be that people in other high-hazard areas have different preferences. Further regression analysis might detect a trend relating other parameters to preferred performance level or to acceptable cost for better performance. Respondents seemed to understand the questions, especially regarding acceptable cost for better performance, but it may be that they would act differently when actually confronted with a real purchasing decision. The present survey only begins to study the public's preferences for the seismic performance of new, code-compliant buildings. More research might better measure any differences between what the code provides and what the public wants. It may be interesting to survey engineers and others involved in the building trades to explore whether and how their preferences differ from those of the public. It would also be interesting to explore the question of preferred performance measure more deeply, such as degree of preference for each option or alternative ways of dealing with probability.

\section{Acknowledgments}

Survey questions were drafted with the assistance of the National Institute of Building Sciences' Multihazard Mitigation Council Public Expectations Subcommittee-Gary Ehrlich,
Juliette Hayes, Kevin Mickey, Evan Reis, and Phil Schneider. Dr. Liesel Ritchie reviewed survey questions and provided valuable advice about wording, demographic questions, and survey size. Sharyl Rabinovici (private consultant), Phil Schneider (National Institute of Building Sciences), and Anne Wein (USGS) provided peer reviews and valuable constructive criticism. The Association of Bay Area Governments and the Association of Contingency Planners provided opportunities to test and administer the preliminary survey. Anne Wein performed some preliminary surveys at meetings of the Association of Bay Area Governments. The author thanks all these people and organizations.

\section{References Cited}

American Society of Civil Engineers, 2006, Code of ethics: American Society of Civil Engineers web page, accessed January 28, 2015, at http://www.asce.org/code_of_ethics/.

American Society of Civil Engineers, 2010, Minimum design loads for buildings and other structures: Reston, Va., Structural Engineering Institute, ASCE/SEI 7-10, 608 p.

Building Seismic Safety Council [BSSC], preparer, 2009, NEHRP recommended seismic provisions for new buildings and other structures, 2009 ed.: Washington, D.C., Federal Emergency Management Agency publication P-750, 388 p., accessed May 21, 2015, at http://www.fema.gov/medialibrary-data/20130726-1730-25045-1580/femap750.pdf.

Daggett, S., 2010, Costs of Major U.S. Wars: Washington, D.C., Congressional Research Service, 7-5700, RS22926, 5 p., accessed December 29, 2015, at https://www.fas.org/sgp/crs/ natsec/RS22926.pdf.

Davis, M., 1991, Thinking like an engineer-The place of a code of ethics in the practice of a profession: Philosophy and Public Affairs, v. 20, no. 2, p. 150-167.

Davis, M., 2015, What part should the public have in writing engineering standards?, in Security and Disaster Preparedness Symposium - Codes and Governance in the Built Environment: National Institute of Building Sciences Third Annual Conference and Expo, Building Innovation, 2015Creating High-Performing Resilient Communities, January 6-9, 2015, Washington D.C., presentations available at https:// www.nibs.org/store/ViewProduct.aspx?id=4108575.

Davis, M., and Porter K., 2016, The public's role in seismic design provisions: Earthquake Spectra, v. 32, no. 3, p. 1345 1361, https://doi.org/10.1193/081715EQS127M.

Dillman, D.A., Tortora, R.D., and Bowker, D., 1998, Principles for constructing web surveys: American Statistical Association, Proceedings of the Joint Meetings of the American Statistical Association, August 9-13, 1998, Dallas, Texas. 
Ellingwood, B., Galambos, T.V., MacGregor, J.G., and Cornell, C.A., 1980, Development of a probability-based load criterion for American National Standard A58: Washington D.C., National Bureau of Standards, Special Publication 577, $222 \mathrm{p}$.

Federal Highway Administration, 1994, Technical AdvisoryMotor Vehicle Accident Costs: Washington, D.C., U.S. Department of Transportation Technical Advisory \#7570.2, $5 \mathrm{p}$.

Howard, R.A., 1980, On making life and death decisions, in Shwing, R.C., and Albers, W.A., eds., Societal Risk Assessment: New York, Plenum Press, p. 89-106.

Howard, R.A., 1989, Microrisks for medical decision analysis: International Journal of Technology Assessment in Health Care, v. 5, p. 357-370.

International Association of Plumbing and Mechanical Officials, International Code Council, National Association of Mutual Insurance Companies, National Institute of Building Sciences, National Fire Protection Association, and Insurance Institute for Business and Home Safety, 2012, Public Survey on Building Codes and Building Safety: Washington, D.C., National Institute of Building Sciences, $3 \mathrm{p}$.

International Conference of Building Officials, 1927, Uniform Building Code: Whittier, Calif., International Conference of Building Officials, $265 \mathrm{p}$.

International Code Council, 2012, International Building Code 2012: Country Club Hills, Ill., 690 p.

Jones, L.M., Bernknopf, R., Cox, D., Goltz, J., Hudnut, K., Mileti, D., Perry, S., Ponti, D., Porter, K., Reichle, M., Seligson, H., Shoaf, K., Treiman, J., and Wein, A., 2008. The ShakeOut Scenario. U.S. Geological Survey OpenFile Report 2008-1150 and California Geological Survey Preliminary Report 25, http://pubs.usgs.gov/of/2008/1150/.

Memphis Chamber of Commerce, 2015, Detailed demographics: Greater Memphis Chamber of Commerce web page, accessed September 1, 2015, at http://www. memphischamber.com/Articles/DoBusiness/pdfMemphis MSA_Demographics.aspx.

Needleman, L., 1982, Methods of valuing life, in Lind, N.C., ed., Technological Risk: Waterloo, Ontario, University of Waterloo Press, p. 89-99.

Office of the Surgeon General, 1966, Surgeon General's directives on human experimentation-Index clinical research human subjects, investigations involving individuals, rights and welfare of: Office of the Surgeon General, p. 350-355, accessed September 8, 2015, at https://history.nih.gov/research/downloads/ Surgeongeneraldirective1966.pdf.
Pew Research Center, 2014, The web at 25: Pew Research Center web page, accessed August 17, 2015, at http://www. pewinternet.org/2014/02/25/the-web-at-25-in-the-u-s.

Porter, K.A., 2002, Life-safety risk criteria in seismic decisions, in Taylor, C.E., and VanMarcke, E., eds., Acceptable Risk Processes-Lifelines and Natural Hazards: Reston, Va., American Society of Civil Engineers, Technical Council for Lifeline Earthquake Engineering, Monograph 21, accessed September, 27, 2015, at http://spot.colorado. edu/ porterka/Porter-2002-Life-Safety-Risk-Criteria.pdf.

Porter, K., and Davis, M., 2015, Not safe enough—The public's expectations for seismic performance: Journal of the National Institute of Building Sciences, no. 3, p. 22-25.

Slovic, P., Fischhoff, B., and Lichtenstein, S., 1981, Perceived risk-Psychological factors and social implications, in The Assessment and Perception of Risk: London, The Royal Society, p. 17-34

SurveyMonkey, 2015, SurveyMonkey Audience: SurveyMonkey web page, accessed July 14, 2015, at http:// help.surveymonkey.com/articles/en_US/kb/SurveyMonkeyAudience.

University of Missouri St. Louis, Public Policy Research Center, 2014, Metropolitan mirror-Facts and Trends Reflecting the St. Louis Region-Changes in educational attainment for the St. Louis Region, 2009 to 2012: University of Missouri St. Louis, Public Policy Research Center, accessed July 19, 2015, at https://pprc.umsl.edu/ pprc.umsl.edu/data/Metro-PDFS/MM-EdAtt-Nov14.pdf.

Urban Institute, 1991, The costs of highway crashes, final report: Washington, D.C., The Urban Institute, Federal Highway Administration contract DTFH61-85-C-00107, $144 \mathrm{p}$.

U.S. Conference of Mayors, 2012, U.S. metro economies - 2012 employment forecast and the impact of exports: U.S. Conference of Mayors, accessed July 19, 2015, at http://usmayors.org/pressreleases/uploads/2012/ MetroEconomiesReport_011812.pdf.

U.S. Census Bureau, 2011, 2010 Census interactive population search: U.S. Census Bureau web page, accessed July 21, 2015, at http://www.census.gov/2010census/popmap/ ipmtext.php?fl=06.

U.S. Census Bureau, 2012, The 2012 statistical abstractEducation-Educational attainment: U.S. Census Bureau web page, accessed December 29, 2015, at https:// www.census.gov/library/publications/2011/compendia/ statab/131ed/education.html.

U.S. Census Bureau, 2015, State and county quickfacts: U.S. Census Bureau web page, accessed July 17, 2015, at http:// quickfacts.census.gov/qfd/states/06000.html. 




\title{
Chapter M
}

\section{An Earthquake Urban Search and Rescue Model for Earthquake Response and its Application to the HayWired Scenario}

\author{
By Keith A. Porter ${ }^{1}$
}

\section{Abstract}

Few researchers have examined the potential for earthquake-induced building collapses and electrical failures to trap building occupants. The HayWired earthquake scenario examines a hypothetical moment magnitude $\left(M_{\mathrm{w}}\right) 7.0$ earthquake (mainshock) occurring on April 18, 2018, at 4:18 p.m., on the Hayward Fault in the east bay part of the San Francisco Bay area. To estimate demand for urban search and rescue (USAR) related to building collapse in the HayWired scenario, I compiled a database of photographic evidence of 73 building collapses in California earthquakes between 1965 and 2014. The database includes all images in the University of California, Berkeley, National Information Service for Earthquake Engineering (NISEE) e-library whose descriptions use any of the words "collapse," "fail," "fell," or "parapet," along with data taken from other sources about 14 additional buildings. I interpreted each image to estimate the fraction of building area that collapsed and the fraction of occupants in the collapsed area who would realistically be trapped and require extrication by others. The proportions vary by structural material, but on average, collapse involves 23 percent of the area of the buildings and traps 66 percent of the occupants in the collapsed area. Using this new knowledge and other information about the number of collapsed buildings, I can estimate the number of people requiring extrication by USAR personnel.

In the case of the HayWired scenario, two alternative methods suggest approximately 5,000 buildings could collapse. The two methods are described elsewhere, but briefly, they are Hazus-MH (Seligson and others, this volume) and the approach described in Porter (2015). The latter essentially relies on the model of building collapse underlying the maps of risk-adjusted maximum considered earthquake ground motions in ASCE Standard ASCE/SEI 7-10 Minimum Design Loads for Buildings and Other Structures (American Society

\footnotetext{
${ }^{1}$ University of Colorado Boulder.
}

of Civil Engineers, 2010). It seems realistic that 2,500 people would be trapped in 5,000 collapsed buildings. (Not every building collapse traps people). If all buildings were designed to be 50 percent stronger than currently required under the International Building Code, both figures could be reduced by approximately a factor of four. Using statistics about how many elevators there are in the United States, how many have emergency power, and what fraction of them are occupied and traveling between floors, I estimated that loss of power in the HayWired mainshock could trap 22,000 people in 4,500 stalled elevators, placing additional demands on USAR personnel. If newer elevators were provided with emergency power, the number trapped in elevators could be reduced to 14,000 people in 3,000 elevators.

\section{Introduction}

The HayWired earthquake scenario examines a hypothetical moment magnitude $\left(M_{\mathrm{w}}\right) 7.0$ earthquake (mainshock) occurring on April 18, 2018, at 4:18 p.m., on the Hayward Fault in the east bay part of the San Francisco Bay area. This chapter estimates demand for urban search and rescue (USAR) related to building collapse in the HayWired scenario.

What is meant when one says a building has collapsed in an earthquake? When it collapses, what does the damage look like? The answer matters for at least two reasons. (1) Engineers would like to create second generation, performancebased earthquake engineering (PBEE-2) models of the effects of collapse on safety (see, for example, an early effort by Yeo and Cornell, 2002). So and Pomonis (2012) recently proposed a process for estimating fatalities in collapsed buildings during earthquake ground shaking using their engineering judgment of fatality rate by building type, informed by fatality data from various recent earthquakes. (2) Building collapse affects the demand for urban search and rescue. Elevators stalled without 
power may also trap substantial numbers of people who must be rescued by USAR personnel (see, for example, Schiff, 2008). The present HayWired study seeks to (1) clarify what is meant by "collapse," (2) advance demand for mathematical modeling of USAR, and (3) illustrate a new model by applying it to the HayWired mainshock.

\section{Objective}

This report describes the use of USAR modeling and addresses the following questions:

1. When engineers use the word "collapse" to describe the seismic performance of a building, what fraction of the occupiable floor area deforms severely enough to threaten lives in that area? (I offer an empirical answer by examining a database of photographs of building collapses. Such an empirical study complements numerous analytical assessments of collapse.)

2. What fraction of occupants in the collapsed areas require extrication, and by whom? (I answer this question by interpreting the image database in light of Federal Emergency Management Agency [FEMA] Urban Search and Rescue guidelines; for example, PerformTech, Inc., 2011.)

3. How many elevators are in the affected metropolitan area, how many of them are carrying passengers (and how many passengers) between floors at the time of the earthquake, and what fraction of those elevators have emergency power to bring the elevator to a floor and open the doors?

To keep the level of effort commensurate with the value of the information, I consider only one extensive, although not exhaustive, data source - the Earthquake Engineering Online Archive provided by the National Information Service for Earthquake Engineering (NISEE), University of California, Berkeley. NISEE refers to the archive as the NISEE e-library (see http://nisee.berkeley.edu/elibrary/). NISEE describes the e-library as "a database of significant, publicly funded research and development literature, photographs, data and software in earthquake, structural, and geotechnical engineering." I exclude manufactured housing, fences, equipment, and bridges from the objective. I also acknowledge that the NISEE e-library is not exhaustive. It is treated here as a sample, not as documentation of the population of collapsed buildings, with the expectation that it is a diverse and representative sample.

One could conceivably address the building collapse questions with structural analysis, either instead of, or in addition to, the empirical approach of examining photographic evidence. But it seems doubtful that structural analysis would reliably reveal the extent of collapse, because structural analysis is not yet capable of reliably predicting the onset of collapse, its dynamics, and the eventual shape of a collapsed building. The authors of FEMA P-695 (Applied Technology Council, 2009), for example, identified collapse as the condition that lateral dynamic instability appeared during incremental dynamic analysis, meaning that collapse occurs when structural analysis of a mathematical representation of the building fails to converge. Failure of a mathematical model to converge following the loss of vertical load-carrying capacity provides little information about how much of or how far a floor or roof diaphragm falls. The authors of FEMA P-695 further cite examples of possible nonsimulated collapse modes, meaning collapse modes that a structural analysis might not reveal. These include "shear failure and subsequent axial failure in reinforced-concrete columns, fracture in the connections or hinge regions of steel moment frame components, or failure of tie-downs in light-frame wood shear walls. Component failures such as these may be difficult to simulate directly." Another reason to favor an empirical study over an analytical study is that empirical models are more credible than analytical ones, at least among the loss-estimation community, where an empirical model is always preferred to an analytical one, all else being equal. Analytical models often serve to validate an empirical one or to provide insight where empirical data are lacking. None of this is to say that an analytical study will never have anything to offer to the question of area affected by collapse, but rather an empirical study seems more likely to provide defensible results in the near term for much less effort.

\section{Literature Review}

\section{Literature About People Trapped by Building Collapse}

It is believed that building collapse dominates earthquake casualty risk and contributes substantially to USAR demands. The 2009 National Earthquake Hazards Reduction Program (NEHRP) provisions (Building Seismic Safety Council, 2009) assert that "Most earthquake injuries and deaths are caused by structural collapse." Although that statement could be true in general, it probably exaggerates the importance of structural collapse for nonfatal injuries, at least in California earthquakes such as those of the late 1980s and early 1990s, judging by the analysis Shoaf and others (1998). The National Fire Protection Association (2014) offers descriptive patterns of earthquakeinduced building collapses in earthquakes and explains the causes and nature of voids where occupants can escape injury in collapsed buildings (fig. 1).

The authors of the Hazus-MH technical manual (Federal Emergency Management Agency, 2012) offer estimates of the fraction of occupants in collapsed area who are killed. Their estimates draw on the judgment-based ATC-13 (Applied Technology Council, 1985), which they "revised based on comparison with a limited amount of historical data," and validated against "several recent events, including the Northridge, 
Loma Prieta and Nisqually earthquakes ...” They estimate that 10 percent of occupants in collapsed areas of buildings are killed and 65 percent are injured to some degree. The two leading public models of earthquake risk, Hazus-MH (Federal Emergency Management Agency, 2012) and ATC-13 (Applied Technology Council, 1985), do not address search and rescue demands.

Collapse fragility functions, which estimate the probability that a building will collapse under various levels of excitation, are available or can be derived (see, for example, Applied Technology Council [2009] or Federal Emergency Management Agency [2012]). However, I could find no prior work that quantifies the fraction of the building area that collapses when a building experiences some collapse.

When buildings in California collapse, they rarely pancake. That is, they rarely collapse such that the floor or roof over every square foot of occupiable floor area drops because of the loss of vertical load carrying capacity of the portion of the gravity system that supports it. One could conceivably use structural analysis to model the collapse behavior of sample buildings, but the state of the practice enables structural engineers only to estimate the excitation associated with the onset of collapse, as the authors of FEMA P-695 (Applied Technology Council, 2009) did quite extensively. Another approach, explored here, is to review postearthquake observations of building collapse. The present work focuses on California buildings.

The International Building Code (International Code Council, 2009) does not use the word "collapse" at all. The authors of ASCE/SEI 7-10 (American Society of Civil Engineers, 2010) use the word "collapse" in defining the probabilistic (MCER) ground motion and in describing the anticipated maximum probability of failure for earthquake loading. It does not define collapse, but it does define progressive collapse as "the spread of an initial local failure from element to element, resulting eventually in the collapse of an entire structure or a disproportionately large part of it." It also defines the term "limited local collapse" with an example: "the containment of damage to adjacent bays and stories following the destruction of one or two neighboring columns in a multibay structure."

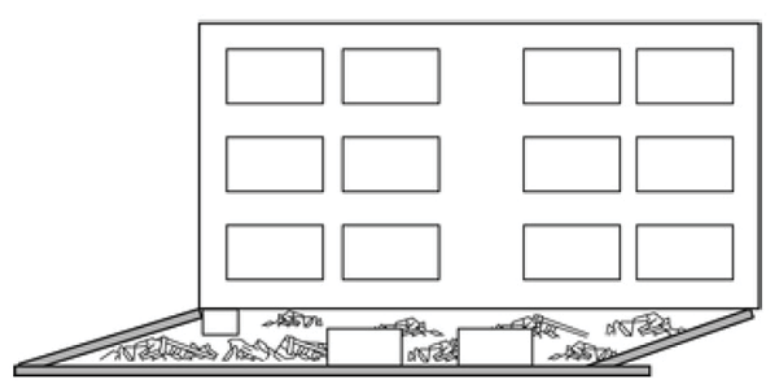

Offset collapse pattern-light-frame construction

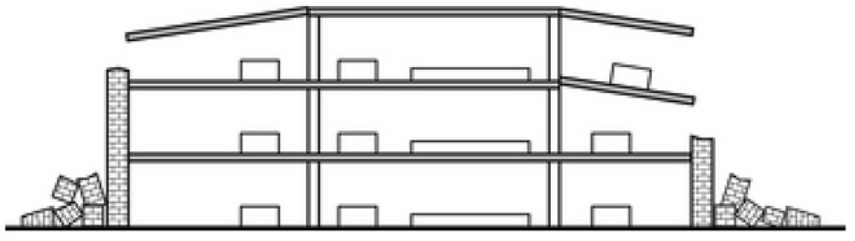

Wall-fall collapse pattern-heavy wallunreinforced-masonry construction

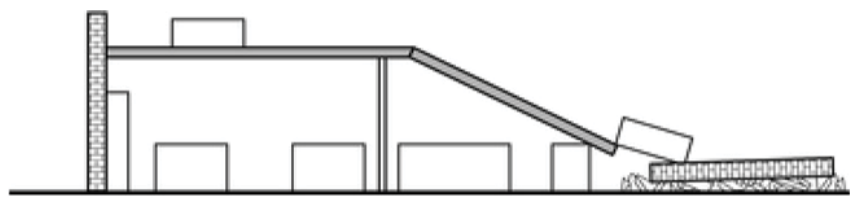

Wall-fall collapse pattern-heavy wall-tilt-up construction

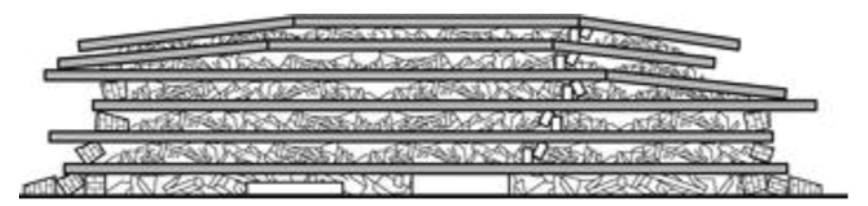

Wall-fall collapse pattern-heavy wall-tilt-up construction

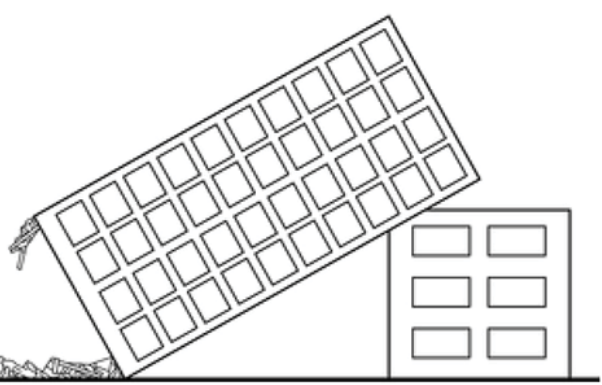

Overturn collapse pattern-heavy-floor or heavy-steel construction

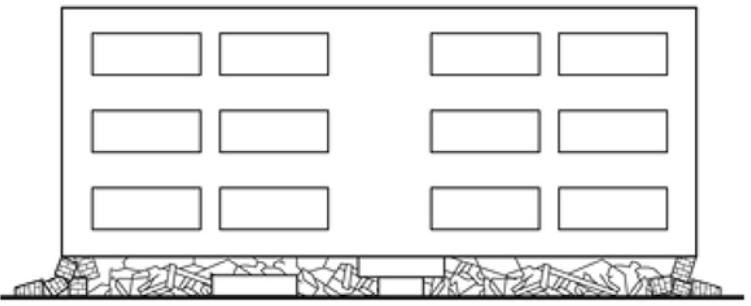

Soft first-story collapse pattern-heavy-floor construction

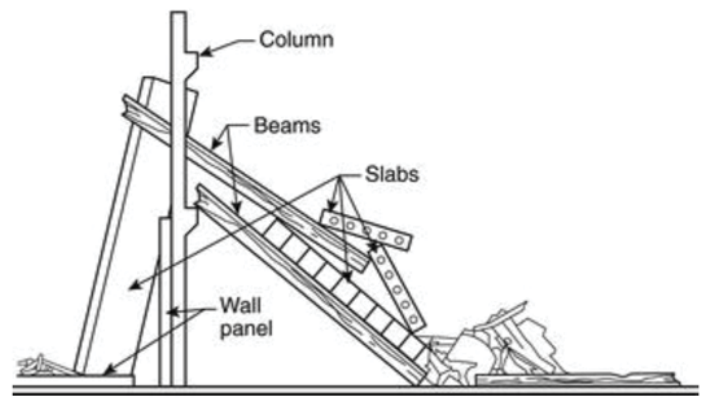

Random-fall collapse pattern-precast-concrete construction

Figure 1. Illustrations of building collapse patterns in earthquakes (modified from National Fire Protection Association, 2014). 
The 2009 NEHRP provisions (Building Seismic Safety Council, 2009) mention structural collapse, collapse of small structural systems (such as a hospital canopy), and collapse of nonstructural components (such as light fixtures, ductwork, and piping systems), but they do not define the word. FEMA P-695 defines collapse as "including both partial and global instability of the seismic-force-resisting system," excluding "local failure of components not governed by global seismic performance factors, such as localized out-of-plane failure of wall anchorage and potential life-threatening failure of nonstructural systems" (Applied Technology Council, 2009). It does not include in its consideration of collapse damage to, or failure of, "components that are not designated as part of the seismic-force-resisting system" because those components "are not controlled by seismic-force-resisting system design requirements," and they are therefore not within the scope of the project. The authors of FEMA P-695 include among the possible definitions of collapse the occurrence of a sidesway mechanism, and more generally the "state of lateral dynamic instability."

In more recent work, I and colleagues developing the third edition of FEMA P-154 and FEMA P-155 (Applied Technology Council, 2015a,b) and proposed the following definition. We generally define building collapse as the condition in which "any part of the gravity system experiences dynamic instability leading to the loss of load-bearing capacity. The dynamic instability leads to severe structural deformation of a potentially life-threatening nature, especially falling of all, or portions of, a structure. Partial building collapse means that the dynamic instability occurs only in a portion of the building ... In the case of manufactured housing and wood frame buildings, building collapse also includes the condition that the manufactured home falls off one or more of its supports, or the cripple walls of a wood frame building experience a sidesway mechanism and lose their vertical load-carrying capacity" (Applied Technology Council, 2015b). Building collapse does not include wood frame buildings sliding relative to their foundations if there is no vertical drop in any part of the floor or roof. Nor is the falling of a parapet from an unreinforced masonry (URM) building or brick veneer or chimney from any FEMA building type considered to constitute building collapse.

The United States Federal Emergency Management Agency National Urban Search and Rescue Response System (2009) estimates that, of people injured in buildings in earthquakes, 50 percent are injured but not trapped, and can be aided by emergent, untrained volunteers - civilians - who happen to be nearby at the time of the earthquake (fig. 2). Another 30 percent are injured and trapped, but not by structural components, for example, by overturning of furniture, and are extracted by trained local community emergency response teams (CERTs). CERTs are trained to perform search and rescue in buildings that have damage to decorative work and to interior contents but are not collapsed or fallen from their foundations; that would presumably include chimney and parapet damage (PerformTech, Inc., 2011). An additional 15 percent of people injured are rescued from the collapse of light structures, such as wood frame construction and manufactured housing, by emergency services rescue forces-generally firefighters - without the need for heavy excavation equipment. The remaining 5 percent must be extricated by trained urban search and rescue forces aided by equipment to penetrate heavy structures - masonry, concrete, and structural steel.

There do not appear to be any published statistics on the frequency of each collapse pattern or what fraction of occupants require extrication by search and rescue personnel, although there is limited anecdotal evidence about individual buildings, such as Krimgold's (1988) statistics from the 12-story Juarez Hospital that collapsed in the 1985 Mexico City earthquake.

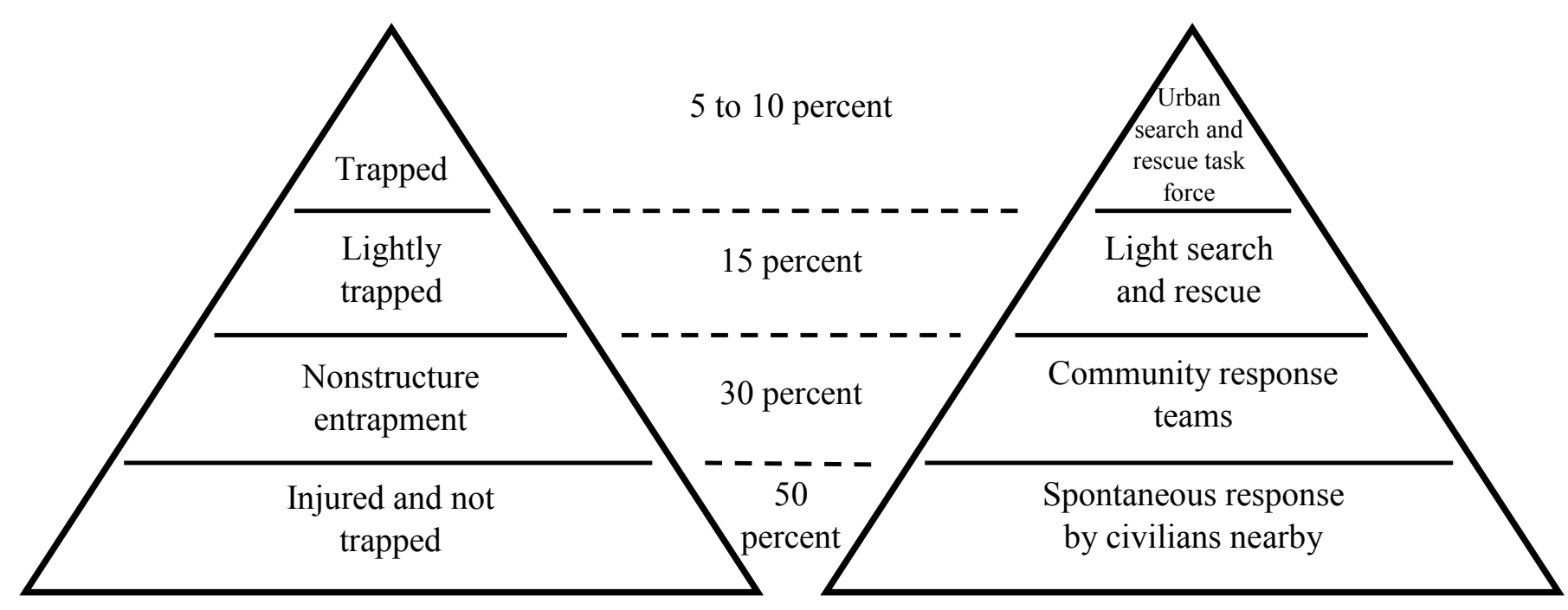

Figure 2. Pyramid charts showing the distribution of assistance in a large earthquake (after National Urban Search and Rescue Response System, 2009). 


\section{Literature About People Trapped in Elevators}

The vast majority of San Francisco Bay area buildings do not have uninterruptible power supplies or emergency generators to power elevators in the absence of commercial power. According to National Elevator Industry, Inc. (2014), there are 900,000 elevator units in the United States, or approximately one elevator per 344 people. Each elevator makes an average rise of 4 to 5 floors, or 40 feet, and each carries an average of 5 people per trip. Each passenger averages 4 trips per day, 250 days per year. According to the Emporis Corporation (2007) database of high-rise buildings, there are approximately 600 high-rise buildings with approximately 3,700 elevators in the San Francisco Bay area.

Sample calculations in Strakosch and Caporale (2010) suggest that an elevator is in motion with the doors closed approximately 30 percent of the time that it is in use with passengers inside. Some elevators have battery power to operate briefly to move the cab to a floor and open doors.

According to San Francisco Bay area elevator consultant von Klan (written commun., 2015), elevators installed in highrise buildings in the past 40 years or so have been required to have emergency power for elevators, and he estimates that perhaps 60 percent of high-rise buildings in the bay area were constructed since this time. He also estimates that less than 5 percent of elevators in mid- and low-rise buildings have emergency power. Even if there were emergency power available, seismic safety devices installed in newer elevators may stop the elevator between floors until a technician inspects the elevator.

\section{Methodology}

\section{Methodology for Estimating the Number of People Trapped by Collapse}

The illustrations in figure 1 do not represent an exhaustive typology of collapses that could trap occupants or passersby. If a portion of a parapet falls, it does not constitute building collapse, but engineers do speak of parapets collapsing, and parapet collapse does not appear in figure 1. I therefore include in collapse (1) the falling of a floor or roof such that the clear height is reduced to less than 2 meters (m), and (2) the falling of parapets, chimneys, and other elements, but I exclude the falling of other contents and movable furnishings, such as cubicles. For purposes of estimating the probability of being injured or trapped by collapse, I define collapse as follows:

Collapse constitutes the condition where, in a portion of the building or in the entire building, the gravity load-carrying system (for example, its beams, columns, floors, and shear walls) loses the ability to carry its own weight and the weight of whatever else it supports. That failure leads to severe building deformation of a potentially life-threatening nature, especially if all or portions of a building fall. The nonstructural portions of a building are included in our definition of collapse, along with the structural portions, such as parapets, chimneys, and porches. Thus, some nonstructural collapses are included (parapets, chimneys, and porches), but some structural failures are not (permanent lateral displacement of the building relative to the foundation where no vertical drop occurs).

I estimate fatality rate and USAR needs in future earthquakes as follows. I estimate fatality rate as the product of the collapse probability conditioned on ground motion, the fraction of the building floor area that actually collapses when there is at least some collapse, and the fraction of occupants in that collapsed area that are killed, as in equation 1 :

$$
F(h)=P(h) \times A \times R
$$

In the equation, $F(h)$ represents the fatality rate in a building (fraction of occupants killed) that is shaken with severity $h$. $P(h)$ denotes collapse probability given shaking $h . A$ denotes affected area, that is, the fraction of the building area that collapses, given that at least some collapse occurs. $R$ denotes the fatality rate in the collapsed area.

I model search and rescue needs by an analogous equation where $S(h)$ and $E$ denote, respectively, the fraction of building occupants requiring extrication, and the fraction of occupants in the collapsed area who need extrication, as in equation 2:

$$
S(h)=P(h) \times A \times E
$$

Implicit in equation 2 is the assumption that people are uniformly distributed throughout the building: an occupant is as likely to be in one place as another. This assumption might be conservative; for example, buildings with soft-story conditions are likely to collapse onto the soft story, which tends to be less densely occupied garage space rather than more densely occupied living space. To account for that fact requires a model of the number of buildings that collapse onto soft garage levels. I assume for the remainder of this work that one lacks a damage model that detailed.

If one already has an estimate of the number of collapsed buildings (I denote this number by $N_{\mathrm{b}}$ ), then the estimated number of people, $N_{\mathrm{c}}$, who are trapped in collapsed buildings and require extrication by USAR personnel can be estimated as:

$$
N_{\mathrm{c}}(t)=N_{\mathrm{b}} \times O(t) \times A \times E,
$$

where $O(t)$ denotes the average number of occupants per building at time $t$, and $A$ and $E$ again denote the fraction of the building area that collapses and the average fraction of occupants in the collapsed area who need extrication by USAR personnel, respectively.

One might condition each term in equations 1,2 , and 3 on building type, era of construction, or other parameters. The analyst must estimate the quantity $O(t)$, for example, using estimates of average building area per occupant from Hazus-MH 
(Federal Emergency Management Agency, 2012) or ATC-13 (Applied Technology Council, 1985).

To estimate $A$, I examined every photograph of a building in the NISEE e-library images database from every California earthquake in the past 50 years in which the photo description uses the word "collapse," "fail," "fell," or "parapet." I supplemented these images with photos of buildings where I knew collapse had occurred. I also added data on tilt-up roof collapses in the 1971 San Fernando earthquake extracted from a 1973 National Oceanic and Atmospheric Administration (NOAA) report that showed building plan area and area of roof collapse.

I labeled each building with a building category: wood (consisting of FEMA model building types W1, W1A, and W2), steel (types S1 through S5), concrete (C1 through C3), precast concrete (PC1 and $\mathrm{PC} 2$ ), reinforced masonry (RM1 and RM2), and unreinforced masonry (URM). To make the assignments I used the procedures recommended in FEMA P-154 and FEMA P-155 (Applied Technology Council, 2015a,b). Finally, I aggregated these to four simpler categories: tiltup concrete (PC1), all concrete and precast concrete except tiltup, wood, and unreinforced masonry. No other building types appeared in the photo database. Of course, making these assignments based mostly on photographic evidence can be problematic, because architectural finishes often conceal the true structural system. I do not claim complete accuracy in making the assignments. Still, it is hard to mistake wood, URM, and tiltup construction, especially when one is familiar with the historic architectural styles of the region and given that collapse tends to peel away architectural finishes.

I estimated $E$, the fraction of occupants in the collapsed area requiring extrication, as the fraction of the collapsed area in which heavy debris or structural elements fell to the floor or ground. For example, in the case of bricks littering a sidewalk from collapsed parapets or chimneys, it seems reasonable to assume that anyone in that debris field would be injured or killed and would require extrication by others. In the case of collapsed porch roofs resting entirely on the ground or porch, anyone beneath the porch would require extrication. In the case of houses off their foundations, but where the roof or upper floors do not fall, I assume that residents can generally escape through a window or a door that is not blocked. It seems realistic that there will be cases of injured or physically disabled people who cannot escape through a window unaided, but I assigned $E=0$ based on the assumption of the more likely case, that the occupant is not physically disabled or seriously injured.

Social scientists speak of such an approach to sampling as a convenience sample, a nonprobability sampling technique where subjects are selected because of their convenient accessibility and proximity to the researcher. The main problem with convenience sampling is the potential for sampling bias, in which one does not know that the sample is representative of the entire population. If a database existed of all collapsed buildings in a particular earthquake or particular geographic region, one could perform a randomized sample or an exhaustive survey and avoid worries about sampling bias, but such a database does not exist, so for present purposes I fall back on this convenience sample and advocate for a better database in the future.

In the present convenience sample, the first California earthquake in the 50-year period studied here is the $M_{\mathrm{w}} 6.5$ 1968 Borrego Mountain earthquake; the last is the $M_{\mathrm{w}} 6.0$ 2014 South Napa earthquake. In each case, I estimated the fraction of the building area affected by the collapse. In many cases, particularly ones where only a small portion of a large building was affected, the photograph shows the affected area but not the overall size of the building, and the building no longer exists. In many cases, I found additional evidence of the building location and other photographs that show more of the building, and in several cases, I estimated building area from the area of building shown in Google Earth Pro, which includes parcel outlines and recent and historical satellite imagery, and has a tool for measuring area.

The results of my analysis are summarized in table 1. The columns list the earthquake associated with the collapse, NISEE's image identifier number, NISEE's photo description, the building type (using FEMA's building typology), the estimated fraction of the building's occupiable floor area that was affected by the collapse $(A)$, the fraction of occupants in the affected area that would require extrication by others $(E)$, and the technical qualifications of the people most likely to perform the extrication ( $T$ ). The quantities $A$ and $E$ are bounded by 0 and 1 . Options for $T$ are labeled by the order in which USAR personnel would arrive: $1=$ emergent civilian volunteers (neighbors); $2=$ CERT; $3=$ firefighters; and 4=FEMA USAR Task Force.

Details of each estimate of $A$ are provided in the appendixes. I binned the fraction of affected area on a quarter orderof-magnitude basis, that is, approximately $10^{-2}, 10^{-1.75}, 10^{-1.5}, \ldots$ $10^{0}$, which is to say 1 percent, 2 percent, 3 percent, 6 percent, 10 percent, 18 percent, 32 percent, 56 percent, and 100 percent. From these data, one can create histograms of the data as a whole and subdivide by the structural material (wood, unreinforced masonry, or concrete).

I estimated $T$, the technical qualifications of the USAR personnel, as 1 (untrained emergent civilian volunteer) if the extrication could be done by a single person without tools, as in picking up bricks. I assigned $T=2$ (CERT) if the extrication requires two or more people but no heavy equipment and would not violate the CERT training guidelines (PerformTech, Inc., 2011). I assigned $T=3$ if the extrication requires equipment but not heavy lifting or cutting of reinforced concrete, such as in the case of a collapsed wood frame building where a roof or an upper floor falls onto the floor or furnishings below. For example, firefighters extracted Sherra Cox from a collapsed building in the San Francisco Marina District after the 1989 Loma Prieta earthquake (Scawthorn and others, 1992). I assigned $T=4$ if the extrication requires heavy lifting or cutting of reinforced concrete. I made no assignment ( $T=$ blank) if $E=0$, that is, no extrication is required.

The database of photos of collapse that I compiled from NISEE and the other sources contains 73 California buildings that experienced at least some collapse in earthquakes between 
Table 1. Summary of parameters used in the urban search and rescue (USAR) model for the HayWired earthquake scenario.

[ID, image identifier from Earthquake Engineering Online Archive; type, model building type according to the Applied Technology Council (2015a); A, affected area; $E$, fraction of occupants trapped; $T$, technical qualifications of USAR personnel; $M_{w}$, moment magnitude; \%, percent; in., inch; ft, feet; St., Street, Rd., Road; Ave., Avenue]

\begin{tabular}{|c|c|c|c|c|c|c|}
\hline Earthquake & ID & Damage description & Type & $\boldsymbol{A}$ & $\boldsymbol{E}$ & $T$ \\
\hline \multirow[t]{2}{*}{$\begin{array}{l}\text { Santa Rosa } 1969 \\
\left(M_{\mathrm{w}} 5.6 \text { and }\right. \\
5.7)\end{array}$} & S3715 & $\begin{array}{l}\text { Two-story wood frame building off foundations. Foundations } \\
\text { were rotted and poorly braced. Gas lines ruptured when house } \\
\text { fell. } 718 \text { Beaver St., Santa Rosa, California. }\end{array}$ & W1 & $0 \%$ & 0 & \\
\hline & S3726 & $\begin{array}{l}\text { Miramar Building. Collapsed portion of a wall fell on a car. } 203 \\
\text { Old Courthouse Square, Santa Rosa, California. }\end{array}$ & URM & $1 \%$ & 1.0 & 1 \\
\hline \multirow[t]{24}{*}{$\begin{array}{l}\text { San Fernando } \\
\qquad 1971\left(M_{\mathrm{w}} 6.7\right)\end{array}$} & S4473 & $\begin{array}{l}\text { Damage to porches (probable cripple wall failure?); chimney fell } \\
\text { away from house. In the vicinity of Knox and Orange Grove } \\
\text { Streets, in the fault zone. }\end{array}$ & W1 & $8 \%$ & 0.5 & 3 \\
\hline & S4533 & Chimney fell towards otherwise undamaged wood frame house. & $\mathrm{W} 1$ & $0 \%$ & 0 & \\
\hline & S4581 & $\begin{array}{l}\text { Furniture store. Unreinforced masonry parapet collapsed, } \\
\text { dumping bricks into the street and on to the sidewalk. Large } \\
\text { plate-glass windows are gone, presumably shattered by the } \\
\text { earthquake. }\end{array}$ & URM & $19 \%$ & 1.0 & 1 \\
\hline & S4597-S4602 & $\begin{array}{l}\text { Apartments over retail space. Note that the failure of the unrein- } \\
\text { forced bearing walls did not result in collapse. Unit masonry } \\
\text { construction, built prior to 1933. Downtown San Fernando } \\
\text { commercial area. }\end{array}$ & URM & $3 \%$ & 1.0 & 1 \\
\hline & S4489 & $\begin{array}{l}\text { Partial collapse on older wood frame house, probable cripple wall } \\
\text { failure of house. Between Glen Oaks and Hubbard Streets. }\end{array}$ & $\mathrm{W} 1$ & $0 \%$ & 0 & \\
\hline & S4491, S4492 & $\begin{array}{l}\text { Pink structure at the rear was a residence over a garage. The first } \\
\text { story collapsed; note remains of automobile under the building. }\end{array}$ & $\mathrm{W} 1$ & $50 \%$ & 1.0 & 3 \\
\hline & S4624 & $\begin{array}{l}\text { Roof to the wall failed first. Ground cracks in the vicinity. Rear } \\
\text { wall bulged out, and rear roof fell. See S4625-4633. Light } \\
\text { industrial buildings. Bradley Tract. } 12884 \text { Bradley Ave. }\end{array}$ & $\mathrm{TU}$ & $11 \%$ & 0.1 & 3 \\
\hline & \multirow{13}{*}{$\begin{array}{l}\text { Benfe and Coff- } \\
\text { man }(1973, \mathrm{p} . \\
123)\end{array}$} & 12840 Bradley Ave. & $\mathrm{TU}$ & $44 \%$ & 0.1 & 3 \\
\hline & & 12874 Bradley Ave. & $\mathrm{TU}$ & $12 \%$ & 0.1 & 3 \\
\hline & & 12950 Bradley Ave. & $\mathrm{TU}$ & $10 \%$ & 0.1 & 3 \\
\hline & & 12881 Bradley Ave. & $\mathrm{TU}$ & $10 \%$ & 0.1 & 3 \\
\hline & & 12975 Bradley Ave. & $\mathrm{TU}$ & $23 \%$ & 0.1 & 3 \\
\hline & & 13001 Bradley Ave. & $\mathrm{TU}$ & $8 \%$ & 0.1 & 3 \\
\hline & & 13069 Bradley Ave. & $\mathrm{TU}$ & $16 \%$ & 0.1 & 3 \\
\hline & & 15200 Bledsoe St. & $\mathrm{TU}$ & $19 \%$ & 0.1 & 3 \\
\hline & & 15151 Bledsoe St. & $\mathrm{TU}$ & $8 \%$ & 0.1 & 3 \\
\hline & & 12860 San Fernando Rd. & $\mathrm{TU}$ & $16 \%$ & 0.1 & 3 \\
\hline & & 12806 San Fernando Rd. & $\mathrm{TU}$ & $18 \%$ & 0.1 & 3 \\
\hline & & 12744 San Fernando Rd. & $\mathrm{TU}$ & $26 \%$ & 0.1 & 3 \\
\hline & & 12814 Bradley Ave. & $\mathrm{TU}$ & $15 \%$ & 0.1 & 3 \\
\hline & GoddenJ53 & $\begin{array}{l}\text { Collapse of a split-level wooden home. Large numbers of these } \\
\text { split-level homes suffered significant damage because of a lack } \\
\text { of adequate ties between the two levels. The upper level ripped } \\
\text { away and crushed the lower garage walls, which did not have } \\
\text { adequate lateral bracing. }\end{array}$ & $\mathrm{W} 1$ & $33 \%$ & 1.0 & 3 \\
\hline & S4195 & $\begin{array}{l}\text { Collapsed Semi-Ambulant Building at Veterans Authority Hospi- } \\
\text { tal, built in 1925, masonry construction. }\end{array}$ & URM & $50 \%$ & 1.0 & 3 \\
\hline & S4529 & Damage to older house caused by cripple wall collapse. & $\mathrm{W} 1$ & $0 \%$ & 0 & \\
\hline & S4065 & $\begin{array}{l}\text { Collapsed tower at southeast corner. Olive View Hospital. Rear } \\
\text { [east] elevation of Medical Treatment Building. }\end{array}$ & $\mathrm{C} 2$ & $3.3 \%$ & 1.0 & 3 \\
\hline
\end{tabular}




\begin{tabular}{|c|c|c|c|c|c|c|}
\hline Earthquake & ID & Damage description & Type & $\boldsymbol{A}$ & $\boldsymbol{E}$ & $T$ \\
\hline & S4070 & $\begin{array}{l}\text { Ambulance garage collapsed. Olive View Hospital. Southern } \\
\text { elevation of Medical Treatment Building. See also S4139-44. }\end{array}$ & $\mathrm{C} 1$ & $100 \%$ & 0.5 & 3 \\
\hline & S4115, S4117 & $\begin{array}{l}\text { Soft-story collapse, most evident at upper right of photo. Original- } \\
\text { ly a one- and two-story building, irregular in plan, the first story } \\
\text { collapsed in the earthquake. }\end{array}$ & $\mathrm{C} 1$ & $67 \%$ & 1.0 & 4 \\
\hline & S4519 & $\begin{array}{l}\text { Collapsed wood frame house under construction on Tucker Street } \\
\text { near Pacoima Dam. }\end{array}$ & W1 & $67 \%$ & 0.5 & 3 \\
\hline & S4501 & $\begin{array}{l}\text { Two-story section over garage of this wood frame house on } \\
\text { Almetz Street has collapsed in the first story. In a new housing } \\
\text { tract in Sylmar at base of hills and between Olive View and } \\
\text { Veterans Administration Hospitals. }\end{array}$ & W1 & $33 \%$ & 1.0 & 3 \\
\hline & R0070 & $\begin{array}{l}\text { Old masonry building in upper center of photo has completely } \\
\text { collapsed. Constructed in 1925-26, with major additions in } \\
1938 \text { and 1949, the entire complex was demolished after the } \\
1971 \text { earthquake and the entire } 97 \text { acres were dedicated in } 1977 \\
\text { as Veterans Memorial Park. }\end{array}$ & URM & $100 \%$ & 1.0 & 4 \\
\hline
\end{tabular}

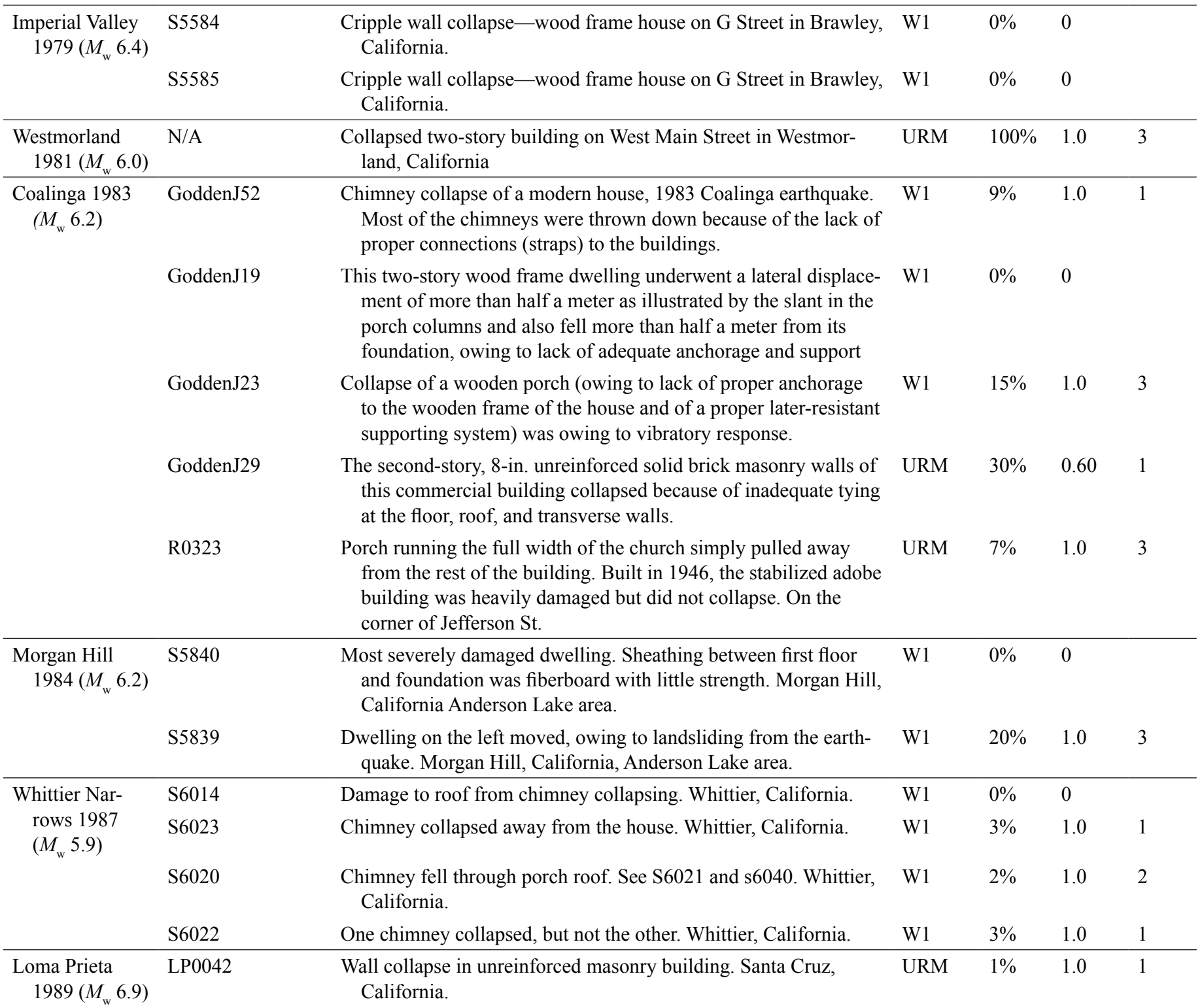




\begin{tabular}{|c|c|c|c|c|c|c|}
\hline Earthquake & ID & Damage description & Type & $A$ & $\boldsymbol{E}$ & $T$ \\
\hline & LP0070 & $\begin{array}{l}\text { Older building with failed parapets on Main Street. } 307 \text { Main } \\
\text { Street, Watsonville, California. }\end{array}$ & URM & $18 \%$ & 1.0 & 1 \\
\hline & LP0072 & $\begin{array}{l}\text { Older building with failed parapets on Main Street. } 311 \text { Main } \\
\text { Street, Watsonville, California. }\end{array}$ & URM & $9.4 \%$ & 1.0 & 1 \\
\hline & LP0462, LP0460 & $\begin{array}{l}\text { Collapse of unreinforced brick wall. 6th and Bluxome Streets, } \\
\text { South of Market District, San Francisco, California. }\end{array}$ & URM & $5.3 \%$ & 1.0 & 1 \\
\hline & LP0375 & $\begin{array}{l}\text { Collapse of two four-story apartment buildings (soft ground } \\
\text { floors). Marina District, San Francisco, California. }\end{array}$ & W1A & $25 \%$ & 1.0 & 3 \\
\hline & LP0375, S6120 & $\begin{array}{l}\text { Collapse of two four-story apartment buildings (soft ground } \\
\text { floors); there were two buildings in the image. }\end{array}$ & W1A & $25 \%$ & 1.0 & 3 \\
\hline & LP0499 & $\begin{array}{l}\text { Collapsed apartment building at } 2090 \text { Beach Street, after the } \\
\text { fire was much advanced. Note the firefighter directing water } \\
\text { onto exposed side of building. Marina District, San Francisco, } \\
\text { California. }\end{array}$ & W1A & $75 \%$ & 1.0 & 3 \\
\hline & S6144 & $\begin{array}{l}\text { Soft-story collapse of apartment building in the Marina District, } \\
\text { San Francisco, California. }\end{array}$ & W1A & $33 \%$ & 1.0 & 3 \\
\hline & LP0459 & $\begin{array}{l}\text { Collapse of unreinforced masonry wall from third floor of build- } \\
\text { ing. } 235 \text { Front St. at Davis St., Embarcadero/Financial District, } \\
\text { San Francisco. }\end{array}$ & URM & $2.9 \%$ & 1.0 & 1 \\
\hline & LP0041 & $\begin{array}{l}\text { Interior structural failures at Ford's Department Store. Santa Cruz, } \\
\text { California. }\end{array}$ & URM & $33 \%$ & 1.0 & 3 \\
\hline & LP0081-LP0085 & $\begin{array}{l}\text { Front view of damaged St. Patrick's church. Watsonville, } \\
\text { California. }\end{array}$ & URM & $4.5 \%$ & 1.0 & 1 \\
\hline & LP0087 & Damaged bike store with failed parapet. Watsonville, California. & URM & $25 \%$ & 1.0 & 1 \\
\hline & LP0090 & Pink frame house with failed foundation. Watsonville, California. & $\mathrm{W} 1$ & $0 \%$ & 0 & \\
\hline \multirow[t]{8}{*}{$\begin{array}{l}\text { Northridge } 1994 \\
\quad\left(M_{\mathrm{w}} 6.7\right)\end{array}$} & \multirow[t]{4}{*}{$\begin{array}{l}\text { NR327, NR353, } \\
\text { NR357, NR358 }\end{array}$} & $\begin{array}{l}\text { Collapsed apartment building, three-story wood frame. North- } \\
\text { ridge, California. According to Todd and others (1994, p. 23), } \\
\text { four buildings experienced collapse. This is the first. }\end{array}$ & W1A & $33 \%$ & 1.0 & 3 \\
\hline & & $\begin{array}{l}\text { Collapsed apartment building, three-story wood frame. North- } \\
\text { ridge, California. Second building. }\end{array}$ & W1A & $33 \%$ & 1.0 & 3 \\
\hline & & $\begin{array}{l}\text { Collapsed apartment building, three-story wood frame. North- } \\
\text { ridge, California. Third building. }\end{array}$ & W1A & $17 \%$ & 1.0 & 3 \\
\hline & & $\begin{array}{l}\text { Collapsed apartment building, three-story wood frame. North- } \\
\text { ridge, California. Fourth building. }\end{array}$ & W1A & $4 \%$ & 1.0 & 3 \\
\hline & NR408-409 & $\begin{array}{l}1004 \text { West Channel Road at Pacific Coast Highway (near Pacific } \\
\text { Palisades). Damage to two-story masonry building. Heavy } \\
\text { shear cracking on side walls. Out of plane failure of the second } \\
\text { story. State Beach Cafe, Santa Monica, California. }\end{array}$ & URM & $13 \%$ & 1.0 & 1 \\
\hline & NR412-414 & $\begin{array}{l}\text { Four-story masonry building, } 827 \text { Fourth Street, Santa Monica, } \\
\text { California. Damage to the fourth and third floor of the build- } \\
\text { ing. The masonry facade fell out of plane and took with it the } \\
\text { fourth-floor terrace. This building had been scheduled for a ret- } \\
\text { rofit to begin on Monday, January } 17,1994 \text {. Three-layers-thick } \\
\text { unreinforced masonry. Damage in the top story and balcony. } \\
\text { Little damage on the sides and below the third story. See also } \\
\text { NR412-414. }\end{array}$ & URM & $2.1 \%$ & 1.0 & 1 \\
\hline & 20101224 & This residential chimney of unreinforced blocks collapsed. & $\mathrm{W} 1$ & $2.7 \%$ & 1.0 & 1 \\
\hline & NR559 & $\begin{array}{l}\text { Parking structure on Zelzah Ave., California State University, } \\
\text { Northridge, campus. This is a three-story precast concrete park- } \\
\text { ing structure. Overall view showing collapse at east end of the } \\
\text { structure. }\end{array}$ & $\mathrm{C} 1$ & $35 \%$ & 1.0 & 4 \\
\hline
\end{tabular}




\begin{tabular}{|c|c|c|c|c|c|c|}
\hline Earthquake & ID & Damage description & Type & $\boldsymbol{A}$ & $\boldsymbol{E}$ & $T$ \\
\hline & NR579 & $\begin{array}{l}\text { Collapse of parking garage floors. See NR459-461 for damage } \\
\text { to Broadway department store. Fashion Center, Northridge, } \\
\text { California. }\end{array}$ & PC1 & $35 \%$ & 1.0 & 4 \\
\hline & NR221 & $\begin{array}{l}\text { Northridge Fashion Island Center. Interior reinforced-concrete } \\
\text { columns remain standing following collapse of second- and } \\
\text { third-floor concrete waffle slabs. Intact portion of waffle slab } \\
\text { roof shows typical slab construction. }\end{array}$ & $\mathrm{C} 1$ & $78 \%$ & 1.0 & 4 \\
\hline & NR303 & $\begin{array}{l}\text { View of partial roof collapse. South elevation, east of front entry. } \\
\text { View from east. Taken at } 3 \text { p.m. California State University, } \\
\text { Northridge. }\end{array}$ & $\begin{array}{l}\mathrm{C} 1 ? \\
\mathrm{C} 2 ?\end{array}$ & $1 \%$ & 1.0 & 4 \\
\hline & NR542, NR543 & Complete collapse of parking structure. Los Angeles, California. & $\mathrm{C} 1$ & $100 \%$ & 1.0 & 4 \\
\hline & NR328 & $\begin{array}{l}\text { Soft-story collapse of apartment building, at Hazeltine Ave. and } \\
\text { Milbank St. Sherman Oaks, California. }\end{array}$ & W1A & $33 \%$ & 1.0 & 3 \\
\hline & NR160, NR162 & $\begin{array}{l}\text { Overall view of Kaiser Permanente office building looking toward } \\
\text { the northeast. The brick facades at either end of the structure } \\
\text { have separated from the concrete frame, and the second floor } \\
\text { of the structure has completely collapsed. The bays at the north } \\
\text { and south ends of the building are also partly collapsed from } \\
\text { the second to the fifth floor. Granada Hills, California. }\end{array}$ & $\mathrm{C} 1$ & $30 \%$ & 1.0 & 4 \\
\hline $\begin{array}{l}\text { San Simeon } \\
\qquad 2003\left(M_{\mathrm{w}} 6.7\right)\end{array}$ & NM0001-NM0012 & $\begin{array}{l}\text { House of Bread, was located in the Mastagni/Acorn Building, } \\
\text { which collapsed. By the time these pictures were taken, emer- } \\
\text { gency personnel had removed the front wall of the building and } \\
\text { a great deal of debris. Built in 1892, the clock tower of this un- } \\
\text { reinforced masonry building had become a symbol of the town } \\
\text { of Paso Robles. The second story of the building collapsed } \\
\text { during the earthquake, killing two employees of Ann's Dress } \\
\text { Shop. The roof of the building collapsed directly westward onto } \\
\text { Park Street and landed on a row of parked cars. Debris from the } \\
\text { north wall went through the roof of an adjacent shop at } 1220 \\
\text { Park Street. Paso Robles, California. }\end{array}$ & URM & $78 \%$ & 1.0 & 3 \\
\hline $\begin{array}{l}\text { South Napa } \\
2012\left(M_{\mathrm{w}} 6.6\right)\end{array}$ & $\begin{array}{l}\text { P9050177, } \\
\text { P9080152 }\end{array}$ & $\begin{array}{l}\text { Don Perico's Restaurant in Napa. At the time of the earthquake, } \\
\text { the restaurant was located at } 10251 \mathrm{st} \text { St., Napa, California, } \\
\text { in the west end of the building at lat } 38.299029 \text { N., long } \\
122.285868 \mathrm{~W} \text {. That address seems to occupy approximately } 60 \\
\mathrm{ft} \times 60 \mathrm{ft} \text {. The collapsed wall appears to fill } 25 \mathrm{ft} \text { by } 12 \mathrm{ft} \text {, sug- } \\
\text { gesting a collapsed portion of } 8.3 \% \text {. }\end{array}$ & W2 & $8.3 \%$ & 1.0 & 1 \\
\hline
\end{tabular}

1965 and 2014. The database contains wood, concrete, and unreinforced masonry buildings. Areas affected range from zero (for example, cripple wall collapse that did not cause height reduction of an occupiable area) to 100 percent (for example, complete collapse of a parking structure). Among the sample of collapsed California buildings of the last 50 years, the average had 23 percent of its occupiable floor affected area. Therefore, on average 23 percent of occupants or passersby - people walking within a few feet of the building - could have been trapped or injured by a portion of building falling on them. On average, I estimate that 66 percent of occupants in the collapsed area would need extrication by USAR personnel, even if only by emergent civilian volunteers. Statistics by structural material are shown in table 2 .
In California, the 1934 Field Act outlawed the use of unreinforced masonry in most buildings. Consequently, URM buildings have become rarer in California than elsewhere in the Western United States, and many have been retrofitted, thus including the data of their past performance could conceivably bias estimates of future performance. Nonetheless, removing unreinforced masonry buildings and chimneys from the data does not substantially change the average affected area. The weighted average considering only tilt-up, other reinforced concrete, and wood is 22 percent. If one removes the cases where the collapse was limited to or caused by chimney collapse (that is, also removing the case where a chimney penetrated a roof), the average increases to 25 percent. 
Table 2. Average affected area $(A)$ and average fraction of occupants in collapsed areas requiring extrication $(E)$ in the urban search and rescue (USAR) model for the HayWired earthquake scenario.

$[\%$, percent $]$

\begin{tabular}{lccc}
\hline \multicolumn{1}{c}{ Material } & Count & Average $\boldsymbol{A}$ & Average $\boldsymbol{E}$ \\
\hline All & 73 & $23 \%$ & 0.66 \\
Tilt-up concrete & 14 & $17 \%$ & 0.10 \\
Other concrete & 9 & $50 \%$ & 0.94 \\
Unreinforced masonry & 18 & $28 \%$ & 0.98 \\
Wood & 32 & $17 \%$ & 0.66 \\
All except unreinforced & 54 & $22 \%$ & 0.56 \\
$\quad$ masonry & & & \\
All except chimneys & 66 & $25 \%$ & 0.65 \\
\hline
\end{tabular}

The estimated distribution of minimum USAR technical qualifications is shown in table 3 . It suggests that most search and rescue would have to be done by firefighters, rather than by untrained emergent civilian volunteers. This estimate is not necessarily inconsistent with figure 2 , whose bottom two strata are people who are not trapped by collapse and are not represented in the collapse photos examined here.

Considering all buildings, the distribution of affected area resembles an exponential distribution (though it does not pass a Lilliefors, 1967, goodness-of-fit test at the 5-percent significance level). An exponential distribution would mean that a building is approximately equally likely to collapse on 1 percent $\left(10^{-2}\right)$ of its occupiable area, 2 percent $\left(10^{-1.75}\right), 3$ percent $\left(10^{-1.5}\right)$, and so on, through 100 percent $\left(10^{\circ}\right)$. Among the wood buildings, the affected area tends to be lower; among the nine concrete buildings, the affected area tends to be higher, but nearly the full range is exhibited among each building type (reinforced concrete, tilt-up unreinforced masonry, and wood), as discussed later.

Suppose one wanted to perform a Monte Carlo simulation of USAR needs using a simple parametric model, for example, a mathematic idealization of the data presented here. To inform such simulations, I evaluated a few common parametric cumulative distribution functions for affected area: uniform, exponential, lognormal, power-law, and the distribution shown in equation 4 . The equation reflects a model in which there is a constant probability $f$ that the affected area is zero. If the affected area is nonzero, it is exponentially distributed:

$$
P[X \leq x]=1-f \times \exp (-L x) ; X \geq 0,
$$

where $f$ and $L$ are constants. The affected area data and equation 4 are plotted together in figure 3 for comparison. I refer to equation 4 as a frequency-and-exponential-severity model.

Of all the forms examined, only the one shown in equation 4 passed the Lilliefors (1967) goodness-of-fit test at the 5 percent significance level. The Lilliefors test is intended to check whether a sample is drawn from a normally distributed population with parameters of the distribution estimated from the sample. The test is not intended for this frequency-andexponential-severity model. I am aware of no comparable test for this frequency-and-exponential-severity model, so let the passing of the Lilliefors test merely indicate reasonableness in a qualitative manner. A parametric expression similar to a power law is also shown in figure 3 . It does not fit quite as well as the frequency-and-exponential distribution, but it is simpler.

Given a building that is modeled as having collapsed, one could simulate affected area by inverting equation 4 at the value of a sample of a random variable uniformly distributed between 0 and 1 ; that is, if I draw a sample $u \sim U(0,1)$, then the sample of affected area is the following:

$$
\begin{aligned}
x & =0 & & u \geq f \\
& =\frac{-1}{L} \ln \frac{(1-u)}{f} & & u<f
\end{aligned} .
$$

The mean number of people trapped in the collapsed area can be estimated as $n$ in equation 6 where the symbols \lfloor\rfloor mean "floor," that is, the largest integer less than or equal to the value inside:

$$
n=\lfloor x \times N \times E\rfloor,
$$

where $N$ denotes the number of occupants in the building and $E=0.66$. Alternatively, to account for building type and to treat uncertainty at least to a limited degree, use the cumulative distribution function of area affected from figure $3 B$. Invert the expression for $P[X \leq x]$ shown in the figure at a random sample of $\mathrm{U}(0,1)$ to simulate the affected area $x$. Then calculate $n$ according to equation 6 using the value of $E$ from table 2, and invert the

Table 3. Distribution of minimum technical qualifications for urban search and rescue (USAR) personnel, in percent.

[CERT, community emergency response team; URM, unreinforced masonry]

\begin{tabular}{lrrrrrrrr}
\hline Technical qualifications & All & URM & Not URM & Tilt-up & $\begin{array}{c}\text { Other con- } \\
\text { crete }\end{array}$ & Wood & Chimney & Not chimney \\
\hline 1 Civilian & 27 & 67 & 11 & 0 & 0 & 23 & 80 & 22 \\
2 CERT & 2 & 0 & 2 & 0 & 0 & 5 & 20 & 0 \\
3 Firefighter & 59 & 28 & 71 & 100 & 22 & 73 & 0 & 64 \\
4 USAR Task Force & 13 & 6 & 16 & 0 & 78 & 0 & 0 & 14 \\
\hline
\end{tabular}


binomial cumulative distribution function with parameters $n$ and $p$, where $p$ is another sample of $\mathrm{U}(0,1)$. One could go farther, treating $N$ as random and using a separate cumulative distribution function for affected area that varies by building type, but such a treatment is omitted here for brevity.

If one wanted to use the data presented here for modeling future performance of buildings, one must assume that the past is indicative of the future. Is it? There does not appear to be a correlation between affected area and earthquakes occurring in later years, as shown in figure 4 . The trend line has almost no slope, and the coefficient of determination $\left(R^{2}\right)$ is so low (0.0006) that one can be fairly confident that no trend actually exists. Because each earthquake affects an existing building stock that was built up over decades, the relation would be a lagging indicator, meaning a measurable factor that changes only after the process it measures has begun to follow a particular pattern or trend. But because approximately half the building stock was replaced over the five decades examined here, if newer buildings tended to experience lower collapse areas, one would expect to see a stronger downward trend. The implication is that, while collapse probability of an arbitrary building in the building stock may or may not change over time, if a building does collapse, its collapse area is not related to the year of collapse. To be clear, figure 4 does not say anything about the collapse probability of older versus newer buildings. It says only that, in that subset of buildings where at least some collapse occurs, the affected area does not vary with the year in which the earthquake occurred. One can reasonably assume that buildings in near-future earthquakes (the next several decades) will have approximately the same distribution of affected area as in the previous five decades. Note that the catalog does not indicate the age of the building that collapsed. Newer buildings presumably have a lower collapse probability than older buildings, all else being held equal, but that issue is separate from the one examined here.

A few additional observations of the nature and extent of collapse.

- Figure 5 shows that collapse of buildings with bearing walls composed of wood or unreinforced masonry generally affected the smallest total area in these buildings, followed by tilt-up concrete, then other reinforced concrete.

- Most collapses involving wood frame buildings affect less than 10 percent of the building area, that is, the median affected area is less than 10 percent. Furthermore, 95 percent of collapses affect less than half the building area. More than 30 percent do not collapse into occupied space at all. As shown in figure 5, the modal affected area (the tallest bar on the $1 / 4-\log$ increment bar charts) for wood frame buildings was between 0 and 1 percent. A common example of a building with such an affected area is one in which the unbraced cripple wall collapsed, without the loss of load-bearing capacity supporting a ceiling or roof above an occupied space (fig. $6 A$ ). The median affected
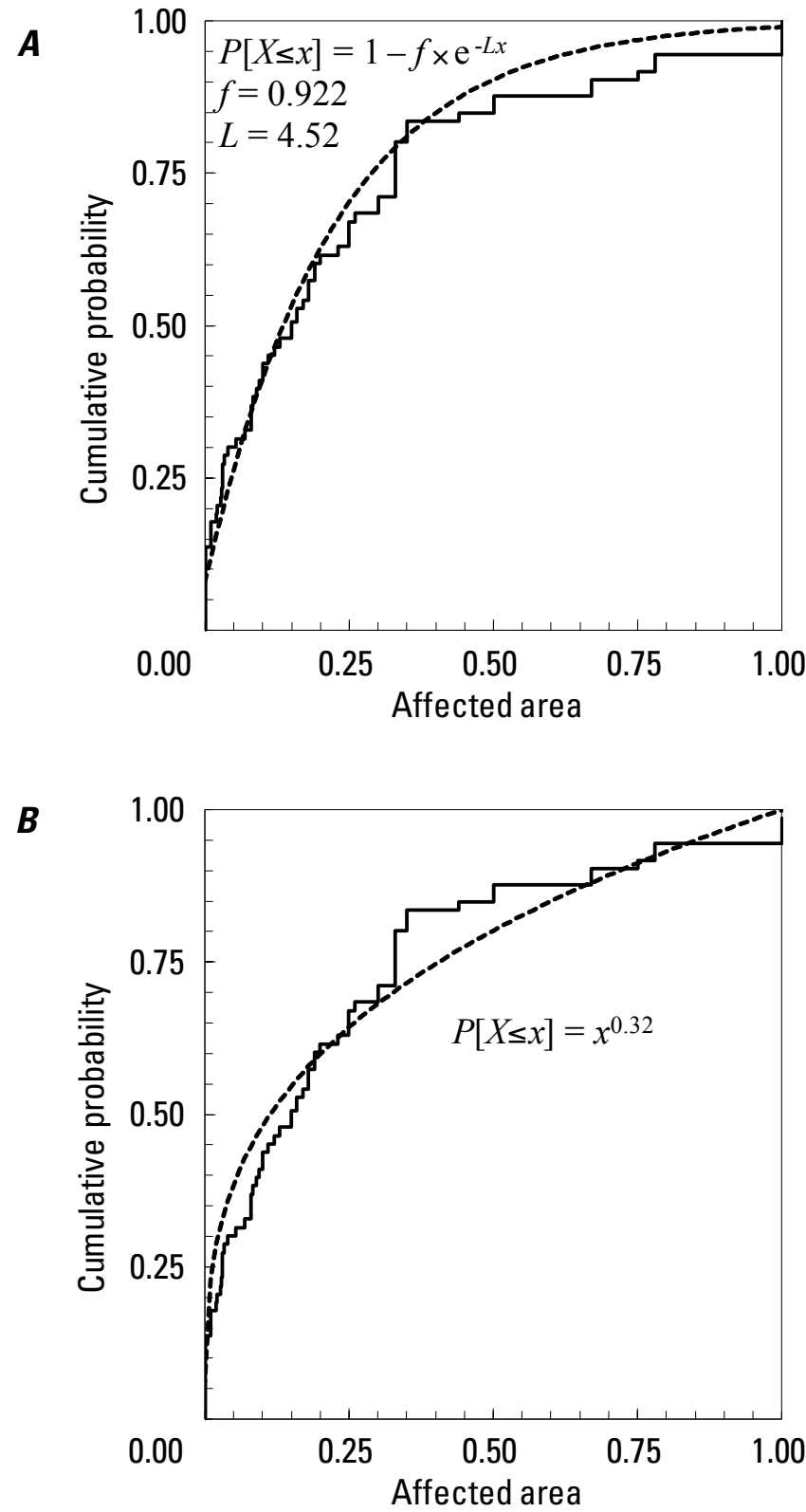

Figure 3. Graphs showing approximate parametric forms of the cumulative distribution function for affected area of all building types- $A$, frequency-and-exponential-severity; $B$, a simpler expression similar to a power law. The axis of affected area spans from 0.00 (no area affected) to 1.00 (100 percent of area affected).

area (the value with 50 percent probability of being exceeded) was between 6 percent and 10 percent of building area, commonly the collapse of a chimney or porch roof (for example, fig. $6 B$ ). The distribution of affected area in wood frame collapses is likely biased high. The reason for this is that the collapse of brick chimneys was likely too widespread and too uninteresting for NISEE e-library contributors to photograph instances in proportion to their actual occurrence within the population of wood frame buildings with collapse. 


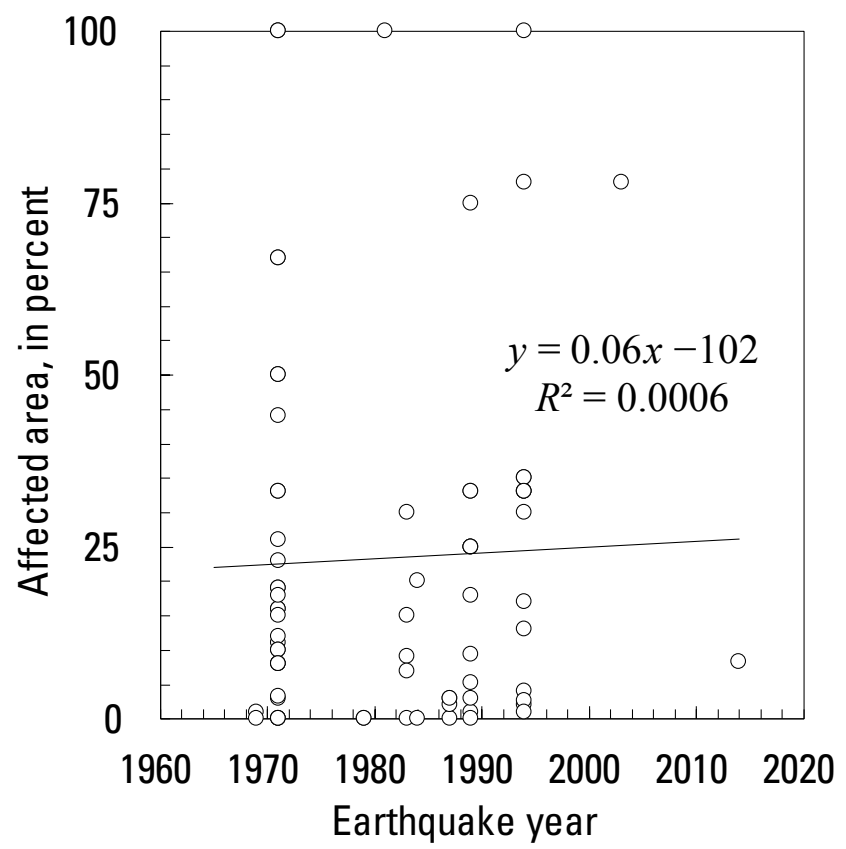

Figure 4. Graph showing affected area of all types of buildings versus year of earthquake, 1965-2014.

- Although the database includes instances of complete collapses of URM buildings, most URM collapses affect less than 18 percent of floor area. The modal affected area is between 18 and 32 percent of the building area, such as the collapse of brick parapets on the sidewalk, parking areas, and lower buildings adjacent to the URM building. That is, the URM collapses sampled here are commonly more dangerous to neighbors and passersby than to occupants. See figure 7 for representative examples.

- In the case of pre-1971 tilt-up construction examined here, most collapses affected less than 18 percent of the building area. The modal affected area was between 10 and 18 percent of the building area, almost always just inside the building perimeter where roofto-wall connection fractures occurred. The interior gravity system kept supporting interior subdiaphragms (away from the edge) even after perimeter subdiaphragms collapsed. See figure 8 for an example.

- Complete collapses of concrete buildings in California have occurred, but they are the exception rather than the rule. In most cases, less than 50 percent of the floor area is affected. The modal affected area on this $1 / 4$-log-increment scale was between 32 and 56 percent of building area. An example of such a modal collapse was that of a partial collapse of a parking structure, shown in figure 9. No obvious spatial pattern of collapse was observed in these images.

\section{Methodology for Estimating the Number of People Trapped in Elevators}

It is reasonable to assume that electric power will go out across the bay area as soon as substation equipment and perhaps buildings in the area near the earthquake's epicenter are damaged. Hence, the vast majority of elevators in the bay area will lose power before P-waves trigger seismic switches or ring-on-a-string devices. How many people will be in elevators with doors closed and traveling between floors when power goes out? I take the number of elevators in a metropolitan area $V_{\mathrm{m}}$ as:

$$
V_{\mathrm{m}}=\frac{P_{\mathrm{m}}}{p},
$$

where $P_{\mathrm{m}}$ is the population of the metropolitan area, and $p$ is the average number of people per elevator, which as noted earlier is approximately 344 in the United States. Let $V_{\mathrm{o}}$ of $(t)$ denote the number of elevators in motion with people inside and no emergency power at time $t$, and I estimate it as shown in equation 8 :

$$
V_{\mathrm{o}}(t)=V_{\mathrm{m}} \times f_{\mathrm{o}}(t) \times f_{\mathrm{c}} \times\left(1-f_{\mathrm{b}}\right)
$$

where $f_{\mathrm{b}}$ denotes the fraction of elevators with emergency power, $f_{\mathrm{o}}(t)$ is the estimated fraction of all elevators that are in use at time $t$, and $f_{\mathrm{c}}$ is the fraction of the time that an elevator in use with passengers in it is traveling between floors with the doors closed, which as noted earlier is on the order of 30 percent of the time. If the average elevator with passengers has $d$ passengers (as previously noted, $\mathrm{d} \approx 5$ ), then the number of people that will be trapped in elevators $N_{\mathrm{e}}$ can be estimated as shown in equation 9:

$$
\begin{aligned}
N_{\mathrm{e}} & =V_{\mathrm{o}}(t) \times d \\
& =\frac{P_{\mathrm{m}}}{p} \times f_{\mathrm{o}}(t) \times f_{\mathrm{c}} \times\left(1-f_{\mathrm{b}}\right) \times d
\end{aligned}
$$

\section{Application to HayWired Scenario}

\section{People Trapped in Collapsed Buildings, Based on the Building-Code Objectives}

I now turn to the question of urban search and rescue needs in the HayWired earthquake scenario. The HayWired scenario uses two approaches to estimate building damage-(1) based on building-code objectives (the Safe Enough approach documented in Porter [2015] and Porter [Not Safe Enough, this volume]) and (2) based on a combination of empirical observations, structural analysis, and engineering judgment, as encoded in the Hazus-MH model. FEMA performed a Hazus-MH analysis for the 
$\boldsymbol{A}$

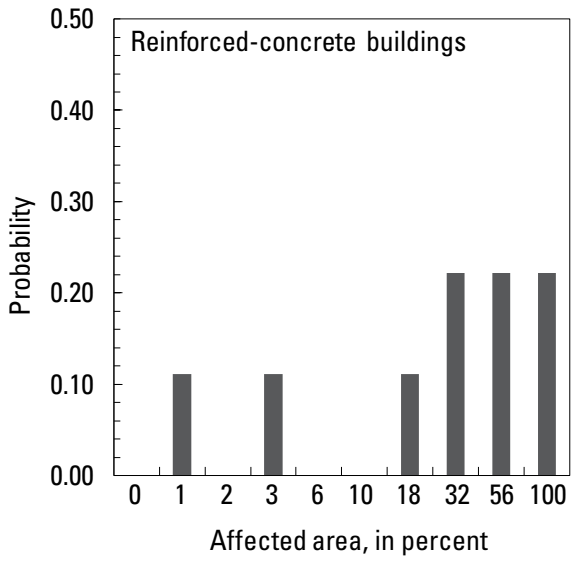

$\boldsymbol{B}$

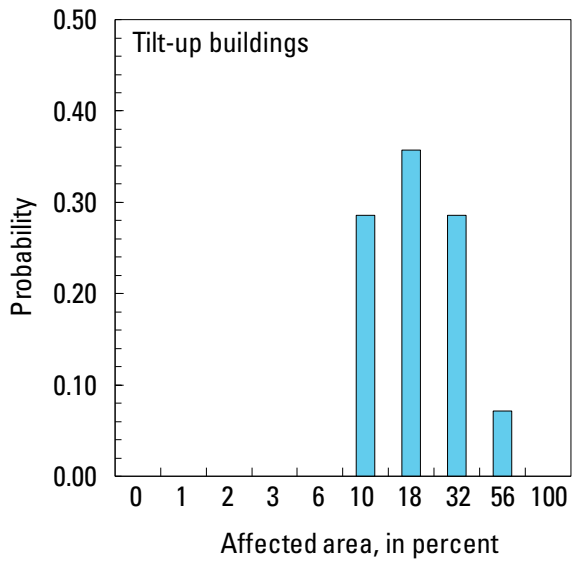

C

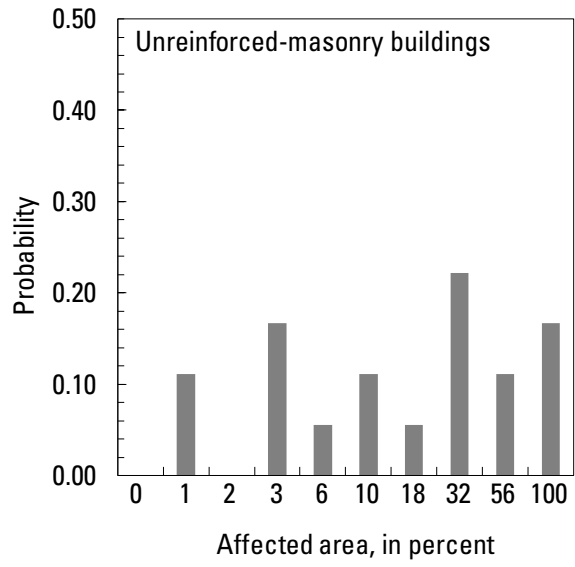

D

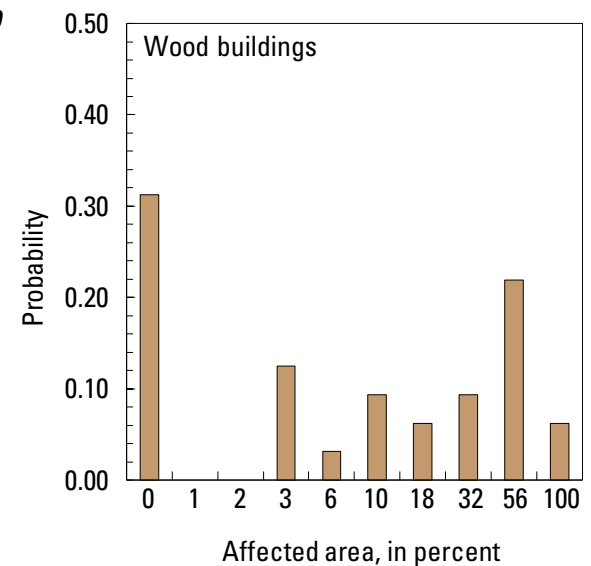

mainshock (Doug Bausch, written commun., Federal Emergency Management Agency, 2014), and Seligson and others (this volume) performed the Hazus-MH analysis for selected aftershocks.

Using the Safe Enough approach, I estimated the number of collapsed buildings in the HayWired mainshock to be $N_{\mathrm{b}}=7,800$ - if all buildings were to perform as well as modern (code-compliant) buildings - as estimated by a recent FEMA study (Applied Technology Council, 2009).

California is home to 38 million people and approximately 11 million buildings, or approximately 3.5 people per building. If 80 percent of people were indoors at the time of the earthquake (which seems realistic at 4:18 p.m. on a workday and consistent with Hazus-MH on an overall average basis), then there would be an average of about $O(t)=2.8$ occupants in each collapsed building at 4:18 p.m. As previously observed, the overall average fraction of building area that experiences collapse can be taken as $A \approx 0.25$. The overall average fraction of occupants in the collapsed area requiring USAR extrication can be taken as $E \approx 0.66$. Thus, if all buildings in the bay area just met current code requirements, equation 3 can estimate the number of people trapped in collapsed buildings:

$$
\begin{aligned}
N_{\mathrm{c}}(t) & =N_{\mathrm{b}} \times O(t) \times A \times E \\
& =7,800 \text { buildings } \times 2.8 \frac{\text { people }}{\text { building }} \times 0.25 \times 0.66 . \\
& =3,600 \text { people }
\end{aligned}
$$

That is, by the approach that uses building-code objectives, I estimate 3,600 people trapped in 7,800 collapsed buildings; however, many buildings with collapse would not have people trapped in them requiring USAR assistance.

\section{People Trapped in Collapsed Buildings, Based on Hazus-MH}

Hazus-MH does not estimate the number of people trapped in collapsed buildings, but it does estimate the number of buildings in the complete structural damage state and the fraction of their area that experiences collapse, the product of which I can take as $N_{\mathrm{b}} \times A$. Applying the values of $E$, estimated here by structural material, and applying a uniform occupant load of 2.8 occupants per collapsed building, I can estimate:

$$
N_{\mathrm{c}}(t)=O(t) \times \sum_{i}\left(\left(N_{\mathrm{b}, i} \times A_{i}\right) \times E_{i}\right)
$$

where $i$ is an index for the structural materials, $N_{\mathrm{b}, i} \times A_{i}$ is taken as the product of Hazus-MH's estimated number of buildings in the complete damage state and its estimate of the fraction of that building area that collapses, and $E_{i}$ is the fraction of

Figure 5. Graphs showing distribution of affected area by structural material: $A$, reinforced-concrete buildings except tilt-up; $B$, tilt-up concrete buildings; $C$, unreinforced-masonry buildings; and $D$, wood buildings. 


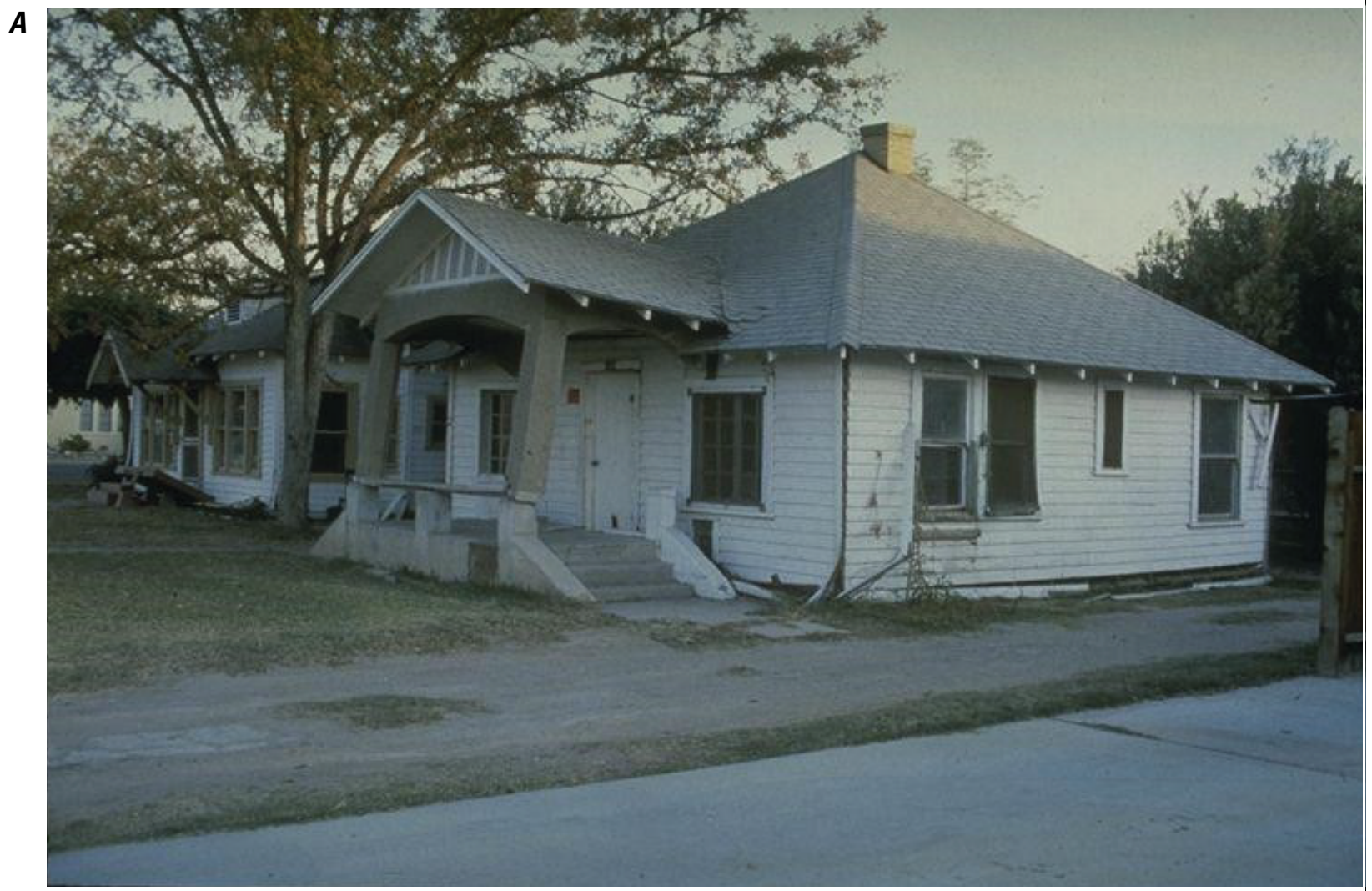

B

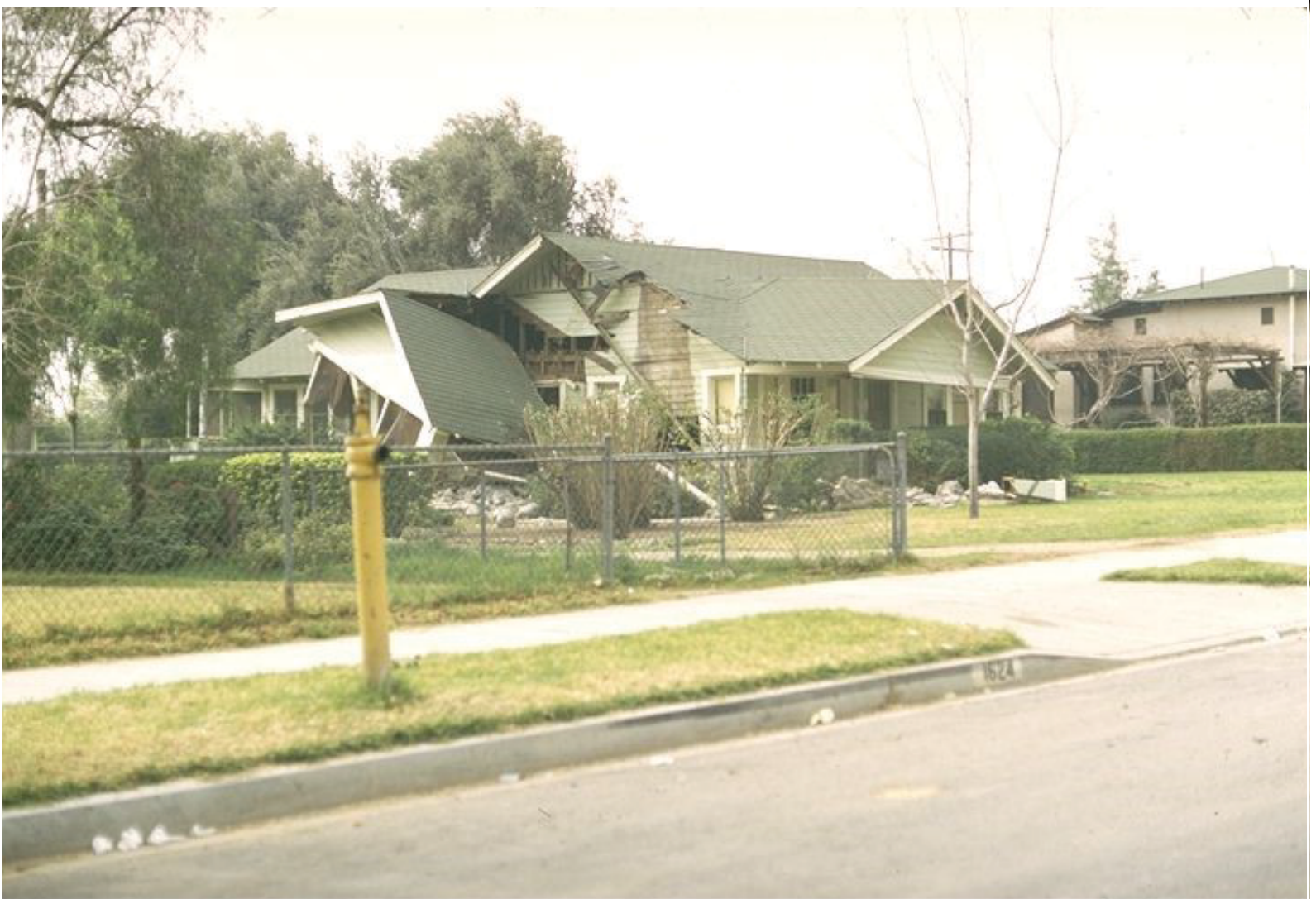

Figure 6. Photographs of homes damaged in earthquakes. $A$, An example of the modal affected area ( 0 percent) of a collapsed wood frame building - in the moment-magnitude-6.4 1979 Imperial Valley, California, earthquake. B, An example of the median affected area (6-10 percent) — collapse of a porch roof in the moment-magnitude-6.6 1971 San Fernando Valley, California, earthquake. (Photographs by M. Hopper, and V. Bertero, respectively, courtesy of the National Information Service for Earthquake Engineering, PEER-NISEE, University of California, Berkeley.) 


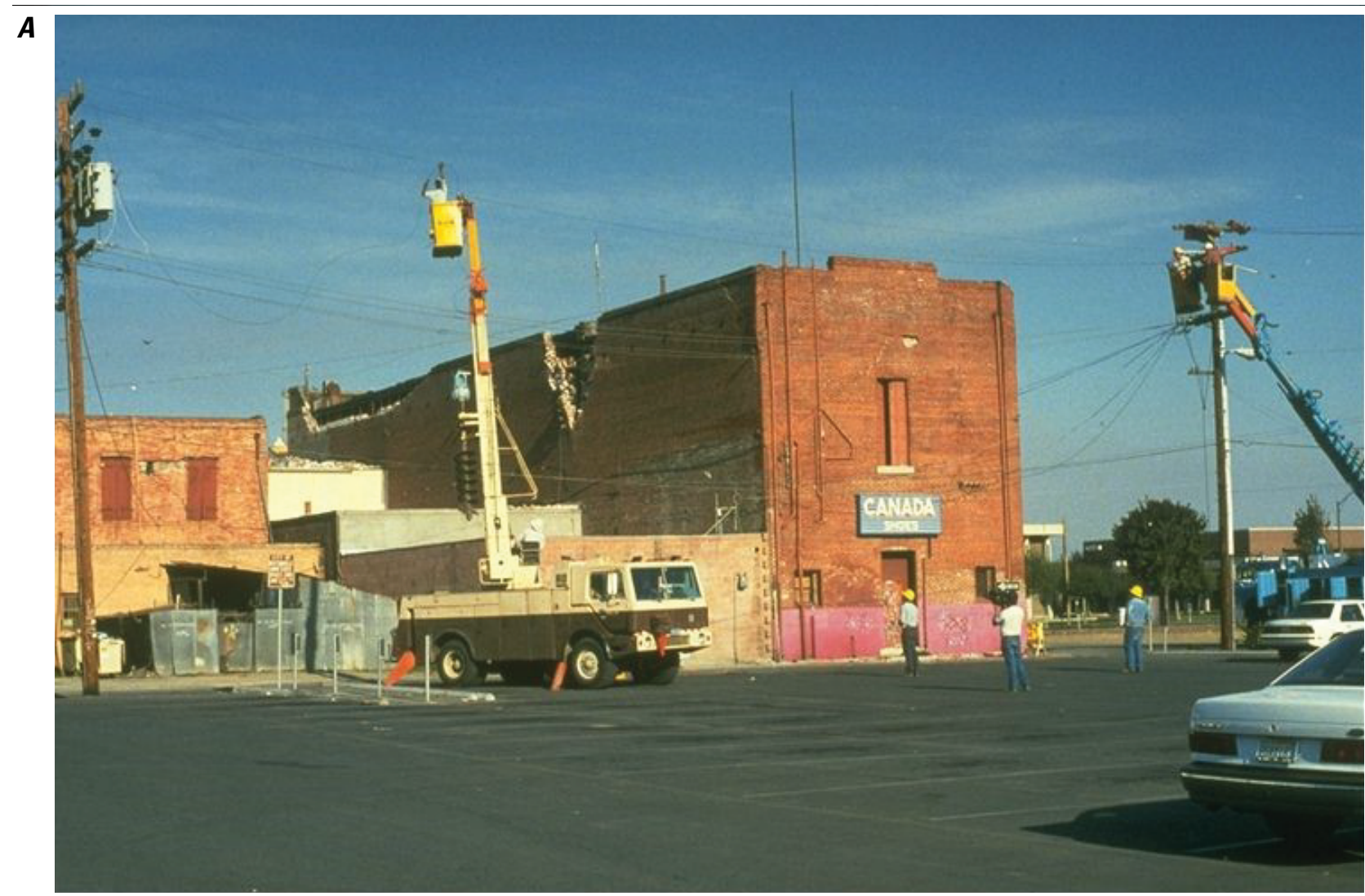

B

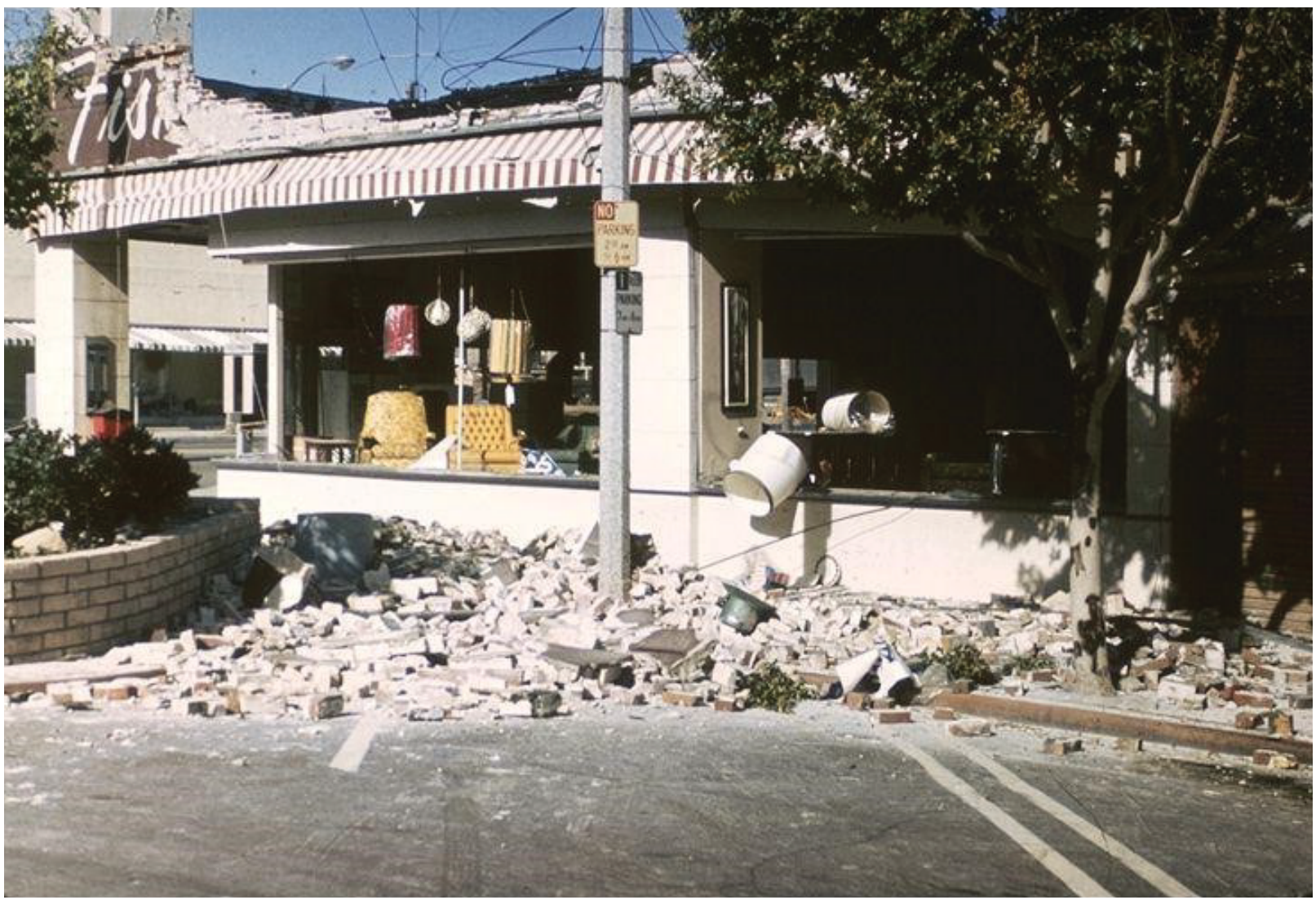

Figure 7. Photographs of examples of modal $(A)$ and median $(B)$ affected areas in unreinforced masonry (URM) buildings. $A$, Brick building damage in the moment-magnitude 6.9 1989 Loma Prieta, California, earthquake; $B$, store front collapsed in the momentmagnitude-6.6 1971 San Fernando Valley, California, earthquake. (Photographs by J. Blacklock and E. Schader, respectively, courtesy of the National Information Service for Earthquake Engineering, PEER-NISEE, University of California, Berkeley). 


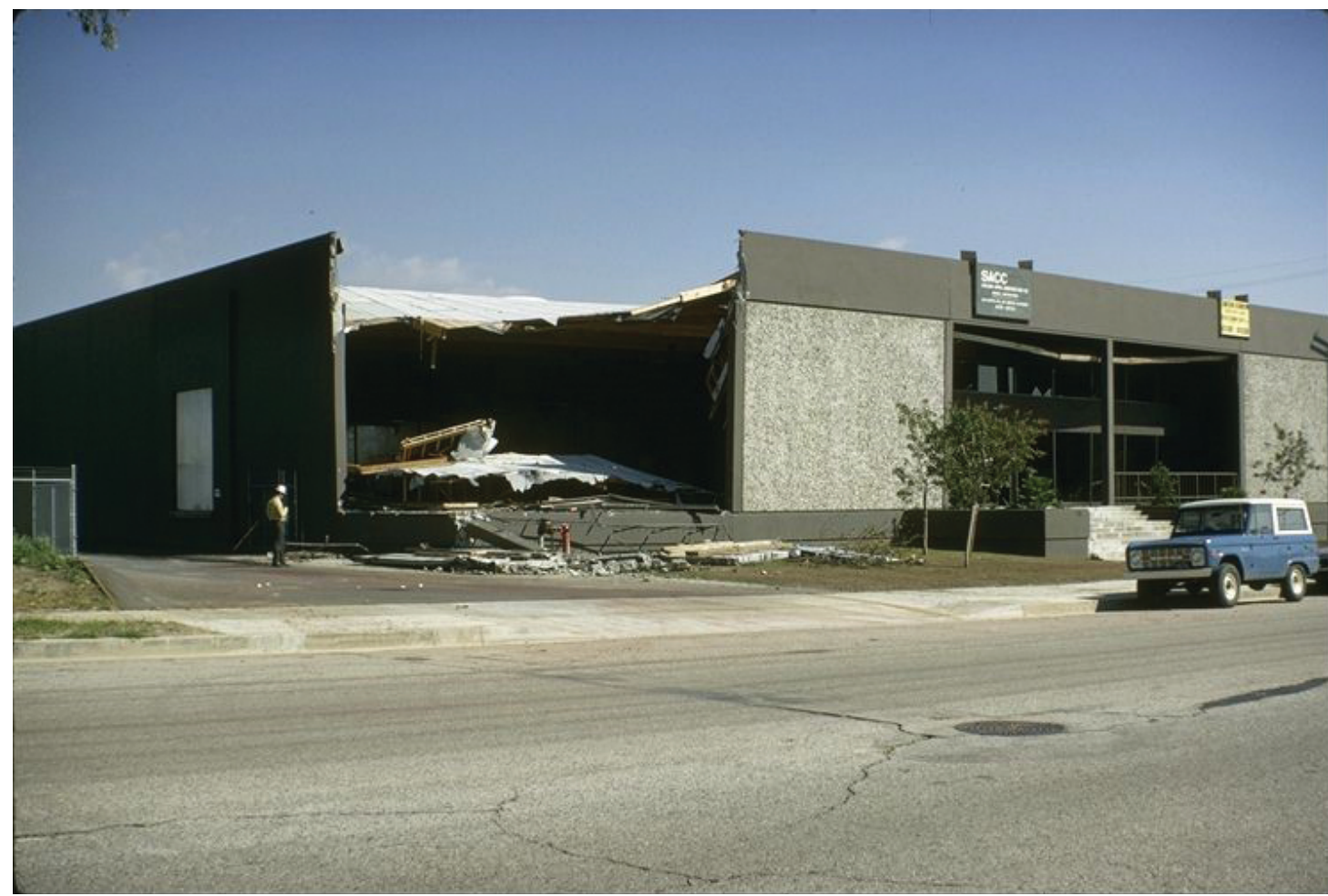

Figure 8. Photograph of an example of both modal and median collapse of tilt-up construction. damage was caused in the moment-magnitude-6.6 1971 San Fernando Valley, California, earthquake (Photograph by V. Bertero, courtesy of the National Information Service for Earthquake Engineering, PEER-NISEE, University of California, Berkeley.)

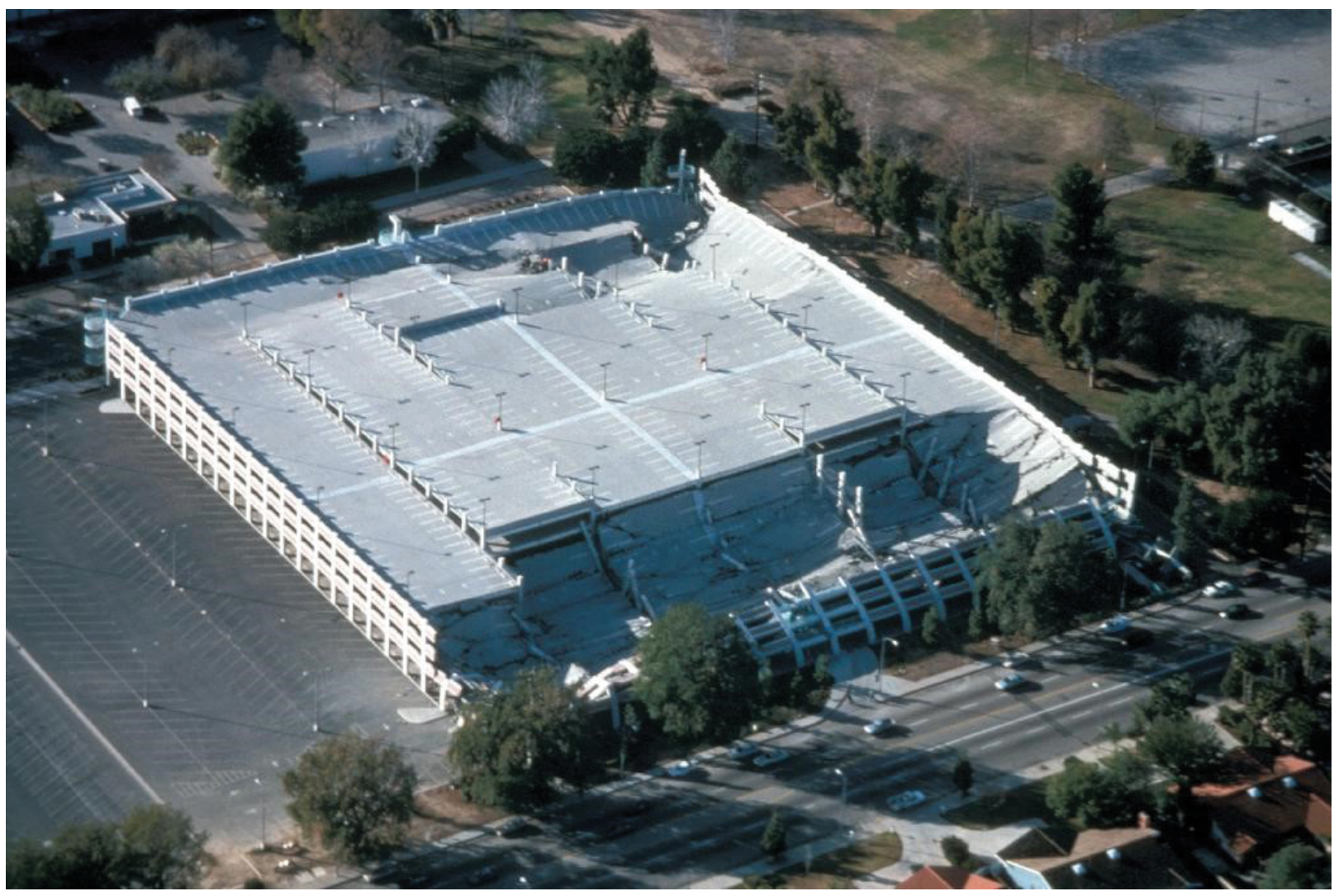

Figure 9. Photograph of an example of a partly collapsed reinforced-concrete structure, a parking garage at California State University, Northridge, damaged in the moment-magnitude-6.7 Northridge earthquake. (Photograph by P. Weigand, courtesy of the National Information Service for Earthquake Engineering, PEER-NISEE, University of California, Berkeley.) 
occupants requiring extrication for structural material $i$, from table 2. See table 4 for results.

How many buildings would Hazus-MH estimate had collapsed? Hazus-MH does not provide that estimate, but I can infer:

$$
M_{\mathrm{c}}=\sum_{i} \frac{M_{\mathrm{compl}, i} \times f_{\mathrm{colllcompl}, i}}{A_{i}}
$$

where $M_{\text {compl,i }}$ denotes Hazus-MH's estimate of the number of buildings of structural material $i$ in the complete structural damage state (column 2 in table 4 ); $f_{\text {coll leompl, } i}$ denotes the fraction of area collapsed, given that it is in the complete damage state (column 3 in table 4); $A_{i}$ is the fraction of building area that collapses (from table 2); and $i$ is an index for structural material. See table 5 for results.

Thus, one can infer from the combination of Hazus-MH's damage estimates and the observations of collapsed buildings made here that the HayWired mainshock would trap approximately 1,100 people in 2,100 collapsed buildings.

\section{Scenario Estimate of People Trapped in Collapsed Buildings}

Using Hazus-MH damage estimates for the HayWired scenario mainshock, 1,100 people will be trapped in 2,100 collapsed buildings, whereas by the Safe Enough approach, 3,600 people will be trapped in 7,800 collapsed buildings. That the two approaches differ by a factor of 3 essentially means that they agree within a half order of magnitude, which in the present state of loss modeling represents reasonable agreement.

However, the agreement is actually poorer than that, because the Safe Enough figures represent the expected behavior of post-1980 construction, and the Hazus-MH estimates are of the existing building stock, of which 60 to 70 percent predates 1980. One would expect the Safe Enough estimates to be less than those of Hazus-MH, if both were correct; they use the same inventory of buildings. However,
I use their estimates as benchmarks, their range representing two approaches to a realistic answer, and their medians, 2,500 people trapped in 5,000 collapsed buildings (in round numbers), as realistic estimates for the HayWired scenario.

\section{Number of People Trapped in Stalled Elevators}

I turn now to the question of people trapped in elevators. In a large bay area earthquake, power would be lost immediately throughout the bay area and return slowly as power plants are inspected, load is carefully restored, and damage is repaired. When power is lost, most elevators in the bay area (those that do not have emergency power) would stop, even before P-waves reached the elevators and triggered their ringand-string safety devices. What would be the USAR impacts of that loss of power to elevators? How many people would be trapped in elevators with their doors closed, traveling between floors?

Considering a San Francisco Bay area population of 10 million and using the previously observed average of one elevator per 344 people, one can use equation 7 to estimate the number of elevators in the San Francisco Bay area $\left(V_{\mathrm{m}}\right)$ :

$$
\begin{aligned}
V_{\mathrm{m}} & =\frac{P_{\mathrm{m}}}{p} \\
& =\frac{10,000,000 \text { people }}{344 \frac{\text { people }}{\text { elevators }}} . \\
& =29,000 \text { elevators }
\end{aligned}
$$

Subtracting 60 percent of the estimated 3,700 elevators in bay area high-rise buildings that have emergency power, and 2.5 percent of the remaining elevators and low- and mid-rise buildings with emergency power, an estimated 25,300 elevators in the bay area lack emergency power-I estimate 25,000 in round numbers. Recall the fraction of the time that an elevator that is in use with passengers in it is traveling between floors with the doors closed is $f_{\mathrm{c}} \approx 0.3$. I assume that at peak

Table 4. Number of people trapped in collapsed buildings, using Hazus-MH (Federal Emergency Management Agency, 2012) building damage estimates by Seligson and others (this volume) for the moment-magnitude-7 mainshock of the HayWired earthquake scenario.

$[E$, fraction of occupants in collapsed portion of buildings requiring extrication; $O(t)$, number of building occupants per collapsed building on a Thursday at $4: 18$ p.m.; $N_{\mathrm{c}}$, number of people in collapsed buildings requiring extrication]

\begin{tabular}{lccccc}
\hline \multicolumn{1}{c}{ Material } & $\begin{array}{c}\text { Number of buildings in com- } \\
\text { plete structural damage state }\end{array}$ & $\begin{array}{c}\text { Fraction of building area col- } \\
\text { lapsed, given complete damage }\end{array}$ & $\boldsymbol{E}$ & $\boldsymbol{O}^{(\boldsymbol{t})}$ & $\boldsymbol{N}_{\mathbf{c}}$ \\
\hline Wood & 4,946 & 0.03 & 0.66 & 2.8 & 274 \\
Steel & 1,595 & 0.05 & 0.66 & 2.8 & 147 \\
Concrete & 1,241 & 0.10 & 0.94 & 2.8 & 327 \\
Precast & 71 & 0.15 & 0.10 & 2.8 & 3 \\
Reinforced masonry & 725 & 0.10 & 0.66 & 2.8 & 134 \\
Unreinforced masonry & 639 & 0.15 & 0.98 & 2.8 & 263 \\
Manufactured housing & 4,340 & 0.03 & 0 & & 2.8 \\
\hline Total & & & & & \\
\hline
\end{tabular}


Table 5. Number of collapsed buildings, using Hazus-MH (Federal Emergency Management Agency, 2012) building damage estimates by Seligson and others (this volume) for the moment-magnitude-7 mainshock of the HayWired earthquake scenario.

\begin{tabular}{lcccc}
\hline Material & $\begin{array}{c}\text { Number in complete } \\
\text { structural damage } \\
\text { state }\end{array}$ & $\begin{array}{c}\text { Fraction of area } \\
\text { collapsed, given } \\
\text { complete damage }\end{array}$ & $\begin{array}{c}\text { Fraction of area col- } \\
\text { lapsed in collapsed } \\
\text { buildings }\end{array}$ & $\begin{array}{c}\text { Collapsed } \\
\text { buildings }\end{array}$ \\
\hline Wood & 4,946 & 0.03 & 0.17 & 873 \\
Steel & 1,595 & 0.05 & 0.23 & 347 \\
Concrete & 1,241 & 0.10 & 0.50 & 248 \\
Precast & 71 & 0.15 & 0.17 & 63 \\
Reinforced masonry & 725 & 0.10 & 0.28 & 259 \\
Unreinforced masonry & 639 & 0.15 & 0.28 & 342 \\
Manufactured housing & 4,340 & 0.03 & 0.00 & \\
\hline Total & & & & 2,132 \\
\hline
\end{tabular}

hours (and 4:18 p.m. on a weekday is likely a peak hour), most elevators are in use and most are carrying passengers primarily in one direction, so I assume $f_{\mathrm{o}}(t) \approx 0.6$. Then by equation 8 , the number of elevators stalled with people inside at the time of the HayWired mainshock can be estimated as:

$$
\begin{aligned}
V_{0}(t) & =V_{\mathrm{m}} \times f_{\mathrm{o}}(t) \times f_{\mathrm{c}} \times\left(1-f_{\mathrm{b}}\right) \\
& =25,000 \times 0.6 \times 0.3 \\
& =4,500 \text { elevators }
\end{aligned}
$$

And as previously noted, the average elevator carries $d=5$ people when occupied, so one can use equation 9 to estimate $N_{\mathrm{e}}$, the number of occupants trapped in elevators by the HayWired mainshock:

$$
\begin{aligned}
N_{\mathrm{e}} & =V_{\mathrm{o}}(t) \times d \\
& =4,500 \text { elevators } \times 5 \frac{\text { occupants }}{\text { elevator }} \\
& =22,500 \text { occupants }
\end{aligned} .
$$

So it seems realistic that on the order of 22,500 people could be trapped in 4,500 elevators by the sudden loss of electric power after the HayWired mainshock, requiring fire department assistance to escape. Untrained first responders will be unable to assist the people trapped in elevators because technical skills and equipment are required to extricate people from elevators.

It is possible to retrofit some existing elevators with emergency power to reduce the demand for elevator rescue. Kornfield (San Francisco Department of Building Inspection, retired, written commun., 2015) estimates the cost of retrofitting elevators to be on the order of $\$ 20,000$ per elevator, and only 30 to 40 percent of elevators in the bay area could be retrofitted, so retrofit could reduce elevator entrapment to 14,000 people in 3,000 stalled elevators.

\section{Conclusions}

\section{USAR Demands Under Current Conditions}

There are currently no public models of urban search and rescue demands after earthquakes. Although engineers can estimate the number of buildings that collapse in an earthquake, we do not know what fraction of building area experiences collapse when at least some collapse occurs, nor do we know what fraction of occupants in those collapsed areas require extrication by urban search and rescue personnel.

To estimate the search-and-rescue demands after the HayWired earthquake scenario mainshock, I compiled a photographic database of 72 buildings known to have experienced at least some collapse (structural or nonstructural) in 10 California earthquakes in the last 50 years. These include all buildings with images in the NISEE e-library whose description includes the word "collapse," "fail," "fell," or "parapet," plus 12 tilt-up buildings with roof collapse documented in a NOAA report on the 1971 San Fernando earthquake and one collapse from the 2014 South Napa earthquake. Slightly more than half of these were wood frame buildings, 13 were unreinforced masonry, and 9 were of reinforced concrete. I found that on average, about 25 percent of the total square footage collapses, given that at least some collapse occurs. The fraction varies by structural material, from about 17 percent (tilt-up concrete and wood) to about 50 percent (cast-in-place reinforced concrete). I also estimated the fraction of occupants in the collapsed area who would require USAR assistance by various levels of technical expertise, based on CERT training guidelines. Applying the observations from these historical California building collapses, I estimated that on the order of 2,400 people could realistically require extrication from approximately 5,000 collapsed buildings. Older buildings are generally more likely 
to collapse, so the trapped population will tend to be in older buildings.

There is no public model of USAR demands resulting from power loss to elevators. However, using relevant estimates of the total number of elevators nationwide and local experts' observations that few San Francisco Bay area elevators have emergency power, I estimated that on the order of 22,500 people would be trapped in 4,500 stalled elevators.

\section{USAR Demands Under Ideal-World Conditions}

In Porter (Societal Consequences, this volume), I estimated that the number of collapsed buildings in the HayWired mainshock could be reduced by a factor of four if all buildings were designed with an earthquake importance factor of $I=1.5$ (as defined in American Society of Civil Engineers, 2010). Doing so would reduce the number of people trapped in collapsed buildings proportionately, from 2,500 people trapped in 5,000 collapsed buildings to perhaps 600 people trapped in 1,200 collapsed buildings. Retrofit of newer elevators with emergency power could reduce elevator entrapment to 14,000 people in 3,000 stalled elevators.

\section{Limitations}

Other buildings have collapsed in California earthquakes over the last 50 years that do not appear in the NISEE e-library or the other sources examined here. The distribution of affected area in these images may be biased relative to the distribution of affected area in the population of collapsed buildings, for example, if photographers who contributed to the NISEE e-library preferred to photograph buildings with more or less affected area than they would have done if they selected collapsed buildings at random to photograph. Absent a big California earthquake in which one can deliberately select collapsed buildings to examine in an unbiased way, I do not know how to test whether the photographers introduced bias in this way. However, the presence of numerous buildings with affected areas across the entire possible range of 0 to 100 percent shows that the observations are at least diverse, even if their representativeness cannot be known without more data. I find the database sufficiently useful for estimating the distribution of affected area, at least until better data - more definitely representative - come along. Some readers may object that the buildings shown here do not represent an exhaustive list of collapsed California buildings, but few surveys are exhaustive. Samples commonly provide useful statistical information.

\section{Acknowledgments}

Sarah Durphy (Estructure), Craig Stevenson (Aurecon), Lawrence Kornfield (San Francisco Department of Building Inspection, retired), John Osteraas (Exponent Failure Analysis
Associates), Marko Schotanus (Rutherford and Chekene), George von Klan (GVK-ECS, Inc.), and Anne Wein (U.S. Geological Survey) reviewed the draft report and offered valuable comments and recommendations. The author thanks them for their contributions.

\section{References Cited}

American Society of Civil Engineers, 2010, Minimum design loads for buildings and other structures, ASCE/SEI 7-10: Reston, Va., American Society of Civil Engineers, 608 p.

Applied Technology Council, 1985, ATC-13, Earthquake damage evaluation data for California: Redwood City, Calif., Applied Technology Council, 492 p.

Applied Technology Council, 2009, Quantification of building seismic performance factors: Prepared for the Federal Emergency Management Agency, FEMA P-695, 421 p.

Applied Technology Council, 2015a, Rapid visual screening of buildings for potential seismic hazards - A handbook ( $3 \mathrm{~d}$ ed.): Prepared for the Federal Emergency Management Agency, FEMA P-154, 388 p.

Applied Technology Council, 2015b, Rapid visual screening of buildings for potential seismic hazards-Supporting documentation ( $3 \mathrm{~d}$ ed.): Prepared for the Federal Emergency Management Agency, FEMA P-155, 206 p. [Also available online at https://www.fema.gov/medialibrary-data/1426210695613-d9a280e72b32872161efab26a602283b/FEMAP-155 508.pdf.]

Benfer, N.A., and Coffman, J.L., eds.,1973, San Fernando, California, earthquake of February 9, 1971-Effects on building structures; volume 1: U.S. Department of Commerce, National Oceanic and Atmospheric Administration, $448 \mathrm{p}$.

Bibliop, 2010, Bullock's Northridge, Northridge - 3rd Floor: Flickr online image taken on September 12, 2010, accessed December 11, 2017, at https://www.flickr.com/photos/53409445@N04/sets/72157625752688863/.

Building Seismic Safety Council, 2009, NEHRP recommended seismic provisions for new buildings and other structures: Prepared for the Federal Emergency Management Agency, FEMA P-750, 406 p.

California State University Northridge, 2017, Building information: California State University Northridge Oviatt Library web page, accessed June 2015, at https://library. csun.edu/About/BuildingInformation.

Celebi, M., and Page, R., 2005, Monitoring earthquake shaking in federal buildings: U.S. Geological Survey Fact Sheet 2005-3052, 2 p. [Also available at https://pubs.usgs.gov/ fs $/ 2005 / 3052 /$. 
Christensen, A., 2009, Remembering the Loma Prieta earthquake: Loma Prieta Stories blog, November 5, 2009, accessed June 2015, at https://lomaprietastories.wordpress. $\mathrm{com} / \mathrm{tag} /$ santa-cruz-fires-and-earthquakes/.

Earth Science World Image Bank, 2017, Photo ID h32fh3: Earth Science World Image Bank web page, accessed November 2017, at http://www.earthscienceworld.org/ images $/$ search $/$ results.html?begin $=10 \&$ num $=2 \&$ numBe gin $=1 \&$ Category $=\&$ Continent $=\&$ Country $=\&$ Keyword $=$ San\%20Andreas\%20Fault\#null.

Emporis Corporation, 2007, Emporis research: Emporis Web page, accessed June 19, 2007, at www.emporis.com.

Federal Emergency Management Agency, 2002, Rapid visual screening of buildings for potential seismic hazardsTraining slide set: Federal Emergency Management Agency, Washington, DC, $144 \mathrm{p}$.

Federal Emergency Management Agency, 2012, Hazus multi-hazard loss estimation methodology, earthquake model, Hazus ${ }^{\circledR}-$ MH 2.1 technical manual: Federal Emergency Management Agency, Mitigation Division, 718 p., accessed July 18, 2017, at https:// www.fema. gov/media-library-data/20130726-1820-25045-6286/ hzmh2_1_eq_tm.pdf.

International Code Council, 2009, International building code 2009: Country Club Hills, Ill., International Code Council, 716 p.

JPG Magazine LLC, 2017, Photograph eq8: JPG Magazine web page, accessed November 2017, at http://jpgmag.com/ photos/1989999.

Krimgold, F., 1988, Search and rescue in collapsed reinforced concrete buildings: Proceedings of the Ninth World Conference on Earthquake Engineering, Tokyo and Kyoto, Japan, August 2-9, 1988, v. VII, p. 693-696.

Lilliefors, H., 1967, On the Kolmogorov-Smirnov test for normality with mean and variance unknown: Journal of the American Statistical Association, v. 62, no. 318, p. $399-402$

Moore, D., 2014, Loma Prieta's legacy, 25 years later: Press Democrat, October 16, 2014, accessed June 2015, at http:// www.pressdemocrat.com/news/2983451-181/loma-prietaslegacy-25-years.

National Elevator Industry, Inc., 2014, Elevator and escalator fun fact: Salem NY, National Elevator Industry, 1 p.

National Fire Protection Association, 2014, NFPA 1670Standard on operations and training for technical search and rescue incidents: National Fire Protection Association, NFPA 1670, 116 p., accessed November 15, 2015, at http://www.nfpa.org/codes-and-standards/documentinformation-pages? mode $=$ code $\&$ code $=1670$.
National Oceanic and Atmospheric Administration, n.d., Natural hazard images database: National Oceanic and Atmospheric Administration, National Centers for Environmental Information, database, doi:10.7289/V5154F01.

National Urban Search and Rescue Response System, 2009, Structural collapse technician course student manual: Washington, D.C., Federal Emergency Management Agency, $501 \mathrm{p}$.

PerformTech, Inc., 2011, Community emergency response team basic training participant manual: Developed for National CERT Program, Federal Emergency Management Agency, accessed November 17, 2015, at http://www.fema.gov/medialibrary/assets/documents/27403.

Porter, K.A., 2015, Safe enough? A building code to protect our cities as well as our lives: Earthquake Spectra, v. 32, no. 2, p. 677-695, doi: http://dx.doi.org/10.1193/112213EQS286M.

Scawthorn, C.R., Porter, K.A., and Blackburn, F.T., 1992, Performance of emergency-response services after the earthquake, in O'Rourke, T.D., ed., The Loma Prieta, California, earthquake of October 17, 1989-Marina District: U.S. Geological Survey Professional Paper 1551-F, p. F195F215.

Schiff, A., 2008, The ShakeOut scenario supplemental studyElevators: Denver, Colo., SPA Risk LLC, accessed November 17, 2015, at https://goo.gl/jYJJfZ.

Shoaf, K.I., Nguyen, L.H., Sareen, H.R., and Bourque, L.B., 1998, Injuries as a result of California earthquakes in the past decade: Disasters, v. 22, no. 3, p. 218-235.

So, E.M.K., and Pomonis, A., 2012, Derivation of globally applicable casualty rates for use in earthquake loss estimation models, in World Conference on Earthquake Engineering, 15th, Lisbon, Portugal, September 24-28, 2012.

Strakosch, G.R., and Caporale, R.S., 2010, The vertical transportation handbook: Hoboken, NJ, John Wiley \& Sons, $624 \mathrm{p}$.

Taylor, A., 2014, The Northridge earthquake-20 years ago today: The Atlantic, January 17, 2014, accessed June 2015, at https://www.theatlantic.com/photo/2014/01/the-northridgeearthquake-20-years-ago-today/100664/.

Todd, D., Carino, N., Chung, R.M., Lew, H.S., Taylor, A.W., Walton, W.D., Cooper, J.D., and Nimis, R., 1994, 1994 Northridge earthquake-Performance of structures, lifelines, and fire protection systems: National Institute of Standards and Technology Special Publication 862, 187 p.

Yeo, G.L., and Cornell, C.A., 2002, Building-specific seismic fatality estimation methodology: Proceedings of the Fourth U.S.-Japan Workshop on Performance-Based Earthquake Engineering Methodology for Reinforced Concrete Building Structures, October 22-24, 2002, Toba, Japan, p. 59-74. 


\section{Appendixes 1 through 12-National Information Service for Earthquake Engineering e-Library Images of Building Collapse in California, 1965-2014}

These appendixes present images of building collapse caused by earthquakes in California in the past 50 years. The appendixes are organized by earthquake in chronological order, beginning with the Borrego Mountain earthquake of 1968 (a list of earthquakes with no available images, such as Borrego Mountain, is in appendix 12). Within each section, collapses are documented with their descriptions and other metadata, followed by the author's estimate of the affected area, and then images of the collapse. Unless noted otherwise, metadata and images are from collections in the National Information Service for Earthquake Engineering (NISEE) e-library. Permission for their use is granted at http://nisee.berkeley.edu/elibrary/about.html. Note that earthquake magnitudes may not exactly match final moment magnitudes determined by the U.S. Geological Survey. Because of the large number of images, figures are numbered by appendix.

[Abbreviations used in the appendixes—-ft, feet; $\mathrm{ft}^{2}$, square feet; in., inch; \%, percent, Calif., California; St., Street, Ave., Avenue; Rd., Road. --, no data]

\section{Appendix 1. Santa Rosa (1969) Collapse Images}

\section{Image Metadata and Description for Figure 1-1}

Karl V. Steinbrugge Collection: S3715

\begin{tabular}{cccccc}
\hline $\begin{array}{c}\text { Earthquake date } \\
\text { and magnitude }(\boldsymbol{M})\end{array}$ & Title & Creator & Date & Location & Description \\
\hline $\begin{array}{ccccc}\text { October 1, 1969; } \\
\text { M5.59 }\end{array}$ & $\begin{array}{c}\text { Damage to wood } \\
\text { frame house in } \\
\text { the fault zone }\end{array}$ & $\begin{array}{c}\text { Steinbrugge, } \\
\text { Karl V. }\end{array}$ & October 6, 1969 & $\begin{array}{c}\text { North America/ Sonoma } \\
\text { County/ United States/ }\end{array}$ & $\begin{array}{c}\text { Two-story wood frame building } \\
\text { off foundations. Foundations } \\
\text { were rotted and poorly braced. } \\
\end{array}$ \\
& & & Santa Rosa/ California & $\begin{array}{l}\text { Gas lines ruptured when house } \\
\text { fell. 718 Beaver St., Santa Rosa, } \\
\text { California. }\end{array}$ \\
\end{tabular}

Author's Estimate of Affected Area

$0 \%$

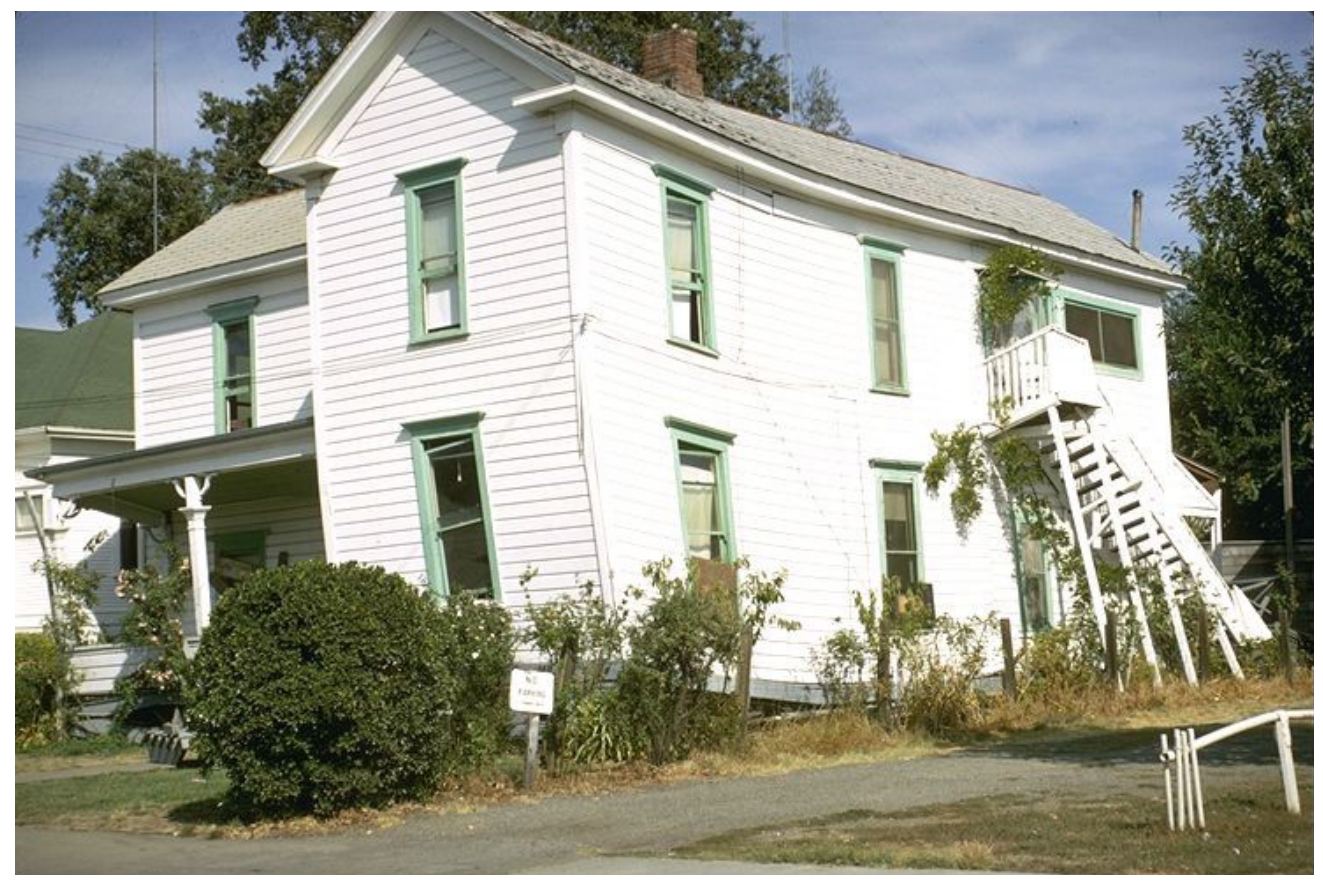

Figure 1-1. Photograph showing two-story wood frame house that collapsed in the 1969 Santa Rosa, California, earthquake. 


\section{Image Metadata and Description for Figure 1-2}

Karl V. Steinbrugge Collection: S3726

\begin{tabular}{|c|c|c|c|c|c|}
\hline $\begin{array}{c}\text { Earthquake date and } \\
\text { magnitude }(M)\end{array}$ & Title & Creator & Date & Location & Description \\
\hline $\begin{array}{l}\text { October 1, 1969; } \\
\quad \text { M5.59 }\end{array}$ & $\begin{array}{l}\text { Damage to wood } \\
\text { frame house in } \\
\text { the fault zone }\end{array}$ & Steinbrugge, Karl V. & October 6, 1969 & $\begin{array}{l}\text { North America/ } \\
\text { Sonoma } \\
\text { County/ United } \\
\text { States/ Santa } \\
\text { Rosa/ California }\end{array}$ & $\begin{array}{l}\text { Two-story wood frame } \\
\text { building off foundations. } \\
\text { Foundations were rotted } \\
\text { and poorly braced. Gas lines } \\
\text { ruptured when house fell. } \\
718 \text { Beaver St., Santa Rosa, } \\
\text { California. }\end{array}$ \\
\hline
\end{tabular}

\section{Author's Estimate of Area}

Plan area $\approx 13,000 \mathrm{ft}^{2} \times 3$ stories. Area littered by bricks $\approx 25 \mathrm{ft} \times 15 \mathrm{ft}=1 \%$ of $39,000 \mathrm{ft}^{2}$.

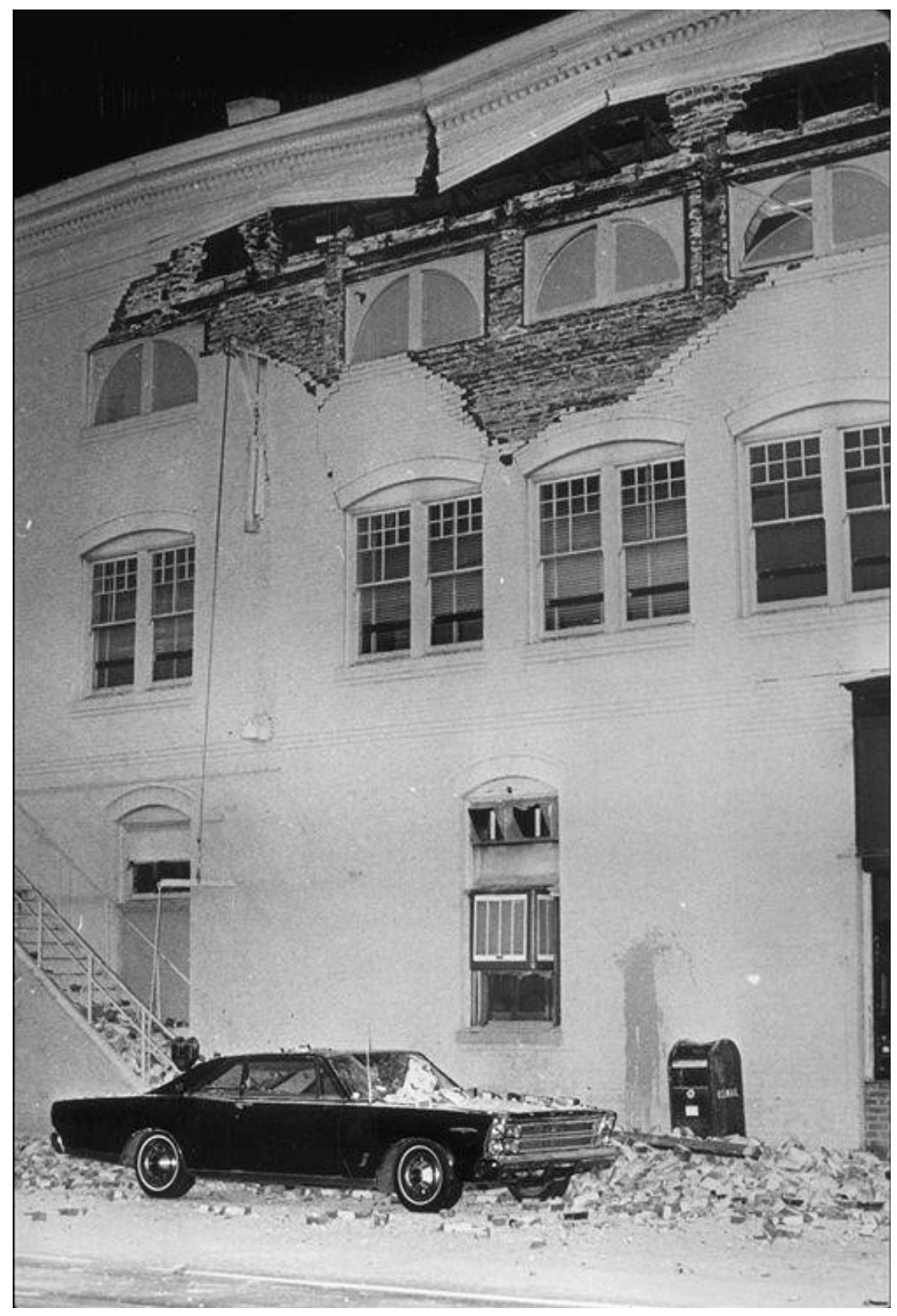

Figure 1-2. Photograph showing part of a wall that collapsed onto a car in the 1969 Santa Rosa, California, earthquake. 


\section{Appendix 2. San Fernando (1971) Collapse Images}

\section{Image Metadata and Description for Figure 2-1}

Karl V. Steinbrugge Collection: S4473

\begin{tabular}{cccccc}
\hline $\begin{array}{c}\text { Earthquake date } \\
\text { and magnitude }(\boldsymbol{M})\end{array}$ & Title & Creator & Date & Location & Description \\
\hline $\begin{array}{l}\text { February 9, 1971; } \\
\text { M6.6 }\end{array}$ & $\begin{array}{c}\text { Damage to wood } \\
\text { frame house in } \\
\text { the fault zone }\end{array}$ & $\begin{array}{c}\text { Steinbrugge, } \\
\text { Karl V. }\end{array}$ & February 16, 1971 & $\begin{array}{c}\text { North America/ Los } \\
\text { Angeles County/ }\end{array}$ & $\begin{array}{c}\text { Damage to porches (probable cripple } \\
\text { wall failure); chimney fell away } \\
\text { from house. In the vicinity of Knox } \\
\text { and Orange Grove Streets, in the } \\
\text { fault zone. }\end{array}$ \\
\hline
\end{tabular}

\section{Author's Estimate of Affected Area}

Approximately $\left(120 \mathrm{ft}^{2}\right.$ porch $) /\left(1,500 \mathrm{ft}^{2}\right.$ house $)=8.0 \%$.

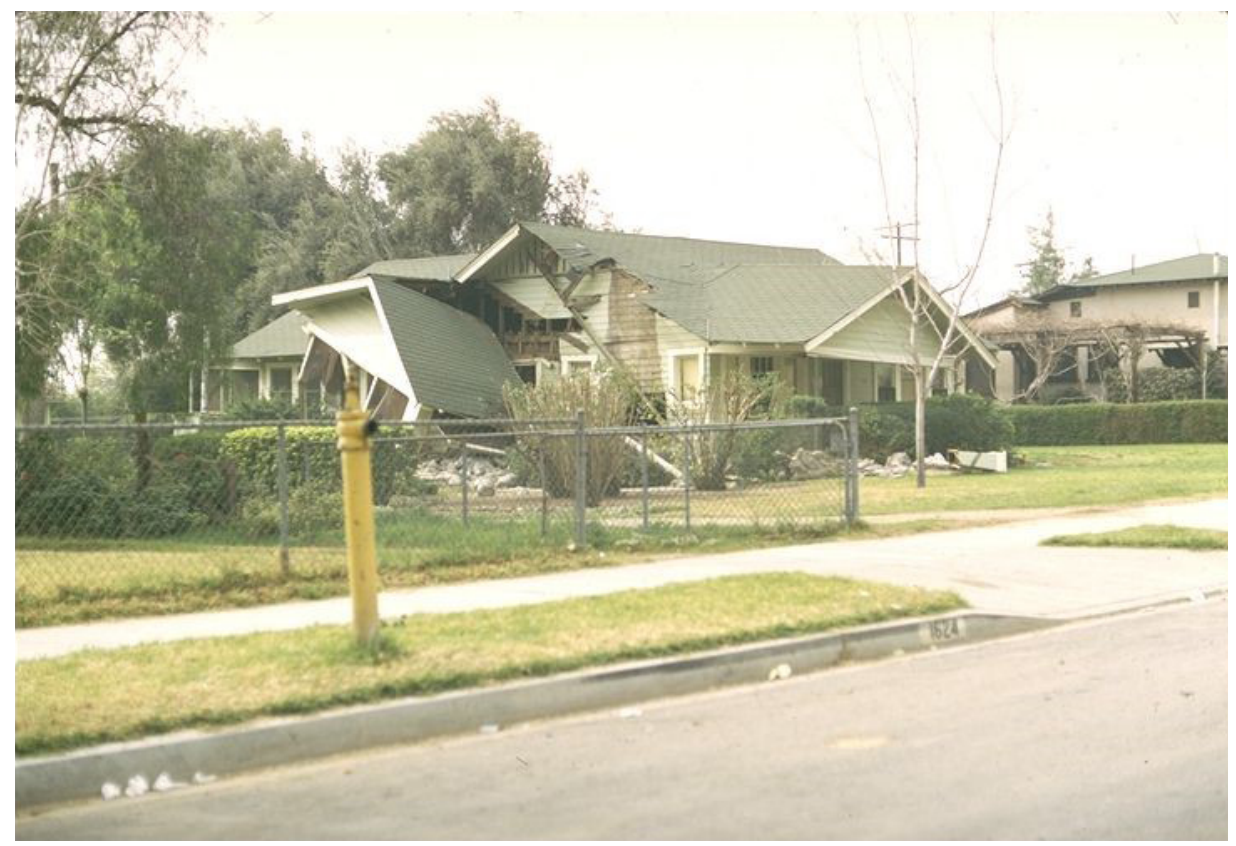

Figure 2-1. Photograph showing damage to a wood frame house after the 1971 San Fernando, California, earthquake.

\section{Image Metadata and Description for Figure 2-2}

Karl V. Steinbrugge Collection: S4533

\begin{tabular}{|c|c|c|c|c|c|}
\hline $\begin{array}{c}\text { Earthquake date } \\
\text { and magnitude }(M)\end{array}$ & Title & Creator & Date & Location & Description \\
\hline $\begin{array}{l}\text { February } 9,1971 ; \\
\quad M 6.6\end{array}$ & Chimney damage & $\begin{array}{l}\text { Schader, Eu- } \\
\text { gene E. }\end{array}$ & -- & $\begin{array}{l}\text { North America/Los } \\
\text { Angeles County/ } \\
\text { United States/Cali- } \\
\text { fornia }\end{array}$ & $\begin{array}{l}\text { Chimney fell towards otherwise un- } \\
\text { damaged wood frame house. }\end{array}$ \\
\hline
\end{tabular}

\section{Author's Estimate of Affected Area}




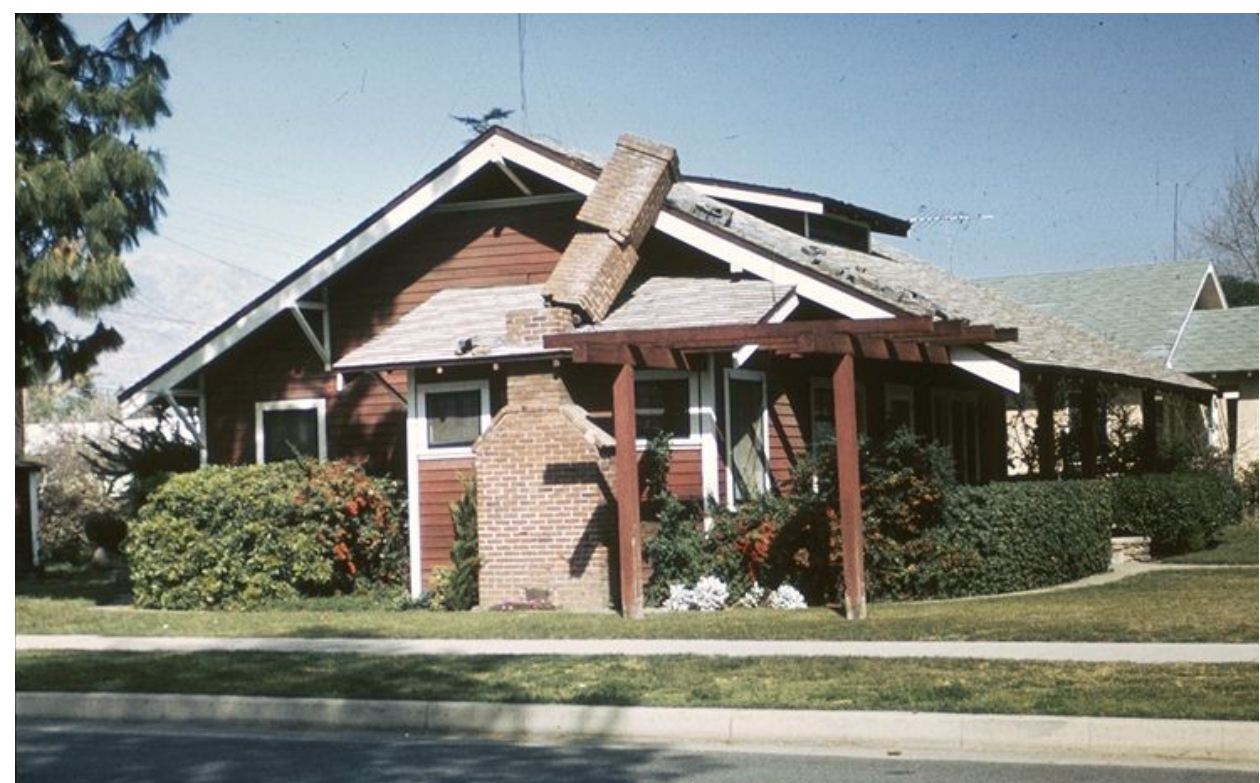

Figure 2-2. Photograph showing chimney damage after the 1971 San Fernando, California, earthquake.

\section{Image Metadata and Description for Figure 2-3}

Karl V. Steinbrugge Collection: S4581

\begin{tabular}{cccccc}
\hline $\begin{array}{c}\text { Earthquake date } \\
\text { and magnitude }(\boldsymbol{M})\end{array}$ & Title & Creator & Date & Location & Description \\
\hline $\begin{array}{c}\text { February 9, 1971; } \\
\text { M6.6 }\end{array}$ & Furniture store & $\begin{array}{c}\text { Schader, } \\
\text { Eugene E. }\end{array}$ & February 16,1971 & $\begin{array}{c}\text { United States/ } \\
\text { San Fernando/ }\end{array}$ & $\begin{array}{c}\text { Furniture store. Unreinforced masonry } \\
\text { parapet has collapsed, dumping bricks } \\
\text { into the street and on to the sidewalk. } \\
\end{array}$ \\
& & & California/North & America/ Los & Large plate-glass windows are gone, \\
& & & Angeles County & presumably shattered by the earthquake. \\
& & & & San Fernando, California. & \\
\hline
\end{tabular}

\section{Author's Estimate of Affected Area}

Plan area $\approx 40 \mathrm{ft} \times 60 \mathrm{ft}(?)$; area littered by bricks $\approx 30 \mathrm{ft} \times 15 \mathrm{ft}=19 \%$.

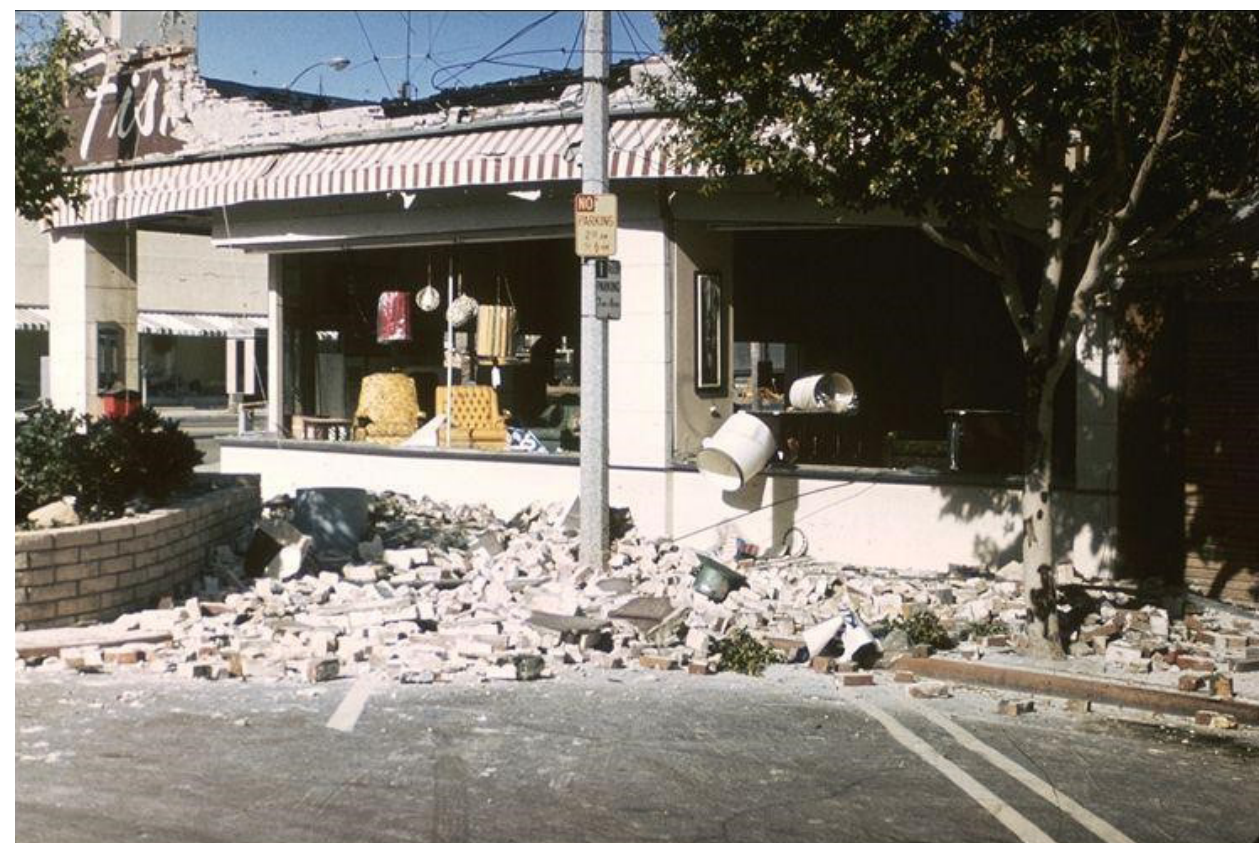

Figure 2-3. Photograph showing furniture store damage after the 1971 San Fernando, California, earthquake. 


\section{Image Metadata and Description for Figure 2-4}

Karl V. Steinbrugge Collection: S4597, S4598, S4599, S4600, S4601, S4602.

\begin{tabular}{|c|c|c|c|c|c|}
\hline $\begin{array}{l}\text { Earthquake date } \\
\text { and magnitude ( } M)\end{array}$ & Title & Creator & Date & Location & Description \\
\hline $\begin{array}{l}\text { February } 9,1971 ; \\
\quad M 6.6\end{array}$ & $\begin{array}{l}\text { Apartments } \\
\text { over retail } \\
\text { space }\end{array}$ & $\begin{array}{c}\text { Steinbrugge, } \\
\text { Karl V. }\end{array}$ & -- & $\begin{array}{l}\text { United States/ } \\
\text { San Fernando/ } \\
\text { California/North } \\
\text { America/ Los } \\
\text { Angeles County }\end{array}$ & $\begin{array}{l}\text { Apartments over retail space. Note that the } \\
\text { failure of the nonreinforced bearing walls } \\
\text { did not result in collapse. Unit masonry } \\
\text { construction, built prior to } 1933 \text {. Down- } \\
\text { town San Fernando commercial area. }\end{array}$ \\
\hline
\end{tabular}

\section{Author's Estimate of Affected Area}

Plan area: $50 \mathrm{ft} \times 75 \mathrm{ft} \times 3$ stories; masonry littering $250 \mathrm{ft}(?) \times 15 \mathrm{ft}(?)=3 \%$.
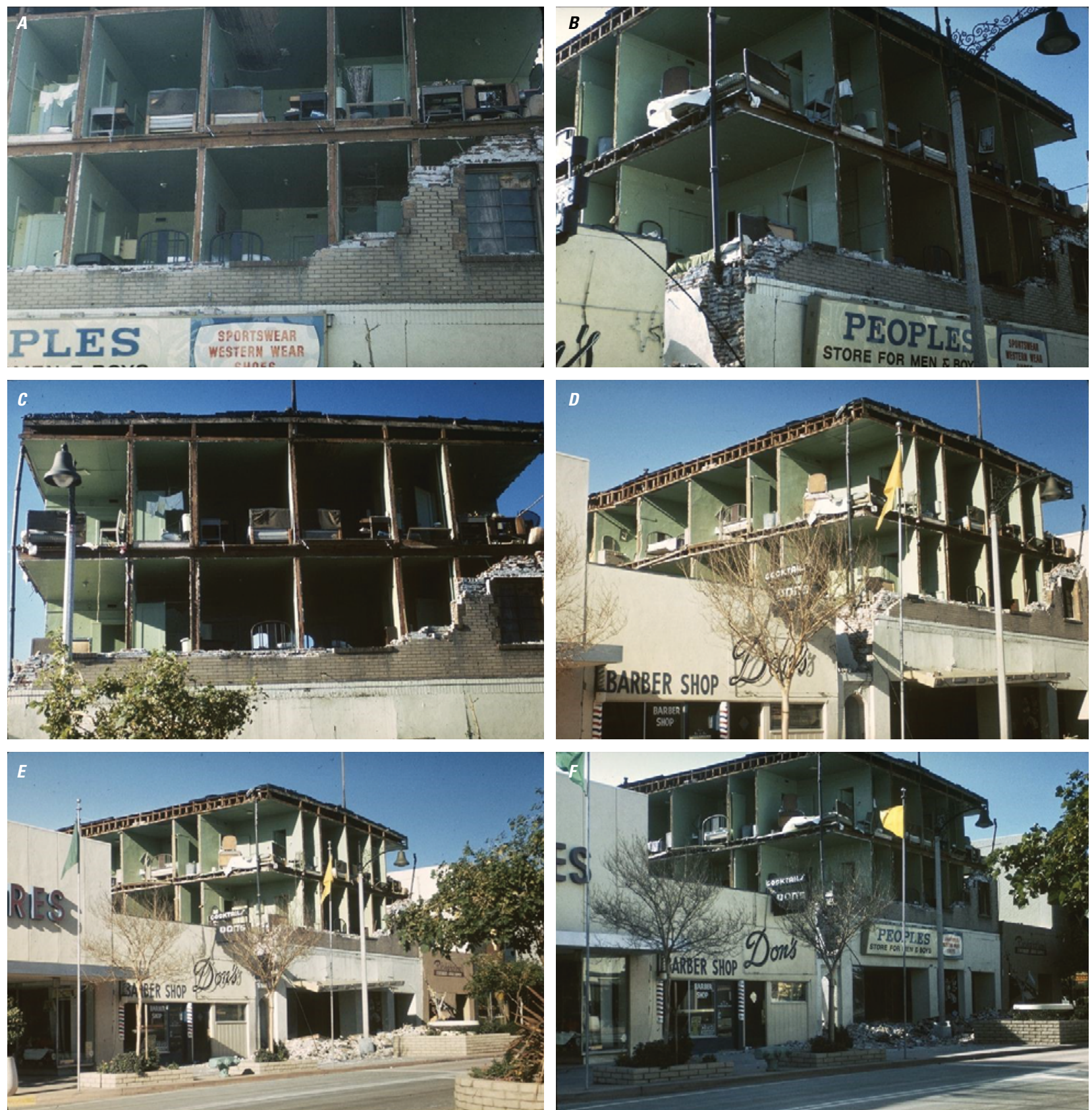

Figure 2-4. Photographs $(A-F)$ showing damage to apartments over retail space after the 1971 San Fernando, California, earthquake. 


\section{Image Metadata and Description for Figure 2-5}

Karl V. Steinbrugge Collection: S4624, S4625, S4626, S4628, S4629, S4630, S4631, and S4633

\begin{tabular}{cccccc}
\hline $\begin{array}{c}\text { Earthquake date } \\
\text { and magnitude }(\boldsymbol{M})\end{array}$ & Title & Creator & Date & Location & Description \\
\hline $\begin{array}{l}\text { February 9, 1971; } \\
\text { M6.6 }\end{array}$ & $\begin{array}{c}\text { Roof to the } \\
\text { wall failed } \\
\text { first }\end{array}$ & $\begin{array}{c}\text { Steinbrugge, } \\
\text { Karl V. }\end{array}$ & February 18, 1971 & $\begin{array}{c}\text { North America/ Los } \\
\text { Angeles County/ }\end{array}$ & $\begin{array}{c}\text { Roof to the wall failed first. Ground cracks } \\
\text { in the vicinity. Rear wall bulged out and } \\
\text { rear roof fell. See S4625-4633. Light } \\
\text { industrial buildings. Bradley Tract. }\end{array}$ \\
\hline
\end{tabular}

\section{Author's Estimate of Affected Area}

No long shots show the length of any wall, address, or way to estimate overall size of the building. Benfer and Coffman (1973, p. 123) show 14 tilt-up buildings in the Bradley Tract with this kind of failure, including the one pictured in S4624. Steinbrugge's photos seem to show a building on the north side of an east-west street, with failure on along the entire north wall and on the southwest bay. That only matches one building: 12884 Bradley Avenue, $131.5 \mathrm{ft}$ wide (east-west) and $276 \mathrm{ft}$ north-south, for a total floor area of $36,294 \mathrm{ft}^{2}$. Collapses appear to cover $26 \mathrm{ft} \times 26 \mathrm{ft}$ on the southwest corner and $26 \mathrm{ft} \times 131 \mathrm{ft}$ on the north wall. I estimate 26 -ft bays because the panels look approximately square and $131 \mathrm{ft}$ equals 5 bays plus two 6-inch panel thicknesses. Affected area: $(6 \times 26 \mathrm{ft} \times 26 \mathrm{ft}) /(36,294 \mathrm{ft})=11 \%$. Other tilt-ups in the Bradley Tract: I extracted the map of tilt-up damage from Benfer and Coffman (1973, p. 123) and overlaid it in Google Earth Pro, measuring the collapsed area with Google Earth Pro's ruler tool. Results are shown in table 2-1.

Table 2-1. Collapsed tilt-up roofs in Bradley Tract, Los Angeles, after the 1971 San Fernando, California, earthquake.

\begin{tabular}{lccc}
\hline \multicolumn{1}{c}{ Address } & $\begin{array}{c}\text { Collapsed area, in } \\
\text { square feet }\end{array}$ & $\begin{array}{c}\text { Plan area, in } \\
\text { square feet }\end{array}$ & $\begin{array}{c}\text { Affected area, in } \\
\text { percent }\end{array}$ \\
\hline 12840 Bradley Avenue & 21,461 & 48,400 & 44 \\
12874 Bradley Avenue & 2,460 & 21,000 & 12 \\
12884 Bradley Avenue & 4,056 & 36,294 & 11 \\
12950 Bradley Avenue & 3,060 & 30,240 & 10 \\
12881 Bradley Avenue & 5,678 & 58,500 & 10 \\
12975 Bradley Avenue & 18,180 & 77,600 & 23 \\
13001 Bradley Avenue & 6,400 & 85,050 & 8 \\
13069 Bradley Avenue & 7,030 & 45,000 & 16 \\
15200 Bledsoe Street & 3,700 & 19,800 & 19 \\
15151 Bledsoe Street & 4,050 & 51,800 & 8 \\
12860 San Fernando Road & 4,650 & 29,340 & 16 \\
12806 San Fernando Road & 11,260 & 63,400 & 18 \\
12744 San Fernando Road & 26,600 & 101,400 & 26 \\
12814 Bradley Avenue & 2,400 & 15,600 & 15 \\
\hline
\end{tabular}



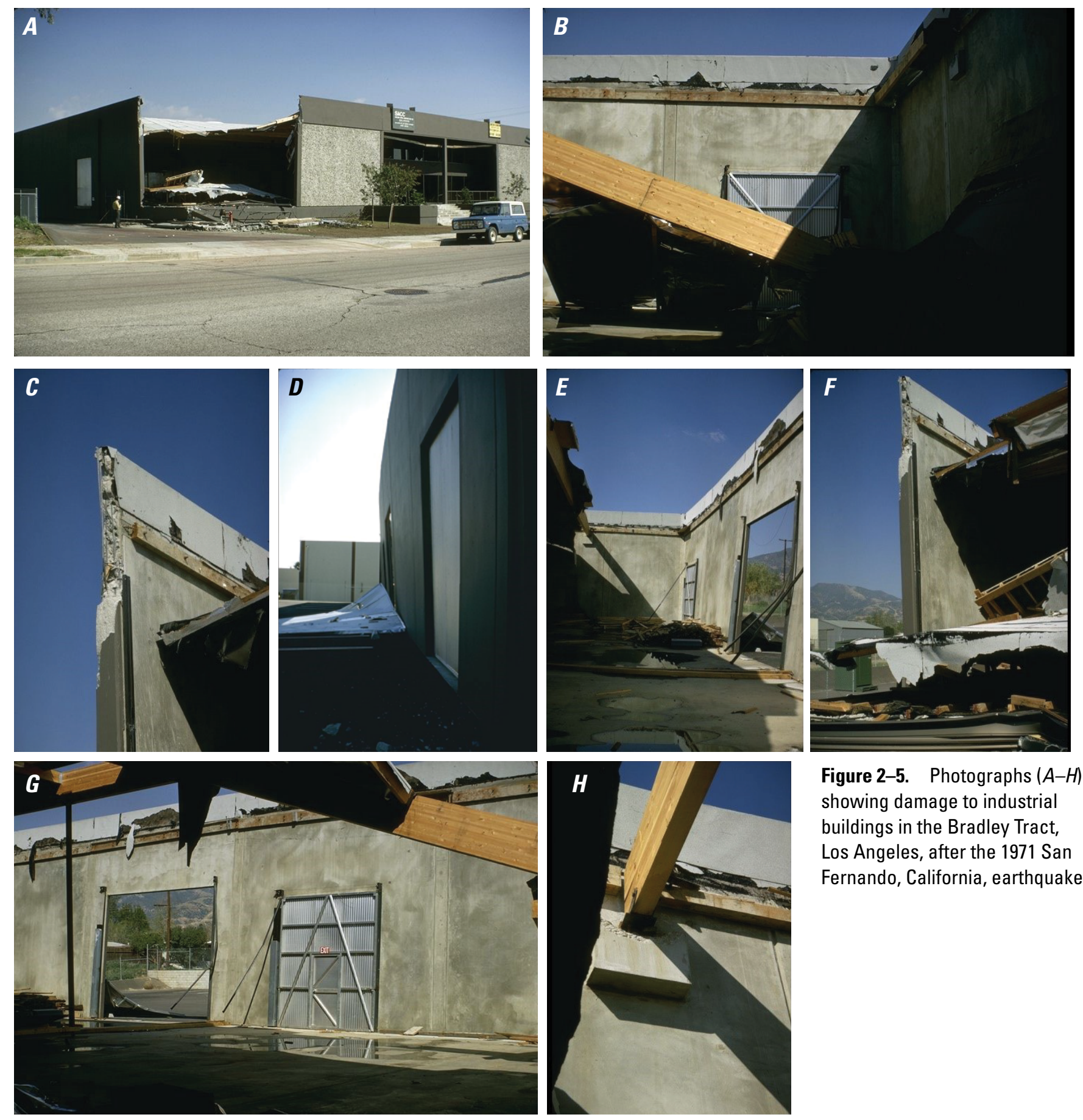

Figure 2-5. Photographs $(A-H)$ showing damage to industrial buildings in the Bradley Tract, Los Angeles, after the 1971 San Fernando, California, earthquake. 


\section{Image Metadata and Description for Figure 2-6}

Karl V. Steinbrugge Collection: S4489

\begin{tabular}{llclll}
\hline $\begin{array}{c}\text { Earthquake date } \\
\text { and magnitude }(\boldsymbol{M})\end{array}$ & Title & Creator & Date & Location & Description \\
\hline $\begin{array}{lllll}\text { February 9, 1971; } \\
\text { M6.6 }\end{array}$ & $\begin{array}{c}\text { Older wood } \\
\text { frame house }\end{array}$ & $\begin{array}{c}\text { Steinbrugge, } \\
\text { Karl V. }\end{array}$ & 1971 & $\begin{array}{c}\text { United States/ San Fer- } \\
\text { nando/California/North } \\
\text { America/ Los Angeles } \\
\text { County }\end{array}$ & $\begin{array}{c}\text { Porch partial collapse on older wood } \\
\text { frame house, probable cripple wall fail- } \\
\text { ure of house. Between Glen Oaks and } \\
\text { Hubbard Streets. }\end{array}$ \\
\hline
\end{tabular}

Author's Estimate of Affected Area

Plan area $\approx 1,500 \mathrm{ft}^{2}($ ?); collapsed area where people could be trapped $=0 \%$.

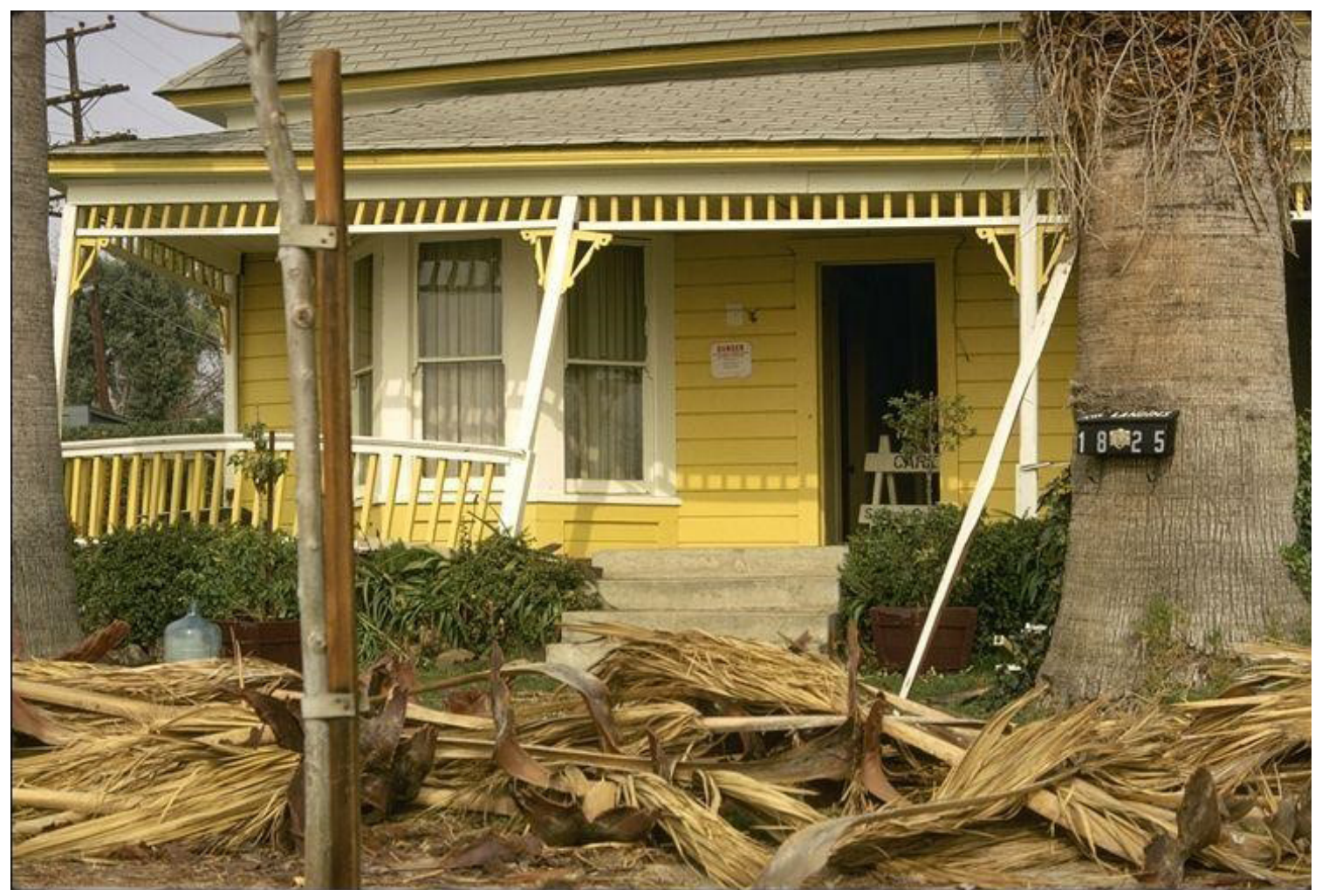

Figure 2-6. Photograph showing the partial collapse of a porch on older wood frame house, with probable cripple wall failure.

\section{Image Metadata and Description for Figure 2-7}

Karl V. Steinbrugge Collection: S4491, S4492

\begin{tabular}{|c|c|c|c|c|c|}
\hline $\begin{array}{c}\text { Earthquake date } \\
\text { and magnitude }(M)\end{array}$ & Title & Creator & Date & Location & Description \\
\hline $\begin{array}{l}\text { February } 9,1971 ; \\
\quad M 6.6\end{array}$ & $\begin{array}{l}\text { Soft-story } \\
\text { failure }\end{array}$ & $\begin{array}{c}\text { Steinbrugge, } \\
\text { Karl V. }\end{array}$ & -- & $\begin{array}{l}\text { United States/ San Fer- } \\
\text { nando/ California/North } \\
\text { America/ Los Angeles } \\
\text { County }\end{array}$ & $\begin{array}{l}\text { Pink structure at the rear was a residence } \\
\text { over a garage. The first story collapsed, } \\
\text { note remains of automobile under the } \\
\text { building. }\end{array}$ \\
\hline
\end{tabular}

Author's Estimate of Affected Area

Building area $=30 \mathrm{ft} \times 20 \mathrm{ft}(?) \times 2$; collapsed area $=30 \mathrm{ft} \times 20 \mathrm{ft}(?) \times 1=50 \%$. 

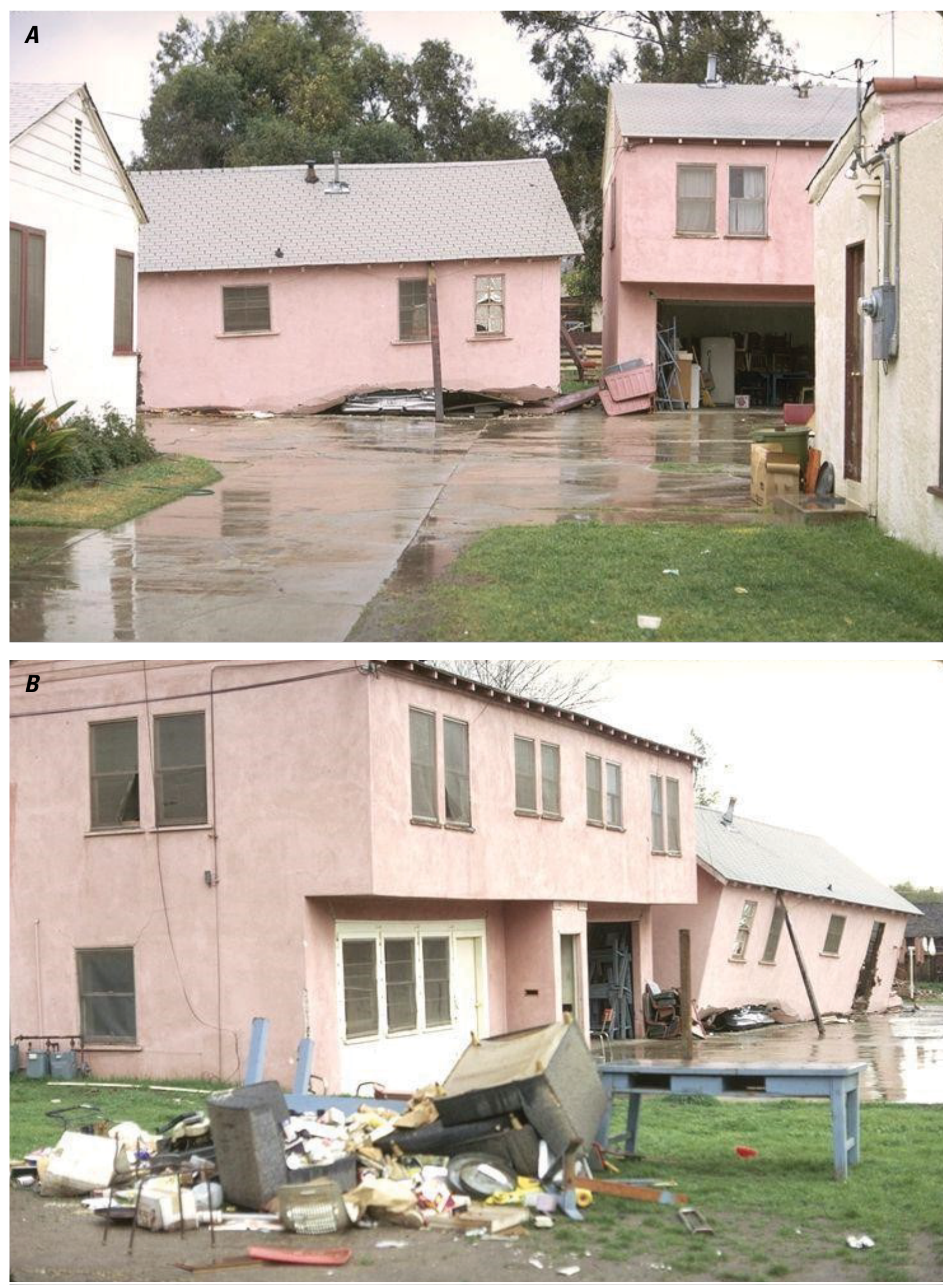

Figure 2-7. Photographs $(A, B)$ showing soft-story failure after the 1971 San Fernando, California, earthquake. 


\section{Image Metadata and Description for Figure 2-8}

William G. Godden (v. 4) Collection: GoddenJ53

\begin{tabular}{cccccc}
\hline $\begin{array}{c}\text { Earthquake date } \\
\text { and magnitude }(\boldsymbol{M})\end{array}$ & Title & Creator & Date & Location & Description \\
\hline $\begin{array}{l}\text { February 9, 1971; } \\
\text { M6.6 }\end{array}$ & $\begin{array}{c}\text { Split-level } \\
\text { house, San } \\
\text { Fernando } \\
\text { Valley }\end{array}$ & $\begin{array}{c}\text { Bertero, Vi- } \\
\text { telmo V. }\end{array}$ & -- & United States/California/ \\
& & & North America & $\begin{array}{c}\text { Collapse of a split-level wooden home. Large } \\
\text { numbers of these split-level homes suf- } \\
\text { fered significant damage because of a lack } \\
\text { of adequate ties between the two levels. } \\
\text { The upper level ripped away and crushed } \\
\text { the lower garage walls, which did not have } \\
\text { adequate lateral bracing.1 }\end{array}$ \\
\hline
\end{tabular}

${ }^{1}$ Additional discussion of this image is available in Godden Set $\mathrm{J}$.

Author's Estimate of Affected Area

Building area $\approx 15 \mathrm{ft} \times 30 \mathrm{ft} \times 3$; collapsed area $\approx 15 \mathrm{ft} \times 30 \mathrm{ft} \times 1=33 \%$.

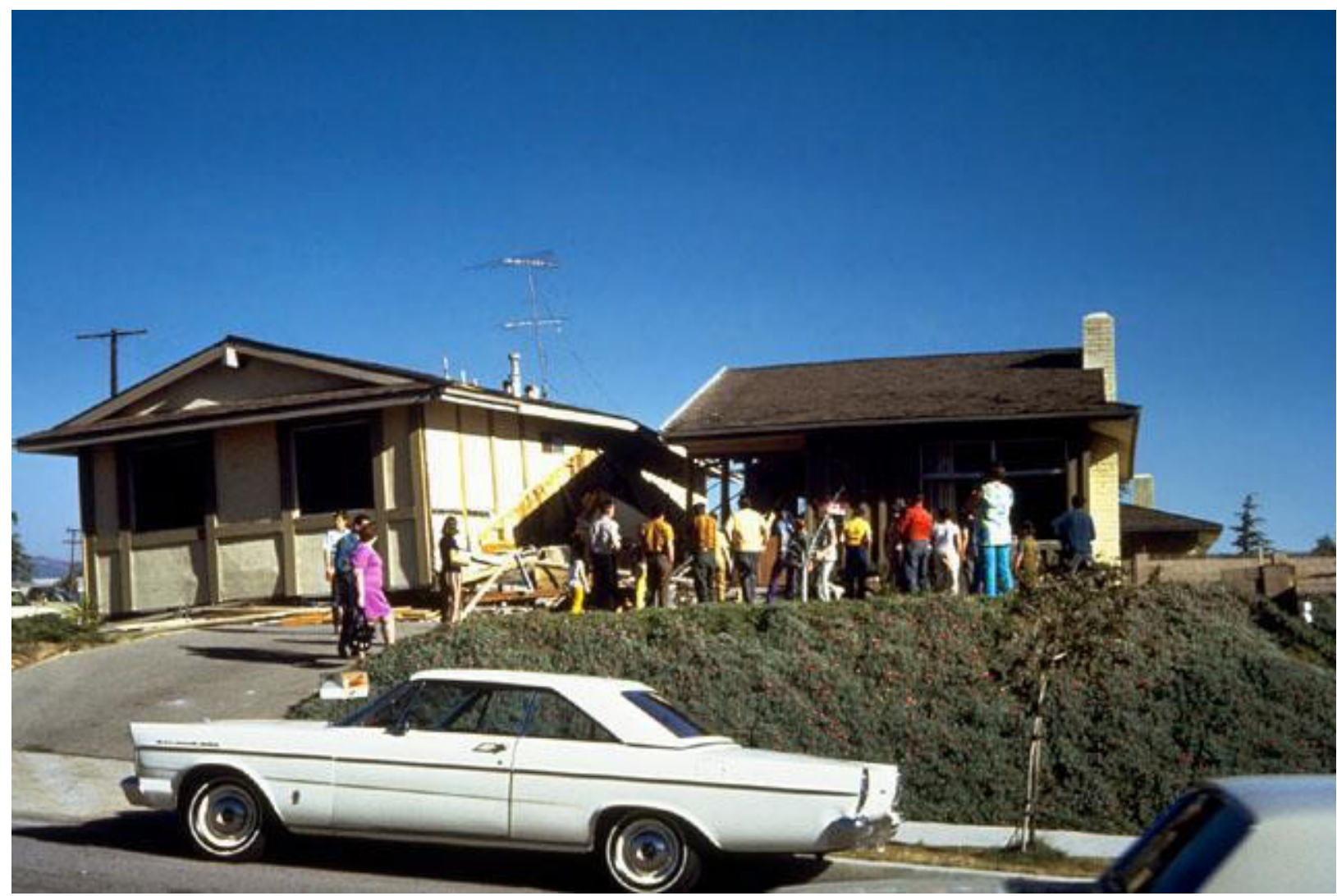

Figure 2-8. Photograph showing damage to a split-level house after the 1971 San Fernando, California, earthquake.

\section{Image Metadata and Description for Figure 2-9}

Karl V. Steinbrugge Collection: S4195

\begin{tabular}{cccccc}
\hline $\begin{array}{c}\text { Earthquake date } \\
\text { and magnitude }(\boldsymbol{M})\end{array}$ & Title & Creator & Date & Location & Description \\
\hline $\begin{array}{l}\text { February 9, 1971; } \\
\text { M6.6 }\end{array}$ & $\begin{array}{c}\text { Severe damage } \\
\text { to masonry } \\
\text { building }\end{array}$ & $\begin{array}{c}\text { Bertero, Vi- } \\
\text { telmo V. }\end{array}$ & $\begin{array}{c}\text { February } \\
1971\end{array}$ & $\begin{array}{c}\text { United States/ Los Ange- } \\
\text { les/ California/ North }\end{array}$ & $\begin{array}{c}\text { Collapsed semi-ambulent building, built in } \\
\text { 1925, masonry construction. Struc- } \\
\text { ture: Veterans Administration Hospital } \\
\text { (Sylmar). }\end{array}$ \\
\hline
\end{tabular}




\section{Author's Estimate of Affected Area}

Collapsed area: from this photo, it looks as if the lower story collapsed, so $50 \%$.

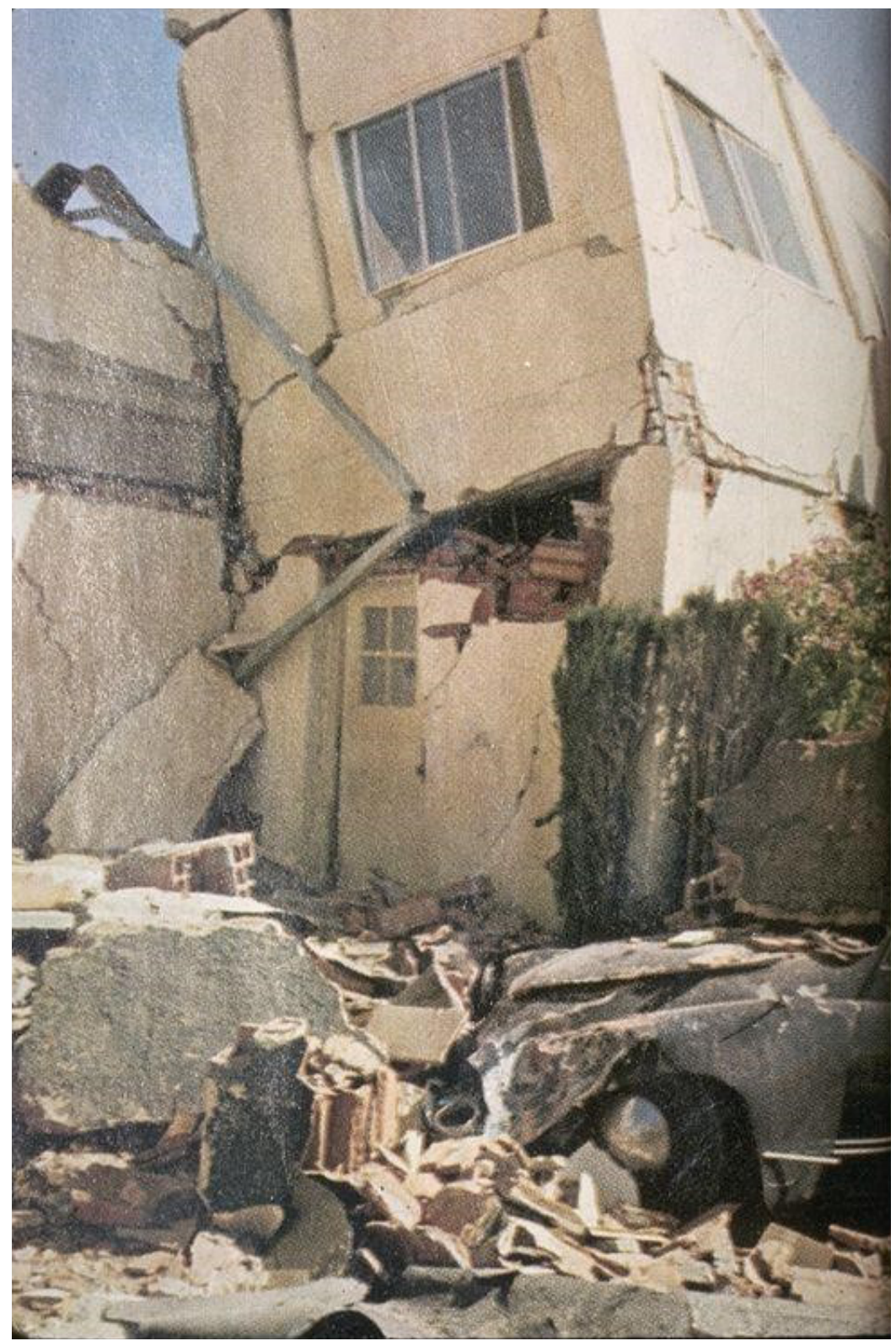

Figure 2-9. Photograph showing severe damage to masonry building at the Veterans Administration Hospital (Sylmar) after the 1971 San Fernando, California, earthquake.

\section{Image Data and Description for Figure 2-10}

The 1971 San Fernando earthquake (magnitude 6.7) collapsed four buildings at the San Fernando Veterans Administration Hospital complex, killing 47 people. The buildings had been built in 1925, before modern building codes were in effect. Image and description are from Celebi and Page (2005).

\section{Author's Estimate of Affected Area}

The view is from the west. The semi-ambulent building was a long building oriented east to west, the second building from the south (that is, second from right), in the middle of the photo. Portions of the building are leaning at various angles to the north. The wing is a complete loss, but it appears as if it did not pancake. The estimate of 50\% from NISEE S4195 seems reasonable. 


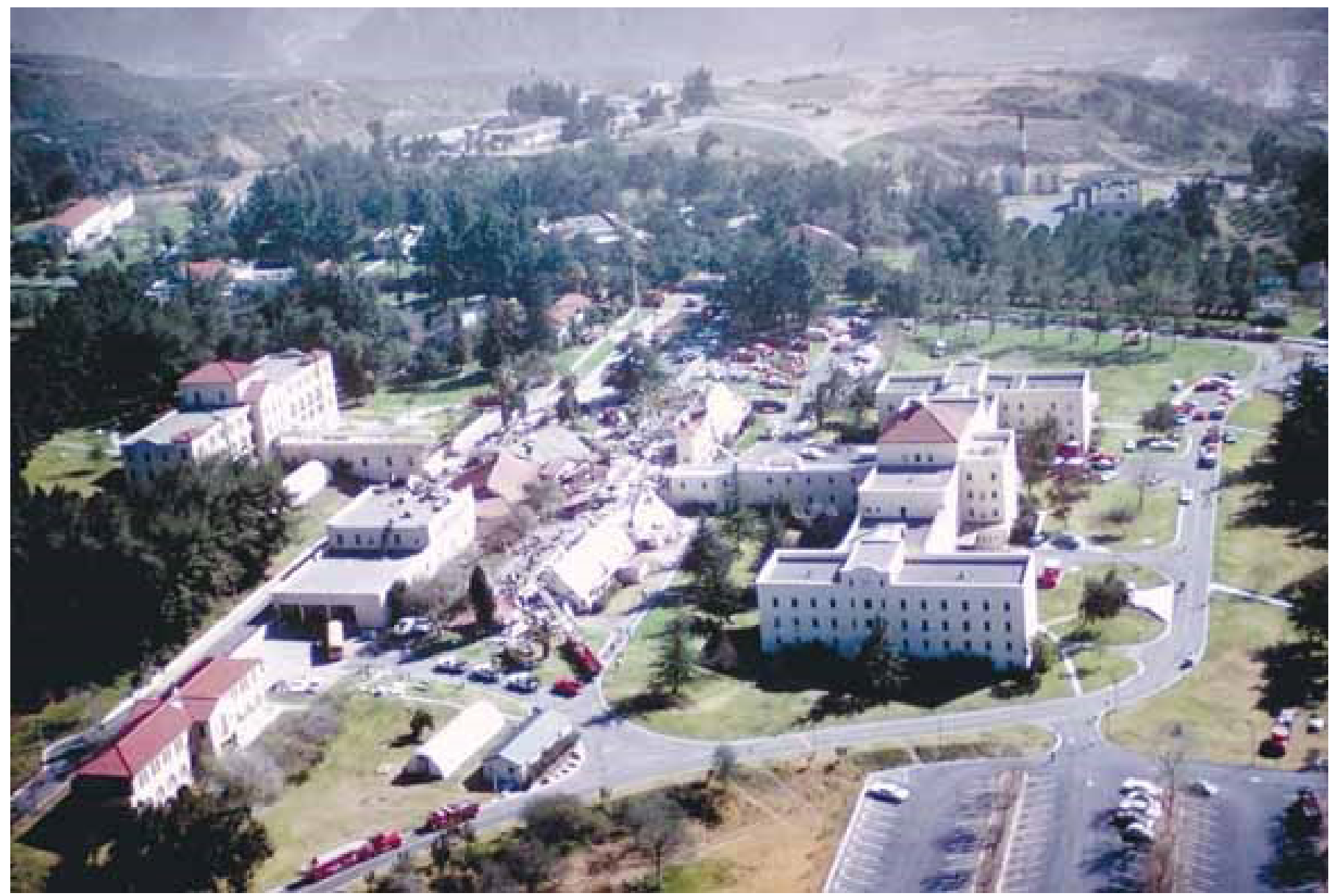

Figure 2-10. Photograph showing four collapsed buildings at the San Fernando Veterans Administration Hospital complex in the 1971 San Fernando, California, earthquake (from Celebi and Page, 2005).

\section{Image Metadata and Description for Figure 2-11}

Karl V. Steinbrugge Collection: S4529

\begin{tabular}{llcccc}
\hline $\begin{array}{c}\text { Earthquake date } \\
\text { and magnitude }(\boldsymbol{M})\end{array}$ & \multicolumn{1}{c}{ Title } & Creator & Date & Location & Description \\
\hline $\begin{array}{l}\text { February 9, 1971; } \\
\text { M6.6 }\end{array}$ & $\begin{array}{c}\text { Damage to } \\
\text { older dwell- } \\
\text { ings }\end{array}$ & $\begin{array}{c}\text { Olson, Rob- } \\
\text { ert A. }\end{array}$ & -- & $\begin{array}{c}\text { United States/ California/ } \\
\text { North America/ Los } \\
\text { Angeles County }\end{array}$ & $\begin{array}{c}\text { Damage to older house caused by cripple } \\
\text { wall collapse. }\end{array}$ \\
\hline
\end{tabular}

\section{Author's Estimate of Affected Area}

Although the cripple wall collapsed, the living space does not appear to have experienced any drop in a roof or ceiling relative to the floor, so $0 \%$. 


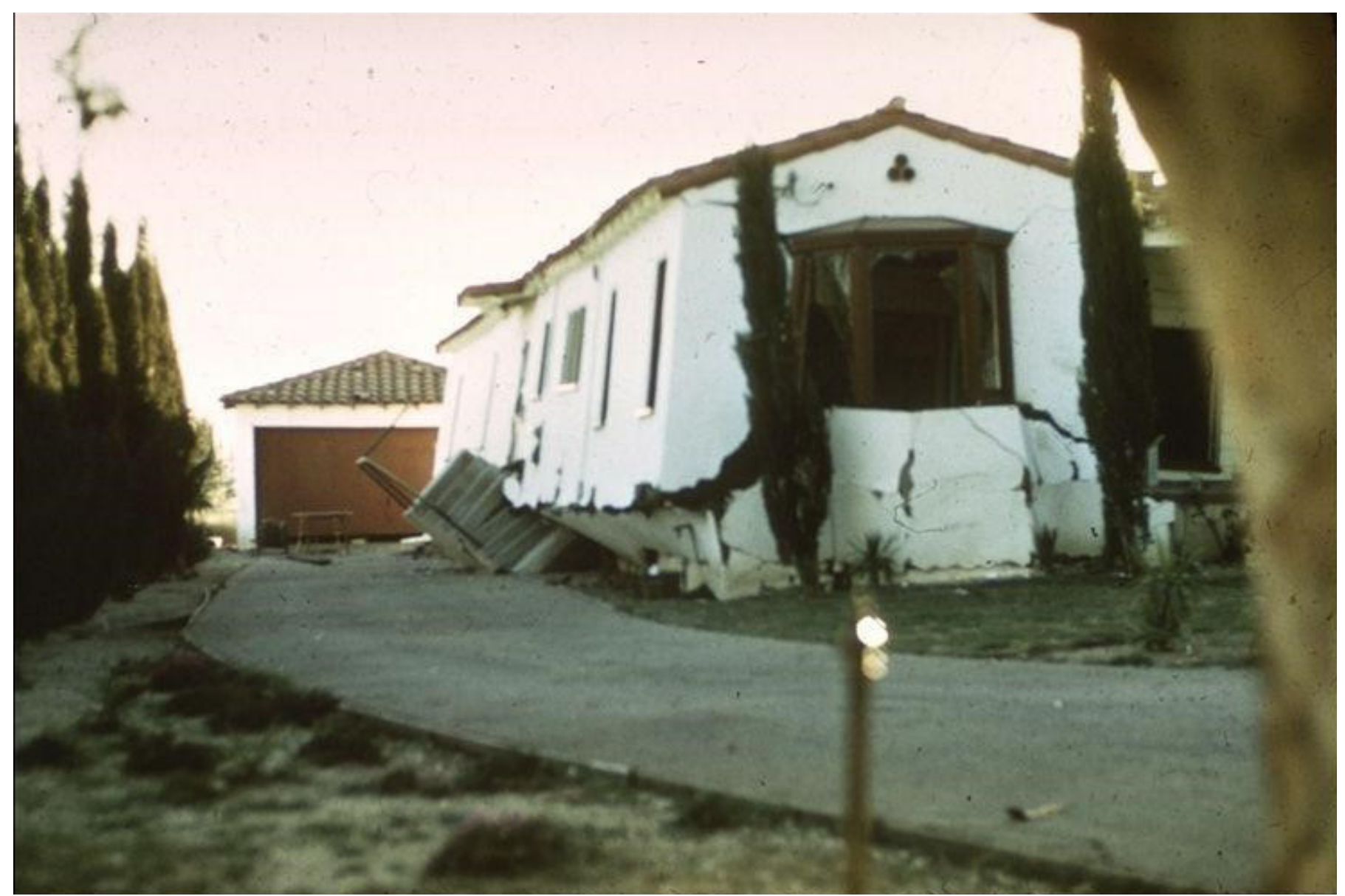

Figure 2-11. Photograph showing damage to older dwelling after the 1971 San Fernando, California, earthquake.

\section{Image Metadata and Description for Figure 2-12}

Karl V. Steinbrugge collection: S4065

\begin{tabular}{|c|c|c|c|c|c|}
\hline $\begin{array}{c}\text { Earthquake date } \\
\text { and magnitude }(M)\end{array}$ & Title & Creator & Date & Location & Description \\
\hline $\begin{array}{l}\text { February 9, 1971; } \\
\quad \text { M6.6 }\end{array}$ & $\begin{array}{l}\text { Collapsed } \\
\text { tower at } \\
\text { southeast } \\
\text { corner }\end{array}$ & $\begin{array}{c}\text { Steinbrugge, } \\
\text { Karl V. }\end{array}$ & -- & $\begin{array}{l}\text { United States/ Sylmar/ } \\
\text { California/North } \\
\text { America/ Los Angeles } \\
\text { County }\end{array}$ & $\begin{array}{l}\text { Collapsed tower at southeast corner. Olive } \\
\text { View Hospital. Rear (east) elevation of } \\
\text { Medical Treatment Building. Structure: } \\
\text { Olive View Medical Treatment Build- } \\
\text { ing. }\end{array}$ \\
\hline
\end{tabular}




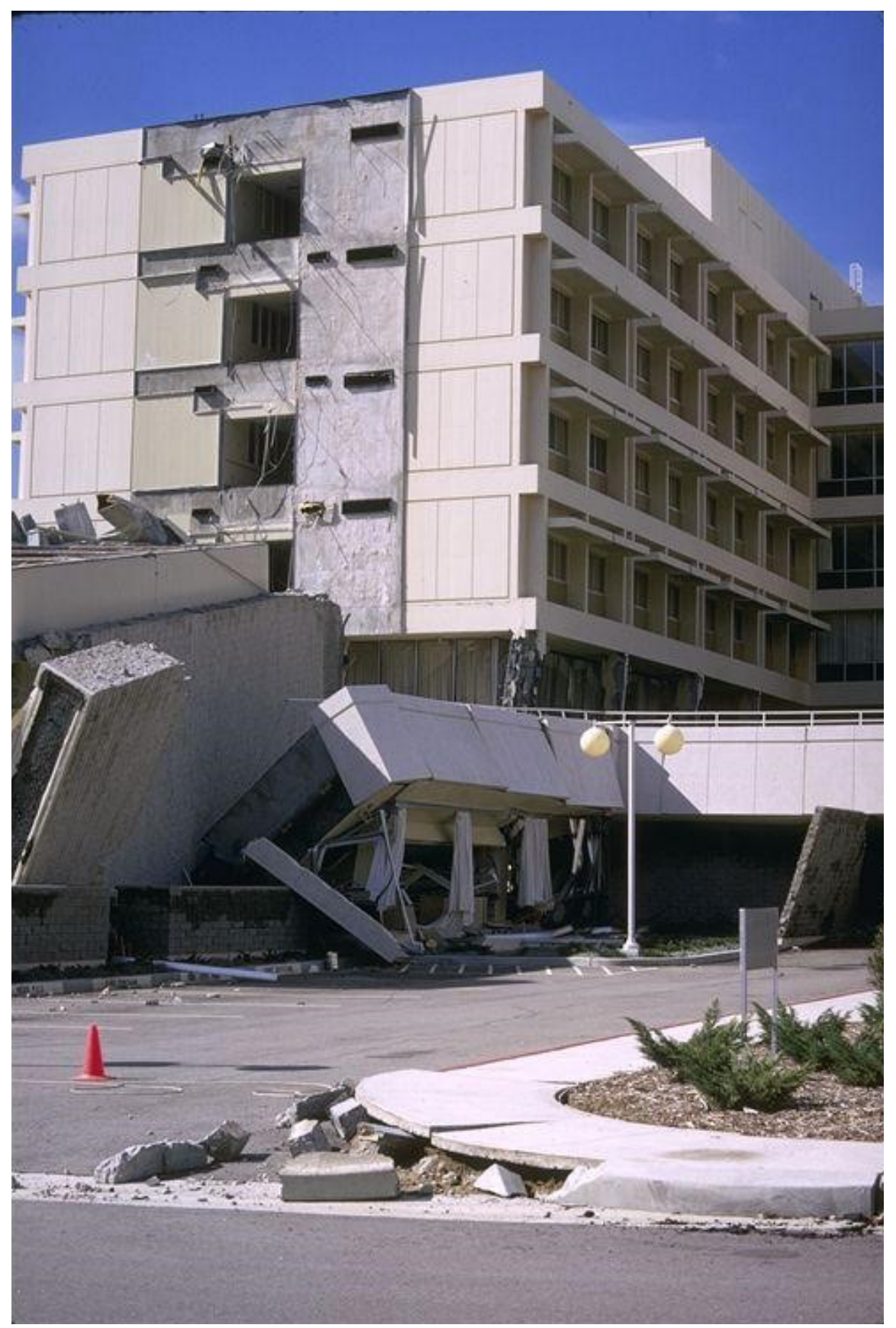

Figure 2-12. Photograph showing collapsed tower at Olive View Hospital, Sylmar, after the 1971 San Fernando, California, earthquake.

\section{Image Data and Description for Figure 2-13}

San Fernando earthquake, February 1971, California. Fallen, structurally separated stair tower and leaning north stair tower (left) at Olive View Hospital. Emergency vehicles are visible in the foreground. View is from the west. Image taken by Reuben Kachadoorian, U.S. Geological Survey.

\section{Author's Estimate of Affected Area}

Each wing appears to be approximately $240 \mathrm{ft} \times 50 \mathrm{ft} \times 5$ stories $\times 4$ wings $=240,000 \mathrm{ft}^{2}$. The collapsed stair towers appear to be approximately $20 \mathrm{ft} \times 40 \mathrm{ft} \times 5$ stories $\times 2$ towers $=8,000 \mathrm{ft}^{2}$, or $3.3 \%$. 


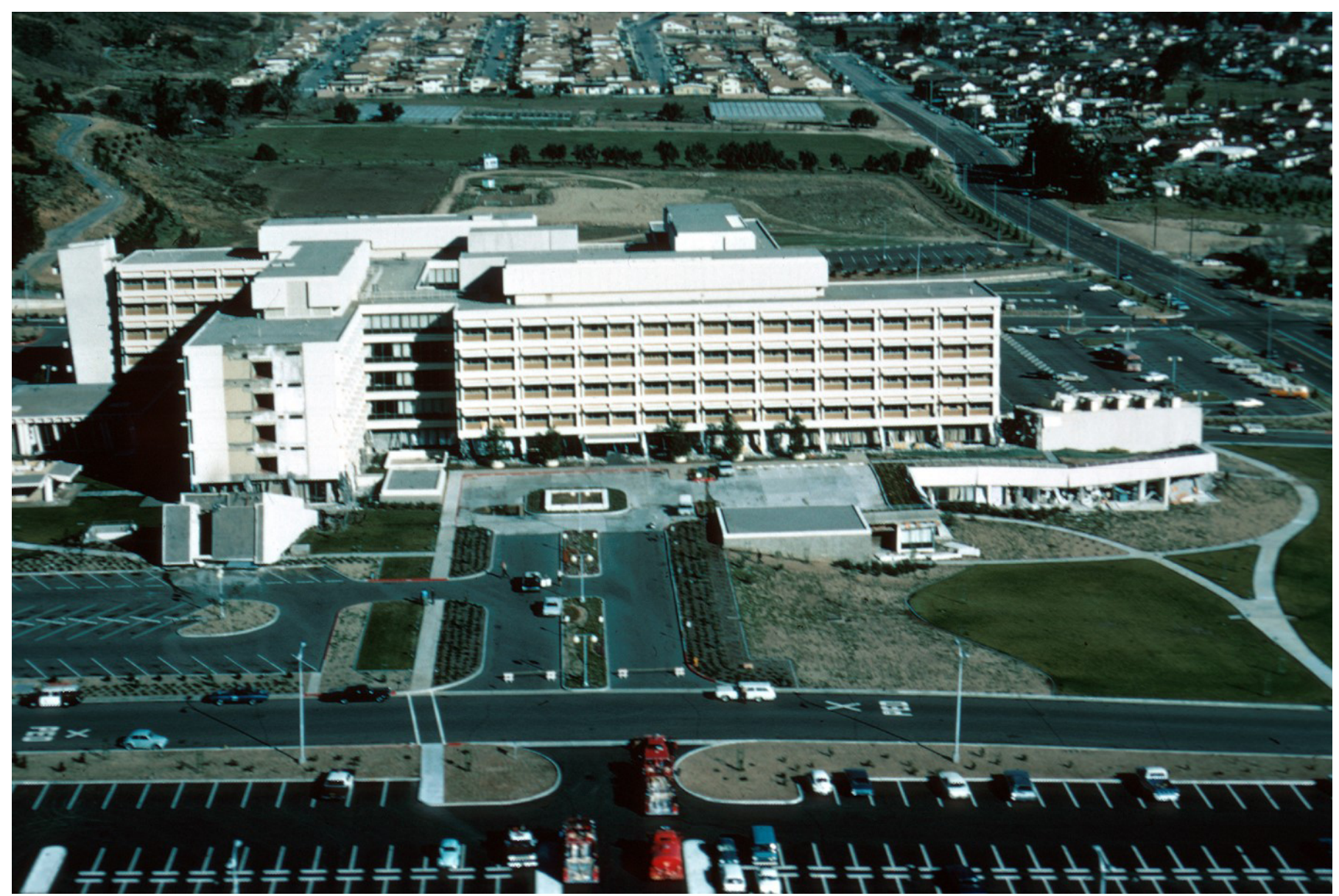

Figure 2-13. Photograph showing collapsed and leaning stair towers at Olive View Hospital, Sylmar, after the 1971 San Fernando, California, earthquake.

\section{Image Metadata and Description for Figure 2-14}

Karl V. Steinbrugge Collection: S4070

\begin{tabular}{|c|c|c|c|c|c|}
\hline $\begin{array}{c}\text { Earthquake date } \\
\text { and magnitude (M) }\end{array}$ & Title & Creator & Date & Location & Description \\
\hline $\begin{array}{l}\text { February } 9,1971 ; \\
\quad M 6.6\end{array}$ & $\begin{array}{l}\text { Ambulance } \\
\text { garage col- } \\
\text { lapsed }\end{array}$ & $\begin{array}{c}\text { Steinbrugge, } \\
\text { Karl V. }\end{array}$ & -- & $\begin{array}{l}\text { United States/ Sylmar/ } \\
\text { California/ North } \\
\text { America/ Los Angeles } \\
\text { County }\end{array}$ & $\begin{array}{l}\text { Ambulance garage collapsed. Olive View } \\
\text { Hospital. Southern elevation of Medical } \\
\text { Treatment Building. See also S4139-44. } \\
\text { Structure: Olive View ambulance } \\
\text { garage. }\end{array}$ \\
\hline
\end{tabular}

Author's Estimate of Affected Area

By inspection (an engineering term meaning “just by looking at it”), 100\%. 


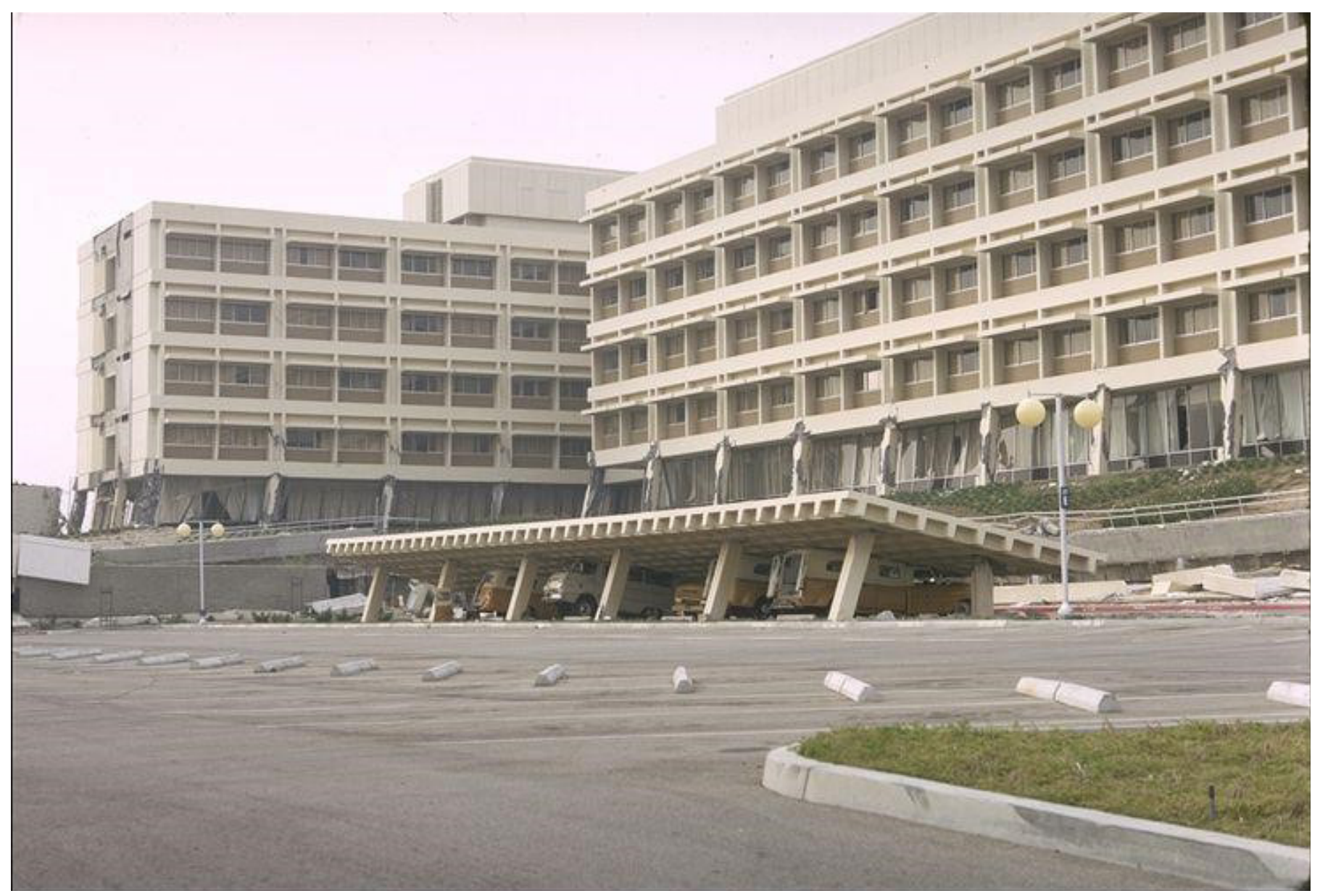

Figure 2-14. Photograph showing a collapsed ambulance garage at Olive View Hospital, Sylmar, after the 1971 San Fernando, California, earthquake.

\section{Image Metadata and Description for Figure 2-15}

Karl V. Steinbrugge Collection: S4115

\begin{tabular}{|c|c|c|c|c|c|}
\hline $\begin{array}{l}\text { Earthquake date } \\
\text { and magnitude }(M)\end{array}$ & Title & Creator & Location & Description & Description \\
\hline $\begin{array}{l}\text { February 9, 1971; } \\
\text { M6.6 }\end{array}$ & $\begin{array}{l}\text { Olive View } \\
\text { psychiatric } \\
\text { building }\end{array}$ & $\begin{array}{l}\text { Steinbrugge, } \\
\text { Karl V. }\end{array}$ & $\begin{array}{l}\text { United States/ } \\
\text { Sylmar/ Cali- } \\
\text { fornia/ North } \\
\text { America/ } \\
\text { Los Angeles } \\
\text { County }\end{array}$ & $\begin{array}{l}\text { Soft-story collapse, most evi- } \\
\text { dent at upper right of photo. } \\
\text { Originally a one- and two-story } \\
\text { building, irregular in plan, the } \\
\text { first story collapsed in the earth- } \\
\text { quake. Structure: Olive View } \\
\text { Medical Center, Calif. }\end{array}$ & $\begin{array}{l}\text { Ambulance garage collapsed. } \\
\text { Olive View Hospital. South- } \\
\text { ern elevation of Medical } \\
\text { Treatment Building. See also } \\
\text { S4139-44. Structure: Olive } \\
\text { View ambulance garage. }\end{array}$ \\
\hline
\end{tabular}

\section{Author's Estimate of Affected Area}

Collapsed area: it appears as if the first story was about twice the area of the second, and all of the area of the first story has collapsed, so $67 \%$. 


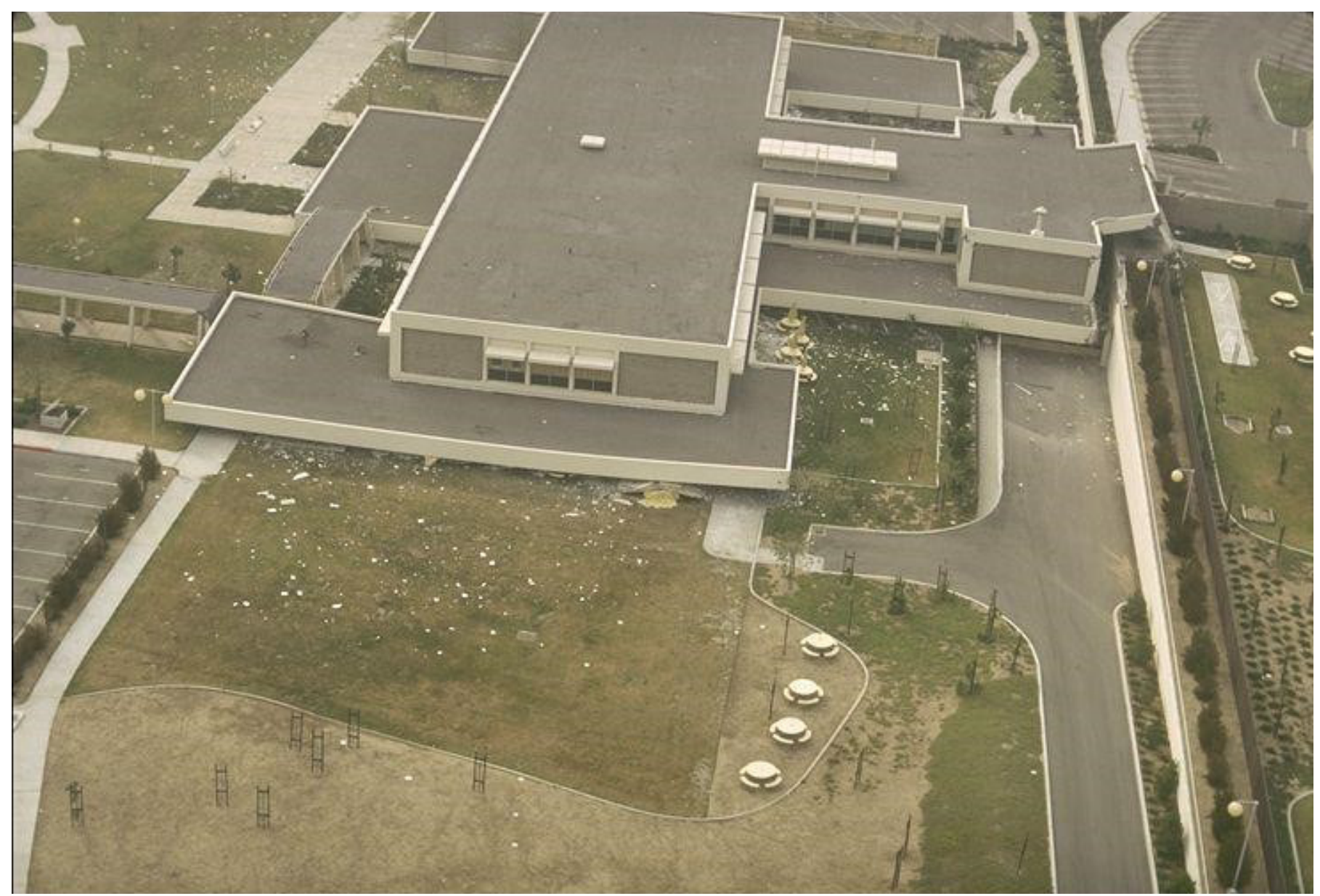

Figure 2-15. Photograph showing soft-story collapse of psychiatric building at Olive View Hospital, Sylmar, after the 1971 San Fernando, California, earthquake.

\section{Image Metadata and Description for Figure 2-16}

Karl V. Steinbrugge collection: S4117

\begin{tabular}{|c|c|c|c|c|c|}
\hline $\begin{array}{c}\text { Earthquake date } \\
\text { and magnitude }(M)\end{array}$ & Title & Creator & Location & Description & Description \\
\hline $\begin{array}{l}\text { February } 9,1971 ; \\
\quad M 6.6\end{array}$ & $\begin{array}{l}\text { Psychiatric } \\
\text { building } \\
\text { collapsed }\end{array}$ & $\begin{array}{l}\text { Olson, Rob- } \\
\text { ert A. }\end{array}$ & $\begin{array}{l}\text { United States/ } \\
\text { Sylmar/ Cali- } \\
\text { fornia/ North } \\
\text { America/ Los } \\
\text { Angeles County }\end{array}$ & $\begin{array}{l}\text { West elevation, psychiatric build- } \\
\text { ing. This was a two-story build- } \\
\text { ing - the first story collapsed. } \\
\text { Olive View. Structure: Olive } \\
\text { View Medical Center, Calif. }\end{array}$ & $\begin{array}{l}\text { Ambulance garage collapsed. } \\
\text { Olive View Hospital. South- } \\
\text { ern elevation of Medical } \\
\text { Treatment Building. See also } \\
\text { S4139-44. Structure: Olive } \\
\text { View ambulance garage. }\end{array}$ \\
\hline
\end{tabular}

\section{Author's Estimate of Affected Area}

This is another view of the previous building. 

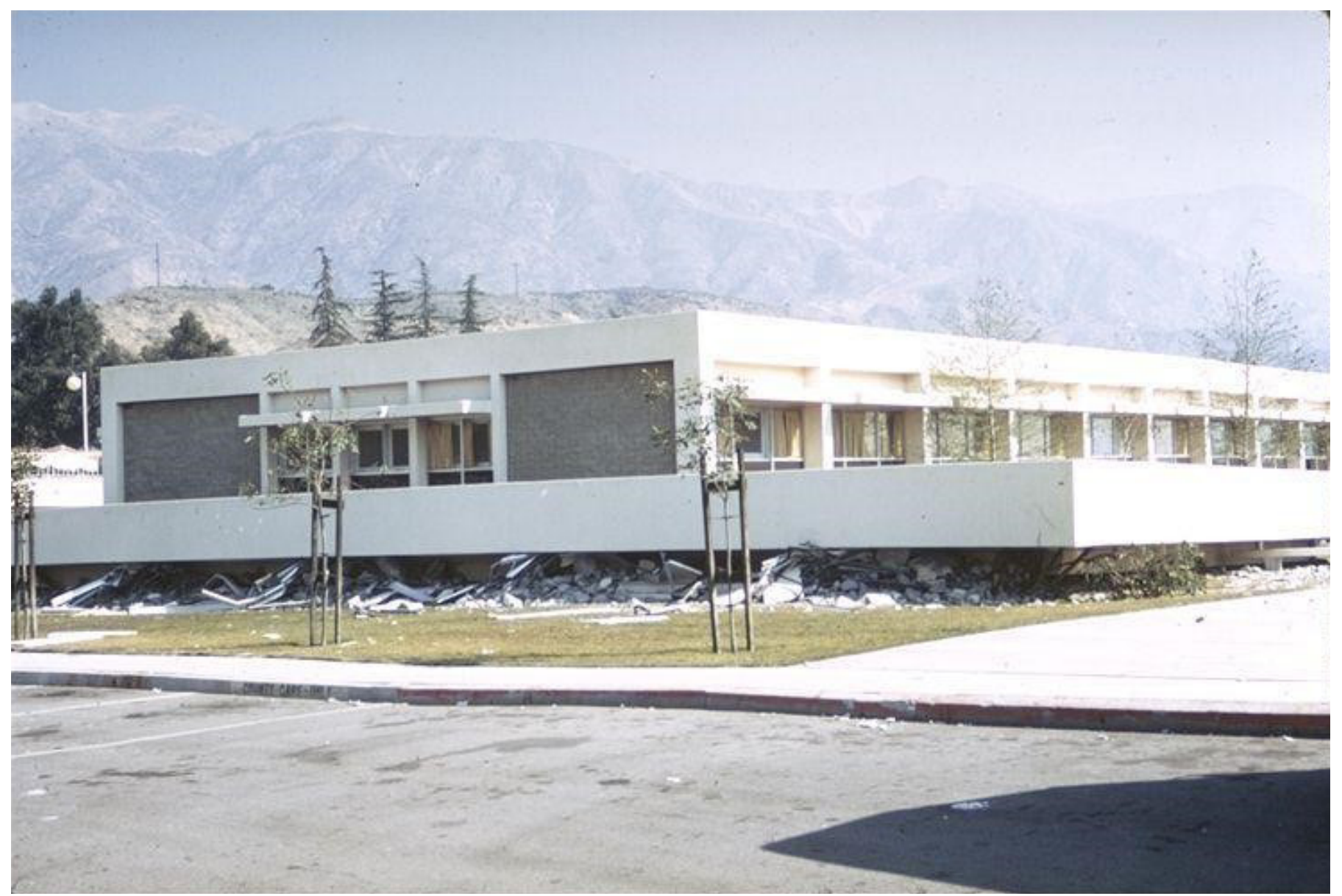

Figure 2-16. Photograph showing first story collapse of psychiatric building at Olive View Hospital, Sylmar, after the 1971 San Fernando, California, earthquake.

\section{Image Metadata and Description for Figure 2-17}

Karl V. Steinbrugge Collection: S4519

\begin{tabular}{llcccc}
\hline $\begin{array}{c}\text { Earthquake date } \\
\text { and magnitude }(\boldsymbol{M})\end{array}$ & Title & Creator & Date & Location & Description \\
\hline $\begin{array}{l}\text { February 9, 1971; } \\
\text { M6.6 }\end{array}$ & $\begin{array}{c}\text { Collapsed } \\
\text { wood frame } \\
\text { house }\end{array}$ & $\begin{array}{c}\text { Steinbrugge, } \\
\text { Karl V. }\end{array}$ & February 16, 1971 & $\begin{array}{c}\text { United States/ Sylmar/ Cali- } \\
\text { fornia/ North America/ Los } \\
\text { Angeles County }\end{array}$ & $\begin{array}{c}\text { Collapsed wood frame house } \\
\text { under construction on Tucker } \\
\text { St. near Pacoima Dam. }\end{array}$ \\
\hline
\end{tabular}

\section{Author's Estimate of Affected Area}

There is no other view of this house. It looks as if the garage (front left) and perhaps half of the living space (in the rear) at least partly collapsed, so approximately $67 \%$. 


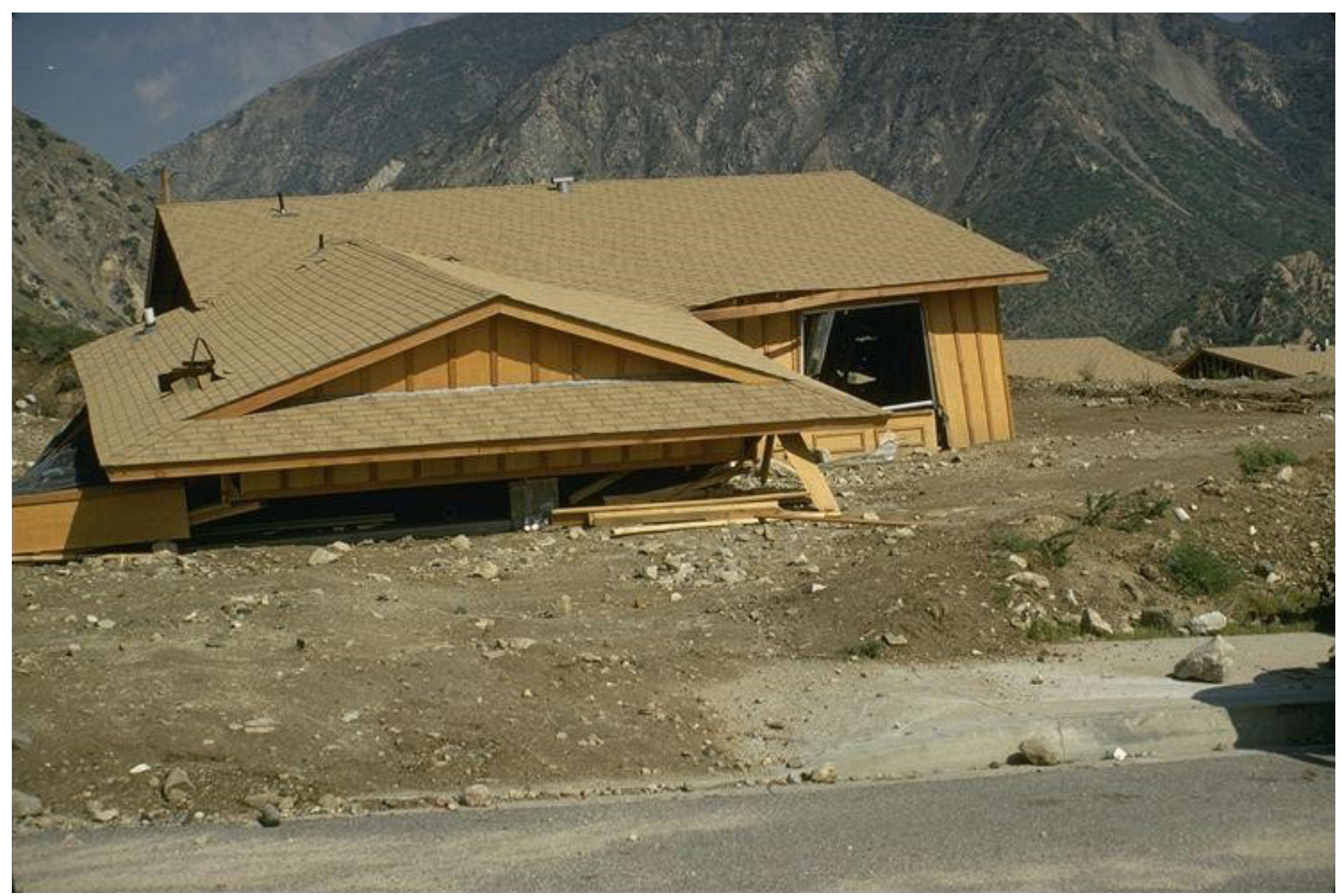

Figure 2-17. Photograph showing a collapsed wood frame house after the 1971 San Fernando, California, earthquake.

\section{Image Metadata and Description for Figure 2-18}

Karl V. Steinbrugge Collection: S4501

\begin{tabular}{lccccc}
\hline $\begin{array}{c}\text { Earthquake date } \\
\text { and magnitude }(\boldsymbol{M})\end{array}$ & Title & Creator & Date & Location & Description \\
\hline $\begin{array}{l}\text { February 9, 1971; } \\
\text { M6.6 }\end{array}$ & $\begin{array}{c}\text { Soft-story } \\
\text { failure }\end{array}$ & $\begin{array}{c}\text { Steinbrugge, } \\
\text { Karl V. }\end{array}$ & 1971 & $\begin{array}{c}\text { United States/ Sylmar/ Cali- } \\
\text { fornia/North America/ Los } \\
\text { Angeles County }\end{array}$ & $\begin{array}{c}\text { Two-story section over garage of this wood } \\
\text { frame house on Almetz St. has collapsed in } \\
\text { the first story. In a new housing tract in Syl- } \\
\text { mar at base of hills and between Olive View } \\
\text { and Veterans Administration Hospitals. }\end{array}$ \\
\hline
\end{tabular}

\section{Author's Estimate of Affected Area}

There are no other views of this house. Judging by the description, this building resembled S4514 in layout, so approximately $33 \%$. 


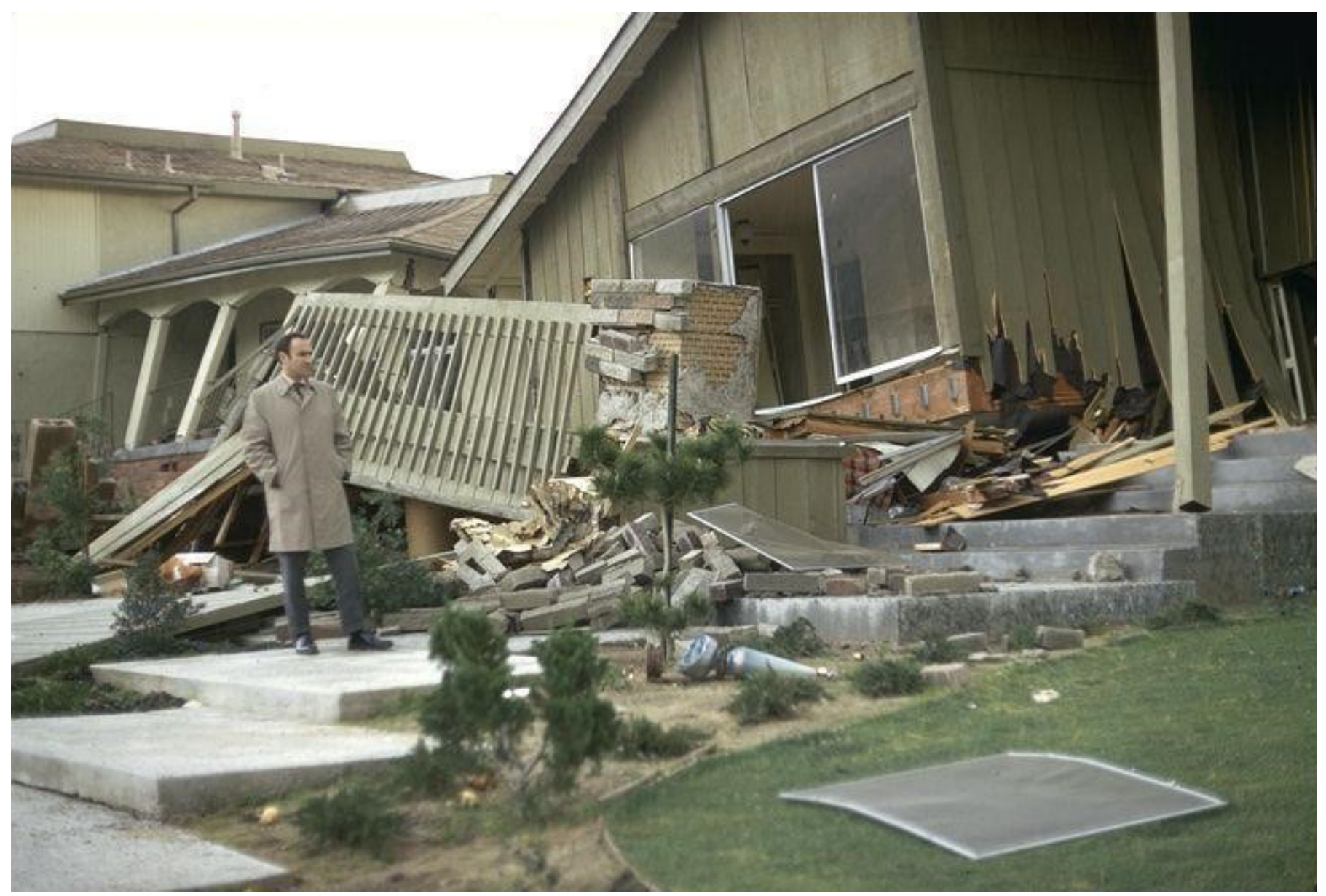

Figure 2-18. Photograph showing soft-story failure in a wood frame house after the 1971 San Fernando, California, earthquake.

\section{Image Metadata and Description for Figure 2-19}

Robert A. Olson Collection: R0070

\begin{tabular}{|c|c|c|c|c|c|}
\hline $\begin{array}{c}\text { Earthquake date } \\
\text { and magnitude (M) }\end{array}$ & Title & Creator & Date & Location & Description \\
\hline $\begin{array}{l}\text { February } 9,1971 ; \\
\quad \text { M6.6 }\end{array}$ & VA Hospital & -- & 1971 & -- & $\begin{array}{l}\text { Veterans Administration Hospital (Sylmar). Old masonry } \\
\text { building in upper center of photo has completely col- } \\
\text { lapsed. Constructed in 1925-26, with major additions } \\
\text { in } 1938 \text { and } 1949 \text {, the entire complex was demolished } \\
\text { after the } 1971 \text { earthquake, and the entire } 97 \text { acres were } \\
\text { dedicated in } 1977 \text { as Veterans Memorial Park. Structure: } \\
\text { Veterans Administration Hospital (Sylmar). }\end{array}$ \\
\hline
\end{tabular}

\section{Author's Estimate of Affected Area}

The collapsed building is the gray-roofed one, which appears to have been a one-story building whose entire area collapsed. $100 \%$. 


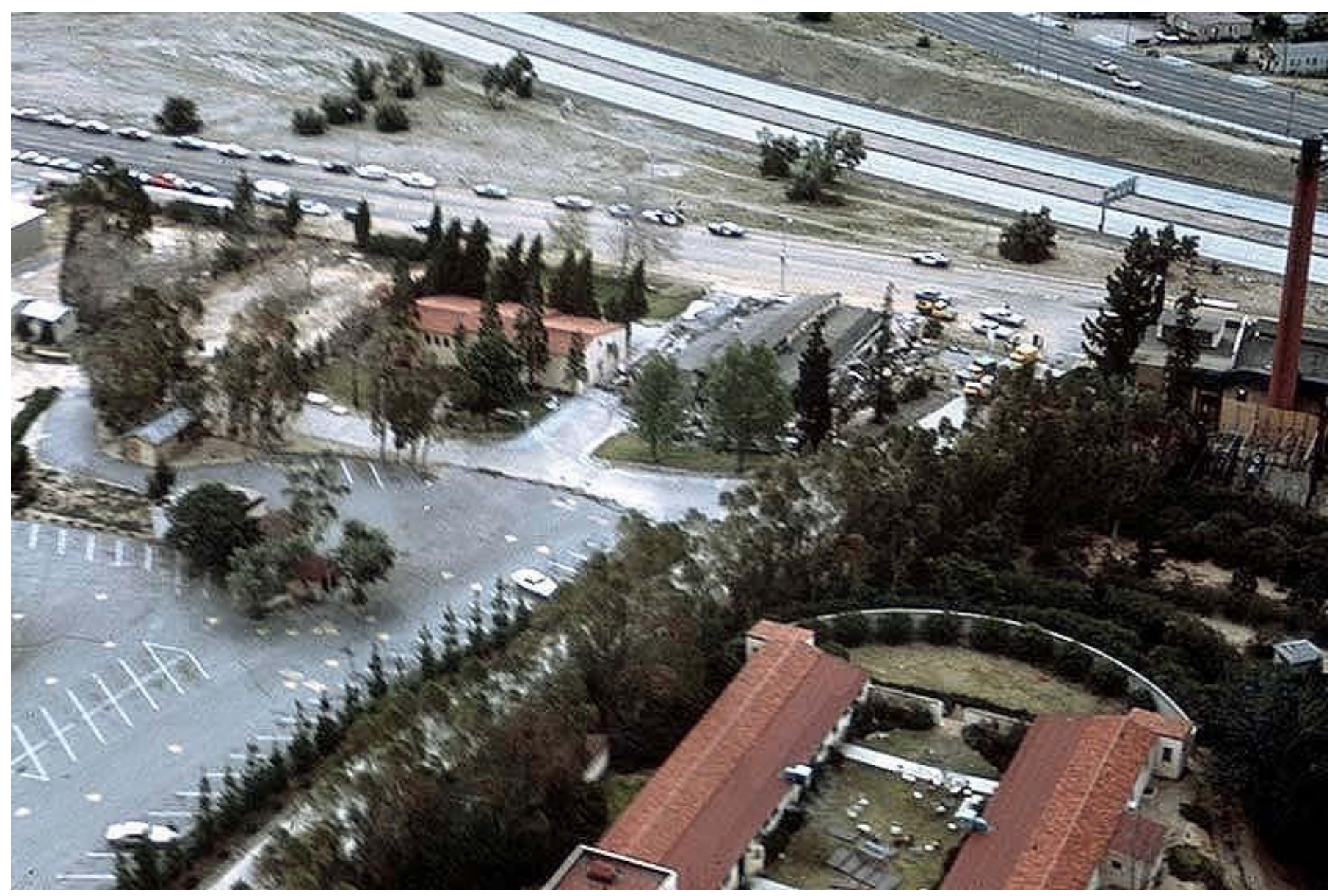

Figure 2-19. Photograph showing damage to the Veterans Administration Hospital, Sylmar, after the 1971 San Fernando, California, earthquake. 


\section{Appendix 3. Imperial Valley (1979) Collapse Images}

\section{Image Metadata and Description for Figure 3-2}

Karl V. Steinbrugge Collection: S5584

\begin{tabular}{|c|c|c|c|c|c|}
\hline $\begin{array}{l}\text { Earthquake date } \\
\text { and magnitude }(M)\end{array}$ & Title & Creator & Date & Location & Description \\
\hline $\begin{array}{l}\text { October } 15,1979 \\
\quad M 7.0\end{array}$ & $\begin{array}{l}\text { Cripple wall } \\
\text { collapse }\end{array}$ & $\begin{array}{l}\text { Hopper, Mar- } \\
\text { garet G. }\end{array}$ & October 1979 & $\begin{array}{l}\text { United States/ California/ } \\
\text { North America/ Impe- } \\
\text { rial County }\end{array}$ & $\begin{array}{l}\text { Cripple wall collapse - wood frame } \\
\text { house on G St. }\end{array}$ \\
\hline
\end{tabular}

Author's Estimate of Affected Area

By inspection, $0 \%$.

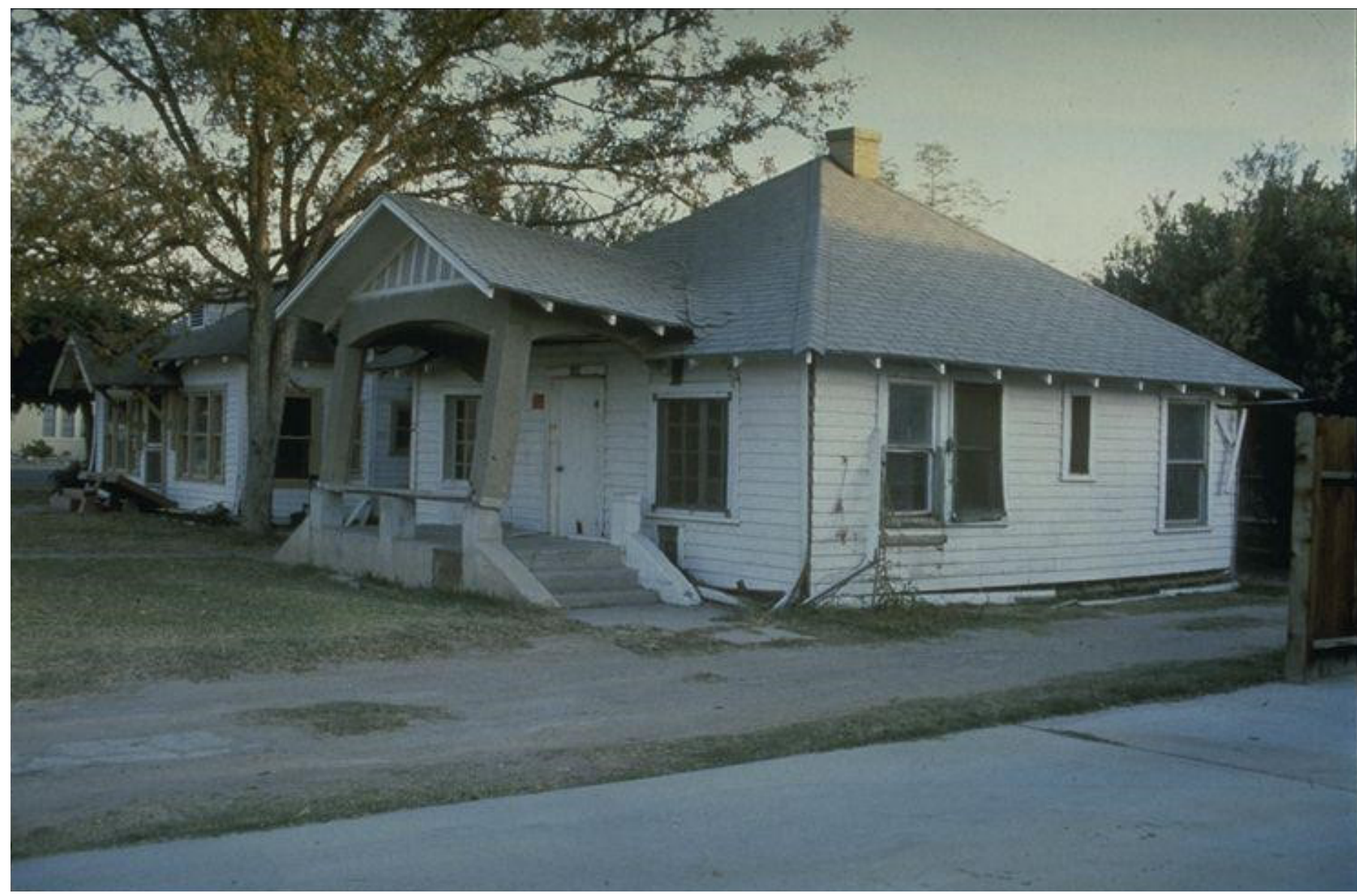

Figure 3-2. Photograph showing cripple wall collapse on a wood frame house after the 1979 Imperial Valley, California, earthquake. 


\section{Image Metadata and Description for Figure 3-3}

Karl V. Steinbrugge Collection: S5585

\begin{tabular}{lccccc}
\hline $\begin{array}{c}\text { Earthquake date } \\
\text { and magnitude }(\boldsymbol{M})\end{array}$ & Title & Creator & Date & Location & Description \\
\hline $\begin{array}{l}\text { October 15, 1979; } \\
M 7.0\end{array}$ & $\begin{array}{c}\text { Cripple wall } \\
\text { collapse }\end{array}$ & Hopper, Margaret G. & October 1979 & $\begin{array}{c}\text { Brawley, Imperial County, } \\
\text { Calif. }\end{array}$ & $\begin{array}{c}\text { Cripple wall collapse-wood frame } \\
\text { house on G St. }\end{array}$ \\
\hline
\end{tabular}

\section{Author's Estimate of Affected Area}

By inspection, $0 \%$.

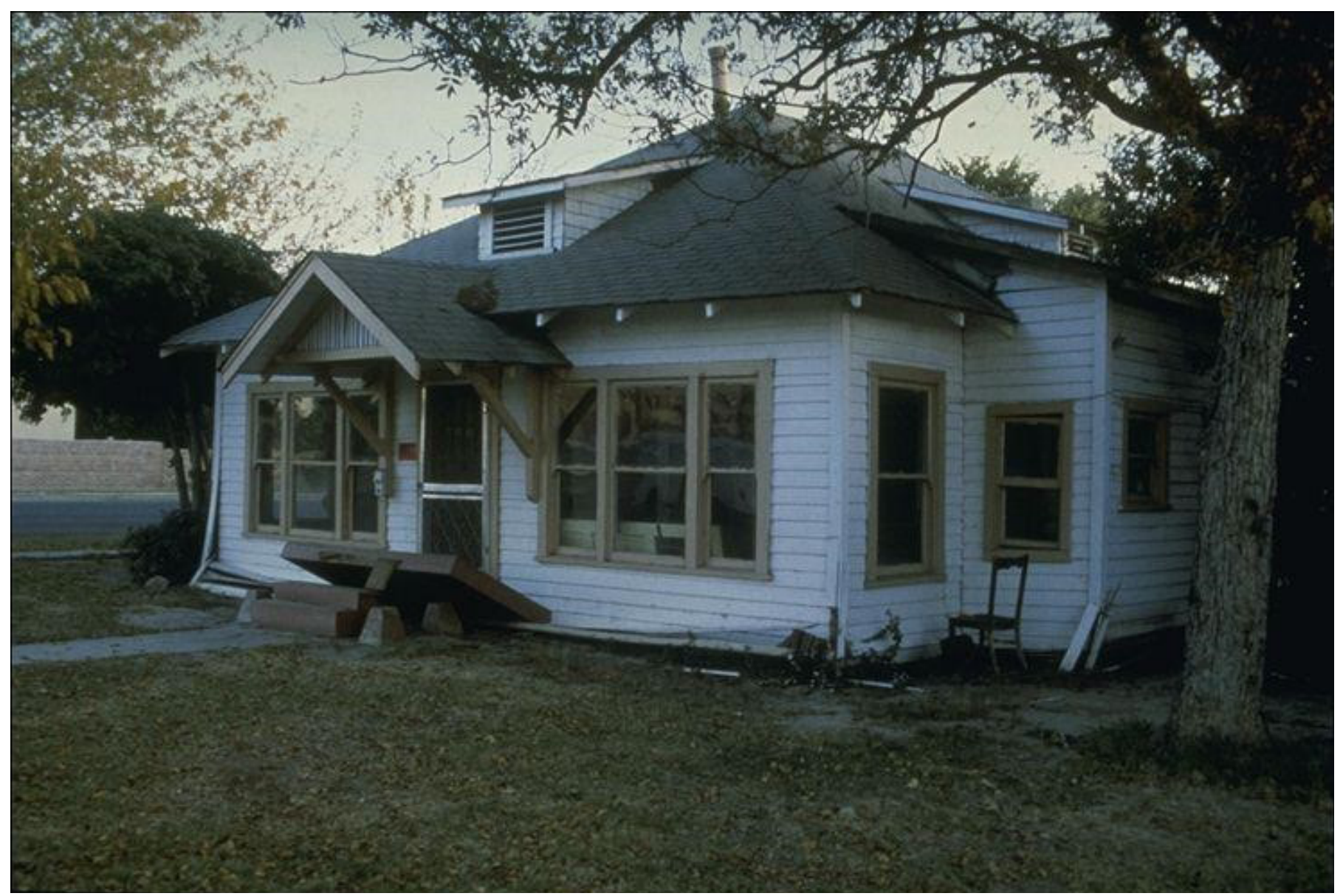

Figure 3-3. Photograph showing cripple wall collapse on a wood frame house after the 1979 Imperial Valley, California, earthquake. 


\section{Appendix 4. Westmorland (1981) Collapse Images}

\section{Image Metadata and Description for Figure 4-1}

National Oceanic and Atmospheric Administration (n.d.)

\begin{tabular}{|c|c|c|c|c|c|}
\hline $\begin{array}{c}\text { Earthquake date } \\
\text { and magnitude }(M)\end{array}$ & Title & Creator & Date & Location & Description \\
\hline $\begin{array}{l}\text { April 26, 1981; } \\
\quad \text { M5.6 }\end{array}$ & Westmorland 1981 & Olsen, Robert O. & -- & $\begin{array}{l}\text { North America/ United } \\
\text { States/ California }\end{array}$ & $\begin{array}{l}\text { View of a two-story building which } \\
\text { partly collapsed in the earthquake. } \\
\text { Note the undamaged one story build- } \\
\text { ing on the left. Photo credit: Califor- } \\
\text { nia Governor's Office of Emergency } \\
\text { Services Earthquake Program. }\end{array}$ \\
\hline
\end{tabular}

Author's Estimate of Affected Area

$100 \%$

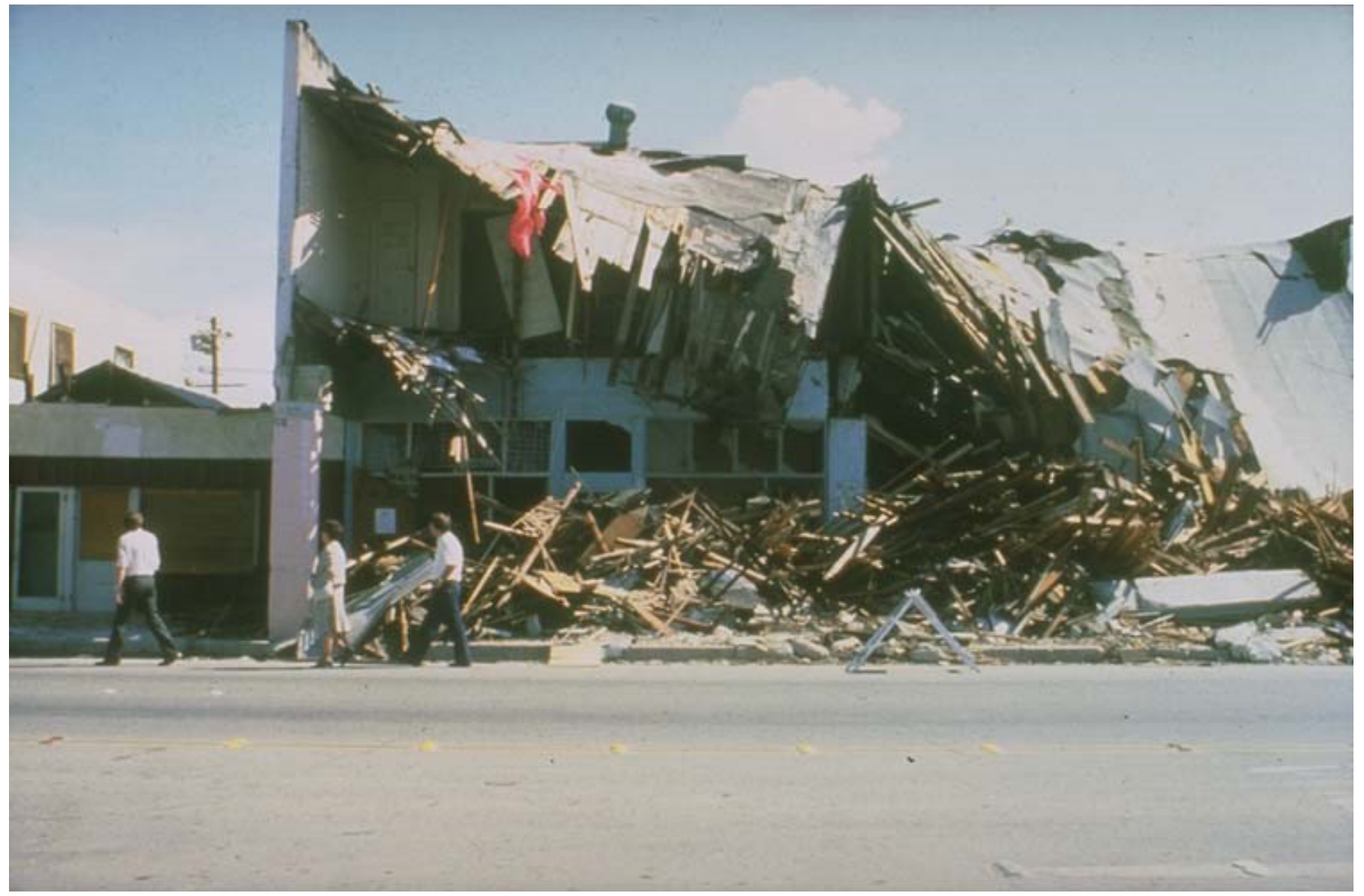

Figure 4-1. View of a two-story building on West Main Street, Westmorland, after the April 26, 1981, Westmorland, California, earthquake. 


\section{Appendix 5. Coalinga (1983) Collapse Images}

\section{Image Metadata and Description for Figure 5-1}

William G. Godden (v. 4) Collection: GoddenJ19

\begin{tabular}{|c|c|c|c|c|c|}
\hline $\begin{array}{c}\text { Earthquake date } \\
\text { and magnitude }(M)\end{array}$ & Title & Creator & Date & Location & Description \\
\hline May 2,$1983 ;$ M6.5 & $\begin{array}{l}\text { 2-story building, } \\
\text { Coalinga }\end{array}$ & Bertero, Vitelmo V. & -- & $\begin{array}{l}\text { North America/ United } \\
\text { States/ California }\end{array}$ & $\begin{array}{l}\text { This two-story wood frame dwelling } \\
\text { underwent a lateral displacement of } \\
\text { more than half a meter, as illustrated } \\
\text { by the slant in the porch columns, } \\
\text { and also fell more than half a meter } \\
\text { from its foundation, owing to lack of } \\
\text { adequate anchorage and support. }\end{array}$ \\
\hline
\end{tabular}

\section{Author's Estimate of Affected Area}

$0 \%$

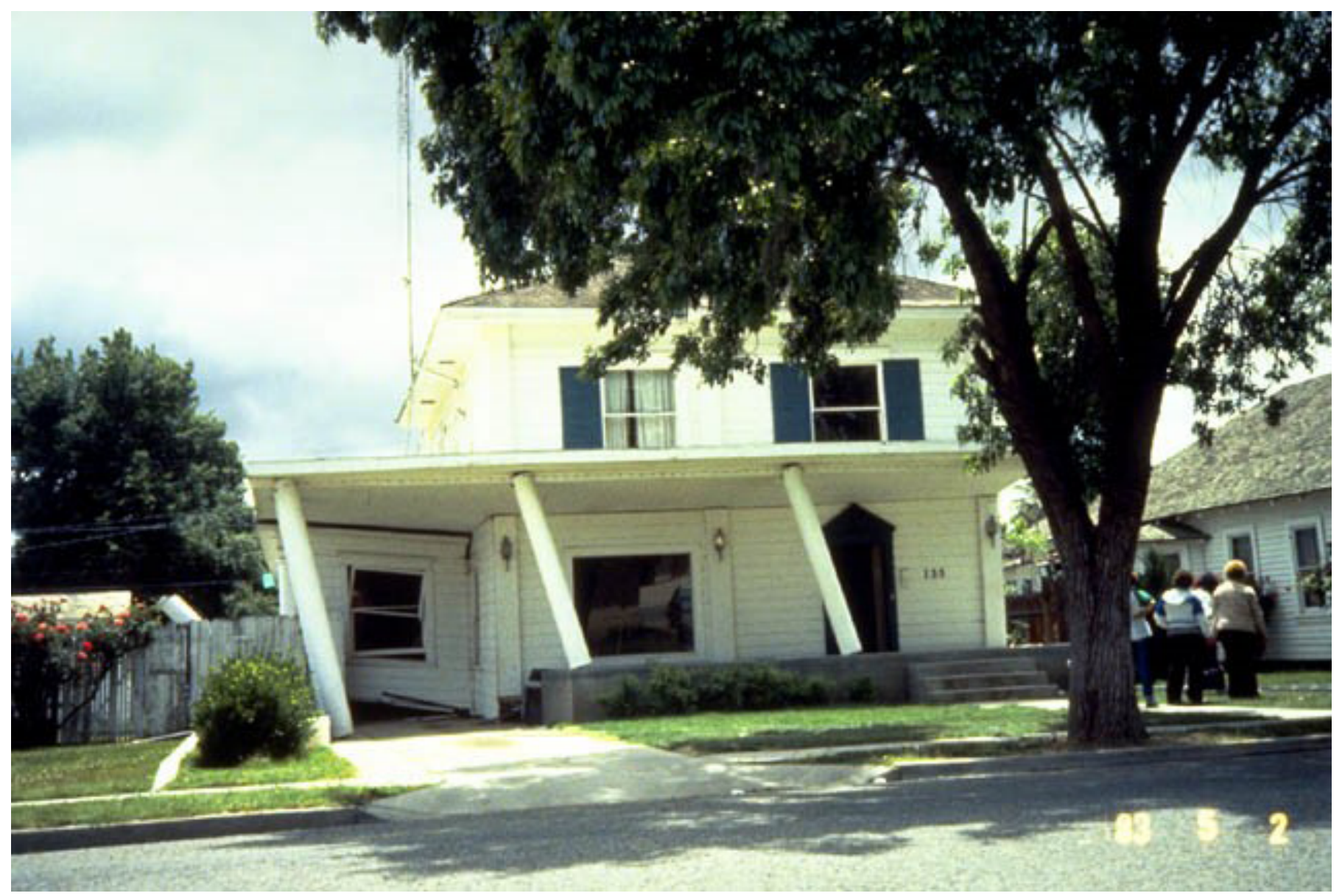

Figure 5-1. Photograph showing lateral displacement of two-story wood frame dwelling after the 1983 Coalinga, California, earthquake. 


\section{Image Metadata and Description for Figure 5-2}

William G. Godden (v. 4) collection: GoddenJ52

\begin{tabular}{cccccc}
\hline $\begin{array}{c}\text { Earthquake date } \\
\text { and magnitude }(\boldsymbol{M})\end{array}$ & Title & Creator & Date & Location & Description \\
\hline May 2, 1983; M6.5 & $\begin{array}{c}\text { Chimney } \\
\text { collapse, } \\
\text { Coalinga }\end{array}$ & Bertero, Vitelmo V. & -- & $\begin{array}{c}\text { United States/ Coal- } \\
\text { inga/ California/ }\end{array}$ & $\begin{array}{c}\text { Chimney collapse of a modern house, } \\
\text { 1983 Coalinga earthquake. Most } \\
\text { of the chimneys were thrown down } \\
\text { because of the lack of proper connec- } \\
\text { tions (straps) to the building. }{ }^{1}\end{array}$ \\
\hline
\end{tabular}

${ }^{1}$ Additional discussion of this image is available in Godden Set $\mathrm{J}$.

\section{Author's Estimate of Affected Area}

There are no other views of this building. Typical single-family dwelling is approximately $1,500 \mathrm{ft}^{2}$, but this one looks a little larger, say $50 \%$ larger or $2,250 \mathrm{ft}^{2}$. Bricks litter an area approximately $20 \mathrm{ft} \times 10 \mathrm{ft}=200 \mathrm{ft}^{2}$, or $9 \%$.

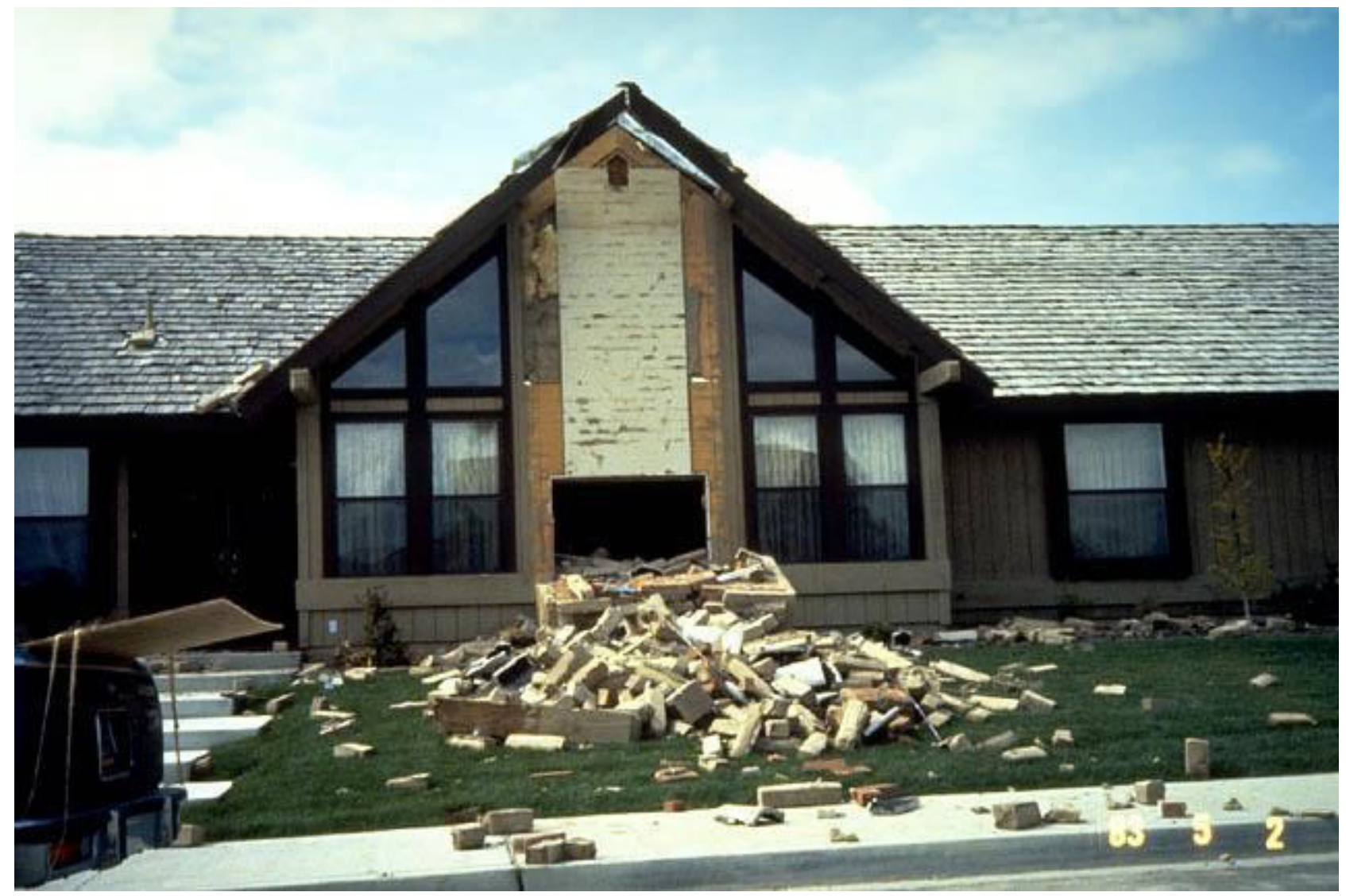

Figure 5-2. Photograph showing chimney collapse of a modern house after the 1983 Coalinga, California, earthquake.

\section{Image Metadata and Description for Figure 5-3}

William G. Godden (v. 4) Collection: GoddenJ23

\begin{tabular}{|c|c|c|c|c|c|}
\hline $\begin{array}{c}\text { Earthquake date } \\
\text { and magnitude }(M)\end{array}$ & Title & Creator & Date & Location & Description \\
\hline May 2,$1983 ; M 6.5$ & $\begin{array}{l}\text { Collapse of } \\
\text { wooden porch, } \\
\text { Coalinga }\end{array}$ & Bertero, Vitelmo V. & -- & $\begin{array}{l}\text { United States/ } \\
\text { California/ North } \\
\text { America }\end{array}$ & $\begin{array}{l}\text { Collapse of a wooden porch (owing to lack of } \\
\text { proper anchorage to the wooden frame of the } \\
\text { house and of a proper lateral-resistant sup- } \\
\text { porting system) owing to vibratory response. }\end{array}$ \\
\hline
\end{tabular}

${ }^{1}$ Additional discussion of this image is available in Godden Set J. 


\section{Author's Estimate of Affected Area}

There are no other views of this building. Typical single-family dwelling is approximately $1,500 \mathrm{ft}^{2}$. This porch appears to have measured $12 \mathrm{ft} \times 20 \mathrm{ft}$, so $200 \mathrm{ft}^{2} / 1,500 \mathrm{ft}^{2} \approx 15 \%$.

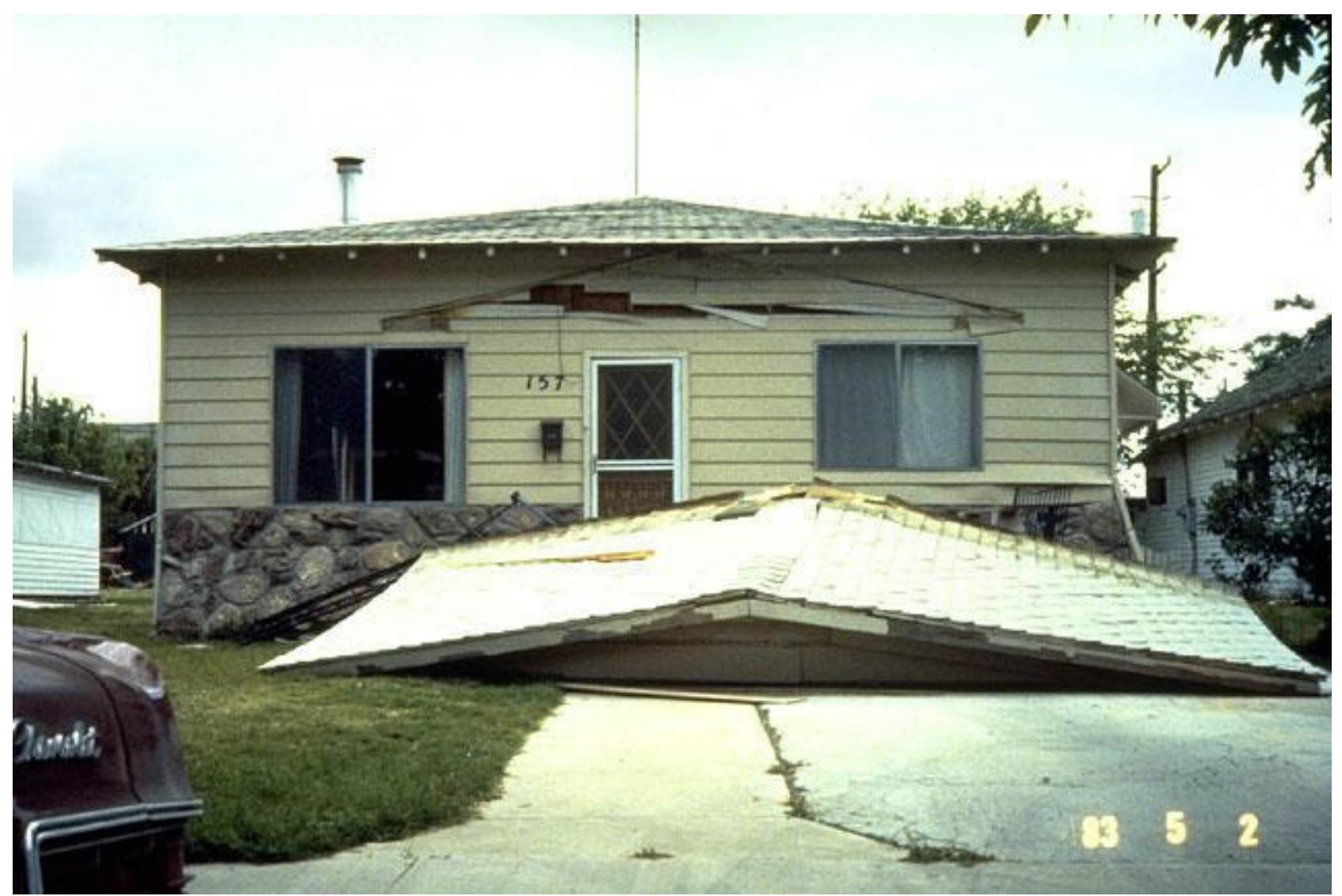

Figure 5-3. Photograph showing collapse of a wooden porch after the 1983 Coalinga, California, earthquake.

\section{Image Metadata and Description for Figure 5-4}

William G. Godden (v. 4) collection: GoddenJ29

\begin{tabular}{|c|c|c|c|c|c|}
\hline $\begin{array}{c}\text { Earthquake date } \\
\text { and magnitude }(M)\end{array}$ & Title & Creator & Date & Location & Description \\
\hline May 2,$1983 ;$ M6.5 & $\begin{array}{l}\text { Unreinforced } \\
\text { brick building, } \\
\text { Coalinga }\end{array}$ & Bertero, Vitelmo V. & -- & $\begin{array}{l}\text { United States/ } \\
\text { California/ North } \\
\text { America }\end{array}$ & $\begin{array}{l}\text { The second story, } 8 \text {-in., unreinforced solid brick } \\
\text { masonry walls of this commercial building } \\
\text { in Coalinga collapsed, owing to inadequate } \\
\text { tying at the floor, roof, and transverse walls. }{ }^{1}\end{array}$ \\
\hline
\end{tabular}

${ }^{1}$ Additional discussion of this image is available in Godden Set $\mathrm{J}$.

\section{Author's Estimate of Affected Area}

There are no other views of this building. It looks as if about half of the upper story of a two-story building collapsed (25\%), plus bricks litter the perimeter, so say $30 \%$. 


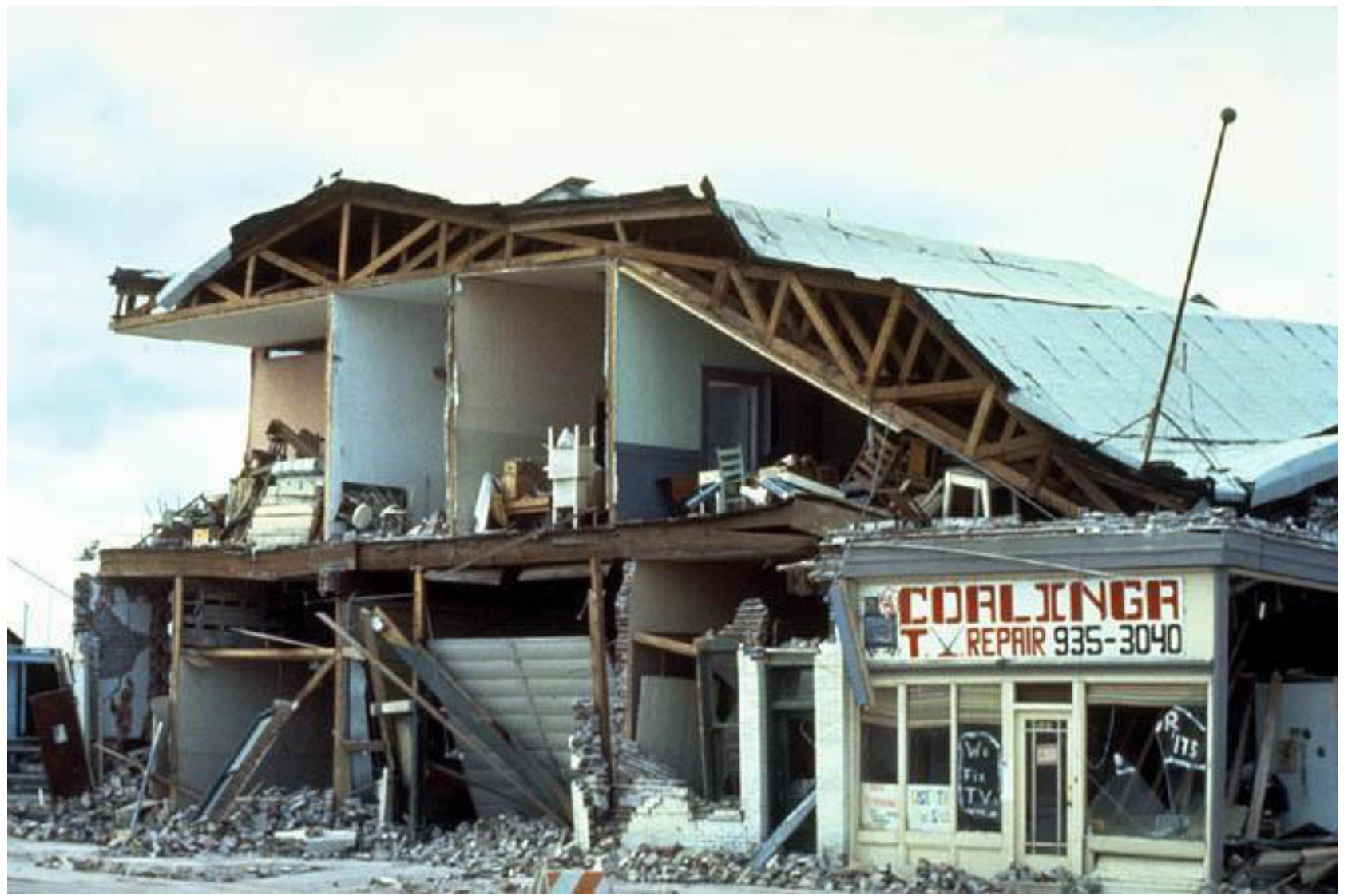

Figure 5-4. Photograph showing collapse of an unreinforced brick building after the 1983 Coalinga, California, earthquake.

\section{Image Metadata and Description for Figure 5-5}

Robert A. Olson Collection: R0321

\begin{tabular}{cccccc}
\hline $\begin{array}{c}\text { Earthquake date } \\
\text { and magnitude }(\boldsymbol{M})\end{array}$ & Title & Creator & Date & Location & Description \\
\hline May 2, 1983; M6.5 & $\begin{array}{c}\text { Heavy wooden } \\
\text { overhang fell } \\
\text { on sidewalk }\end{array}$ & -- & -- & -- & $\begin{array}{c}\text { Heavy wooden overhang fell from storefront } \\
\text { on to the sidewalk. Damaged concrete block } \\
\text { wall at the right. }\end{array}$ \\
\hline
\end{tabular}

\section{Author's Estimate of Affected Area}

No long shot to show how long the building is. No address. No estimate of affected area. 


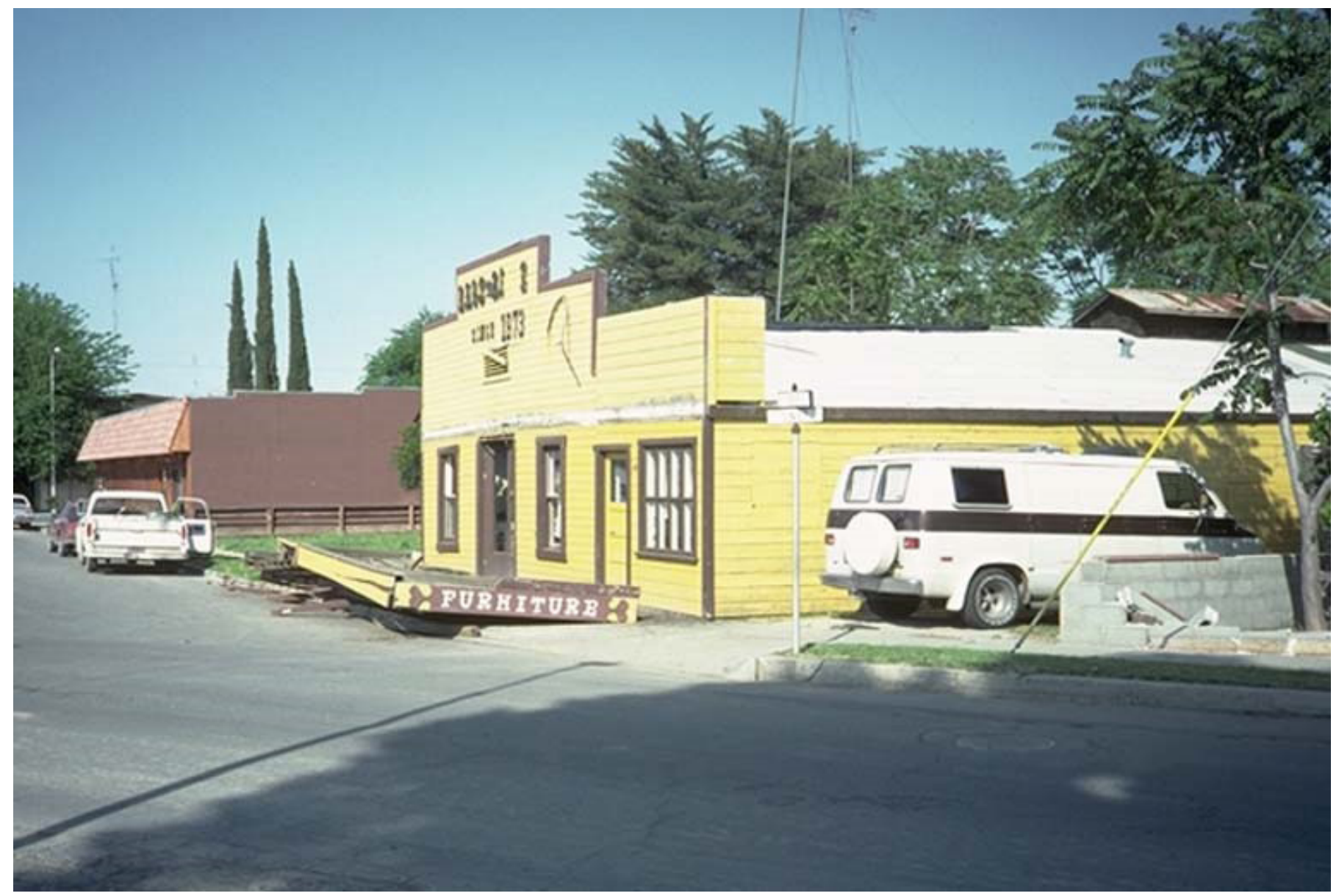

Figure 5-5. Photograph showing a heavy wooden overhang fallen onto sidewalk in the 1983 Coalinga, California, earthquake.

\section{Image Metadata and Description for Figure 5-6}

Robert A. Olson Collection: R0323

\begin{tabular}{|c|c|c|c|c|c|}
\hline $\begin{array}{c}\text { Earthquake date } \\
\text { and magnitude }(M)\end{array}$ & Title & Creator & Date & Location & Description \\
\hline May 2,$1983 ; 6.5$ & $\begin{array}{l}\text { Porch pulled away } \\
\text { from church } \\
\text { building }\end{array}$ & -- & -- & -- & $\begin{array}{l}\text { Porch running the full width of the church simply } \\
\text { pulled away from the rest of the building. Built in } \\
\text { 1946, the stabilized adobe building was heavily } \\
\text { damaged, but did not collapse. On the corner of } \\
\text { Jefferson St. }\end{array}$ \\
\hline
\end{tabular}

\section{Author's Estimate of Affected Area}

There are no other views of this building. Guess building area $\approx 30 \mathrm{ft} \times 90 \mathrm{ft}=2,700 \mathrm{ft}^{2}$, guess porch measured $20 \mathrm{ft} \times 10 \mathrm{ft}=7 \%$. 


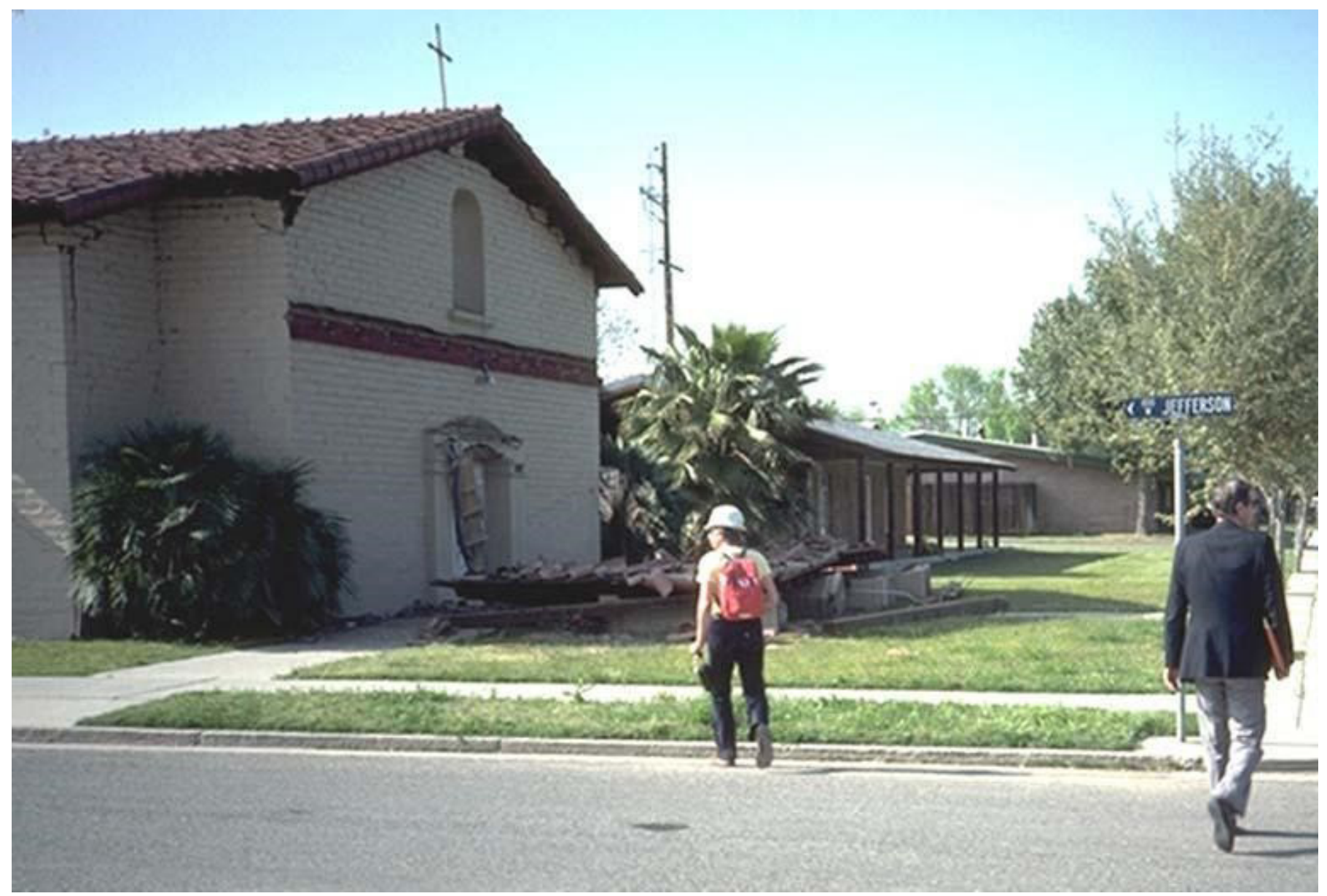

Figure 5-6. Photograph showing porch pulled away from church building after the 1983 Coalinga, California, earthquake.

\section{Image Metadata and Description for Figure 5-7}

Karl V. Steinbrugge Collection: S5765

\begin{tabular}{lccccc}
\hline $\begin{array}{c}\text { Earthquake date } \\
\text { and magnitude }(\boldsymbol{M})\end{array}$ & Title & Creator & Date & Location & Description \\
\hline May 2, 1983; M6.5 & $\begin{array}{c}\text { Veneer also fell } \\
\text { into the first } \\
\text { story }\end{array}$ & $\begin{array}{c}\text { Steinbrugge, } \\
\text { Karl V. }\end{array}$ & May 3, 1983 & $\begin{array}{c}\text { North America/ Fresno } \\
\text { County/ United States/ } \\
\text { Coalinga/ California }\end{array}$ & $\begin{array}{c}\text { Veneer also fell into the first story. } \\
\text { All reinforced brick buildings in } \\
\text { the downtown Coalinga area were } \\
\text { demolished. }\end{array}$ \\
\hline
\end{tabular}

\section{Author's Estimate of Affected Area}

No long shots, no address, no estimate of affected area. 


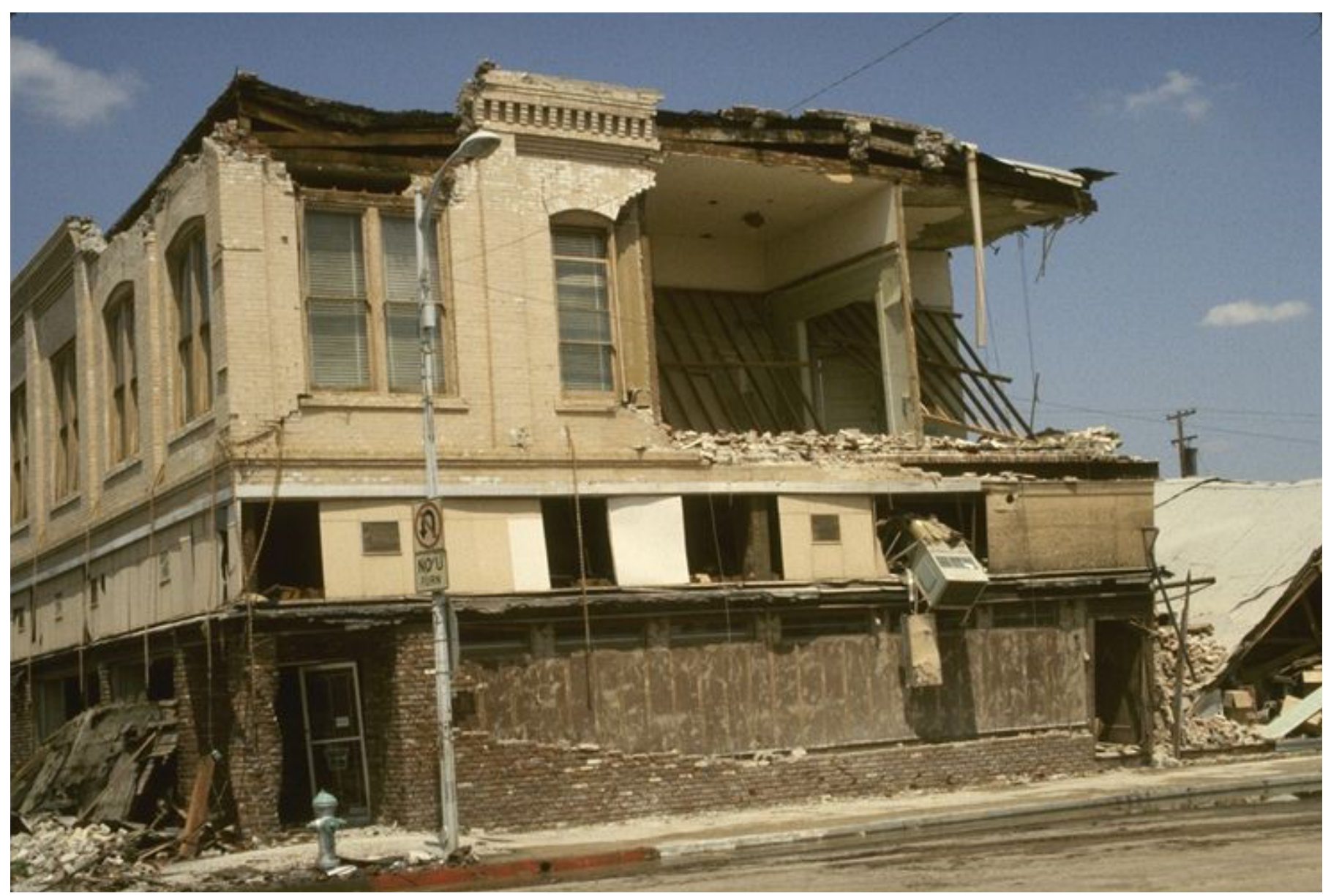

Figure 5-7. Photograph showing veneer fallen into first story of downtown building after the 1983 Coalinga, California, earthquake.

\section{Image Metadata and Description for Figure 5-8}

Karl V. Steinbrugge Collection: S5773

\begin{tabular}{cccccc}
\hline $\begin{array}{c}\text { Earthquake date } \\
\text { and magnitude }(\boldsymbol{M})\end{array}$ & Title & Creator & Date & Location & Description \\
\hline May 2, 1983; M6.5 & Parapet damaged & $\begin{array}{c}\text { Steinbrugge, } \\
\text { Karl V. }\end{array}$ & May 3, 1983 & $\begin{array}{c}\text { North America/ Fresno } \\
\text { County/ United States/ } \\
\text { Coalinga/ California }\end{array}$ & $\begin{array}{c}\text { Parapet damage. All reinforced brick } \\
\text { buildings in the downtown Coalinga } \\
\text { area were demolished. See S5828- } \\
5830 \text { for "after" views. }\end{array}$ \\
\hline
\end{tabular}

\section{Author's Estimate of Affected Area}

Building was at E. Durian Avenue and Coalinga Plaza, Coalinga, Calif. (https://www.masonryinstitute.org/pdf/909.pdf), possibly 286 Coalinga Plaza. No old satellite imagery. No estimate of plan area. No estimate of effected area. 


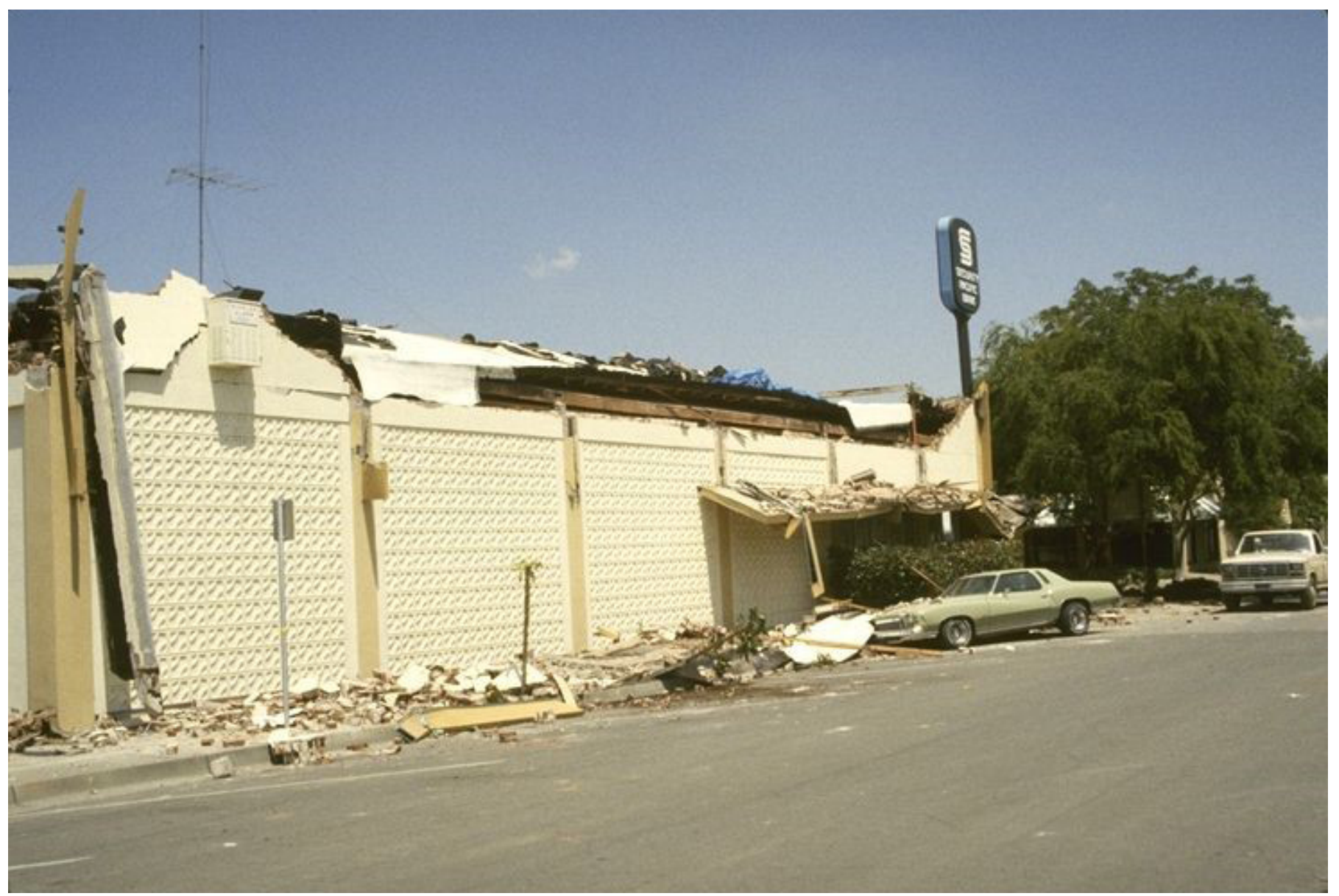

Figure 5-8. Photograph showing parapet damage to a building in downtown Coalinga after the 1983 Coalinga, California, earthquake. 


\section{Appendix 6. Morgan Hill (1984) Collapse Images}

\section{Image Metadata and Description for Figure 6-1}

Karl V. Steinbrugge Collection: S5840

\begin{tabular}{|c|c|c|c|c|c|}
\hline $\begin{array}{c}\text { Earthquake date } \\
\text { and magnitude (M) }\end{array}$ & Title & Creator & Date & Location & Description \\
\hline $\begin{array}{l}\text { April 24, 1984; } \\
\quad \text { M6.19 }\end{array}$ & $\begin{array}{c}\text { Most severely } \\
\text { damaged } \\
\text { dwelling }\end{array}$ & $\begin{array}{c}\text { Steinbrugge, } \\
\text { Karl V. }\end{array}$ & April 28, 1984 & $\begin{array}{l}\text { United States/ Morgan } \\
\text { Hill/ California/ North } \\
\text { America/ Santa Clara } \\
\text { County }\end{array}$ & $\begin{array}{l}\text { Most severely damaged dwelling. } \\
\text { Sheathing between first floor and } \\
\text { foundation was fiberboard with little } \\
\text { strength. Morgan Hill, California, } \\
\text { Anderson Lake area. }\end{array}$ \\
\hline
\end{tabular}

Author's Estimate of Affected Area

By inspection, $0 \%$.

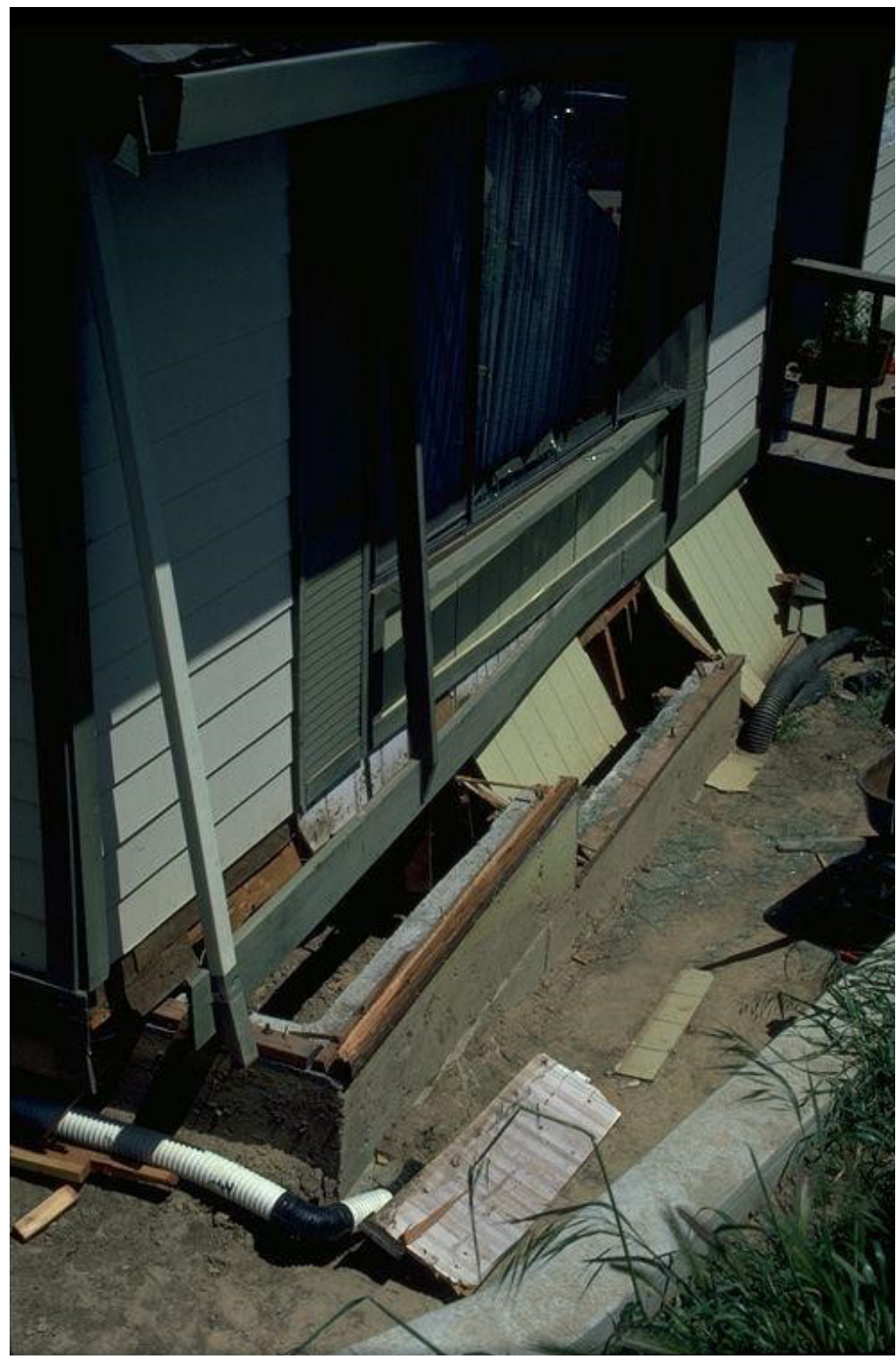

Figure 6-1. Photograph showing the most severely damaged dwelling in the 1984 Morgan Hill, California, earthquake. 


\section{Image Metadata and Description for Figure 6-2}

Karl V. Steinbrugge Collection: S5839 and Federal Emergency Management Agency (2002).

\begin{tabular}{|c|c|c|c|c|c|}
\hline $\begin{array}{c}\text { Earthquake date } \\
\text { and magnitude }(M)\end{array}$ & Title & Creator & Date & Location & Description \\
\hline $\begin{array}{l}\text { April 24, 1984; } \\
\quad M 6.19\end{array}$ & $\begin{array}{l}\text { Dwelling on the } \\
\text { left moved ow- } \\
\text { ing to landslide }\end{array}$ & $\begin{array}{c}\text { Steinbrugge, } \\
\text { Karl V. }\end{array}$ & April 28, 1984 & $\begin{array}{l}\text { Morgan Hill/ California/ } \\
\text { North America/ Santa Clara } \\
\text { County/ United States }\end{array}$ & $\begin{array}{l}\text { Dwelling on the left moved, } \\
\text { owing to landsliding from the } \\
\text { earthquake. Morgan Hill, Cali- } \\
\text { fornia. Anderson Lake area. }\end{array}$ \\
\hline
\end{tabular}

\section{Author's Estimate of Affected Area}

The right-hand image is from the FEMA National Earthquake Technical Assistance Training Program training slideset, entitled "Postearthquake Safety Evaluation of Buildings" (Federal Emergency Management Agency, 2002). Plan area from top to bottom floors appear to be 2:2:1. The bottom floor experienced some collapse, so say $20 \%$.
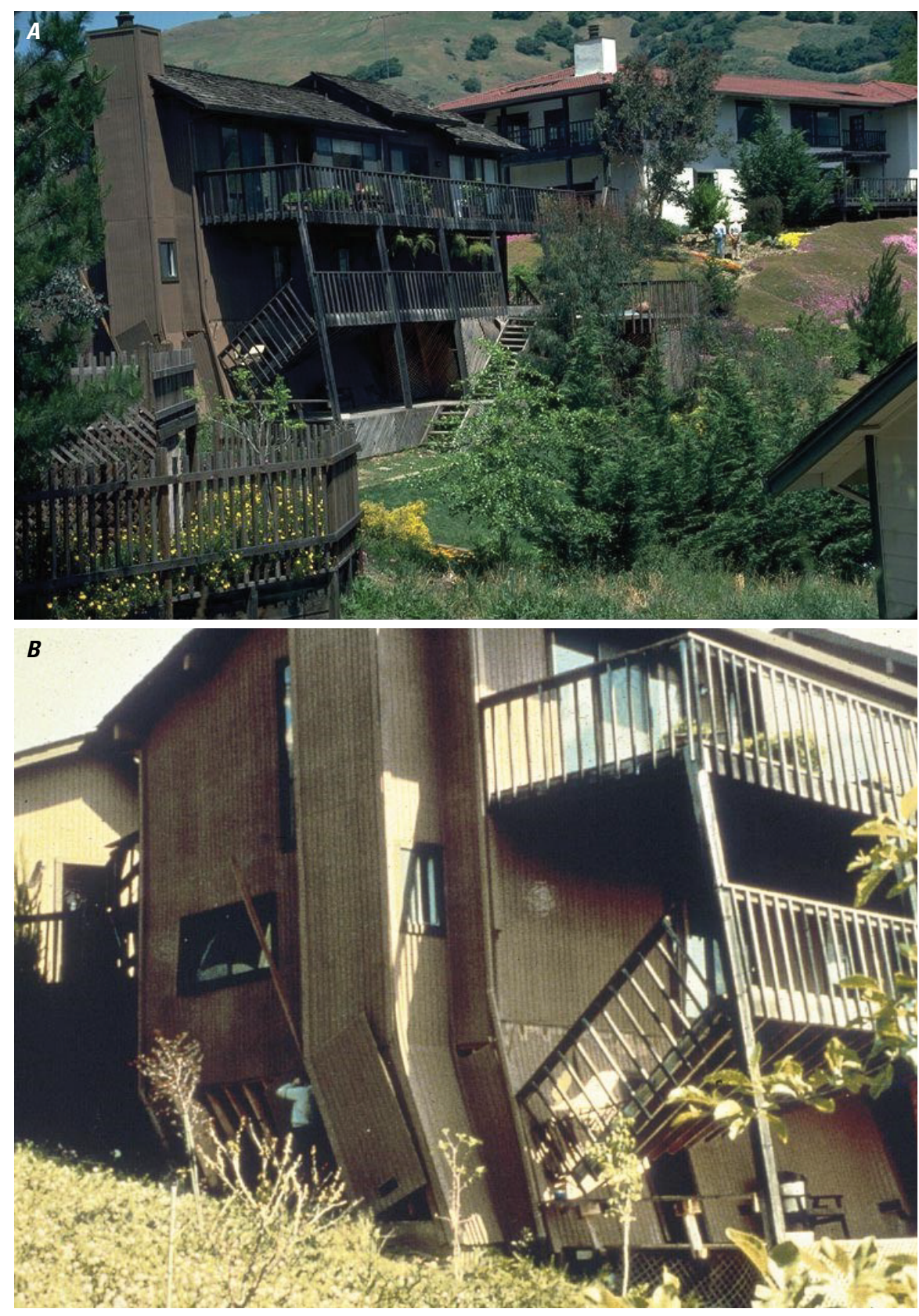

Figure 6-2. Photographs $(A, B)$ showing dwellings that have moved, owing to landslide in the 1984 Morgan Hill, California, earthquake. 


\section{Appendix 7. Whittier Narrows (1987) Collapse Images}

\section{Image Metadata and Description for Figure 7-1}

Karl V. Steinbrugge Collection: S6014

\begin{tabular}{|c|c|c|c|c|c|}
\hline $\begin{array}{c}\text { Earthquake date } \\
\text { and magnitude }(M)\end{array}$ & Title & Creator & Date & Location & Description \\
\hline $\begin{array}{l}\text { October 1, 1987; } \\
\quad M 6.0\end{array}$ & $\begin{array}{l}\text { Chimney col- } \\
\text { lapsed }\end{array}$ & $\begin{array}{c}\text { Steinbrugge, } \\
\text { Karl V. }\end{array}$ & October 3,1987 & $\begin{array}{l}\text { United States/ Whittier/ Cali- } \\
\text { fornia/North America/ Los } \\
\text { Angeles County }\end{array}$ & $\begin{array}{l}\text { Damage to roof from chim- } \\
\text { ney collapsing. Whittier, } \\
\text { California. }\end{array}$ \\
\hline
\end{tabular}

Author's Estimate of Affected Area

By inspection, $0 \%$.

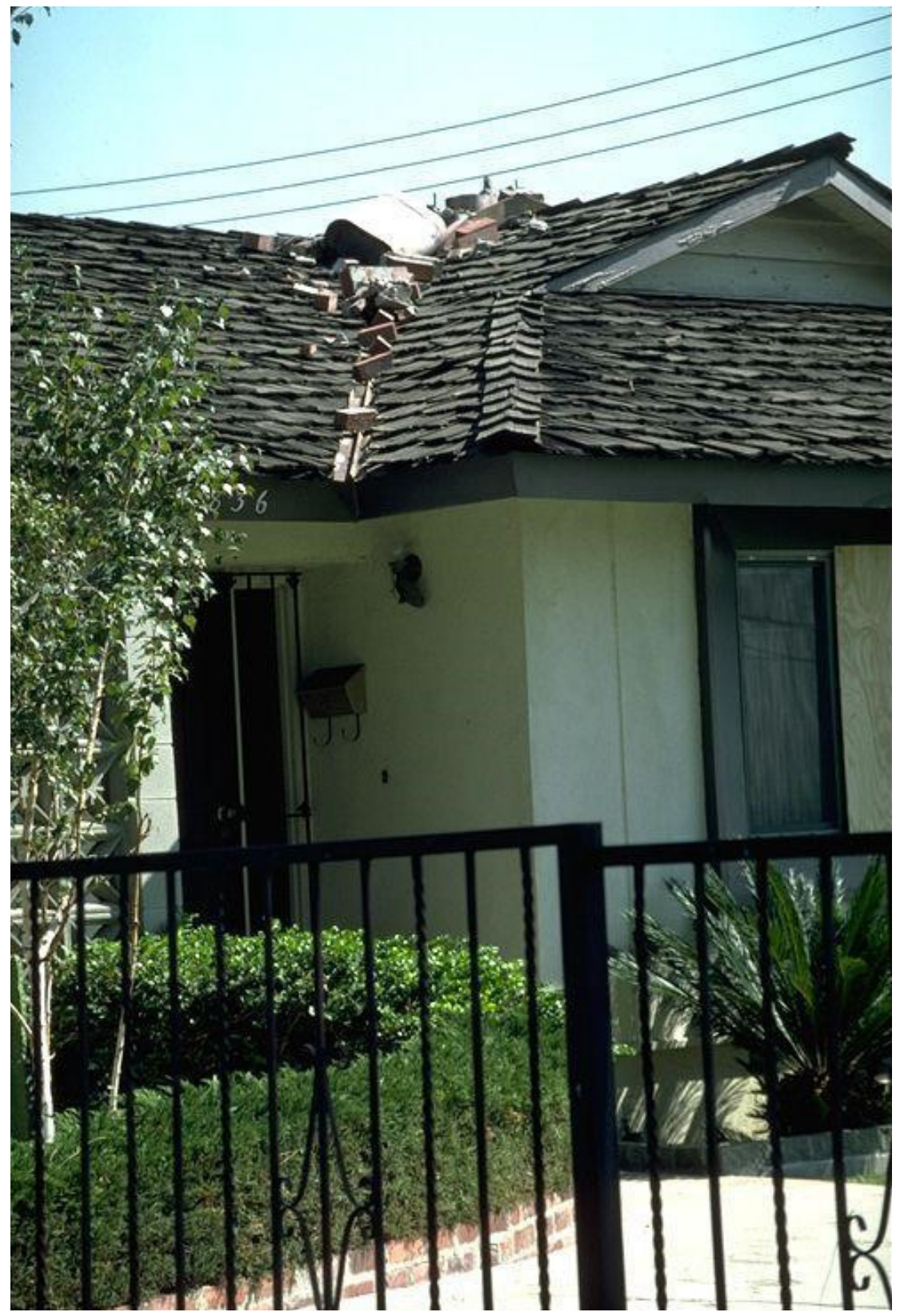

Figure 7-1. Photograph showing damage to roof from collapsed chimney after the 1987 Whittier Narrows, California, earthquake. 


\section{Image Metadata and Description for Figure 7-2}

Karl V. Steinbrugge Collection: S6023

\begin{tabular}{cccccc}
\hline $\begin{array}{c}\text { Earthquake date } \\
\text { and magnitude }(\boldsymbol{M})\end{array}$ & Title & Creator & Date & Location & Description \\
\hline $\begin{array}{l}\text { October 1, 1987; } \\
\text { M6.0 }\end{array}$ & $\begin{array}{c}\text { Chimney col- } \\
\text { lapsed }\end{array}$ & $\begin{array}{c}\text { Steinbrugge, } \\
\text { Karl V. }\end{array}$ & October 3, 1987 & $\begin{array}{c}\text { United States/ Whittier/ Cali- } \\
\text { fornia/ North America/ Los } \\
\text { Angeles County }\end{array}$ & $\begin{array}{c}\text { Chimney collapsed away } \\
\text { from the house. Whittier, } \\
\text { California. }\end{array}$ \\
\hline
\end{tabular}

Author's Estimate of Affected Area

There are no other views of this house in adjacent records, so assume typical area $1,500 \mathrm{ft}^{2}$ and that bricks litter an area $5 \mathrm{ft} \times 10 \mathrm{ft}=3 \%$.

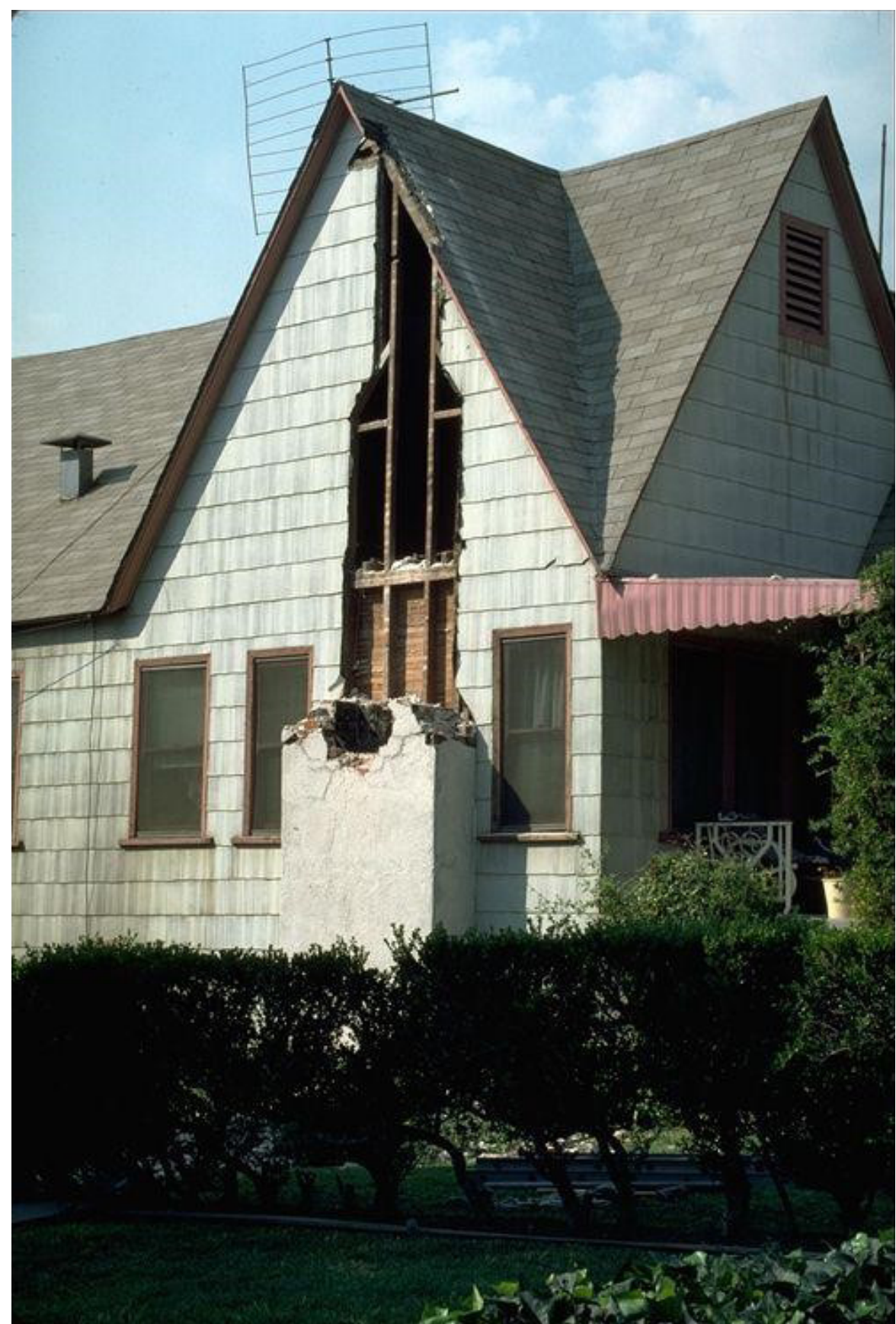

Figure 7-2. Photograph showing collapsed chimney in a house in Whittier after the 1987 Whittier Narrows, California, earthquake. 


\section{Image Metadata and Description for Figure 7-3}

Karl V. Steinbrugge Collection: S6020

\begin{tabular}{|c|c|c|c|c|c|}
\hline $\begin{array}{c}\text { Earthquake date } \\
\text { and magnitude (M) }\end{array}$ & Title & Creator & Date & Location & Description \\
\hline $\begin{array}{l}\text { October 1, 1987; } \\
\quad \text { M6.0 }\end{array}$ & Chimney damage & $\begin{array}{l}\text { Steinbrugge, } \\
\text { Karl V. }\end{array}$ & October 3, 1987 & $\begin{array}{l}\text { United States/ Whittier/ Cali- } \\
\text { fornia/ North America/ Los } \\
\text { Angeles County }\end{array}$ & $\begin{array}{l}\text { One chimney collapsed, but not } \\
\text { the other. Whittier, California. }\end{array}$ \\
\hline
\end{tabular}

Author's Estimate of Affected Area

House looks larger than typical: assume $3,000 \mathrm{ft}^{2}$. Bricks litter an area $8 \mathrm{ft} \times 8 \mathrm{ft}=2 \%$.
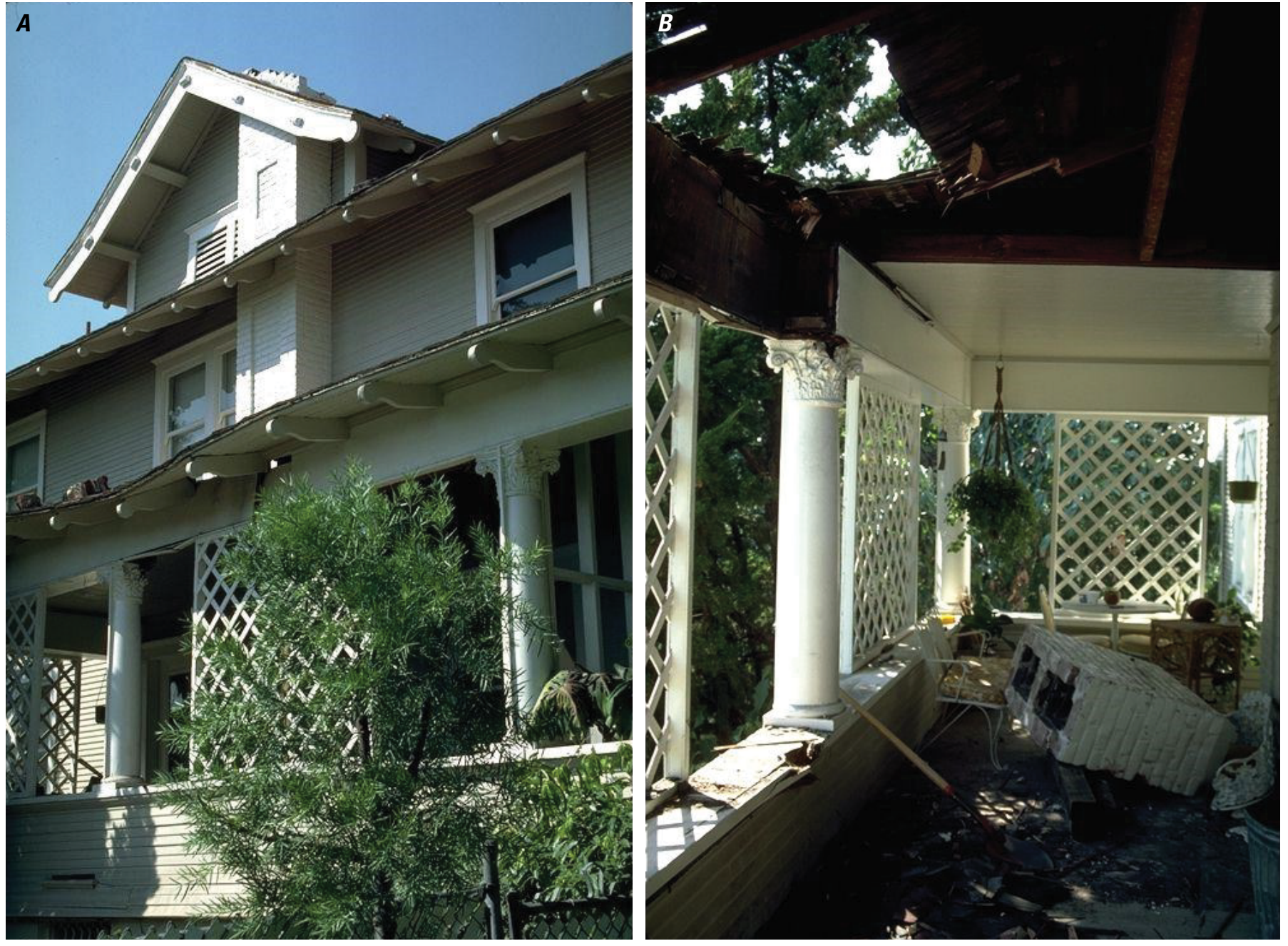

Figure 7-3. Image showing collapsed chimney in the 1987 Whittier Narrows, California, earthquake. 


\section{Image Metadata and Description for Figure 7-4}

Karl V. Steinbrugge Collection: S6022

\begin{tabular}{lccccc}
\hline $\begin{array}{c}\text { Earthquake date } \\
\text { and magnitude }(\boldsymbol{M})\end{array}$ & Title & Creator & Date & Location & Description \\
\hline $\begin{array}{l}\text { October 1, 1987; } \\
\text { M6.0 }\end{array}$ & Chimney damage & $\begin{array}{c}\text { Steinbrugge, } \\
\text { Karl V. }\end{array}$ & October 3, 1987 & $\begin{array}{c}\text { United States/ Whittier/ Cali- } \\
\text { fornia/ North America/ Los } \\
\text { Angeles County }\end{array}$ & $\begin{array}{c}\text { One chimney collapsed, but not } \\
\text { the other. Whittier, California. }\end{array}$ \\
\hline
\end{tabular}

Author's Estimate of Affected Area

Assume typical plan area for single-family dwelling of 1,500 $\mathrm{ft}^{2}$. Bricks litter an area approximately $5 \mathrm{ft} \times 10 \mathrm{ft}=3 \%$.

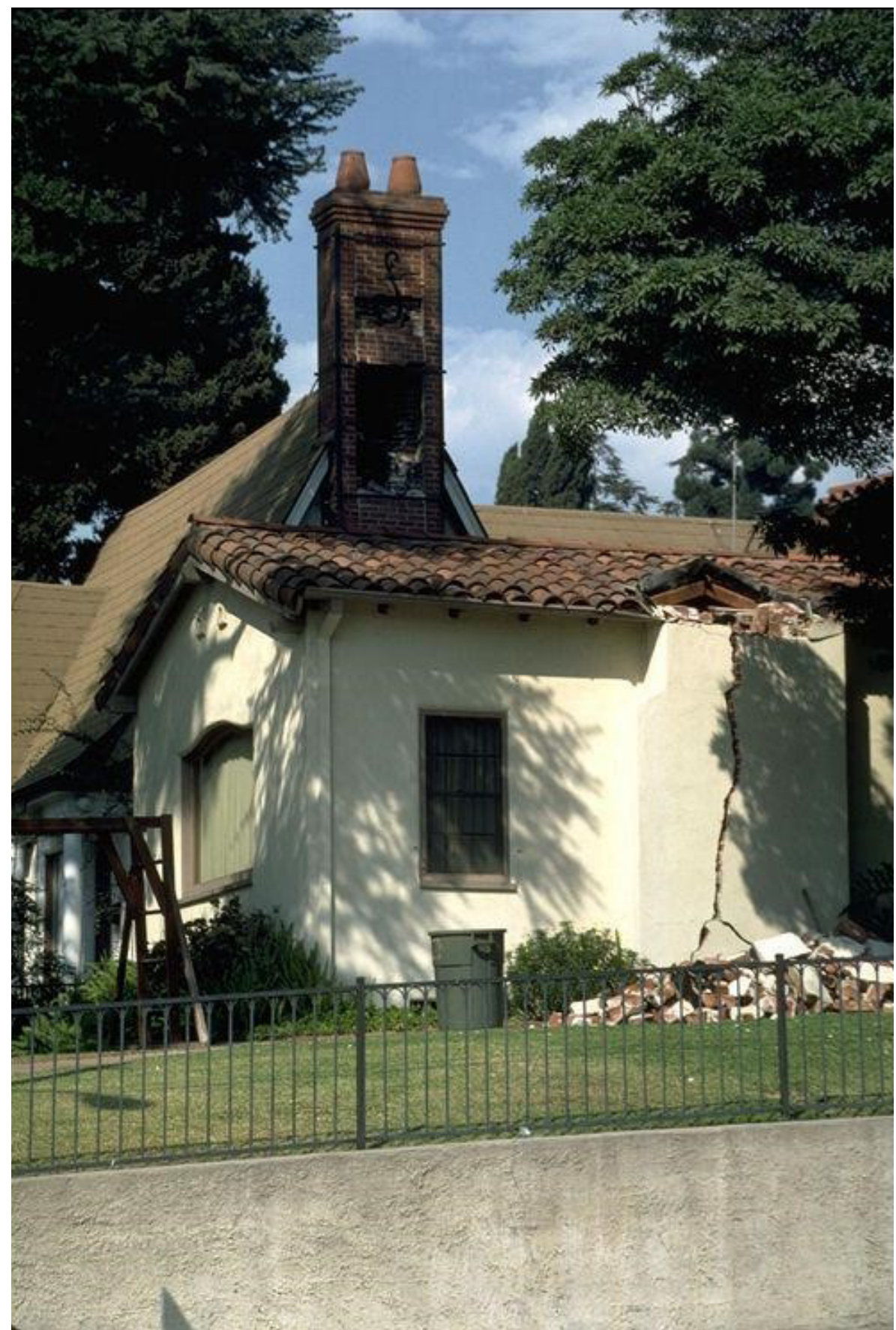

Figure 7-4. Photograph showing chimney damage from the 1987 Whittier Narrows, California, earthquake. 


\section{Image Metadata and Description for Figure 7-5}

Karl V. Steinbrugge Collection: S6024

\begin{tabular}{cccccc}
\hline $\begin{array}{c}\text { Earthquake date } \\
\text { and magnitude }(\boldsymbol{M})\end{array}$ & Title & Creator & Date & Location & Description \\
\hline $\begin{array}{l}\text { October 1, 1987; } \\
M 6.0\end{array}$ & $\begin{array}{c}\text { May Company } \\
\text { parking }\end{array}$ & $\begin{array}{c}\text { Steinbrugge, } \\
\text { Karl V. }\end{array}$ & October 3, 1987 & $\begin{array}{c}\text { North America/ Los Angeles } \\
\text { County/ United States/ }\end{array}$ & $\begin{array}{c}\text { May Company parking struc- } \\
\text { ture. Roof failed; damage } \\
\text { shown is from demolition. } \\
\text { Whittier, California. }\end{array}$ \\
\hline
\end{tabular}

\section{Author's Estimate of Affected Area}

No long shots. Google Earth imagery does not date back to 1987, so there is no way to estimate total area of lot. No estimate of affected area.

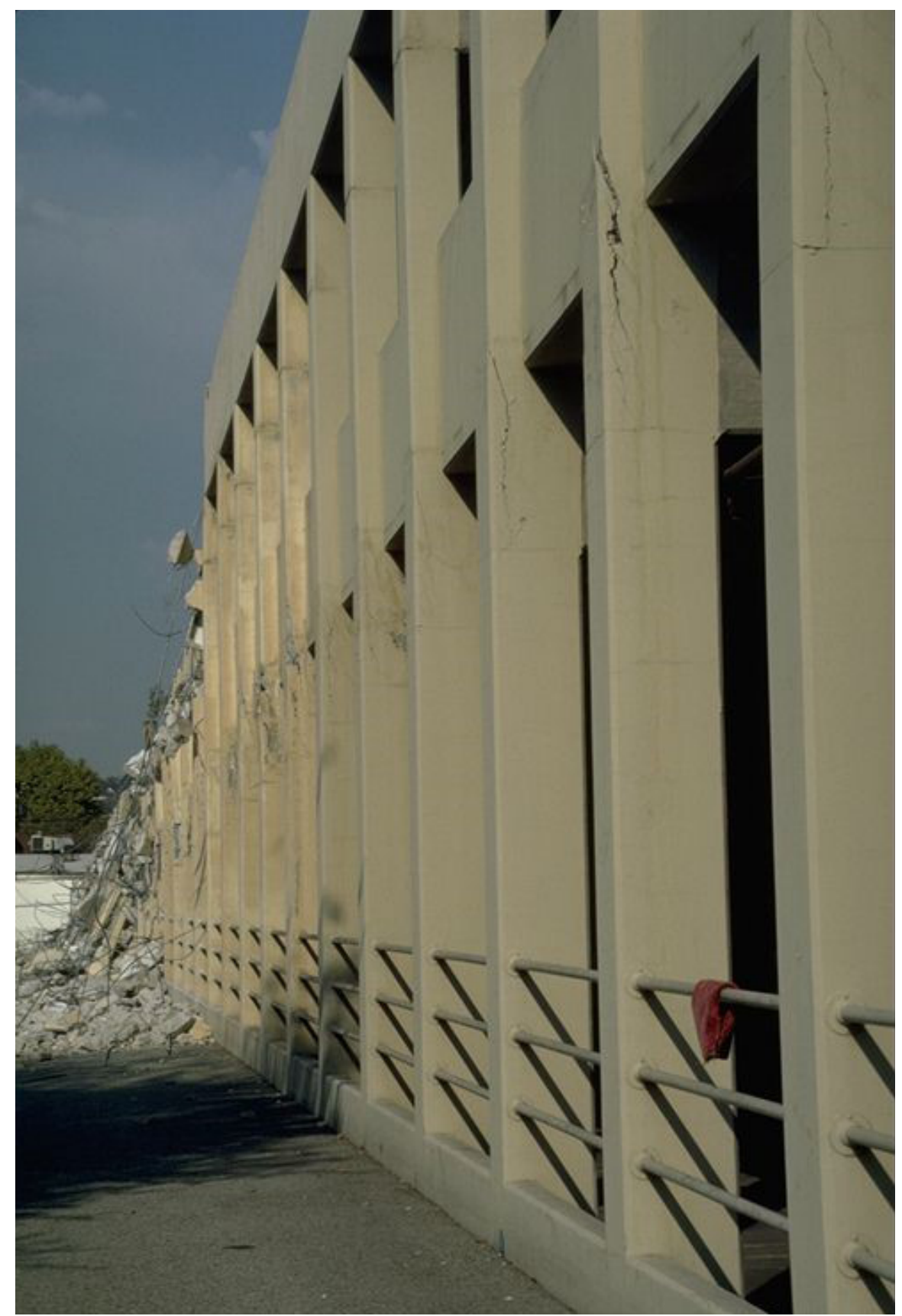

Figure 7-5. Photograph showing failure of parking structure roof after the 1987 Whittier Narrows, California, earthquake. 


\section{Appendix 8. Loma Prieta (1989) Collapse Images}

\section{Image Metadata and Description for Figure 8-1}

Loma Prieta Blacklock Collection: LP0042

\begin{tabular}{|c|c|c|c|c|c|}
\hline $\begin{array}{c}\text { Earthquake date } \\
\text { and magnitude }(M)\end{array}$ & Title & Creator & Date & Location & Description \\
\hline $\begin{array}{l}\text { October 17, 1989; } \\
\quad M 7.09\end{array}$ & $\begin{array}{l}\text { Wall collapse in } \\
\text { unreinforced } \\
\text { masonry }\end{array}$ & $\begin{array}{l}\text { Blacklock, } \\
\text { James R. }\end{array}$ & 1989 & $\begin{array}{l}\text { United States/ Santa Cruz/ } \\
\text { California/ North America/ } \\
\text { Santa Cruz County }\end{array}$ & $\begin{array}{l}\text { Wall collapse in unreinforced } \\
\text { masonry building. Santa Cruz, } \\
\text { California. }\end{array}$ \\
\hline
\end{tabular}

\section{Author's Estimate of Affected Area}

This is the historic Hihn Building, 1205 Pacific Avenue, Santa Cruz, California 95060. The parcel (APN 00507517000) covers $8,180 \mathrm{ft}^{2}$ according to Google Earth. Another photograph with a wider field of vision shows that the building stood two stories tall in 1989 (Moore, 2014) Total building area $=16,360 \mathrm{ft}^{2}$. Bricks litter an area about $16 \mathrm{ft} \times 12 \mathrm{ft}$, or $1 \%$.
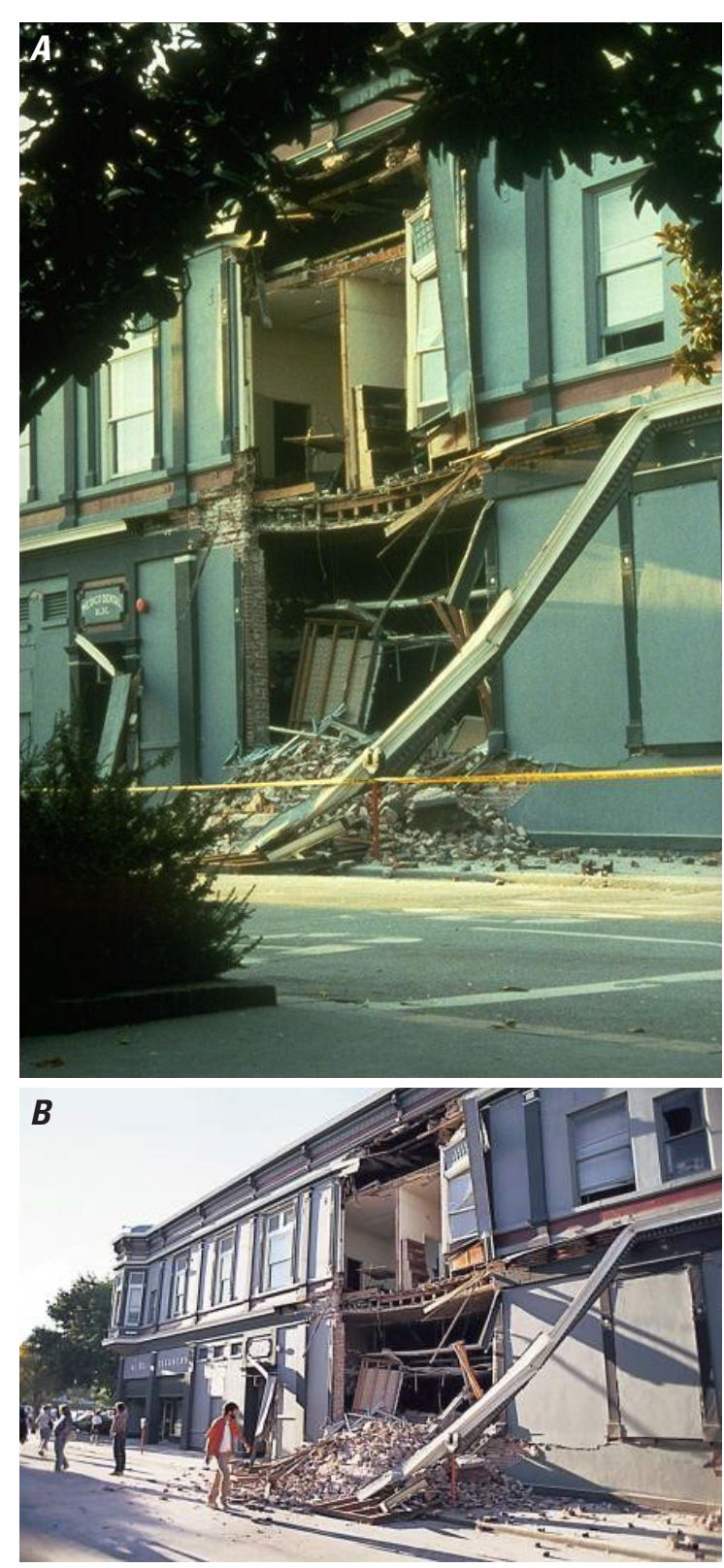

Figure 8-1. Photographs $(A, B)$ showing wall collapse in an unreinforced masonry building after the 1989 Loma Prieta, California, earthquake. 


\section{Image Metadata and Description for Figure 8-2}

Loma Prieta Blacklock Collection: LP0066

\begin{tabular}{cccccc}
\hline $\begin{array}{c}\text { Earthquake date } \\
\text { and magnitude }(\boldsymbol{M})\end{array}$ & Title & Creator & Date & Location & Description \\
\hline $\begin{array}{c}\text { October 17, 1989; } \\
\text { M7.09 }\end{array}$ & $\begin{array}{c}\text { Parapet and wall } \\
\text { failures in bak- } \\
\text { ery building }\end{array}$ & $\begin{array}{c}\text { Blacklock, } \\
\text { James R. }\end{array}$ & 1989 & $\begin{array}{c}\text { North America/ Santa Cruz } \\
\text { County/ United States/ } \\
\text { Watsonville/ California }\end{array}$ & $\begin{array}{c}\text { Parapet and wall failures in } \\
\text { bakery building. Watsonville, } \\
\text { California. }\end{array}$ \\
\hline
\end{tabular}

\section{Author's Estimate of Affected Area}

Location: 15 E. Beach Street (at Union Street), Watsonville, California. No long shot. No 1989 satellite imagery exists, so there is no estimate of shape or size of the damaged building. No estimate of affected area.

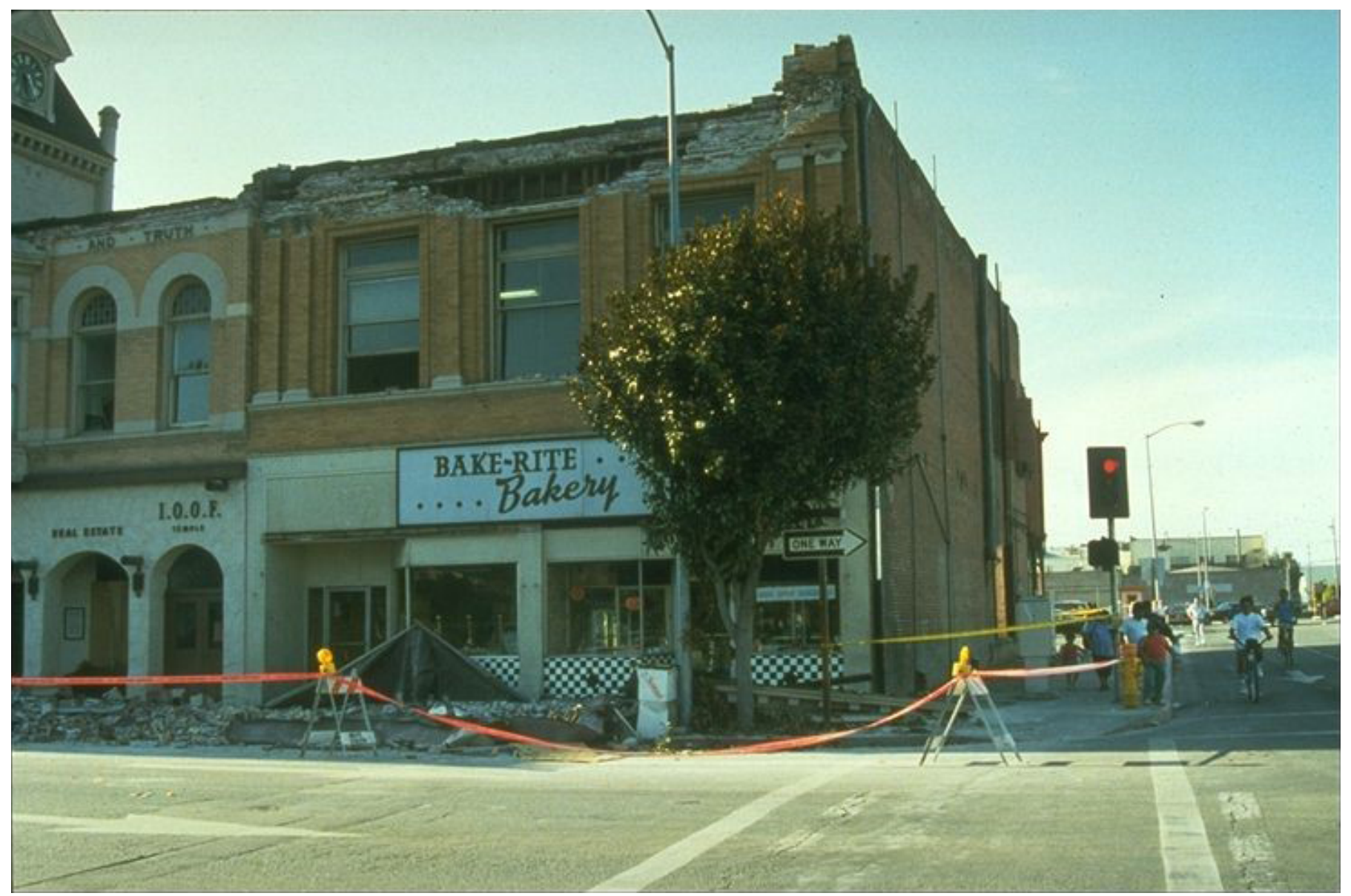

Figure 8-2. Photograph showing parapet and wall failures in Watsonville after the 1989 Loma Prieta, California, earthquake.

\section{Image Metadata and Description for Figure 8-3}

Loma Prieta Blacklock Collection: LP0070, LP0072, LP0073, and LP0074

\begin{tabular}{cccccc}
\hline $\begin{array}{c}\text { Earthquake date } \\
\text { and magnitude }(\boldsymbol{M})\end{array}$ & Title & Creator & Date & Location & Description \\
\hline $\begin{array}{c}\text { October 17, 1989; } \\
\text { M7.09 }\end{array}$ & $\begin{array}{c}\text { Failed parapets } \\
\text { on Main Street }\end{array}$ & $\begin{array}{c}\text { Blacklock, } \\
\text { James R. }\end{array}$ & 1989 & $\begin{array}{c}\text { North America/ Santa Cruz } \\
\text { County/ United States/ } \\
\text { Watsonville/ California }\end{array}$ & $\begin{array}{c}\text { Older building with failed para- } \\
\text { pets on Main St. Watsonville, } \\
\text { California. }\end{array}$ \\
\hline
\end{tabular}




\section{Author's Estimate of Affected Area}

Two buildings are addressed here. The tall building labeled "Canada" on front and back appears to be 307 Main Street, Watsonville (see https://www.ngdc.noaa.gov/hazardimages/picture/show/259). According to Google Earth Pro, the lot at 307 Main Street measures $30 \mathrm{ft} \times 125 \mathrm{ft}$. The building (now removed) appears to fill the parcel, with a total building area of 7,500 $\mathrm{ft}^{2}$. Collapsed parapet and second story wall appears to litter an area about $90 \mathrm{ft}$ long (counting collapsed portions of both long walls, on the north and south sides) and perhaps $15 \mathrm{ft}$ wide, for total affected area $=(90 \mathrm{ft} \times 15 \mathrm{ft}) /\left(7,500 \mathrm{ft}^{2}\right)=18 \%$. The building with the collapsed parapet on its front facade appears to be located at what is now 311 Main Street, Watsonville, the middle one of three buildings on what is now one parcel. The center building appears to be about $65 \mathrm{ft}$ wide, with the front $35 \mathrm{ft}$ or so, occupying two stories and the back $90 \mathrm{ft}$ a single story. Bricks litter the $65 \mathrm{ft}$ length by $15 \mathrm{ft}$, for an affected area of $(65 \mathrm{ft} \times 15 \mathrm{ft}) /(65 \mathrm{ft} \times 125 \mathrm{ft}+$ $65 \mathrm{ft} \times 35 \mathrm{ft})=9.4 \%$.
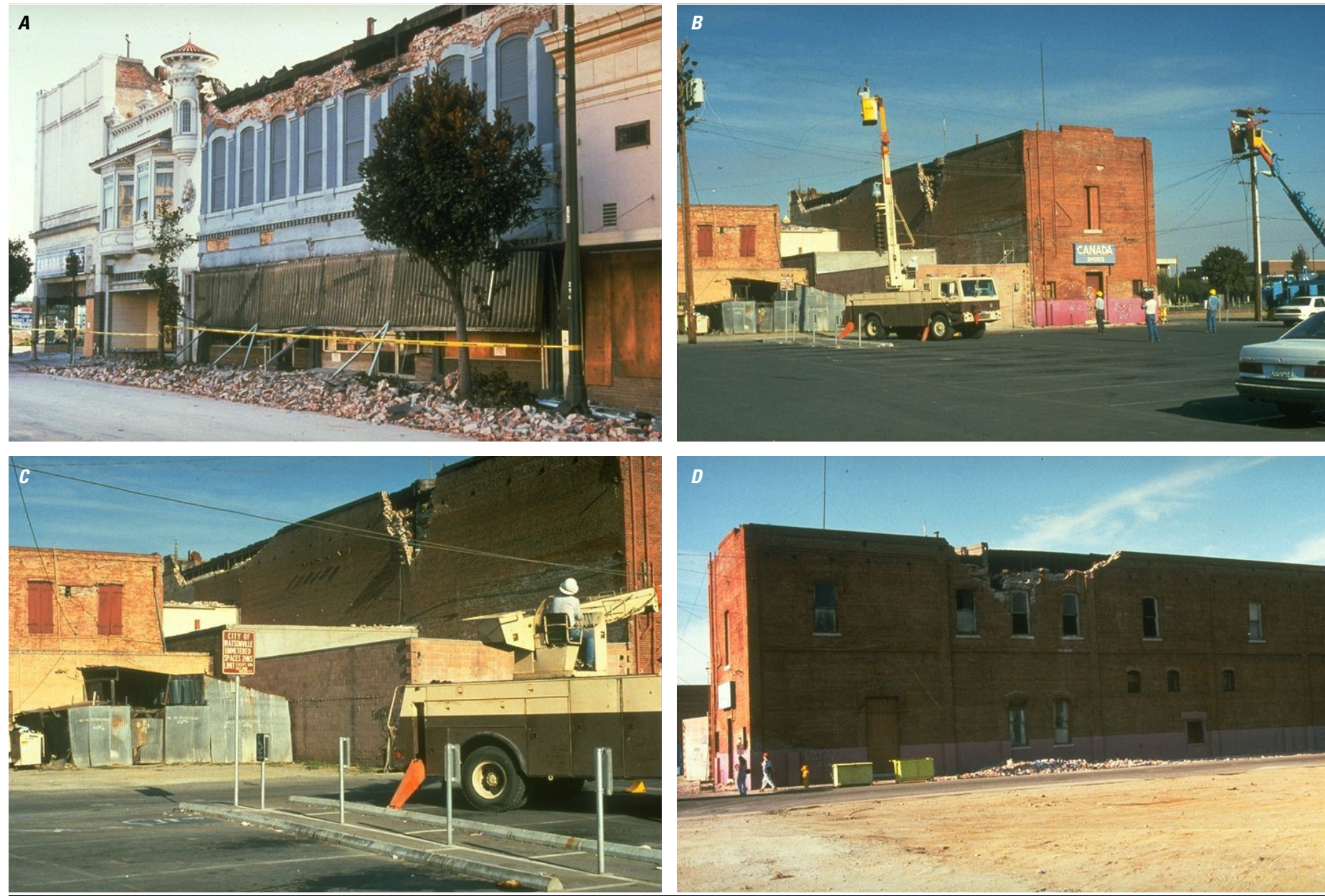

Figure 8-3. Photographs showing failed parapets in Watsonville after the 1989 Loma Prieta, California, earthquake. $A$, The building at the far left is 307 Main Street; the building in the foreground is 311 Main Street. $B-D$, Three views of the sides and rear of 307 Main Street.

\section{Image Metadata and Description for Figure 8-4}

Loma Prieta Blacklock Collection: LP0080

\begin{tabular}{lccccc}
\hline $\begin{array}{c}\text { Earthquake date } \\
\text { and magnitude }(\boldsymbol{M})\end{array}$ & Title & Creator & Date & Location & Description \\
\hline $\begin{array}{l}\text { October 17, 1989; } \\
M 7.09\end{array}$ & $\begin{array}{c}\text { Failed brick } \\
\text { parapet fell on } \\
\text { sidewalk }\end{array}$ & $\begin{array}{c}\text { Blacklock, } \\
\text { James R. }\end{array}$ & 1989 & $\begin{array}{c}\text { North America/ Santa Cruz } \\
\text { County/ United States/ } \\
\text { Watsonville/California }\end{array}$ & $\begin{array}{c}\text { Damaged building near Main St. } \\
\text { Failed brick parapet fell on } \\
\text { sidewalk }\end{array}$ \\
\hline
\end{tabular}




\section{Author's Estimate of Affected Area}

No address, no long shots. There is no way to tell how long this wall is or how deep the building is perpendicular to this wall. No estimate of affected area.

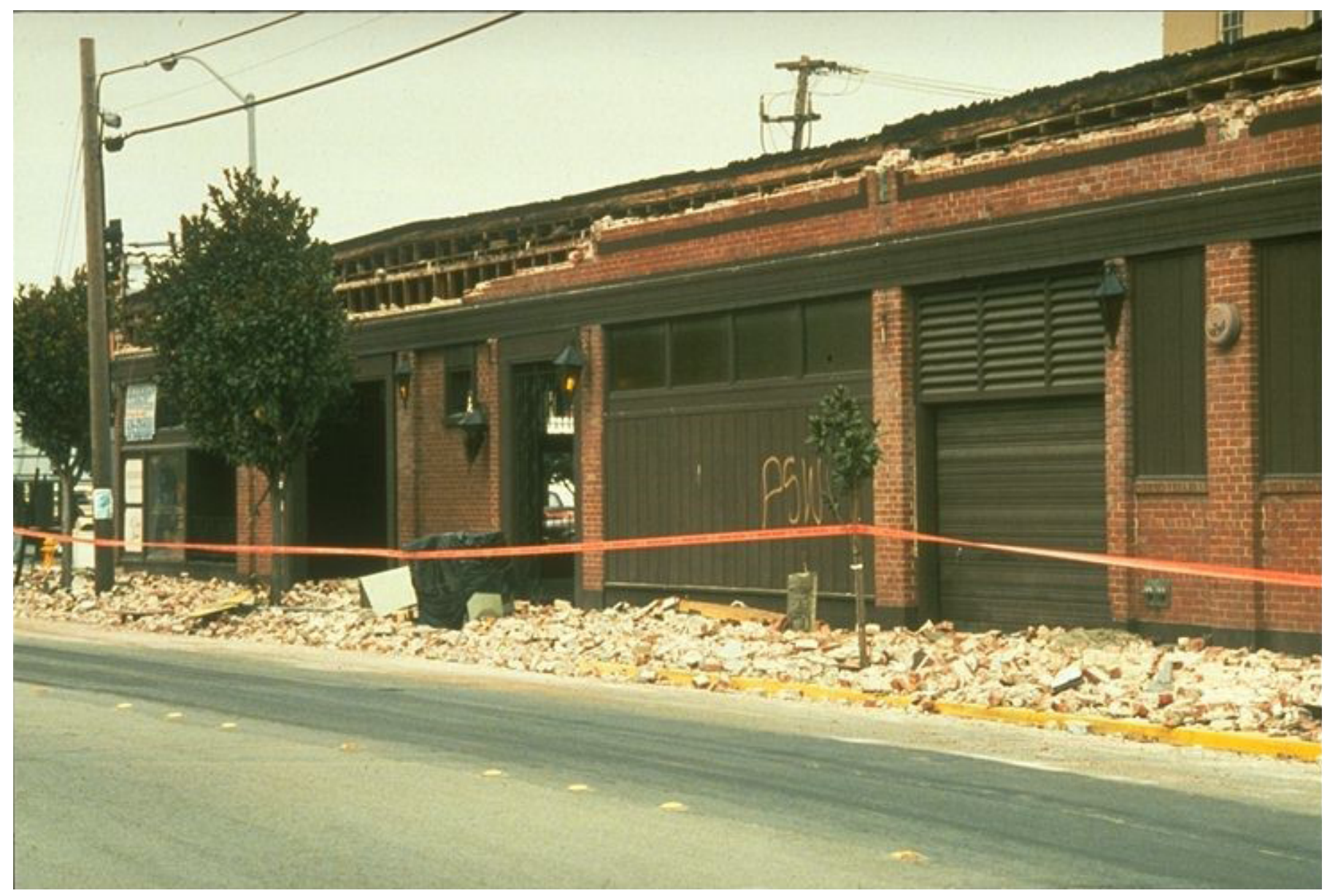

Figure 8-4. Photograph showing failed brick parapet fallen onto sidewalk in Watsonville after the 1989 Loma Prieta, California, earthquake.

\section{Image Metadata and Description for Figure 8-5}

Loma Prieta Blacklock Collection: LP0081-LP0085

\begin{tabular}{|c|c|c|c|c|c|}
\hline $\begin{array}{c}\text { Earthquake date } \\
\text { and magnitude }(M)\end{array}$ & Title & Creator & Date & Location & Description \\
\hline $\begin{array}{l}\text { October 17, 1989; } \\
\quad \text { M7.09 }\end{array}$ & $\begin{array}{l}\text { St. Patrick's } \\
\text { Church }\end{array}$ & $\begin{array}{r}\text { Blacklock, } \\
\text { James R. }\end{array}$ & 1989 & $\begin{array}{l}\text { North America/ Santa Cruz } \\
\text { County/ United States/ } \\
\text { Watsonville/ California }\end{array}$ & $\begin{array}{l}\text { Front view of damaged street. } \\
\text { Patrick's Church. Watsonville, } \\
\text { California. }\end{array}$ \\
\hline
\end{tabular}

\section{Author's Estimate of Affected Area}

Littered area $\approx 200 \mathrm{ft}^{2}$ at front (east) entrance, about $200 \mathrm{ft}^{2}$ at south transept, and $50 \mathrm{ft}^{2}$ at east end of north facade. Plan area $\approx 9,070 \mathrm{ft}^{2}$, and assume $1,000 \mathrm{ft}^{2}$ of additional galleries. Affected area $\approx\left(450 \mathrm{ft}^{2}\right) /\left(10,000 \mathrm{ft}^{2}\right)=4.5 \%$. 

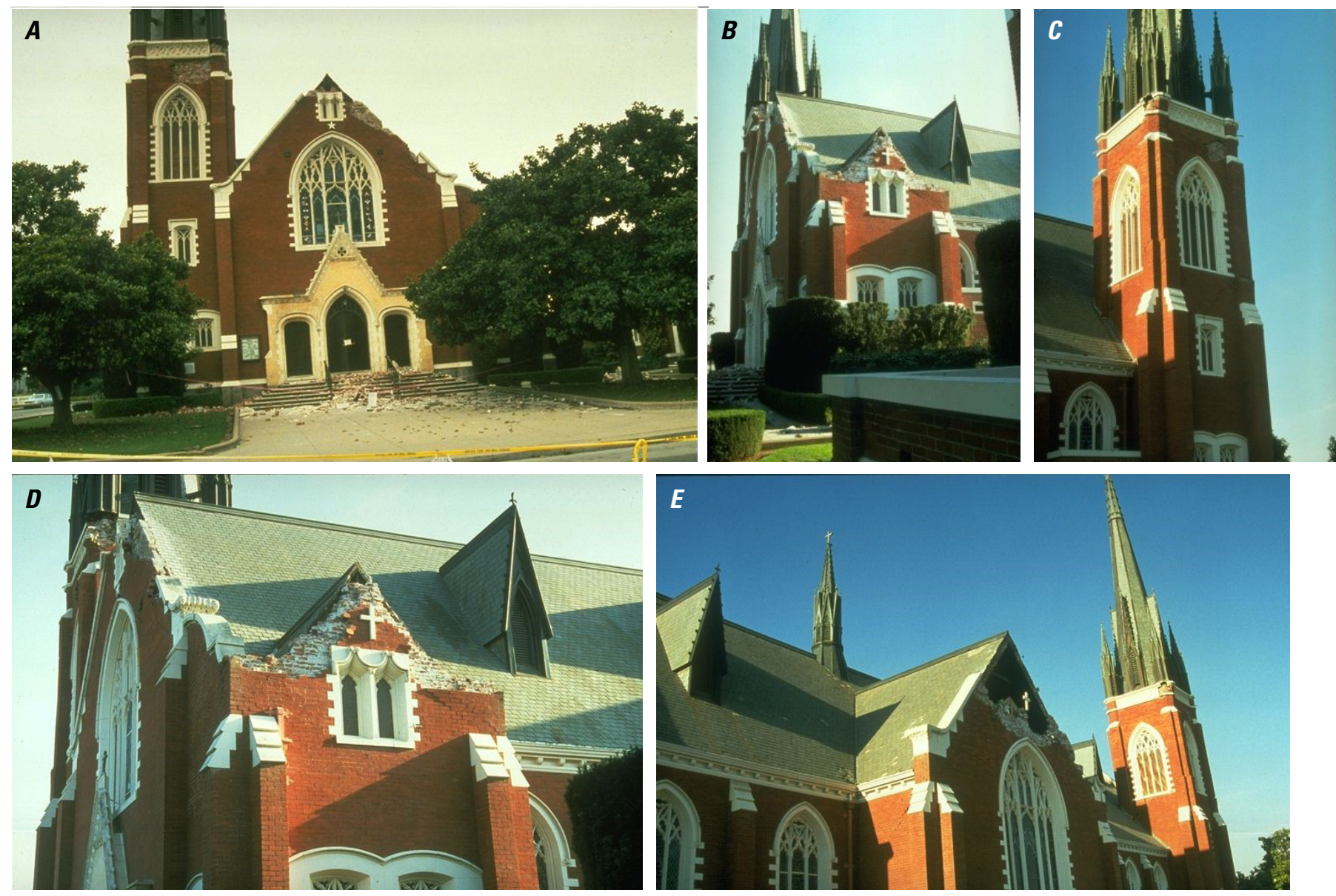

Figure 8-5. Photographs $(A-E)$ showing damage to St. Patrick's Church, Watsonville, after the 1989 Loma Prieta, California, earthquake.

\section{Image Metadata and Description for Figure 8-6}

Loma Prieta Blacklock Collection: LP0087

\begin{tabular}{|c|c|c|c|c|c|}
\hline $\begin{array}{c}\text { Earthquake date } \\
\text { and magnitude }(M)\end{array}$ & Title & Creator & Date & Location & Description \\
\hline $\begin{array}{l}\text { October 17, 1989; } \\
\quad M 7.09\end{array}$ & $\begin{array}{l}\text { Damaged bike } \\
\text { store with } \\
\text { failed parapet }\end{array}$ & $\begin{array}{l}\text { Blacklock, } \\
\text { James R. }\end{array}$ & Late 1989 & $\begin{array}{c}\text { North America/ Santa Cruz } \\
\text { County/ United States/ } \\
\text { Watsonville/ California }\end{array}$ & $\begin{array}{l}\text { Damaged bike store with failed } \\
\text { parapet. Watsonville, Cali- } \\
\text { fornia. }\end{array}$ \\
\hline
\end{tabular}

Author's Estimate of Affected Area

No other shots. No street name. No indication as to the former location of Watsonville Cyclery. 202 Main Street does not look like this. Littered area $\approx 50 \mathrm{ft} \times 12 \mathrm{ft}$. Plan area $\approx 40 \mathrm{ft} \times 60 \mathrm{ft}$. Affected area $\approx 25 \%$. 


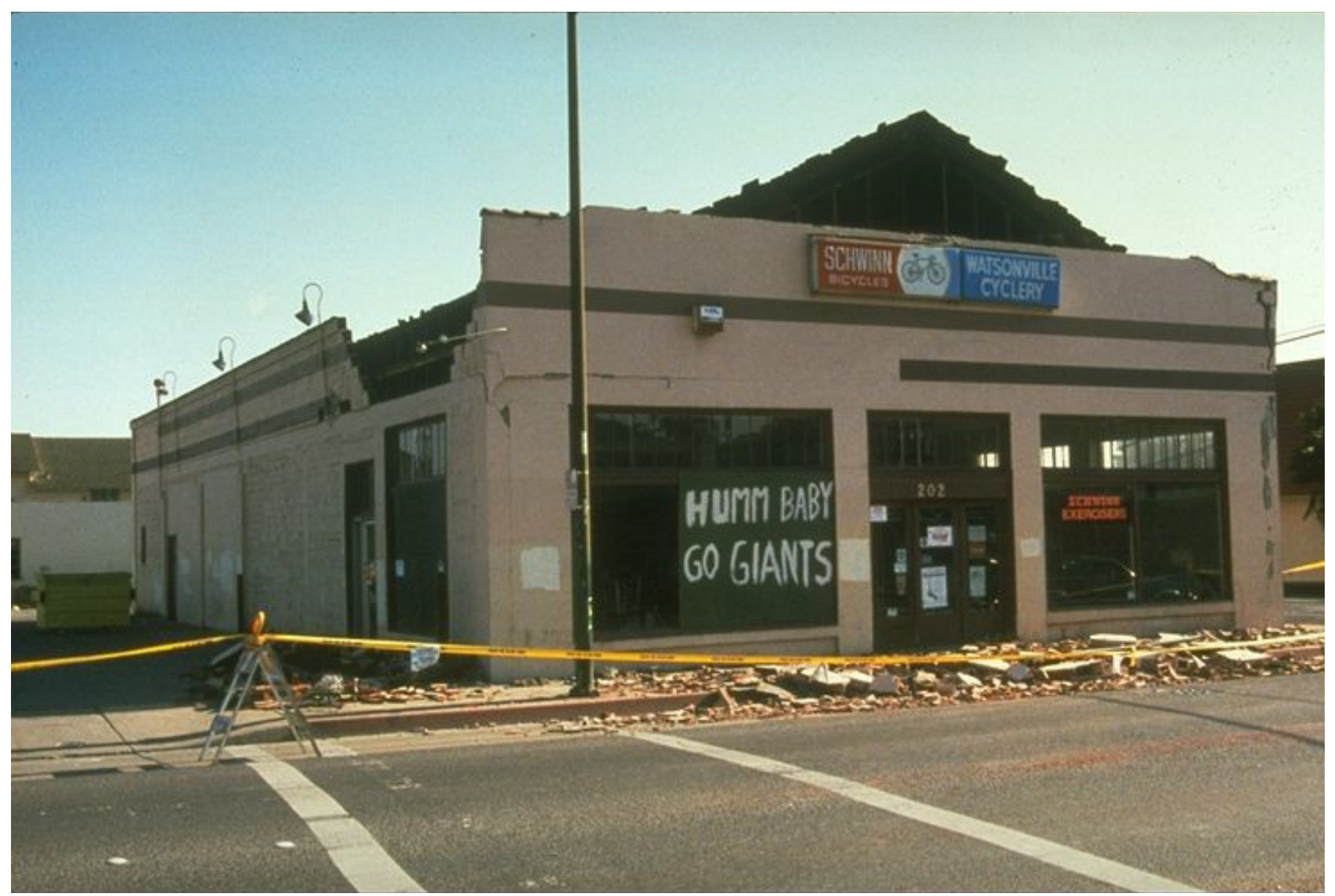

Figure 8-6. Photograph showing damaged bike store in Watsonville with failed parapet after the 1989 Loma Prieta, California, earthquake.

\section{Image Metadata and Description for Figure 8-7}

Loma Prieta Blacklock Collection: LP0090

\begin{tabular}{|c|c|c|c|c|c|}
\hline $\begin{array}{c}\text { Earthquake date } \\
\text { and magnitude }(M)\end{array}$ & Title & Creator & Date & Location & Description \\
\hline $\begin{array}{l}\text { October 17, 1989; } \\
\quad M 7.09\end{array}$ & $\begin{array}{l}\text { Wood frame house } \\
\text { with failed } \\
\text { foundation }\end{array}$ & $\begin{array}{r}\text { Blacklock, } \\
\text { James R. }\end{array}$ & Late 1989 & $\begin{array}{c}\text { North America/ Santa Cruz } \\
\text { County/ United States/ } \\
\text { Watsonville/ California }\end{array}$ & $\begin{array}{l}\text { Pink frame house with failed } \\
\text { foundation. Watsonville, } \\
\text { California. }\end{array}$ \\
\hline
\end{tabular}

\section{Author's Estimate of Affected Area}

By inspection, $0 \%$. 


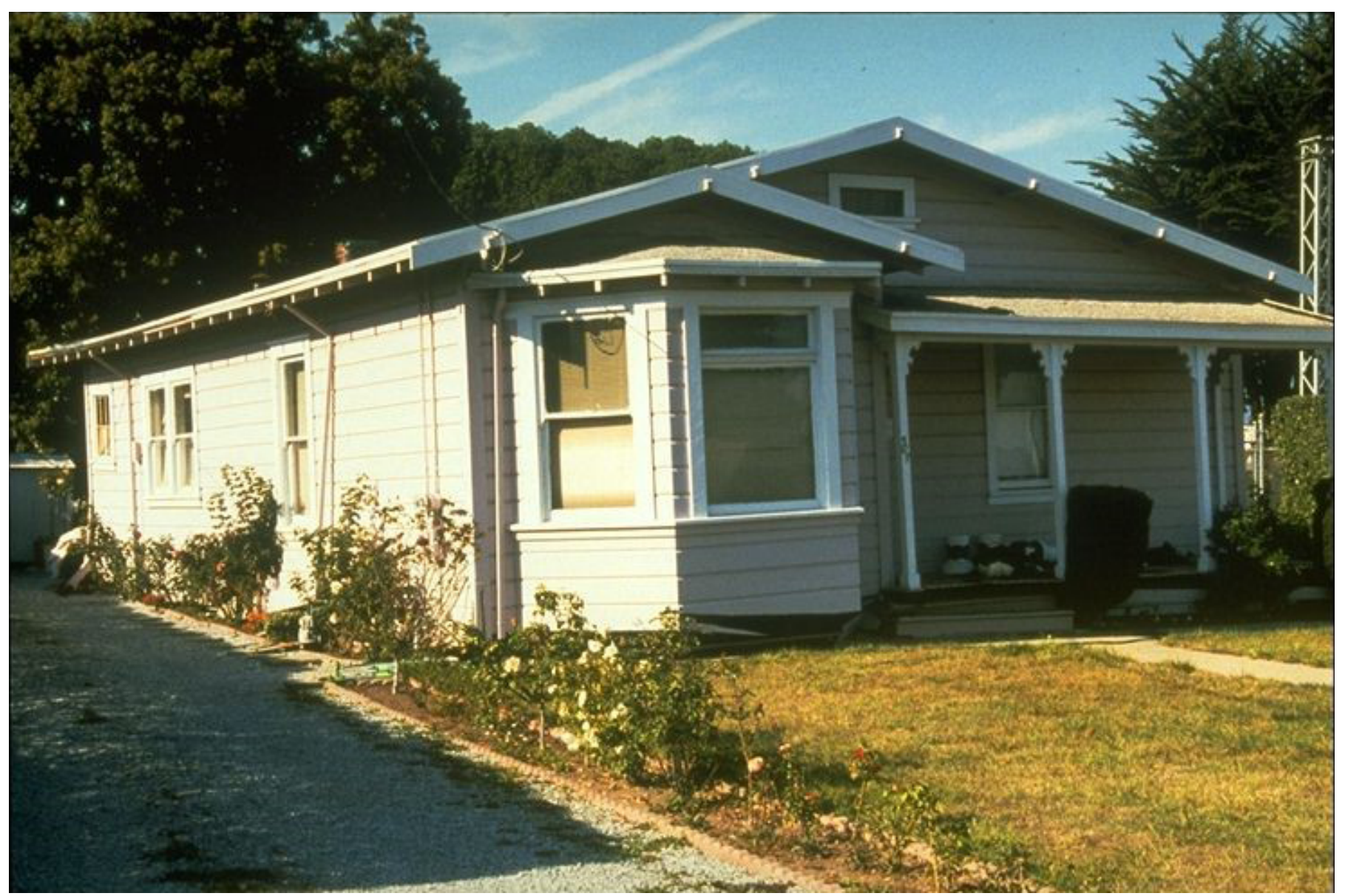

Figure 8-7. Photograph showing house with failed foundation in Watsonville after the 1989 Loma Prieta, California, earthquake.

\section{Image Metadata and Description for Figure 8-8}

Loma Prieta Collection: LP0462

\begin{tabular}{llllll}
\hline $\begin{array}{c}\text { Earthquake date } \\
\text { and magnitude }(\boldsymbol{M})\end{array}$ & Title & Creator & Date & Location & Description \\
\hline $\begin{array}{l}\text { October 17, 1989; } \\
M 7.09\end{array}$ & 6th and Bluxome St. & $\begin{array}{c}\text { Dickenson, } \\
\text { Stephen E. }\end{array}$ & 1989 & $\begin{array}{l}\text { United States/ California/ } \\
\text { North America/San Fran- } \\
\text { cisco }\end{array}$ & $\begin{array}{c}\text { Collapse of fourth story wall from } \\
\text { unreinforced brick building at } \\
\text { 6th and Bluxome Streets, San } \\
\text { Francisco, South of Market. }\end{array}$ \\
\hline
\end{tabular}

\section{Author's Estimate of Affected Area}

Also see LP0460 (below). The location is sometimes reported as near 5th and Townsend Streets, sometimes on Bluxome Street near 6th and Townsend Streets. If the latter, the building appears to be 178 Bluxome Street, at the south end of Bluxome on the north side of the street (assessor's parcel number [APN] 3785135), with parcel area 15,300 $\mathrm{ft}^{2}$ according to Google Earth Pro. With four stories, the total building area would be $61,200 \mathrm{ft}^{2}$. The debris runs the length of the facade (135 $\mathrm{ft}$ ) and twice as wide as the sidewalk, perhaps $24 \mathrm{ft}$. Five people were killed by the wall collapse. Affected area $=(135 \times 24) /(61,200)=5.3 \%$. 


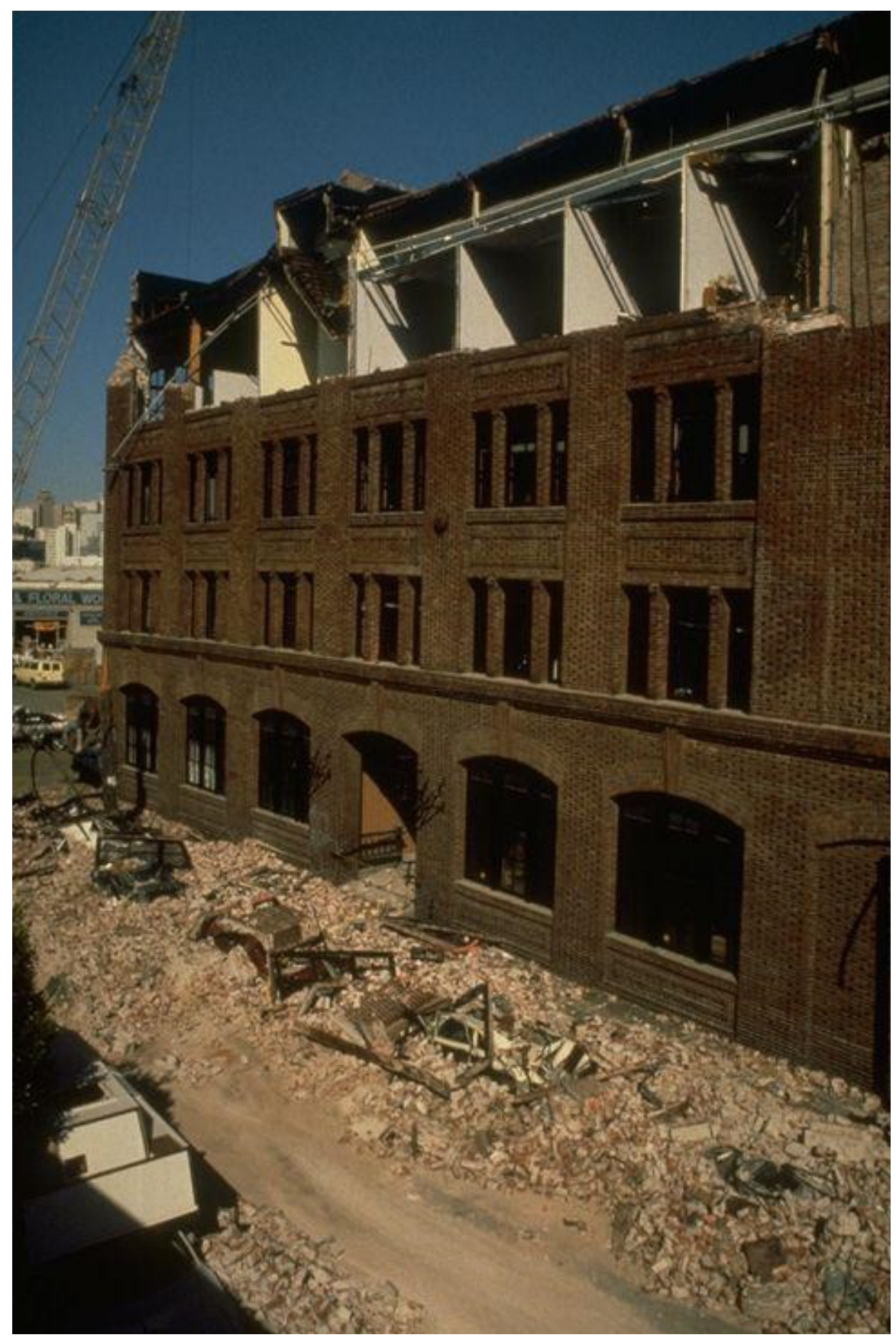

Figure 8-8. Photograph showing collapse of fourth story wall from unreinforced brick building after the 1989 Loma Prieta, California, earthquake.

\section{Image Metadata and Description for Figure 8-9}

Loma Prieta Collection: LP0460

\begin{tabular}{lccccc}
\hline $\begin{array}{c}\text { Earthquake date } \\
\text { and magnitude }(\boldsymbol{M})\end{array}$ & Title & Creator & Date & Location & Description \\
\hline $\begin{array}{l}\text { October 17, 1989; } \\
M 7.09\end{array}$ & $\begin{array}{c}\text { Unreinforced brick } \\
\text { building }\end{array}$ & Kayen, Robert E. & Late 1989 & $\begin{array}{c}\text { United States/ California/ } \\
\text { North America/ San } \\
\text { Francisco }\end{array}$ & $\begin{array}{c}\text { 6th and Bluxome Streets, south } \\
\text { of Market. Collapse of unrein- } \\
\text { forced brick wall. }\end{array}$ \\
\hline
\end{tabular}

\section{Author's Estimate of Affected Area}

Same as LP0462 (above). 


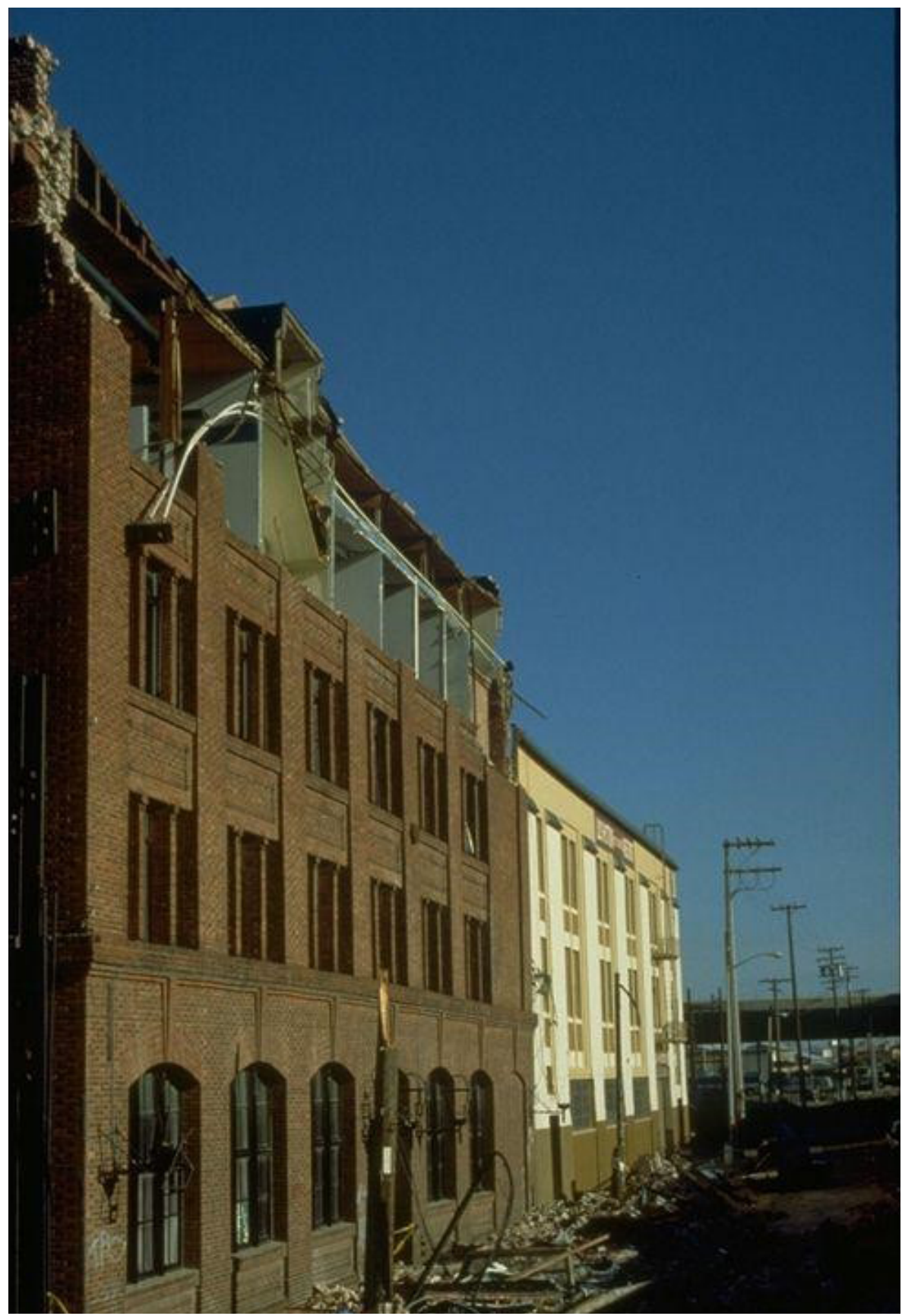

Figure 8-9. Photograph showing collapse of unreinforced brick wall from the 1989 Loma Prieta, California, earthquake.

\section{Image Metadata and Description for Figure 8-10}

Loma Prieta Collection: LP0375

\begin{tabular}{|c|c|c|c|c|c|}
\hline $\begin{array}{c}\text { Earthquake date } \\
\text { and magnitude }(M)\end{array}$ & Title & Creator & Date & Location & Description \\
\hline $\begin{array}{l}\text { October } 17,1989 \\
\quad M 7.09\end{array}$ & $\begin{array}{l}\text { Collapse of apart- } \\
\text { ment buildings }\end{array}$ & Seed, Raymond B. & Late 1989 & $\begin{array}{l}\text { United States/ California/ } \\
\text { North America/ San } \\
\text { Francisco }\end{array}$ & $\begin{array}{l}\text { Collapse of two four-story apart- } \\
\text { ment buildings (soft ground } \\
\text { floors). Marina District, San } \\
\text { Francisco, California. }\end{array}$ \\
\hline
\end{tabular}

Author's Estimate of Affected Area

By inspection, two buildings, each with $25 \%$ collapse. 


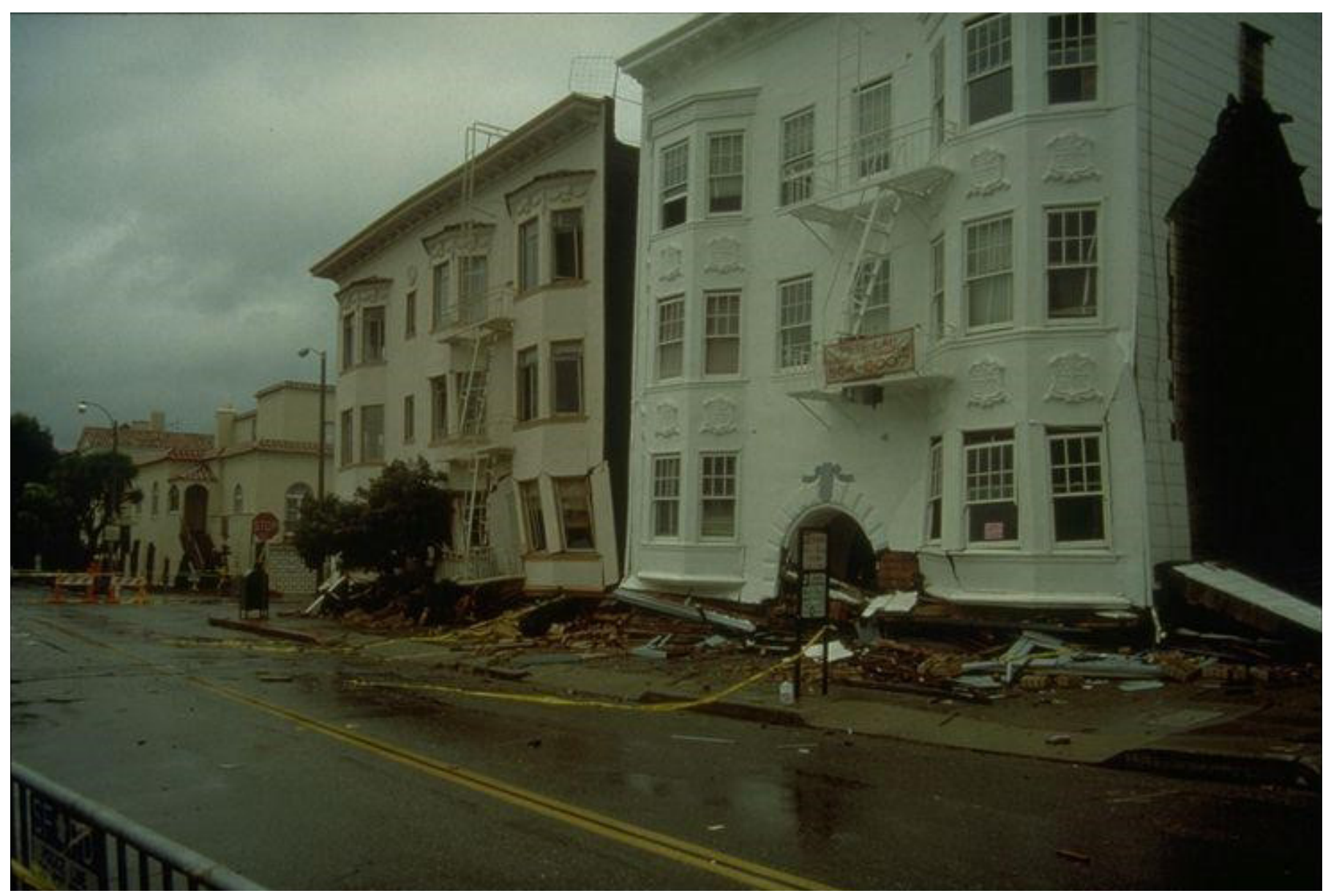

Figure 8-10. Photograph showing collapse of apartment buildings with soft ground floors in the Marina District of San Francisco after the 1989 Loma Prieta, California, earthquake.

\section{Image Metadata and Description for Figure 8-11}

Loma Prieta Collection: LP0499

\begin{tabular}{|c|c|c|c|c|c|}
\hline $\begin{array}{c}\text { Earthquake date } \\
\text { and magnitude }(M)\end{array}$ & Title & Creator & Date & Location & Description \\
\hline $\begin{array}{l}\text { October 17, 1989; } \\
\quad M 7.09\end{array}$ & $\begin{array}{l}\text { Collapsed building } \\
\text { in Marina District }\end{array}$ & Harris, S. P. & $\begin{array}{c}\text { October } 17, \\
1989\end{array}$ & $\begin{array}{l}\text { United States/ California/ } \\
\text { North America/ San } \\
\text { Francisco }\end{array}$ & $\begin{array}{l}\text { Collapsed apartment building at } \\
2090 \text { Beach St, after the fire } \\
\text { was much advanced. Note } \\
\text { firefighter directing water } \\
\text { onto exposed side of building. } \\
\text { Marina District, San Francisco, } \\
\text { California. }\end{array}$ \\
\hline
\end{tabular}

\section{Author's Estimate of Affected Area}

This had been a four-story building, now with only one story remaining somewhat intact, so $75 \%$ collapse. 


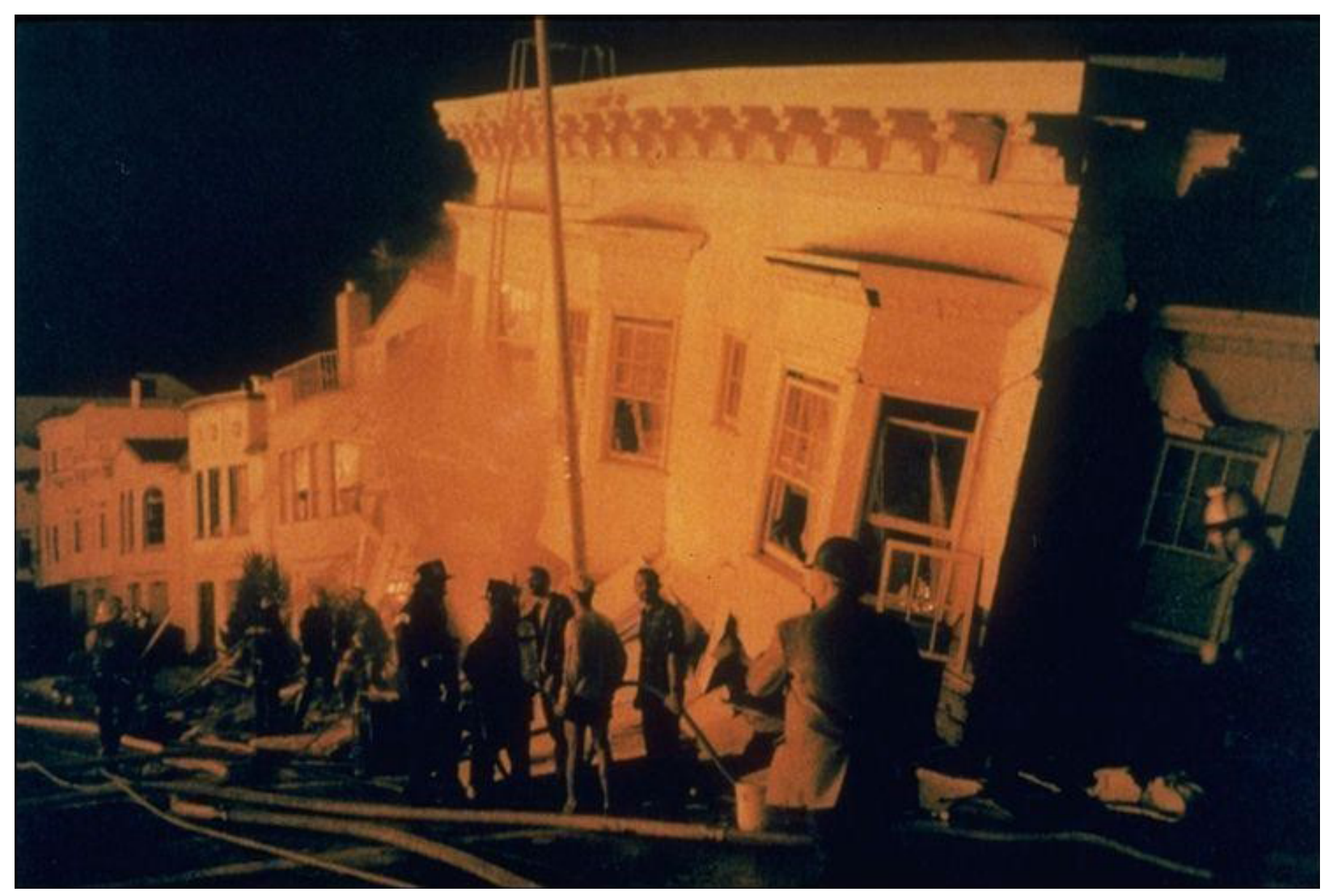

Figure 8-11. Photograph showing collapsed four-story building in the Marina District, San Francisco, after the 1989 Loma Prieta, California, earthquake (photograph from Scawthorn and others, 1992, p. 204, fig. 11).

\section{Image Metadata and Description for Figure 8-12}

Karl V. Steinbrugge Collection: S6144

\begin{tabular}{|c|c|c|c|c|c|}
\hline $\begin{array}{l}\text { Earthquake date } \\
\text { and magnitude }(M)\end{array}$ & Title & Creator & Date & Location & Description \\
\hline $\begin{array}{l}\text { October 17, 1989; } \\
\quad M 7.09\end{array}$ & Soft-story collapse & unknown & -- & $\begin{array}{l}\text { United States/ California/ } \\
\text { North America/ San } \\
\text { Francisco }\end{array}$ & $\begin{array}{l}\text { Soft-story collapse of apartment } \\
\text { building in the Marina District, } \\
\text { San Francisco, California. }\end{array}$ \\
\hline
\end{tabular}

\section{Author's Estimate of Affected Area}

To the author's personal knowledge, this had been a three-story building, so affected area $=67 \%$. What is remarkable about this building is that it appears in many photos of the Marina District, almost entirely without identifying information other than the neighborhood. One photo caption says the building was at Beach Street and Divisadero Street. The view of the Golden Gate Bridge tower in the background tells us that it was at the northwest corner, apparently 3700 Divisadero Street, San Francisco, California 94123-1000 (APN 0913037). 


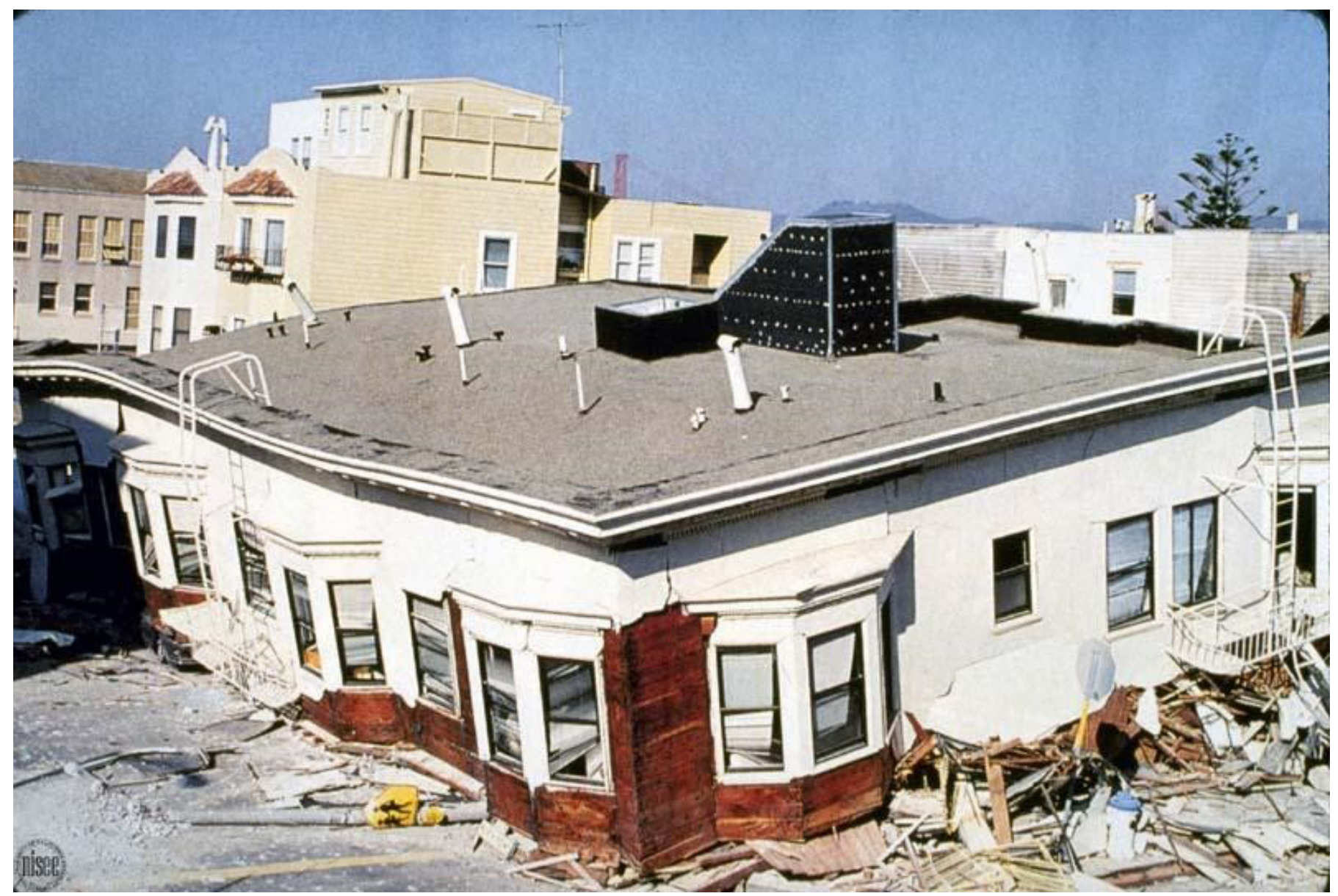

Figure 8-12. Photograph showing soft-story collapse of an apartment building in the Marina District, San Francisco, in the 1989 Loma Prieta, California, earthquake.

\section{Image Metadata and Description for Figure 8-13}

Loma Prieta Collection: LP0459

\begin{tabular}{|c|c|c|c|c|c|}
\hline $\begin{array}{c}\text { Earthquake date } \\
\text { and magnitude }(M)\end{array}$ & Title & Creator & Date & Location & Description \\
\hline $\begin{array}{l}\text { October 17, 1989; } \\
\quad M 7.09\end{array}$ & Front and Davis St. & $\begin{array}{l}\text { Dickenson, } \\
\text { Stephen E. }\end{array}$ & Late 1989 & $\begin{array}{l}\text { United States/ California/ } \\
\text { North America/ San } \\
\text { Francisco }\end{array}$ & $\begin{array}{l}\text { Front and Davis Streets. Collapse } \\
\text { of unreinforced masonry wall } \\
\text { from third floor of building. } \\
\text { Embarcadero/ Financial Dis- } \\
\text { trict, San Francisco. }\end{array}$ \\
\hline
\end{tabular}

\section{Author's Estimate of Affected Area}

Front Street is parallel to Davis Street, so the recorded location makes no sense. Matching the background buildings, the address seems to be 235 Front Street, San Francisco, California, on the northwest corner of Front Street and Halleck Street. The view is toward the northwest. The building appears to be on APN 0237047, whose area is 4,960 $\mathrm{ft}^{2}$. Aerial photography dating from 1938 and available in Google Earth Pro shows a building of uniform height covering the entire parcel, suggesting a total building area of 14,880 $\mathrm{ft}^{2}$. The collapsed wall faces Front Street. The facade length is $72 \mathrm{ft}$, so the affected area appears to be $36 \mathrm{ft}$. I can find no images of the masonry on the sidewalk. I assume it litters an area $36 \mathrm{ft} \times 16 \mathrm{ft}$ wide, for an affected area of ( 36 $\mathrm{ft} \times 12 \mathrm{ft}) /\left(14,880 \mathrm{ft}^{2}\right)=2.9 \%$. 


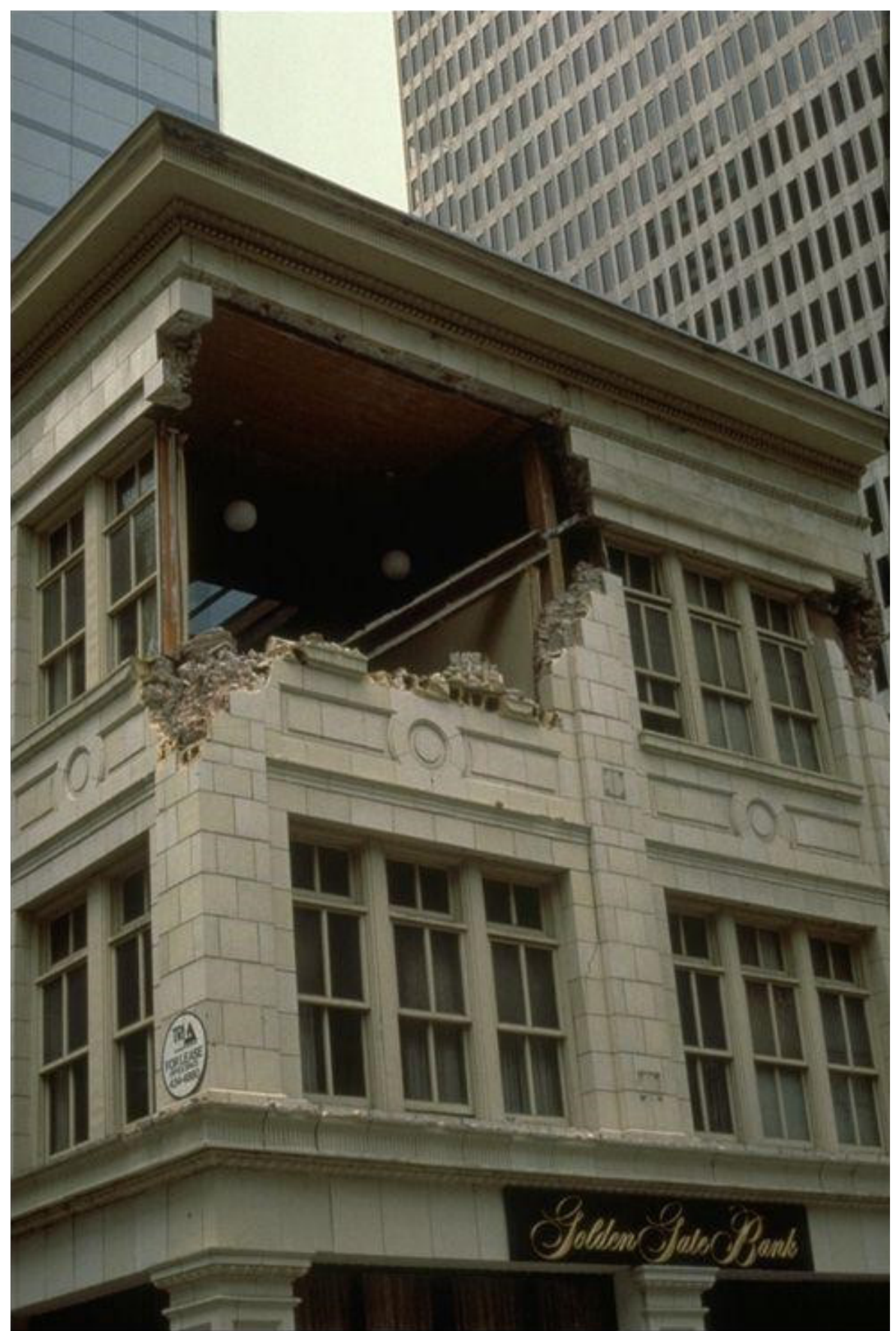

Figure 8-13. Photograph showing collapse of unreinforced masonry wall in the Embarcadero/Financial District, San Francisco, after the 1989 Loma Prieta, California, earthquake.

\section{Image Metadata and Description for Figure 8-14}

Loma Prieta Blacklock Collection: LP0041

\begin{tabular}{cccccc}
\hline $\begin{array}{c}\text { Earthquake date } \\
\text { and magnitude }(\boldsymbol{M})\end{array}$ & Title & Creator & Date & Location & Description \\
\hline $\begin{array}{l}\text { October 17, 1989; } \\
\text { Interior structural } \\
\text { failures at depart- } \\
\text { ment store }\end{array}$ & $\begin{array}{c}\text { Blacklock, } \\
\text { James R. }\end{array}$ & Late 1989 & $\begin{array}{c}\text { North America/ Santa Cruz } \\
\text { County/United States/ } \\
\text { Santa Cruz/ California }\end{array}$ & $\begin{array}{c}\text { Interior structural failures at } \\
\text { department store. Santa Cruz, } \\
\text { California. }\end{array}$ \\
\hline
\end{tabular}




\section{Author's Estimate of Affected Area}

This may be Ford's Department Store, the only department store mentioned in connection with collapse in Santa Cruz after the Loma Prieta earthquake. The building was located at the corner of Pacific Avenue and Cathcart Street, Santa Cruz, California. The address is 1101 Pacific Avenue, Santa Cruz, California (APN 00514120000), on the northwest corner of Pacific Avenue and Cathcart Street. The parcel measures 20,900 $\mathrm{ft}^{2}$, according to Google Earth Pro. One can see an exhaust vent above the truss in the background, so Ford's Department Store must have been one story tall in this portion of the building. The affected area here appears to be perhaps 1,000 ft ${ }^{2}$. A personal-injury law firm's website (http://csfwlaw.com/successful_personal_injury_lawsuits) says that the "back of the Ford's Department Store collapsed," indicating that the entire interior did not collapse. More images from a local blog (Christensen, 2009) and JPG Magazine LLC (2017) suggest that something like the back one-third of the store collapsed, or roughly $33 \%$.

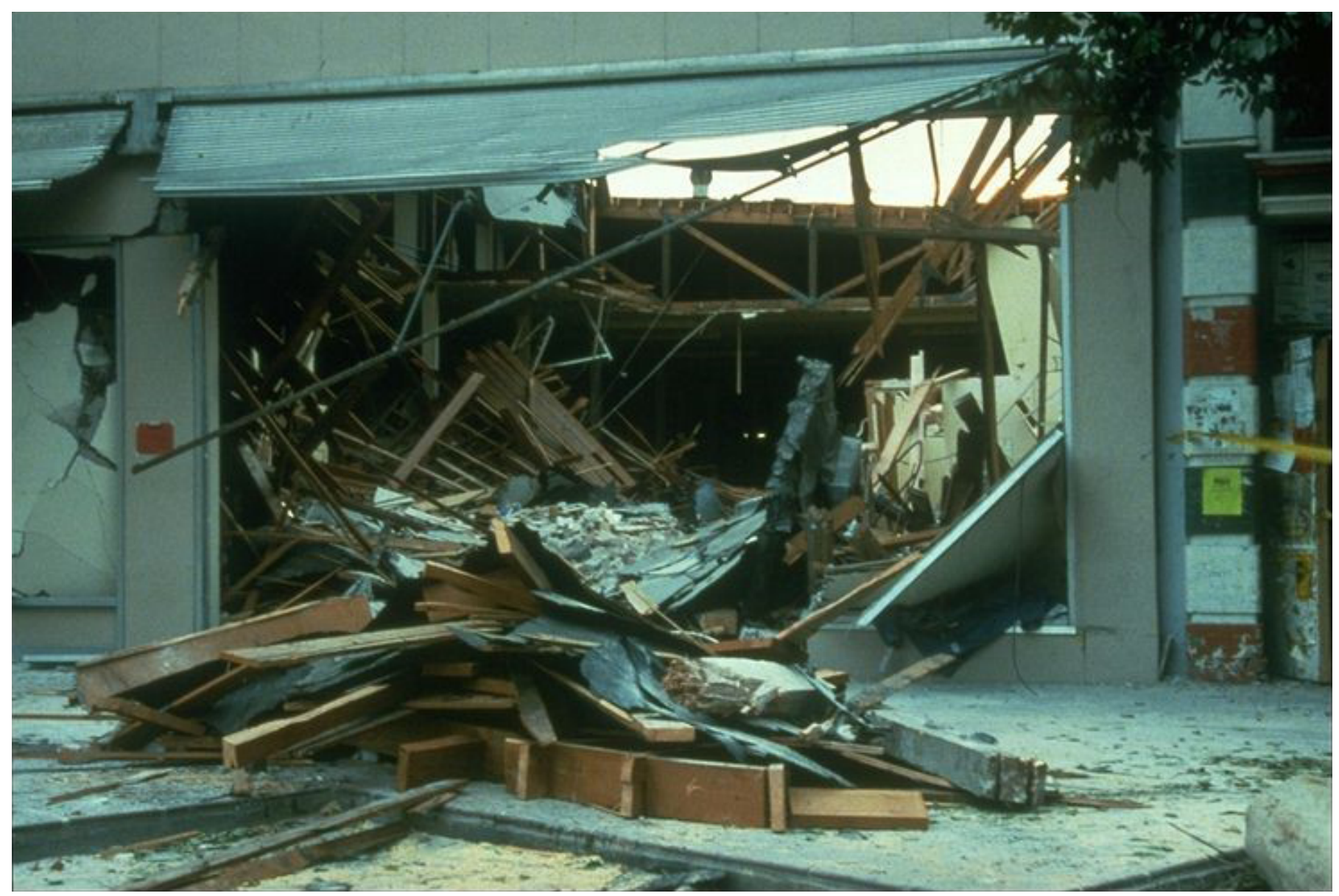

Figure 8-14. Photograph showing interior structural failure in a department store in Santa Cruz after the 1989 Loma Prieta, California, earthquake. 


\section{Appendix 9. Northridge (1994) Collapse Images}

\section{Image Metadata and Description for Figure 9-1}

Northridge Collection: NR327

\begin{tabular}{|c|c|c|c|c|c|}
\hline $\begin{array}{c}\text { Earthquake date } \\
\text { and magnitude (M) }\end{array}$ & Title & Creator & Date & Location & Description \\
\hline $\begin{array}{l}\text { January } 17,1994 ; \\
\quad \text { M6.69 }\end{array}$ & $\begin{array}{l}\text { Collapsed apartment } \\
\text { building }\end{array}$ & Unknown & 1994 & $\begin{array}{l}\text { Northridge/ California/ } \\
\text { North America/ Los } \\
\text { Angeles County/ United } \\
\text { States }\end{array}$ & $\begin{array}{l}\text { Collapsed apartment building, } \\
\text { three-story wood frame. North- } \\
\text { ridge, California. }\end{array}$ \\
\hline
\end{tabular}

\section{Author's Estimate of Affected Area}

According to Todd and others (1994, p. 23; fig. 9-2), there were four collapsed three-story buildings. The ground story of two of the buildings completely collapsed, the ground story of about half of a third three-story building collapsed, and approximately one-eighth of a fourth. Thus, the affected areas are $33 \%, 33 \%, 17 \%$, and $4 \%$.

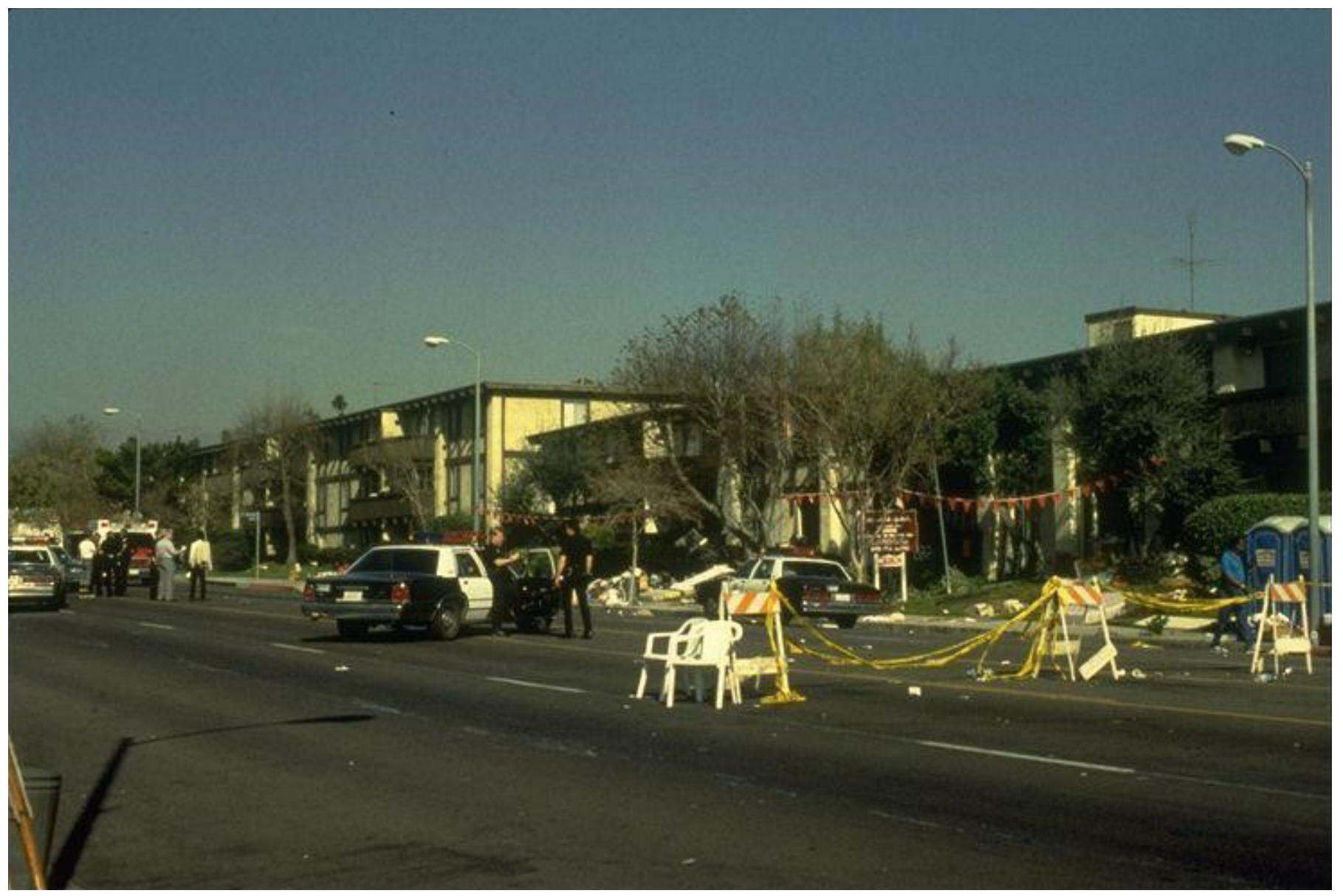

Figure 9-1. Photograph showing collapsed apartment building after the 1994 Northridge, California, earthquake. 


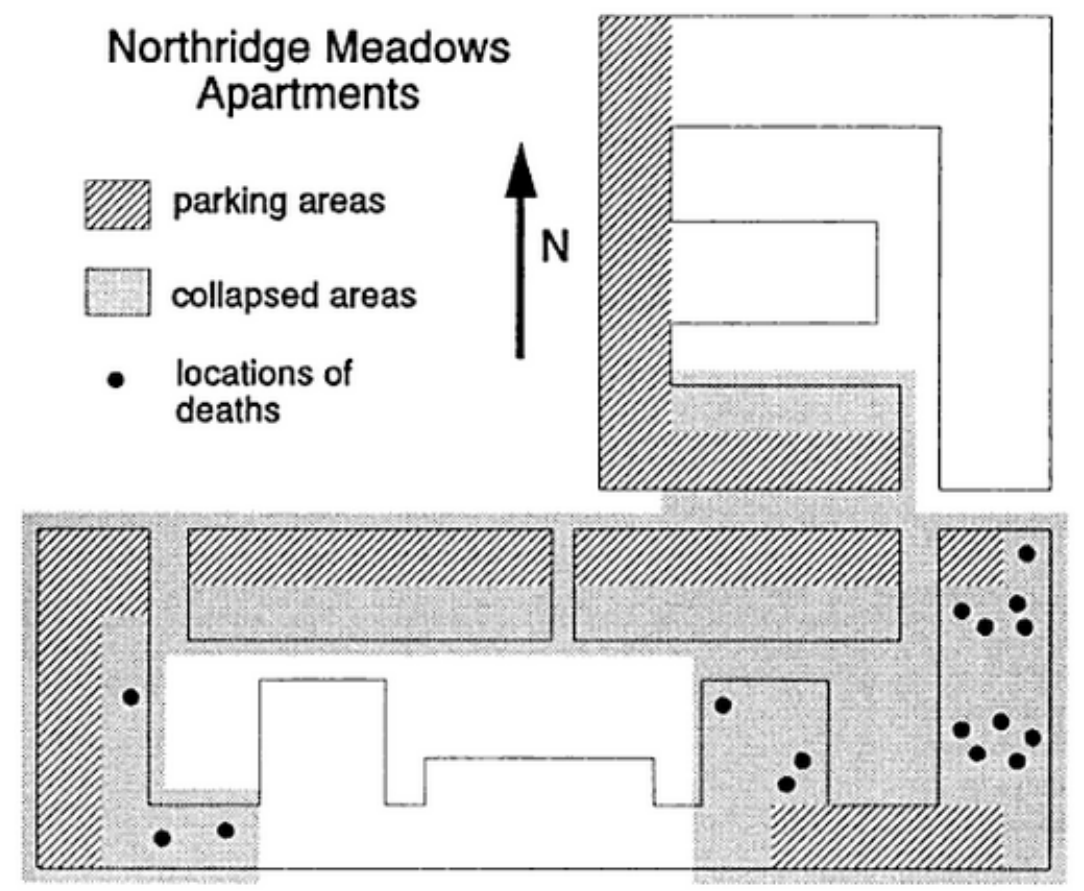

Figure 9-2. Diagram showing parking areas, collapsed areas, and locations of deaths on the first level of Northridge Meadows Apartments after the 1994 Northridge, California, earthquake (Todd and others, 1994, p. 23).

\section{Image Metadata and Description for Figure 9-3}

Northridge Collection: NR335

\begin{tabular}{cccccc}
\hline $\begin{array}{c}\text { Earthquake date } \\
\text { and magnitude }(\boldsymbol{M})\end{array}$ & Title & Creator & Date & Location & Description \\
\hline $\begin{array}{c}\text { January 17, 1994; } \\
\text { M6.69 }\end{array}$ & $\begin{array}{c}\text { Building compo- } \\
\text { nents fell onto } \\
\text { off-ramp }\end{array}$ & $\begin{array}{c}\text { Aschheim, } \\
\text { Mark A. }\end{array}$ & January 19, 1994 & $\begin{array}{c}\text { North America/ Los } \\
\text { Angeles County/ United }\end{array}$ & $\begin{array}{c}\text { Building at eastbound off-ramp of } \\
\text { Route 101 south at Van Nuys } \\
\text { exit. View to south. Failed build- } \\
\text { ing components fell onto off- } \\
\text { ramp. Los Angeles, California. }\end{array}$ \\
\hline
\end{tabular}

\section{Author's Estimate of Affected Area}

This building was repaired. It is located at 4717 Van Nuys Boulevard, Sherman Oaks, California 91403. According to Google Earth Pro, the building area is 16,094 $\mathrm{ft}^{2}$. There are no long shots or aerial shots to show the extent of the roof collapse. No estimate of affected area. 


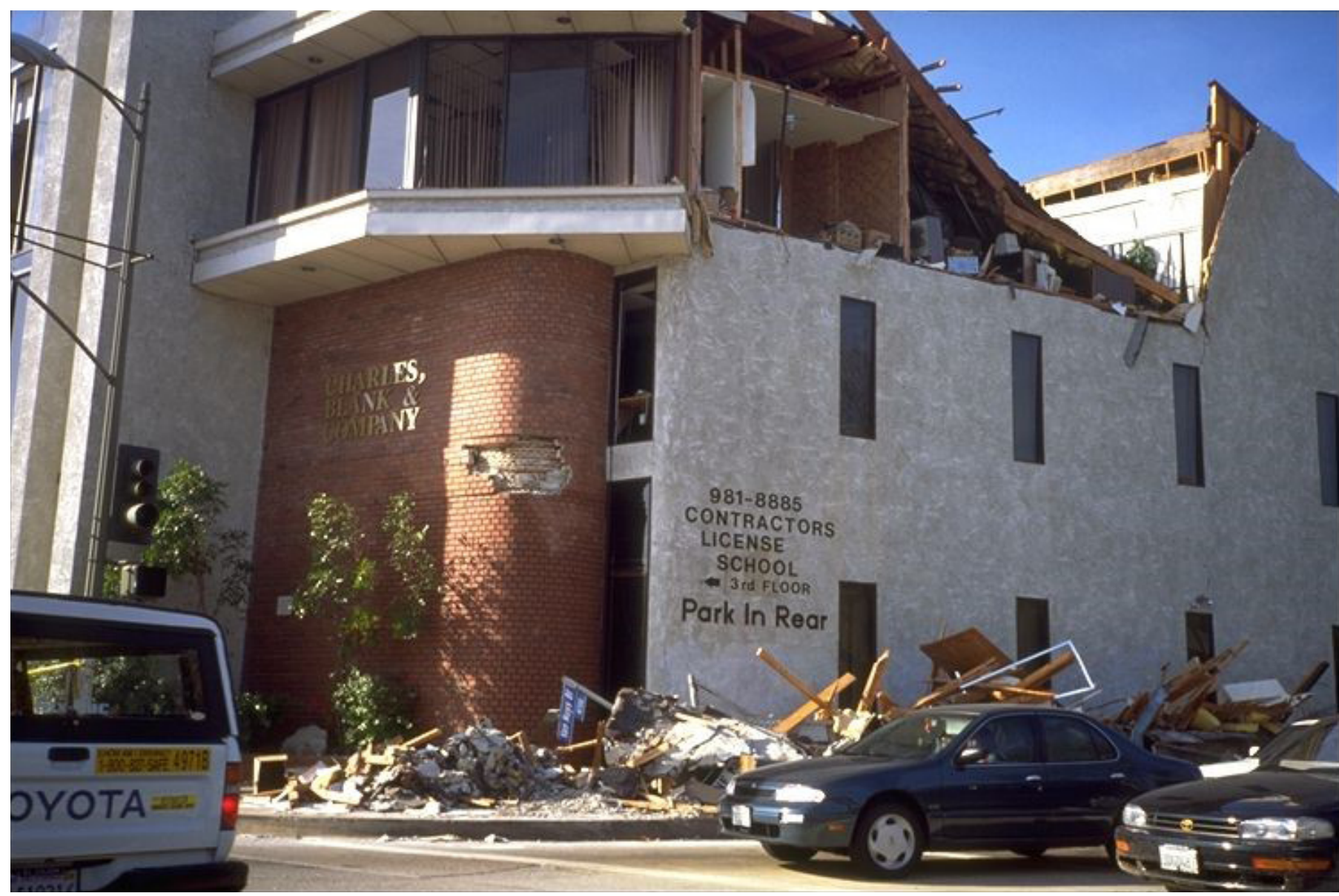

Figure 9-3. Photograph showing building components fallen onto off-ramp after the 1994 Northridge, California, earthquake.

\section{Image Metadata and Description for Figure 9-4}

Northridge Collection: NR353

\begin{tabular}{cccccc}
\hline $\begin{array}{c}\text { Earthquake date } \\
\text { and magnitude }(\boldsymbol{M})\end{array}$ & Title & Creator & Date & Location & Description \\
\hline $\begin{array}{l}\text { January 17, 1994; } \\
\text { M6.69 }\end{array}$ & $\begin{array}{r}\text { Northridge Mead- } \\
\text { ows Apartments }\end{array}$ & $\begin{array}{r}\text { Reitherman, } \\
\text { Robert K. }\end{array}$ & February 12, 1994 & $\begin{array}{l}\text { Northridge/ California/ } \\
\text { North America/ Los }\end{array}$ & $\begin{array}{c}\text { Collapse of ground story in } \\
\text { Northridge, California. Struc- } \\
\text { ture: Northridge Meadows } \\
\text { Apartments. }\end{array}$ \\
\hline
\end{tabular}

Author's Estimate of Affected Area

Same as figure $9-1$. 


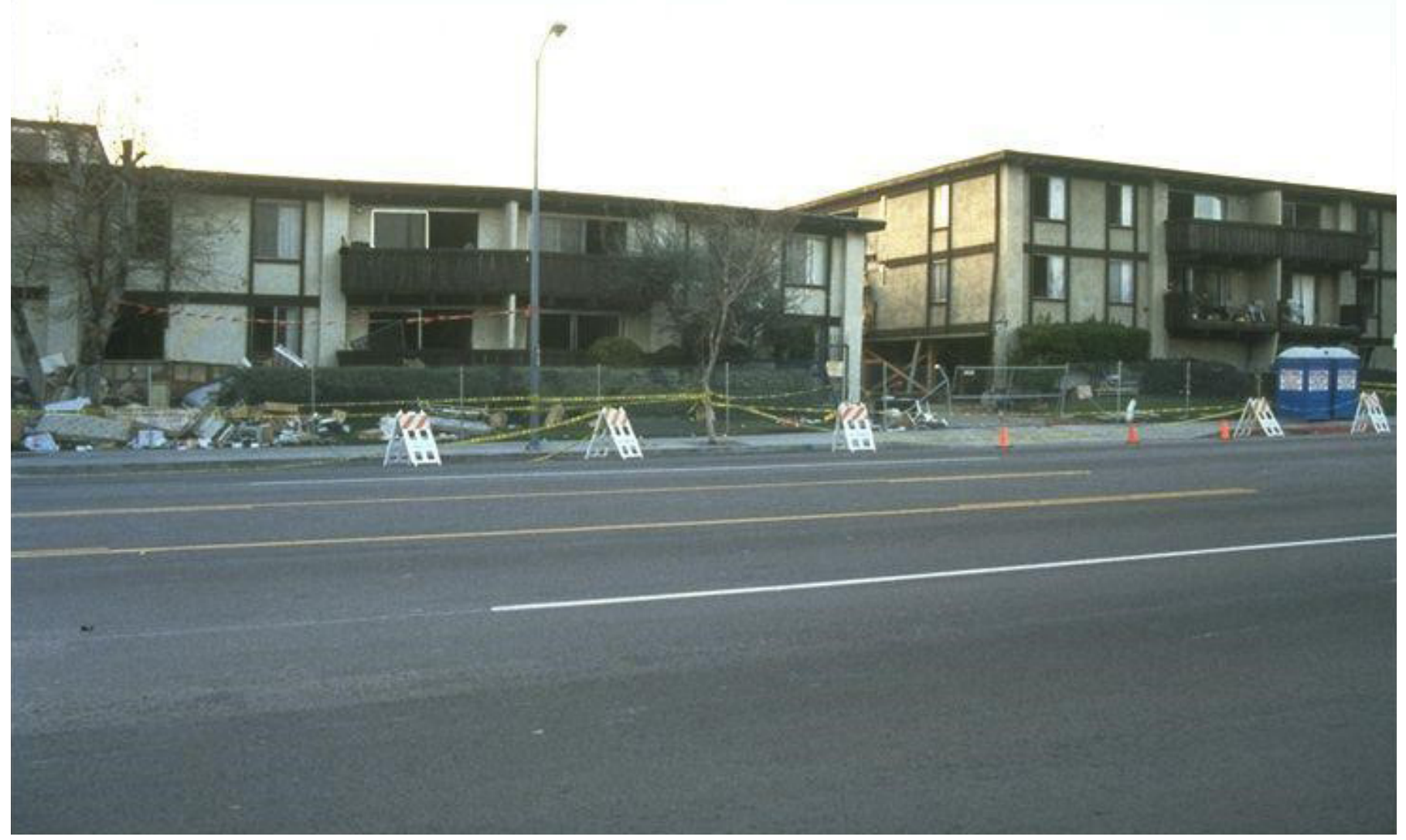

Figure 9-4. Photograph showing collapse of ground story at Northridge Meadows Apartments after the 1994 Northridge, California, earthquake.

\section{Image Metadata and Description for Figure 9-5}

Northridge Collection: NR357

\begin{tabular}{cccccc}
\hline $\begin{array}{c}\text { Earthquake date } \\
\text { and magnitude }(\boldsymbol{M})\end{array}$ & Title & Creator & Date & Location & Description \\
\hline $\begin{array}{c}\text { January 17, 1994; } \\
\text { M6.69 }\end{array}$ & $\begin{array}{r}\text { Northridge Mead- } \\
\text { ows Apartment }\end{array}$ & $\begin{array}{c}\text { Reitherman, } \\
\text { Robert K. }\end{array}$ & February 12,1994 & Northridge/ California/ & Northridge Meadows Apart- \\
& & & North America/ Los & $\begin{array}{l}\text { ments. Collapse of ground } \\
\text { story. Northridge, California. } \\
\end{array}$ \\
& & & Angeles County/ United & Structure: Northridge Mead- \\
& & & States & ows Apartments. \\
\hline
\end{tabular}

\section{Author's Estimate of Affected Area}

Same as figure 9-1. 


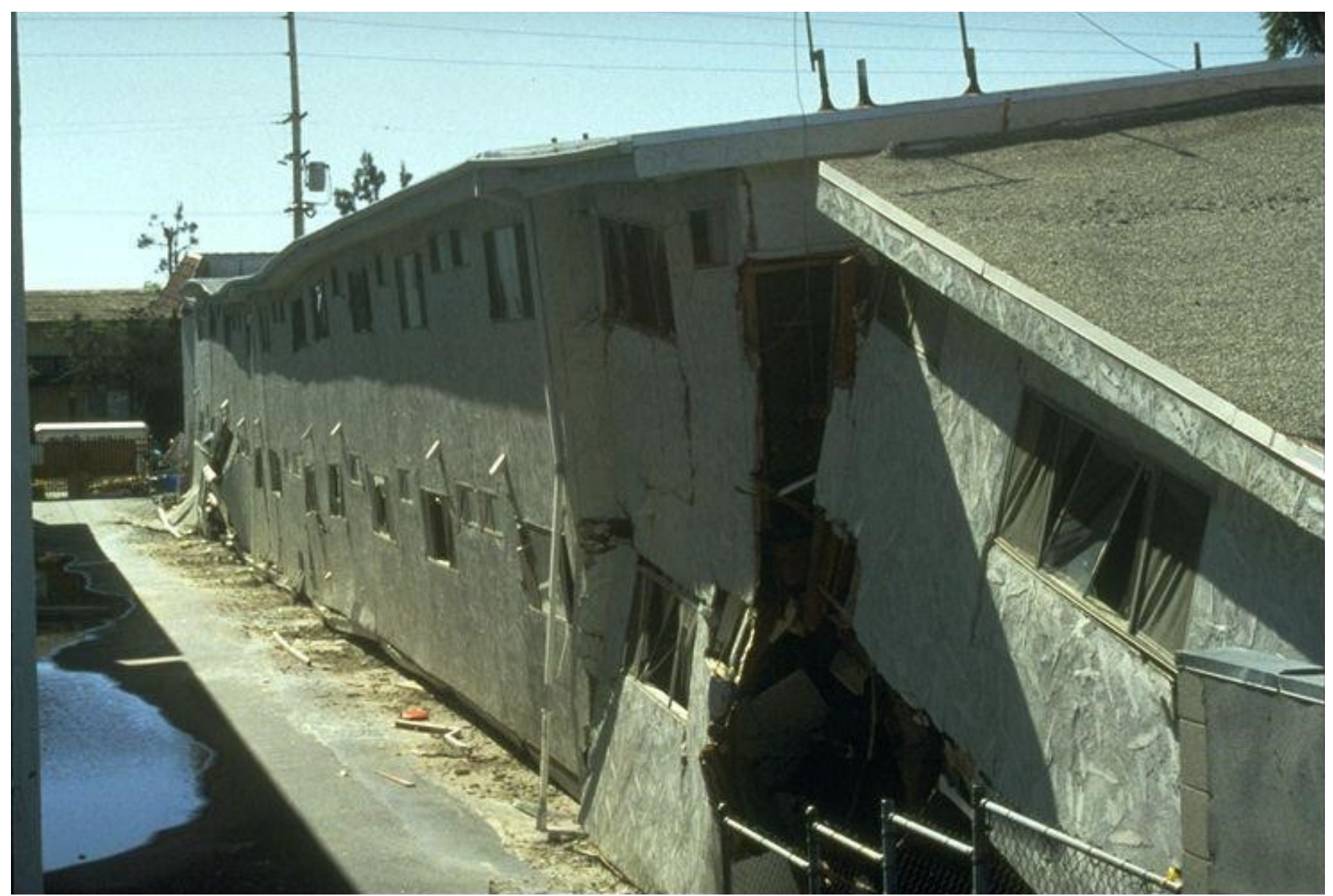

Figure 9-5. Photograph showing collapse of ground story at Northridge Meadows Apartments after the 1994 Northridge, California, earthquake.

\section{Image Metadata and Description for Figure 9-6}

Northridge Collection: NR358

\begin{tabular}{cccccc}
\hline $\begin{array}{c}\text { Earthquake date } \\
\text { and magnitude }(\boldsymbol{M})\end{array}$ & Title & Creator & Date & Location & Description \\
\hline $\begin{array}{c}\text { January 17, 1994; } \\
\text { M6.69 }\end{array}$ & $\begin{array}{r}\text { Northridge Mead- } \\
\text { ows Apartment }\end{array}$ & $\begin{array}{c}\text { Reitherman, } \\
\text { Robert K. }\end{array}$ & February 12, 1994 & $\begin{array}{c}\text { United States/ North- } \\
\text { ridge/ California/ North }\end{array}$ & $\begin{array}{c}\text { Northridge Meadows Apart- } \\
\text { ments. Collapse of ground } \\
\text { story. Northridge, California. } \\
\end{array}$ \\
& & & America/ Los Angeles & Structure: Northridge Mead- \\
& & & County & ows Apartments. \\
\hline
\end{tabular}

Author's Estimate of Affected Area

Same as figure $9-1$. 


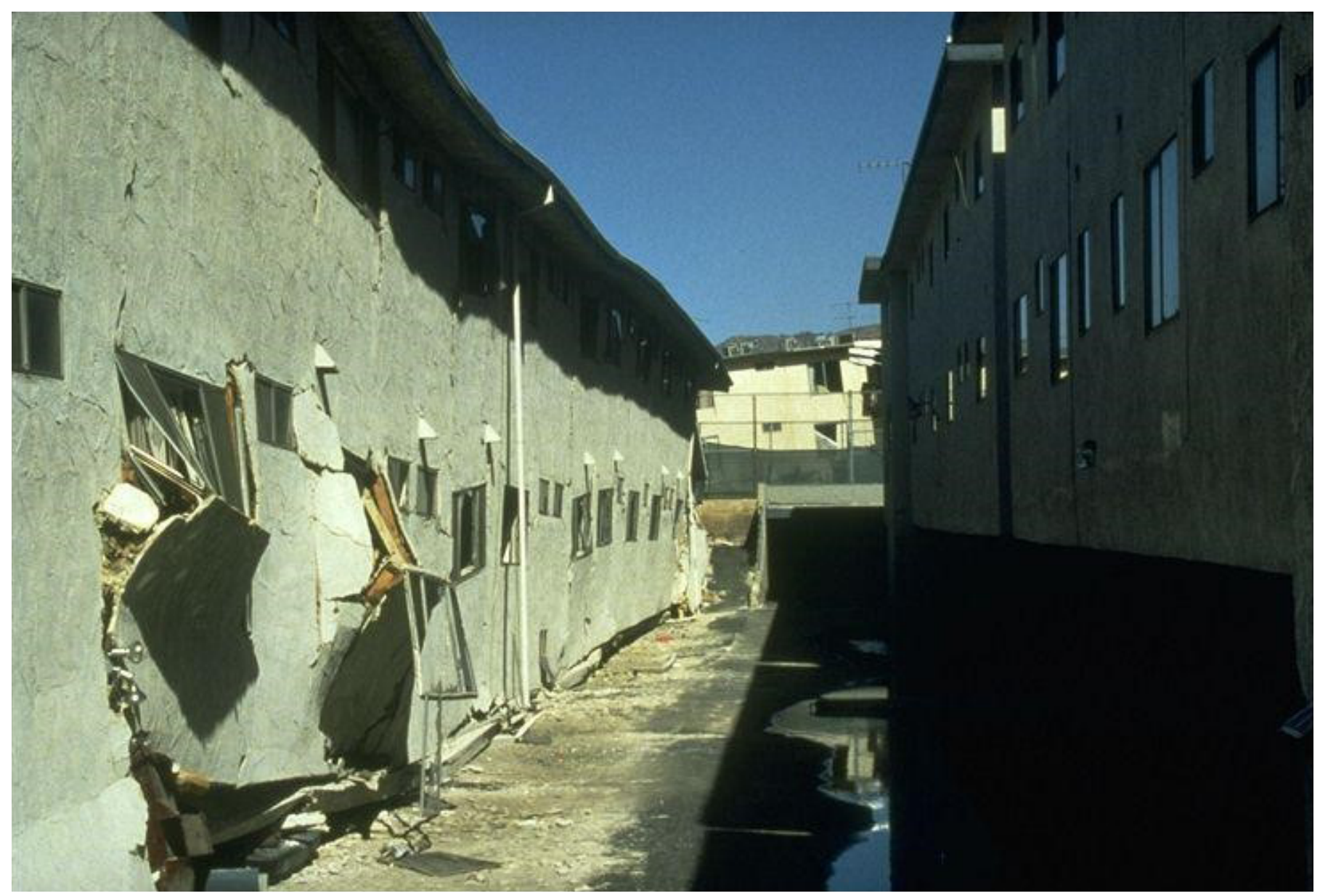

Figure 9-6. Photograph showing collapse of ground story at Northridge Meadows Apartments after the 1994 Northridge, California, earthquake.

\section{Image Metadata and Description for Figure 9-7}

Northridge Collection: NR408-NR409

\begin{tabular}{|c|c|c|c|c|c|}
\hline $\begin{array}{c}\text { Earthquake date } \\
\text { and magnitude }(M)\end{array}$ & Title & Creator & Date & Location & Description \\
\hline $\begin{array}{l}\text { January 17, 1994; } \\
\quad \text { M6.69 }\end{array}$ & $\begin{array}{l}\text { 2-story masonry } \\
\text { building }\end{array}$ & $\begin{array}{l}\text { Stojadinovic, } \\
\text { Bozidar }\end{array}$ & January 19, 1994 & $\begin{array}{l}\text { North America/ Los An- } \\
\text { geles County/ United } \\
\text { States/ Santa Monica/ } \\
\text { California }\end{array}$ & $\begin{array}{l}1004 \text { West Channel Road at } \\
\text { Pacific Coast Highway (near } \\
\text { Pacific Palisades). Damage to } \\
\text { two-story masonry building. } \\
\text { Heavy shear cracking on side } \\
\text { walls. Out of plane failure of the } \\
\text { second story. State Beach Cafe, } \\
\text { Santa Monica, California. }\end{array}$ \\
\hline
\end{tabular}

\section{Author's Estimate of Affected Area}

The address appears to be 108 West Channel Road, Santa Monica, which is adjacent to 112 (it is not 1004). From size of replacement building, which fills the lot, the damaged building appears to be 1,500 $\mathrm{ft}^{2}$ in plan, or 3,000 $\mathrm{ft}^{2}$ total. Bricks litter $40 \mathrm{ft}^{2}$ of facade $\times 10 \mathrm{ft}$ across sidewalk. Affected area is therefore approximately $400 \mathrm{ft}^{2} / 3,000 \mathrm{ft}^{2}=13 \%$. 


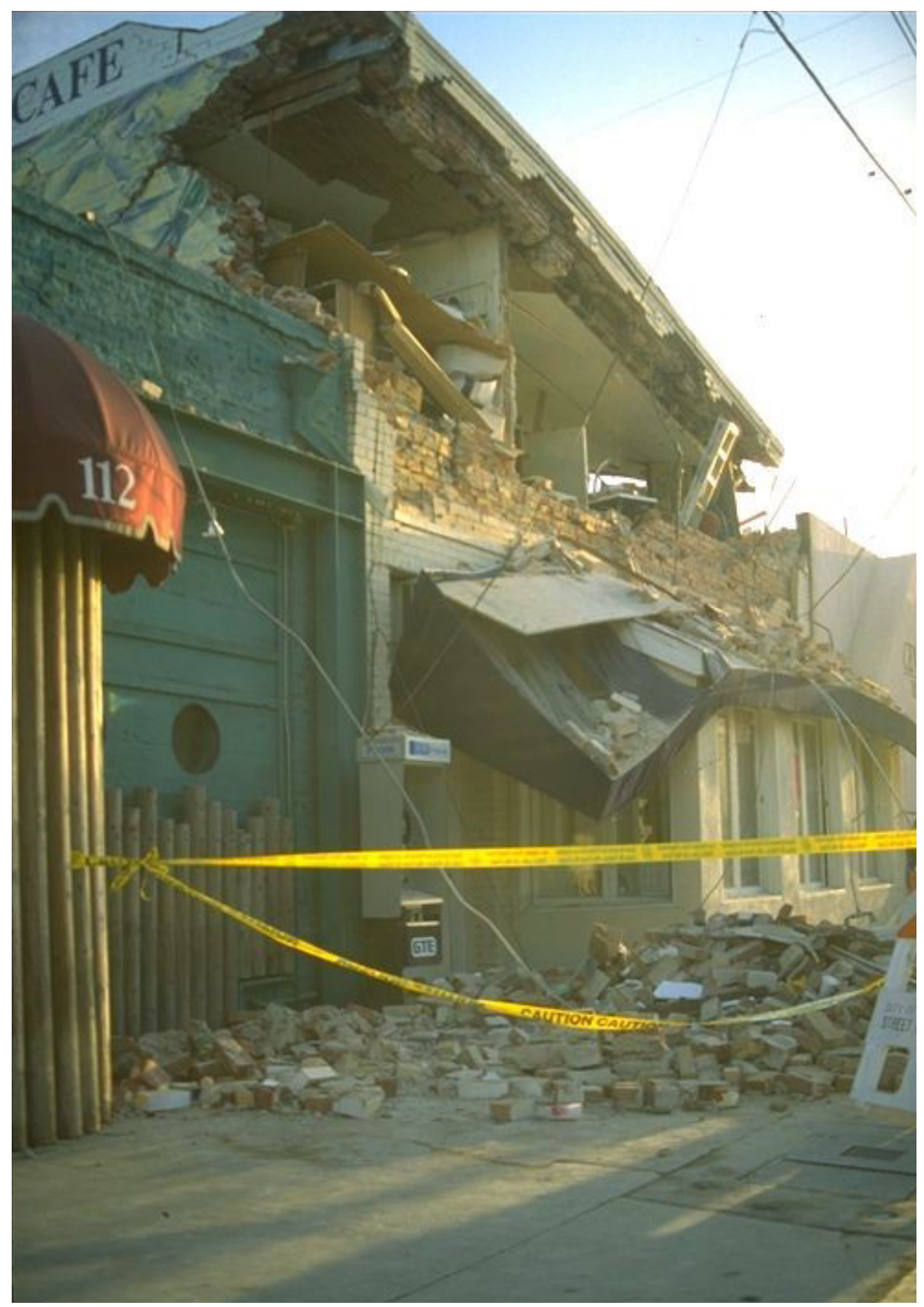

Figure 9-7. Photograph showing damage to twostory masonry building in Santa Monica after the 1994 Northridge, California, earthquake.

\section{Image Metadata and Description for Figure 9-8}

Northridge Collection: NR413, NR414

\begin{tabular}{|c|c|c|c|c|c|}
\hline $\begin{array}{c}\text { Earthquake date } \\
\text { and magnitude }(M)\end{array}$ & Title & Creator & Date & Location & Description \\
\hline $\begin{array}{l}\text { January } 17,1994 ; \\
\quad M 6.69\end{array}$ & $\begin{array}{l}\text { Four-story ma- } \\
\text { sonry building }\end{array}$ & $\begin{array}{l}\text { Stojadinovic, } \\
\text { Bozidar }\end{array}$ & January 19, 1994 & $\begin{array}{l}\text { North America/ Los } \\
\text { Angeles County/ } \\
\text { United States/ Santa } \\
\text { Monica/ California }\end{array}$ & $\begin{array}{l}\text { Four-story masonry building, } 827 \\
\text { Fourth St. Damage to the fourth } \\
\text { and third floor of the building. The } \\
\text { masonry facade fell out of plane and } \\
\text { took with it the fourth floor terrace. } \\
\text { This building had been scheduled for } \\
\text { a retrofit to begin on Monday, Janu- } \\
\text { ary } 17,1994 \text {. Three layers of thick } \\
\text { unreinforced masonry. Damage to the } \\
\text { top story and balcony. Little damage } \\
\text { on the sides and below the third story. } \\
\text { Santa Monica, California. }\end{array}$ \\
\hline
\end{tabular}




\section{Author's Estimate of Affected Area}

Building still exists and has been repaired. Google Earth Pro says building area $=31,314 \mathrm{ft}^{2}$. Affected area looks like $(55 \mathrm{ft} \times 12 \mathrm{ft}) /\left(31,314 \mathrm{ft}^{2}\right)=2.1 \%$.
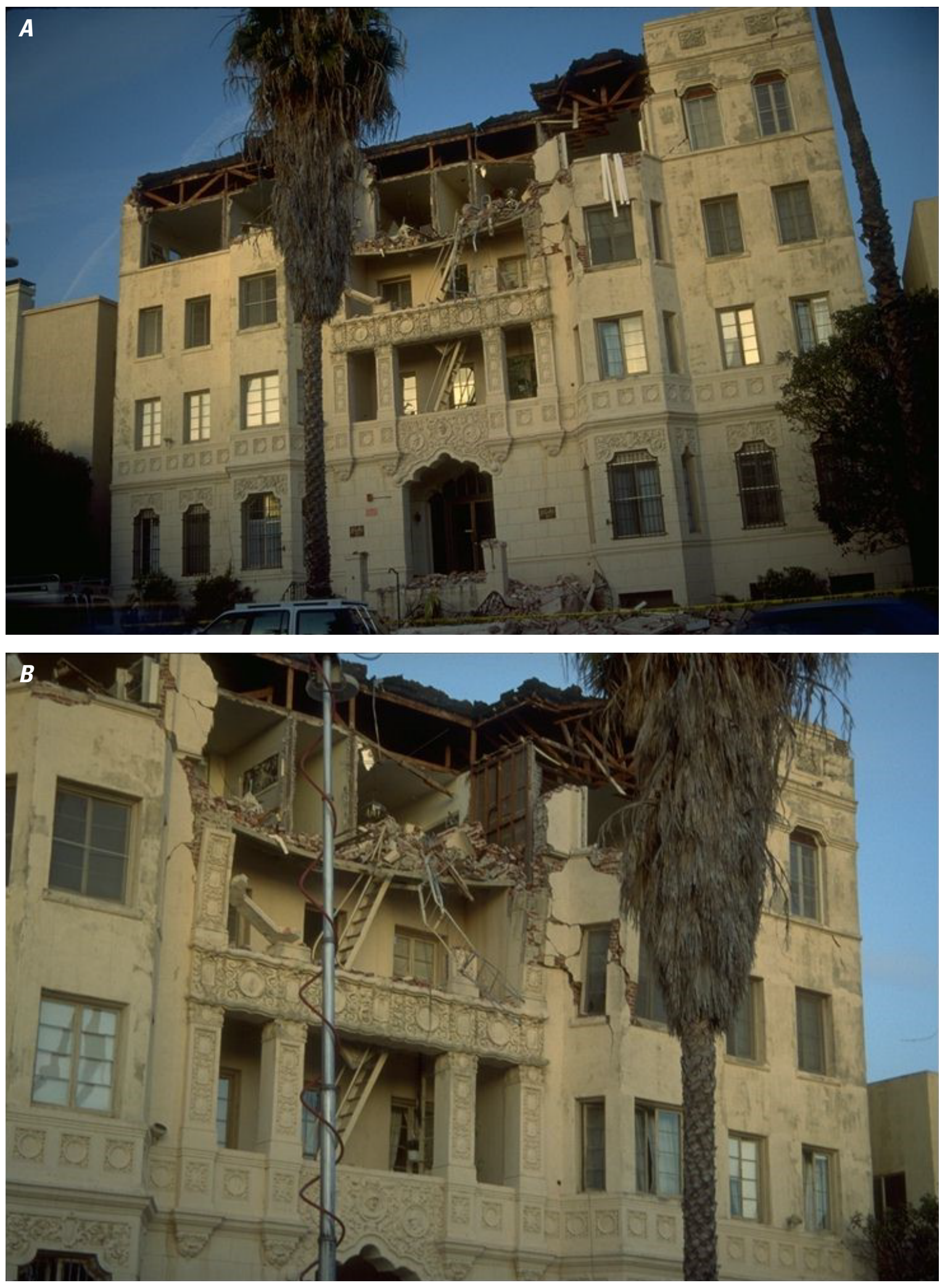

Figure 9-8. Photograph showing damage to four-story masonry building in Santa Monica after the 1994 Northridge, California, earthquake. 


\section{Image Metadata and Description for Figure 9-9}

Northridge Collection: 201012024

\begin{tabular}{cccccc}
\hline $\begin{array}{c}\text { Earthquake date } \\
\text { and magnitude }(\boldsymbol{M})\end{array}$ & Title & Creator & Date & Location & Description \\
\hline $\begin{array}{c}\text { January 17, 1994; } \\
M 6.69\end{array}$ & $\begin{array}{c}\text { Collapsed } \\
\text { unreinforced } \\
\text { chimney }\end{array}$ & $\begin{array}{c}\text { Reitherman, } \\
\text { Robert K. }\end{array}$ & 2010 & Unknown & $\begin{array}{c}\text { This residential chimney of unreinforced } \\
\text { blocks collapsed during the 1994 } \\
\text { Northridge earthquake. }\end{array}$ \\
\hline
\end{tabular}

\section{Author's Estimate of Affected Area}

Masonry litters an area about $10 \mathrm{ft} \times 4 \mathrm{ft}$, or $40 \mathrm{ft}^{2}$. Assuming a typical $1,500 \mathrm{ft}^{2}$ home, the affected area is $2.7 \%$.

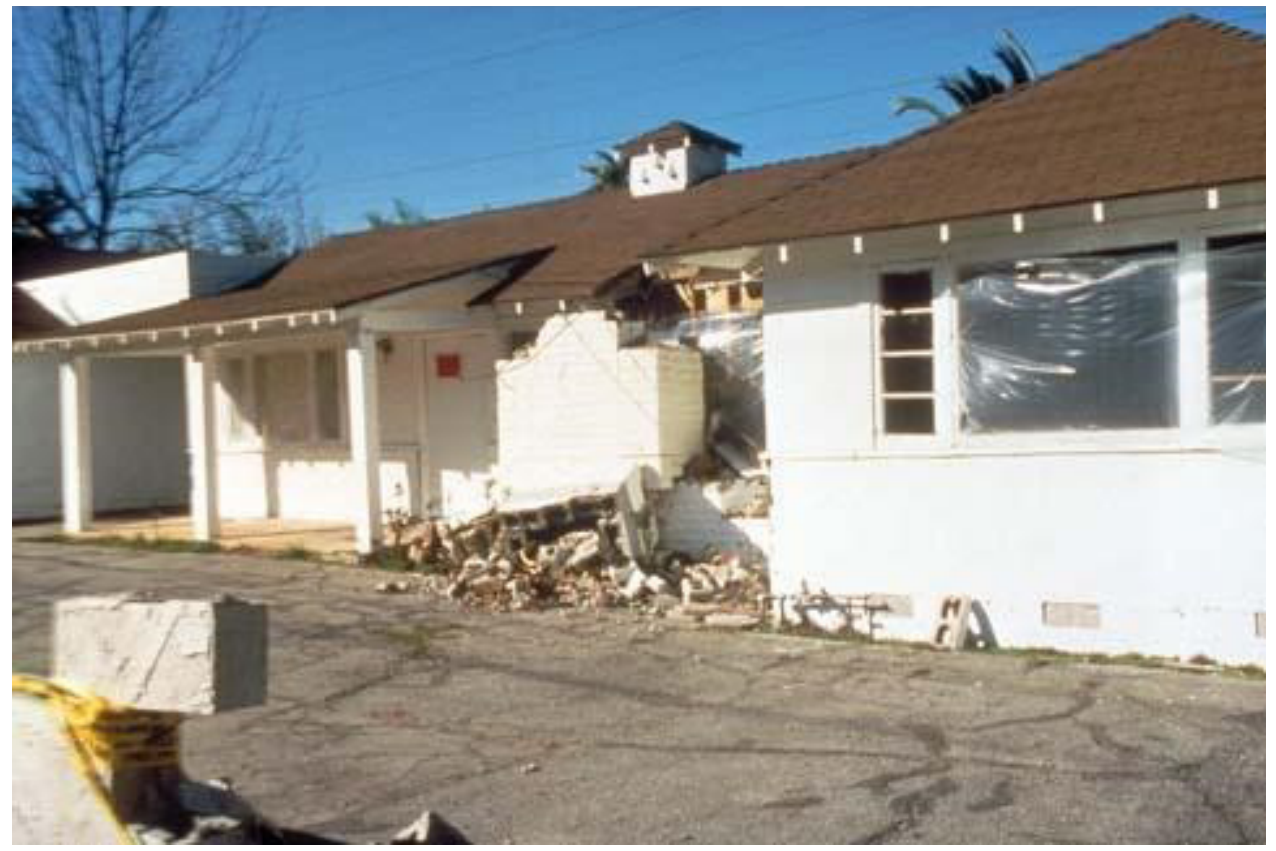

Figure 9-9. Photograph showing collapsed unreinforced chimney after the 1994 Northridge, California, earthquake.

\section{Image Metadata and Description for Figure 9-10}

Northridge Collection: NR559

\begin{tabular}{|c|c|c|c|c|c|}
\hline $\begin{array}{c}\text { Earthquake date } \\
\text { and magnitude }(M)\end{array}$ & Title & Creator & Date & Location & Description \\
\hline $\begin{array}{l}\text { January } 17,1994 ; \\
\quad M 6.69\end{array}$ & $\begin{array}{l}\text { Parking structure } \\
\text { on Cal State } \\
\text { Northridge } \\
\text { campus }\end{array}$ & Unknown & 1994 & $\begin{array}{l}\text { Northridge/ California } \\
\text { /North America/ } \\
\text { Los Angeles Coun- } \\
\text { ty/ United States }\end{array}$ & $\begin{array}{l}\text { Parking structure on Zelzah Ave., California } \\
\text { State University, Northridge, campus. } \\
\text { This is a three-story precast concrete } \\
\text { parking structure. Overall view show- } \\
\text { ing collapse at east end of the structure. } \\
\text { Structure: Cal State Northridge Parking }\end{array}$ \\
\hline
\end{tabular}

\section{Author's Estimate of Affected Area}

From figure 9-11, looks like about 35\%. 


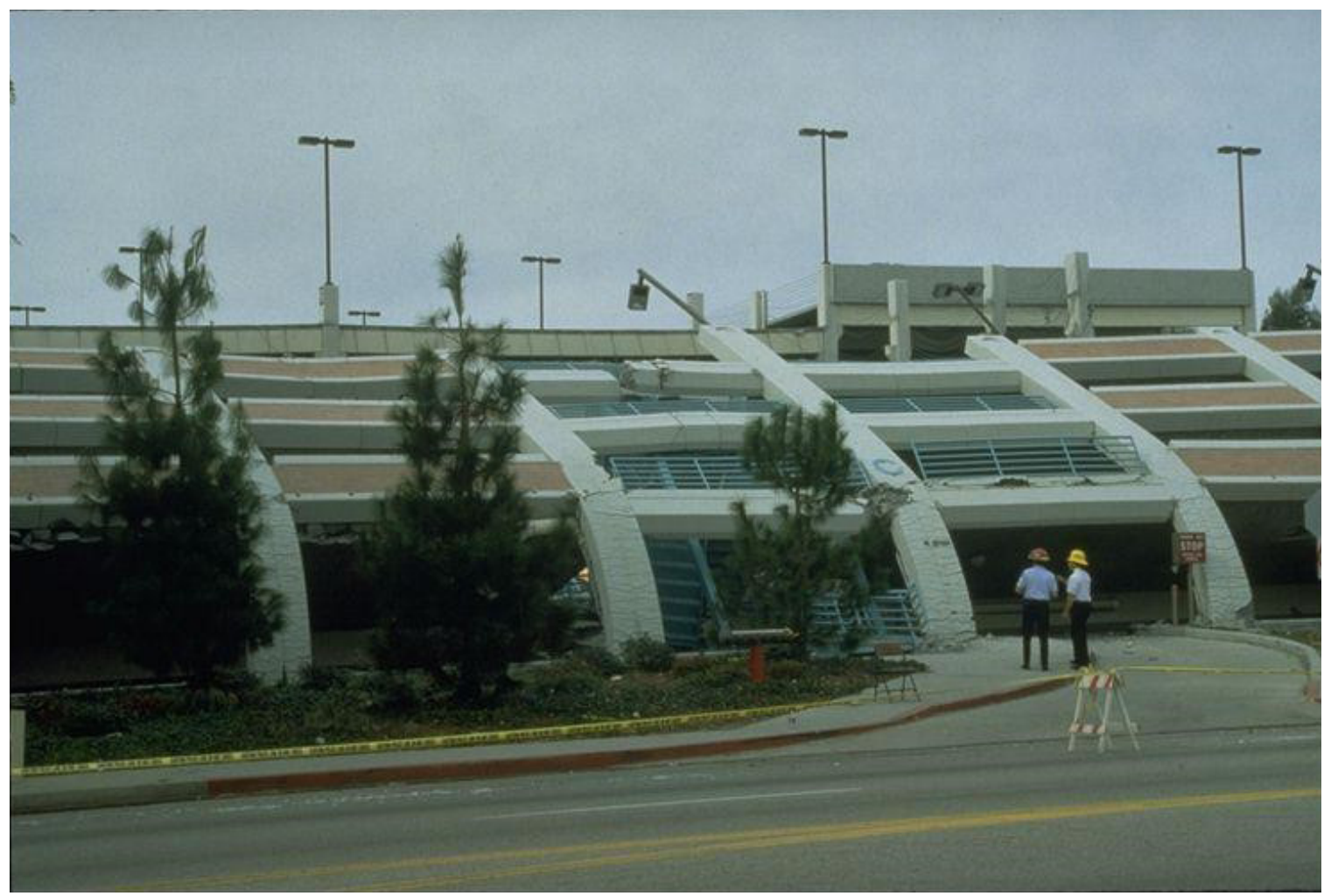

Figure 9-10. Photograph showing collapse of a parking structure on the California State University, Northridge, campus after the 1994 Northridge, California, earthquake.

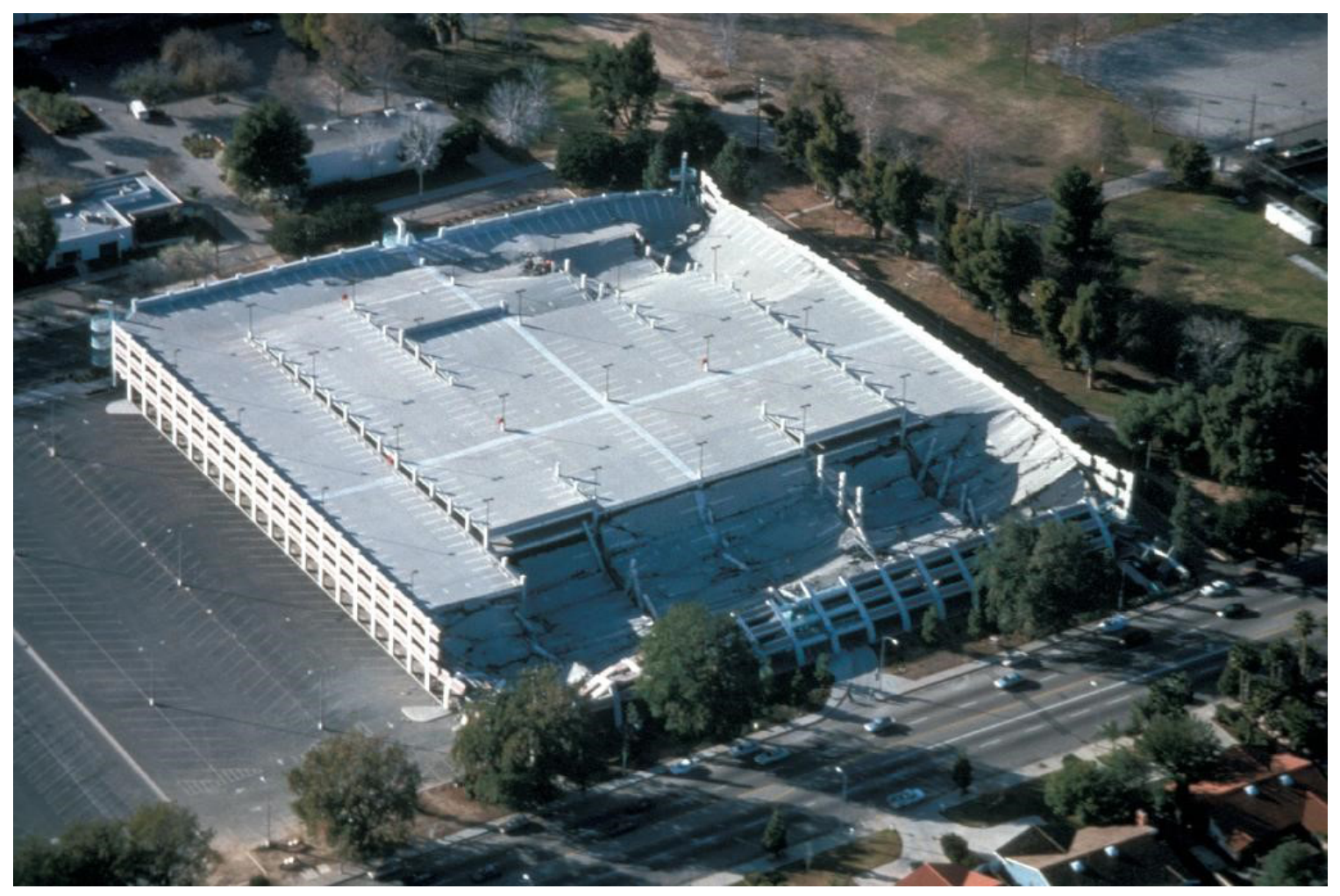

Figure 9-11. Photograph from the 1994 Northridge, California, earthquake. Image is from Earth Science World Image Bank (2017), which describes it as follows: California State University, Northridge parking structure that partly collapsed during the 1994 earthquake. Scientists believe it was the lack of shear walls, being precast, and lack of extra steel reinforcements in vertical columns that led to the damage seen here. This is 5 kilometers northeast of the epicenter. (Photograph by P.W. Weigand. Copyright California State University, Northridge, Geology Department, permission granted per earthscienceworld.org.) 


\section{Image Metadata and Description for Figure 9-12}

Northridge Collection: NR579

\begin{tabular}{|c|c|c|c|c|c|}
\hline $\begin{array}{c}\text { Earthquake date } \\
\text { and magnitude }(M)\end{array}$ & Title & Creator & Date & Location & Description \\
\hline $\begin{array}{l}\text { January 17, 1994; } \\
\quad M 6.69\end{array}$ & $\begin{array}{l}\text { Fashion Center } \\
\text { parking garage }\end{array}$ & $\begin{array}{l}\text { Reitherman, } \\
\text { Robert K. }\end{array}$ & February 12, 1994 & $\begin{array}{l}\text { Northridge/ Califor- } \\
\text { nia/North America/ } \\
\text { Los Angeles Coun- } \\
\text { ty/ United States }\end{array}$ & $\begin{array}{l}\text { Collapse of parking garage floors. See } \\
\text { NR459-461 for damage to Broadway } \\
\text { department store. Fashion Center, } \\
\text { Northridge, California. Structure: } \\
\text { Northridge Fashion Center Parking. }\end{array}$ \\
\hline
\end{tabular}

\section{Author's Estimate of Affected Area}

From an Atlantic Magazine image (Taylor, 2014), the collapsed area looks like about 35\%.

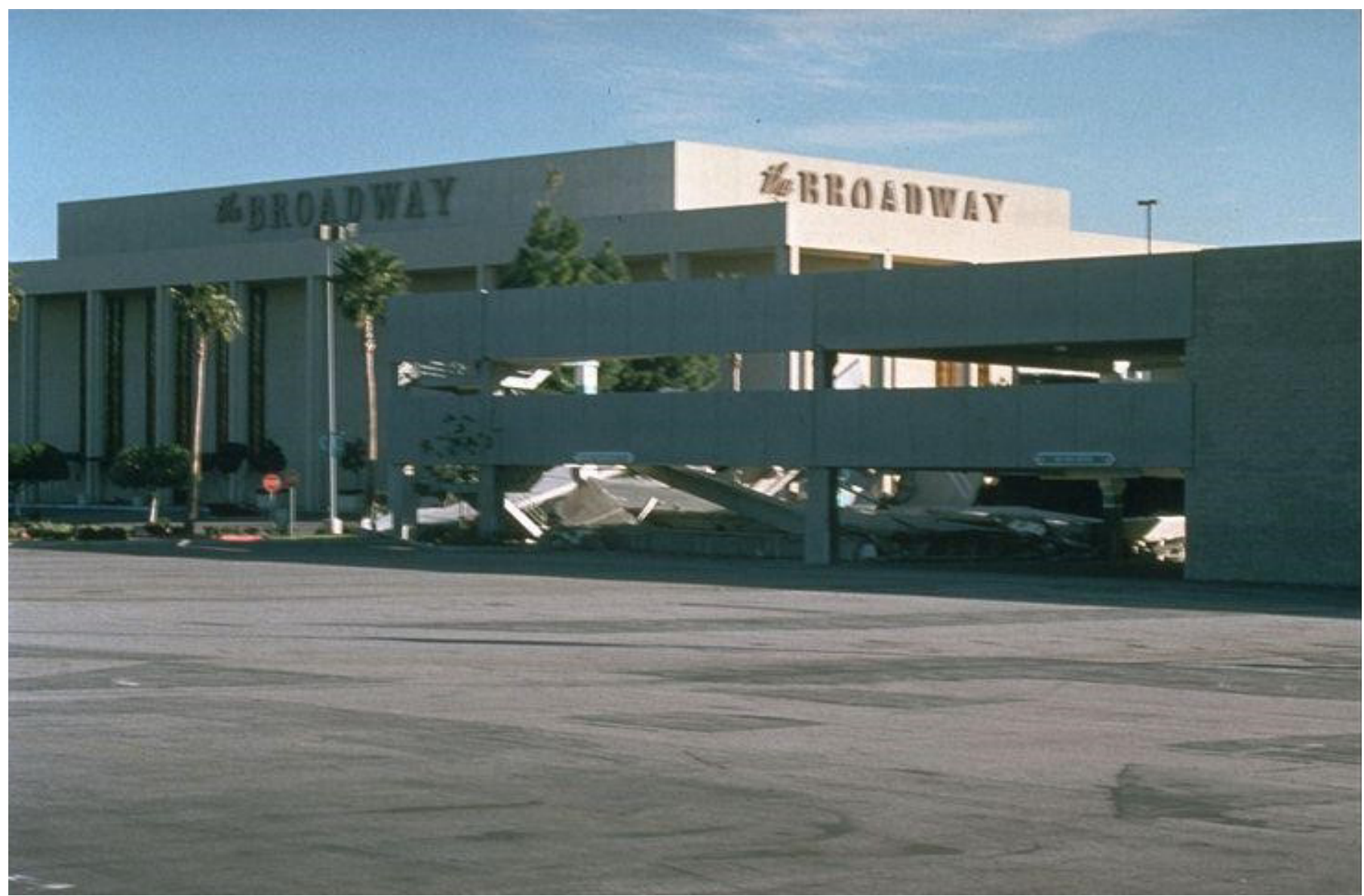

Figure 9-12. Photograph showing collapse of floors in the Northridge Fashion Center parking garage from the 1994 Northridge, California, earthquake. 


\section{Image Metadata and Description for Figure 9-13}

Northridge Collection: NR221

\begin{tabular}{|c|c|c|c|c|c|}
\hline $\begin{array}{l}\text { Earthquake date } \\
\text { and magnitude }(M)\end{array}$ & Title & Creator & Date & Location & Description \\
\hline $\begin{array}{l}\text { January } 17,1994 \\
\quad M 6.69\end{array}$ & $\begin{array}{l}\text { Bullock's retail } \\
\text { store }\end{array}$ & Unknown & 1994 & $\begin{array}{l}\text { Northridge/ California/ } \\
\text { North America/ Los } \\
\text { Angeles County/ } \\
\text { United States }\end{array}$ & $\begin{array}{l}\text { Northridge Fashion Island Center. Interior } \\
\text { reinforced-concrete columns remain } \\
\text { standing following collapse of second- } \\
\text { and third-floor concrete waffle slabs. } \\
\text { Intact portion of waffle slab roof shows } \\
\text { typical slab construction. Structure: } \\
\text { Bullock's Department Store. }\end{array}$ \\
\hline
\end{tabular}

\section{Author's Estimate of Affected Area}

A plan of Bullock's shows that the building has eight bays in each direction (Bibliop, 2017). It appears that the second floor collapsed onto the first floor in all but about 14 square bays: the one on the left and the one in the rear as viewed from the photographer's viewpoint, so 150 out of 192 floor-bays collapsed, or $78 \%$.

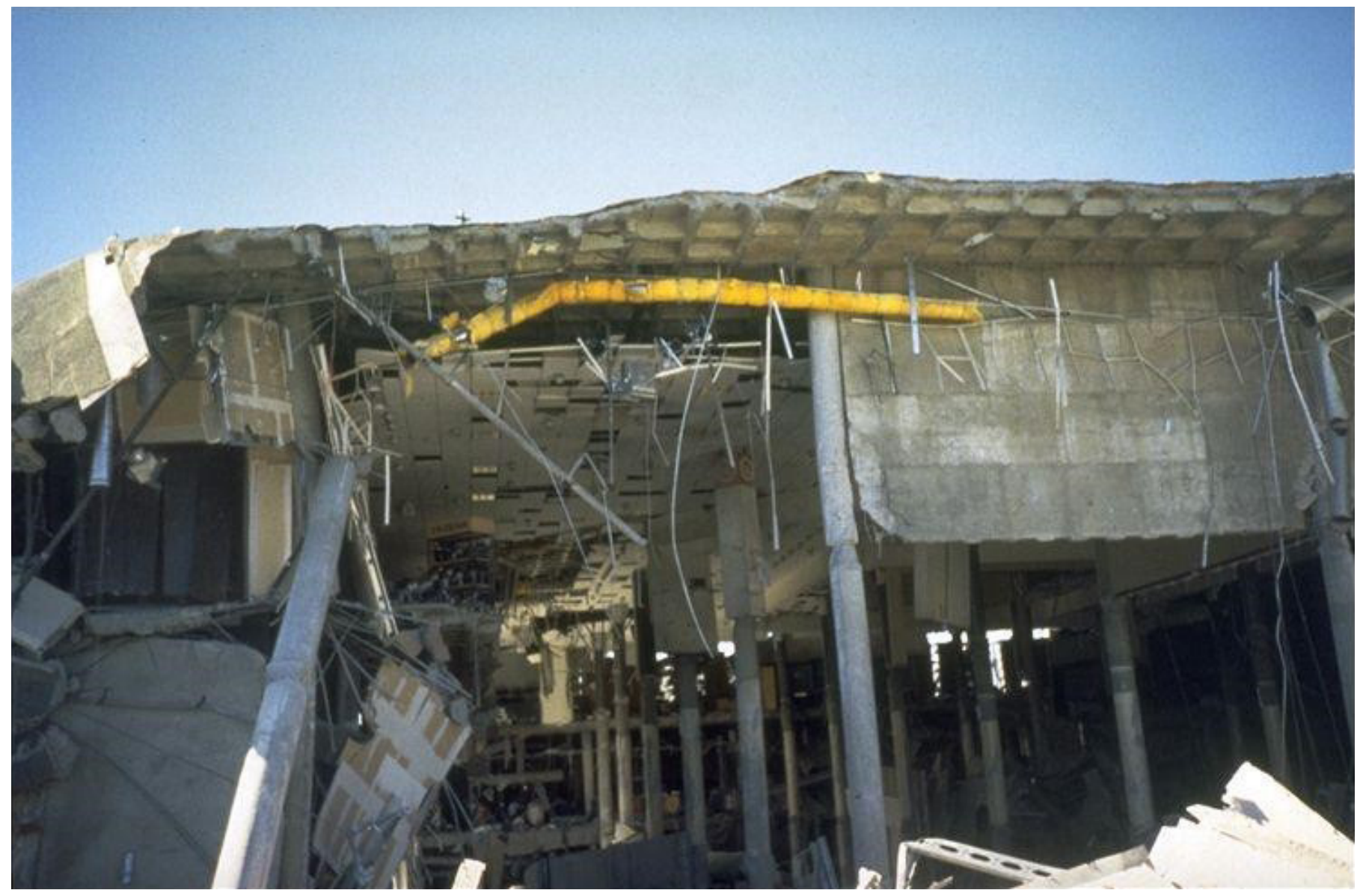

Figure 9-13. Photograph showing collapse of second- and third-floor concrete waffle slabs at Bullock's retail store after the 1994 Northridge, California, earthquake. 


\section{Image Metadata and Description for Figure 9-14}

Northridge Collection: NR303

\begin{tabular}{|c|c|c|c|c|c|}
\hline $\begin{array}{c}\text { Earthquake date } \\
\text { and magnitude }(M)\end{array}$ & Title & Creator & Date & Location & Description \\
\hline $\begin{array}{l}\text { January } 17,1994 ; \\
\quad M 6.69\end{array}$ & $\begin{array}{l}\text { Oviatt Library, } \\
\text { Cal State } \\
\text { campus }\end{array}$ & $\begin{array}{l}\text { McMullin, } \\
\text { Kurt M. }\end{array}$ & January 20, 1994 & $\begin{array}{l}\text { Northridge/ California/ } \\
\text { North America/ Los } \\
\text { Angeles County/ } \\
\text { United States }\end{array}$ & $\begin{array}{l}\text { View of partial roof collapse. South el- } \\
\text { evation, east of front entry. View from } \\
\text { east. Taken at } 3 \text { p.m. California State } \\
\text { University, Northridge. Structure: } \\
\text { Oviatt Library. }\end{array}$ \\
\hline
\end{tabular}

\section{Author's Estimate of Affected Area}

Other photographs, omitted for brevity (Northridge Collection numbers NR299, NR300, and NR302), show about $4 \times 1$ bays of roof collapse. One bay generally refers to the space between two columns, so $4 \times 1$ bay means a rectangular space between a sequence of five columns in one direction and between two columns in the perpendicular direction. The building has 14 bays east to west and 6 bays north to south and 5 floors, according to California State University Northridge's web page (California State University Northridge, 2017). Thus, $4 \times 1$ bays on 1 story collapsed out of 5 stories, each with $14 \times 6$ bays, suggesting a collapsed area of $(4 \times 1) /(5 \times 14 \times 6)=1.0 \%$

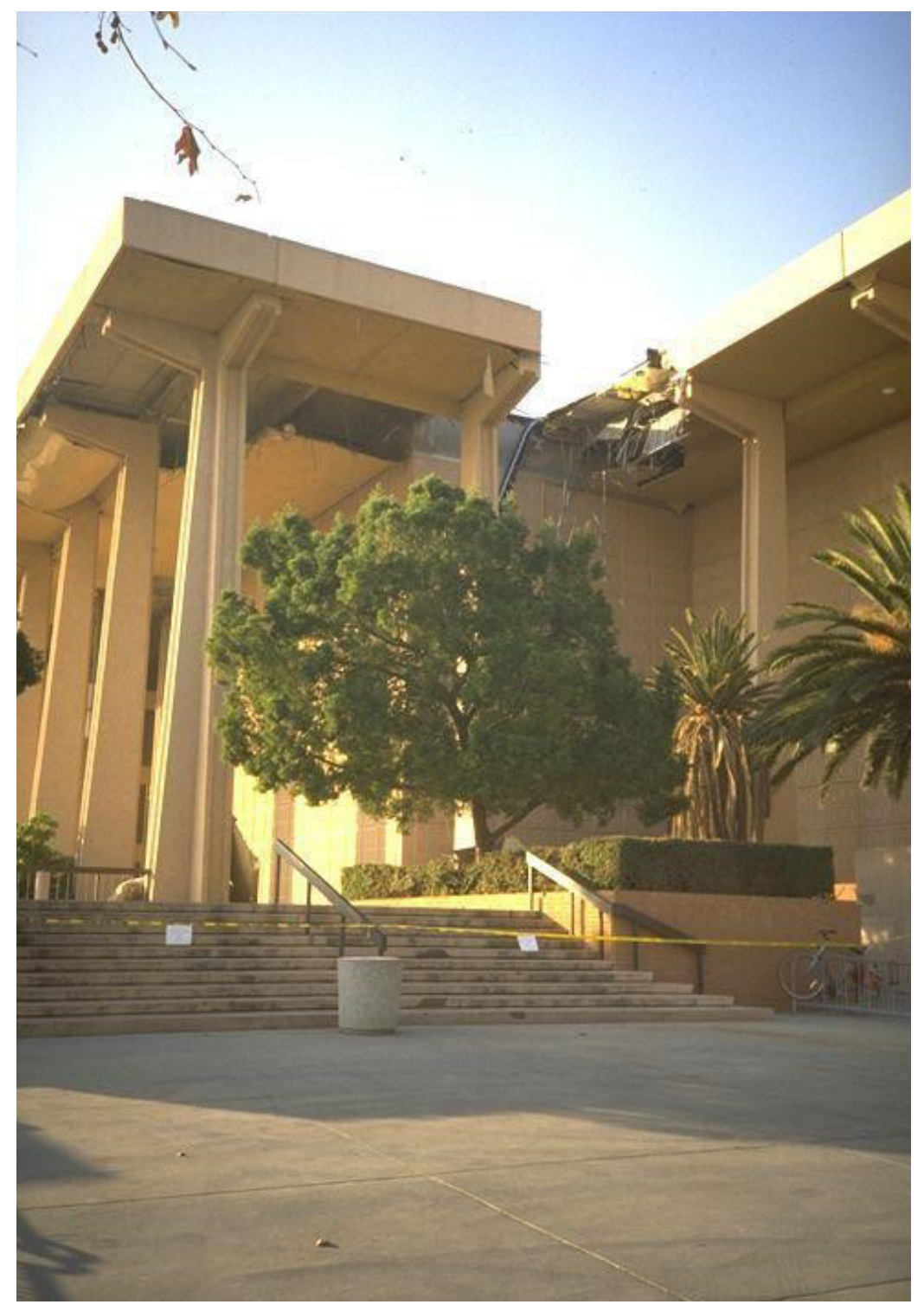

Figure 9-14. Photograph showing partial roof collapse of Oviatt Library, California State University, after the 1994 Northridge, California, earthquake. 


\section{Image Metadata and Description for Figure 9-15}

Northridge Collection: NR543

\begin{tabular}{|c|c|c|c|c|c|}
\hline $\begin{array}{c}\text { Earthquake date } \\
\text { and magnitude }(M)\end{array}$ & Title & Creator & Date & Location & Description \\
\hline $\begin{array}{l}\text { January } 17,1994 ; \\
\quad M 6.69\end{array}$ & $\begin{array}{l}\text { Kaiser parking } \\
\text { structure }\end{array}$ & $\begin{array}{l}\text { Reitherman, } \\
\text { Robert K. }\end{array}$ & January 19, 1994 & $\begin{array}{l}\text { Los Angeles/ Califor- } \\
\text { nia/ North America/ } \\
\text { Los Angeles County/ } \\
\text { United States }\end{array}$ & $\begin{array}{l}\text { Complete collapse of parking structure. } \\
\text { Los Angeles, California. Structure: } \\
\text { Kaiser Hospital parking. }\end{array}$ \\
\hline
\end{tabular}

\section{Author's Estimate of Affected Area}

See also the NISEE e-libraries Northridge Collection, photographs NR519, NR528, NR530, NR539, NR540, NR542, NR544, NR545, NR546, NR549, NR551, NR552, NR543, and NR544. All the photo descriptions ostensibly describe the Kaiser Hospital parking structure, but it appears there were two parking structures. Some descriptions say "complete collapse" and other photos such as NR519, NR528, and NR530 show a parking structure that has not collapsed. Reitherman, in NR549, names the location "Kaiser West Los Angeles Medical Center," which Google says is located at 6041 Cadillac Avenue, Los Angeles, California, 90034, which Google Earth locates at lat 34.0384 N., long -118.3757 E. Three satellite images from August 1989, April 1994, and March 2002, and shown in Google Earth, reveal two parking structures near here; one with a center near lat 34.0391 N., long -118.3759 E. appears to be the one that did not collapse. Another with a center at lat 34.0389 N., long -118.3733 E. appears in 1989, but is absent in April 1994 (after the earthquake), and it reappears (a replacement) in 2002. I can find no aerial images of the latter collapsed structure or long shots to show the extent of the collapse, so I take the affected area as $100 \%$.

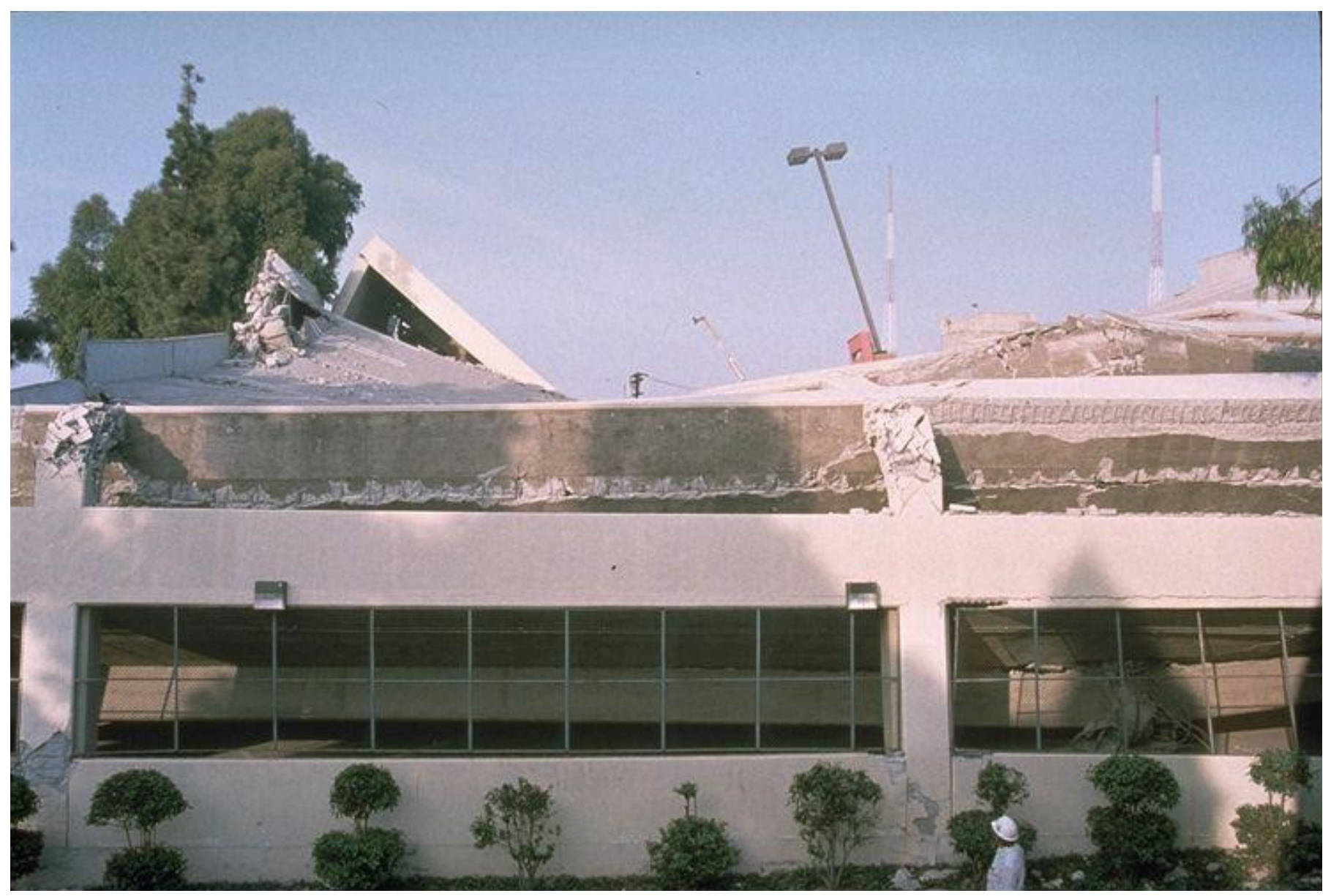

Figure 9-15. Photograph showing complete collapse of the Kaiser parking structure, Los Angeles, after the 1994 Northridge, California, earthquake. 


\section{Image Metadata and Description for Figure 9-16}

Northridge Collection: NR328

\begin{tabular}{cccccc}
\hline $\begin{array}{c}\text { Earthquake date } \\
\text { and magnitude }(\boldsymbol{M})\end{array}$ & Title & Creator & Date & Location & Description \\
\hline $\begin{array}{cccc}\text { January 17, 1994; } \\
\text { M6.69 }\end{array}$ & $\begin{array}{c}\text { Soft-story } \\
\text { collapse of } \\
\text { apartment }\end{array}$ & Unknown & 1994 & $\begin{array}{c}\text { Sherman Oaks/ Califor- } \\
\text { nia/ North America/ }\end{array}$ & $\begin{array}{c}\text { Soft-story collapse of apartment building, at Ha- } \\
\text { zeltine Ave. and Milbank St., Sherman Oaks, } \\
\end{array}$ \\
building & & & $\begin{array}{l}\text { Los Angeles County/ } \\
\text { California. }\end{array}$ & United States & \\
\hline
\end{tabular}

Author's Estimate of Affected Area

By inspection, $33 \%$.

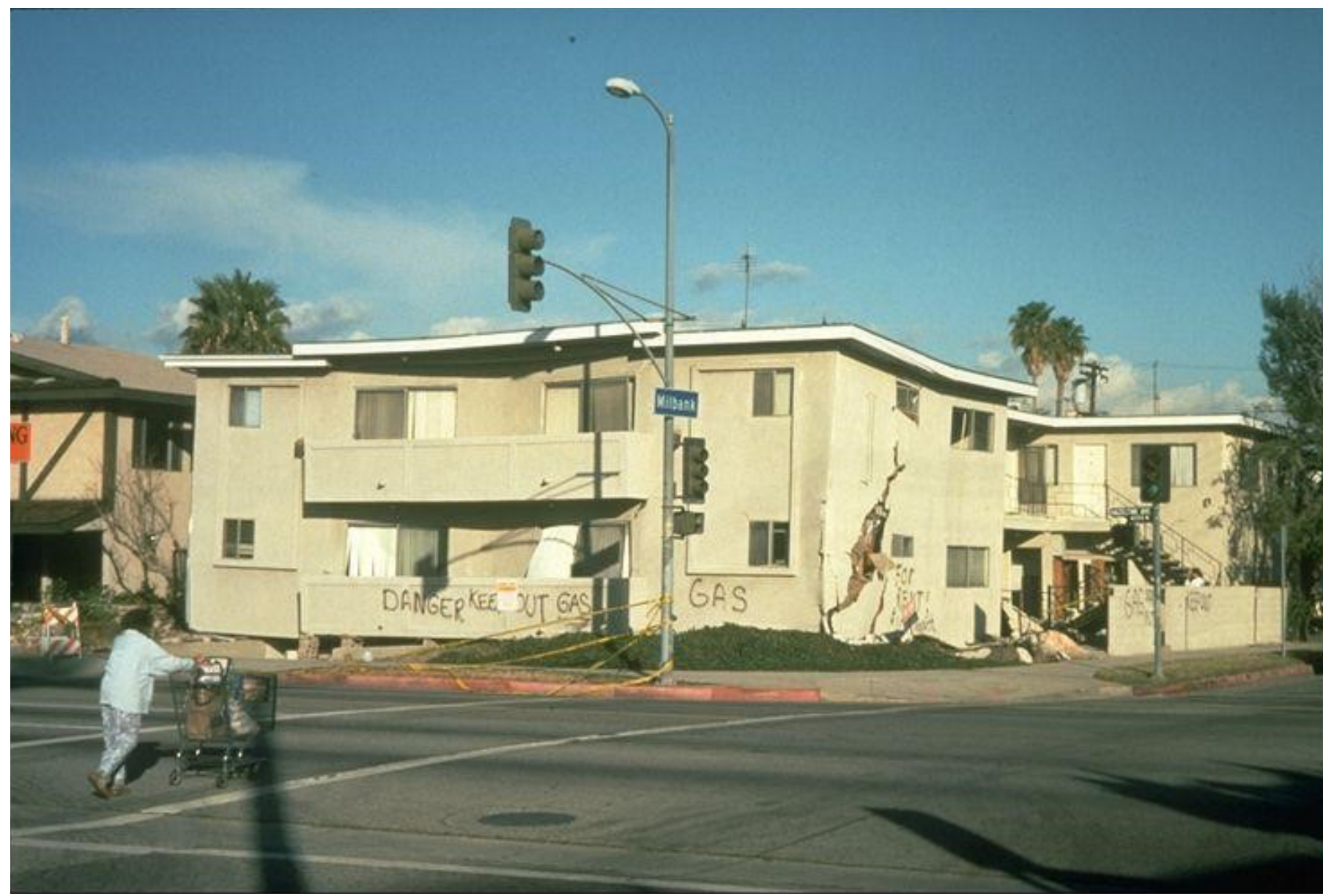

Figure 9-16. Photograph showing soft-story collapse of apartment building in Sherman Oaks after the 1994 Northridge, California, earthquake. 


\section{Image Metadata and Description for Figure 9-17}

Northridge Collection: NR160

\begin{tabular}{|c|c|c|c|c|c|}
\hline $\begin{array}{c}\text { Earthquake date } \\
\text { and magnitude }(M)\end{array}$ & Title & Creator & Date & Location & Description \\
\hline $\begin{array}{l}\text { January 17, 1994; } \\
\quad \text { M6.69 }\end{array}$ & $\begin{array}{l}\text { Soft-story col- } \\
\text { lapse of apart- } \\
\text { ment building }\end{array}$ & Unknown & 1994 & $\begin{array}{l}\text { Sherman Oaks/ Califor- } \\
\text { nia/ North America/ } \\
\text { Los Angeles County/ } \\
\text { United States }\end{array}$ & $\begin{array}{l}\text { Soft-story collapse of apartment building, at } \\
\text { Hazeltine Ave. and Milbank St., Sherman } \\
\text { Oaks, California. }\end{array}$ \\
\hline
\end{tabular}

\section{Author's Estimate of Affected Area}

See also the NISEE e-library's Northridge Collection, photograph NR162. The collapsed second floor amounts to $20 \%$ of the building area. The partly collapsed north and south end bays from floors three to five add another $10 \%$, for a total of $30 \%$.

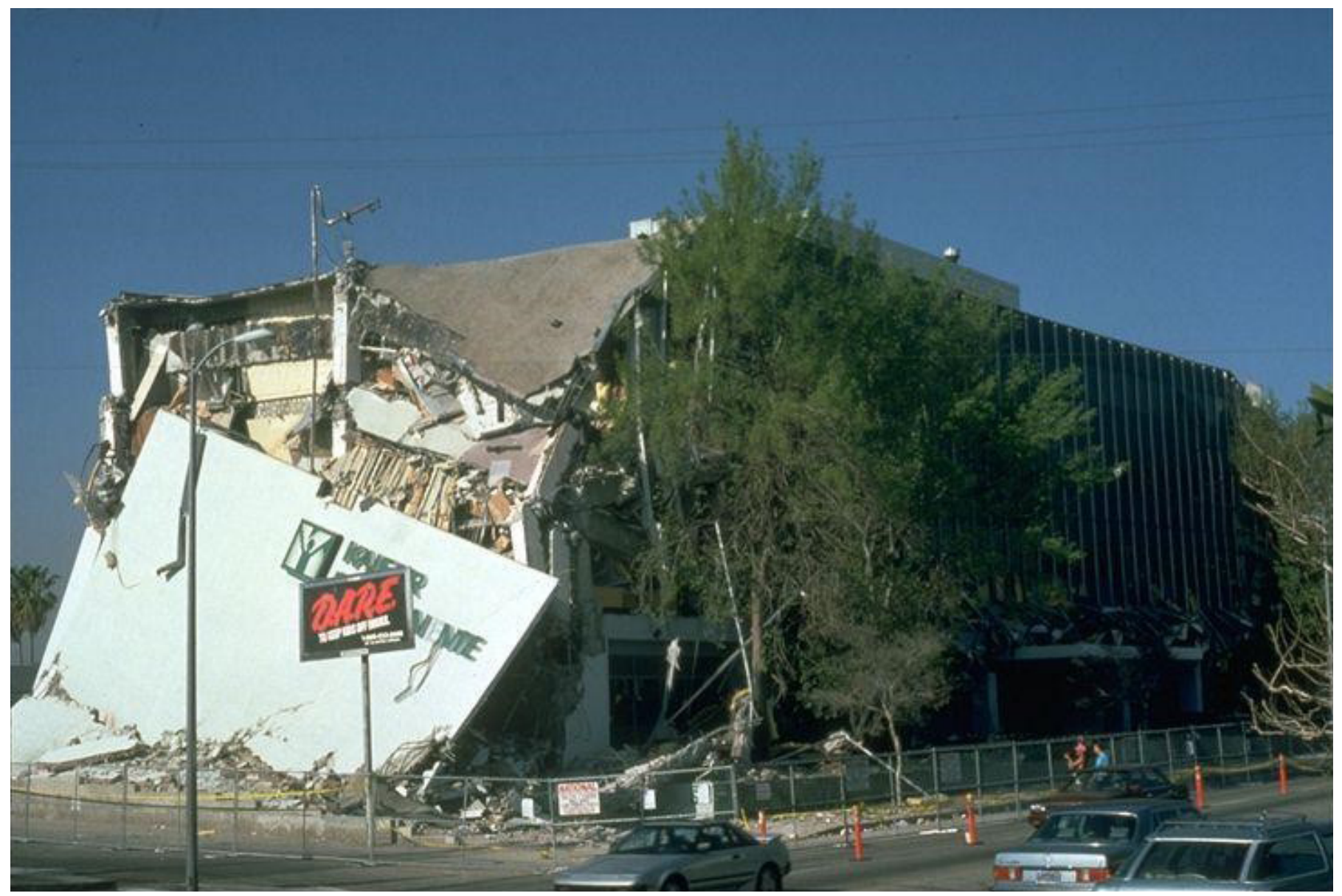

Figure 9-17. Photograph showing second-floor collapse at Kaiser Permanente office building, Granada Hills, after the 1994 Northridge, California, earthquake. 


\section{Appendix 10. San Simeon (2003) Collapse Images}

\section{Image Metadata and Description for Figure 10-1}

NISEE Miscellaneous Collection: NM0008

\begin{tabular}{|c|c|c|c|c|c|}
\hline $\begin{array}{c}\text { Earthquake date } \\
\text { and magnitude }(M)\end{array}$ & Title & Creator & Date & Location & Description \\
\hline $\begin{array}{r}\text { December } 22, \\
2003 ; M 6.6\end{array}$ & $\begin{array}{l}\text { View of } \\
\text { collapsed } \\
\text { build- } \\
\text { ing from } \\
\text { intersection } \\
\text { of 12th } \\
\text { and Park } \\
\text { Streets }\end{array}$ & $\begin{array}{l}\text { Sakai, } \\
\text { Junichi }\end{array}$ & December 23, 2003 & $\begin{array}{l}\text { Paso Robles/ Cali- } \\
\text { fornia/ North } \\
\text { America/ San } \\
\text { Luis Obispo } \\
\text { County/ United } \\
\text { States }\end{array}$ & $\begin{array}{l}\text { This unreinforced masonry building was } \\
\text { built in 1892, and its clock tower became } \\
\text { a symbol for the town of Paso Robles. The } \\
\text { second story of the building collapsed dur- } \\
\text { ing the earthquake, killing two employees } \\
\text { of Ann's Dress Shop as they tried to flee } \\
\text { onto Park Street. The roof of the build- } \\
\text { ing collapsed directly westward onto Park } \\
\text { Street and landed on a row of parked cars. } \\
\text { Debris from the north wall went through } \\
\text { the roof of an adjacent shop at } 1220 \text { Park } \\
\text { Street, Paso Robles, California. Structure: } \\
\text { Mastagni Building. }\end{array}$ \\
\hline
\end{tabular}

\section{Author's Estimate of Affected Area}

Also see the NISEE e-library's Northridge Collection, photographs NM0009 and NM0012 for this building and its photographs NM0001-NM0004 for 1220 Park Street. The building at the west end of the 800 block of 12th Street (807 12th Street is mentioned in the description of NM0009) and the south end of the 800 block of Park Street appears in September 1994 satellite imagery in Google Earth. It has a plan area of approximately $5,960 \mathrm{ft}^{2}$, so a total area of approximately 11,920 $\mathrm{ft}^{2}$. The collapse of the second floor constitutes 5,960 $\mathrm{ft}^{2}$. In addition, the roof collapsed onto 12th Street. The building was approximately $120 \mathrm{ft}$ long north to south, and it looks as if the roof covered the sidewalk and half the depth of the diagonal street parking, about $19 \mathrm{ft}$ total, so another $120 \mathrm{ft} \times 19 \mathrm{ft}=2,280 \mathrm{ft}^{2}$. The building at 1220 Park Street, just to the north, was a one-story building that appears from photograph NM0009 to have had its roof completely collapse under debris falling from the Mastagni Building. The floor area of 1220 Park Street looks like $50 \mathrm{ft}$ deep by perhaps $20 \mathrm{ft}$ wide. The total affected area is therefore approximately $\left(5,960 \mathrm{ft}^{2}\right.$ $\left.+2280 \mathrm{ft}^{2}+1,000 \mathrm{ft}^{2}\right) /\left(11,920 \mathrm{ft}^{2}\right)=78 \%$.

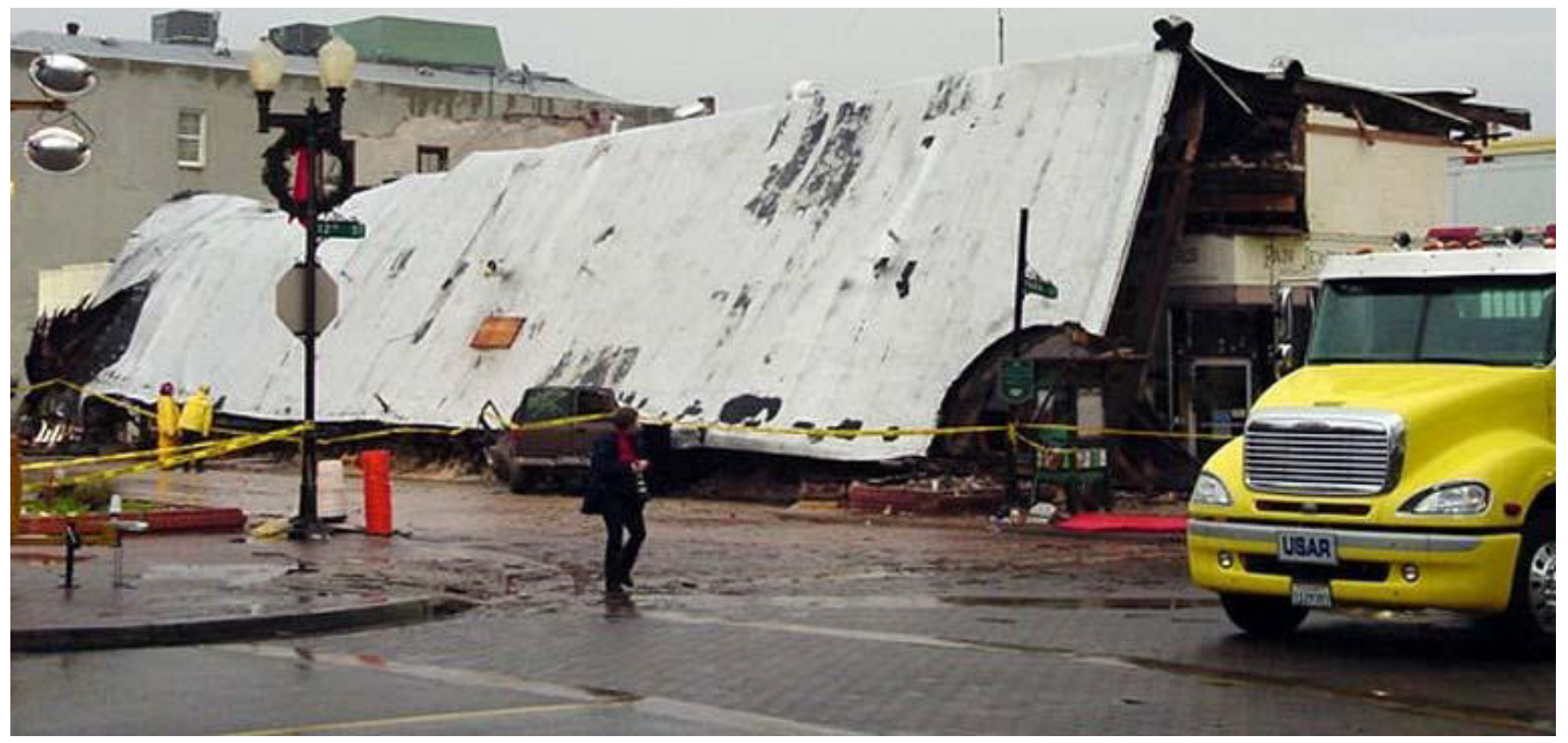

Figure 10-1. Photograph showing collapsed building from intersection of 12th and Park Streets in Paso Robles after the 2003 San Simeon, California, earthquake. 


\section{Image Metadata and Description for Figure 10-2}

NISEE Miscellaneous Collection: NM0012

\begin{tabular}{cccccc}
\hline $\begin{array}{c}\text { Earthquake date } \\
\text { and magnitude }(\boldsymbol{M})\end{array}$ & Title & Creator & Date & Location & Description \\
\hline $\begin{array}{c}\text { December 22, } \\
2003 ; M 6.6\end{array}$ & Old Clocktower & Unknown & $\begin{array}{c}\text { December } \\
23,2003\end{array}$ & $\begin{array}{c}\text { Paso Robles/ California/ } \\
\text { North America/ San } \\
\text { Luis Obispo County/ } \\
\text { United States }\end{array}$ & $\begin{array}{c}\text { Before and after images of the Old Clock- } \\
\text { tower. This unreinforced masonry building } \\
\text { was built in 1892, and its clock tower had } \\
\text { become a symbol of Paso Robles. The sec- } \\
\text { ond story of the building collapsed directly } \\
\text { westward onto Park Street. Paso Robles, } \\
\end{array}$ \\
& & & & California. \\
\hline
\end{tabular}

\section{Author's Estimate of Affected Area}

The author could not find an image that provides a wide enough perspective to judge the affected area. The image is included for completeness.
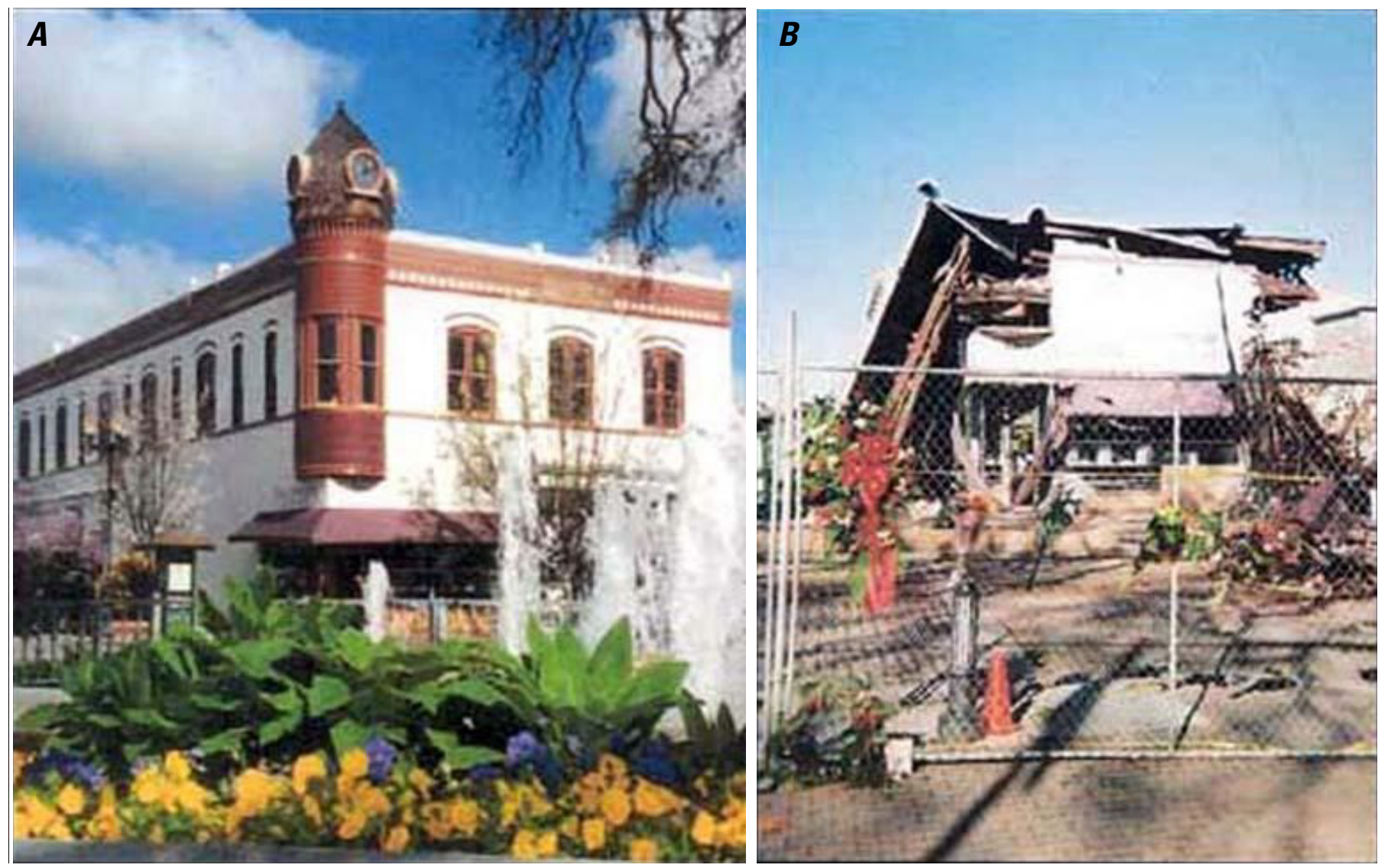

Figure 10-2. Photographs of the Old Clock Tower, Paso Robles, before $(A)$ and after $(B)$ the 2003 San Simeon, California, earthquake. This unreinforced masonry building was built in 1892, and its clock tower had become a symbol of Paso Robles. The second story of the building collapsed directly westward onto Park Street. 


\section{Appendix 11. South Napa (2014) Collapse Images}

\section{Image Metadata and Description for Figure 11-1}

Sarah Durphy: P9050177 (outside) and P9080152 (inside).

\begin{tabular}{|c|c|c|c|c|c|}
\hline $\begin{array}{l}\text { Earthquake date } \\
\text { and magnitude }(M)\end{array}$ & Title & Creator & Date & Location & Description \\
\hline $\begin{array}{l}\text { August } 24,2014 \text {, } \\
\quad \text { M6.0 }\end{array}$ & $\begin{array}{l}\text { Don Perico's } \\
\text { Restaurant }\end{array}$ & Sarah Durphy & Unknown & $\begin{array}{l}\text { Napa/ California/ North } \\
\text { America/ Napa County/ } \\
\text { United States }\end{array}$ & $\begin{array}{l}\text { Exterior and interior of Don Perico's } \\
\text { Resturant. Napa, California. }\end{array}$ \\
\hline
\end{tabular}

\section{Author's Estimate of Affected Area}

At the time of the earthquake, the restaurant was located at 1025 1st Street, Napa, California, in the west end of the building at lat $38.299029 \mathrm{~N}$., long $-122.285868 \mathrm{E}$. That address seems to occupy approximately $60 \mathrm{ft} \times 60 \mathrm{ft}$. The collapsed wall appears to fill $25 \mathrm{ft} \times 12 \mathrm{ft}$, suggesting an affected area of $8.3 \%$.
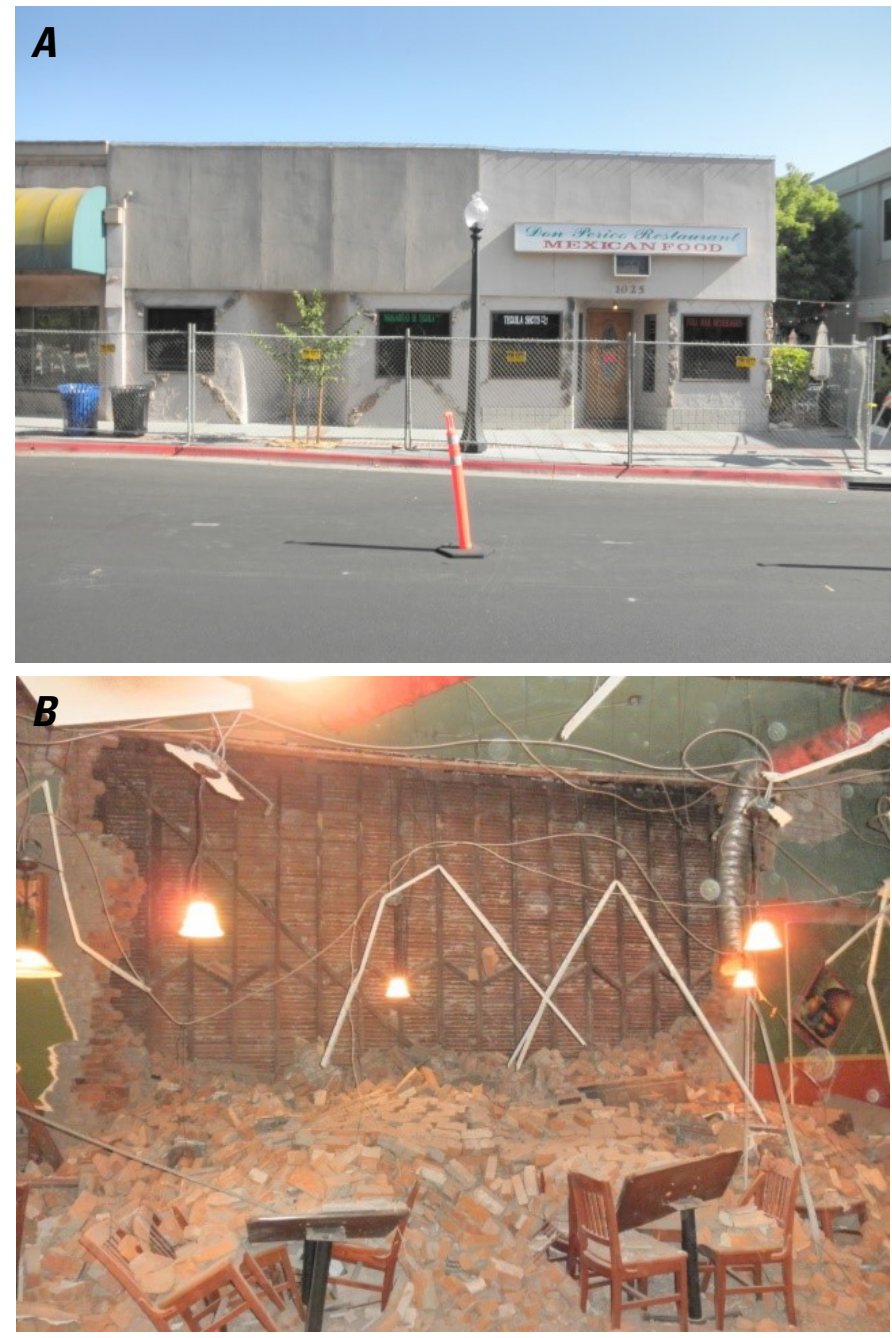

Figure 11-1. Photographs $(A, B)$ showing damage to Don Perico's Restaurant in Napa in the 2014 South Napa, California, earthquake. 


\section{Appendix 12. Earthquakes With No Available Collapse Images}

Borrego Mountain (1968)

Livermore (1980)

Mammoth Lakes (1980)

Cape Mendocino (1980)

Humboldt County (1980)

North Palm Springs (1986)

Oceanside (1986)

Chalfant Valley (1986)

Superstition Hills (1987)

Lake Elsman (1989)

Sierra Madre (1991)

Joshua Tree (1992)

Cape Mendocino (1992)

Landers (1992)

Big Bear (1992)
Eureka Valley (1993)

Hector Mine (1999)

Yountville (2000)

Parkfield (2004)

Anza (2005)

Cape Mendocino (2005)

Alum Rock (2007)

Chino Hills (2008)

Inglewood (2009)

Eureka (2010)

Pico Rivera (2010)

El Mayor-Cucapah (2010)

Borrego Springs (2010)

Brawley swarm (2012)

Avalon (2012) 




\title{
Chapter $\mathbf{N}$
}

\section{A New Model of Water-Network Resilience, with Application to the HayWired Scenario}

\author{
By Keith A. Porter ${ }^{1}$
}

\section{Abstract}

Damage to potable water-supply systems can profoundly affect a society after an earthquake. For at least 25 years, engineers have performed computerized risk analyses of earthquake damage to water-supply systems to estimate earthquake damage and restoration. A new stochastic simulation model is offered here that employs a fairly traditional lossestimation approach but with three notable improvements(1) it deals with lifeline interaction by directly modeling how individual repairs are slowed by limitations in so-called upstream lifelines and other prerequisites; (2) it quantifies damage and restoration over the entire earthquake sequence, that is, considering damage in the mainshock, aftershocks, and afterslip; and (3) it offers an empirical model of service restoration as a function of the number of pipeline repairs performed (as opposed to more rigorous, but computationally demanding, hydraulic analysis). A fourth improvement is that it offers a procedure to adjust estimates of restoration from the Federal Emergency Management Agency's Hazus-MH computer program to account for an earthquake-sequence's interactions with lifelines and corrects for Hazus-MH's default assumptions about the number of available repair crews.

The model is applied for two water-supply systems in California's San Francisco Bay region subjected to the hypothetical but highly realistic HayWired earthquake sequence-a moment magnitude $\left(M_{\mathrm{w}}\right) 7.0$ mainshock on the Hayward Fault in the east bay part of the San Francisco Bay area, plus 16 aftershocks of magnitude 5 or greater occurring over 17 months after the mainshock. The model quantifies water-system damage and restoration, including delays due to fuel and other lifeline limitations, and setbacks in restoration because of aftershocks. It estimates the benefit of a fuel-management plan and an accelerated pipe-replacement plan in terms of accelerated restoration of service. The model is validated several ways for each of the two case-study water-supply systems and seems reasonable. One San Francisco Bay region water utility anticipates using the model to target vulnerable segments of its system for accelerated pipe replacement.

\footnotetext{
${ }^{1}$ University of Colorado Boulder.
}

\section{Introduction}

The HayWired scenario examines a hypothetical earthquake (mainshock) with a moment magnitude $\left(M_{\mathrm{w}}\right)$ of 7.0 occurring on April 18, 2018, at 4:18 p.m. on the Hayward Fault in the east bay part of California's San Francisco Bay area. The HayWired scenario evaluates, among other things, the potential for damage to water-supply systems in the San Francisco Bay region during the HayWired mainshock and subsequent aftershocks.

\section{How Water Supply is Important in an Earthquake}

People need potable water for daily life. Businesses need water for air conditioning and as a raw material for production. Water is an input to many natural and manufactured products and processes. Damage to a water-supply system can contribute greatly to the life-safety and economic consequences of an earthquake, as illustrated by the economic analyses performed for the 2008 ShakeOut scenario (Rose and others, 2011). In that study, the authors found that water-supply interruption from a hypothetical $M_{\mathrm{w}} 7.8$ earthquake on the San Andreas Fault in southern California could result in $\$ 24$ billion in business interruption losses when macroeconomic responses are not considered and only minimal business-resilience actions are taken to reduce the losses. The figure that represents more than one third of the $\$ 68$ billion in total business interruption losses and 13 percent of the total of property damage plus business interruption. A potable water supply is crucial for residences, businesses, government facilities, and hospitals and other critical-care facilities. Long aware of the importance of water supply and the potential for earthquakes to interrupt water supply, earthquake experts recommend that homes and businesses have enough water to provide for 1 gallon per person per day after a major earthquake to last at least 3 days and ideally for 2 weeks.

Loss of water supply in the hypothetical ShakeOut earthquake would also contribute substantially to the fire damage to property, which itself could realistically account for $\$ 65$ billion of the $\$ 113$ billion in property losses (Scawthorn, 2008). The ShakeOut scenario was not a worst-case earthquake; the earthquake fault rupture it dealt with has a mean recurrence interval 
of 150 years, and it has been 300 years since the last rupture. Furthermore, the fire simulation assumed mild winds rather than the fast, hot, dry, Santa Ana winds that commonly blow in the fall and notoriously fan wildfires.

These earlier estimates, although particular to the ShakeOut, reflect a general truth - earthquake damage to water-supply systems in the United States (and elsewhere) threatens the health, safety, and welfare of the population, possibly more than earthquake damage to any other utility or other element of the built environment, in part because repairs are so costly and time consuming. More narrowly, earthquakes can pose a serious financial threat to any water supply utility in a seismically active region. If a utility cannot deliver water it cannot collect revenues, which can threaten its ability to make payroll. Every water utility in earthquake country may be at risk.

The HayWired scenario hypothetical mainshock is a large but not exceedingly rare $M_{\mathrm{w}} 7.0$ earthquake that damages water-supply systems in the San Francisco Bay region. Earthquakes damage water-supply systems, and the damage causes other problems, such as for firefighting. The $M_{\mathrm{w}} 7.8$ 1906 San Francisco earthquake damaged so much of that city's potable water-supply system that pressure dropped too low for firefighters to fight the fires that eventually destroyed much of the city. The $M_{\mathrm{w}} 6.91989$ Loma Prieta earthquake caused at least 761 breaks and leaks to water mains and pipelines made of various materials throughout the San Francisco Bay area (Lund and Schiff, 1991). The loss of firefighting water supply in San Francisco's Marina District contributed to the fire that damaged 7 structures, destroying 4 buildings containing 33 apartments and flats (Scawthorn and others, 1991). Cast iron, steel, ductile iron, plastic, and copper pipes all broke both within and outside areas of liquefaction and other ground failure. The $M_{\mathrm{w}} 6.02014$ South Napa earthquake caused 249 pipeline breaks or leaks in the City of Napa, in the northern San Francisco Bay area (Douglas DeMaster, Engineer, City of Napa, written commun., March 23, 2017).

The largest total number of breaks and leaks and the highest repair rate (repairs per mile) in the 1989 earthquake occurred in cast-iron pipe subjected to liquefaction-induced ground failure, but other materials were also damaged, including ductile iron, polyvinyl chloride (PVC), and steel. Pipes were damaged in 1989 in places that were not known to have experienced ground failure, so that damage has been attributed to ground strain associated with wave passage, especially Rayleigh surface waves. There was no observed liquefaction damage to buried pipeline in Napa in the 2014 earthquake, reinforcing the idea that wave passage alone can damage buried pipe. Even the modest $M_{\mathrm{w}} 4.0$ Piedmont, California, earthquake of August 17, 2015, caused at least 7 instances of damage to buried cast iron water-supply pipe in the east bay (Bay City News, 2015).

Repairs to an earthquake-damaged water-supply system can take months or more. Each repair can take as little as 2 hours to repair, but large numbers of repairs and larger pipes can take much longer. A 30-inch water main that broke near the UCLA campus at 3:30 p.m. on Tuesday July 29, 2014, took almost 5 days, until 11:00 a.m. Sunday, August 3 to repair (Los Angeles Department of Water and Power, 2014). During an earthquake sequence, with many simultaneous instances of damage, repairs take longer for many reasons. Some of these are:

1. When a pressure zone loses pressure because of many breaks and leaks, it can be necessary to repair damage closer to the source (that is, nearer the tank, reservoir, or other water source) before one discovers damage farther from the source.

2. Similarly, it may be necessary to repair damage to a pumping plant, reservoir, or regulator before damage in the downstream pipeline network can be addressed.

3. Water districts have an upper limit to their ability to field and manage multiple repair crews operating in parallel, even when the crews are from outside contractors or from water districts that provide mutual aid.

4. Limited supplies of repair resources such as spare pipe, clamps, fuel, and repair crews.

5. Damage to other systems - for example, electrical and gas - can hinder pipeline repair, and in some cases those repairs can cause pipeline damage. Coordination with other agencies can conceivably idle repair crews.

6. Aftershocks can hinder repair efforts because they pose an ongoing safety threat to repair crews. They can also cause new damage or aggravate earlier damage.

\section{Study Objectives}

In this work, I attempt to depict a realistic outcome of the damage and restoration of water supply in the HayWired earthquake sequence. I review available models of earthquakeinduced pipeline damage and repair, propose one for use in the HayWired scenario, and apply it to the water-supply systems of two San Francisco Bay area water utilities - the San Jose Water Company and the East Bay Municipal Utility District (EBMUD). These two systems were chosen because they are strongly shaken in the scenario, are affected by the mainshock and by aftershocks, and were willing to share their system maps. The maps were shared under strict requirements of confidentiality, so map details are not available to the reader.

This study supplements conventional loss estimation by examining the detailed activities involved in discovering and repairing water-pipeline damage. It identifies steps in the repair process that rely on other lifelines to inform a new model of the effects of lifeline interaction to delay water service repairs and restoration.

This study focuses on damage and repair of buried water pipe, which tends to dominate the effort to restore water supply. It considers damage resulting from wave passage, liquefaction, landsliding, and fault offset. It ignores earthquake damage to other elements in the water-supply system, including raw-water aqueducts, tanks, tunnels, canals, valves, and reservoirs. The decision to focus this study on buried pipelines without including 
other critical facilities, such as tanks, reservoirs, and tunnels, seems reasonable, because a majority of water utilities have implemented seismic improvement programs (SIP) that, for the most part, focused on seismically retrofitting their tanks, reservoirs, and other such facilities but not their old distribution pipelines. As such, old distribution pipelines, as an asset class, present the most significant seismic vulnerability for most water utilities, because for the most part smaller diameter distribution mains were not replaced with seismic-resistant mains because it simply wasn't economically feasible to replace them all as part of a SIP.

Elsewhere, the HayWired scenario quantifies damage to buildings; this chapter does not address restoration of water utilities' customer base or the change in demand for water as homes and businesses relocate because of building damage or other reasons.

\section{Literature Review}

Before proposing a model to estimate water-supply pipeline restoration considering an earthquake sequence and lifeline interaction, I first consider some key aspects of previous efforts. At least two general approaches exist to estimating damage and restoration of water supply after earthquakes - (1) expert opinion and (2) engineering analysis. The present work will pursue an analytical approach, which requires one to consider some important details - pipe damageability, repair effort, postearthquake serviceability, lifeline interaction, afterslip, and measuring loss of resilience.

\section{A Panel Approach to Estimating Water-Supply Impacts}

The ShakeOut scenario (Jones and others, 2008) assessed Earth-science impacts, physical damage, and socioeconomic impacts of a hypothetical $M_{\mathrm{w}} 7.8$ southern San Andreas Fault earthquake. Among many detailed studies were special studies of 12 lifelines, 7 of which were performed by panels of employees of the utilities at risk. The panel process is described in detail in Porter and Sherrill (2011). Briefly, panels meet for several hours (generally 4 hours in the case of ShakeOut). Panelists are presented with a scenario's Earth-science impacts and previously estimated damage to supposedly upstream lifelines - lifelines whose damage would seem to affect the damage or repair to the lifeline in question but not vice versa. They then hypothesize a realistic outcome of the earthquake on damage and service restoration, identifying research needs and mitigation options. Panels' discussion and initial findings are documented in brief memos, which are then circulated to the panelists. Panelists are asked to review the memos and asked to reconsider lifeline interaction in light of damage to supposedly downstream lifelines, as well as upstream ones. The process iterates until panelists are satisfied with their estimates of damage and restoration. In practice in the ShakeOut, as well as in ARkStorm (see Porter and others, 2011), only one iteration was used and only two or so panelists from each panel actually reviewed and revised the write-ups. However, the panel process worked reasonably well. Panelists were well qualified and seemed to fairly assess realistic earthquake impacts and restoration. They gained insight into lifeline interaction, mutual-aid needs, communication capabilities, and backup supplies.

Figure 1 shows the water-supply restoration timeline that the water-supply panel estimated for strongly shaken (Modified Mercalli Intensity, MMI, VIII+) geographic areas using expert opinion (Jones and others, 2008). See Porter and Sherrill (2011) for electric power restoration curves in ShakeOut and Porter and others (2011) for various restoration curves and modes of lifeline interaction in the ARkStorm scenario.

\section{Analytical Approaches to Estimating Water Supply Impacts}

Analytical approaches to estimating impacts to watersupply from an earthquake typically involve acquiring a map of a water-supply system, identifying component materials and sizes, associating each with one or more vulnerability functions or fragility functions (depending on the desired output), estimating ground motion and ground-failure severity in one or more scenarios, estimating mean damage and sometimes uncertainty in damage with reference to the vulnerability functions, and sometimes estimating repair costs and duration of loss of function.

The Federal Emergency Management Agency's (FEMA) publication FEMA 224 (Applied Technology Council, 1991),

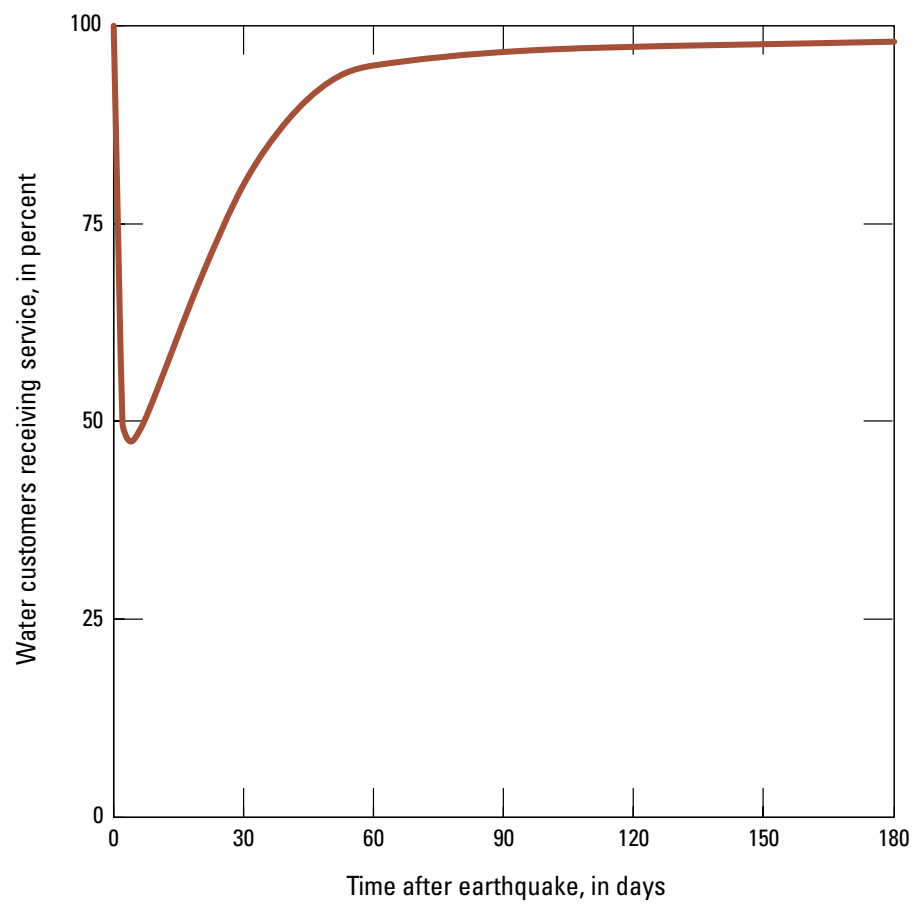

Figure 1. Graph showing water-restoration timeline in the ShakeOut scenario-a hypothetical magnitude-7.8 earthquake on the southern San Andreas Fault-for water customers in areas that experienced shaking of Modified Mercalli Intensity VIII or higher (modified from Jones and others, 2008). 
Scawthorn and others (1992), Hazus-MH (Federal Emergency Management Agency, 2012), the Mid-America Earthquake Center's seismic loss estimation system MAEViz (Mid-America Earthquake Center, 2006), and Marconi (Prashar and others, 2012) all use such an approach. The last three implement their methodologies in software, as do many others. In the case of Hazus-MH, the software assumes that a water main exists under each street, 80 percent of pipes are brittle (such as cast iron), and 20 percent of pipes are ductile (such as ductile iron). MAEViz and Marconi allow the user to specify the location and characteristics of each pipe segment. Neither Hazus-MH, MAEViz, nor Marconi performs hydraulic analysis. MAEViz and Marconi estimate damage. Hazus-MH estimates damage and estimates repair costs and system restoration time using methods described later.

Khater and Grigoriu (1989) describe an analytical model of water-supply damage and serviceability that does perform hydraulic analysis. Coded in software called GISALLE, it involves three tasks - (1) generate damage states for water-system components consistent with the seismic intensity at the site, (2) perform hydraulic analysis for simulated damage state of the system, and (3) develop statistics on the available water flow for postulated levels of seismic intensity.

Some of the available software, such as MAEViz and Urban Infrastructure and Lifelines Interactions of Systems (UILLIS) (Javanbarg and Scawthorn, 2012), have the ability to treat lifeline interaction - how damage or loss of function in one lifeline system affects the functionality or restoration of another. For example, loss of power and limitations in fuel supply can affect the functionality of a water-supply system or delay repairs. These programs use a system-of-systems approach to modeling the lifelines. That is, they model two or more lifelines in the same framework, relating the condition of an element of one lifeline to the condition of an element in another.

\section{Damageability of Buried Pipe}

The first step of a water-network resilience analysis once a ground-motion map has been developed is to estimate damage. Many authors have written extensively about the damageability of buried pipe, only some of this work is discussed here.

\section{Vulnerability and Fragility Functions}

As used here, a vulnerability function relates the degree of damage - in this case, number of breaks or leaks per unit length of pipeline - as a function of the degree of environmental excitation such as peak ground velocity (PGV). A fragility function by contrast measures the probability of reaching or exceeding some undesirable state conditioned on the degree of environmental excitation. The terminology is not universal but will be consistently applied here.

In the present context, vulnerability functions are most useful for estimating the number of breaks and leaks in a pipeline network subjected to ground shaking (usually referred to as wave passage in the pipeline literature), landsliding, and liquefaction.
However, at a fault crossing, a fragility function is more usefulhere, I am interested in the probability that a pipeline requires repair at the point where it crosses the fault, as a function of the fault offset and possibly as a function of the angle at which the pipeline crosses the fault. Both vulnerability functions and fragility functions are commonly conditioned on the pipeline's engineering attributes, such as material, diameter, connections at joints, and sometimes soil conditions.

\section{Hazus-MH, O'Rourke and Ayala (1993), and Honneger and Eguchi (1992)}

The Hazus-MH computer software (Federal Emergency Management Agency, 2012) currently uses a vulnerability function for pipeline subjected to wave passage by O'Rourke and Ayala (1993) and one for pipe in liquefied soil from Honegger and Eguchi (1992). The median rates of repairs per kilometer of pipeline for these two relations are given by equations 1 and 2, respectively:

$$
\begin{gathered}
\hat{R}=0.0001 \times K \times P G V^{2.25}, \\
\bar{R}=P_{\mathrm{L}} \times K \times P G D^{0.56},
\end{gathered}
$$

where $P_{\mathrm{L}}$ denotes the probability of liquefaction; $K=1.0$ for asbestos cement, concrete, and cast-iron pipe; $K=0.3$ for steel, ductile iron, and PVC; $P G V$ denotes peak ground velocity measured in centimeters per second $(\mathrm{cm} / \mathrm{s})$; and $P G D$ denotes permanent ground deformation - the absolute distance a point on the ground permanently moves due to landsliding, fault offset, or liquefaction-induced ground failure - measured in inches. Equation 1 draws on a number of observed repairs in asbestos cement, concrete, cast iron, and prestressed concrete pipe, with diameters between 3 and 72 inches, in four U.S. and two Mexican earthquakes experiencing ground motion of as much as $50 \mathrm{~cm} / \mathrm{s}$ of peak ground velocity. (O'Rourke and Ayala, 1993, do not publish the number of repairs or the lengths of pipe.) O'Rourke and Ayala's (1993) data for equation 1 imply a coefficient of variation in the ratio of observed to estimated repair rate of 0.76 and a ratio of mean repair rate to median repair rate of 1.22 .

The work by Honneger and Eguchi (1992) used to develop equation 2 reflects an unknown quantity of pipe and number of breaks and leaks. Their data mostly come from four earthquakes - 1923 Kanto (Japan), 1971 San Fernando (California), 1976 Tangshan (China), and 1985 Michoacán (Mexico). Pipe diameters range from 4 inches to 48 inches. Materials included cast iron, concrete, precast concrete, and steel.

\section{Eidinger (2001)}

More recently, Eidinger (2001) proposed two vulnerability functions - one for wave passage (that is, ground shaking absent liquefaction) and one for permanent ground deformation (that is, in the presence of liquefaction or landslide-induced ground 
displacement). Equations 3 and 5 present Eidinger's recommended vulnerability functions.

In the equations, $R_{\mathrm{w}}(\mathrm{PGV}, p)$ and $R_{\mathrm{l}}(P G D, p)$ denote repair rate per 1,000 linear feet of pipe associated with nonexceedance probability $p$, as a result of wave passage and liquefaction, respectively. For example, the median repair rate is estimated using $p=0.5$. $P G V$ refers to geometric mean horizontal peak ground velocity in inches per second, $P G D$ denotes permanent ground displacement relative to pre-earthquake location, measured in inches, and $\Phi^{-1}(p)$ denotes the inverse standard normal cumulative distribution function evaluated at $p$.

For the reader who is unfamiliar with probability distributions, the standard normal distribution is the bell-shaped curve that represents how likely are various possible values of an uncertain quantity. Uncertain or random variables can take on a variety of probability distributions; the standard normal distribution is one of many. It has a peak (the expected or mean value and also the value with 50-percent probability of not being exceeded, called the median) at 0 . Its standard deviation (a measure of how wide the bell is, and therefore how uncertain is the random quantity) is 1.0. Its cumulative distribution function is an S-shaped curve that tells the probability that a sample of a quantity with a standard normal distribution takes on a value less than or equal to any given quantity between $-\infty$ and $\infty$. The inverse of the standard normal cumulative distribution function is the value of the uncertain quantity that has a specified probability of not being exceeded. Most statistics textbooks provide more information about probability distributions (see, for example, Ang and Tang, 1975, or Benjamin and Cornell, 1970).

The quantities $K_{1}$ and $K_{2}$ are factors to account for pipe material, joints, soil corrosivity, and pipe diameter - either small
(4 to 12 inches diameter) or large (16-inch diameter or greater). See table 1 for their values. Eidinger (2001) does not provide values for some combinations, so they appear blank in the table. The authors acknowledge that permanent ground displacement produces damage rates two orders of magnitude greater than wave passage and that damage rate in areas with ground failure is fairly insensitive to PGD.

The terms $\exp \left(\beta \times \Phi^{-1}(p)\right)$ in equations 3 and 5 reflect that the equations treat the repair rate as uncertain and lognormally distributed conditioned on the value of PGV or PGD.

(Lognormal is like normal, except that the natural logarithm of the uncertain quantity in question is normally distributed. A lognormal variable can take on any positive value but not zero or a negative number. The bell shape is skewed to the right.) Setting $p$ to 0.5 sets the exp term to 1.0 and makes $R(p)$ produce the median (not the mean) repair rate. The mean repair rate would be substantially higher than the median. Equations 4 and 6 provide the mean (average) repair rate, given Eidinger's values of $\beta$ shown in equations 3 and 5 and Eidinger's assumption of lognormality. The interested reader who is unfamiliar with lognormally distributed variables can refer to any of several common textbooks (see, for example, Ang and Tang, 1975). The interested reader who is unfamiliar with vulnerability functions can refer to Porter (2017a) for a short primer.

Equation 3 gives Eidinger's (2001) pipe vulnerability function for wave passage, drawn from 81 sources reporting 3,350 repairs recorded in 12 earthquakes. The plurality of data come from the $M_{\mathrm{w}} 6.71994$ Northridge (California) earthquake. The data reflect 38 data points for damage to cast iron, 13 data points for damage to steel, 10 data points for damage to asbestos

Table 1. Eidinger (2001) pipe-vulnerability equation factors $K_{1}$ and $K_{2}$, which account for pipe material, joints, soil corrosivity, and pipe diameter.

\begin{tabular}{|c|c|c|c|c|c|c|}
\hline ID & Pipe material & Joint type & Soils & Diameter & $K_{1}$ & $K_{2}$ \\
\hline 1 & Cast iron & Cement & All & Small & 1.0 & 1.0 \\
\hline 2 & Cast iron & Cement & Corrosive & Small & 1.4 & 1.0 \\
\hline 3 & Cast iron & Cement & Noncorrosive & Small & 0.7 & 1.0 \\
\hline 4 & Cast iron & Rubber gasket & All & Small & 0.8 & 0.8 \\
\hline 5 & Cast iron & Mechanical restrained & All & Small & $0.7^{1}$ & 0.7 \\
\hline 6 & Welded steel & Lap-arc welded & All & Small & 0.6 & 0.15 \\
\hline 7 & Welded steel & Lap-arc welded & Corrosive & Small & 0.9 & 0.15 \\
\hline 8 & Welded steel & Lap-arc welded & Noncorrosive & Small & 0.3 & 0.15 \\
\hline 9 & Welded steel & Lap-arc welded & All & Large & 0.15 & 0.15 \\
\hline 10 & Welded steel & Rubber gasket & All & Small & 0.7 & 0.7 \\
\hline 11 & Welded steel & Screwed & All & Small & 1.3 & 1.31 \\
\hline 12 & Welded steel & Riveted & All & Small & 1.3 & 1.31 \\
\hline 13 & Asbestos cement & Rubber gasket & All & Small & 0.5 & 0.8 \\
\hline 14 & Asbestos cement & Cement & All & Small & 1.0 & 1.0 \\
\hline 15 & Concrete with steel cylinder & Lap-arc welded & All & Large & 0.7 & 0.6 \\
\hline 16 & Concrete with steel cylinder & Cement & All & Large & 1.0 & 1.0 \\
\hline 17 & Concrete with steel cylinder & Rubber gasket & All & Large & 0.8 & 0.7 \\
\hline 18 & PVC & Rubber gasket & All & Small & 0.5 & 0.8 \\
\hline 19 & Ductile iron & Rubber gasket & All & Small & 0.5 & 0.5 \\
\hline
\end{tabular}

${ }^{1}$ Assumed here because no $K$-value is offered by the source. 
cement, 9 data points for damage to ductile iron, and 2 data points for damage to concrete. Data reflect PGV values between 2 and $52 \mathrm{~cm} / \mathrm{s}$.

$$
\begin{aligned}
R_{\mathrm{w}}(P G V, p)= & K_{1} \times 0.00187 \times P G V \times \exp \left(1.15 \times \Phi^{-1}(p)\right), \\
& \bar{R}_{\mathrm{w}}(P G V)=K_{1} \times 0.003623 \times P G V .
\end{aligned}
$$

Equations 5 and 6 give Eidinger's (2001) pipe vulnerability function for permanent ground deformation, drawn from 42 data points from 4 earthquakes between the $M_{\mathrm{w}} 7.81906$ San Francisco earthquake and the $M_{\mathrm{w}} 6.71989$ Loma Prieta earthquake. The plurality of data points come from the $M_{\mathrm{w}} 7.81983$ NihonkaiChubu (Japan) earthquake. The plurality of pipe material is asbestos cement (20 data points) followed by cast iron (17 data points), and a mixture of cast iron and steel — presumably meaning that the material was one or the other, but it is not known which ( 5 data points). None of the data appear to reflect ductile iron. They reflect PGD values between 0 and 110 inches. In these two equations, $R_{1}(P G D, p)$ denotes the liquefaction-induced damage rate associated with nonexceedance probability $p$, and $\bar{R}_{1}(P G D)$ denotes the expected value of the liquefaction-induced damage rate:

$$
\begin{aligned}
R_{1}(P G D, p)= & K_{2} \times 1.06 \times P G D^{0.319} \times \exp \left(0.74 \times \Phi^{-1}(p)\right), \\
& \bar{R}_{1}(P G D)=K_{2} \times 1.39 \times P G D^{0.319}
\end{aligned}
$$

Eidinger (2001) also proposed models for damage to pipe that crosses an earthquake fault - one for continuous pipelines (equation 7) and one for segmented pipe (equation 8). In the equations, $P G D$ denotes mean offset (in inches, in.) over the entire length of the fault, presumably at the fault trace rather than averaged over the area of the fault, and presumably considering coseismic slip and afterslip. In the equations, $\bar{P}$ denotes the probability that the pipe crossing the fault will break:

$$
\begin{aligned}
\bar{P} & =0.70 \times \frac{P G D}{60 \text { in. },} \\
& \leq 0.95
\end{aligned}
$$

$$
\begin{aligned}
\bar{P} & =0 & & P G D<1 \mathrm{in.} \\
& =0.5 & & 1 \text { in. } \leq P G D \leq 12 \text { in. } \\
& =0.8 & & 12 \text { in. }<P G D \leq 24 \text { in. } . \\
& =0.95 & & 24 \text { in. }<P G D
\end{aligned}
$$

\section{O'Rourke and others (2014)}

O'Rourke and others (2014) offer vulnerability functions for the median repair rate per kilometer of asbestos cement or cast-iron pipes subjected to wave passage. They draw on data about 2,051 repairs in 3,400 kilometers (km) of pipe in the $M_{\mathrm{w}} 6.2$ February 22, 2011, Christchurch, New Zealand, earthquake and the $M_{\mathrm{w}} 6.0$ June 13, 2011, Christchurch earthquake. The majority of pipe length in the database was asbestos cement, but the data also included cast iron, PVC, modified PVC, and unnamed other materials. The data were drawn from locations with PGV between 10 and $80 \mathrm{~cm} / \mathrm{s}$. Their vulnerability functions are given by equations 9 and 10 :

$$
\begin{gathered}
\log _{10}\left(R_{\mathrm{AC}}\right)=2.83 \times \log _{10}(G M P G V)-5, \\
\log _{10}\left(R_{\mathrm{CI}}\right)=2.38 \times \log _{10}(G M P G V)-4.52,
\end{gathered}
$$

where $R_{\mathrm{AC}}$ denotes the median repairs per kilometer of asbestos cement pipe, $R_{\mathrm{CI}}$ is the analogous value for cast-iron pipe, and according to the authors, "GMPGV is the mean of the natural logs of the two maximum horizontal peak ground velocity (PGV) values taken from ground motion recordings available from GNS Science ... at each station.” Despite that definition of GMPGV, the authors seem actually to mean the geometric mean of the peak ground velocity values in centimeters per second of the two horizontal orthogonal components. (The inverse of the natural logarithm of the mean of the natural logarithms of two quantities equals their geometric mean.) They offer vulnerability functions for pipe subjected to liquefaction, where the ground deformation is measured in terms of (1) the larger principal component of ground strain in the horizontal plane and (2) the rotation of the axis of the pipe about a horizontal axis normal to the axis of the pipe, which the authors call angular distortion - essentially a differential permanent vertical displacement of two points on the pipe axis, divided by the distance between the two points.

\section{O’Rourke (2003)}

There does not appear to exist any empirical relation between fault offset and probability of pipeline damage. A few authors offer analytical formulations between offset and stress or strain in a pipeline that crosses a fault. O'Rourke (2003) summarizes some of these, considering under two conditions that depend on the geometry of the pipeline at the fault crossing - (1) a combination of bending and axial tension and (2) a combination of bending and axial compression. For the former, he illustrates a relation between tolerable fault offset as a function of distance between points at which the pipeline is anchored on either side of the fault (which he refers to as "unanchor length"; see fig. $2 A$ ) and the angle $\beta$ subtended by the fault and the pipeline, in which the offset puts the pipeline in tension. Figure $2 A$ is merely an illustration for a particular pipe material and diameter. He offers a second analytical relation (fig. $2 B$ ) for segmented pipe subject to fault offset, again for fault-crossing geometry where offset puts the pipe into tension. 

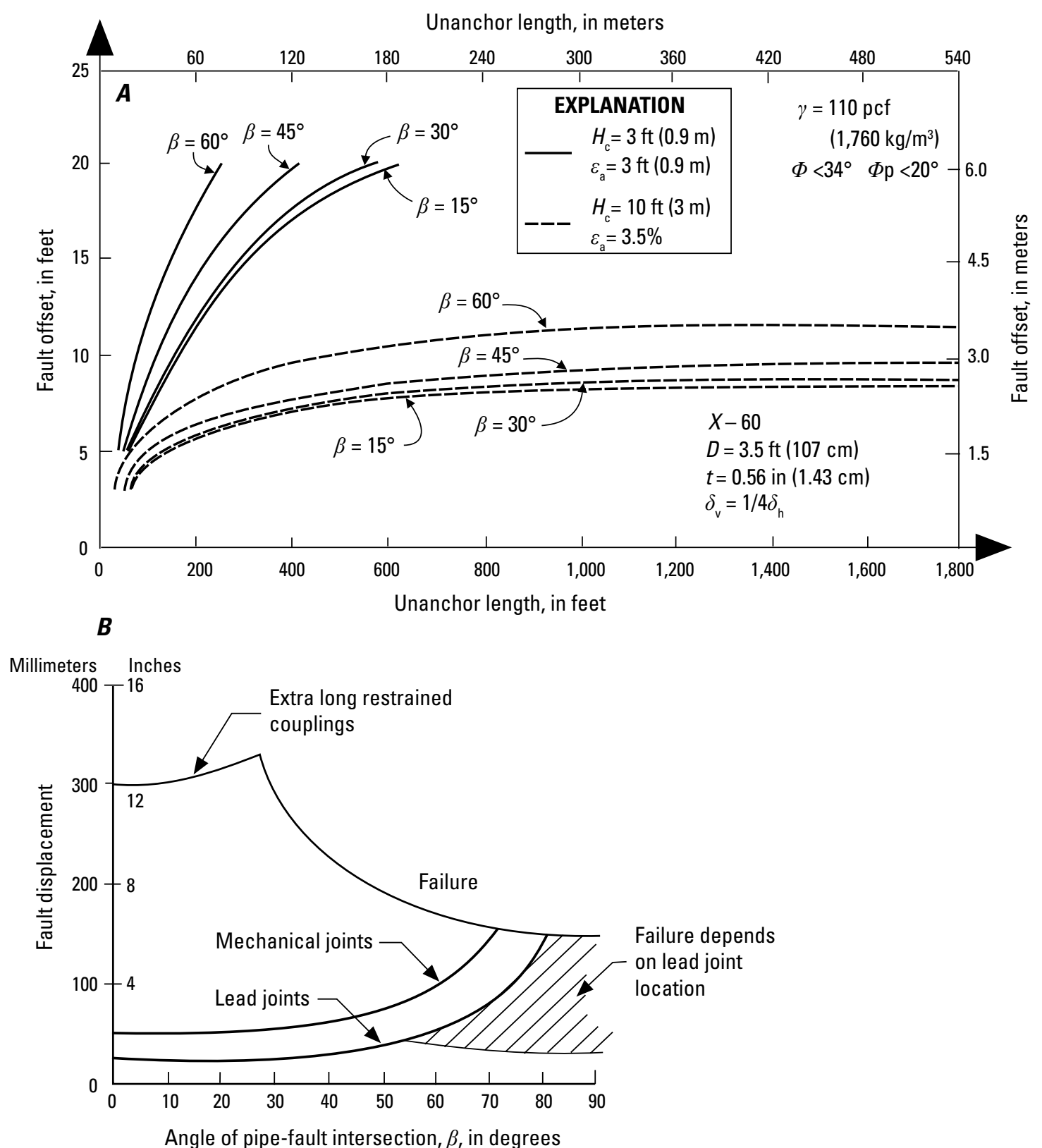

Figure 2. Graphs showing $(A)$ tolerable fault offset versus unanchor length in continuous pipe (O'Rourke 2003, citing Kennedy and others, 1977) and (B) tolerable fault offset versus pipe-fault intersection angle in segmented pipe (O'Rourke 2003, citing O'Rourke and Trautmann, 1980). (Images modified from O'Rourke 2003.) mm, millimeters; $\mathrm{cm}$, centimeters; $\mathrm{m}$, meters; in, inches; $\mathrm{ft}$, feet; \%, percent; $\mathrm{kg} / \mathrm{m}^{3}$, kilograms per cubic meter; $X-60$, grade of pipe material; $\varepsilon_{\mathrm{a}^{\prime}}$ maximum axial strain due to the elongation of the pipe induced by the fault offset; $\beta$, angle at which the pipeline intersects a right lateral strike-slip fault; $\gamma$, effective unit weight of soil; $D$, pipe diameter; $t$, pipe wall thickness; $\delta_{\mathrm{V}^{\prime}}$ vertical component of fault offset; $\delta_{\mathrm{h}^{\prime}}$ horizontal component of fault offset; $H_{\mathrm{c}}$, burial depth from ground surface to top of pipe; $\Phi$, soil internal friction angle; $\Phi_{\mathrm{p}^{\prime}}$ contact friction angle. 


\section{Tasks and Methods to Repair Leaks and Breaks}

The City of Winnipeg (2014) in Canada offers a list of tasks to repair a water main break or leak, written for the general public. The tasks are shown in chronological order in the lefthand column of table 2 . The task list is generally consistent with a more detailed checklist created by the American Water Works Association (2009), although it omits lists of tools, equipment, disinfecting chemicals, documentation, and testing materials. Column 2 of table 2 lists my interpretation of rate-limiting factors, that is, prerequisites for each task. The rate-limiting factors are mostly potential impacts from other lifelines, that is, lifeline interactions. If they are unavailable, repairs cannot proceed or they proceed more slowly - that is, their rate is limited. These items include communications, electricity, fuel, site safety (that is, no fire or hazardous material release), roadway access, repair crews, and repair supplies (replacement pipe, replacement fittings, clamps, and paving materials). Regarding crew availability, public and private water agencies plan to provide mutual assistance for emergencies (see, for example, California Water/Wastewater Agency Response Network, CalWARN, 2009). Crews may have to travel from great distances, hundreds of miles or more, so their availability can change over time. Table 2 probably omits tasks that are unnecessary or trivial for day-to-day repairs but become significant in a large earthquake. For example, a water agency may also have to arrange repair contracts with contractors, track and prioritize repairs, and manage an unusually large number of repair crews operating simultaneously.

Lund and Schiff (1991) surveyed operators of pipeline utilities, asking them to provide detailed information about each pipeline failure they repaired after the 1989 Loma Prieta earthquake (see fig. 3 for the survey form). The resulting database includes information about 862 pipeline failures among 65 water, sewer, drainage, and gas agencies. The data may be useful for estimating repair times, so I extracted the following statistics from the database.
- Burial depth -Among 67 records with reported burial depth, the average was 4.0 feet (ft) and the standard deviation was $2.2 \mathrm{ft}$.

- Break or leak -Among the failures where the respondent indicated whether the failure was a break or a leak, it was more common for the pipeline to break (336 failures) than to leak (140 failures).

- Pipe failure modes-Among pipe failures, the most common were circumferential cracks (99), followed by splits (43) and corrosion (33). Only one blowout was reported.

- Joint failure modes -Almost as common as pipe failures were joint failures (102 pulled, 29 cracks at joints, 25 gasket failures, and 12 other joint failures).

- Fitting failure modes - There were a variety of fitting failures (57 threaded couplings, 9 elbows, 6 offsets, 4 hydrants, 3 tees, and 45 miscellaneous other fitting failures).

- Repair methods - The most common repair method was to replace the damaged element (185 replacements), which was more than twice the number of clamps installed (77), followed by mechanical couplings (50), epoxy glue (16), and miscellaneous others such as flex couplings and pressure grout.

\section{Time to Repair Pipe Leaks and Breaks}

To repair damaged water-supply pipe, a repair crew must locate the damage, usually eliminate pressure in the pipe by closing an upstream valve, excavate the damaged element (usually with a backhoe), perform the repair, reopen the upstream valve, backfill the excavation, and repave any driving surface over the

Table 2. Water-pipeline repair tasks (City of Winnipeg, 2014), with an interpretation of rate-limiting factors for repairs after an earthquake.

\begin{tabular}{|c|c|}
\hline Tasks & Rate-limiting factors \\
\hline Receive a notice from our 311 Centre about a water main break. & Communications, electricity \\
\hline Dispatch a crew to the location. & Fuel, site safety (for example, no fire), roadway access, crew availability \\
\hline $\begin{array}{l}\text { Contact other utilities to make sure that we can dig without damaging } \\
\text { other services or endangering staff or the public. }\end{array}$ & Communications \\
\hline Dig down to the water main and confirm the cause of the leak. & Fuel \\
\hline $\begin{array}{l}\text { Repair the water main. Depending on the type of break, we may apply a } \\
\text { repair clamp or replace a length of pipe. }\end{array}$ & Pipe, fitting, or repair hardware such as clamps \\
\hline \multicolumn{2}{|l|}{$\begin{array}{l}\text { Open valves to turn the water main back on, flush the water main and } \\
\text { sample water quality. }\end{array}$} \\
\hline
\end{tabular}




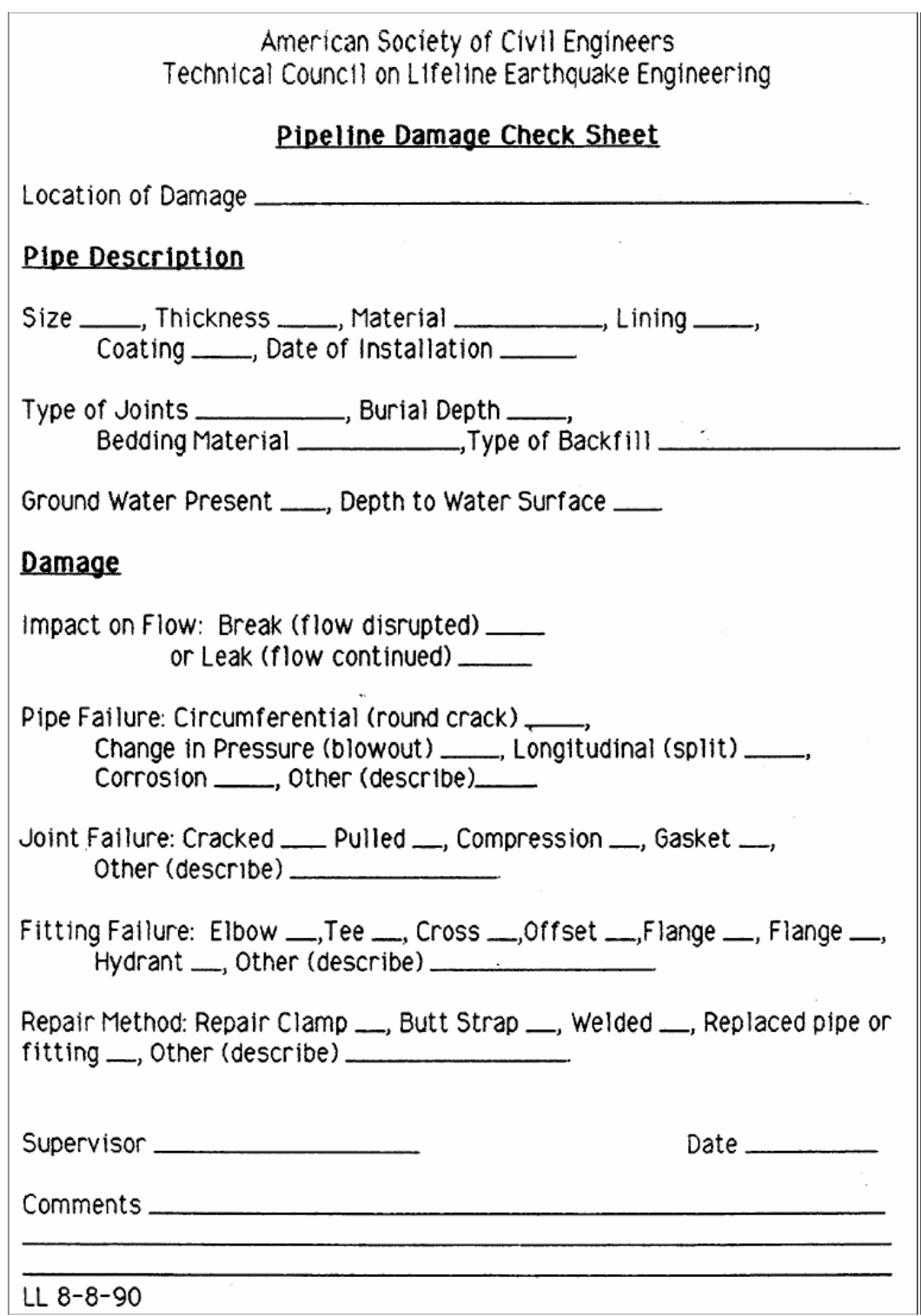

Figure 3. Image of Lund and Schiff (1991) survey form given to operators of pipeline utilities, asking them to provide detailed information about each pipeline failure they repaired after the moment-magnitude-6.7 1989 Loma Prieta, California, earthquake. location of the repair. Pipe damage can be repaired by replacing the damaged element, by welding over the crack, or by installing repair hardware - generally either a clamp that is mechanically secured over the damage or a closure ring called a butt strap that is welded to the outside of the pipe over the damage. The time required to perform the repair depends on several issues:

- How long it takes people to report the damage to the utility or otherwise for the utility to become aware of and locate the damage, which itself depends on power and communication;

- Site accessibility;

- Availability of crews and equipment;

- Availability of fuel and consumable repair material;

- Pipe burial depth;
- Groundwater presence and depth;

- Diameter, material, and jointing of the pipe;

- Impact on water flow (break or leak);

- Nature of the damaged element—whether to pipe, joint, or fitting;

- If pipe, whether circumferential crack, longitudinal split, corrosion, or other such failure;

- If joint, whether a crack, pull-out, compression failure, gasket failure, or other such failure; and

- If fitting, the nature of the fitting (such as elbow, tee, cross, offset).

Schiff (1988) offers repair times for 21 individual water-pipe repairs after the $M_{\mathrm{w}} 5.91987$ Whittier Narrows earthquake in 
southern California, mostly of cracks and breaks in 4- to 8-inch steel and cast-iron mains. Repair times were reported by the City of Whittier water distribution superintendent. Times varied between 1 and 16 hours, as shown in table 3. Schiff reports that water pressure in Whittier dropped to 50 pounds per square inch (psi) from the normal 80 to $100 \mathrm{psi}$ as a result of 40 repairs in 133 miles of pipe (or 0.06 repairs per 1,000 linear feet of pipe).

EBMUD reports on its mutual assistance to the City of Napa after the August 24, 2014, magnitude ( $M$ ) 6.0 South Napa earthquake (East Bay Municipal Utility District, 2014). EBMUD crews performed 56 repairs in approximately 252 crew-hours, for an average duration of 4.5 hours per repair. It should be noted that this average duration for completing repairs does not reflect the time it took for the City of Napa or its contractors to complete the excavation and backfill (EBMUD crews focused on repair work and did not complete excavation/backfill/paving-related work).
Tabucchi and others (2010) elicited opinions from personnel at the Los Angeles Department of Water and Power (LADWP) on water-pipe repair productivity. They propose a model with triangular probability distributions for each of several repair operations. Each distribution is characterized by a minimum value (the left end of the triangle), a modal value (the peak of the triangle, which is the most likely value), and a maximum value (the right end of the triangle). Table 4 repeats LADWP's estimates. Distribution-system leak and break repairs are estimated to require no less than 3 hours and no more than 12 hours with modes of 4 to 6 hours.

Hazus-MH (Federal Emergency Management Agency, 2012) employs four restoration times for pipe repair- two each for large and small diameter pipes (20-inch diameter and above is large, 12-inch diameter or less is small) times two to distinguish between breaks and leaks (see table 5).

Table 3. Repair times for water-supply pipeline damage in the moment magnitude $\left(M_{\mathrm{w}}\right) 5.91987$ Whittier Narrows Earthquake and $M_{\mathrm{w}} 5.2$ aftershock in southern California (modified from Schiff, 1988).

[CI, concrete insert, RC, reinforced concrete; --, no data]

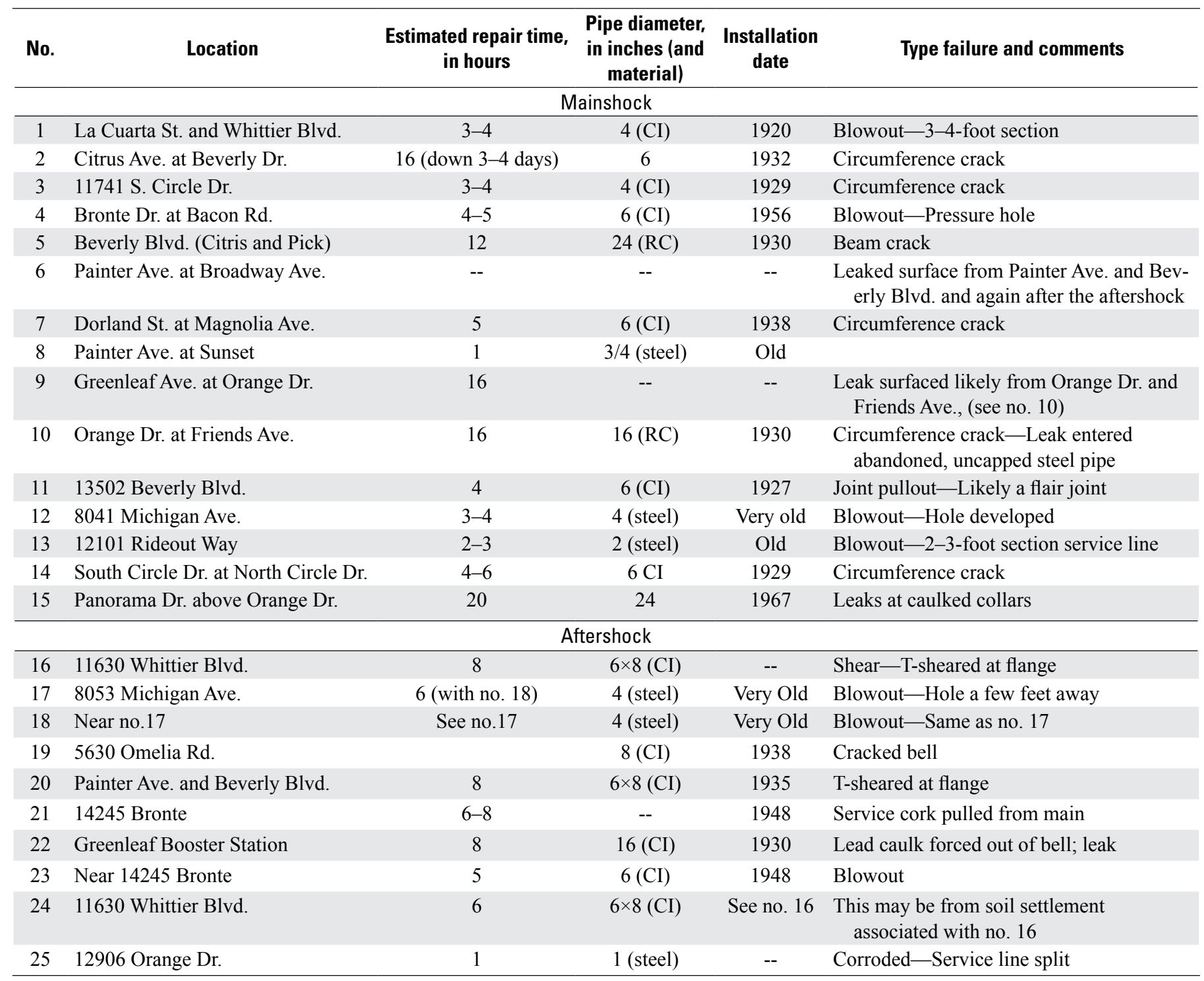


Table 4. Los Angeles Department of Water and Power (LADWP) water-pipe repair productivity estimates (modified from Tabucchi and others, 2010). [MWD, Metropolitan Water District; hr, hour; km, kilometer]

\begin{tabular}{|c|c|c|c|}
\hline Event & Minimum & Mode & Maximum \\
\hline \multicolumn{4}{|c|}{ Inspect a: } \\
\hline Trunk or distribution damage location & $0.5 \mathrm{hr}$ & $0.5 \mathrm{hr}$ & $1 \mathrm{hr}$ \\
\hline Pump station & $1 \mathrm{hr}$ & $1 \mathrm{hr}$ & $2 \mathrm{hr}$ \\
\hline Tank & $1 \mathrm{hr}$ & $1 \mathrm{hr}$ & $2 \mathrm{hr}$ \\
\hline Small reservoir & $2 \mathrm{hr}$ & $2 \mathrm{hr}$ & $3 \mathrm{hr}$ \\
\hline Trunk redundancy (minor) ${ }^{1}$ & $3 \mathrm{hr}$ & $4 \mathrm{hr}$ & $8 \mathrm{hr}$ \\
\hline Connecting to $\mathrm{MWD}^{1}$ & $3-4 \mathrm{hr}$ & $6 \mathrm{hr}$ & $8-12 \mathrm{hr}$ \\
\hline Connecting to well ${ }^{1}$ & $4-6 \mathrm{hr}$ & $6-8 \mathrm{hr}$ & $8-12 \mathrm{hr}$ \\
\hline Using a fire truck ${ }^{1}$ & $1-2 \mathrm{hr}$ & $2-3$ days & 3-4 days \\
\hline Isolate distribution damage at one demand node & $1 \mathrm{hr}$ & $2 \mathrm{hr}$ & $4 \mathrm{hr}$ \\
\hline Trunk leak & 4 days & 4 days & 6 days \\
\hline Trunk break & 6 days & 8 days & 10 days \\
\hline Travel a distance $D(\mathrm{~km})$ & $D / 25 \mathrm{hr}$ & $D / 40 \mathrm{hr}$ & $D / 80 \mathrm{hr}$ \\
\hline
\end{tabular}

${ }^{1}$ Major trunk lines are the pipelines that are the sources for each of the 13 LADWP subsystems; minor trunk lines are the remaining ones. Task duration for major trunk line rerouting operations vary by specific trunk line, as listed in Tabucchi and Davidson (2008).

Table 5. Hazus-MH estimates of repair time per pipe repair as a result of earthquake (modified from Federal Emergency Management Agency, 2012).

\begin{tabular}{|c|c|c|c|c|c|}
\hline Diameter from, in inches & Diameter to, in inches & $\begin{array}{c}\text { Number of fixed breaks } \\
\text { per day per worker }\end{array}$ & $\begin{array}{l}\text { Number of fixed leaks } \\
\text { per day per worker }\end{array}$ & $\begin{array}{c}\text { Number of } \\
\text { available workers }\end{array}$ & Priority \\
\hline 60 & 300 & 0.33 & 0.66 & User specified & 1 (highest) \\
\hline 36 & 60 & 0.33 & 0.66 & User specified & 2 \\
\hline 12 & 20 & 0.50 & 1.0 & User specified & 4 \\
\hline 8 & 12 & 0.50 & 1.0 & User specified & 5 (lowest) \\
\hline
\end{tabular}

Seligson and others (1991) offer an empirical relation for time required to restore water service as a function of number of pipeline repairs per square mile, based on evidence from two earthquakes in southern California, the $M_{\mathrm{w}} 6.71971$ San Fernando and $M_{\mathrm{w}} 5.91987$ Whittier earthquakes. In equation 11, $B$ denotes repairs per square mile and $d$ denotes number of days of watersupply outage:

$$
\begin{aligned}
d & =2.18+2.51 \times \ln B & & B>0.42 \\
& =0 & & B \leq 0.42
\end{aligned} .
$$

\section{Serviceability of Water Supply}

As previously noted, some analytical models are capable of modeling the serviceability of a damaged water-supply system using hydraulic or connectivity analysis (see, for example, Khater and Grigoriu, 1989). As in the case of the closely related Life Line Earthquake Engineering (LLEQE) software, the Applied Technology Council (1991) noted that such systems can be data intensive and computationally demanding. What can be done to estimate water-supply serviceability without a hydraulic model?

Isoyama and Katayama (1982) proposed to measure a quantity they called serviceability as the probability that the demand at a system node (such as a customer-service connection) is fully satisfied, or in the aggregate, the average fraction of nodes in the entire system whose demand is fully satisfied. Demand seems to mean the pre-earthquake consumption plus postearthquake leakage.

Markov and others (1994) propose to measure serviceability using a serviceability index, $S_{\mathrm{S}}$ defined as the ratio of the total available flow to the total required flow, 
which is similar but not identical to Isoyama and Katayama's serviceability. If demand at 10 nodes were fully satisfied and demand at 10 other nodes were partially satisfied, the two measures of serviceability would take on different values -0.5 in the case of Isoyama and Katayama (1982) and somewhat higher in the case of Markov and others (1994).

The developers of the Hazus-MH water system use data from Isoyama and Katayama (1982) and Markov and others (1994) to propose to estimate the serviceability index, $s(r)$, as a function of break rate (breaks, not leaks, per km of service main pipe) using equation 12 . They seem to use the serviceability index to measure the fraction of customers receiving any water service, because the software expresses loss of serviceability in terms of "households without water":

$$
s(r)=1-\Phi\left(\frac{\ln ((r / L) / q)}{b}\right) .
$$

In equation 12 , ln denotes natural logarithm, $r / L$ denotes the average break rate ( $r$ main breaks per $L$ kilometer of pipe), $q$ and $b$ are model parameters, and $\Phi$ is the standard normal cumulative distribution function (the $y$-value of the S-shaped curve in $x-y$ space that depicts the probability that an uncertain quantity with standard normal distribution will take on a value less than or equal to $x$ ). Hazus-MH employs values of $q=0.1$ and $b=0.85$, respectively, fitting the curve to Isoyama and Katayama's (1982) modeling of Tokyo's water-supply system, Markov and others (1994), modeling of the San Francisco Auxiliary Water-Supply System (a dedicated firefighting system), and analyses of EBMUD's water-supply system. Hazus-MH's serviceability model is illustrated in figure 4, in the curve labeled "NIBS."

Thus, the Hazus-MH serviceability index might measure:

- The fraction of service connections receiving preearthquake flows, regardless of the degree of postearthquake flow received at other service connections, which would seem to be consistent with Isoyama and Katayama's (1982) serviceability;

- The fraction of pre-earthquake flow being delivered after the earthquake, consistent with Markov and others (1994); or

- The fraction of service connections receiving any water, as the Hazus-MH reports indicate.

Lund and others (2005), citing Kobe, Japan, Municipal Waterworks Bureau's M. Matsushita, present a restoration curve for the Kobe water system after the $M_{w} 6.91995$ Kobe earthquake. Tabucchi and Davidson (2008) offer an analogous plot for the restoration of water service in the San Fernando Valley after the 1994 Northridge earthquake. The two restoration curves are shown in figure 5. Restoration after Northridge appears fairly linear; Kobe less so.

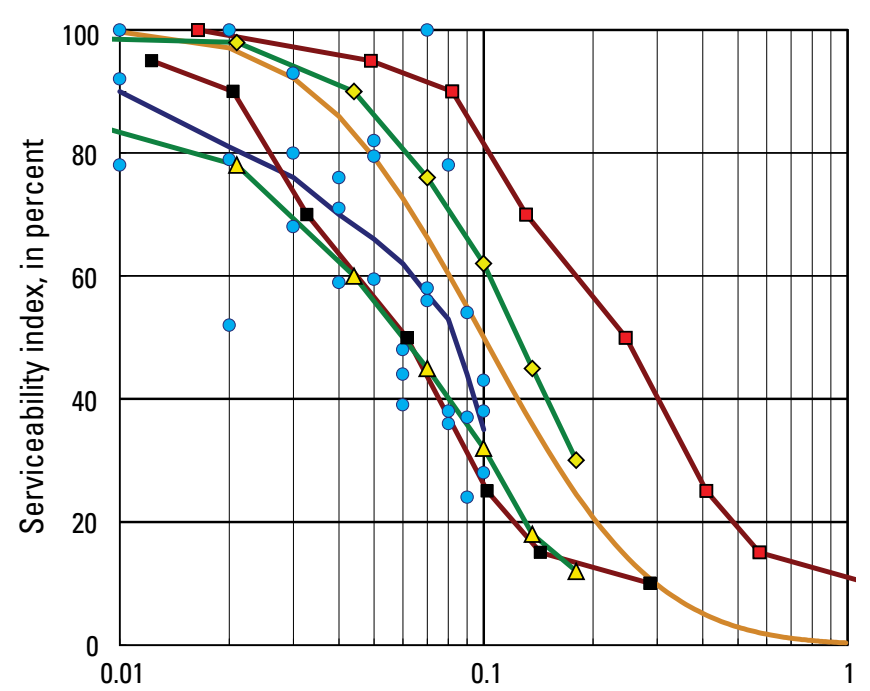

Average break rate, in breaks per kilometer

\section{EXPLANATION}

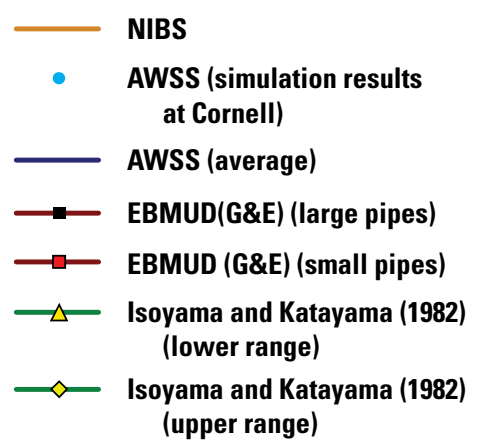

Figure 4. Graph showing Hazus-MH (Federal Emergency Management Agency, 2012) water-pipe serviceability model and other models of water-pipe serviceability. Hazus-MH uses the curve labeled "NIBS." AWSS, San Francisco Auxiliary Water Supply System (Markov and others,1994); EBMUD, East Bay Municipal Utility District; G\&E, G\&E Engineering Systems, Inc.; NIBS, National Institute of Building Sciences (Federal Emergency Management Agency, 2012).

\section{Lifeline Interaction}

Many authors have characterized lifeline interaction after natural disasters. A few but not all relevant works are summarized here.

For ease of reference, I recall here some evidence previously noted - City of Winnipeg (2014) and American Water Works Association (2008) suggest that prerequisites for the repair of buried pipeline include cellular communications and electricity to learn about and coordinate repairs, fuel and roadway access to travel to and perform the repairs, site safety (especially that no fires, gas leaks, or electrical hazards are present), and consumable repair materials including pipe, fittings, repair hardware, and disinfecting chemicals. 


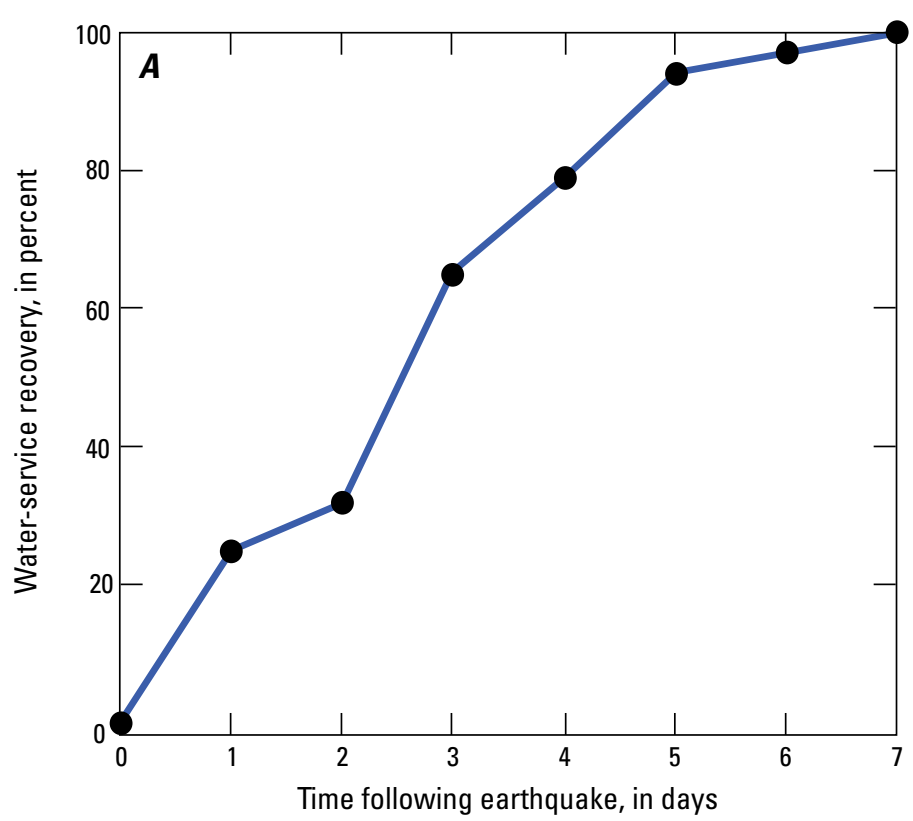

Nojima and Kameda (1991) compiled instances of lifeline interaction in the 1989 Loma Prieta earthquake, noting particularly the loss of wastewater treatment because of the loss of electricity, and the degradation of telecommunications resulting from the loss of electricity and difficulty acquiring fuel for central offices' emergency generators as a result of highway problems. See table 6 for a matrix summarizing lifeline interaction in the Loma Prieta earthquake. It shows that water supply was impaired for 18 hours in Santa Cruz because of loss of electric power for pumping. It also shows that electricity failure impaired EBMUD's Lafayette filtration plant and its Oakland control center. Repairs in Santa Cruz were also impaired by delays transporting repair equipment over the damaged Oakland-San Francisco Bay Bridge. In San Francisco and Santa Cruz, overloaded telecommunications impaired repair efforts.

Scawthorn (1993) reviews literature and then-recent disaster experience on lifeline interaction in several disasters (for example, 1989 Loma Prieta Earthquake and 1991 Oakland Hills firestorm in the east bay) to construct a model and analytical methodology for lifeline interaction. He points out that water supply in the 1991 Oakland Hills fire was impaired in part because of breakage of service connections in buildings that collapsed in the fire and the reliance of water supply on electric power to pumps stations that were required to resupply ridge-top tanks. He suggests characterizing lifeline interactions as (1) cross-impact (impact on one lifeline's function due to impairment of service to that lifeline by a second lifeline), (2) collocation (direct damage or impact on one lifeline's function due to failure of another lifeline in a very proximate location), or (3) cascade (increasing impacts on a lifeline due to initial inadequacies, such as water-supply damage as buildings collapse and sever service connections). In Scawthorn's (1993) quantitative model, one characterizes initial damage to a set of lifelines through a vector, $D$, of $n$ scalar quantities, each element

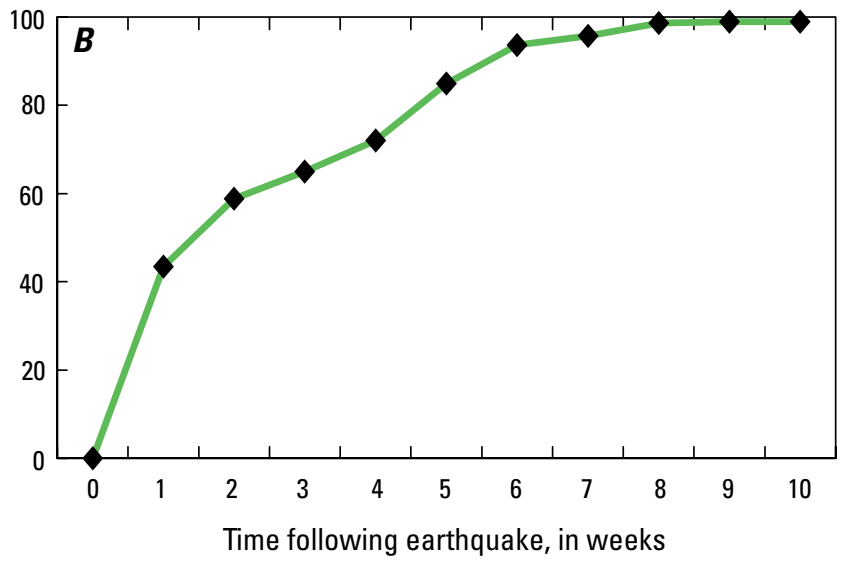

Figure 5. Graphs showing $(A)$ restoration of water service to customers experiencing outages after the moment magnitude $\left(M_{\mathrm{w}}\right) 6.71994$ Northridge, California, earthquake and $(B)$ after the $M_{\mathrm{w}} 6.91995$ Kobe, Japan, earthquake. $A$, Modified from Tabucchi and Davidson (2008); $B$, modified from Lund and others (2005).

representing a fraction of customers receiving service for one of $n$ lifelines if there were no interaction, that is, if only damage to that lifeline mattered. Lifeline interaction is quantified by an $n \times n$ matrix denoted by $L$, where element $L_{i, j}$ (row $i$, column $j$ ) denotes the fraction of service of lifeline $i$ that is contributed by lifeline $j$. A higher value of $L_{i, j}$ indicates greater reliance of lifeline $i$ service on lifeline $j$. A value $L_{i, j}=0$ indicates no interaction. The final functional state of the $n$ lifelines is represented by vector $F$, whose value is given by equation 13 . Element $i$ of vector $F$ measures the fraction of customers receiving service from lifeline $i$, where any reduction below $F_{i}=1.0$ is a result of initial damage $D$ to all the lifelines and interaction $L$ between them. Equation 13 is as follows:

$$
F=L \times D
$$

Scawthorn offers the model but does not propose particular values for matrix $L$. Note that, because $0 \leq D_{i} \leq 1.0$, to ensure that $0 \leq F_{i} \leq 1.0, L$ must be constrained per equation 14:

$$
\sum_{j=1}^{n} L_{i j}=1.0 \quad i \in\{1,2, \ldots n\} .
$$

The San Francisco Lifelines Council (2014) adapted the panel process of Porter and Sherrill (2011) to involve San Francisco Bay region lifeline operators in qualitatively characterizing the potential effects of lifeline interaction on the post-earthquake functionality of their systems. The authors sought to identify key assets and restoration schemes to prioritize postdisaster restoration and reconstruction activities for San Francisco and ultimately the entire region. Through panel discussion with 11 lifeline operators, the authors identified lifeline interaction effects in the context of a hypothetical M7.9 earthquake on the northern San Andreas Fault. They propose a qualitative interaction matrix (table 7) that describes modes of interaction similar to Nojima 
Table 6. Lifeline interaction matrix in the moment-magnitude-6.7 1989 Loma Prieta, California, earthquake (modified from Nojima and Kameda, 1991).

[SF, San Francisco; BART, Bay Area Rapid Transit; EBMUD, East Bay Municipal Utility District; PBX, private branch exchange; hrs, hours; *, general interaction, meaning among components of the same system]

\begin{tabular}{|c|c|c|c|c|c|c|c|}
\hline $\begin{array}{c}\text { Lifeline } \\
\text { type }\end{array}$ & Electricity & Gas & Water & Sewer & Road & Rail & Telephone \\
\hline Electricity & * & $\begin{array}{l}\text { Santa Cruz gas } \\
\text { explosion due } \\
\text { to electricity } \\
\text { comeback } \\
\text { (spark ignition). } \\
\text { Recovery work } \\
\text { arrangement with } \\
\text { electric power- } \\
\text { supply system. }\end{array}$ & $\begin{array}{l}\text { Santa Cruz: pump } \\
\text { stopped for } 18 \mathrm{hrs} \\
\text { (gravity flow area } \\
\text { survived; no water } \\
\text { in pump-based } \\
\text { supply area) } \\
\text { SF: power failure } \\
\text { due to gas leak } \\
\text { inspection, no } \\
\text { water in pump- } \\
\text { based supply area } \\
\text { and Marina district. } \\
\text { No power for } \\
\text { repair work. } \\
\text { EBMUD: short-term } \\
\text { loss of power at } \\
\text { Lafayette filtration } \\
\text { plant. Oakland } \\
\text { Control Center } \\
\text { power loss, no } \\
\text { service. }\end{array}$ & $\begin{array}{l}\text { SF and Santa } \\
\text { Cruz: } \\
\text { power } \\
\text { failure } \\
\text { at pump } \\
\text { station. }\end{array}$ & $\begin{array}{l}\text { SF and Santa } \\
\text { Cruz: traffic } \\
\text { jam due to } \\
\text { malfunction of } \\
\text { traffic signal. }\end{array}$ & $\begin{array}{l}\text { SF: BART } \\
\text { omitted stops } \\
\text { at some } \\
\text { stations } \\
\text { to save } \\
\text { electricity. }\end{array}$ & $\begin{array}{l}\text { Capacity diminished } \\
\text { by use of storage } \\
\text { cells. PBX } \\
\text { with no battery, } \\
\text { malfunction. } \\
\text { Pacific Bell Bush/ } \\
\text { Pine Street office } \\
\text { (SF) coolant } \\
\text { trouble; no } \\
\text { service for } 3 \text { hrs. } \\
\text { Pacific Bell } \\
\text { Hollister office } \\
\text { generator failure } \\
\text { no service for } \\
3 \text { hrs. } \\
\text { GTE Corp.: Monte } \\
\text { Bello office (Los } \\
\text { Gatos) failure of } \\
\text { generator fuel } \\
\text { tank; malfunction } \\
\text { (6-7 hrs). }\end{array}$ \\
\hline Gas & $\begin{array}{l}\text { SF and Santa } \\
\text { Cruz: gas leak } \\
\text { inspection } \\
\text { before } \\
\text { recovering } \\
\text { electricity. }\end{array}$ & $*$ & $\begin{array}{l}\text { Santa Cruz: no } \\
\text { home treatment. } \\
\text { Recovery work } \\
\text { arrangement with } \\
\text { gas supply system. }\end{array}$ & & $\begin{array}{l}\text { SF: road closed } \\
\text { due to propane } \\
\text { fire (Route } 80 \\
\text { westbound } \\
\text { at Central } \\
\text { Avenue). }\end{array}$ & & \\
\hline Water & & $\begin{array}{l}\text { Santa Cruz: recovery } \\
\text { work arrangement } \\
\text { with water-supply } \\
\text { system. }\end{array}$ & $*$ & $\begin{array}{l}\text { Santa Cruz: } \\
\text { damage } \\
\text { detection } \\
\text { by analogy. }\end{array}$ & $\begin{array}{l}\text { SF Marina } \\
\text { District: road } \\
\text { failure due to } \\
\text { water leakage. }\end{array}$ & & \\
\hline Road & & & $\begin{array}{l}\text { Santa Cruz: no } \\
\text { transporting } \\
\text { machinery due to } \\
\text { bridge damage. }\end{array}$ & $\begin{array}{l}\text { Santa Cruz: } \\
\text { damage } \\
\text { detection } \\
\text { by analogy. }\end{array}$ & $*$ & $\begin{array}{l}\text { BART riders } \\
\text { increased } \\
\text { (October } \\
23,+40 \\
\text { percent) due } \\
\text { to Bay Bridge } \\
\text { closure. }\end{array}$ & \\
\hline Rail & & & & & & $*$ & \\
\hline Telephone & & & $\begin{array}{l}\text { SF and Santa Cruz: } \\
\text { overload. }\end{array}$ & & & & $*$ \\
\hline
\end{tabular}




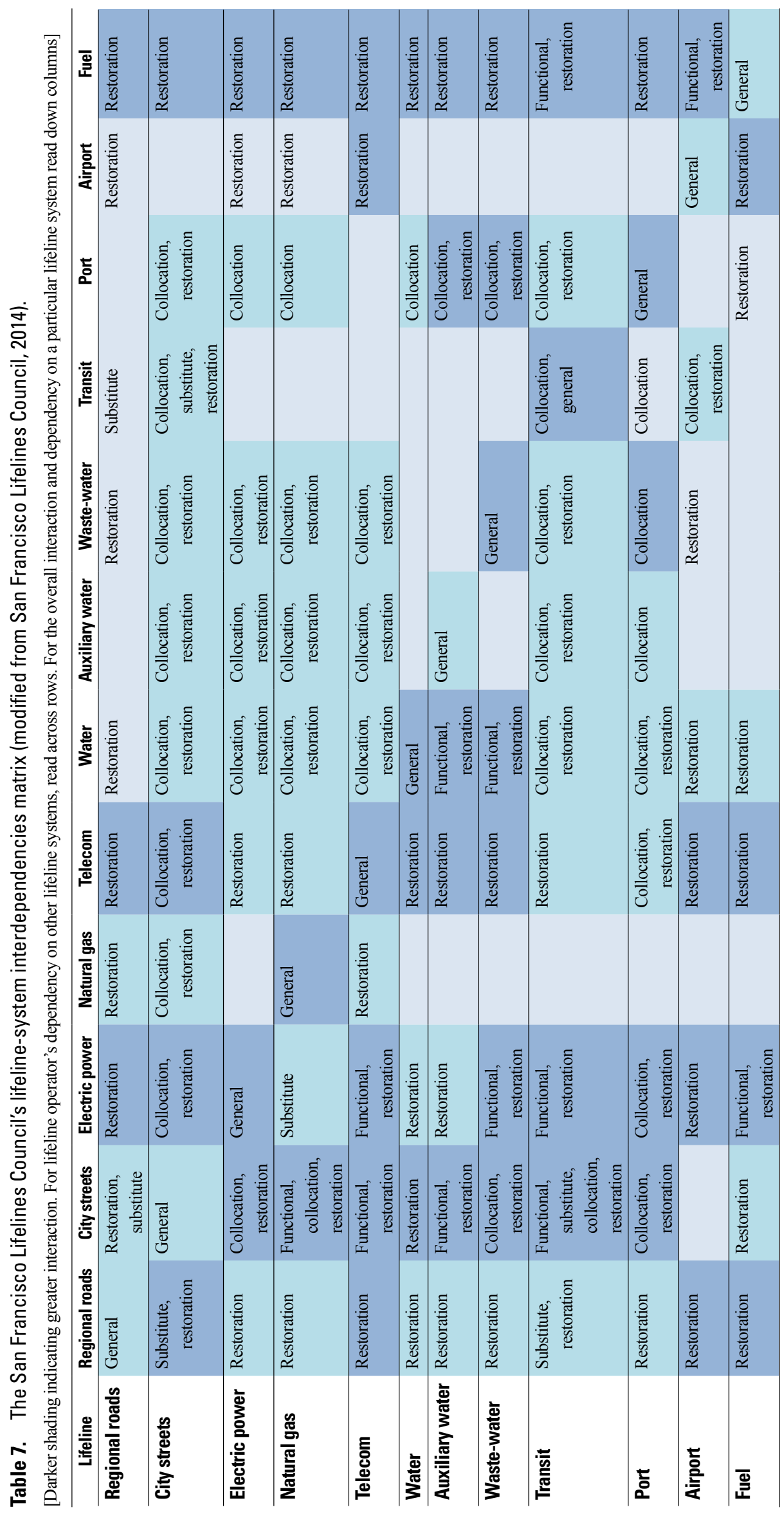


and Kameda (1991) and shows a degree of interaction, with darker shading indicating greater interaction, like a higher value in Scawthorn's (1993) matrix. The authors found that restoring water supply in San Francisco depends significantly on city streets, telecommunications, and fuel and to a lesser extent on regional roads, electric power, and the Port of San Francisco. The matrix characterizes the mode of each interaction, with five possible modes. The following quotations are taken from San Francisco Lifelines Council (2014) but the interpretations are mine:

- "Functional disaster propagation and cascading interactions from one system to another due to interdependence." This means that a system relies on one or more other systems to operate, each of which can rely on still others. I refer to these other systems as "upstream," in the sense that failure of an upstream system flows or cascades down to the system in question and causes its failure. For example, consider water service in a pressure zone that is supplied from tanks whose source is water pumped from lower elevation. Water service in that pressure zone is functionally dependent on electricity, which may be functionally dependent on natural gas. Failure of fuel supplies or electric generation, transmission, or distribution propagates or cascades to cause water-supply failure through interdependence.

- "Collocation interaction, meaning physical disaster propagation among lifeline systems." This means that one or more elements of the system in question are located close to one or more elements of another system and that the other system can fail in such a way that an area around the failure can impair the system in question. For example, fiber optic cable that serves the telecommunications network may be installed in a conduit on a roadway bridge. Excessive displacement of the bridge, such as a result of settlement of an abutment, can sever the fiber conduit.

- "Restoration interaction, meaning various hindrances in the restoration and recovery stages." This means that one or more elements of the system in question are located close to one or more elements of another system, and that repairs to the other system can damage or hinder the repair of the system in question. For example, consider a water main (the system in question) that is located above a damaged sewer line. Repair to the sewer line could require the temporary removal of or inadvertently lead to damage to the water main.

- "Substitute interaction, meaning one system's disruption influences dependencies on alternative systems." This means that the system in question may have substitutes (alternative systems), and that disruption of one of the alternatives can affect the system in question. For example, damage to the San Francisco-Oakland Bay Bridge in the $M_{\mathrm{w}} 6.91989$ Loma Prieta earthquake caused a 32-percent increase in Bay Area Rapid Transit (BART) ridership during October and November 1989 (Bay Area Rapid Transit District, 2015).
- "General interaction, meaning between components of the same system." Nojima and Kameda (1991) use an asterisk $\left.{ }^{*}\right)$ to mean the same thing. This means that impairment of elements of the system in question can affect other elements of the same system. For example, overturning of electrical switchgear in a pumping station can cause the pumps to fail.

\section{Pipeline Damage in Afterslip}

Several authors have considered lifeline damage due to afterslip, which is fault slip immediately following an earthquake rupture that involves creep much faster than the interseismic rate. According to Aagaard and others (2012), "Afterslip develops very quickly and can have similar impacts as coseismic slip, with the added complexity that the slip continues for months to years, albeit with a decreasing rate." They discuss afterslip in various Hayward Fault earthquake scenarios, including the one adopted for use in HayWired"Afterslip makes a substantial contribution to the long-term geologic slip and may be responsible for up to $0.5-1.5 \mathrm{~m}$ [meters] (median plus one standard deviation) of additional slip following an earthquake rupture." The authors offer a powerlaw expression for afterslip as a function of time $t$, denoted $D(t)$, as follows in equations 15-19 (s, second):

$$
\begin{gathered}
D(t)=A+B \times \frac{1}{(1+T / t)^{C}}, \\
A=\frac{1}{1-a} \times\left(D_{\text {total }}-a \times D_{\text {coseismic }}\right), \\
B=\frac{-a}{1-a} \times\left(D_{\text {total }}-D_{\text {coseismic }}\right), \\
a=\left(1+\frac{T}{1 \mathrm{~s}}\right)^{C} \\
C_{\text {median }}=0.881-0.111 \times M_{\mathrm{w}},
\end{gathered}
$$

where $T$ is referred to as the afterslip time constant, taken here as 365 days per Aagaard and others (2012). For example, with $M_{\mathrm{w}}=7.0$, equation 19 leads to $C_{\text {median }}=0.0984$. With $T=365$ days, equation 18 leads to $a=5.47$. With $D_{\text {total }}=1.86$ meters (m) and $D_{\text {coseismic }}=0.83 \mathrm{~m}$, equations 15,16 , and 17 produce $A=0.608 \mathrm{~m}$, $B=1.25 \mathrm{~m}$, and the estimate of slip versus time shown in figure 6 .

O'Rourke and Palmer (1996) point out that understanding observations of pipeline damage at fault crossings requires estimating fault slip from the time of pipeline installation to the time of its excavation for inspection after an earthquake, including preseismic slip, coseismic slip, and afterslip. Treiman and Ponti (2011) suggested that afterslip could realistically account for 40 percent of the total surface slip in the Coachella Valley, California, resulting from a M7.8 earthquake on the southern San Andreas Fault. The afterslip could aggravate damage to the Coachella 
Canal, railroads, fiber optic cable, electrical lines, gas and oil pipelines, and highways.

Hudnut and others (2014) measured deformation in a temporarily decommissioned 26 -inch diameter gas pipeline that crosses the fault rupture involved in the 2014 South Napa earthquake. They observed that the pipeline was "subtly warped more than $35 \mathrm{~cm}$ [centimeters] by fault offset, most of which accumulated as afterslip that is still continuing as of 3 months after the earthquake." They argue that "Lifeline performance in future events, with both coseismic slip and afterslip, deserves additional consideration."

\section{Measuring Loss of Resilience}

Bruneau and others (2003) propose to measure the loss of resilience as the area above the curve $Q(t)$, where $Q(t)$ is defined (somewhat vaguely) as the "quality of the infrastructure of a community" They denote a quantity they call "community earthquake loss of resilience" by $R$ and calculate it as in equation 20:

$$
R=\int_{0}^{t_{1}}(1-Q(t)) d t,
$$

where $t=0$ and $t=t_{1}$ denote the times of the initiating event and the time of full restoration, respectively. For brevity, I refer to $R$ more simply as the loss of resilience. Bruneau and others (2003) do not define $t=0$ and $t=t_{1}$ precisely. I define $t=0$ here as the time of the first earthquake in the earthquake sequence

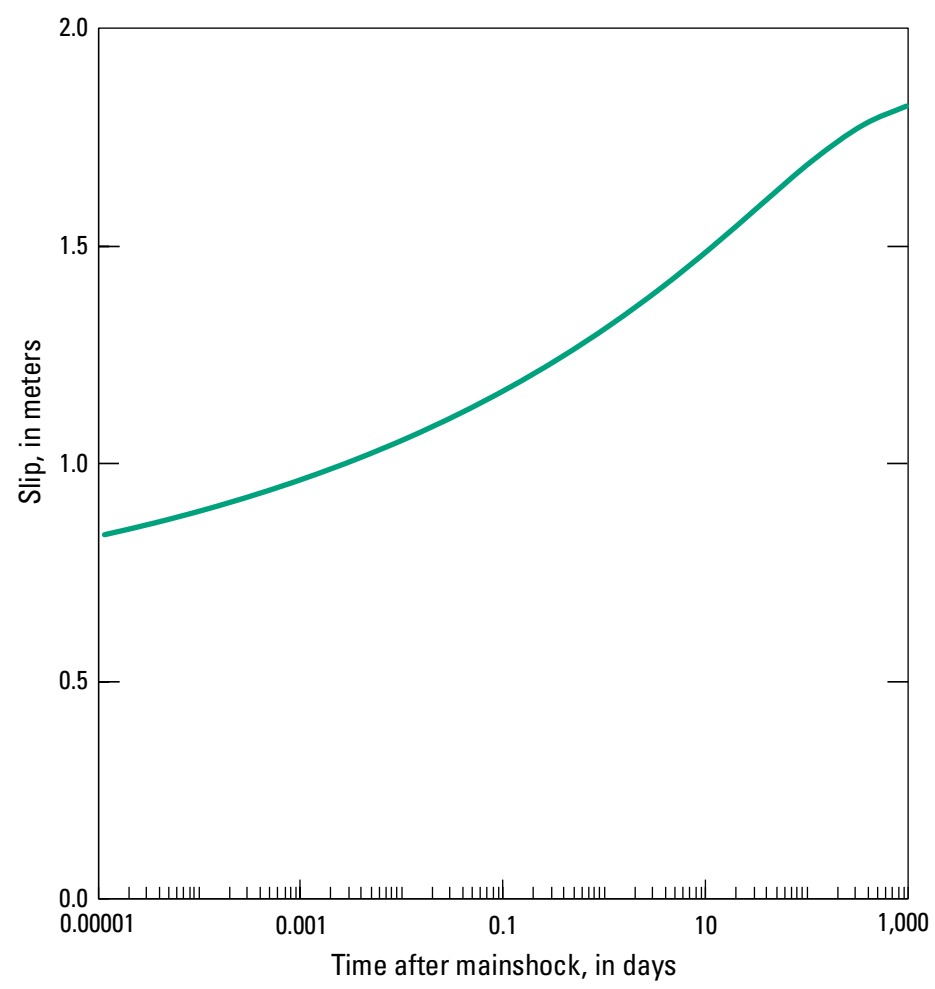

Figure 6. Graph showing afterslip versus time after a moment-magnitude-7.0 mainshock as derived from equations 15 through 19 (see text). under consideration, and I define $t_{1}$ as the time when $Q(t)=1$ after the last earthquake in the sequence under consideration. Let $Q(t)$ measure the fraction of water customers receiving at least an adequate degree of service at time $t$, meaning sufficient water flow and pressure at the tap for drinking (even if it needs to be boiled first), bathing, and using toilets. $R$ has units of time, and as applied here, can be seen here as the expected value of the time that an arbitrary customer receives less water than a useful degree of service.

To be clear, a reduction in the loss of resilience indicates a briefer average time that an arbitrary customer lacks adequate service, but I will not equate a reduction in the loss of resilience with an increase in resilience. In Bruneau and others' (2003) terminology, resilience is not a quantity but rather a quality that means "the ability of the system to reduce the chances of a shock, to absorb a shock if it occurs (abrupt reduction of performance) and to recover quickly after a shock (reestablish normal performance)." Resilience is not the mathematical complement of the loss of resilience.

\section{Methodology}

Using the brief literature review described above as a basis, I now turn to the proposed methodology. The methodology used in this chapter to evaluate water-network resilience for the HayWired scenario is discussed below.

\section{Overview of the Methodology}

A lifeline earthquake performance and restoration model typically involves the following analytical elements:

1. Asset definition, in which the system is described in terms of nodes and links. Nodes have a location, flow capacity, sometime a value (for example, replacement cost), and an asset category that associates the component with one or more relations among environmental excitation (for example, severity of shaking) and loss (for example, in terms of dollars, deaths, downtime, or some combination). Links connect nodes. They have a path, sometime a direction, flow capacity, sometimes a value, and an asset category. The assets in question here are defined in the San Jose Water Company case study (described later in this chapter).

2. Hazard model, relating geographic location to environmental excitation. In the case of earthquake hazard, the hazard model typically includes a mathematical idealization of seismic sources in the region, their locations, the frequency with which they can produce earthquakes of various magnitudes, and one or more ground motion prediction equations to relate earthquake magnitude and location to shaking and other site effects. In the present study, the hazard model is presented elsewhere. Briefly, it is a physics-based model of the San Francisco Bay Area, depicted in Aagaard and others (2010a, b). 
3. Hazard analysis, in which one evaluates the hazard model for one or more realizations of an earthquake. In the present analysis, I use the realization from Aagaard and others (2010a, b) depicting a $M_{\mathrm{w}} 7.0$ rupture of the Hayward Fault north and south segments with an epicenter under Oakland. Accompanying the model of shaking from the mainshock are estimates of liquefaction probability, landslide probability, coseismic slip, and afterslip associated with the mainshock, along with shaking in each of a sequence of 16 aftershocks of M5.0 and greater, as described in Wein and others (2017).

4. Vulnerability model (described later in this chapter), which relates environmental excitation at a particular location to the potentially uncertain loss in each of a set of asset classes.

5. Damage analysis (described later in this chapter), in which one evaluates the vulnerability model for each lifeline component at the level of environmental excitation to which the component is subjected.

6. Restoration model (described later in this chapter), which characterizes the time to restore the damaged components to their pre-disaster condition, and calculates the degree of service at each of many points in time. (The restoration model developed for the HayWired scenario is new. It includes a new method for quantifying the effects of lifeline interaction. It includes an initial assessment period suggested by engineers of the East Bay Municipal Utility District, along with a period during which repair crews and other resources ramp up from an initial, in-house quantity to one that includes mutual aid.)

7. Aftershock analysis, in which one inserts one or more aftershocks into the restoration process, which in a sense restarts the hazard, damage, and restoration analyses with a still-damaged lifeline system.

\section{Vulnerability Model}

Here, "vulnerability model" means a mathematical formulation of the relation between loss (usually normalized by quantity; for example, pipeline breaks and leaks per 1,000 feet, $\mathrm{ft}$, of pipe) and environmental excitation (for example, degree of PGV).

\section{Basic Elements of a Vulnerability Model}

These relations often apply to classes of components that share common engineering features (for example, pipe sharing common material, diameter range, or joint type). All specimens of the class are assumed to be interchangeable and indistinguishable for purposes of estimating loss. A vulnerability model can be deterministic, providing for example only a mean estimate of loss conditioned on excitation, or probabilistic, providing both a mean value and error term. Some terms need to be defined:
- $y_{i}(x)$, the expected value of the degree of loss experienced by a component of class $\mathrm{i}$ when subjected to excitation $\mathrm{x}$. One can refer to $y_{i}(x)$ as the mean vulnerability function for class i.

- $\varepsilon_{i}(x)$, the error term for class $i$. The error term can be constant for class $i$ or it can depend on degree of excitation $x$. The error term has unit mean and usually has some parametric distribution, such as lognormal with a specified standard deviation of the natural logarithm of the error term, referred to here as the logarithmic standard deviation. The vulnerability model can provide mean vulnerability functions and error terms for one or more modes of damage $j$, such as damage by wave passage and damage by ground failure due to liquefaction, landslide, or fault offset.

- $y_{i, j}\left(x_{i, j}\right)=$ the mean loss to a component $i$ of a specified class in damage mode $j$ when component $i$ is subjected to mode-j excitation $x_{i, j}$, such as the peak ground velocity to which a particular segment of pipe is subjected.

- $\varepsilon_{i, j}\left(x_{i, j}\right)=$ the mode- $j$ vulnerability error term for the class to which component $\mathrm{i}$ belongs, when the component is subjected to excitation $x_{i, j}$.

- $Y_{i, j}\left(x_{i, j}\right)=$ the uncertain normalized loss is denoted by (for example, uncertain total pipeline breaks and leaks per 1,000 linear feet of pipe), where the index $i$ refers to the component class to which component $i$ belongs, $j$ refers to the damage mode under consideration (for example, pipeline breaks and leaks per 1,000 linear feet of pipe as a result of wave passage), and $x_{i, j}$ is as previously defined.

The uncertain normalized loss is calculated as:

$$
Y_{i, j}\left(x_{i, j}\right)=y_{i, j}\left(x_{i, j}\right) \times \varepsilon_{i, j}\left(x_{i, j}\right) .
$$

The vulnerability model comprises the set of functions $y$ and $\varepsilon$, the component classes to which they refer, and the domain of excitations for which the functions are valid.

\section{Selecting a Vulnerability Model for a Pipeline Network}

Several authors have created and published pipeline vulnerability functions; a few are discussed above in the Literature Review. There are no commonly accepted rating systems for pipeline vulnerability functions, but it seems reasonable to choose among competing vulnerability functions based on at least the following criteria:

- Vulnerability functions reflect diverse conditions - pipe material, diameters, joint systems, age, and corrosivity similar to the conditions where the vulnerability functions will be applied.

- Vulnerability functions are drawn from numerous damage data. 
- Vulnerability functions are drawn from ground-motion levels reaching as strong as those where they will be applied.

- The articles in which the vulnerability functions are presented are respected, highly cited, and frequently used for similar applications, which here means estimating and depicting realistic outcomes of a hypothetical U.S. earthquake (table 8).

O'Rourke and others (2014) have been more cited in far fewer years than Eidinger (2001), suggesting somewhat greater credibility. Maximum PGV values are greater in the O'Rourke work, suggesting greater applicability in strong shaking. However, Eidinger (2001) draws on a larger dataset and his vulnerability functions cover both wave passage and ground failure. For these reasons, it seems the Eidinger vulnerability functions are most suited to the present problem.

Thus, for wave passage, one can use equation 3 to calculate repair rate with probability $p$ of nonexceedance, or alternatively equation 4 for the mean repair rate. However, there is a problem applying a liquefaction and landslide model that requires permanent ground displacement to HayWired, as in Eidinger's (2001) model equations 5 or 6 . The problem here is that PGDs are unavailable for the HayWired scenario. HayWired instead has liquefaction probability and landslide probability. How to apply Eidinger's ground-failure model without an estimate of PGD?

The solution employed here takes advantage of the fact that equation 6 is not very sensitive to $P G D$. One can see the limited sensitivity in the small power to which $P G D$ is raised, 0.319 . At the same time, the logarithmic standard deviation $\beta=0.74$ in equation 5 , which gives the marginal distribution of repair rate, is very large, suggesting the 90th percentile bounds differ by more than an order of magnitude. In this case, the 95th and 5th percentiles of repair rate conditioned on PGD differ by a factor of 11.4 .

So Eidinger's (2001) liquefaction equation tells us that an increase in PGD from 1 inch to 10 inches only increases mean repair rate by a factor of 2 . See figure 7 ; for $K_{2}=1$, the repair rate for $P G D=1 \mathrm{inch}$ and the repair rate for $P G D=10$ inches are 1.4 and 2.9 repairs per 1,000 linear feet, respectively. At either point, $P G D=1$ inch or 10 inches, the uncertainty in repair rate is much greater, that is, even if I knew PGD, I would still be very uncertain as to repair rate. The apparent improvement in accuracy gained by estimating liquefactioninduced or landslide-induced $P G D$ would be illusory. That is

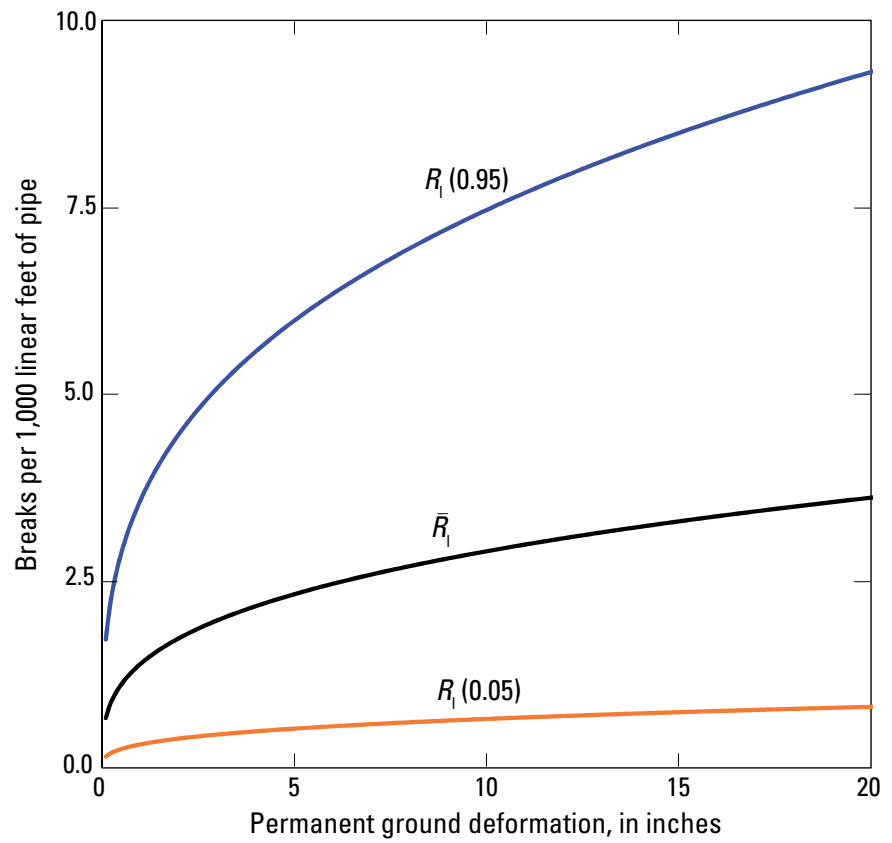

Figure 7. Graph showing Eidinger's (2001) pipe liquefaction vulnerability $\left(R_{1}\right)$ for $K_{2}=1.0$, mean and 90 -percent bounds (see equations 5 and 6 ). Factor $K_{2}$ accounts for pipe material, joints, soil corrosivity, and pipe diameter.

not to say that it would not be a little better to estimate PGD, it just would not be much better.

In light of the very high uncertainty in repair rate and the relatively modest sensitivity of the vulnerability function to PGD, I assume a reasonable moderate PGD associated with liquefaction, say 6 inches, and rewrite equations 5 and 6 using liquefaction probability, as shown in equations 22 and 23 :

$$
\begin{gathered}
R_{1}\left(P_{\mathrm{L}}, p\right)=K_{2} \times P_{\mathrm{L}} \times 1.06 \times 6^{0.319} \times \exp \left(0.74 \times \Phi^{-1}(p)\right), \\
=1.88 \times K_{2} \times P_{\mathrm{L}} \times \exp \left(0.74 \cdot \Phi^{-1}(p)\right), \\
\bar{R}_{1}\left(P_{\mathrm{L}}\right)=K_{2} \times 1.39 \times 6^{0.319} \times P_{\mathrm{L}}, \\
= \\
=2.46 \times K_{2} \times P_{\mathrm{L}},
\end{gathered}
$$

where $P_{\mathrm{L}}$ denotes probability of ground failure, either through liquefaction, landslide, or fault offset. The equation estimates mean repair rate per 1,000 linear feet of pipe.

How does one sum repair rates from wave passage and ground failure if one uses Eidinger's (2001) model? He says that

\begin{tabular}{|c|c|c|c|c|c|}
\hline Source & Diverse pipe & Repairs & Max PGV & Max PGD & Citations \\
\hline O'Rourke and Ayala (1993) & Yes & Unknown & $50 \mathrm{~cm} / \mathrm{s}$ & NA & 87 \\
\hline Honneger and Eguchi (1992) & Yes & Unknown & Unknown & Unknown & 21 \\
\hline O'Rourke and others (2014) & Yes & 2,051 & $80 \mathrm{~cm} / \mathrm{s}$ & NA & 20 \\
\hline
\end{tabular}
"wave propagation effects are masked within the more destructive

Table 8. Comparison of criteria for selecting pipeline vulnerability functions.

[PGV, peak ground velocity; PGD, permanent ground displacement; $\mathrm{cm} / \mathrm{s}$, centimeter per second; NA, not applicable] 
effects of [peak ground displacements]." If one knew where ground failure occurs, one would ignore the wave-passage model so as not to double-count it. The problem here is that Eidinger's (2001) empirical model of damage due to liquefaction probably includes some damage that was caused by wave passage, but he does not know which breaks and leaks were caused by which peril. In zones of liquefaction, he treats all damage as caused by liquefaction. That is, his empirical relation for damage in zones of liquefaction include an unknown (but probably small) fraction of damage caused by wave passage.

As a result, one must not double-count wave passage damage by applying both the liquefaction and wave-passage models in zones of liquefaction. To eliminate double-counting, I modify the wave-passage model of equations 3 and 4 by multiplying the repair rate by a factor $\left(1-P_{\mathrm{L}}\right)$, where $P_{\mathrm{L}}$ denotes ground-failure probability. After eliminating double-counting, one can sum the wave-passage and ground-failure models as shown in equations 24 and 25 . In both equations, $R$ denotes repair rate in repairs per $1,000 \mathrm{ft}$ of buried pipe, $P G V$ is peak ground velocity in inches per second, and $p$ denotes nonexceedance probability. In equation 24 , $R$ gives repair rate with nonexceedance probability $p$, whereas equation 25 gives mean (average) repair rate. The coefficients are smaller in equation 24 than they are in equation 25 because the median is smaller than the average for a lognormally distributed random variable, and the difference depends on the logarithmic standard deviation:

$$
\begin{aligned}
R\left(P G V, P_{\mathrm{L}}, p\right)= & \left(1-P_{\mathrm{L}}\right) \times R_{\mathrm{w}}(P G V, p)+R_{\mathrm{L}}\left(P_{\mathrm{L}}, p\right) \\
= & \left(1-P_{\mathrm{L}}\right) \times K_{1} \times 0.00187 \times P G V \times \\
& \exp \left(1.15 \cdot \Phi^{-1}(p)\right)+1.88 \times K_{2} \times P_{\mathrm{L}} \\
& \times \exp \left(0.74 \times \Phi^{-1}(p)\right) \\
\bar{R}\left(P G V, P_{\mathrm{L}}\right)= & \left(1-P_{\mathrm{L}}\right) \times \bar{R}_{\mathrm{w}}(P G V)+\bar{R}_{1}\left(P_{\mathrm{L}}\right) \\
= & \left(1-P_{\mathrm{L}}\right) \times K_{1} \times 0.003623 \times P G V . \\
& +2.46 \times K_{2} \times P_{\mathrm{L}} .
\end{aligned}
$$

For damage resulting from fault offset, one could apply Eidinger's (2001) proposed model. Given the absence of supporting data, the relatively small number of breaks that occur at the fault trace compared with breaks and leaks that occur as a result of wave passage and liquefaction, and the desire to model breaks as a function of offset at the location of the pipe rather than average offset over the entire trace; a simpler model is adopted here. I assume that any pipe segment that crosses a fault is broken if the fault offset exceeds 6 inches and use the same threshold regardless of pipe material, jointing, and angle subtended by the fault and pipeline alignment. The fault trace is treated as a collection of line segments rather than as a zone on the surface of the Earth with a finite width. The offset therefore is lumped at the line rather than distributed over the width of the zone. Mathematically, let $Z_{i}$ denote a binary variable to indicate that pipe segment $i$ is damaged by fault offset ( 1 if true, 0 if false), $d$ denotes the fault offset distance, $d_{\mathrm{f}}$ denotes the threshold of fault offset distance that produces damage, and $I(\cdot)$ is the indicator function ( 1.0 if the value in parentheses is positive, 0.0 if negative), then

$$
Z_{i}=I\left(d-d_{\mathrm{f}}\right),
$$

where $d_{\mathrm{f}}=6$ inches, consistent with the fault offset that Eidinger (2001) equates with a 50-percent failure probability for all segmental pipe. One could use a more refined model such as American Society of Civil Engineers (ASCE) (1984), which applies engineering first principles of stress and strain, the engineering characteristics of pipe and backfill, the geometry of how a pipe crosses a fault, and other factors. In the context of an earthquake-planning scenario in which we care about the total number of pipe breaks and leaks over an entire strongly shaken region, such an analysis seems like excessive effort for a relatively small contributor to overall damage. Furthermore, considering the necessary assumptions about unknown backfill characteristics and probably other model parameters, such an analysis would probably provide illusory precision.

\section{Damage Analysis (Number of Repairs Required)}

A damage analysis applies the vulnerability model and the hazard model to the assets under consideration to estimate degree of damage or loss. An example would be the total number of pipeline repairs required when a particular pipeline network is affected by a particular earthquake.

\section{Basic Elements of a Damage Analysis}

I employ a common general formulation for number of repairs required for a system of $n_{i}$ discrete components (for example, segments of pipe) that can each be uniquely identified with a class of components (for example, type of pipe).

Each component $i$ has an associated quantity or value $V_{i}$ (for example, length of pipeline segment), and is assumed to be subject to damage from up to $n_{j}$ modes of damage (for example, wave passage and liquefaction). Each combination of component class and mode of damage is assigned a vulnerability model $y_{i, j}\left(x_{i, j}\right)$ and $\varepsilon_{i, j}\left(x_{i, j}\right)$ as previously defined. Let $R$ denote the total uncertain loss (for example, total number of instances of pipeline damage). It is estimated as shown in equation 27 :

$$
R=\sum_{i}^{n_{i}} \sum_{j}^{n_{j}} V_{i} \times y_{i, j}\left(x_{i, j}\right) \times \varepsilon_{i, j}\left(x_{i, j}\right) .
$$

Equation 27 assumes that damage to one component or in one model is independent of damage to other components or in other modes. That is, that the degree of damage to component $i$ in mode $j$ is unaffected by damage to a different component, and that if component $i$ is damaged in one mode, it can also be damaged in another mode and that the losses resulting from the two modes of damage simply sum.

In the case of water-supply pipelines, one implication of this assumption of independence is that it assumes that repairs 
are spaced widely enough apart that it makes sense to repair individual breaks or leaks, at least initially, rather than to remove and replace pipe and thus repair two or more instances of damage with a single repair.

\section{Applying the Damage Analysis to a Water-Supply System}

Applying equation 27 to water-supply pipelines using Eidinger's (2001) vulnerability model, and adding an additional term for fault crossings, one can estimate mean total number of repairs $r$ as shown in equation 28:

$$
\begin{aligned}
& r=\sum_{i=1}^{n} \bar{R}_{\mathrm{w}}\left(P G V_{i}\right) \times L_{i}+\sum_{i=1}^{n} \bar{R}_{1}\left(P_{\mathrm{L}, i}\right) \times L_{i}+\sum_{i=1}^{n} I\left(d-d_{\mathrm{f}}\right) \\
&=\sum_{i=1}^{n}\left(1-P_{\mathrm{L}, i}\right) \times 0.003623 \times K_{1, i} \times P G V_{i} \times L_{i} \\
& \quad+\sum_{i=1}^{n} 2.46 \times K_{2, i} \times P_{\mathrm{L}, i} \times L_{i}+\sum_{i=1}^{n} I\left(d-d_{\mathrm{f}}\right)
\end{aligned}
$$

where $i$ is an index to pipe segments, $n$ is the total number of segments in the network, $K_{1, \mathrm{i}}$ and $K_{2, i}$ denote the values of $K_{1}$ and $K_{2}$ for pipe segment $i, P G V_{i}$ is the peak ground velocity to which segment $i$ is subjected, $P_{L, i}$ denotes the ground-failure probability at pipe segment $i, L_{i}$ is the length of pipe segment $i$ in thousands of linear feet, $I(\cdot)$ is an indicator function that takes on the value 1.0 if the expression in parentheses is positive, 0.0 if negative, $d_{i}$ is the fault offset to which a segment of pipe $i$ is subjected, and $d_{\mathrm{f}}$ is the offset at which breakage occurs. Here, I propose to take $d_{\mathrm{f}}$ as deterministically equal to 6 inches $(15 \mathrm{~cm})$. Note that as long as pipe segments $i$ are relatively short, less than a few hundred meters, there should be little difference between shaking at the ends and thus little error introduced by discretizing a pipeline network in this way.

Because the present analysis does not require a probabilistic estimate of loss, I ignore the error term $\varepsilon$ and deal only with the expected value of loss. I use the lower-case $r$ in equation 28 to indicate a deterministic value rather than the upper-case $R$ of equation 27 that stands for an uncertain quantity.

To carry out equation 28 , one uses a geographic information system (GIS) to create a table of system components; for example, a table of pipe segments. Components are listed in rows. For each component, assign an identifier, determine its quantity (for example, its length), assign it to a class that has one or more vulnerability or fragility functions (for example, Eidinger's, 2001, classes that group water-supply pipe by material, joint, soil corrosivity, and diameter), and determine its location (for example, the latitude and longitude of a pipe segment midpoint). Then using the GIS, look up the groundmotion parameter values $x_{i, j}$. Equation 28 can then be calculated for each component (each row) and the losses summed over all rows to calculate the expected value of loss $r$ (for example, the number of instances of pipeline damage requiring repairs).

\section{Breaks or Leaks?}

Lund and Schiff (1991) define leaks and breaks for purposes of compiling damage data. Under their definition, a pipe with a leak continues to function with minimal loss of service, whereas a pipe with a break completely loses function. It seems as if another, equivalent definition is that a pipe break separates a pipe segment into two, and a leak only partially fractures a pipe. Hazus-MH assumes an 80 percent $/ 20$ percent break/leak ratio for liquefaction and 20 percent $/ 80$ percent breaks/leaks ratio for wave-passage damage. The authors of the technical manual do not cite a source for their choices.

Lund and Schiff (1991) found that, among all pipeline failures in the $M_{\mathrm{w}} 6.91989$ Loma Prieta earthquake, where it was known whether the failure was a break or a leak, it was more common for the pipeline to break (336 repairs, 71 percent) than to leak (140 repairs, 29 percent). A study by Ballantyne and others (1990) of pipe damage in the $M_{\mathrm{w}} 6.71949$ Olympia and $M_{\mathrm{w}} 6.71969$ Seattle (Washington), $M_{\mathrm{w}} 5.6$ and 5.71969 Santa Rosa (California), $M_{\mathrm{w}} 6.71971$ San Fernando Valley, $M_{\mathrm{w}} 6.2$ 1983 Coalinga (California), and $M_{\mathrm{w}} 5.91987$ Whittier Narrows earthquakes, found that ground failure resulted in a 50 percent $/ 50$ percent break/leak ratio, and absent ground failure, the ratio was 15 percent $/ 85$ percent breaks versus leaks. Because the present model allows one to distinguish between repairs associated with ground failure versus wave passage, and because Ballantyne and others (1990) are highly regarded and offer their evidence, I employ their ratios.

\section{Degraded Vulnerability?}

The model presented here applies the same vulnerability functions to the same system map in the aftershocks that it applies to the mainshock. Is it correct to do so? Perhaps I should consider a system that has already been degraded by the mainshock or a large aftershock to be weaker. Perhaps the mainshock causes small undetected leaks or incipient breaks that become large leaks or breaks in an aftershock. However, there does not seem to be sufficient research available to support explicitly modeling system degradation - making the mathematical model of the system more vulnerable in aftershocks than before the mainshock. This is a topic deserving of future research.

\section{Restoration Model}

As used here, a restoration model relates the damage (the output of the damage model) to a system's functionality over time. It usually depicts a system's return to its predisaster condition.

\section{Basic Elements of the Lifeline Restoration Model}

Functionality can be measured a variety of ways, but in the case of a utility such as a pipeline network, it is common 
to measure functionality in terms of the number of service connections that receive the lifeline service as a function of time. I do not offer a general mathematical formulation of a lifelinerestoration model, but merely list its elements here, and then propose a particular solution for water-supply pipeline systems. A lifeline-restoration model includes the following elements:

- A model of the level of functionality immediately after the disaster

- A model of the repair resources - crews and suppliesavailable over time.

- A model of the number of services restored by each repair

- A model of the elapsed time after each repair

- Ideally, a model of lifeline interaction (that is, accounting for how damage or restoration of other lifelines affects or delays damage or restoration of the lifeline in question).

\section{Number of Services Lost Because of Earthquake}

A hydraulic or connectivity analysis similar to those of Khater and Grigoriu (1989) or Applied Technology Council (1991) is too demanding for present purposes. I use the same simplification as Hazus-MH does. As noted above in the section on Serviceability of Water Supply, Hazus interprets the serviceability index, which measures the drop-in water pressure as a function of the average number of pipe breaks (not leaks) per kilometer of pipe, as a proxy for the fraction of customers receiving service. I employ the serviceability index the same way - immediately after an earthquake, when the number of repairs required is $r, L$ is the kilometers of pipe in the system, and $M$ is the total number of customers, then the number of services available immediately after the earthquake is given by $M$ times the serviceability index of equation 12 . Let $V_{0}$ denote the number of services available after the earthquake and before repairs begin as shown in equation 29 :

$$
\begin{aligned}
V_{0} & =M \times s(r) \\
& =M \times\left(1-\Phi\left(\frac{\ln \left(\frac{r}{L \times q}\right)}{b}\right)\right),
\end{aligned}
$$

where $M$ is the total number of services, $r$ is the number of main breaks (not leaks), $L$ is the length of pipe in the distribution system (kilometers), $q=0.1$, and $b=0.85$. The parameter $q$ determines the number of breaks (not leaks) per kilometer (0.1) at which $V_{0}$ reaches $0.5 M$. The parameter $b$ determines the width of the S-shaped curve labeled NIBS in figure 4. How long does it take to complete $n$ repairs?

\section{Number of Services Restored by the $n$th Repair}

Equation 29 suggests one approach to estimating service as repairs proceed - measure the remaining repairs $r$ as a function of the damage caused by the earthquake sequence, reduced by the number of repairs, and evaluate services available after $n$ repairs have been completed as shown in equation 30 , which I will refer to as the serviceability-index approach:

$$
V(n)=M \times\left(1-\Phi\left(\frac{\ln \left(\frac{r-n}{L \times q}\right)}{\beta}\right)\right) .
$$

Or one could model services as being restored in proportion to the number of repairs remaining, as shown in equation 31 . I refer to equation 31 as the proportional approach.

$$
V(n)=V_{0}+\left(M-V_{0}\right) \times\left(\frac{n}{r}\right) .
$$

A more general approach is suggested by conversations with engineers of EBMUD. They indicated that their repair strategy in an earthquake would be to focus most of EBMUD's resources to repair water-transmission lines that serve large areas, then smaller diameter distribution lines that serve smaller numbers of customers, and so on. The strategy would depend on how parts of the system, which may have been impacted by damage in large diameter pipes, could first be isolated to continue to maintain services to as many customers as possible by rerouting water using a combination of temporary system such as portable pumps and flexible hoses. If one were to plot a restoration curve with the fraction of customers receiving service on the $y$-axis and time after the earthquake on the $x$-axis, then a plot for EBMUD's strategy would maximize slope as soon as repairs begin. The slope might increase if the number of crews increases, but with constant resources, the slope will decrease as individual repairs restore fewer and fewer services. Equation 32 would have such a form for values of $0<a<1$. The smaller the value of $a$, the more the restoration curve would rise quickly early. Setting $a=1$ in equation 32 yields the proportional repair-restoration approach of equation 31 . I refer to equation 32 as the power approach.

$$
V(n)=V_{0}+\left(M-V_{0}\right) \times\left(\frac{n}{r}\right)^{a} .
$$

If I assume that repairs after the 1994 Northridge and 1995 Kobe earthquakes were completed at a constant pace, then the power approach with $a=0.67$ resembles the observed restoration of water service in the San Fernando Valley after the 1994 Northridge earthquake (fig. $5 A$ ), whereas the power approach with $a=0.33$ resembles restoration after the Kobe earthquake (fig. $5 B$ ). Figure 8 shows the three approaches all on the same plot (with two curves for the power approach, with $a=0.33$ and $a=0.67$ ). The $y$-axis is normalized by pre-earthquake number of services, and the $x$-axis is normalized by number of pipeline repairs.

Of the three, the power approach matches the two earthquakes the best, proportional next best, and serviceabilityindex approach the worst. There may be many other reasonable approaches, but considering the three examined here, I will employ the power approach with the more conservative of the two $a$-parameter values considered here, that is, $a=0.67$. 


\section{Repair Resources and Repair Rate with Lifeline Interaction}

Now that I can estimate the number of services available after completing $n$ repairs, I consider how long it takes to perform $n$ repairs.

The section above on Time to Repair Pipe Leaks and Breaks summarizes a few sources of pipe repair-time information - an empirical model of repair time per break or leak, an empirical model of regional repair time as a function of regional damage rate, and expert opinion of repair time that generally agrees with the empirical evidence, albeit slightly lower both in terms of lower mean repair time and narrower confidence bounds. Loss estimation practitioners generally prefer empirical models with explanatory power; for this reason, I employ Schiff's (1988) pipeline repair data.

Schiff's repair data show an average repair time of 7.6 hours and a standard deviation of 5.3 hours. Staff of the San Jose Water Company found that figure to be reasonable (J. Walsh, San Jose water Company, oral commun., October 14, 2015). A lognormal distribution with median repair time of 6.5 hours and logarithmic standard deviation of 0.70 fits the data sufficiently well to satisfy the Lilliefors (1967) goodness of fit test, as shown in figure $9 \mathrm{~A}$. Separating the data for the small-diameter pipe repairs from the data for two large-diameter pipe repairs (24-inch damage instances, requiring 12 and 20 hours, respectively), the smalldiameter pipe median and logarithmic standard deviation are 6.1 hours and 0.58 , respectively, as illustrated in figure $9 B$. Schiff (1988) offers too few samples of large-diameter pipe repair time to derive an empirical distribution, so I assume a median of 16 hours and a logarithmic standard deviation of 0.6 .

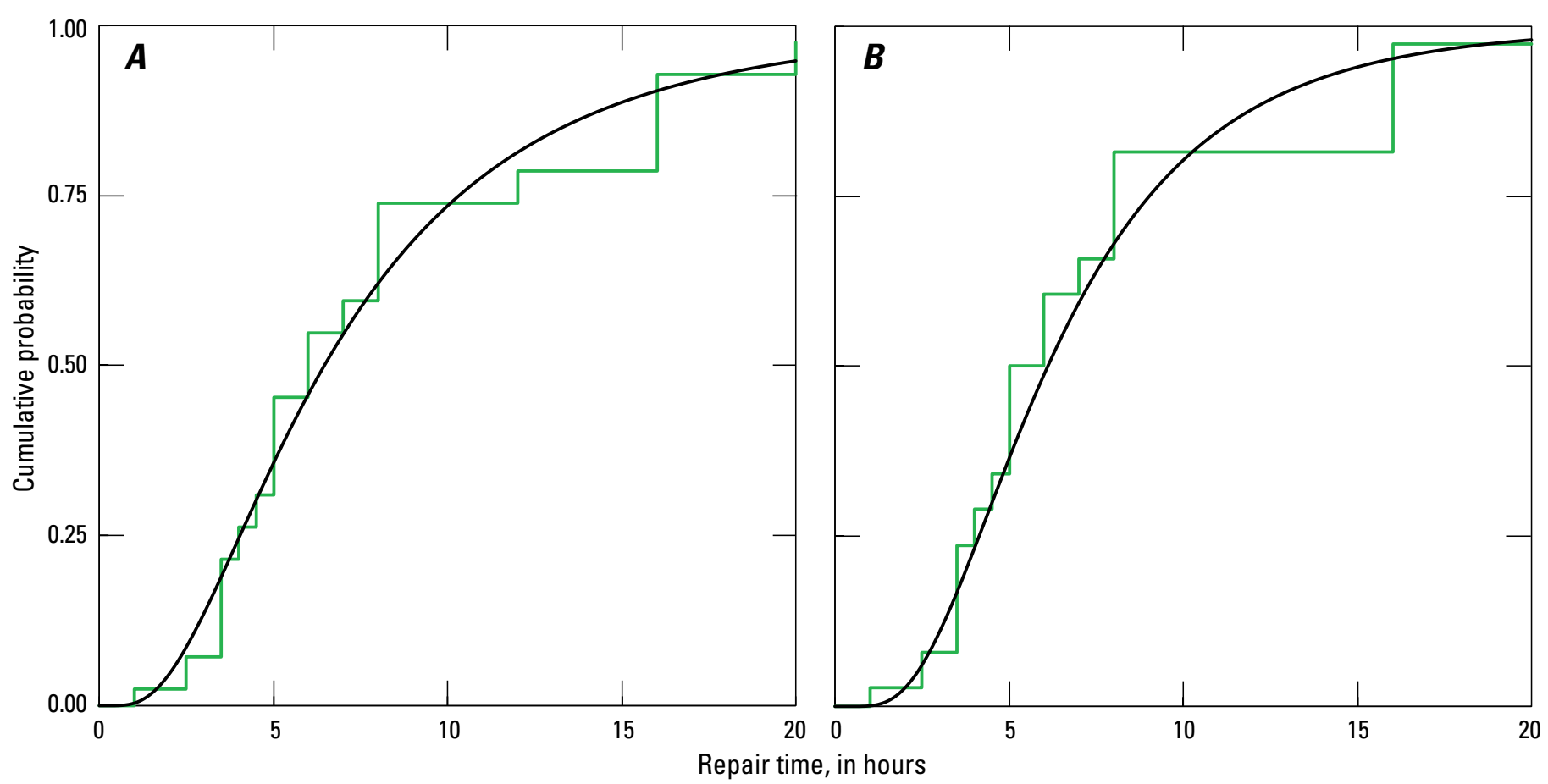

Figure 9. Graphs showing pipe repair times based on data from Schiff (1988). A, all pipe repairs; $B$, pipe repairs excluding repairs to large diameter pipe. Stair-step lines represent Shiff's (1988) data; curved lines are best fits.

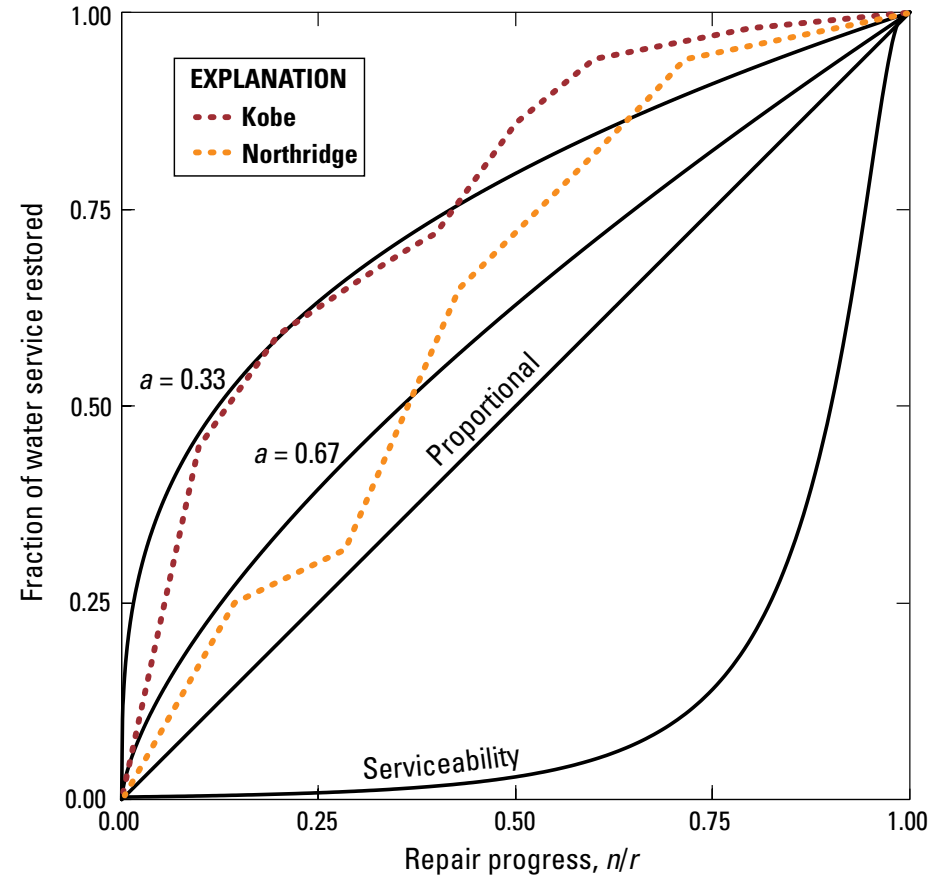

Figure 8. Graph showing parametric water-supply restoration curves plotted using equation 32 , annotated with curves from the moment magnitude $\left(M_{\mathrm{w}}\right) 6.71994$ Northridge, California, the $M_{\mathrm{w}} 6.91995$ Kobe, Japan, earthquakes. The $y$-axis is normalized by pre-earthquake number of services, and the $x$-axis is normalized by number of pipeline repairs. Variables are- $a$, power-approach exponent; $n$, repairs completed; $r$, remaining repairs. 
The LADWP estimates of repair duration for distribution pipelines (Tabuchhi and others, 2010) generally agree with actual earthquake experience reported by Schiff (1988). However, they seem to underestimate uncertainty, with lower and upper limits that include only 70 percent of the repairs reported by Schiff, omitting the lower and upper 15 percent of repair times of figure $9 A$. They are also slightly optimistic, with modes at the 20th and 40th percentiles of repair times in figure $9 A$.

It is difficult to compare the Hazus repair times with Schiff (1988) or Tabucchi and others (2010) because the former measures repair time per worker and the latter two measure repair time per repair. However, assuming a crew size of four, Hazus' perworker repair times equate with 6 to 18 hours, or the 35 th and $90 \mathrm{~h}$ percentiles of figure $9 A$.

For a deterministic model, it seems reasonable to use the mean estimate ( 7.6 hours per repair per crew, or 0.32 days per repair per crew) for small-diameter pipe repairs (here, assuming crews work 12 hours on, 12 hours off, until repairs are completed.

When will crews become available? As discussed earlier, public and private water agencies plan to provide mutual assistance for emergencies. CalWARN (California Water/ Wastewater Agency Response Network, n.d.) and East Bay Municipal Utility District (2014) report how three San Francisco Bay region water agencies dispatched teams to assist in the repair of water-supply pipelines in the City of Napa after the 2014 South Napa earthquake. The assistance took 24 hours to arrive, which suggests a delay in the arrival of mutual aid from across a metropolitan region. Mutual aid in a major metropolitan earthquake would likely come from hundreds, possibly thousands of miles away, and probably take longer to mobilize, arrive, house, and integrate into repair operations. Repair resources ramp up over time, and the larger the disaster, probably the longer the ramp-up time. It may take several days to first assess the extent of damage and locate leaks before actual repairs can be initiated. I parameterize this assessment time and time to ramp-up crews using a time-dependent model of the number of repair crews available to an agency:

- $c(t)=$ number of repair crews operating on the day of time $t$.

- $w(t)=$ crew workload, fraction of day that crews work, for example, 0.5 for 12 hours on and 12 hours off.

- $d_{0}=$ unconstrained repair duration, days per repair for one crew under ideal conditions, that is, without constraints on materials, coordination, and other prerequisites -0.32 days on average.

- $i=$ an index of rate-limiting factors. In table 2 , there are six such factors: communications, electricity, fuel, site safety (that is, no fire), roadway access, and repair supplies.

- $t_{0}=$ time at which the $1^{\text {st }}$ repair is performed.

- $t=$ time at which the nth repair is performed.
- $g(t)=$ flow of a rate-limiting factor (I refer to it as a flow factor) at time $t$.

Flow factors are as follow $-g_{i}(t)=$ flow of rate-limiting factor $i$ at time $t$, normalized so that $g_{i}(t)=1.0$ indicates unlimited availability, $g_{i}(t)=0.5$ indicates that the flow or supply rate of factor $i$ is half of what is normally available, and $g_{i}(t)=0$ indicates that factor $i$ is unavailable at time $t$. If, for example, there is no limit on fuel, $g$ of fuel is 1.0. If a utility could only fuel half its repair vehicles, its g-value would be 0.5 . If completing a phone call to coordinate repairs took twice as long as normal because of communications network congestion, its g-value would be 0.5 . If one could not complete a phone call at all, the $g$-value for communications would be 0 . In the case of a rate-limiting factor that is a lifeline with a number of service connections $M_{i}$ and a number of service connections available at time $t$ denoted by $V_{i}(t)$, then equation 33 follows:

$$
g_{i}(t)=\frac{V_{i}(t)}{M_{i}} .
$$

A rate-limiting factor, $u_{i}$, is a constant to indicate the reduction in repair productivity in the absence of a resources required to perform a repair, also called a $u$-factor, and indexed by $i$. One assigns $u$-factors based on an estimate of the additional time required to carry out one repair if it is necessary to do so without the required resource. It is estimated as shown in equation 34:

$$
u=1-\frac{d_{0}}{d_{\text {impaired }}},
$$

where $d_{0}$ is the average time required to perform a repair under normal conditions and $d_{\text {impaired }}$ is the average time it takes to perform a repair when the required resource required is unavailable. For example, if a repair takes 8 hours (hr) normally, but it takes $9 \mathrm{hr}$ in the absence of a required resource, one assigns $u=1-8 \mathrm{hr} / 9 \mathrm{hr}=0.11$. That is, productivity drops by 11 percent in the absence of the required resource. Thus, $u_{i}=1.0$ indicates that resource $i$ is crucial to repairs - without it, repairs do not proceed. A $u$-value of 0.5 indicates that repairs proceed by half their normal rate when resource $i$ is unavailable.

I denote by $f(t)$ the repair rate (repairs per unit time) at time $t$ of the $n$th repair and estimate it as:

$$
f(t)=\frac{w(t) \times c(t) \times\left(\prod_{i}\left(1-u_{i} \times\left(1-g_{i}(t)\right)\right)\right)}{d_{0}} .
$$

And let $\tau(n, t)$ denote the amount of time required to perform the $n^{\text {th }}$ repair, given that it starts at time $t$ :

$$
\tau(n, t)=\frac{1}{f(t)}=\frac{d_{0}}{w(t) \times c(t)\left(\prod_{i}\left(1-u_{i} \times\left(1-g_{i}(t)\right)\right)\right)} .
$$

I can now calculate $F(t)$, the total number of repairs completed by time $t+\tau$. It is given by equation 37 : 


$$
\begin{array}{rlr}
F(t) & =0 & t<t_{0} \\
& =\int_{t_{0}}^{t} f(t) d t & t \geq t_{0} \\
& =\int_{t_{0}}^{t} \frac{a(t) \times c(t) \times\left(\prod_{i}\left(1-u_{i} \times\left(1-g_{i}(t)\right)\right)\right)}{d_{0}} d t & \\
& \leq r &
\end{array}
$$

Recall that $c(t)$ denotes the number of crews working on the day of time $t, u_{i}$ denotes the importance of rate-limiting factor $i$ (such as another lifeline), $g_{i}(t)$ denotes the flow of rate-limit factor $i$ at time $t$ (such as the fraction of fuel required that is actually available at time $t), d_{0}$ denotes the unconstrained repair duration, and $r$ denotes the total number of repairs.

Equation 35 treats the effect of multiple required resources as multiplicative rather than a simple sum, but conceivably the effect is greater. The loss of only one out of two redundant resources (for example, commercial power and emergency onsite power) might not hinder repairs at all, whereas the loss of both might entirely prevent repairs. I acknowledge that such a complication is possible, but for simplicity do not treat it here.

Note that for other lifelines, $F(t)$ might be part of a ratelimiting factor. For example, communication might require water service for evaporative cooling to cool some central offices. Suppose for example that from the perspective of communication, water has a $u$-value of 0.5 (half of central offices have evaporative cooling) and a $g$-value equal to the fraction of water services available, that is;

$$
g_{\text {water }}(t)=\frac{V(n)}{M} .
$$

Water might in turn rely on communications, so a time series of simultaneous equations would have to be solved to find the simultaneous serviceability of multiple lifelines and other resources such as consumable repair supplies over time. I refer to the time series of restoration curves that satisfy their mutual restoration rates at all points in time as the equilibrium restoration solution.

\section{Ordering Lifelines to Avoid Circular Lifeline Interaction}

It would be desirable to avoid having to solve simultaneous equations to find the equilibrium restoration solution. I introduce a simplification for practicality by constraining the model of lifeline interdependencies so that lifelines do not affect one another in a circle - that is, there are no pairs of lifelines $i$ and $j$ where $j$ depends on $i$ and $i$ depends on $j$, either directly or through some intermediate lifeline $k$.

The lifeline interaction matrices presented above in the Lifeline Interaction section do not clearly order the lifelines; there is no sense that the third row is somehow more or less of anything than is the second row. However, to deal with circular interactions I introduce an order to the lifeline interaction matrix so that lifelines appear in it in an approximate one-way chain of dependence, from so-called upstream lifelines first (upper rows, left-hand columns) to downstream lifelines last (lower rows, right-hand columns). If lifeline $j$ depends on lifeline $i$, either directly or through an intermediary, but not vice versa, then I refer to lifeline $i$ as being upstream of lifeline $j$, and order $i$ before $j$. In our one-way model, downstream lifelines depend only on upstream lifelines or on none at all, and not vice versa.

This simplification requires compromising the fidelity of the model, because circular interactions probably exist. It takes fuel to repair a road, but to deliver fuel, one must drive over roads. This complication is ignored here for computational simplicity. There may be no right way to perfectly order these resources, and different people may judge the proper order differently. I propose the following order of lifeline repair resources, from upstream to downstream, based on the following rationale:

1. Consumable repair supplies.-Without repair supplies, one cannot repair fuel supplies, roads, electricity, communications, water, or wastewater. They are commonly stored and do not spoil or otherwise depend on fuel, roads, electricity, mobile telecommunications, natural gas, water, or wastewater.

2. Fuel.-Without fuel for repair vehicles, one cannot repair roads, electricity, communications, gas, water, or wastewater. One cannot pump fuel until damaged equipment at fuel depots is repaired, which requires consumables, but repairs do not require roads, electricity, mobile telecommunications, natural gas, water, or wastewater to use. Admittedly without water, one cannot create fuel, but fuel can be transported from somewhere else that has water. One must also use roads to access and to deliver fuel; however, the road network is so redundant, and it is often easy enough to travel at least slowly over damaged roads that any dependence seems weak.

3. Roads.-To repair roads requires consumable repair supplies and fuel, but one can operate roads without electricity, natural gas, water, or wastewater. One can communicate with road repair crews through direct, faceto-face meeting.

4. Electricity.-To repair damaged electric generation, transmission, and distribution facilities requires consumable repair supplies, fuel, and access by roads. One can repair electrical systems without electricity, natural gas, water, and wastewater. One can communicate with electrical repair crews through direct, face-to-face meeting.

5. Communication, especially mobile telephones.-Damage to central office and cell-tower equipment requires consumable 
repair supplies. Powering then requires electricity or fuel. As with fuel, the dependency of communication on roads is weak but the dependency of roads on communication seems weaker. Operating or repairing central offices and cell towers does not seem to require natural gas, water, or wastewater. An exception is that some central offices may employ evaporative cooling, which requires makeup water.

6. Natural gas.-The repair of damaged natural-gas pipelines and other components requires consumable repair supplies, fuel, and roads (to a modest extent). Repair of damaged natural-gas pipelines seems like a time-critical need that requires rapid communication and coordination, which seems to call for electricity and communication. To operate a natural-gas system does not seem to require water or wastewater.

7. Water.-The repair of a damaged water system requires consumable repair supplies, fuel, and roads (to a modest extent). To supply water in a pressure zone that relies on pumping requires electricity. Repair of damaged water pipelines seems like a time-critical need that requires rapid communication and coordination, which seems to call for electricity and communication. To operate a water system does not seem to require natural gas, so the order of natural gas and water repairs is arbitrary. The operate a water system does not seem to require a functioning wastewater system.

8. Wastewater.-The repair of a damaged wastewater system requires consumable repair supplies, fuel, and roads (to a modest extent). To treat wastewater and to operate water-lift stations requires electricity. Coordinating the repair of damaged wastewater pipelines seems to depend to a limited extent on electricity and communication. To operate a wastewater system does not seem to require natural gas, so the relative order of natural gas and wastewater is arbitrary. To operate a wastewater system does not seem to require a functioning water system, so their relative order also seems arbitrary.

\section{Rate-limiting Factors for Lifeline Repairs}

In the present formulation, the effect of the loss of a repair resource is quantified by the rate-limiting factor $u$ that measures the reduction in repair productivity (repairs per unit time) when the required resource is unavailable. In the case of water supply, the list of tasks required to repair a pipeline break or leak (table 2) indicates that the rate-limiting factors include communications, electricity, fuel, site safety (for example, no fire), roadway access, and consumable repair materials. How much does the loss of each resource slow repairs?:

- Consumables.-Without replacement pipe and fittings, clamps, and other components, repairs do not proceed. Let $u_{\text {consum }}=1.0$.
- Fuel.- Required for a repair crew to travel to the location of the damage, operate a backhoe to dig down to the water main, and to backfill the excavated area (tasks 2,6 , and 9 in table 2). Repairs do not proceed at all without fuel. I therefore assign $u_{\text {fuel }}=1-8 \mathrm{hr} / \infty=1.0$. That is, repair productivity drops by 100 percent while fuel is unavailable.

- Roads.-Damage to roads could delay the initial delivery of additional equipment and crews, but the roadway network is highly redundant. Let $u_{\text {road }}=0.0$.

- Electricity 1.-In the case of a water-supply system that relies entirely on gravity to supply water, electricity is required for receiving notices about damage (task 1), referring to GIS-based system maps (not shown in table 2), and powering stoplights that control traffic and facilitate crews traveling from repair to repair. I assume that the addition time required to refer to paper maps occurs at headquarters while repairs are ongoing and does not actually slow repair crews but that travel from repair to repair increases repair duration by 15 minutes: $u_{\text {electr }}=1-8 \mathrm{hr} / 8.25 \mathrm{hr}=0.03$. That is, repair productivity drops by 3 percent while electricity is unavailable.

- Electricity 2.-In the case of a water-supply system with pumped pressure zones, repairs may require electricity to provide water in order to locate leaks. For a utility with pumped pressure zones that relies on the commercial electric utility to provide a fraction $z$ of its services (that is, after accounting for the utility's own emergency generators), I add the quantity $z$ to $u_{\text {electr }}$ as calculated above, that is, $u_{\text {electr }}=0.03+z$.

- Communications.-I treat this solely as cellular communications and assume that utilities possess or can quickly acquire portable radios to communicate between their headquarters, repair crews, and a county emergency operations center. Compared with cellular, using a radio to communicate might slow the effort of receiving notices about water-main damage (task 1) and contacting other utilities to coordinate safety (task 4). Using radios might reduce repair productivity slightly, but not enormously. I assume that radio communication would increase the time to perform one repair by say 30 minutes in an 8-hour repair, suggesting $u_{\text {commun }}=1-8 \mathrm{hr} / 8.5 \mathrm{hr}=0.06$ for communications. That is, repair productivity drops by 6 percent while cellular service is unavailable.

Site safety is not discussed in the Lifeline Interaction section but seems worth addressing if only to dismiss it. I assume that fires do not alter the order in which repairs are performed but do prevent repairs and that gas leaks will be shut off in a matter of hours after the earthquake and will not substantially hinder pipeline repairs afterwards. Let $u_{\text {safety }}=0.0$.

I tentatively assign the $u$-values shown in table 9 . The table shows for example that consumables (such as pipe and clamps) have a $u$-value of 1.0 for water supply. By equation $35, u=1$ means 
that repairs depend so strongly on consumables that without them repairs halt. That is, if at some point in time $t$, the available supply runs out, $g(t)=0$ for consumables, and repair rate $f(t)$ goes to 0 until supply is restored.

I have assigned the same $u$-values to other lifelines that I have proposed for water, with one exception. It seems as if restoring mobile telephone service (under the label of communication) is more dependent on electricity than are water-pipeline repairs. Presumably the repair of equipment in central offices and the repair of cell towers requires either on-site generators or commercial power to power the equipment. Cell towers are generally supplied with onsite power in the form of uninterruptible power supply (UPS) sufficient for 4 to $8 \mathrm{hr}$ of service if commercial power is interrupted (S. Daneshkhah, Sprint, oral commun., November 4, 2014). In the case of Verizon Wireless, 90 percent of cell sites in northern California are also equipped with generators in addition to UPS (T. Serio, Verizon Wireless, oral commun., January 14, 2014).

I guess that all central offices and 1 in 3 cell towers have a generator on site (as in the case of most Verizon towers) and that, telecommunication being a national security priority, carriers can supply fuel to those central offices and towers. I guess that repairing the cell towers is what dominates repair efforts for cellular communications. If 33 percent of cell towers have generators, then the loss of commercial electricity prevents 67 percent of repairs entirely and does not hinder the other 33 percent at all, hence productivity drops by 67 percent, implying $u=0.67=0.33$. The $u$-values are qualitatively consistent with the San Francisco Lifeline Council's (2014) lifeline system interdependency matrix, in that darker shading in table 7 corresponds to higher numerical values in table 9 .

\section{Depicting Lifeline Interaction with an Influence Diagram}

It can sometimes help to depict the relations among decisions, uncertain quantities, and value outcomes using an influence diagram. These diagrams, sometimes also called a relevance diagrams, decision diagrams, and decision networks, are graphical representations of a decision situation. They can represent a mathematical model that relates the decisions, uncertain quantities, and uncertain value outcomes with functional relations. They are commonly used in decision analysis. They tend to be more compact than decision trees, able to show more information in less space. The interested reader is referred for more background on influence diagrams to Howard (1990). The interdependencies implied by table 9 are depicted in an influence diagram in figure 10.

In figure 10, decisions are depicted in rectangles, uncertain quantities in ovals, and mathematical dependency by arrows. Time generally flows from left to right or from top to bottom in an influence diagram; here time flows from left to right. Each arrow starts at a quantity (a decision or an uncertainty) and points to another quantity. An arrow implies that the second quantity depends to some extent on the first. Where there is no arrow connecting one quantity to another, the implication is that neither quantity depends on the other. For example, there is no arrow from roadway restoration to any of the other lifeline restoration uncertainties. This is not strictly true, at least according to the San Francisco Lifelines Council (2014) and other lifeline interaction matrices, but for practical reasons any such dependency can be ignored because the roadway network is so redundant that it seems unlikely that realistic roadway damage could significantly impair restoration of other lifelines. There is an arrow corresponding to each nonzero quantity in the interdependency matrix of table 9. The arrow is omitted where the corresponding $u$-value in table 9 has a zero value.

Figure 10 omits the dependence of lifeline restoration after aftershock 1 on fuel supply and on consumable repair resources, but the omission is just for clarity. In practice, or at least in the calculations performed here, those dependencies exist.

Figure 11 distills the influence diagram to combine all upstream lifelines together and all downstream lifelines together. The figure also adds value outcomes - the quantities that in the end the analyst cares about, which in the present case is indirect business interruption loss. In this more canonical influence diagram, value outcomes are shown in hexagons at the right side of the diagram. Indirect business interruption will be quantified later in the HayWired project as a function of the restoration of the lifelines.

Table 9. Tentative interdependency $u$-values.

[ $u$ is a constant to indicate the reduction in repair productivity in the absence of a resources required to perform a repair, also called a $u$-factor. $u$-factors are assigned based on an estimate of the additional time required to carry out one repair if it is necessary to do so without the required resource. $z$ denotes the fraction of services in pumped pressure zones]

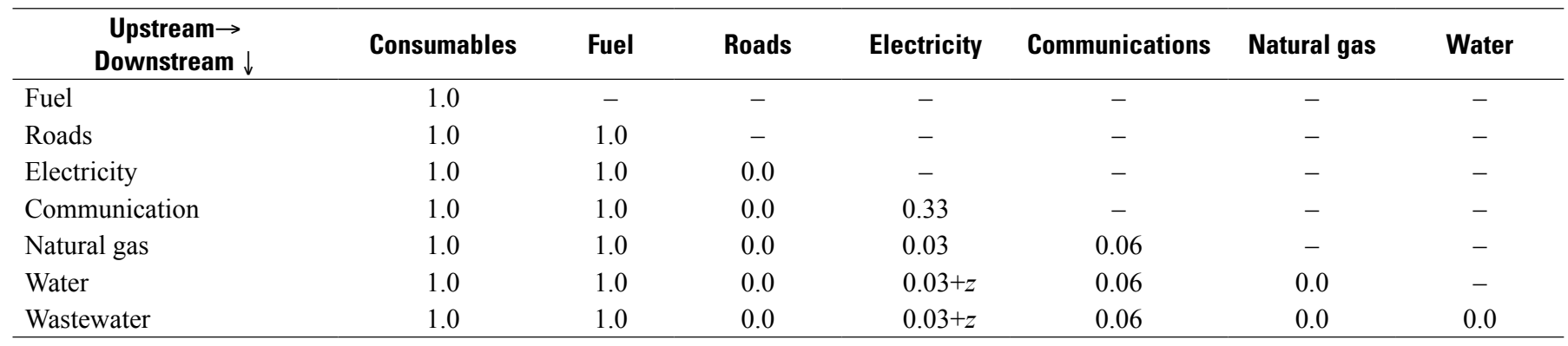




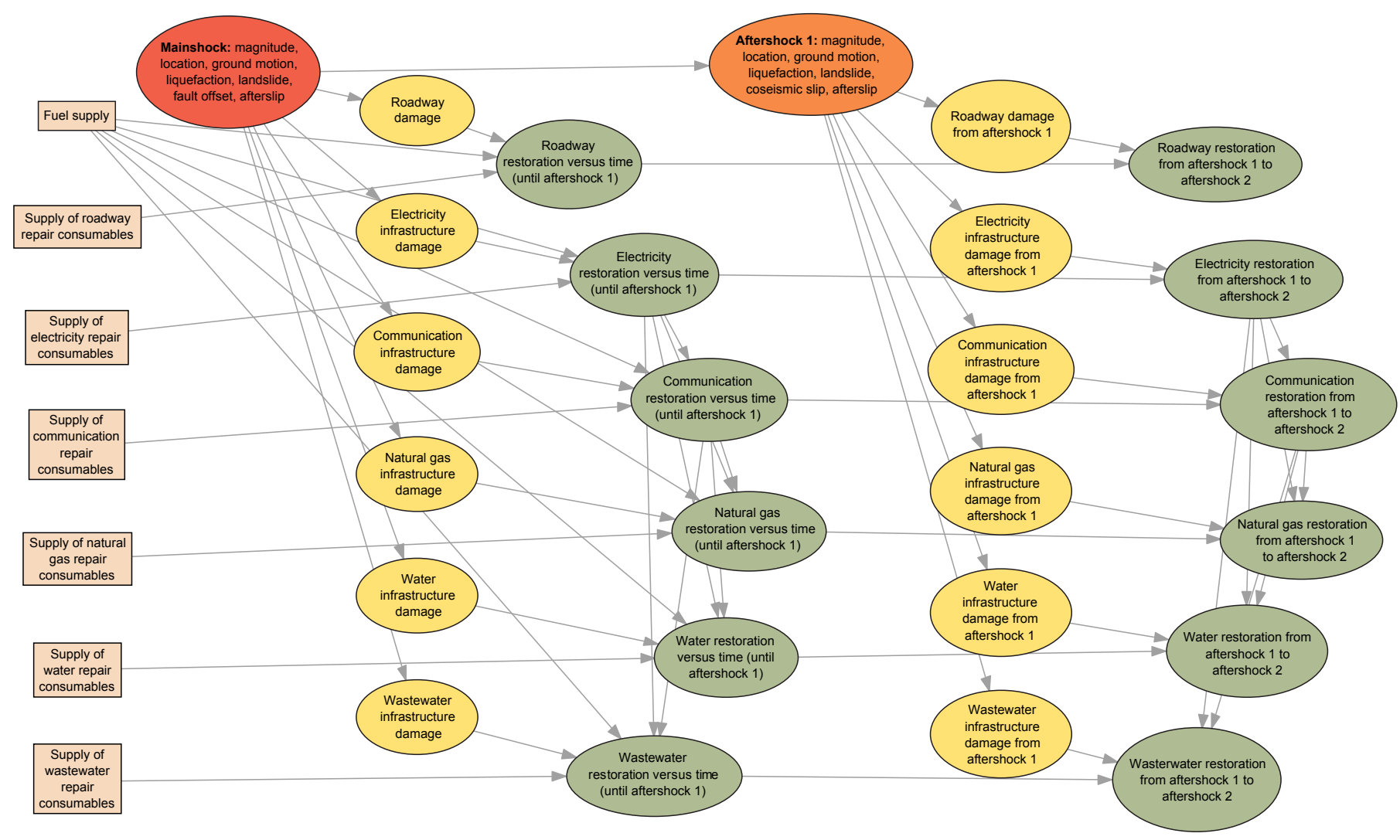

Figure 10. Lifeline interaction influence diagram. Decisions are depicted in rectangles, uncertain quantities in ovals, and mathematical dependency by arrows. An arrow implies that the second quantity may depend to some extent on the first. Colors are only used to group generalized categories.

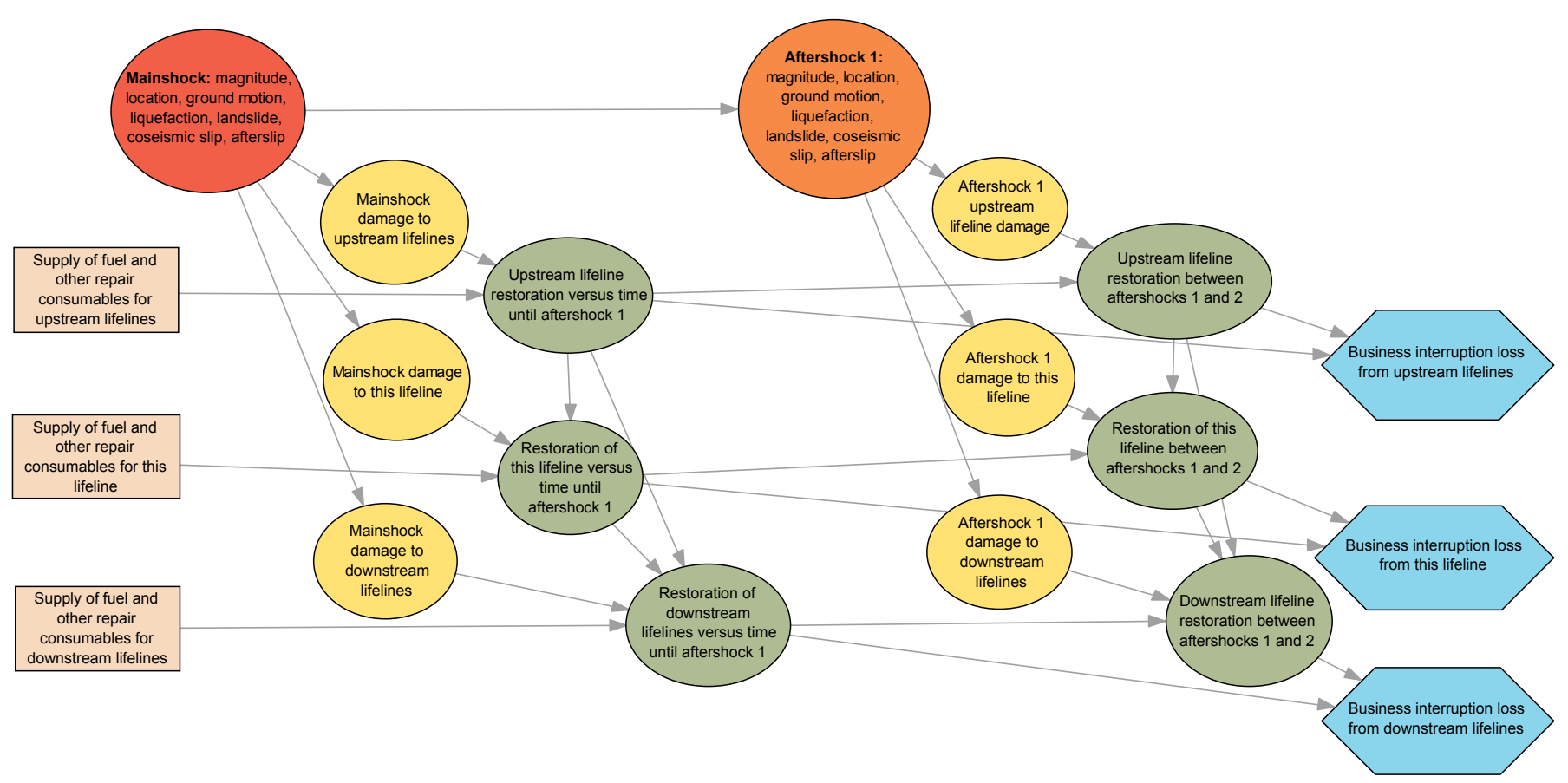

Figure 11. Alternate lifeline interaction influence diagram, with value outcomes. This diagram distills the influence diagram in figure 10 to combine all upstream lifelines together and all downstream lifelines together. Decisions are depicted in rectangles, uncertain quantities in ovals, and mathematical dependency by arrows. Value outcomes (business-interruption losses) are shown in hexagons. Colors are only used to group generalized categories. 


\section{Measuring Water-Supply Resilience}

As proposed by Bruneau and others (2003), I view the area above the restoration curve $R$ as a measure of the loss of resilience - less area means less impact, faster recovery, or both. Recall that Bruneau and others (2003) measured $R$ as in equation 39:

$$
R=\int_{0}^{t_{1}}(1-Q(t)) d t,
$$

where $Q(t)$ denotes the degree of service as a fraction of full service at time $t$ and times $t=0$ and $t=t_{1}$ denote the initiating event (the earthquake) and the time of full restoration, respectively. For present purposes, I measure $Q(t)$ as the fraction of all service connections receiving water at time $t$, whether treated or not, whether at normal pressure or not (which one can call "wet water," as opposed to treated water). Because the present analysis calculates $V(t)$, the number of service connections receiving water at time $t$, one can normalize $V(t)$ by the number of service connections, denoted here by $M$, and substitute:

$$
R=\int_{0}^{t_{1}}\left(1-\frac{V(t)}{M}\right) d t .
$$

$R$ can be seen as the average number of days a service connection loses service. It will be useful to estimate the total economic impact of the loss of resilience, which relates more closely to the number of service-days lost, $R \times M$ :

$$
R \times M=\int_{0}^{t_{1}}(M-V(t)) d t .
$$

I measure the benefit of a mitigation option in terms of the reduction in $R \times M$ relative to some baseline condition such as as-is conditions:

$$
(R \times M)=(R \times M)_{\text {baseline }}-(R \times M)_{\text {what if }},
$$

where "what-if" indicates the loss of resilience with the mitigation measure.

Suppose that in some cases, loss of water supply is the sole cause that a home or business loses function, and the home residents or business occupants experience a financial loss as a consequence. (Loss of water service caused 18 percent of business closures after the 1994 Northridge earthquake, according to Tierney's, 1995, survey.) A household might have to move temporarily to a hotel until water is restored. A business might also relocate or suspend operations until water is restored. What would be the daily cost of lost service?

One can in principle perform a proper economic analysis, similar to the analysis described by Rose and others (2011) for a hypothetical $M_{\mathrm{w}} 7.8$ earthquake on the San Andreas Fault in southern California. If an analyst finds it impractical to carry out an economic analysis such as with input-output or computable general equilibrium, one could estimate on a preliminary, orderof-magnitude basis, the economic losses to society that result from loss of water supply. To do so, one estimates societal economic losses by assigning a dollar value $L_{1}$ to one lost service-day. One then estimates the economic value of the lost water service $L$ as in equation 43 , and the economic value of a mitigation option, $\Delta L$, using equation 44 . (The monetary loss quantities $L$ and $L_{1}$ should not be confused with pipe lengths $L_{i}$ from previous equations.) To avoid confusion with the results of detailed economic analyses presented in a later volume, equations 43 and 44 are not evaluated here, nor do I offer an estimate of $L_{1}$ :

$$
L=(R \times M) \times L_{1},
$$

$$
\Delta L=\Delta(R \times M) \times L_{1} .
$$

\section{Optional Stochastic Simulation Methodology}

The present work was developed for use in the U.S. Geological Survey's HayWired earthquake scenario, which requires only a single realistic outcome, not best, worst, or mean cases or any particular probabilistic outcome. However, to make the work more generally useful, it is convenient to add features that allow the analyst to treat earthquake damage to a water-supply system as stochastic, that is, uncertain, random.

\section{Simulation of Earthquake Excitation}

I will treat the simulation of the earthquake excitation only superficially; the interested reader is referred to Chen and Scawthorn (2003) for methods to generate a stochastic set of earthquakes that are consistent with the seismicity of regional faults and their possible earthquake magnitudes and rupture locations. In the United States, the U.S. Geological Survey (USGS) National Seismic Hazard Maps (for example, Petersen and others, 2014) can offer a model of seismicity.

For each mainshock rupture in the stochastic set, one generates an earthquake sequence of foreshocks, mainshock, and aftershocks. Ogata (1998) provides a general reference for modeling aftershocks using an epidemic-type aftershock sequence (ETAS). The version of the ETAS model used for the HayWired scenario also distributes the aftershocks in space (Felzer and others, 2003). More sophisticated models mesh aftershock models with traditional fault and stress-renewal based seismic-hazard models (for example, the Uniform California Earthquake Rupture Forecast, version 3, ETAS; Field and others, 2013).

Median ground motion and logarithmic standard deviations of ground motion in each earthquake in a sequence can be calculated using convenient and regionally appropriate groundmotion prediction equations. In the case of the HayWired mainshock, the results of a physics-based model by Aagaard and others $(2010 \mathrm{a}, \mathrm{b})$ were adopted, but one can also use lessexpensive methods. For example, for shallow crustal earthquakes in active tectonic regimes, one can use the NGA-West 2 groundmotion prediction equations (see Boore and others, 2014).

Ground motion is uncertain and spatially correlated. Here, uncertain means that ground motion can be higher or lower than the median predicted by the ground-motion prediction equations, potentially many times higher and lower. It is important to treat 
that variability about the median - ignoring it will tend to bias damage and loss estimates low, as explained elsewhere in the HayWired study (Porter 2017b). One can simulate a properly varying and spatially correlated field of ground motion using the model of Jayaram and Baker (2009).

\section{Simulation of Pipeline Vulnerability}

Vulnerability of buried pipeline is uncertain. To simulate damage rate in buried pipe subjected to wave passage, landslide, and liquefaction, one can draw two samples, $u_{1}$ and $u_{2}$, from a $U(0,1)$ uniform distribution (that is, equally likely to take on any value between 0 and 1) and simulate damage rates in buried pipeline by substituting $u$ for the nonexceedance probability $p$. For example, in the present adaptation of Eidinger's (2001) model, equation 24 , one substitutes $u$ for $p$ as shown in equations 45 and 46 :

$$
\begin{aligned}
& u_{1} \sim u_{2} \sim U(0,1), \\
& R\left(P G V, P_{\mathrm{L}}, u_{1}, u_{2}\right)=\left(1-P_{\mathrm{L}}\right) \times K_{1} \times 0.00187 \times P G V \\
& \times \exp \left(1.15 \times \Phi^{-1}\left(u_{1}\right)\right)+1.88 \times K_{2} . \\
& \times P_{\mathrm{L}} \times \exp \left(0.74 \times \Phi^{-1}\left(u_{2}\right)\right)
\end{aligned}
$$

The symbol $\sim$ here means "is a sample taken from the distribution" or "is distributed like." Equation 45 says, "draw a sample $u_{1}$ and another sample $u_{2}$ from a $U(0,1)$ distribution." Each assignment can be carried out in a spreadsheet using, for example Microsoft Excel's rand() function, which produces a sample $U(0,1)$ and changes it each time the spreadsheet is recalculated.

The simulation equations assume that vulnerability to wave passage varies independently from vulnerability to ground failure but that the intrasystem vulnerability for each peril and each type of pipe is completely correlated. That is, all wave-passage damage rates for small-diameter cast-iron pipe within a system will be uniformly higher or lower than average in a given system, and all ground-failure damage rates for large-diameter asbestos cement pipe within a system will be uniformly higher or lower than average in a given system.

\section{Simulation of Damage to Buried Pipeline}

Next, simulate the damage to the buried water-supply pipeline system. The simulation treats the damage rates as uncertain as shown in equation 46. I denote by $r_{i}$ the simulated damage rate in each segment of pipe. The simulation then treats the number of leaks or breaks in any given segment of buried pipe $i$ as distributed with a Poisson distribution whose mean rate $r$ is estimated from equation 28 for summand $i$. The Poisson distribution is a discrete probability distribution that expresses the probability of a given number of events occurring in a fixed interval of time or space if these events occur with a known average rate and independently of the time or distance between events. In this case, the events are breaks or leaks and the fixed interval of space is the length of the pipe segment.
So, conditioned on the mainshock shaking and ground failure values (here, $P G V$ and $P_{\mathrm{L}}$ ) at each pipe segment's midpoint, and on the vulnerability function assigned to each component (here, $K_{1}, K_{2}$, and length $L$ values for each pipeline segment), the simulation assumes that the probability of exactly $y$ breaks or leaks on segment $i(y \in\{0,1,2, \ldots\})$ is given by equation 47 . The probability that $y$ or fewer breaks or leaks occur is given by equation 48 , which is the cumulative distribution function for the Poisson distribution with rate parameter $r_{i}$ :

$$
\begin{gathered}
P\left[Y_{i}=y\right]=\frac{r_{i}^{y} \exp \left(-r_{i}\right)}{y !}, \\
P\left[Y_{i} \leq y\right]=\sum_{n=0}^{y} \frac{r_{i}^{n} \exp \left(-r_{i}\right)}{n !}, \\
Y_{i}=\max \left(y: u_{i} \leq P\left[Y_{i} \leq y\right]\right) .
\end{gathered}
$$

To simulate a particular number of repairs in segment $i$, one draws a sample $u_{i}$ from a uniform distribution $u_{i} \sim U(0,1)$ and solves equation 49 for $y$. The equation inverts the cumulative distribution function of a Poisson distribution with rate $r_{i}$ at $u_{i}$ to produce the number of simulated breaks on segment $i$. I know of no closed-form expression for the value of $Y_{i}$ in equation 49, but simulation software such as @Risk (http://www.palisade.com/ decisiontools_suite/) can perform the simulation.

Equation 49 does not include breaks at where the pipeline crosses the fault. To deal with pipe breakage at fault offset, I take $d_{f}$ from equation 28 as uncertain. It is common to take fragility functions as approximated by a lognormal cumulative-distribution function, so absent a better empirical or analytical model, I do so here, and assume a median value $\theta=4$ inches and logarithmic standard deviation $\beta=0.6$. I propose this particular median value because it seems like a reasonable threshold in light of Eidinger's liquefaction vulnerability function in figure 7. I propose this particular logarithmic standard deviation because it reflects a relatively large degree of uncertainty, compared with other fragility functions such as those in FEMA P-58-1 (Applied Technology Council, 2012).

To use these fragility parameters to model pipe breaks due to fault offset, for each segment $i$ that crosses the fault, add 0 or 1 pipe breaks per equation 50 . In the equation $Z_{i}$ denotes either 0 or 1 pipe breaks produced by fault offset at segment $i, I(\cdot)$ is the indicator function (1.0 if the term in parentheses is positive, 0.0 if negative), $\Phi(\cdot)$ is the standard normal cumulative distribution function evaluated at the term in parentheses, $d_{i}$ is the fault offset distance where the fault intersects pipeline segment $i, \theta$ and $\beta$ are as just defined, and $u_{i}$ is another sample from a uniform distribution $u_{i} \sim U(0,1)$. To explain the equation, the $\Phi$ term gives the probability that segment $i$ is broken. If $u_{i}$ is less than that probability, then the simulation says that that segment is broken, that is, that that segment's uncertain capacity to resist fault offset was less than $d_{i}$ :

$$
Z_{i}=I\left(\Phi\left(\frac{\ln \left(d_{i} / \theta\right)}{\beta}\right)-u_{i}\right)
$$


Finally, one can sum over all pipeline segments to simulate the total simulated number of breaks $W$, as in equation 51:

$$
W=\sum_{i=1}^{n}\left(Y_{i}+Z_{i}\right) .
$$

\section{Simulation of Restoration}

As shown in figure 9, time to repair a break or leak is uncertain and approximately lognormally distributed. I use the parameters derived from Schiff's (1988) data for small-diameter pipe and the assumed parameters for large-diameter pipe as recapped in table 10. Repair duration for a single break or leak can be estimated using equation 52 . In the equation, $u_{i}$ is a random number drawn from a uniform distribution, $u_{i} \sim U(0,1)$, and is not the same $u_{i}$ value as used elsewhere in this section:

$$
d_{0, i}=\theta \cdot \exp \left(\beta \cdot \Phi^{-1}\left(u_{i}\right)\right) .
$$

It is problematic to offer a stochastic model for number of services lost as a function of damage (the serviceability index), partly because the use of the serviceability index seems so tenuous to begin with. Treating it as uncertain with a specified model seems like illusory thoroughness - "cutting the baloney too thin." However, until a better model comes along, I treat the initial level of service $V_{0}$ (now an uncertain quantity rather than a deterministic value) as beta-distributed with bounds 0 and 1 , mean value given by equation 53 , and coefficient of variation $\delta=0.5$ (this last by eye from fig. 4). (For the reader who is unfamiliar with the beta distribution, it is a commonly used probability distribution for an uncertain quantity that can take on a value only between two bounds, such as between 0 and 1 , and has a specified mean and standard deviation.) The parameters of the beta distribution, denoted here by $\alpha$ and $\beta$, can be calculated as shown in equations 55 and 56 . The inverse cumulative distribution function for the beta distribution is approximated by the inverse of the Kumaraswamy cumulative distribution function (Kumaraswamy, 1980; Jones, 2009), which is easier to calculate. One generates a sample of a uniform distribution $v \sim U(0,1)$ and evaluates the inverse cumulative distribution function of the Kumaraswamy distribution as shown in equation 57 to produce a sample of the initial level of service $V_{0}$ :

$$
\begin{gathered}
\mu=M \times s(r) \\
=M \times\left(1-\Phi\left(\frac{\ln \left(\frac{r}{L \times q}\right)}{b}\right)\right), \\
\delta=0.5, \\
\alpha=\frac{(1-\mu)}{\delta^{2}}-\mu, \\
\beta=\alpha \times\left(\frac{1}{\mu}-1\right),
\end{gathered}
$$

Table 10. Parameters for uncertain pipe-repair duration (see equation 52).

\begin{tabular}{lccc}
\hline \multicolumn{1}{c}{ Diameter } & $\begin{array}{c}\text { Median, } \\
\boldsymbol{\theta}\end{array}$ & $\begin{array}{c}\text { Logarithmic standard } \\
\text { deviation, } \boldsymbol{\beta}\end{array}$ & Basis \\
\hline $\begin{array}{l}\text { Small } \\
(<20 \text { inches })\end{array}$ & 6.1 hours & 0.58 & Schiff $(1988)$ \\
$\begin{array}{l}\text { Large } \\
(\geq 20 \text { inches })\end{array}$ & 16 hours & 0.6 & $\begin{array}{c}\text { Schiff }(1988) \text { and } \\
\text { this chapter }\end{array}$ \\
\hline
\end{tabular}

$$
V_{0}=F^{-1}(v)=\left(1-(1-v)^{1 / \beta}\right)^{1 / \alpha} .
$$

The rate-limiting factors for lifeline repairs can similarly be treated as beta-distributed (which one can approximate using the Kumaraswamy distribution as before) bounded by 0 and 1 , with means as proposed in table 9 . Values that are assigned 0 or 1 in the table can be taken as certain, that is, with coefficient of variation equal to 0 . Rate-limiting factors greater than 0.0 and less than 1.0 are uncertain; I take their coefficient of variation as substantial, say 1.0. That is, let:

- $u=$ a sample of the (possibly uncertain) rate-limiting factor,

- $m=$ expected value of the rate-limiting factor, from table 9,

- $d=$ assumed coefficient of variation of the rare-limiting factor,

- $d=1, m \notin\{0,1\}$ (the symbol $\notin$ means "is not a member of the set listed here"), $d=0, m \in\{0,1\}$ (the symbol $\in$ means "is a member of the set listed here"),

- $v=$ a sample of a uniform distribution bounded by 0 and 1 , that is, $v \sim U(0,1)$. (I use $v$ here for the sample uniform variate because $u$ is already in use in this step.)

Then, equations 58 through 60 follow as:

$$
\begin{array}{rlr}
a=\frac{(1-m)}{d^{2}}-m & d \neq 0, \\
b=a \times\left(\frac{1}{m}-1\right) & d \neq 0, \\
u=\left(1-(1-v)^{1 / b}\right)^{1 / a} & d \neq 0 \\
=m & d=0, \text { that is, } m \in\{0,1\}
\end{array}
$$

\section{Accounting for Afterslip and Aftershocks}

Aftershocks produce new damage to a system that may be only partially repaired. To estimate the number of required repairs after an aftershock, I estimate new damage as if it occurred to a pristine system. Add the number of repairs that have not yet been completed, and recommence the calculation of services restored by the $n$th repair and time required to perform the $n$th repair. 
Afterslip can increase the deformation on a pipeline segment at a fault crossing where a pipeline is already strained by coseismic (and possibly preseismic) slip. One way to model pipeline damage due to afterslip is to treat the pipe as having a fixed capacity to resist deformation.

When the coseismic slip plus afterslip at a point where a pipeline segment crosses a fault reaches that capacity, the pipe breaks. The capacity can be treated as having a deterministic value or a probabilistic value. As discussed above in the Literature Review section, the capacity in reality depends on the material, pipe diameter, jointing, and sense of deformation; that is, whether in tension, shear, or compression. For simplicity for present purposes, I propose to treat the capacity as having a single scalar quantity for all materials (for example, diameters) per equation 26 for a deterministic model or equation 50 for a stochastic model.

\section{Adjusting Hazus-MH's Lifeline Restoration Model}

As discussed in the Literature Review section, Hazus-MH (Federal Emergency Management Agency, 2012) is FEMAfunded software. It is used to perform risk analysis for earthquakes, hurricanes, and floods in the United States.

\section{Why One Might Need to Adjust the Restoration Curves Offered by Hazus-MH}

Hazus performs hazard analysis, damage analysis, loss analysis and recovery analysis, including repair costs, life-safety impacts, and the duration and economic losses resulting from loss of function. It includes built-in asset definitions for virtually the entire built environment of the United States, including lifelines, and encodes other restoration parameters such as the number of workers available to perform repairs. It is a very powerful tool.

In the author's experience, loss-estimation software, no matter how advanced, becomes obsolete soon after its release. Users see that the software's capability extends to $\mathrm{X}$ and soon conceive of a new need " $\Delta \mathrm{X}$ " that that the software does not satisfy. Hazus-MH is like that. The new need identified here is the ability to treat lifeline interactions and aftershocks. Hazus-MH is currently closed source, so the analyst who wants to add the ability to treat lifeline interaction and aftershocks cannot do so by changing the source code, although many parameters can be changed. How can one modify the outputs, using principles presented here to do so?

\section{Adjusting Hazus-MH's Estimates of Lifeline Restoration to Account for Repair Crews}

Before addressing lifeline interaction and aftershocks, I consider the situation where a Hazus-MH analysis has already been performed and the user realizes that an important adjustable parameter - the number of workers available to perform repairs - was wrong? The Hazus-MH default value for the number of water-supply pipeline repair workers available in each county appears to be 100 regardless of the size of a county, which may be far from accurate in many cases. If the analyst has a supposedly better estimate of the number of repair workers in a particular county, how can the analyst adjust Hazus's restoration estimate to account for that better estimate of repair crews after the fact? I assume that repair progress increases linearly with number of repair crews. It seems uncontroversial to adjust Hazus' estimated restoration curve to account for a different estimate of repair-crew resources as shown in equations 61 through 63 :

$$
\begin{aligned}
V(\tau) & =\int_{t=0}^{\tau} \frac{q(t)}{q_{0}} \times\left(\frac{d \hat{V}(t)}{d t}\right) d t, \\
& \leq M
\end{aligned}
$$

where

$$
\begin{array}{rlrl}
\frac{d \hat{V}\left(t_{j}\right)}{d t} & \approx \frac{\hat{V}\left(t_{j+1}\right)-\hat{V}\left(t_{j}\right)}{t_{j+1}-t_{j}} & & j \in\{1,2, \ldots .5\} \\
& \geq \frac{d \hat{V}\left(t_{j-1}\right)}{d t} & j \in\{2,3,4,5\}
\end{array} .
$$

I also assume

where

$$
\hat{V}\left(t_{6}\right)=M,
$$

- $V(\tau)=$ estimate of the number of service connections with water service at time $\tau$, after adjusting for the number of workers in the grographic area of interest (for example, a county),

- $\hat{V}\left(t_{j}\right)=$ Hazus-MH's estimate of the number of service connections with water service at time $t_{j}$, assuming default values of the number of workers in the geographic area of interest,

- $j=$ an index to points in time after the earthquake, $j \in\{1,2, \ldots 6\}$,

- $t_{j}=$ time after the earthquake, $t_{j} \in\{1,3,7,30,90,210\}$ days, where $t_{6}, 210$ days, is added to Hazus' basic list of five points in time $(1,3,7,30,90)$ days to account for the fact that Hazus-MH might report incomplete restoration at 90 days and that the analyst may need to evaluate restoration after 90 days, assuming full restoration by 7 months (I use 7 months because a later calculation shows that a rounder number like 6 months is not enough for one agency):

- $q(t)=$ analyst's estimate of the number of water pipeline repair workers available in a county at time $t$,

- $q_{0}=$ Hazus-MH default value used in the analysis (for example, 100),

- $M=$ number of service connections in the geographic area of interest (a county). 
The inequality in equation 62 is necessary in case $\hat{V}\left(t_{j+1}\right)$ $=M$, that is, the unadjusted Hazus estimate of restoration is complete in the time between $t_{j}$ and $t_{j}+1$, which would produce an unrealistically low restoration slope.

I refer to $q(t) / q_{0}$ as the repair-crew availability factor, and I refer to $V(t)$ as the repair-crew-adjusted estimate of restoration before accounting for lifeline interaction. Equation 61 says that the pace of repairs at time $\tau$ is estimated as Hazus' estimate (the derivate gives the rate of restoration; that is, services restored per unit time), increased by the repair-crew availability factor (that is, to account for the analyst's estimate of the correct number of repair workers available at time $\tau$, and integrated from time 0 to time $t$ ).

For the special case of constant $q(t)$, I substitute the constant $q$ for $q(t)$. Given constant $q$ and piecewise linear restoration $V(t)$ to go with Hazus-MH's limited set of $\hat{V}(t)$ values, one can evaluate equation 61 to evaluate the repair-crew-adjusted estimate of restoration before accounting for lifeline interaction as shown in equation 64:

$$
\begin{aligned}
V\left(t_{j}\right) & =V\left(t_{1}\right)+\sum_{k=1}^{j-1} \frac{q}{q_{0}} \times\left(\frac{d \hat{V}\left(t_{k}\right)}{d t}\right)\left(t_{k+1}-t_{k}\right) \quad j \in\{1,2,3,4,5\} \\
& \leq M
\end{aligned}
$$

\section{Accounting for Lifeline Interaction in Hazus-MH}

Hazus-MH's restoration curves do not consider lifeline interaction. As of this writing, Hazus-MH evaluates restoration at five points in time after an earthquake: 1, 3, 7, 30, and 90 days. I further modify the restoration rate from equation 61 as shown in equation 65 :

$$
\frac{d V^{\prime}(t)}{d t}=\frac{d V^{\prime}(t)}{d t} \times \prod_{i=1}^{n}\left(1-u_{i} \times\left(1-g_{i}(t)\right)\right),
$$

where

$$
V^{\prime}(t)=V\left(t_{0}\right)+\int_{\tau=0}^{t} \frac{d V^{\prime}(\tau)}{d \tau} d \tau
$$

$u_{i}$ is as previously defined (see table 9 ), and $g_{i}(t)$ is as defined in equation 33 (that is, the flow of rate-limiting factor $i$ divided by the pre-earthquake flow). In the case of a lifeline, $g$ is the fraction of service connections in upstream lifeline $i$ receiving service at time $t$, after accounting for lifeline interaction with their upstream lifelines. In the case of consumable repair supplies, $g$ is the flow of repair supplies as a fraction of the amount needed.

The product in equation 65 is just another factor that modifies the restoration rate, like $q / q_{0}$ in equation 64. I can include lifeline interaction by multiplying the restoration rate by this additional factor, as in equation 67 :

$$
\begin{aligned}
V^{\prime}\left(t_{j}\right)= & V^{\prime}\left(t_{1}\right)+\sum_{k=1}^{j-1} \frac{q}{q_{0}} \times\left(\frac{d \hat{V}\left(t_{k}\right)}{d t}\right) \times \\
& \left(\prod_{i=1}^{n}\left(1-u_{i} \times\left(1-g_{i}(t)\right)\right)\right)\left(t_{k+1}-t_{k}\right)
\end{aligned}
$$

\section{Accounting for Aftershocks in Hazus-MH}

To adjust Hazus-MH results to account for aftershock occurrence, I reduce $V(t)$ by the amount of service estimated lost when the virgin system is damaged by aftershock $j$; that is:

$$
V^{\prime \prime}(t)=V^{\prime}(t)-\left(M-V_{j}(0)\right),
$$

where $M$ denotes the number of services in the county and $V(0)$ denotes the number of service connections receiving lifeline service immediately after the aftershock, as estimated by Hazus-MH for the virgin system (that is, as if the system were undamaged at the time of the aftershock).

\section{Mitigation Options}

I consider only two mitigation options - (1) to reduce a water utility's reliance on commercial fuel and (2) to reduce the quantity of brittle pipe or pipe running through liquefiable soil. Other mitigation options certainly exist. Notable among these is the judicious replacement of selected segments of brittle pipe that are particularly important in some way, such as because they carry high flow or because they are necessary for service to an important facility.

\section{Fuel Plan}

A utility can reduce its reliance on commercial fuel supplies by installing above-ground fuel storage tanks in its service centers. An above-ground storage tank of 3,000 gallons, such as shown in figure 12, would be sufficient for 10 repair crews to operate for a week or more before needing to be refilled. The above-ground fuel tank in figure 12 has a fuel transfer pump (the red box) that can be powered by a small vehicle-mounted generator that a repair

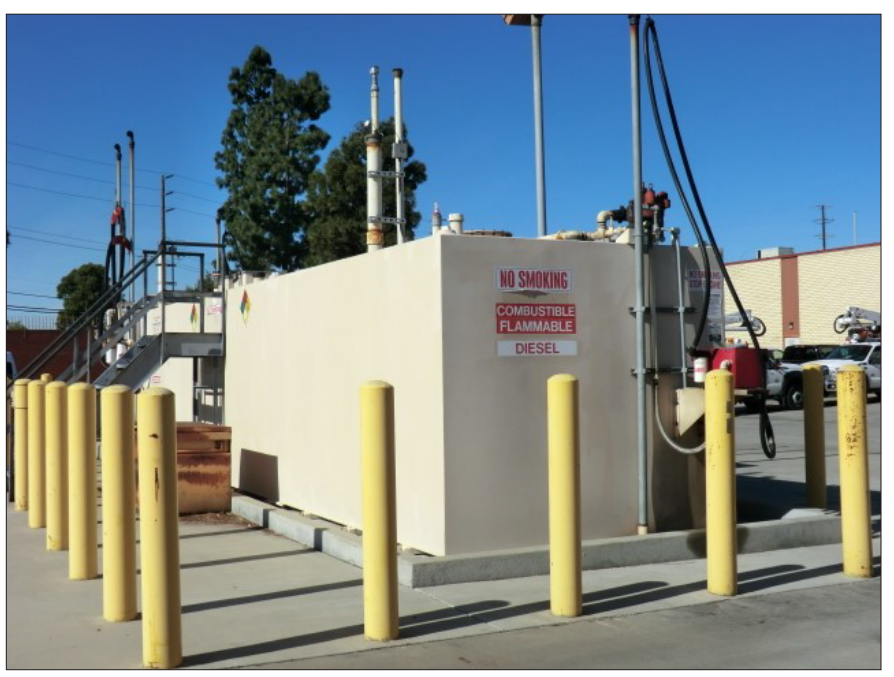

Figure 12. Photograph of a 3,000 gallon above-ground petroleum storage tank. This tank has a fuel transfer pump (the red box) that can be powered by a small vehicle-mounted generator that a repair truck can easily carry. (Photograph by Keith Porter.) 
truck can easily carry. An electrical contractor can be dispatched to connect a secondary electrical generator to a fuel island in a few hours. If trucks are regularly refilled at the end of each day, the time required to connect a fuel pump to a generator need not affect repair operations. Alternatively, service centers can be equipped with an emergency generator and switchgear to power fuel pumps in the case of commercial electric failure. At least one large California utility carries such a generator on all its repair vehicles, maintains a fuel supply of as much as 3,000 gallons or more at its service centers, and has installed emergency generators at several of its service centers.

\section{Pipe Replacement}

With an aggressive pipe-replacement program, a water utility can realistically replace 1 percent of buried pipe per year, although lower replacement rates are more common. For example, San Francisco planned to replace 1.3 percent of its water distribution pipe (15.5 miles of its 1,230-mile distribution system) in fiscal year (FY) 2016 (San Francisco Public Utilities Commission, 2015). With a sustained program that focuses on replacing brittle pipe (for example, cast iron and asbestos cement), or pipe installed in liquefiable soil, a utility could replace the majority of its brittle or vulnerable system within a few decades.

\section{Summary of the Methodology}

To summarize, the methodology proposed here models damage and restoration of buried pipelines subject to earthquake shaking (called wave passage) and ground failure (liquefaction, landslide, and surface rupture of a fault). Briefly, its steps are as follows:

1. One acquires maps of ground motion, especially PGV and ground failure (liquefaction, landslide, and fault offset), for each earthquake of interest. One uses equation 28 and then carries out the following steps.

2. Equation 28 estimates $r$, the number of repairs required because of earthquake damage, using basic loss-estimation principles.

3. Equation 29 estimates $V_{0}$, the number of service connections that have service available immediately after the earthquake. It assumes that the serviceability index (a measure of water-supply pressure loss as a function of water-supply pipeline breaks per kilometer of pipe) can be used as a proxy to estimate the fraction of services available. It would be desirable to replace this assumption, but doing so seems to require hydraulic modeling that would make the present analysis prohibitively time consuming.

4. Equation 32 estimates $V(n)$, the number of services available after $n$ repairs have been completed. It employs a parametric form for service restoration, one that reflects EBMUD engineers' strategy to perform the most effective repairs (the ones that restore the most services per repair) first and one that generally agrees with experience in the Kobe and Northridge earthquakes.

5. Equation 37 estimates $F(t)$, the number of services restored by time $t$. Lifeline interaction is quantified at this stage by a set of time-independent rate-limiting factors $u$ that indicate loss of repair productivity resulting from the loss of each upstream lifeline or other required repair resource. The lifeline interaction model modulates the time-dependent effect of the loss of required resources with a set of timedependent factors $g(t)$ that measure the flow of each resource at time $t$. One calculates $F(t)$ for each of many points in time, $t=0, \Delta t, 2 \Delta t$, and so on, where the datum $t=0$ refers to the time when the mainshock occurs.

6. To apply these equations to a mainshock, one estimates damage and immediate loss of service. Then estimate the service restoration and time required to perform the service restoration for each repair $n \in\{1,2, \ldots r\}$. Finally, one relates time to number of services available.

7. To account for aftershocks, repeat tasks $2-6$, adding the damage that remains unrepaired as if the remaining damage occurred with the aftershock.

8. To treat the entire model as stochastic (that is, random, uncertain), simulate pipeline vulnerability using equation 46 , damage using equation 49 , initial loss of service using equation 57 , and the rate limiting factors for each upstream resource using equation 60 . Carry out tasks 2-7 as before, many times. Each time represents one possible outcome. Compile the samples of whichever parameter values are of interest, and estimate any moments (such as mean and variance) of interest.

9. To account for lifeline interaction in Hazus-MH, apply equation 66, which adjusts the slope of the Hazus-calculated restoration curve to account for rate-limiting factors among upstream lifelines and then integrates the adjusted slope to produce a new restoration curve.

10. To account for aftershocks in Hazus-MH, apply equation 68 after each aftershock, which reduces each lifeline's functionality as estimated by Hazus-MH for the virgin system shaken by the aftershock. One then continues the integration over time using the adjusted mainshock restoration curve of the previous step.

\section{Case Study 1-San Jose Water Company}

I test the proposed methodology on a real water-supply system subjected to the hypothetical HayWired earthquake sequence. First consider summary features of the case study system - the San Jose Water Company's (SJWC) water-supply system's buried pipeline network. 


\section{San Jose Water Company Asset Definition}

The following statistics are taken from Elvert (2015). SJWC is 150 years old, has 225,000 service connections, and employs 345 people. It serves 80 percent of San Jose, 50 percent of Cupertino, all of Saratoga, Los Gatos, Monte Sereno, and Campbell, and unincorporated parts of Santa Clara County. Daily demand for drinking water varies from 85 to 165 million gallons, with an average daily demand for drinking water of approximately 120 million gallons. It has 2,400 miles $(4,000 \mathrm{~km})$ of water pipes (mains), 105 active wells, a 6,500-acre watershed in the Santa Cruz Mountains, 96 distribution reservoirs, two surface-water treatment plants, and performs approximately 370 water-quality tests each month.

SJWC provided an ArcGIS map of its water-supply system. The system map is shown in figure 13. The map shows $3,959 \mathrm{~km}$ of pipe of various types and lengths. Quantities of pipe are summarized by material in table 11 and by diameter in figure 14. In table 11, "Eidinger type" and "ID" refer to the assumed corresponding vulnerability functions by Eidinger (2001) and their associated vulnerability factors $K_{1}$ and $K_{2}$ from table 1. Some of SJWC's pipe does not map well to an Eidinger type, especially SJWC's steel pipe, which generally has lead or cement caulk rather than any of the joint types that Eidinger considers.

Some of the material codes do not appear in SJWC's glossary of pipe types, and are probably data-entry errors. I have made a reasonable assumption about the intended meaning, but in any case the total quantities of these questionable materials are small-30.2 of 2,459 miles, or just more than 1 percent.

\section{San Jose Water Company Hazard Analysis}

The HayWired earthquake sequence is described by Wein and others (2017). It begins with an M7.0 mainshock on the Hayward Fault, with an epicenter near the City of Oakland, that ruptures the north and south segments of the fault from a point

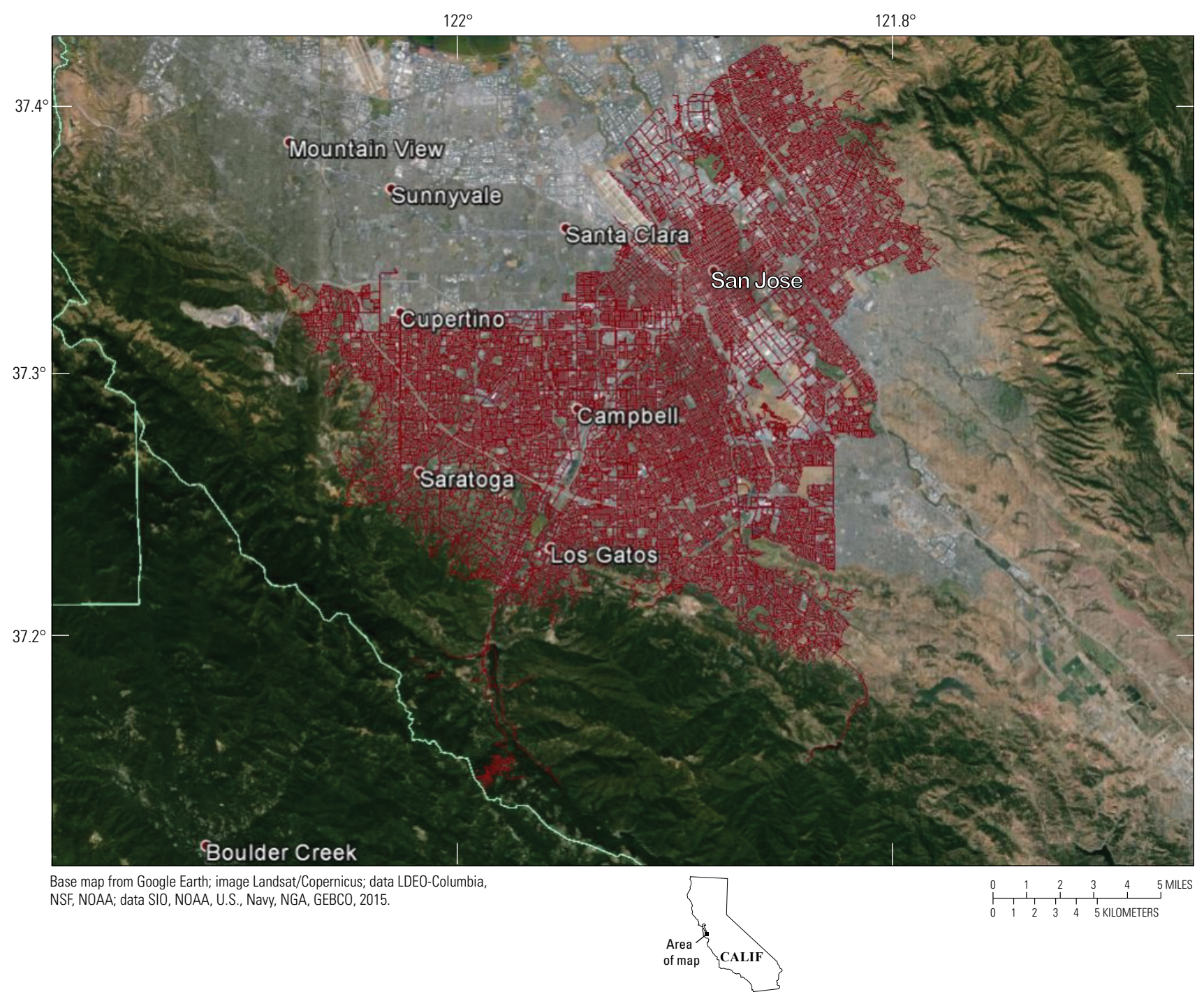

Figure 13. Satellite image of Santa Clara Valley, California, at the southern end of San Francisco Bay, annotated with a map of the San Jose Water Company's water-supply system. The 3,959 kilometers of pipe in the system are shown in red. 
Table 11. San Jose Water Company, California, pipe construction, associated with Eidinger (2001) vulnerability functions.

[Code, code for pipe material; count, number of segments of that material in San Jose Water Company buried water-pipeline system; miles and kilometers, total length of pipe material; material description, description of pipe material; Eidinger type and ID, assumed corresponding vulnerability functions of Eidinger (2001) and their associated vulnerability factors $K_{1}$ and $K_{2}$ from table 1; PVC, polyvinyl chloride]

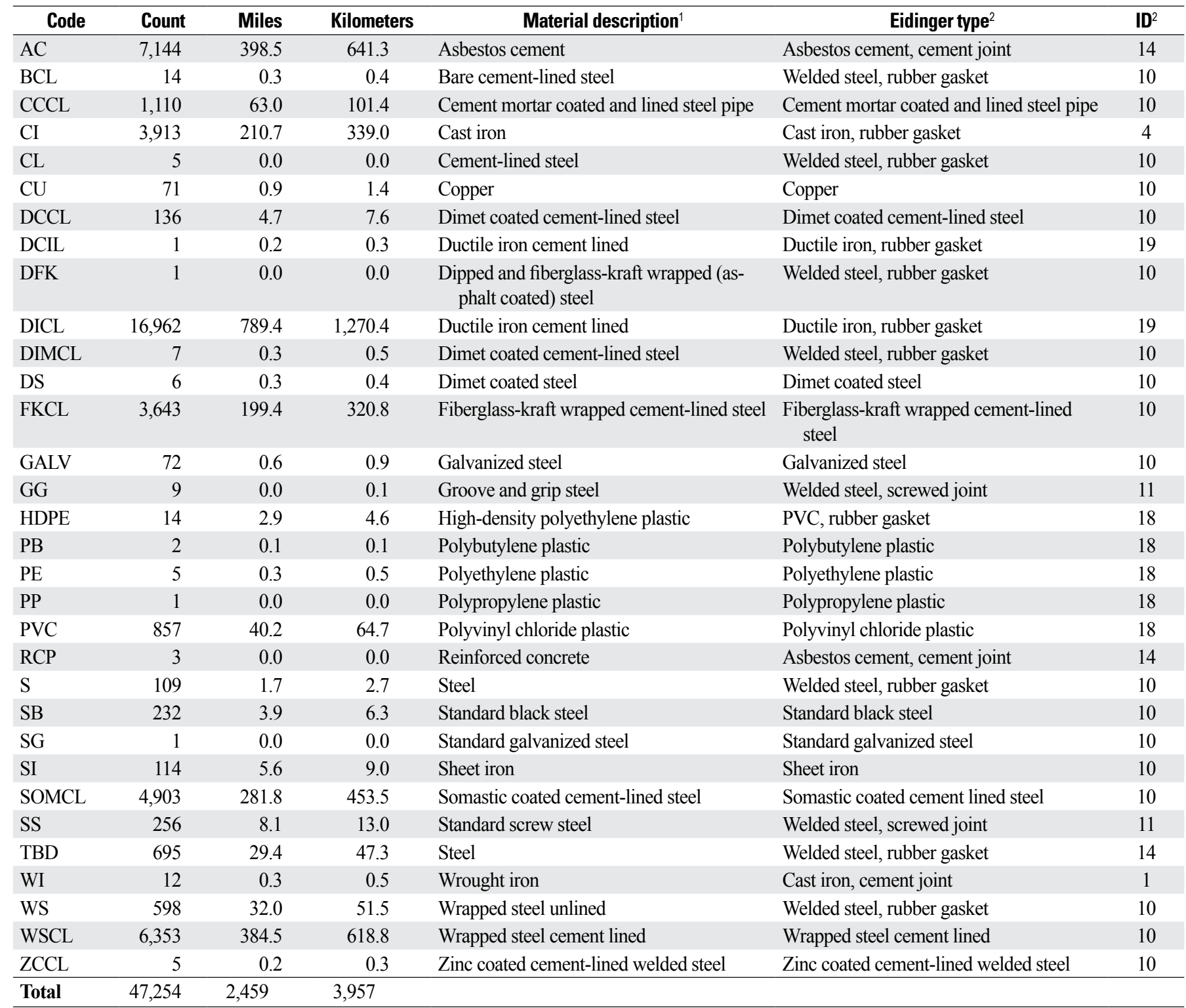

${ }^{1}$ Descriptions in italics are assumptions.

${ }^{2}$ Assumed corresponding vulnerability function from table 1 .

under San Pablo Bay at the north end to a point near the City of Hayward at the south end. It is followed by a hundreds of aftershocks of $M 2.5$ or greater. Of these aftershocks, 16 are of M5.0 or greater. Table 12 summarizes the day, location, label, and magnitude of each event. In the table, day 1 corresponds to April 18, 2018.

Figures 15, 16, and 17 show the SJWC system map overlain with HayWired mainshock peak ground velocity, liquefaction probability, and landslide probability, respectively (see Aagaard and others, 2017, Jones and others, 2017, McCrink and Perez, 2017, respectively). The mainshock surface rupture does not reach SJWC's system, so it does not appear in the figures. Figure 18 shows peak ground velocity contours in a M6.4 aftershock that occurs on day 166, that is, 5 months after the HayWired mainshock.

\section{San Jose Water Company Damage Analysis}

Table 13 summarizes mean damage to SJWC buried pipeline in the HayWired scenario mainshock (1,054 repairs). Aftershocks continue to aggravate damage, contributing 903 more repairs - 29 more in large-diameter pipe and 873 more in small-diameter pipe. See table 14 for the expected value 


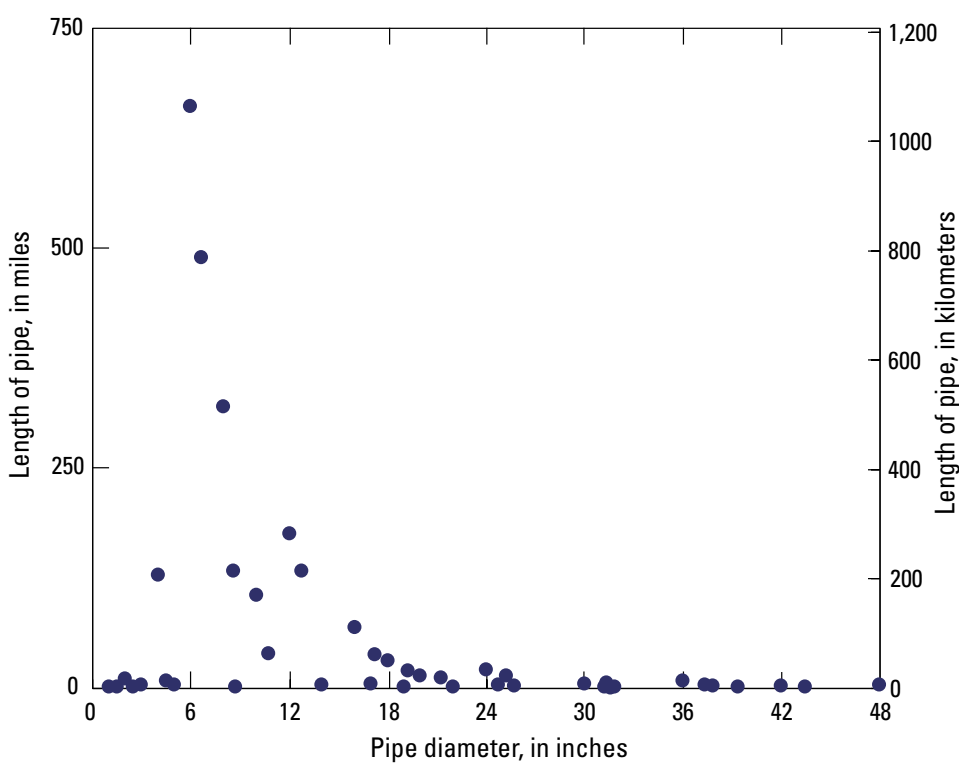

Figure 14. Graph showing pipe length by diameter in the San Jose Water Company, California, water-supply system.

Table 12. Hypothetical earthquake sequence for the HayWired earthquake scenario (Wein and others, 2017).

[Day 1 corresponds to April 18, 2018. $M_{\mathrm{w}}$, moment magnitude]

\begin{tabular}{clcl}
\hline Day & Epicenter & Name & $\boldsymbol{M}_{w}$ \\
\hline 1 & Oakland & Mainshock & 7.05 \\
1 & Union City & uc523 & 5.23 \\
1 & San Pablo & sp504 & 5.04 \\
12 & Fairfield & ff558 & 5.58 \\
15 & Fremont & fr51 & 5.10 \\
32 & Oakland & ok542 & 5.42 \\
40 & Palo Alto & pa62 & 6.21 \\
40 & Menlo Park & mp552 & 5.52 \\
41 & Palo Alto & pa569 & 5.69 \\
41 & Atherton & at511 & 5.11 \\
67 & Palo Alto & pa522 & 5.22 \\
74 & Palo Alto & pa526 & 5.26 \\
166 & Cupertino & cu64 & 6.40 \\
166 & Mountain View & mv598 & 5.98 \\
166 & Sunnyvale & sv535 & 5.35 \\
166 & Santa Clara & sc509 & 5.09 \\
492 & Palo Alto & pa501 & 5.01 \\
\hline
\end{tabular}

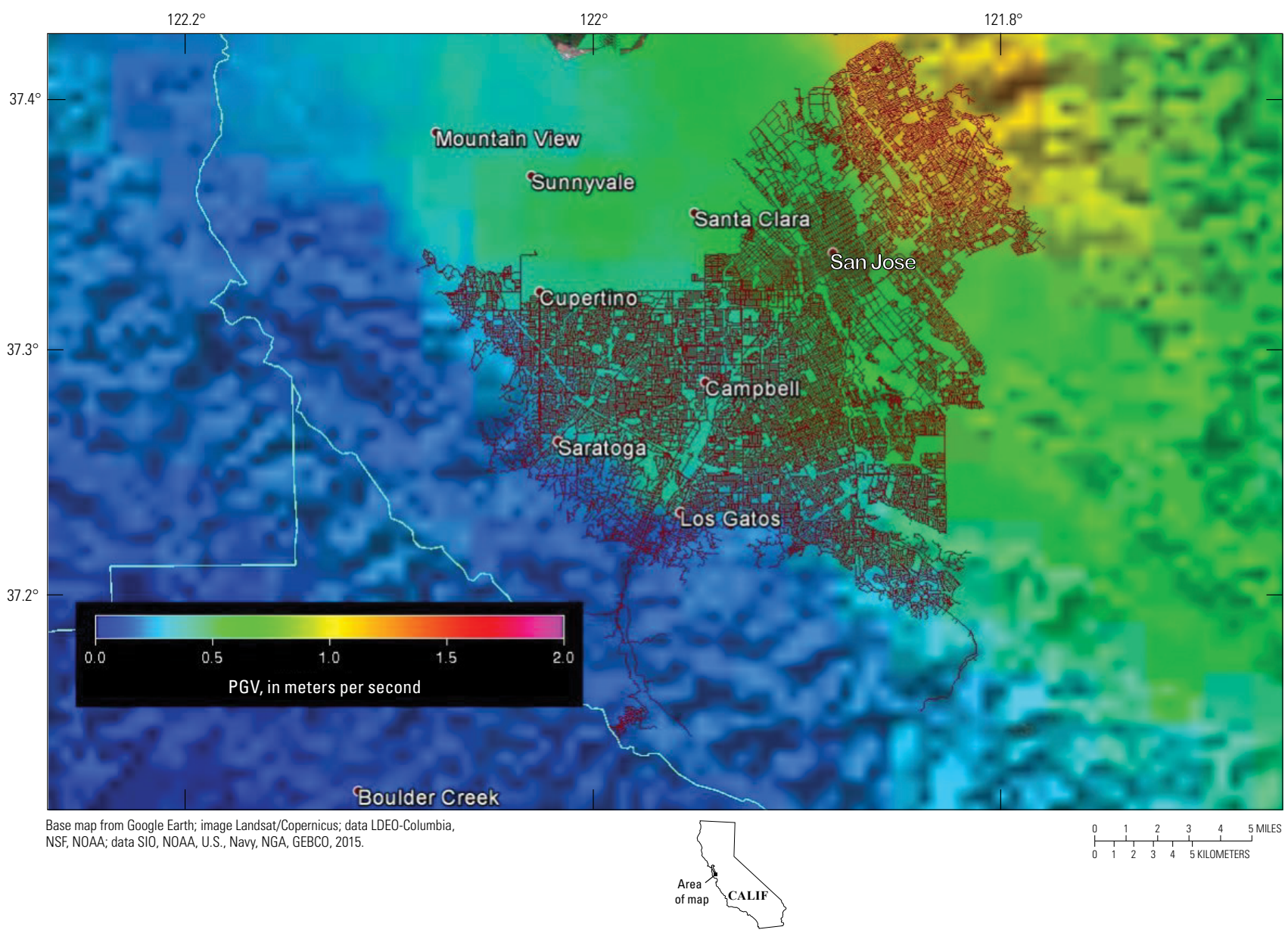

Figure 15. Satellite image of Santa Clara Valley, California, at the southern end of San Francisco Bay, annotated with a map of the San Jose Water Company's buried water-pipeline system (red). Image is overlaid with peak ground velocity (PGV) for the hypothetical moment-magnitude-7.0 mainshock of the HayWired earthquake scenario. 


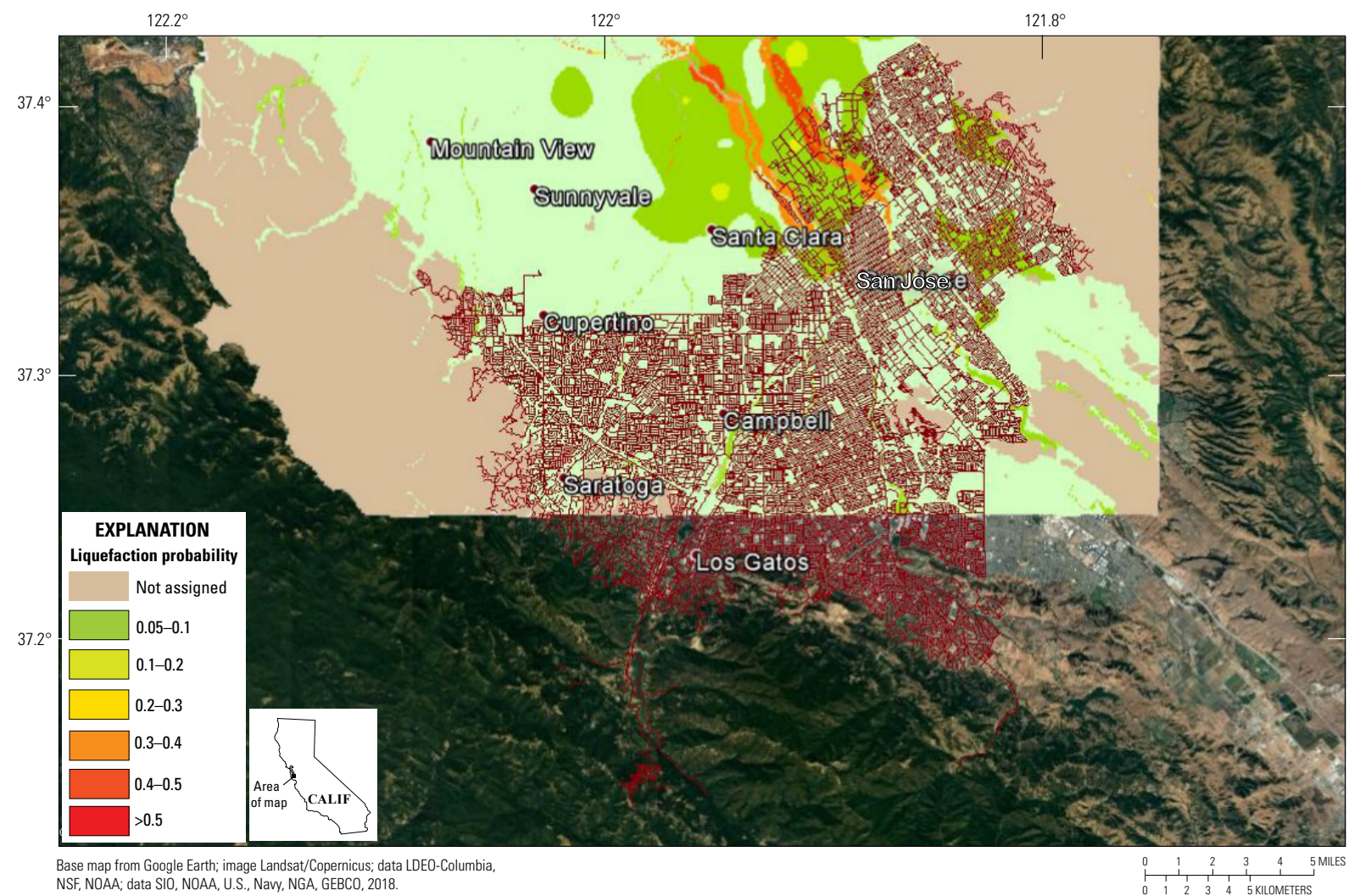

NSF, NOAA: data SIO, NOAA, U.S. Navy, NGA, GEBCO, 2018.

Figure 16. Satellite image of Santa Clara Valley, California, at the southern end of San Francisco Bay, annotated with a map of the San Jose Water Company's buried water-pipeline system (red). Image is overlaid with liquefaction probability for the hypothetical moment-magnitude-7.0 mainshock of the HayWired earthquake scenario.

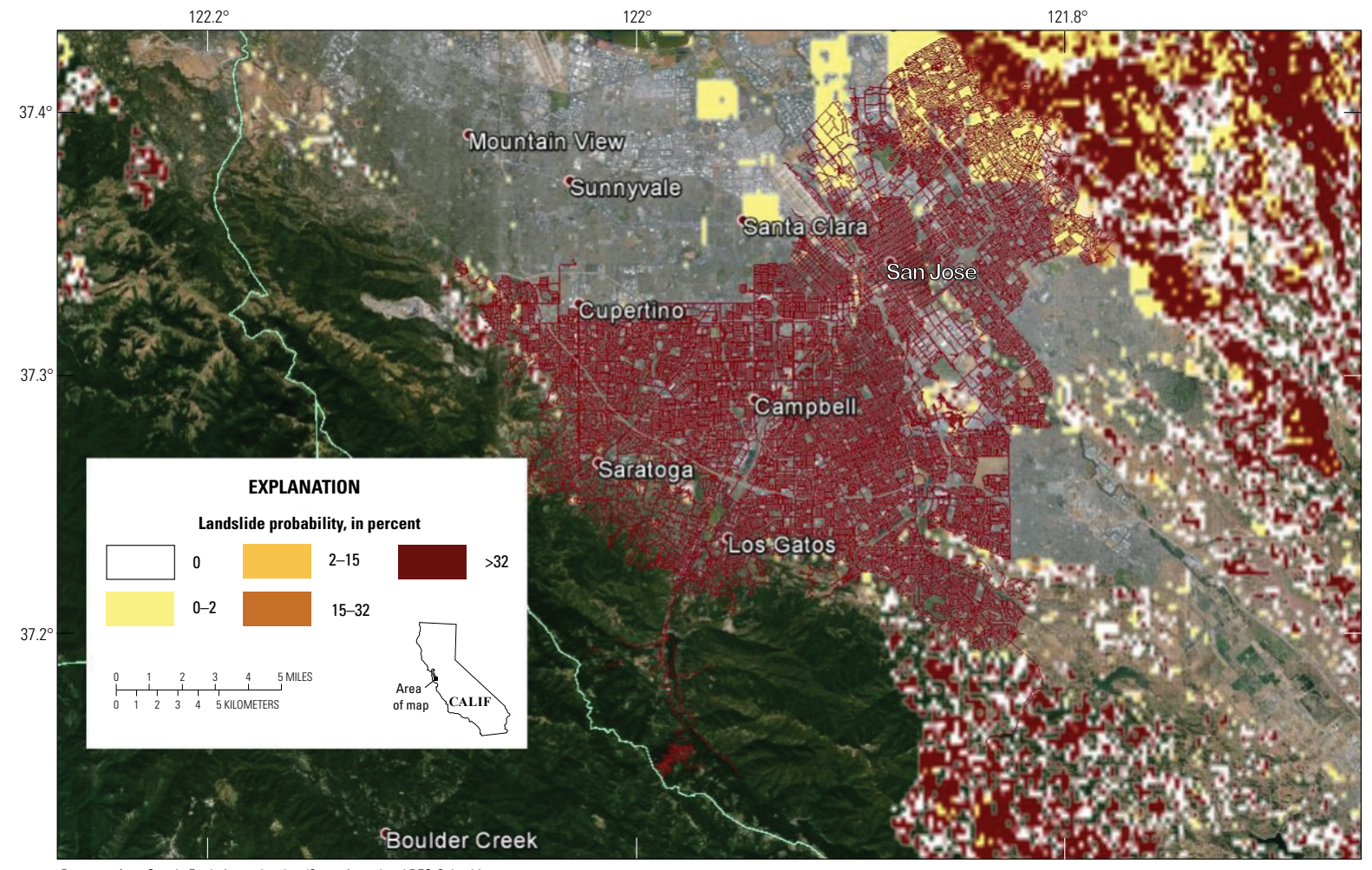

Base map from Google Earth; image Landsat/Copernicus; data LDEO-Columbia,

Figure 17. Satellite image of Santa Clara Valley, California, at the southern end of San Francisco Bay, annotated with a map of the San Jose Water Company's buried water-pipeline system (red). Image is overlaid with landslide probability for the hypothetical moment-magnitude-7.0 mainshock of the HayWired earthquake scenario. 


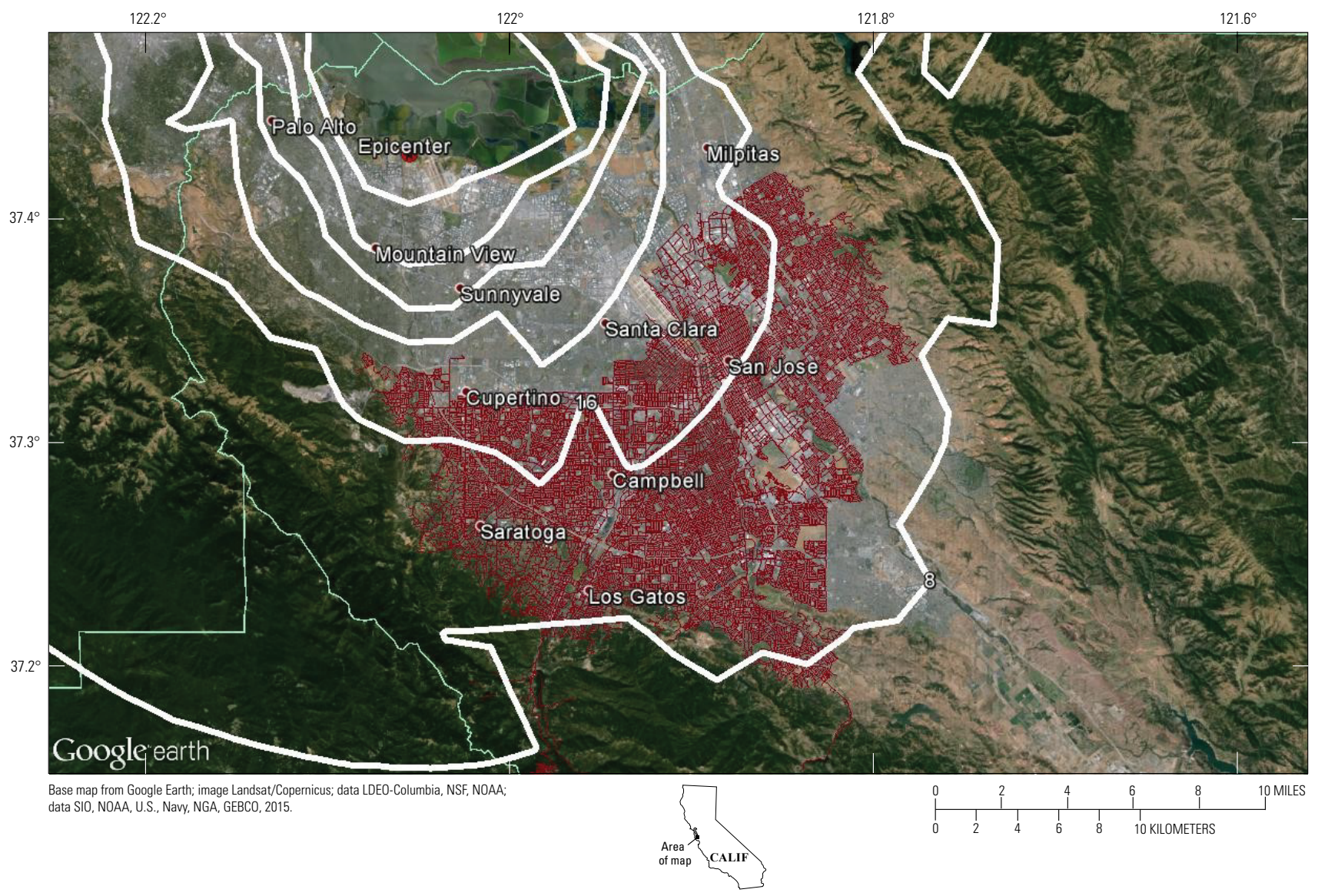

Figure 18. Satellite image of Santa Clara Valley, California, at the southern end of San Francisco Bay, annotated with a map of the San Jose Water Company's buried water-pipeline system (red). Image is overlaid with peak ground velocity contours (white lines; in increments of 8 centimeters per second) for a moment-magnitude-5.98 aftershock that occurs beneath the City of Mountain View 5 months after the mainshock of the HayWired earthquake scenario.

of number of pipe repairs by event in the HayWired scenario earthquake sequence and table 15 for subtotals by day. In those tables, "large diameter" means at least 20 inches. Table 16 summarizes the expected value of the number of repairs by material, summing damage over the entire HayWired earthquake sequence. The table shows that the plurality of repairs are in asbestos cement pipe (481 breaks or leaks), and although the next-largest contributor is ductile-iron pipe (470 breaks or leaks), repairs are disproportionately from damage to asbestos-cement pipe, with an expected value of 0.23 repairs per 1,000 linear feet of pipe ( 0.75 per $\mathrm{km})$ versus 0.11 repairs per 1,000 linear feet $(0.37$ per $\mathrm{km})$ for ductile-iron pipe. The unsurprising implication is that it is better to have ductile-iron water pipe than asbestoscement water pipe.

Table 13. Damage estimates for San Jose Water Company, California, buried water pipeline in the hypothetical momentmagnitude-7.0 mainshock of the HayWired earthquake scenario.

$[\%$, percent $]$

\begin{tabular}{lc}
\hline \multicolumn{1}{c}{ Description } & Number \\
\hline Mean number of repairs & 1,054 \\
Repairs per kilometer of pipe & 0.27 \\
Repairs due to wave passage & $665(63 \%)$ \\
Repairs due to liquefaction & $345(33 \%)$ \\
Repairs due to landslide & $44(4 \%)$ \\
Damage to large diameter pipe $(\geq 20$ inch diameter $)$ & $30(3 \%)$ \\
Damage to small diameter pipe $(<20$ inch diameter) & $1,024(97 \%)$ \\
Breaks & $294(28 \%)$ \\
Leaks & $760(72 \%)$ \\
\hline
\end{tabular}


Table 14. Estimated number of leaks and breaks in San Jose Water Company, California, buried water pipeline in the HayWired scenario earthquake sequence (see table 12).

[Day 1 corresponds to April 18, 2018. $M_{\mathrm{w}}$, moment magnitude]

\begin{tabular}{cllrrrr}
\hline Day & Epicenter & Name & $\boldsymbol{M}_{\mathbf{w}}$ & $\begin{array}{c}\text { Leaks } \\
\text { breaks }\end{array}$ & $\begin{array}{c}\text { Large } \\
\text { diameter } \\
\text { pipe }\end{array}$ & $\begin{array}{c}\text { Small } \\
\text { diameter } \\
\text { pipe }\end{array}$ \\
\hline 1 & Oakland & Mainshock & 7.05 & 1,054 & 30 & 1,024 \\
\hline 1 & Union City & uc523 & 5.23 & 34 & 1 & 33 \\
\hline 1 & San Pablo & sp504 & 5.04 & 6 & 0 & 6 \\
\hline 12 & Fairfield & ff558 & 5.58 & 2 & 0 & 2 \\
\hline 15 & Fremont & fr51 & 5.10 & 47 & 1 & 46 \\
\hline 32 & Oakland & ok542 & 5.42 & 30 & 1 & 29 \\
\hline 40 & Palo Alto & pa62 & 6.21 & 102 & 3 & 99 \\
\hline 40 & Menlo Park & mp552 & 5.52 & 30 & 1 & 29 \\
\hline 41 & Palo Alto & pa569 & 5.69 & 58 & 2 & 56 \\
\hline 41 & Atherton & at511 & 5.11 & 30 & 1 & 29 \\
\hline 67 & Palo Alto & pa522 & 5.22 & 47 & 2 & 45 \\
\hline 74 & Palo Alto & pa526 & 5.26 & 48 & 2 & 46 \\
\hline 166 & Mountain View & mv598 & 5.98 & 93 & 3 & 90 \\
\hline 166 & Cupertino & cu64 & 6.40 & 172 & 6 & 166 \\
\hline 166 & Sunnyvale & sv535 & 5.35 & 73 & 2 & 71 \\
\hline 166 & Santa Clara & sc509 & 5.09 & 102 & 3 & 98 \\
\hline 492 & Palo Alto & pa501 & 5.01 & 29 & 1 & 28 \\
\hline Total & & & & 1,957 & 59 & 1,897 \\
\hline & & & & & & \\
\hline
\end{tabular}

Table 15. Total leaks and breaks by day in San Jose Water Company, California, buried water pipeline in the HayWired scenario earthquake sequence (see table 12).

[Day 1 corresponds to April 18, 2018]

\begin{tabular}{cccr}
\hline Day & $\begin{array}{c}\text { Total leaks + } \\
\text { breaks }\end{array}$ & $\begin{array}{c}\text { Large } \\
\text { diameter } \\
\text { pipe }\end{array}$ & $\begin{array}{c}\text { Small } \\
\text { diameter } \\
\text { pipe }\end{array}$ \\
\hline 1 & 1,094 & 31 & 1,063 \\
\hline 12 & 2 & 0 & 2 \\
\hline 15 & 47 & 1 & 46 \\
\hline 32 & 30 & 1 & 29 \\
\hline 40 & 132 & 4 & 127 \\
\hline 41 & 88 & 3 & 85 \\
\hline 67 & 47 & 2 & 45 \\
\hline 74 & 48 & 2 & 46 \\
\hline 166 & 440 & 14 & 426 \\
\hline 492 & 29 & 1 & 28 \\
\hline Total & 1,957 & 59 & 1,897 \\
\hline
\end{tabular}

Table 16. Repair rate by material for San Jose Water Company, California, buried water pipeline in the HayWired scenario earthquake sequence (see table 12).

\begin{tabular}{|c|c|c|}
\hline Material $^{1}$ & $\begin{array}{c}\text { Repairs } \\
\text { per } \\
1,000 \text { linear feet }\end{array}$ & $\begin{array}{c}\text { Repairs } \\
\text { per } \\
\text { kilometer }\end{array}$ \\
\hline $\mathrm{AC}$ & 0.23 & 0.75 \\
\hline BCL & 0.13 & 0.42 \\
\hline CCCL & 0.19 & 0.62 \\
\hline CI & 0.19 & 0.62 \\
\hline CL & 0.12 & 0.40 \\
\hline CU & 0.31 & 1.00 \\
\hline DCCL & 0.14 & 0.45 \\
\hline DCIL & 0.09 & 0.29 \\
\hline DFK & 0.23 & 0.74 \\
\hline DICL & 0.11 & 0.37 \\
\hline DIMCL & 0.25 & 0.81 \\
\hline DS & 0.07 & 0.21 \\
\hline FKCL & 0.13 & 0.41 \\
\hline GALV & 0.08 & 0.26 \\
\hline GG & 0.23 & 0.74 \\
\hline HDPE & 0.05 & 0.16 \\
\hline PB & 0.08 & 0.27 \\
\hline
\end{tabular}

\begin{tabular}{|c|c|c|}
\hline Material $^{1}$ & $\begin{array}{c}\text { Repairs } \\
\text { per } \\
\mathbf{1 , 0 0 0} \text { linear feet }\end{array}$ & $\begin{array}{c}\text { Repairs } \\
\text { per } \\
\text { kilometer }\end{array}$ \\
\hline $\mathrm{PE}$ & 0.06 & 0.20 \\
\hline PP & 0.05 & 0.17 \\
\hline PVC & 0.09 & 0.29 \\
\hline RCP & 0.08 & 0.26 \\
\hline S & 0.13 & 0.42 \\
\hline SB & 0.15 & 0.50 \\
\hline SG & 0.12 & 0.39 \\
\hline SI & 0.14 & 0.45 \\
\hline SOMCL & 0.16 & 0.53 \\
\hline SS & 0.19 & 0.63 \\
\hline TBD & 0.18 & 0.60 \\
\hline WI & 0.22 & 0.71 \\
\hline WS & 0.12 & 0.39 \\
\hline WSCL & 0.13 & 0.43 \\
\hline ZCCL & 0.07 & 0.24 \\
\hline Total & 0.15 & 0.50 \\
\hline
\end{tabular}


The estimates in tables 14 and 15 ignore the potential for liquefaction outside the area with estimated liquefaction probability (that is, in places where liquefaction could occur but HayWired has no maps). They also ignore damage from ground failure in aftershocks, for which liquefaction and landslide probability were not estimated. However, because liquefaction requires long duration as well as strong shaking, and because aftershocks would tend to have short duration because of their moderate and small magnitude, they would tend to produce relatively few pipeline repairs as a result of liquefaction. Note that after the mainshock, the $M_{\mathrm{w}} 6.4$ aftershock near the City of Cupertino (table 14) adds the largest number of aftershock-related breaks and leaks in buried pipelines, likely setting SJWC back in restoring service.

Figure 19 is a heatmap (warmer color indicates greater concentration of damage) of SJWC pipeline repair rate in the HayWired scenario mainshock. To be clear, if any additional emphasis is needed, this map shows estimated damage rates in one scenario earthquake - the HayWired mainshock - not all possible earthquakes, not even all possible $M 7.0$ earthquakes on the Hayward Fault. Different earthquakes produce different damage patterns. However, the point of a scenario is to understand what might realistically happen, and a heatmap makes a possible outcome more tangible, more useful for planning purposes. By planning for one scenario, one becomes more prepared for what actually happens, which will invariably differ from a scenario.

Figure 19 unsurprisingly shows greater damage near the fault and on soil with high liquefaction probability, with maximum values approaching 12 breaks or leaks per square kilometer $\left(\mathrm{km}^{2}\right)$. Figure 20 shows an analogous map for the $M_{\mathrm{w}}$ 6.4 Cupertino aftershock. Damage rates just exceed 1 break or leak per square kilometer in the aftershock in the neighborhoods

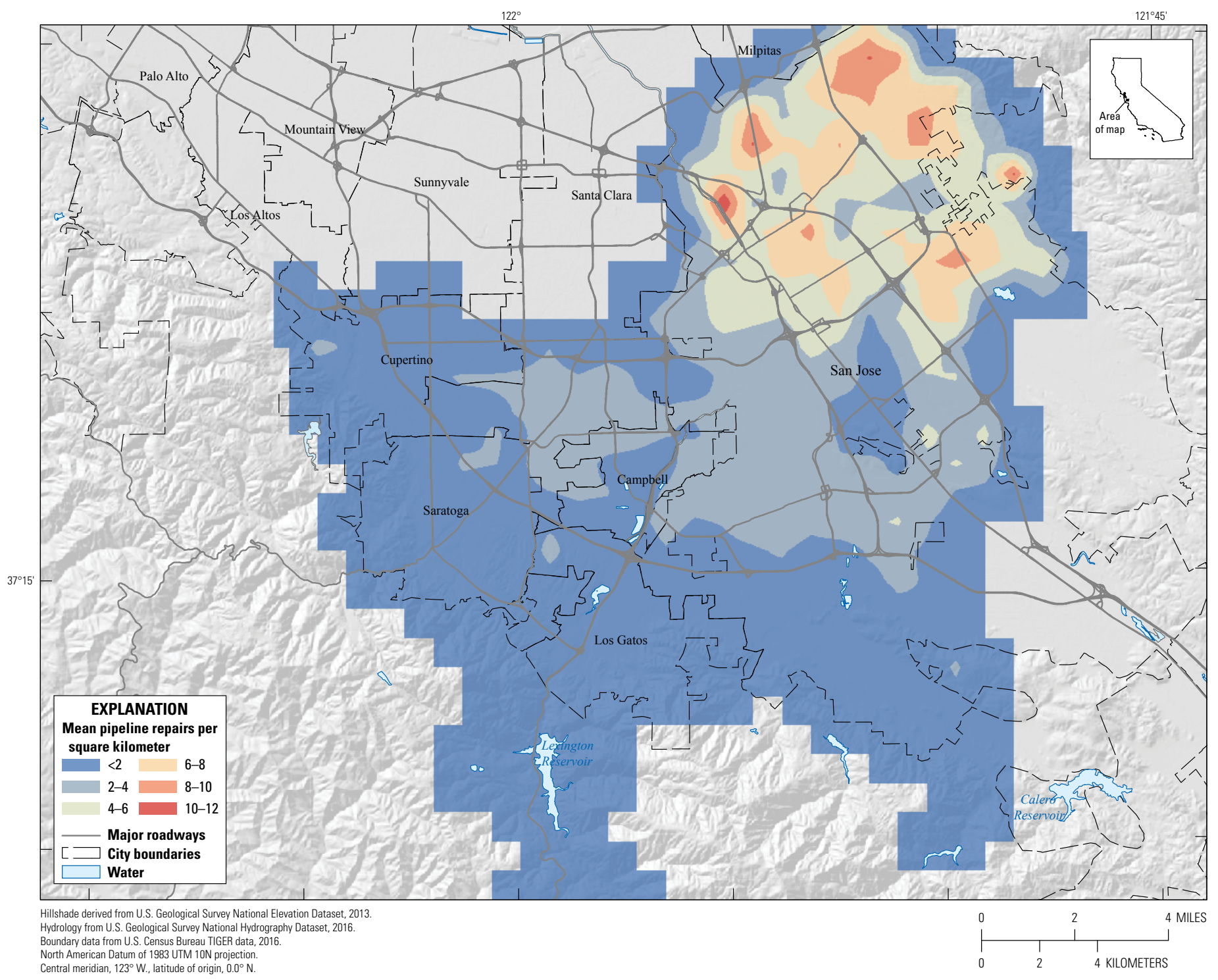

Figure 19. Map of buried water-pipeline damage in San Jose Water Company's, California's, service area for the hypothetical momentmagnitude-7.0 mainshock of the HayWired earthquake scenario. Colors indicate mean repairs (breaks and leaks) per square kilometer. A warmer color indicates greater concentration of damage. To be informative, the color scale is shifted from those used in figures 20 and 21. 


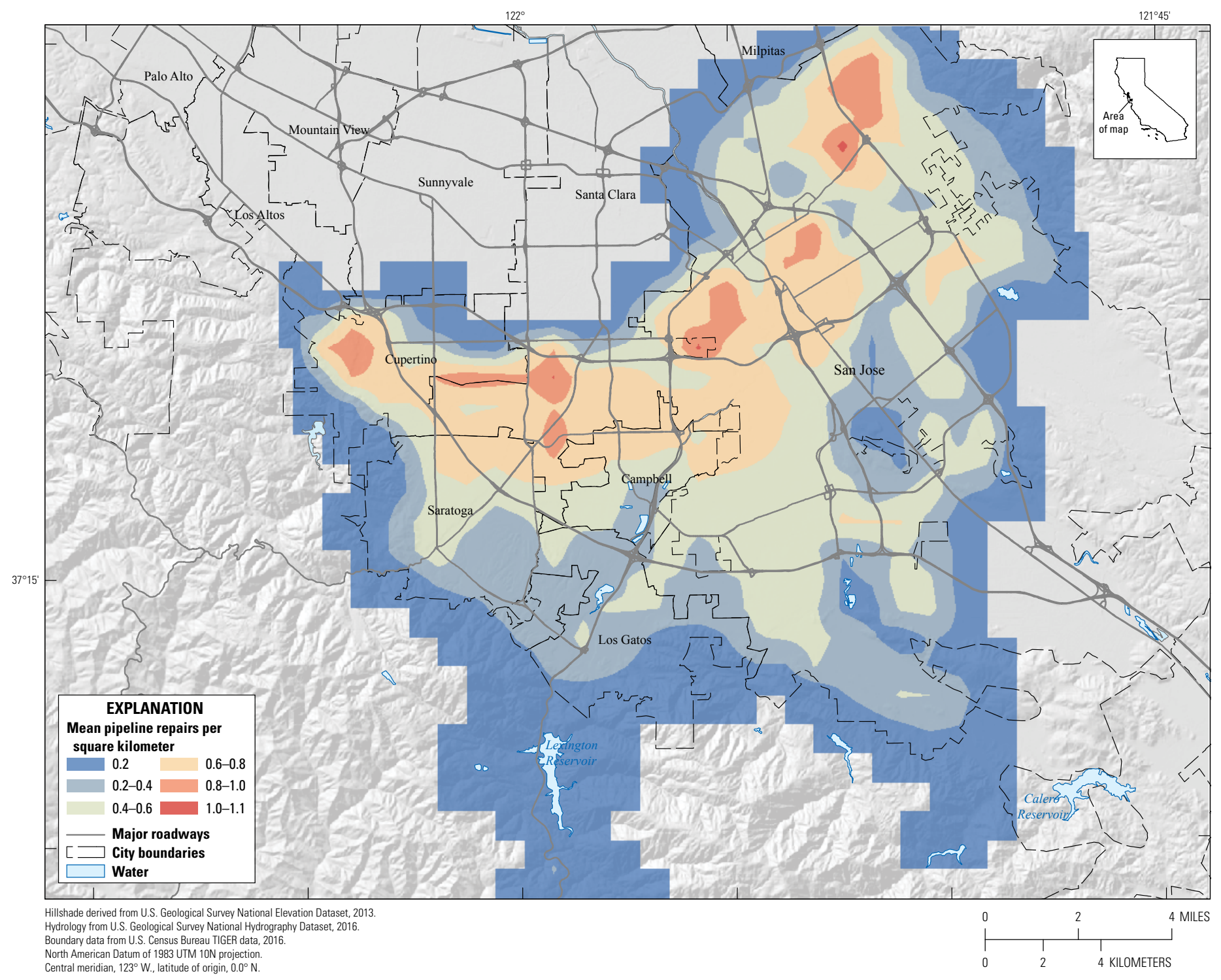

Figure 20. Map of buried water-pipeline damage in San Jose Water Company's, California's, service area for the hypothetical moment-magnitude-6.4 Cupertino aftershock in the HayWired scenario earthquake sequence. Colors indicate mean repairs (breaks and leaks) per square kilometer. A warmer color indicates greater concentration of damage. To be informative, the color scale is shifted from those used in figures 19 and 21.

along the northern edge of the SJWC service area. Figure 21 shows the heatmap for the entire sequence, with damage rates of approximately 15 repairs $/ \mathrm{km}^{2}$ in the northeastern part of the service area.

I simulated damage locations by applying equation 49 once for the mainshock and once for each aftershock. Figure 22 shows pipeline segments with at least one simulated repair resulting from the $M_{\mathrm{w}} 7.0$ HayWired mainshock. Figure 23 shows pipeline segments with at least one simulated repair resulting from the $M_{\mathrm{w}}$ 6.4 Cupertino aftershock. Figure 24 shows pipeline locations with at least one simulated repair resulting from the entire HayWired earthquake sequence.

\section{San Jose Water Company Restoration Analysis}

I take the following $g$-value (flow factor as discussed earlier) time series for lifelines upstream of water, and iterate later if necessary:

Consumables.- SJWC has one of the best stock of repair materials in the Bay Area (J. Wollbrinck, SJWC, oral commun., October 14, 2015). I assume sufficient repair consumable materials (such as pipe and clamps) are on hand or can be acquired as they are needed, that is, $g(t)=1.0$ for all $t$.

Fuel.-As of this writing, SJWC is in the process of preparing its fuel plan (J. Wollbrinck, SJWC, oral commun., 


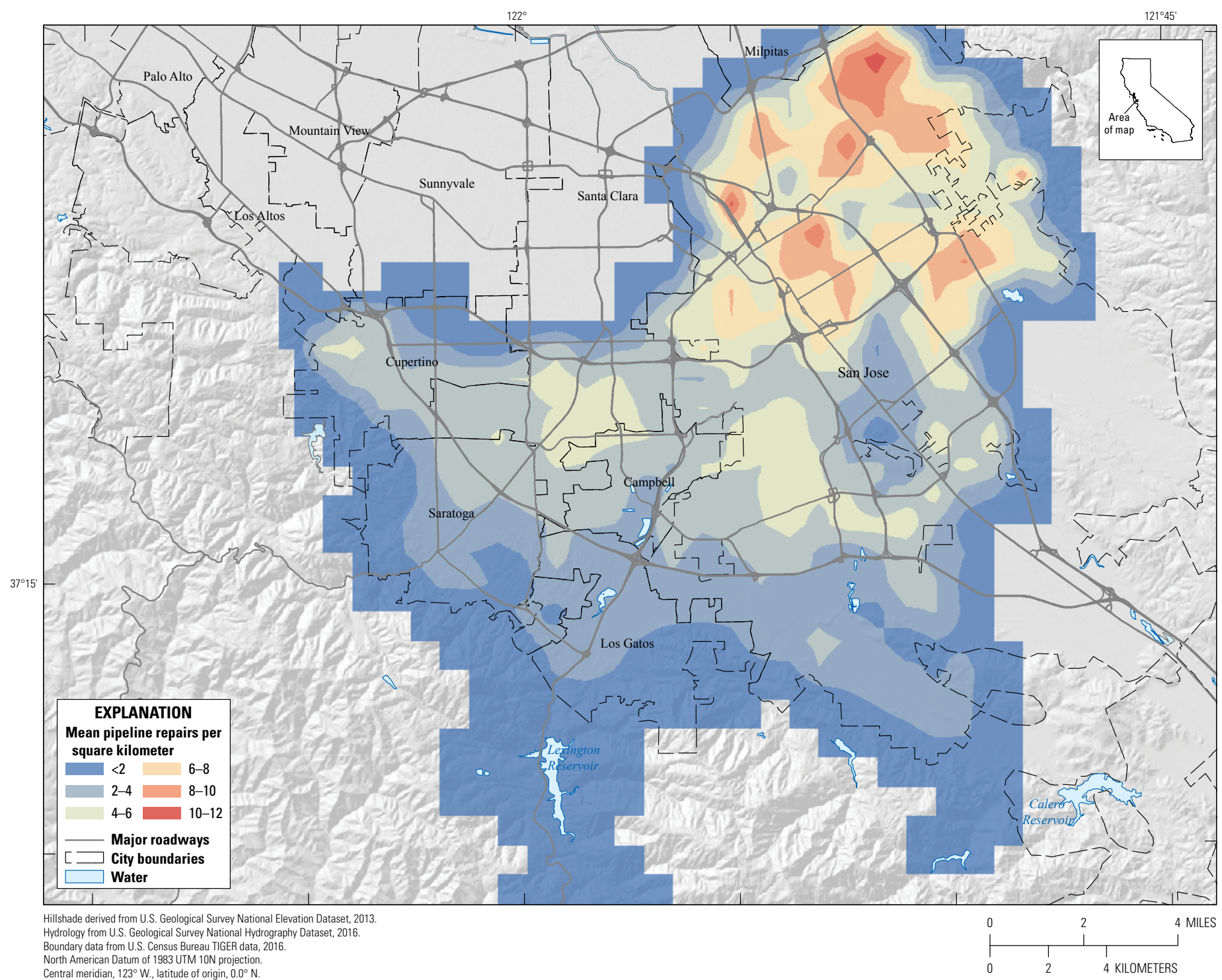

Figure 21. Map of buried water-pipeline damage in San Jose Water Company's, California's, service area for the entire hypothetical HayWired scenario earthquake sequence (events larger than moment-magnitude 5). Colors indicate mean repairs (breaks and leaks) per square kilometer. A warmer color indicates greater concentration of damage. To be informative, the color scale is shifted from those used in figures 19 and 20.

October 14, 2015). I treat two possible outcomes-(1) the earthquake ( $M_{\mathrm{w}} 7.0$ HayWired scenario mainshock) happens before the plan is implemented and (2) the earthquake happens afterwards. If afterwards, I assume that the fuel plan is sufficient to ensure adequate supplies throughout the repair and restoration process, in which case $g(t)=1.0$ for all $t$.

Without the fuel plan, I assume that there is sufficient fuel initially, but that shortages would impair restoration for a few days until emergency supplies were secured. Quantitatively, I assume that before implementing fuel plan:

$g(t)=1.0$ for $0 \leq t<3$ days,

$$
\begin{aligned}
& g(t)=0.25 \text { for } 3 \leq t<7 \text { days, } \\
& g(t)=1.0 \text { for } t>7 \text { days. }
\end{aligned}
$$

After implementing a fuel plan, I assume $g(t)=1.0$.

Electricity.-Pacific Gas and Electric Company (PG\&E) was unable to offer a public estimate of the time required to restore power throughout the San Francisco Bay area after the HayWired scenario mainshock. On the basis, in part, of a Hazus-MH analysis, the HayWired project team and SJWC's emergency manager believe it is realistic that 99.9 percent of customers in Santa Clara County will have power restored within 


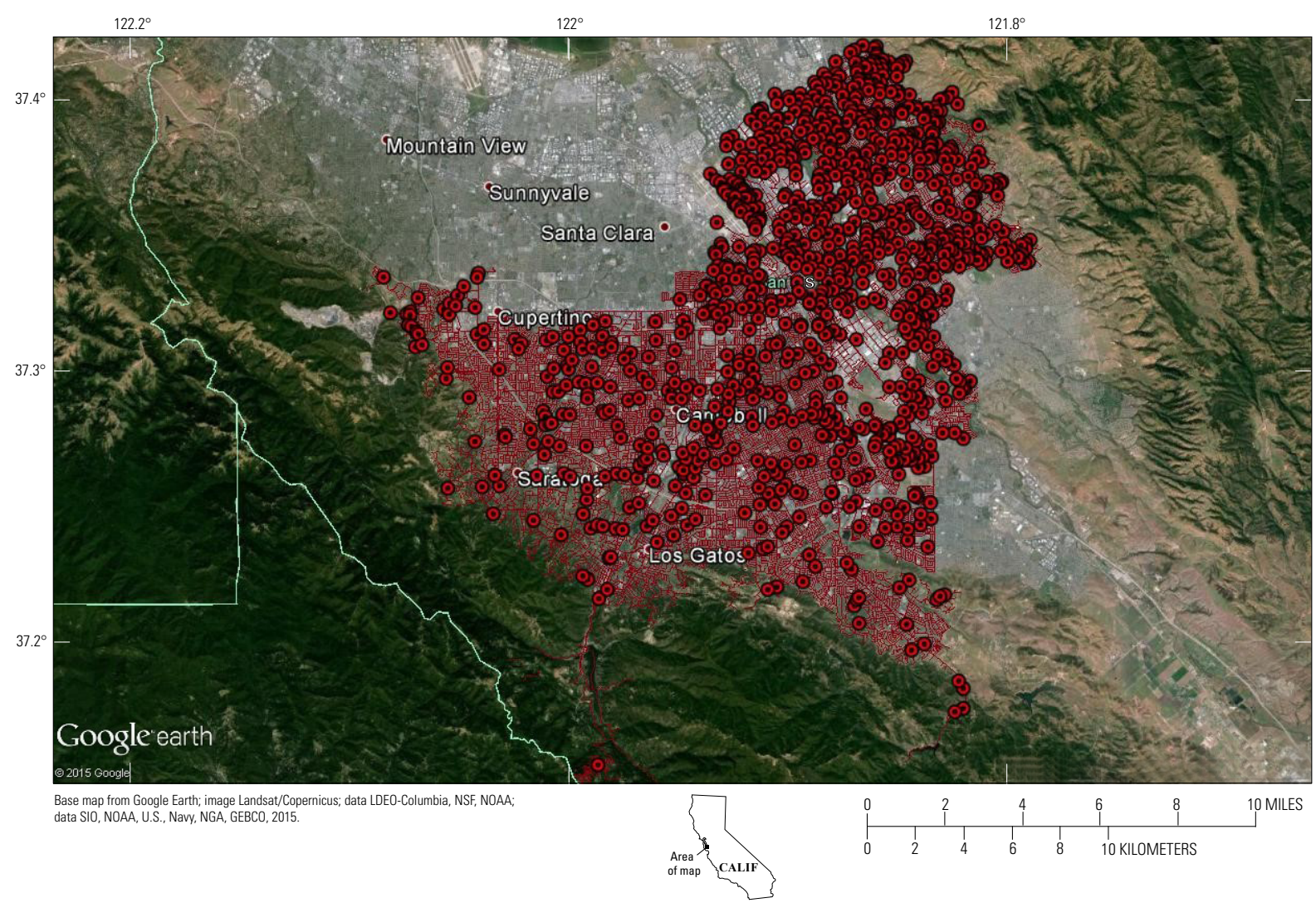

Figure 22. Satellite image of Santa Clara Valley, California, at the southern end of San Francisco Bay, annotated with a map of San Jose Water Company's buried water-pipeline system. Simulated repairs (red circles) resulting from the hypothetical momentmagnitude-7.0 Cupertino aftershock in the HayWired scenario earthquake sequence are shown as red circles.

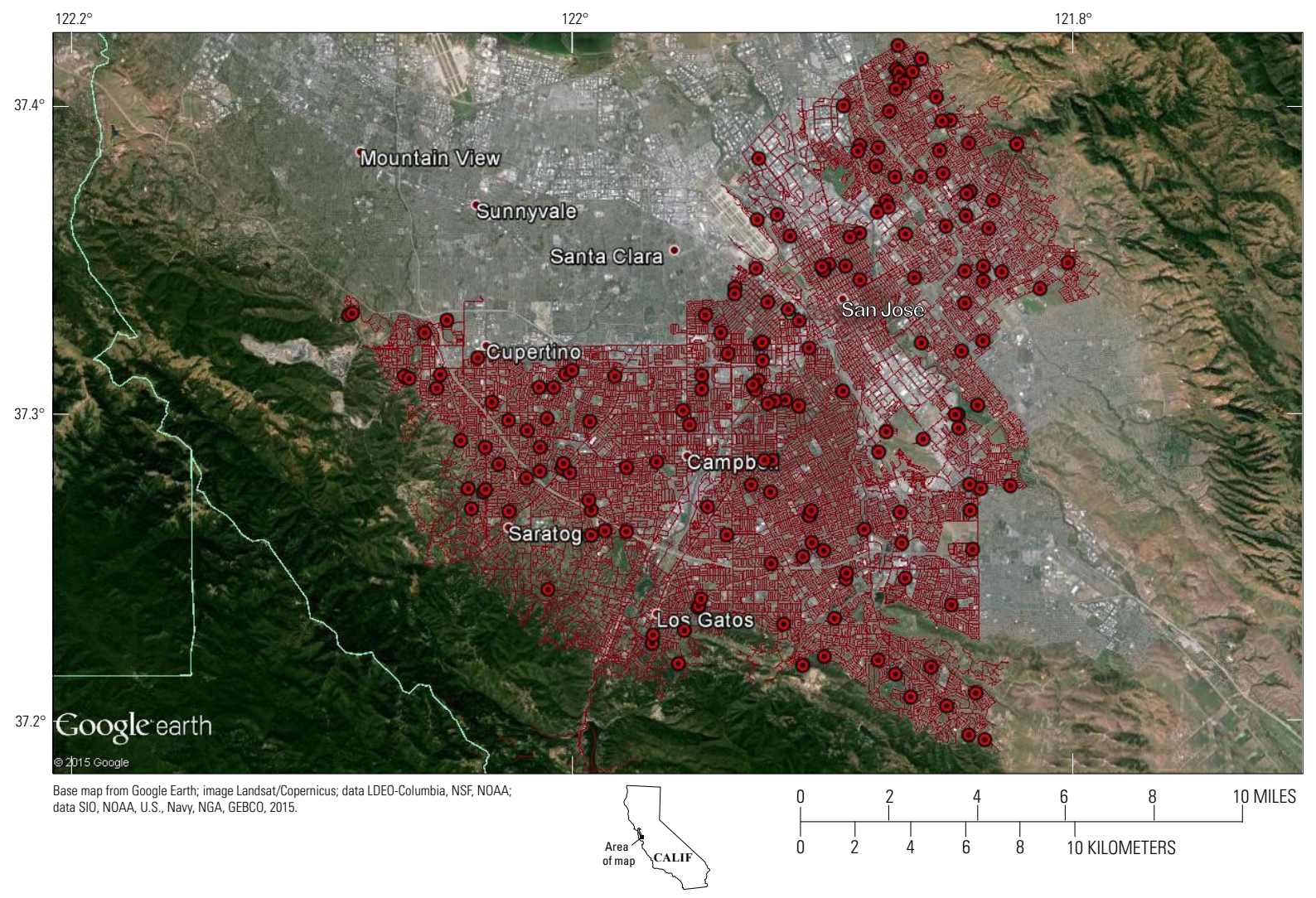

Figure 23. Satellite image of Santa Clara Valley, California, at the southern end of San Francisco Bay, annotated with a map of San Jose Water Company's buried water-pipeline system. Simulated repairs (red circles) resulting from the hypothetical momentmagnitude-6.4 mainshock of the HayWired earthquake scenario are shown as red circles. 


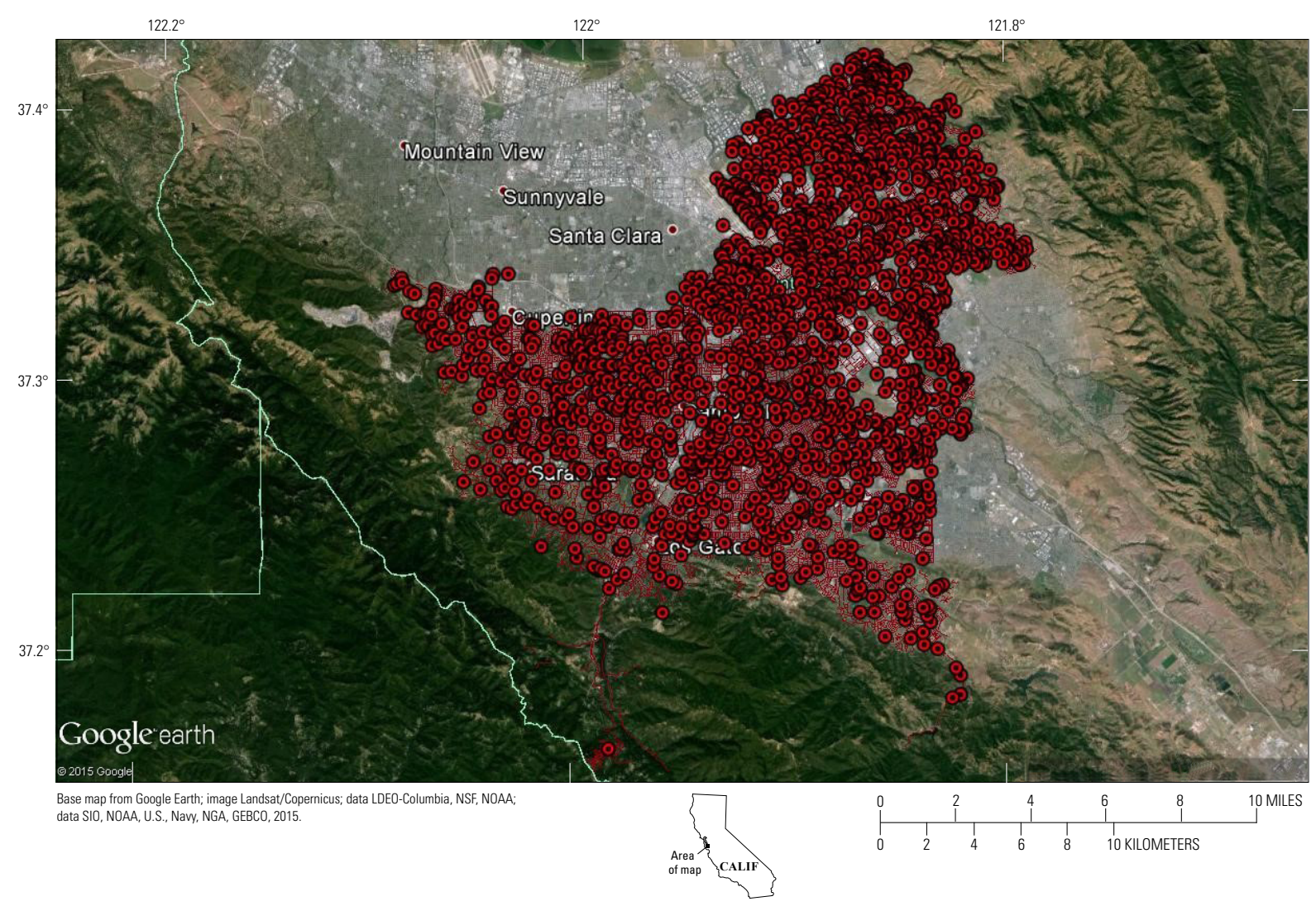

Figure 24. Satellite image of Santa Clara Valley, California, at the southern end of San Francisco Bay, annotated with a map of San Jose Water Company's buried water-pipeline system. Simulated repairs (red circles) resulting from the entire hypothetical HayWired scenario earthquake sequence are shown as red circles.

2 weeks of the mainshock or 2 days after a $M 6+$ aftershock. Quantitatively, I therefore take:

$g(t)=1-\exp (-0.4934 \times t), t$ measured in days after the mainshock,

$g(t)=1-\exp (-3.45 \times t), t$ in days after the aftershocks on days 40 and 166.

Communication.-SJWC has battery powered radios for its repair crews that reach almost its entire service area. I assume that communication to facilitate coordination between utilities will be such a high priority that coordination will not be a constraint. I therefore assume $g(t)=1.0$.

Crews.-SJWC personnel estimated that they could realistically field between 20 and 25 crews on a work basis of 12 hours on and 12 hours off. I therefore take $w(t)=0.5$ and $c(t)=22$ for purposes of equation 35 .

I consider one more remediation measure. Suppose all of the more vulnerable SJWC buried pipe (especially 609 miles of asbestos-cement and cast-iron pipe) could be replaced with less-vulnerable pipe (for example, ductile-iron or plastic pipe). What would be the benefit in terms of damage reduction and accelerated recovery? To explore this question, I assume that all asbestos cement and cast-iron pipe is replaced with ductileiron or plastic pipe before the HayWired earthquake sequence occurs. I refer to this as the "ideal world" assumption. An SJWC engineer (J. Walsh, SJWC, oral commun., October 2, 2015) informed the HayWired project team that SJWC replaces 1 percent, or 24 miles, of existing water mains every year. He did not imagine this study being used to change that percentage of replacement, but they might change their mix of pipes. Their replacement program is based on both consequences of failure and probability of failure. They consider a multitude of factors and then apply genetic algorithm software to predict leaks. They will likely add additional weighting to asbestos-cement and cast-iron pipe in close proximity to earthquake fault lines based on the present work. If SJWC were to focus on asbestos-cement and cast-iron pipe and were to continue to replace 24 miles of pipe per year, all 609 miles of asbestos-cement and cast-iron pipe could be replaced within 25 years.

Figure 25 shows the repair timeline for SJWC water-supply pipelines before and after implementing the fuel-management plan and after replacing all cast-iron and asbestos-cement pipe with ductile-iron or plastic pipe (the "ideal world"). Figure 26 illustrates the simulated restoration curve. If the Hazus-MH serviceability index realistically measures the fraction of services receiving any water, as reports produced by the Hazus software suggest, then "services available" in figure 26 measures the fraction of service connections receiving even small flows. If it means the postearthquake flow as a fraction of pre-earthquake flow, then figure 26 underestimates the number of service connections receiving at least some water. 


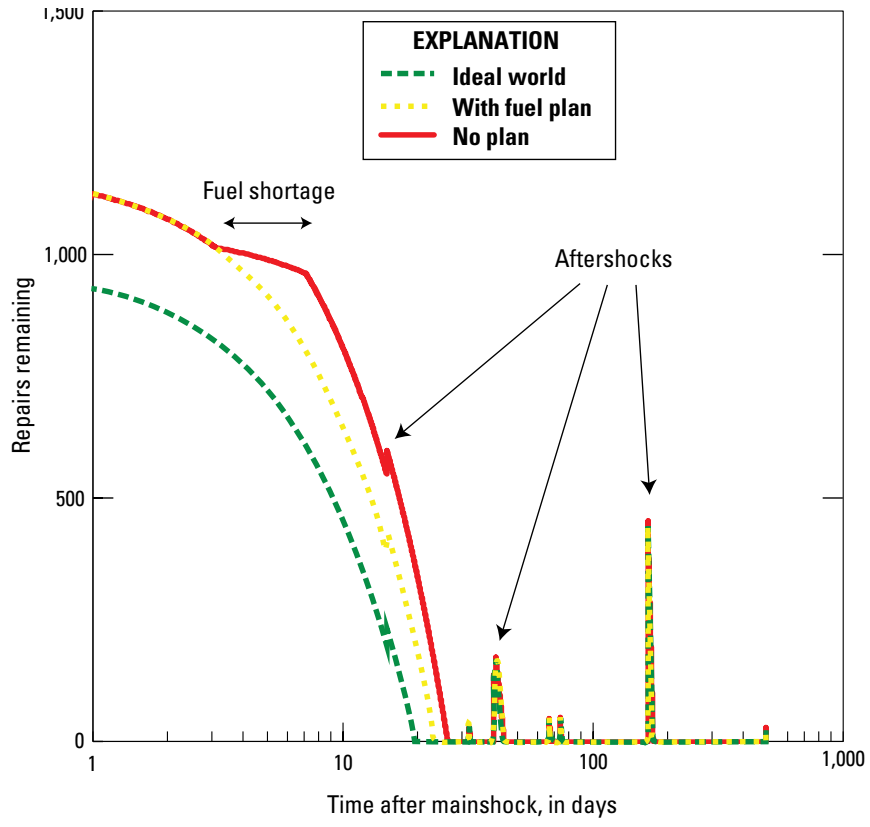

Figure 25. Graph showing simulated repair timeline of San Jose Water Company, California, water-supply pipelines under three conditions for the HayWired scenario earthquake sequence. Conditions are (1) ideal world (all asbestos cement and cast-iron pipe is replaced with ductile-iron or plastic pipe before the earthquake sequence occurs and with a fuelmanagement plan), (2) with a fuel-management plan but no pipe replacement, and (3) without fuel-management plan or pipe replacement.

As discussed earlier, I view the area above the curves in figure 26 as a measure of resilience-less area means less impact, faster recovery, or both. The areas above the three curves are measured in units of service-days. That is, each day of lost water supply to a service connection equates with one service day. The areas above the three curves are shown in table 17-lost service days under as-is conditions, with a fuel-management plan, and under ideal-world conditions, that is, assuming that all brittle pipe is replaced before the HayWired scenario mainshock. The table shows the lost service days as a multiple of number of water service connections, that is, the average number of days that each service connection is without potable water under as-is conditions, with a fuel-management plan, and under ideal-world conditions. The difference between lost service days under as-is and what-if conditions (fuel-management plan or ideal world) measures the resilience benefit of the what-if condition - with a fuel-management plan and if all brittle pipe were replaced before the HayWired scenario mainshock occurs.

\section{Validation of San Jose Water Company Restoration Analysis}

It is possible to compare the foregoing results for SJWC with other analyses as an initial check of the results. This validation is discussed below.

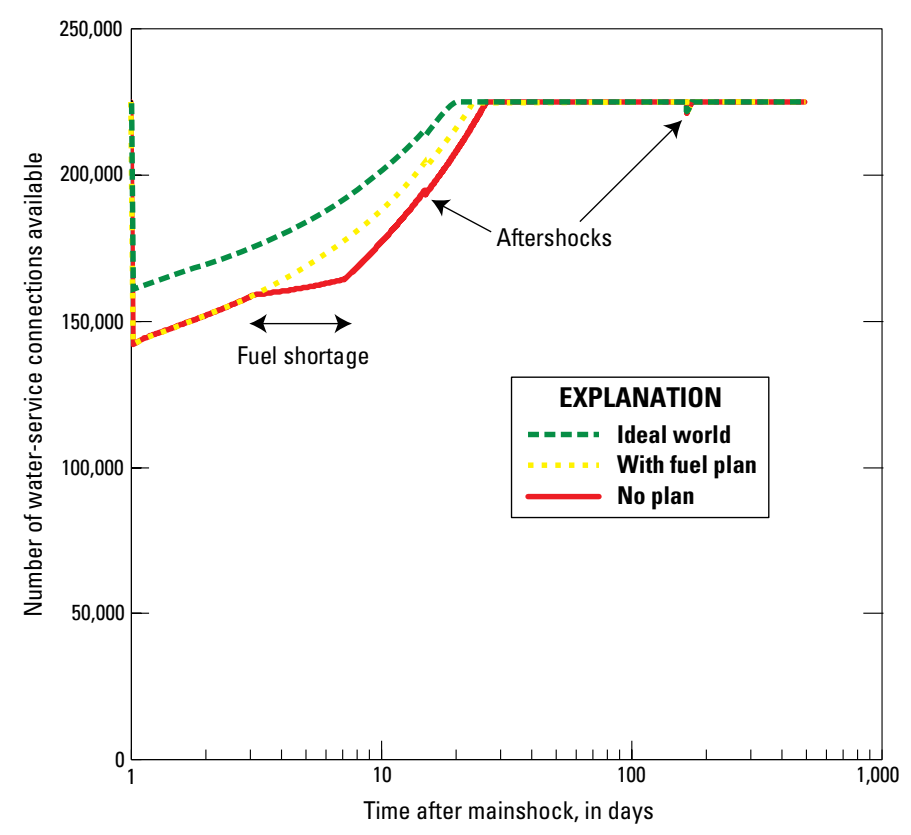

Figure 26. Graph showing simulated service availability of San Jose Water Company, California, water-supply system under three conditions for the HayWired scenario earthquake sequence. Conditions are (1) ideal world (all asbestos cement and cast-iron pipe is replaced with ductile-iron or plastic pipe before the earthquake sequence occurs and with a fuelmanagement plan), (2) with a fuel-management plan but no pipe replacement, and (3) without fuel-management plan or pipe replacement.

\section{Cross Validation with San Jose Water Company's Internal Damage Estimate}

By scaling up the number of water pipeline breaks and leaks in the $M_{\mathrm{w}} 6.02014$ South Napa earthquake, SJWC personnel estimated that the $M_{\mathrm{w}} 7.0$ HayWired scenario mainshock would cause 1,200 water main breaks or leaks to their company's system (J. Wollbrinck written commun., SJWC, October 19, 2015). The estimate follows this logic - the City of Napa has 370 miles of

Table 17. San Jose Water Company, California, total and per-customer average lost service days following the hypothetical moment-magnitude-7.0 mainshock of the HayWired earthquake scenario.

[Numbers rounded to reduce the impression of excessive precision. Ideal world - all asbestos cement and cast-iron pipe is replaced with ductile-iron or plastic pipe before the earthquake sequence occurs and with fuel-management plan. $R$, number of days that service connection is without potable water; $M$, number of water service connections]

\begin{tabular}{lccc}
\hline \multicolumn{1}{c}{ Condition } & $\begin{array}{c}\text { Lost service } \\
\text { days, } \\
\boldsymbol{R} \times \boldsymbol{M}\end{array}$ & $\begin{array}{c}\text { Resilience } \\
\text { benefit, } \\
\boldsymbol{D}(\boldsymbol{R} \times \boldsymbol{M})\end{array}$ & $\begin{array}{c}\text { Average lost } \\
\text { service days } \\
(\boldsymbol{R})\end{array}$ \\
\hline As-is & 940,000 & 0 & 4 \\
$\begin{array}{c}\text { With fuel- } \\
\quad \text { management plan }\end{array}$ & 750,000 & 190,000 & 3 \\
Ideal world & 470,000 & 470,000 & 2 \\
\hline
\end{tabular}


water main and experienced 120 pipeline leaks the first week and more than 170 pipeline leaks in the first 6 months following the 2014 earthquake. Scaling up by system size, SJWC estimates that Napa's 120 leaks would equate with 850 leaks for SJWC and the 170 leaks would equate with 1,200 leaks for SJWC. The South Napa earthquake was weaker than the mainshock modeled in the HayWired scenario, so the number of leaks could be more. The similarity between SJWC's estimates of 850 increasing to 1,200 and the ones produced here $(1,054$ increasing to 1,956$)$ suggests that either or both are reasonable or neither is. That the two set of figures used two different approaches to arrive at a basically similar set of numbers tends to support both being reasonable, rather than neither. In either case, SJWC engineers found the results presented here to be reasonable (J. Walsh, written commun., SJWC, October 19, 2015), with the exception that Wollbrinck (written commun., SJWC, December 4, 2015) expected more damage to wrapped steel pipe because of its age and corrosion susceptibility.

\section{Validation Against Northridge, Kobe, and South Napa Earthquakes}

Jeon and O'Rourke (2005) report that the 1994 Northridge earthquake caused 1,095 breaks or leaks to buried pipeline operated by the Los Angeles Department of Water and Power, most of the damage occurring in the San Fernando Valley. Lund and others (2005) report that repairs took about 1 week. The present calculation suggests that SJWC would take 23 days to repair 1,176 repairs (mainshock plus 4 aftershocks through day 15) - that is, about 3 times as long for about the same number of repairs. Lund and others (2005) do not report the number of crews required to perform those repairs. Presumably LADWP fielded more crews than SJWC has at its disposal.

Lund and others (2005) report that, according to $\mathrm{M}$. Matsushita of the Kobe Municipal Waterworks Bureau, 1,757 breaks and leaks occurred in buried water-supply distribution pipe in Kobe after the $M_{\mathrm{w}} 6.91995$ Kobe earthquake and that repairs took 10 weeks. The present estimate of 3 weeks to repair 1,176 breaks and leaks suggests one-third the time to repair two-thirds of the breaks and leaks. Thus, in a sense, the water-pipeline repair estimates for the Northridge and Kobe earthquakes bracket the restoration estimates for SJWC presented here.

The City of Napa repaired approximately 120 leaks and breaks in 5 days with approximately 10 crews working 12-hour shifts (SPA Risk LLC, 2014), for a repair productivity of approximately 2.4 repairs per crew-day. The present model suggests that, before its fuel plan is implemented, San Jose Water Company would repair 1,176 breaks and leaks in 26 days with 22 crews working 12-hour shifts, or 2.1 repairs per crew day, suggesting fairly good agreement.

\section{Cross Validation with Hazus-MH}

Using Hazus-MH (Federal Emergency Management Agency, 2012), the estimated restoration of water supply in Santa Clara
County following the HayWired scenario mainshock (table 18). The estimates are for the mainshock only and do not reflect lifeline interaction. Applying the percentages to the number of SJWC's customers, one can compare the HayWired scenario model with fuel management plan discussed in this chapter with the Hazus-MH model (fig. 27).

The present model and Hazus-MH disagree wildly in terms of initial level of water service and restoration time, with the Hazus-MH model estimating a six-times increase in time to restore service compared with the present model. Considering the validation against the Napa repair timeline, the present restoration model seems more plausible than the Hazus-MH restoration model. Why would Hazus-MH's restoration model differ so markedly from the present one? The difference can be partly explained by the user-specified number of repair crews.

Table 18. Hazus-MH estimate of Santa Clara County, California, loss of water supply following the hypothetical momentmagnitude-7.0 mainshock of the HayWired earthquake scenario (Federal Emergency Management Agency, 2012).

$[\%$, percent]

\begin{tabular}{cccccc}
\hline \multirow{2}{*}{$\begin{array}{c}\text { Total } \\
\text { households }\end{array}$} & \multicolumn{5}{c}{ Households without potable water following mainshock } \\
\cline { 2 - 6 } & Day 1 & Day 3 & Day 7 & Day 30 & Day 90 \\
\hline 565,853 & 504,596 & 502,302 & 497,394 & 458,220 & 137,185 \\
& $89.20 \%$ & $88.80 \%$ & $87.90 \%$ & $81.00 \%$ & $24.20 \%$ \\
\hline
\end{tabular}

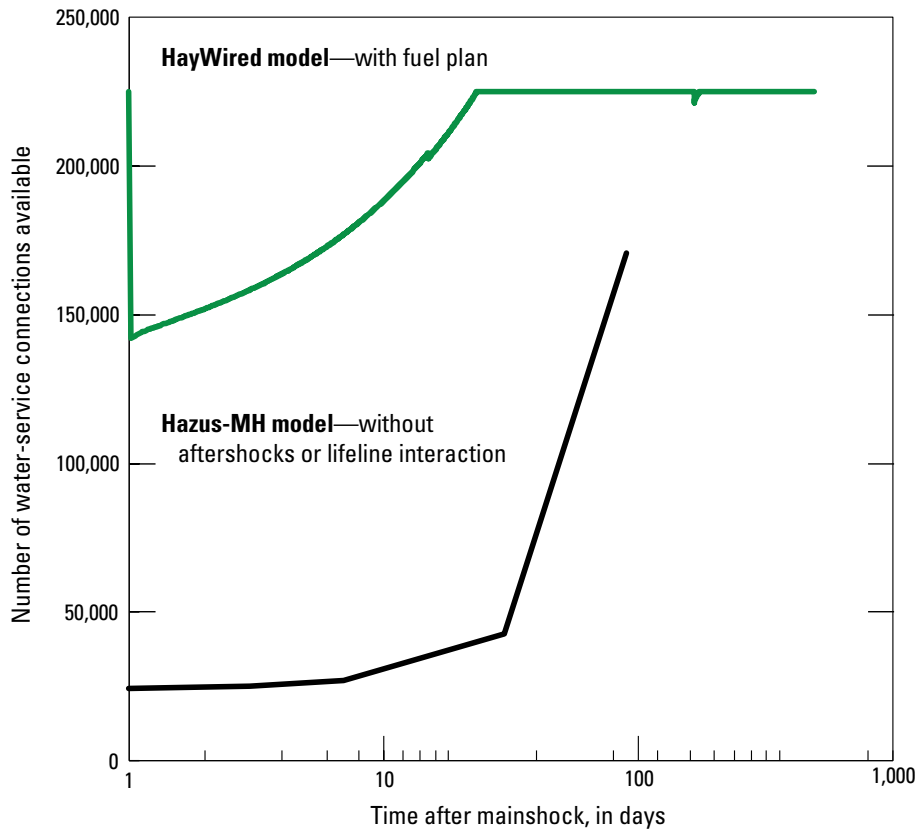

Figure 27. Graph comparing the estimated restoration of water supply in Santa Clara County, California, between the HayWired scenario model with fuel management plan and the Hazus-MH model (Federal Emergency Management Agency, 2012) for the hypothetical moment-magnitude-7.0 mainshock of the HayWired earthquake scenario. 


\section{Effect of Lifeline Interaction and Consumable Limits}

Suppose one ignored limitations in fuel and other consumables, and ignored impairment of electricity, telecommunications, and so on. How much difference do lifeline interaction and consumable limits make? Without these effects, damage is unaffected, but repairs could potentially proceed faster. Recall that equation 36 gives the time $\tau(n, t)$ required to perform the $n$th repair, which occurs at time $t$. It can be expressed as a baseline productivity increased by a factor $S(t)$ that accounts for how lifeline interaction and consumable limits slow repairs, that is:

$$
\tau(n, t)=\frac{d_{0}}{w(t) \times c(t)} \times S(t),
$$

where

$$
S(t)=\frac{1}{\left(\prod_{i}\left(1-u_{i} \times\left(1-g_{i}(t)\right)\right)\right)} .
$$

The first multiplicand in equation 69 is the baseline productivity, that is, the time required to perform the $n$th repair, without lifeline interaction and consumable limits. The factor $S(t)$, which is always at least 1.0, increases the repair time to account for lifeline interaction and consumable limits. Repeating the calculations for SJWC under as-is conditions but with $S(t)=1$ produces an estimated 740,000 lost service days, about 80 percent of the value estimated considering lifeline interaction. Viewed another way, lifeline interaction and consumable limits decrease the calculated water-supply resilience in the area served by San Jose Water Company by 25 percent in the HayWired scenario. The factor would vary in other earthquakes, generally being larger the more dependent the utility is on other lifelines and consumables and the more these lifelines and consumables are impaired.

\section{Case Study 2-East Bay Municipal Utility District}

A second water system subjected to the same hypothetical earthquake sequence can be examined to see whether the model can produce plausible results twice. This section considers the East Bay Municipal Utility District's (EBMUD) water-supply buried pipeline network.

\section{East Bay Municipal Utility District Asset Definition}

The following description is largely quoted from Contra Costa Local Agency Formation Commission (2008) and from conversations with EBMUD. EBMUD provides water- and sewage- treatment services for an area of approximately 331 square miles in the eastern side of the San Francisco Bay.
EBMUD serves approximately 1.3 million people in portions of Alameda County and Contra Costa County in California. EBMUD currently has an average annual growth rate of 0.8 percent and is projected to serve 1.6 million people by 2030 . As of 2015 it provides water to approximately 390,000 service connections. Approximately 100,000 service connections are located east of the East Bay Hills, and the other 290,000 service connections are to the west between the hills and San Francisco Bay. EBMUD's administrative offices are located in The City of Oakland. EBMUD owns and maintains:

- 2 water storage reservoirs on the Mokelumne River,

- 5 terminal reservoirs,

- 91 miles of three separate water-transmission aqueducts,

- 4,162 miles of water mains (the only part of the system modeled here),

- 6 water-treatment plants,

- 29 miles of wastewater interceptor sewer lines, and

- A wastewater treatment facility rated at a maximum treatment capacity of 320 million gallons a day.

EBMUD provided an ArcGIS map of its water mains. The system is shown in figure 28. The map shows $6,698 \mathrm{~km}$ (4,162 miles) of pipe of various types and lengths. Approximately $2,091 \mathrm{~km}$ of pipe are located east of the East Bay Hills, and the other 4,607 km of pipe are to the west between the hills and San Francisco Bay. Total quantities of pipe are summarized by material in table 19 and by diameter in table 20. EBMUD's system is discretized into segments with an average length of $64 \mathrm{~m}$ and a standard deviation of $79 \mathrm{~m}$ - short enough that earthquake shaking should vary little between ends of segments. Some of EBMUD's pipe does not map well to an Eidinger type. One of the material codes do not appear in EBMUD's glossary of pipe types and is probably a data-entry error. I have made a reasonable assumption about the intended meaning, but in any case, the total quantity is small- 0.1 miles.

Terentieff and others (2015) report that 176,000 of 390,000 water services are in pumped pressure zones. These pressure zones rely on 130 pumping stations, of which 117 (90 percent) have no emergency generators. Therefore, I set the parameter $z$ used in the lifeline interaction matrix for EBMUD to be $0.9 \times 176,000 / 390,000=0.41$, and $u_{\text {electr }}=0.41+0.03=0.44$. The factor 0.9 reflects the 90 percent of pumping stations that have no generator. Conceivably EBMUD could install emergency generators with large fuel tanks at all its pumping stations, in which case I can take $u_{\text {electr }}=0.03$. I take the former as the "real-world" scenario and the latter as an "ideal-world" scenario. I also assume that fuel limitations affect EBMUD the same as SJWC, and like SJWC, EBMUD can optionally develop a fuel-management plan and storage to ensure that fuel does not limit its ability to perform pipeline repairs. 


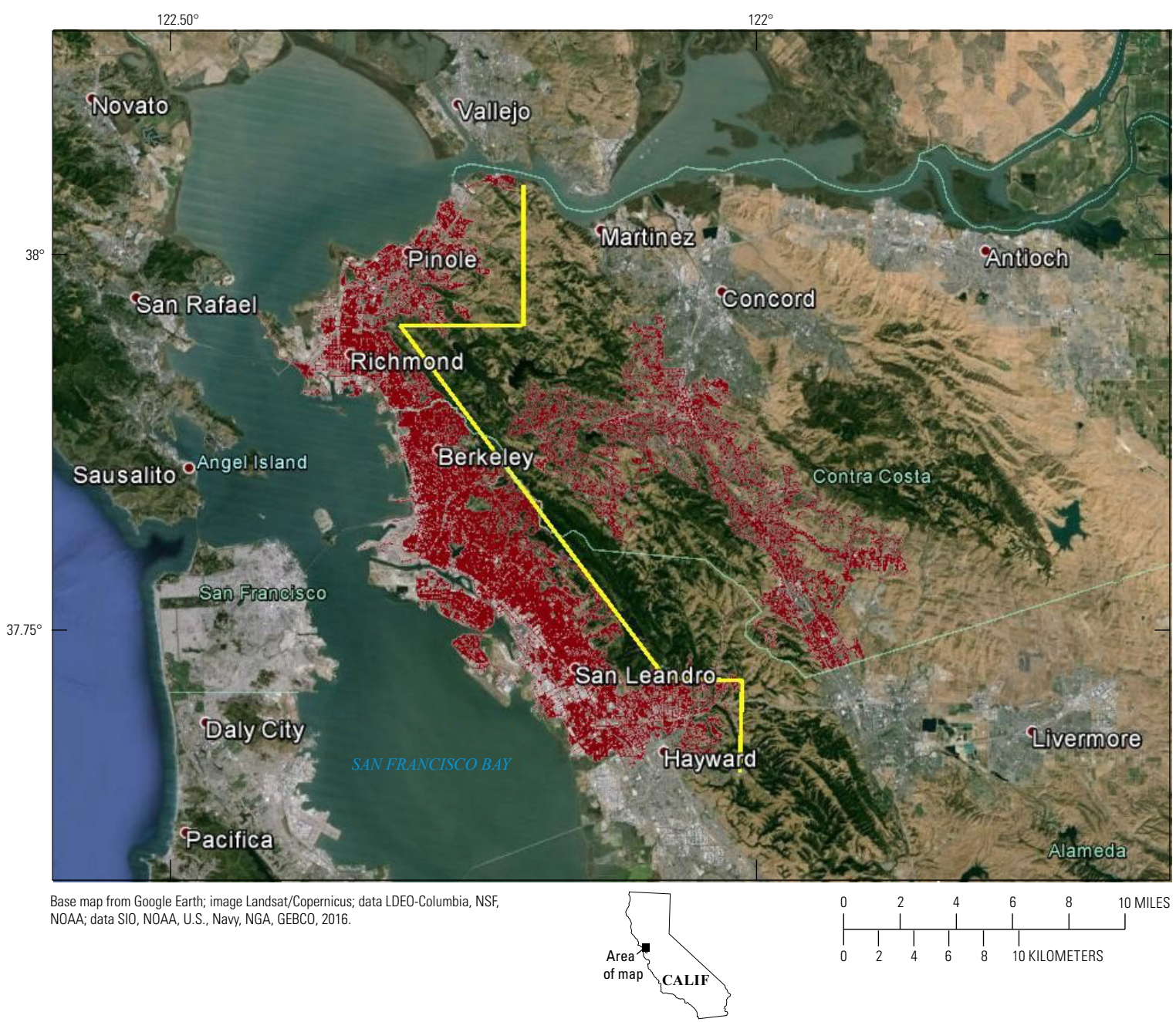

Figure 28. Satellite image of the San Francisco Bay region, California, annotated with a map of the East Bay Municipal Utility District's buried water-pipeline system (red) with dividing line (yellow) to approximately separate pipe and services east and west of the East Bay Hills.

Table 19. East Bay Municipal Utility District, California, pipe construction, associated with Eidinger (2001) vulnerability functions.

[Code, code for pipe material; count, number of segments of that material in East Bay Municipal Utility District buried water-pipeline system; miles, total length of pipe material; material description, description of pipe material; Eidinger type and ID, assumed corresponding vulnerability functions of Eidinger (2001) and their associated vulnerability factors $K_{1}$ and $K_{2}$ from table 1 ; PVC, polyvinyl chloride]

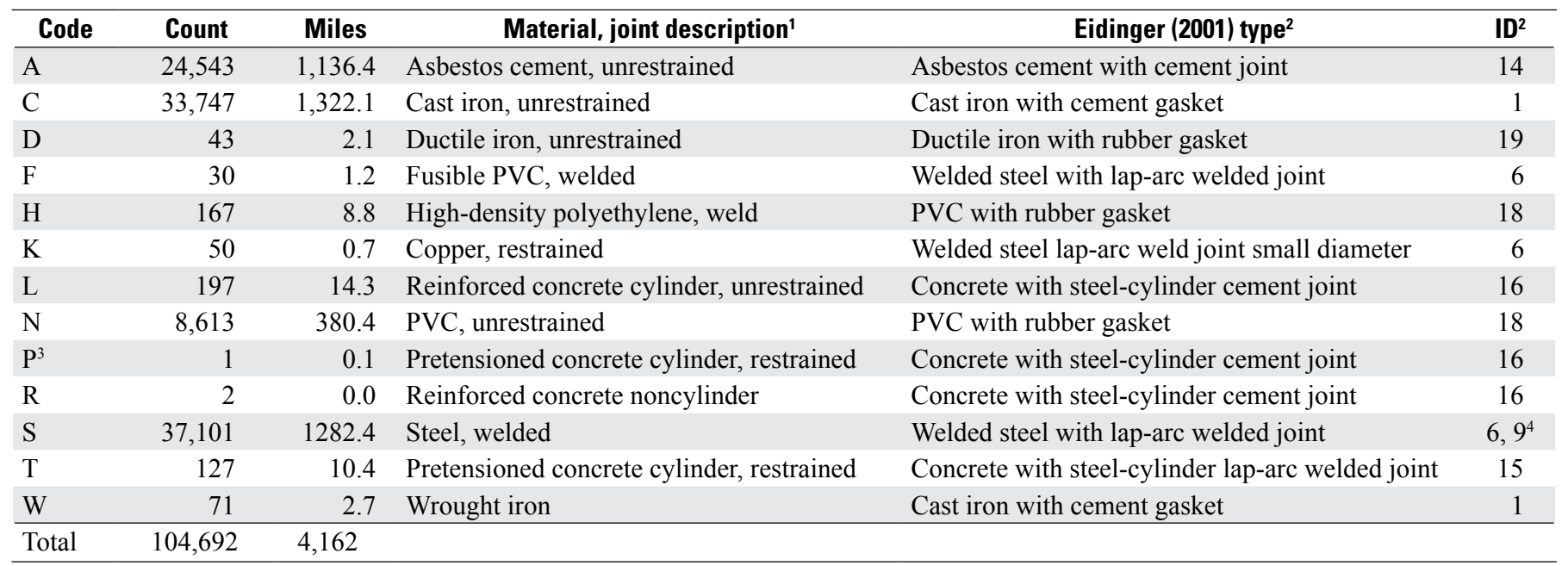

'East Bay Municipal Utility District pipe material and description of joint; descriptions in italics are assumptions.

${ }^{2}$ Closest equivalent corresponding vulnerability function from table 1.

${ }^{3}$ One length of 48-inch-diameter pipe from 1927; $\mathrm{P}$ is probably a typo for T.

${ }^{4}$ ID $6=$ small diameter $(<20$ inches $)$; ID 9=large diameter $(\geq 20$ inches $)$. 
Table 20. Quantities of pipe by diameter in the East Bay Municipal Utility District, California, buried water-pipeline system.

\begin{tabular}{rr}
\hline $\begin{array}{c}\text { Diameter, } \\
\text { in inches }\end{array}$ & $\begin{array}{r}\text { Length, } \\
\text { in miles }\end{array}$ \\
\hline 0.00 & 0.4 \\
0.75 & 0.2 \\
1.00 & 1.0 \\
2.00 & 18.6 \\
3.00 & 0.7 \\
4.00 & 294.6 \\
6.00 & $1,728.2$ \\
8.00 & $1,105.7$ \\
10.00 & 38.0 \\
12.00 & 475.8 \\
14.00 & 1.4 \\
16.00 & 157.6 \\
18.00 & 1.4 \\
\hline 20.00 & 78.1 \\
\hline 24.00 & 74.4 \\
\hline
\end{tabular}

\begin{tabular}{rr}
\hline $\begin{array}{r}\text { Diameter, } \\
\text { in inches }\end{array}$ & $\begin{array}{r}\text { Length, } \\
\text { in miles }\end{array}$ \\
\hline 25.00 & 0.5 \\
30.00 & 36.5 \\
\hline 36.00 & 66.8 \\
42.00 & 18.5 \\
48.00 & 38.3 \\
54.00 & 8.8 \\
\hline 60.00 & 2.6 \\
\hline 66.00 & 6.8 \\
\hline 69.00 & 4.6 \\
\hline 72.00 & 0.0 \\
\hline 78.00 & 0.2 \\
\hline 84.00 & 1.8 \\
\hline 90.00 & 0.2 \\
\hline 96.00 & 0.1 \\
\hline 108.00 & 0.0 \\
\hline Total & $4,161.7$ \\
\hline
\end{tabular}

\section{EBMUD Hazard Analysis}

Ground motion, liquefaction, landslide, coseismic slip, and afterslip for the HayWired scenario are quantified in Detweiler and Wein (2017). Figure 29 shows EBMUD's buried waterpipeline system and PGV for the $M_{\mathrm{w}}$ 7.0 HayWired scenario mainshock. Figure 30 shows EBMUD's buried water-pipeline system with liquefaction probabilities for the HayWired scenario mainshock. Liquefaction probability was not calculated for Contra Costa County, but it is assumed that liquefaction damage occurs in Contra Costa County in approximately the same proportion to shaking-induced damage as in Alameda County. Landslide probability in the EBMUD service area is mapped in figure 31 . See figure 32 for a map of EBMUD's water-supply buried pipeline system with a fence diagram showing coseismic slip. Figure 33 shows PGV in one of the more damaging HayWired scenario aftershocks, a $M_{\mathrm{w}} 5.4$ earthquake with an epicenter near Oakland.

The HayWired scenario does not have a map of afterslip, which progresses with time and varies spatially along the Hayward Fault. For present purposes, I assume that for most of the fault length, total slip (coseismic slip plus afterslip) equals $1.9 \mathrm{~m}$, except where coseismic slip exceeds that amount. Afterslip evolves

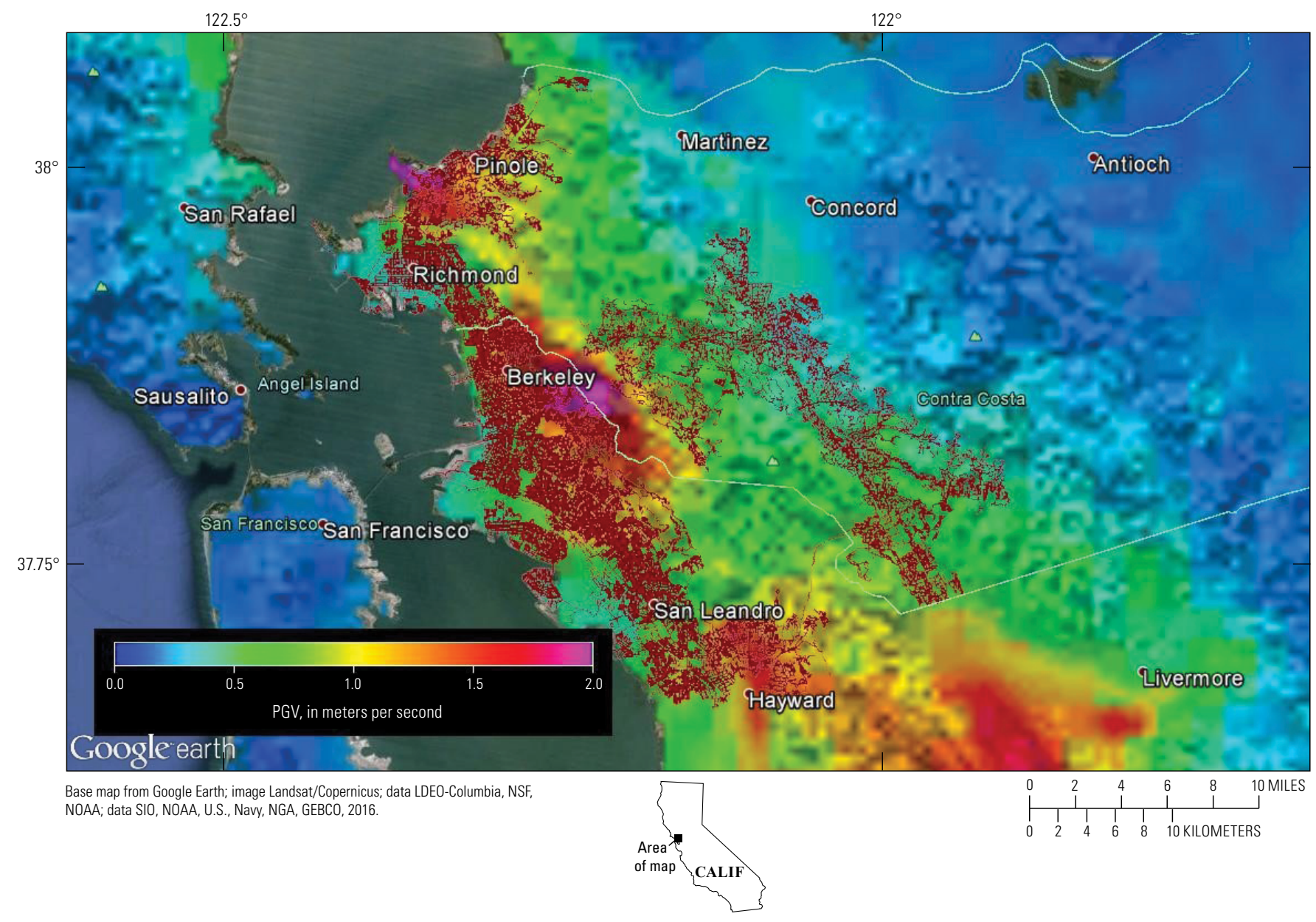

Figure 29. Satellite image of the San Francisco Bay region, California, annotated with a map of the East Bay Municipal Utility District buried water-pipeline system (red). Image is overlaid with mainshock peak ground velocities (PGV) for the hypothetical moment-magnitude-7.0 mainshock of the HayWired earthquake scenario. 


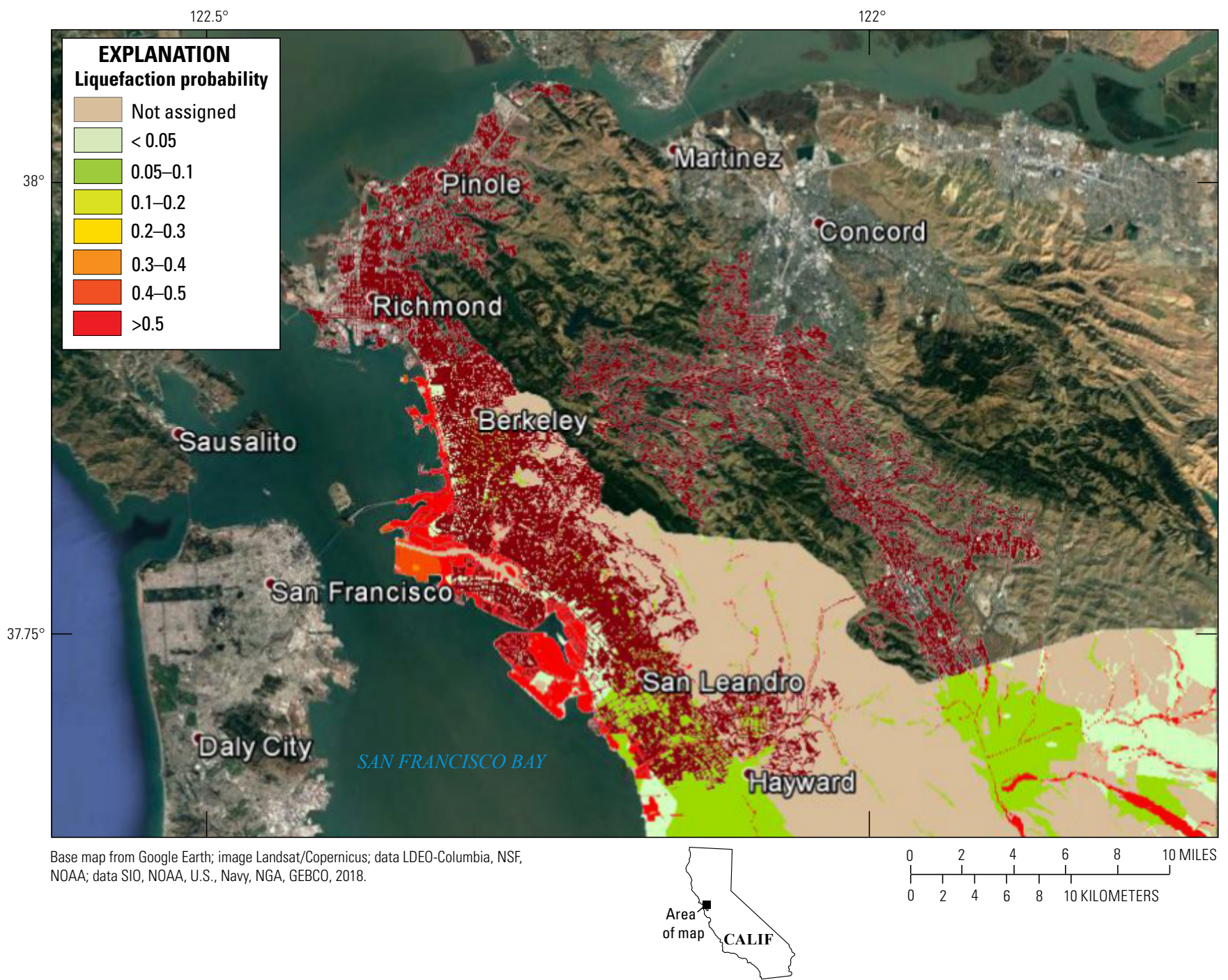

Figure 30. Satellite image of the San Francisco Bay region, California, annotated with a map of the East Bay Municipal Utility District buried water-pipeline system (red). Image is overlaid with liquefaction probability for the hypothetical momentmagnitude-7.0 mainshock of the HayWired earthquake scenario.

over time following equations 6-9 in Aagaard and others (2012), with coseismic slip $=0.09845$, calculated using their figure 11 and $M_{w}=7.0$.

\section{EBMUD Damage Analysis}

Table 21 summarizes the estimated damage to EBMUD buried water pipelines from the HayWired scenario mainshock and aftershocks. Damage in the mainshock includes ground shaking, liquefaction, landsliding, and surface rupture. Because the liquefaction map does not include Contra Costa County, liquefaction damage in Contra Costa County is assumed to be proportional to earthquake shaking damage in Contra Costa County, in the same proportions as in Alameda County. An analysis of fire following earthquake for the HayWired scenario mainshock (Scawthorn, this volume) requires that the assumed liquefaction damage in Contra Costa
County be assigned to particular locations; the damage is assigned to the cities of Pinole, Hercules, and Rodeo, where PGV values are very high and time-averaged shear-wave velocity to a depth of $30 \mathrm{~m}\left(V_{\mathrm{S} 30}\right)$ values are low. As table 21 illustrates, aftershock damage ignores landslides, liquefaction, and surface rupture. Note that the mainshock damage estimate for afterslip assumes that pipes that are ruptured by fault slip are damaged a second time by afterslip, EBMUD may decide to either install earthquake-resistant pipe (for example, highdensity polyethylene-plastic pipe or steel pipe with flexible joints that can tolerate extension, compression, and lateral deformation) or to temporarily install flexible hose until the damaged water main can be repaired or earthquake-resistant pipe can be installed. The table shows that the mainshock produces the majority of the overall damage but that after the mainshock 36 percent more damage occurs in aftershocks. Half the mainshock damage is associated with wave passage, the other half to liquefaction, landsliding, and fault offset. 


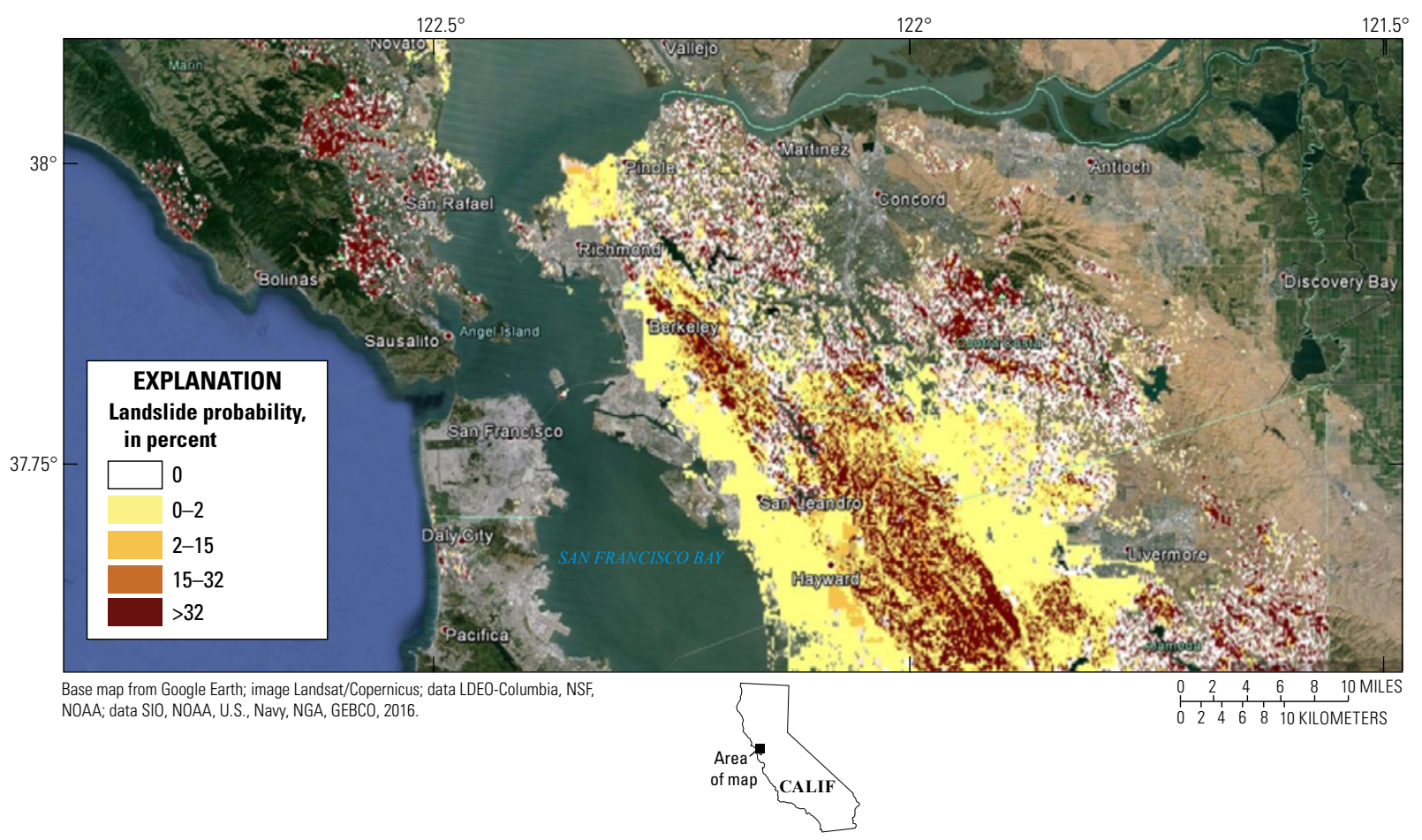

Figure 31. Satellite image of the San Francisco Bay region, California, annotated with a map of the East Bay Municipal Utility District (EBMUD) buried water-pipeline system (red). Image is overlaid with landslide probabilities near the EBMUD service area for the hypothetical moment-magnitude-7.0 mainshock of the HayWired earthquake scenario.

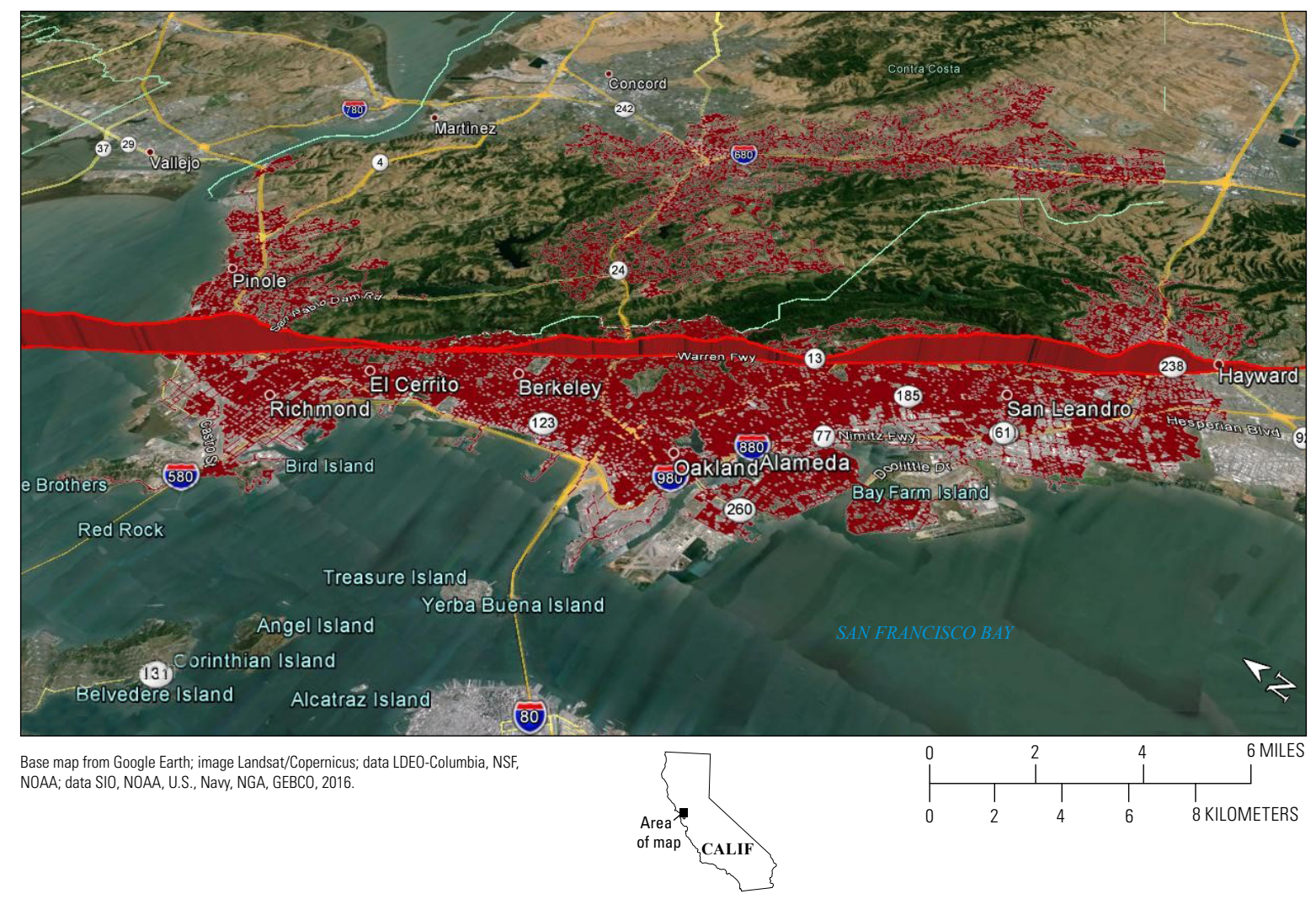

Figure 32. Oblique satellite image of the east bay part of California's San Francisco Bay area, California, annotated with a map of the East Bay Municipal Utility District (EBMUD) buried water-pipeline system (red). Image is overlaid with a red "fence" along the northern Hayward Fault. The height of the red fence represents the right-lateral surface slip occurring on the Hayward Fault at the time of the hypothetical moment-magnitude-7.0 mainshock of the HayWired earthquake scenario. The tallest point on the fence, near the location where Interstate 80 crosses the fault between Richmond and Pinole, represents 2.1 meters of offset. At California Route 24 near Berkeley, the offset is $0.84 \mathrm{~m}$. At Interstate 238 near Castro Valley, the offset is approximately $1.68 \mathrm{~m}$. 


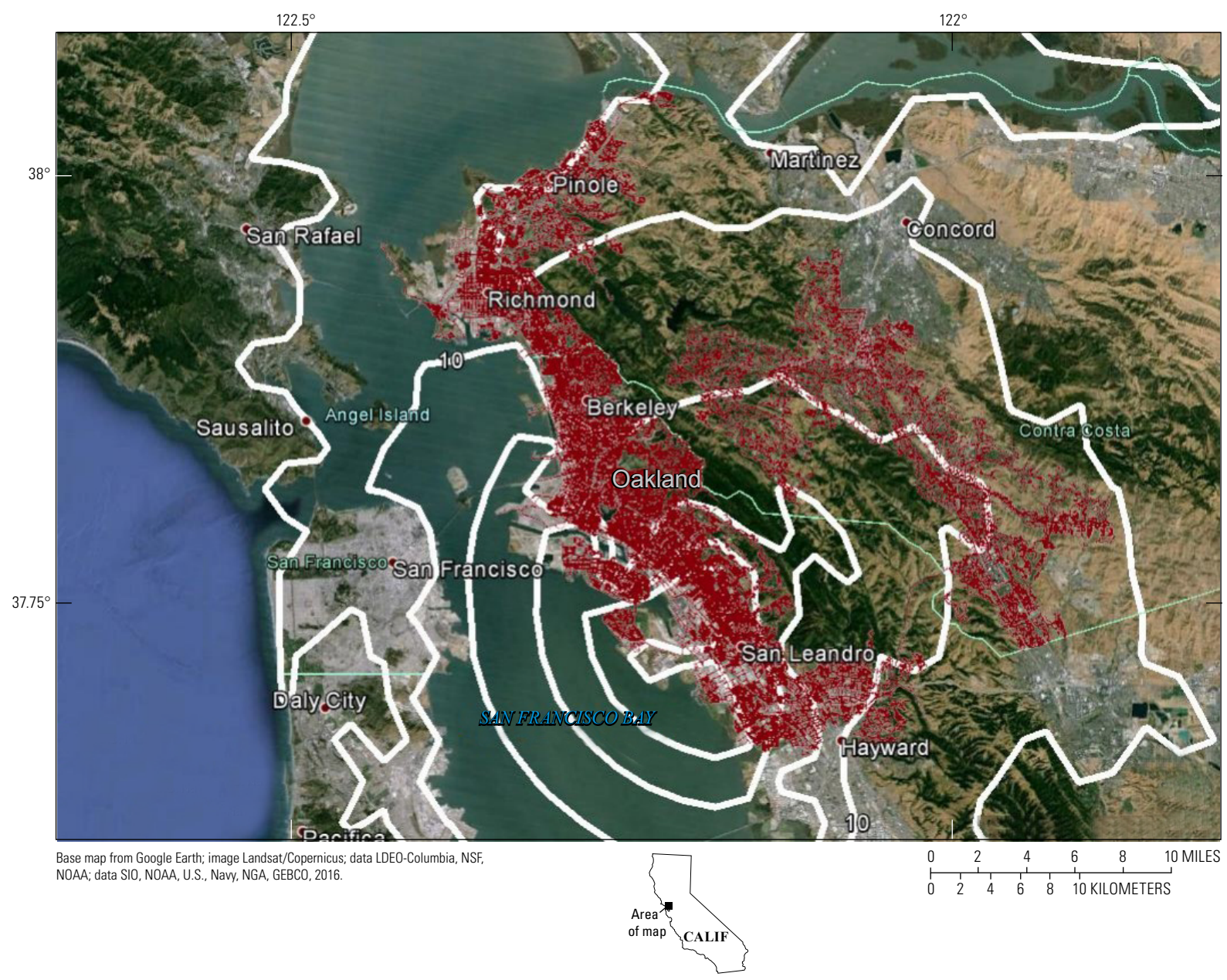

Figure 33. Satellite image of the San Francisco Bay region, California, annotated with a map of the East Bay Municipal Utility District (EBMUD) buried water-pipeline system (red). Image is overlaid with peak ground velocity contours (white lines; in increments of 5 centimeters per second) for a moment-magnitude-5.42 aftershock that occurs beneath the City of Oakland 32 days after the mainshock of the HayWired earthquake scenario.

Table 21. Mean damage estimate for East Bay Municipal Utility District, California, buried water pipeline in the moment-magnitude-7 mainshock and aftershocks HayWired scenario earthquake sequence (see table 12).

\begin{tabular}{lccc}
\hline$\%$, percent] & Mainshock & Aftershocks & Total \\
\hline Mean number of repairs & 4,294 & 1,395 & 5,688 \\
\hline Repairs per kilometers of pipe & 0.64 & 0.21 & 0.85 \\
Due to wave passage & $2,037(47 \%)$ & $1,395(100 \%)$ & $3,432(60 \%)$ \\
Due to liquefaction & $1,642(38 \%)$ & Not calculated & $1,642(29 \%)$ \\
Due to landslide & $185(4 \%)$ & Not calculated & $185(3 \%)$ \\
Due to coseismic slip & $214(5 \%)$ & Not calculated & $214(4 \%)$ \\
Due to afterslip & $214(5 \%)$ & Not calculated & $214(4 \%)$ \\
\hline Large diameter $(\geq 20$ inches diameter) & $218(5 \%)$ & $84(6 \%)$ & $302(5 \%)$ \\
\hline Small diameter $(<20$ inches diameter) & $4,076(95 \%)$ & $1,311(94 \%)$ & $5,386(95 \%)$ \\
\hline Breaks & $1,582(37 \%)$ & $209(15 \%)$ & $1,791(31 \%)$ \\
\hline Leaks & $2,712(63 \%)$ & $1,185(85 \%)$ & $3,898(69 \%)$ \\
\hline
\end{tabular}


Table 22 presents the estimated number of leaks plus breaks in EBMUD buried pipeline in each earthquake of the HayWired sequence. After the mainshock, 6 of 16 aftershocks each produces at least 100 breaks or leaks, and one produces more than 300, with significant numbers of breaks and leaks occurring almost 6 months after the mainshock, a point that is made somewhat clearer by table 23, which summarizes damage by day after the mainshock.
Table 24 details repair rate over the entire HayWired sequence by pipe material. Unsurprisingly, it shows that most damage is in brittle cast-iron and asbestos-cement pipe, with damage rates approaching 0.3 per 1,000 linear feet. Table 25 presents repair rate over the entire sequence by pipe diameter, with most repairs required in 6-inch- and 8-inch- diameter pipe, which together represent the majority of pipe in the system.

Table 22. Estimated number of leaks plus breaks in East Bay Municipal Utility District, California, buried water pipeline in the HayWired scenario earthquake sequence (see table 12).

[Day 1 corresponds to April 18, 2018. $M_{\mathrm{w}}$, moment magnitude]

\begin{tabular}{rlllrrr}
\hline Day & Epicenter & Name & $\boldsymbol{M}_{\mathbf{w}}$ & $\begin{array}{r}\text { Leaks + } \\
\text { breaks }\end{array}$ & $\begin{array}{r}\text { Diameter } \\
\text { 220 inches }\end{array}$ & $\begin{array}{c}\text { Diameter } \\
<20 \text { inches }\end{array}$ \\
\hline 1 & Oakland & Mainshock & 7.0 & 4,294 & 218 & 4,076 \\
1 & San Pablo & sp504 & 5.04 & 102 & 6 & 96 \\
\hline 1 & Union City & uc523 & 5.23 & 101 & 6 & 95 \\
\hline 12 & Fairfield & ff558 & 5.58 & 49 & 3 & 46 \\
\hline 15 & Fremont & fr510 & 5.1 & 37 & 2 & 35 \\
\hline 32 & Oakland & ok542 & 5.42 & 323 & 20 & 304 \\
\hline 40 & Menlo Park & mp552 & 5.52 & 44 & 3 & 41 \\
\hline 40 & Palo Alto & pa62 & 6.2 & 141 & 8 & 133 \\
\hline 41 & Atherton & pa569 & 5.11 & 61 & 4 & 57 \\
\hline 41 & Palo Alto & at511 & 5.69 & 44 & 3 & 42 \\
\hline 67 & Palo Alto & pa522 & 5.22 & 54 & 3 & 51 \\
\hline 74 & Palo Alto & pa526 & 5.26 & 59 & 4 & 55 \\
\hline 166 & Cupertino & sc509 & 6.4 & 25 & 2 & 24 \\
\hline 166 & Mountain View & cu640 & 5.98 & 173 & 10 & 162 \\
\hline 166 & Santa Clara & sv535 & 5.09 & 52 & 3 & 49 \\
\hline 166 & Sunnyvale & mv598 & 5.35 & 102 & 6 & 96 \\
\hline 492 & Palo Alto & pa501 & 5.01 & 28 & 2 & 26 \\
\hline Total & & & & 5,688 & 302 & 5,386 \\
\hline
\end{tabular}

Table 23. Total leaks plus breaks in East Bay Municipal Utility District, California, buried water pipeline by day in the HayWired scenario earthquake sequence (see table 12).

[Day 1 corresponds to April 18, 2018]

\begin{tabular}{rccc}
\hline Day & Leaks + breaks ${ }^{1}$ & $\begin{array}{c}\text { Diameter } \\
\mathbf{2 0} \text { inches }\end{array}$ & $\begin{array}{c}\text { Diameter } \\
<\mathbf{2 0} \text { inches }\end{array}$ \\
\hline 1 & 4,496 & 230 & 4,266 \\
12 & 49 & 3 & 46 \\
15 & 37 & 2 & 35 \\
32 & 323 & 20 & 304 \\
40 & 185 & 11 & 174 \\
41 & 105 & 6 & 98 \\
67 & 54 & 3 & 51 \\
\hline 74 & 59 & 4 & 55 \\
\hline 166 & 352 & 21 & 330 \\
\hline 492 & 28 & 2 & 26 \\
\hline Total & 5,688 & 302 & 5,386 \\
\hline
\end{tabular}

${ }^{1}$ Slight differences from numbers in table 22 and summation differences are due to rounding. 
Table 24. Repair rate for East Bay Municipal Utility District, California, buried water pipeline in the HayWired scenario earthquake sequence.

\begin{tabular}{clrrr}
\hline Material ${ }^{1}$ & \multicolumn{1}{c}{ Description } & Length, in feet & Repairs ${ }^{2}$ & $\begin{array}{c}\text { Repairs per } \\
\text { 1,000 linear } \\
\text { feet }\end{array}$ \\
\hline A & Asbestos cement, unrestrained & $6,000,452$ & 1,874 & 0.312 \\
\hline C & Cast iron, unrestrained & $6,980,888$ & 2,206 & 0.316 \\
D & Ductile iron, unrestrained & 10,841 & 5 & 0.433 \\
\hline F & Fusible PVC, welded & 6,478 & 1 & 0.156 \\
H & High-density polyethylene, weld & 46,472 & 10 & 0.218 \\
\hline K & Copper, restrained & 3,646 & 0 & 0.135 \\
\hline L & Reinforced-concrete cylinder, unrestrained & 75,622 & 22 & 0.285 \\
\hline N & PVC, unrestrained & $2,008,486$ & 438 & 0.218 \\
\hline P & Reinforced-concrete cylinder & 372 & 0 & 0.081 \\
\hline R & Reinforced-concrete noncylinder & 174 & 0 & 0.147 \\
\hline S & Steel, welded & $6,771,086$ & 1,119 & 0.165 \\
\hline T & Pretensioned concrete cylinder, restrained & 55,106 & 10 & 0.183 \\
W & Wrought iron & 14,319 & 4 & 0.284 \\
\hline Total & & $21,973,942$ & 5,688 & 0.259 \\
\hline
\end{tabular}

${ }^{1}$ See material codes and descriptions in table 19.

${ }^{2}$ Excludes damage estimated to occur in zones of liquefaction in Contra Costa County.

Table 25. Repair rate for East Bay Municipal Utility District, California, buried water pipeline by diameter in the HayWired scenario earthquake sequence.

\begin{tabular}{crrc}
\hline $\begin{array}{c}\text { Diameter, } \\
\text { in inches }\end{array}$ & $\begin{array}{c}\text { Length, } \\
\text { in feet }\end{array}$ & Repairs $^{1}$ & $\begin{array}{c}\text { Repairs per 1,000 } \\
\text { linear feet }^{1}\end{array}$ \\
\hline 0 & 2,201 & 0 & 0.000 \\
\hline 0.75 & 834 & 0 & 0.000 \\
\hline 1 & 5,342 & 3 & 0.562 \\
\hline 2 & 98,006 & 28 & 0.286 \\
\hline 3 & 3,665 & 1 & 0.273 \\
\hline 4 & $1,555,655$ & 466 & 0.300 \\
\hline 6 & $9,124,837$ & 2,583 & 0.283 \\
\hline 8 & $5,838,048$ & 1,554 & 0.266 \\
\hline 10 & 200,527 & 69 & 0.344 \\
\hline 12 & $2,512,027$ & 501 & 0.199 \\
\hline 14 & 7,502 & 2 & 0.267 \\
\hline 16 & 831,998 & 178 & 0.214 \\
\hline 18 & 7,394 & 1 & 0.135 \\
\hline 20 & 412,261 & 83 & 0.201 \\
\hline 24 & 393,015 & 68 & 0.173 \\
\hline
\end{tabular}

\begin{tabular}{crrc}
\hline $\begin{array}{c}\text { Diameter, } \\
\text { in inches }\end{array}$ & $\begin{array}{r}\text { Length, } \\
\text { in feet }\end{array}$ & Repairs $^{1}$ & $\begin{array}{c}\text { Repairs per 1,000 } \\
\text { linear feet }^{1}\end{array}$ \\
\hline 25 & 2,581 & 0 & 0.000 \\
30 & 192,540 & 30 & 0.156 \\
\hline 36 & 352,938 & 51 & 0.145 \\
42 & 97,882 & 16 & 0.163 \\
48 & 202,222 & 35 & 0.173 \\
\hline 54 & 46,248 & 11 & 0.238 \\
\hline 60 & 13,778 & 3 & 0.218 \\
\hline 66 & 35,784 & 3 & 0.084 \\
\hline 69 & 24,207 & 2 & 0.083 \\
72 & 70 & 0 & 0.000 \\
\hline 78 & 978 & 0 & 0.000 \\
\hline 84 & 9,598 & 1 & 0.104 \\
\hline 90 & 994 & 0 & 0.000 \\
\hline 96 & 689 & 0 & 0.000 \\
\hline 108 & 122 & 0 & 0.000 \\
\hline Total & $21,973,942$ & 5,688 & 0.259 \\
\hline & & & \\
\hline
\end{tabular}

${ }^{1}$ Where expected number of repairs is less than 0.5 , number of repairs and repair rate per 1,000 linear feet are rounded to 0 ; table excludes damage assumed to occur in zones of liquefaction in Contra Costa County. 
Figures 34, 35, and 36 are damage heatmaps for EBMUD's system. They map mean repairs (estimated per the present methodology) per square kilometer in the HayWired scenario mainshock, most-damaging aftershock (a $M_{\mathrm{w}} 5.4$ event with an Oakland epicenter), and the entire HayWired earthquake sequence. Damage rates reach 50 repairs $/ \mathrm{km}^{2}$ along the Hayward Fault and in zones of high liquefaction probability. The heatmap for the mainshock shows $20-50$ repairs $/ \mathrm{km}^{2}$ in large areas west of the fault, and no levels so high east of the fault, consistent with older pipe and higher liquefaction probability west of the fault. As a check of validity of the mainshock heatmap (fig. 34), notice that it shows on the order of 10 leaks or breaks per square kilometer over an area of about $500 \mathrm{~km}^{2}$, approximately the 5,200 leaks and breaks estimated here.

As with the SJWC case study, the heatmaps show estimated repairs in the HayWired sequence. Different earthquakes would produce different damage patterns. The EBMUD heatmaps depict a single realistic damage pattern to make the HayWired scenario more tangible. EBMUD and its customers, by planning for this scenario, could better prepare for what actually happens in a future earthquake, which will invariably differ in total damage quantities, spatial distribution of damage, and over time.

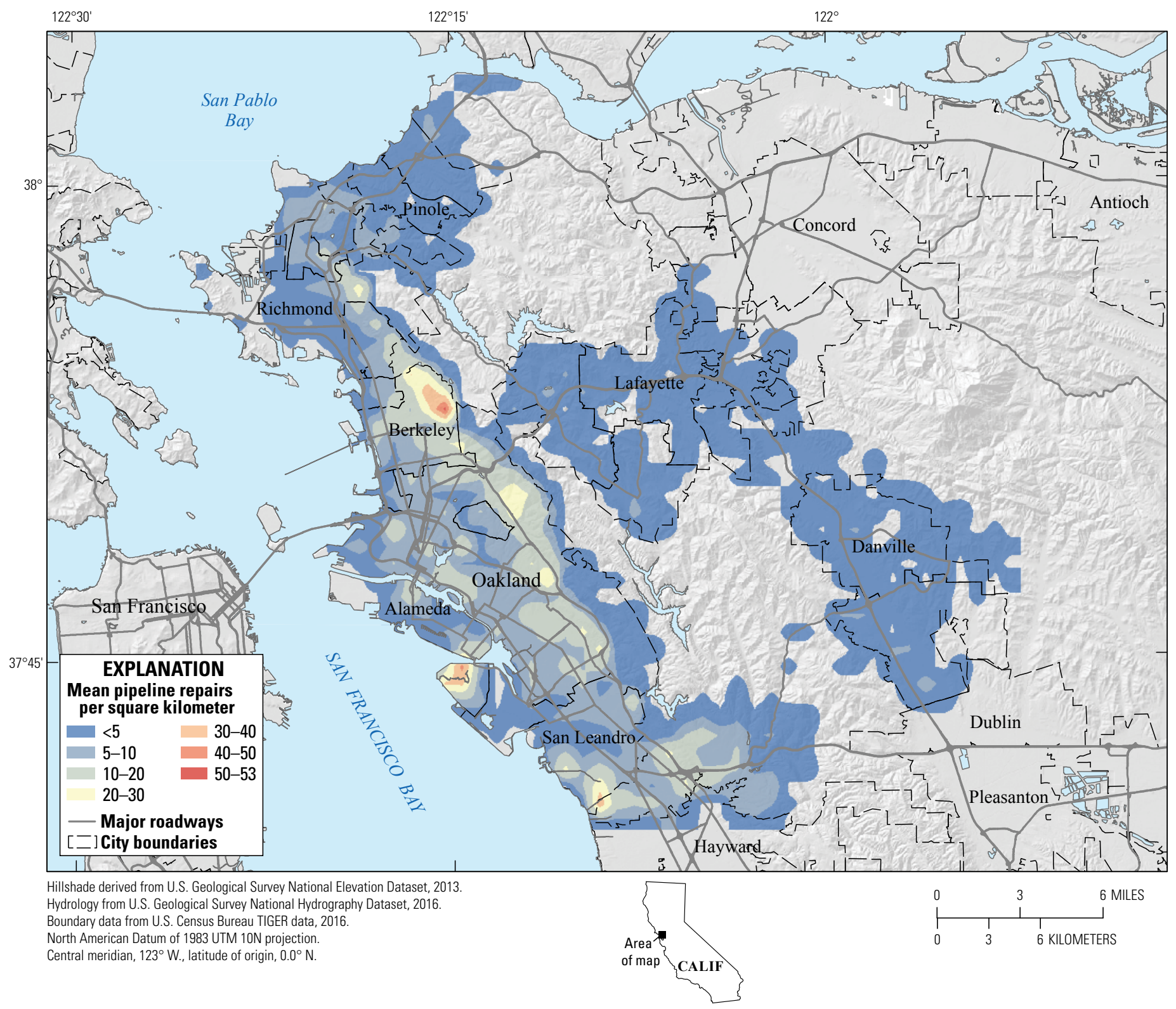

Figure 34. Map of buried water-pipeline damage in East Bay Municipal Utility District's, California's, service area for the hypothetical moment-magnitude-7.0 mainshock of the HayWired earthquake scenario. Colors indicate mean repairs per square kilometer. A warmer color indicates greater concentration of damage. To be informative, the color scale is shifted from those used in figures 35 and 36. 


\section{EBMUD Restoration Analysis}

See the San Jose Water Company Restoration Analysis section for the HayWired scenario's assumptions about electricity, fuel, and communication. I further assume that EBMUD can acquire consumables-for example, pipe, clamps, and replacement valves - as quickly as needed to make repairs after the $M_{\mathrm{w}} 7.0$ HayWired scenario mainshock. Regarding the availability of repair crews, EBMUD agrees with the scenario assumption that it would take as long as a week to assess the extent of damage and locate leaks before repairs can be initiated on a larger scale and that repair efforts would likely need to initially focus on larger diameter water mains. EBMUD staff also estimated that they may be able to field 20 of their own repair crews plus 15 crews provided through mutual aid, for a total about 35 repair crews. Of these, one-quarter are deployed east of the East Bay Hills, the other three-quarters are deployed to the west of the hills. I assume that repairs begin 5 days after the mainshock (the mainshock occurs on day 1 ), and that $c(t)$ ramps up from 20 to 35 crews over the following 14 days, and that crews work 8 -hour days until repairs are completed. Figure 37 illustrates

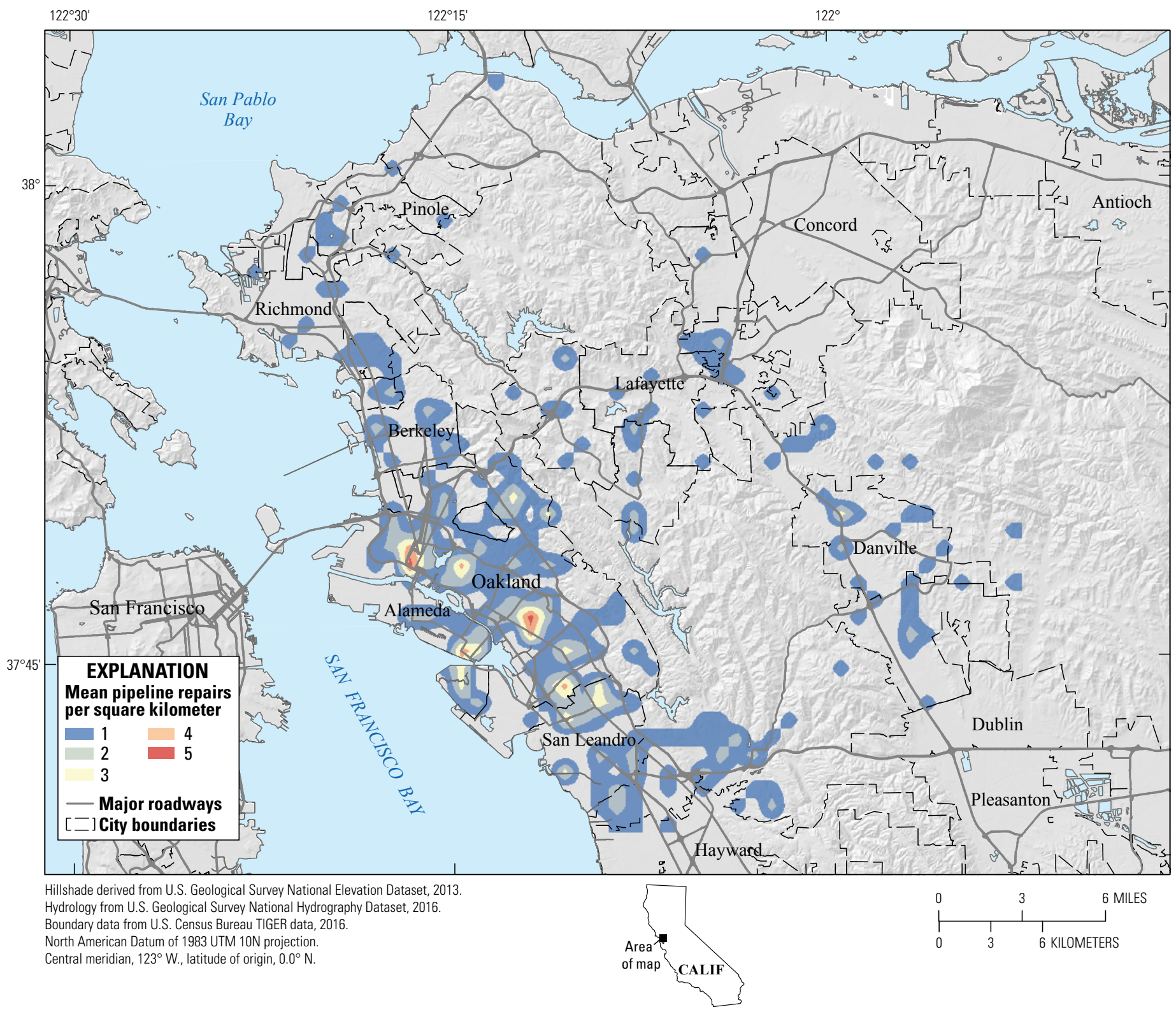

Figure 35. Map of buried water-pipeline damage in East Bay Municipal Utility District's, California's, service area for the hypothetical moment-magnitude-5.3 aftershock (located in 0akland) of the HayWired earthquake scenario. Colors indicate mean repairs per square kilometer. A warmer color indicates greater concentration of damage. To be informative, the color scale is shifted from those used in figures 34 and 36 . 


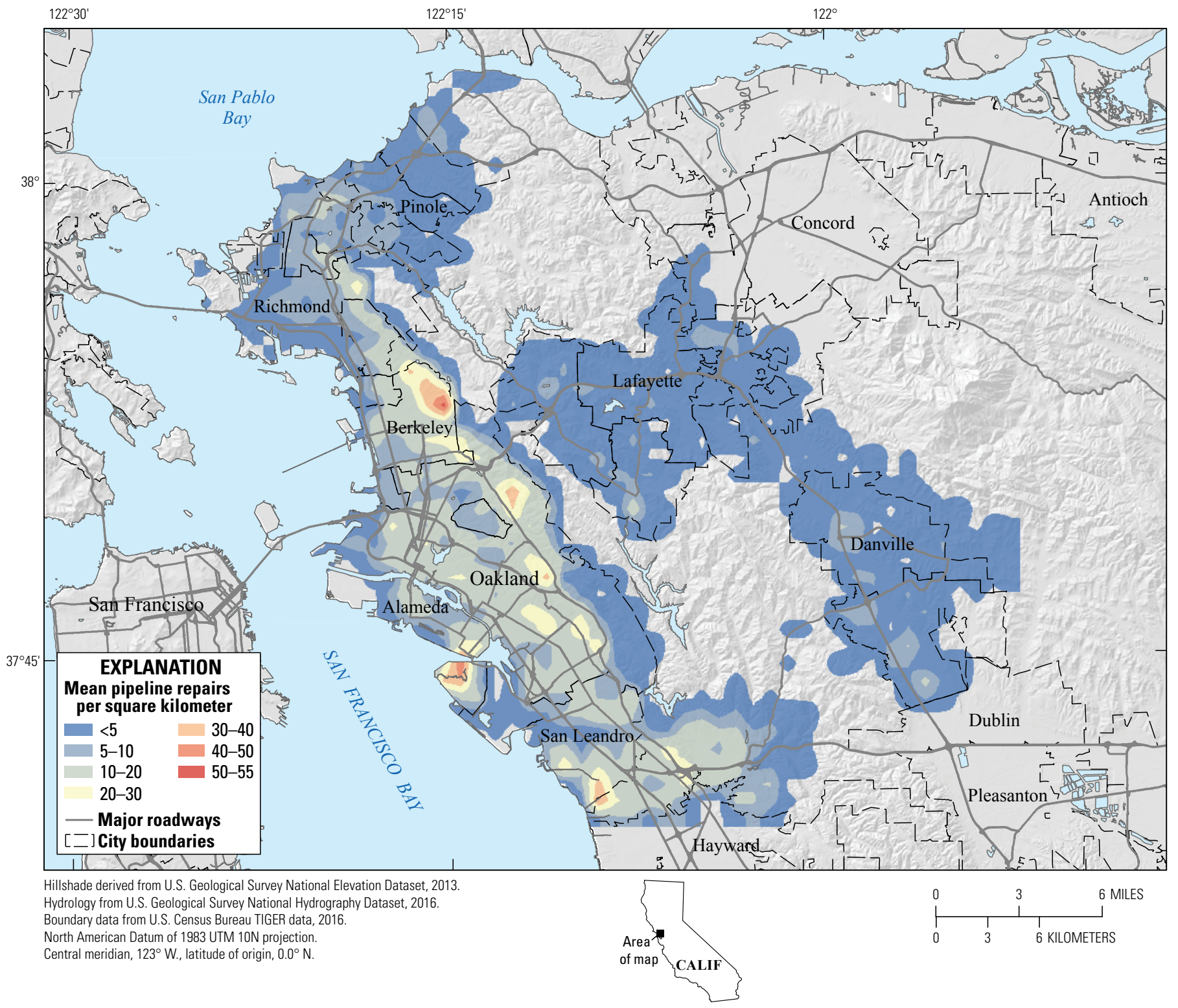

Figure 36. Map of buried water-pipeline damage in East Bay Municipal Utility District's, California's, service area for the entire hypothetical HayWired scenario earthquake sequence (events larger than moment-magnitude 5). Colors indicate mean repairs per square kilometer. A warmer color indicates greater concentration of damage. To be informative, the color scale is shifted from those used in figures 34 and 35 .

repair crew availability, which is expressed mathematically here:

$$
\begin{array}{rlrl}
a(t) & =0.33 & \\
c(t) & =2 & & t<6 \\
& =[2 t-5] & 6 & \leq t<20 \\
& =35 & 20 \leq t<41 \\
& =20 & & 41 \leq t
\end{array}
$$

The notation $[x]$ means the integer part of the quantity $x$, used here because there are no such things as fractional crews.

Figure 38 illustrates the initial level of water service according to equation 29-the loss of system pressure results in approximately 87 percent of service connections east of the East Bay Hills receiving water shortly after the mainshock, 8 percent of those west of the hills.
It seems reasonable to assume that PG\&E will take 2 weeks to restore electricity to 99.9 percent of customers in Alameda and Contra Costa Counties. EBMUD personnel concur. I therefore use the following electricity restoration curve for these counties:

$$
g(t)=1-\exp (-0.493 t) .
$$

Figure 39 shows the estimated service restoration curve for EBMUD under three conditions - (1) as is, (2) assuming EBMUD develops a fuel-management plan to ensure that repair crews are never slowed or idled from lack of fuel, and (3) under ideal conditions. If the Hazus-MH serviceability index realistically measures the fraction of service connections receiving any water, as reports produced 


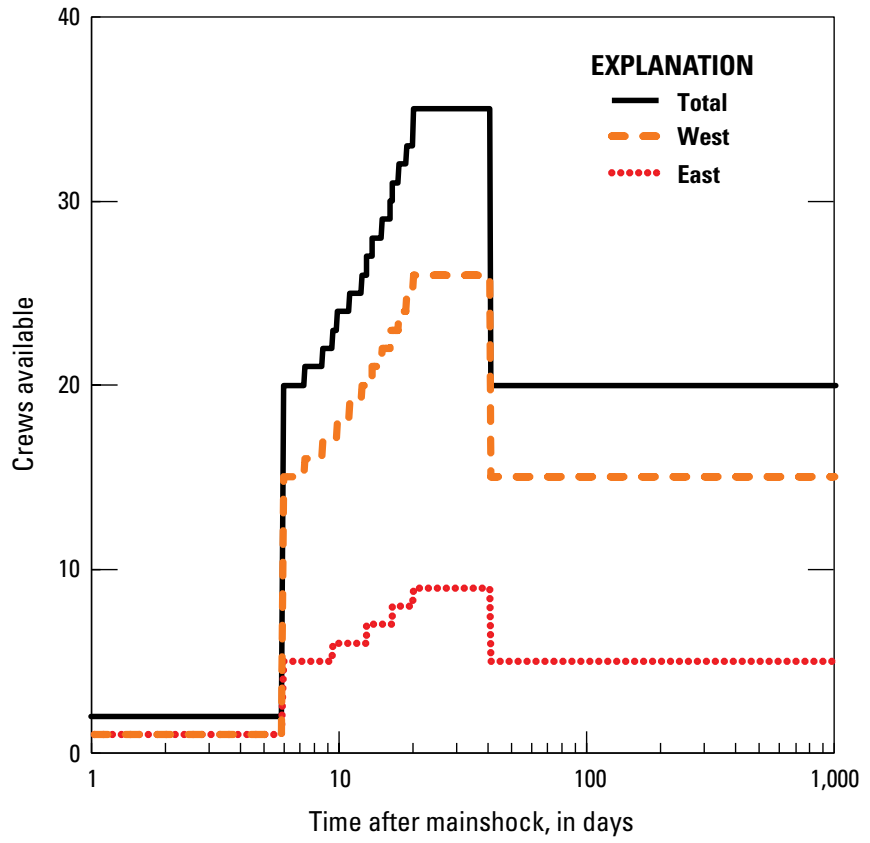

Figure 37. Graph showing East Bay Municipal Utility District, California, repair-crew availability by day following the hypothetical moment-magnitude-7.0 mainshock of the HayWired earthquake scenario. East, areas east of the East Bay Hills; west, areas west of the East Bay Hills between the hills and San Francisco Bay.

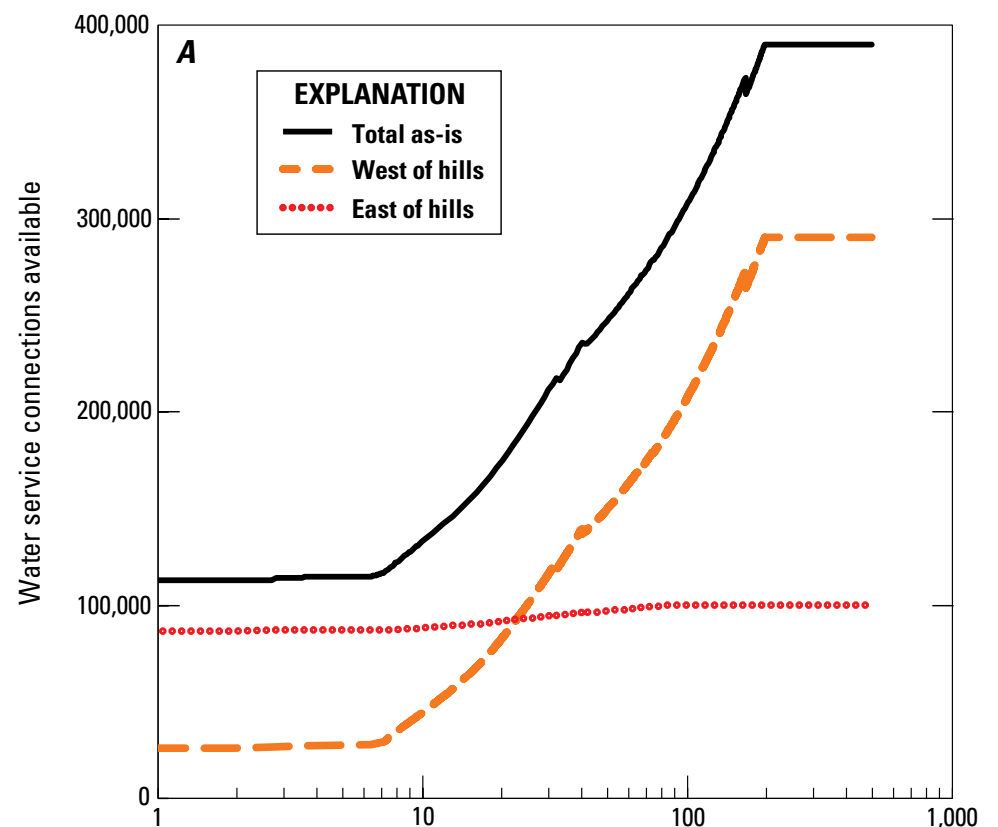

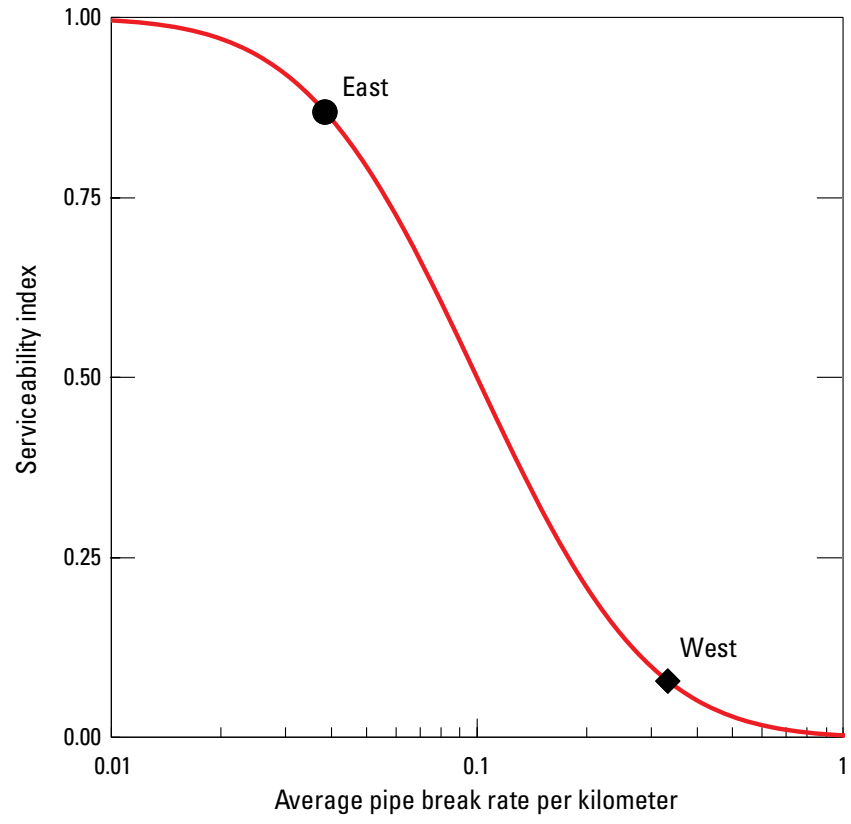

Figure 38. Graph showing initial East Bay Municipal Utility District, California, water service availability (equation 29) east and west of the East Bay Hills, in the east bay part of the San Francisco Bay area, following the hypothetical momentmagnitude-7.0 mainshock of the HayWired earthquake scenario.

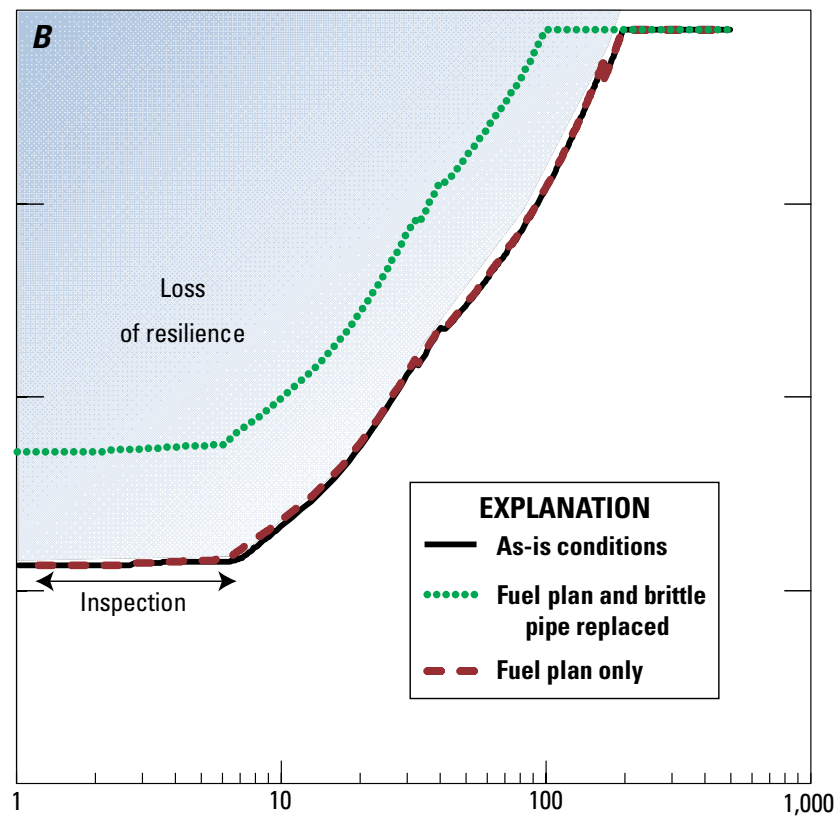

Time after mainshock, in days

Figure 39. Graphs showing East Bay Municipal Utility District, California, water-service restoration curves by day following the hypothetical moment-magnitude-7.0 mainshock of the HayWired earthquake scenario. $A$, water-service restoration curves under as-is conditions, including total for the system and service east and west of the East Bay Hills, in the east bay part of the San Francisco Bay area. $B$, Total-system water-service restoration curves under several conditions-(1) with a fuel-management plan in place and all brittle pipe replaced, (2) with a fuel-management plan only, and (3) as-is conditions. With a fuel-management plan in place and all brittle pipe replaced before the mainshock, about 8 million service days are lost (lost connections $\times$ days), with average lost service days per lost connection being 21 days. With only a fuel-management plan in place and brittle pipe not replaced before the mainshock, about 18.9 million service days are lost, with average lost service days per lost connection being 48 days. Under as-is conditions following the mainshock, about 19.91 million service days are lost, with average lost service days per lost connection being 49 days. 
by the Hazus software suggest, then "services available" means the fraction of service connections receiving even small flows. If it means the post-earthquake flow as a fraction of pre-earthquake flow, then the charts underestimate the number of service connections receiving at least some water. Note that "ideal conditions" refers to the case in which the HayWired mainshock occurs after all of EBMUD's brittle pipe is replaced and all pumping stations are supplied with emergency generators and fuel. The curves show that under as-is conditions, full restoration takes 28 weeks (just more than 6 months). Under ideal-world conditions, full service is restored in 14 weeks (just more than 3 months), roughly 3 months earlier than under as-is conditions.

Figure 40 shows the progress of EBMUD repairs in the HayWired earthquake sequence, again illustrating the possible effects of fuel limitations, an estimate of the benefit of an in-place fuel-management plan, and the potential benefit of replacing brittle pipe in advance.

One can view the area above the curves in figure 40 as a measure of resilience - less area means less negative impact, faster recovery, or both. The areas above the three curves (as-is conditions, with fuel plan, and ideal-world) are measured in units of service days. That is, each day of lost water supply to a service connection equates with one service day. The areas above the three curves are shown in table 26. The table shows lost service-days under as-is conditions, with a fuel plan, and under ideal-world conditions, that is, in which all cast iron and asbestos cement pipe is replaced before the earthquake. The difference between lost service days under as-is and what-if conditions (fuel-management plan or ideal world) measures the resilience benefit of the what-if condition - with a fuel-management plan and if all brittle pipe were replaced before the hypothetical earthquake occurred. Although full restoration takes much longer, the table also shows average number of days that each service connection goes without potable water under as-is conditions, with the fuel-management plan, and under ideal-world conditions.

\section{Validation of EBMUD Damage and Recovery Estimates}

As with SJWC, it is possible to perform some initial checks of the foregoing results, to see at least whether they are reasonable. This validation is discussed below.

\section{Cross Validation with EBMUD Internal Damage Estimates}

EBMUD commissioned a private study that estimated, among other things, the potential for water-supply pipeline damage resulting from a M7.0 earthquake on the Hayward Fault. As described by Terentieff and others (2015), that 1997 study estimated 4,054 pipe breaks and leaks, most of which occur in cast-iron and asbestos-cement pipe. EBMUD performed an internal study in 1997 of large-diameter pipe (at least 16- to

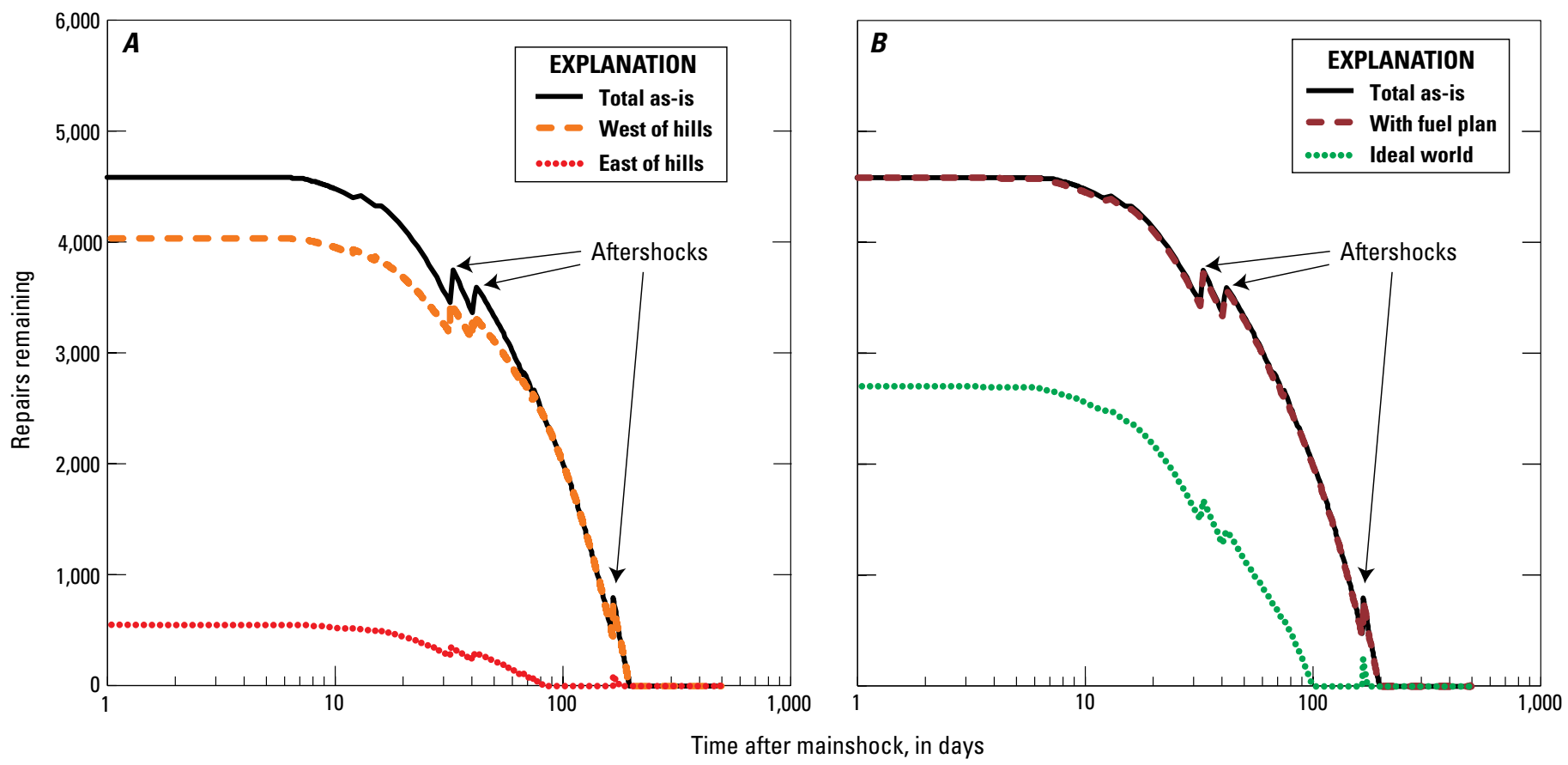

Figure 40. Graphs showing East Bay Municipal Utility District, California, water-service repair progress following the hypothetical momentmagnitude-7 mainshock and aftershocks HayWired scenario earthquake sequence (see table 12). $A$, Curves for remaining repairs under as-is conditions, including total for the system and service east and west of the East Bay Hills, in the east bay part of the San Francisco Bay area. $B$, Curves for remaining repairs in the total system with (1) a fuel-management plan in place only and (2) a fuel-management plan in place and all brittle pipe replaced (the "ideal world"). 
Table 26. East Bay Municipal Utility District, California, average lost service days following the hypothetical moment-magnitude-7.0 mainshock of the HayWired earthquake scenario.

[Numbers rounded to reduce the impression of excessive precision. Ideal world - fuel-management plan in place and all asbestos cement and cast-iron pipe is replaced with ductile-iron or plastic pipe before the earthquake sequence occurs. $R$, number of days that service connection is without potable water; $M$, number of water service connections]

\begin{tabular}{lccc}
\hline \multicolumn{1}{c}{ Condition } & Lost service-days $\boldsymbol{R} \times \boldsymbol{M}$ & Resilience benefit, $\boldsymbol{D}(\boldsymbol{R} \times \boldsymbol{M})$ & Average lost days $\boldsymbol{R}$ \\
\hline Total as-is & $19,100,000$ & & 49 \\
With fuel-management plan & $18,900,000$ & 200,000 & 48 \\
Ideal world & $8,100,000$ & $11,000,000$ & 21 \\
\hline
\end{tabular}

24-inch diameter, depending on pipe material) and estimated 334 breaks and leaks could result from a $M 7.0$ earthquake on the Hayward Fault. Terentieff and others (2015) report that EBMUD has initiated an infrastructure renewal program with a goal of replacing approximately 1 percent of its pipe per year, focusing first on cast-iron and asbestos-cement pipe.

The 1997 estimate of 4,054 breaks and leaks is close to the 4,300 breaks and leaks estimated here for the $M_{\mathrm{w}} 7.0$ HayWired scenario mainshock and somewhat smaller than the present estimate of 5,688 breaks and leaks in the entire HayWired earthquake sequence. The 1997 estimate of 334 breaks and leaks in large diameter pipes is somewhat higher than the present estimate of 218 breaks and leaks in pipe of at least 20 -inches diameter in the HayWired mainshock, although similar to the present estimate of 302 large-diameter breaks and leaks in the entire HayWired sequence.

It seems realistic that EBMUD will complete much of its replacement of the 61 percent of its pipes that are constructed of cast iron or asbestos cement before a large earthquake occurs on the Hayward Fault. The issue is more complicated than just whether a $M_{\mathrm{w}} 7.0$ or larger earthquake occurs on the Hayward Fault. According to the Uniform California Earthquake Rupture Forecast, version 3 (UCERF3), fault section data (Field and others, 2013), the chance that such an earthquake will occur in the next 61 years is approximately 16 percent on the northern segment of the Hayward Fault, 12 percent on the southern segment of the fault, and 26 percent on either of these fault segments - significant, but nowhere near certain.

\section{Comparison with EBMUD Judgment, Northridge, Kobe, and Napa Restoration}

As previously noted, Jeon and O'Rourke (2005) report that the 1994 Northridge earthquake caused 1,095 breaks or leaks to buried pipeline operated by the LADWP, whereas Lund and others (2005) report that repairs took about 1 week. The calculation discussed here for the HayWired scenario suggests that EBMUD would take 28 weeks to repair 5,700 breaks and leaks from the entire HayWired earthquake sequence. Although the estimate of just more than 6 months to restore EBMUD buried water pipelines following the HayWired mainshock agrees with EBMUD's judgment, it is about 28 times as long for about five times the number of repairs, or about one-fifth on average as fast as LADWP's actual repair rate following the Northridge earthquake.
Also, as previously noted, the Kobe Municipal Waterworks Bureau experienced 1,757 breaks and leaks after the 1995 Kobe earthquake and that repairs took 10 weeks, that is, 176 repairs per week. The present estimate of 28 weeks to repair 5,700 breaks and leaks (200 repairs per week) is roughly on par with Kobe.

The City of Napa repaired approximately 120 leaks and breaks in 5 days (170 repairs per week) after the 2014 South Napa earthquake, approximately equal to the 200 repairs per week estimated here.

\section{Cross Validation with Hazus-MH}

Table 27 shows the Hazus-MH estimate of water-supply restoration in Contra Costa and Alameda Counties, where EBMUD operates. As before, the estimates are for the HayWired mainshock only and do not reflect lifeline interaction. Applying the percentages to the number of EBMUD's customers, one can compare the two models, as shown in figure 41 . The two models substantially disagree in terms of initial service availability and in terms of restoration time.

\section{Effect of Lifeline Interaction and Consumable Limits on EBMUD}

EBMUD does not expect to begin repairs until about day 7 following the HayWired scenario mainshock, after power and telecommunications have been largely (though not completely) restored. Therefore, lifeline interaction will have little effect on EBMUD in the HayWired scenario.

\section{Performance of Other Water Utilities Based on Hazus-MH}

It is time consuming to acquire the necessary data and to perform the analysis of a water-supply system. The San Francisco Bay region has on the order of 30 of them. To estimate the effects of the HayWired earthquake sequence on the metropolitan area, I apply the proposed modification of the Hazus-MH (Federal Emergency Management Agency, 2012) methodology to the analysis of the bay region's water-supply system (see Seligson and others, this volume). First, I adjust estimates of water-supply restoration time to account for the 
Table 27. Hazus-MH estimate of Contra Costa and Alameda County, California, loss of water supply following the hypothetical moment-magnitude-7.0 mainshock of the HayWired earthquake scenario.

$[\%$, percent $]$

\begin{tabular}{lccccc}
\hline \multirow{2}{*}{ Analysis } & \multicolumn{5}{c}{ Households without water following mainshock } \\
\cline { 2 - 5 } & Day 1 & Day 3 & Day 7 & Day 30 & Day 90 \\
\hline Hazus-MH ${ }^{1}$ & 855,207 & 854,738 & 853,731 & 845,534 & 762,299 \\
& $98.58 \%$ & $98.53 \%$ & $98.41 \%$ & $97.47 \%$ & $87.87 \%$ \\
This analysis & $71 \%$ & $71 \%$ & $70 \%$ & $46 \%$ & $24 \%$ \\
\hline
\end{tabular}

${ }^{1}$ Hazus-MH figures as reported by the software (Doug Bausch, written commun., Federal Emergency Management Agency, 2014), with its estimate of 867,495 total households.

${ }^{2}$ Estimates rounded to the nearest percent to reduce the appearance of excessive accuracy. Hazus-MH figures are as reported by the software.

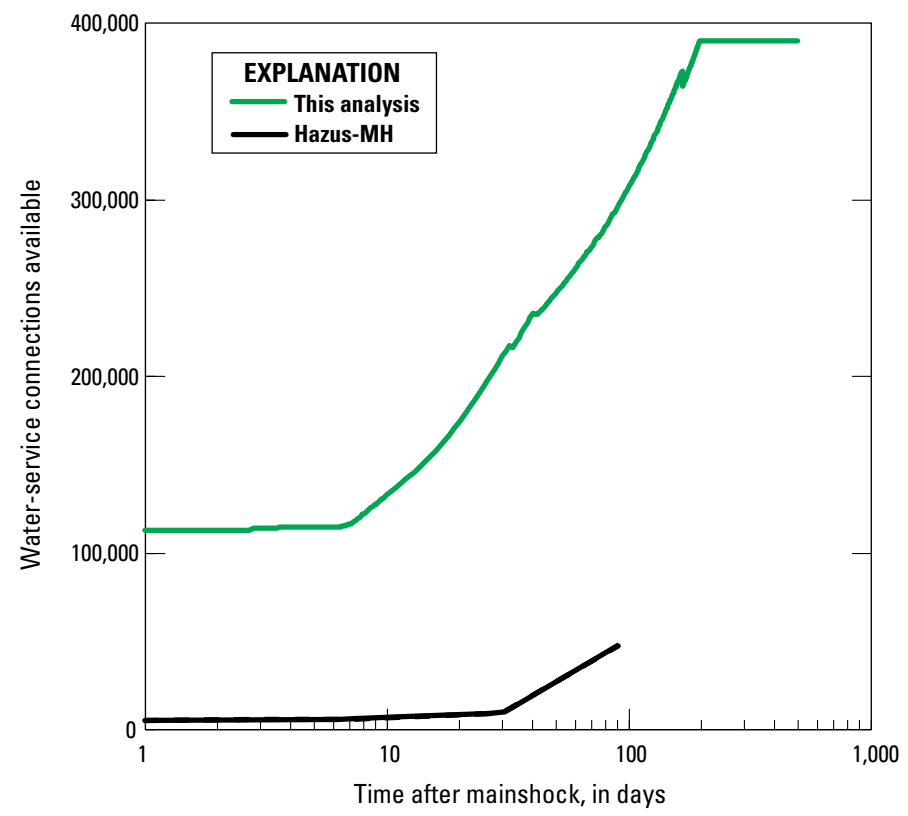

Figure 41. Graph comparing the estimated restoration of water supply connections for East Bay Municipal Utility District between the HayWired scenario model in this analysis and the Hazus-MH model for the hypothetical moment-magnitude-7.0 mainshock of the HayWired earthquake scenario (Seligson and others, this volume).

differences between Hazus' default assumptions of repair crew availability.

SJWC estimates it can field 22 repair crews to respond to damage in its service area of 225,000 service connections, or approximately 1 crew per 10,000 service connections. Hazus-MH seems to equate households with service connections. With the inventory that FEMA enhanced for the San Francisco Bay region before the HayWired project, Hazus-MH estimates that Santa Clara County has 565,863 households, which it seems to equate with the number of service connections. To adjust Hazus' default number of pipeline repair crews for purposes of equation 61, I take:

$$
\begin{aligned}
\frac{q}{q_{0}} & =\frac{1}{100} \times\left(\frac{565,863}{10,000} \times 4\right) . \\
& =2.26
\end{aligned}
$$

EBMUD engineers agree with the HayWired scenario assumption that EBMUD can field 35 crews to respond to damage in its system that provides water to 390,000 service connections. Those figures indicate approximately $1 \mathrm{crew}$ per 11,000 service connections, versus SJWC's estimate of as many as 1 crew per 9,000 service connections. I assume therefore that Alameda and Contra Costa Counties (EBMUD's service area) have approximately $1 \mathrm{crew}$ (4 workers) per 11,000 households, Santa Clara County (SJWC's service area) has 1 crew per 9,000 households, and other counties have 1 crew per 10,000 households (an approximate mean of EBMUD and SJWC, in round numbers). Table 28 shows corresponding restoration-rate adjustment factors for repair-crew availability. The household-weighted average value of the repair-crew factor $q / q_{0}$ is 1.37 , although it is higher in the strongly shaken counties of Alameda and Santa Clara.

To address lifeline interaction for the purposes of equation 67- the product term inside the summation - I take rate-limiting factors $u$ and the flow of rate-limiting factors $g$ as those proposed for EBMUD. That is, I assume that approximately half of services are in pumped pressure districts that require electricity, that electricity is restored within 1 week, and that there is a temporary fuel shortage between days 3 and 7 .

Hazus' estimates of the number of service connections with water service at time $t_{j}$ (normalized by the number of households) are recapped in table 29. The assumption of complete restoration at day 210 is mine. Hazus-MH does not report level of service beyond 90 days, but I suggest that full restoration would likely be completed within 7 months. The table reports values of $\hat{V}(t)$ in the sense of equation 61 . Table 30 shows the restoration curves adjusted for repair-crew availability and lifeline interaction but using the restoration curves for Alameda, Contra Costa, and Santa Clara Counties as those calculated in the case studies under as-is conditions. Table 31 shows the restoration curves adjusted with a fuelmanagement plan in place in all counties. Alameda, Contra Costa, and Santa Clara Counties are as those calculated in the case studies with a fuel plan. Table 32 shows the restoration curves with emergency generators and fuel in all counties. Alameda, Contra Costa, and Santa Clara counties are as those calculated in the case studies under ideal-world conditions. The tables are illustrated in figure $42 A$ through $D$. Note that, because Hazus-MH analyses were unavailable for lifelines subjected to aftershocks in the HayWired earthquake sequence, the restoration curves for counties other than Santa Clara, Alameda, and Contra Costa Counties do not reflect aftershock damage. 
Table 28. Repair-crew adjustment factor, $q / q_{0}$, for San Francisco Bay region, California, buried water-supply pipeline restoration.

\begin{tabular}{lrrrl}
\hline \multicolumn{1}{c}{ County } & Households & Crews & Workers & $\boldsymbol{q / q _ { 0 }}$ \\
\hline Alameda & 523,366 & 48 & 190 & 1.90 \\
\hline Contra Costa & 344,129 & 31 & 125 & 1.25 \\
Marin & 100,650 & 10 & 40 & 0.40 \\
Merced & 63,815 & 6 & 26 & 0.26 \\
Monterey & 121,236 & 12 & 48 & 0.48 \\
\hline Napa & 45,402 & 5 & 18 & 0.18 \\
Sacramento & 453,602 & 45 & 181 & 1.81 \\
\hline San Benito & 15,885 & 2 & 6 & 0.06 \\
San Francisco & 329,700 & 33 & 132 & 1.32 \\
San Joaquin & 181,629 & 18 & 73 & 0.73 \\
San Mateo & 254,103 & 25 & 102 & 1.02 \\
Santa Clara & 565,863 & 63 & 251 & 2.51 \\
Santa Cruz & 91,139 & 9 & 36 & 0.36 \\
Solano & 130,403 & 13 & 52 & 0.52 \\
\hline Sonoma & 172,403 & 17 & 69 & 0.69 \\
\hline Stanislaus & 145,146 & 15 & 58 & 0.58 \\
\hline Yolo & 59,375 & 6 & 24 & 0.24 \\
\hline
\end{tabular}

Table 30. Hazus-MH-based estimate of water-service restoration after adjusting for repair crew availability and lifeline interaction without a fuel-management plan for San Francisco Bay region, California, counties following the hypothetical momentmagnitude-7.0 mainshock of the HayWired earthquake scenario.

[Santa Clara, Alameda, and Contra Costa Counties are as calculated in case studies. \%, percent]

\begin{tabular}{lrrrrrl}
\hline \multirow{2}{*}{ County } & \multicolumn{6}{c}{ Day } \\
\cline { 2 - 7 } & $\mathbf{1}$ & \multicolumn{1}{c}{$\mathbf{3}$} & \multicolumn{1}{c}{$\mathbf{3}$} & $\mathbf{3 0}$ & $\mathbf{9 0}$ & $\mathbf{2 1 0}$ \\
\hline Alameda & $29 \%$ & $29 \%$ & $30 \%$ & $54 \%$ & $76 \%$ & $100 \%$ \\
\hline Contra Costa & $29 \%$ & $29 \%$ & $30 \%$ & $54 \%$ & $76 \%$ & $100 \%$ \\
\hline Marin & $91 \%$ & $94 \%$ & $95 \%$ & $100 \%$ & $100 \%$ & $100 \%$ \\
\hline Merced & $98 \%$ & $98 \%$ & $98 \%$ & $100 \%$ & $100 \%$ & $100 \%$ \\
Monterey & $100 \%$ & $100 \%$ & $100 \%$ & $100 \%$ & $100 \%$ & $100 \%$ \\
\hline Napa & $100 \%$ & $100 \%$ & $100 \%$ & $100 \%$ & $100 \%$ & $100 \%$ \\
\hline Sacramento & $100 \%$ & $100 \%$ & $100 \%$ & $100 \%$ & $100 \%$ & $100 \%$ \\
\hline San Benito & $98 \%$ & $98 \%$ & $100 \%$ & $100 \%$ & $100 \%$ & $100 \%$ \\
\hline San Francisco & $40 \%$ & $55 \%$ & $67 \%$ & $100 \%$ & $100 \%$ & $100 \%$ \\
\hline San Joaquin & $100 \%$ & $100 \%$ & $100 \%$ & $100 \%$ & $100 \%$ & $100 \%$ \\
\hline San Mateo & $30 \%$ & $34 \%$ & $35 \%$ & $80 \%$ & $100 \%$ & $100 \%$ \\
\hline Santa Clara & $63 \%$ & $70 \%$ & $73 \%$ & $100 \%$ & $100 \%$ & $100 \%$ \\
\hline Santa Cruz & $100 \%$ & $100 \%$ & $100 \%$ & $100 \%$ & $100 \%$ & $100 \%$ \\
\hline Solano & $98 \%$ & $99 \%$ & $99 \%$ & $100 \%$ & $100 \%$ & $100 \%$ \\
\hline Sonoma & $100 \%$ & $100 \%$ & $100 \%$ & $100 \%$ & $100 \%$ & $100 \%$ \\
\hline Stanislaus & $100 \%$ & $100 \%$ & $100 \%$ & $100 \%$ & $100 \%$ & $100 \%$ \\
\hline Yolo & $100 \%$ & $100 \%$ & $100 \%$ & $100 \%$ & $100 \%$ & $100 \%$ \\
\hline
\end{tabular}

Table 29. Hazus-MH unadjusted estimate of water-service restoration for San Francisco Bay region, California, counties following the hypothetical moment-magnitude-7.0 mainshock of the HayWired earthquake scenario.

$[\%$, percent $]$

\begin{tabular}{lrrrrrr}
\hline \multirow{2}{*}{ County } & \multicolumn{7}{c}{ Day } \\
\cline { 2 - 7 } & $\mathbf{1}$ & \multicolumn{1}{c}{$\mathbf{3}$} & $\mathbf{7}$ & $\mathbf{3 0}$ & $\mathbf{9 0}$ & $\mathbf{2 1 0}$ \\
\hline Alameda & $1 \%$ & $1 \%$ & $1 \%$ & $1 \%$ & $2 \%$ & $100 \%$ \\
\hline Contra Costa & $3 \%$ & $3 \%$ & $3 \%$ & $5 \%$ & $28 \%$ & $100 \%$ \\
\hline Marin & $91 \%$ & $98 \%$ & $100 \%$ & $100 \%$ & $100 \%$ & $100 \%$ \\
\hline Merced & $98 \%$ & $99 \%$ & $100 \%$ & $100 \%$ & $100 \%$ & $100 \%$ \\
\hline Monterey & $100 \%$ & $100 \%$ & $100 \%$ & $100 \%$ & $100 \%$ & $100 \%$ \\
\hline Napa & $100 \%$ & $100 \%$ & $100 \%$ & $100 \%$ & $100 \%$ & $100 \%$ \\
\hline Sacramento & $100 \%$ & $100 \%$ & $100 \%$ & $100 \%$ & $100 \%$ & $100 \%$ \\
\hline San Benito & $98 \%$ & $100 \%$ & $100 \%$ & $100 \%$ & $100 \%$ & $100 \%$ \\
\hline San Francisco & $40 \%$ & $52 \%$ & $87 \%$ & $100 \%$ & $100 \%$ & $100 \%$ \\
\hline San Joaquin & $100 \%$ & $100 \%$ & $100 \%$ & $100 \%$ & $100 \%$ & $100 \%$ \\
\hline San Mateo & $30 \%$ & $34 \%$ & $41 \%$ & $100 \%$ & $100 \%$ & $100 \%$ \\
\hline Santa Clara & $11 \%$ & $11 \%$ & $12 \%$ & $19 \%$ & $76 \%$ & $100 \%$ \\
\hline Santa Cruz & $100 \%$ & $100 \%$ & $100 \%$ & $100 \%$ & $100 \%$ & $100 \%$ \\
\hline Solano & $98 \%$ & $100 \%$ & $100 \%$ & $100 \%$ & $100 \%$ & $100 \%$ \\
\hline Sonoma & $100 \%$ & $100 \%$ & $100 \%$ & $100 \%$ & $100 \%$ & $100 \%$ \\
\hline Stanislaus & $100 \%$ & $100 \%$ & $100 \%$ & $100 \%$ & $100 \%$ & $100 \%$ \\
\hline Yolo & $100 \%$ & $100 \%$ & $100 \%$ & $100 \%$ & $100 \%$ & $100 \%$ \\
\hline
\end{tabular}

Table 31. Hazus-MH-based estimate of water-service restoration after adjusting for repair crew availability and lifeline interaction with a fuel-management plan for San Francisco Bay region, California, counties following the hypothetical momentmagnitude-7.0 mainshock of the HayWired earthquake scenario.

[Santa Clara, Alameda, and Contra Costa Counties are as calculated in case studies. $\%$, percent]

\begin{tabular}{lrrrrrr}
\hline \multirow{2}{*}{\multicolumn{1}{c}{ County }} & \multicolumn{6}{c}{ Day } \\
\cline { 2 - 7 } & $\mathbf{1}$ & \multicolumn{1}{c}{$\mathbf{3}$} & \multicolumn{1}{c}{} & \multicolumn{1}{c}{$\mathbf{3 0}$} & $\mathbf{9 0}$ & $\mathbf{2 1 0}$ \\
\hline Alameda & $32 \%$ & $33 \%$ & $35 \%$ & $59 \%$ & $81 \%$ & $100 \%$ \\
Contra Costa & $32 \%$ & $33 \%$ & $35 \%$ & $59 \%$ & $81 \%$ & $100 \%$ \\
Marin & $91 \%$ & $94 \%$ & $100 \%$ & $100 \%$ & $100 \%$ & $100 \%$ \\
Merced & $98 \%$ & $98 \%$ & $99 \%$ & $100 \%$ & $100 \%$ & $100 \%$ \\
\hline Monterey & $100 \%$ & $100 \%$ & $100 \%$ & $100 \%$ & $100 \%$ & $100 \%$ \\
\hline Napa & $100 \%$ & $100 \%$ & $100 \%$ & $100 \%$ & $100 \%$ & $100 \%$ \\
\hline Sacramento & $100 \%$ & $100 \%$ & $100 \%$ & $100 \%$ & $100 \%$ & $100 \%$ \\
\hline San Benito & $98 \%$ & $98 \%$ & $100 \%$ & $100 \%$ & $100 \%$ & $100 \%$ \\
\hline San Francisco & $40 \%$ & $55 \%$ & $100 \%$ & $100 \%$ & $100 \%$ & $100 \%$ \\
\hline San Joaquin & $100 \%$ & $100 \%$ & $100 \%$ & $100 \%$ & $100 \%$ & $100 \%$ \\
\hline San Mateo & $30 \%$ & $34 \%$ & $41 \%$ & $86 \%$ & $100 \%$ & $100 \%$ \\
\hline Santa Clara & $63 \%$ & $70 \%$ & $73 \%$ & $100 \%$ & $100 \%$ & $100 \%$ \\
\hline Santa Cruz & $100 \%$ & $100 \%$ & $100 \%$ & $100 \%$ & $100 \%$ & $100 \%$ \\
\hline Solano & $98 \%$ & $99 \%$ & $100 \%$ & $100 \%$ & $100 \%$ & $100 \%$ \\
\hline Sonoma & $100 \%$ & $100 \%$ & $100 \%$ & $100 \%$ & $100 \%$ & $100 \%$ \\
\hline Stanislaus & $100 \%$ & $100 \%$ & $100 \%$ & $100 \%$ & $100 \%$ & $100 \%$ \\
\hline Yolo & $100 \%$ & $100 \%$ & $100 \%$ & $100 \%$ & $100 \%$ & $100 \%$ \\
\hline
\end{tabular}


Table 32. Hazus-MH-based estimate of water-service restoration after adjusting for repair crew availability and lifeline interaction with a fuel-management plan, emergency generators and fuel at all pumping stations, and brittle pipe replaced (ideal world) for San Francisco Bay region, California, counties following the hypothetical moment-magnitude-7.0 mainshock of the HayWired earthquake scenario.

[Santa Clara, Alameda, and Contra Costa Counties are as calculated in case studies. $\%$, percent]

\begin{tabular}{lrrrrrr}
\hline \multirow{2}{*}{ County } & \multicolumn{7}{c}{ Day } \\
\cline { 2 - 7 } & $\mathbf{1}$ & $\mathbf{3}$ & $\mathbf{7}$ & $\mathbf{3 0}$ & $\mathbf{9 0}$ & $\mathbf{2 1 0}$ \\
\hline Alameda & $44 \%$ & $44 \%$ & $47 \%$ & $73 \%$ & $97 \%$ & $100 \%$ \\
\hline Contra Costa & $44 \%$ & $44 \%$ & $47 \%$ & $73 \%$ & $97 \%$ & $100 \%$ \\
\hline Marin & $91 \%$ & $94 \%$ & $100 \%$ & $100 \%$ & $100 \%$ & $100 \%$ \\
\hline Merced & $98 \%$ & $98 \%$ & $99 \%$ & $100 \%$ & $100 \%$ & $100 \%$ \\
\hline Monterey & $100 \%$ & $100 \%$ & $100 \%$ & $100 \%$ & $100 \%$ & $100 \%$ \\
\hline Napa & $100 \%$ & $100 \%$ & $100 \%$ & $100 \%$ & $100 \%$ & $100 \%$ \\
\hline Sacramento & $100 \%$ & $100 \%$ & $100 \%$ & $100 \%$ & $100 \%$ & $100 \%$ \\
\hline San Benito & $98 \%$ & $98 \%$ & $100 \%$ & $100 \%$ & $100 \%$ & $100 \%$ \\
\hline San Francisco & $40 \%$ & $55 \%$ & $100 \%$ & $100 \%$ & $100 \%$ & $100 \%$ \\
\hline San Joaquin & $100 \%$ & $100 \%$ & $100 \%$ & $100 \%$ & $100 \%$ & $100 \%$ \\
\hline San Mateo & $30 \%$ & $34 \%$ & $41 \%$ & $86 \%$ & $100 \%$ & $100 \%$ \\
\hline Santa Clara & $71 \%$ & $78 \%$ & $85 \%$ & $100 \%$ & $100 \%$ & $100 \%$ \\
\hline Santa Cruz & $100 \%$ & $100 \%$ & $100 \%$ & $100 \%$ & $100 \%$ & $100 \%$ \\
\hline Solano & $98 \%$ & $99 \%$ & $100 \%$ & $100 \%$ & $100 \%$ & $100 \%$ \\
\hline Sonoma & $100 \%$ & $100 \%$ & $100 \%$ & $100 \%$ & $100 \%$ & $100 \%$ \\
\hline Stanislaus & $100 \%$ & $100 \%$ & $100 \%$ & $100 \%$ & $100 \%$ & $100 \%$ \\
\hline Yolo & $100 \%$ & $100 \%$ & $100 \%$ & $100 \%$ & $100 \%$ & $100 \%$ \\
\hline
\end{tabular}

\section{Conclusions}

This chapter introduces an analytical model of watersupply damage and restoration that can be implemented solely with GIS and spreadsheet software - no black-box, proprietary tool required. (Note: the damage part of the new model is not novel; the restoration part is.)

\section{Summary}

The analytical model of water-supply damage and restoration introduced in this chapter suggests that a $M_{\mathrm{w}} 7.0$ Hayward Fault earthquake could damage buried pipeline networks that supply potable water to the East Bay part of the San Francisco Bay area to the extent that the average customer of the EBMUD would be without water for 6 weeks. Some EBMUD customers would be without water service for 6 months. The total loss of resilience (measured as the area above graph curves of number of customers receiving service versus time) totals 19 million service-days lost. That loss can be reduced by half if current efforts to replace brittle pipe are completed before the next large earthquake occurs - the replacement taking six decades at a reasonably aggressive rate of 1 percent per year. The loss can be reduced on the order of
200,000 service days by reducing or eliminating EBMUD's dependence on commercial fuel supplies.

The model suggests that a HayWired-like earthquake could cost the average customer of SJWC 4 days of lost water service, with a total loss of resilience equal to 940,000 service days. Implementing a fuel-management plan could reduce both calculations by about a quarter. If SJWC completes replacement of all cast-iron and asbestos-cement pipe before a significant earthquake occurs (about 25 years at current replacement rates), the as-is losses (no fuel-management plan of replacement of brittle pipe) would be reduced by about half.

Both case-study utilities (EBMUD and SJWC) reviewed the study described in this chapter and find its results reasonable and in line with previous studies, their own judgment, and comparison with restoration of other water-supply systems in other earthquakes. Results of the present study are greatly at odds with restoration estimates produced by Hazus-MH, which estimates much-longer restoration times and much-greater loss of resilience.

\section{Innovations Introduced Here}

The methodology proposed here models damage and restoration of buried water-supply pipelines subject to earthquake shaking (called wave passage) and ground failure (liquefaction, landslide and surface rupture of a fault). The methodology assumes that the analyst already has maps of the earthquake excitation (especially PGV and ground-failure probability) and of the pipeline system in question. Many authors have proposed such models in the past. The present model may be unique in combining some unusual features:

1. It treats lifeline interaction and limited consumables by reducing the speed with which repairs are completed in relation to how important those upstream lifelines and other resources are to repair productivity. In the example of SJWC, it was estimated that lifeline interaction and limited consumables increase the loss of resilience (measured in terms of lost service days) by 25 percent.

2. The model considers aftershocks.

3. It can be evaluated either deterministically (with no uncertainty) or as stochastic model (accounting for major sources of uncertainty).

4. It can be carried out with a GIS system and a spreadsheet and does not require other special software such as Hazus-MH. Doing so provides the analyst more insight into the reasonableness of model results and underlying sources of damage and restoration delay.

5. It offers an approximate method to modify Hazus-MH lifeline damage and restoration-time estimates to account for lifeline interaction.

6. It does not require hydraulic analysis of the damaged system or the system as repairs proceed. That simplification necessarily involves a common but 
questionable assumption relating break rate to loss of service, and it prevents the analyst from gaining important insight into variation in pressure throughout the system.

7. It mostly avoids reliance on expert opinion and unpublished data. Expert opinion seems to be required to quantify the rate-limiting factors $u$ and the service time

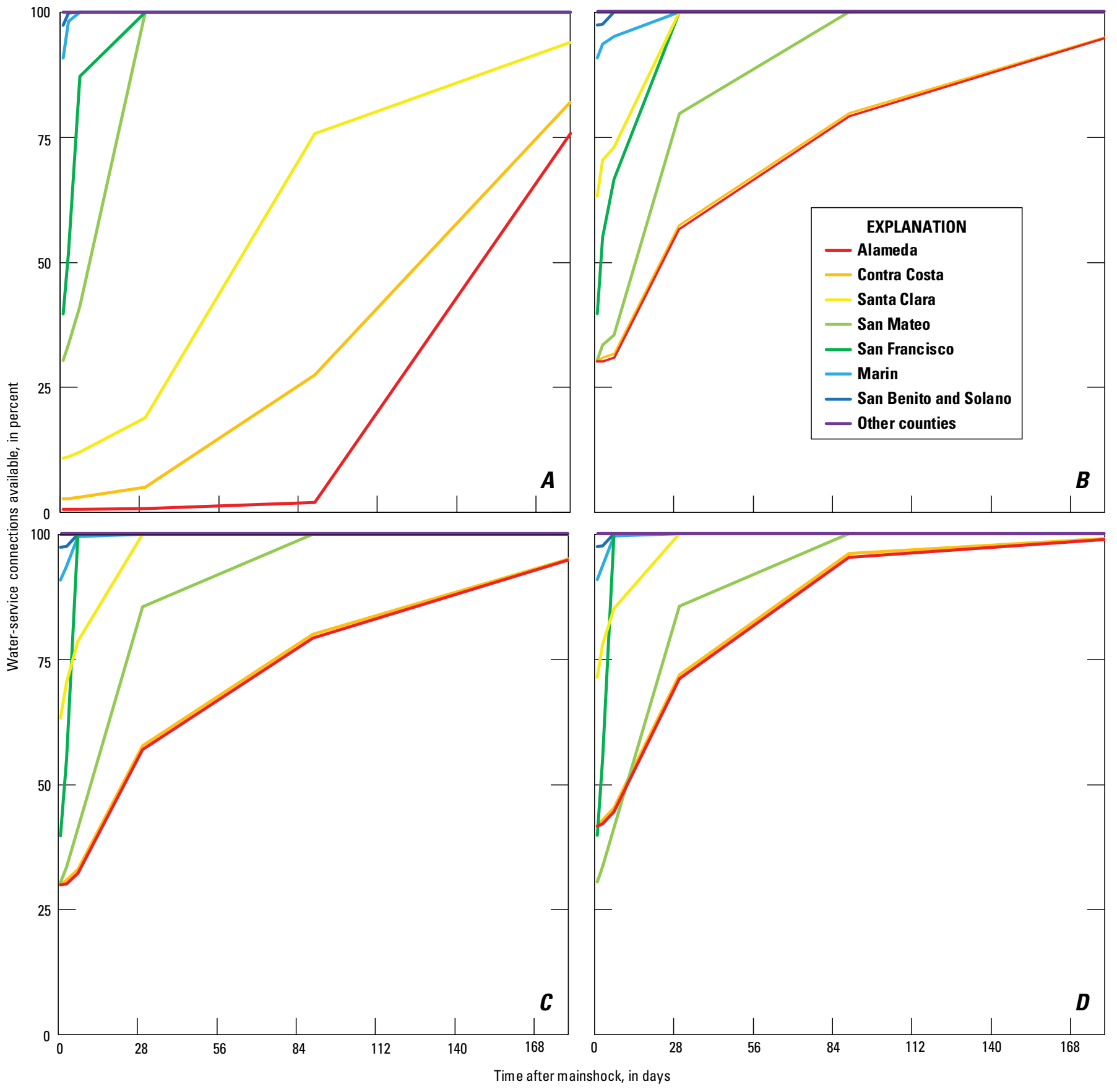

Figure 42. Graphs showing restoration of water service connections for San Francisco Bay region, California, counties following the hypothetical moment-magnitude-7.0 mainshock of the HayWired earthquake scenario. $A$, Restoration curves according to initial Hazus-MH calculations. $B$, Restoration curves after adjusting for repair-crew availability and lifeline interaction. $C$, Restoration curves after all utilties have implemented a fuel-management plan. $D$, Restoration curves with fuelmanagement plan in place and all brittle pipe replaced (the ideal world). Curves in $B, C$, and $D$ use the more-detailed case-study calculations for Contra Costa, Alameda, and Santa Clara counties instead of calculations from Hazus-MH. 
various restoration measures observed in past earthquakes, and comparable aspects of other models.

Like all other aspects of the HayWired earthquake scenario, the outcomes presented here will invariably differ in quantity, spatial distribution, and over time from whatever actually happens when (not if) a large earthquake next strikes on the Hayward Fault or other San Francisco Bay region fault. By preparing for the water-supply impacts of this hypothetical earthquake sequence, the region can better prepare for whatever real earthquake actually occurs.

\section{Research Needs}

The methodology proposed here mostly avoids reliance on opinion and judgment, but it would be practical to eliminate reliance on much of the opinion and judgment that remains. Presumably the $u$ factors based on expert opinion could be replaced by compiling sufficient earthquake experience from utilities, perhaps by some survey analogous to that of Lund and Schiff (1991). The time series $g(t)$ could be replaced by explicit modeling. It would be interesting to know if there were some theoretical justification for water service restoration following a power law as in equation 32, and whether or why the power should be approximately $2 / 3$. It would be also desirable:

- To examine more closely or replace the Hazus-MH formulation of the serviceability index. Can one relate water-pipeline break rate to the fraction of customers receiving various thresholds of flow, such as minimal flows for cooking and basic sanitary needs?;

- To know whether and how a large mainshock degrades the seismic resistance of apparently undamaged pipe;

- To add treatment of earthquake damage to other elements in a water-supply system, including tanks, tunnels, canals, valves, and reservoirs;

- Regarding the Lund and Schiff (1991) database, it would be desirable for water utilities to adopt a standard database for recording leaks and breaks, especially in earthquakes, so as to inform future improvements in mathematical functions for pipe-fragility; and

- To model the damage to water-supply systems subjected to the August 24, 2014, South Napa earthquake to see how well it agrees with experience.

\section{Acknowledgments}

The author thanks Jacob Walsh and James Wollbrinck of SJWC, along with Julia Halsne, Andrea Chen, Clifford Chan, Xavier Irias, Roberts McMullin, Mike Ambrose, Devina Ojascastro, and Serge Terentieff of EBMUD for their help constructing and testing the models presented here and reviewing the report.

\section{References Cited}

Aagaard, B.T., Graves, R.W., Schwartz, D.P., Ponce, D.A., and Graymer, R.W., 2010a, Ground-motion modeling of Hayward Fault scenario earthquakes, part I; Construction of the suite of scenarios: Bulletin of the Seismological Society of America, v.100, no. 6, p. 2927-2944, https://doi. org/10.1785/0120090324.

Aagaard, B.T., Graves, R.W., Rodgers, A., Brocher, T.M., Simpson, R.W., Dreger, D., Petersson, N.A., Larsen, S.C., Ma, S., and Jachens, R.C., 2010b, Ground-motion modeling of Hayward Fault scenario earthquakes, part II; Simulation of long-period and broadband ground motions: Bulletin of the Seismological Society of America, v. 100, no. 6, p. 2945-2977, https://doi. org/10.1785/0120090379.

Aagaard, B.T., Lienkaemper, J.J., and Schwartz, D.P., 2012, Probabilistic estimates of surface coseismic slip and afterslip for Hayward Fault earthquakes: Bulletin of the Seismological Society of America, v.102, no. 3, p. 961-979, https://doi.org/10.1785/0120110200.

Aagaard, B.T., Boatwright, J.L., Jones, J.L., MacDonald, Keith A. Porter, K.A., Wein, A.M., 2017, HayWired scenario mainshock ground motions, chap. C of Detweiler, S.T., and Wein, A.M., eds., The HayWired earthquake scenario_-Earthquake hazards: U.S. Geological Survey Scientific Investigations Report 2017-5013-A-H, 126 p., https://doi.org/10.3133/ sir20175013v1.

American Society of Civil Engineers, 1984, Guidelines for the seismic design of oil and gas pipeline systems, committee on gas and liquid fuel lifeline: Reston, Va., American Society of Civil Engineers, 473 p.

American Water Works Association, 2008, AWWA small systems pipe repair checklist, as published in July 2008 Opflow Question of the Month: American Water Works Association, 7 p., accessed August 8, 2017, at http://www. awwa.org/Portals/0/files/resources/water\%20knowledge/ rc\%20small\%20systems/piperepairchecklist.pdf.

Ang, A.H.S., and Tang, W.H., 1975, Probability concepts in engineering planning and design, vol. 1-Basic Principles: John Wiley \& Sons, New York, 409 p.

Applied Technology Council, 2012, Seismic performance assessment of buildings; volume 1-methodology: Washington, D.C., Federal Emergency Management Agency, 278 p., accessed August 8, 2017, at https:// www.fema.gov/media-library-data/13964950198480c9252aac91dd1854dc378feb9e69216/FEMAP-58_ Volume1_508.pdf. 
Applied Technology Council, 1991, Seismic vulnerability and impact of disruption of lifelines in the conterminous United States (FEMA 224, ATC-25): Washington, D.C., Federal Emergency Management Agency, 439 p., accessed August 8, 2017, at https://www.fema.gov/media-librarydata/20130726-1452-20490-1854/fema_224.pdf.

Ballantyne, D., Berg, E., Kennedy, J., Reneau, R., and Wu, D., 1990, Earthquake loss estimation modeling of Seattle water system: Seattle, Wash., Kennedy/Jenks/Chilton, Inc., report to U.S. Geological Survey, Grant No.14-08-000 I-G 1526.

Bay Area Rapid Transit District, 2015, Remembering Loma Prieta: Bay Area Rapid Transit District web page, accessed August 8, 2017, at http://www.bart.gov/marketing/25-yearsafter-Loma-Prieta-quake.

Bay City News, 2015, East by earthquake rupture more than a dozen water lines: Bay City News, Inc., August 18, 2015, accessed December 27, 2015, at http://blog.sfgate.com/ stew/2015/08/18/east-bay-earthquake-ruptures-more-than-adozen-water-lines/.

Benjamin, J.R., and Cornell, C.A., 1970, Probability, statistics, and decision for civil engineers: Dover Books on Engineering, $704 \mathrm{p}$.

Boore, D.M., Stewart, J.P., Seyhan, E., and Atkinson, G.M., 2014, NGA-West2 equations for predicting PGA, PGV, and 5\% damped PSA for shallow crustal earthquakes: Earthquake Spectra, v. 30, no. 3, p. 1057-1085.

Bruneau, M., Chang, S.E., Eguchi, R.T., Lee, G.C., O'Rourke, T.D., Reinhorn, A.M., Shinozuka, M., Tierney, K., Wallace, W.A., and von Winterfeldt, D., 2003, A framework to quantitatively assess and enhance the seismic resilience of communities: Earthquake Spectra, v. 19, no. 4, p. 733-752.

California Water/Wastewater Agency Response Network, 2009, Mutual aid/assistance operational plan: California Water/Wastewater Agency Response Network, 67 p., accessed August 8, 2017, at https://goo.gl/kyT8qE.

California Water/Wastewater Agency Response Network, n.d., CalWARN mutual assistance activated in response to Napa earthquake: California Water/Wastewater Agency Response Network web page, accessed August 8, 2017, at http:// prod.i-info.com/dashboard/Layout/41EFB108A3534676930 96E1D202485DB/about/aboutPublic/ events.htm.

Chen, W.F., and Scawthorn, C.R., eds., 2003, Earthquake engineering handbook: New York, N.Y., CRC Press, 1480 p.

City of Winnipeg, 2014, Water main breaks frequent asked questions (FAQs): City of Winnipeg, Canada, web page, accessed October 6, 2015, at http://www.winnipeg.ca/ waterandwaste/water/mainbreaks.stm.
Contra Costa Local Agency Formation Commission, 2008, Section 9.0 East Bay Municipal Utility District Water and Wastewater Service, in West Contra Costa County water and wastewater MSR adopted 8/13/08: Martinez, Calif., Contra Costa Local Agency Formation Commission, 8 p., accessed October 26, 2015, at http://www.contracostalafco. org/municipal_service_reviews.htm.

Detweiler, S.T., and Wein, A.M., eds., 2017, The HayWired earthquake scenario-Earthquake hazards: U.S. Geological Survey Scientific Investigations Report 2017-5013-A-H, 126 p., https://doi.org/10.3133/sir20175013v1.

East Bay Municipal Utility District, 2014, Napa's neighbors to the rescue: East Bay Municipal Utility District Customer Pipeline, Nov.-Dec. 2014, 1 p., accessed August 8, 2017, at https://www.ebmud.com/files/1314/3197/7857/customerpipeline_0.pdf.

Eidinger, J., 2001, Seismic fragility formulations for water systems: American Lifelines Alliance, 96 p., accessed August 8, 2017, at http://www.americanlifelinesalliance. com/pdf/Part_1_Guideline.pdf.

Elvert, Kurt, 2015, Water supply and conservation: San Jose Water Supply Company presentation, accessed, July 25, 2017, at http://www.avca-sj.org/presentations/2015-07-13 KurtElvert_min.pdf.

Federal Emergency Management Agency, 2012, Hazus multihazard loss estimation methodology, earthquake model, Hazus ${ }^{\circledR}-M H 2.1$ technical manual: Federal Emergency Management Agency, Mitigation Division, accessed July 18, 2017, 718 p., at https:// www.fema.gov/media-librarydata/20130726-1820-25045-6286/hzmh2_1_eq_tm.pdf.

Felzer, K.R., Abercrombie, R.E., and Ekström, G., 2003, Secondary aftershocks and their importance for aftershock prediction: Bulletin of the Seismological Society of America, v. 93, no.4, p. 1433-1448.

Field, E.H., Biasi, G.P., Bird, P., Dawson, T.E., Felzer, K.R., Jackson, D.D., Johnson, K.M., Jordan, T.H., Madden, C., Michael, A.J., Milner, K.R., Page, M.T., Parsons, T., Powers, P.M., Shaw, B.E., Thatcher, W.R., Weldon, R.J., II, and Zeng, Y., 2013, Uniform California earthquake rupture forecast, version 3 (UCERF3) - The time-independent model: U.S. Geological Survey Open-File Report 20131165, 97 p., California Geological Survey Special Report 228, and Southern California Earthquake Center Publication 1792, accessed August 8, 2017, at https://pubs.usgs.gov/ of $/ 2013 / 1165 /$.

Honegger, D.G., and Eguchi, R.T., 1992, Determination of relative vulnerabilities to seismic damage for San Diego County Water Authority (SDCWA) water transmission pipelines: Costa Mesa, CA: EQE Engineering, 19 p. 
Howard, R.A., 1990, From influence to relevance to knowledge, in Oliver R.M., and Smith, J.Q., eds., Influence diagrams, belief nets and decision analysis: New York, N.Y., John Wiley \& Sons, p. 3-23.

Hudnut, K.W., Brocher, T.M., Prentice, C.S., Boatwright, J., Brooks, B.A., Aagaard, B.T., Blair, J.L., Fletcher, J.B., Erdem, J.E., Wicks, C.W., Murray, J.R., Pollitz, F.F., Langbein, J., Svarc, J., Schwartz, D.P., Ponti, D.J., Hecker, S., DeLong, S., Rosa, C., Jones, B., Lamb, R., Rosinski, A., McCrink, T.P., Dawson, T.E., Seitz, G., Rubin, R.S., Glennie, C., Hauser, D., Ericksen, T., Mardock, D., Hoirup, D.F., and Bray, J.D., 2014, Key recovery factors for the August 24, 2014, South Napa earthquake: U.S. Geological Survey Open-File Report 2014 1249, 51 p., accessed August 8, 2017, at https://doi.org/10.3133/ ofr20141249.

Isoyama, R., and Katayama, T., 1982, Reliability evaluation of water supply systems during earthquakes: University of Tokyo, Report of the Institute of Industrial Science, v. 30, no. 1, p. 1-64.

Javanbarg, M., and Scawthorn, C., 2012, UILLIS-Urban Infrastructure and Lifelines Interactions of Systems: Proceedings of the 15th World Conference on Earthquake Engineering, September 2012, Lisbon Portugal, p. 1035810364.

Jayaram, N., and Baker, J., 2009, Correlation model for spatially distributed ground-motion intensities: Earthquake Engineering and Structural Dynamics, v. 38, p. 1687-1708.

Jeon, S.S., and O'Rourke, T.D., 2005, Northridge earthquake effects on pipelines and residential buildings: Bulletin of the Seismological Society of America, v. 95, no. 1, p. 294-318.

Jones, J.L., Knudsen, K.L., and Wein, A.M., 2017, HayWired scenario mainshock - Liquefaction probability mapping, chap. E of Detweiler, S.T., and Wein, A.M., eds., The HayWired earthquake scenario-Earthquake hazards: U.S. Geological Survey Scientific Investigations Report 2017-5013-A-H, 126 p., https://doi.org/10.3133/sir20175013v1.

Jones, L.M., Bernknopf, R., Cox, D., Goltz, J., Hudnut, K., Mileti, D., Perry, S., Ponti, D., Porter, K., Reichle, M., Seligson, H., Shoaf, K., Treiman, J., and Wein, A., 2008, The ShakeOut scenario: U.S. Geological Survey Open-File Report 20081150 and California Geological Survey Preliminary Report 25, 312 p. and appendixes, accessed April 12, 2017, at https://pubs. usgs.gov/of/2008/1150/.

Jones, M.C., 2009, Kumaraswamy's distribution—A beta-type distribution with some tractability advantages: Statistical Methodology, v. 6, p. 70-81.

Kennedy, R.P., Chow, A.W., and Williamson, R.A., 1977, Fault movement effects on buried oil pipeline: Journal of Transportation Engineering, v. 103, no. TE5, p. 617-633.
Khater, M., and Grigoriu, M., 1989, Graphical demonstration of serviceability analysis: Reston, Va., American Society of Civil Engineers, Proceedings of the 5th International Conference on Structural Safety and Reliability, San Francisco, California, August 7-11, 1989, p. 525-532t.

Kumaraswamy, P., 1980, A generalized probability density function for double-bounded random processes: Journal of Hydrology, v. 46, p. 79-88.

Los Angeles Department of Water and Power, 2014, Westwood/Sunset trunk line repair update: Los Angeles Department of Water and Power press release, Sunday August 3, 2014, accessed July 11, 2017, at https://www. ladwpnews.com/westwood-sunset-trunk-line-repair-updatesunday-august-3-2014/.

Lilliefors, H., 1967, On the Kolmogorov-Smirnov test for normality with mean and variance unknown: Journal of the American Statistical Association, v. 62, no. 318, p. 399-402.

Lund, L., and Davis, C.A., 2005, Multihazard mitigation Los Angeles water system-A historical perspective, in Taylor, C., and VanMarcke, E., eds., Infrastructure risk management processes - Natural, accidental, and deliberate hazards: Reston, Va., American Society of Civil Engineers, p. 224-279.

Lund, L., Davis, C.A., and Adams, M.L., 2005, Water system seismic performance 1994 Northridge-1995 Kobe earthquakes: American Water Works Association and Japan Water Works Association, Proceedings of the 4th Japan-U.S. Workshop on Seismic Measures for Water Supply, Kobe, Japan, January 2005, p. 19-30, accessed August 8, 2017, at http://www.waterrf.org/PublicReportLibrary/3156.pdf.

Lund, L., and Schiff, A., 1991, TCLEE pipeline failure database: Reston, Va., American Society of Civil Engineers, Technical Council on Lifeline Earthquake Engineering, $36 \mathrm{p}$.

Markov I., Grigoriu, M., and O’Rourke, T.D., 1994, An evaluation of seismic serviceability of water supply networks with application to San Francisco auxiliary water supply system: Buffalo N.Y., National Center for Earthquake Engineering Research report no. 94-0001, 154 p.

McCrink, T.P., and Perez, F.G., 2017, HayWired scenario mainshock-Earthquake-induced landslide hazards, chap. F of Detweiler, S.T., and Wein, A.M., eds., The HayWired earthquake scenario-Earthquake hazards: U.S. Geological Survey Scientific Investigations Report 2017-5013-A-H, 126 p., https://doi.org/10.3133/sir20175013v1.

Mid-America Earthquake Center, 2006, MAEViz Software: Urbana, Ill., Multihazard Approach to Engineering Center, University of Illinois at Urbana-Champaign. 
Nojima, N., and Kameda, H., 1991, Cross-impact analysis for lifeline interaction: American Society of Civil Engineering, Technical Council on Lifeline Earthquake Engineering, Proceedings of the 3rd U.S. Conference on Lifeline Earthquake Engineering, Los Angeles, California, August 22-23, 1991, p. 629-638.

Ogata, Y., 1998, Space-time point-process models for earthquake occurrences: Annals of the Institute of Statistical Mathematics, v. 50, no. 2, p. 379-402.

O'Rourke, M.J., 2003, Buried pipelines, chap. 23 of Chen, W.F., and Scawthorn, C.R., eds., New York, N.Y., CRC Press, $1480 \mathrm{p}$.

O'Rourke M.J., and Ayala, G., 1993, Pipeline damage due to wave propagation: Reston, Va., American Society of Civil Engineers, Journal of Geotechnical Engineering, v. 119, no. 9 , p. 1490-1498.

O'Rourke, T.D., Jeon, S.S., Toprak, S., Cubrinovski, M., Hughes, M., van Ballegooy, S., and Bouziou, D., 2014, Earthquake response of underground pipeline networks in Christchurch, NZ: Earthquake Spectra, v. 30, no. 1, p. 183-204.

O'Rourke, T.D., and Palmer, M.C., 1996, Earthquake performance of gas transmission pipelines: Earthquake Spectra, v. 12, no. 3, p. $493-527$.

O'Rourke, T.D., and Trautmann, C.H., 1980, Analytical modeling of buried pipeline response to permanent earthquake displacements: Ithaca, N.Y., Cornell University, School of Civil Engineering and Environmental Engineering, report no. 80-4, 102 p.

Petersen, M.D., Moschetti, M.P., Powers, P.M., Mueller, C.S., Haller, K.M., Frankel, A.D., Zeng, Yuehua, Rezaeian, Sanaz, Harmsen, S.C., Boyd, O.S., Field, Ned, Chen, Rui, Rukstales, K.S., Luco, Nico, Wheeler, R.L., Williams, R.A., and Olsen, A.H., 2014, Documentation for the 2014 update of the United States national seismic hazard maps: U.S. Geological Survey Open-File Report 2014-1091, 243 p., accessed July 11, 2017, at https://doi.org/10.3133/ ofr20141091.

Porter, K.A., 2017a, A beginner's guide to fragility, vulnerability, and risk: SPA Risk LLC and University of Colorado Boulder, 92 p., accessed January 18, 2018, at http://www.sparisk.com/pubs/Porter-beginners-guide.pdf.

Porter, K.A., 2017b, HayWired scenario three-dimensional numerical ground-motion simulation maps, chap. $\mathrm{H}$ of Detweiler, S.T., and Wein, A.M., eds., The HayWired earthquake scenario - Earthquake hazards: U.S. Geological Survey Scientific Investigations Report 2017-5013-A-H, 126 p., accessed July 11, 2017, at https://doi.org/10.3133/ sir20175013v1.
Porter, K.A., and Sherrill, R., 2011, Utility performance panels in the ShakeOut scenario: Earthquake Spectra, v. 27, no. 2, p. 443-458, accessed July 11, 2017, at https://doi. org/10.1193/1.3584121.

Porter, K., Wein, A., Alpers, C., Baez, A., Barnard, P., Carter, J., Corsi, A., Costner, J., Cox, D., Das, T., Dettinger, M., Done, J., Eadie, C., Eymann, M., Ferris, J., Gunturi, P., Hughes, M., Jarrett, R., Johnson, L., Dam Le-Griffin, H., Mitchell, D., Morman, S., Neiman, P., Olsen, A., Perry, S., Plumlee, G., Ralph, M., Reynolds, D., Rose, A., Schaefer, K., Serakos, J., Siembieda, W., Stock, J., Strong, D., Sue Wing, I., Tang, A., Thomas, P., Topping, K., and Wills, C.; Jones, L., chief scientist, Cox, D., project manager, 2011, Overview of the ARkStorm scenario: U.S. Geological Survey Open-File Report 2010-1312, 183 p. and appendixes, accessed April 10, 2017, at https://pubs. usgs.gov/of/2010/1312/.

Prashar, Y., McMullin, R., Cain, B., and Irias, X., 2012, Pilot large diameter pipeline seismic fragility assessment, in Card, R.J., and Kenny, M.K., eds., Proceedings of the Pipelines 2012 Conference, Miami Beach, Florida, August 19-22, 2012: Reston, Va., American Society of Civil Engineers, p. 396-407.

Rose, A., Wei, D., and Wein, A., 2011, Economic impacts of the ShakeOut earthquake scenario: Earthquake Spectra v. 27 , no. 2 , p. $521-538$.

San Francisco Lifelines Council, 2014, Lifelines interdependency study 1 report: San Francisco Office of the City Administrator, San Francisco, 56 p., accessed July 20, 2017, at http://sfgov.org/esip/sites/default/files/Documents/ homepage/LifelineCouncil\%20Interdependency\%20Study_ FINAL.pdf.

San Francisco Public Utilities Commission, 2015, Quarterly report-Water Enterprise Capital Improvement Program-Local—January 2015-March 2015: San Francisco Public Utilities Commission, accessed July 20, 2017, at https://sfwater.org/modules/showdocument. aspx?documentid $=7182$.

Scawthorn, C.R., 1993, Lifeline interaction and postearthquake functionality: Proceedings of the 5th U.S.-Japan Workshop on Earthquake Disaster Prevention for Lifeline Systems, Tsukuba Science City, Japan, October 26-27, 1992, p. 441-450.

Scawthorn, C.R., 2008, The ShakeOut scenario supplemental study - Fire following earthquake: Denver Colo., SPA Risk LLC, 33 p., accessed August 9, 2017, at http://books. google.com/books?id=mDGrFAw5zqYC\&lpg=PA1\&dq=s hakeout $\% 20$ fire $\% 20$ following \&pg $=\mathrm{PA} 1 \# \mathrm{v}=$ onepage $\& \mathrm{q} \& \mathrm{f}$ $=$ false. 
Scawthorn, C.R., Porter, K.A, Khater, M., Seidel, D., Ballantyne, D., Taylor, H.T., Darragh, R.D., and Ng, C., 1992, Utility performance aspects, liquefaction study, Marina and Sullivan Marsh areas, San Francisco California, in Hamada, M., and O'Rourke, T., Proceedings from the fourth Japan-U.S. Workshop on Earthquake Resistant Design of Lifeline Facilities and Countermeasures for Soil Liquefaction, Tokai University Pacific Center, Honolulu, Hawaii, May 27-29, 1992, vol. 1: National Center for Earthquake Engineering Research, Technical Report NCEER-92-0019, p. 317-333, accessed August 9, 2017, at http://www.sparisk.com/pubs/Scawthorn1992-SF-Liquefaction-Study.pdf.

Schiff, A., 1988, The Whittier Narrows, California earthquake of October 1, 1987-Response of lifelines and their effect on emergency response: Earthquake Spectra, v. 4, no. 2, p. 339-366.

Seligson, H.A., Eguchi, R.T., Lund, L., and Taylor, C.E., 1991, Survey of 15 utility agencies serving the areas affected by the 1971 San Fernando and 1987 Whittier Narrows earthquakes: Los Angeles, Calif., Dames \& Moore, Inc., report prepared for the National Science Foundation, $100 \mathrm{p}$.

Small Business Administration Office of Advocacy, 2012, Frequently asked questions about small business: Washington, D.C., Small Business Administration, accessed December 14, 2017, at https://www.sba.gov/sites/defaul/files/FAQ Sept_2012.pdf.

Tabucchi, T., Brink, S., and Davidson, R., 2010, Simulation of post-earthquake water supply system restoration: Civil Engineering and Environmental Systems, v. 27, no. 4, accessed July 14, 2017, at http://dx.doi.org/10.1080/10286600902862615.
Tabucchi, T.H.P., and Davidson, R.A., 2008, Post-earthquake restoration of the Los Angeles Water Supply System: University at Buffalo, State University of New York, Multidisciplinary Center for Earthquake Engineering Research, Technical Report MCEER-08-0008, 127 p., accessed July 14, 2017, at https://mceer.buffalo.edu/pdf/ report/08-0008.pdf.

Terentieff, S., Chen, A. McMullin, R., Prashar, Y., and Irias, X.J., 2015, Emergency planning and response damage prediction modeling to mitigate interdependency impacts on water service restoration: Water Research Foundation, Proceedings 9th Water System Seismic Conference, Sendai, Japan October 14-16, 2015, p. 80-91, accessed August 9, 2017, at http://www.waterrf.org/PublicReportLibrary/4603. pdf.

Tierney, K.J., 1995, Impacts of recent U.S. disasters on businesses-The 1993 Midwest floods and the 1994 Northridge earthquake: Proceedings of the National Center for Earthquake Engineering Research Conference on the Economic Impacts of Catastrophic Earthquakes-Anticipating the Unexpected, New York, N.Y., September 12 and 13, 1995, 52 p.

Treiman, J., and Ponti, D., 2011, Estimating surface faulting impacts from the ShakeOut scenario earthquake: Earthquake Spectra, v. 27, no. 2, p. 315-330.

Wein, A.M., Felzer, K.R., Jones, J.L., and Porter, K.A., 2017, HayWired scenario aftershock sequence, chap. G of Detweiler, S.T., and Wein, A.M., eds., The HayWired earthquake scenario-Earthquake hazards: U.S. Geological Survey Scientific Investigations Report 2017-5013-A-H, 126 p., https://doi.org/10.3133/sir20175013v1. 




\title{
Chapter 0
}

\section{Case Studies of Tall-Building Structural Analyses and Downtime and Loss Assessment for the HayWired Scenario Mainshock}

\author{
By Ibrahim M. Almufti, ${ }^{1}$ Carlos Molina-Hutt, ${ }^{2}$ Michael W. Mieler, ${ }^{1}$ Nicole A. Paul, ${ }^{1}$ and Chad R. Fusco ${ }^{1}$
}

\section{Abstract}

The HayWired scenario examines a hypothetical earthquake (mainshock) with a moment magnitude $\left(M_{\mathrm{w}}\right)$ of 7.0 occurring on April 18, 2018, at 4:18 p.m. on the Hayward Fault in the east bay part of California's San Francisco Bay area. The tall-building performance assessment for the scenario includes a structural analysis and downtime and loss estimates for three archetype buildings that generally represent typical tall-building construction in the San Francisco and Oakland downtown areas. Two of the archetype buildings are steel-frame office towers (20 story and 40 story) designed to 1970s-era building code and professional practice, and one is a reinforced-concrete residential tower (42 story) designed using the current state-of-the-art performance-based design approach. An inventory of tall buildings in San Francisco is also provided. Time histories of ground motions from the simulated mainshock fault rupture were provided by the U.S. Geological Survey (USGS). The simulated records closest to the San Francisco and Oakland downtown locations were selected to assess the performance of the archetype buildings.

A nonlinear response-history analysis (NLRHA) of each building was done using LS-DYNA software to ascertain the expected building performance. From a structural-engineering perspective, new concrete residential buildings performed relatively well with minimal structural damage. However, older steel-frame buildings sustained structural damage, including widespread yielding and some fractures of the (pre-Northridge) moment-frame beam connections in the upper stories. This did not result in collapse nor significant residual drifts, which indicates that the steel-frame buildings may be repairable. The interstory drifts for all analyses were within the interstory drift limit (story height/50) allowed by current building codes under the design basis earthquake. Peak floor accelerations (as much as roughly the acceleration due to gravity at the Earth's surface, $g$ )

${ }^{1}$ Arup, North America, Ltd.

${ }^{2}$ University College, London. were significant due to higher mode effects, particularly in the reinforced concrete tower. (The period, or mode of vibration, of a building is a dynamic property that typically refers to the time it takes for a building, if excited horizontally by ground shaking, to complete one cycle of sway back and forth.)

A loss assessment was performed using the probabilistic approach (that is, Monte Carlo simulation) outlined in the Federal Emergency Management Agency's (FEMA) P-58 document. The likely costs to repair and (or) replace damaged components are calculated based solely on FEMA P-58, whereas repair time and downtime are estimated using the FEMA P-58 based methodology outlined in the 2013 REDi $^{\mathrm{TM}}$ (Resilience-based Earthquake Design Initiative for the Next Generation of Buildings) rating system. The engineering-demand parameters from the NLRHA were used as input parameters to assess the likelihood that each building component (structural and nonstructural) would sustain a discrete state of damage (defined by fragility functions). The extent and severity of the expected damage is used to assess the likelihood that building reoccupancy and (or) functionality is hindered (by repair-class assignments defined in REDi) enabling the estimation of repair time and total downtime (to achieve reoccupancy and (or) functionality). It is noted that the estimation of downtime has considerable uncertainty due to a number of interdependent factors that are difficult to quantify. The downtime estimates include the potential for delays to the initiation of repairs (termed impeding factors), including contractor mobilization, financing repairs, and permitting. The estimates for the impeding factors are based on those quantified in REDi and our additional research. The time to achieve functionality is also dependent on utility disruption times estimated elsewhere for the HayWired mainshock, but these did not govern any of the scenarios considered.

All scenarios resulted in significant downtime to achieve functional recovery, primarily due to nonstructural component damage. Existing steel-frame office towers had a median repair cost of 7.4-17.5 percent of replacement value, a median time to achieve reoccupancy of 186-250 days, and median time to achieve functional recovery of 242-288 days. New reinforced-concrete residential towers had a median repair cost of 3.1-5.1 percent of replacement value, a median time to achieve reoccupancy of 
121-139 days, and median time to achieve functional recovery of 224-245 days. The time to mobilize contractors (accounting for the bidding process, scarcity of contractors, and time to mobilize labor, material and equipment) often governed the total downtime. In the scenario, buildings located in Oakland generally sustained higher losses (see upper end of ranges provided in the table) than those in San Francisco due to the closer proximity to the Hayward Fault. Although the nonlinear analysis indicated that steel-frame buildings sustain some fractured beam connections, it is unlikely that an inspector would observe them because there are so few instances of this behavior.

Although the older steel-frame buildings have welldocumented structural deficiencies, none of the analyses undertaken resulted in structural collapse. This is primarily due to the relatively low shaking intensity from the HayWired scenario mainshock as compared to the maximum considered earthquake (MCE) and even design level defined in modern building codes. A 55-percent probability of collapse at MCE for the same San Francisco archetype steel-frame buildings in this study (approximately five times the acceptable collapse limit in modern codes) was estimated in a previous work. It is important to note that this study is limited to one structurally regular archetype steel-frame building, whereas in reality, many older buildings exhibit structural irregularities such as setbacks (and some even lack corner columns) that may make them more collapse-prone. In addition, the assessment considers only one scenario ground-motion record and thus does not account for the variability of ground shaking important for assessing collapse risk. Therefore, the results should not necessarily be interpreted to mean that a large earthquake on the Hayward Fault would not cause any tall-building collapses. Even one tall building damaged to the point of near collapse in a downtown area could cause closure of a significant number of surrounding buildings, even if the surrounding buildings are undamaged.

\section{Introduction}

The HayWired scenario examines a hypothetical earthquake (mainshock) with a moment magnitude $\left(M_{\mathrm{w}}\right)$ of 7.0 occurring on April 18, 2018, at 4:18 p.m. on the Hayward Fault in the east bay part of California's San Francisco Bay area. The U.S. Geological Survey (USGS) is currently leading an effort to study the implications of the scenario mainshock and aftershock sequence for the greater San Francisco Bay region. As part of this work, the USGS identified the need to assess the performance of the existing tall-building stock in downtown San Francisco and Oakland. We undertook an analysis of archetype tall buildings representative of the building stock to estimate damage levels, downtime, and repair costs for the HayWired mainshock scenario in San Francisco and Oakland. A 55-percent probability of collapse at the maximum considered earthquake (MCE) for the same San Francisco archetype steel-frame building in this study (approximately five times the acceptable collapse limit in modern codes) was estimated in a previous work (Molina-Hutt and others, 2015).

\section{Objectives}

This study describes the performance of three building types found to be representative of the tall-building stock in the respective cities' downtown areas:

- 1970s 40-story steel moment-resisting frame office building in San Francisco only.

- 1970s 20-story steel moment-resisting frame office building in San Francisco and Oakland.

- New 42-story reinforced-concrete core-only building designed to current code and Pacific Earthquake Engineering Research Center (PEER) (TBI Guidelines Working Group, 2010) in San Francisco and Oakland. (Although no new concrete towers of this height currently exist in Oakland, future development plans are likely to include them.)

Structural analysis results include peak interstory drifts, residual drifts, racking drift (where applicable), floor accelerations, and coupling beam rotation (where applicable). Repair costs are expressed in terms of both absolute dollars and percentage of building replacement cost. A breakdown of repair costs by building components (both structural and nonstructural) is also provided for each building.

Downtime estimates include repair time and downtime (the time to achieve either reoccupancy, functionality, or full recovery) in days. Downtime accounts for repair time plus impeding factors (such as the time required to mobilize contractors and engineers) and utility disruption.

\section{Report Structure}

Including the Introduction, this report is organized into seven sections - (1) Introduction; (2) HayWired Ground Motions, which describes the ground motions used in the nonlinear dynamic analyses, and provides a comparison of the HayWired scenario and the code design spectrum for each location; (3) Description of Archetype Buildings, Design and Analysis Assumptions, which describes the structural design - including the structural configuration, structural properties, and typical details —of the three archetype buildings, and the numerical modeling of the buildings; (4) Loss-Assessment Methodology, which describes the loss-assessment methodology; (5) Summary of Loss-Assessment Results, which provides a summary comparison of the lossassessment results; (6) Conclusion; and (7) References Cited.

The report also has 12 appendixes. Appendix 1 provides lists of the structural and nonstructural building components in each archetype building, including component quantities, median engineering design parameters (EDPs) and dispersions for each damage state, and repair-class assignments defined in REDi $^{\mathrm{TM}}$ (Resilience-based Earthquake Design Initiative for the Next Generation of Buildings). Appendixes 2 through 11 provide detailed structural analysis and loss assessment results for each building, as shown in table 1. Appendix 12 provides an inventory of tall building stock in San Francisco. 
Table 1. Contents of appendixes 2 through 12.

\begin{tabular}{clc}
\hline Appendix & \multicolumn{1}{c}{ Building case study } & Abbreviation \\
\hline 2 & 40 -story steel-frame building in San Francisco, baseline orientation & S-SF-B-43 \\
3 & 40 -story steel-frame building in San Francisco, rotated orientation & S-SF-R-43 \\
4 & 20-story steel-frame building in San Francisco, baseline orientation & S-SF-B-20 \\
5 & 20-story steel-frame building in San Francisco, rotated orientation & S-SF-R-20 \\
6 & 20 -story steel-frame building in Oakland, baseline orientation & S-OK-B-20 \\
7 & 20-story steel-frame building in Oakland, rotated orientation & S-OK-R-20 \\
8 & 42 -story reinforced-concrete building in San Francisco, baseline orientation & C-SF-B-46 \\
9 & 42 -story reinforced-concrete building in San Francisco, rotated orientation & C-SF-R-46 \\
10 & 42-story reinforced-concrete building in Oakland, baseline orientation & C-OK-B-46 \\
11 & 42-story reinforced-concrete building in Oakland, rotated orientation & C-OK-R-46 \\
\hline
\end{tabular}

\section{HayWired Ground Motions}

The performance of the archetype building is assessed at two locations for which ground-motion time histories have been provided for the HayWired mainshock - southwest of downtown San Francisco $\left(37.775^{\circ} \mathrm{N}, 122.402^{\circ} \mathrm{W}\right)$ and downtown Oakland $\left(37.804^{\circ} \mathrm{N}, 122.270^{\circ} \mathrm{W}\right)$. These record sets are USGS code number CT06075018000 and SF384, respectively (see Aagaard and others, 2010). Figure 1 illustrates these locations within the San Francisco Bay area. Out of the five ground-motion sets that USGS provided for Oakland, the one in downtown Oakland was selected, because this is where most tall buildings in Oakland are located. Five ground-motion sets were also provided for San Francisco, but none were located in the Financial District, where most tall buildings are located. The ground-motion record located roughly 1.5 kilometers $(\mathrm{km})$ southwest of the Financial District (see fig. 1) was selected because its time-averaged shear-wave velocity to a depth of 30 meters $\left(V_{\mathrm{S} 30}\right)$ value was most representative of the soil conditions (site class D of the International Building Code) in the Financial District.

Time histories for the Oakland and San Francisco ground motions in the $M_{\mathrm{w}} 7.0$ HayWired scenario mainshock are shown in figures 2 and 3, respectively. These are surface motions generated by a three-dimensional (3D) physics-based simulation for the scenario mainshock (Aagaard and others, 2017).

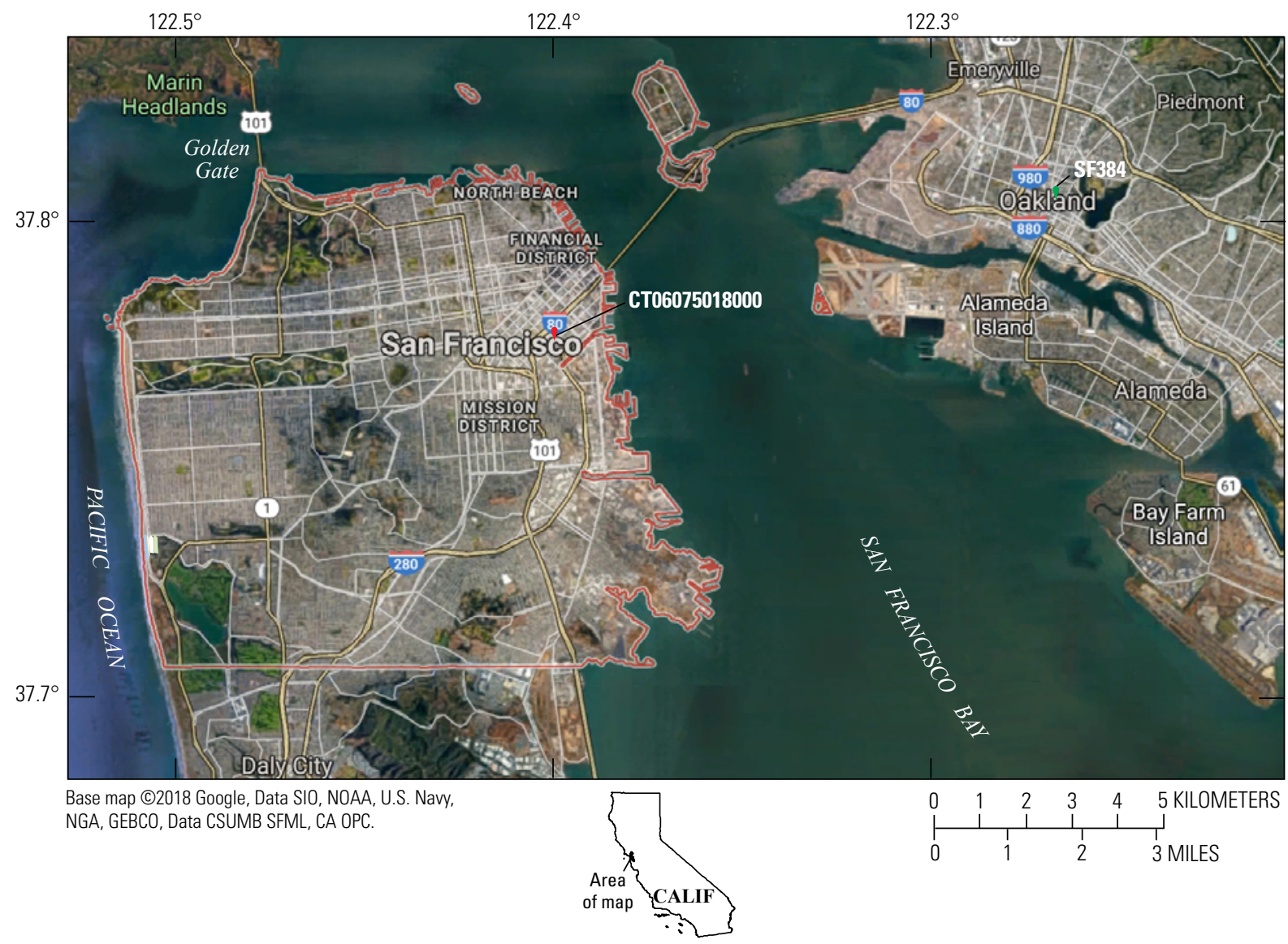

Figure 1. Map of the central San Francisco Bay area, California, showing locations at which archetype buildings were assessed in San Francisco (code CT06075018000, see Aagaard and others, 2010) and downtown Oakland (code SF384, see Aagaard and others, 2010) for performance in ground-motions for the hypothetical moment-magnitude-7.0 mainshock of the HayWired earthquake scenario. 

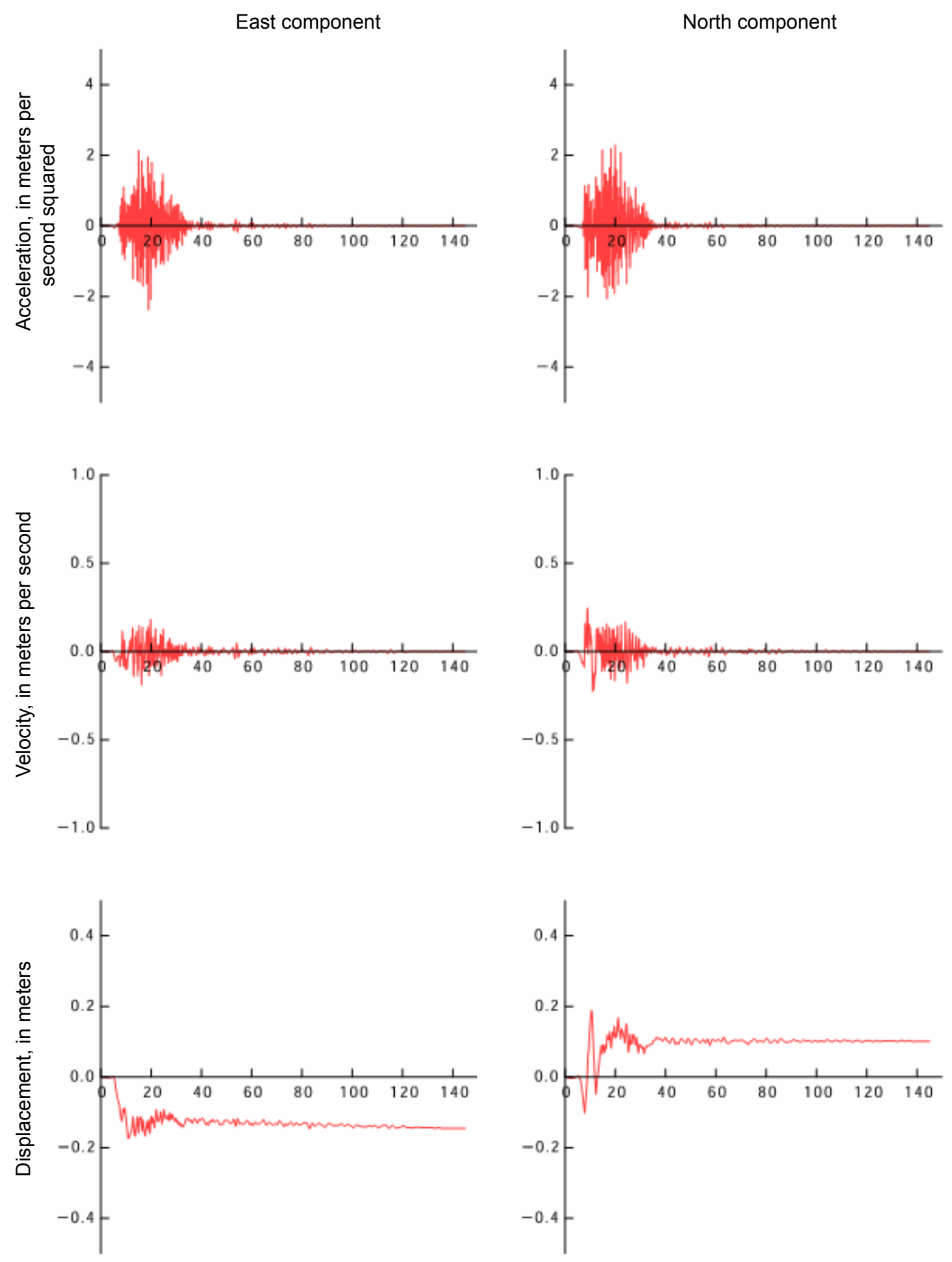

Time, in seconds

Figure 2. Graphs showing acceleration, velocity, and displacement time histories of the east-west and north-south components of the hypothetical moment-magnitude-7.0 mainshock of the HayWired earthquake scenario for downtown San Francisco, California (code ct06075018000, see Aagaard and others, 2010). 

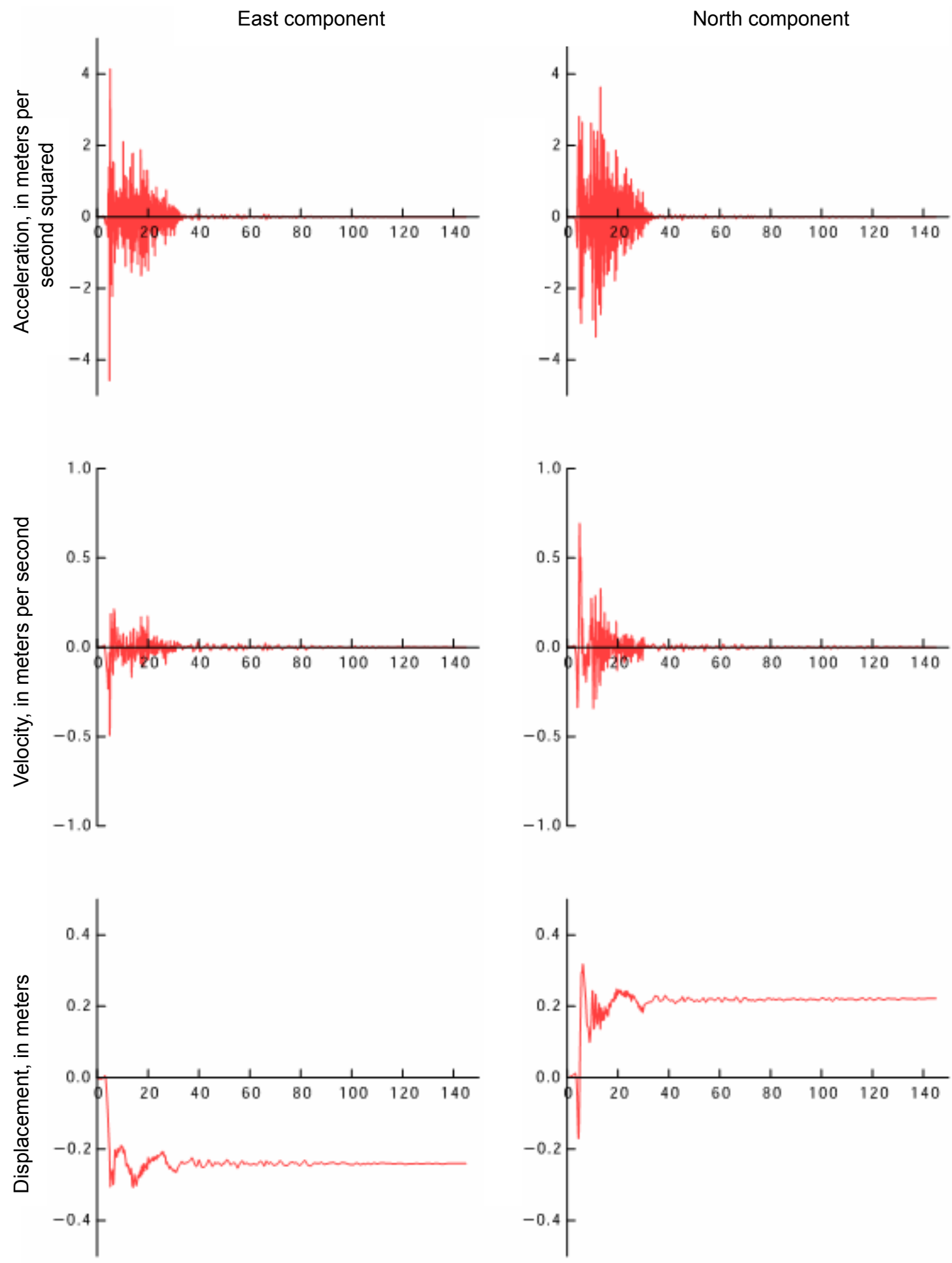

Time, in seconds

Figure 3. Graphs showing acceleration, velocity, and displacement time histories of the east-west and north-south components of the hypothetical moment-magnitude-7.0 mainshock of the HayWired earthquake scenario for downtown Oakland, California (code SF384, see Aagaard and others, 2010). 
For comparison purposes, figures 4 and 5 show the ASCE 7-10 (American Society of Civil Engineers, 2010) design acceleration-response spectrum for the design-basis earthquake (DBE) scenario and the HayWired scenario ground-motion spectra selected for the Oakland and San Francisco sites, respectively. It can be observed that the HayWired groundmotion spectra selected for assessment have relatively low spectral accelerations near the fundamental period of the tall buildings (and consequently, relatively low spectral-displacement demands), although significant structural demands could be induced from higher mode effects. ${ }^{3}$ Moreover, because the epicenter of the HayWired mainshock is located in Oakland, there is less forward directivity for the cities of Oakland and San Francisco than if the epicenter was at either end of the Hayward Fault rupture, particularly compared to an epicenter at the south end of the rupture. Therefore, the HayWired mainshock ground motions may represent a nonconservative scenario for the buildings in this study.

\section{Description of Archetype Buildings, Design, and Analysis Assumptions}

This section describes the building archetypes developed for this study of tall-building performance in the HayWired scenario mainshock. This includes a discussion of design and analysis assumptions.

\section{Steel Office Tower}

Forty-story and 20-story steel moment-resisting frame (MRF) office buildings designed according to the 1973 Uniform Building Code (International Conference of Building Officials, 1973) were selected as archetype buildings for this study. The archetype buildings are rectangular in plan and represent the state of design and construction practice from the mid-1970s to the mid-1980s.
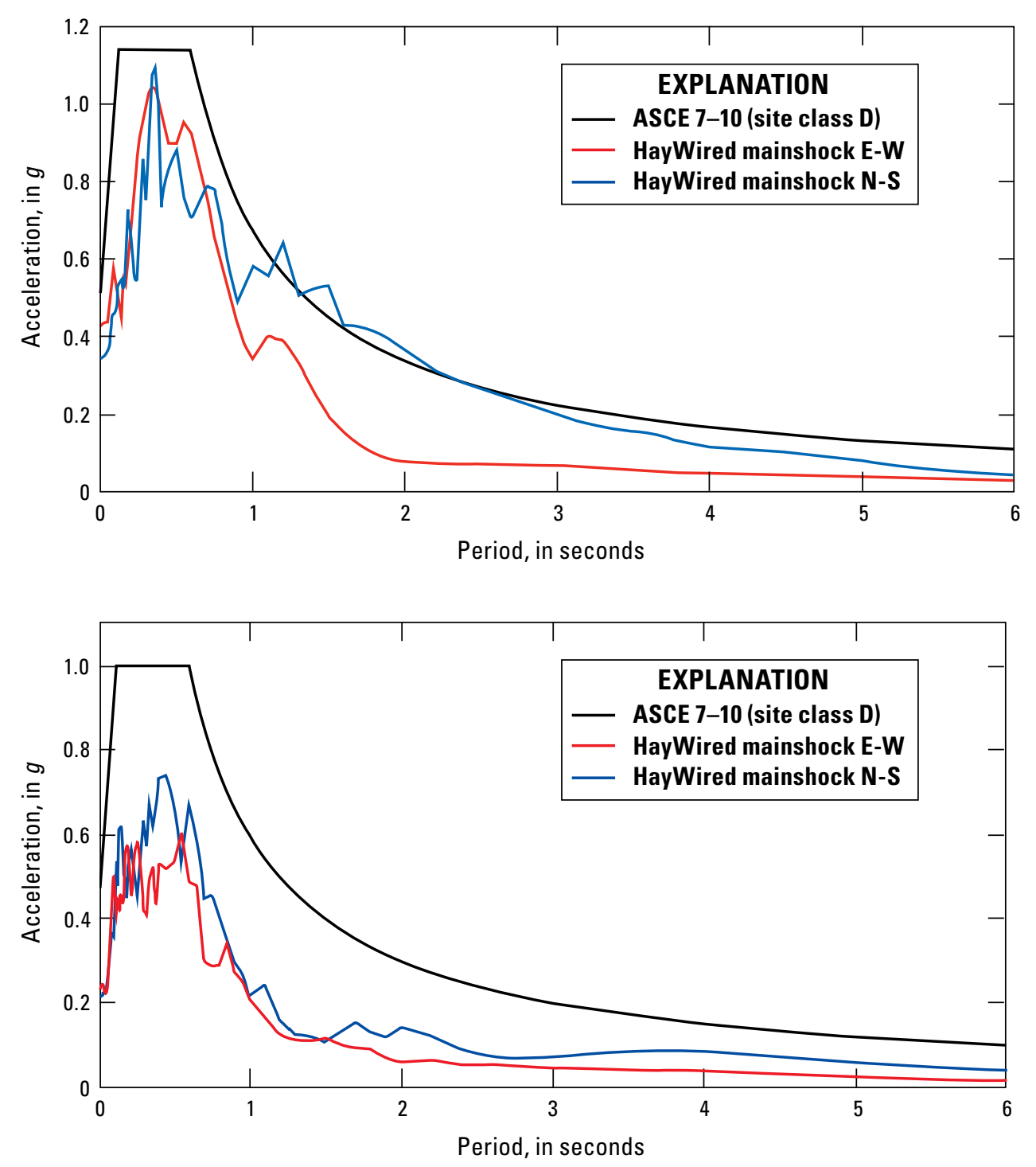

Figure 4. Graph showing ASCE 7-10 (American Society of Civil Engineers, 2010) design acceleration-response spectrum for its design-basis earthquake (DBE) versus ground-motion spectra for hypothetical momentmagnitude-7.0 mainshock of the HayWired earthquake scenario for the representative site in 0 akland, California. $g$, acceleration due to gravity at the Earth's surface; N-S, north-south; E-W, east-west.

Figure 5. Graph showing ASCE 7-10 (American Society of Civil Engineers, 2010) design acceleration-response spectrum for its design-basis earthquake (DBE) versus ground-motion spectra for hypothetical moment-magnitude-7.0 mainshock of the HayWired earthquake scenario for the representative site in San Francisco, California. $g$, acceleration due to gravity at the Earth's surface; N-S, north-south; E-W, east-west.

${ }^{3}$ The period (or mode of vibration) of a building is a dynamic property that typically refers to the time it takes for a building, if excited horizontally by ground shaking, to complete one cycle of sway back and forth. 


\section{Design}

The design of the archetype steel-MRF buildings is in accordance with the provisions of the 1973 Uniform Building Code and 1973 Structural Engineers Association of California (SEAOC) Bluebook (Structural Engineers Association of California, 1973), which was commonly used to supplement minimum design requirements. The design criteria for the $1970 \mathrm{~s}$ archetype buildings would have been equivalent, whether in Oakland or in San Francisco, according to the requirements of the Uniform Building Code (UBC) in 1973 (both locations fall within the same seismic and wind zones). The 40 -story and 20 -story archetype buildings represent the existing building stock in San Francisco, whereas the building stock in Oakland is generally limited in height to 20 stories.

Based on examination of existing building drawings, the 40-story building layout consists of 38 levels of office space, 2 levels for mechanical equipment - one at mid-height and one at the top of the building - and three basement levels for parking. The overall height of the structure is 507.5 feet ( $\mathrm{ft}$ ) (154.7 meters, $\mathrm{m})$ above ground and $30 \mathrm{ft}(9.1 \mathrm{~m})$ below grade. The 20-story building consists of 19 levels of office space — one level for mechanical equipment at the top of the building and one basement level for parking. The overall height of the structure is $267.5 \mathrm{ft}$ $(81.5 \mathrm{~m})$ above ground and $10 \mathrm{ft}(3.0 \mathrm{~m})$ below grade.

For both buildings, the enclosure is composed of precast concrete panels and glass windows. The floor system is composed of 3-inch (in.) (76 millimeters, mm) concrete slab over 2.5-in.
(64 mm) metal deck supported by steel beams meeting ASTM standard A36 (see ASTM International, 2014) with a yield stress of 36 kilopounds per square inch (ksi) (248 megapascal, MPa). The steel columns are ASTM A572 (see ASTM International, $2015)$ with a yield stress of $42 \mathrm{ksi}(290 \mathrm{MPa})$. As shown in figure 6 , the archetype structural system consists of a space frame with $20-40 \mathrm{ft}(6.1-12.2 \mathrm{~m})$ spans using wide flange beams, built-up box columns, and welded beam-column connections. Typical story heights are $10 \mathrm{ft}(3.0 \mathrm{~m})$ for basement levels, $20 \mathrm{ft}(6.1 \mathrm{~m})$ at ground level (lobby), and $12.5 \mathrm{ft}(3.8 \mathrm{~m})$ for typical office levels as stated in Molina-Hutt and others (2016).

Because the buildings are rectangular in plan, two analyses were performed in which the building was aligned in two different orientations (with grid lines aligned in the cardinal directions) in consideration that an earthquake produces different ground shaking intensity normal and parallel to a fault, respectively. These orientations are shown in figure 7.

For the archetype buildings, because wind drift limits governed the MRF section sizes, beams and columns have low strength-utilization ratios under the building code prescribed seismic forces of the 1970s. Typical member sizes and connection details were verified against available existing building drawings. Consistent with these records, built-up box columns and wide flange beams were selected for the archetype buildings. A summary of the design section sizes of the 40-story steel MRF and of the 20-story MRF are provided in tables 2 and 3, respectively. More information on the design and analysis of the steel-frame buildings can be found in Molina-Hutt and others (2016).
Figure 6. Diagrams showing archetype 40-story steelmoment-frame office building $(A)$ plan and $(B)$ isometric (from Molina-Hutt and others, 2016). MF, moment frame; ', feet.
$\boldsymbol{A}$

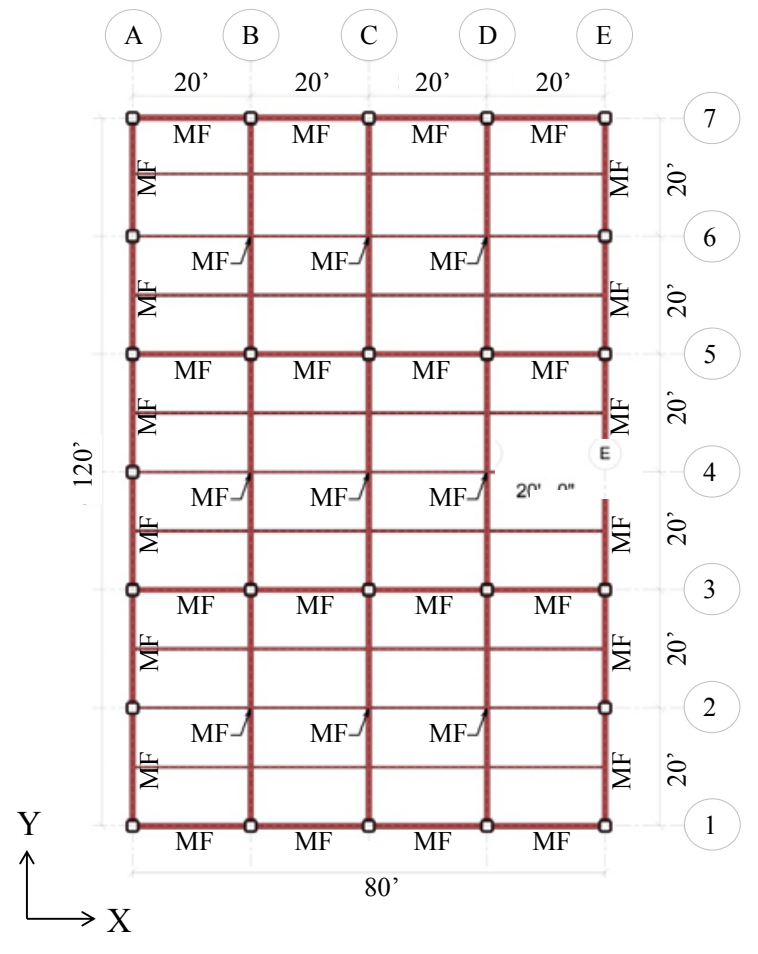

B

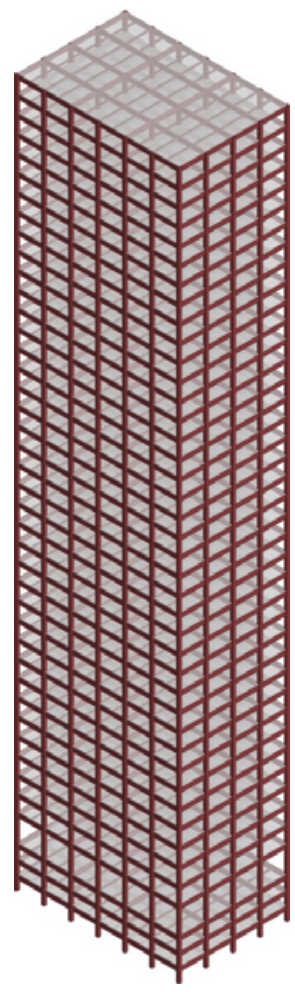



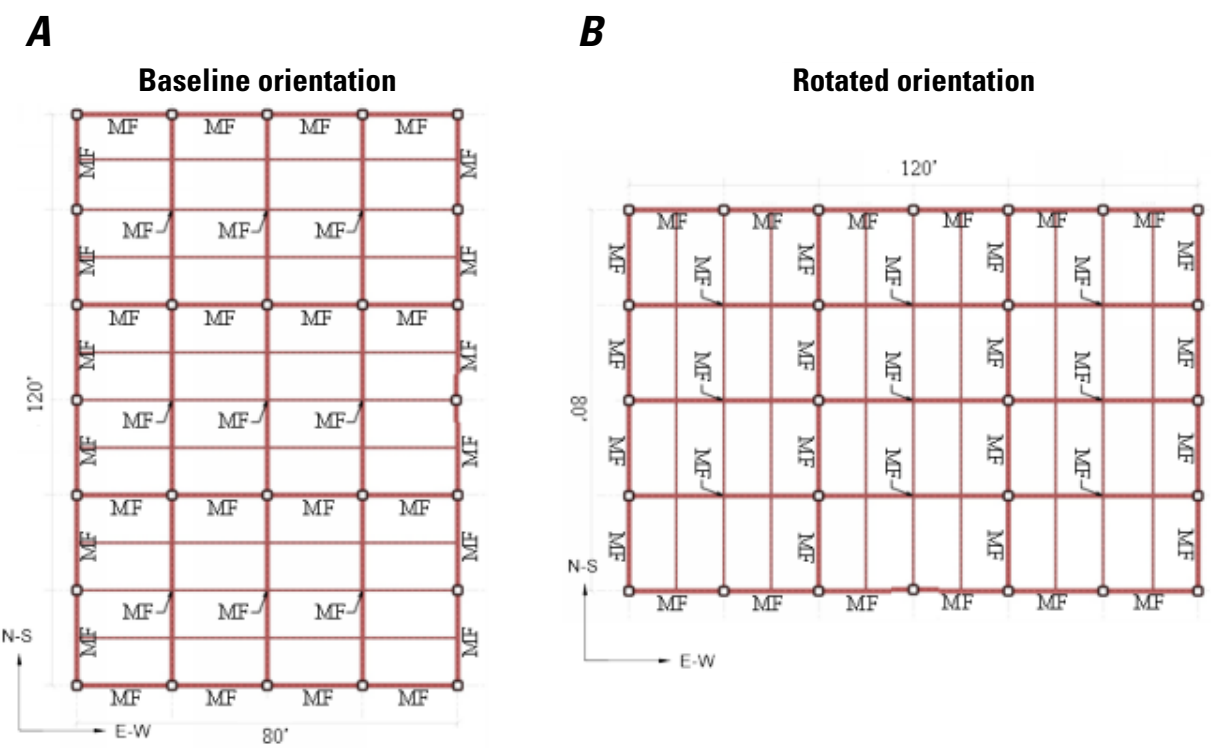

Figure 7. Diagrams showing $(A)$ baseline and $(B)$ rotated orientations of the archetype 40-story steel-moment-frame office building shown in figure 6 (from Molina-Hutt and others, 2016). MF, moment frame; N-S, north-south; E-W, east-west; ', feet.

Table 2. Lateral resisting system section sizes for the 40-story archetype steel-moment-frame office building (modified from MolinaHutt and others, 2016).

[t, flange thickness; W, wide-flange beam width, in inches; lb/ft, pound per foot]

\begin{tabular}{|c|c|c|c|c|c|c|}
\hline \multirow[b]{2}{*}{$\begin{array}{c}\text { Level } \\
\text { range, in feet }\end{array}$} & \multicolumn{3}{|c|}{ Wide flange beams } & \multicolumn{3}{|c|}{ Box columns } \\
\hline & $\begin{array}{l}\text { Exterior short } \\
\text { span }(\mathbf{W} \times \mathbf{l b} / \mathrm{ft})\end{array}$ & $\begin{array}{l}\text { Interior short } \\
\text { span (Wx|b/ft) }\end{array}$ & $\begin{array}{l}\text { Interior long } \\
\text { span (Wx|b/ft) }\end{array}$ & $\begin{array}{l}\text { Interior, in } \\
\text { inches }\end{array}$ & $\begin{array}{l}\text { Exterior short } \\
\text { elevation }(x) \text {, in } \\
\text { inches }\end{array}$ & $\begin{array}{c}\text { Exterior long } \\
\text { elevation }(y) \text {, in } \\
\text { inches }\end{array}$ \\
\hline Base to 10 & $\mathrm{~W} 36 \times 256$ & W36×282 & $\mathrm{W} 30 \times 124$ & $22 \times 22, t=3$ & $26 \times 26, t=3$ & $20 \times 20, t=2.5$ \\
\hline Base to 10 & W33×169 & W36×194 & W27×84 & $20 \times 20, t=2$ & $26 \times 26, \mathrm{t}=2.5$ & $20 \times 20, t=2$ \\
\hline 11 to 20 & $\mathrm{~W} 33 \times 118$ & W33×169 & W27×84 & $18 \times 18, \mathrm{t}=1$ & $24 \times 24, \mathrm{t}=1.5$ & $18 \times 18, \mathrm{t}=1$ \\
\hline 30 to roof & $\mathrm{W} 36 \times 256$ & W36×282 & $\mathrm{W} 30 \times 124$ & $22 \times 22, \mathrm{t}=3$ & $26 \times 26, t=3$ & $20 \times 20, t=2.5$ \\
\hline
\end{tabular}

Table 3. Lateral resisting system section sizes for the 20-story archetype steel-moment-frame building (modified from Molina-Hutt and others, 2016).

[t, flange thickness; W, wide-flange beam width, in inches; lb/ft, pound per foot]

\begin{tabular}{|c|c|c|c|c|c|c|}
\hline \multirow[b]{2}{*}{$\begin{array}{l}\text { Level } \\
\text { range, in feet }\end{array}$} & \multicolumn{3}{|c|}{ Wide flange beams } & \multicolumn{3}{|c|}{ Box columns } \\
\hline & $\begin{array}{l}\text { Exterior short } \\
\text { span }(\mathbf{W} \times \mathbf{l b} / \mathrm{ft})\end{array}$ & $\begin{array}{l}\text { Interior short } \\
\text { span (Wxlb/ft) }\end{array}$ & $\begin{array}{l}\text { Interior long } \\
\text { span }(\mathbf{W} \times \mathbf{l b} / \mathrm{ft})\end{array}$ & $\begin{array}{l}\text { Interior, in } \\
\text { inches }\end{array}$ & $\begin{array}{l}\text { Exterior short } \\
\text { elevation }(x) \text {, in } \\
\text { inches }\end{array}$ & $\begin{array}{c}\text { Exterior long } \\
\text { elevation }(y) \text {, in } \\
\text { inches }\end{array}$ \\
\hline Base to 10 & $\mathrm{~W} 30 \times 148$ & $\mathrm{~W} 30 \times 173$ & $\mathrm{~W} 30 \times 211$ & $22 \times 22 t=2$ & $22 \times 22, \mathrm{t}=2.5$ & $22 \times 22, \mathrm{t}=1.5$ \\
\hline 11 to 20 & $\mathrm{~W} 27 \times 129$ & $\mathrm{~W} 27 \times 146$ & $\mathrm{~W} 30 \times 191$ & $22 \times 22 \mathrm{t}=1.5$ & $22 \times 22, \mathrm{t}=2.0$ & $22 \times 22, \mathrm{t}=1$ \\
\hline
\end{tabular}




\section{Typical Details}

Figure 8 shows some of the typical details frequently observed in existing building drawings. Welds in beam-column connections before 1994 had very low toughness, as evidenced by fractures observed in the $M_{\mathrm{w}} 6.71994$ Northridge, California, earthquake (Bonowitz and Maison, 2003). It is assumed that these fracture-prone pre-Northridge moment connections are common in 1970s construction. Therefore, all beam-column connections were modeled as pre-Northridge moment connections. Column splices are typically located $4 \mathrm{ft}$ above the floor level, approximately every three floors. Observed typical splice connection details consist of partial joint-penetration welds of roughly half the thickness of the smaller section being connected. When subject to tensile forces, these splices can only carry a fraction of the moment capacity and (or) axial-tension capacity of the smallest section size being connected. Furthermore, experimental tests on heavy steel section-welded splices have illustrated sudden failures with limited ductility (Bruneau and Mahin, 1990). Based on this evidence, column splice failures are considered in this assessment.

\section{Building Dynamic Properties}

The dynamic properties, including the fundamental and second mode period of vibration in each translational direction, from a modal analysis of the archetype steel-frame buildings is presented in table 4 . The table shows that 80 percent of the modal mass is mobilized in the first two translational modes for the 40-story tower (that is, mode 1 and 4 in the $x$ direction and mode 2 and 5 in the $y$ direction), whereas 90 percent of the modal mass is mobilized in the first two translational modes for the 20 -story tower.

\section{Finite Element Modeling}

The steel-moment-frame office buildings were modeled using LS-DYNA, an advanced general-purpose multiphysics simulation software package developed by Livermore Software Technology Corporation (2009). The use of LS-DYNA for performance-based seismic analysis has become more common, and several recent building projects in California have undergone rigorous seismic peer review by experts. A nonlinear response-history analysis, using an explicit solverwhich accounts for secondary moment effects and nonlinear materials - was done using the ground motions discussed above in HayWired Ground Motions, which were applied at the base of the model.

The model was subjected to the ground motions in conjunction with expected gravity loads, which include self-weight, superimposed dead loads, and 25 percent of the unreduced live loads. Fixed supports were assumed at the base of the structure. Soil-structure interaction was not considered.

Table 4. Dynamic properties in $x$ and $y$ directions of archetype 20- and 40-story steel-moment-frame buildings examined for response in the hypothetical moment-magnitude-7.0 mainshock of the HayWired earthquake scenario.

\begin{tabular}{|c|c|c|c|c|}
\hline \multirow[b]{2}{*}{$\begin{array}{l}\text { Vibration } \\
\text { mode }\end{array}$} & \multicolumn{2}{|c|}{ Steel-frame building (40 story) } & \multicolumn{2}{|c|}{ Steel-frame building (20 story) } \\
\hline & Period, in seconds & $\begin{array}{l}\text { Effective/total mass, in } \\
\text { percent }\end{array}$ & Period, in seconds & $\begin{array}{c}\text { Effective/total mass, in } \\
\text { percent }\end{array}$ \\
\hline 1 & $5.62(\mathrm{x})$ & $60.79(x)$ & $2.33(\mathrm{x})$ & $75.15(x)$ \\
\hline 2 & $5.29(\mathrm{y})$ & $60.80(\mathrm{y})$ & $2.04(\mathrm{y})$ & $73.33(\mathrm{y})$ \\
\hline 3 & 2.86 (torsional) & -- (torsional) & 1.47 (torsional) & -- (torsional) \\
\hline 4 & 1.86 & $21.33(\mathrm{x})$ & 0.78 & $13.44(\mathrm{x})$ \\
\hline 5 & 1.66 & $19.28(y)$ & 0.65 & $15.74(y)$ \\
\hline
\end{tabular}

$\boldsymbol{A}$

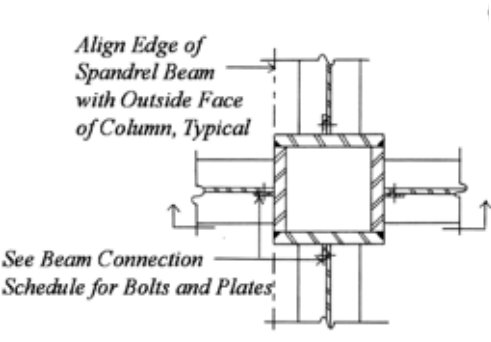

B

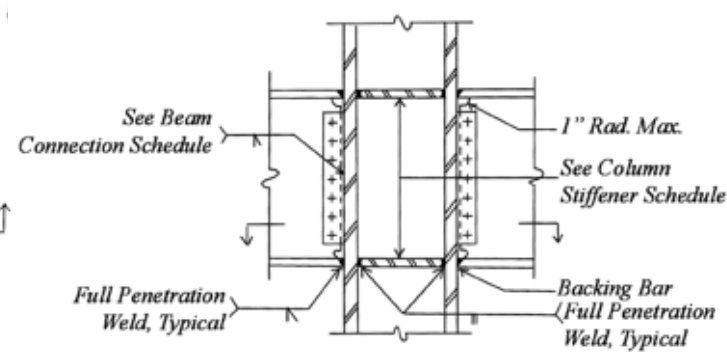

C

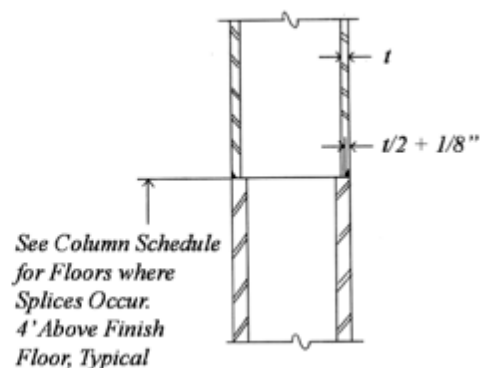

Figure 8. Diagrams showing typical details observed in existing building drawings. $A$, Plan section of typical moment connection; $B$, elevation of typical moment connection; $C$, typical splice. t, flange thickness; ', inch; ", feet; Rad. Max., maximum radius. (From Molina-Hutt and others, 2016.) 
For tall buildings with embedded basements in soft soils, the kinematic effects are likely to slightly reduce the peak floor accelerations associated with higher modes. The embedment depth is important and we note that older steel-frame buildings typically have one or two basement levels. A 2.5-percent critical damping was assumed based on work by PEER (TBI Guidelines Working Group, 2010).

The steel-frame office buildings were modeled with the following element types:

- One-dimensional (1D) lumped plasticity elements for the beams with nonlinear behavior intended to represent pre-Northridge connections which may fracture prematurely. Each beam connection was assigned a unique backbone curve based on the probability it would fracture at a given rotation based on experimental evidence (Molina-Hutt and others, 2016).

- 1D lumped plasticity elements for the columns.

- Two-dimensional (2D) elastic shell elements for the floors using stiffness modifiers.

- Nonlinear rotational springs for the steel-panel zones.

- Nonlinear rotational springs for the steel-column splices, with nonlinear behavior intended to represent the typical weld details that may fracture at demands lower than the column axial and moment strength.

For full details on the steel-frame building modeling, see Molina-Hutt and others (2016).

\section{Reinforced-Concrete Residential Tower}

A 42-story reinforced-concrete core-only residential building was selected as one of the archetype buildings for this study, because it has become a prevalent construction type in San Francisco. The building design is intended to represent the current state of practice for tall buildings in San Francisco.

\section{Design}

The archetype reinforced-concrete building design is originally based on the PEER Task 12 study (Moehle and others, 2011) for an archetypical building in Los Angeles and was redesigned for San Francisco seismic demands by Tipler (2014) following the PEER Tall Building Initiative guidelines (TBI Guidelines Working Group, 2010). The general performances objectives for the structure are no different than modern code objectives - to provide "collapse-prevention" in the MCE, "life-safety" in a DBE, and minimal damage in serviceability-level earthquakes (SLE). The design guidelines set out in PEER (TBI Guidelines Working Group, 2010) require that the structure be evaluated through a NLRHA to explicitly verify that the building has a low probability of collapse under the MCE. An isometric view of the building is shown in figure 9 . As above for the steel-frame buildings, two building

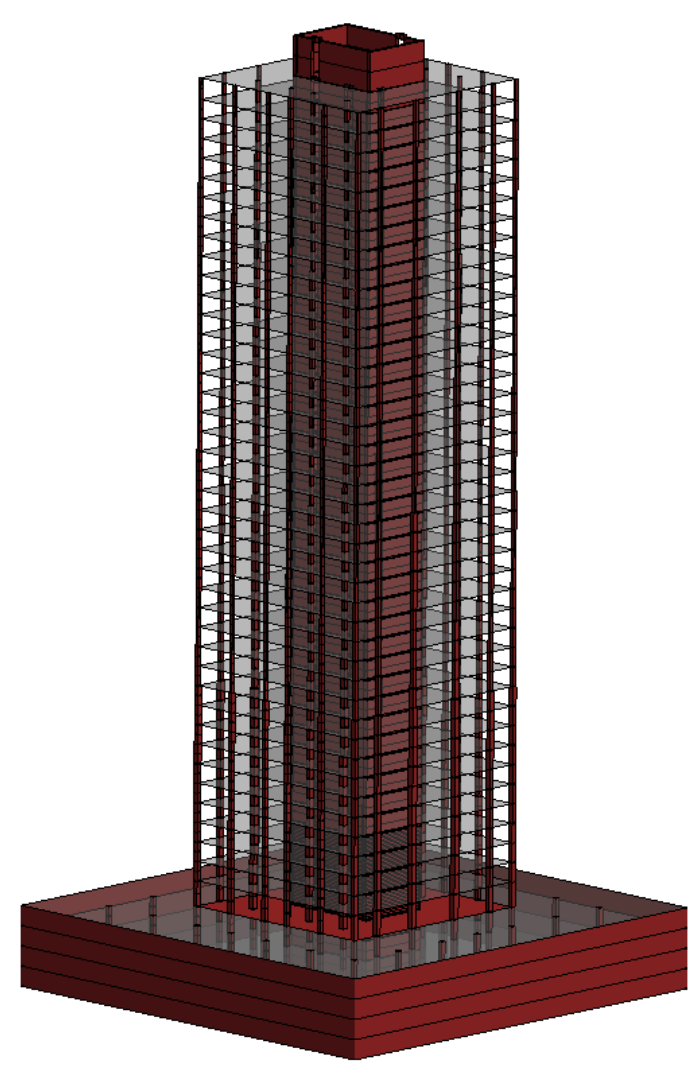

Figure 9. Diagram showing an isometric view of the archetype 42-story reinforced-concrete residentialbuilding analytical model.

orientations were analyzed for the reinforced-concrete building. These orientations are shown in figure 10. The core-only lateral system (fig. 11) is designed such that energy is dissipated through two flexural yield mechanisms - (1) plastic hinges at the base of each wall pier and (2) the ends of the coupling beams up the height of the building.

The reinforced-concrete residential building has 42 above-ground levels and 4 below-ground levels for parking. The building is $457 \mathrm{ft}(139.3 \mathrm{~m})$ tall above grade, including the roof bulkhead. The superstructure floor plate is $107.9 \times 107.0 \mathrm{ft}(32.9 \times 32.6 \mathrm{~m})$ in plan. Floor-to-floor heights are typically $9.7 \mathrm{ft}(3.0 \mathrm{~m})$. The substructure is $228.0 \times 227.0 \mathrm{ft}$ $(69.5 \times 69.2 \mathrm{~m})$ in plan. The gravity system is 8 in $(203 \mathrm{~mm})$ thick prestressed concrete slab and reinforced concrete columns. Columns sizes typically range from 36 in. (914 mm) square at the ground to 18 in. $(457 \mathrm{~mm})$ square at the roof. Core wall thickness is 32 in. $(813 \mathrm{~mm})$ thick up to superstructure level 13 and 24 in. $(610 \mathrm{~mm})$ thick from superstructure level 13 to the roof. Coupling beam depth is $30 \mathrm{in} .(762 \mathrm{~mm})$ everywhere except the basement, where the beams are $34 \mathrm{in}$. (864 mm) deep. Core-wall design (nominal) strength is $8 \mathrm{ksi}$ $(55 \mathrm{MPa})$. Shear-wall steel-reinforcement nominal yield strength is $60 \mathrm{ksi}(410 \mathrm{MPa})$. Coupling-beam steel-reinforcement nominal yield strength is $75 \mathrm{ksi}(520 \mathrm{MPa})$.

More information on the design of the reinforced-concrete residential building can be found in Tipler (2014). Note that 

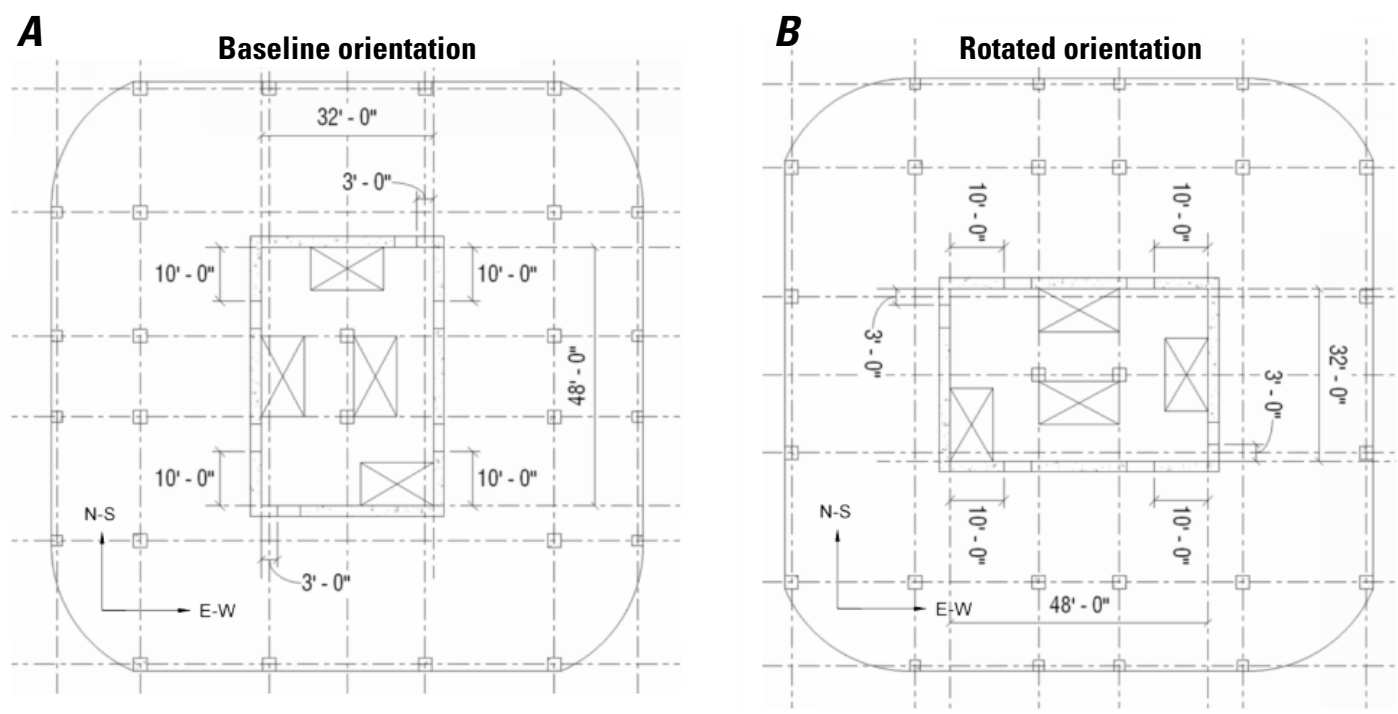

Figure 10. Diagrams showing $(A)$ baseline and $(B)$ rotated orientations of the archetype 42-story reinforced-concrete residential-building analytical model (from Moehle and others, 2011). N-S, northsouth; E-W, east-west; ', feet; ", inches.

$\boldsymbol{A}$
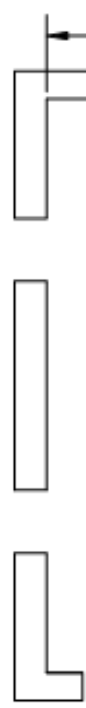

B
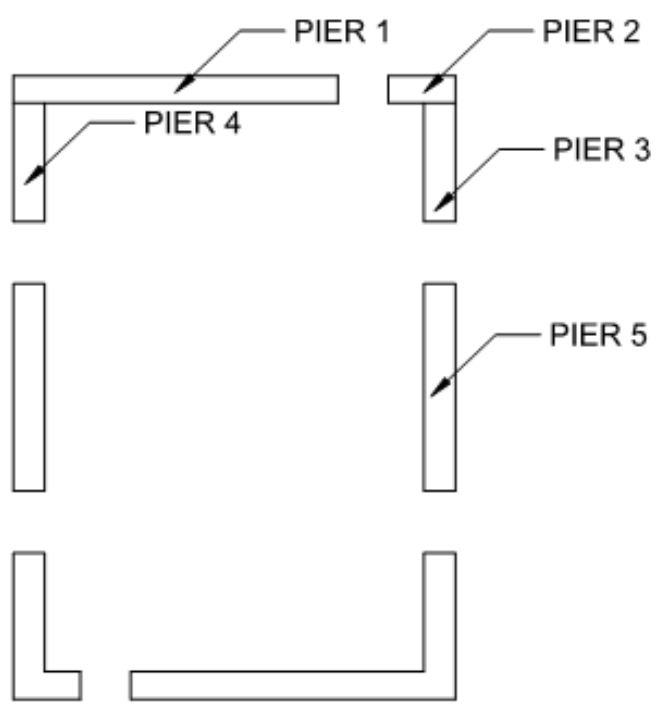

Figure 11. Diagrams showing $(A)$ core-wall layout with dimensions and $(B)$ pier labeling (right) for the archetype 42-story reinforced-concrete residential-building analytical model (from Tipler, 2014). m, meters.

Tipler's design was based on a San Francisco location, but we used it for Oakland (even though there are currently no 40-story towers in Oakland) to obtain a general understanding of how this type of building would perform.

\section{Building Dynamic Properties}

The dynamic properties of the archetype 42-story reinforcedconcrete residential building, using effective stiffness properties that account for flexural cracking, are shown in table 5. For further details see Tipler (2014).
Table 5. Dynamic properties of the archetype 42-story reinforcedconcrete residential-building analytical model (modified from Tipler, 2014).

[DBE, design-basis earthquake (American Society of Civil Engineers, 2010), $\mathrm{T} 1$, first mode period in specified direction, $\mathrm{T} 2$, second mode period in specified direction]

\begin{tabular}{cc}
\hline \multicolumn{2}{c}{ Period (DBE), in seconds } \\
\hline Strong direction $(\boldsymbol{y}$-axis) & Weak direction ( $\boldsymbol{x}$-axis) \\
\hline $\mathrm{T} 1=4.37$ & $\mathrm{~T} 1=5.27$ \\
$\mathrm{~T} 2=0.93$ & $\mathrm{~T} 2=1.10$ \\
\hline
\end{tabular}




\section{Modeling}

Tipler (2014) modeled a reinforced-concrete building using LS-DYNA (Livermore Software Technology Corporation, 2009). We made some modifications to the LS-DYNA model to reflect updated knowledge of concrete-material modeling. A nonlinear response history analysis, using an explicit solver, which accounts for secondary moment effects and nonlinear materials, was undertaken with the ground motions discussed above in HayWired Ground Motions applied at the base of the model.

The reinforced-concrete residential buildings were modeled with the following element types:

- 1D distributed plasticity fiber beam elements for the shear walls, with fiber representing steel reinforcement, confined/unconfined concrete, and corresponding nonlinear material behavior. The use of fiber beam elements to represent core walls is industry practice. It enforces "plane sections remain plane" behavior which may underestimate the localized damage at the ends or corners of walls and may therefore underpredict losses.

- 1D lumped plasticity elements for the coupling beams, which have been validated against testing at the University of California Los Angeles (UCLA) (Naish and others, 2009) to reproduce the hysteretic behavior.

- 2D elastic shell elements for the floors using stiffness modifiers.

- 2D elastic shell elements for the basement walls.

- 1D elastic beam elements for the columns.

The reinforced-concrete model was subjected to the ground motions in conjunction with expected gravity loads, which includes self-weight, superimposed dead loads, and 25 percent of the unreduced live loads. Fixed supports were assumed at the base of the structure and soil-structure interaction was not considered. For tall buildings with deep embedded basements in soft soils, the kinematic effects are likely to reduce the peak floor accelerations associated with higher modes. The embedment depth is important, and we note that newer reinforced-concrete buildings typically have three to five basement levels. It can be inferred that the damage to some acceleration-sensitive nonstructural components may be overestimated. A 2.5-percent critical damping was assumed based on work by PEER (TBI Guidelines Working Group, 2010). For full details on the reinforced-concrete building modeling, see Tipler (2014).

\section{Loss-Assessment Methodology}

The FEMA P-58 methodology (Applied Technology Council, 2012) was followed in to determine the risk metrics of interest for the buildings in this study. The fragility curves in the September 2016 update of FEMA P-58 volume 3 were used (Applied Technology Council, 2016). Using those results, the
REDi $^{\mathrm{TM}}$ downtime methodology (with some enhancements) was employed to calculate building downtime until reoccupancy and functional recovery is achieved (Almufti and Willford, 2013). Note that components which suffer only cosmetic damage do not contribute to the time required to achieve reoccupancy or functionality (only full recovery, which is not reported herein). These calculations are implemented using in-house software at Arup (Arup, North America, Ltd.), which runs Monte Carlo simulations (that is, realizations) for each building.

The loss-assessment methodology in FEMA P-58 relates expected building movements to expected damage in individual components to expected consequences (for example, repair costs and repair times). The structural response from the ground motions for the HayWired mainshock was assumed to be 'best estimate' structural response. A modeling dispersion was applied to obtain variability in response, accounting for uncertainty in analysis model quality and construction quality. The modeling dispersion assumed was 0.35 for steel-frame buildings and 0.27 reinforced-concrete buildings based on guidance in FEMA P-58 (Applied Technology Council, 2012). A lognormal distribution was assumed for this purpose, where each floor, parameter type, and direction was assumed independent of one another. Using the "best estimate" structural response and modeling dispersion, each individual building underwent 1,000 Monte Carlo loss simulations to capture the uncertainty in building damage and consequences. This results in a distribution of repair-cost and repair-time estimates with corresponding probabilities of nonexceedance (often referred to as "confidence levels") for the HayWired scenario mainshock and archetype buildings. As a result of this being a scenario study, the risk results have a much narrower range as compared with intensity-based studies. In those cases, the motion to motion variability adds a significant amount to the overall dispersion on structural response.

\section{REDi Downtime Methodology}

The REDi ${ }^{\mathrm{TM}}$ downtime methodology builds on the FEMA P-58 methodology to calculate the time required to achieve discrete downtime recovery states such as reoccupancy, functionality, and full recovery (Almufti and Willford, 2013). This is dependent on the extent and severity of damage to individual building components and their criticality in supporting occupancy or functionality. The REDi methodology maps each of the damaged components into repair classes, which indicate whether the extent and severity of damage to that component would hinder reoccupancy (repair class 3), functionality (repair class 2), and full recovery (repair class 1 ). Figure 12 provides an overview of the methodology, whereas figure 13 illustrates the aspects of the REDi downtime method for functional recovery.

\section{Probability of Observing Damage}

The FEMA P-58 methodology allows the estimation of the extent and severity of damage to specific building components. 


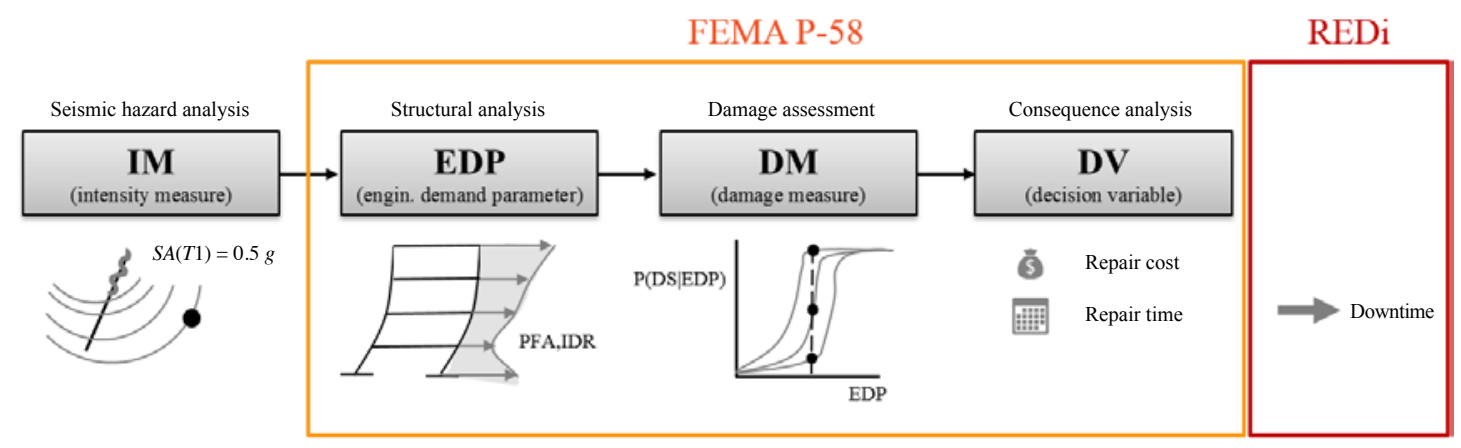

Figure 12. Diagram showing overview of methodologies used for the loss assessment for tall buildings for the hypothetical moment-magnitude-7.0 mainshock of the HayWired earthquake scenario. MethodologiesFEMA P-58 (Applied Technology Council, 2012); REDi (see Almufti and Willford, 2013). SA, spectral

acceleration; $T 1$, fundamental mode of vibration; $g$, acceleration due to gravity; PFA, peak floor acceleration; IDR, interstory drift ratio; P, probability; DS, damage state; EDP, engineering design parameter.

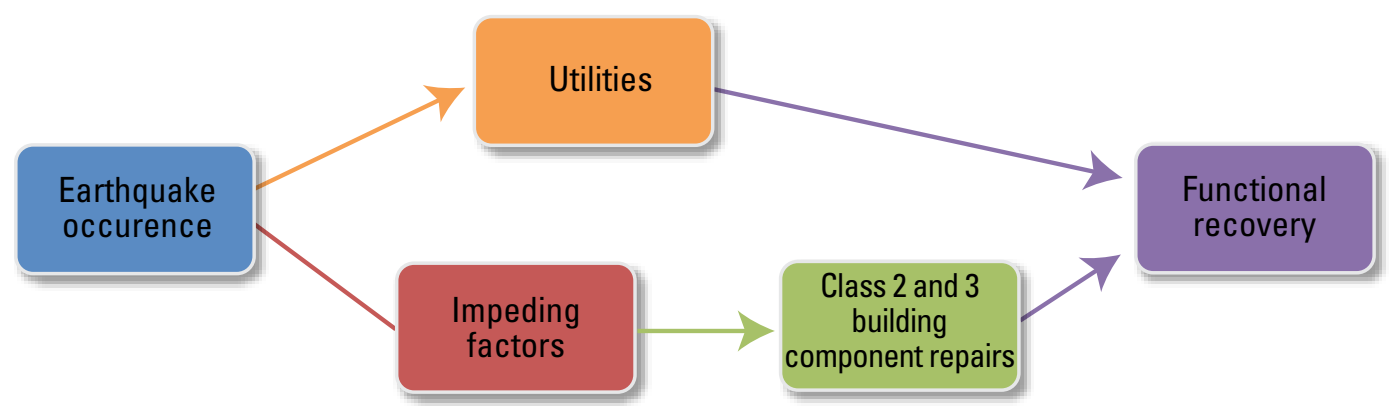

Figure 13. Illustration showing REDiTM (Almufti and Willford, 2013) downtime framework for assessing the functional recovery of tall buildings after the hypothetical moment-magnitude-7.0 mainshock of the HayWired earthquake scenario.

However, the impact of the damage on whether downtime is triggered depends to a great extent on whether the damage is observed or hidden (particularly true of structural components). The REDi methodology explicitly accounts for the probability that an inspector would observe a certain type of damage (and thus influence their decision how to tag a building) by assigning a 50-percent chance that an inspector would observe the damage when 10 percent of all components of that type are in the highest realized damage state.

In this study, this assumption is particularly important for the pre-Northridge moment-frame connections in existing steel-frame buildings. Jurisdictions such as San Francisco do not have specific policies for post-earthquake inspection of the moment-frame connections and are unlikely to require such an inspection unless the building exhibited a lean (Laurence Kornfield, Earthquake Engineering Research Institute, written commun., 2017). However, many owners of older buildings retain structural engineers through the Building Occupancy Resumption Program (BORP) (Structural Engineers Association of Northern California, 2003). It likely that structural engineers, having become acutely aware of the deficiencies in such steel moment-frame connections, would recommend inspection of some connections (but not all). Section 3.3.3 of FEMA 352 (SAC Joint Venture, 2000) recommends that one connection in each framing line in each direction (east-west and north-south) is exposed for inspection under certain circumstances that would appear to be satisfied by the HayWired mainshock. For the archetype steel-frame building, with 6 bays (12 connections) in one direction and 4 in the other ( 8 connections), this is between 8.3 percent and 12.5 percent of all connections, respectively. This is relatively consistent with the 10-percent inspectionexposure assumption by REDi. In addition, the connections may be fire-proofed, which according to FEMA 352, may "tend to obscure many types of damage, unless the damage is very severe." FEMA 352 also indicates that even for bare steel connections, certain types of damage "may be impossible to detect by visual observation alone." This supports the REDi assumption that the likelihood of observing a fracture, having exposed the connection, is not 100 percent guaranteed. Because the number of beam fractures from the steel-frame building analysis in this study (see appendixes) is less than a few percent of all beam components in the building, it is unlikely that an inspector would observe one, and thus beam fractures do not contribute to downtime in the majority of realizations. 


\section{Impeding Factors}

The time to make corresponding repairs to earthquakedamaged buildings is calculated based on FEMA P-58 but modified by REDi to consider likely construction repair sequences and labor allocation. Based on the type and extent of repairs, the total time to achieve reoccupancy or functionality must also consider impeding factors (that is, delays to the initiation of repairs). The following impeding factors are considered, the default values of which are generally taken from REDi but have been modified as indicated below:

- Postearthquake inspection.

- Financing (assumes that the buildings are insured, based on the authors' knowledge of earthquakeinsurance coverage for tall buildings in San Francisco).

- Engineering mobilization and review.

- Contractor mobilization (modified based on extent, type, and severity of damage and height of building; estimates based on survey of contractors administered by Arup).

- Permitting.

Utility disruption is also considered in the downtime, as described above under Utility Disruption.

\section{Input Parameters}

The basic building information used in the assessment methodology for the archetype tall-buildings included number of stories and square footage per floor. Sources for the assumed component types and corresponding quantities are provided in the appendixes. Building contents- such as modular workstations, bookcases, art pieces, and caseworkwere not included in the loss assessment. For the steel-frame buildings, heavy mechanical equipment (that is, cooling tower and chiller) capacities were modified based on input from mechanical engineering experts at Arup. The structural analysis results for given ground motions for the HayWired mainshock at a site were interpreted to be "best estimate" results about which a modelling dispersion was assumed to account for uncertainty in analytical model quality and assumed construction quality.

\section{Demolition Fragility}

The probability that a building might need to be demolished as a result of the HayWired mainshock was considered in our analysis. If a building has a peak residual interstory drift (RIDR) of 0.5 percent or less, there is a negligible chance the structure would need to be demolished. If a building has a peak RIDR of 1 percent, there is a 50-50 chance that it would need to be demolished.

\section{Component Fragilities}

A full list of the archetype building-component quantities and fragility criteria can be found in appendix 1 . Appendix 1 provides information on both structural components and information on nonstructural components. In addition to the default fragilities provided by FEMA P-58, we modified fragilities for elevators and precast facades. Two elevator components were modeled to capture two possible types of damage:

1. Acceleration-sensitive component which is correlated to the elevator cabin damage.- This is modelled at the ground floor of the building because the FEMA P-58 fragility is a function of peak ground acceleration (PGA). It is our opinion that these are likely conservative for taller buildings, as the default FEMA P-58 fragilities were developed from shorter buildings in which the floor accelerations increased up the height (with roof accelerations likely to be 2-3 times PGA). The fragility does not account for the location of the elevator in the building, but presumably, the elevators that were damaged in observation were those at the upper stories. In a tall building, where the fundamental mode of vibration and higher mode effects contribute to the acceleration response, it is not necessarily the case that the PGA is amplified significantly.

2. RIDR sensitive component which is correlated to the shaft rail damage.- This is modeled at the superstructure level where the peak RIDR occurs, which varies from building to building.

The fragility function for the precast facades used in the steel-frame buildings were developed based on the methodology in section 7.4 of FEMA P-58 (Applied Technology Council, 2012). The median interstory drift to cause damage was backcalculated by the gaps between façade panels and floor heights (determined through examination of drawings). The dispersion of 0.5 was adopted per section 7.4. Damage to façades is assumed to cause reoccupancy issues due to the risk of loose façade materials potentially falling and injuring passersby.

\section{Replacement Value}

The replacement value of steel-frame buildings is based on a class-5 rough cost estimate of the Association for the Advancement of Cost Engineering (AACE) and has an accuracy range of -5 to +30 percent as discussed in Molina-Hutt and others (2016). It includes all structure; exterior enclosure; mechanical, electrical, and plumbing (MEP) infrastructure; and partitions. It does not include demolition and site clearance.

The replacement value of reinforced-concrete buildings is based on those of Tipler (2014), which used cost estimates from Moehle and others (2011) for most components, including structural elements. The cost of interior partitions and doors were provided by an experienced Arup estimator. Cost estimates for elevators and façade were obtained from vendors. The replacement value also includes MEP infrastructure and partitions. It does not include demolition and site clearance. 


\section{Utility Disruption}

Utility disruption times are considered when determining the time required to achieve building functionality. These are from other parts of the HayWired project (for example, Porter, Water-Network Resilience, this volume), except for natural gas. For natural gas, the values for utility disruption are based off of a study of several moderate to large magnitude earthquakes which have affected regions with modern infrastructure, including California, Japan, Chile, and New Zealand, as well as studies estimating utility disruption times with consideration of future earthquakes in the Western United States (Almufti and Willford, 2013). The utilities of interest include:

- Water

- Natural gas

- Electricity

- Voice/data
The estimated building-restoration delays for due to disruptions of each of those utilities is shown in tables 6 and 7 for San Francisco and Oakland, respectively.

\section{Summary of Loss-Assessment Results}

The results of the loss assessment (repair cost and downtime estimates) for all 10 case-study buildings are discussed below. Both the median (50-percent confidence level) and probable maximum (90-percent confidence level) are presented.

Because the HayWired mainshock is a scenario event, the difference between the median and 90th-percentile losses is small in comparison to the results from an intensity-based assessment involving many ground motions, where the motion to motion variability adds significantly to the overall dispersion.

Figure 14 and table 8 show the results of the repair-cost assessment for the 10 buildings. Figure 15 and table 9 show the results of the downtime assessment for the 10 buildings. See the appendixes for detailed repair-cost and downtime results for each individual building.

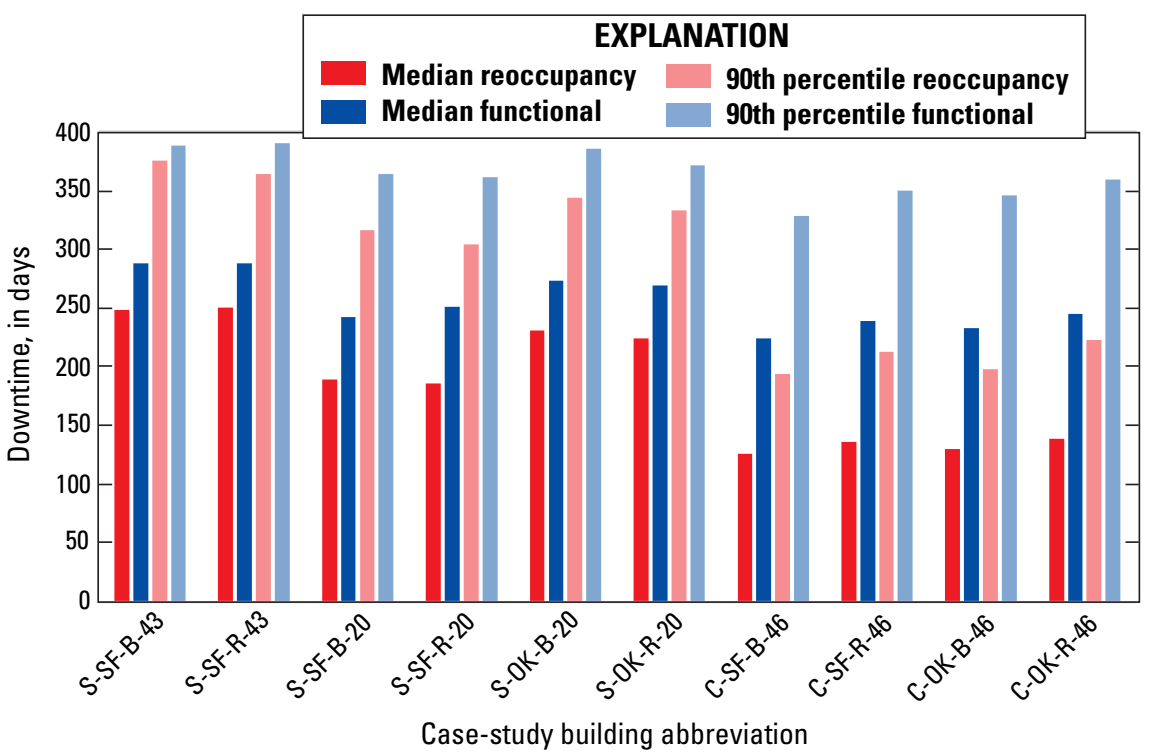

Figure 14. Graph showing median and 90th-percentile building-repair costs following the hypothetical momentmagnitude- 7.0 mainshock of the HayWired earthquake scenario for all case study buildings (see table 1) as a percentage of replacement value.

Case-study building abbreviation

Table 6. Estimated building-restoration delays due to utility disruption at the San Francisco, California, site following the hypothetical momentmagnitude-7.0 mainshock of the HayWired earthquake scenario.

\begin{tabular}{|c|c|c|}
\hline Utility & 50-percent restoration & Tail restoration \\
\hline Water $^{1}$ & 3 days & 100 percent at 7 days \\
\hline Natural gas ${ }^{2}$ & $\sim 9$ days & 90 percent at $\sim 33$ days \\
\hline Electricity $^{3}$ & 1 day & 99.5 percent at 30 days \\
\hline Voice/data ${ }^{4}$ & 5 days & 100 percent at 7 days \\
\hline
\end{tabular}

${ }^{1}$ Porter (Water-Network Resilience, this volume).

${ }^{2}$ Per REDi (Almufti and Willford, 2013) for peak ground velocities associated with the HayWired mainshock.

${ }^{3}$ Preliminary Hazus-MH (Federal Emergency Management Agency, 2012) estimate run for the HayWired scenario (Doug Bausch, written commun., Federal Emergency Management Agency, 2014).

${ }^{4}$ Preliminary estimate provided by John Erichsen (oral commun., 2016 HayWired Telecommunications Workshop).
Table 7. Estimated building-restoration delays due to utility disruption at the Oakland, California, site following the hypothetical momentmagnitude-7.0 mainshock of the HayWired earthquake scenario.

\begin{tabular}{lcc}
\hline \multicolumn{1}{c}{ Utility } & 50-percent restoration & Tail restoration \\
\hline Water $^{1}$ & 30 days & 100 percent at 90 days \\
Natural gas $^{2}$ & $\sim 10$ days & 90 percent at $\sim 36$ days \\
Electricity $^{3}$ & 2 days & 96 percent at 30 days \\
${\text { Voice } / \text { data }^{4}}$ & 7 days & 100 percent at 30 days \\
\hline
\end{tabular}

${ }^{1}$ Porter (Water-Network Resilience, this volume).

${ }^{2}$ Per REDi (Almufti and Willford, 2013) for peak ground velocities associated with the HayWired mainshock.

${ }^{3}$ Preliminary Hazus-MH (Federal Emergency Management Agency, 2012) estimate run for the HayWired scenario (Doug Bausch, written commun., Federal Emergency Management Agency, 2014).

${ }^{4}$ Preliminary estimate provided by John Erichsen (oral commun., 2016 HayWired Telecommunications Workshop). 
Table 8. Summary of total building-repair costs following the hypothetical momentmagnitude-7.0 mainshock of the HayWired earthquake scenario for each case-study building (see table 1).

\begin{tabular}{lcccc}
\hline $\begin{array}{c}\text { Case-study building } \\
\text { abbreviation }\end{array}$ & $\begin{array}{c}\text { Median total } \\
\text { repair cost, in } \\
\text { dollars }\end{array}$ & $\begin{array}{c}\text { Percentage of } \\
\text { replacement } \\
\text { value }\end{array}$ & $\begin{array}{c}\text { 90th-percentile } \\
\text { total repair cost, in } \\
\text { dollars }\end{array}$ & $\begin{array}{c}\text { Percentage of } \\
\text { replacement } \\
\text { value }\end{array}$ \\
\hline S-SF-B-43 & $15,057,000$ & 10.8 & $17,132,000$ & 12.3 \\
\hline S-SF-R-43 & $13,512,000$ & 9.7 & $15,690,958$ & 11.3 \\
\hline S-SF-B-20 & $5,138,200$ & 7.4 & $6,592,184$ & 9.5 \\
\hline S-SF-R-20 & $5,687,900$ & 8.2 & $7,261,380$ & 10.4 \\
\hline S-OK-B-20 & $12,172,000$ & 17.5 & $14,395,814$ & 20.7 \\
\hline S-OK-R-20 & $11,510,000$ & 16.5 & $13,065,046$ & 18.7 \\
\hline C-SF-B-46 & $5,517,497$ & 3.1 & $6,470,705$ & 3.7 \\
\hline C-SF-R-46 & $9,023,409$ & 5.1 & $9,839,828$ & 5.6 \\
\hline C-OK-B-46 & $8,604,872$ & 4.9 & $9,393,212$ & 5.3 \\
\hline C-OK-R-46 & $8,864,100$ & 5.0 & $10,829,600$ & 6.2 \\
\hline
\end{tabular}

Table 9. Summary of building reoccupancy and functional-repair-time results following the hypothetical moment-magnitude-7.0 mainshock of the HayWired earthquake scenario for each case-study building (see table 1).

\begin{tabular}{lcccc}
\hline $\begin{array}{c}\text { Case-study building } \\
\text { abbreviation }\end{array}$ & \multicolumn{2}{c}{ Median repair time } & \multicolumn{2}{c}{ 90th-percentile repair time } \\
\cline { 2 - 5 } & $\begin{array}{c}\text { Reoccupancy, } \\
\text { in days }\end{array}$ & $\begin{array}{c}\text { Functional, in } \\
\text { days }\end{array}$ & $\begin{array}{c}\text { Reoccupancy, in } \\
\text { days }\end{array}$ & $\begin{array}{c}\text { Functional, in } \\
\text { days }\end{array}$ \\
\hline S-SF-B-43 & 41 & 45 & 61 & 126 \\
\hline S-SF-R-43 & 37 & 39 & 54 & 102 \\
\hline S-SF-B-20 & 20 & 29 & 39 & 145 \\
\hline S-SF-R-20 & 22 & 33 & 47 & 189 \\
S-OK-B-20 & 54 & 92 & 116 & 272 \\
\hline S-OK-R-20 & 54 & 82 & 97 & 237 \\
C-SF-B-46 & 3 & 15 & 5 & 27 \\
\hline C-SF-R-46 & 6 & 16 & 11 & 26 \\
C-OK-B-46 & 5 & 16 & 9 & 26 \\
C-OK-R-46 & 6 & 16 & 11 & 26 \\
\hline
\end{tabular}

Figure 15. Graph showing building downtime results in days following the hypothetical moment-magnitude-7.0 mainshock of the HayWired earthquake scenario for all case-study buildings (see table 1).

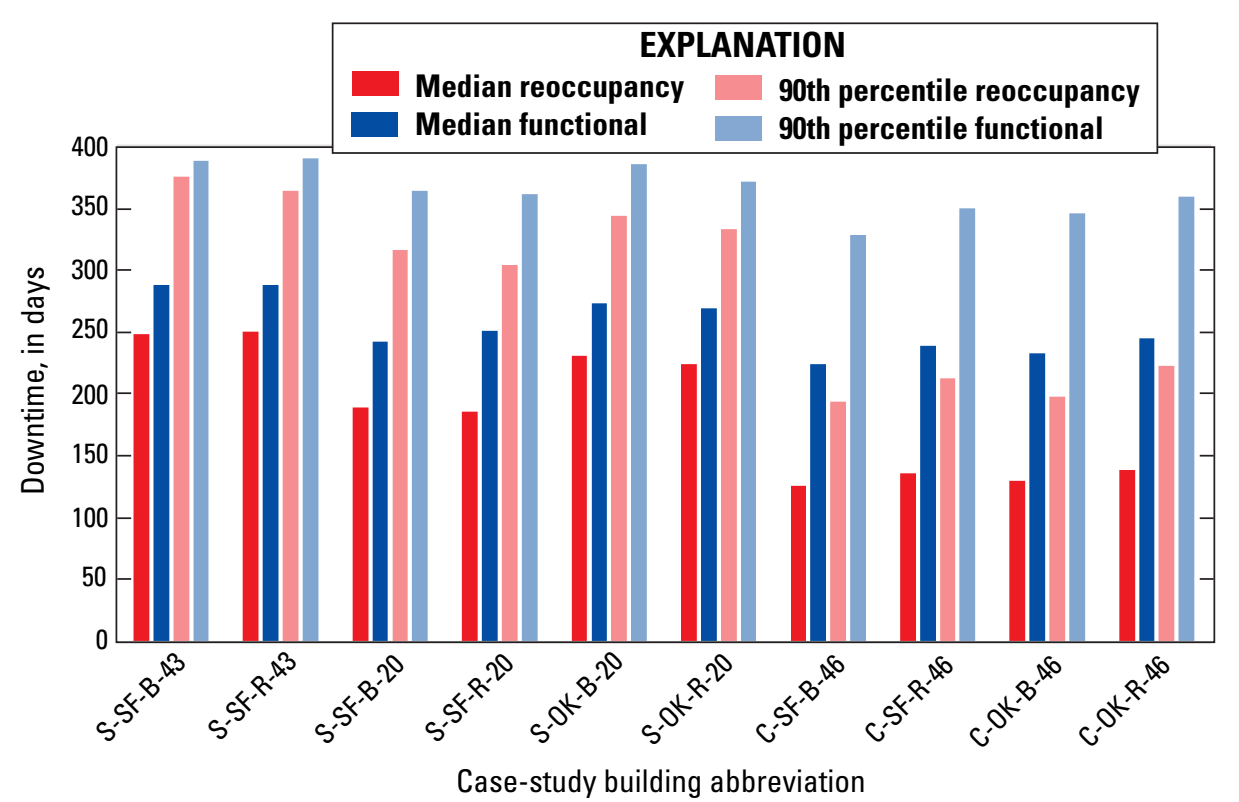


Table 10. Summary of building reoccupancy and functional downtime results following the hypothetical moment-magnitude-7.0 mainshock of the HayWired earthquake scenario for each case-study building (see table 1).

\begin{tabular}{|c|c|c|c|c|}
\hline \multirow[b]{2}{*}{$\begin{array}{l}\text { Case-study building } \\
\text { abbreviation }\end{array}$} & \multicolumn{2}{|c|}{ Median repair time } & \multicolumn{2}{|c|}{ 90th-percentile repair time } \\
\hline & $\begin{array}{c}\text { Reoccupancy, in } \\
\text { days }\end{array}$ & $\begin{array}{c}\text { Functional, in } \\
\text { days }\end{array}$ & $\begin{array}{c}\text { Reoccupancy, in } \\
\text { days }\end{array}$ & $\begin{array}{c}\text { Functional, in } \\
\text { days }\end{array}$ \\
\hline S-SF-B-43 & 248 & 288 & 375 & 388 \\
\hline S-SF-R-43 & 250 & 288 & 364 & 390 \\
\hline S-SF-B-20 & 189 & 242 & 316 & 364 \\
\hline S-SF-R-20 & 186 & 251 & 304 & 361 \\
\hline S-OK-B-20 & 231 & 273 & 344 & 385 \\
\hline S-OK-R-20 & 224 & 269 & 333 & 371 \\
\hline C-SF-B-46 & 126 & 224 & 194 & 328 \\
\hline C-SF-R-46 & 121 & 239 & 213 & 545 \\
\hline C-OK-B-46 & 130 & 233 & 198 & 346 \\
\hline C-OK-R-46 & 139 & 245 & 223 & 359 \\
\hline
\end{tabular}

\section{Conclusion}

This study used state of the art structural analysis and risk assessment to examine tall-building performance in the $M_{\mathrm{w}} 7.0$ mainshock of the HayWired earthquake scenario. It is important to recognize that existing (and new) tall buildings have largely been untested by real earthquakes of this magnitude; thus the analytical methods have not been confirmed. The building-downtime estimates in particular rely on multiple assumptions that have not yet been robustly validated, including:

- The fragility functions and underlying methodology in FEMA P-58 (Applied Technology Council, 2012) are suitable for the purposes of predicting repair time.

- The severity and extent of damage to specified building components are the basis for the type of downtime incurred (that is, reoccupancy, functionality, or full recovery).

- The length of time before repairs can be initiated (that is, impeding factors)

- The time it takes to make repairs (dependent on the availability of laborers and the specific repair sequence schedule).

In many respects, the loss results seem reasonable. The financial losses for the new reinforced-concrete buildings are significantly lower than for the existing steel-frame buildings; the reoccupancy time for the new reinforcedconcrete buildings are roughly half those of the steel-frame buildings; and the losses for buildings located in Oakland are higher than those in San Francisco, primarily due to the much larger ground accelerations for HayWired mainshock in Oakland. However, the time to achieve functional recovery is relatively similar between the new and old buildings, which on the face of it seems suspicious. In studying the results in more detail, this seems plausible as new reinforced-concrete buildings experience higher peak floor accelerations than the steel-frame buildings, causing more nonstructural damage to acceleration-sensitive components that support building functions. Contractor mobilization times, which are dependent on the height of the building and the type and severity of component damage (primarily nonstructural for both building types), are similarly large and govern the total downtime for each building type.

Of course, in the event that the few beam fractures in the steel-frame buildings are observed by an inspector, the estimated downtimes between new and old buildings would significantly widen. This would suggest that just a slightly larger earthquake scenario than that modeled in the HayWired scenario (perhaps at the design level or greater) would pose a greater risk to existing tall steel-frame buildings than new reinforced-concrete tall buildings. In other words, existing and new tall buildings may perform relatively similarly up to a certain seismic demand (that is, before widespread fractures in steel-frame buildings), but the performance would diverge considerably after that point, with the steel-frame buildings more prone to irreparable damage and collapse. This is supported by the high collapse-risk rates of existing tall steel-frame buildings (Molina-Hutt and others, 2016) relative to the code objectives for new tall buildings.

\section{Acknowledgments}

The report was enhanced in response to comprehensive review by Terry Paret (Wiss, Janey, and Eistner Associates, Inc.; WJE), Andrew Shuck (WJE), Tony Yang (University of British Columbia), and Erol Kalkan (USGS). The study was funded by USGS Land Change Science Program (reference number G16PS00702; USGS HayWired Scenario-Tall Building Performance). 


\section{References Cited}

Aagaard, B.T., Boatwright, J.L., Jones, J.L., MacDonald, T.G, Porter, K.A., and Wein, A.M., 2017, HayWired scenario mainshock ground motions, chap. C of Detweiler, S.T., and Wein, A.M., eds., The HayWired earthquake scenarioEarthquake hazards: U.S. Geological Survey Scientific Investigations Report 2017-5013-A-H, 126 p., https://doi. org/10.3133/sir20175013v1.

Aagaard, B.T., Graves, R.W., Rodgers, A., Brocher, T.M., Simpson, R.W., Dreger, D., Petersson, N.A., Larsen, S.C., Ma, S., and Jachens, R.C., 2010, Ground-motion modeling of Hayward Fault scenario earthquakes, part II-Simulation of long-period and broadband ground motions: Bulletin of the Seismological Society of America, v. 100, no. 6, p. 2945-2977, https://doi.org/10.1785/0120090379.

Almufti, I., and Willford, M., 2013, REDi ${ }^{\mathrm{TM}}$ rating systemResilience-based earthquake design initiative for the next generation of buildings (version 1.0): Arup, Ltd., 68 p., accessed February 8, 2018, at http://usrc.org/files/technicalresource/ REDi_Final\%20Version\%201.0_October\%202013.pdf.

American Society of Civil Engineers, 2010, Minimum design loads for buildings and other structures: Reston, Va., American Society of Civil Engineers, ASCE/SEI 7-10, 608 p.

American Society of Civil Engineers, 2014, Seismic evaluation and retrofit of existing buildings: Reston, Va., American Society of Civil Engineers, ASCE/SEI 41-13, 518 p., https://doi. org/10.1061/9780784412855.

Applied Technology Council, 2012, Seismic performance assessment of buildings, including PACT software and background documents: Federal Emergency Management Agency, FEMA P-58, v. 1-3, accessed January 31, 2018, https:// www.fema.gov/media-library/assets/documents/90380.

ASTM International, 2014, ASTM A36/A36M-14, Standard specification for carbon structural steel: West Conshohocken, Pa., ASTM International, https://doi.org/10.1520/A0036 A0036M-14.

ASTM International, 2015, ASTM A572/A572M-15, standard specification for high-strength low-alloy columbium-vanadium structural steel: West Conshohocken, Pa., ASTM International, https://doi.org/10.1520/A0572_A0572M-15.

Bonowitz, D., and Maison, B., 2003, Northridge welded steel-moment-frame damage data and its use for rapid loss estimation: Earthquake Spectra, v. 19, no. 2, p. 335-364.

Charette, R.P., and Marshall, H.E., 1999, UNIFORMAT II elemental classification for building specifications, cost estimating, and cost analysis: U.S. Department of Commerce, National Institute of Standards Technology Interagency Report 6389, 109 p., accessed March 12, 2018, at https://arc-solutions. org/wp-content/uploads/2012/03/Charette-Marshall-1999UNIFORMAT-II-Elemental-Classification....pdf.
Federal Emergency Management Agency, 2012, Hazus multihazard loss estimation methodology, earthquake model, Hazus ${ }^{\circledR}-\mathrm{MH} 2.1$ technical manual: Federal Emergency Management Agency, Mitigation Division, accessed July 18, 2017, 718 p., at https://www.fema.gov/media-librarydata/20130726-1820-25045-6286/hzmh2_1_eq_tm.pdf.

International Conference of Building Officials, 1973, Uniform Building Code: Whittier, Calif., International Conference of Building Officials, 700 p., accessed January 31, 2018, at http://digitalassets.lib.berkeley.edu/ubc/UBC_1973.pdf.

Livermore Software Technology Corporation, 2009, LSDYNA keyword user's manual-Volume 1 (ver. 971, release 4 beta): Livermore, Calif., Livermore Software Technology Corporation, 2435 p., accessed January 31, 2018, at http://www.dynasupport.com/manuals/ls-dynamanuals/LS-DYNA_971_R4_manual_k-beta-June2009.pdf.

Moehle, J., Bozorgnia, Y., Jayaram, N., Jones, P., Rahnama, M., Shome, N., Tuna, Z., Wallace, J., Yang, T., and Zareian, F., 2011, Case studies of the seismic performance of tall buildings designed by alternative means, task 12 report for the Tall Buildings Initiative: Berkeley, Calif., Pacific Earthquake Engineering Research Center, University of California, no. 2011/05, 596 p., accessed January 31, 2018, at https://peer.berkeley.edu/publications/peer_reports/ reports_2011/webPEER-2011-05-TBI_Task12.pdf.

Molina Hutt, C., 2017, Risk-based seismic performance assessment of existing tall steel framed buildings: London, UK., University College London, Ph.D. dissertation, 438 p., accessed February 28, 2018, at http://discovery. ucl.ac.uk/10040499/7/Molina\%20Hutt_10040499_thesis_ redacted.pdf.

Molina-Hutt, C., Deierlein, G., Almufti, I., and Willford, M., 2015, Risk-based seismic performance assessment of existing tall steel-framed buildings in San Francisco: Society for Earthquake and Civil Engineering Dynamics, 2015 Conference-Earthquake Risk and Engineering Towards a Resilient World, July 9-10, 2015, Cambridge, U.K., 11 p., accessed January 31, 2018, at http://www. seced.org.uk/images/newsletters/MOLINA \%20HUTT, \%20 DEIERLEIN,\%20ALMUFTI,\%20WILLFORD.pdf.

Molina-Hutt, C., Ibrahim, A., Willford, M., and Deierlein, G., 2016, Seismic loss and downtime assessment of existing tall steel-framed buildings and strategies for increased resilience: Journal of Structural Engineering, v. 142, no. 8, https://doi.org/10.1061/(ASCE)ST.1943541X.0001314.

Naish, D., Wallace, J.W., Fry, J.A., and Klemencic, R., 2009, Experimental evaluation and analytical modeling of ACE 318-05/08 reinforced concrete coupling beams subjected to reversed cyclic loading: University of California at Los Angeles, Structural and Geotechnical Engineering Laboratory, report 2009-06, 109 p. 
SAC Joint Venture, 2000, Recommended Post-Earthquake Evaluation and Repair Criteria for Welded Steel Moment Frame Buildings: Federal Emergency Management Agency, FEMA-352, 200 p., accessed January 31, 2018, at https://www.fema.gov/medialibrary-data/20130726-1444-20490-4440/fema-352.pdf.

Structural Engineers Association of California, 1973, Recommended lateral force requirements and commentary: Sacramento, Calif., Structural Engineers Association of California.

Structural Engineers Association of Northern California, 2003, Building occupancy resumption program (BORP): Structural Engineers Association of Northern California, accessed February 28, 2018, at http://sfdbi. org/borp-guidelines-engineers.
TBI Guidelines Working Group, 2010, Tall Buildings InitiativeGuidelines for performance-based seismic design of tall buildings (ver. 1.0): Berkeley, Calif., Pacific Earthquake Engineering Research Center, University of California, no. 2010/05, 104 p., accessed January 31, 2018, at http://peer.berkeley.edu/publications/peer reports/reports_2010/web_PEER2010_05_GUIDELINES.pdf.

Tipler, J.F., 2014, Seismic resilience of tall buildings—benchmarking performance and quantifying improvements: Stanford University master's thesis, 91 p., accessed January 30, 2018, at https:// stacks.stanford.edu/file/druid:xh842sm8488/Thesis\%20Final\%20 Jennisie\%20Tipler-augmented.pdf.

Yang, T.Y., Moehle, J., Stojadinovic, B., and Der Kiureghian, A., 2009, Performance evaluation of structural systems-Theory and implementation: Journal of Structural Engineering, v. 135, no. 10, p. 1146-1154.

\section{Appendix 1. Building Structural and Nonstructural Components}

The tables below list the following information for the three building archetypes in the baseline orientation (40-story steelframe building, 20-story steel-frame building, and reinforcedconcrete building):

- Component quantities.

- Component National Institute of Standards and Technology Interagency Reports (NISTIR) fragility classification number (shown as "NISTIR" in tables).

- Component units, as specified by the NISTIR fragility.

- The source of the component quantity; sources are:

- The building design (for example, counting explicitly the number of base plates in the building design).

- National Institute of Standards and Technology (NIST) Normative Quantity estimation tool packaged with FEMA's Performance Assessment
Calculation Tool (PACT; see Applied Technology Council, 2012) (marked as simply "Norm Qty" in the tables).

- Moehle and others (2011), which documents the original structural design of reinforced concrete building before the San Francisco redesign by Tipler (2014).

- Arup estimator.

- Component medians and dispersions for each damage state.

Tables 11-13 show structural components for each archetype building (40-story steel-frame building, 20-story steel-frame building, and reinforced-concrete building, respectively). Tables 14-16 show nonstructural components for each building type. Components for buildings with rotated orientation are generally the same as listed below, but with the east-west and north-south quantities flipped. 


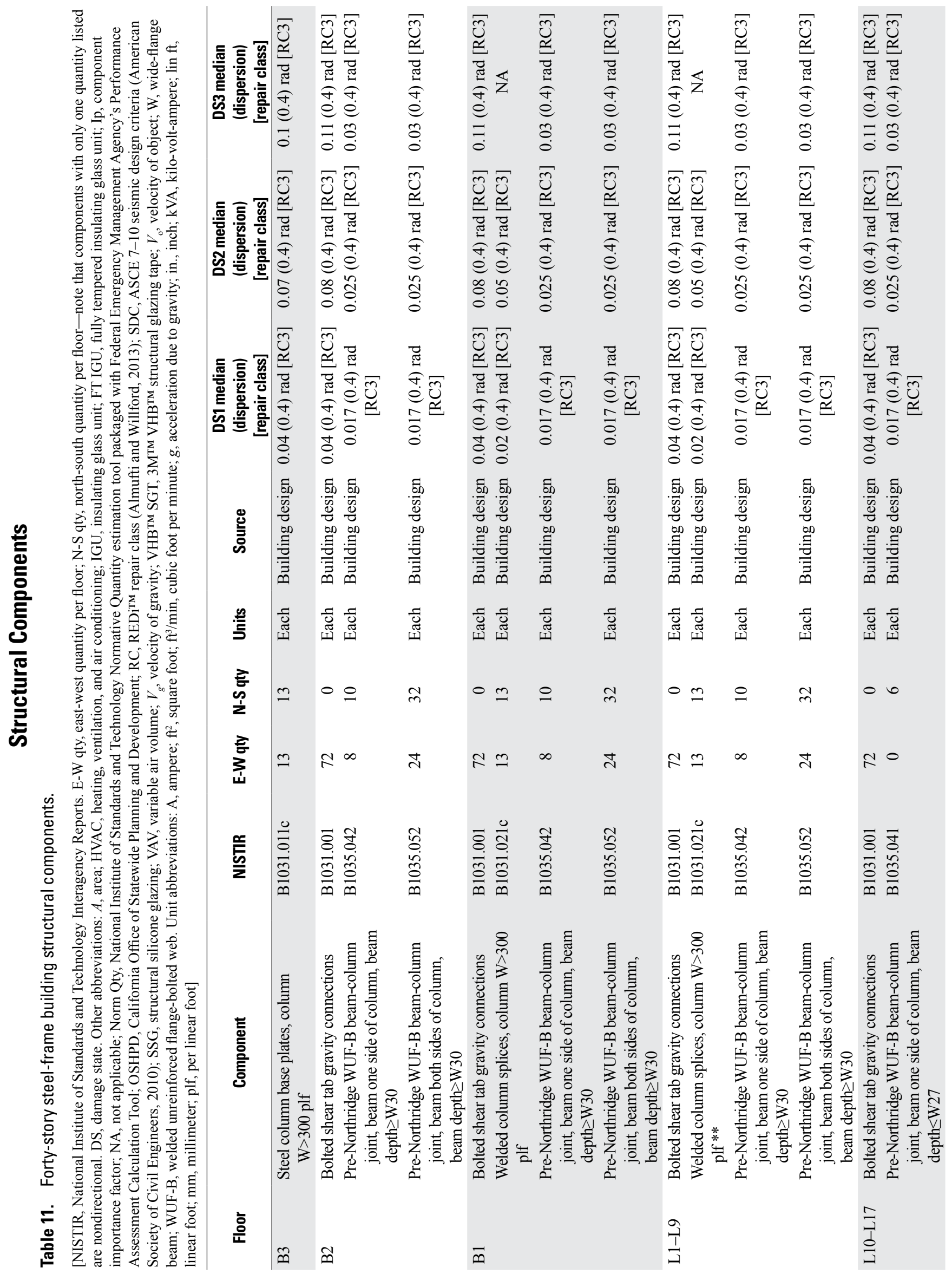




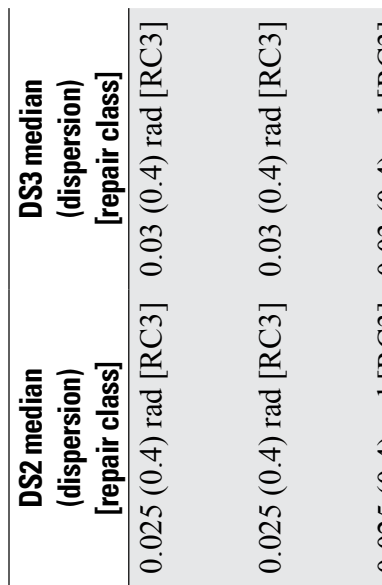

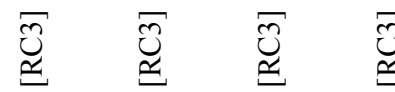

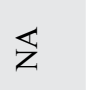

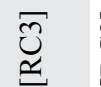

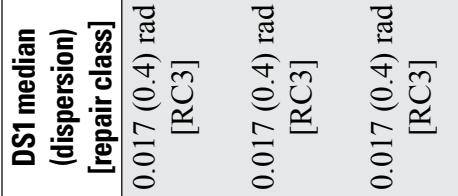

అृ

\section{苐}

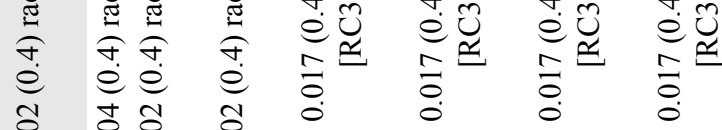

胥

¿.

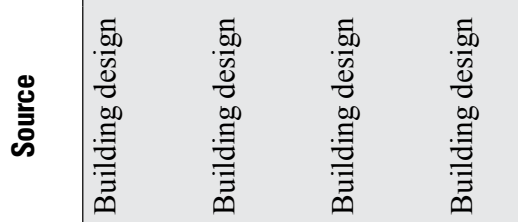

旁

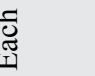

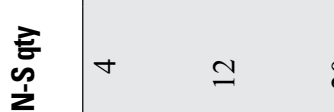

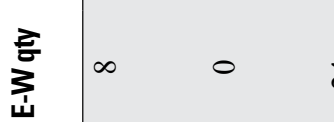

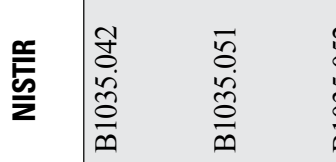

है

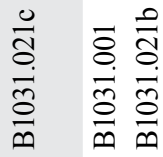

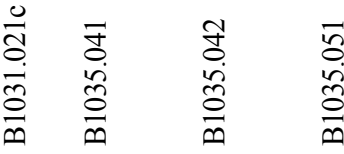

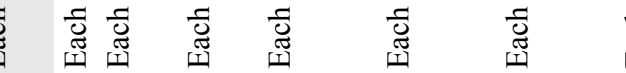

总
そֶ

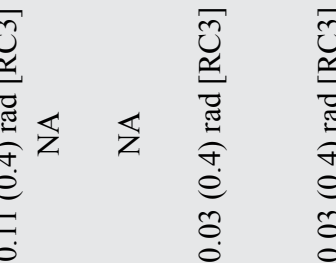

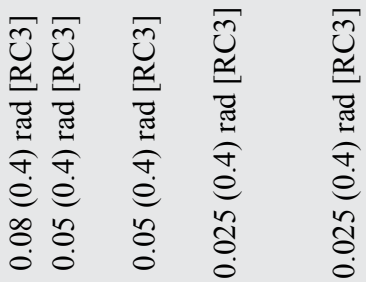

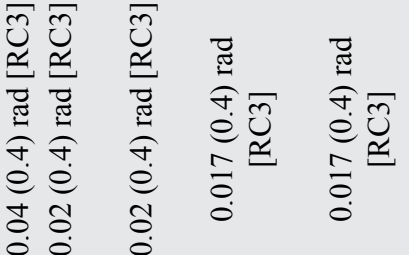

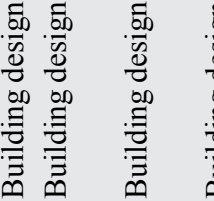

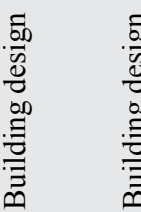

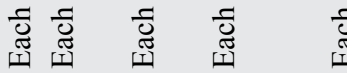

$0 \infty$ in 0

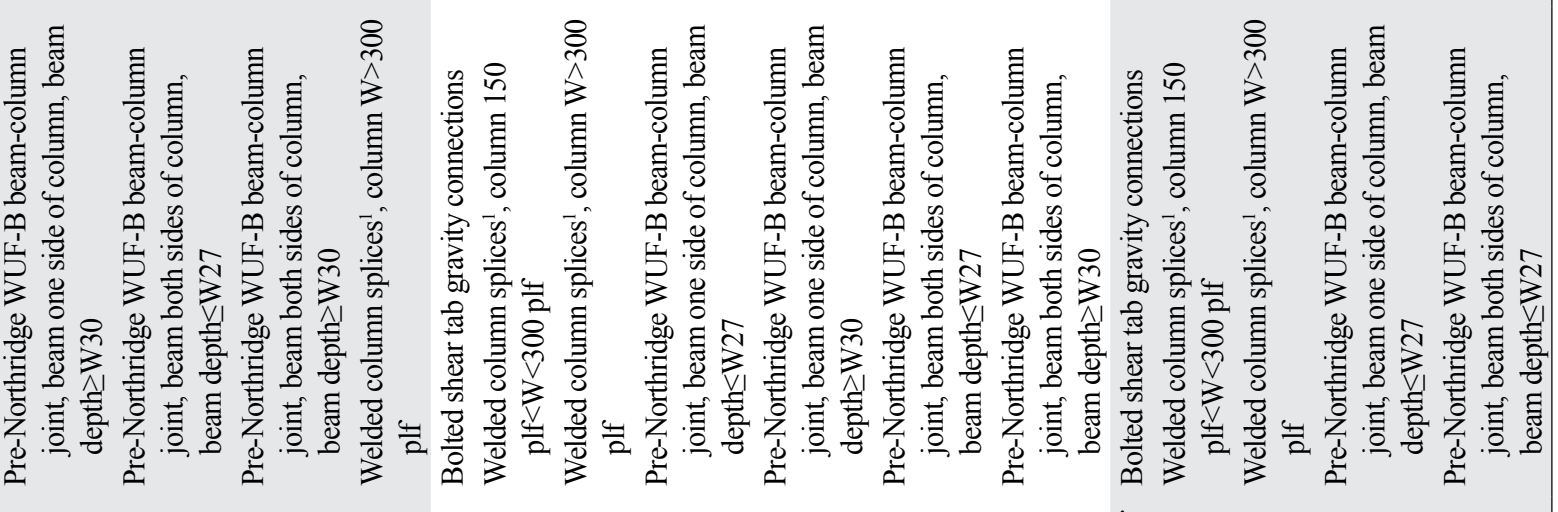




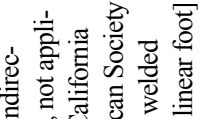

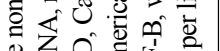

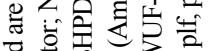

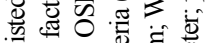

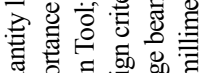

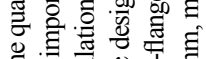

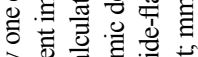

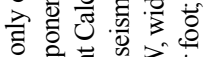

ह है चै

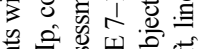

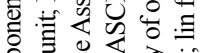

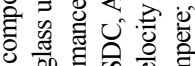

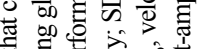

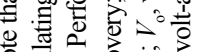

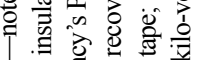

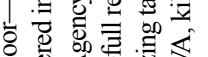

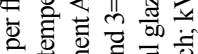

党焉

还

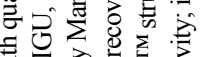

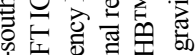

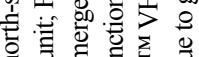

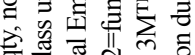

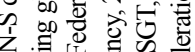

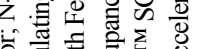

. क्ष

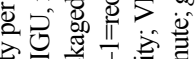

bo 0

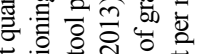

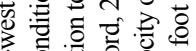

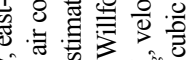

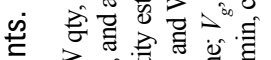

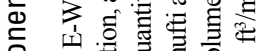

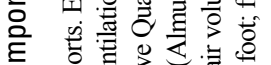

a

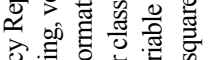

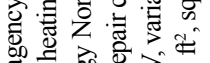

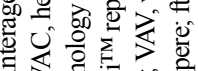

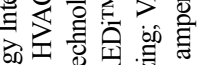

然

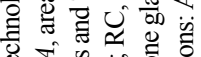

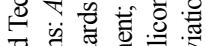

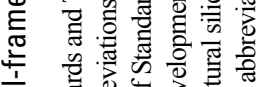

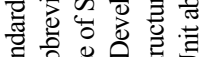

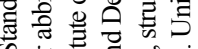

¿

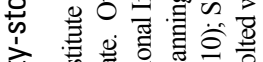

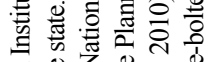

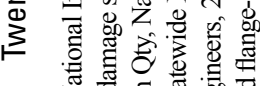

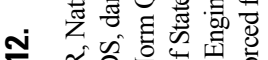

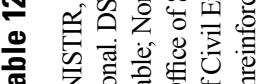

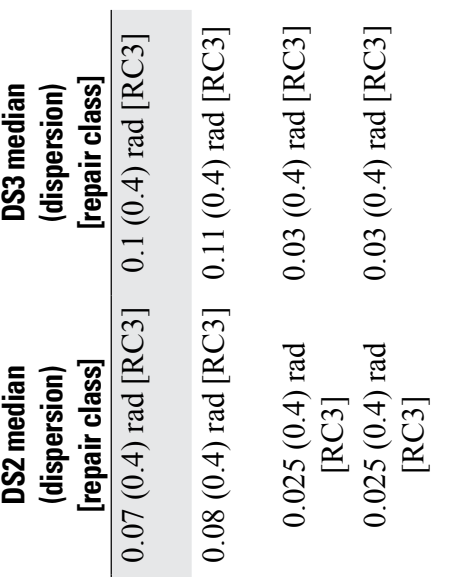

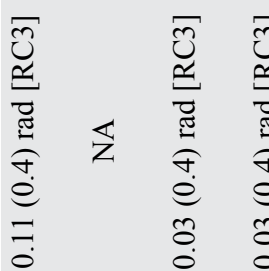

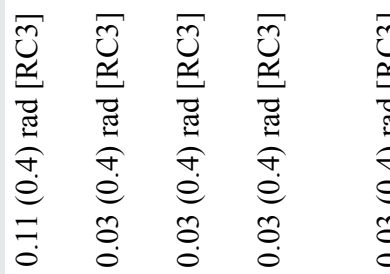

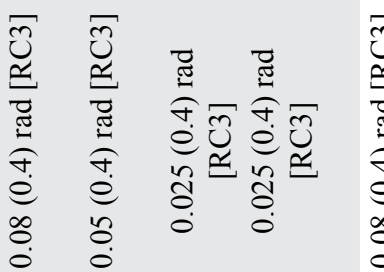

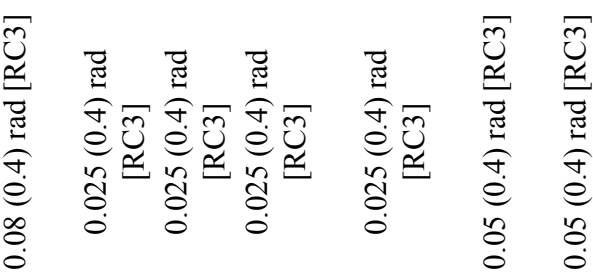

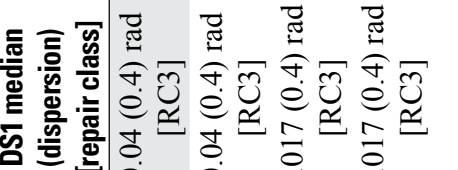

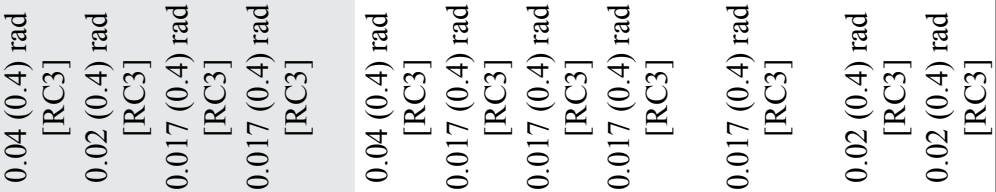

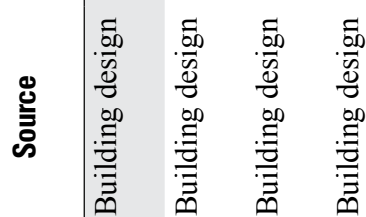

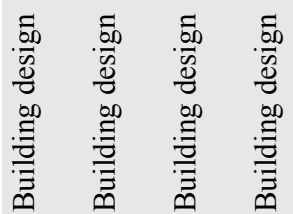

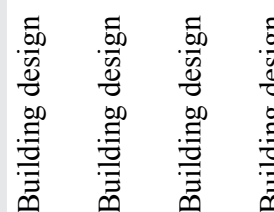

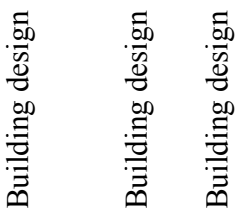

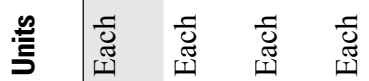

芯

这

造

卷 $\quad \frac{5}{0} \quad \overline{0}$

m $m$ m 0 क

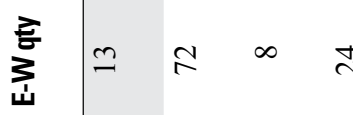

$\stackrel{2}{\infty} \stackrel{4}{\sim}$

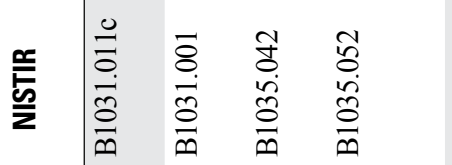

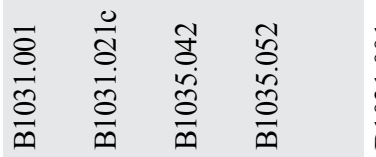

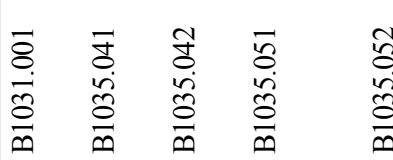

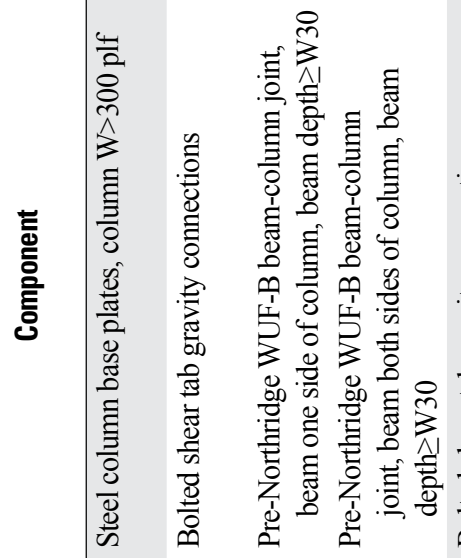

(2)

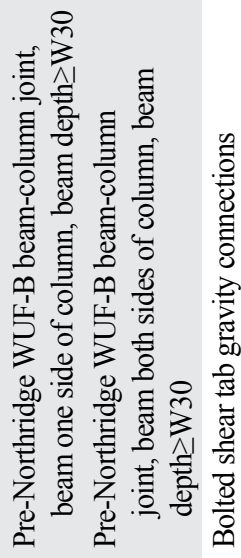

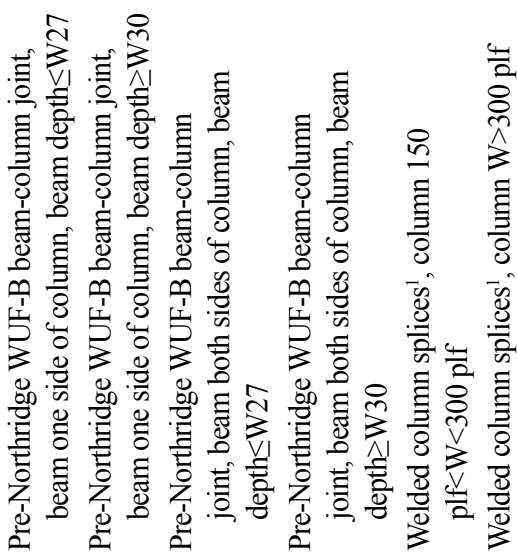

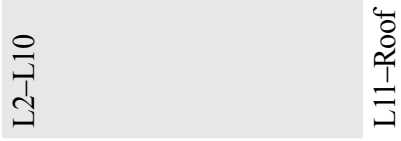

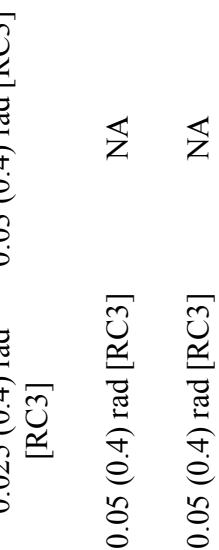




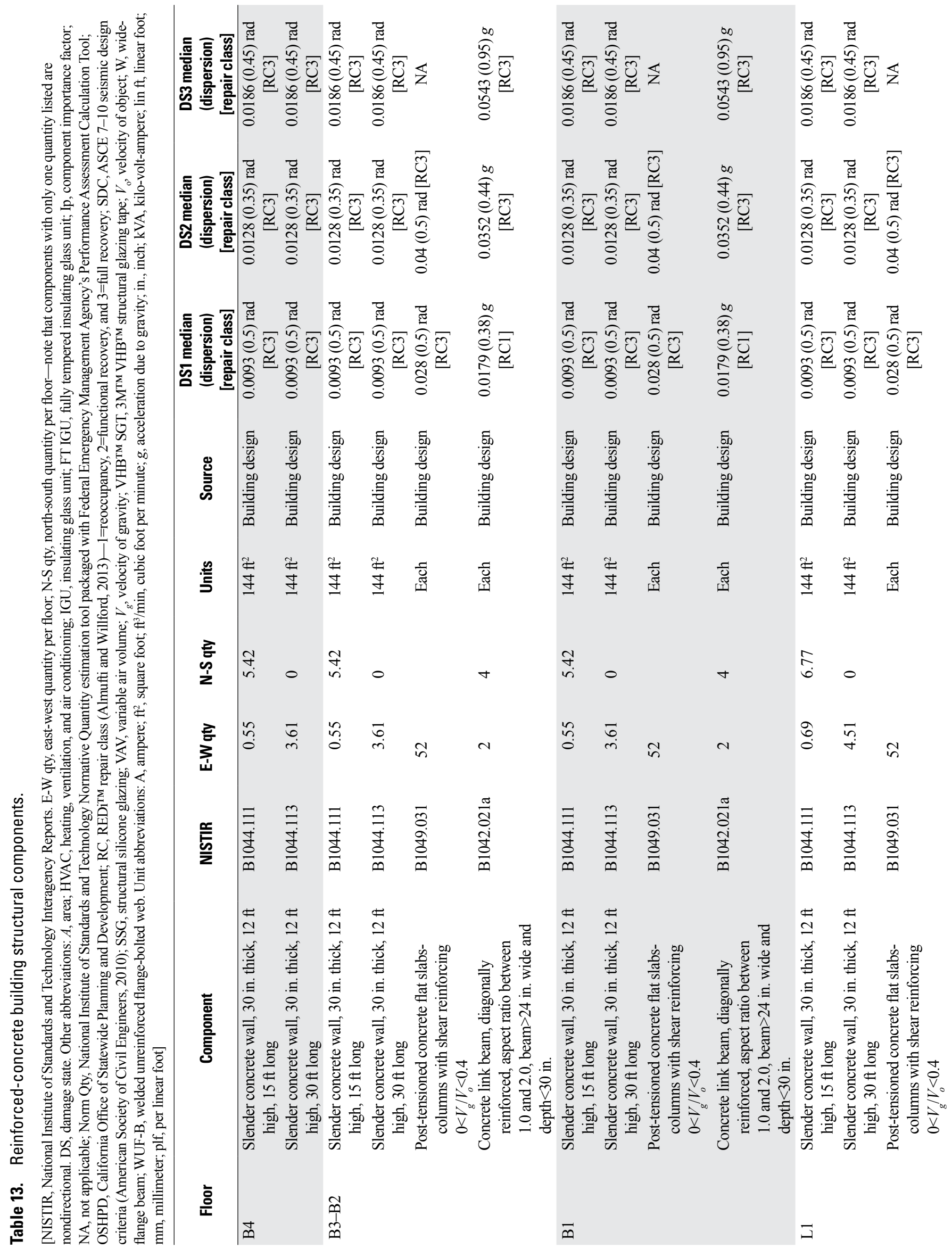




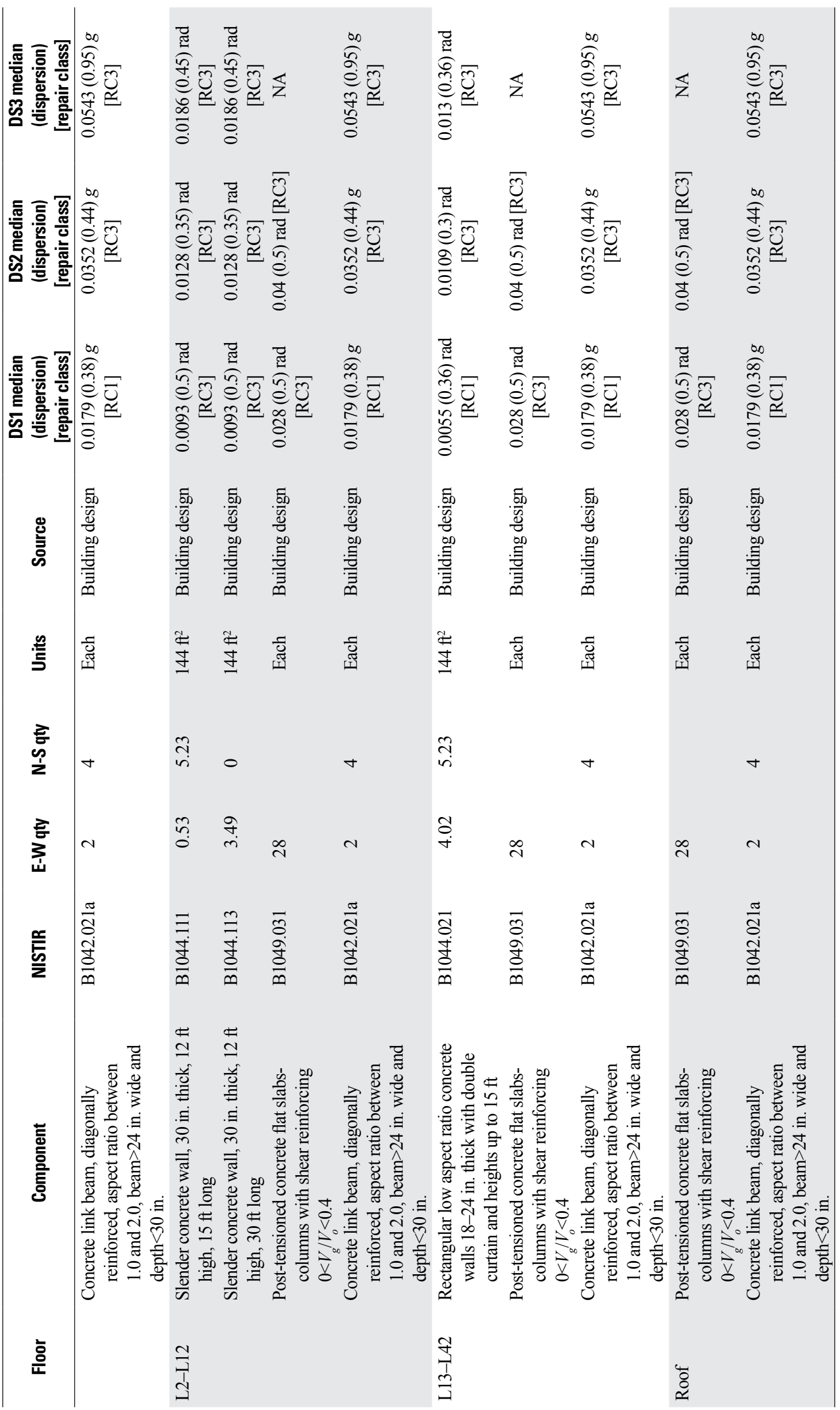




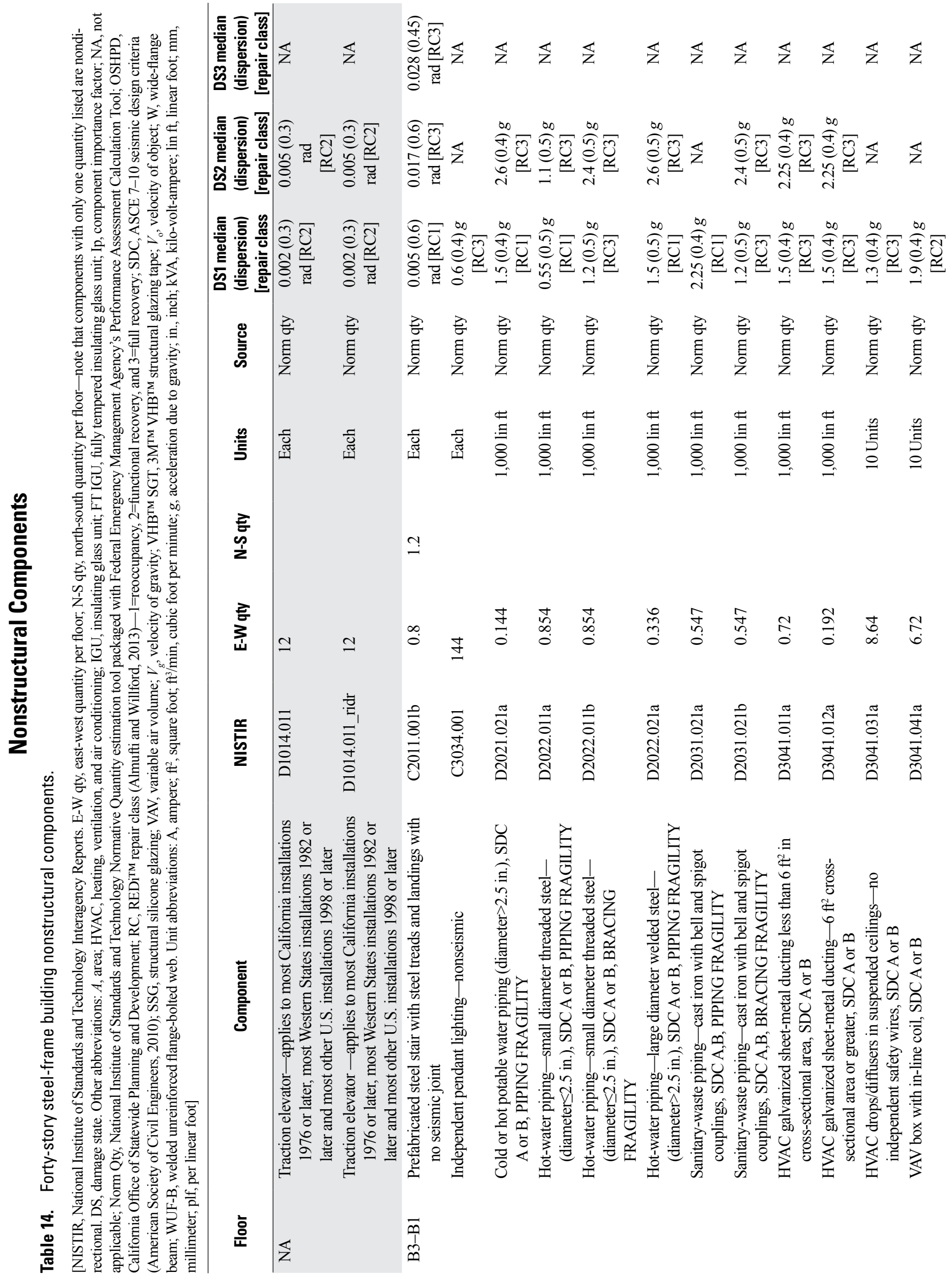




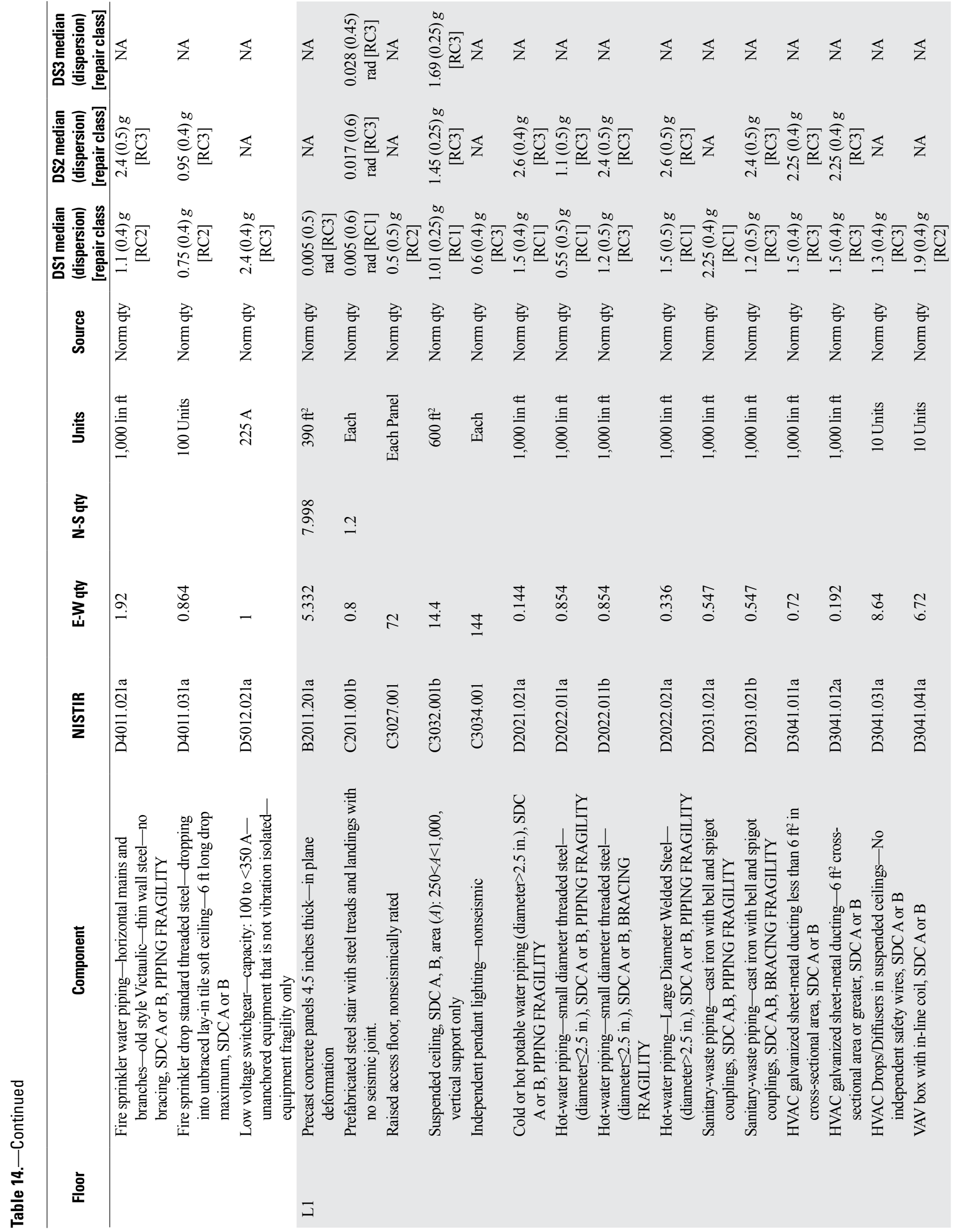




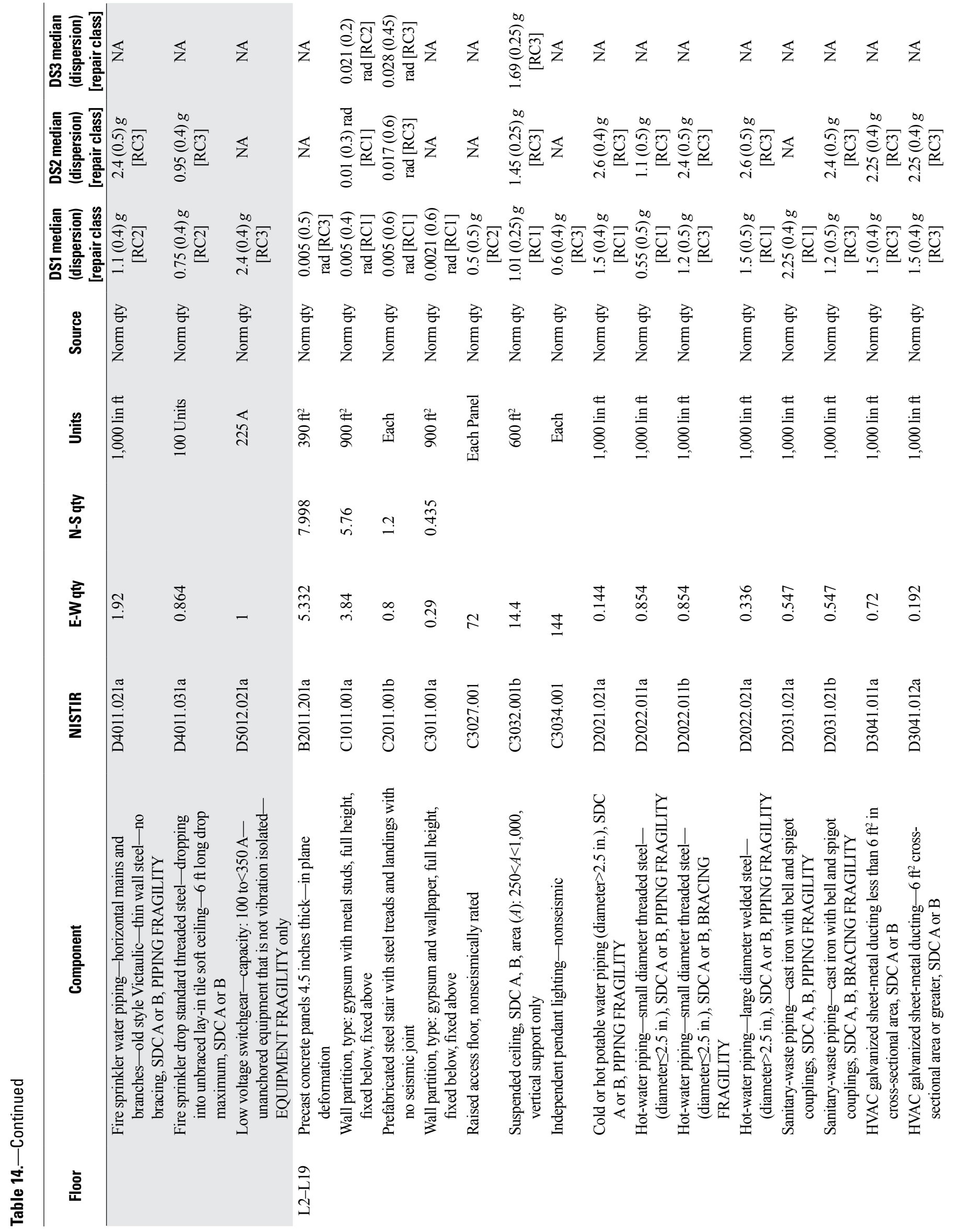




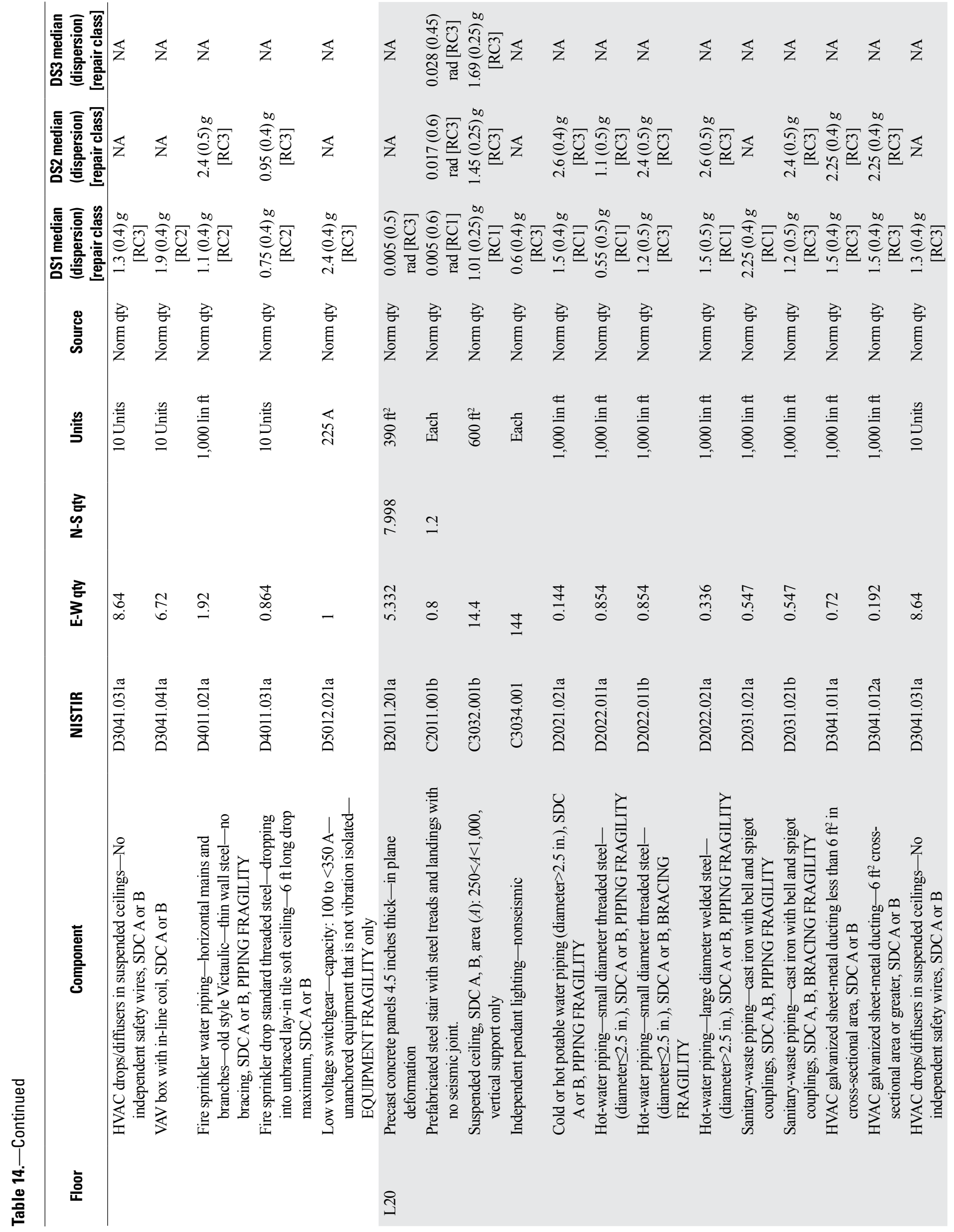




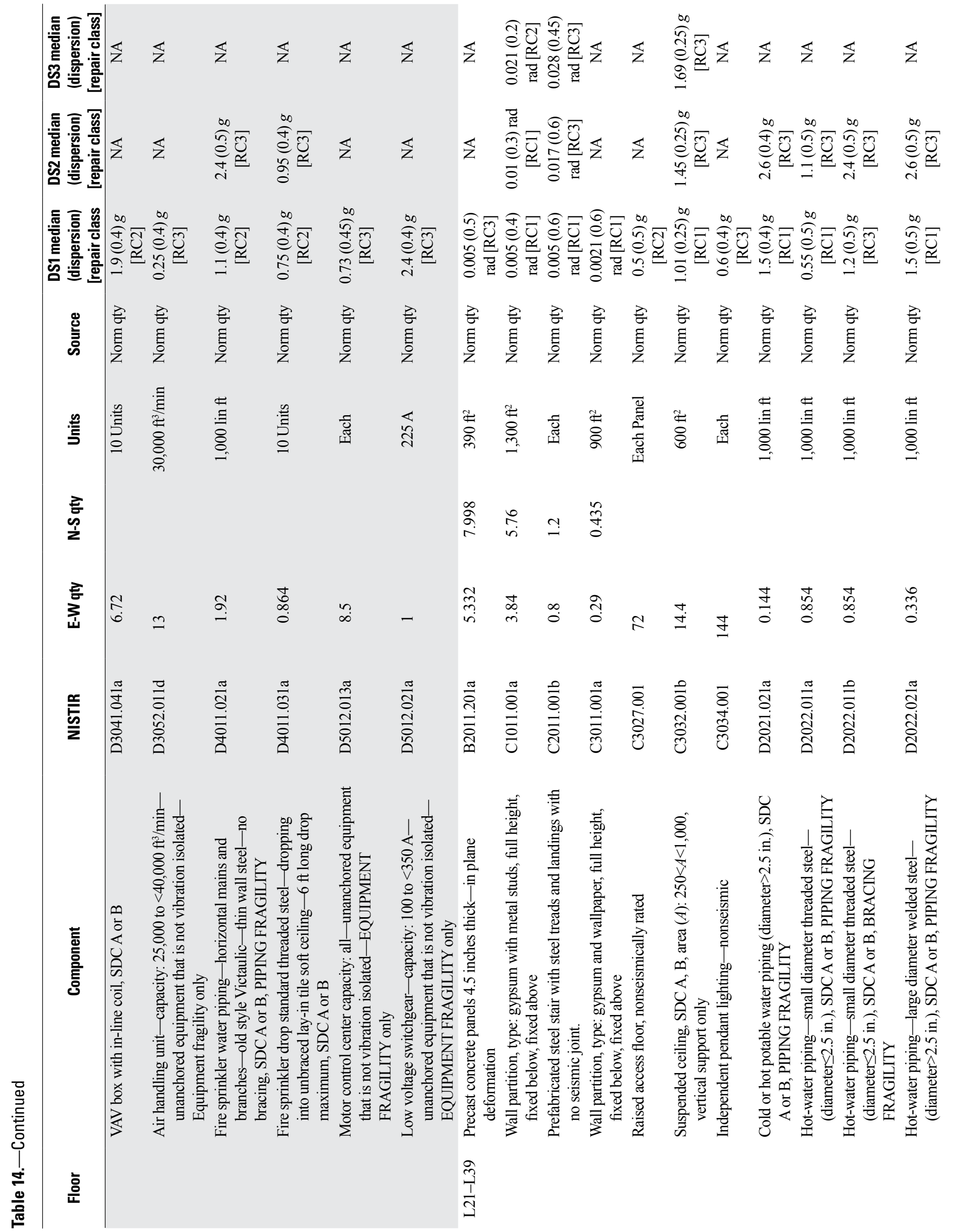




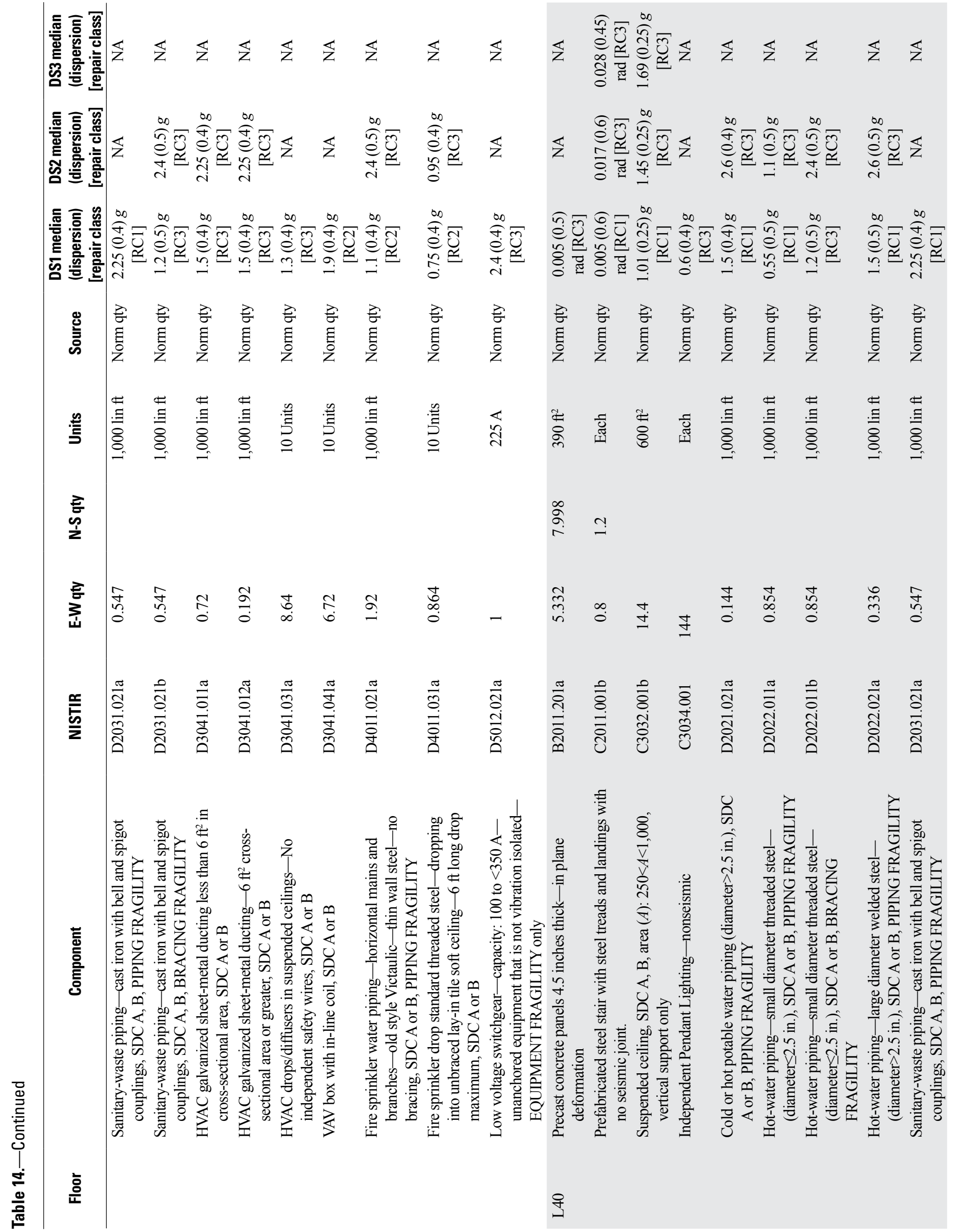




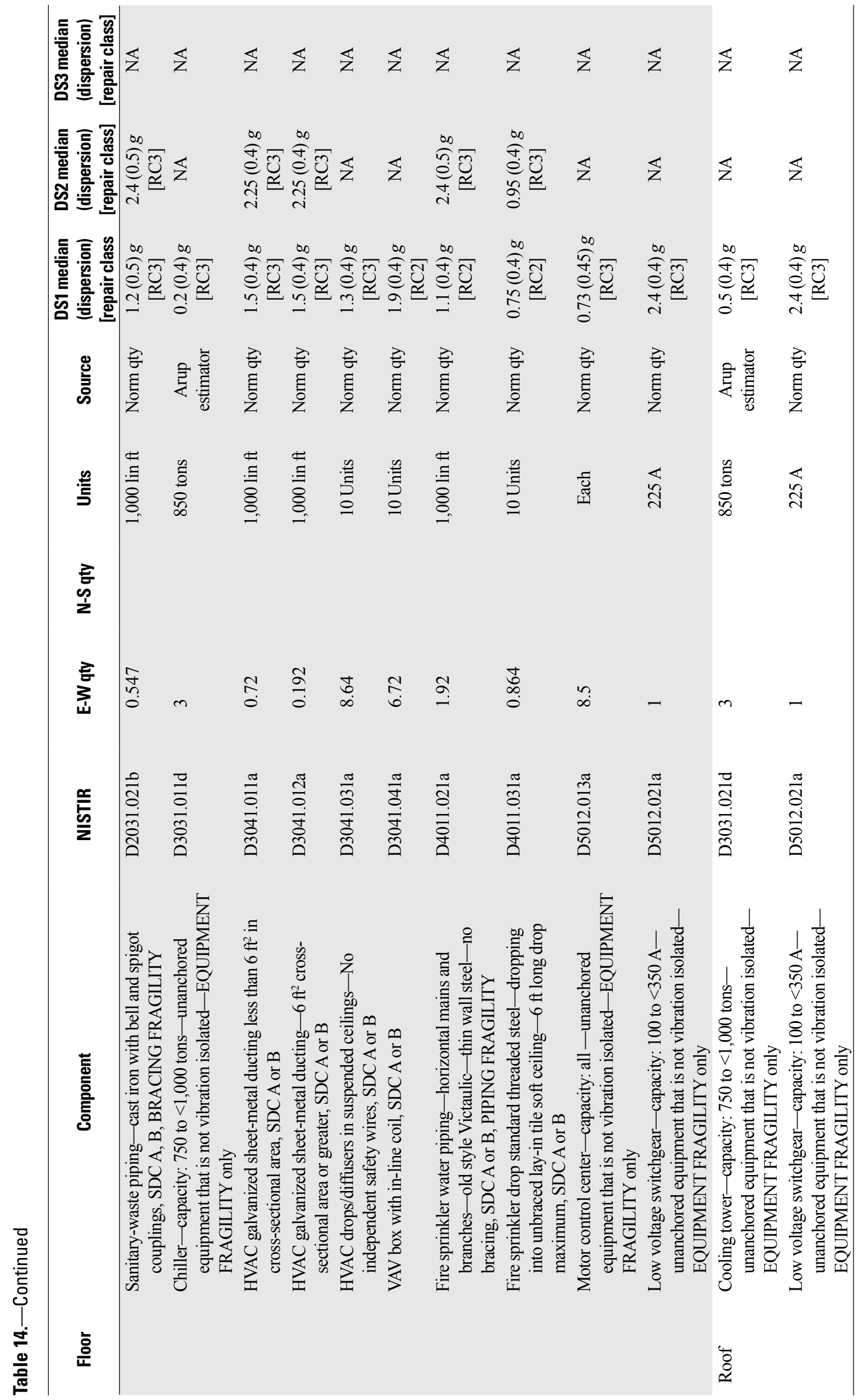




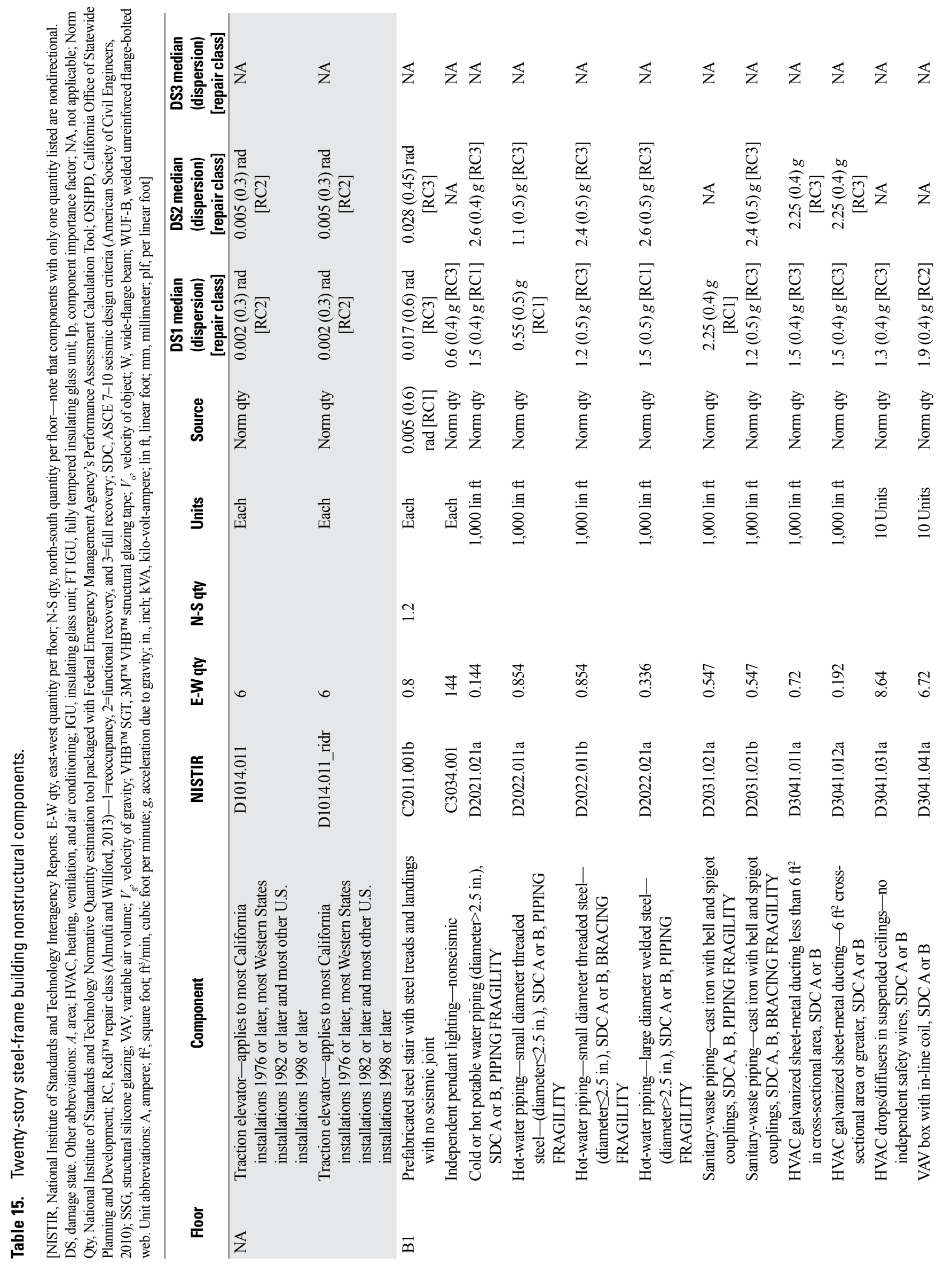




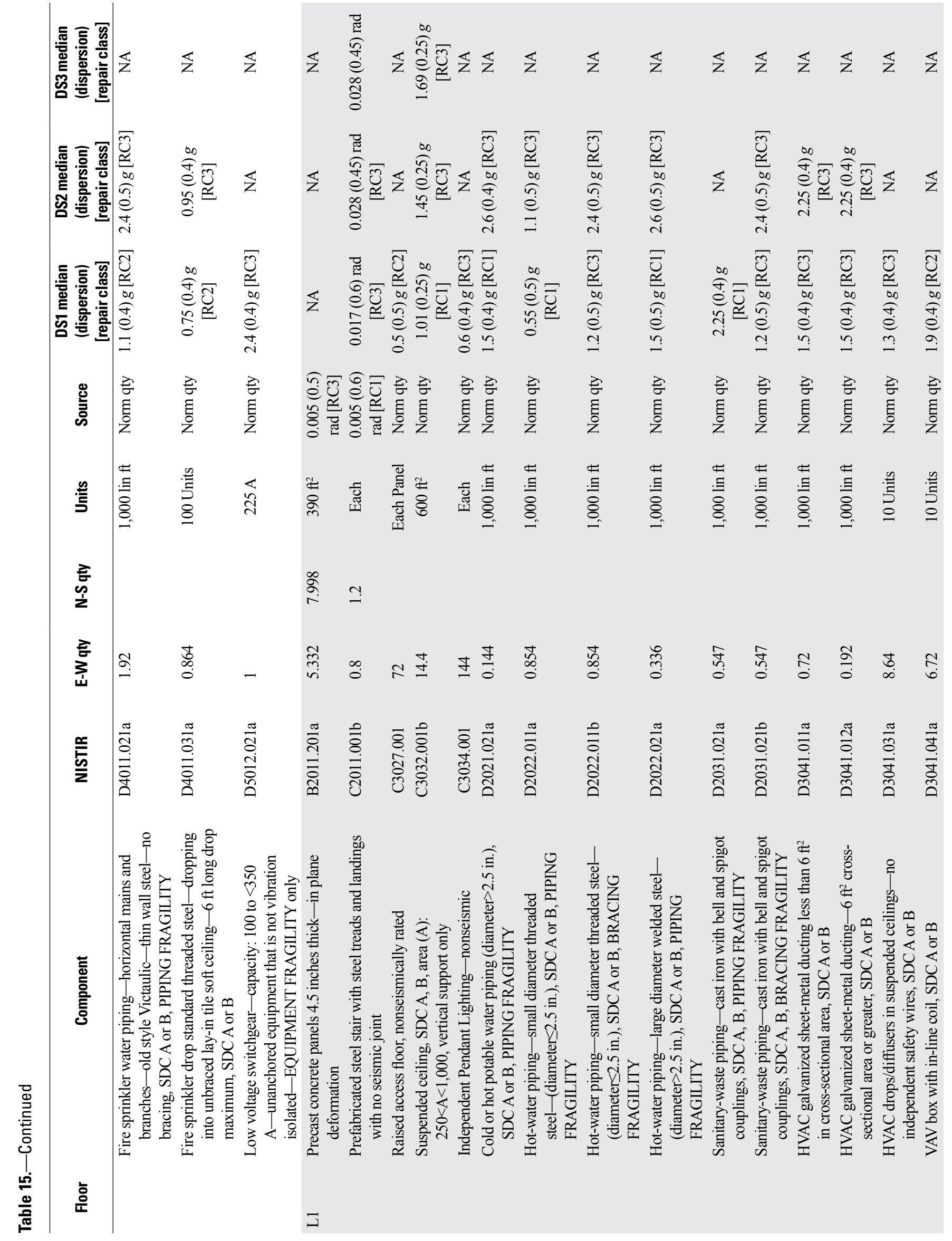




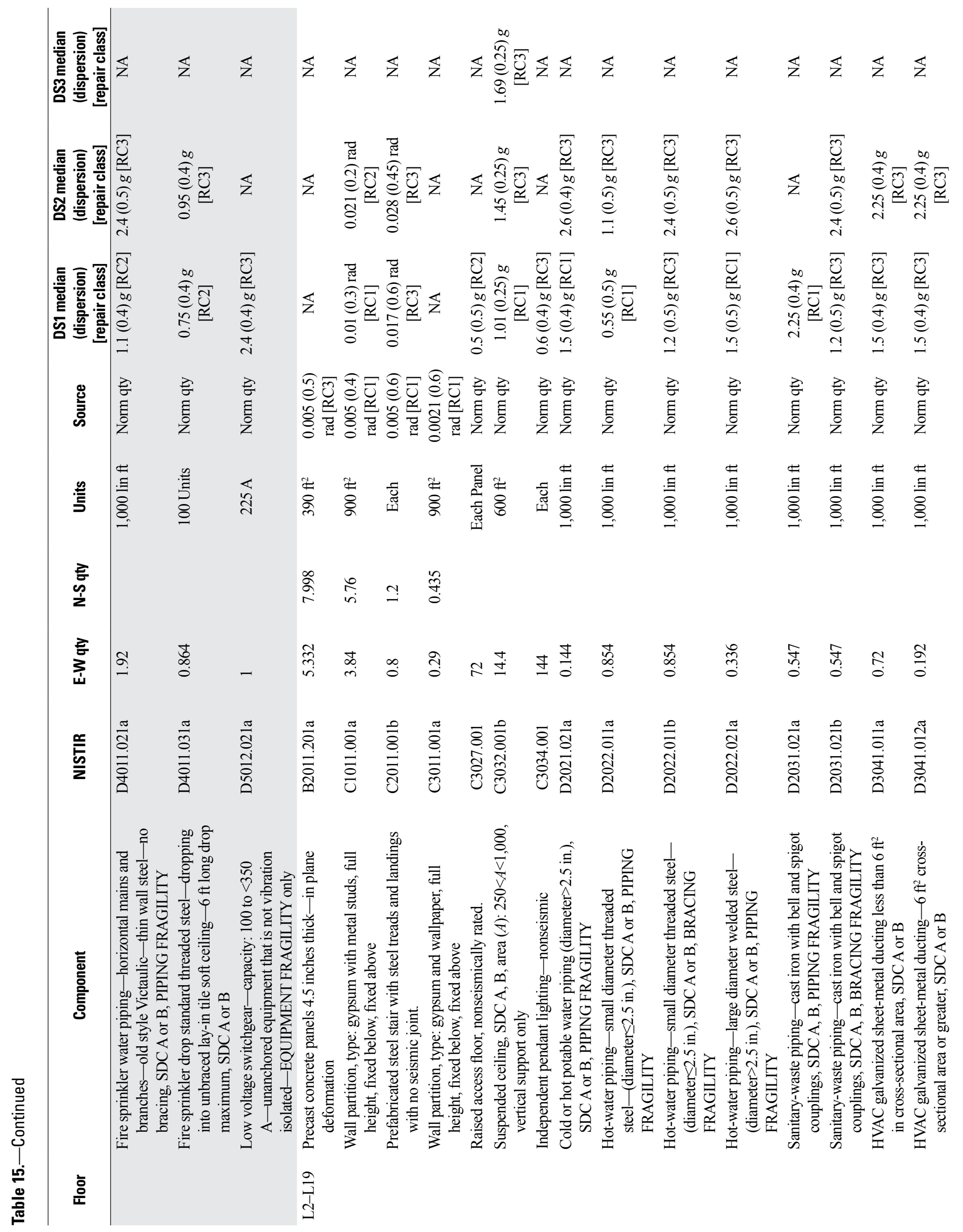




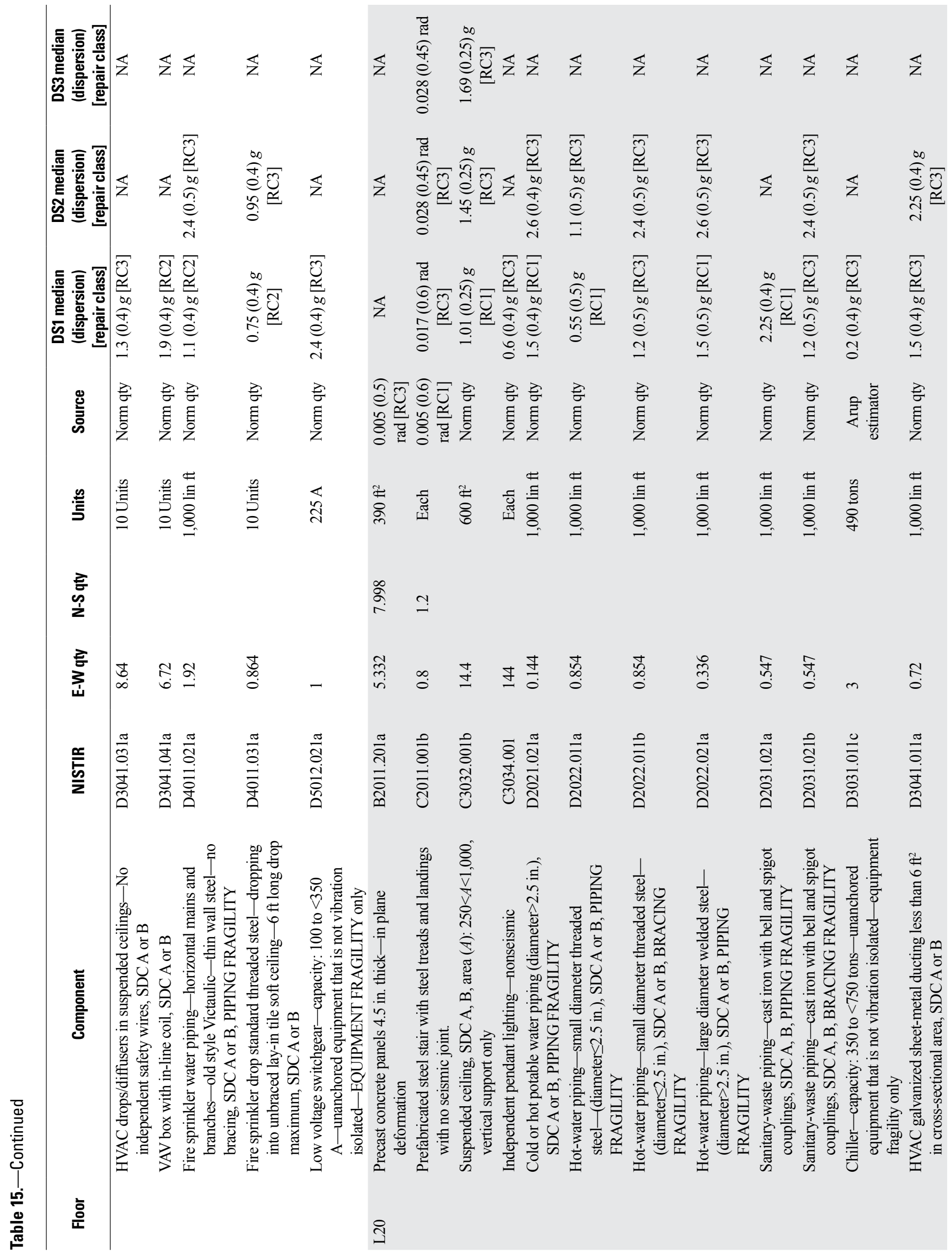




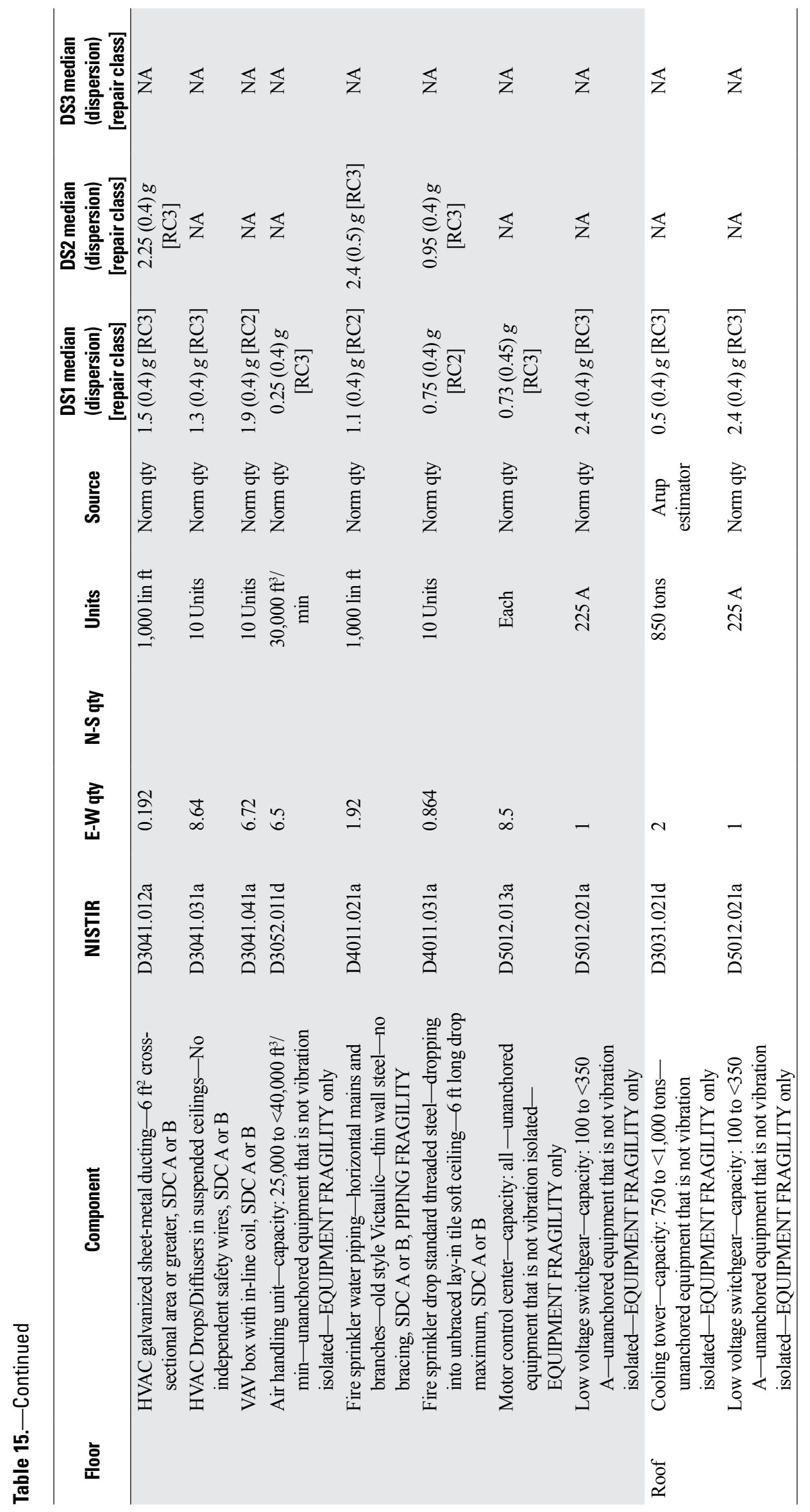




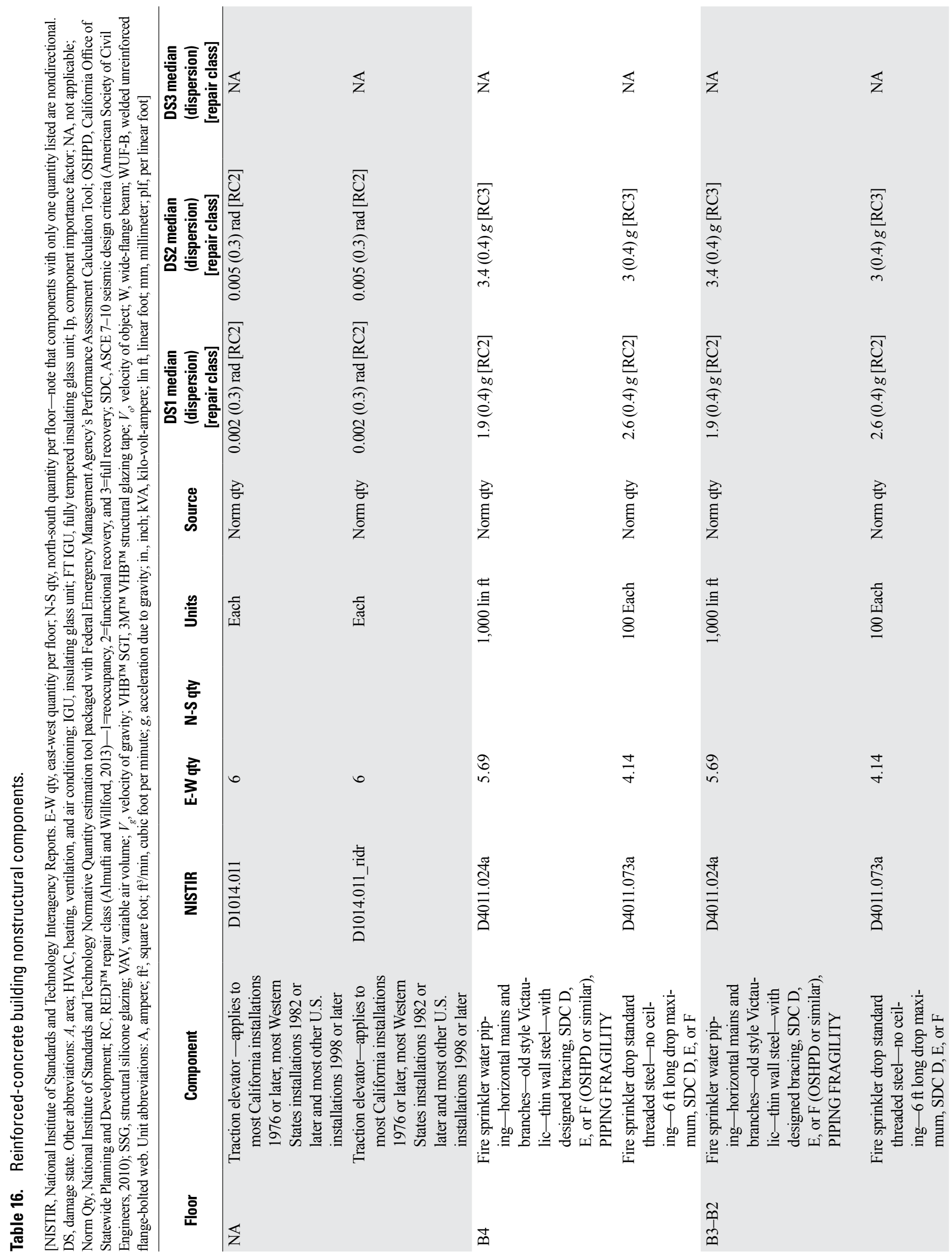




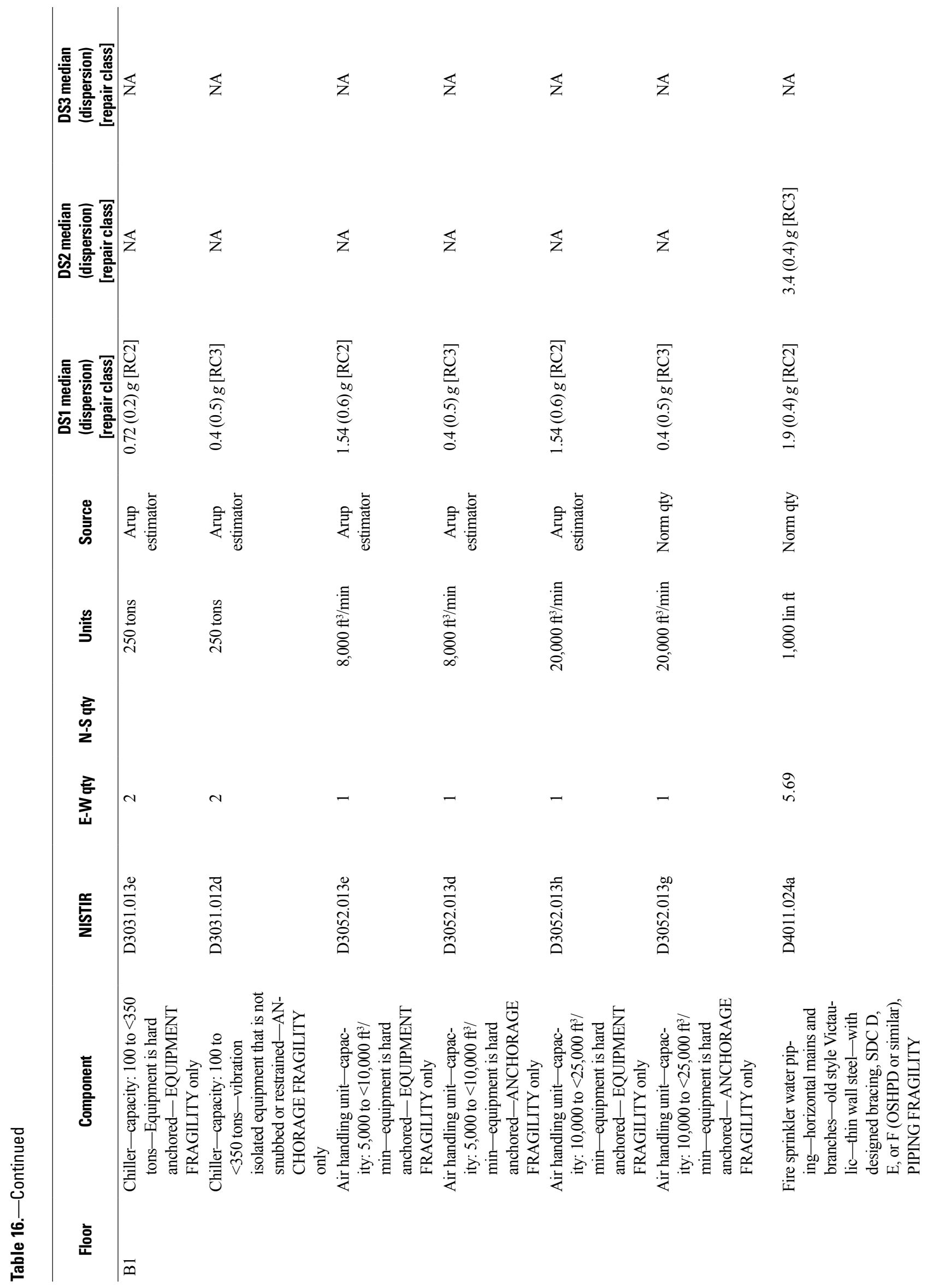




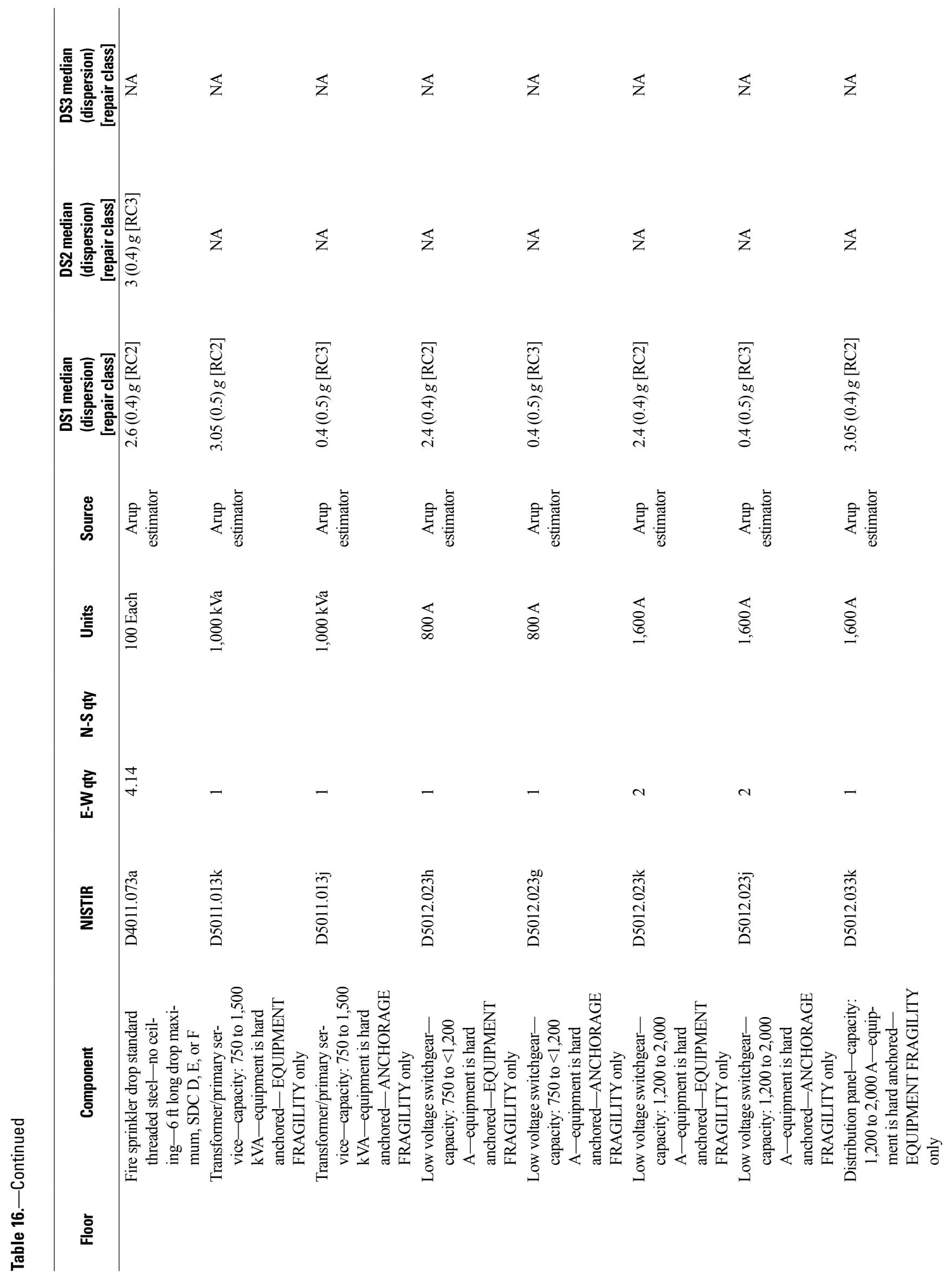




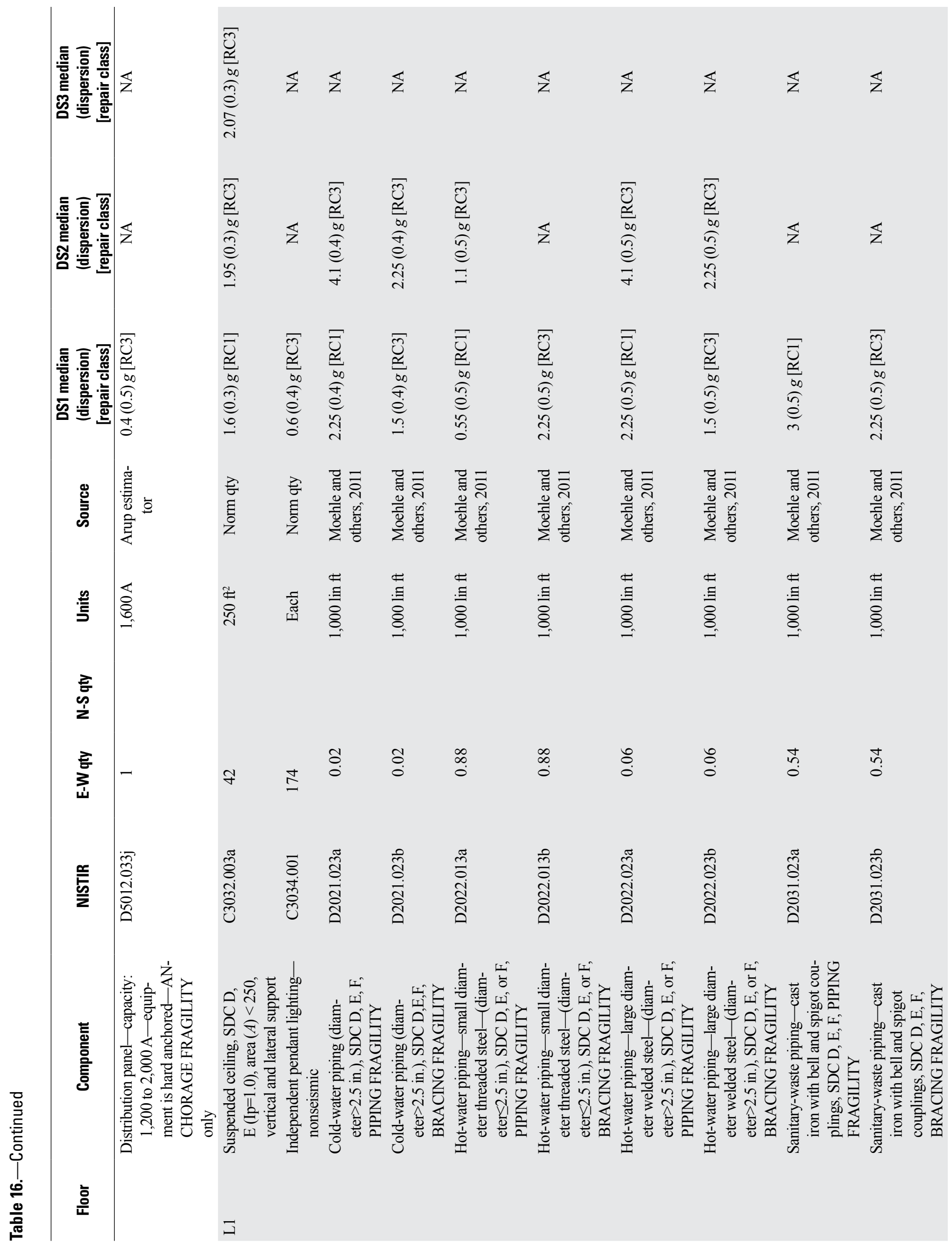




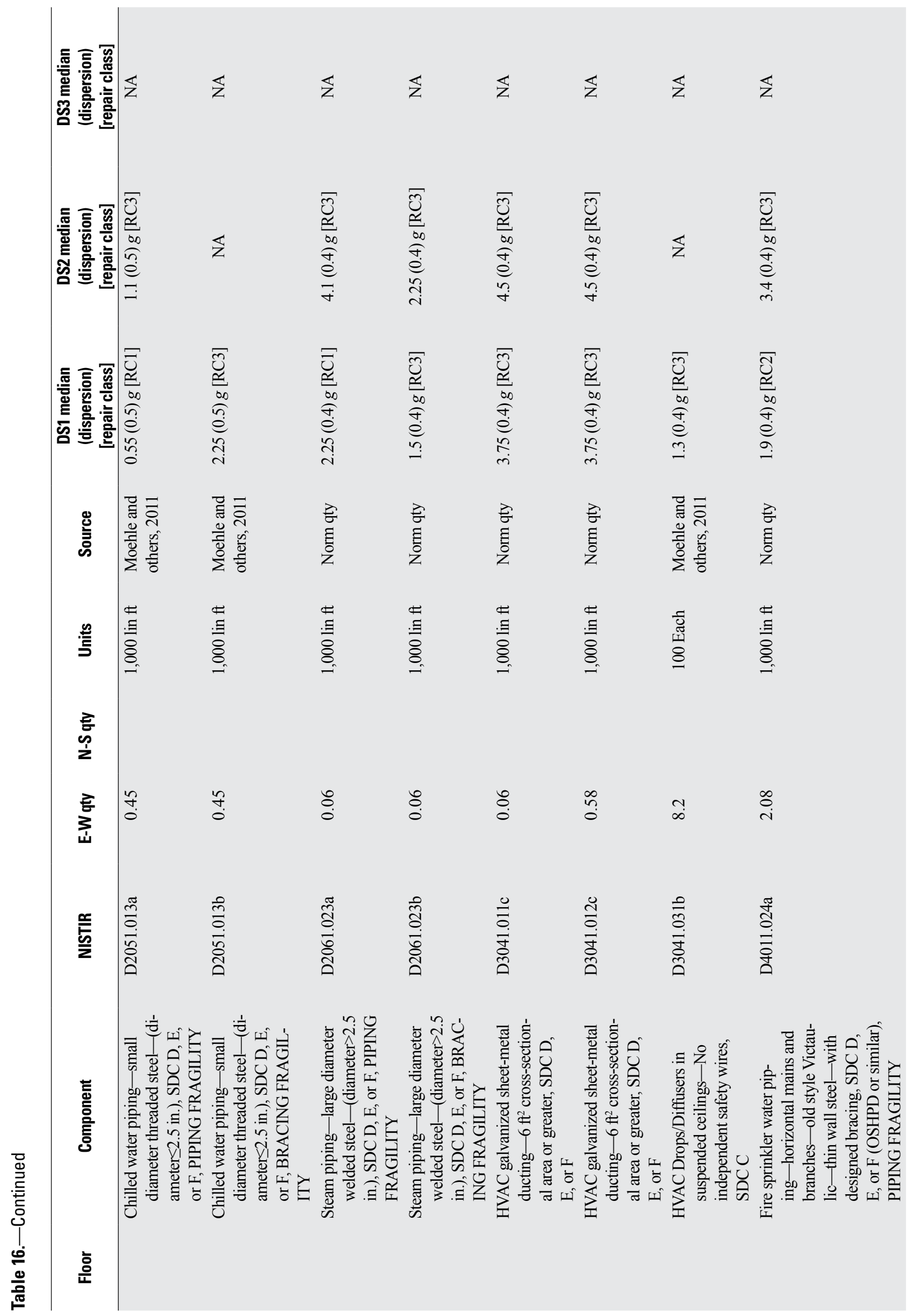




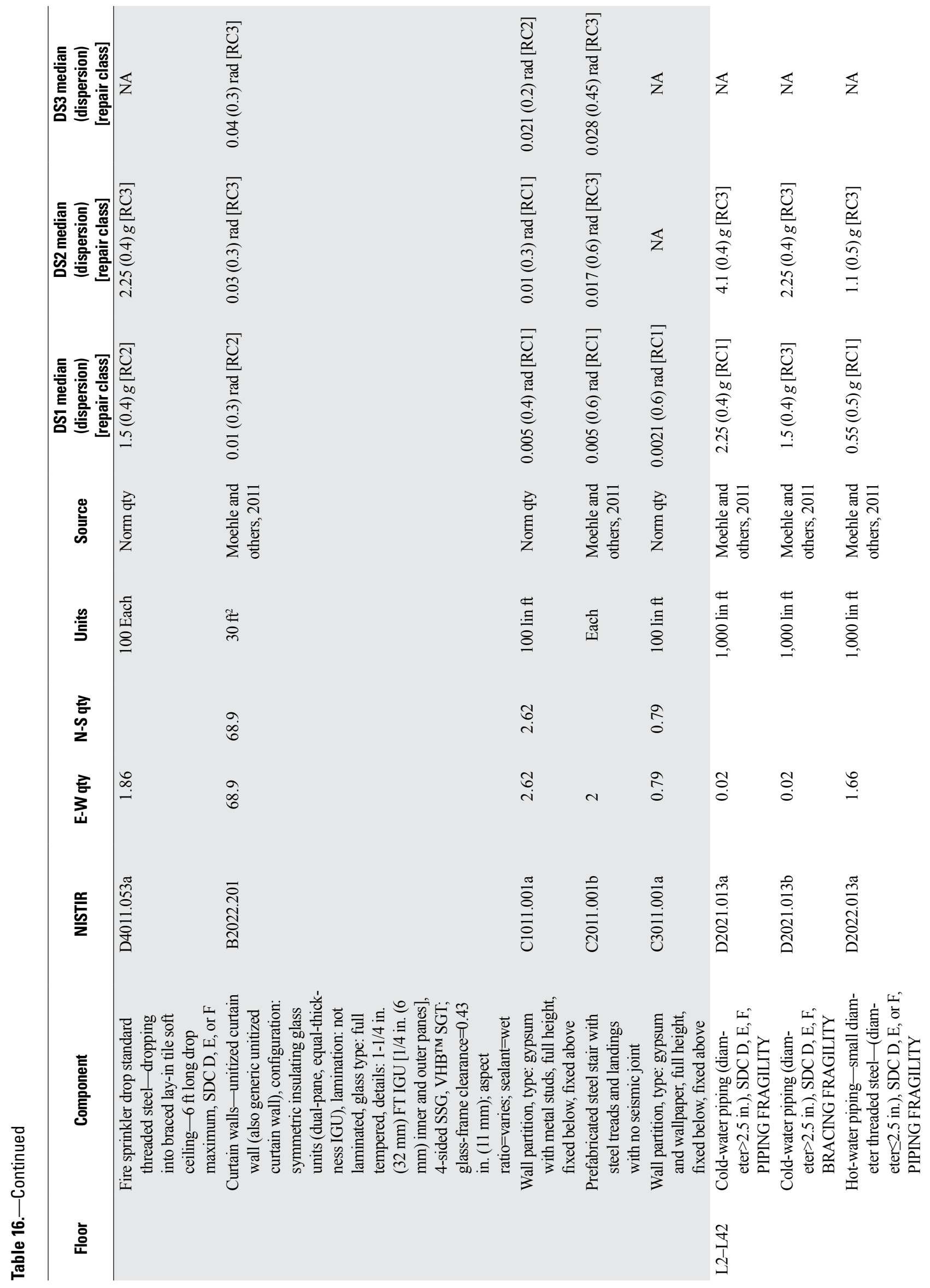




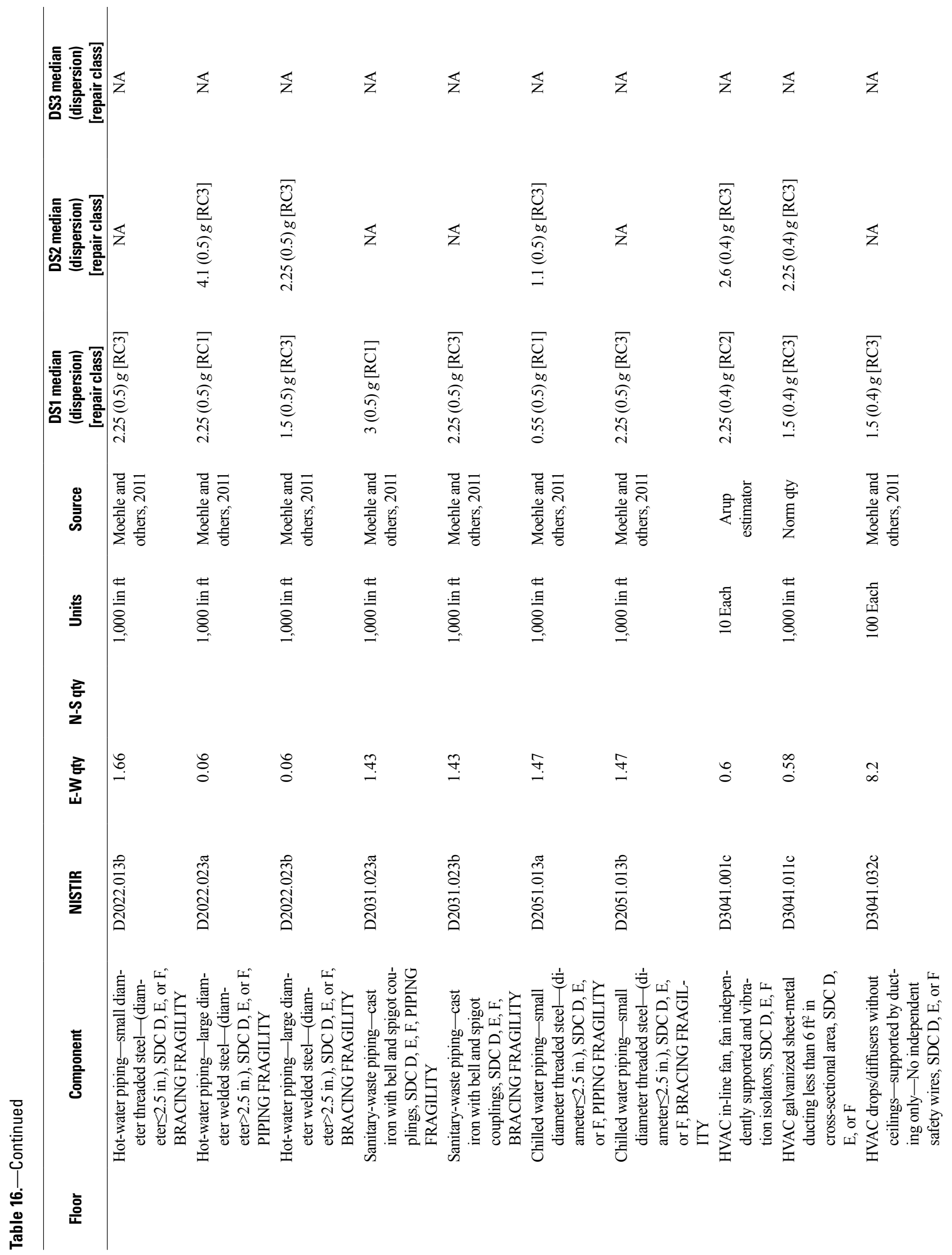




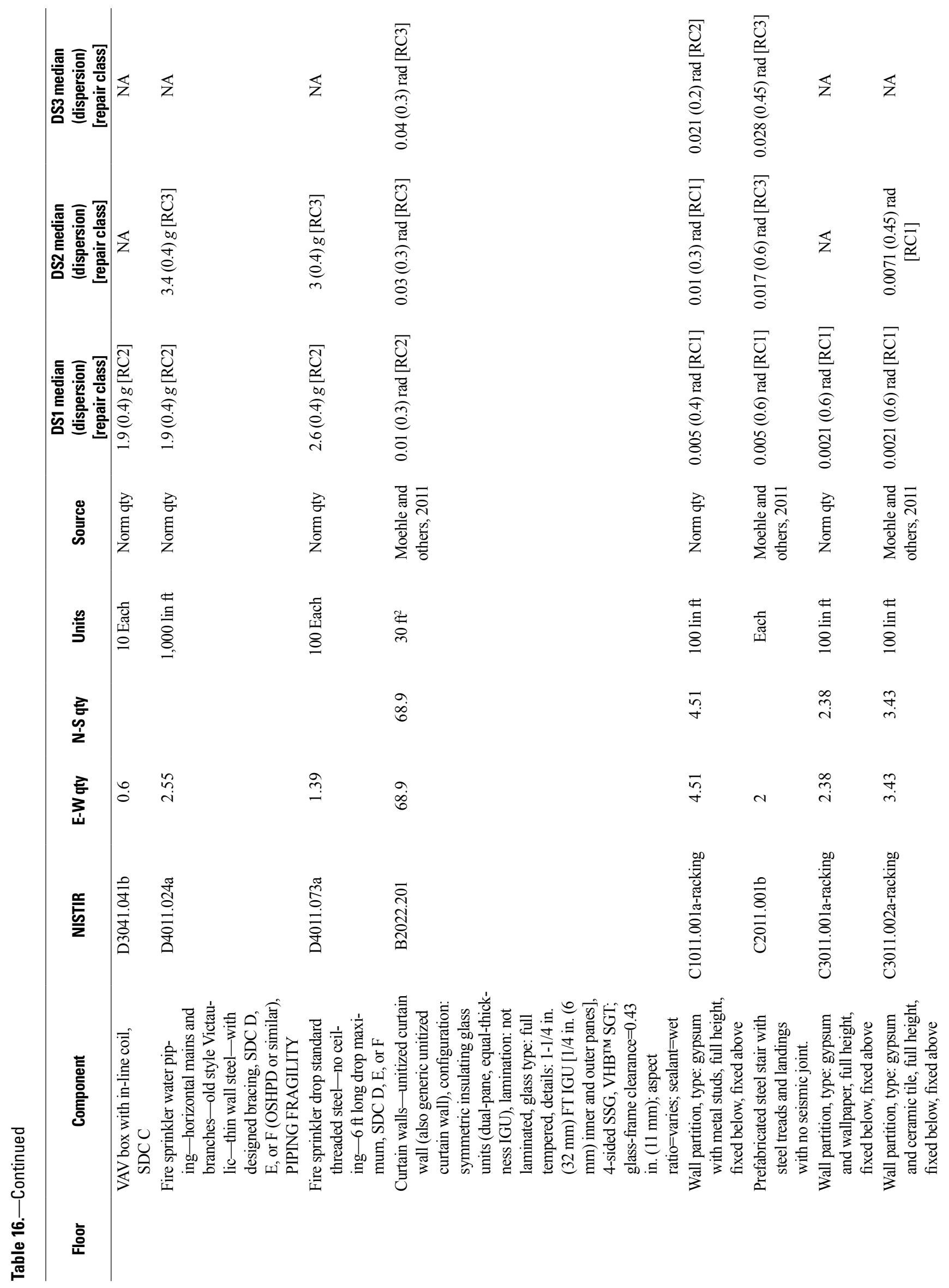




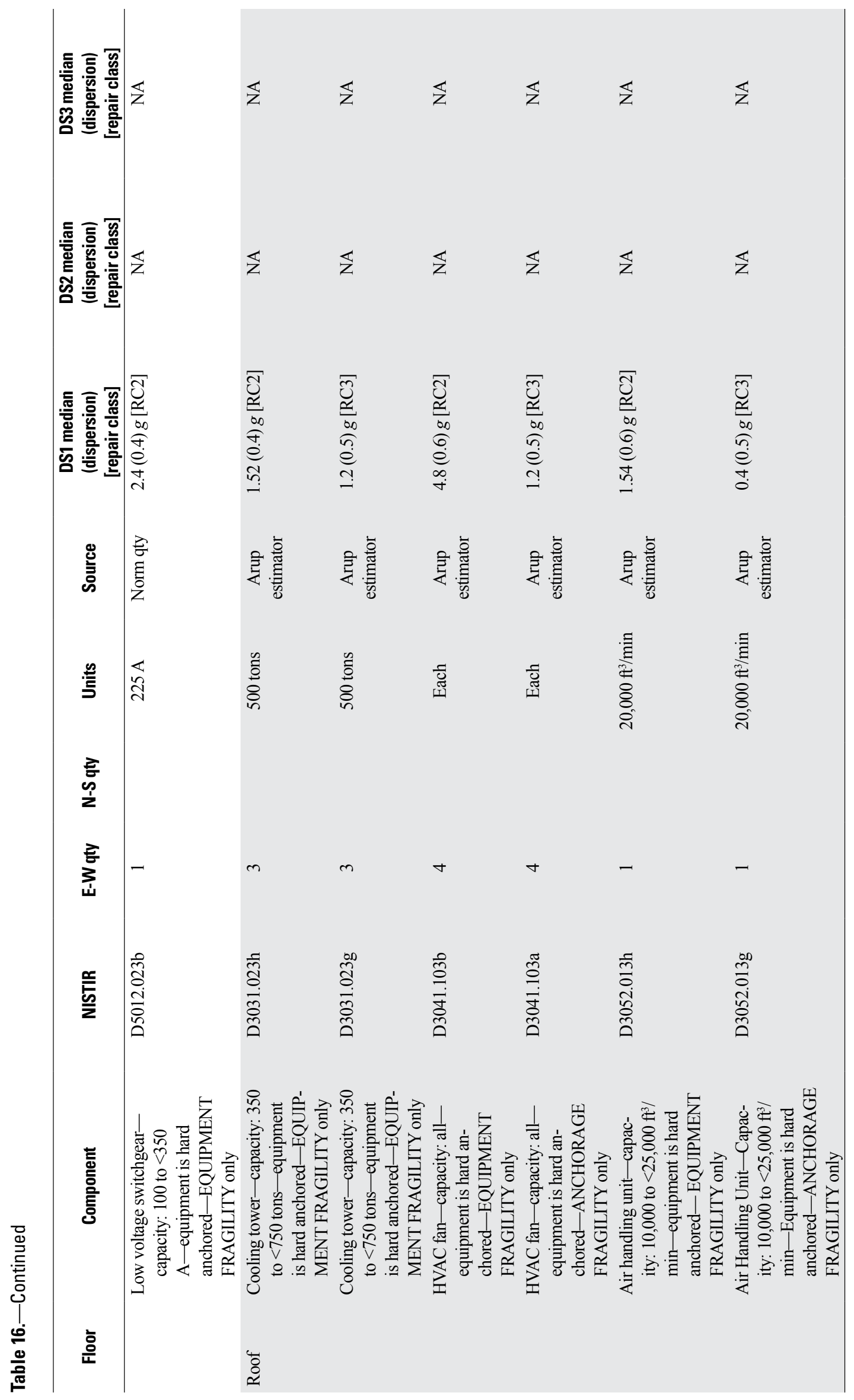




\section{Appendix 2. S-SF-B-43-40-Story Steel-Frame Building in San Francisco (Baseline Orientation)}

\section{S-SF-B-43 Description}

This appendix summarizes the results of interest for the HayWired mainshock from the structural analysis and loss assessment of building S-SF-B-43 - a 40-story steel-frame office building in San Francisco with the baseline orientation shown in figure 7.

\section{Engineering-Demand Parameters}

The "best estimate" EDPs were obtained from the NLRHA. To capture uncertainty associated with modeling and construction quality, the EDPs for each realization in the loss assessment follows the method recommended by FEMA P-58 (Applied Technology Council, 2012) for buildings with nonlinear response history analysis results available. This algorithm was developed by Yang and others (2009).

Building S-SF-B-43 sees low-moderate acceleration demands, with peak nondirectional median floor acceleration for the whole building at $0.63 \mathrm{~g}$. Peak median interstory drift ratio for the whole building is 1 percent, and the peak residual interstory

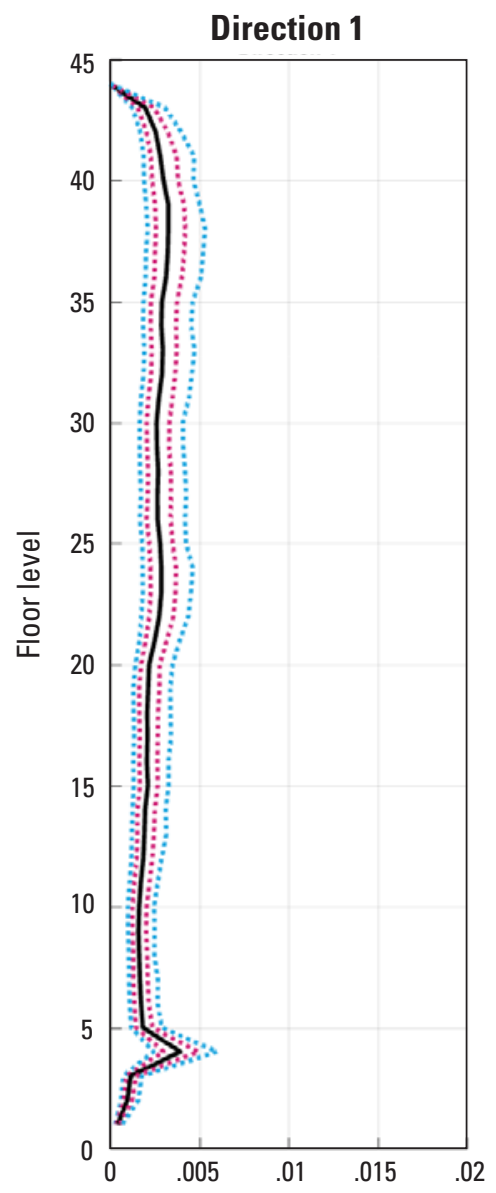

\section{Direction 2}

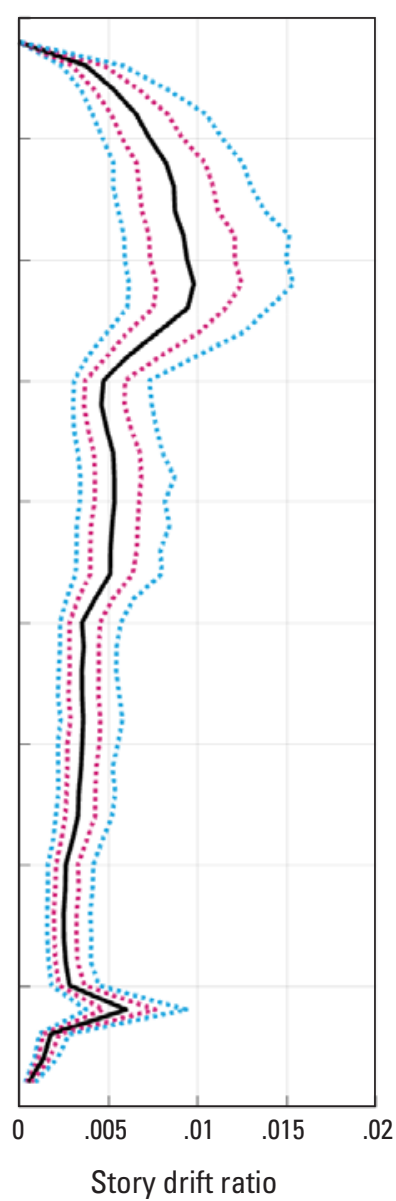

drift ratio is 0.04 percent. As shown in figures 16 and 17, the peak drifts occur around level 34 (31st superstructure floor). This is because beam fracturing and yielding is concentrated in the top third of the building as shown in figure 18. This concentration of damage is due to 1970 s design procedure that distributed seismic design forces up the building height according to solely the first mode translational response. In addition, wind forces were applied as uniform up the height rather than in an inverted triangle as done in practice today. It should be noted that beam yielding does not necessarily mean repair is required. Conversely, the column performance for this building is good, with nearly all columns remaining elastic. All column splices remain elastic. Realized peak floor-acceleration demands for the building are shown in figure 19.

\section{Loss-Assessment Results}

The loss assessment is based on a Monte Carlo simulation with 1,000 realizations. The loss assessment was performed using the probabilistic approach outlined in the Federal Emergency Management Agency’s (FEMA) P-58 document

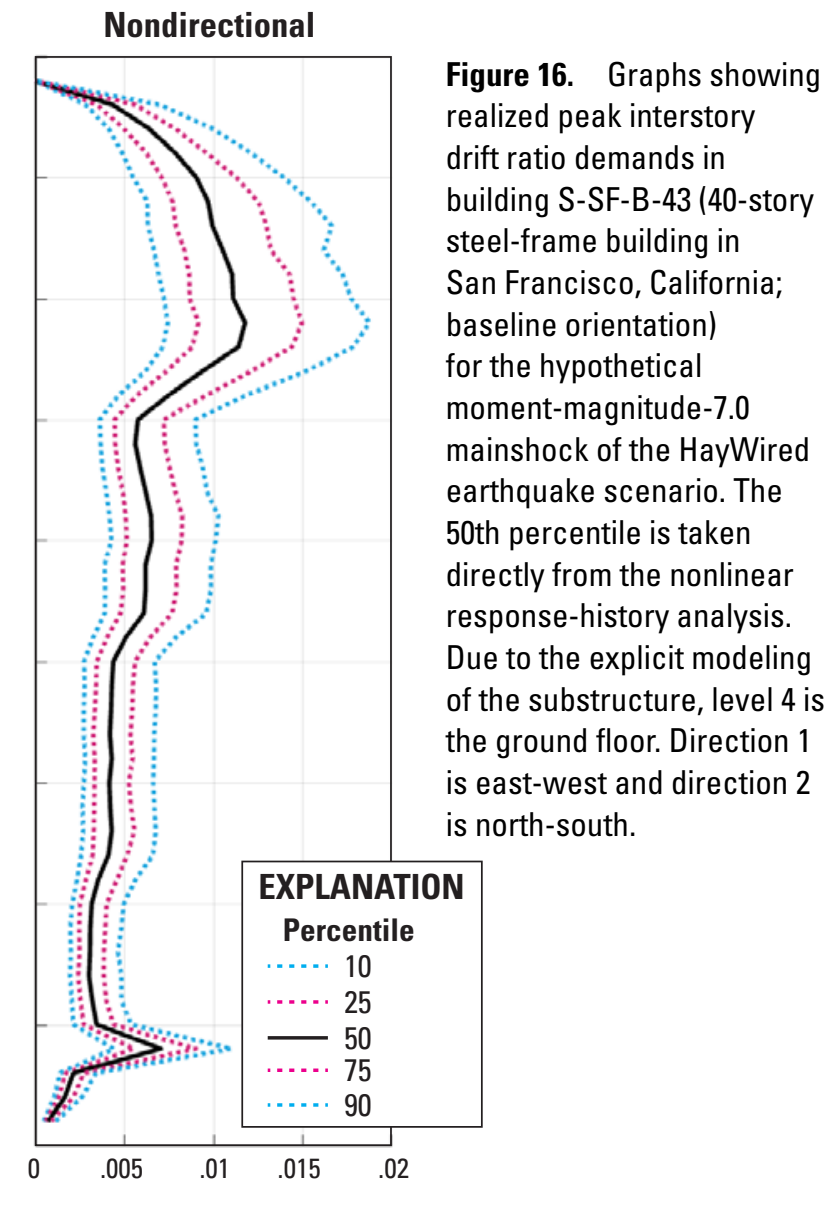



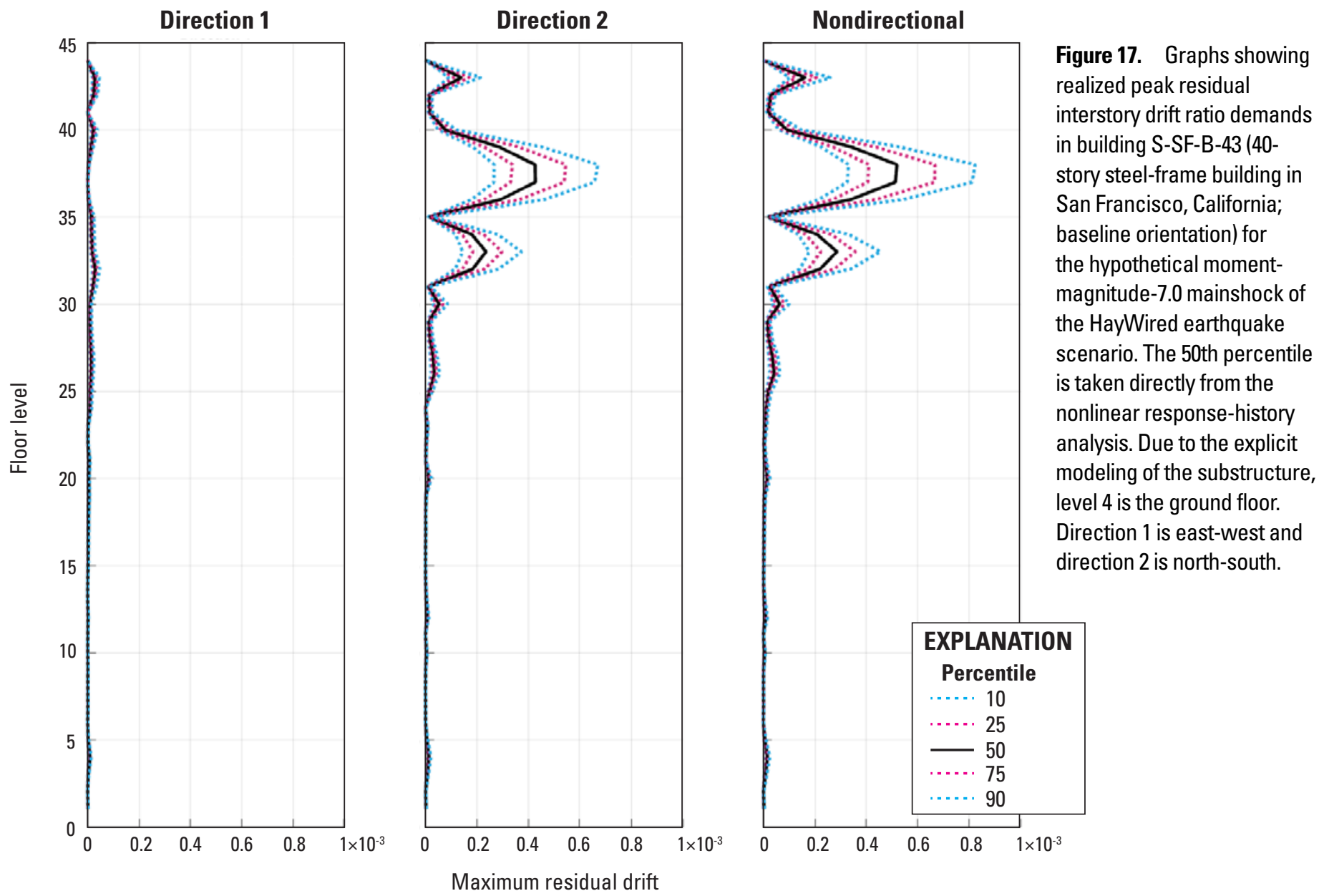

A

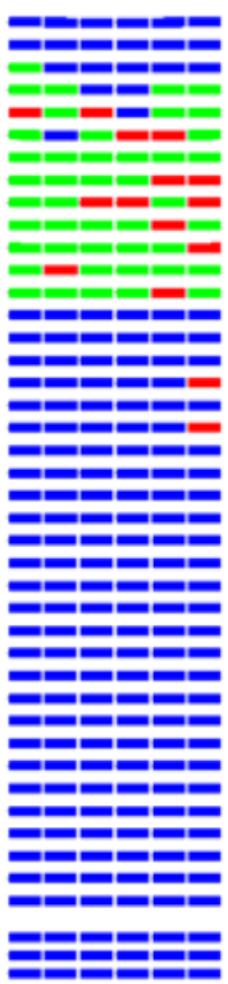

B

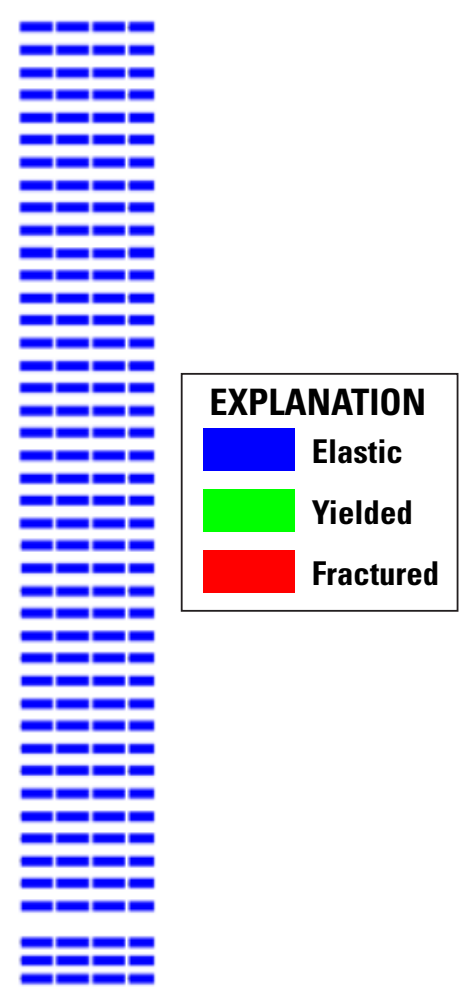

Figure 18. Diagrams showing beam performance for sample $(A)$ long and $(B)$ short elevations of building S-SF-B-43 (40-story steel-frame building in San Francisco, California; baseline orientation) for the hypothetical moment-magnitude-7.0 mainshock of the HayWired earthquake scenario. The 50th percentile is taken directly from the nonlinear response-history analysis. Due to the explicit modeling of the substructure, level 4 is the ground floor. 

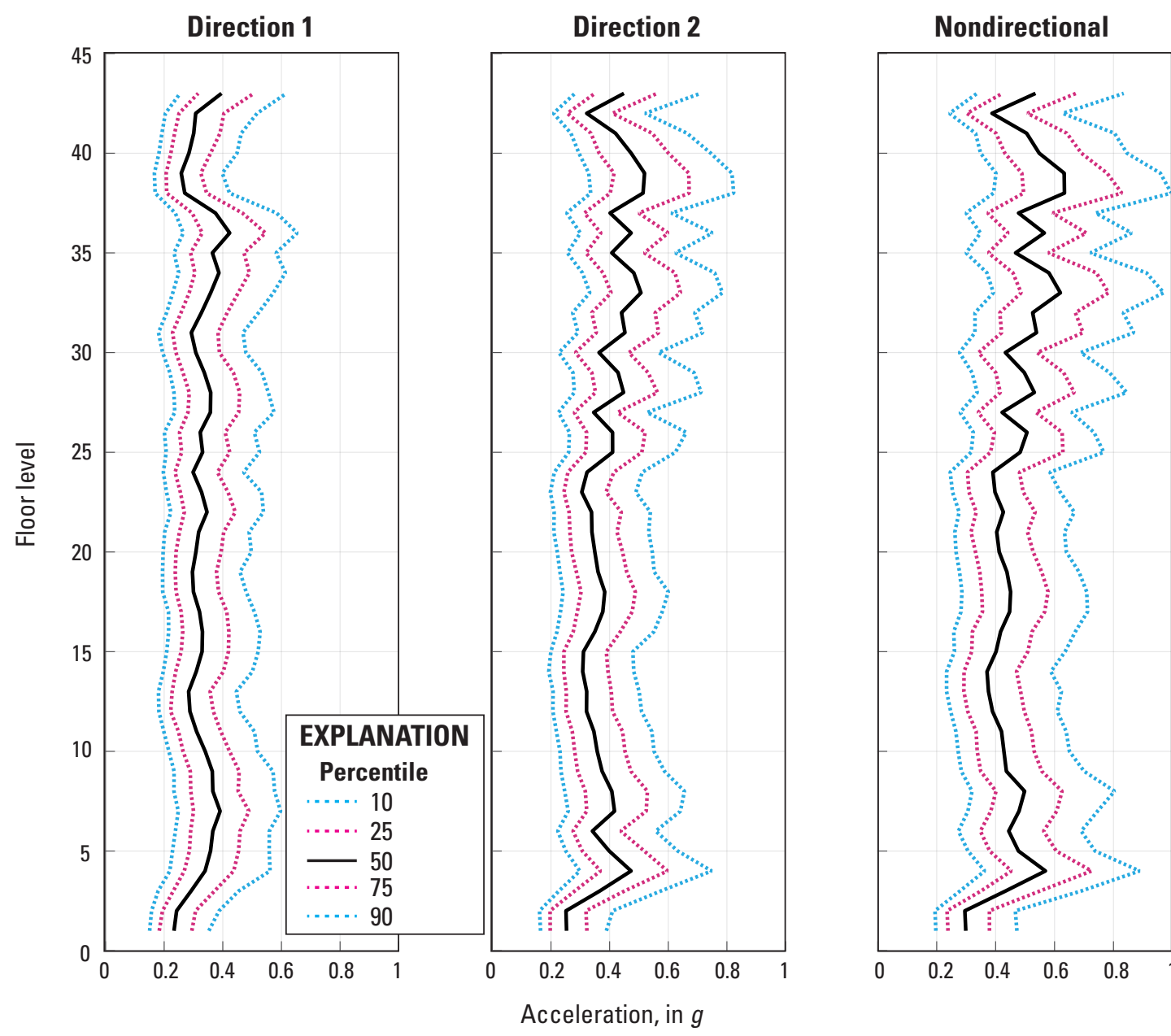

Figure 19. Graphs showing realized peak floor-acceleration demands (relative to acceleration due to gravity, $g$ ) in building S-SF-B-43 (40-story steel-frame building in San Francisco, California; baseline orientation) for the hypothetical momentmagnitude-7.0 mainshock of the HayWired earthquake scenario. The 50th percentile is taken directly from the nonlinear response-history analysis. Due to the explicit modeling of the substructure, level 4 is the ground floor. Direction 1 is east-west and direction 2 is north-south.

(Applied Technology Council, 2012). The likely costs to repair and (or) replace damaged components are calculated based solely on FEMA P-58, whereas repair time and downtime are estimated using the FEMA P-58 based methodology outlined REDi (Almufti and Willford, 2013).

\section{Damaged Components}

The probability that a component type in building S-SFB-43 incurs damage that hinders either reoccupancy, functionality, or full recovery was examined in the realizations. The results are shown in figure 20.

\section{Repair Costs, Repair Time, Downtime, and Impending Factors}

The median repair cost for building S-SF-B-43 is 10.8 percent of the total building replacement value, or $\$ 15.1$ million. The 90th-percentile total repair cost is 12.3 percent of the total building replacement value, or $\$ 17.1$ million. For this study, the total building replacement value is defined as the hard costs only required to replace the building, based on a construction cost estimate, including at minimum all structural and nonstructural components plus the value of damageable building contents if they are known. Figure 21 shows the contribution of building component groups to realized median total repair cost. Table 17 shows realized median and 90thpercentile repair time and total downtime, and table 18 shows realized median and 90th-percentile delays due to impeding factors to functional recovery.

Table 17. Realized median and 90th-percentile repair time and total downtime for building S-SF-B-43 (40-story steel-frame building in San Francisco, California; baseline orientation) due to the hypothetical moment-magnitude- 7.0 mainshock of the HayWired earthquake scenario.

\begin{tabular}{cccc}
\hline REDi (Almufti and Willford, 2013)] & \multicolumn{3}{c}{ REDi repair class } \\
\cline { 2 - 4 } Repair time & $\begin{array}{c}\text { Reoccupancy, } \\
\text { in days }\end{array}$ & $\begin{array}{c}\text { Functional } \\
\text { recovery, } \\
\text { in days }\end{array}$ & $\begin{array}{c}\text { Full } \\
\text { recovery, } \\
\text { in days }\end{array}$ \\
\hline $\begin{array}{c}\text { Median repair } \\
\text { time }\end{array}$ & 41 & 45 & 52 \\
$\begin{array}{c}\text { Median total } \\
\text { downtime }\end{array}$ & 248 & 288 & 292 \\
$\begin{array}{c}\text { 90th-percentile } \\
\text { repair time }\end{array}$ & 61 & 126 & 132 \\
$\begin{array}{c}\text { 90th-percentile } \\
\text { downtime }\end{array}$ & 374 & 388 & 395 \\
\hline
\end{tabular}




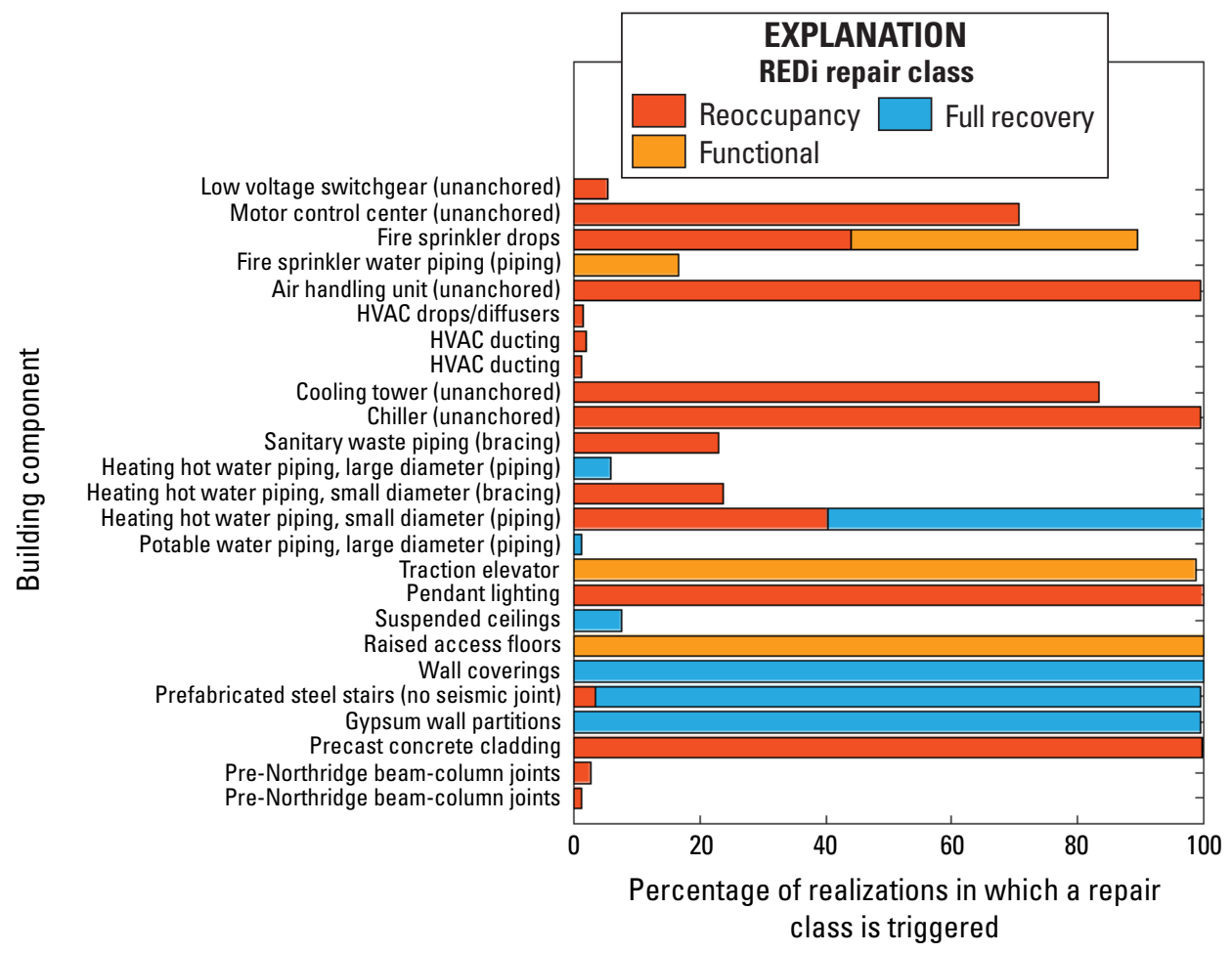

Figure 20. Graph showing the percentage of realizations in which a building component type in building S-SF-B-43 (40-story steel-frame building in San Francisco, California; baseline orientation) incurs damage from the hypothetical momentmagnitude-7.0 mainshock of the HayWired earthquake scenario. Damaged components are assigned to a given REDi repair class (Almufti and Willford, 2013)—reoccupancy, functional recovery, or full recovery. HVAC, heating, ventilation, air conditioning.

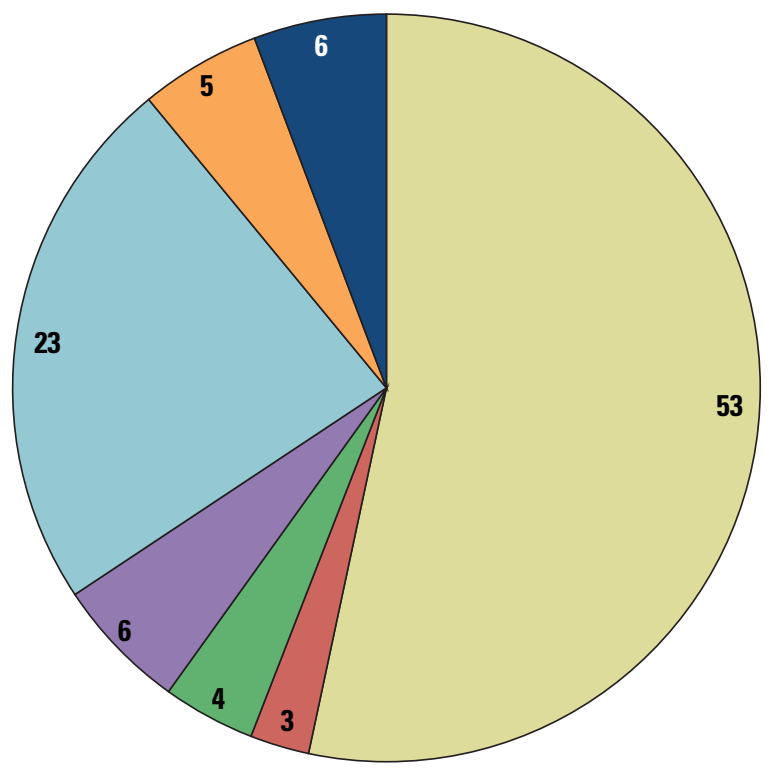

\section{EXPLANATION}

\section{Building component group}

Air handling unit (unanchored) Chiller (unanchored) Gypsum wall partitions Pendant lighting

Figure 21. Pie chart showing the percentage contribution of building component groups to realized median total repair cost for building S-SF-B-43 (40-story steel-frame building in San Francisco, California; baseline orientation) due to the hypothetical momentmagnitude-7.0 mainshock of the HayWired earthquake scenario. 
Table 18. Realized median and 90th-percentile delays due to impeding factors to functional recovery for building S-SF-B-43 (40-story steel-frame building in San Francisco, California; baseline orientation) due to the hypothetical moment-magnitude-7.0 mainshock of the HayWired earthquake scenario.

\begin{tabular}{lccl}
\hline \multicolumn{1}{c}{ Impeding factor } & $\begin{array}{c}\text { Median disruption, } \\
\text { in days }\end{array}$ & $\begin{array}{c}\text { 90th-percentile disruption, } \\
\text { in days }\end{array}$ & Comment \\
\hline Inspection & 5 & 10 & None. \\
Financing & 55 & 200 & None. \\
\hline Engineer mobilization & 0 & 0 & $\begin{array}{c}\text { The median engineer mobilization time is zero even though } \\
\text { some beam-joint joints are redamaged because REDi } \\
\text { (Almufti and Willford, 2013) assumes the likelihood of } \\
\text { an inspector seeing structural damage decreases as the } \\
\text { percentage of structural components damaged decreases. }\end{array}$ \\
Contractor mobilization & 253 & 354 & $\begin{array}{l}\text { None. } \\
\text { The median permitting time is zero even though some beam- } \\
\text { joint joints are redamaged because REDi (Almufti and } \\
\text { Permitting }\end{array}$ \\
& 0 & 0 & $\begin{array}{l}\text { Willford, 2013) assumes the likelihood of an inspector } \\
\text { seeing structural damage decreases as the percentage of } \\
\text { structural components damaged decreases. }\end{array}$ \\
\hline
\end{tabular}

\section{Appendix 3. S-SF-R-43 - 40-Story Steel-Frame Building in San Francisco (Rotated Orientation)}

\section{S-SF-R-43 Description}

This appendix summarizes the results of interest for the HayWired mainshock from the structural analysis and loss assessment of building S-SF-R-43 - a 40-story steel-frame office building in San Francisco with the rotated orientation shown in figure 7. Results are shown in figures 22-24.

\section{Engineering-Demand Parameters}

The simulation of EDPs follows the method recommended by FEMA P-58 (Applied Technology Council, 2012) for buildings with nonlinear response history analysis results available. This algorithm was developed by Yang and others (2009).

Building S-SF-R-43 sees low-moderate acceleration demands, with peak nondirectional median floor acceleration for the whole building at $0.56 \mathrm{~g}$. Peak median interstory drift ratio for the whole building is 0.7 percent, and the peak residual interstory drift ratio is 0.025 percent. The peak interstory drift ratio is governed by the ground-floor frames. All beams and columns remain elastic. All column splices remain elastic.

\section{Loss-Assessment Results}

The loss assessment is based on a Monte Carlo simulation with 1,000 realizations. The loss assessment was performed using the probabilistic approach outlined in the Federal Emergency Management Agency's (FEMA) P-58 document (Applied Technology Council, 2012). The likely costs to repair and (or) replace damaged components are calculated based solely on FEMA P-58, whereas repair time and downtime are estimated using the FEMA P-58 based methodology outlined REDi (Almufti and Willford, 2013).

\section{Damaged Components}

The probability that a component type in building S-SF-R-43 incurs damage that hinders either reoccupancy, functionality, or full recovery was examined in the realizations. The results are shown in figure 25.

\section{Repair Costs, Repair Time, Downtime, and Impending Factors}

The median total repair cost for building S-SF-R-43 is 9.7 percent of the total building replacement value, or $\$ 13.5$ million. The 90th-percentile total repair cost is 11.3 percent of the total building replacement value, or $\$ 15.7$ million. For this study, the total building replacement value is defined as the hard costs only required to replace the building, based on a construction cost estimate including at minimum all structural and nonstructural components plus the value of damageable building contents if they are known. Figure 26 shows the contribution of building component groups to realized median total repair cost. Table 19 shows realized median and 90th-percentile repair time and total downtime, and table 20 shows realized median and 90th-percentile delays due to impeding factors to functional recovery. 

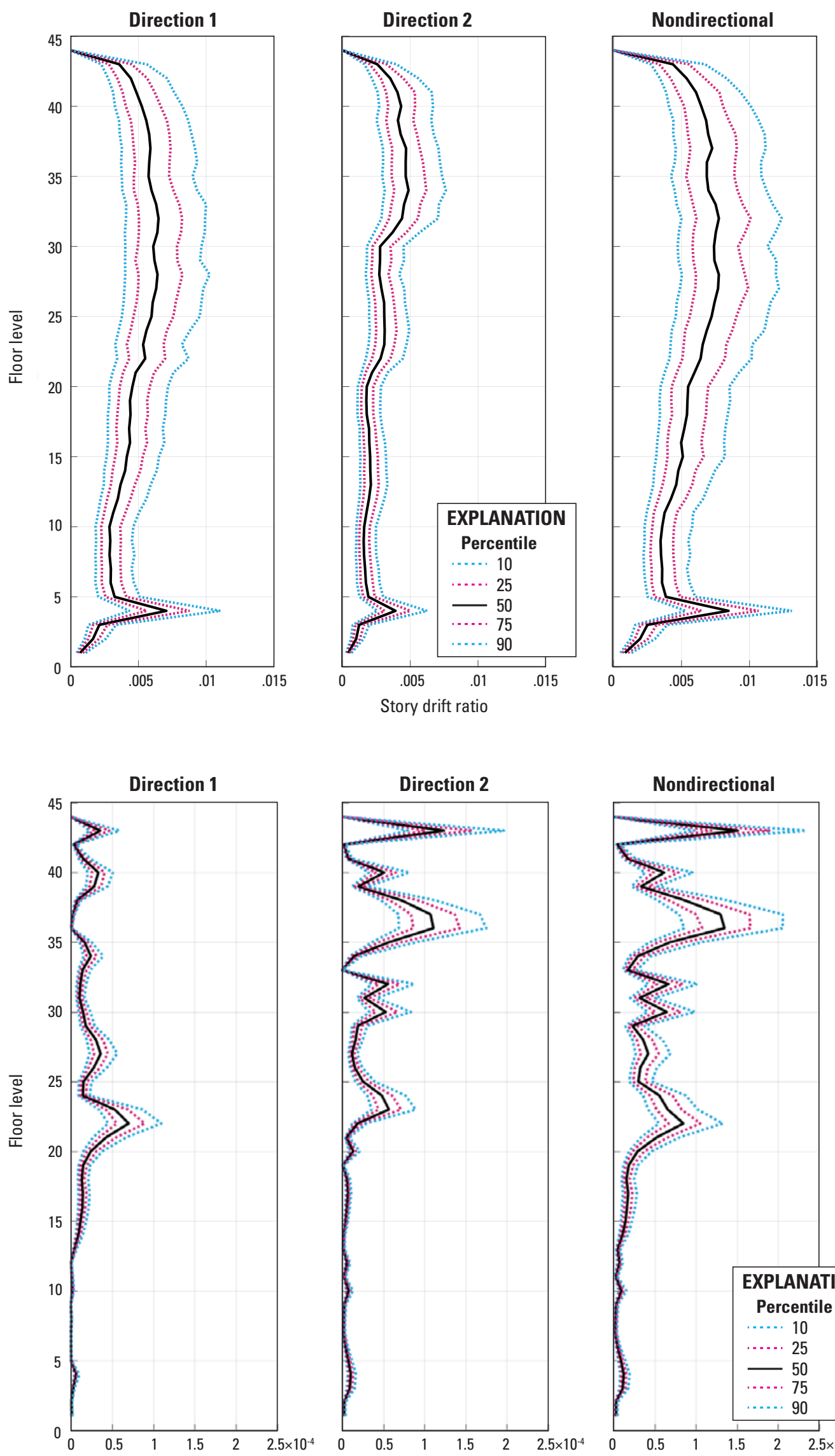
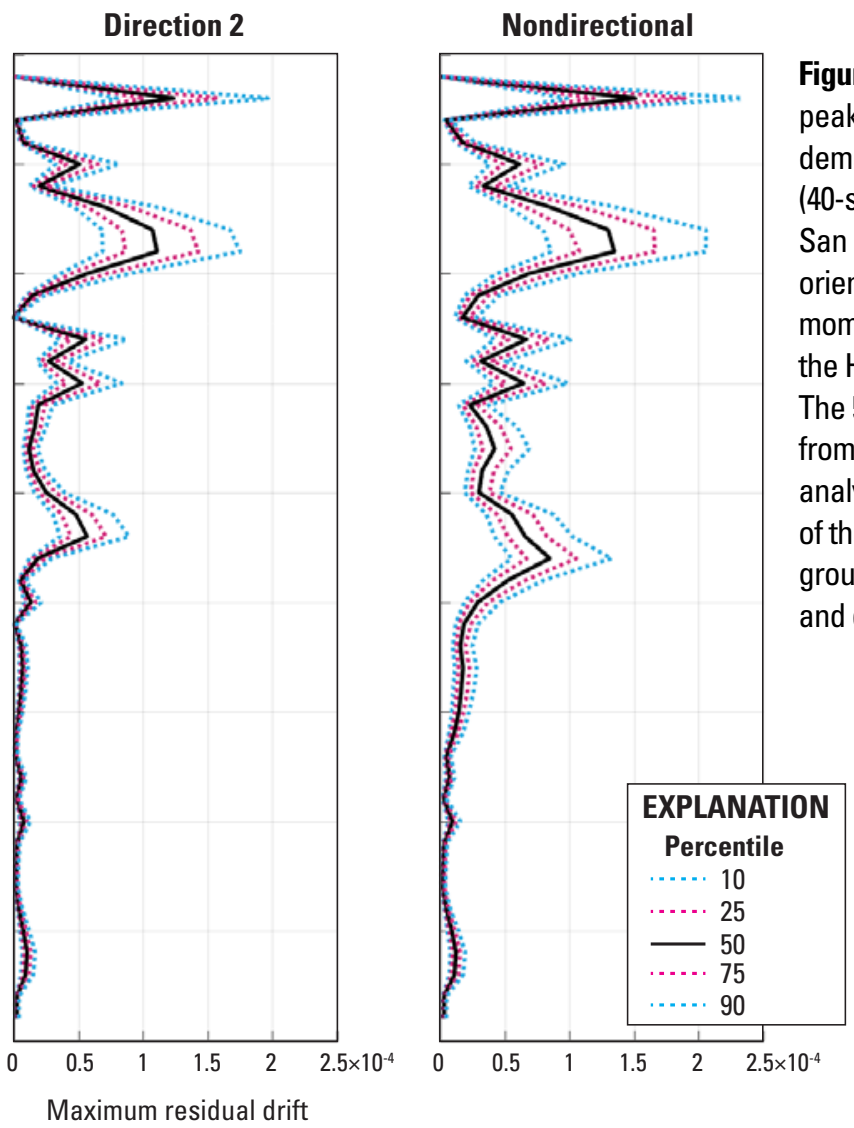

Figure 22. Graphs showing realized peak interstory drift ratio demands in building S-SF-R-43 (40-story steel-frame building in San Francisco, California; rotated orientation) for the hypothetical moment-magnitude-7.0 mainshock of the HayWired earthquake scenario. The 50th percentile is taken directly from the nonlinear response-history analysis. Due to the explicit modeling of the substructure, level 4 is the ground floor. Direction 1 is east-west and direction 2 is north-south.
Figure 23. Graphs showing realized peak residual interstory drift ratio demands in building S-SF-R-43 (40-story steel-frame building in San Francisco, California; rotated orientation) for the hypothetical moment-magnitude-7.0 mainshock of the HayWired earthquake scenario. The 50th percentile is taken directly from the nonlinear response-history nalysis. Due to the explicit modeling of the substructure, level 4 is the ground floor. Direction 1 is east-west and direction 2 is north-south. 

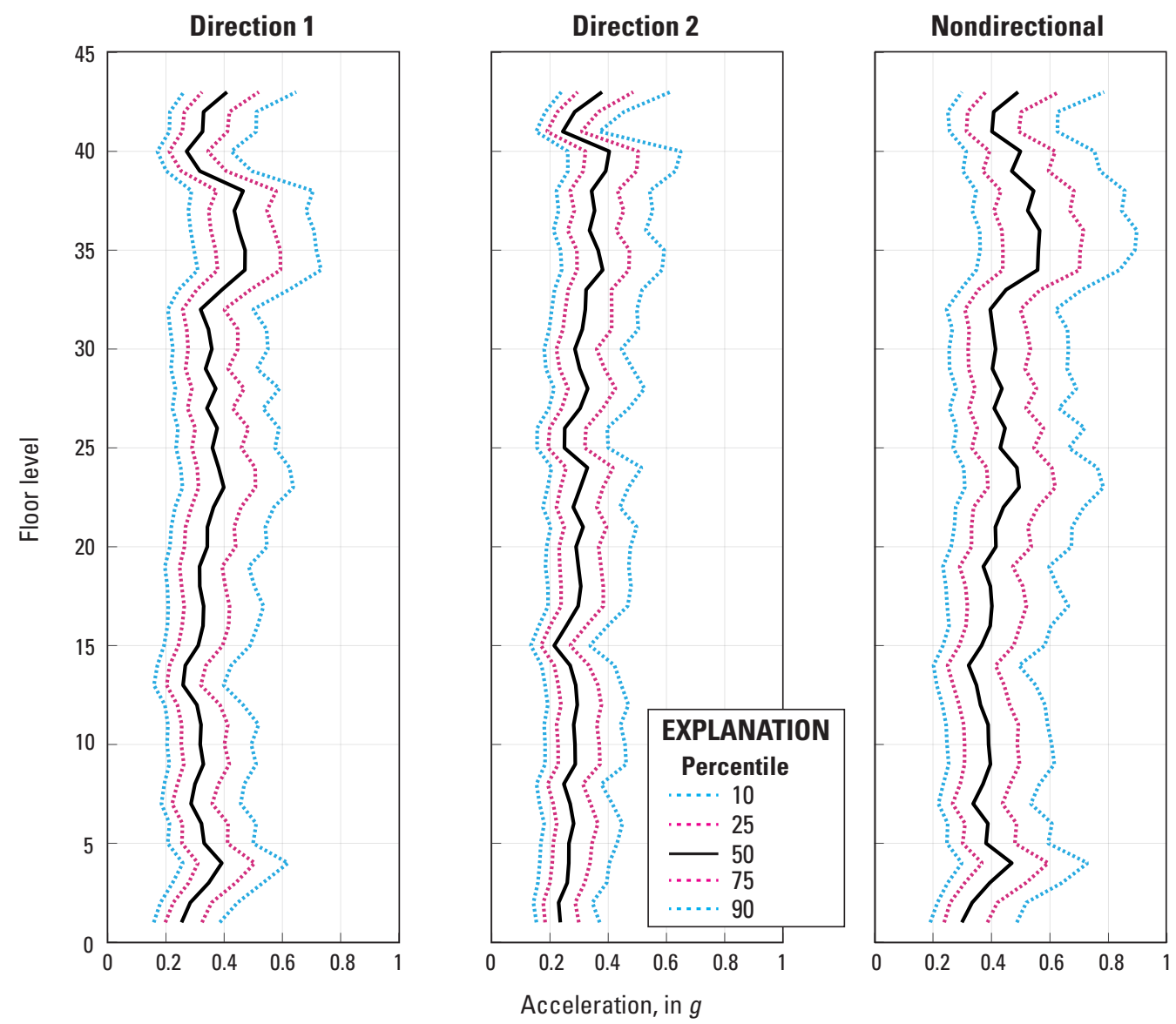

Figure 24. Graphs showing realized peak floor-acceleration demands (relative to acceleration due to gravity, $g$ ) in building S-SF-R-43 (40-story steel-frame building in San Francisco, California; rotated orientation) for the hypothetical momentmagnitude-7.0 mainshock of the HayWired earthquake scenario. The 50th percentile is taken directly from the nonlinear response-history analysis. Due to the explicit modeling of the substructure, level 4 is the ground floor. Direction 1 is east-west and direction 2 is north-south.

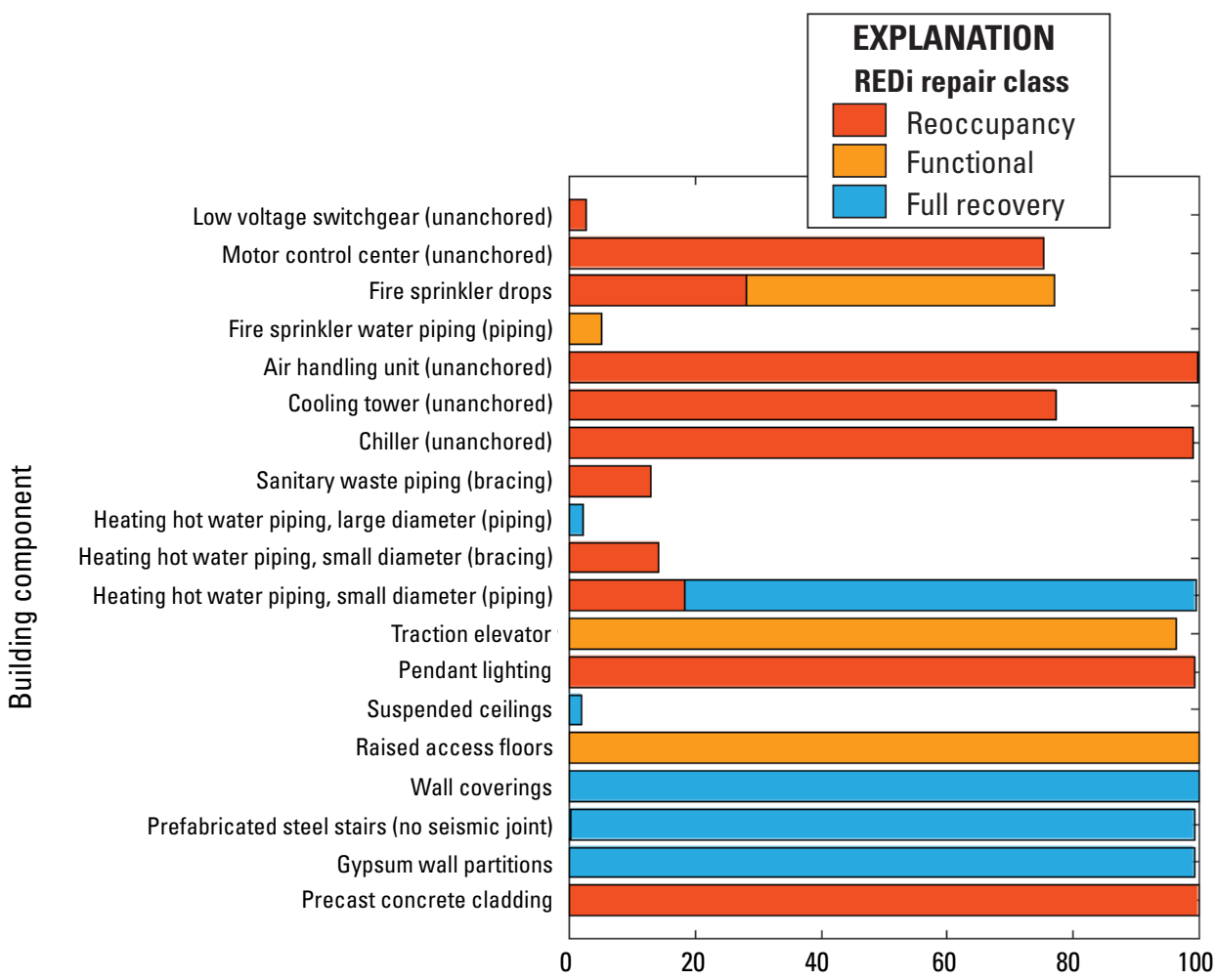

Figure 25. Graph showing the percentage of realizations in which a building component type in building S-SF-R-43 (40-story steel-frame building in San Francisco, California; rotated orientation) incurs damage from the hypothetical moment-magnitude-7.0 mainshock of the HayWired earthquake scenario. Damaged components are assigned to a given REDi repair class (Almufti and Willford, 2013) reoccupancy, functional recovery, or full recovery. HVAC, heating, ventilation, air conditioning.

Percentage of realizations in which a repair class is triggered 


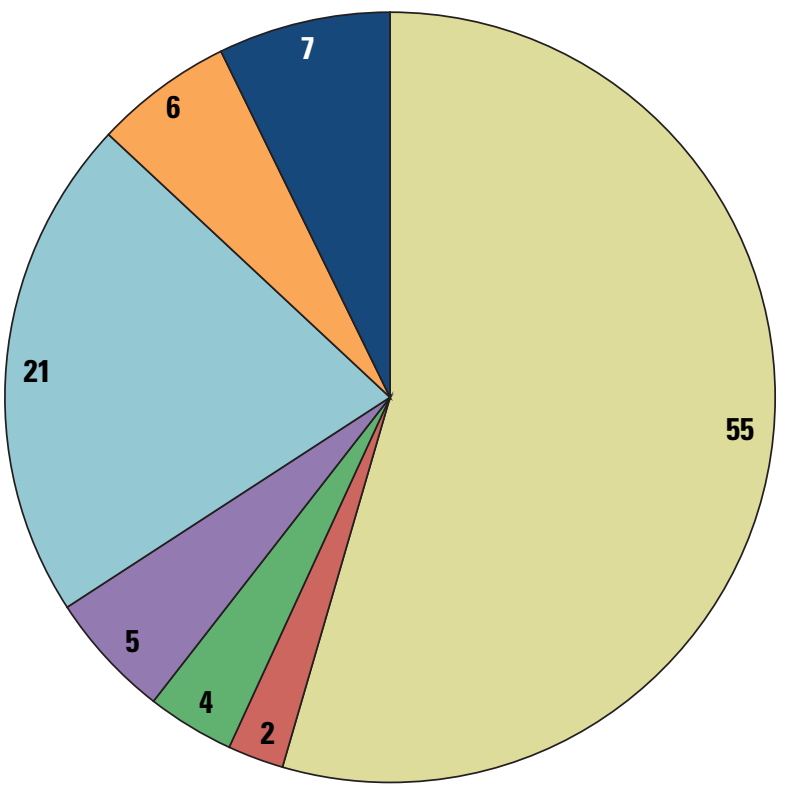

\section{EXPLANATION}

Building component group

Air handling unit (unanchored)

Chiller (unanchored)

Gypsum wall partitions

Pendant lighting

Precast concrete cladding

Traction elevator

Other

Figure 26. Pie chart showing the percentage contribution of building component groups to realized median total repair cost for building S-SF-R-43 (40-story steel-frame building in San Francisco, California; rotated orientation) due to the hypothetical momentmagnitude-7.0 mainshock of the HayWired earthquake scenario.

Table 19. Realized median and 90th-percentile repair time and total downtime for building S-SF-R-43 (40-story steel-frame building in San Francisco, California; rotated orientation) due to the hypothetical moment-magnitude-7.0 mainshock of the HayWired earthquake scenario.

[REDi (Almufti and Willford, 2013)]

\begin{tabular}{lccc}
\hline \multicolumn{1}{c}{ Repair time } & \multicolumn{3}{c}{ REDi repair class } \\
\cline { 2 - 4 } & $\begin{array}{c}\text { Reoccupancy, } \\
\text { in days }\end{array}$ & $\begin{array}{c}\text { Functional recovery, } \\
\text { in days }\end{array}$ & $\begin{array}{c}\text { Full recovery, } \\
\text { in days }\end{array}$ \\
\hline Median repair time & 37 & 39 & 44 \\
Median total downtime & 250 & 288 & 292 \\
90th-percentile repair time & 54 & 102 & 110 \\
90th-percentile downtime & 364 & 390 & 398 \\
\hline
\end{tabular}

Table 20. Realized median and 90th-percentile delays due to impeding factors to functional recovery for building S-SF-R-43 (40-story steel-frame building in San Francisco, California; rotated orientation) due to the hypothetical moment-magnitude-7.0 mainshock of the HayWired earthquake scenario.

\begin{tabular}{lccl}
\hline \multicolumn{1}{c}{ Impeding factor } & $\begin{array}{c}\text { Median } \\
\text { disruption, } \\
\text { in days }\end{array}$ & $\begin{array}{c}\text { 90th-percentile } \\
\text { disruption, } \\
\text { in days }\end{array}$ & Comment \\
\hline Inspection & 5 & 10 & None. \\
\hline Financing & 80 & 222 & None. \\
\hline Engineer mobilization & 0 & 0 & $\begin{array}{c}\text { The median engineer mobilization is zero because } \\
\text { no structural components are damaged. }\end{array}$ \\
\hline Contractor mobilization & 255 & 366 & None. \\
\hline Permitting & 0 & 0 & No structural damage. \\
\hline
\end{tabular}




\section{Appendix 4. S-SF-B-20-20-Story Steel-Frame Building in San Francisco (Baseline Orientation)}

\section{S-SF-B-20 Description}

This appendix summarizes the results for the HayWired mainshock of interest from the structural analysis and loss assessment of building S-SF-B-20 - a 20-story steel-frame office building in San Francisco with the baseline orientation shown in figure 7. Results are shown in figures 27-29.

\section{Engineering-Demand Parameters}

The simulation of EDPs follows the method recommended by FEMA P-58 (Applied Technology Council, 2012) for buildings with nonlinear response history analysis results available. This algorithm was developed by Yang and others (2009).

Building S-SF-B-20 sees low-moderate acceleration demands, with peak nondirectional median floor acceleration for the whole building at $0.63 \mathrm{~g}$, slightly higher than the 40-story San Francisco building. Peak median interstory drift ratio for the whole building is 0.45 percent, and the peak residual interstory drift ratio is 0.006 percent. All columns

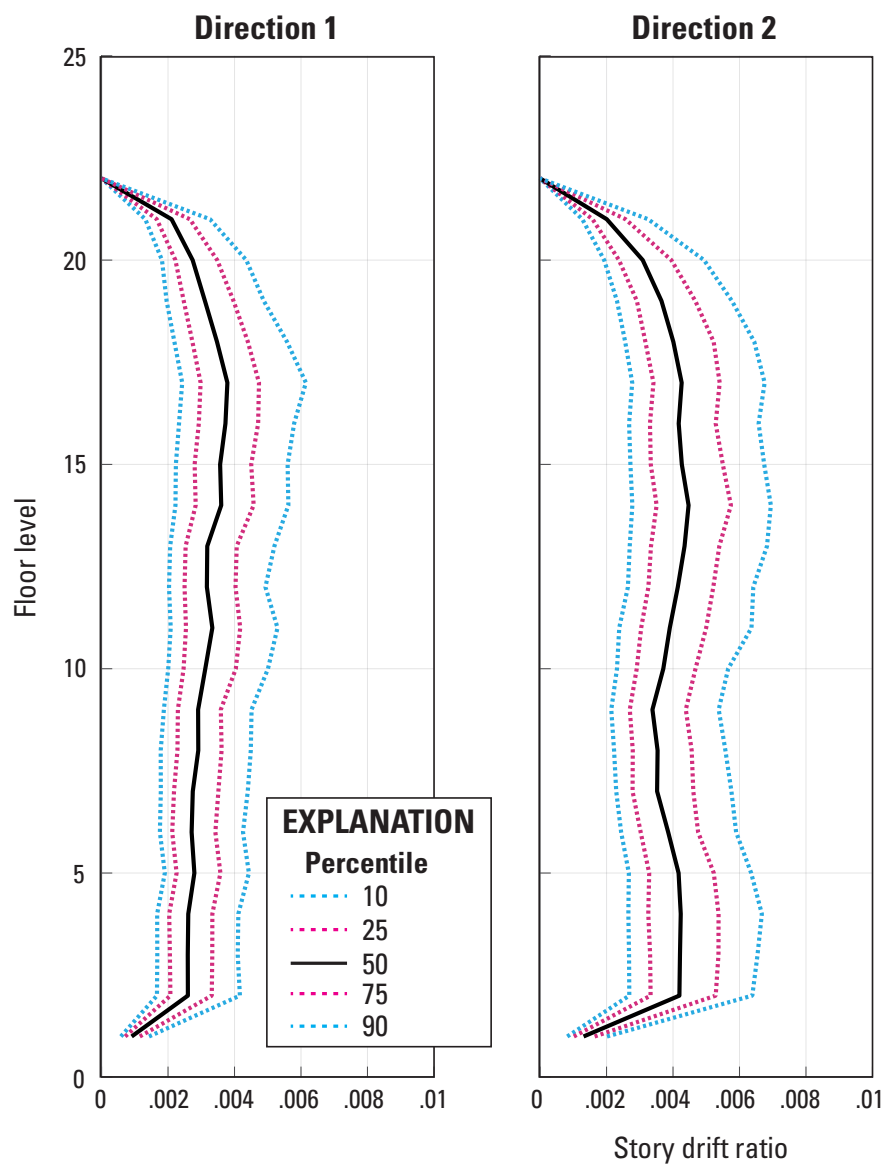

and beams remain elastic for this building. All column splices remain elastic.

\section{Loss-Assessment Results}

The loss assessment is based on a Monte Carlo simulation with 1,000 realizations. The loss assessment was performed using the probabilistic approach outlined in the Federal Emergency Management Agency's (FEMA) P-58 document (Applied Technology Council, 2012). The likely costs to repair and (or) replace damaged components are calculated based solely on FEMA P-58, whereas repair time and downtime are estimated using the FEMA P-58 based methodology outlined REDi (Almufti and Willford, 2013).

\section{Damaged Components}

The probability that a component type in building S-SFB-20 incurs damage that hinders either reoccupancy, functionality, or full recovery was examined in the realizations. The results are shown in figure 30 .

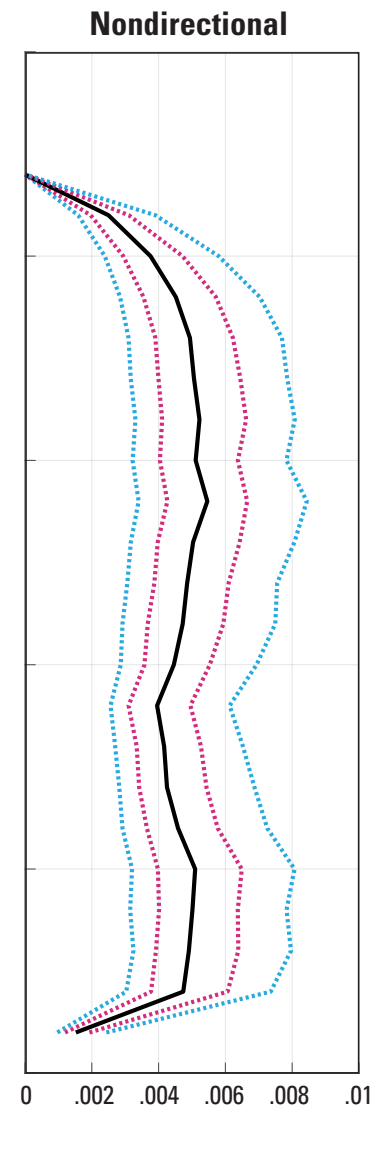

Figure 27. Graphs showing realized peak interstory drift ratio demands in building S-SF-B-20 (20-story steel-frame office building in San Francisco, California; baseline orientation) for the hypothetical momentmagnitude- 7.0 mainshock of the HayWired earthquake scenario. The 50th percentile is taken directly from the nonlinear response-history analysis. Due to the explicit modeling of the substructure, level 2 is the ground floor. Direction 1 is east-west and direction 2 is north-south. 

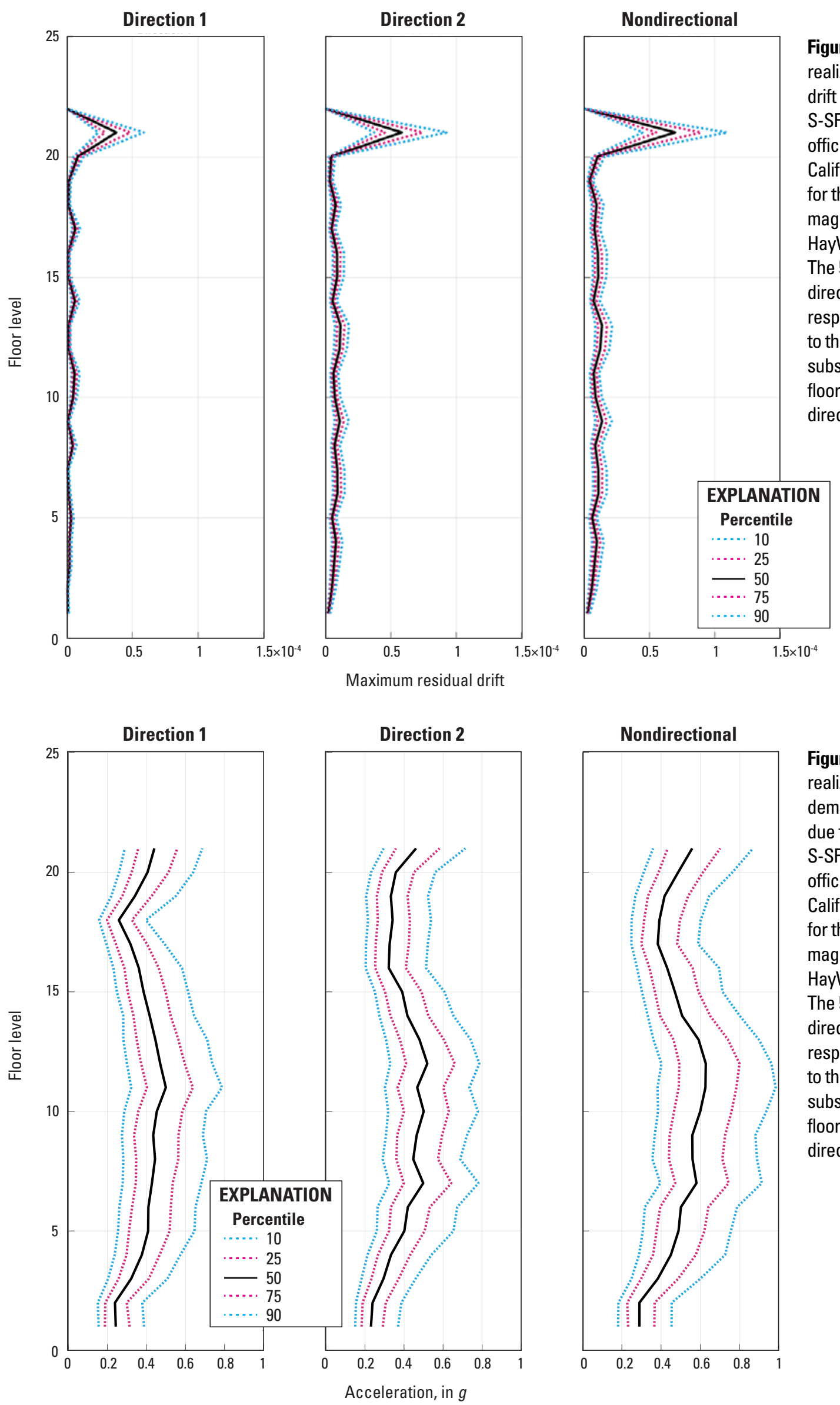

Figure 29. Graphs showing realized peak floor-acceleration demands (relative to acceleration due to gravity, $g$ ) in building S-SF-B-20 (20-story steel-frame office building in San Francisco, California; baseline orientation) for the hypothetical momentmagnitude-7.0 mainshock of the HayWired earthquake scenario. The 50th percentile is taken directly from the nonlinear response-history analysis. Due to the explicit modeling of the substructure, level 2 is the ground floor. Direction 1 is east-west and direction 2 is north-south. 


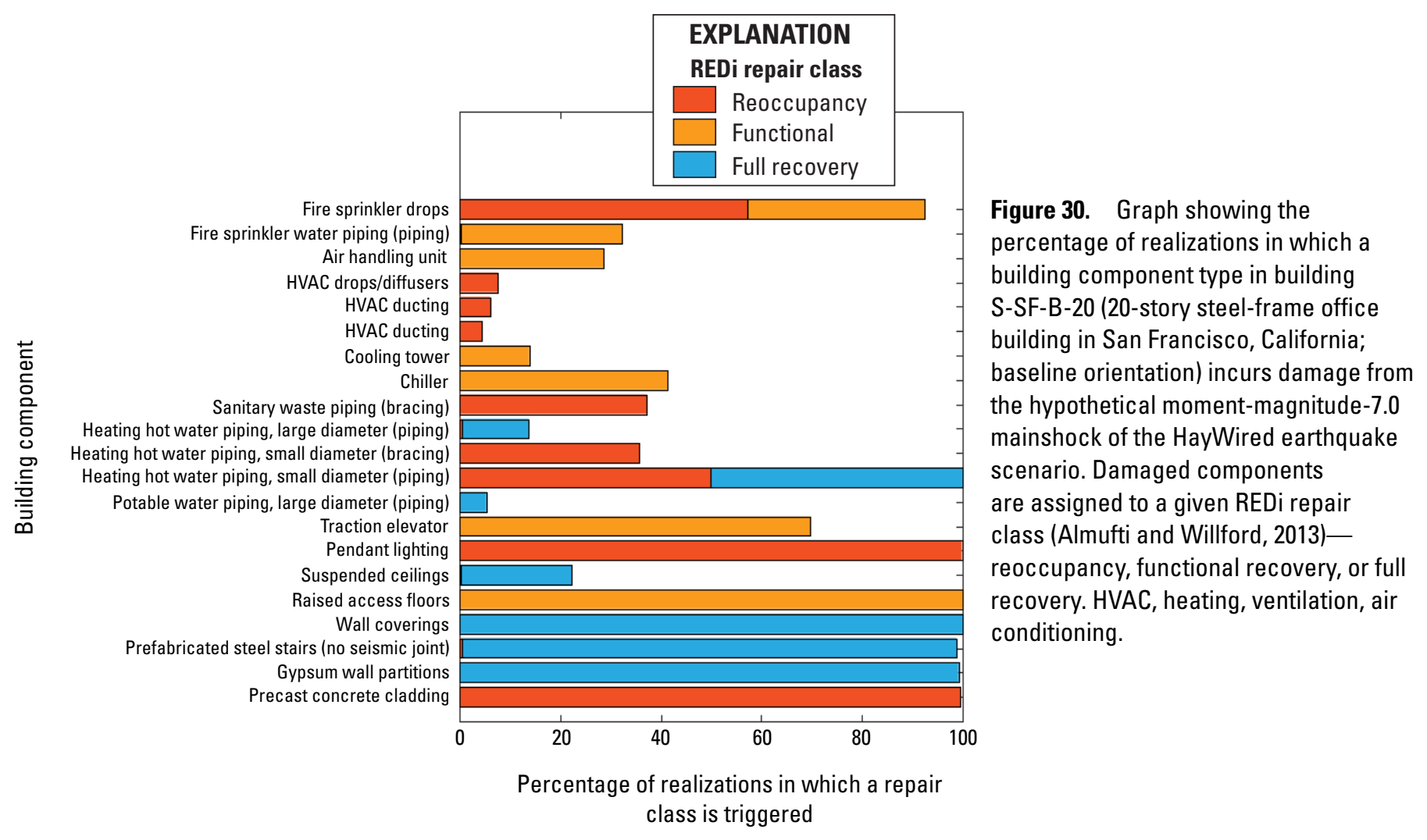

\section{Repair Costs, Repair Time, Downtime, and Impending Factors}

The median total repair cost for building S-SF-B-20 is 9.7 percent of the total building replacement value, or $\$ 5.1$ million. The 90th-percentile total repair cost is 9.5 percent of the total building replacement value, or $\$ 6.6$ million. For this study, the total building replacement value is defined as the hard costs only required to replace the building, based on a construction cost estimate including at minimum all structural and nonstructural components plus the value of damageable building contents if they are known. Figure 31 shows the contribution of building component groups to realized median total repair cost. Table 21 shows realized median and 90th-percentile repair time and total downtime, and table 22 shows realized median and 90th-percentile delays due to impeding factors to functional recovery.

Table 21. Realized median and 90th-percentile repair time and total downtime for building S-SF-B-20 (20-story steel-frame office building in San Francisco, California; baseline orientation) due to the hypothetical momentmagnitude-7.0 mainshock of the HayWired earthquake scenario.

[REDi (Almufti and Willford, 2013)]

\begin{tabular}{lccc}
\hline \multirow{2}{*}{ Repair time } & \multicolumn{1}{c}{ REDi repair class } & \\
\cline { 2 - 4 } & $\begin{array}{c}\text { Reoccupancy, } \\
\text { in days }\end{array}$ & $\begin{array}{c}\text { Functional recovery, } \\
\text { in days }\end{array}$ & $\begin{array}{c}\text { Full recovery, } \\
\text { in days }\end{array}$ \\
\hline Median repair time & 20 & 29 & 35 \\
Median total downtime & 189 & 242 & 243 \\
\hline 90th-percentile repair time & 39 & 145 & 159 \\
\hline 90th-percentile downtime & 316 & 364 & 364 \\
\hline
\end{tabular}




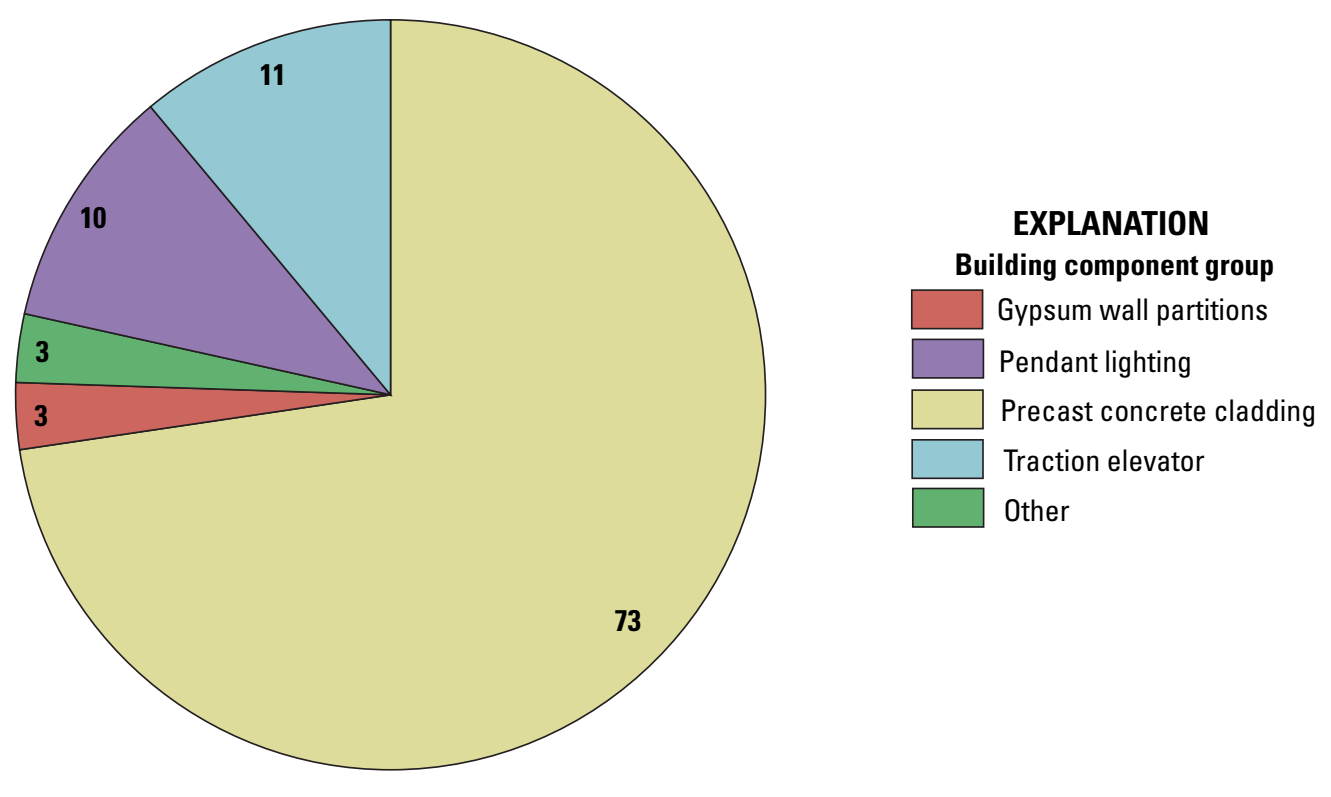

Figure 31. Pie chart showing the percentage contribution of building component groups to realized median total repair cost for building S-SF-B-20 (20-story steel-frame office building in San Francisco, California; baseline orientation) due to the hypothetical moment-magnitude-7.0 mainshock of the HayWired earthquake scenario.

Table 22. Realized median and 90th-percentile delays due to impeding factors to functional recovery for building S-SF-B-20 (20-story steelframe office building in San Francisco, California; baseline orientation) due to the hypothetical moment-magnitude-7.0 mainshock of the HayWired earthquake scenario.

\begin{tabular}{lccc}
\hline \multicolumn{1}{c}{ Impeding factor } & $\begin{array}{c}\text { Median disruption, } \\
\text { in days }\end{array}$ & $\begin{array}{c}\text { 90th-percentile disruption, } \\
\text { in days }\end{array}$ & Comment \\
\hline Inspection & 5 & 10 & None. \\
Financing & 101 & 239 & None. \\
Engineer mobilization & 0 & 0 & The median engineer mobilization is zero because \\
& 229 & 347 & no structural components are damaged. \\
Contractor mobilization & 0 & 0 & None. \\
Permitting & & No structural damage. \\
\hline
\end{tabular}




\section{Appendix 5. S-SF-R-20-20-Story Steel-Frame Building in San Francisco (Rotated Orientation)}

\section{S-SF-R-20 Description}

This appendix summarizes the results of interest for the HayWired mainshock from the structural analysis and loss assessment of building S-SF-R-20 - a 20-story steel-frame office building in San Francisco with the rotated orientation shown in figure 7. Results are shown in figures 32-34.

\section{Engineering-Demand Parameters}

The simulation of EDPs follows the method recommended by FEMA P-58 (Applied Technology Council, 2012) for buildings with nonlinear response history analysis results available. This algorithm was developed by Yang and others (2009).

Building S-SF-R-20 sees low-moderate acceleration demands, with peak nondirectional median floor acceleration for the whole building at $0.68 \mathrm{~g}$, slightly higher than the 40 -story San Francisco building. Peak median interstory drift ratio for the whole building is 0.60 percent and the peak residual interstory drift ratio is 0.0075 percent. All columns

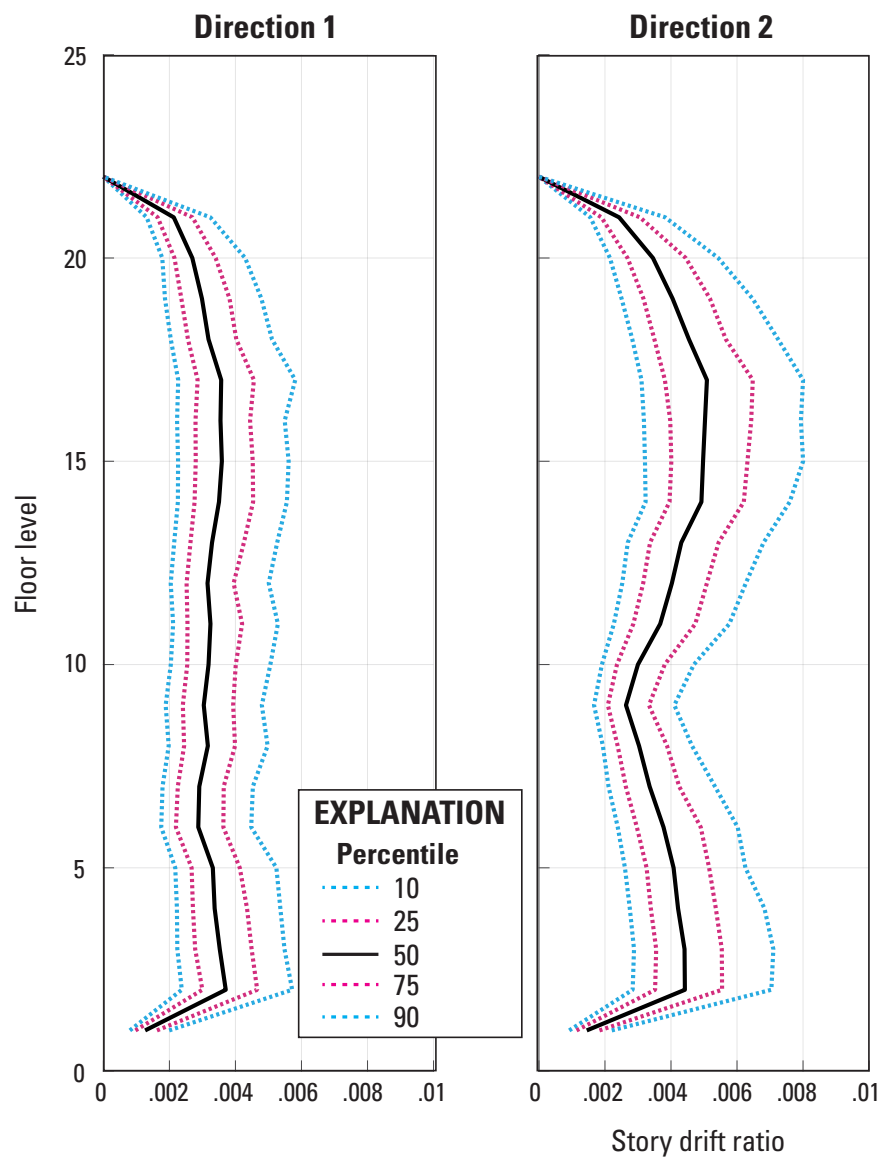

and beams remain elastic for this building. All column splices remain elastic.

\section{Loss-Assessment Results}

The loss assessment is based on a Monte Carlo simulation with 1,000 realizations. The loss assessment was performed using the probabilistic approach outlined in the Federal Emergency Management Agency's (FEMA) P-58 document (Applied Technology Council, 2012). The likely costs to repair and (or) replace damaged components are calculated based solely on FEMA P-58, whereas repair time and downtime are estimated using the FEMA P-58 based methodology outlined REDi (Almufti and Willford, 2013).

\section{Damaged Components}

The probability that a component type in building S-SF-R-20 incurs damage that hinders either reoccupancy, functionality, or full recovery was examined in the realizations. The results are shown in figure 35 .

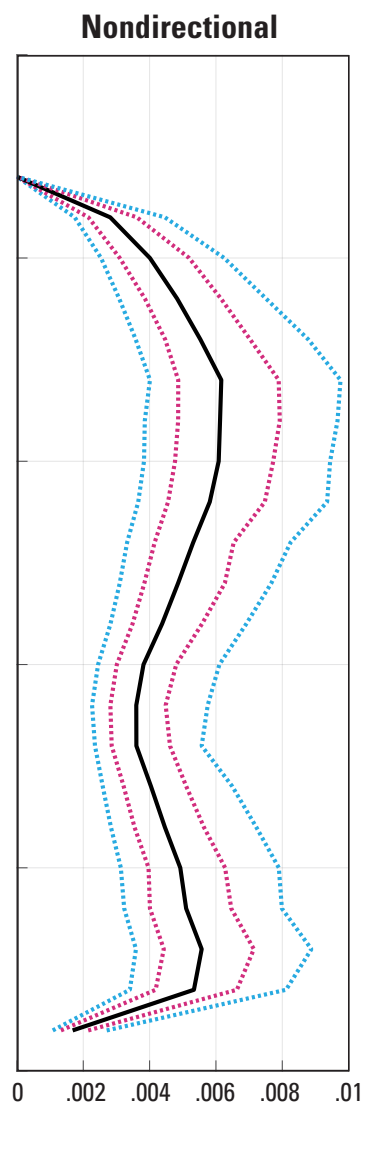

Figure 32. Graphs showing realized peak interstory drift ratio demands in building S-SF-R-20 (20-story steel-frame office building in San Francisco, California; rotated orientation) for the hypothetical momentmagnitude-7.0 mainshock of the HayWired earthquake scenario. The 50th percentile is taken directly from the nonlinear response-history analysis. Due to the explicit modeling of the substructure, level 2 is the ground floor. Direction 1 is east-west and direction 2 is north-south. 

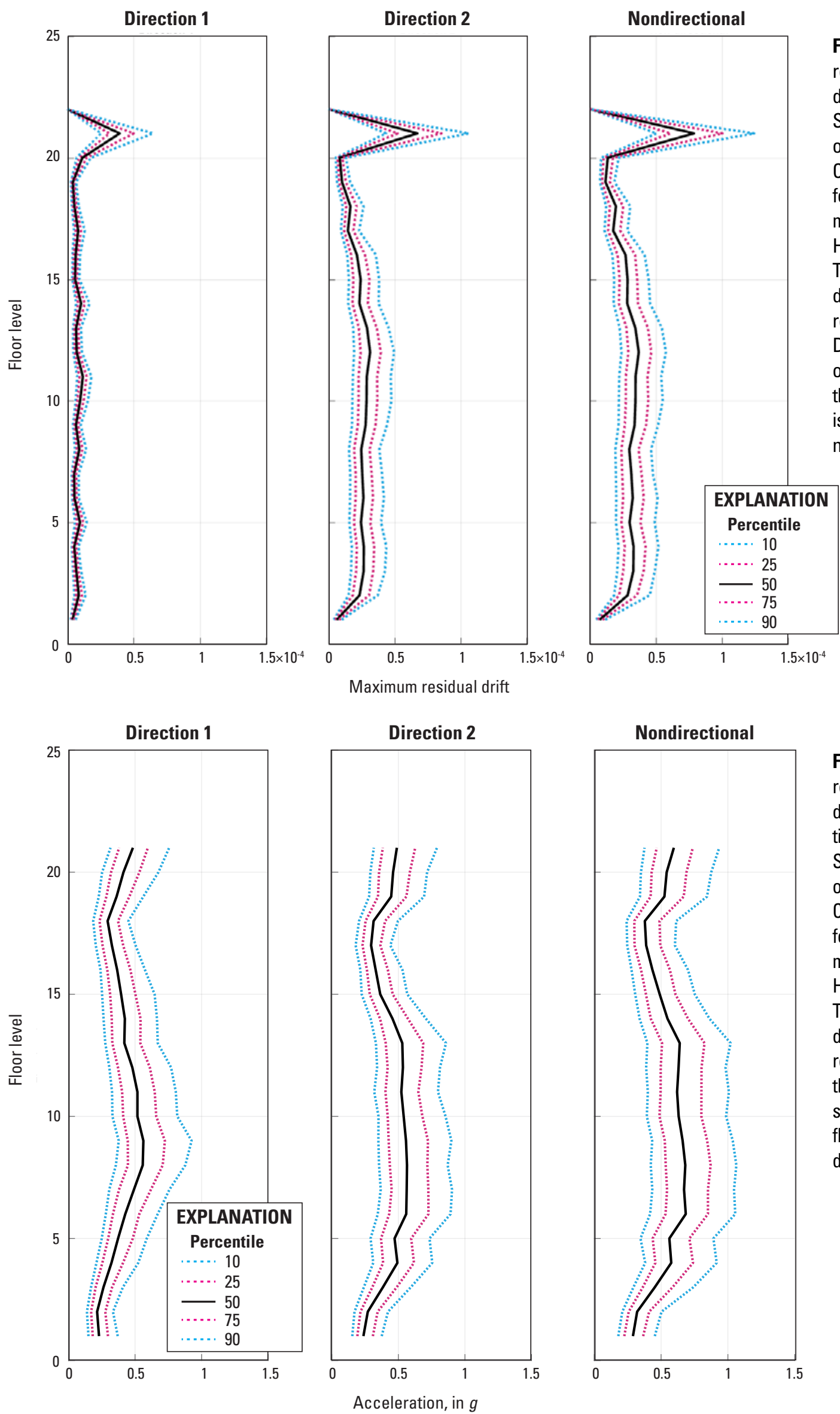

Figure 34. Graphs showing realized peak floor-acceleration demands (relative to acceleration due to gravity, $g$ ) in building S-SF-R-20 (20-story steel-frame office building in San Francisco, California; rotated orientation) for the hypothetical momentmagnitude-7.0 mainshock of the HayWired earthquake scenario. The 50th percentile is taken directly from the nonlinear response-history analysis. Due to the explicit modeling of the substructure, level 2 is the ground floor. Direction 1 is east-west and direction 2 is north-south. 


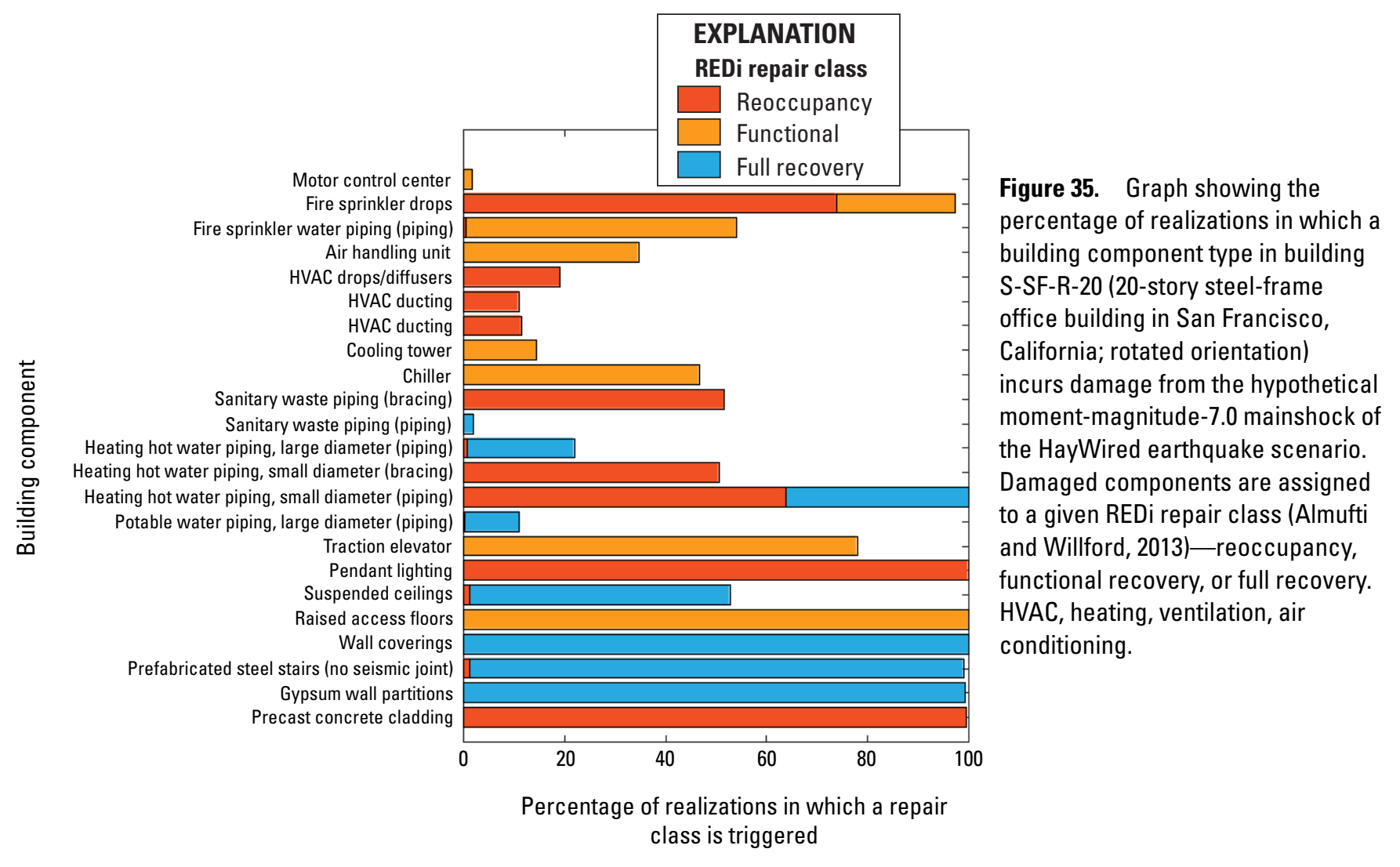

\section{Repair Costs, Repair Time, Downtime, and Impending Factors}

The median total repair cost in building S-SF-R-20 is 8.2 percent of the total building replacement value, or $\$ 5.7$ million. The 90th-percentile total repair cost is 10.4 percent of the total building replacement value, or $\$ 7.3$ million. For this study, the total building replacement value is defined as the hard costs only required to replace the building, based on a construction cost estimate including at minimum all structural and nonstructural components plus the value of damageable building contents if they are known. Figure 36 shows the contribution of building component groups to realized median total repair cost. Table 23 shows realized median and 90th-percentile repair time and total downtime, and table 24 shows realized median and 90th-percentile delays due to impeding factors to functional recovery.

Table 23. Realized median and 90th-percentile repair time and total downtime for building S-SF-R-20 (20-story steel-frame office building in San Francisco, California; rotated orientation) due to the hypothetical momentmagnitude-7.0 mainshock of the HayWired earthquake scenario.

[REDi (Almufti and Willford, 2013)]

\begin{tabular}{lccc}
\hline \multicolumn{1}{c}{ Repair time } & Reoccupancy, & REDi repair class & \\
\cline { 2 - 4 } & in days & $\begin{array}{c}\text { Functional recovery, } \\
\text { in days }\end{array}$ & $\begin{array}{c}\text { Full recovery, } \\
\text { in days }\end{array}$ \\
\hline Median repair time & 23 & 33 & 41 \\
Median total downtime & 186 & 251 & 253 \\
90th-percentile repair time & 47 & 189 & 199 \\
90th-percentile downtime & 304 & 361 & 363 \\
\hline
\end{tabular}




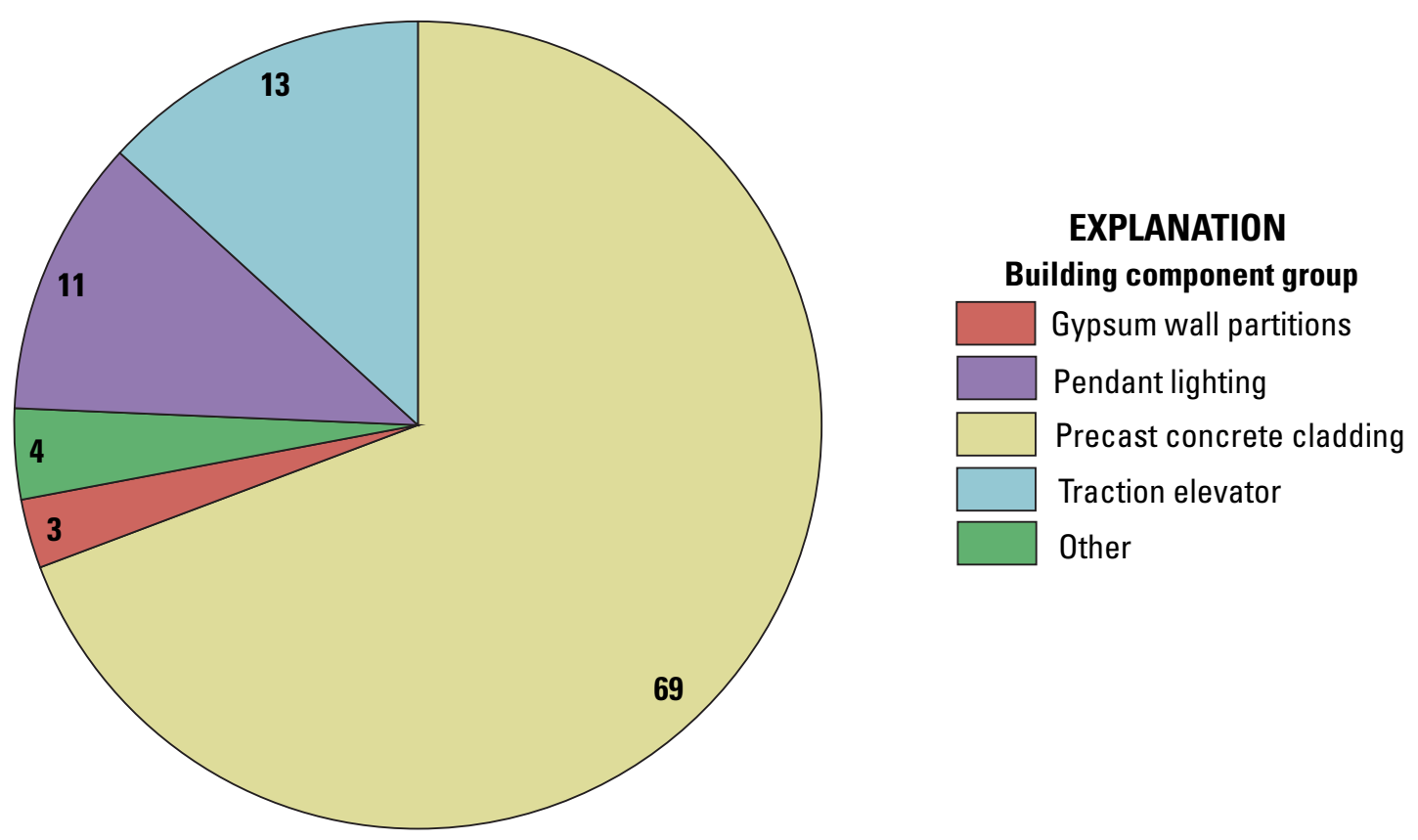

Figure 36. Pie chart showing the percentage contribution of building component groups to realized median total repair cost for building S-SF-R-20 (20-story steel-frame office building in San Francisco, California; rotated orientation) due to the hypothetical moment-magnitude-7.0 mainshock of the HayWired earthquake scenario.

Table 24. Realized median and 90th-percentile delays due to impeding factors to functional recovery for building S-SF-R-20 (20-story steel-frame office building in San Francisco, California; rotated orientation) due to the hypothetical moment-magnitude-7.0 mainshock of the HayWired earthquake scenario.

\begin{tabular}{lccl}
\hline \multicolumn{1}{c}{ Impeding factor } & $\begin{array}{c}\text { Median disruption, } \\
\text { in days }\end{array}$ & $\begin{array}{c}\text { 90th-percentile disruption, } \\
\text { in days }\end{array}$ & Comment \\
\hline Inspection & 5 & 10 & None. \\
Financing & 93 & 229 & None. \\
Engineer mobilization & 0 & 0 & $\begin{array}{c}\text { The median engineer mobilization is zero because no } \\
\text { structural components are damaged. }\end{array}$ \\
Contractor mobilization & 237 & 344 & None. \\
Permitting & 0 & 0 & No structural damage. \\
\hline
\end{tabular}




\section{Appendix 6. S-OK-B-20-20-Story Steel-Frame Building in Oakland (Baseline Orientation)}

\section{S-OK-B-20 Description}

This appendix summarizes the results of interest for the HayWired mainshock from the structural analysis and loss assessment of building S-OK-B-20 - a 20 -story steel-frame office building in Oakland with the baseline orientation shown in figure 7.

\section{Engineering-Demand Parameters}

The simulation of EDPs follows the method recommended by FEMA P-58 (Applied Technology Council, 2012) for buildings with nonlinear response history analysis results available. This algorithm was developed by Yang and others (2009).

Building S-OK-B-20 sees moderate acceleration demands, with peak nondirectional median floor acceleration for the whole building at $1.04 \mathrm{~g}$, significantly higher than the San Francisco buildings. Peak median interstory drift ratio for the whole building is 1.5 percent and the peak residual interstory drift ratio is 0.1 percent. As shown in figure 37, the peak residual drift occurs in the building's long direction (north-south) around level 10. This is because, as shown in figure 38 , the beams in the long direction see yielding and fracturing around the mid-height of the building. It should be noted that beam yielding doesn't necessarily mean repair is

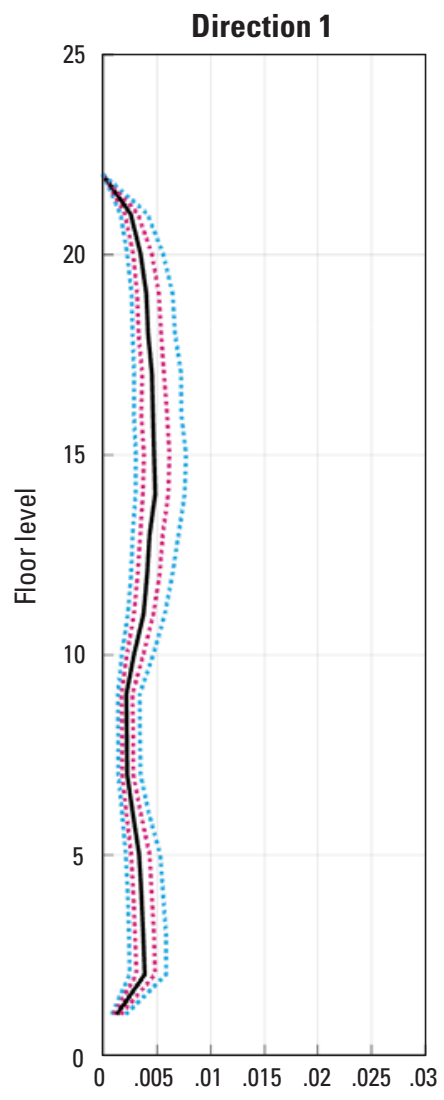

required. Conversely, the columns all remain elastic during the analysis. All column splices remain elastic. Realized peak interstory drift ratio demands are shown in figure 39 , and realized peak floor-acceleration demands for the building are shown in figure 40 .

\section{Loss Assessment Results}

The loss assessment is based on a Monte Carlo simulation with 1,000 realizations. The loss assessment was performed using the probabilistic approach outlined in the Federal Emergency Management Agency's (FEMA) P-58 document (Applied Technology Council, 2012). The likely costs to repair and (or) replace damaged components are calculated based solely on FEMA P-58, whereas repair time and downtime are estimated using the FEMA P-58 based methodology outlined REDi (Almufti and Willford, 2013).

\section{Damaged Components}

The probability that a component type in building S-OK-B-20 incurs damage that hinders either reoccupancy, functionality, or full recovery was examined in the realizations. The results are shown in figure 41.

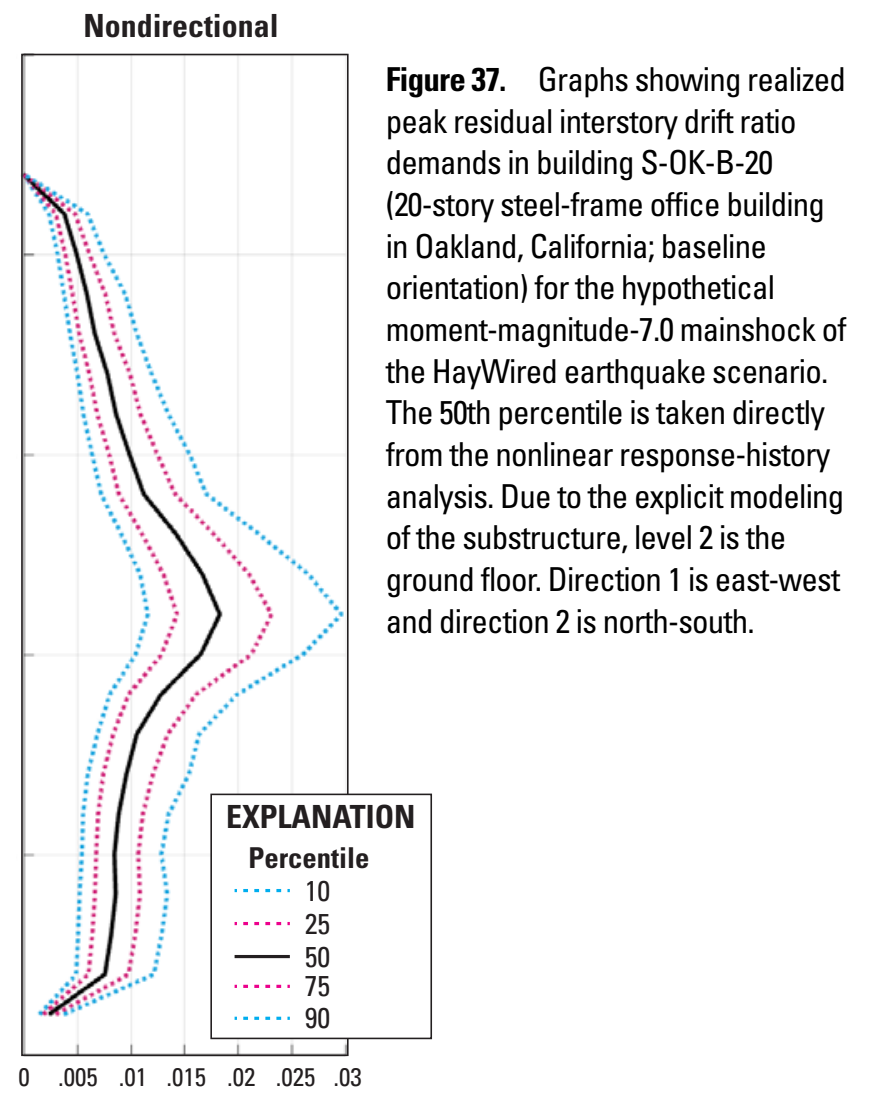




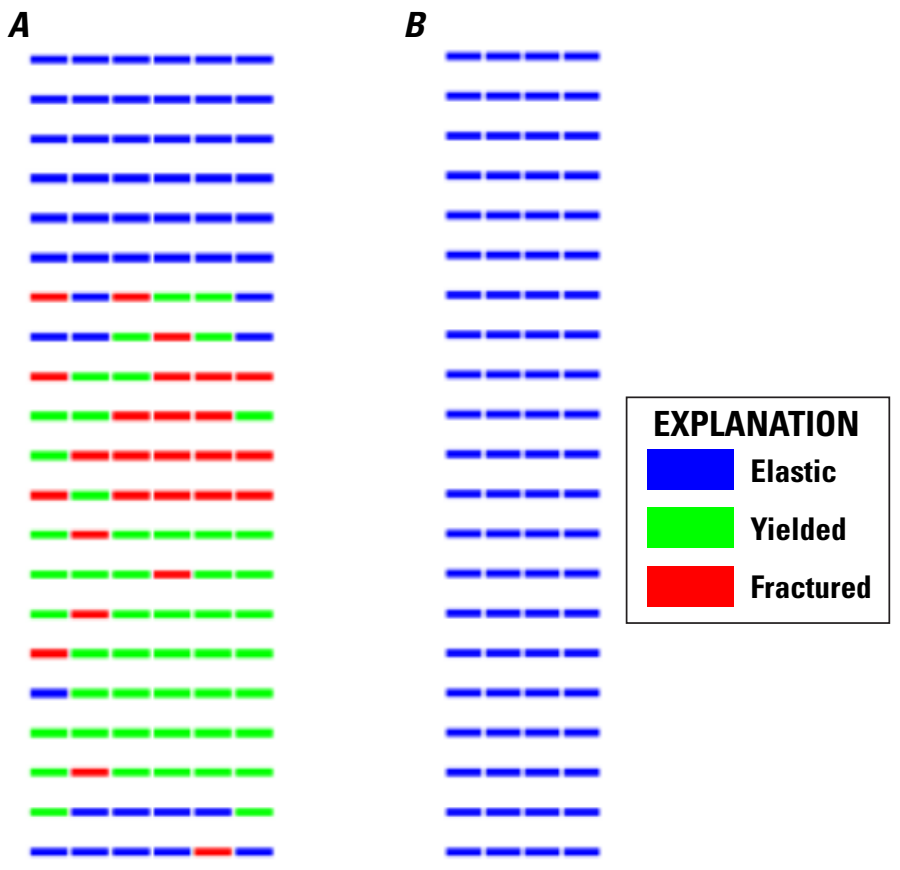

Figure 38. Diagrams showing beam performance for sample $(A)$ long and $(B)$ short elevations of building S-OK-B-20 (20-story steel-frame office building in Oakland, California; baseline orientation) for the hypothetical moment-magnitude-7.0 mainshock of the HayWired earthquake scenario. The 50th percentile is taken directly from the nonlinear response-history analysis. Due to the explicit modeling of the substructure, level 2 is the ground floor.
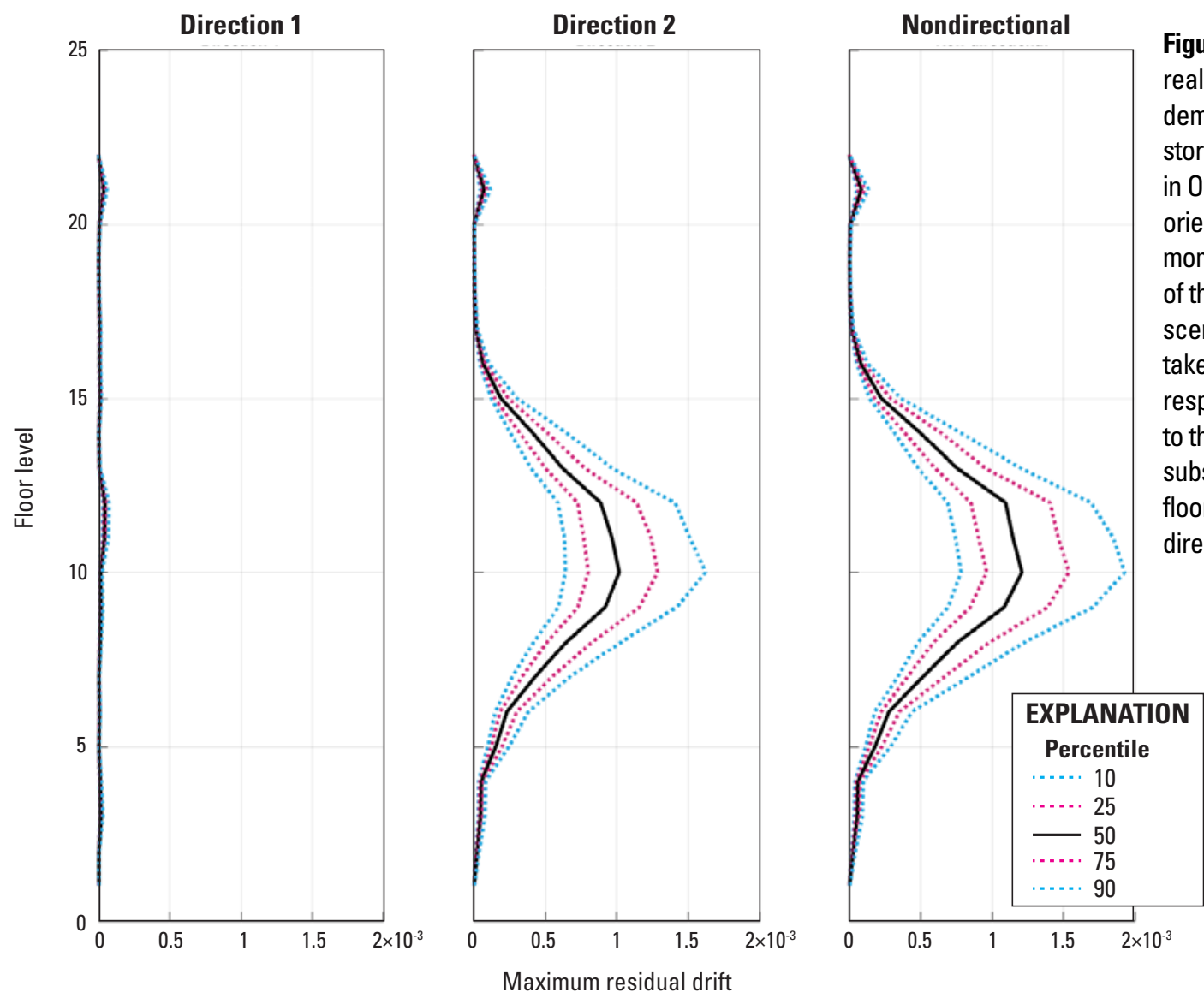

Figure 39. Graphs showing realized peak interstory drift ratio demands in building S-OK-B-20 (20story steel-frame office building in Oakland, California; baseline orientation) for the hypothetical moment-magnitude-7.0 mainshock of the HayWired earthquake scenario. The 50th percentile is taken directly from the nonlinear response-history analysis. Due to the explicit modeling of the substructure, level 2 is the ground floor. Direction 1 is east-west and direction 2 is north-south. 


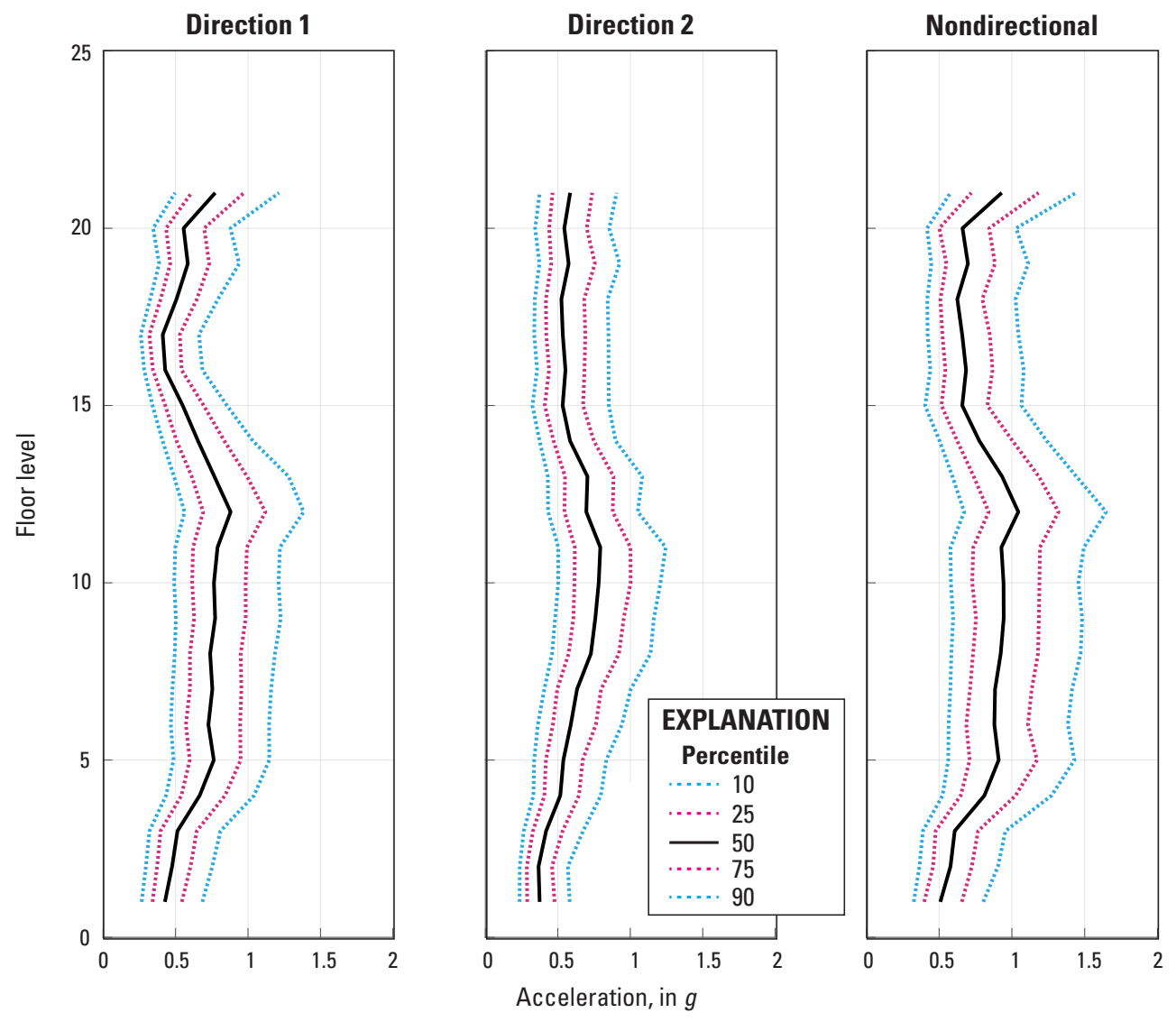

Figure 40. Graphs showing realized peak floor-acceleration demands (relative to acceleration due to gravity, $g$ ) in building S-OK-B-20 (20-story steel-frame office building in Oakland, California; baseline orientation) for the hypothetical momentmagnitude-7.0 mainshock of the HayWired earthquake scenario. The 50th percentile is taken directly from the nonlinear response-history analysis. Due to the explicit modeling of the substructure, level 2 is the ground floor. Direction 1 is east-west and direction 2 is north-south.

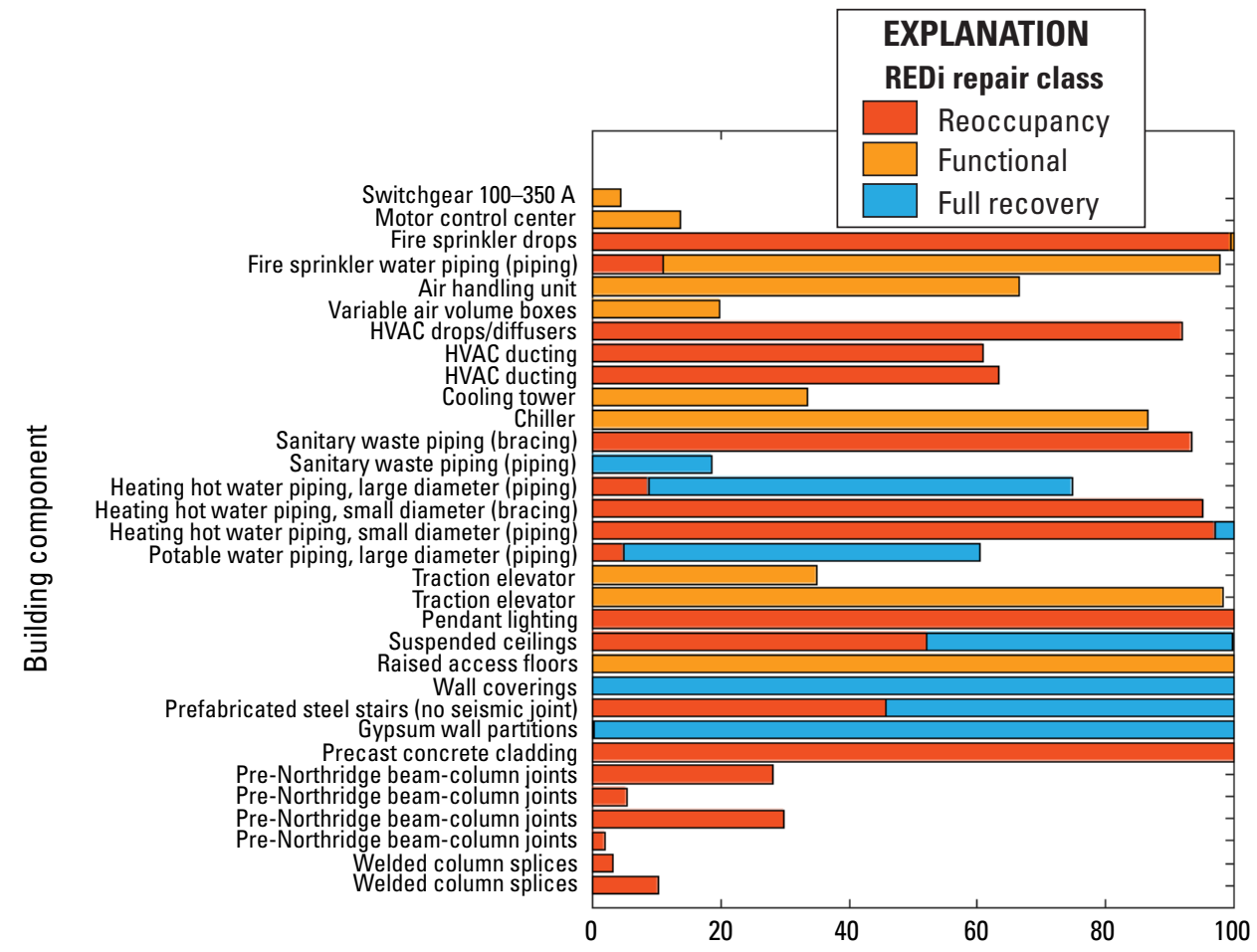

Percentage of realizations in which a repair class is triggered
Figure 41. Graph showing the percentage of realizations in which a building component type in building S-OK-B-20 (20-story steel-frame office building in Oakland, California; baseline orientation) incurs damage from the hypothetical momentmagnitude-7.0 mainshock of the HayWired earthquake scenario. Damaged components are assigned to a given REDi repair class (Almufti and Willford, 2013) - reoccupancy, functional recovery, or full recovery. HVAC, heating, ventilation, air conditioning; $A$, ampere. 


\section{Repair Costs, Repair Time, Downtime, and Impending Factors}

The median total repair cost for building S-OK-B-20 is 17.5 percent of the total building replacement value, or $\$ 12.2$ million. The 90th-percentile total repair cost is 20.7 percent of the total building replacement value, or $\$ 14.4$ million. For this study, the total building replacement value is defined as the hard costs only required to replace the building, based on a construction cost estimate including at minimum all structural and nonstructural components plus the value of damageable building contents if they are known. Figure 42 shows the contribution of building component groups to realized median total repair cost. Table 25 shows realized median and 90th-percentile repair time and total downtime, and table 26 shows realized median and 90th-percentile delays due to impeding factors to functional recovery.

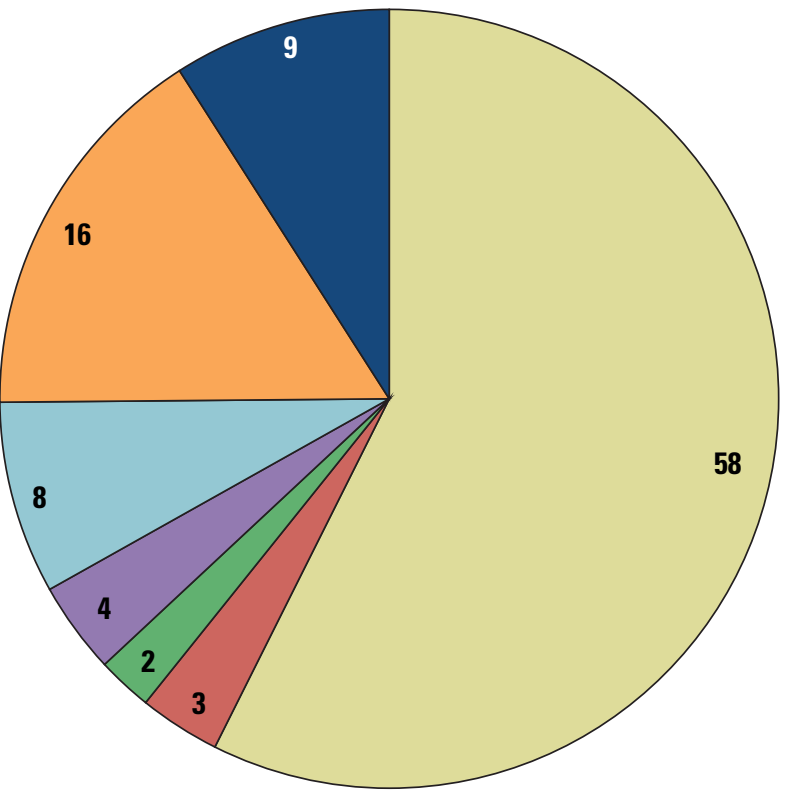

\section{EXPLANATION}

Building component group

Chiller

Gypsum wall partitions

Pendant lighting

Precast concrete cladding

Figure 42. Pie chart showing the percentage contribution of building component groups to realized median total repair cost for building S-OK-B-20 (20-story steel-frame office building in Oakland, California; baseline orientation) due to the hypothetical moment-magnitude-7.0 mainshock of the HayWired earthquake scenario.

Table 25. Realized median and 90th-percentile repair time and total downtime for building S-0K-B-20 (20-story steel-frame office building in Oakland, California; baseline orientation) due to the hypothetical moment-magnitude-7.0 mainshock of the HayWired earthquake scenario.

[REDi (Almufti and Willford, 2013)]

\begin{tabular}{lccc}
\hline \multicolumn{1}{c}{ Repair time } & \multicolumn{3}{c}{ REDi repair class } \\
\cline { 2 - 4 } & $\begin{array}{c}\text { Reoccupancy, } \\
\text { in days }\end{array}$ & $\begin{array}{c}\text { Functional recovery, } \\
\text { in days }\end{array}$ & $\begin{array}{c}\text { Full recovery, } \\
\text { in days }\end{array}$ \\
\hline Median repair time & 54 & 92 & 100 \\
Median total downtime & 231 & 273 & 277 \\
90th-percentile repair time & 116 & 272 & 274 \\
90th-percentile downtime & 343 & 385 & 388 \\
\hline
\end{tabular}

Table 26. Realized median and 90th-percentile delays due to impeding factors to functional recovery for building S-0K-B-20 (20-story steel-frame office building in Oakland, California; baseline orientation) due to the hypothetical moment-magnitude-7.0 mainshock of the HayWired earthquake scenario.

\begin{tabular}{lccl}
\hline \multicolumn{1}{c}{ Impeding factor } & $\begin{array}{c}\text { Median disruption, } \\
\text { in days }\end{array}$ & $\begin{array}{c}\text { 90th-percentile disruption, } \\
\text { in days }\end{array}$ & Comment \\
\hline Inspection & 5 & 10 & None. \\
Financing & 45 & 189 & None. \\
Engineer mobilization & 46 & 123 & Engineer mobilization is triggered by structural damage. \\
Contractor mobilization & 254 & 363 & None. \\
Permitting & 33 & 74 & Permitting is triggered by structural damage. \\
\hline
\end{tabular}




\section{Appendix 7. S-OK-R-20-20-Story Steel-Frame Building in Oakland (Rotated Orientation)}

\section{S-OK-R-20 Description}

This appendix summarizes the results of interest for the HayWired mainshock from the structural analysis and loss assessment of building S-OK-R-20 - a 20-story steel-frame office building in Oakland with the rotated orientation shown in figure 7. Results are shown in figures 43-45.

\section{Engineering-Demand Parameters}

The simulation of EDPs follows the method recommended by FEMA P-58 (Applied Technology Council, 2012) for buildings with nonlinear response history analysis results available. This algorithm was developed by Yang and others (2009).

Building S-OK-R-20 sees moderate acceleration demands, with peak nondirectional median floor acceleration for the whole building at $1.06 \mathrm{~g}$, significantly higher than the San Francisco buildings. Peak median interstory drift ratio for the whole building is 1.0 percent, and the peak residual interstory drift ratio is 0.007 percent. Roughly a quarter of the beams either yield or fracture on average. Conversely, the columns all remain elastic during the analysis. All column splices remain elastic.

\section{Loss-Assessment Results}

The loss assessment is based on a Monte Carlo simulation with 1,000 realizations. The loss assessment was performed using the probabilistic approach outlined in the Federal Emergency Management Agency's (FEMA) P-58 document (Applied Technology Council, 2012). The likely costs to repair and (or) replace damaged components are calculated based solely on FEMA P-58, whereas repair time and downtime are estimated using the FEMA P-58 based methodology outlined REDi (Almufti and Willford, 2013).

\section{Damaged Components}

The probability that a component type in building S-OK-R-20 incurs damage that hinders either reoccupancy, functionality, or full recovery was examined in the realizations. The results are shown in figure 46.
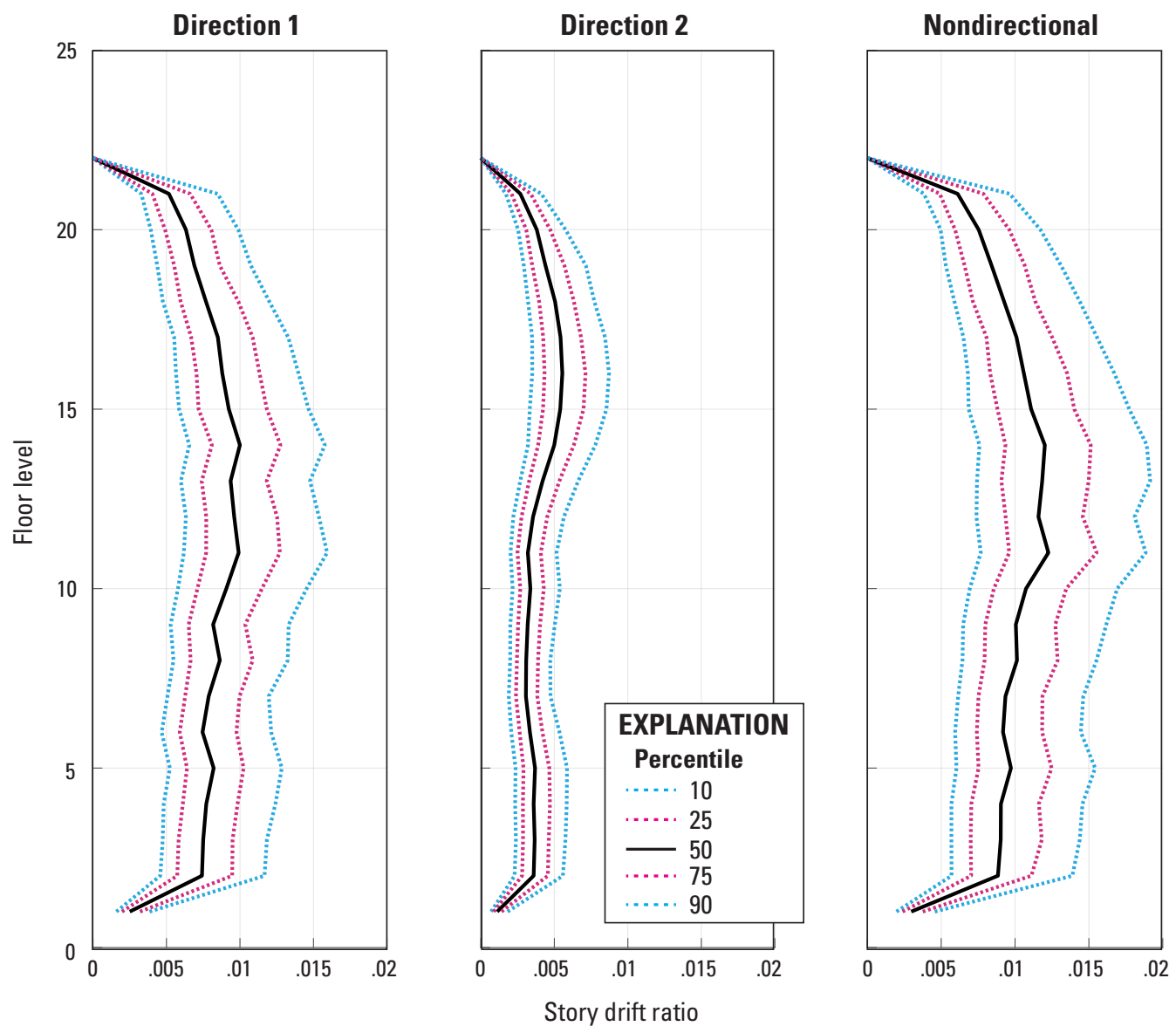

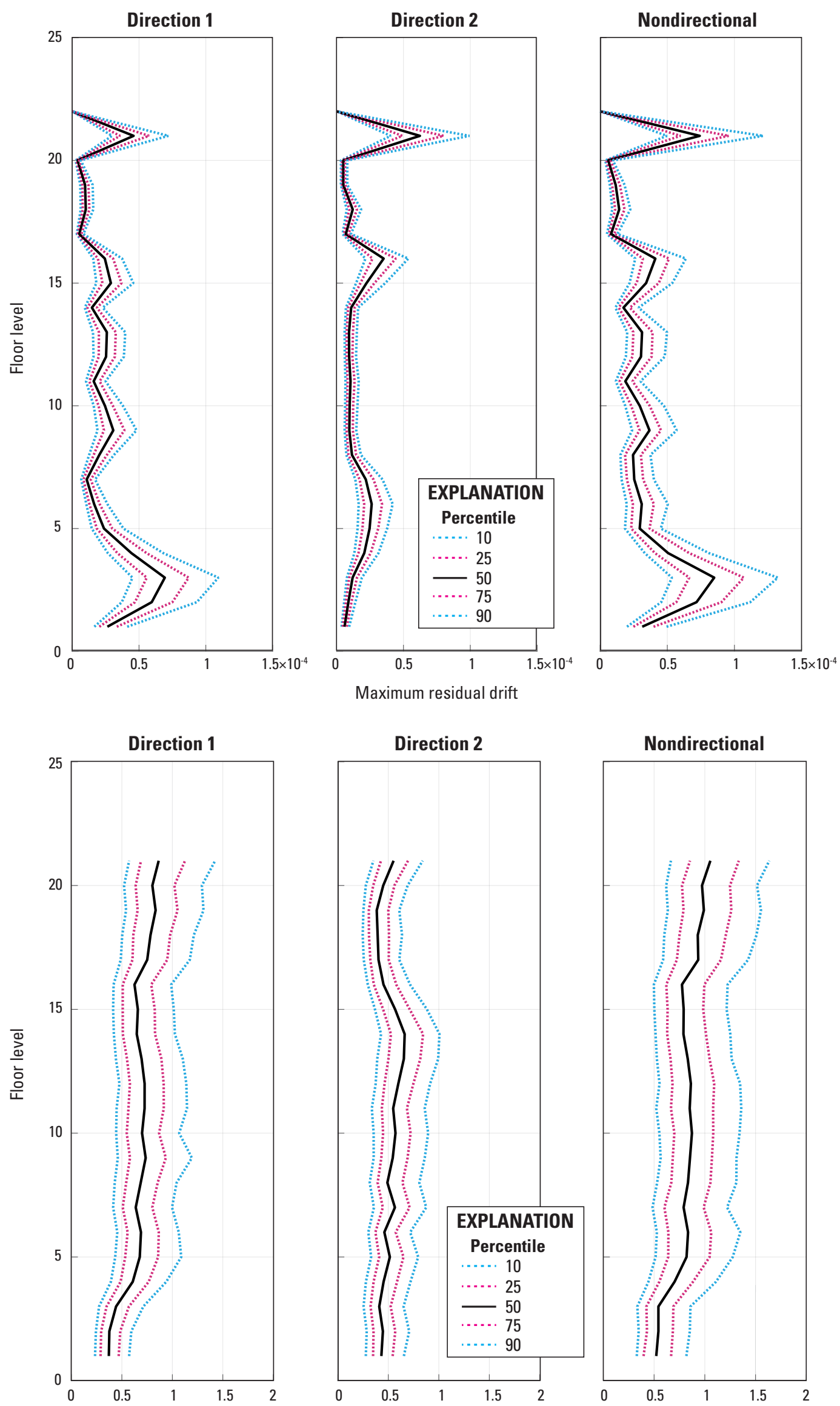

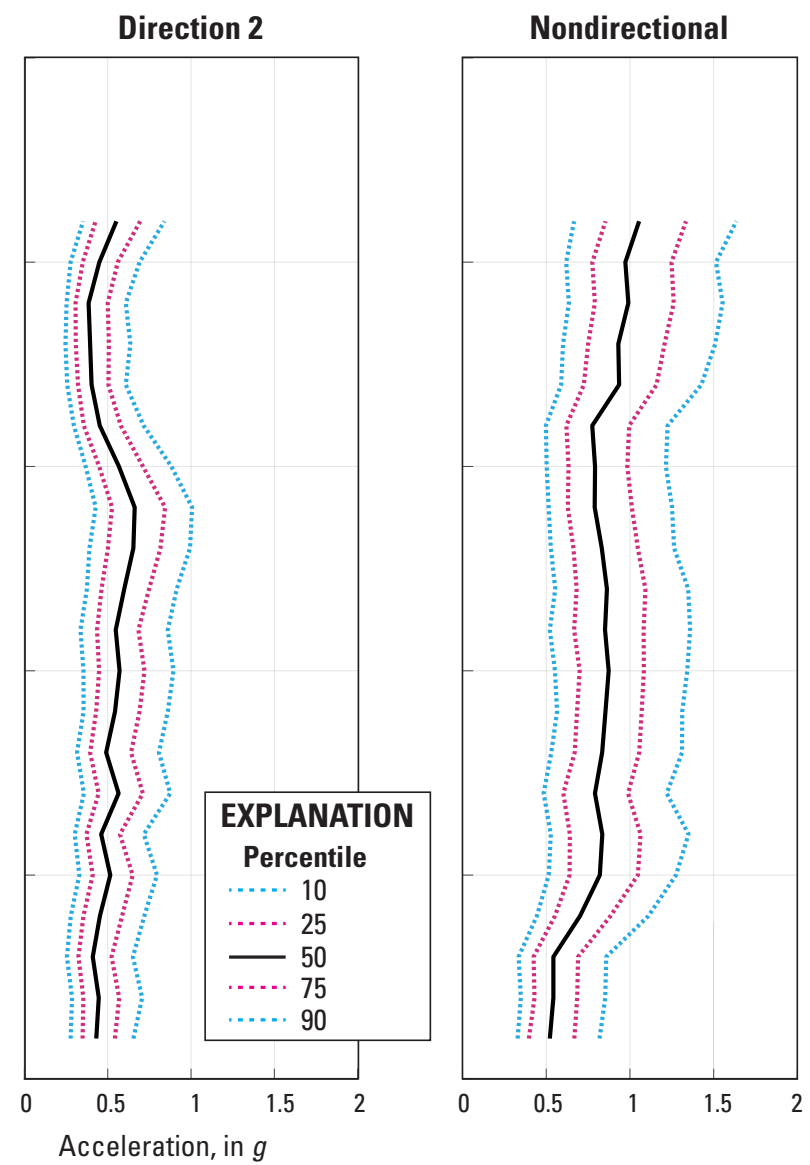

Figure 44. Graphs showing realized peak residual interstory drift ratio demands in building S-OK-R-20 (20-story steel-frame office building in Oakland, California; rotated orientation) for the hypothetical momentmagnitude-7.0 mainshock of the HayWired earthquake scenario. The 50th percentile is taken directly from the nonlinear response-history analysis. Due to the explicit modeling of the substructure, level 2 is the ground floor. Direction 1 is east-west and direction 2 is north-south.
Figure 45. Graphs showing realized peak floor-acceleration demands (relative to acceleration due to gravity, $g$ ) in building S-OK-R-20 (20-story steel-frame office building in Oakland, California; rotated orientation) for the hypothetical moment-magnitude-7.0 mainshock of the HayWired earthquake scenario. The 50th percentile is taken directly from the nonlinear response-history analysis. Due to the explicit modeling of the substructure, level 2 is the ground floor. Direction 1 is east-west and direction 2 is north-south. 


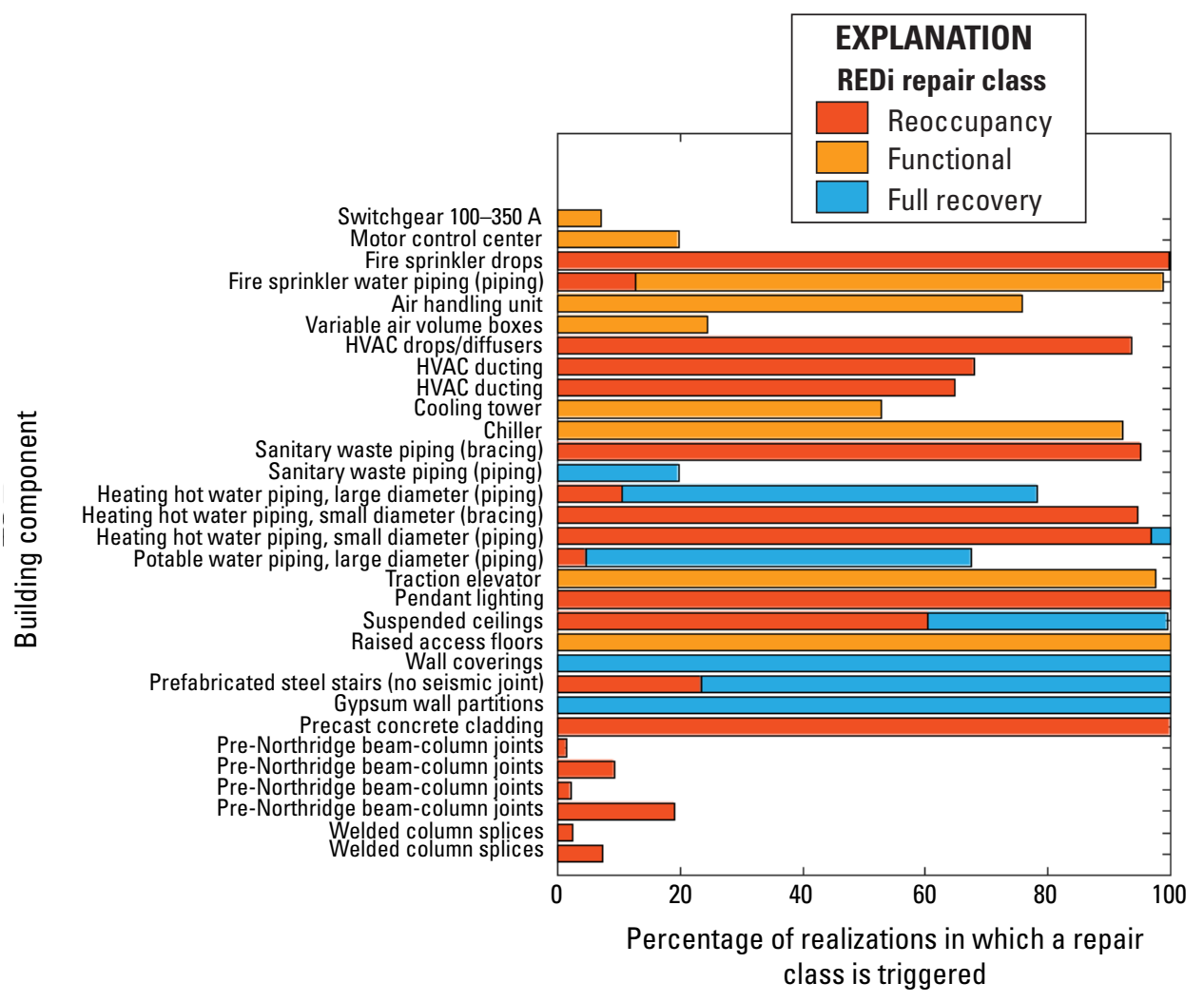

Figure 46. Graph showing the percentage of realizations in which a building component type in building S-OK-R-20 (20-story steel-frame office building in Oakland, California; rotated orientation) incurs damage from the hypothetical momentmagnitude-7.0 mainshock of the HayWired earthquake scenario. Damaged components are assigned to a given REDi repair class (Almufti and Willford, 2013)—reoccupancy, functional recovery, or full recovery. HVAC, heating, ventilation, air conditioning; $A$, ampere.

\section{Repair Costs, Repair Time, Downtime, and Impending Factors}

The median total repair cost for building S-OK-R-20 is 16.5 percent of the total building replacement value, or $\$ 11.5$ million. The 90th-percentile total repair cost is 18.7 percent of the total building replacement value, or $\$ 13.1$ million. For this study, the total building replacement value is defined as the hard costs only required to replace the building, based on a construction cost estimate including at minimum all structural and nonstructural components plus the value of damageable building contents if they are known. Figure 47 shows the contribution of building component groups to realized median total repair cost. Table 27 shows realized median and 90th-percentile repair time and total downtime, and table 28 shows realized median and 90th-percentile delays due to impeding factors to functional recovery.

Table 27. Realized median and 90th-percentile repair time and total downtime for building S-OK-R-20 (20-story steel-frame office building in 0akland, California; rotated orientation) due to the hypothetical moment-magnitude-7.0 mainshock of the HayWired earthquake scenario.

[REDi (Almufti and Willford, 2013)]

\begin{tabular}{lccc}
\hline \multicolumn{1}{c}{ Repair time } & \multicolumn{2}{c}{ REDi repair class } \\
\cline { 2 - 4 } & $\begin{array}{c}\text { Reoccupancy, } \\
\text { in days }\end{array}$ & $\begin{array}{c}\text { Functional recovery, } \\
\text { in days }\end{array}$ & $\begin{array}{c}\text { Full recovery, } \\
\text { in days }\end{array}$ \\
\hline Median repair time & 54 & 82 & 91 \\
Median total downtime & 224 & 269 & 274 \\
90th-percentile repair time & 97 & 237 & 241 \\
90th-percentile downtime & 333 & 371 & 378 \\
\hline
\end{tabular}




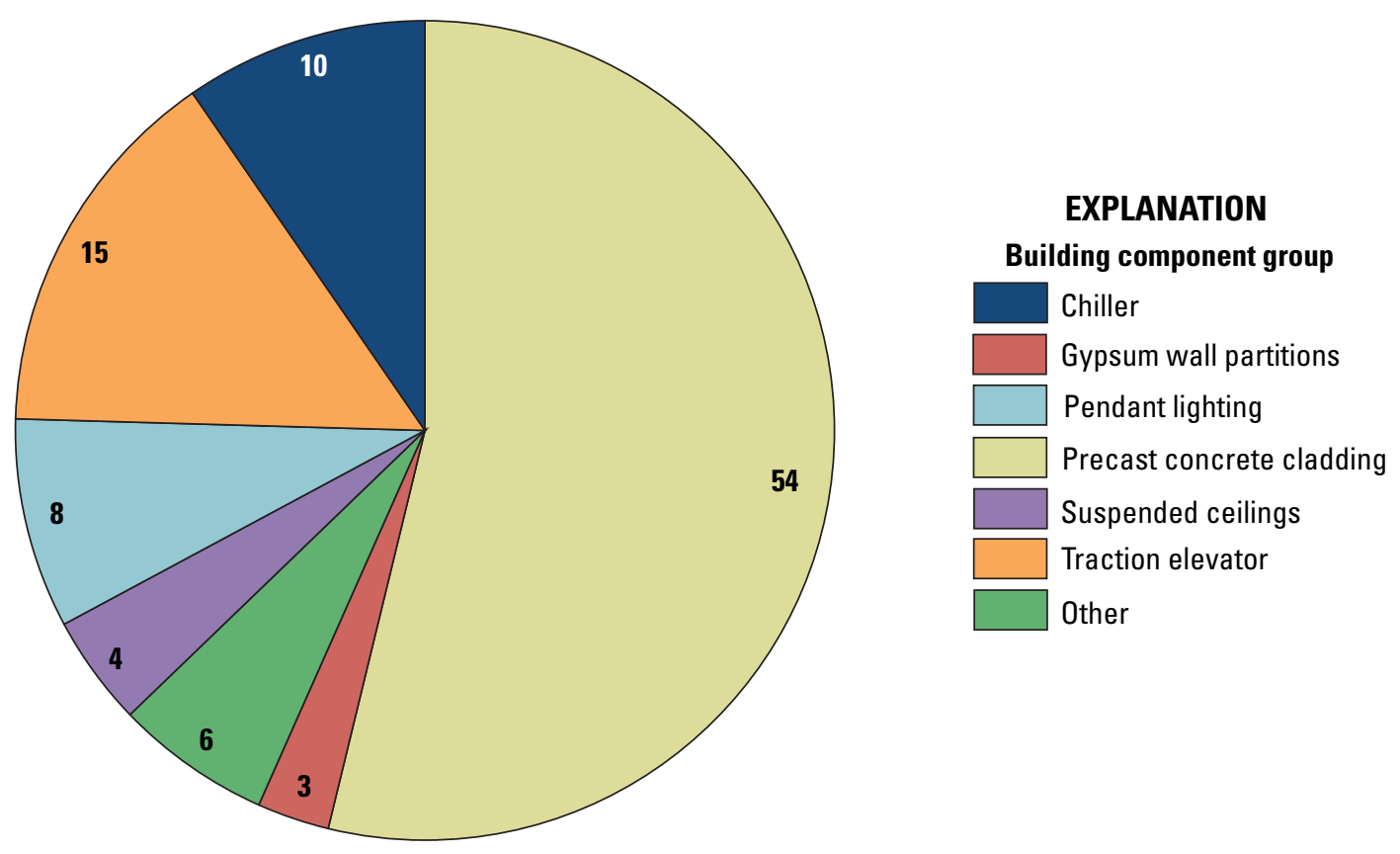

Figure 47. Pie chart showing the percentage contribution of building component groups to realized median total repair cost for building S-OK-R-20 (20-story steel-frame office building in Oakland, California; rotated orientation) due to the hypothetical moment-magnitude-7.0 mainshock of the HayWired earthquake scenario.

Table 28. Realized median and 90th-percentile delays due to impeding factors to functional recovery for building S-0K-R-20 (20-story steel-frame office building in 0akland, California; rotated orientation) due to the hypothetical moment-magnitude-7.0 mainshock of the HayWired earthquake scenario.

\begin{tabular}{lccc}
\hline \multicolumn{1}{c}{ Impeding factor } & $\begin{array}{c}\text { Median disruption, } \\
\text { in days }\end{array}$ & $\begin{array}{c}\text { 90th-percentile disruption, } \\
\text { in days }\end{array}$ & Comment \\
\hline Inspection & 5 & 10 & None. \\
Financing & 41 & 175 & None. \\
Engineer mobilization & 0 & 101 & Engineer mobilization is triggered by structural damage. \\
Contractor mobilization & 249 & 348 & None. \\
Permitting & 0 & 67 & Permitting is triggered by structural damage. \\
\hline
\end{tabular}




\section{Appendix 8. C-SF-B-46-42-Story Reinforced-Concrete Building in San Francisco (Baseline Orientation)}

\section{C-SF-B-46 Description}

This appendix summarizes the results of interest for the HayWired mainshock from the structural analysis and loss assessment of building C-SF-B-46 - a 42-story reinforced-concrete residential building in San Francisco with the baseline orientation shown in figure 10. Results are shown in figures 48-53.

\section{Engineering-Demand Parameters}

The simulation of EDPs follows the method recommended by FEMA P-58 (Applied Technology Council, 2012) for buildings with nonlinear response history analysis results available. This algorithm was developed by Yang and others (2009).

Building C-SF-B-46 sees low demands, with a peak interstory drift (IDR) for whole building of just 0.4 percent. Peak floor acceleration is $0.9 \mathrm{~g}$. Peak coupling beam rotation is 0.006 radian (rad), far below 0.05-0.06 rad, the point at which significant shear strength degradation occurs. The core walls see no crushing. The core-wall rebar experiences little yielding, all occurring at the base of the core walls.
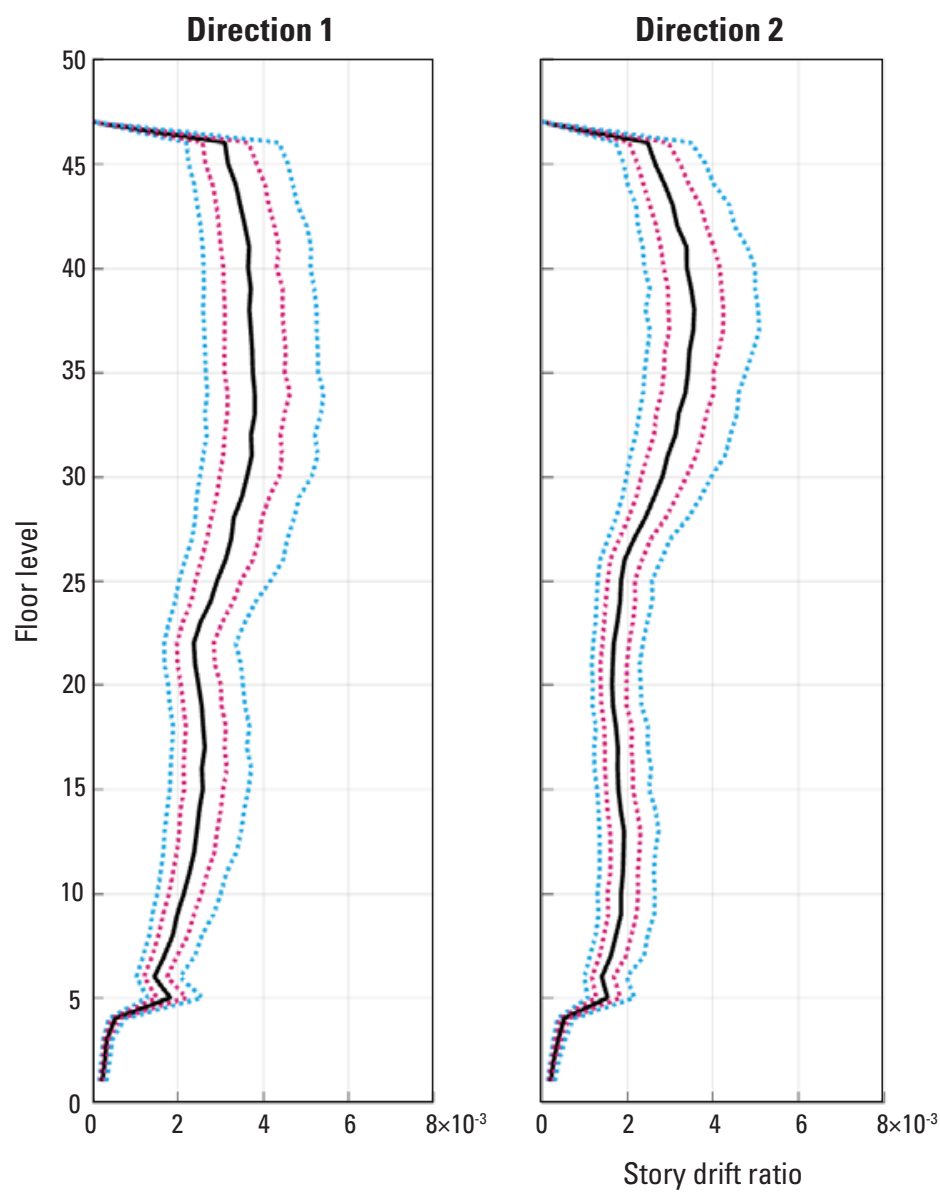

The damage in partitions and slab-column joints is better correlated with racking drift than IDR. Therefore, racking drift was used as the EDP for these components. Racking drift is different from IDR in that it excludes rigid body rotation and includes vertical racking resulting from the relative vertical movement between the core walls and the perimeter columns.

There are a few interesting things to note about the demands. First, figure 51 clearly shows the plastic hinge zone in the core wall at the ground floor level, as evidenced by the large spike in the wall rotation. However, this spike is modest, in an absolute sense, at about $0.00115 \mathrm{rad}$ median. This compares favorably with the acceptable plastic hinge rotation per ASCE 41-13 (American Society of Civil Engineers, 2014) of 0.001-0.002 rad for unconfined walls. Second, figure 53 shows that the coupling beam rotations are fairly constant up the height of the building with the exception of a dip in rotations at level 24 (superstructure floor $20)$, due to a reduction in the core wall reinforcement ratio at level 26 by about half. This reduction in core wall reinforcement is also evidenced by the small spikes in core-wall rotation in figure 52 .

Coupling beam rotation demands were enveloped for all beams on each floor and thus, beam directionality was not considered. Despite this conservatism, beam rotations were very low and had virtually no impact on the loss and downtime assessment.

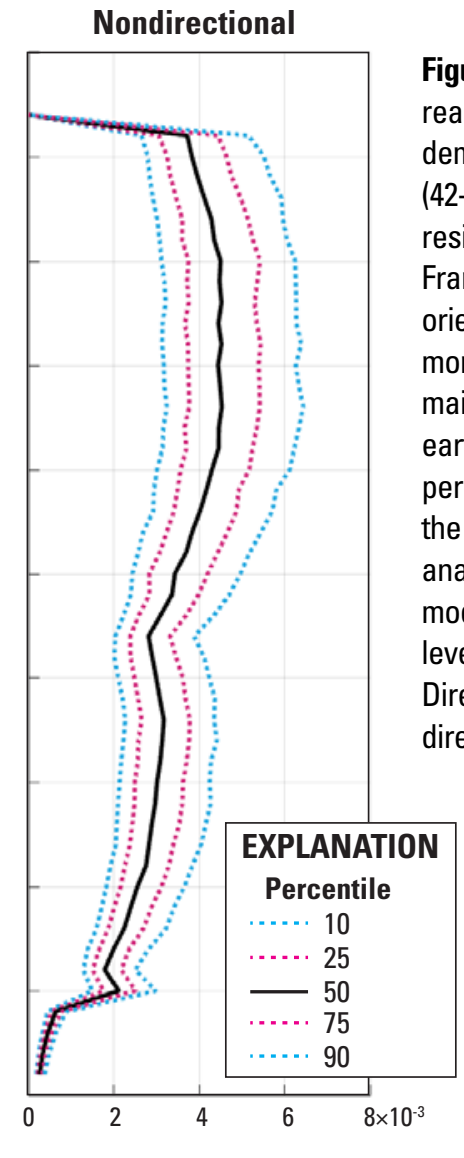

Figure 48. Graphs showing realized peak interstory drift ratio demands in building C-SF-B-46 (42-story reinforced-concrete residential building in San Francisco, California; baseline orientation) for the hypothetical moment-magnitude-7.0 mainshock of the HayWired earthquake scenario. The 50th percentile is taken directly from the nonlinear response-history analysis. Due to the explicit modeling of the substructure, level 5 is the ground floor. Direction 1 is east-west and direction 2 is north-south. 

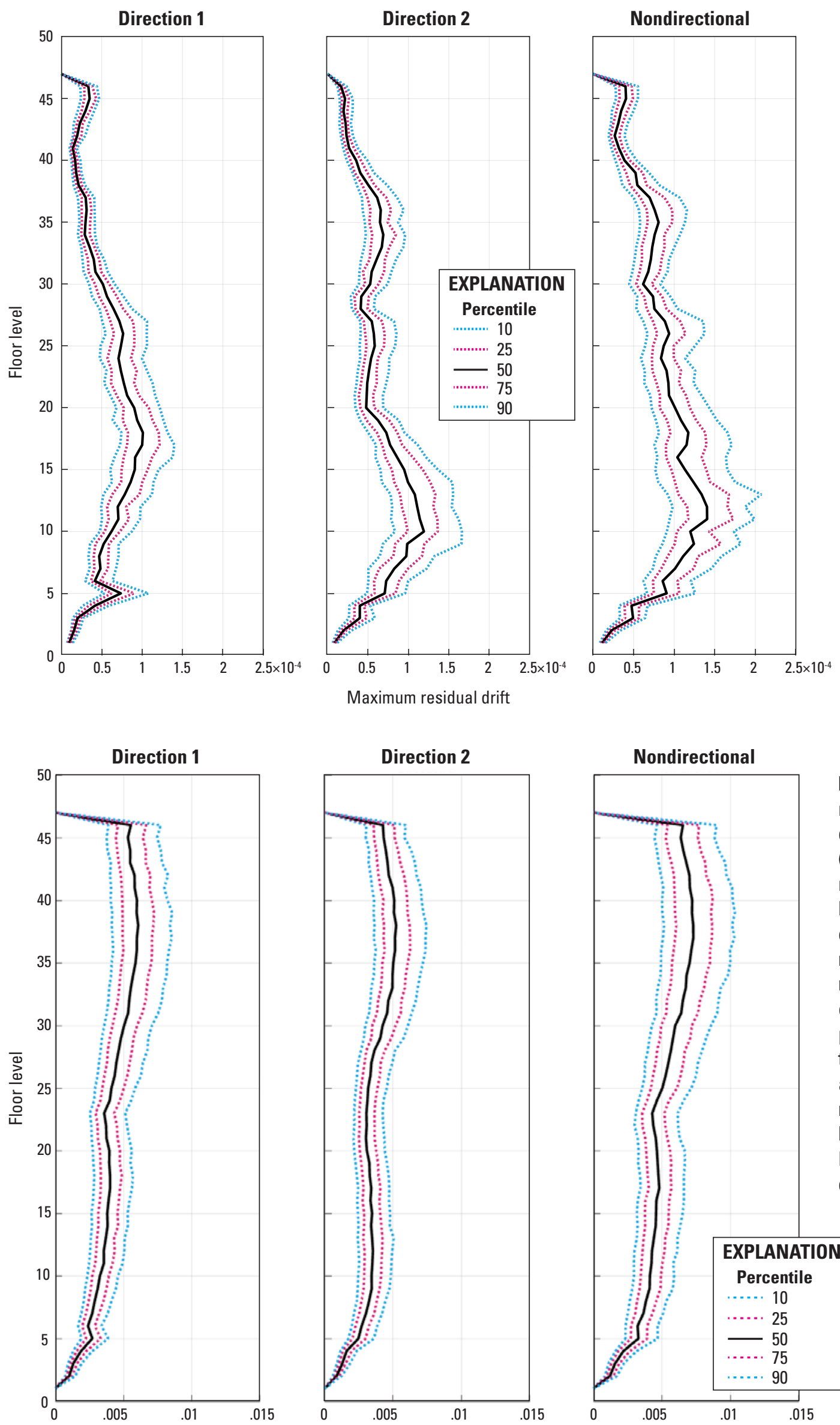

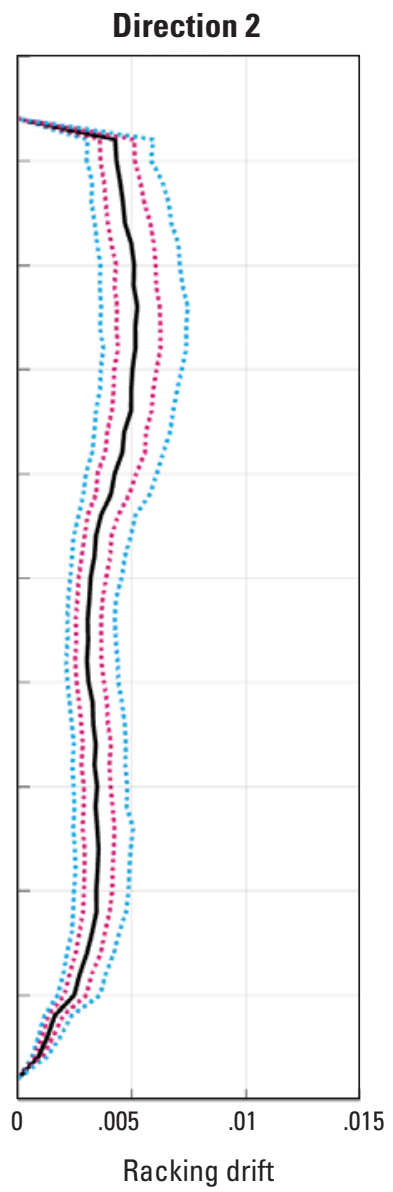

Figure 49. Graphs showing realized peak residual interstory drift ratio demands in building C-SF-B-46 (42story reinforced-concrete residential building in San Francisco, California; baseline orientation) for the hypothetical momentmagnitude-7.0 mainshock of the HayWired earthquake scenario. The 50th percentile is taken directly from the nonlinear responsehistory analysis. Due to the explicit modeling of the substructure, level 5 is the ground floor. Direction 1 is east-west and direction 2 is north-south.
Figure 50. Graphs showing realized peak racking drift ratio demands in building C-SF-B-46 (42-story reinforced-concrete residential building in San Francisco, California; baseline orientation) for the hypothetical moment-magnitude-7.0 mainshock of the HayWired earthquake scenario. The 50th percentile is taken directly from the nonlinear response-history analysis. Due to the explicit modeling of the substructure, level 5 is the ground floor. Direction 1 is east-west and direction 2 is north-south. 

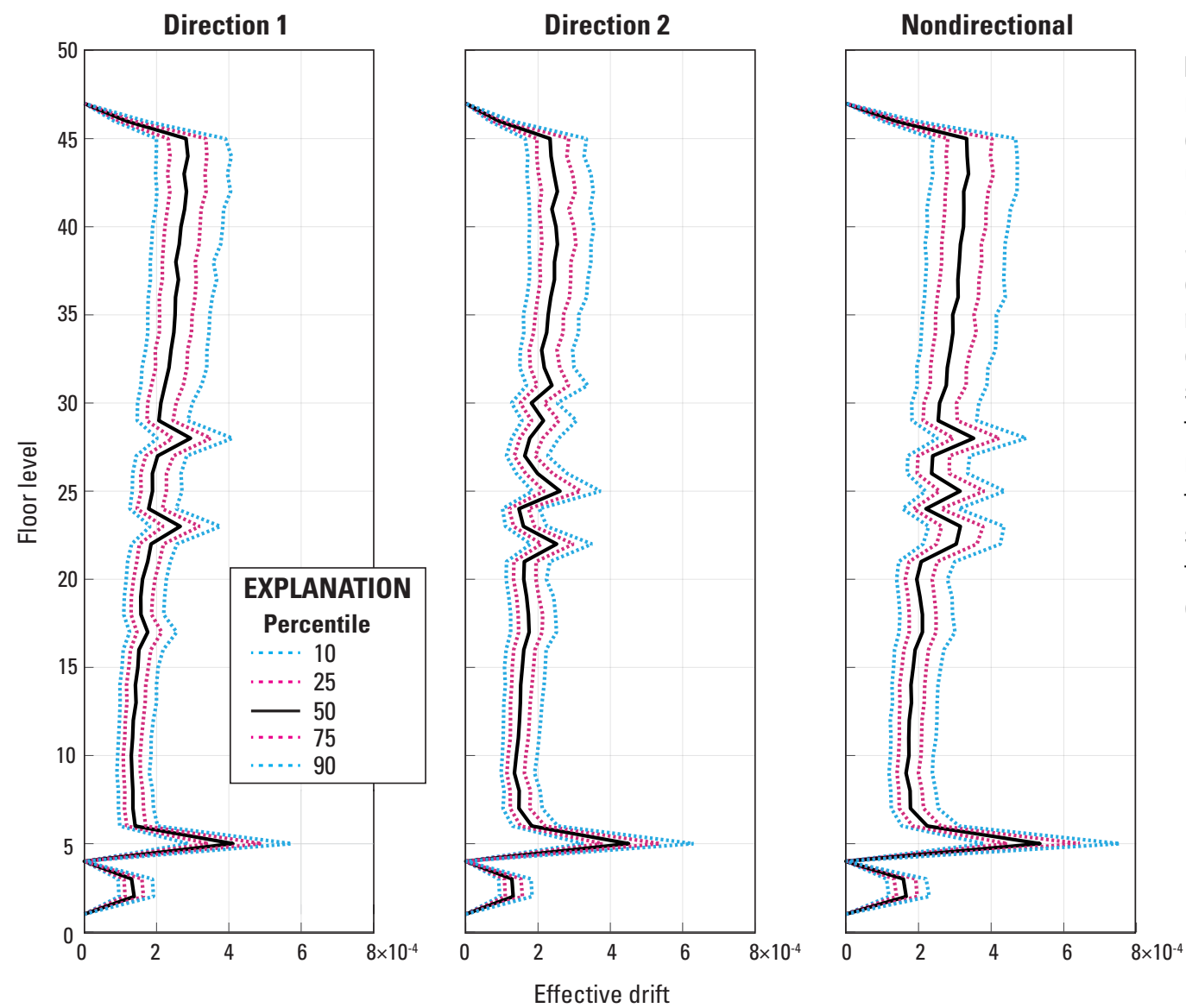

Figure 51. Graphs showing realized peak wall-rotation demands (radians) in building C-SF-B-46 (42-story reinforcedconcrete residential building in San Francisco, California; baseline orientation) for the hypothetical moment-magnitude-7.0 mainshock of the HayWired earthquake scenario. The 50th percentile is taken directly from the nonlinear response-history analysis. Due to the explicit modeling of the substructure, level 5 is the ground floor. Direction 1 is east-west and direction 2 is north-south.
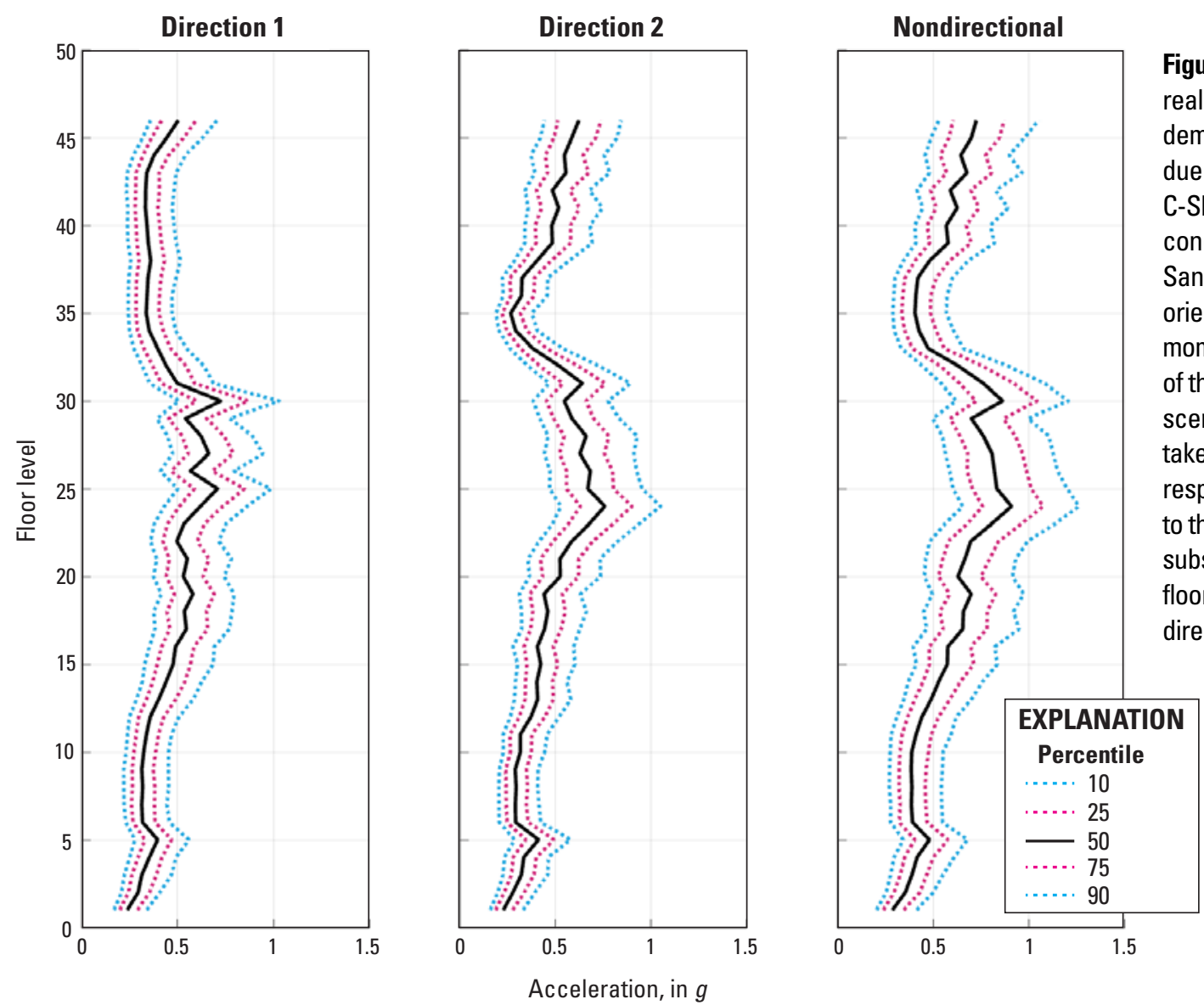

Figure 52. Graphs showing realized peak floor-acceleration demands (relative to acceleration due to gravity, $g$ ) in building C-SF-B-46 (42-story reinforcedconcrete residential building in San Francisco, California; baseline orientation) for the hypothetical moment-magnitude-7.0 mainshock of the HayWired earthquake scenario. The 50th percentile is taken directly from the nonlinear response-history analysis. Due to the explicit modeling of the substructure, level 5 is the ground floor. Direction 1 is east-west and direction 2 is north-south. 


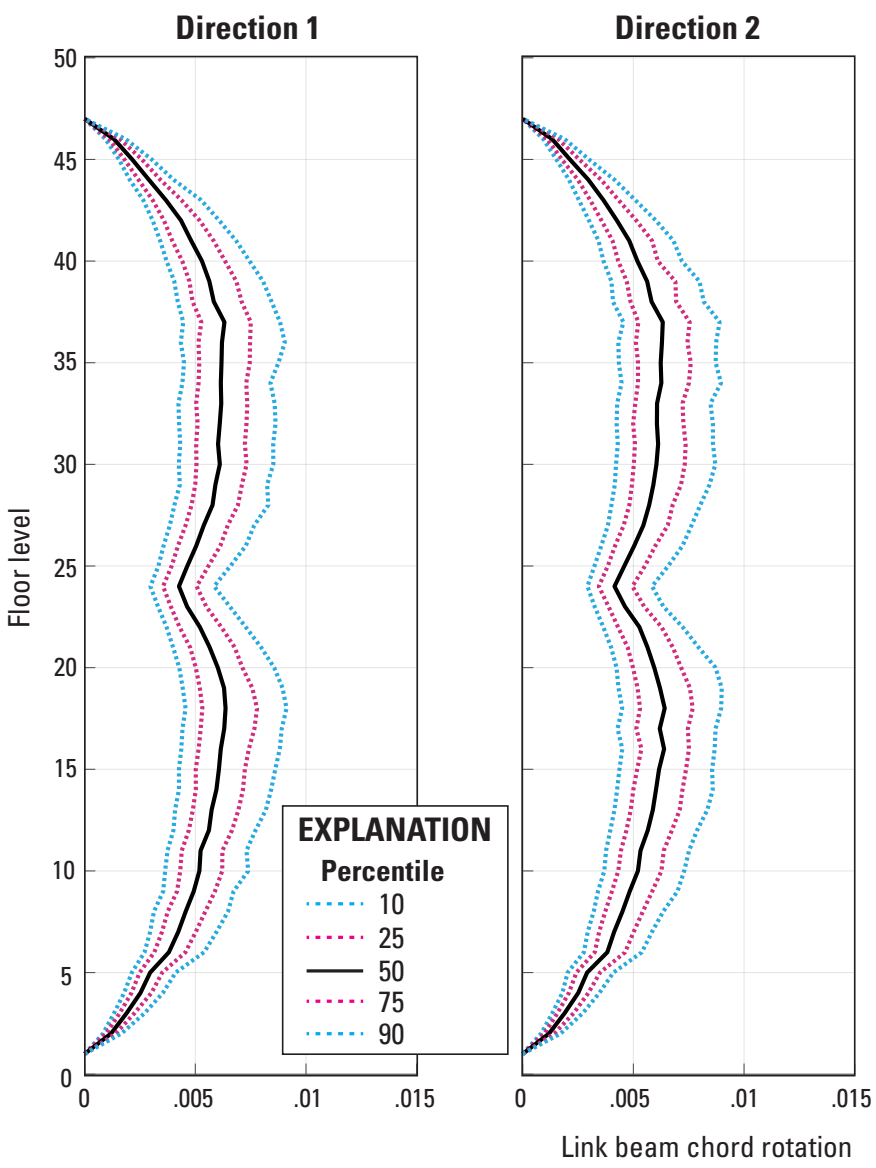

\section{Loss-Assessment Results}

The loss assessment is based on a Monte Carlo simulation with 1,000 realizations. The loss assessment was performed using the probabilistic approach outlined in the Federal Emergency Management Agency's (FEMA) P-58 document (Applied Technology Council, 2012). The likely costs to repair and (or) replace damaged components are calculated based solely on FEMA P-58, whereas repair time and downtime are estimated using the FEMA P-58 based methodology outlined REDi (Almufti and Willford, 2013).

\section{Damaged Components}

The probability that a component type in building C-SF-B-46 incurs damage that hinders either reoccupancy, functionality, or full recovery was examined in the realizations. The results are shown in figure 54.

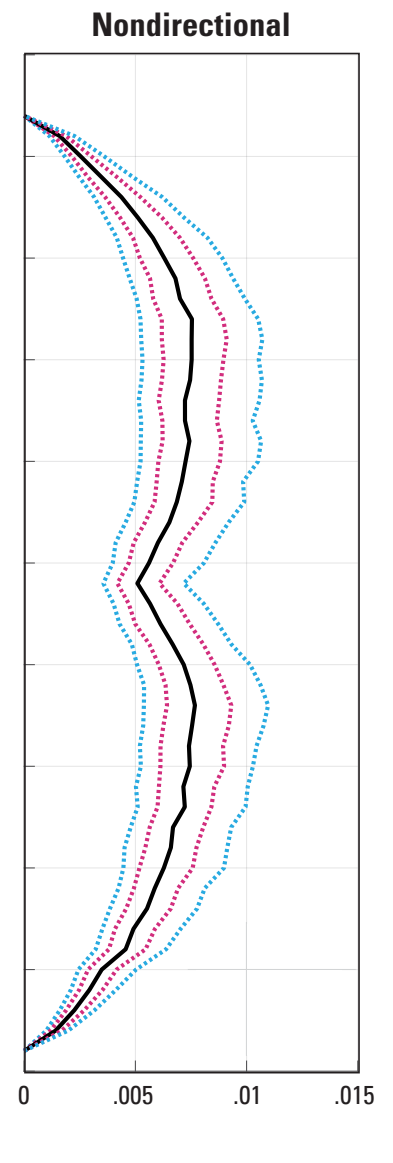

Figure 53. Graphs showing realized peak coupling-beam rotation demands (radians) in building C-SF-B-46 (42-story reinforced-concrete residential building in San Francisco, California; baseline orientation) for the hypothetical momentmagnitude- 7.0 mainshock of the HayWired earthquake scenario. The 50th percentile is taken directly from the nonlinear response-history analysis. Due to the explicit modeling of the substructure, level 5 is the ground floor. Direction 1 is east-west and direction 2 is north-south.

\section{Repair Costs, Repair Time, Downtime, and Impending Factors}

The median total repair cost for building C-SF-B-46 is 3.1 percent of the total building replacement value, or $\$ 5.5$ million. The 90th-percentile total repair cost is 3.7 percent of the total building replacement value, or $\$ 6.5$ million. For this study, the total building replacement value is defined as the hard costs only required to replace the building, based off a construction cost estimate, including at minimum all structural and nonstructural components plus the value of damageable building contents if they are known. The total repair cost is dominated by wall partitions because there are a large number of partitions in a residential building. Figure 55 shows the contribution of building component groups to realized median total repair cost. Table 29 shows realized median and 90th-percentile repair time and total downtime, and table 30 shows realized median and 90th-percentile delays due to impeding factors to functional recovery. 


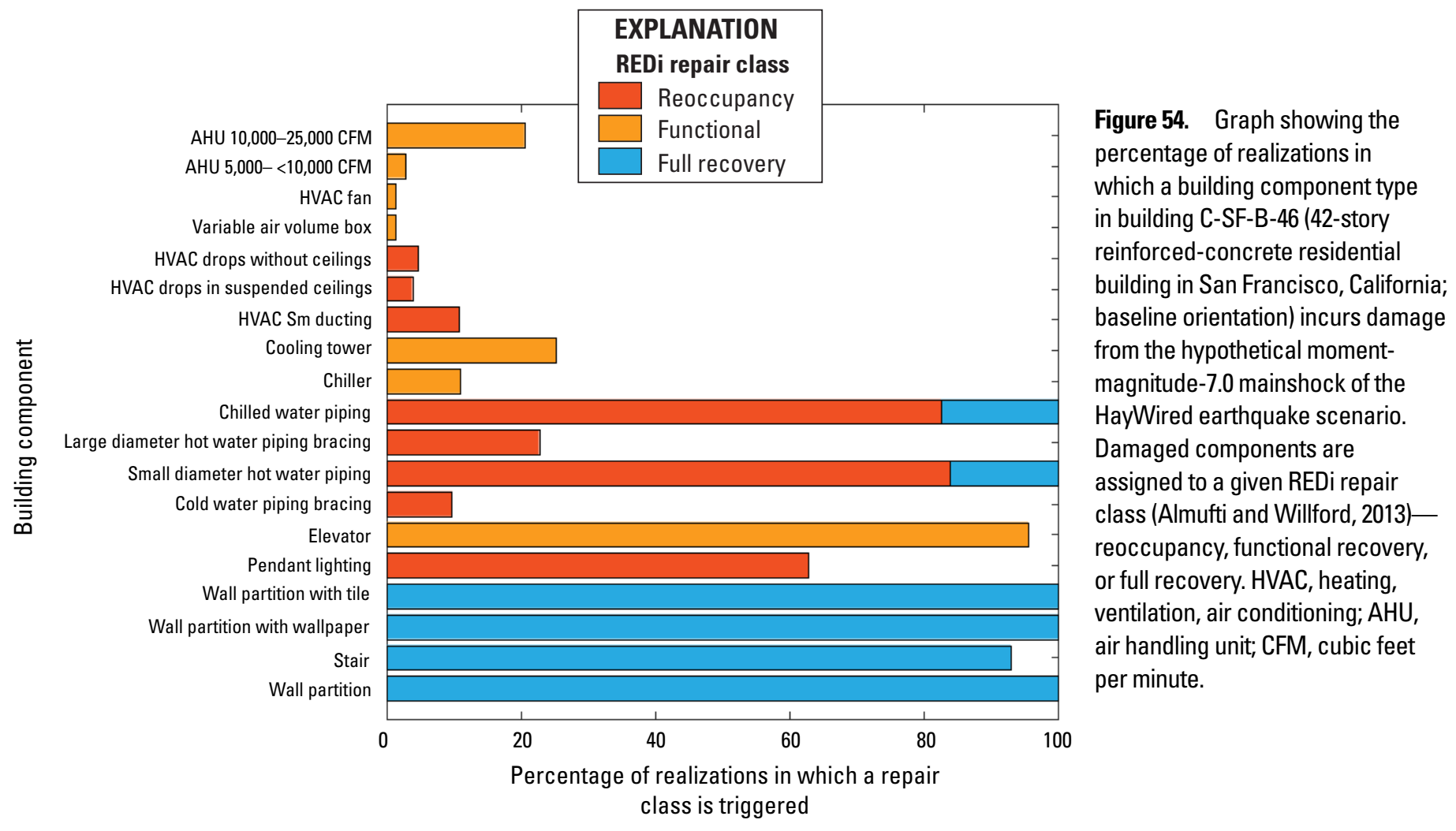

Table 29. Realized median and 90th-percentile repair time and total downtime for building C-SF-B-46 (42-story reinforced-concrete residential building in San Francisco, California; baseline orientation) due to the hypothetical moment-magnitude-7.0 mainshock of the HayWired earthquake scenario.

[REDi (Almufti and Willford, 2013)]

\begin{tabular}{lccc}
\hline \multicolumn{1}{c}{ Repair time } & \multicolumn{2}{c}{ REDi repair class } \\
\cline { 2 - 4 } & $\begin{array}{c}\text { Reoccupancy, } \\
\text { in days }\end{array}$ & $\begin{array}{c}\text { Functional recovery, } \\
\text { in days }\end{array}$ & $\begin{array}{c}\text { Full recovery, } \\
\text { in days }\end{array}$ \\
\hline Median repair time & 3 & 15 & 109 \\
Median total downtime & 126 & 224 & 323 \\
90th-percentile repair time & 5 & 27 & 155 \\
90th-percentile downtime & 194 & 328 & 434 \\
\hline
\end{tabular}




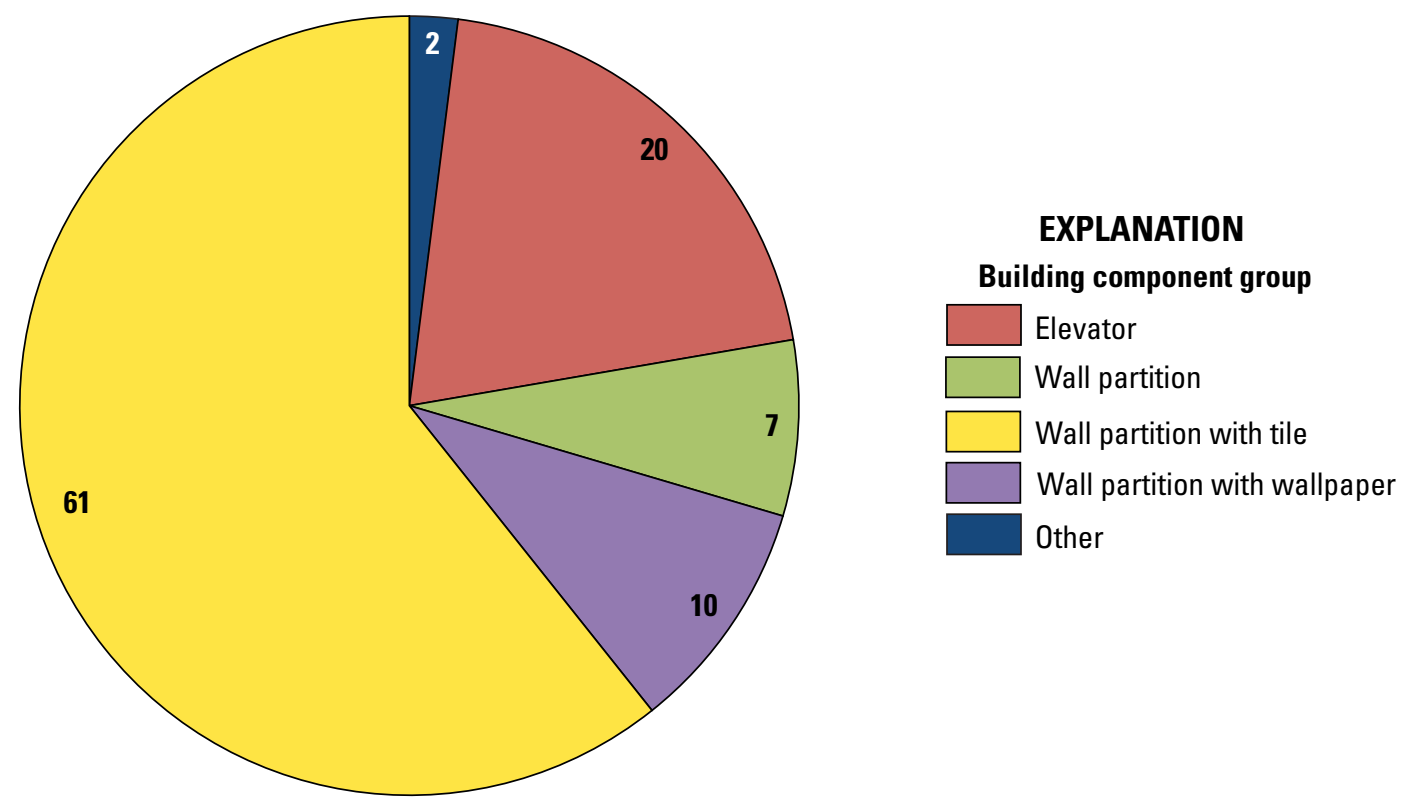

Figure 55. Pie chart showing the percentage contribution of building component groups to realized median total repair cost for building C-SF-B-46 (42-story reinforced-concrete residential building in San Francisco, California; baseline orientation) due to the hypothetical moment-magnitude-7.0 mainshock of the HayWired earthquake scenario.

Table 30. Realized median and 90th-percentile delays due to impeding factors to functional recovery for building C-SF-B-46 (42story reinforced-concrete residential building in San Francisco, California; baseline orientation) due to the hypothetical momentmagnitude-7.0 mainshock of the HayWired earthquake scenario.

\begin{tabular}{lccl}
\hline \multicolumn{1}{c}{ Impeding factor } & $\begin{array}{c}\text { Median disruption, } \\
\text { in days }\end{array}$ & $\begin{array}{c}\text { 90th-percentile disruption, } \\
\text { in days }\end{array}$ & Comment \\
\hline Inspection & 5 & 10 & None. \\
\hline Financing & 0 & 0 & $\begin{array}{c}\text { Total repair cost projections are }<5 \text { percent of the total } \\
\text { replacement cost for median and } 90 \text { th percentile, so } \\
\text { it is assumed that the owner readily has funds avail- } \\
\text { able for these repairs. }\end{array}$ \\
\hline Engineer mobilization & 0 & 0 & No structural damage. \\
\hline Contractor mobilization & 210 & 316 & None. \\
\hline Permitting & 0 & 0 & No structural damage. \\
\hline
\end{tabular}




\section{Appendix 9. C-SF-R-46-42-Story Reinforced-Concrete Building in San Francisco (Rotated Orientation)}

\section{C-SF-R-46 Description}

This appendix summarizes the results of interest for the HayWired mainshock from the structural analysis and loss assessment of building C-SF-R-46 - a 42-story reinforced-concrete residential building in San Francisco with the rotated orientation shown in figure 10. Results are shown in figures 56-61.

\section{Engineering-Demand Parameters}

The simulation of EDPs follows the method recommended by FEMA P-58 (Applied Technology Council, 2012) for buildings with nonlinear response history analysis results available. This algorithm was developed by Yang and others (2009).

Building C-SF-R-46 sees low demands, with a peak interstory drift (IDR) for whole building of just 0.7 percent. Peak floor acceleration is $1.09 \mathrm{~g}$. Peak coupling beam rotation is $0.009 \mathrm{rad}$, far below $0.05-0.06 \mathrm{rad}$, the point at which significant shear strength degradation occurs. The core walls see no crushing. The core-wall rebar experiences little yielding, all occurring at the base of the core walls.
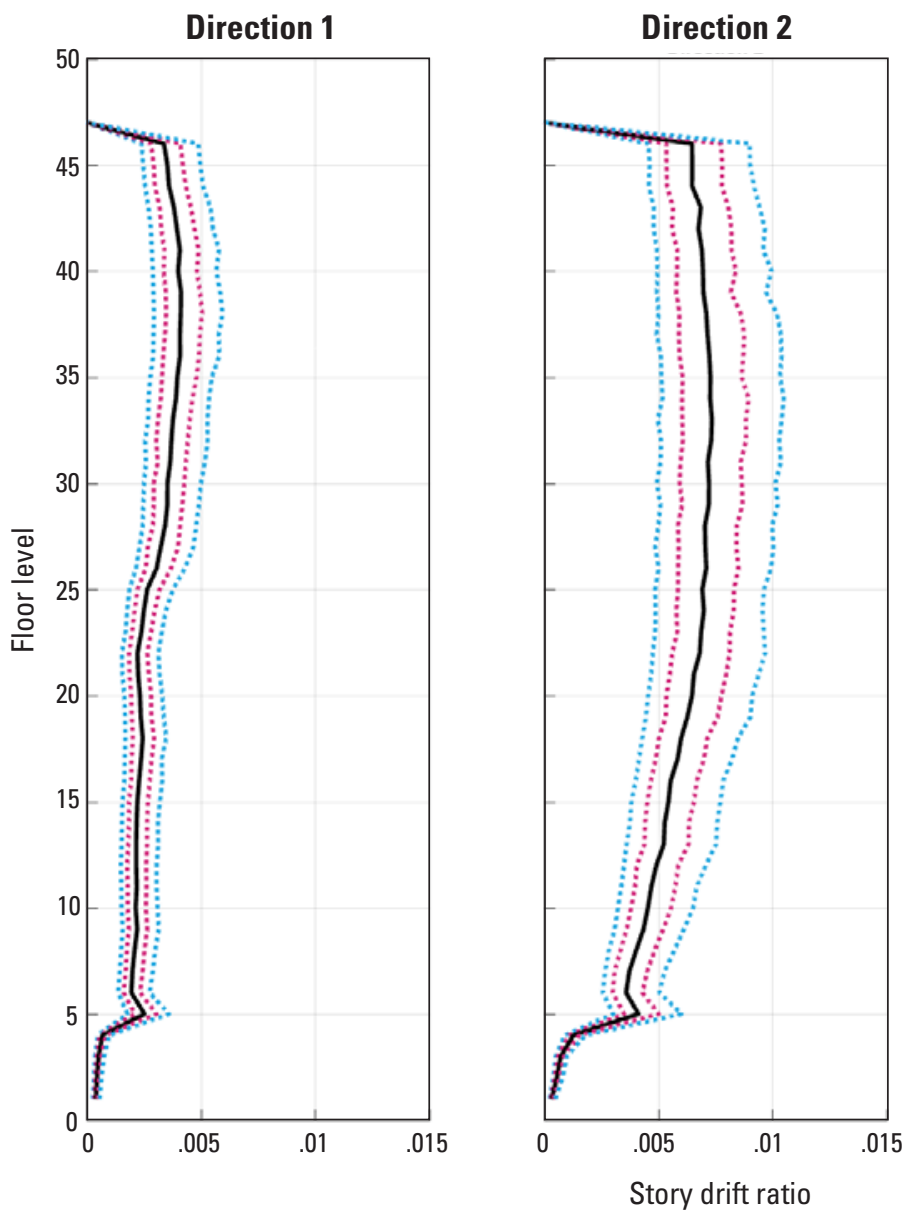

The damage in partitions and slab-column joints is better correlated with racking drift than IDR. Therefore, racking drift was used as the EDP for these components. Racking drift is different from IDR in that it excludes rigid body rotation and includes vertical racking resulting from the relative vertical movement between the core walls and the perimeter columns.

There are a few interesting things to note about the demands. First, figure 59 clearly shows the plastic hinge zone in the core wall at the ground floor level, as evidenced by the large spike in the wall rotation. However, this spike is modest, in an absolute sense, at about $0.00115 \mathrm{rad}$ median. This compares favorably with the acceptable plastic hinge rotation per ASCE 41-13 (American Society of Civil Engineers, 2014) of 0.001-0.002 rad for unconfined walls. Second, figure 61 shows that the coupling beam rotations are fairly constant up the height of the building with the exception of a dip in rotations at level 17 (superstructure floor 13), where the core wall and coupling beam width abruptly changes from 32 to 24 in.

Coupling beam rotation demands were enveloped for all beams on each floor and thus, beam directionality was not considered. Despite this conservatism, beam rotations were very low and had virtually no impact on the loss assessment.

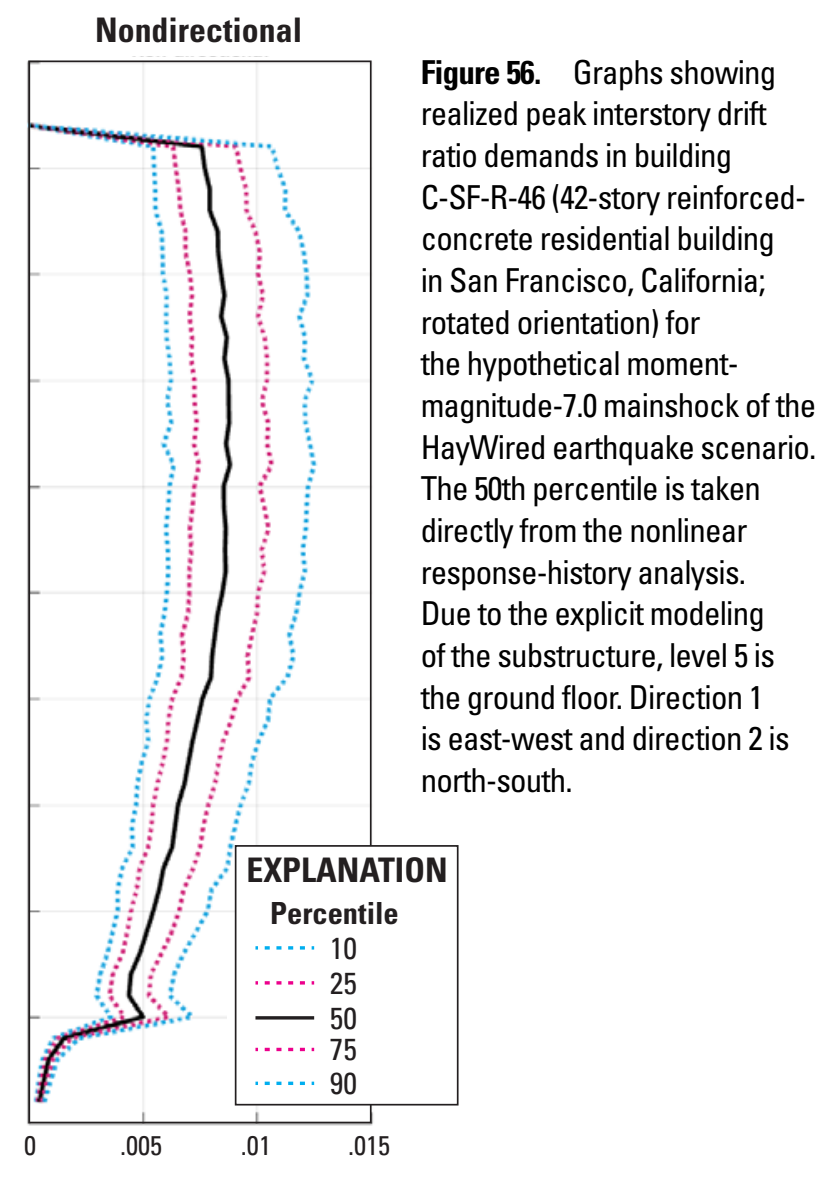



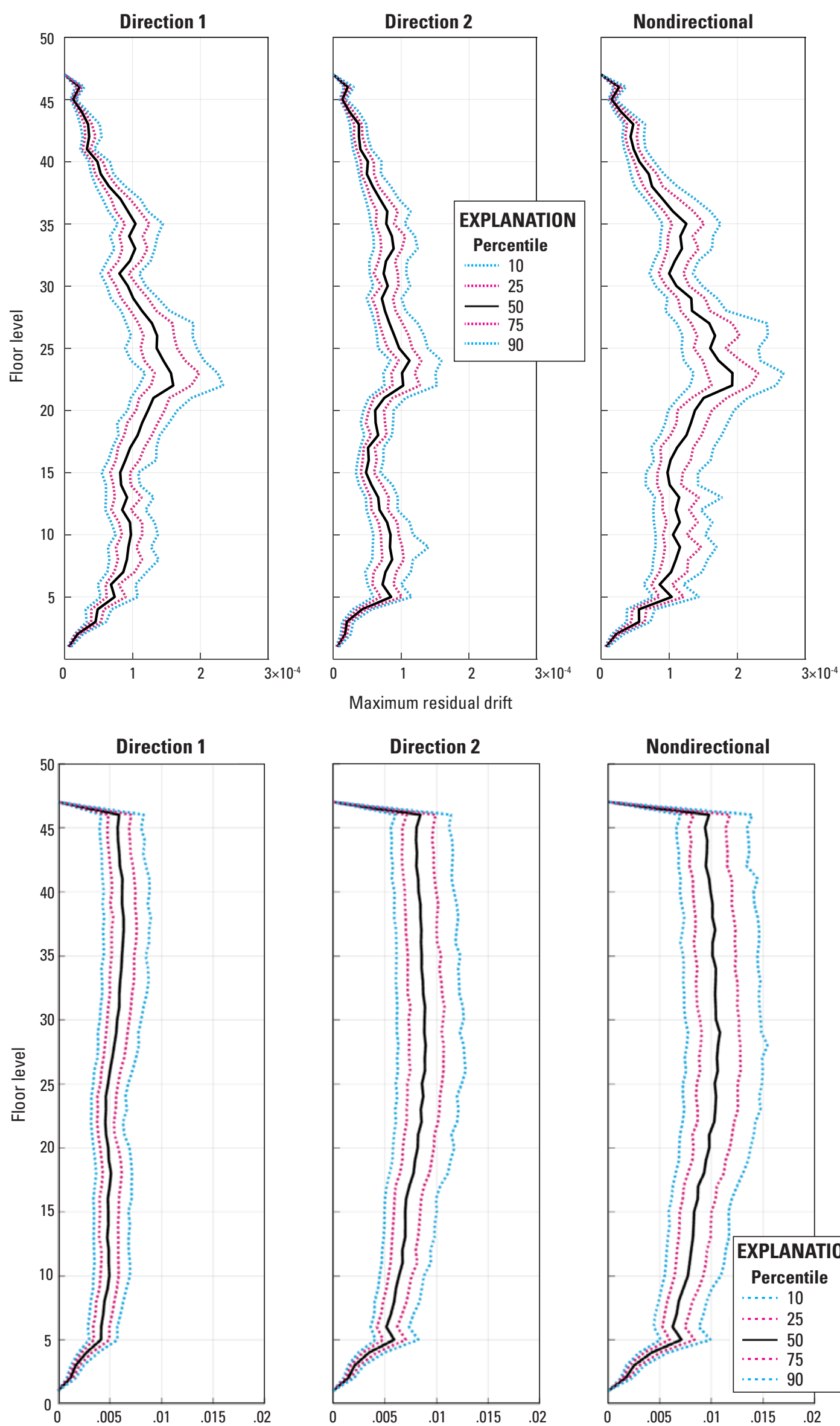

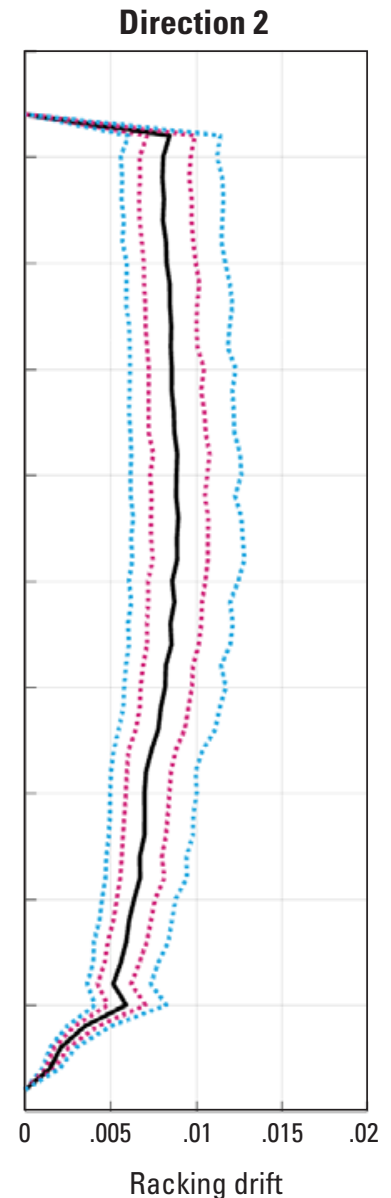

Figure 57. Graphs showing realized peak residual interstory drift ratio demands in building C-SF-R-46 (42-story reinforcedconcrete residential building in San Francisco, California; rotated orientation) for the hypothetical moment-magnitude-7.0 mainshock of the HayWired earthquake scenario. The 50th percentile is taken directly from the nonlinear response-history analysis. Due to the explicit modeling of the substructure, level 5 is the ground floor. Direction 1 is east-west and direction 2 is north-south.
Figure 58. Graphs showing realized peak racking drift ratio demands in building C-SF-R-46 (42-story reinforced-concrete residential building in San Francisco, California; rotated orientation) for the hypothetical moment-magnitude-7.0 mainshock of the HayWired earthquake scenario. The 50th percentile is taken directly from the nonlinear response-history analysis. Due to the explicit modeling of the substructure, level 5 is the ground floor. Direction 1 is east-west and direction 2 is north-south. 

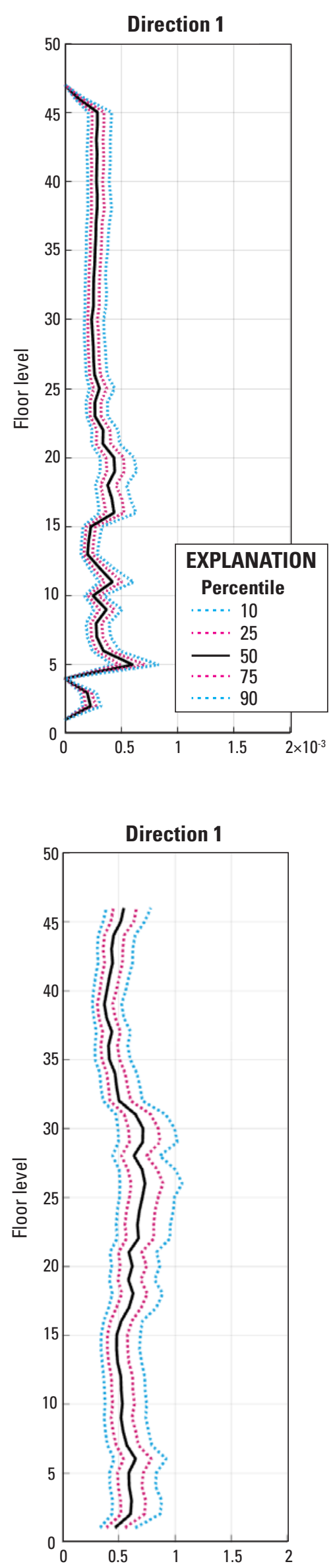
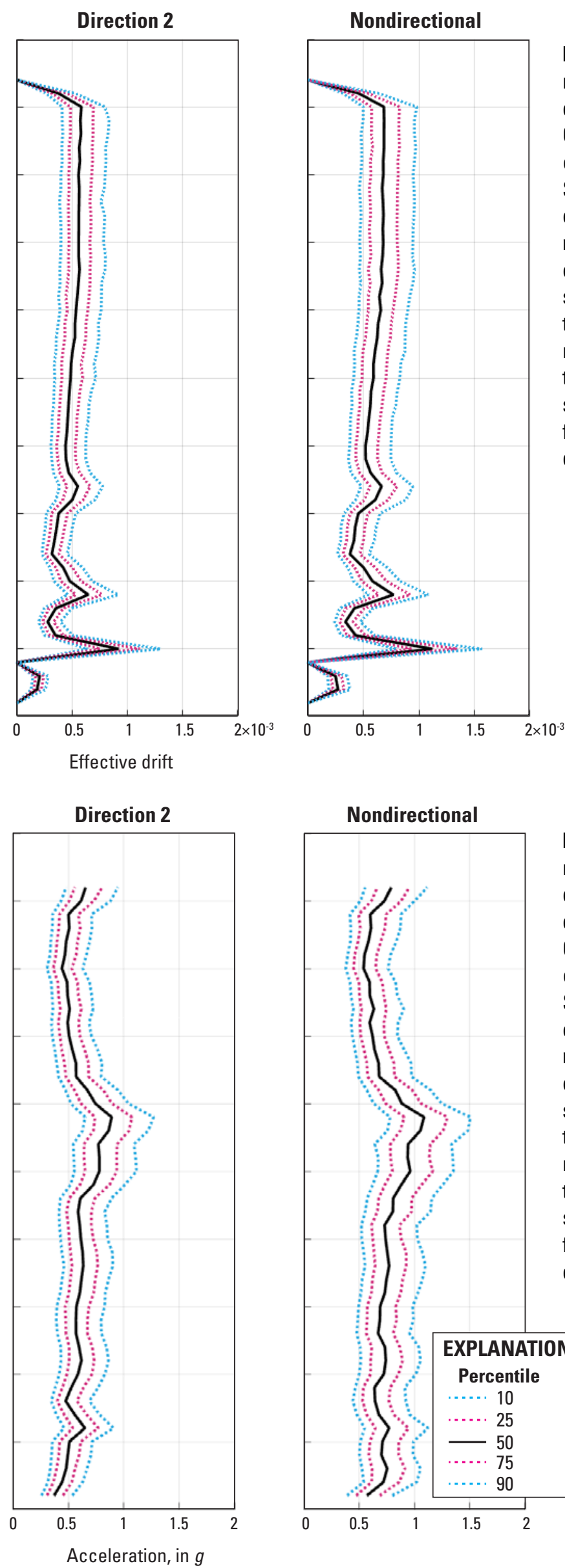

Figure 59. Graphs showing realized peak wall-rotation demands (radians) in building C-SF-R-46 (42-story reinforcedconcrete residential building in San Francisco, California; rotated orientation) for the hypothetical moment-magnitude-7.0 mainshock of the HayWired earthquake scenario. The 50th percentile is taken directly from the nonlinear response-history analysis. Due to the explicit modeling of the substructure, level 5 is the ground floor. Direction 1 is east-west and direction 2 is north-south.

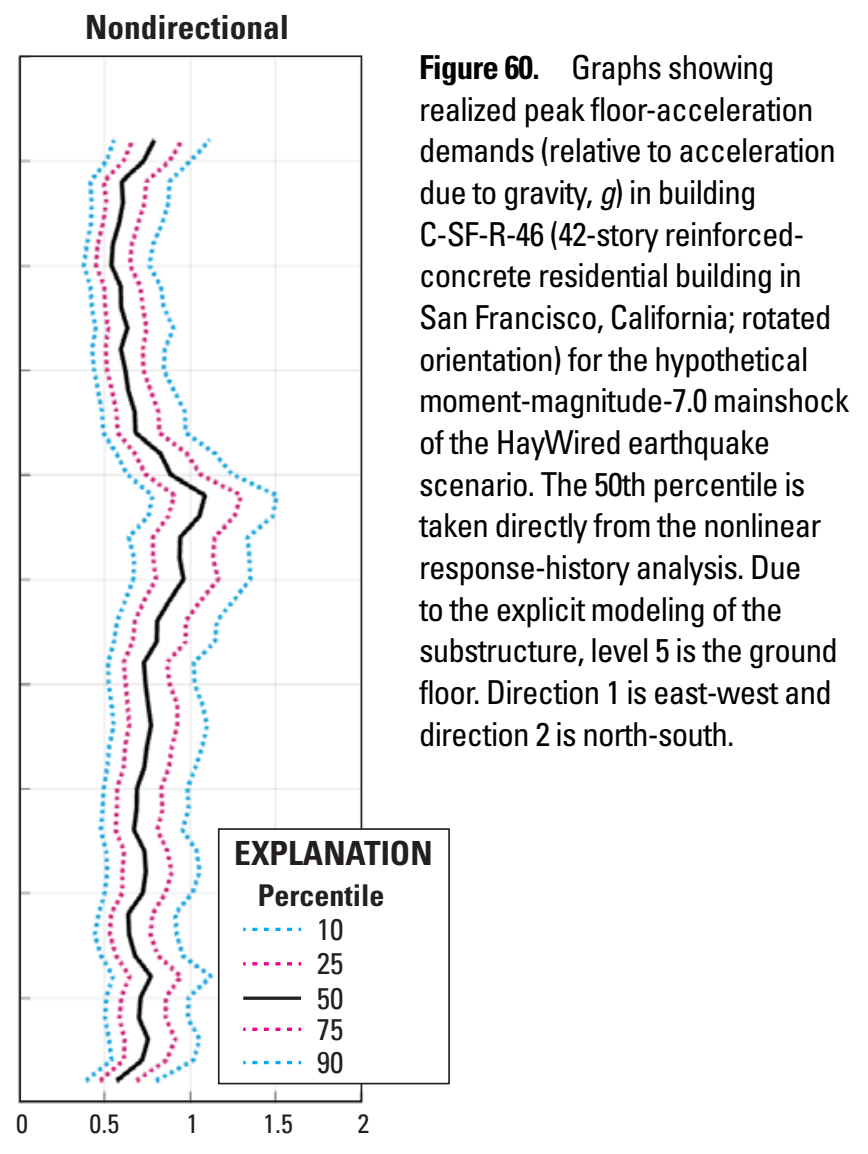




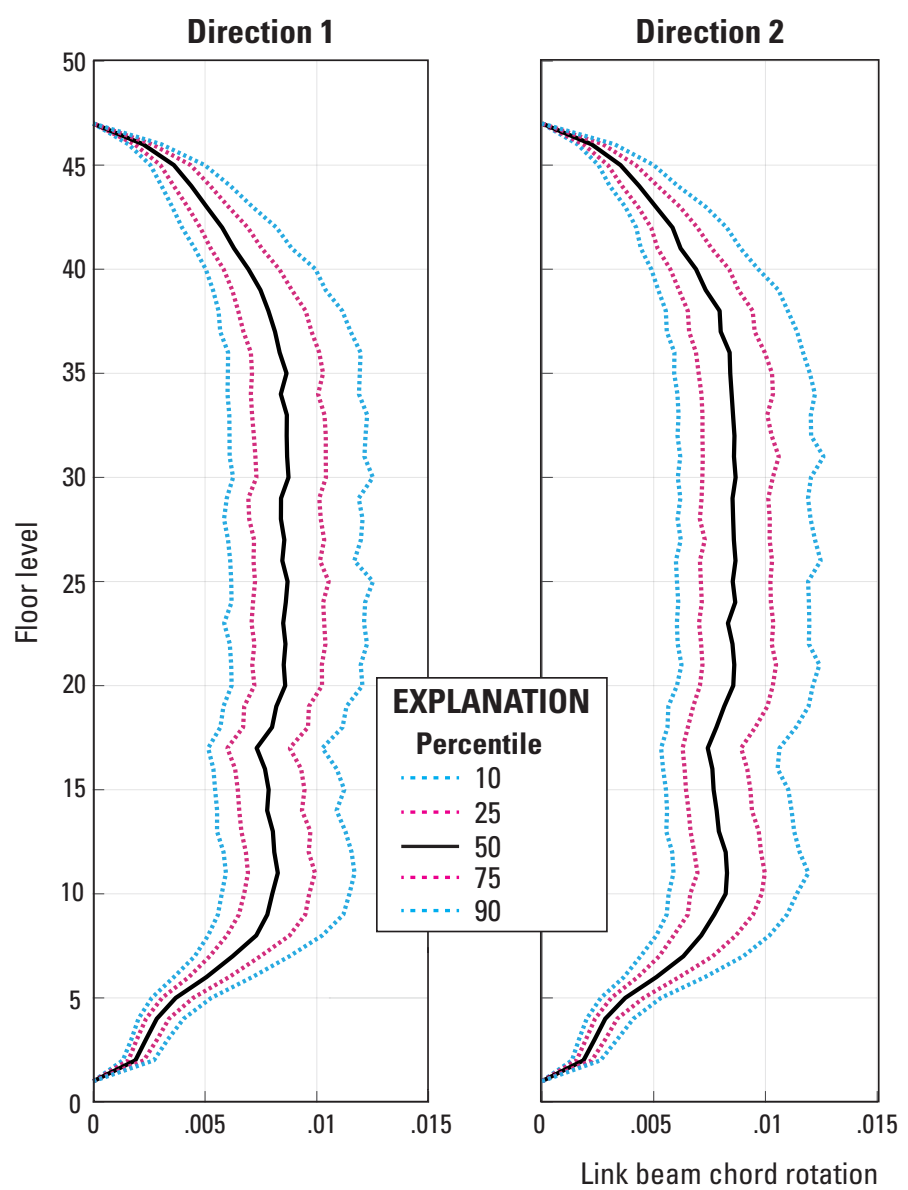

\section{Loss-Assessment Results}

The loss assessment is based on a Monte Carlo simulation with 1,000 realizations. The loss assessment was performed using the probabilistic approach outlined in the Federal Emergency Management Agency's (FEMA) P-58 document (Applied Technology Council, 2012). The likely costs to repair and (or) replace damaged components are calculated based solely on FEMA P-58, whereas repair time and downtime are estimated using the FEMA P-58 based methodology outlined REDi (Almufti and Willford, 2013).

\section{Damaged Components}

The probability that a component type in building C-SF-R-46 incurs damage that hinders either reoccupancy, functionality, or full recovery was examined in the realizations. The results are shown in figure 62 .

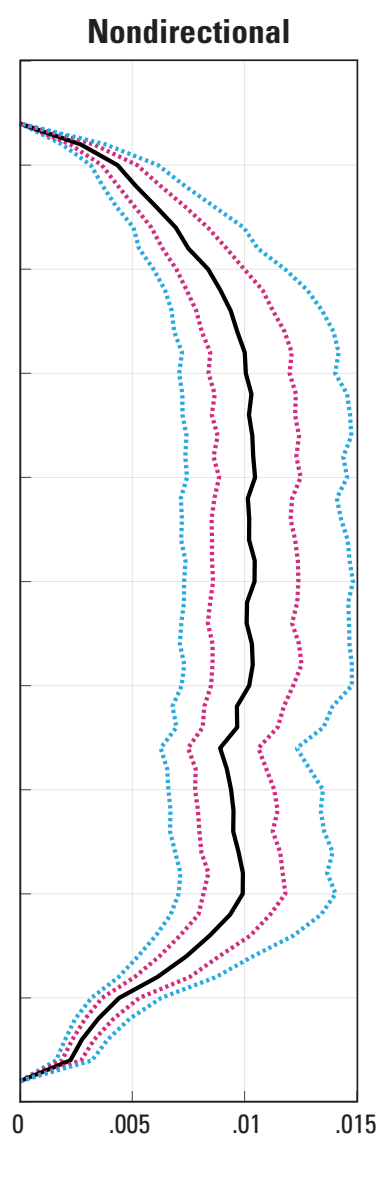

Figure 61. Graphs showing realized peak coupling-beam rotation demands (radians) in building C-SF-R-46 (42-story reinforced-concrete residential building in San Francisco, California; rotated orientation) for the hypothetical momentmagnitude- 7.0 mainshock of the HayWired earthquake scenario. The 50th percentile is taken directly from the nonlinear response-history analysis. Due to the explicit modeling of the substructure, level 5 is the ground floor. Direction 1 is east-west and direction 2 is north-south.

\section{Repair Costs, Repair Time, Downtime, and Impending Factors}

The median total repair cost for building C-SF-R-46 is 5.0 percent of the total building replacement value, or $\$ 8.9$ million. The 90th-percentile total repair cost is 6.1 percent of the total building replacement value, or $\$ 10.8$ million. For this study, the total building replacement value is defined as the hard costs only required to replace the building, based off a construction cost estimate, including at minimum all structural and nonstructural components plus the value of damageable building contents if they are known. The total repair cost is dominated by wall partitions because there are a large number of partitions in a residential building. Figure 63 shows the contribution of building component groups to realized median total repair cost. Table 31 shows realized median and 90th-percentile repair time and total downtime, and table 32 shows realized median and 90th-percentile delays due to impeding factors to functional recovery. 


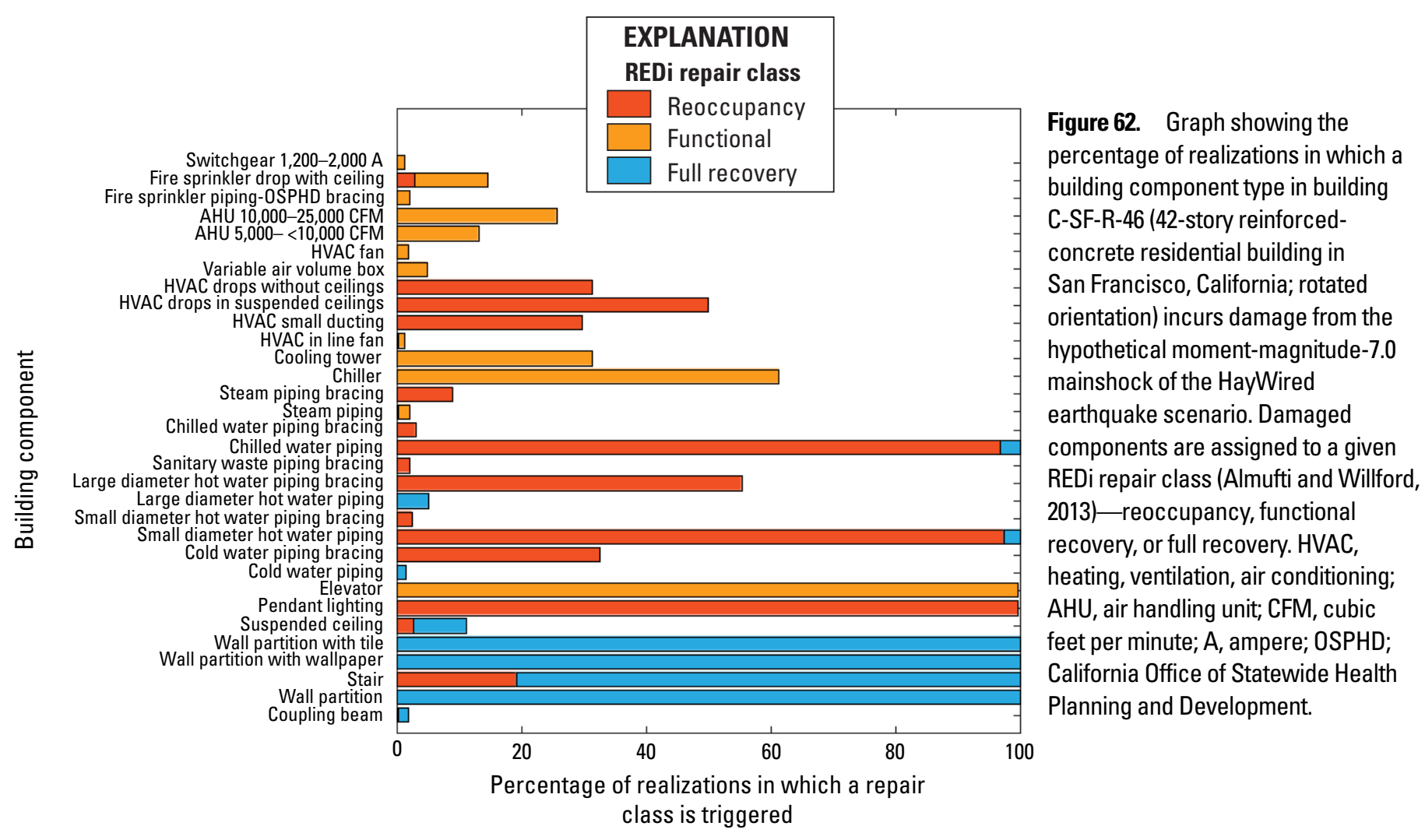

Table 31. Realized median and 90th-percentile repair time and total downtime for building C-SF-R-46 (42-story reinforced-concrete residential building in San Francisco, California; rotated orientation) due to the hypothetical moment-magnitude-7.0 mainshock of the HayWired earthquake scenario.

[REDi (Almufti and Willford, 2013)]

\begin{tabular}{lccc}
\hline \multicolumn{1}{c}{ Repair time } & \multicolumn{2}{c}{ REDi repair class } \\
\cline { 2 - 4 } & $\begin{array}{c}\text { Reoccupancy, } \\
\text { in days }\end{array}$ & $\begin{array}{c}\text { Functional recovery, } \\
\text { in days }\end{array}$ & $\begin{array}{c}\text { Full recovery, } \\
\text { in days }\end{array}$ \\
\hline Median repair time & 6 & 16 & 183 \\
Median total downtime & 136 & 239 & 414 \\
90th-percentile repair time & 11 & 26 & 251 \\
90th-percentile downtime & 213 & 350 & 539 \\
\hline
\end{tabular}




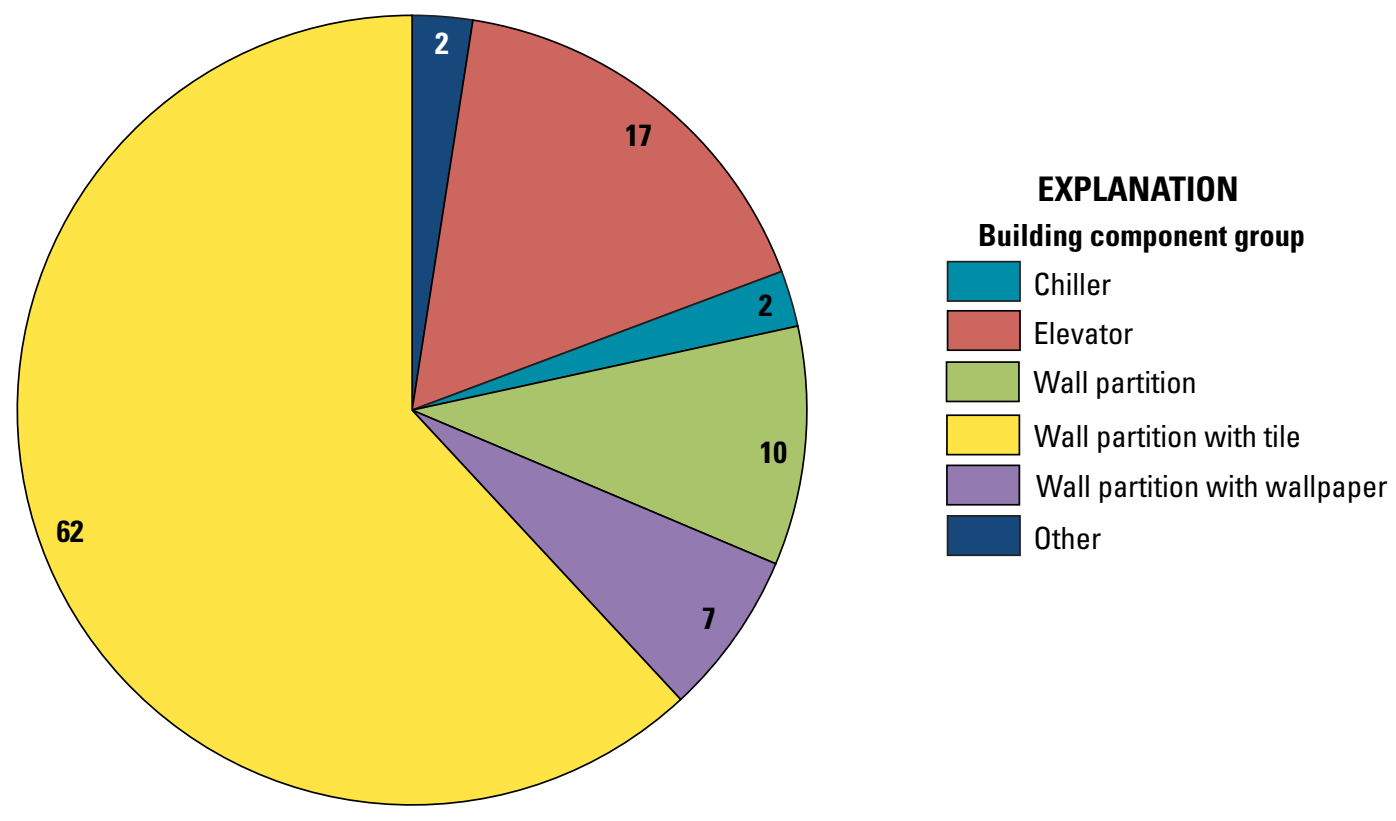

Figure 63. Pie chart showing the percentage contribution of building component groups to realized median total repair cost for building C-SF-R-46 (42-story reinforced-concrete residential building in San Francisco, California; rotated orientation) due to the hypothetical moment-magnitude-7.0 mainshock of the HayWired earthquake scenario.

Table 32. Realized median and 90th-percentile delays due to impeding factors to functional recovery for building C-SF-R-46 (42-story reinforced-concrete residential building in San Francisco, California; rotated orientation) due to the hypothetical moment-magnitude-7.0 mainshock of the HayWired earthquake scenario.

\begin{tabular}{lccl}
\hline \multicolumn{1}{c}{ Impeding factor } & $\begin{array}{c}\text { Median disruption, } \\
\text { in days }\end{array}$ & $\begin{array}{c}\text { 90th-percentile disruption, } \\
\text { in days }\end{array}$ & Comment \\
\hline Inspection & 5 & 10 & None. \\
Financing & 59 & 198 & None. \\
Engineer mobilization & 0 & 0 & No structural damage. \\
Contractor mobilization & 223 & 335 & None. \\
Permitting & 0 & 0 & No structural damage. \\
\hline
\end{tabular}




\section{Appendix 10. C-OK-B-46-42-Story Reinforced-Concrete Building in Oakland (Baseline Orientation)}

\section{C-0K-B-46 Description}

This appendix summarizes the results of interest for the HayWired mainshock from the structural analysis and loss assessment of building C-OK-B-46 - a 42-story reinforced-concrete residential building in Oakland with the baseline orientation shown in figure 10. Results are shown in figures 64-69.

\section{Engineering-Demand Parameters}

The simulation of EDPs follows the method recommended by FEMA P-58 (Applied Technology Council, 2012) for buildings with nonlinear response history analysis results available. This algorithm was developed by Yang and others (2009).

Building C-OK-B-46 sees low demands, with a peak interstory drift (IDR) for whole building of just 0.7 percent. Peak floor acceleration is $1.06 \mathrm{~g}$. Peak coupling beam rotation is $0.009 \mathrm{rad}$, far below $0.05-0.06 \mathrm{rad}$, the point at which significant shear strength degradation occurs. The core walls see no crushing, with a peak compressive strain of 0.0017 . The core-wall rebar experiences little yielding, with a maximum tensile strain at the base of the core walls of 0.003 .
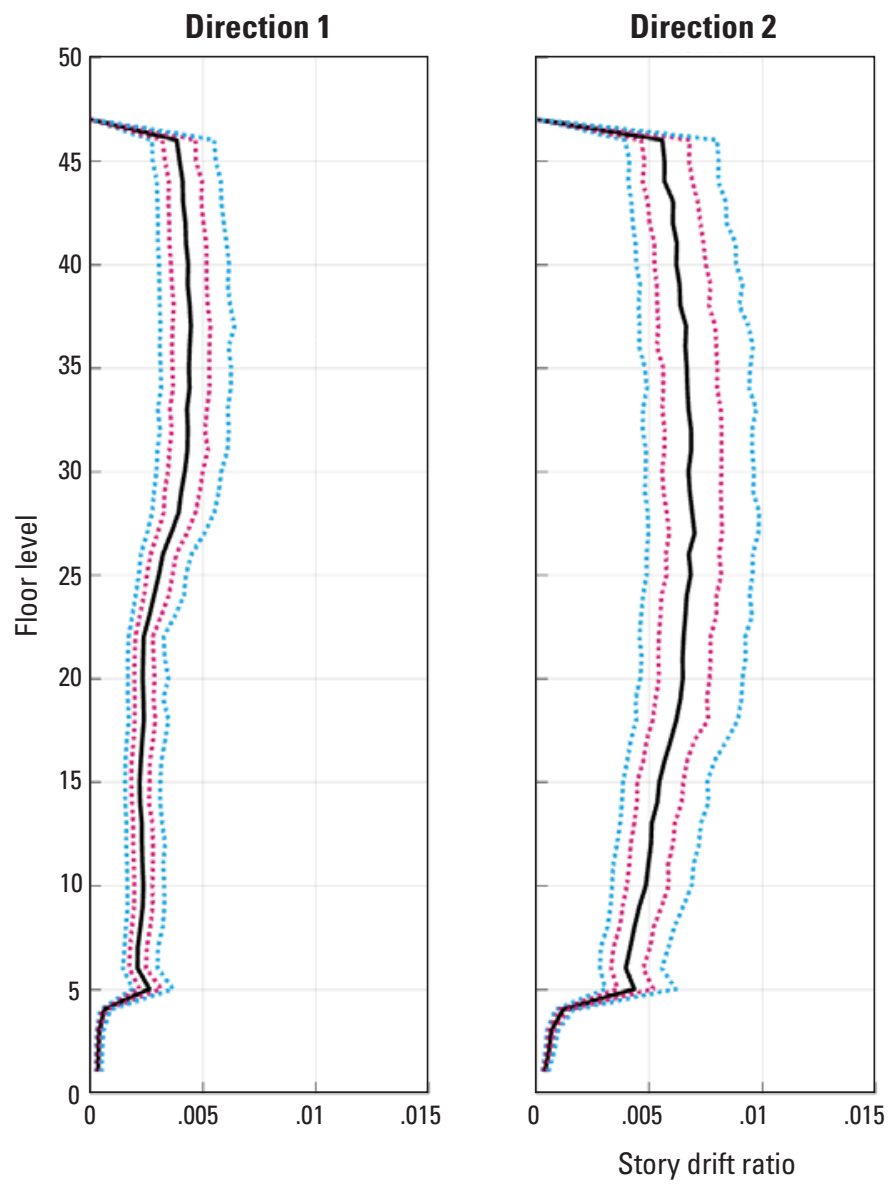

The damage in partitions and slab-column joints is better correlated with racking drift than IDR. Therefore, racking drift was used as the EDP for these components. Racking drift is different from IDR in that it excludes rigid body rotation and includes vertical racking resulting from the relative vertical movement between the core walls and the perimeter columns.

There are a few interesting things to note about the demands. First, figure 67 clearly shows the plastic hinge zone in the core wall at the ground floor level, as evidenced by the large spike in the wall rotation. However, this spike is modest, in an absolute sense, at about 0.00105 rad median. This compares favorably with the acceptable plastic hinge rotation per ASCE 41-13 (American Society of Civil Engineers, 2014) of 0.001$0.002 \mathrm{rad}$ for unconfined walls. Second, figure 69 shows that the coupling beam rotations are fairly constant up the height of the building. This is expected as the coupling beam sizes are the same for almost the full height of the building, with only the width changing with the core wall width one-third up the building height.

Coupling beam rotation demands were enveloped for all beams on each floor and thus, beam directionality was not considered. Despite this conservatism, beam rotations were very low and had virtually no impact on the loss assessment.

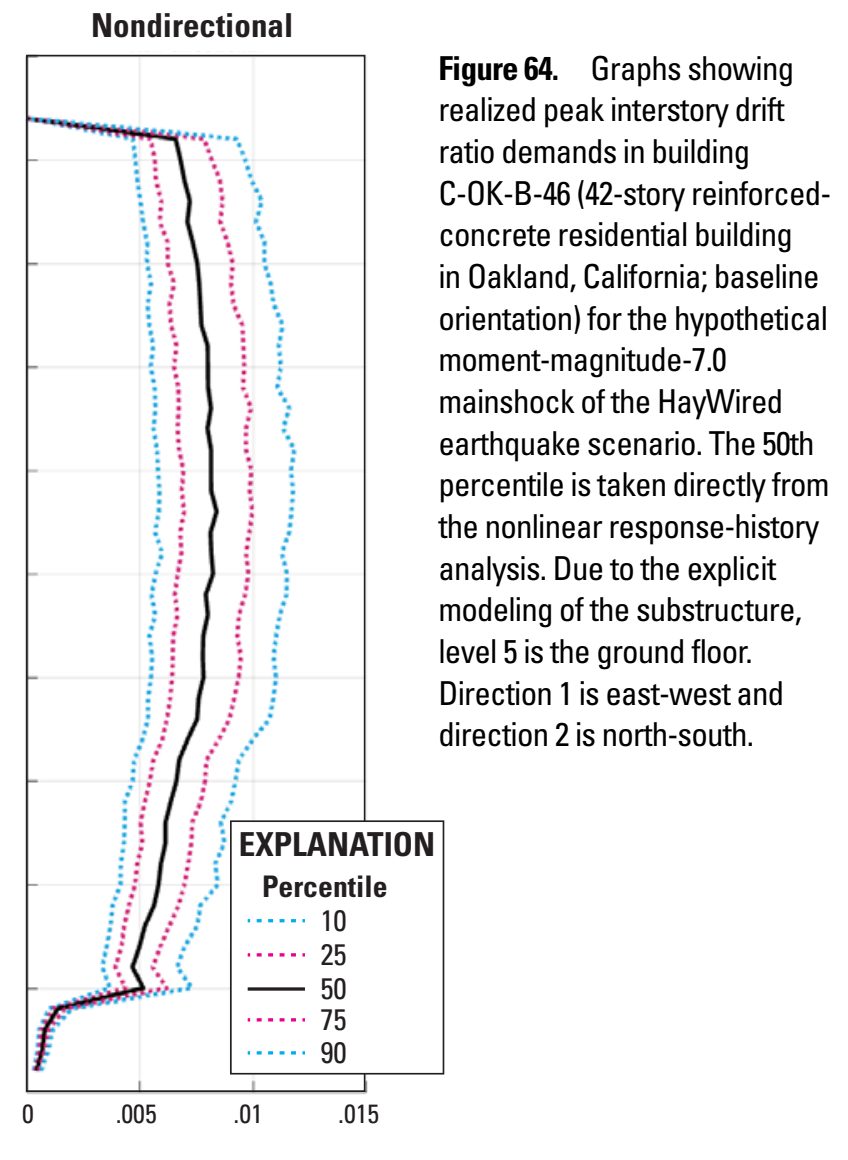



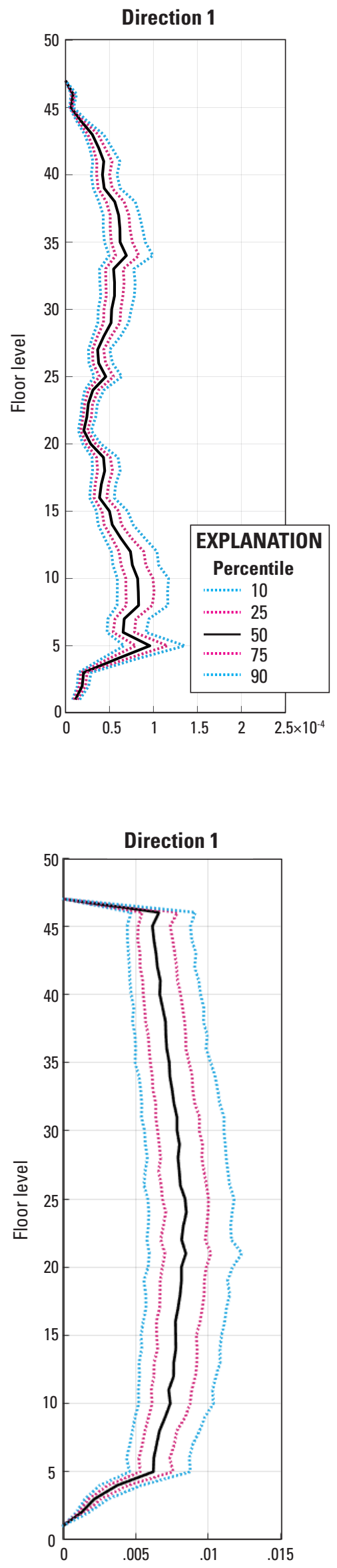
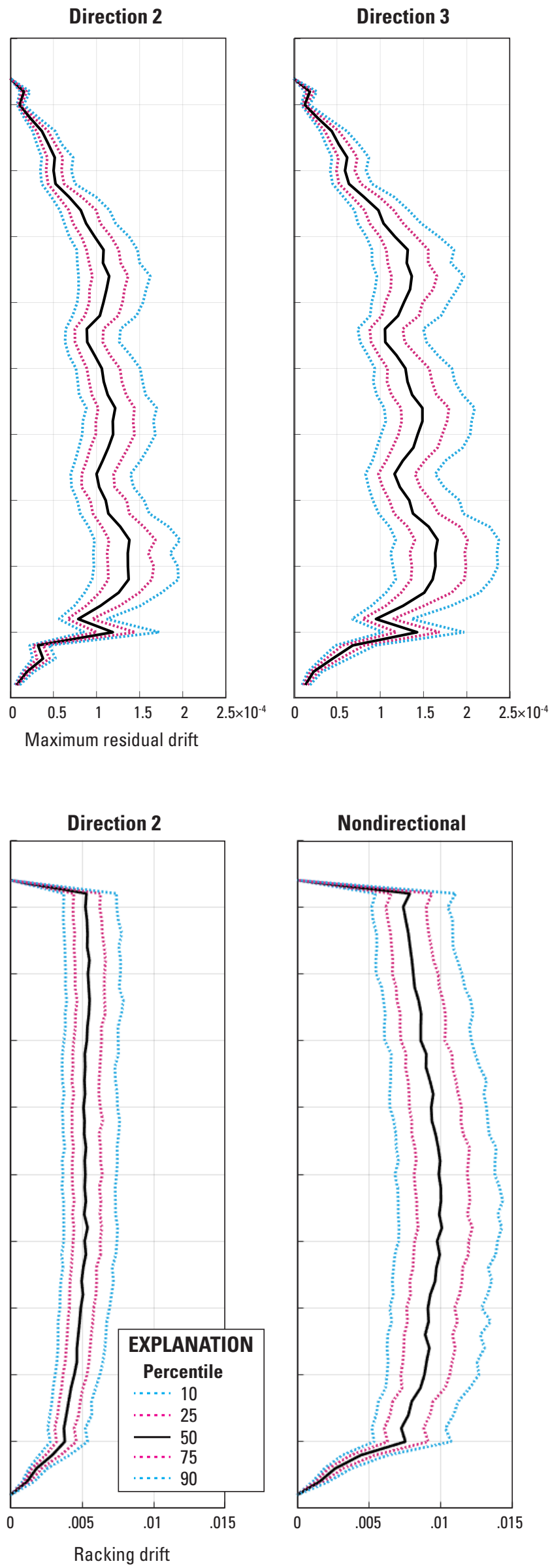

Figure 65. Graphs showing realized peak residual interstory drift ratio demands in building C-OK-B-46 (42-story reinforcedconcrete residential building in Oakland, California; baseline orientation) for the hypothetical moment-magnitude-7.0 mainshock of the HayWired earthquake scenario. The 50th percentile is taken directly from the nonlinear response-history analysis. Due to the explicit modeling of the substructure, level 5 is the ground floor. Direction 1 is east-west and direction 2 is north-south.
Figure 66. Graphs showing realized peak racking drift ratio demands in building C-OK-B-46 (42-story reinforced-concrete residential building in Oakland, California; baseline orientation) for the hypothetical momentmagnitude-7.0 mainshock of the HayWired earthquake scenario. The 50th percentile is taken directly from the nonlinear response-history analysis. Due to the explicit modeling of the substructure, level 5 is the ground floor. Direction 1 is east-west and direction 2 is north-south. 

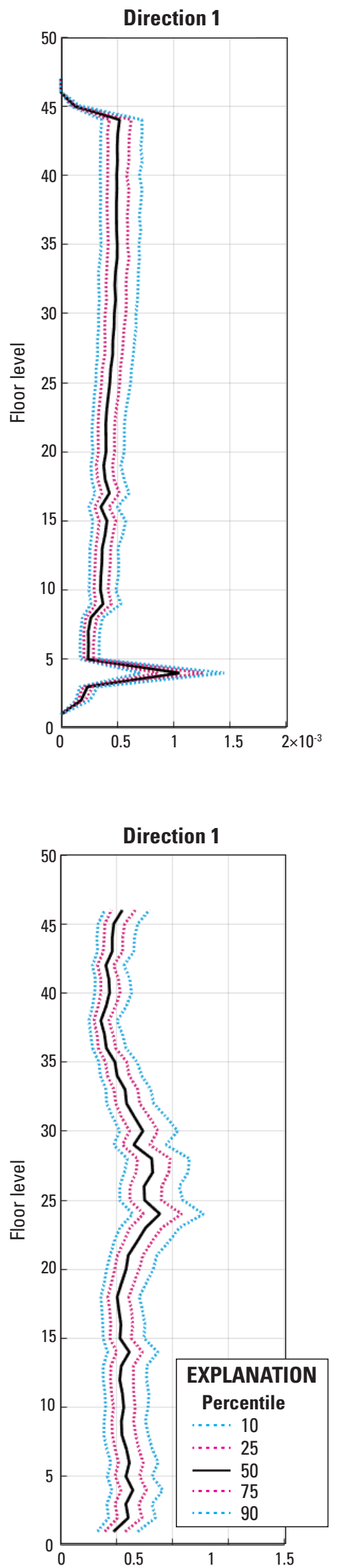
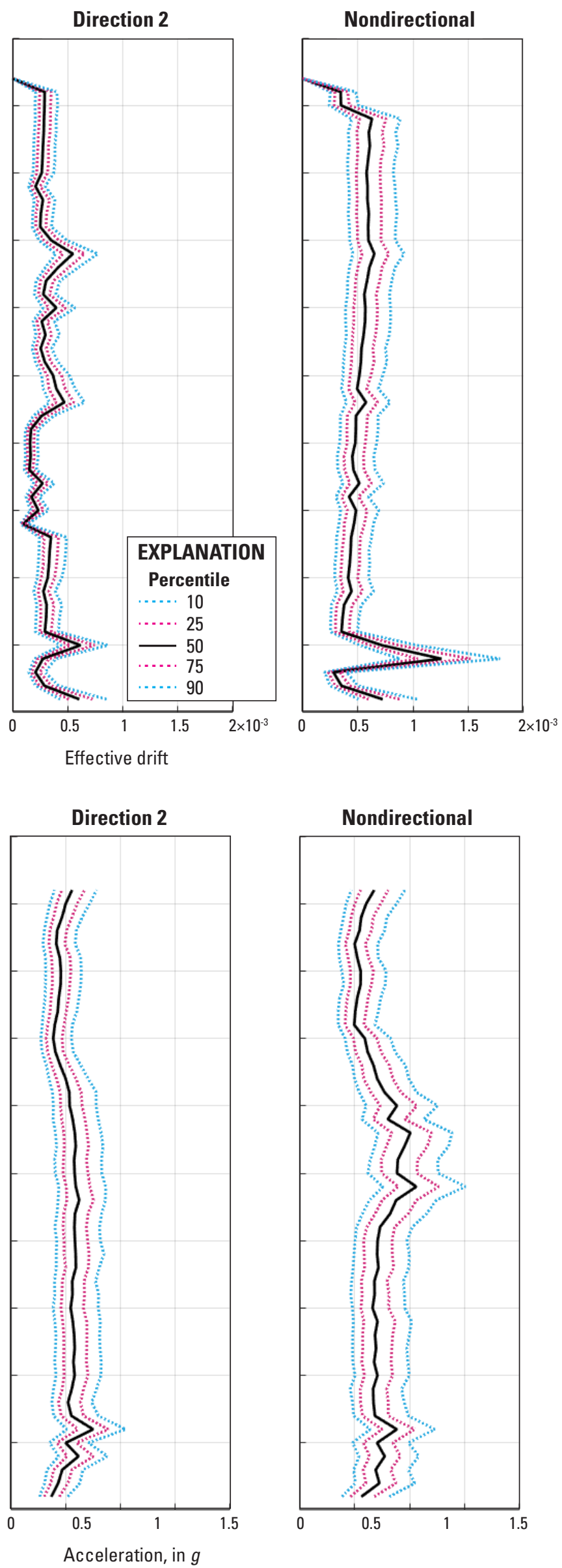

Figure 67. Graphs showing realized peak wall-rotation demands (radians) in building C-OK-B-46 (42-story reinforcedconcrete residential building in Oakland, California; baseline orientation) for the hypothetical moment-magnitude-7.0 mainshock of the HayWired earthquake scenario. The 50th percentile is taken directly from the nonlinear response-history analysis. Due to the explicit modeling of the substructure, level 5 is the ground floor. Direction 1 is east-west and direction 2 is north-south.

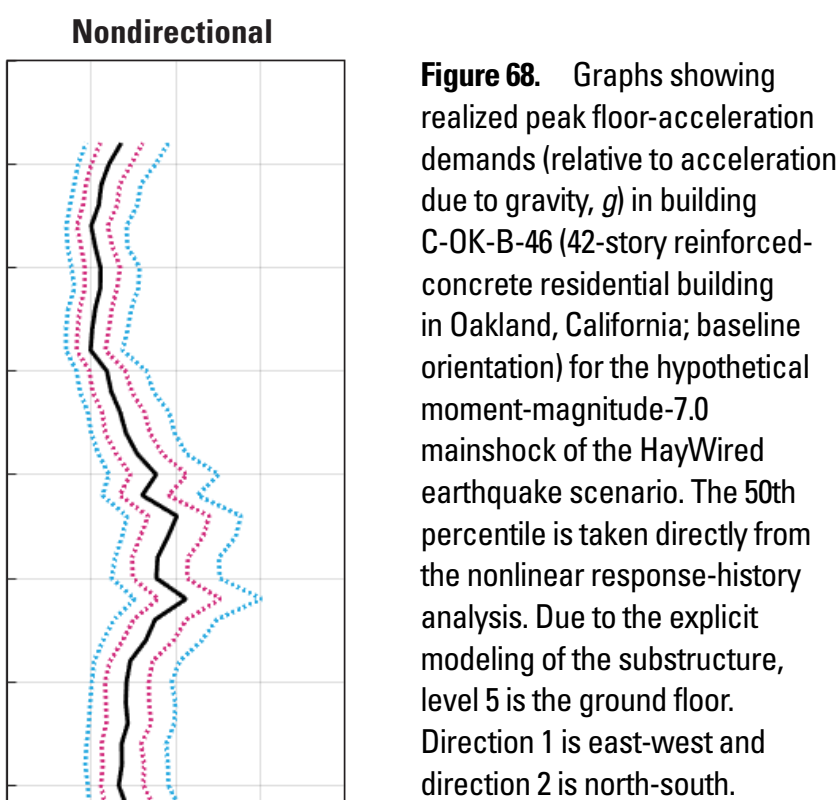



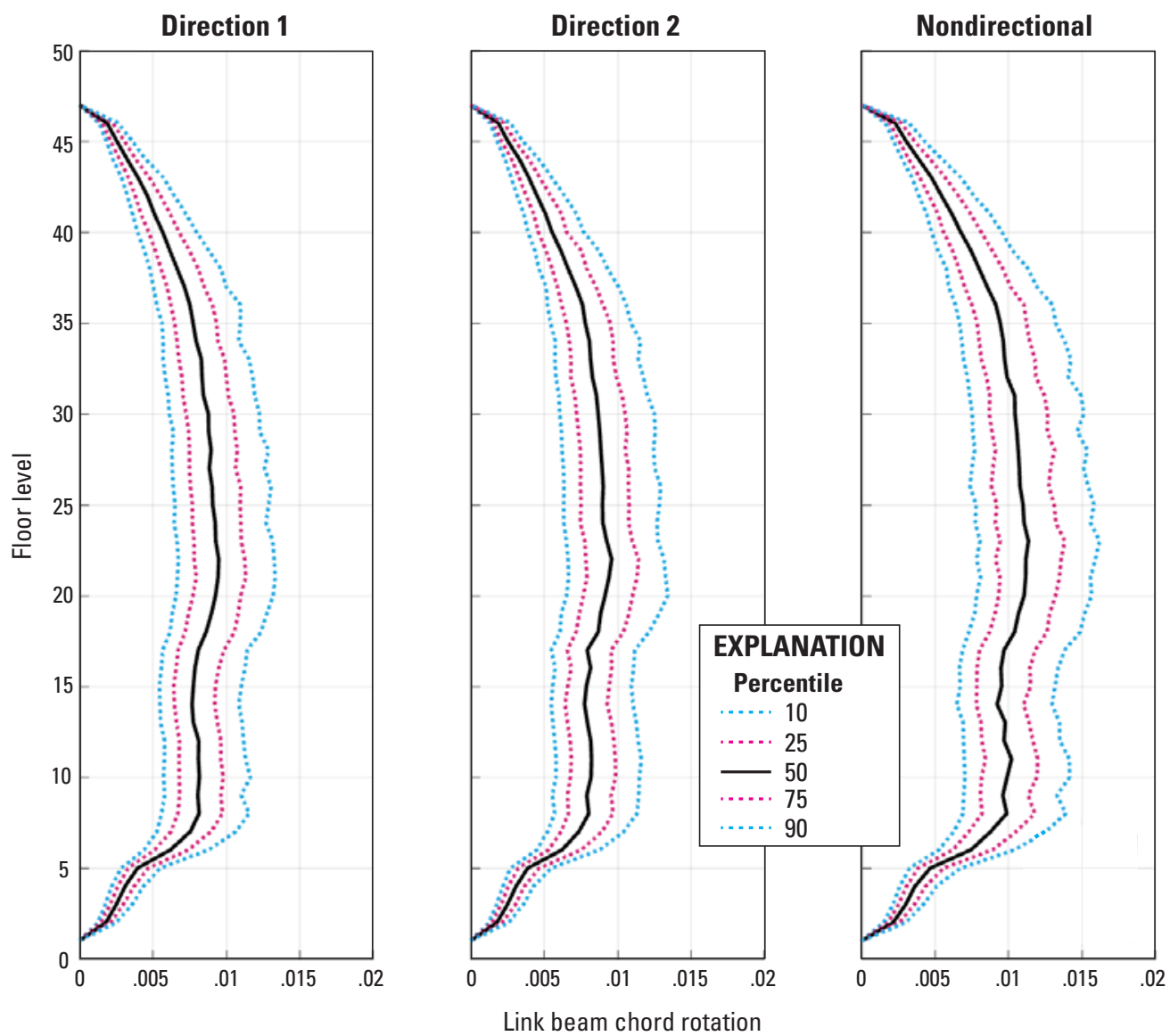

Figure 69. Graphs showing realized peak coupling-beam rotation demands (radians) in building C-OK-B-46 (42story reinforced concrete residential building in Oakland, California; baseline orientation) for the hypothetical momentmagnitude-7.0 mainshock of the HayWired earthquake scenario. The 50th percentile is taken directly from the nonlinear response-history analysis. Due to the explicit modeling of the substructure, level 5 is the ground floor. Direction 1 is east-west and direction 2 is north-south.

\section{Loss-Assessment Results}

The loss assessment is based on a Monte Carlo simulation with 1,000 realizations. The loss assessment was performed using the probabilistic approach outlined in the Federal Emergency Management Agency's (FEMA) P-58 document (Applied Technology Council, 2012). The likely costs to repair and (or) replace damaged components are calculated based solely on FEMA P-58, whereas repair time and downtime are estimated using the FEMA P-58 based methodology outlined REDi (Almufti and Willford, 2013).

\section{Damaged Components}

The probability that a component type in building C-OKB-46 incurs damage that hinders either reoccupancy, functionality, or full recovery was examined in the realizations. The results are shown in figure 70 .

\section{Repair Costs, Repair Time, Downtime, and Impending Factors}

The median total repair cost for building C-OK-B-46 is 4.9 percent of the total building replacement value, or $\$ 8.6$ million. The 90th-percentile total repair cost is 5.3 percent of the total building replacement value, or $\$ 9.4$ million. For this study, the total building replacement value is defined as the hard costs only required to replace the building, based off a construction cost estimate, including at minimum all structural and nonstructural components plus the value of damageable building contents if they are known. The total repair cost is dominated by wall partitions because there are a large number of partitions in a residential building. Figure 71 shows the contribution of building component groups to realized median total repair cost. Table 33 shows realized median and 90th-percentile repair time and total downtime, and table 34 shows realized median and 90th-percentile delays due to impeding factors to functional recovery. 


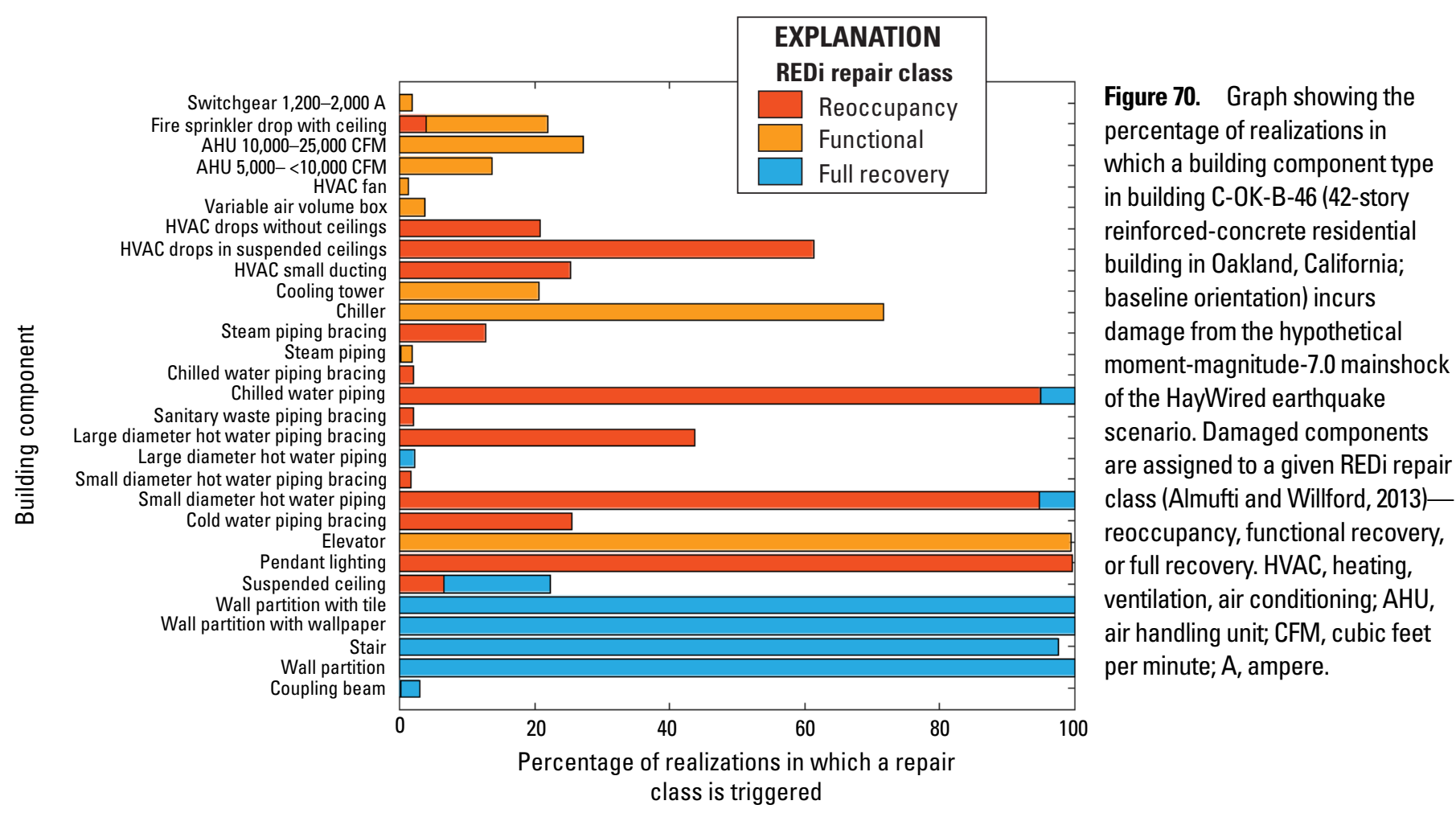

Table 33. Realized median and 90th-percentile repair time and total downtime for building C-OK-B-46 (42-story reinforced-concrete residential building in Oakland, California; baseline orientation) due to the hypothetical moment-magnitude- 7.0 mainshock of the HayWired earthquake scenario

[REDi (Almufti and Willford, 2013)]

\begin{tabular}{lccc}
\hline \multicolumn{1}{c}{ Repair time } & \multicolumn{2}{c}{ REDi repair class } \\
\cline { 2 - 4 } & $\begin{array}{c}\text { Reoccupancy, } \\
\text { in days }\end{array}$ & $\begin{array}{c}\text { Functional recovery, } \\
\text { in days }\end{array}$ & $\begin{array}{c}\text { Full recovery, } \\
\text { in days }\end{array}$ \\
\hline Median repair time & 5 & 16 & 173 \\
Median total downtime & 130 & 233 & 396 \\
90th-percentile repair time & 9 & 26 & 242 \\
90th-percentile downtime & 198 & 346 & 527 \\
\hline
\end{tabular}




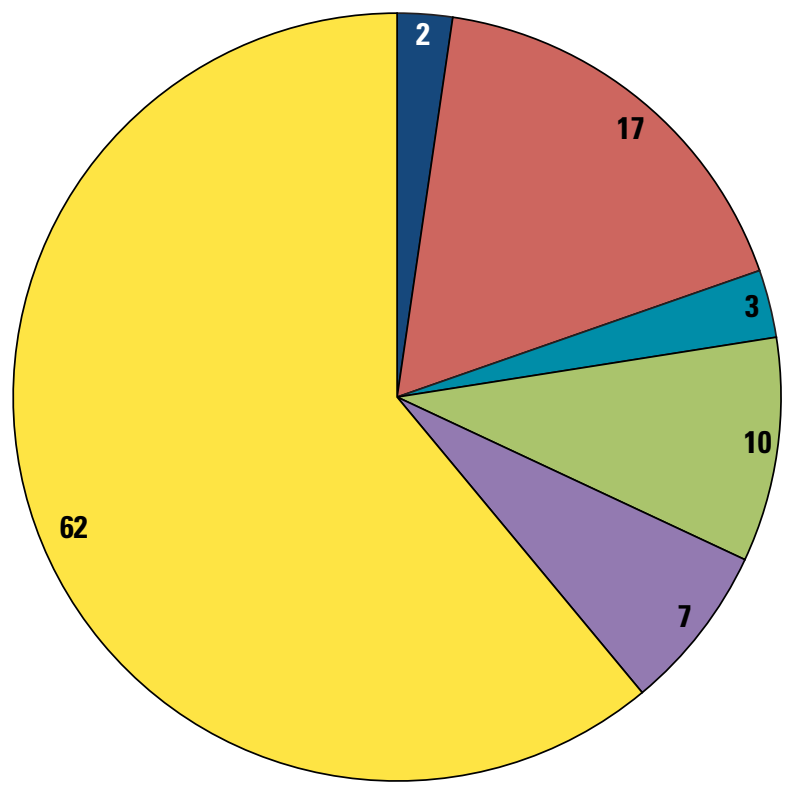

\section{EXPLANATION}

Building component group

Chiller

$\square$ Elevator

Wall partition

Wall partition with tile

Wall partition with wallpaper

Other

Figure 71. Pie chart showing the percentage contribution of building component groups to realized median total repair cost for building C-OK-B-46 (42-story reinforced-concrete residential building in Oakland, California; baseline orientation) due to the hypothetical moment-magnitude-7.0 mainshock of the HayWired earthquake scenario.

Table 34. Realized median and 90th-percentile delays due to impeding factors to functional recovery for building C-OK-B-46 (42-story reinforced-concrete residential building in Oakland, California; baseline orientation) due to the hypothetical moment-magnitude-7.0 mainshock of the HayWired earthquake scenario.

\begin{tabular}{lccl}
\hline \multicolumn{1}{c}{ Impeding factor } & $\begin{array}{c}\text { Median disruption, } \\
\text { in days }\end{array}$ & $\begin{array}{c}\text { 90th-percentile disruption, } \\
\text { in days }\end{array}$ & Comment \\
\hline Inspection & 5 & 10 & None. \\
Financing & 0 & 162 & $\begin{array}{c}\text { Total repair cost projections are }<5 \text { percent of the total } \\
\text { replacement cost for median, so it is assumed that the } \\
\text { owner readily has funds available for these repairs. }\end{array}$ \\
Engineer mobilization & 0 & 0 & No structural damage. \\
Contractor mobilization & 219 & 329 & None. \\
Permitting & 0 & 0 & No structural damage. \\
\hline
\end{tabular}




\section{Appendix 11. C-OK-R-46-42-Story Reinforced-Concrete Building in Oakland (Rotated Orientation)}

\section{C-0K-R-46 Description}

This appendix summarizes the results of interest for the HayWired mainshock from the structural analysis and loss assessment of building C-OK-R-46 - a 42-story reinforced-concrete residential building in Oakland with the rotated orientation shown in figure 10. Results are shown in figures 72-77.

\section{Engineering-Demand Parameters}

The simulation of engineering-demand parameters follows the method recommended by FEMA P-58 (Applied Technology Council, 2012) for buildings with nonlinear response history analysis results available. This algorithm was developed by Yang and others (2009).

Building C-OK-R-46 sees low demands, with a peak interstory drift (IDR) for whole building of just 0.7 percent. Peak floor acceleration is $1.09 \mathrm{~g}$. Peak coupling beam rotation is $0.009 \mathrm{rad}$, far below $0.05-0.06 \mathrm{rad}$, the point at which significant shear strength degradation occurs. The core walls see no crushing. The core-wall rebar experiences little yielding, all occurring at the base of the core walls.
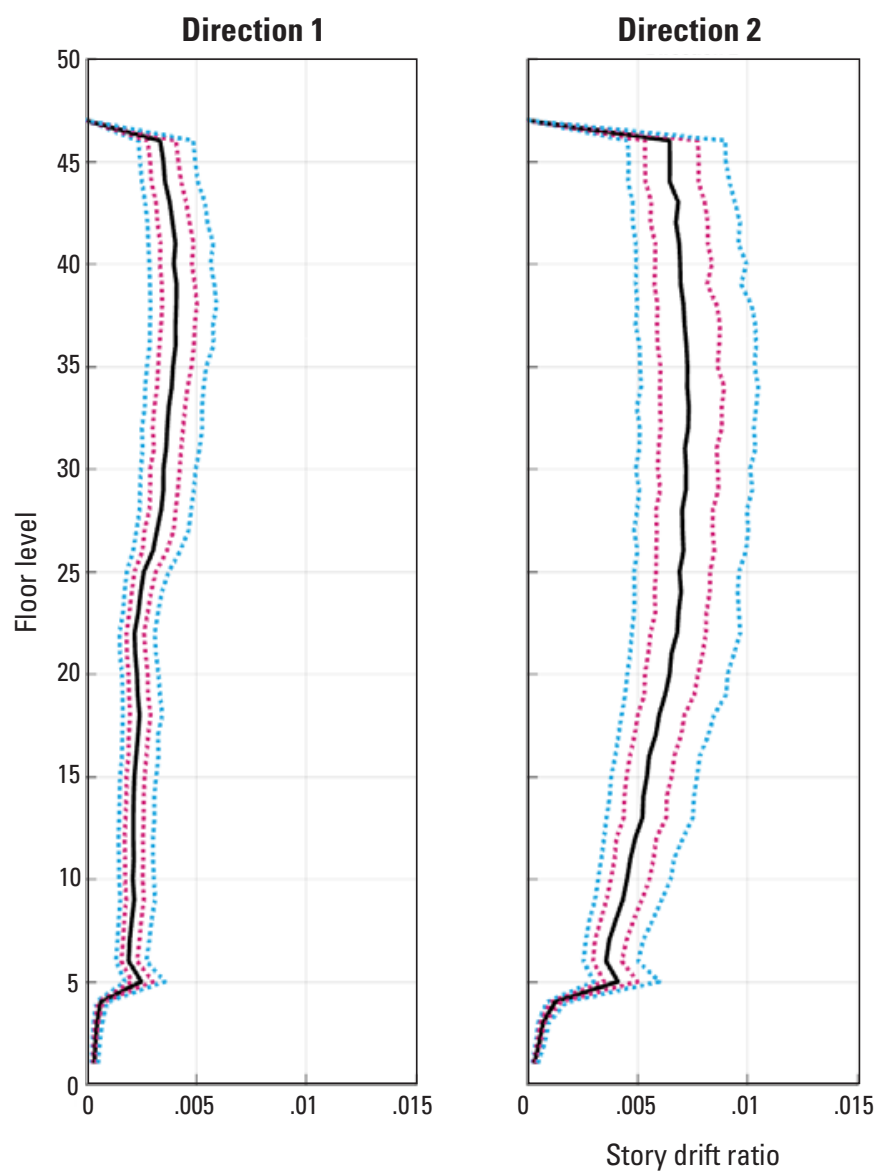

The damage in partitions and slab-column joints is better correlated with racking drift than IDR. Therefore, racking drift was used as the EDP for these components. Racking drift is different from IDR in that it excludes rigid body rotation and includes vertical racking resulting from the relative vertical movement between the core walls and the perimeter columns.

There are a few interesting things to note about the demands. First, figure 75 clearly shows the plastic hinge zone in the core wall at the ground floor level, as evidenced by the large spike in the wall rotation. However, this spike is modest, in an absolute sense, at about $0.00115 \mathrm{rad}$ median. This compares favorably with the acceptable plastic hinge rotation per ASCE 41-13 (American Society of Civil Engineers, 2014) of 0.001-0.002 rad for unconfined walls. Second, figure 77 shows that the coupling beam rotations are fairly constant up the height of the building with the exception of a dip in rotations at level 17 (superstructure floor 13), where the core wall and coupling beam width abruptly changes from 32 to 24 in.

Coupling beam rotation demands were enveloped for all beams on each floor and thus, beam directionality was not considered. Despite this conservatism, beam rotations were very low and had virtually no impact on the loss assessment.

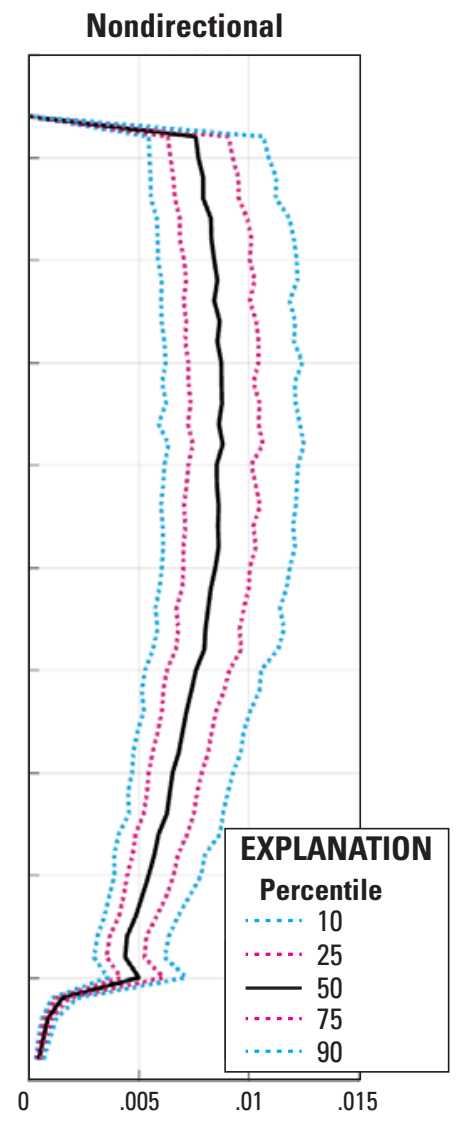

Figure 72. Graphs showing realized peak interstory drift ratio demands in building C-OK-R-46 (42-story reinforcedconcrete residential building in Oakland, California; rotated orientation) for the hypothetical moment-magnitude-7.0 mainshock of the HayWired earthquake scenario. The 50th percentile is taken directly from the nonlinear response-history analysis. Due to the explicit modeling of the substructure, level 5 is the ground floor. Direction 1 is east-west and direction 2 is north-south. 

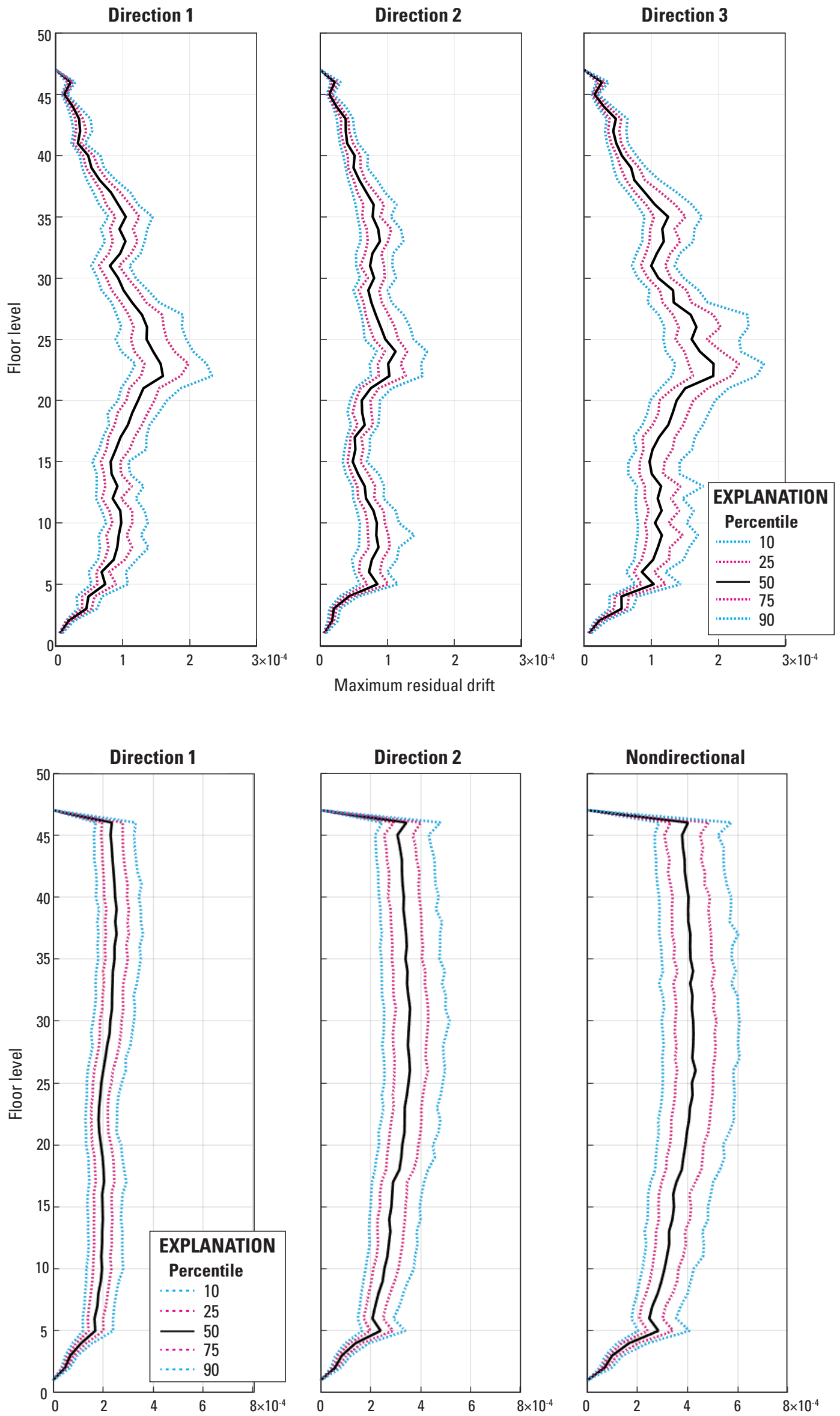
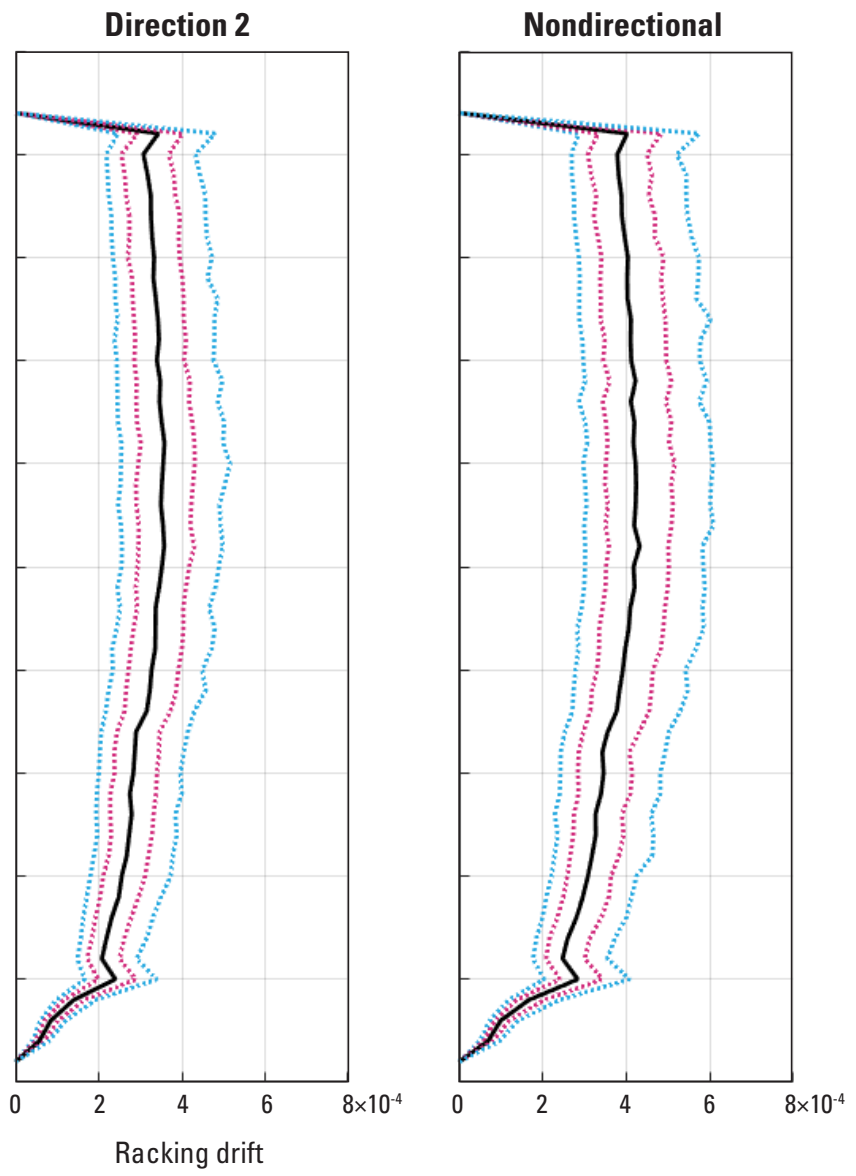

Figure 73. Graphs showing realized peak residual interstory drift ratio demands in building C-OK-R-46 (42story reinforced-concrete residential building in Oakland, California; rotated orientation) for the hypothetical momentmagnitude-7.0 mainshock of the HayWired earthquake scenario. The 50th percentile is taken directly from the nonlinear response-history analysis. Due to the explicit modeling of the substructure, level 5 is the ground floor. Direction 1 is east-west and direction 2 is north-south.
Figure 74. Graphs showing realized peak racking drift ratio demands in building C-OK-R-46 (42-story reinforced-concrete residential building in 0akland, California; rotated orientation) for the hypothetical momentmagnitude-7.0 mainshock of the HayWired earthquake scenario. The 50th percentile is taken directly from the nonlinear response-history analysis. Due to the explicit modeling of the substructure, level 5 is the ground floor. Direction 1 is east-west and direction 2 is north-south. 

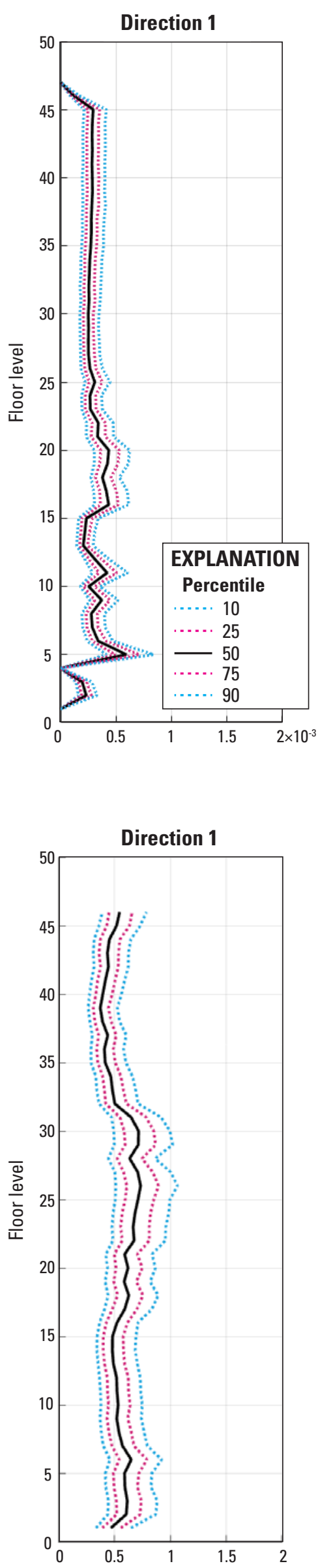
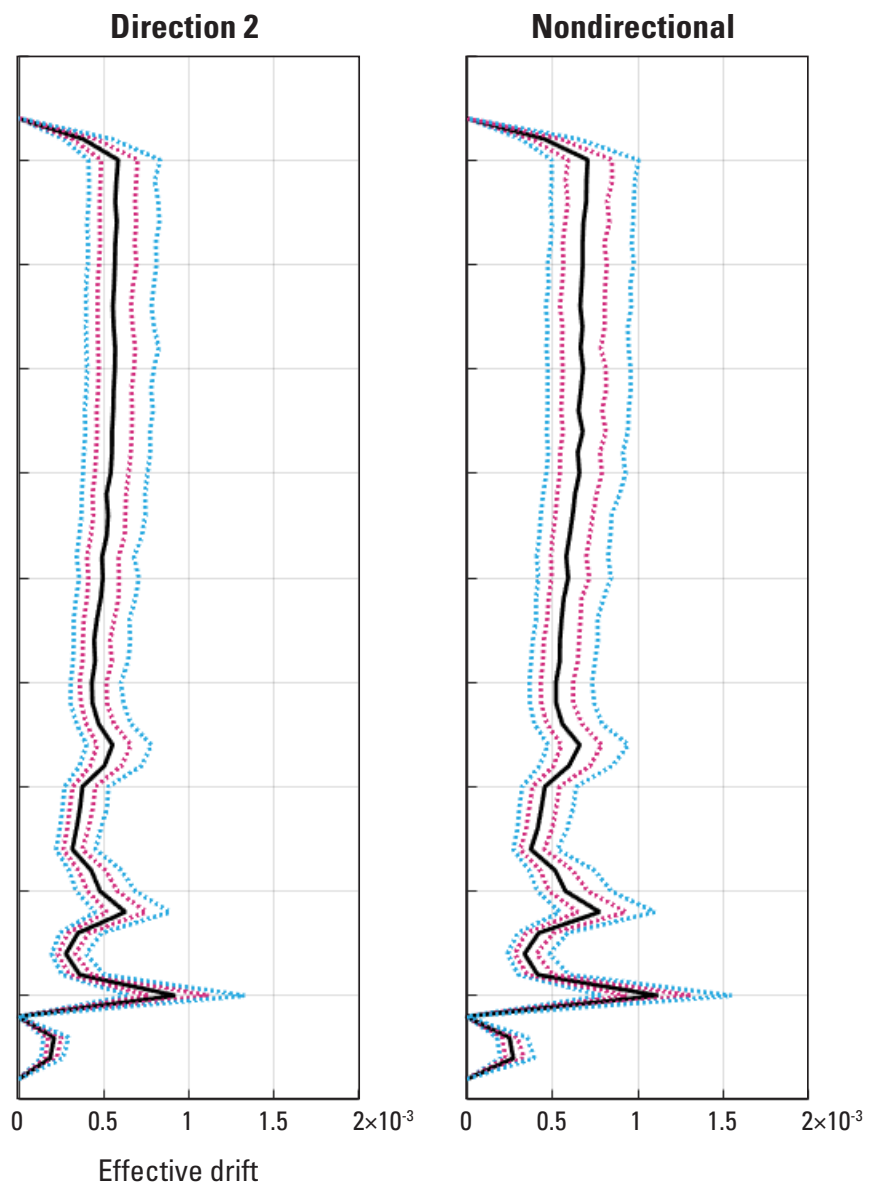

Figure 75. Graphs showing realized peak wall-rotation demands (radians) in building C-0K-R-46 (42-story reinforcedconcrete residential building in Oakland, California; rotated orientation) for the hypothetical moment-magnitude- 7.0 mainshock of the HayWired earthquake scenario. The 50th percentile is taken directly from the nonlinear response-history analysis. Due to the explicit modeling of the substructure, level 5 is the ground floor. Direction 1 is east-west and direction 2 is north-south.
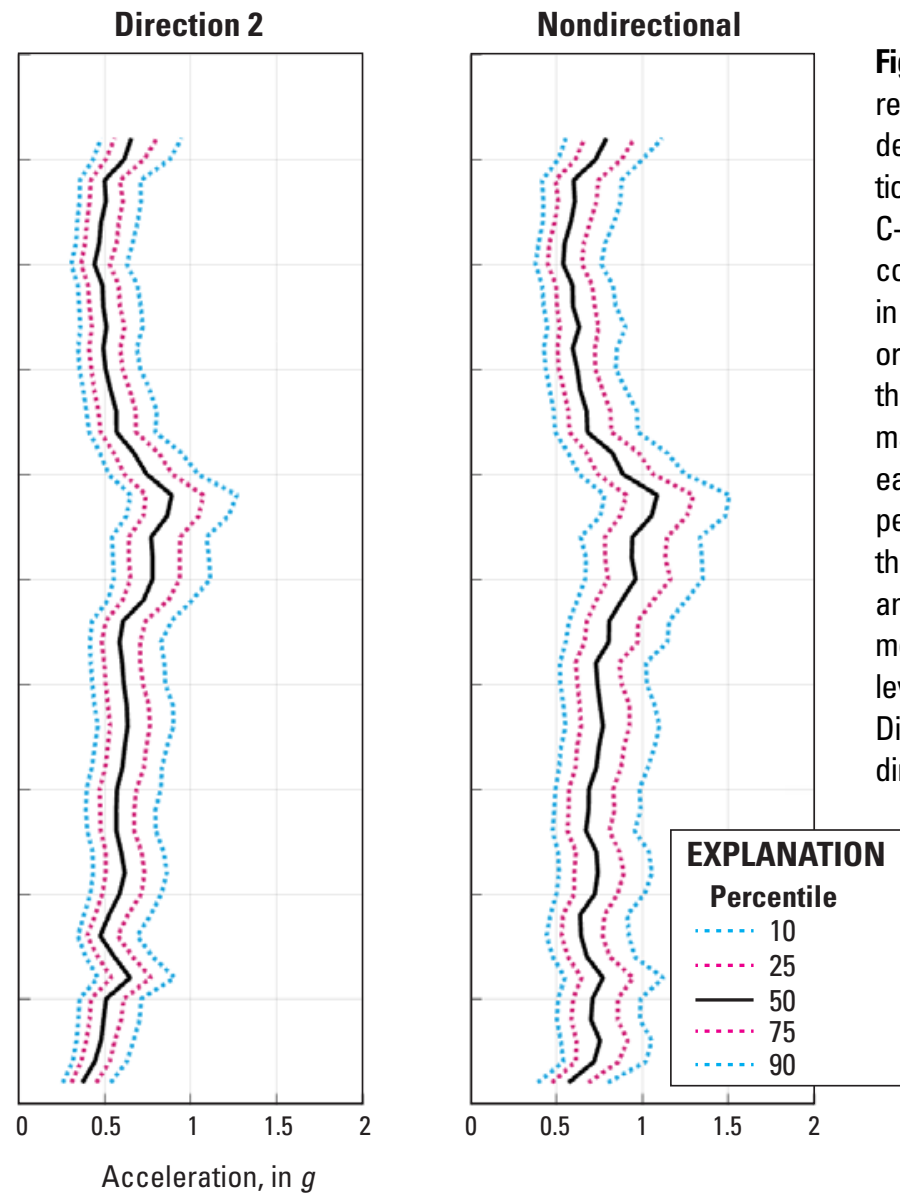

Figure 76. Graphs showing realized peak floor-acceleration demands (relative to acceleration due to gravity, $g$ ) in building C-0K-R-46 (42-story reinforcedconcrete residential building in Oakland, California; rotated orientation) for the hypothetical moment-magnitude-7.0 mainshock of the HayWired earthquake scenario. The 50th percentile is taken directly from the nonlinear response-history analysis. Due to the explicit modeling of the substructure, level 5 is the ground floor. Direction 1 is east-west and direction 2 is north-south. 

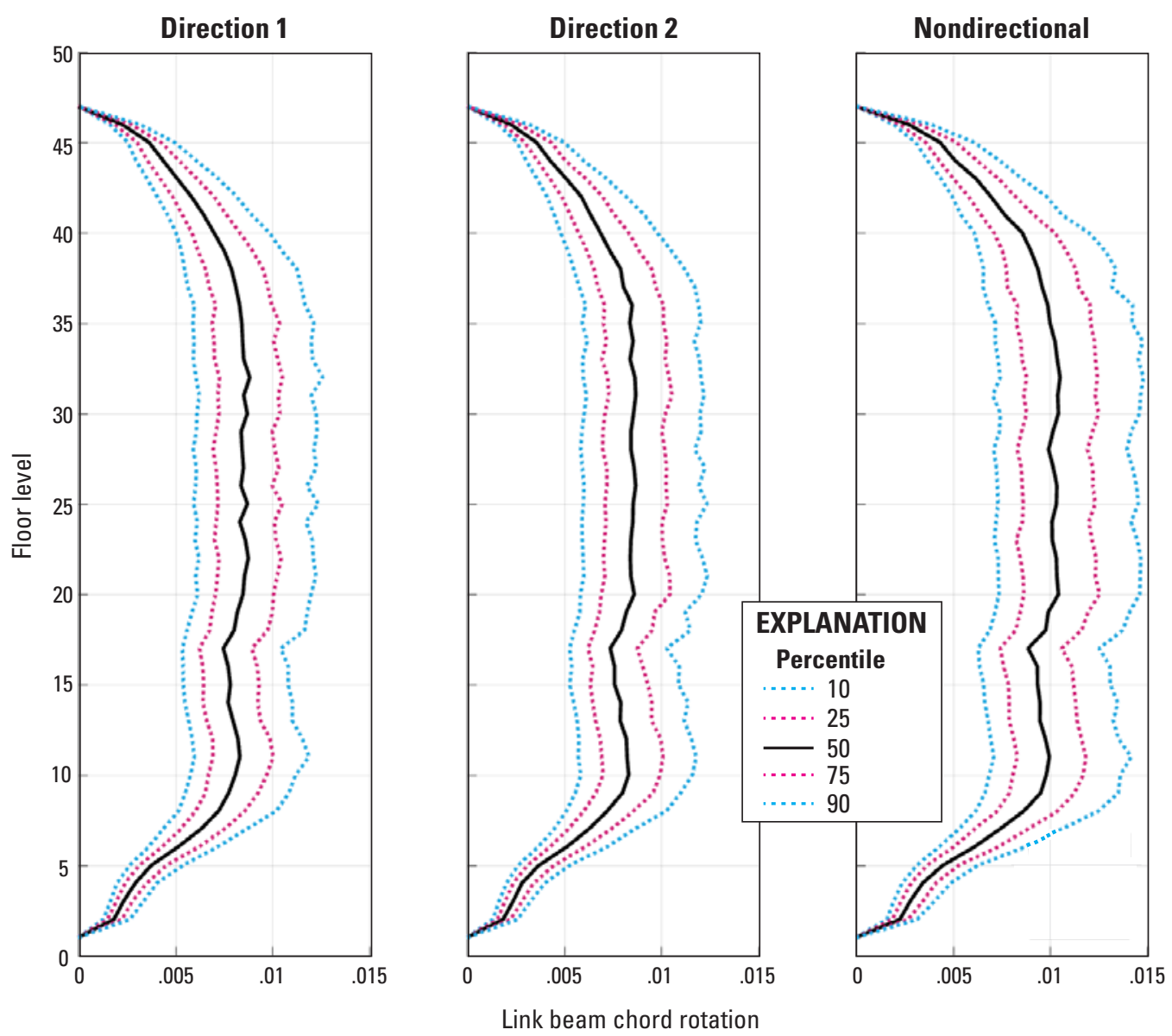

Figure 77. Graphs showing realized peak coupling-beam rotation demands (radians) in building C-OK-R-46 (42story reinforced-concrete residential building in Oakland, California; rotated orientation) for the hypothetical momentmagnitude-7.0 mainshock of the HayWired earthquake scenario. The 50th percentile is taken directly from the nonlinear response-history analysis. Due to the explicit modeling of the substructure, level 5 is the ground floor. Direction 1 is east-west and direction 2 is north-south.

\section{Loss-Assessment Results}

The loss assessment is based on a Monte Carlo simulation with 1,000 realizations. The loss assessment was performed using the probabilistic approach outlined in the Federal Emergency Management Agency's (FEMA) P-58 document (Applied Technology Council, 2012). The likely costs to repair and (or) replace damaged components are calculated based solely on FEMA P-58, whereas repair time and downtime are estimated using the FEMA P-58 based methodology outlined REDi (Almufti and Willford, 2013).

\section{Damaged Components}

The probability that a component type in building C-OK$\mathrm{R}-46$ incurs damage that hinders either reoccupancy, functionality, or full recovery was examined in the realizations. The results are shown in figure 78.

\section{Repair Costs, Repair Time, Downtime, and Impending Factors}

The median total repair cost for building C-OK-R-46 is 5.0 percent of the total building replacement value, or $\$ 8.9$ million. The 90th-percentile total repair cost is 6.2 percent of the total building replacement value, or $\$ 10.8$ million. For this study, the total building replacement value is defined as the hard costs only required to replace the building, based off a construction cost estimate, including at minimum all structural and nonstructural components plus the value of damageable building contents if they are known.

The total repair cost is dominated by wall partitions because there are a large number of partitions in a residential building. Figure 79 shows the contribution of building component groups to realized median total repair cost. Table 35 shows realized median and 90th-percentile repair time and total downtime, and table 36 shows realized median and 90th-percentile delays due to impeding factors to functional recovery. 


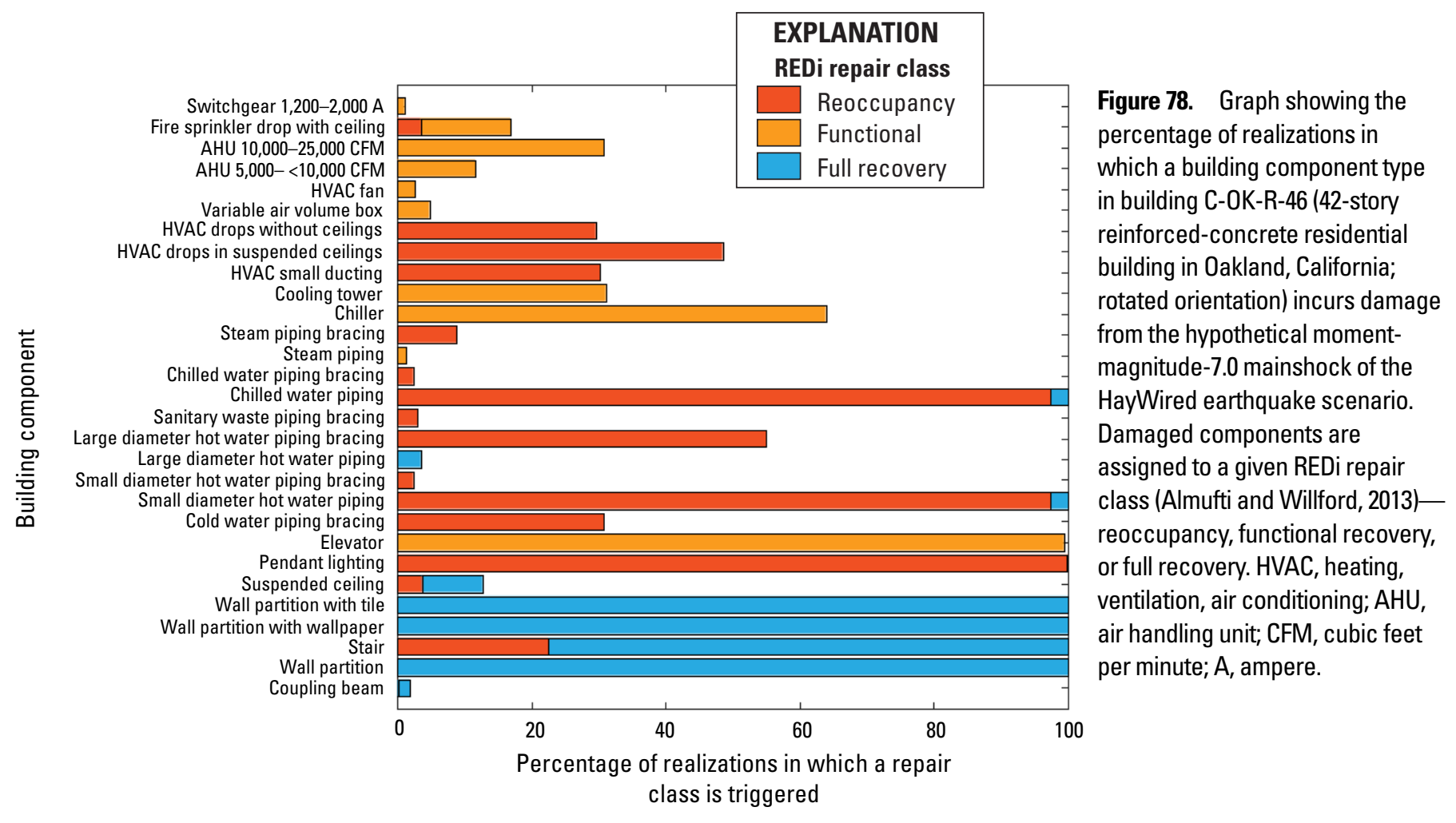

Table 35. Realized median and 90th-percentile repair time and total downtime for building C-OK-R-46 (42-story reinforced-concrete residential building in Oakland, California; rotated orientation) due to the hypothetical moment-magnitude-7.0 mainshock of the HayWired earthquake scenario.

[REDi (Almufti and Willford, 2013)]

\begin{tabular}{lccc}
\hline \multicolumn{1}{c}{ Repair time } & ReDi repair class \\
\cline { 2 - 4 } & $\begin{array}{c}\text { Reoccupancy, } \\
\text { in days }\end{array}$ & $\begin{array}{c}\text { Functional recovery, } \\
\text { in days }\end{array}$ & $\begin{array}{c}\text { Full recovery, } \\
\text { in days }\end{array}$ \\
\hline Median repair time & 6 & 16 & 184 \\
Median total downtime & 139 & 245 & 415 \\
90th-percentile repair time & 11 & 26 & 251 \\
90th-percentile downtime & 222 & 359 & 555 \\
\hline
\end{tabular}




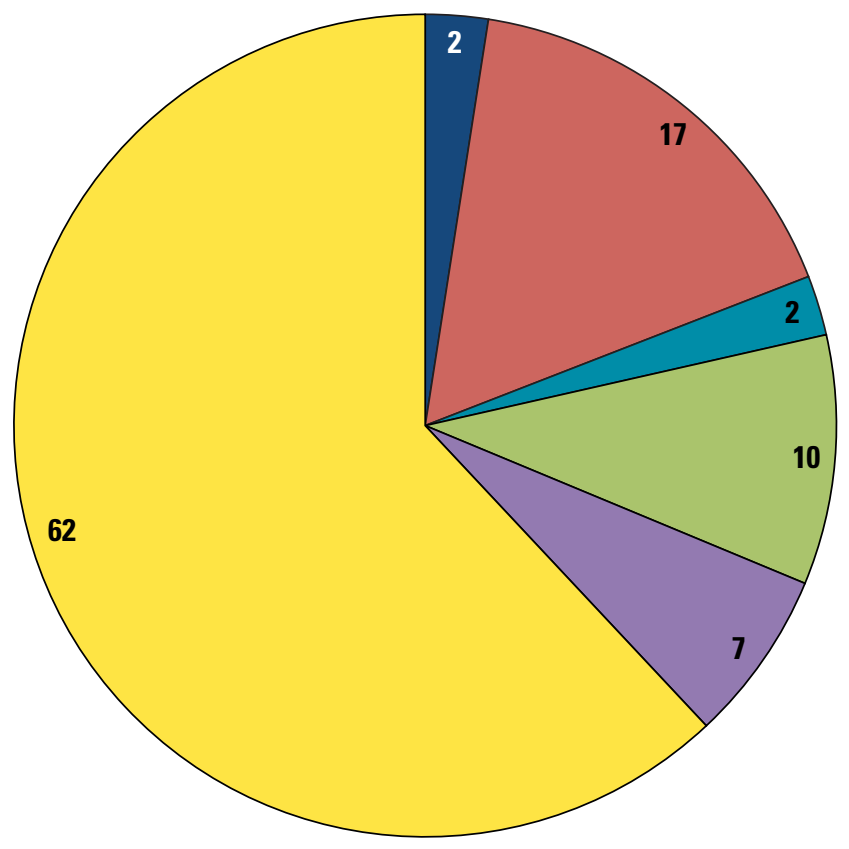

\section{EXPLANATION}

Building component group

Chiller

Elevator

Wall partition

Wall partition with tile

Wall partition with wallpaper

Other

Figure 79. Pie chart showing the percentage contribution of building component groups to realized median total repair cost for building C-0K-R-46 (42-story reinforced-concrete residential building in Oakland, California; rotated orientation) due to the hypothetical moment-magnitude-7.0 mainshock of the HayWired earthquake scenario.

Table 36. Realized median and 90th-percentile delays due to impeding factors to functional recovery for building C-0K-R-46 (42-story reinforced-concrete residential building in Oakland, California; rotated orientation) due to the hypothetical moment-magnitude-7.0 mainshock of the HayWired earthquake scenario.

\begin{tabular}{lccl}
\hline Impeding factor & $\begin{array}{c}\text { Median disruption, } \\
\text { in days }\end{array}$ & $\begin{array}{c}\text { 90th-percentile disruption, } \\
\text { in days }\end{array}$ & Comment \\
\hline Inspection & 5 & 11 & None. \\
Financing & 59 & 204 & None. \\
Engineer mobilization & 0 & 0 & No structural damage. \\
Contractor mobilization & 229 & 342 & None. \\
Permitting & 0 & 0 & No structural damage. \\
\hline
\end{tabular}




\section{Appendix 12. Inventory of Existing Tall-Building Stock in San Francisco}

A list of tall buildings (more than $50 \mathrm{~m} / \sim 160 \mathrm{ft}$ in height) in San Francisco was compiled by the Structural Engineers Association of Northern California (SEAONC) (see MolinaHutt, 2017, table 37). There are roughly 230 buildings that fit this criterion. The building list is ordered by the year of construction and the type of lateral load-resisting system.
Figure 80 summarizes this information (Molina-Hutt and others, 2017). This list should not be considered as definitive because it has not been verified by the San Francisco Department of Building Inspection and it was developed approximately 7 or 8 years ago. We are not aware of a similar database for tall buildings in Oakland.
Figure 80. Graphs showing $(A)$ number of tall buildings built in San Francisco, California, per decade between 1900 and 2010 and $(B)$ type of lateral load-resisting system for tall buildings built in the city between 1960 and 1990 (Modified from MolinaHutt and others, 2016).
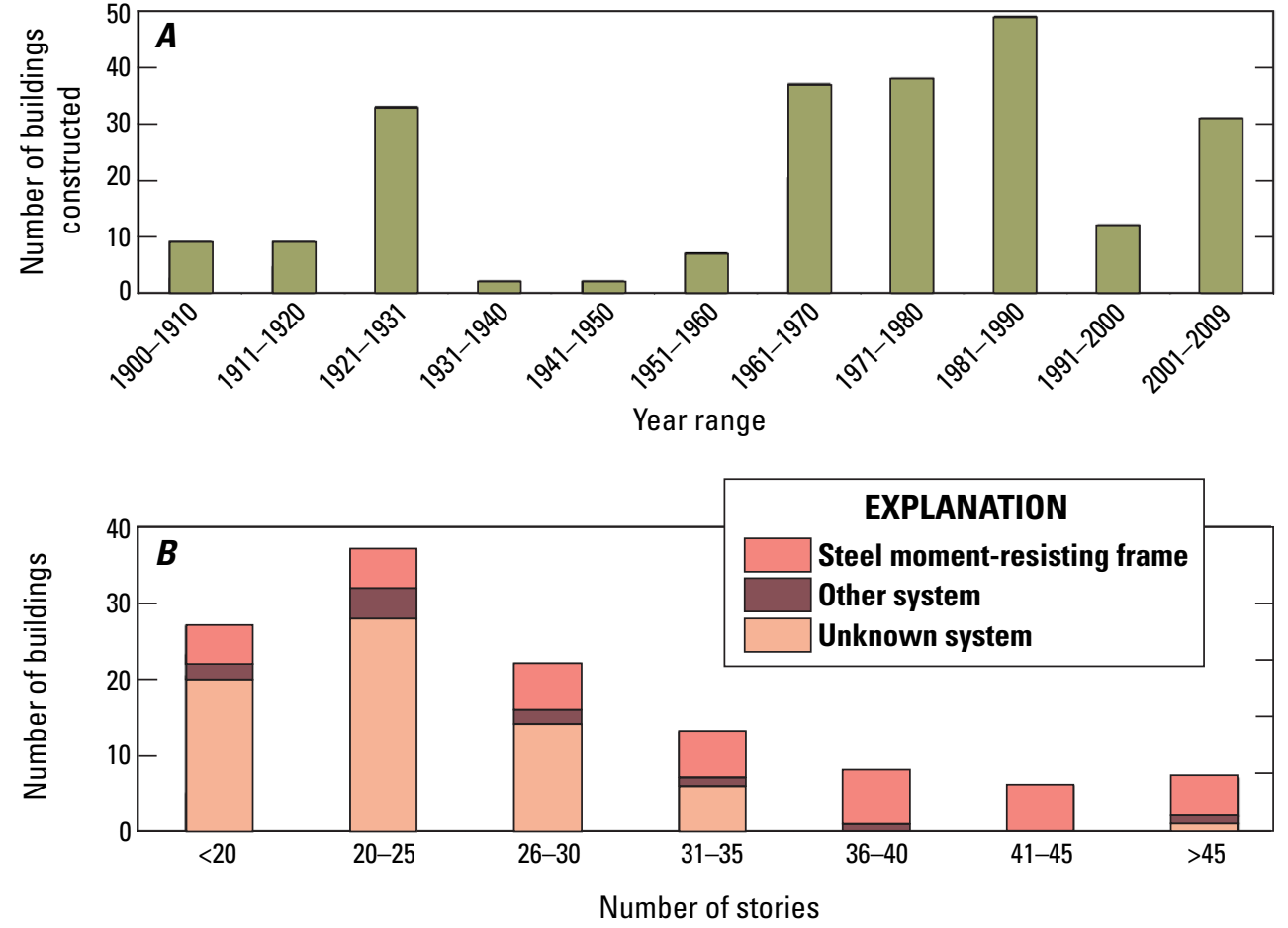

Table 37. List of tall buildings (more than 50 meters/ 160 feet in height) in San Francisco, California, compiled by the Structural Engineers Association of Northern California (SEAONC) (see Molina-Hutt, 2017).

[MF, moment frame; $\mathrm{CBF}$, concentrically braced frame; EBF, eccentrically braced frame; RC, reinforced concrete; NA, not applicable; --, no data]

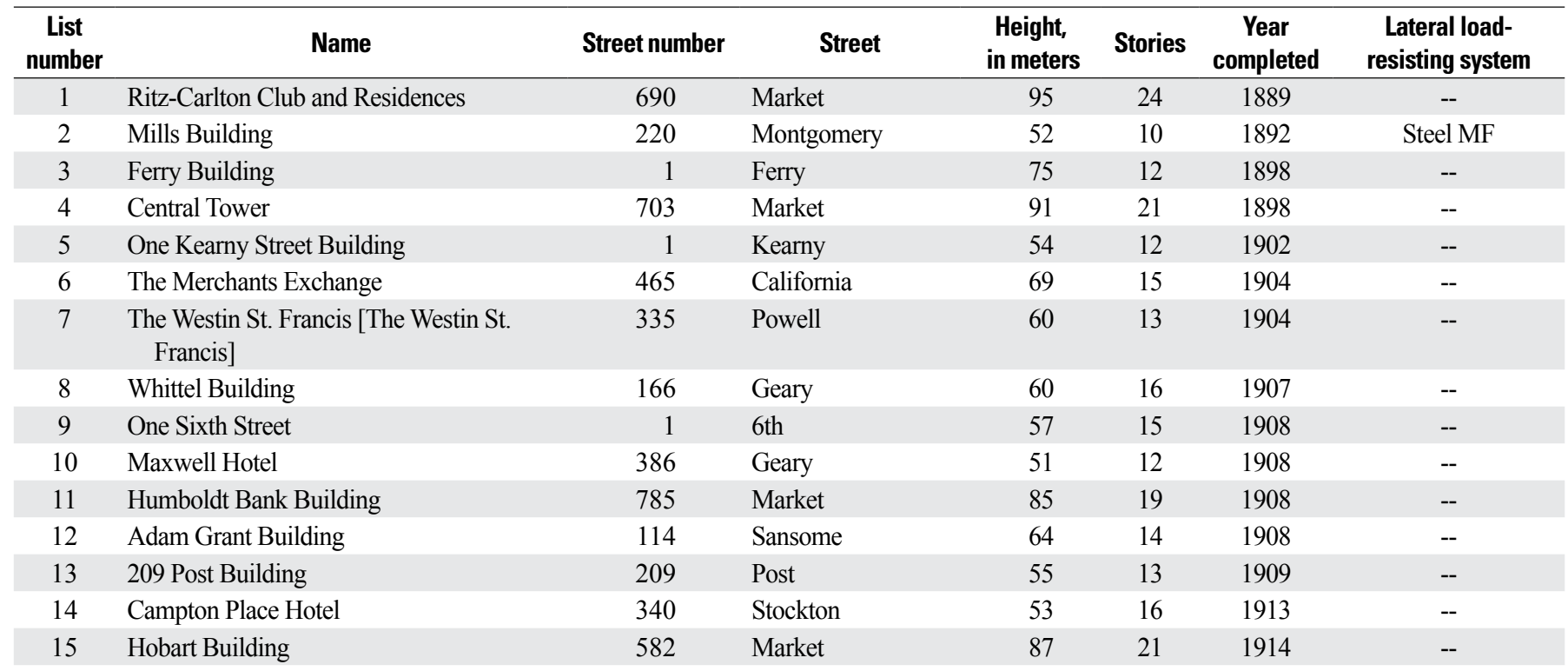


Table 37.-Continued

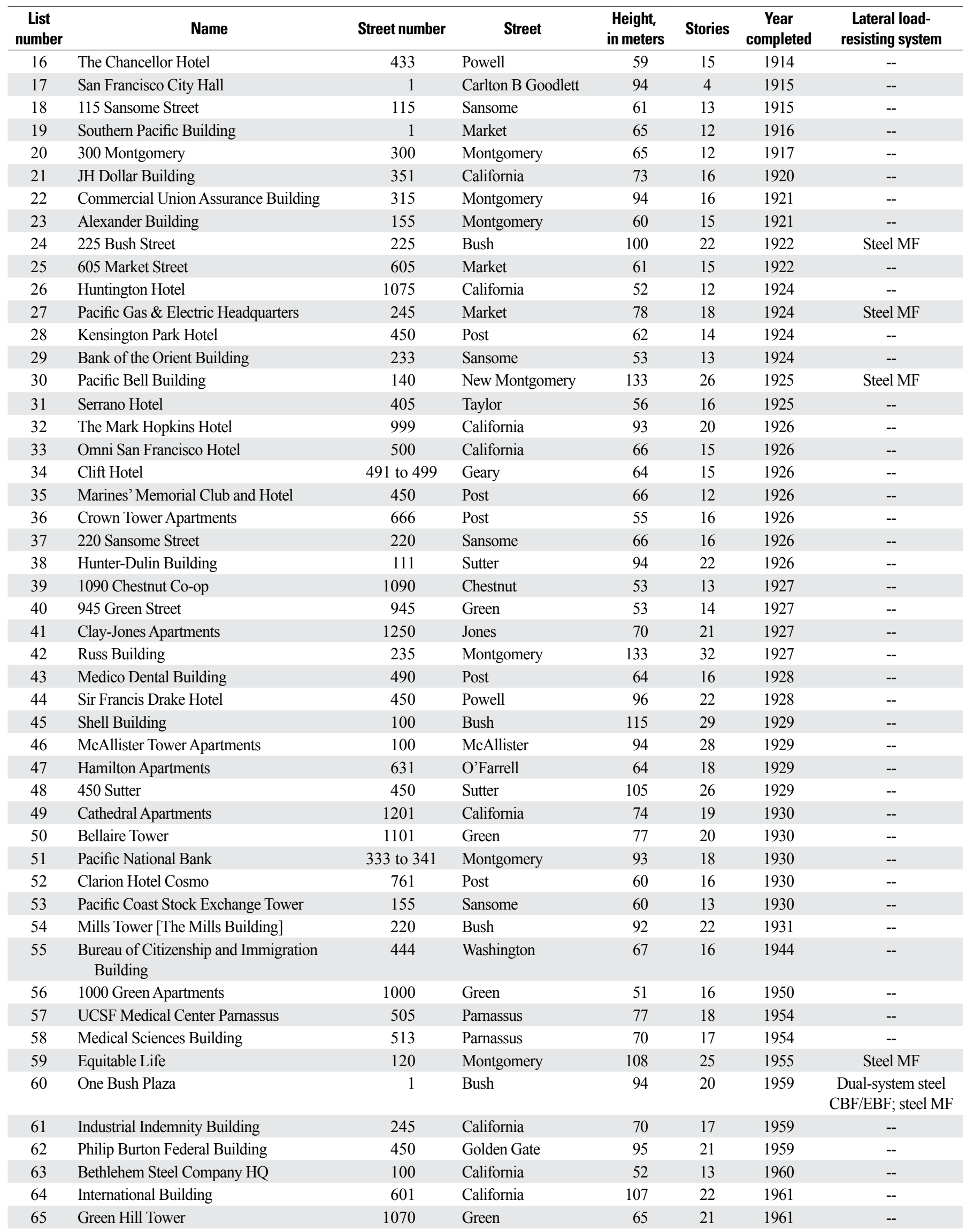


Table 37.-Continued

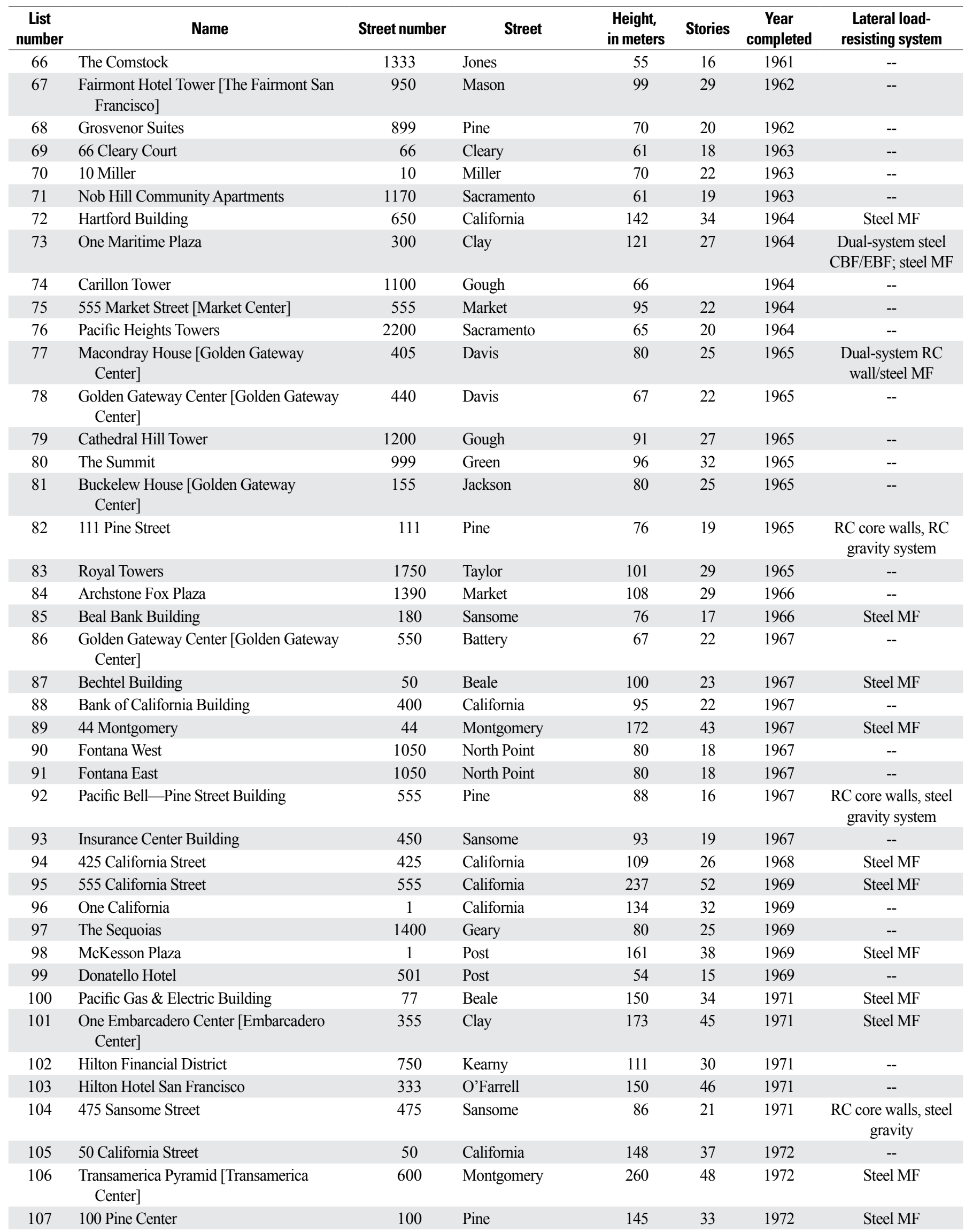


Table 37.-Continued

\begin{tabular}{|c|c|c|c|c|c|c|c|}
\hline $\begin{array}{c}\text { List } \\
\text { number }\end{array}$ & Name & Street number & Street & $\begin{array}{l}\text { Height, } \\
\text { in meters }\end{array}$ & Stories & $\begin{array}{c}\text { Year } \\
\text { completed }\end{array}$ & $\begin{array}{l}\text { Lateral load- } \\
\text { resisting system }\end{array}$ \\
\hline 108 & The Westin St. Francis Hotel & 335 & Powell & 120 & 32 & 1972 & -- \\
\hline 109 & Grand Hyatt San Francisco & 345 & Stockton & 108 & 35 & 1972 & -- \\
\hline 111 & Holiday Inn & 1500 & Van Ness & 88 & 26 & 1972 & -- \\
\hline 114 & First Market Tower & 525 & Market & 161 & 39 & 1973 & Steel MF \\
\hline 115 & 425 Market Street & 425 & Market & 160 & 38 & 1973 & Steel MF \\
\hline 116 & Twelve Hundred California & 1200 & California & 88 & 27 & 1974 & -- \\
\hline 117 & $\begin{array}{l}\text { Two Embarcadero Center [Embarcadero } \\
\text { Center] }\end{array}$ & 255 & Clay & 126 & 30 & 1974 & Steel MF \\
\hline 121 & Hinode Tower & 1615 & Sutter & 55 & 15 & 1975 & -- \\
\hline 122 & Spear Tower [One Market Plaza] & 1 & Market & 172 & 43 & 1976 & Steel MF \\
\hline 123 & Steuart Tower [One Market Plaza] & 1 & Market & 111 & 27 & 1976 & Steel MF \\
\hline 124 & California Building & 350 & California & 99 & 23 & 1977 & -- \\
\hline 125 & $\begin{array}{l}\text { Three Embarcadero Center[Embarcadero } \\
\text { Center] }\end{array}$ & 155 & Clay & 126 & 31 & 1977 & Steel MF \\
\hline 126 & Bank of America Computer Center & 1455 & Market & 88 & 21 & 1977 & -- \\
\hline 127 & 1275 Market Street & 1275 & Market & 81 & 17 & 1977 & -- \\
\hline 128 & Gramercy Towers & 1177 & California & 61 & 17 & 1978 & -- \\
\hline 129 & Bechtel Building & 45 & Fremont & 145 & 34 & 1978 & MF \\
\hline 136 & 201 California & 201 & California & 72 & 17 & 1980 & Steel MF \\
\hline 137 & Two Transamerica Center & 505 & Sansome & 80 & 20 & 1980 & Steel moment frame \\
\hline 138 & Providian Financial Building & 201 & Mission & 127 & 30 & 1981 & $\begin{array}{l}\text { Dual-system steel } \\
\text { CBF/EBF; steel MF }\end{array}$ \\
\hline 139 & 101 California Street & 101 & California & 183 & 48 & 1982 & Steel MF \\
\hline 140 & $\begin{array}{l}\text { Four Embarcadero Center [Embarcadero } \\
\text { Center] }\end{array}$ & 55 & Clay & 174 & 45 & 1982 & $\begin{array}{l}\text { Dual-system steel } \\
\text { CBF/EBF; steel MF }\end{array}$ \\
\hline 141 & Telesis Tower & 1 & Montgomery & 152 & 38 & 1982 & Steel MF \\
\hline 142 & 353 Sacramento & 353 & Sacramento & 95 & 23 & 1982 & -- \\
\hline 143 & 150 Spear & 150 & Spear & 79 & 18 & 1982 & -- \\
\hline 144 & 1 Ecker Square & 1 & Ecker & 85 & 18 & 1983 & Steel MF \\
\hline 145 & Montgomery Washington Tower & 655 & Montgomery & 91 & 26 & 1983 & -- \\
\hline 146 & 100 Spear Street & 100 & Spear & 83 & 22 & 1983 & Steel MF \\
\hline 147 & $\begin{array}{l}\text { Westin San Francisco Hotel-Market } \\
\text { Street }\end{array}$ & 50 & $3 \mathrm{rd}$ & 114 & 34 & 1984 & -- \\
\hline 148 & Renaissance Parc 55 & 55 & Cyril Magnin & 107 & 32 & 1984 & -- \\
\hline 149 & 101 Montgomery [101 Montgomery] & 101 & Montgomery & 123 & 28 & 1984 & Steel MF \\
\hline 150 & United Commercial Bank & 555 & Montgomery & 86 & 18 & 1984 & -- \\
\hline 151 & Citicorp Center & 1 & Sansome & 168 & 43 & 1984 & Steel MF \\
\hline 152 & 50 Fremont Center & 50 & Fremont & 183 & 43 & 1985 & Steel MF \\
\hline 153 & 456 Montgomery Plaza & 456 & Montgomery & 115 & 26 & 1985 & -- \\
\hline
\end{tabular}


Table 37.-Continued

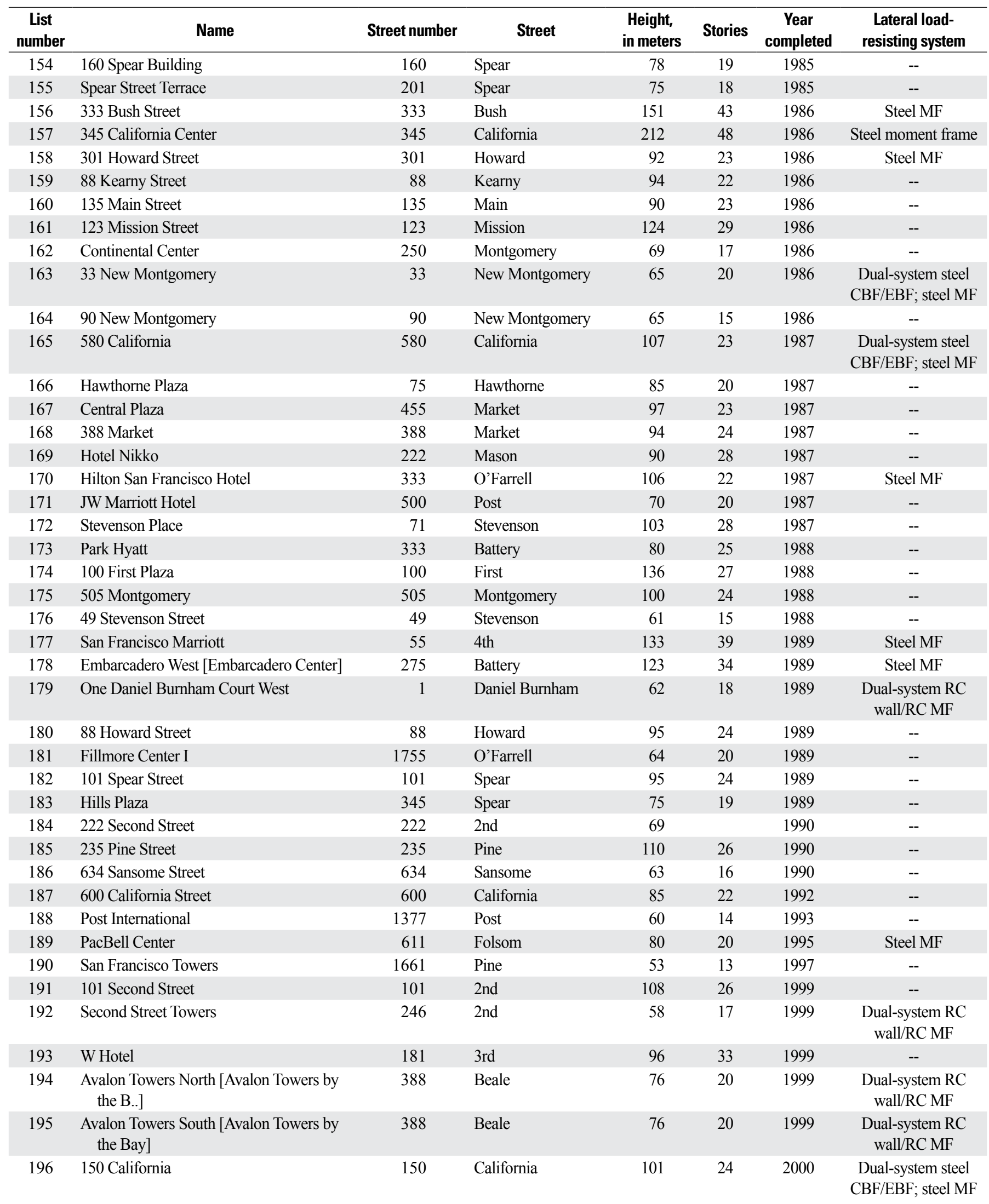


Table 37.-Continued

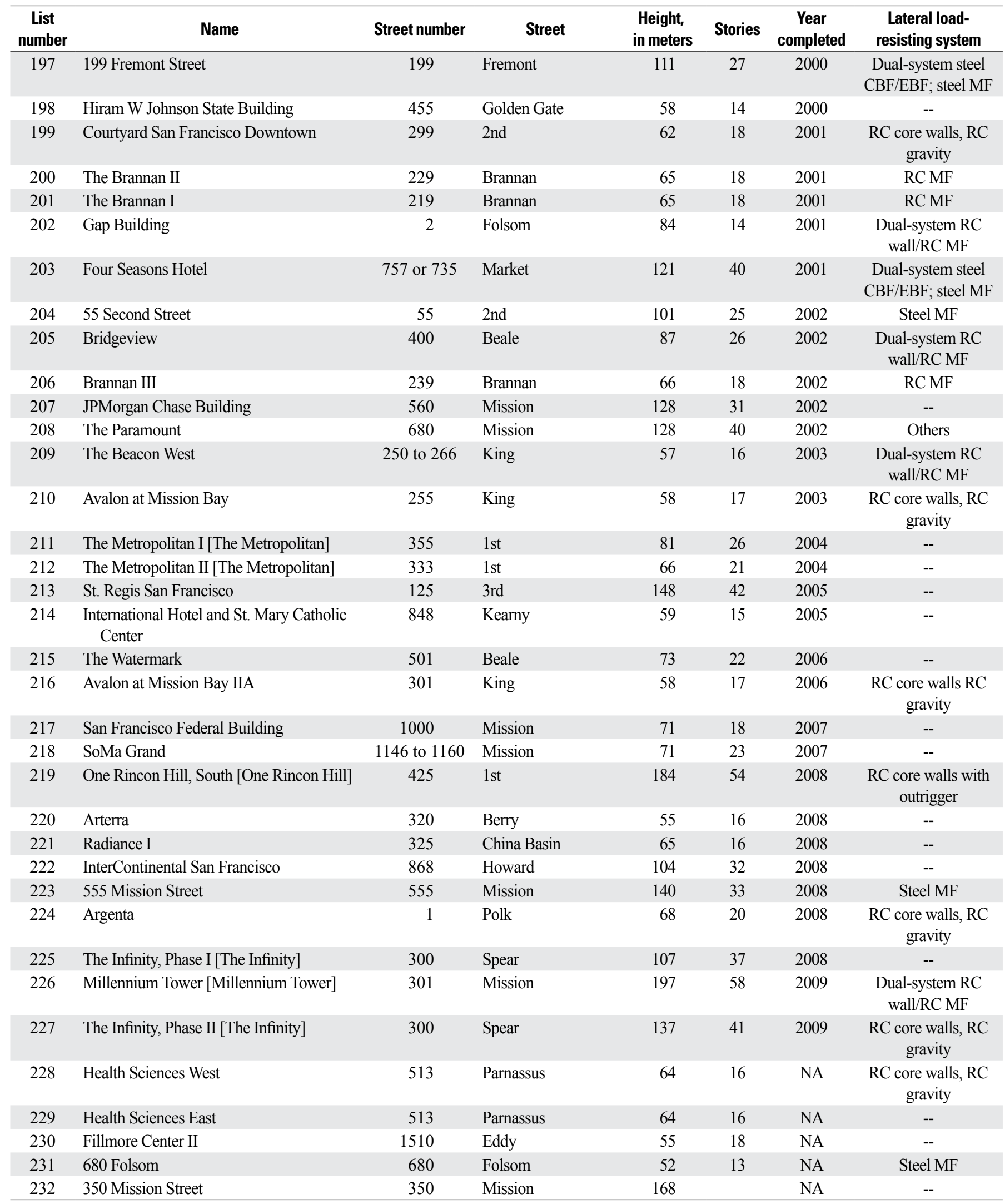





\title{
Chapter P
}

\section{Fire Following the HayWired Scenario Mainshock}

\author{
By Charles Scawthorn'
}

\section{Abstract}

Fire following earthquake is a significant problem in California. This chapter discusses potential losses arising from fires following the HayWired earthquake scenario, a hypothetical moment magnitude $\left(M_{\mathrm{w}}\right) 7.0$ earthquake (mainshock) occurring on April 18, 2018, at 4:18 p.m., on the Hayward Fault in the east bay part of the San Francisco Bay area. The earthquake causes Modified Mercalli Intensities of VI-X in the greater San Francisco Bay region, with very strong shaking along the fault in the densely urbanized east bay. Weather conditions are typical for the season, with strong onshore winds in the afternoon, subsiding to calm in the evening.

Fire following earthquake is a highly nonlinear process, modeling of which does not have great precision and is such that, in many cases, the only clear result is differentiation between situations of a few small fires versus major conflagration. For the $M_{\mathrm{w}} 7.0$ scenario mainshock, it is estimated that approximately 668 ignitions will occur requiring the response of a fire engine. The first responding engine will not be able to adequately contain approximately 450 of these fires, such that in Alameda, Contra Costa, and Santa Clara Counties, dozens to hundreds of large fires are likely to merge into numerous conflagrations destroying tens of city blocks, with several of these potentially merging into one or several super conflagrations destroying hundreds of city blocks.

Under the assumed scenario conditions, it is estimated that the about 450 large fires will result in an ultimate burned area of approximately 79 million square feet of residential and commercial building floor area, equivalent to more than 52,000 single

\footnotetext{
${ }^{1}$ SPA Risk LLC.

${ }^{2}$ Usage of the term conflagration varies within the fire service (and interestingly, does not appear in the 1,449-page National Fire Protection Association's Glossary of Terms, 2013 Edition; http://www.nfpa.org/ /media/ files/codes-and-standards/glossary-of-terms/glossary_of_terms_2013.pdf). It has previously been defined by the author (Scawthorn and others, 2005) as “. . . in the urban context, a conflagration usually denotes a large fire that spreads across one or more city streets."
}

family dwellings. The fires following the scenario mainshock would be directly responsible for the loss of hundreds of lives, a total building replacement value of almost $\$ 16$ billion, and property losses approaching $\$ 30$ billion (2014 dollars). This loss is virtually fully insured and would be one of the largest single-loss events in the history of the insurance industry. Other economic impacts include the loss of perhaps $\$ 1$ billion in local tax revenues. A number of opportunities exist for mitigating this problem, including greatly enhancing the postearthquake supply of water for firefighting and the mandatory use of automated gas shut-off valves, or seismic shut-off meters, in densely built areas.

\section{Introduction}

The HayWired earthquake scenario examines a hypothetical moment magnitude $\left(M_{\mathrm{w}}\right) 7.0$ earthquake (mainshock) occurring on April 18, 2018, at 4:18 p.m., on the Hayward Fault in the east bay part of the San Francisco Bay area. This chapter discusses the potential for fire in the bay region after the mainshock. "Fire following earthquake" refers to a series of events or a stochastic process initiated by a large earthquake. Fires occur following all earthquakes that significantly shake a human settlement but are generally only a significant problem in large metropolitan areas predominantly composed of densely spaced wood buildings. In such circumstances, multiple simultaneous ignitions can lead to catastrophic conflagrations ${ }^{2}$ that may be the dominant agent of damage. Example regions vulnerable to such conflagrations include Japan, New Zealand, parts of Southeast Asia, and western North America. A large earthquake, such as a $M_{\mathrm{w}} 7.0$ event on the Hayward Fault in the San Francisco Bay area (or comparable events in southern California, Washington's Puget Sound region, or the lower mainland of British Columbia), combines all of the requisite factors for major conflagrations that, depending on circumstances, can be uniquely catastrophic, such as the fire following the $M_{\mathrm{w}} 7.8$ Great 1906 San Francisco, California, earthquake. 


\section{Purpose}

The purpose of this chapter is to quantitatively describe fires following a hypothetical $M_{\mathrm{w}} 7.0$ earthquake on the Hayward Fault, with primary emphasis for assisting emergency planning. The HayWired scenario occurs on Wednesday, April 18, 2018, at 4:18 p.m., with average April weather conditions. This analysis is intended to be realistic and not a "worst-case" scenario, and addresses the following questions:

- What is a realistic scenario of ignitions, fire growth, and spread?

- How will ignitions be reported after an earthquake, how will fire departments respond, and what factors will influence the spread of fires? What mutual-aid agreements are in place and how will they be activated?

- How will damage to telecommunications, water supply, and roadways affect response?

- What, if any, effective mitigation actions have been undertaken elsewhere that might be practical in the San Francisco Bay region in addition to those already taken?

- What are the limitations of the fire-following-earthquake scenario and what research would provide a more realistic, perhaps more challenging or detailed, scenario?

\section{Background}

Large fires, measured in terms of square miles of burned area, have not been unique to fires following earthquakesindeed the great fires of London (1666) and Chicago (1871) are only the most noteworthy of a long succession of nonearthquake related urban conflagrations. Large urban conflagrations were common in 19th century America, which allowed the National Board of Fire Underwriters (1905) to state the following with some confidence:

In fact, San Francisco has violated all underwriting traditions and precedent by not burning up. That it has not done so is largely due to the vigilance of the fire department, which cannot be relied upon indefinitely to stave off the inevitable.

Although the 1906 San Francisco earthquake had major geological effects and damaged many buildings, it was the ensuing fire that resulted in 80 percent of the total damage - a fire foreseen and expected, irrespective of an earthquake. As the fire service was professionalized in the 20th centurywith improvements in equipment, communications, training, and organization - large urban conflagrations tended to become much less common (National Commission on Fire
Prevention and Control, 1973). However, they were not entirely eliminated, as witnessed in the San Francisco Bay area in the 1991 East Bay Hills Fire, when 3,500 buildings were destroyed in a matter of hours.

The two largest peacetime, urban conflagrations in history have been fires following earthquakes - 1906 San Francisco $\left(M_{\mathrm{w}} 7.9\right)$ and 1923 Tokyo $\left(M_{\mathrm{w}} 7.9\right)$ earthquakes. In Tokyo, the fires caused the great majority of the 140,000 fatalities.

Much larger wildland fires also occur and continue to be a major source of loss in places such as southern California almost every year. However, historical earthquakes have not caused major wildland fires.

Although the combination of professionalized fire services, improved water supply, and better building practices has largely eliminated nonearthquake-related large urban conflagrations in the United States, fire following earthquakes is still a concern. This is owing to the correlated effects of a large earthquake simultaneously causing numerous ignitions, degrading building fire-resistive features, dropping pressure in water-supply mains, and overwhelming communications and transportation routes, thus allowing some fires to quickly grow into conflagrations that outstrip local resources. It is not sufficiently appreciated that the key to modern fire protection is a well-drilled, rapid response by professional firefighters in the early stages of structural fires, arriving in time to suppress a fire while that is still relatively feasible. For example, a typical response goal for urban fire departments is 4 minutes (from time of report to arrival) for a single ignition. If suppression is delayed, owing to either delayed response or lack of water, a single structural fire can quickly spread to neighboring buildings and grow to the point where an entire municipality's fire resources are required, and perhaps even assistance from neighboring communities. This is for a single ignition. Most fire departments are not sized or equipped to cope with the fires following a major earthquake. A major earthquake and its associated fires is a low probability event for which, although having very high potential consequences, it may not be feasible to adequately prepare. There are exceptions to this; the Cities of San Francisco, Los Angeles, and Vallejo Fire Departments (California) and Vancouver (British Columbia) Fire and Rescue Services have all undertaken special measures, which are discussed below.

\section{Scenario Earthquake and Prevailing Conditions}

This section summarizes the seismological aspects and affected region for the HayWired scenario. The focus is primarily on the fire-related aspects of the scenario. 


\section{Rupture Segment, Magnitude, and Intensity}

The HayWired scenario $M_{\mathrm{w}} 7.0$ mainshock on the Hayward Fault affects the entire San Francisco Bay region (fig. 1). Seismological aspects of the scenario are discussed in Detweiler and Wein (2017). Peak ground acceleration (PGA) and Modified Mercalli Intensity (MMI) distributions were developed by Aagaard and others (2017) for this project and furnished for this report (fig. 2). Noteworthy are the high MMI (VIII-X) along the fault in the entire east bay.

\section{Affected Region}

Ten San Francisco Bay region counties affected by the scenario mainshock were analyzed for fire following earthquake. The region is densely urbanized (fig. 3), and the total affected population is approximately 7.7 million people (table 1; California Department of Finance, 2014), with population density as shown in figure 4.

\section{Exposure}

Building exposure data for the San Francisco Bay area was provided by the Federal Emergency Management Agency
Table 1. Counties and populations in the San Francisco Bay region, California, affected in the HayWired earthquake scenario.

\begin{tabular}{lc}
\hline \multicolumn{1}{c}{ County } & Estimated population (2014) \\
\hline Alameda & $1,573,254$ \\
Contra Costa & $1,087,008$ \\
Marin & 255,846 \\
Napa & 139,255 \\
San Francisco & 836,620 \\
San Mateo & 745,193 \\
Santa Clara & $1,868,558$ \\
Santa Cruz & 271,595 \\
Solano & 424,233 \\
Sonoma & 490,486 \\
\hline Total & $7,692,048$ \\
\hline
\end{tabular}

'From California Department of Finance (2014).

based on Hazus-MH (Federal Emergency Management Agency, 2012) building inventory. There is a total building floor area of 5.77 billion square feet, with an estimated value (structure only) of approximately $\$ 1.15$ trillion, distributed as shown in figure 5.

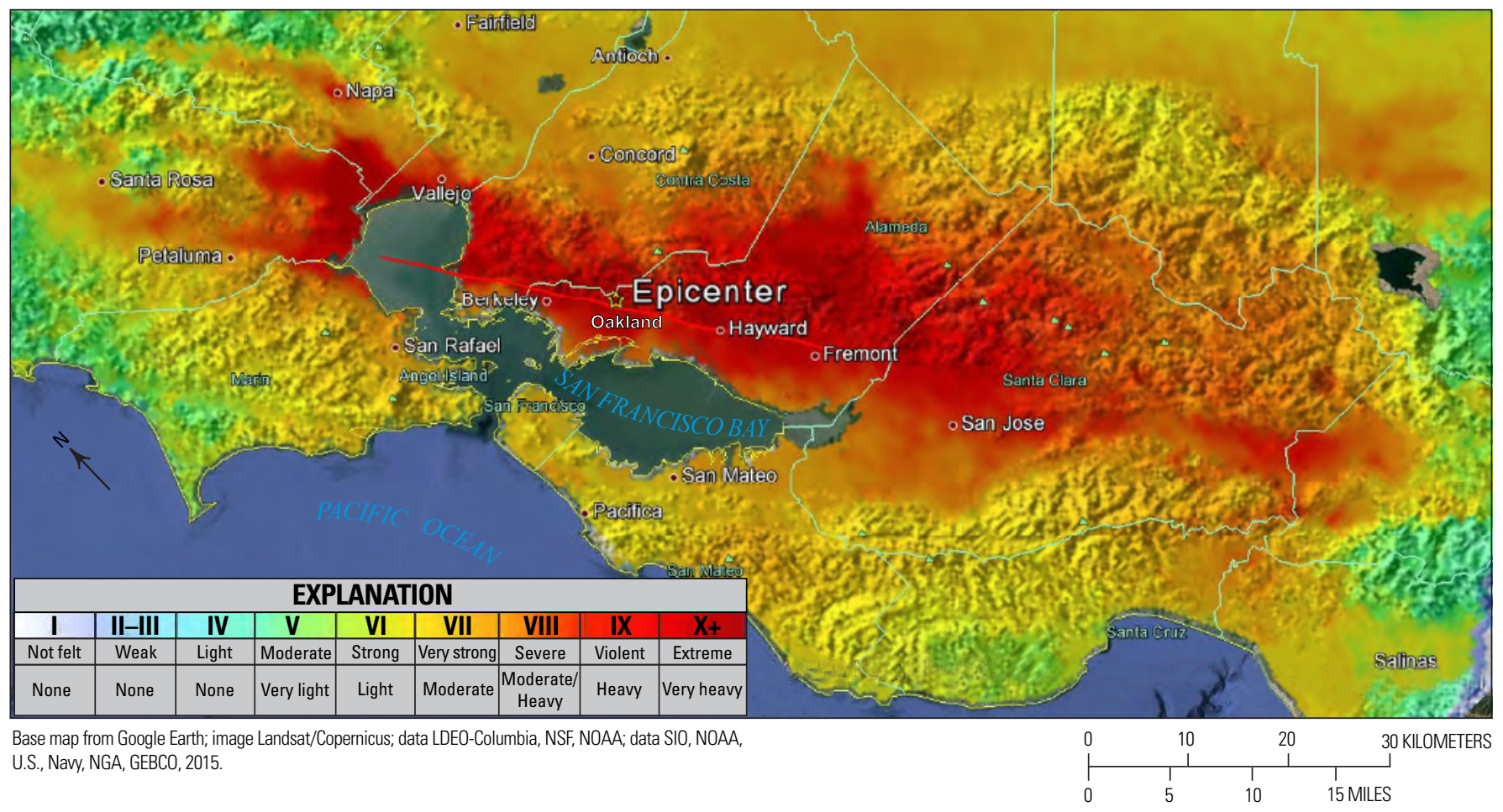

Figure 1. Satellite image of the San Francisco Bay region, California, overlaid with a U.S. Geological Survey ShakeMap for the hypothetical magnitude-7.0 mainshock of the HayWired earthquake scenario on the Hayward Fault (fault rupture shown by bright red line). (Mainshock data from Aagaard and others, 2017.) 
Figure 2. Maps of the San Francisco Bay region, California, showing $(A)$ peak ground acceleration (PGA) and $(B)$ instrumental intensity (approximately Modified Mercalli Intensity) for the hypothetical magnitude-7.0 mainshock of the HayWired earthquake scenario on the Hayward Fault. $g$, acceleration due to gravity. SF, San Francisco. (Mainshock data from Aagaard and others, 2017.)
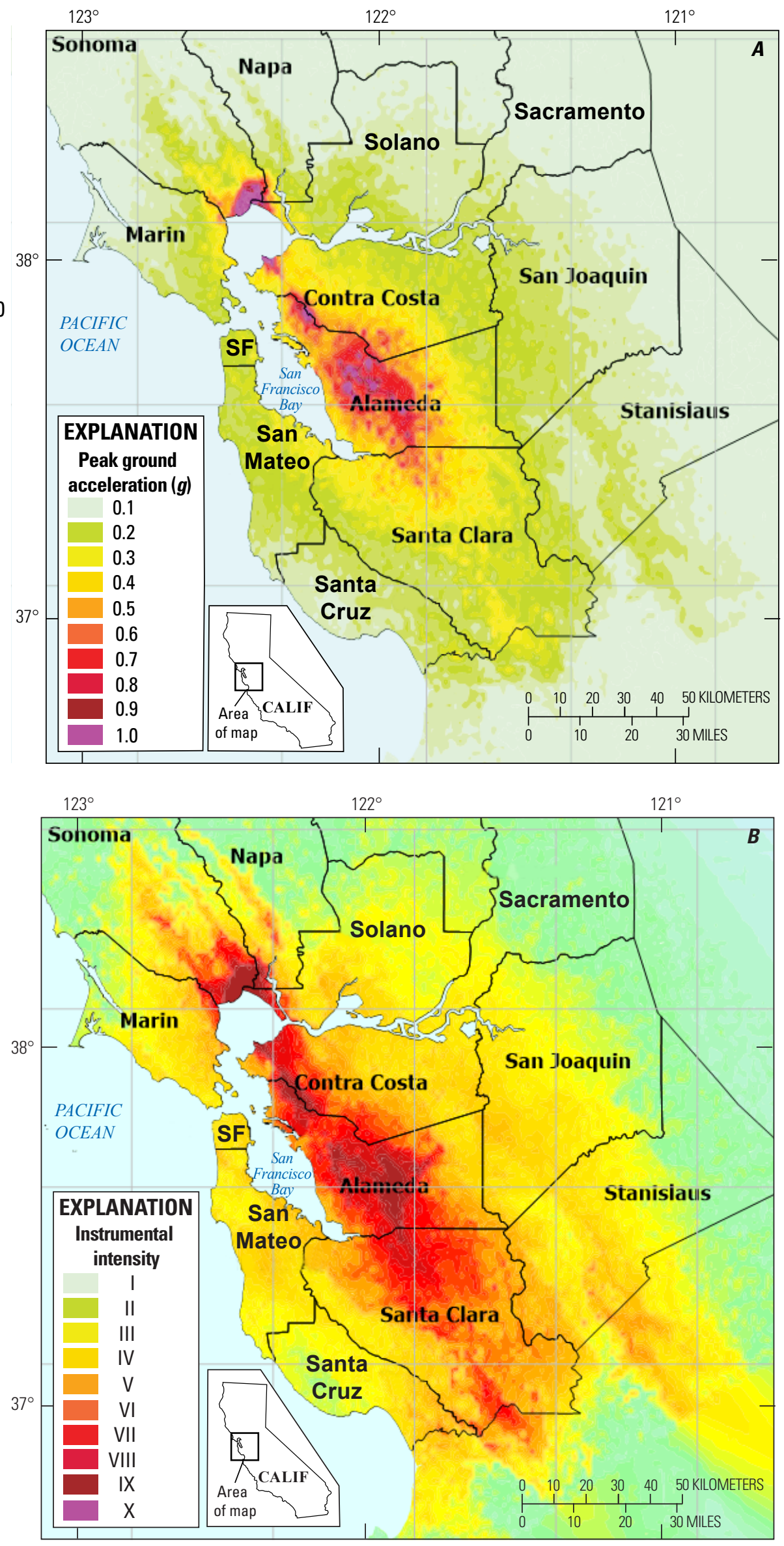


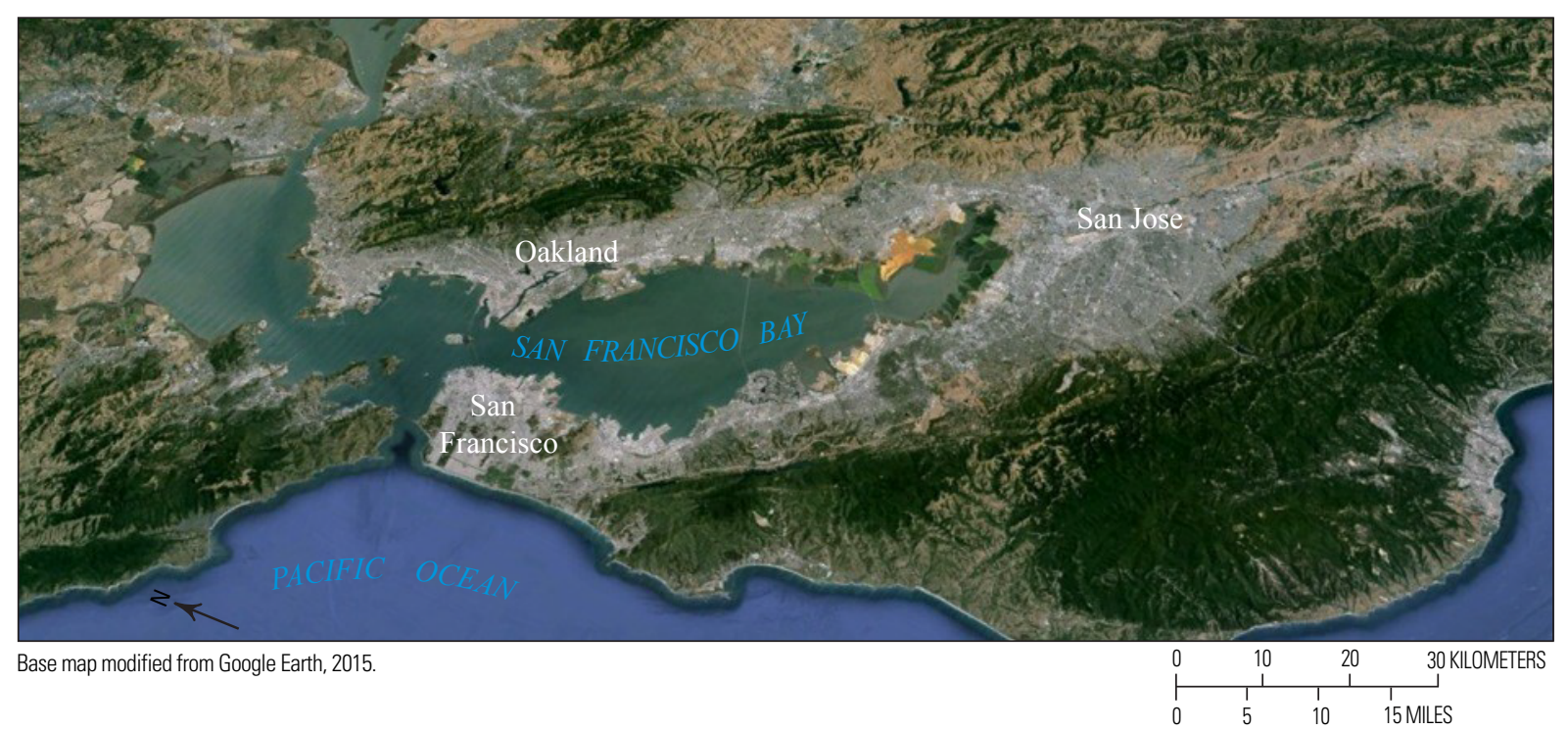

Figure 3. Satellite image of San Francisco Bay region, California. The region is densely urbanized, with a population approximately 7.7 million people (California Department of Finance, 2014).

\section{Fire Protection}

More than 500 fire stations were considered in the analysis of fire protection (fig. 6). In the most heavily impacted area there are a total of 229 fire engines potentially available immediately following the HayWired mainshock.

Although many jurisdictions have seismically retrofitted fire stations (and other critical infrastructure), the functionality of a significant number of fire stations is still questionable (fig. 7). According to Bello and others (2006), an Earthquake Engineering Research Institute survey of these fire stations in 2006:

... indicated that average peak ground acceleration are [sic] $0.5 \mathrm{~g}$, and 52 percent of the stations are in areas mapped as moderate to very high liquefaction susceptibility with 102 stations being located within State designated Seismic Hazard Zone of Required Investigation for liquefaction or landsliding. More than 60 volunteers conducted walk-through field surveys of about 100 stations. In terms of life safety considerations, based on construction type, age and assessment of vulnerability, 42 percent of fire stations are in moderate to high-risk categories. In terms of functionality of the fire stations, based on a subset (293 stations) for which information was available, 67 percent were of moderate to high risk of not functioning after an earthquake.

Based on these results, it is recommended that those fire stations at higher risk be evaluated and retrofitted such that life safety and vulnerability are improved before the next large earthquake occurs.

Each fire station in the affected region was allocated an immediate area using a Voronoi diagram ${ }^{3}$ as an approximation

\footnotetext{
${ }^{3}$ For this analysis, the Voronoi diagram was a partition of the region into polygons, each side of which was a line equidistant from the nearest two fire stations. (For an explanation of Voronoi diagrams see https://en.wikipedia.org/ wiki/Voronoi_diagram.)
}

of the station's primary response area (fig. 8). The subsequent analysis is based on these primary response areas.

\section{Time of Day}

Time of day is relevant in that more human activity occurs during waking hours, typically resulting in higher ignition rates at those times. The HayWired mainshock is specified as occurring Wednesday, April 18, 2018, at 4:18 p.m. However, the specific time of occurrence is not considered in this analysis.

\section{Wind and Humidity}

Weather can affect fire growth and spread, as well as the direction and distance at which communities are affected by hazardous material release. Important meteorological parameters include windspeed, wind direction, temperature, rain, and humidity. For purposes of estimating fire effects in the HayWired scenario, average April conditions were assumed to apply, based on data for the period 1974-2012 (WeatherSpark, 2014). Average conditions for the three San Francisco Bay area international airports are shown in table 2 and figure 9. In the case of precipitation, the most common condition is reported (for example, no rain), along with the probability of precipitation at some point in the day and the most common form of precipitation when it does rain. In the case of wind direction, the most common direction is tabulated. Humidity is reported as average daily low and high.

In April, wind conditions are typically created by a trough of low pressure east of the bay area, which draws in strong, westerly, cooler and more humid air from the ocean in the afternoon, subsiding to more calm conditions in evening. An example of this is shown in figure 10 for April 18, 2012, in which major streaklines are shown at 4 p.m. and 5 p.m., with much shorter streaklines at 9 p.m. Cumulative distribution functions for windspeeds for 4 p.m., 
Figure 4. Maps of the San Francisco Bay region, California, showing population density for $(A)$ the 10-county region and $(B)$ the area adjacent to the fault rupture for the hypothetical magnitude-7.0 mainshock of the HayWired earthquake scenario. The length of the Hayward Fault ruptured in the scenario is shown on the maps. persons/ $\mathrm{km}^{2}$, persons per square kilometer.
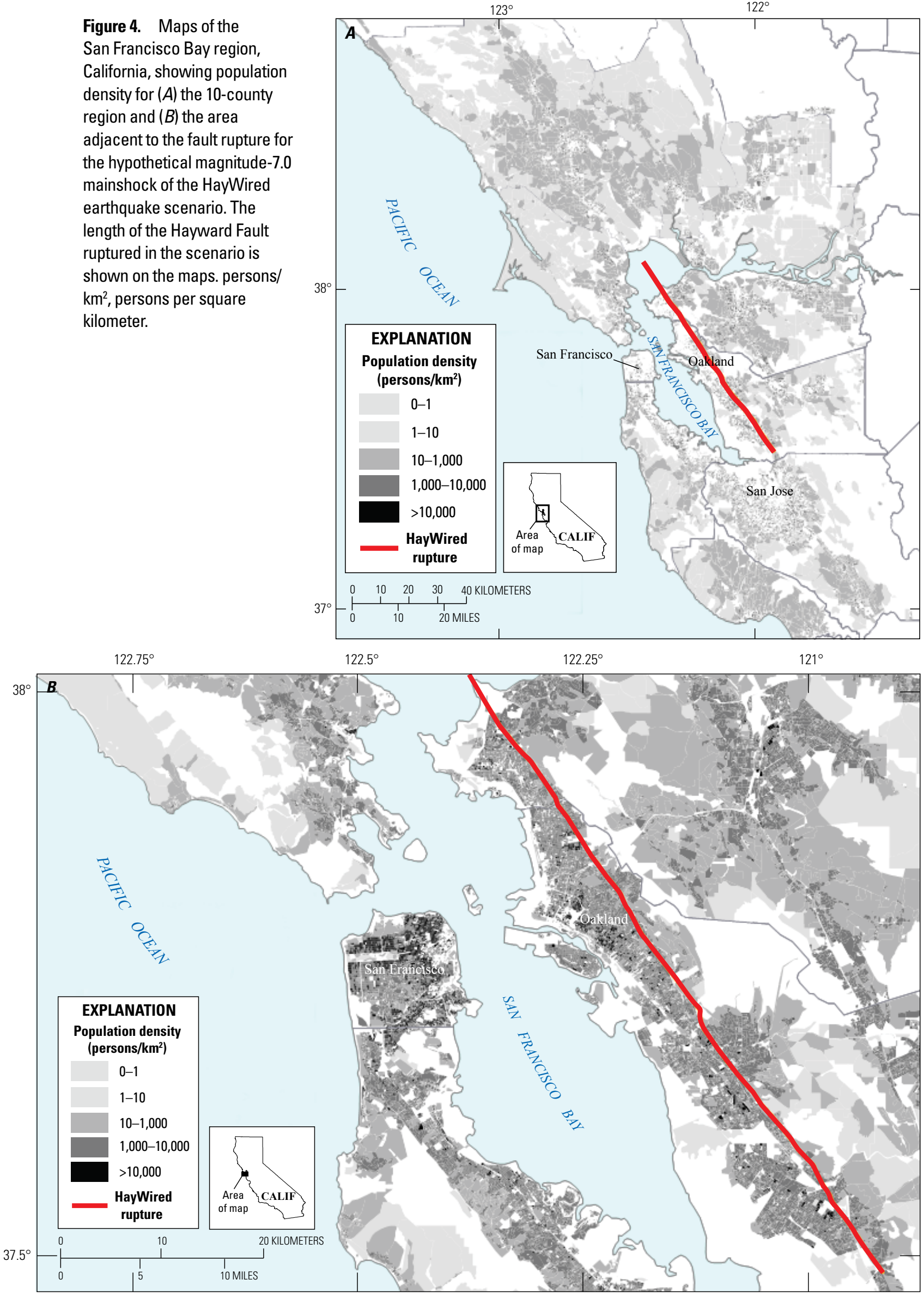


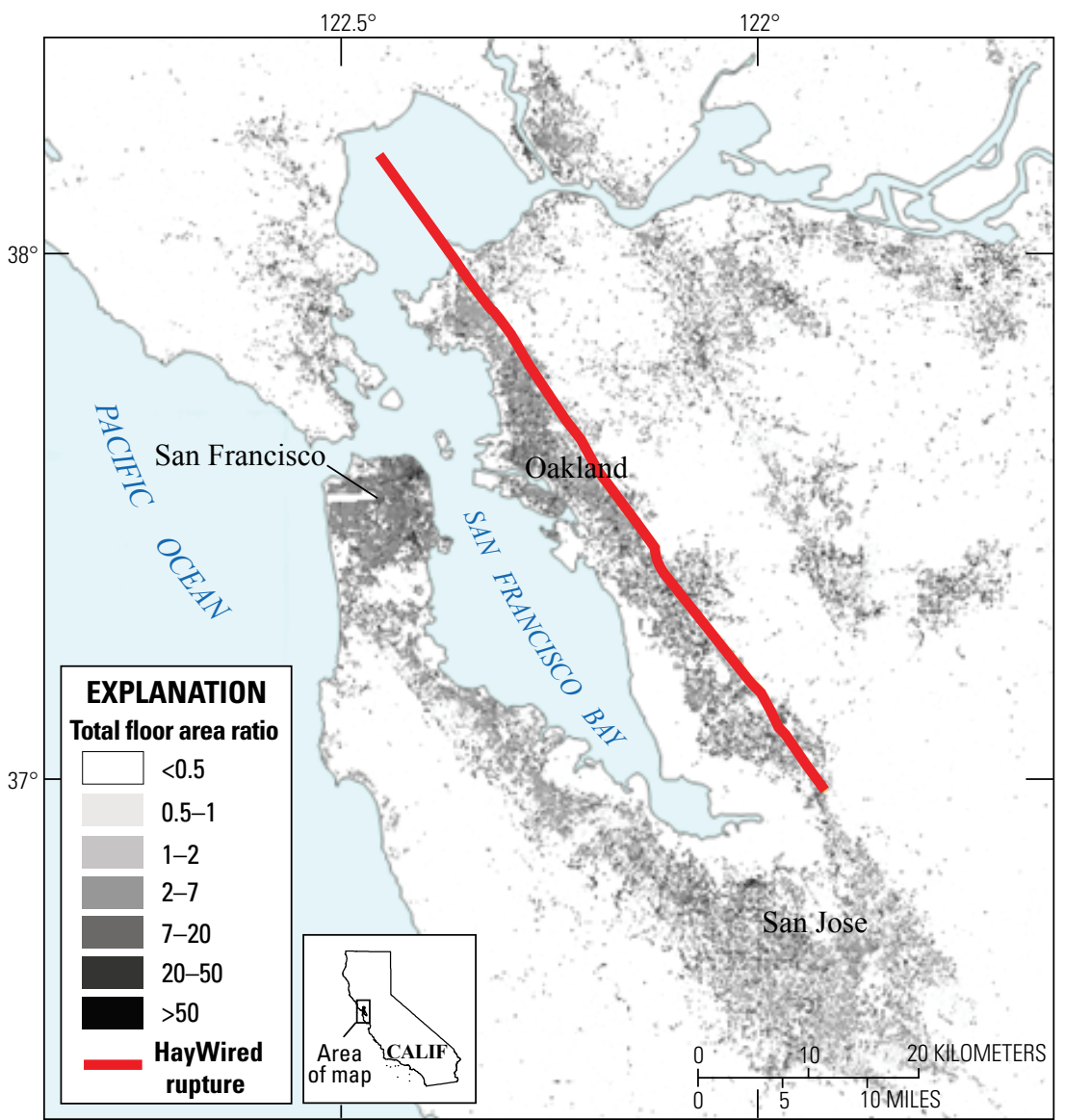

Figure 5. Map showing building density of San Francisco Bay region, California. The length of the Hayward Fault ruptured in the hypothetical magnitude- 7.0 mainshock of the HayWired earthquake scenario is shown on the map. Total floor area ratio, total building floor area in a census block divided by the area of the census block.

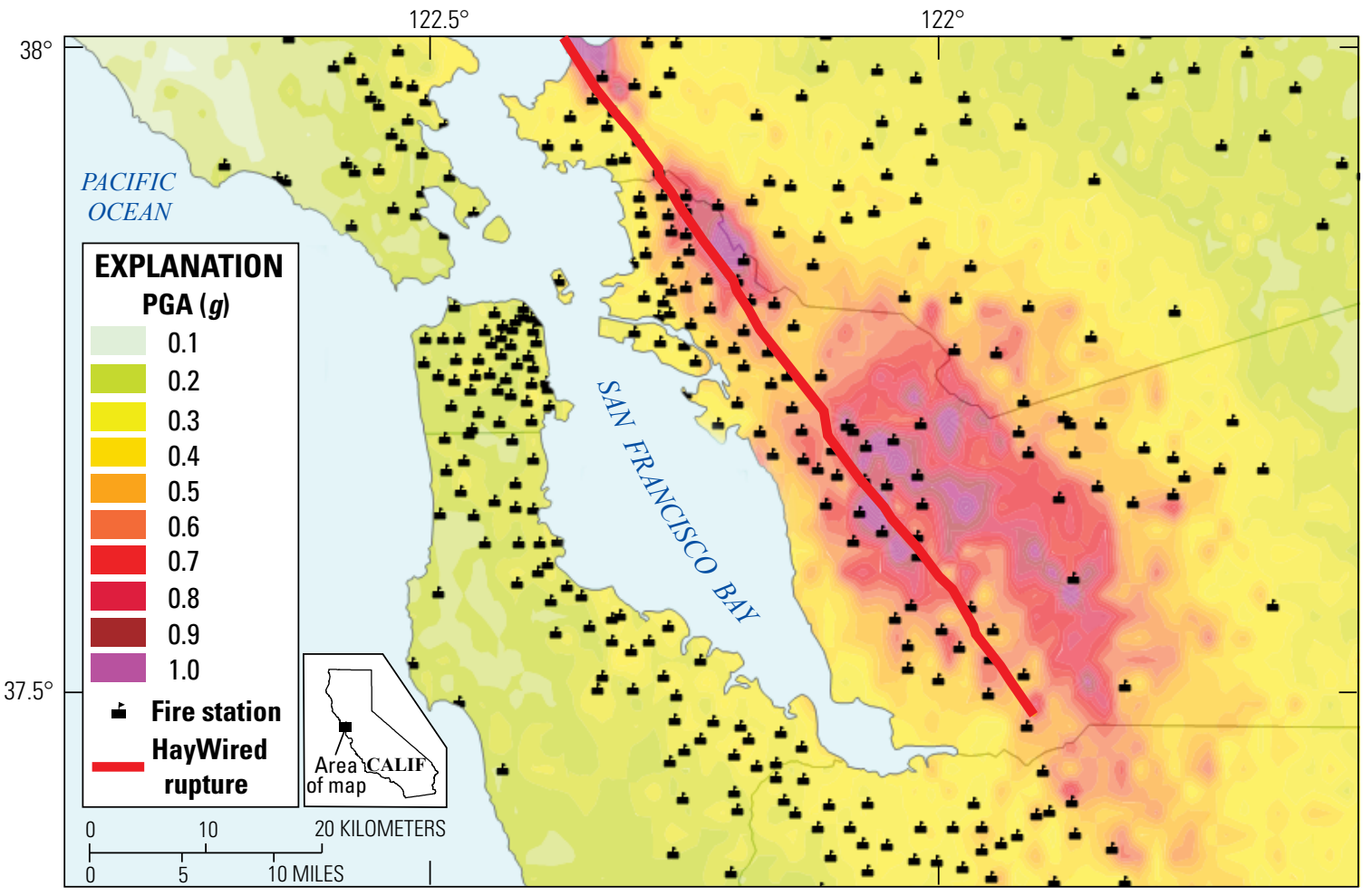

Figure 6. Map of San Francisco Bay area, California, fire stations overlaid on peak ground acceleration (PGA) for the hypothetical magnitude-7.0 mainshock of the HayWired earthquake scenario. The length of the Hayward Fault ruptured in scenario is shown on the map. $g$, acceleration due to gravity. (Mainshock data from Aagaard and others, 2017.) 
Figure 7. Three-dimensional graph showing the number of fire stations in San Francisco Bay area, California, counties that are at low, moderate, and high risk of earthquake damage in the hypothetical magnitude-7.0 mainshock of the HayWired earthquake scenario (data from Bello and others, 2006).
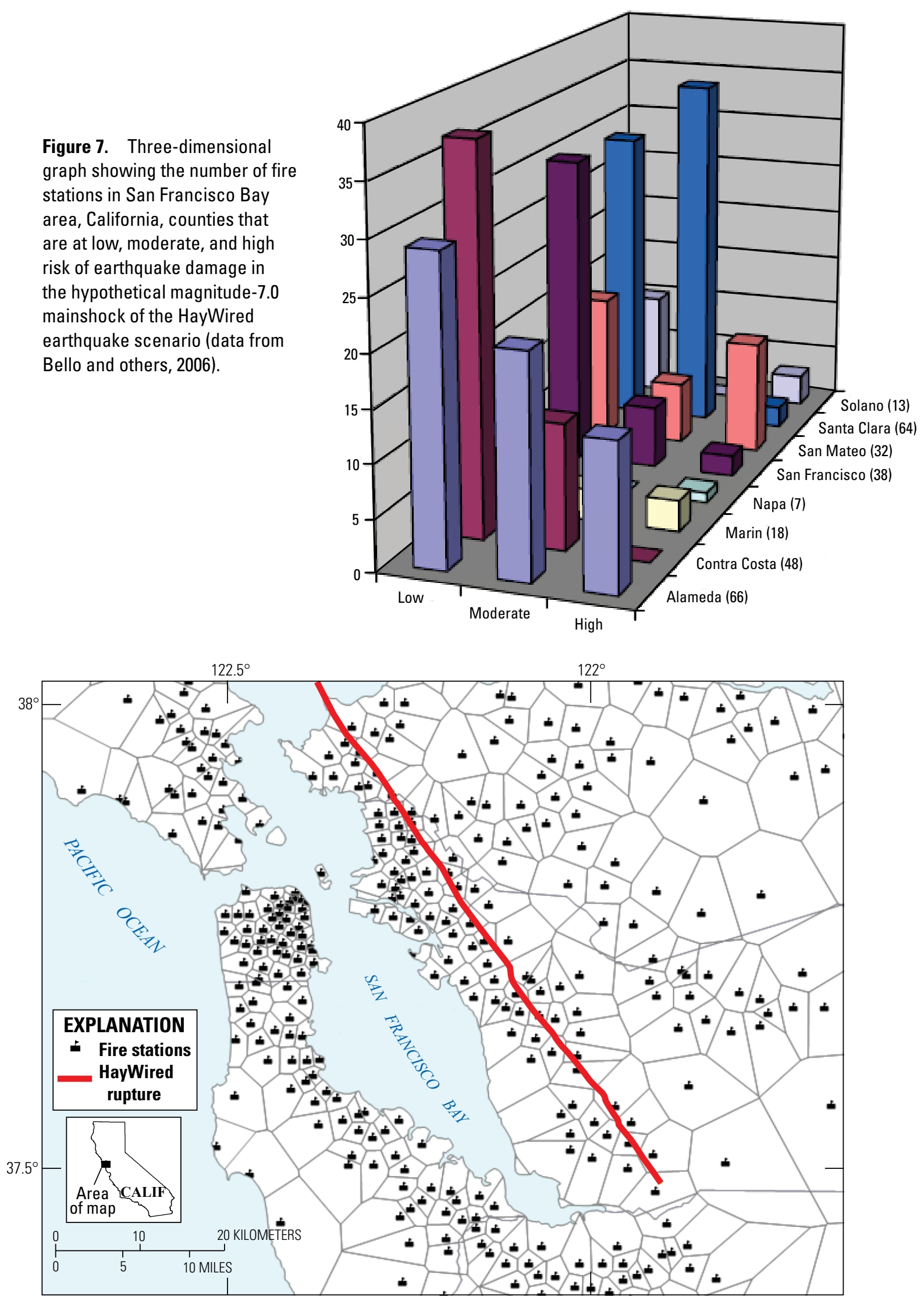

Figure 8. Map of San Francisco Bay area, California, fire stations with associated Voronoi areas. The primary response area for each fire station was approximated by a Voronoi diagram. The length of the Hayward Fault ruptured in the hypothetical magnitude-7.0 mainshock of the HayWired earthquake scenario is shown on the map. 


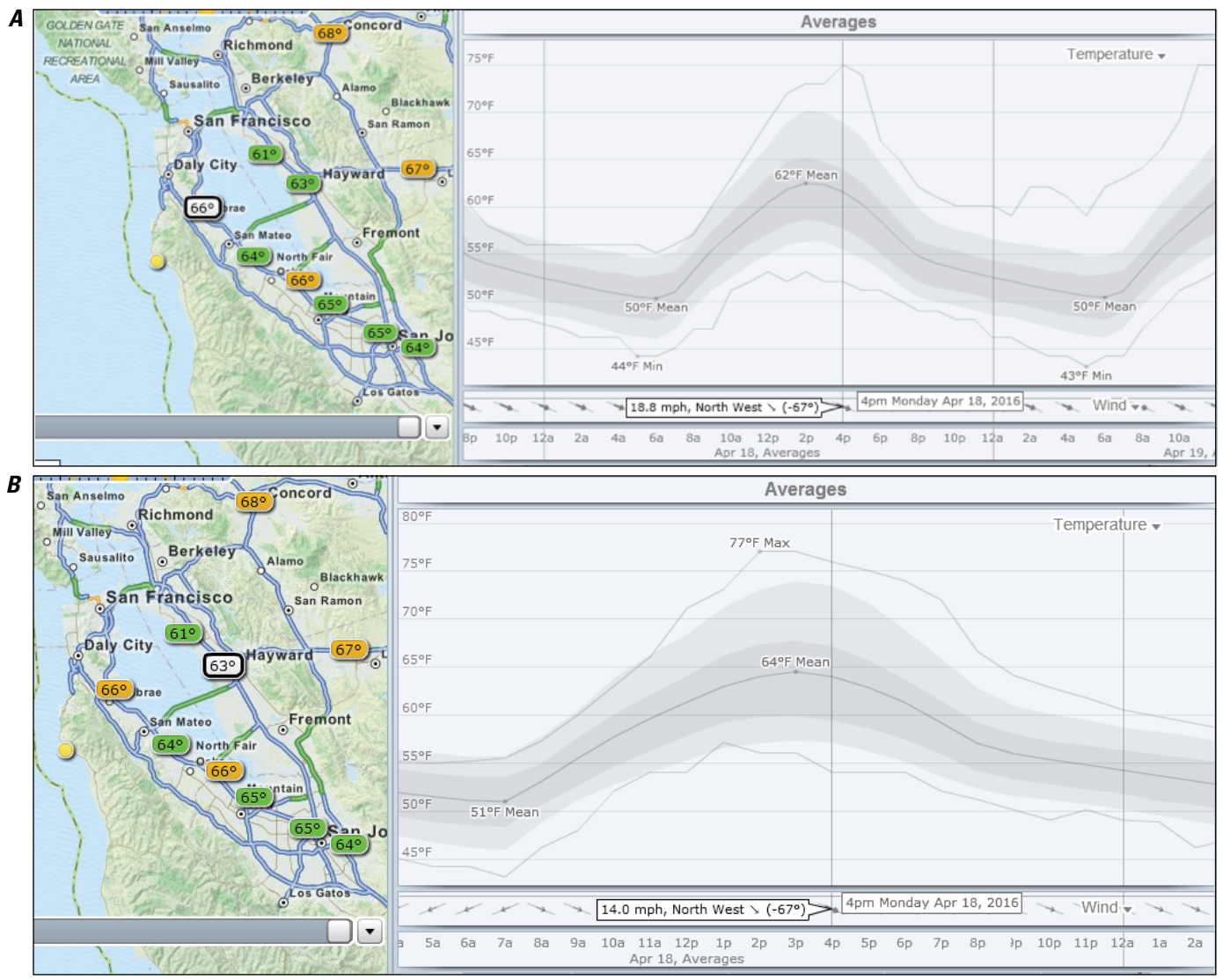

Figure 9. Maps and charts of average temperatures on April 18 at $(A)$ San Francisco International Airport and $(B)$ Hayward Executive Airport in the San Francisco Bay area, California. Average windspeeds are noted. (Images from WeatherSpark, 2014; http://www.weatherspark.com, used with permission.)

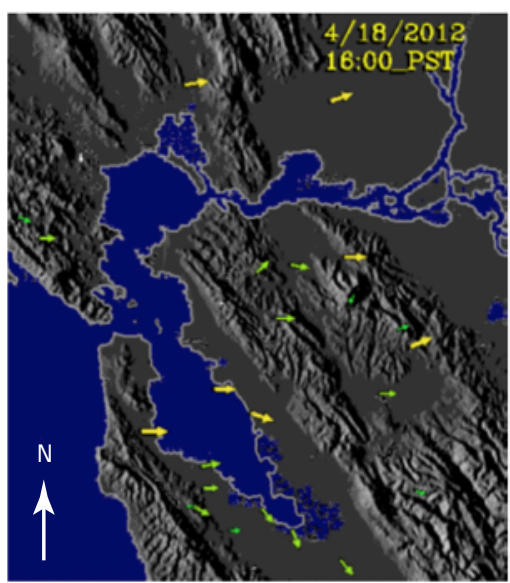

EXPLANATION

Windspeed, in nautical miles per hour

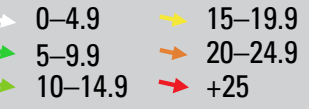
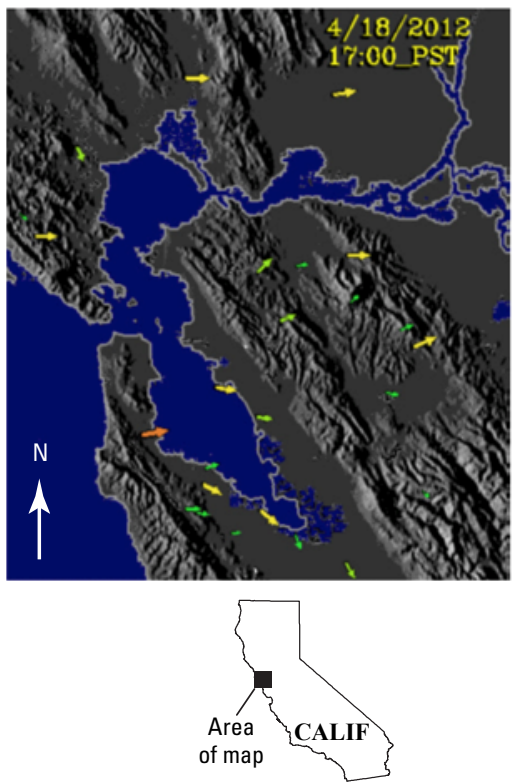

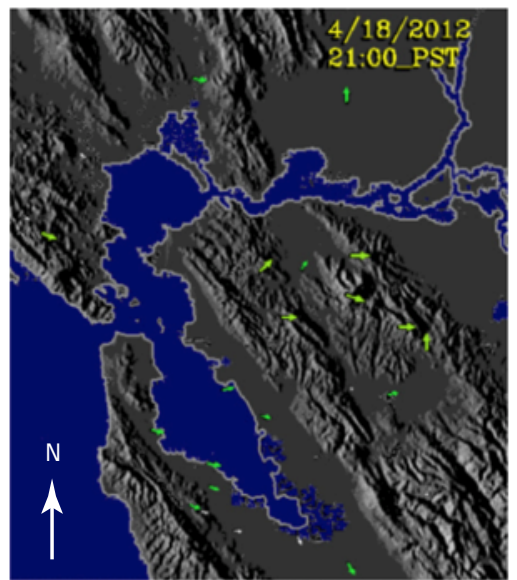

$\begin{array}{llllll}0 & 10 & 20 & 30 & 40 & 50 \text { KILOMETERS }\end{array}$ 30 MILES

Figure 10. Maps showing wind streaklines (arrows) for April 18, 2012 (4/18/2012), at 4 p.m. (left), 5 p.m. (center), and 9 p.m. (right), typical of April wind conditions in the San Francisco Bay region, California. Strong westerly winds in late afternoon subside in evening. Windspeed was measured 10 meters above surface elevation. PST, Pacific Standard Time. (Images from San Jose State University, 2014.) 
Table 2. Average wind conditions in April at San Francisco Bay area, California, major airports.

[Weather data from WeatherSpark (2014); mi/hr, miles per hour; ${ }^{\circ}$ F, degrees Fahrenheit; NW, northwest; W, west]

\begin{tabular}{lccccc}
\hline Airport (city/identifier) & $\begin{array}{c}\text { Windspeed } \\
\text { (mi/hr) }\end{array}$ & Direction & $\begin{array}{c}\text { Temperature } \\
\left.\text { ( }{ }^{\circ} \mathbf{F}\right)\end{array}$ & $\begin{array}{c}\text { Light rain } \\
\text { (percent } \\
\text { chance) }\end{array}$ & $\begin{array}{c}\text { Percent } \\
\text { humidity }\end{array}$ \\
\hline San Jose (SJC) & 7 & NW & $50-65$ & 19 & $42-93$ \\
San Francisco (SFO) & 12 & W & $50-65$ & 28 & $52-88$ \\
Oakland (OAK) & 10 & W & $50-65$ & 22 & $56-92$ \\
\hline
\end{tabular}

5 p.m., and 9 p.m. for the years 2000-2012 are shown in figure 11, and indicate significant variability of the stronger afternoon winds, with consistently calmer conditions later in the evening.

However, a reverse of the typical summertime weather pattern can occur, consisting of occasional intense katabatic winds, locally sometimes termed "Diablo winds." These are hot, dry, offshore winds from the northeast that sometimes occur in the San Francisco Bay region during the spring and fall. These winds differ from the more familiar Southern California Santa Ana winds, and are created by the combination of strong inland high pressure at the surface, strongly sinking air aloft, and lower pressure off the California coast. The air descending from aloft, as well as from the Coast Ranges, compresses at sea level, where it warms as much as 20 degrees Fahrenheit $\left({ }^{\circ} \mathrm{F}\right)$ (11 degrees Celsius, ${ }^{\circ} \mathrm{C}$ ), and loses humidity. If the pressure gradient is large enough, the dry offshore wind can become quite strong with gusts reaching speeds of 40 miles per hour (64 kilometers per hour) or higher, particularly along and in the lee of the ridges of the Coast Ranges, where warm, dry surface air from the windward eastern side is drawn up and over the ridgelines (fig. 12). Such winds were major factors in the 1923 Berkeley and 1991 East Bay Hills Fires (discussed below). This effect is especially significant as it can enhance the updraft generated by large wildland or urban fires. The pattern of windspeeds and direction used for the scenario was the more typical westerly wind subsiding in the evening, rather than the more dangerous Diablo-wind scenario.

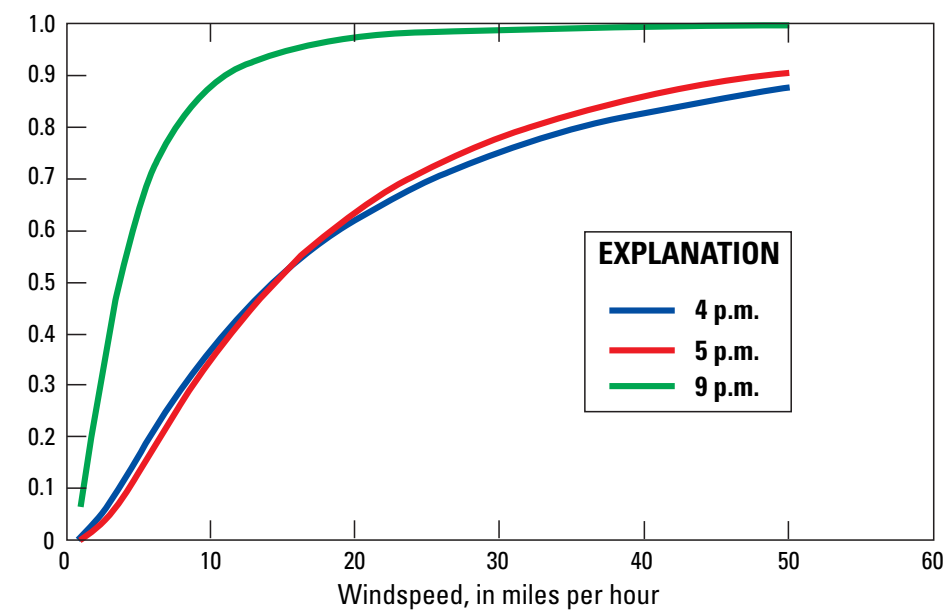

Figure 11. Graph showing cumulative distribution function of windspeeds in the central San Francisco Bay region, California, for 4 p.m., 5 p.m., and 9 p.m. for the years 2000-2012. (Data from San Jose State University, 2014.)

\section{Experience with Large Fires in the San Francisco Bay Region}

The Great 1906 San Francisco earthquake and fire is the archetypical fire following earthquake event. It is so familiar and well documented that we will not spend much time on it here. Simply put, it was the largest peacetime urban fire in history at the time, only exceeded since by the 1923 Tokyo earthquake and fire. The 1906 earthquake and resulting fires caused an estimated 3,000

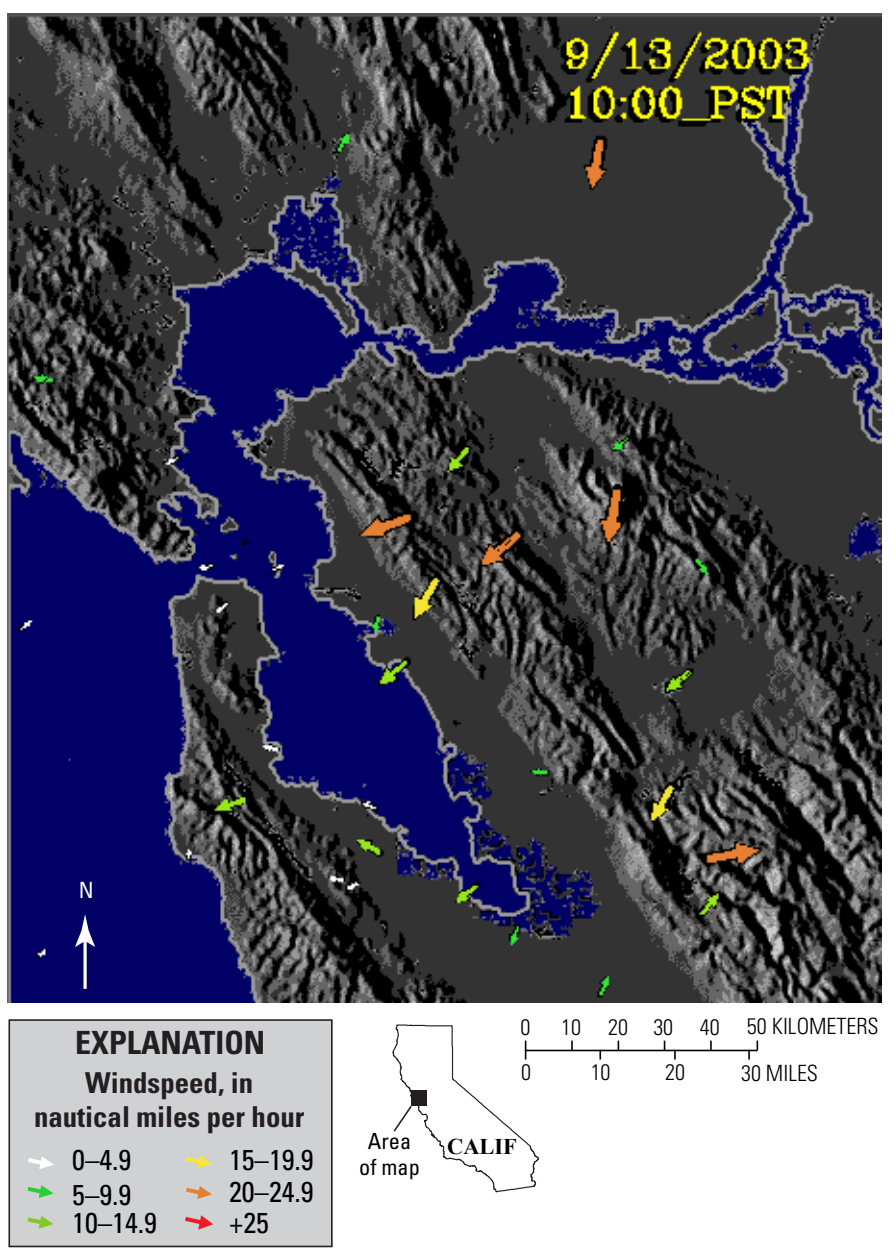

Figure 12. Map showing wind streaklines (arrows) for September 13, 2003 (9/13/2003), at 10 a.m., typical of Diablo wind conditions in the San Francisco Bay region, California. Windspeed was measured at 10 meters above surface elevation. PST, Pacific Standard Time. (Images from San Jose State University, 2014.) 
deaths and \$524 million (1906 dollars) in property loss. Fires that ignited in San Francisco soon after the onset of the earthquake burned for 3 days because of the lack of water to control them. The damage in San Francisco was devastating and 28,000 buildings were destroyed, although 80 percent of the damage was caused by the fire rather than the shaking (fig. 13). Fires also intensified the losses in 1906 at Fort Bragg and Santa Rosa (see Scawthorn and O'Rourke, 1989; Scawthorn and others, 2005; Scawthorn and others, 2006).

Beyond the 1906 San Francisco earthquake and fire, the San Francisco Bay region has a long history of conflagrations (fig. 14), owing in large part to the Diablo winds discussed above. According to the Hills Emergency Forum (2005), over the period from 1923 to 1991 the east bay has averaged a 585 -acre fire every 5 years, destroying on average 266 homes (2005). However, most of these building losses occurred in only two of these fires - the 1923 and 1991 events (fig. 15, table 3). It should also be noted that almost all of these fires occurred in autumn (which is typically the region's greatest fire-risk season), in contrast to the scenario being considered here.

Three recent fires in the San Francisco Bay region are worthy of mention:

- On September 9, 2010, a buried, high-pressure, 30-inch steel natural-gas pipeline exploded in a residential neighborhood in San Bruno, California, near San Francisco. The explosion and ensuing fire killed 8 people and injured 58. It destroyed 38 homes and damaged an additional 70 . During the first 50 hours following the incident, more than 500 firefighters and 90 firefighting apparatus responded, involving 42 fire agencies. The total cost of the disaster was estimated to be approximately $\$ 1.6$ billion (Davidson and others, 2012).

- The Mission Bay fire was a five-alarm fire that occurred shortly before 5 p.m. on March 11, 2014, in the Mission Bay neighborhood of San Francisco, California. The conflagration appeared to completely destroy block 5 , a 172-unit building, part of Mega Blocks 360, a \$227 million apartment complex being developed by San Francisco-based BRE Properties, Inc., at China Basin Street and Fourth Street (San Francisco Chronicle, 2014). The San Francisco Fire Department needed a large amount of resources to combat the fire, including the city's auxiliary water-supply system.

- On the night of October 8, 2017, Diablo winds started and drove widespread wildfires in the northern San Francisco Bay region counties of Napa, Sonoma, and Solano. The fires killed at least 43 people, destroyed 8,900 homes and other structures, and burned 164,000 acres. More than 10,000 firefighters responded to the fires (Wikipedia, 2017). (Note that because of its recency, this fire was not considered further in this chapter.)

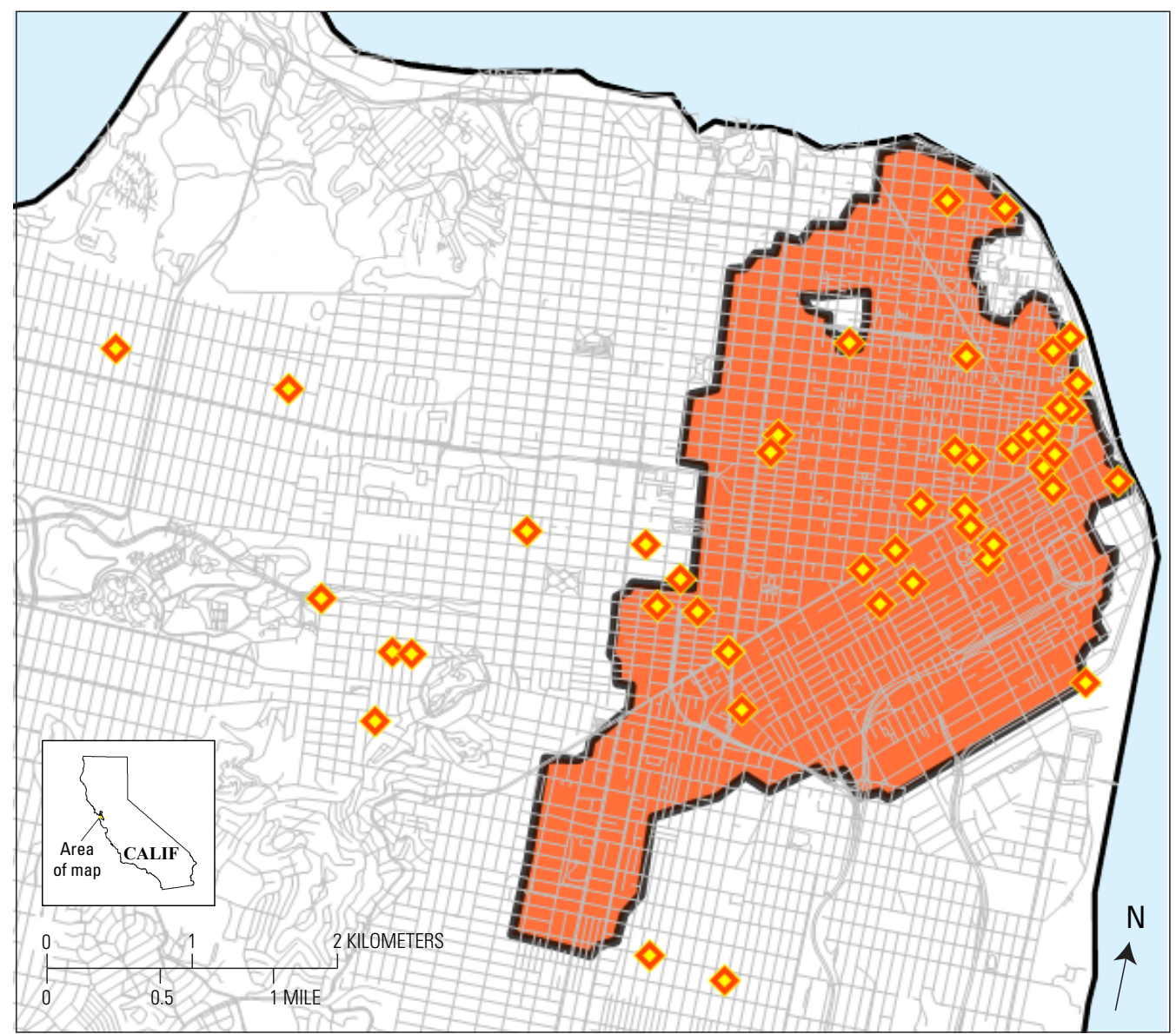

Figure 13. Map of fires (orange and yellow diamonds) caused by the moment-magnitude- 7.8 1906 San Francisco, California, earthquake and area burned in the great conflagration that followed (orange). Ignition data from Scawthorn and O'Rourke (1989) and Scawthorn and others (2005). 
Table 3. List of some large, historical fires driven by Diablo winds in the east bay part of the San Francisco Bay area, California (data from Hills Emergency Forum, 2005; California Governor's Office of Emergency Services, 2013; Routley, [n.d.]; National Board of Fire Underwriters, 1923.

$[--$, no data $]$

\begin{tabular}{|c|c|c|c|c|c|c|}
\hline Month/year & Fire name/location & Deaths & Structures destroyed & $\begin{array}{l}\text { Acres } \\
\text { burned }\end{array}$ & $\begin{array}{l}\text { Estimated } \\
\text { damage, in } \\
\text { billions of } \\
\text { U.S. dollars }\end{array}$ & Ignition cause \\
\hline September 1923 & City of Berkeley & 0 & 584 & 130 & -- & Smoker \\
\hline November 1933 & Joaquin Miller (Redwood Road) & 1 & 20 homes & 1,000 & -- & Smoker \\
\hline September 1946 & $\begin{array}{l}\text { Buckingham Boulevard/Norfolk } \\
\text { Road }\end{array}$ & 0 & 0 & 1,000 & -- & $\begin{array}{l}\text { Arson and } \\
\text { rekindle }\end{array}$ \\
\hline October 1960 & Leona Hillside & 0 & 2 homes & 1,200 & -- & Unknown \\
\hline September 1970 & Oakland Hills & 0 & 37 homes and 21 damaged & 204 & -- & Arson \\
\hline October 1991 & East Bay Hills & 25 & 3,354 homes and 456 apartments & 1,600 & 1.5 & Rekindle \\
\hline
\end{tabular}

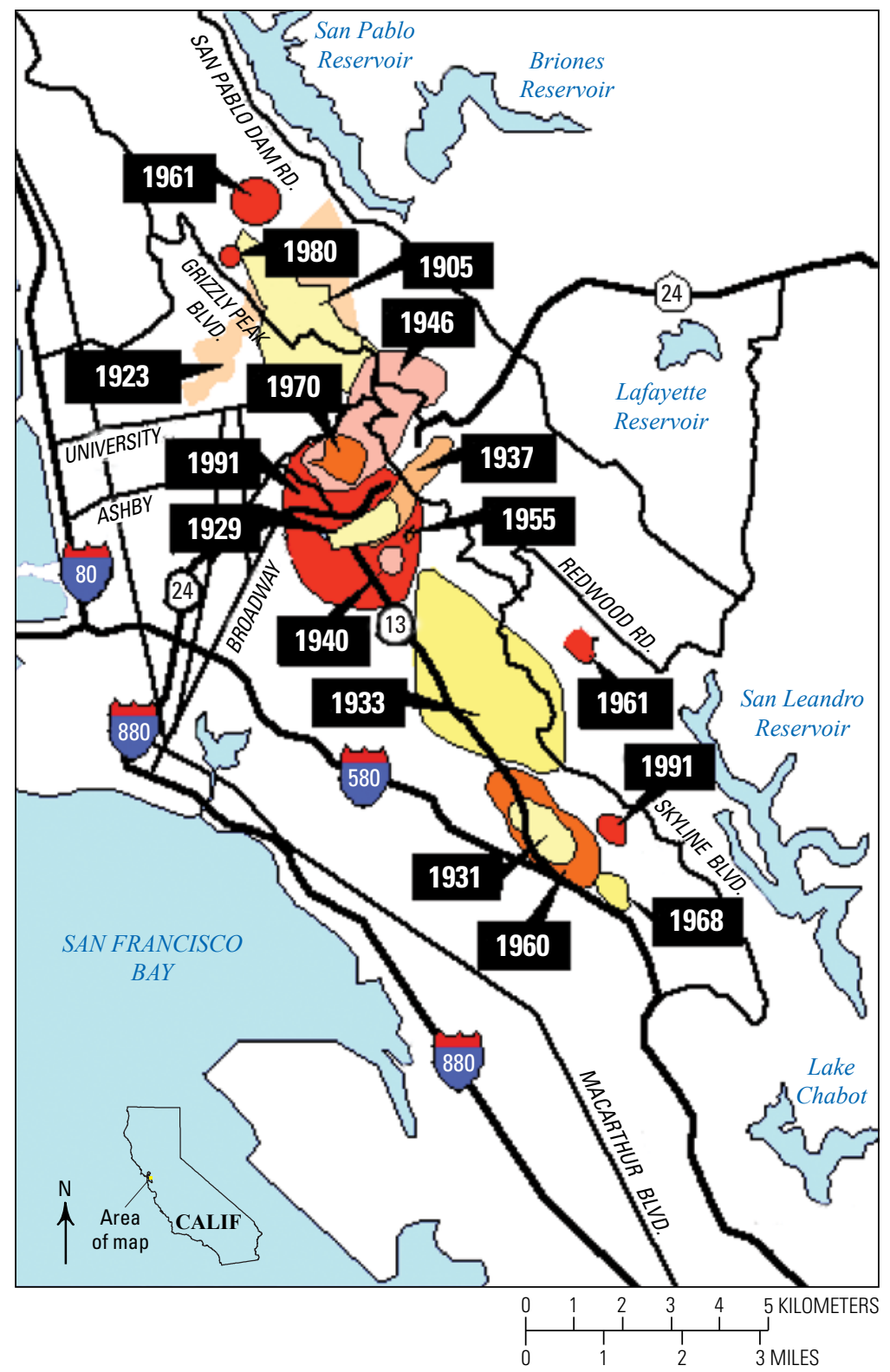

Figure 14. Map of fires in the east bay part of the San Francisco Bay area, California, from 1923 to 1991 . Note that colors are only used to differentiate among areas burned by fires. (Modified from Hills Emergency Forum, 2005.) 


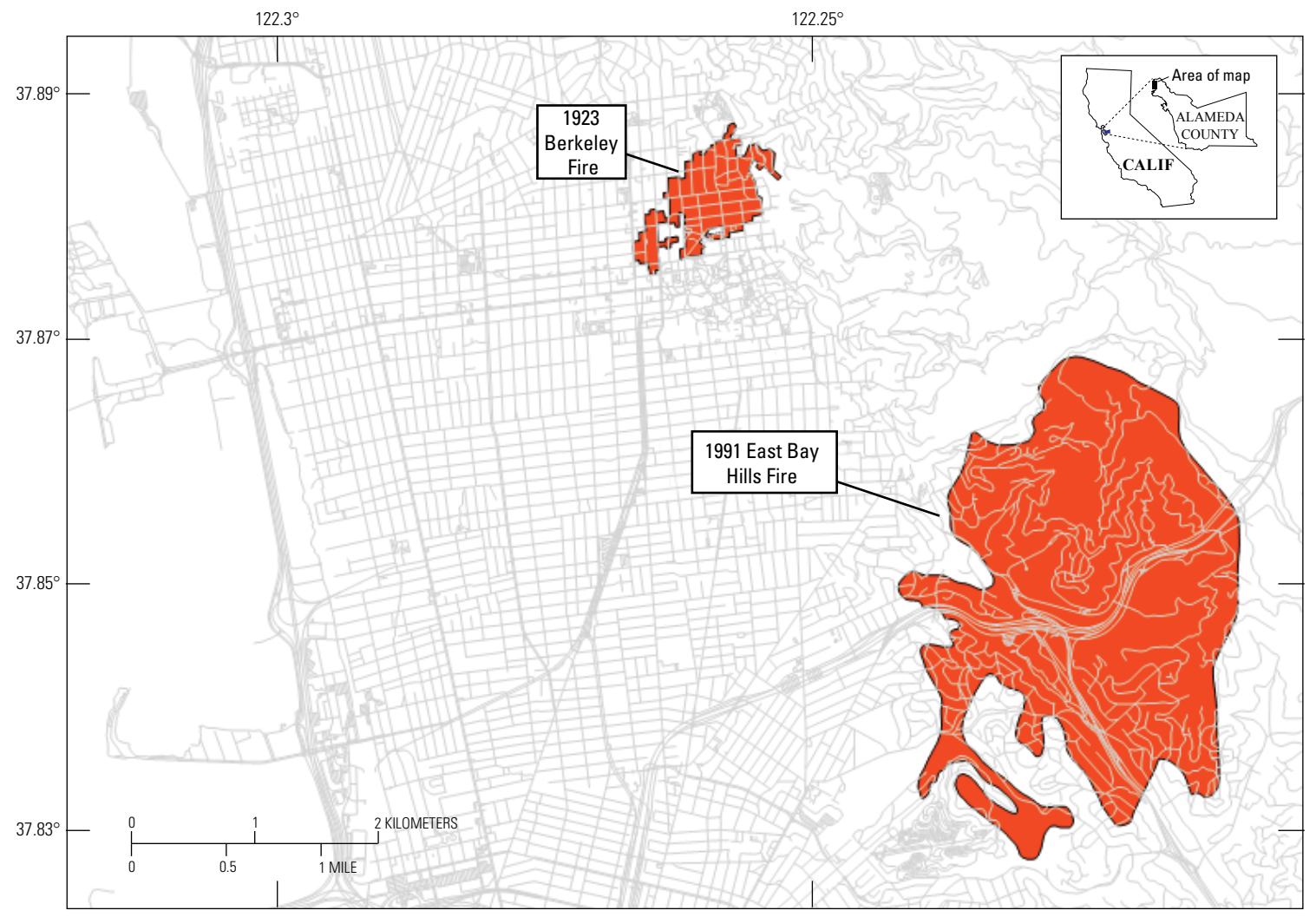

Figure 15. Map of final burned areas (dark orange) for 1923 Berkeley and 1991 East Bay Hills Fires in the east bay part of the San Francisco Bay area, California.

\section{Fire Following Earthquake Aspects of the Scenario}

This section presents the analysis underlying the estimation of fires and losses likely to result from the HayWired scenario mainshock. The section discusses modeling of fire following earthquake, ignitions, initial response, fire spread, and performance of lifelines (for example, utilities and transportation).

\section{Modeling of Fire Following Earthquake}

A full probabilistic methodology for analysis of fire following earthquake was developed in the late 1970s (Scawthorn and others, 1981) and has been applied to major cities in western North America (Scawthorn and Khater, 1992). Scawthorn and others (2005) summarizes modeling for fire following earthquake, so only a brief review is presented here. In summary, the steps in the process of fire following earthquake are shown in figure 16:

- Occurrence of the earthquake - causing damage to buildings and contents, even if the damage is as simple as objects (such as candles or lamps) falling over.

- Ignition - whether a structure has been damaged or not, ignitions can occur as a result of earthquakes. The sources of ignitions are numerous, including overturned heat sources, abraded and shorted electrical wiring, spilled chemicals having exothermic reactions, and friction from objects rubbing together.

- Discovery - at some point, the fire resulting from the ignition will be discovered, if it has not self-extinguished (this aspect is discussed in more detail below). In the confusion following an earthquake, the discovery may take longer than it might otherwise.

- Report-if it is not possible for people discovering a fire to immediately extinguish it, fire department response will be required. For a fire department to respond, a report has to be made to the fire department. Communications-system malfunction and congestion may delay many reports.

- Response - a fire department then has to respond but may be delayed by responding to nonfire emergencies (for example, building collapse) and by transportation disruptions.

- Suppression - a fire department then has to suppress the fire. If the fire department is successful, they move on to the next incident. If not successful, they continue to attempt to control the fire, but it can spread and become a conflagration. Success or failure hinges on numerous factors, including the functionality of the water-supply system, building construction and density, and weather conditions such as wind and 


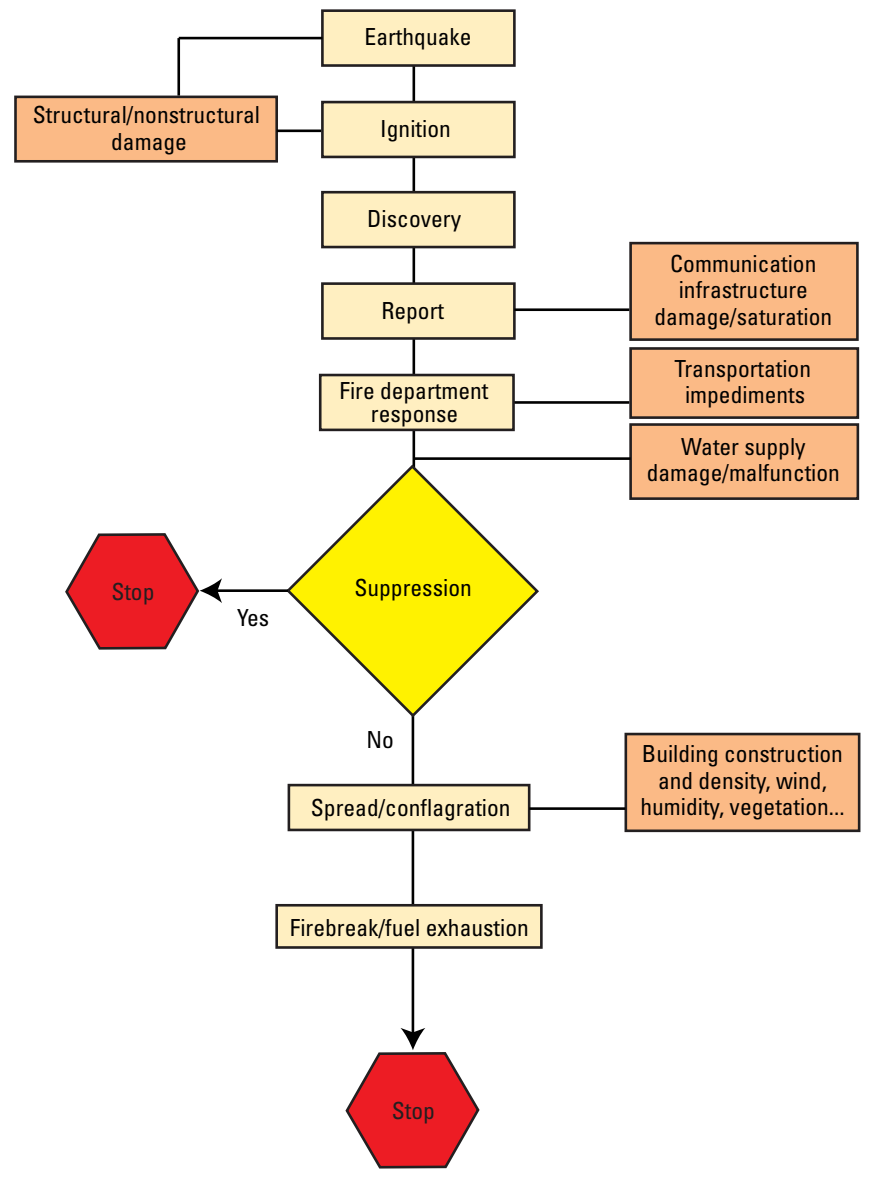

Figure 16. Flow chart of the fire-following-earthquake process (from Scawthorn and others, 2005). humidity. If the fire department is unable to contain the fire, the process ends when the fuel is exhausted or when the fire reaches a firebreak.

This fire-following-earthquake process is also shown in figure 17, which is a fire department operations time line. A rapid response is essential to reduce losses from fire following earthquake. Fire following earthquake is not a linear process, and modeling it is not very precise - in many cases, only a few small fires versus a major conflagration can be distinguished.

\section{Ignitions}

Postearthquake ignition rates in the United States have been studied by a number of investigators (Lee and others, 2008) with the most recent and relevant algorithms for estimating postearthquake ignition rates being developed by Davidson (2009a,b) and SPA Risk LLC (2009), both of which are considered here.

Davidson (2009b) conducted an exhaustive selection to evaluate 48 potential covariates, of which model A.NB2 is:

$$
\ln (\mu)=\beta_{0}+\beta_{i i} I I+\beta_{t b l d g} \ln (t b l d g)+\beta_{\%_{C} \mathrm{CIT}} x_{\% \mathrm{ClT}}+\beta_{\mathrm{dens}} x_{\mathrm{dens}},
$$

where

$$
\begin{aligned}
& \mu \quad \text { is ignitions per census tract, } \\
& \text { II the instrumental intensity of the } \\
& \quad \text { earthquake, }{ }^{4}
\end{aligned}
$$

${ }^{4}$ Modified Mercalli Intensity (MMI) and Instrumental Intensity (II) are used synonymously here.

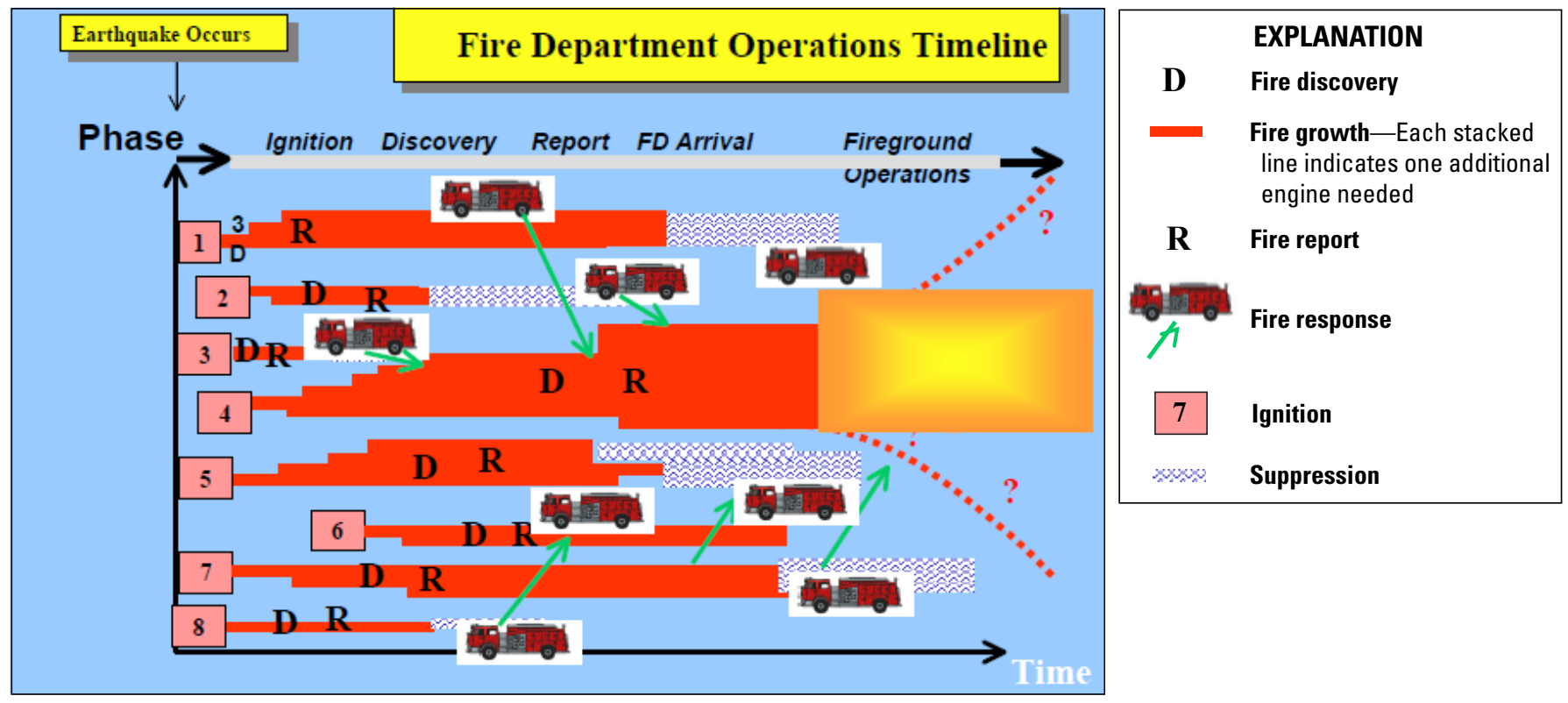

Figure 17. Chart of fire department (FD) operations timeline when responding to fires following an earthquake. Horizontal axis is time, beginning at time of earthquake. Horizontal bars depict development of fires, from ignition through growth or increasing size (size is indicated by width or number of horizontal bars). (From Scawthorn and others, 2005.) 


$$
\begin{gathered}
x_{\% \text { CIT }} \begin{array}{c}
\text { is the percent of land area that is commercial, } \\
\text { industrial, or transportation, }
\end{array} \\
\text { tbldg } \\
\text { is the total building area in thousands of } \\
\text { square meters, } \\
x_{\% \text { URM }} \text { is the percent of building area that is } \\
\text { unreinforced masonry (URM), } \\
x_{\text {dens }} \\
\begin{array}{c}
\text { is the population density (persons per square } \\
\text { kilometer), and }
\end{array}
\end{gathered}
$$

parameter $(\beta)$ estimates are $\beta_{0}=-15.42, \beta_{i i}=1.13, \beta_{\% \text { CIT }}=-32.48$, $\beta_{\text {tbldg }}=0.85, \beta_{0 \mathrm{URM}}=27.72$, and $\beta_{\text {dens }}=0.0000453$.

The SPA Risk LLC (2009) relation used the Davidson

(2009b) dataset restricted to census tracts that (1) fell within jurisdictions for which ignition data was available, (2) experienced $\mathrm{MMI} \geq \mathrm{VI}$, and (3) had population densities greater than 3,000 per square kilometer. Using this approach, relatively simple regressions to model postearthquake ignitions were developed:

Ignitions per million square feet of building floor area $=-0.029444 P G A+0.581895 P G A^{2}$,

Ignitions per million square feet of building floor area $=1.0449-0.338 M M I+0.0277 M M I^{2}$,

where $P G A$ is the peak ground acceleration of the earthquake, relative to the acceleration due to gravity at the Earth's surface $(g)$.

Of the two ignition regressions, the one in equation 1 requires more data, some of which may not be readily available (for example, percentage of URM building). ${ }^{5}$ A comparison of the two ignition models is shown in figure $18 \mathrm{~A}$, where equation 1 is plotted using median values (standard deviations in parentheses) for tbldg=244.7 (164), $x_{\% \text { CIT }}=0.027(0.016), x_{\% \text { URM }}=0.013(0.01)$, and $x_{\text {dens }}=3,445(4,048)$ as provided in Davidson $(2009 \mathrm{~b})$, and equation 3 (SPA Risk LLC, 2009) is plotted in black using 2.6 million square feet of building floor area per census tract. Dotted lines in the figure are equation 1 plus and minus one standard deviation (determined by way of numerical simulation).

Figure $18 B$ and $C$ are similar, except that the variable $x_{\% \text { CIT }}$ in Davidson's (2009b) equation, representing the percentage of land area employed for commercial, industrial, and transportation (CIT) purposes, is varied by plus and minus one sigma (sigma of $x_{\% \mathrm{CIT}}$ ), with equation 3 remaining the same in all plots. In figure $18 A$, it can be seen that the median SPA Risk LLC (2009) model is higher than the Davidson (2009b) model, by a factor of 2.8 at MMI VI and 2.3 at MMI VIII, while actually being lower (0.93) at MMI X. In figure 18B,

\footnotetext{
${ }^{5}$ Davidson (2009b) used default data from Hazus-MH MR2 (Federal Emergency Management Agency, 2003) for building floor area and unreinforced masonry (URM) estimates. An issue exists with the use of "URM" default data since most URM buildings in California have been retrofitted, so whether such buildings are now unreinforced is unclear. Ding and others (2008) have examined the Hazus-MH MR2 building inventory data (in general, in the context of flood) and found it to have significant inaccuracies. That being said, at the regional level the database can be useful, and Davidson's use of it was innovative.
}

corresponding to lower CIT land use (more representative of residential areas), the two models are in closer agreement, whereas $C$ (representative of higher CIT uses) shows a somewhat greater difference of the two models.

Equation 2 was used to estimate the total number of ignitions for the HayWired mainshock, resulting in a mean estimate of 668 ignitions, as shown in figure 19 and table 4. Ninety percent of the ignitions are confined to three countiesAlameda, Contra Costa and Santa Clara - with Alameda County alone having 53 percent of all ignitions. These are only ignitions that require fire department response; there may be other, typically minor, ignitions that are suppressed immediately by citizens, which are often not reported. Of the approximately 668 total ignitions, it is estimated 453 of these will grow to be large fires (defined as fires exceeding the capacity of the first arriving engine).

The cause of these ignitions will likely be similar to causes following the $1994 M_{\mathrm{w}} 6.7$ Northridge, California, earthquake, which is the best U.S. dataset for fire following a recent earthquake; about half of all ignitions would be electrical, a quarter gas related, and the remainder owing to a variety of causes, including chemical reactions (table 5). Also, on the basis of the Northridge experience, nearly half of all ignitions would typically occur in single-family residential dwellings, with another 26 percent in multifamily residential dwellings - that is, about 70 percent of all ignitions occur in residential dwellings (Scawthorn and others, 1998). Ignitions in educational facilities would be a small percentage of the total (3 percent in Northridge), and most of these would be a result of the exothermic reactions of spilled chemicals in chemistry laboratories.

A particular concern is the large number of oil refineries, tank farms, and related facilities in the northern bay area. These facilities refine one-third of the gasoline used west of the Rocky Mountains. When strongly shaken, oil refineries and tank farms have typically had large fires, which have burned for days. Examples include the Showa Refinery fire following the $M_{\mathrm{w}}$ 7.61964 Niigata, Japan, earthquake (Kawasumi, 1968), the Tüpraçs Refinery fire following the $M_{\mathrm{w}} 7.61999$ İzmit, Turkey, earthquake (Scawthorn, 2000), and the Idemitsukosan Hokkaido Refinery fire following the $M_{\mathrm{w}} 8.32003$ Tokachi-Oki, Japan, earthquake (Scawthorn and others, 2005).

\section{Initial Response}

This section discusses the initial response to ignitions following an earthquake. Reporting of fires is particularly crucial, yet problematic, following an earthquake.

\section{Citizen Response}

Initially, citizens will respond to the approximately 668 ignitions requiring fire-department response in the HayWired scenario. When they realize suppressing the fires is beyond their capabilities, they will attempt to contact emergency 

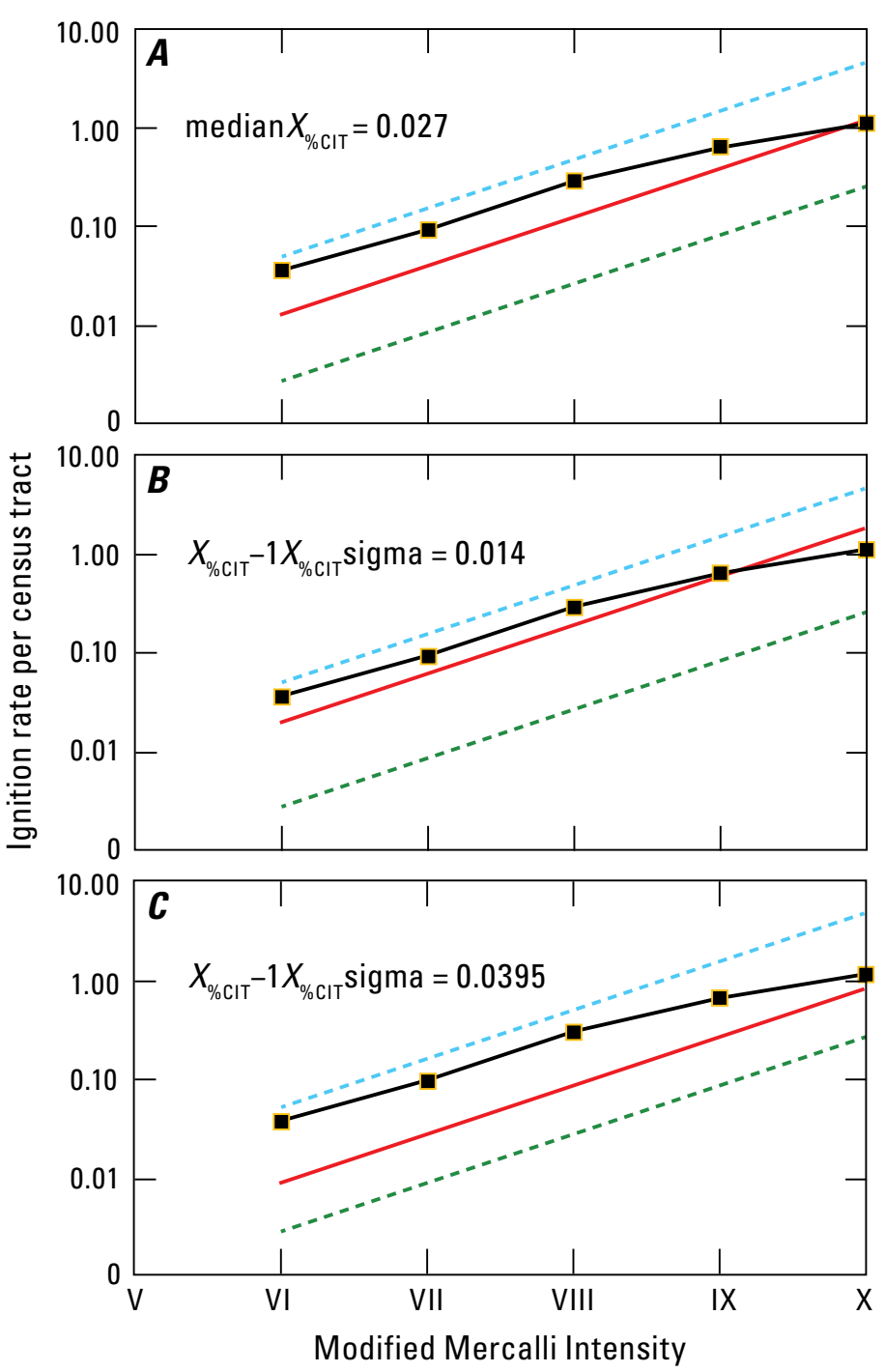

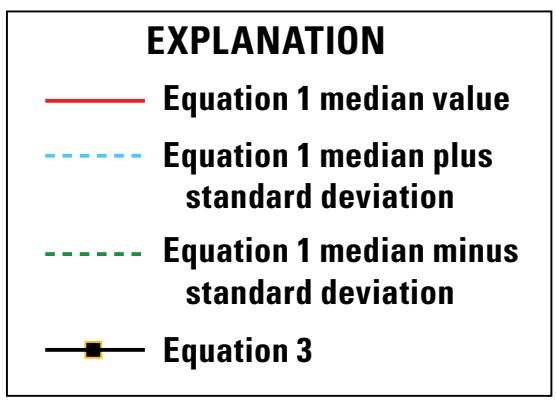

Figure 18. Graphs comparing two regressions (equations 1 and 3 , see text) used to model postearthquake ignitions per census tract. $A$, Graph of equation 1 (Davidson 2009b, A.NB2) plotted in red using median values (standard deviations in parentheses) for $t b / d g=244.7(164), x_{\% \text { CIT }}=0.027(0.016), x_{\% \text { URM }}=0.013(0.01)$, and $x_{\text {dens }}=3445$ (4048) as provided in Davidson (2009b), and equation 3 (SPA Risk LLC, 2009) is plotted in black using 2.6 million square feet of building floor area per census tract. Dashed lines in the graphs are equation 1 plus and minus one standard deviation (determined by way of numerical simulation). Equation 3 (SPA Risk LLC, 2009) is plotted in black. $B$ and $C$ are similar, except that the variable $x_{\% \text { CIT }}$ in Davidson's (2009b) equation, representing the percentage of land area used for commercial, industrial and transportation (CIT) purposes, is varied by plus and minus one sigma (sigma of $x_{\% \mathrm{CIT}}$ ), with equation 3 remaining the same in all plots. It can be seen that the median SPA Risk LLC (2009) model is higher than the Davidson (2009b) model by a factor of 2.8 at Modified Mercalli Intensity (MMI) VI and 2.3 at MMI VIII, while actually being lower (0.93) at $\mathrm{MMI} \mathrm{X}$. In $B$, corresponding to lower land use for commercial, industrial, or transportation purposes (CIT) (more representative of residential areas), the two models are in closer agreement, whereas $C$ (representative of higher CIT uses) shows a somewhat greater difference in the two models.

Table 4. Estimated ignitions and damage from the hypothetical magnitude-7.0 mainshock of the HayWired earthquake scenario on April 18, 2018, at 4:18 p.m. (breezy conditions and moderate humidity).

$[--$, no data; TFA, total floor area]

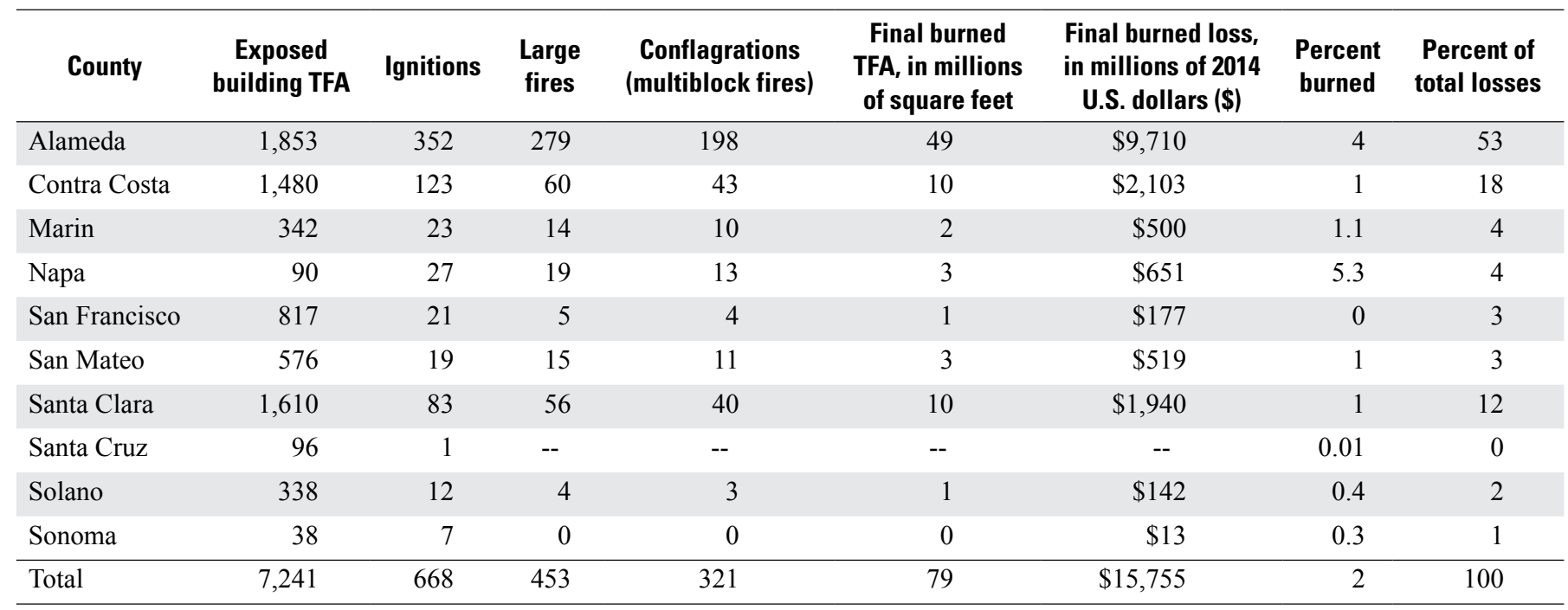


Table 5. General sources of ignition after the momentmagnitude-6.7 1994 Northridge, California, earthquake. (ignition data from Scawthorn and others, 1998).

\begin{tabular}{lc}
\hline \multicolumn{1}{c}{ Source of ignition } & Percentage of ignitions \\
\hline Electrical & 56 \\
Gas-related & 26 \\
Other & 18 \\
\hline
\end{tabular}

services by telephone, because street fire-alarm pull boxes have largely disappeared from the U.S. urban landscape. Attempts to report fires by calling 9-1-1 will likely be unsuccessful, owing to congestion of the system and overwhelmed 9-1-1 dispatch centers. Citizens may then go in person to the nearest fire station, but such "still alarms" will largely be futile because the fire companies will have already responded (self-dispatched) to the nearest fire, if not dispatched by 9-1-1. Experience shows that citizens on scene will respond rationally (Van Anne and Scawthorn, 1994), rescuing as many people as possible and protecting neighboring buildings (exposures). Water supply from mains (discussed below) will often be unavailable.

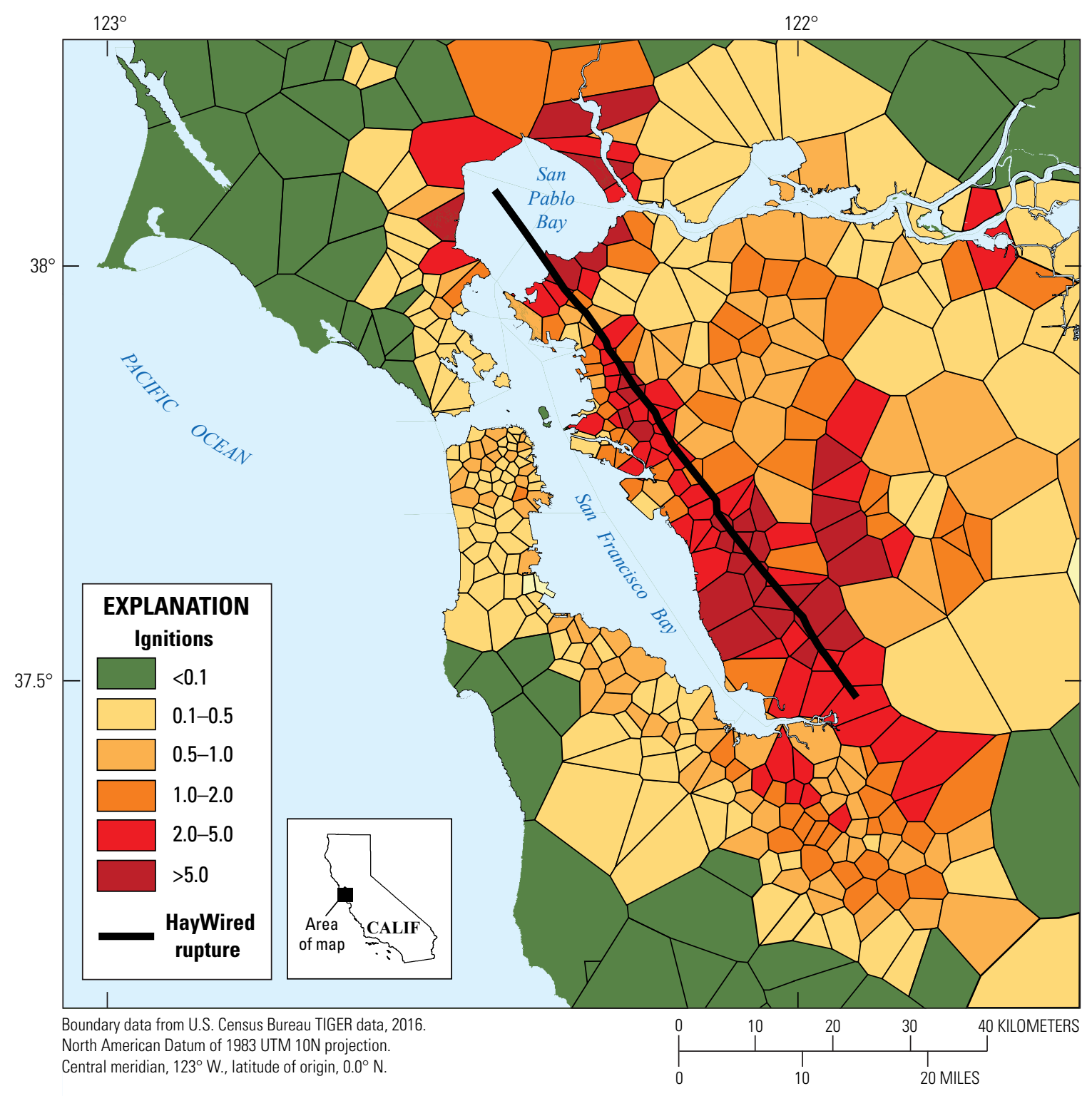

Figure 19. Map of San Francisco Bay region, California, showing estimated number of ignitions within fire station primary response areas (see fig. 8) following the hypothetical magnitude-7.0 mainshock of the HayWired earthquake scenario. Green indicates a small likelihood of ignition and dark red indicates five or more ignitions per area. The length of the Hayward Fault ruptured in the scenario is shown on the map. 


\section{Reporting}

As noted above, 9-1-1 dispatch centers will be overwhelmed and doing as much as possible to triage events and dispatch resources after the HayWired mainshock. Reports of fires during the initial period will be haphazard. Most fire departments do not have their own helicopters, and reporting by television news helicopters will be a valuable resource for a few major incidents, but not most. The first knowledge the San Francisco Emergency Operations Center had of the Marina fire following the $1989 M_{\mathrm{w}} 6.9$ Loma Prieta earthquake was from television news reports (despite several fire companies having responded). Quickly gaining an accurate and complete awareness of fires following an earthquake remains a challenge.

\section{Fire Department Initial Response}

The initial response of fire companies and personnel in the region of the HayWired scenario will be to protect themselves during violent shaking, and as soon as possible, open fire-station doors and remove firefighting apparatus (such as pumpers and ladder trucks). Different fire departments have somewhat varying earthquake procedures, but in general companies will remove firefighting apparatus to a predesignated location (often simply in front of the fire station), check the station for damage, and perform a radio check. By this time, typically within 5 minutes, they will either have self-dispatched to an observed smoke column, responded to a citizen still alarm, or been instructed to mobilize with other fire companies into a strike team.

Local fire department resources will be completely committed, and in need of assistance from outside of the San Francisco Bay region. The primary needs will be personnel, additional hose, hard suction hose (that is, hose that does not collapse when used to draft water from a source that is not already under pressure), firefighting foam, light equipment (gloves, hand tools, self-contained breathing apparatus [SCBA]), and heavy equipment (cranes, bulldozers, backhoes). Additional fire apparatus (pumpers and ladder trucks) will not be the primary need, but will still prove useful as extraregional strike teams arrive.

In the initial stage, personnel needs may be significantly supplemented by the Community Emergency Response Team (CERT) program, but will be more significantly strengthened by the recall of off-duty, trained firefighters. Off-duty personnel can be expected to have doubled staffing within 3-6 hours after the HayWired mainshock, and tripled it within 12-24 hours. How these personnel join their fire companies will be an issue, and there will be some inefficiencies as personnel join first available companies. Nevertheless, arrival of off-duty personnel will be very important to relieve on-duty personnel nearing physical limits.

\section{Fire Spread}

This analysis assumes that after the HayWired mainshock all fire-service resources will initially focus on firefighting, leaving search and rescue, hazmat response, and other emergencies until fires are brought under control. The initial 668 ignitions will not all develop into large fires. Nevertheless, the normal 4-minute structural-fire response time will most likely be delayed. This delayed response, owing primarily to delayed reporting and dispatch, will result in many fires having grown such that a multiengine capacity is needed on arrival. Especially in low humidity conditions, an ignition that has not been suppressed can become a room-sized fire within several minutes and grow into a fully involved, single-family structural fire within several more minutes. To protect neighboring buildings, typically two or more companies are needed. If only one fire company is available, it is possible but unlikely that it might be able to protect two exposures using a monitor (water cannon) and hand line (fire hose) with civilian assistance. In fire following earthquake modeling, fires that have grown to exceed one engine company's capabilities are termed large fires. The number of large fires for the HayWired mainshock is estimated based on several rules, including (1) availability of water for firefighting within each fire-response area and (2) ratio of ignitions to fire engines within each county (the latter to account for limited mutual aid), resulting in an estimate of 453 large fires (table 3). The large number of ignitions developing into large fires is a result of the high earthquake shaking intensities in the east bay combined with fuel provided by the high-density of wood construction between San Francisco Bay and hills to the east (East Bay Hills).

\section{Lifelines}

The performance of lifelines, such as water supply, gas, electric power, communications, and transportation, is integral to the firefighting process during fire following earthquake. A detailed discussion of lifeline performance for this scenario is beyond the scope of this report, which only briefly discusses selected lifelines with regard to fire following earthquake.

\section{Water Supply}

Water supply would be severely impacted by an earthquake like the HayWired scenario mainshock (see Porter, Water Supply, this volume). A significant part of the San Francisco Bay area's water derives from the Sierra Nevada and is conveyed by several major canals and aqueducts, particularly the Mokelumne and Hetch Hetchy Aqueducts (fig. 20). In the last few decades, earthquake hazards mitigation has been largely focused on assuring delivery of water from these distant sources to the bay area. Major seismic retrofit programs have been completed by the East Bay Municipal Utilities District (EBMUD), Contra Costa Water District, and Marin Municipal Water District and are ongoing for the Santa Clara Valley Water District and the Hetch Hetchy system, which is owned by the City of San Francisco and serves that city as well as much of the west and south bay area (fig. 21).

These retrofit programs have focused on the dams, tanks, and major transmission lines; however, most of these 
water operators have found that significant upgrading of their extensive water distribution systems is beyond available resources. As a result, extensive portions of the water distribution systems are very vulnerable and likely to sustain a number of breaks in a large earthquake. The following was noted in a recent study by the Association of Bay Area Governments (2010):

$\ldots 68.1 \%$ of critical water system facilities ... are exposed to extremely high shaking levels (peak ground accelerations, PGA, of greater than $60 \% \mathrm{~g}$ with a $10 \%$ chance of being exceeded in the next 50 years) . . 95.2\% of pipelines are estimated to be exposed to high shaking levels ( $\mathrm{PGA}>40 \% \mathrm{~g}$ ), and $62.8 \%$ are exposed to extremely high shaking levels (PGA $>60 \% g$ ) ... [the Association of Bay Area Governments] has estimated that there could be, for example, 6,000-10,000 water pipeline breaks or major leaks in an earthquake on the Hayward fault (compared to 507 in the Loma Prieta earthquake) ...

Pipe breaks in the 1989 Loma Prieta earthquake are shown in figure 22. Owing to their proximity to the Hayward Fault, east bay water distributions are particularly vulnerable (East Bay Municipal Utility District, 2011):

... earthquake hazard information ... with more detailed information on materials and design of these facilities, and pipeline materials and connections associated with EBMUD, were used to estimate the problems associated with District facilities in a 1994 study. At that time, EBMUD estimated that, should an earthquake occur on the Hayward fault EBMUD customers could have expected:

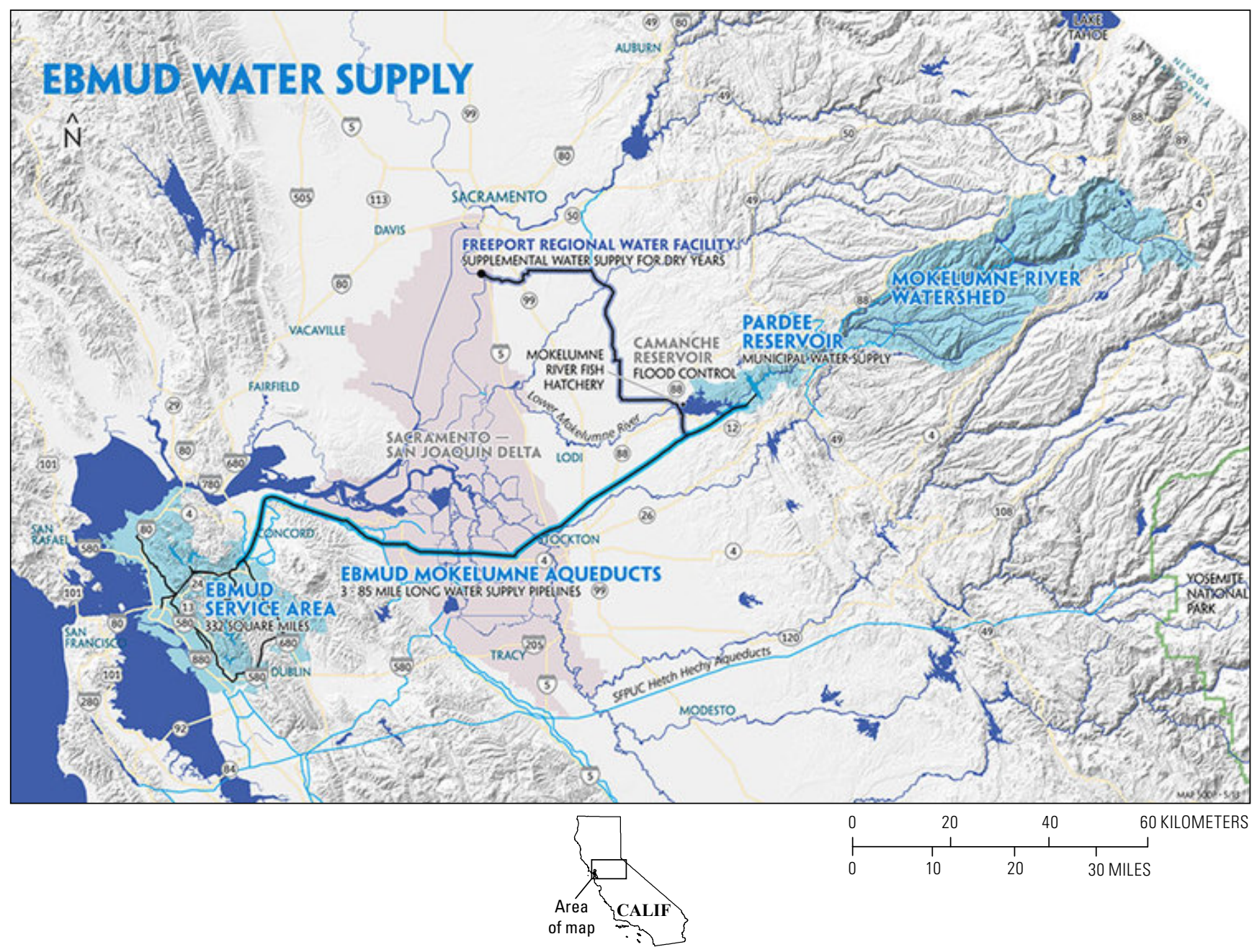

Figure 20. East Bay Municipal Utility District (EBMUD) map showing major water-supply systems of the San Francisco Bay area, California. A significant part of the bay area's water comes from reservoirs in the Sierra Nevada. The Mokelumne Aqueduct supplies much of the water to the EBMUD service area, and the San Francisco Public Utilities Commission's (SFPUC) Hetch Hetchy system primarily conveys water to San Francisco and the west and south bay. (From East Bay Municipal Utility District, 2017). 


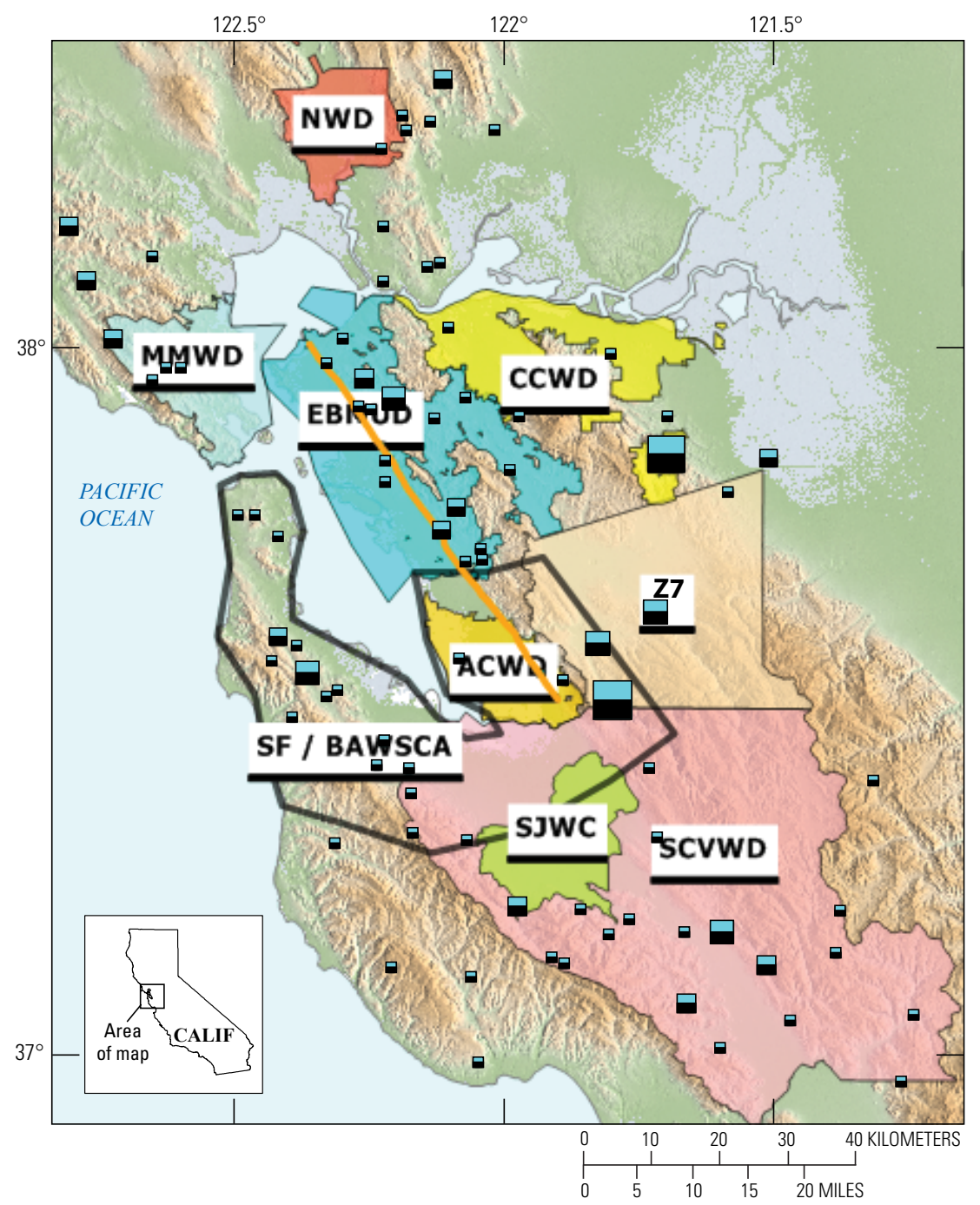

EXPLANATION

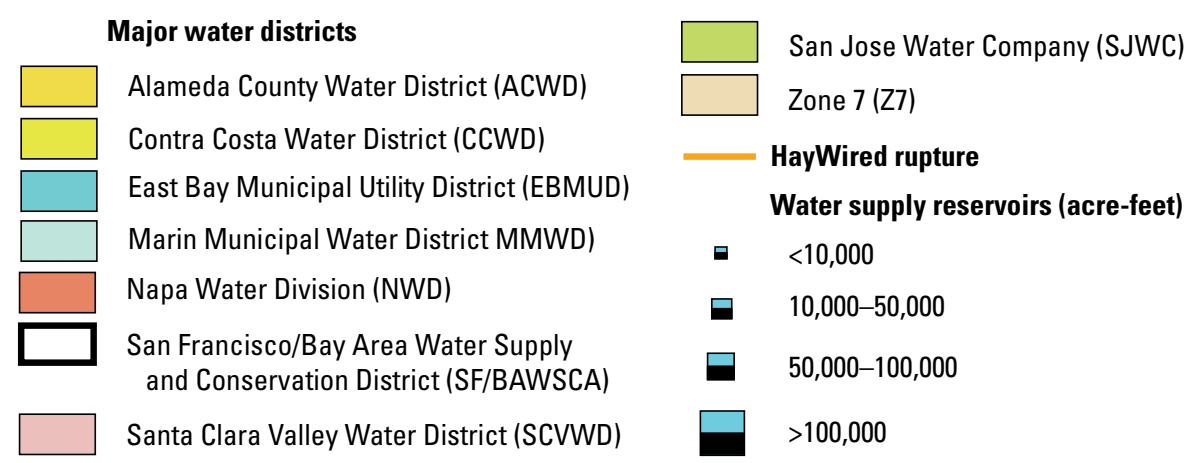

Figure 21. Map of major water districts and water-supply reservoirs in the San Francisco Bay region, California. The length of the Hayward Fault ruptured in the hypothetical magnitude-7.0 mainshock of the HayWired earthquake scenario is shown on the map. (Water district and reservoir data from Bay Area Water Supply and Conservation Agency, [n.d.]; California Department of Water Resources, [n.d.]; and Datahub, [n.d.]) 


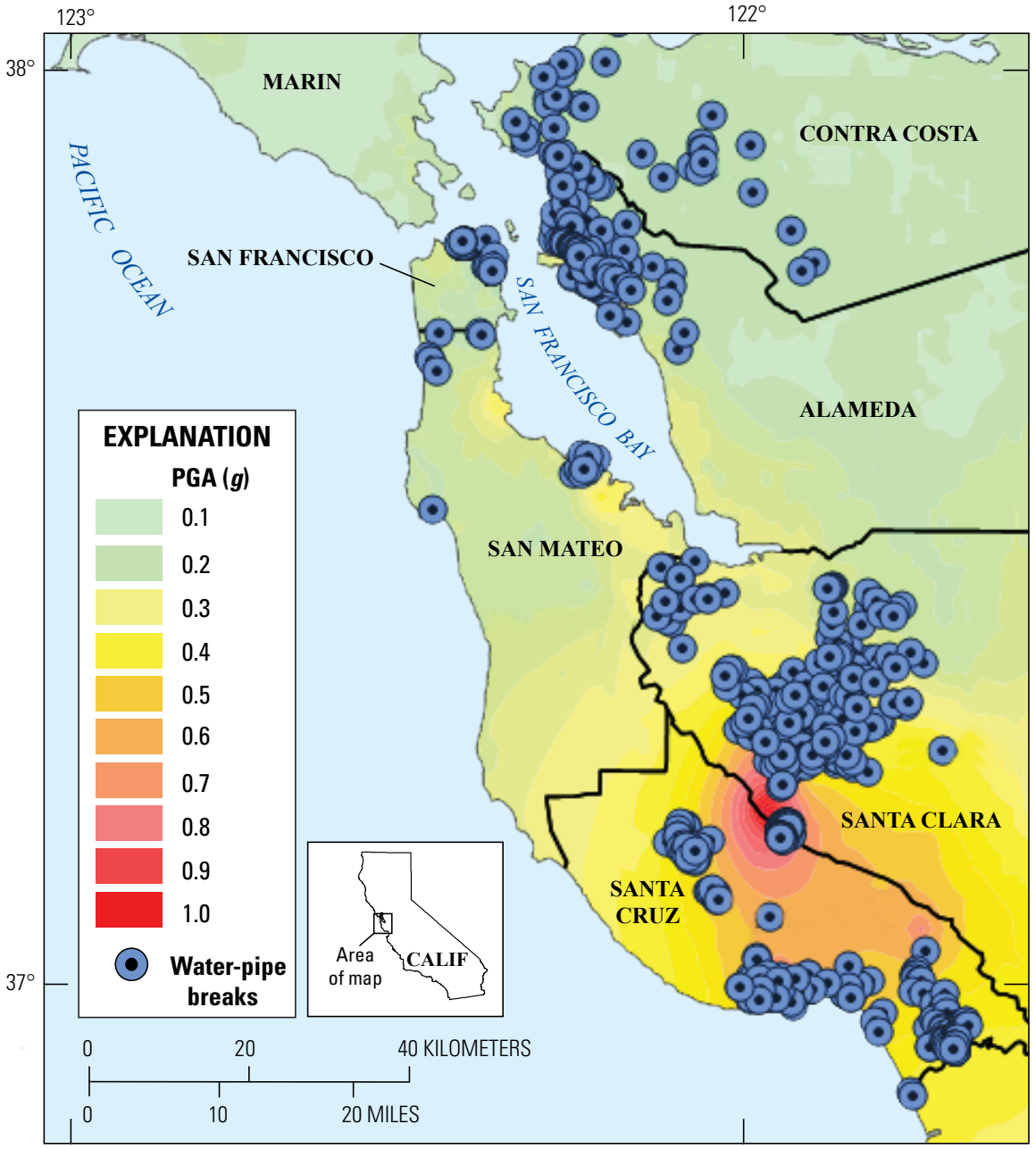

Figure 22. Map of the San Francisco Bay region, California, showing breaks in water-distribution pipes from the moment-magnitude-6.9 1989 Loma Prieta earthquake overlaid on peak ground acceleration (PGA) for the event. $g$, acceleration due to gravity. (Data from Lund and Schiff, 1992.)

- Water cut off immediately to 63 percent of customers, including hospitals and disaster centers;

- Loss of water for fire hydrants and increased fire risk;

- More than 5,500 pipelines serving homes and businesses to break;

-A likelihood of untreated drinking water resulting from damage to four of six treatment plants;

- EBMUD's most critical water conduit, the Claremont Tunnel, to be cut off west of the Oakland/Berkeley hills - affecting 70 percent of EBMUD customers;
- Major damage to 65 water reservoirs and about 87 pumping plants that would require months, or even years, to repair;

- An estimated impact of $\$ 1.2$ billion (in 1994 dollars) to the regional economy owing to fire damage and lack of water; and

- Lack of water weeks after an earthquake, with some customers lacking service for as long as six months afterwards.

... As a result of the 1994 water system study, EBMUD developed a $\$ 189$ million Capital Improvement program that, between 1995 and 2007, resulted in a system-wide mitigation of these impacts with the goal of providing an improved post-earthquake 
functional water system with no redundancies. . . . In addition, portable equipment, such as pumps, hoses and generators, required to maintain operations following a disaster, has been procured. A number of other facilities still require seismic upgrades. . Finally, roadway and building damage in EBMUD's service area may result in delays in recovery that may necessitate on-going communication with service vehicles to ensure that repairs to pipelines and critical facilities are completed in a timely manner.

Although dating from 2011, these estimates (for distribution piping damage) actually rely on analyses developed in 1994. However, although key facilities such as the Claremont Water Tunnel, which crosses the Hayward Fault in Alameda County, have been improved, little has changed since 1994 regarding distribution piping, and the situation remains largely the same today (EBMUD, oral commun., October 30, 2014).

To examine the impacts of this situation following the HayWired mainshock, two sources of information were used to estimate the number and pattern of distribution pipe breaks and leaks. Data on pipe breaks and leaks from Porter (Water Supply, this volume) was used for one of the main water-distribution service areas affected by this earthquake, that of EBMUD. Outside of the EBMUD service area, a more approximate method was used to estimate water-main breaks and leaks, which consisted of assuming an "average" water main was under each street, and basing damage to water-distribution networks on that assumption. Sections of pipe in zones of high liquefaction susceptibility are shown in figure 23 .

Based on this data, the HayWired mainshock devastates the water-supply infrastructure in the affected region, causing a total of about 9,400 buried water mains to require repairs, ${ }^{6}$ owing to a combination of fault rupture, shaking, and permanent ground displacement. The result is a lack of water supply to most hydrants in the east bay (fig. 24).

Without water infrastructure, firefighters will have to resort to alternative water sources, which in many cases require hard suction hose. Hard suction hose is a specific type of fire hose that allows a fire engine to create a vacuum in order to draft water from a source that is not pressurized (such as a swimming pool, river, or bay; fig. 25). The hose is reinforced with embedded metal rings to be circumferentially rigid so as to withstand an external pressure (such as internal vacuum). In the United States, the National Fire Protection Association specifies hard suction hose as standard equipment for class-A fire engines. However, in recent years some fire departments have adopted a practice of keeping hard suction hose in fire stations rather than carried on their engines. A limited survey of San Francisco Bay region fire departments conducted as part of this study found only about one-third of the departments could be confirmed as carrying hard suction hose on their engines.

\footnotetext{
${ }^{6}$ The estimate of 9,400 buried water mains requiring repairs is the total from Porter (Water Supply, this volume) combined with the estimate in this paper based on street lengths.
}
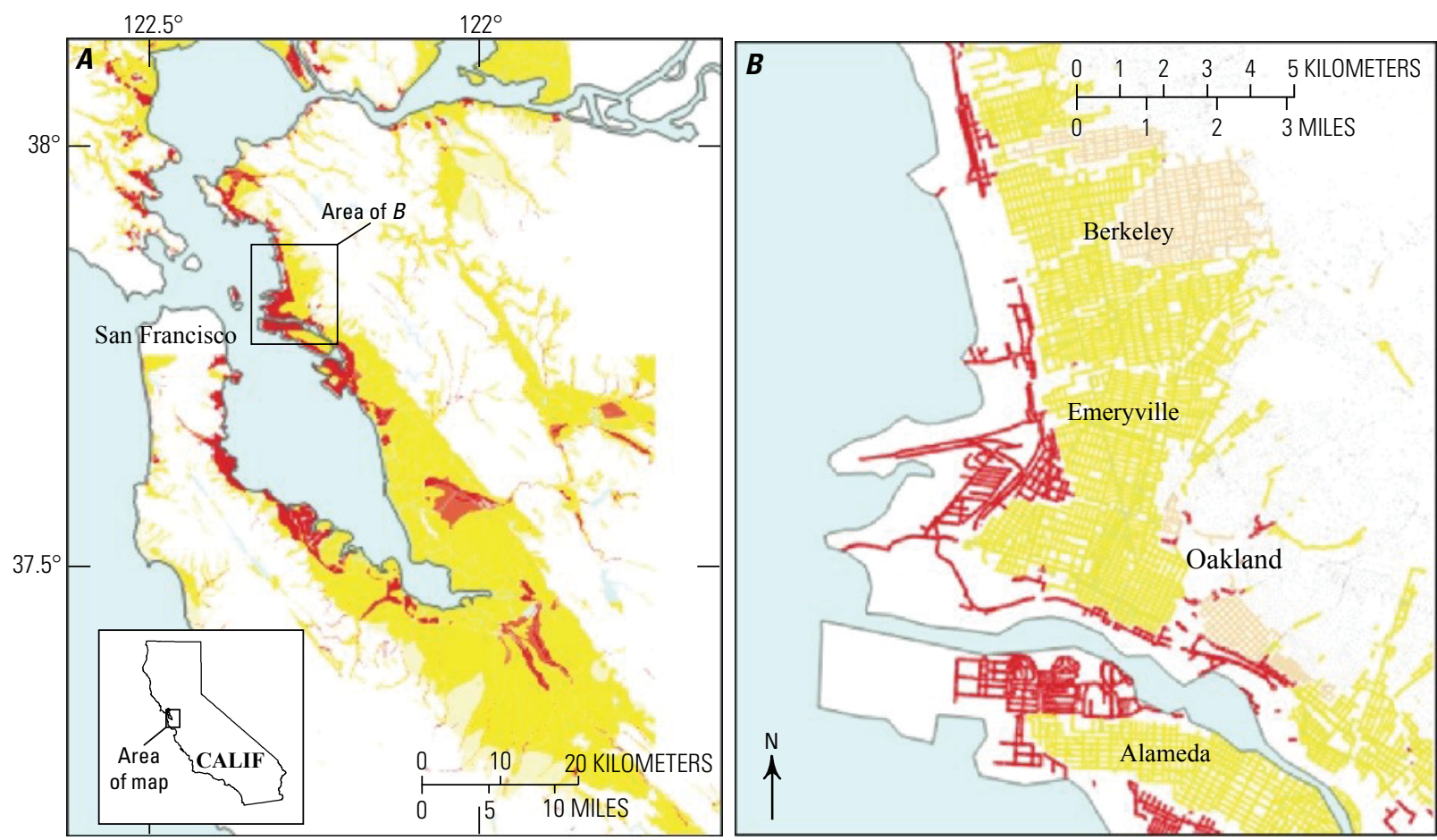

Figure 23. Maps of the San Francisco Bay region, California, showing water mains in areas of high liquefaction susceptibility in an earthquake (water mains were presumed to be under each road). $A$, Overview map of the San Francisco Bay region; $B$, detail map of parts of the Cities of, Berkeley, Emeryville, Oakland, and Alameda. Water-main susceptibility to liquefaction-red, very high; light red, high; yellow, moderate; pink, low. (Roads from U.S. Census Bureau, 2015; liquefaction data for most of the region from Witter and others, 2006, which omits San Francsico County.) 


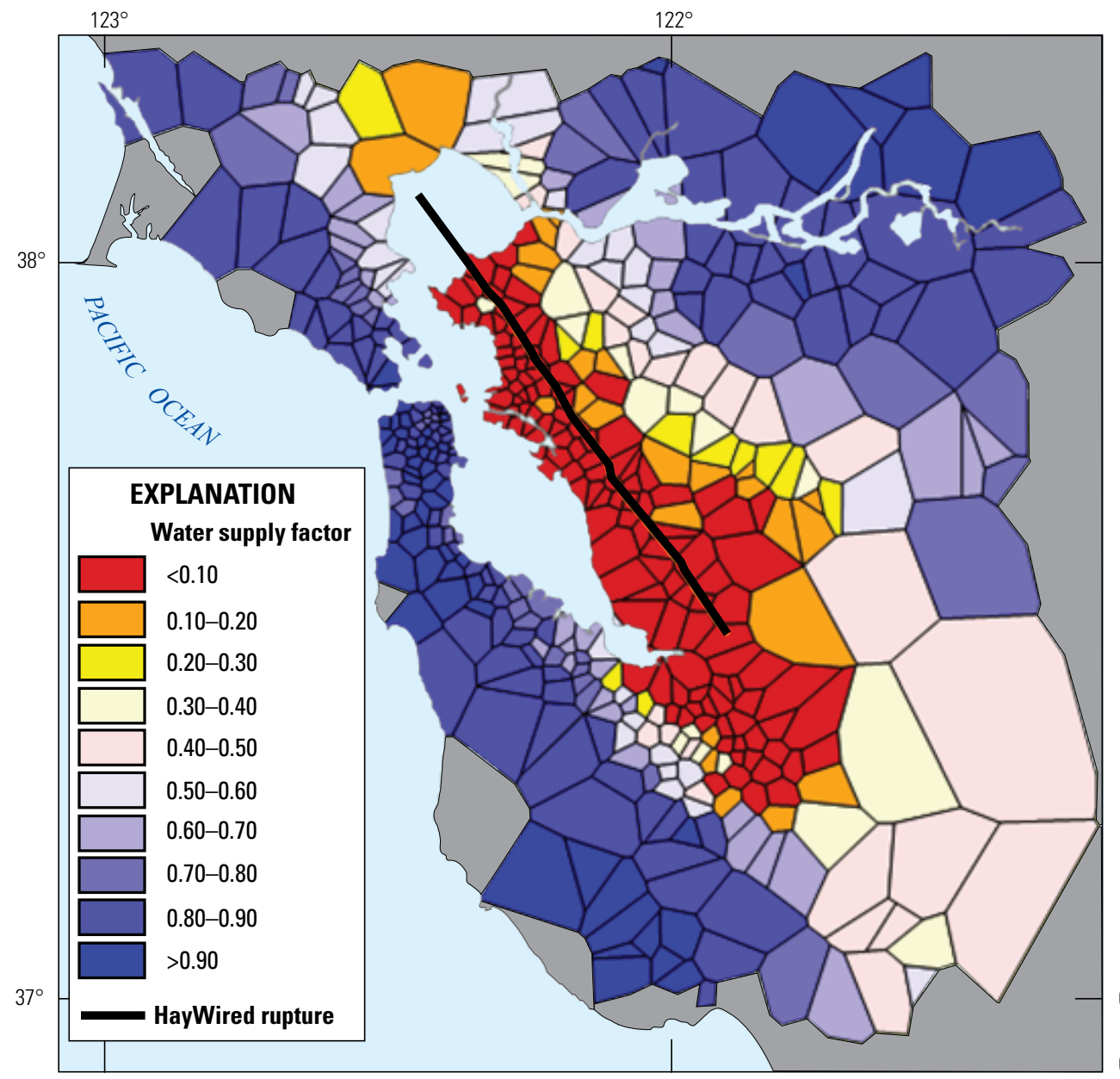

Figure 24. Map of the San Francisco Bay region, California, showing likelihood of the availability of water service within fire station Voronoi areas (a proxy for a fire station's response area, see fig. 8) following the hypothetical magnitude-7.0 mainshock of the HayWired earthquake scenario. Red areas approach zero likelihood of water service. The length of the Hayward Fault ruptured in the scenario is shown on the map.

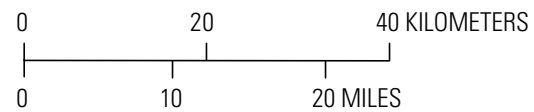

\section{Gas and Liquid Fuels}

Gas and liquid fuel are used throughout many modern cities; there are buried major transmission lines (fig. 26) with associated terminals, refineries, and tank farms. A rupture of one large gas or liquid-fuel transmission line can be catastrophic and require the resources of a major fire department to respond. Similarly, a major petroleum refinery fire requires a major response, which may not be possible in the immediate aftermath of an earthquake. The San Francisco Bay area has five major petroleum refineries, which constitute 40 percent of California's refining capacity. These refineries are concentrated at the north end of the HayWired scenario fault rupture. In the $M_{\mathrm{w}} 7.0$ scenario mainshock, these crucial refineries will experience severe shaking such that at least one (and possibly several) refineries will have major fires that may burn for several days, as has occurred in the past few decades in large earthquakes near refineries, such as the $M_{\mathrm{w}} 8.32003$ Tokachi-Oki, Japan, and $M_{\mathrm{w}} 7.61999$ İzmit, Turkey, earthquakes. In the bay area, and very significantly, gas distribution pipes underlie nearly every street, with connections to nearly every building. Ignitions from these sources typically account for about 25 percent of the total number of fire-following-earthquake ignitions.

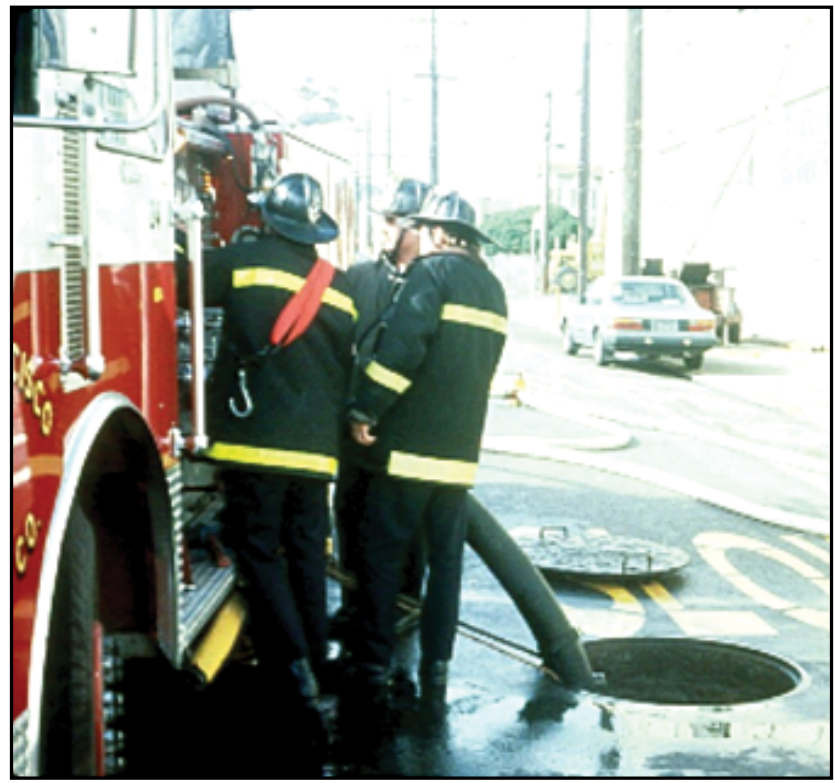

Figure 25. Photograph of a San Francisco Fire Department, California, engine and firefighters using a hard-suction hose to draft water from a cistern (photograph by Charles Scawthorn). 


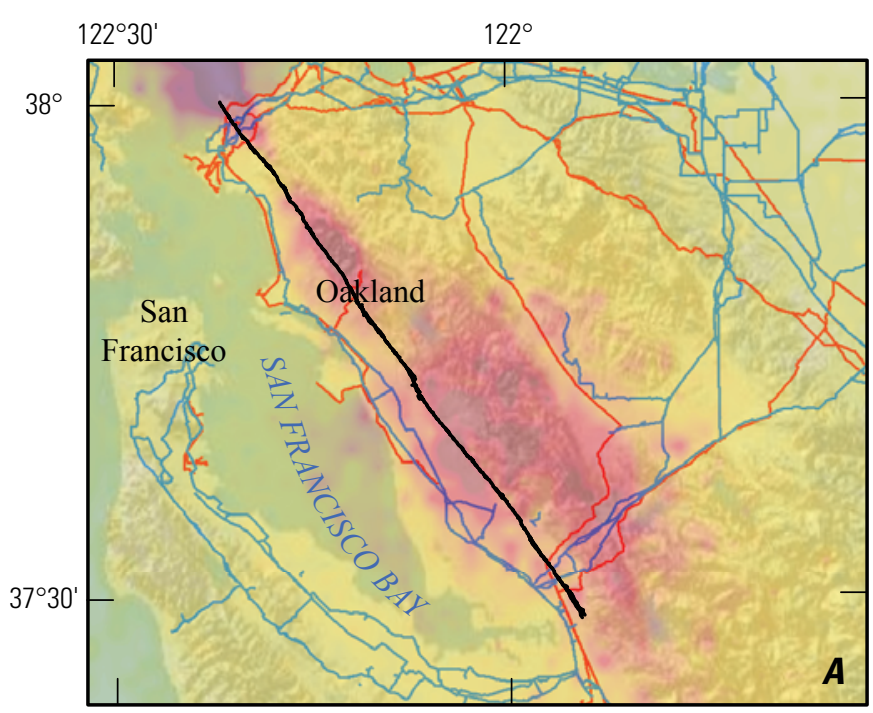

EXPLANATION

Peak ground acceleration (g)

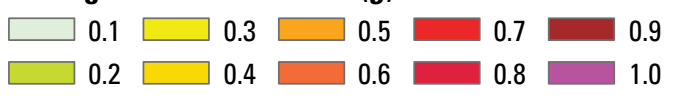

Pipelines

_ Gas pipeline

_ Liquid-fuel pipeline

— HayWired rupture

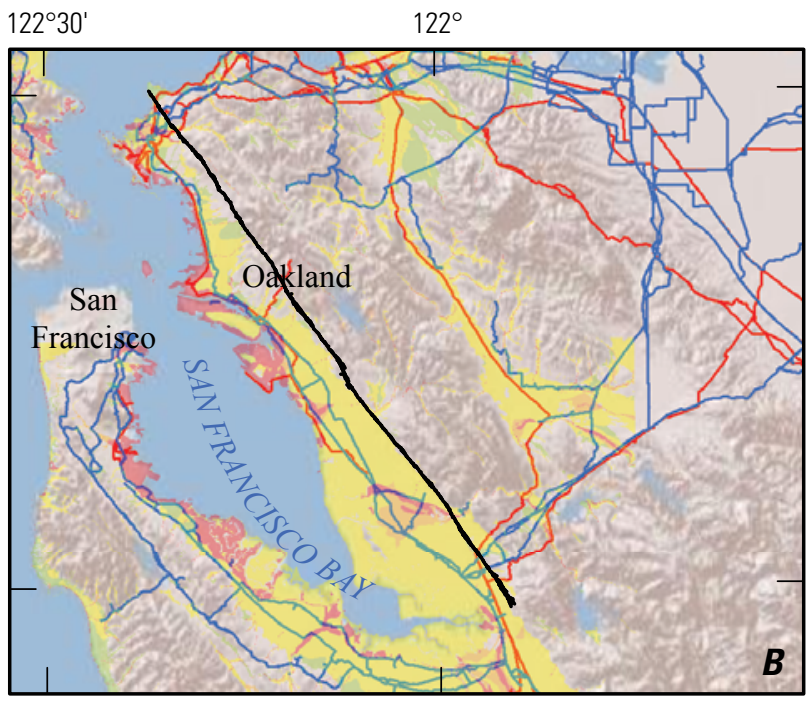

EXPLANATION

Liquefaction susceptibility

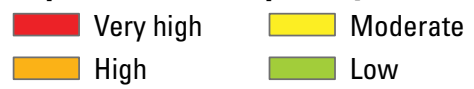

Pipelines

_ Gas pipeline

_ Liquid-fuel pipeline

— HayWired rupture

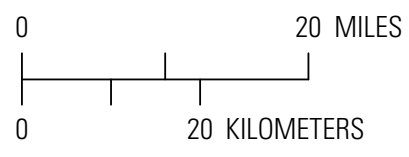

Figure 26. Maps showing gas and liquid-fuel transmission pipelines in the San Francisco Bay region, California. A, Pipelines overlaid on scenario peak ground acceleration distribution for the hypothetical magnitude-7.0 mainshock of the HayWired earthquake scenario on the Hayward Fault. $B$, Pipelines overlaid on zones of high liquefaction susceptibility. Length of fault rupture in the HayWired scenario shown by black lines. $g$, acceleration due to gravity. (Pipeline data from U.S. Department of Transportation, 2015; mainshock data from Aagaard and others, 2017; liquefaction data for most of the region from Witter and others, 2006, which omits San Francisco County.)

\section{Communications}

Communications systems, particularly telephone networks, will sustain some damage but perhaps not enough to reduce functionality following the HayWired mainshock. However, congestion will reduce functionality to a great degree, for several hours or more. This lack of telephone service will result in delayed reporting of fires, with consequences as discussed above.

\section{Transportation}

The transportation system most relevant to fire following earthquake is the road network, which is most vulnerable at bridge crossings. The California Department of Transportation (Caltrans) has nearly completed a major seismic review and retrofit of all bridges under its purview (California Department of Transportation, 2014). Although the local road and highway networks are sufficiently dense in most places that redundant pathways exist within the San Francisco Bay region, heavy traffic following a major earthquake could significantly impede emergency responders. Emergency strike teams arriving from outside of the bay region may also be delayed owing to traffic disruptions at several chokepoints at the boundaries of the region, including U.S. Route 101 north of the Golden Gate Bridge and south of San Jose and westbound Interstates 80 and 580. 


\section{Regional and State Response}

The HayWired scenario mainshock primarily affects California Governor's Office of Emergency Services (Cal OES) region II (fig. 27). The most likely sources of regional resources will be a number of strike teams assembled by $\mathrm{Cal}$ OES from the Central Valley, arriving in the affected region within 6-24 hours. Some of these will be brush rigs (wildland fire engines specifically designed to assist in fighting wildfires), which are more suited to wildland than urban-structural fires. By the time of their arrival in the region affected by the HayWired mainshock, the issue will be large fires that have grown into conflagrations, constituting a much larger challenge.

Outside of region II, Cal OES is likely to stage a number of strike teams, drawn generally from southern California and the Central Valley. Assembling 100 strike teams, consisting of approximately 500 pumpers and other firefighting apparatus, as well as firefighters, is easily within Cal OES capability, and several times this number of people and equipment can be managed if necessary. Within about 12 hours of notification, 100 strike teams can arrive at staging areas, with probably another 100 teams arriving during the next week. In our analysis, however, mutual aid will be largely ineffective in the immediate period following the HayWired mainshock, owing to the following factors:

- Delayed response time to fire scene:

- Fire departments in the San Francisco Bay area (for example, peninsular and Walnut Creek-Concord area) will conserve resources and not be able to respond quickly to the east bay.

- Mutual aid will have to come from farther afield (northern California, southern California, and the Central Valley), requiring at least several hours, and will be arriving at night in blackout conditions (owing to wide-scale failure of electric power).

- Water shortages:

- Water-tanker truck refills will be at some distance from fires, resulting in delays. Although a few fire departments (Berkeley, Oakland, Vallejo, and San Francisco) have portable water-supply systems (PWSS), these are currently inadequate for the demands that will be placed on them.

- Aerial firefighting effectiveness in urban areas is currently unknown.

- Firefighting foam is a "force-multiplier," greatly increasing the effectiveness of a hose stream. However, current local fire-department supplies of foam are limited.
- Access:

- The east bay hills are quite steep, with relatively narrow and winding roads that hinder access.

- The hills are also heavily vegetated which, combined with prevailing winds and topography, will greatly enhance fire spread and impede firefighting.

- Supplying water to higher elevations in the hills will be very difficult.

- Limited access to the San Francisco Bay area.

\section{Final Burned Area}

The 453 large fires estimated to follow the HayWired scenario mainshock will be spread over a large area of varying building density and availability of water for firefighting. The number of large fires that will grow into conflagrations, and the ultimate extent of the final burned area, will depend on the building density, weather conditions, initial unfought size of the fire before fire department response, number of responding fire

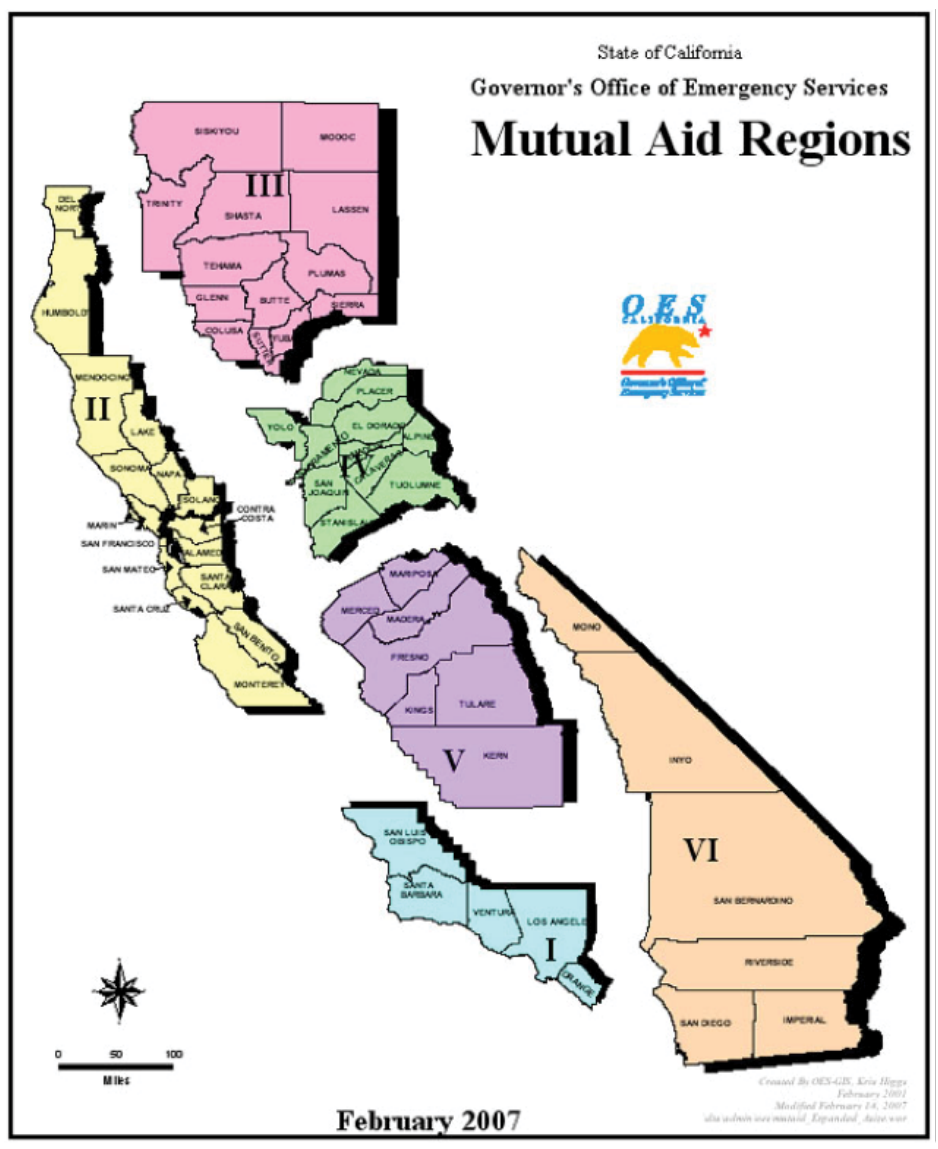

Figure 27. Map showing California Governor's Office of Emergency Services mutual-aid regions (from California Governor's Office of Emergency Services, 2017). 
engines and water supply available for firefighting associated with each large fire. Under the assumed scenario conditions, it is estimated that of the 453 large fires, about 321 will grow to a size such that they will spread beyond the city block of origin (in other words, become a conflagration), with the final burned area then largely dependent on fires crossing streets and other firebreaks. Based on the probability of fire crossings, the estimated final burnt area is approximately 79 million square feet of residential and commercial building floor area equivalent to more than 52,000 single-family dwellings. ${ }^{7}$ This loss is equivalent to a total building replacement value of almost

\footnotetext{
${ }^{7}$ An average single-family equivalent dwelling is 1,500 square feet of residential or commercial occupancy floor area, and this measure is used to normalize and communicate overall building losses in a readily comprehensible way. A loss of 1.5 million square feet of residential and commercial building for example is equivalent to 1,000 single-family dwellings. Most people can more readily interpret the loss of 1,000 houses than 1.5 million square feet of floor area.

${ }^{8}$ Based on a replacement cost of $\$ 200$ per square foot. Note this is a conservative estimate of replacement cost. Hogan (2014) estimates that construction in San Francisco can cost $\$ 300$ per square foot, not counting subsidies, permits, and selling expenses.
}

$\$ 16$ billion $^{8}$ (2014 dollars), representing about 2 percent of the entire exposed value (fig. 28, table 4), with most of the loss concentrated in Alameda County.

Under the assumed wind and humidity conditions during the HayWired mainshock, the areas of most concern for fire following earthquake are parts of Alameda and Santa Clara Counties, where large areas of relatively uniform, dense, low-rise buildings provide a fuel bed such that dozens to hundreds of large fires are likely to merge into many dozens of conflagrations, destroying tens of city blocks. Two particular concerns exist in this regard-(1) if Diablo winds are present (which is not assumed in this scenario), losses could be much larger; and (2) if extremely calm conditions exist (which is also not assumed in this scenario), a symmetric wind pattern could develop where uprising air from conflagrations draws air inward (an example of the stack effect) to create a selfsustaining feedback situation (commonly termed a firestorm), which can be very destructive. Although relatively unlikely, this potential should not be ignored. The first concern is a larger mass conflagration, fed by higher winds; the second is potentially much worse. Both would be catastrophic.
Figure 28. Map of the San Francisco Bay region, California, showing final burned-area losses (in millions of 2014 U.S. dollars) from fire following earthquake after the hypothetical magnitude-7.0 mainshock of the HayWired earthquake scenario. Areas shown are fire station Voronoi areas (a proxy for a fire station's response area, see fig. 8). The length of the Hayward Fault ruptured in the scenario is shown on the map.

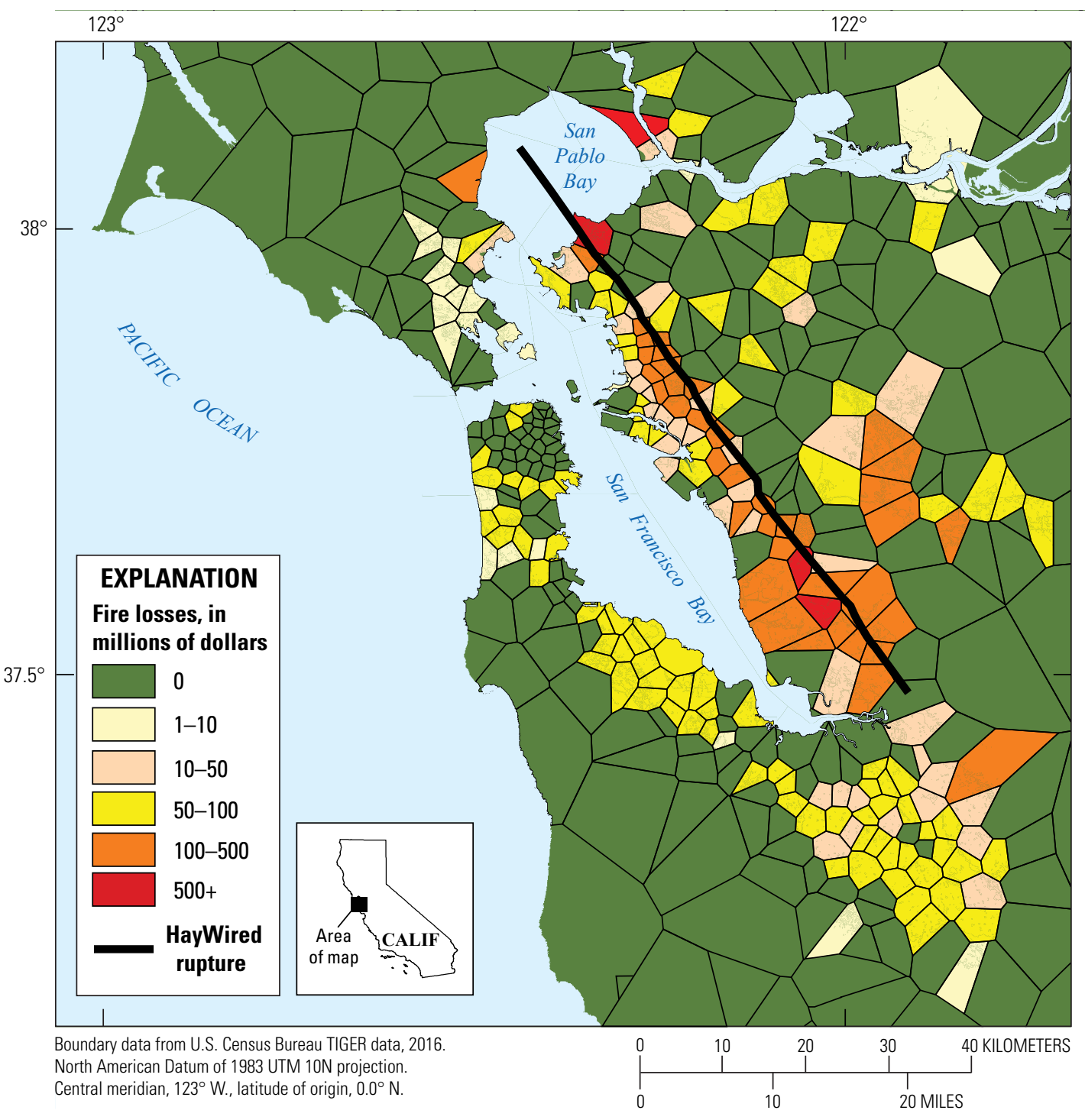


Another major concern is the very large concentration of high-rise buildings in the financial district of San Francisco. Firefighting under postearthquake conditions in more than one of these buildings could be beyond the resources of the San Francisco Fire Department, so the loss of several high-rises is quite possible.

\section{Uncertainty, Verification, and Validation}

There is considerable uncertainty in the estimates of ignitions and final burned area presented above. The United States has been very fortunate in having few large earthquakes within urban areas in the past 50 or more years, so the experience database for ignitions following earthquakes is relatively sparse and has significant uncertainty, as can be seen in the confidence bands shown in figure 18, which span an order of magnitude. Moreover, the majority of data for ignitions ( 178 of 244 or 73 percent) are drawn from very early morning earthquakes, a time of day associated with low normal fire occurrence (U.S. Fire Administration, 2008). A full exploration of uncertainty is beyond the scope of the present study, but the number of ignitions estimated to follow the HayWired mainshock (668) could vary by hundreds, depending on many factors.

Regarding verification (accuracy of the estimate) and validation (meeting the intended need) of estimates of ignitions and final burned area in the HayWired scenario, a large earthquake like the $M_{\mathrm{w}} 7.0$ mainshock is a rare event, and the postearthquake fire situation even rarer, so that verification and validation is very challenging.

Verification is particularly difficult, owing to the sparsity of data and experience. Qualitatively, the following experiences tend to support the scenario losses presented above:

- Precedent — several events support the potential for large postearthquake losses, including in the HayWired study region:

- Catastrophic fires following the 1906 San Francisco $\left(M_{\mathrm{w}} 7.8\right)$ and 1923 Tokyo $\left(M_{\mathrm{w}} 7.9\right)$ earthquakes.
- More than 100 ignitions (each) following the 1971 San Fernando, California $\left(M_{\mathrm{w}} 6.6\right) ; 1994$ Northridge, California $\left(M_{\mathrm{w}} 6.7\right)$; and 1995 Kobe, Japan $\left(M_{\mathrm{w}} 6.9\right)$, earthquakes.

- At least 348 ignitions, more than any other earthquake in history, occurring in the 2011 Tohoku, Japan $\left(M_{\mathrm{w}} 9.0\right)$, earthquake and tsunami (Anderson and others, 2016)

- The 1991 East Bay Hills Fire (East Bay Hills Fire Operations Review Group, 1992), a massive conflagration centered in the study region that overwhelmed fire and water agencies.

- Quantitatively, the methods in this study were used to hindcast (estimate):

- Ignitions in previous California earthquakes (tables 6-8 and fig. 29) with reasonable agreement. The base data is dataset A in Davidson (2009a).

- Large fires for the 1989 Loma Prieta (Mw 6.9) and 2014 South Napa (Mw 6.0), California, earthquakes, the only events for which sufficient data on all aspects (fire resources, firefighting water availability, and so forth) was available.

Although this quantitative verification is quite limited, it tends to confirm the reasonableness of the estimates and also illustrate the uncertainty. Both the SPA Risk LLC (2009) and Davidson (2009b) ignition models produce enough fires following the HayWired mainshock to overwhelm currently available firefighting resources in the San Francisco Bay region, so the conclusions of this chapter would be the same regardless of which model was used.

Validation (meeting the intended need) for fire following earthquake in the HayWired scenario is also a challenge but toward this end the above methodology and findings were presented to a workshop on fire following earthquake, held at the University of California, Berkeley, Richmond Field Station on October 29, 2014. The workshop was attended by 76 personnel, representing 31 fire departments

Table 6. Summary count of ignition data from California earthquakes since 1971 (SPA Risk LLC, 2009, 2014).

\begin{tabular}{lcl}
\hline \multicolumn{1}{c}{ Earthquake } & Number of ignitions & \multicolumn{1}{c}{ Date source $^{\mathbf{1}}$} \\
\hline 1971 San Fernando & 91 & Unpublished data \\
1983 Coalinga & 3 & Scawthorn (1984) \\
1984 Morgan Hill & 6 & Scawthorn (1985) \\
1986 North Palm Springs & 1 & Earthquake Engineering Research Institute (1986) \\
1987 Whittier Narrows & 20 & Wiggins (1988) \\
1989 Loma Prieta & 36 & Mohammadi and others (1992); Scawthorn (1991) \\
1994 Northridge & 81 & Scawthorn and others (1997) \\
2014 Napa & 6 & SPA Risk LLC (2014) \\
\hline Total number of ignitions & 244 & \\
\hline
\end{tabular}

${ }^{1}$ See SPA Risk LLC $(2009,2014)$ for detailed references. 
Table 7. Hindcast (estimated) ignitions for selected California earthquakes (1984-2014), using equations from Davidson (2009b) and SPA Risk LLC (2009) (see discussion in text and equations 1 and 3, respectively).

[NA, not applicable]

\begin{tabular}{lccc}
\hline \multicolumn{1}{c}{ Earthquake } & $\begin{array}{c}\text { Observed } \\
\text { ignitions }\end{array}$ & $\begin{array}{c}\text { Davidson (2009b; model A.NB2) } \\
\text { estimated ignitions }\end{array}$ & $\begin{array}{c}\text { SPA Risk LLC (2009) estimated } \\
\text { ignitions }\end{array}$ \\
\hline 1984 Morgan Hill & $4^{1}$ & 1.2 & 4.0 \\
1986 North Palm Springs & 1 & 2.1 & 4.1 \\
1987 Whittier & 13 & 22.2 & 72.1 \\
1989 Loma Prieta & 36 & 29.5 & 15.9 \\
1994 Northridge & 81 & 99.0 & 166.4 \\
2014 Napa & 6 & NA & 6.24 \\
\hline
\end{tabular}

${ }^{1}$ There were four structural ignitions in Morgan Hill and two in San Jose in the 1984 earthquake. The total of six is indicated in table 6. For validation, only Morgan Hill was modeled, so table 7 shows only four observed ignitions.

Table 8. Observed and hindcast (estimated) large fires for selected northern California earthquakes.

\begin{tabular}{lcc}
\hline \multicolumn{1}{c}{ Fire type } & Observed & Estimated \\
\hline & 1989 Loma Prieta earthquake & \\
\hline Total ignitions & 31 & 24 \\
Large Fires & 12 & Negligible \\
Conflagrations & $1 ?$ & Negligible \\
\hline \multicolumn{4}{c}{ 2014 Napa earthquake } & \\
\hline Total ignitions & 6 & 6.24 \\
Large Fires & 1 & Negligible \\
Conflagrations & $?$ & Negligible \\
\hline
\end{tabular}

${ }^{1}$ Based on 1990 census population (dataset A in Davidson, 2009a). and emergency response agencies. The workshop was subsequently independently evaluated by Allison Madera and others (Natural Hazards Center, University of Colorado Boulder, written commun., 2016), who found "almost all of the survey respondents ( 95.8 percent) indicated that they believed the HayWired scenario accurately represented what a fire following earthquake incident might look like in the San Francisco Bay Area."

\section{Impacts of Fire Following Earthquake}

This section discusses the human and economic impacts of fire following earthquake. Not well understood, but discussed here, is the major impact such events can have on the insurance industry.

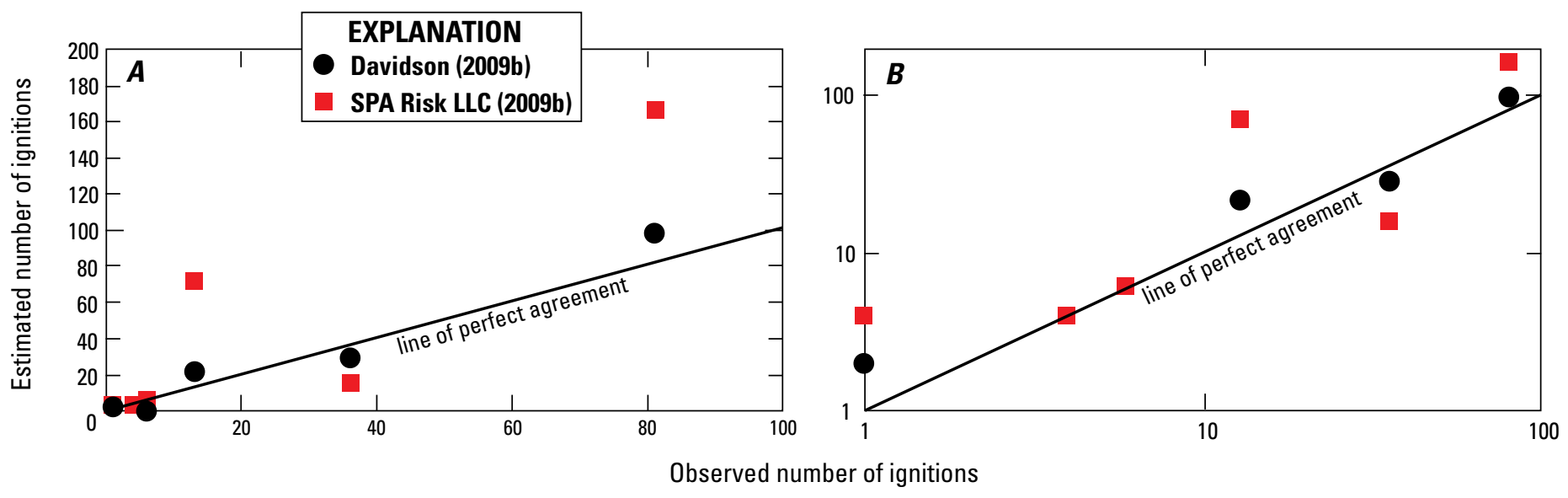

Figure 29. Observed and hindcast (estimated) ignitions for selected California earthquakes (1984-2014), using equations from Davidson (2009b) and SPA Risk LLC (2009) (see discussion in text and equations 1 and 3, respectively; see table 7 for data). A, Number of ignitions plotted on arithmetic axes. $B$, Number of ignitions plotted on log-log axes. 


\section{Human Impacts}

Estimating the fatalities associated with the fires following the HayWired mainshock is very problematic. A very simple approach is taken here; in the 1991 East Bay Hills Fire, which destroyed approximately 3,500 dwellings, 25 people perished. The building losses projected here are approximately 20 times larger. In proportion, there would be hundreds of deaths caused by fire following the scenario mainshock. Such an approach is admittedly very simplistic and does not account for the potential overwhelming of the regional emergency medical capacity in a large earthquake, as opposed to the isolated nature of the 1991 fire. Injuries would probably be an order of magnitude greater. For the HayWired scenario, an estimated 500,000 to 1 million people will need shelter as a result of fire following earthquake.

\section{Economic and Insurance Impacts}

Regarding the estimated $\$ 16$ billion value of the structures burned by fire following earthquake in the HayWired scenario, the value of contents and other improvements (for example, landscaping) will add to this loss. For example, the contents of residences are commonly insured to 70 percent of the replacement cost of the building, so content loss could realistically amount to an additional $\$ 11$ billion. An additional loss is loss of use; that is, the people normally living in these destroyed buildings (or conducting business in them) must find other accommodations, which most likely would not be available in the San Francisco Bay region given the impact of the scenario mainshock. This loss, termed "additional living expenses" by the insurance industry, can be consequential, equivalent to many tens of billions of dollars. Accounting for this can be difficult; if people who have lost their dwellings are housed in hotels at insurance company expense, the loss is simply the hotel bill. If people are forced to live in tents following the mainshock, at public expense, there may be no bill. ${ }^{9}$ In such a situation, people have not paid for their tents, and cannot therefore claim against the insurance company for a financial loss. However, they have lost value in services (of their house) approximately equivalent to the rental value of their house (minus the rental value of the tent) but would not be compensated for those losses. Nevertheless, this is a loss that should be accounted for, overall. One approximation is to estimate the additional living expenses in proportion to the typical limit of liability for homeowner's insurance-20 percent of the replacement cost of the buildings, which for the HayWired scenario is about $\$ 3$ billion.

Because virtually all buildings and contents in the United States are insured for fire, and U.S. insurance contracts include losses from fire following earthquake under the fire policy, the direct fire-following-earthquake losses for the HayWired mainshock are likely to result in a loss approaching $\$ 30$ billion of insurance claims. Because $\$ 30$ billion amounts to nearly 6 percent of the gross domestic product of the San Francisco Bay region - and shaking, liquefaction, and landslide-related

\footnotetext{
${ }^{9}$ Note that public authorities may attempt to recoup their expenses, if the sheltered people are insured.
}

damage adds to the demands for construction services - it is likely that demand surge will occur (the temporary increase in construction costs following major natural disasters). Losses of this magnitude are probably sustainable by the U.S. insurance industry (the $\$ 60$ billion in insured claims arising from the September 11, 2001, attacks were handled without great strain). The 1991 East Bay Hills Fire, in which 3,500 homes were lost, at the time resulted in about $\$ 1$ billion in insured losses - the event projected here is 23 years of inflation later and about 60 times as large. In summary, losses from fire following earthquake are likely to be the largest part of the insured losses in the scenario event, and would be one of the largest single-loss events in the history of the insurance industry.

Another aspect of the economic impacts is the loss of real-estate tax revenues. A loss of tens of billions of dollars in the value of property improvements is likely to result in perhaps a decrease of a billion dollars in regional real-estate tax revenues for several years, directly attributable to fire following earthquake.

\section{Mitigation of Fire Following Earthquake}

Mitigation of fire following earthquake has been extensively discussed elsewhere (Scawthorn and others, 2005). Only some limited observations specific to the HayWired scenario are provided here.

\section{Fire-Service Opportunities}

The fire service in California is perhaps the most experienced in the world in dealing with large conflagrations, owing to the wildland fires recurring annually in the region. Fire departments have also been relatively diligent in preparing for a large earthquake - the CERT program is a model in that regard. However, the following opportunities for improvement are noted:

- Improvements are needed in the ability to more quickly assess the event and facilitate fire incident reporting. Reconnaissance using unmanned aerial vehicles, as well as cellular text-messaging incident reports directly to a 9-1-1 portal, could be developed and operationalized.

- Alternative water sources need to be better identified and access and water movement capabilities enhanced. Hard suction hoses could be carried on all engines. Large diameter hose (LDH) systems, comparable to San Francisco Fire Department's PWSS (Scawthorn and others, 2006), could be developed on a regional basis. In this regard and as part of the HayWired scenario project, the earlier mentioned October 29, 2014, workshop was held at the University of California's Richmond Field Station. The four existing PWSSs, belonging to Berkeley, Oakland, San Francisco, and Vallejo Fire Departments 
(fig. 30) were brought together and used in a joint exercise for the first time.

- A regional multidisciplinary task force could be formed within the fire service, to examine urban conflagration potential in more detail.

\section{Water-Service Opportunities}

Water-service providers in California have worked to prepare for a major earthquake, but more can still be done (Scawthorn, 2011a,b). One overriding issue with regard to fire following earthquake is that water agencies typically are not institutionally responsible for fire protection. That is, although they provide hydrants, if the hydrants fail to supply water, the water agency is not responsible. Therefore, water-system upgrades are typically more oriented to maintenance of customer service and minimizing direct damage to the system than to maximizing water-supply reliability. A mandate could be developed to make water agencies more responsive to this need. Given the realities of the limited water supply in California, this may be unlikely to occur, but should at least be raised for discussion. A real way in which water agencies could be more responsive to the problem of fire following earthquake is if each agency were to configure and upgrade their system so as to provide a "backbone" system of water mains of high seismic reliability, which would both help ensure the reliability of water services to communities and provide fire departments with sources to draw water from to suppress a conflagration using an LDH system. This entire aspect is discussed in more detail in Scawthorn (2011a,b).

\section{Building-Standards Opportunities}

Since the 1906 San Francisco earthquake, significant progress has been made in making buildings more earthquake and fire resistant, yet there are still opportunities for improvement. For example, residential fire sprinklers are now required by many communities for new construction (at a cost less than the carpeting), but generally there are no requirements for existing homes (where the cost is significantly higher). Similarly, seismic retrofitting of existing buildings is increasingly being considered for older commercial buildings, but very few communities have requirements for existing single-family homes. Seismic retrofitting would reduce the number of postearthquake ignitions. Both seismic retrofitting and installation of fire sprinklers could be more widely mandated for existing buildings.

\section{Energy-Industry Opportunities}

The gas industry could contribute significantly to reducing the fire following earthquake by developing a program to either install automated gas shut-off valves (fig. 31) or redesign gas meters to have seismic shutoffs, particularly in densely built up areas. If the number of ignitions could be reduced by 25 percent, the number of large fires would be decreased in greater proportion and the total losses further reduced. For example, the City of Los Angeles Fire Department has shown leadership in seeking legislation to require gas shut-off valves. Note that the gas industry in Japan moved to do this proactively following the 1995 Kobe earthquake.

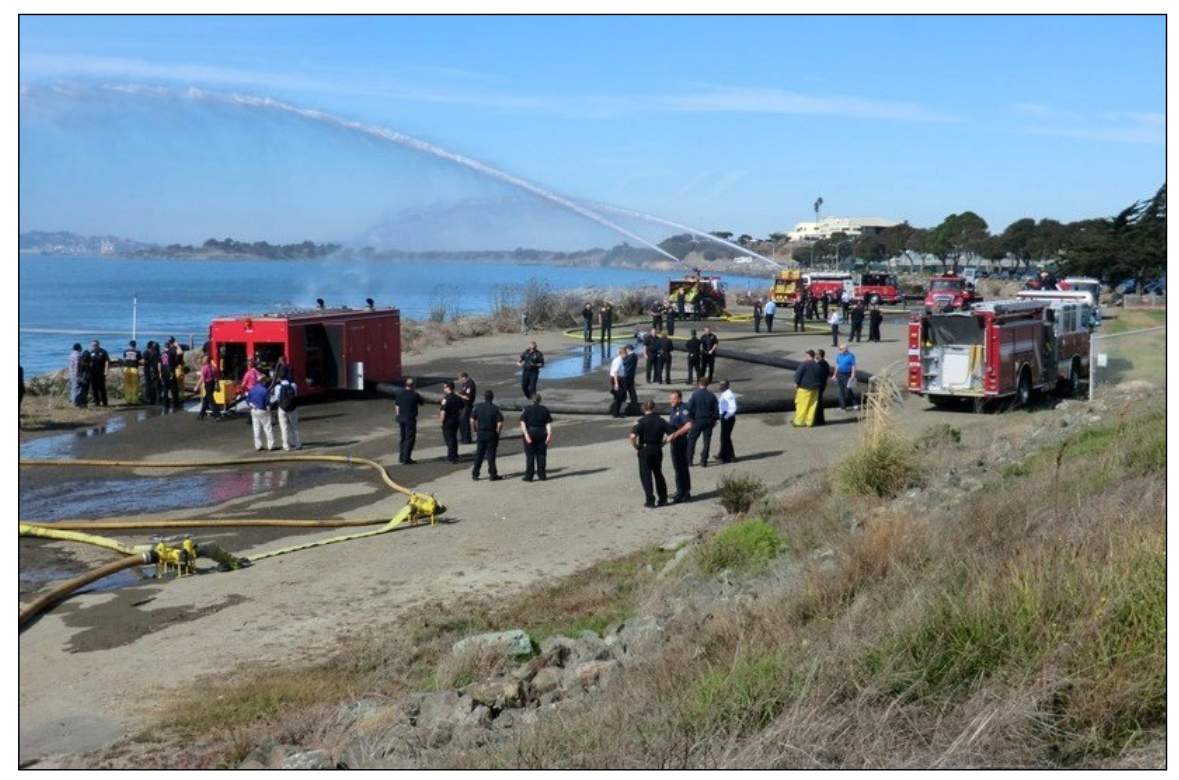

Figure 30. Photograph of four portable water-supply systems, belonging to the Berkeley, Oakland, San Francisco, and Vallejo Fire Departments, at the edge of San Francisco Bay in Berkeley, California, on October 29, 2014. This was the first time the four systems were brought together and used in a joint exercise. (Photograph by Charles Scawthorn.) 


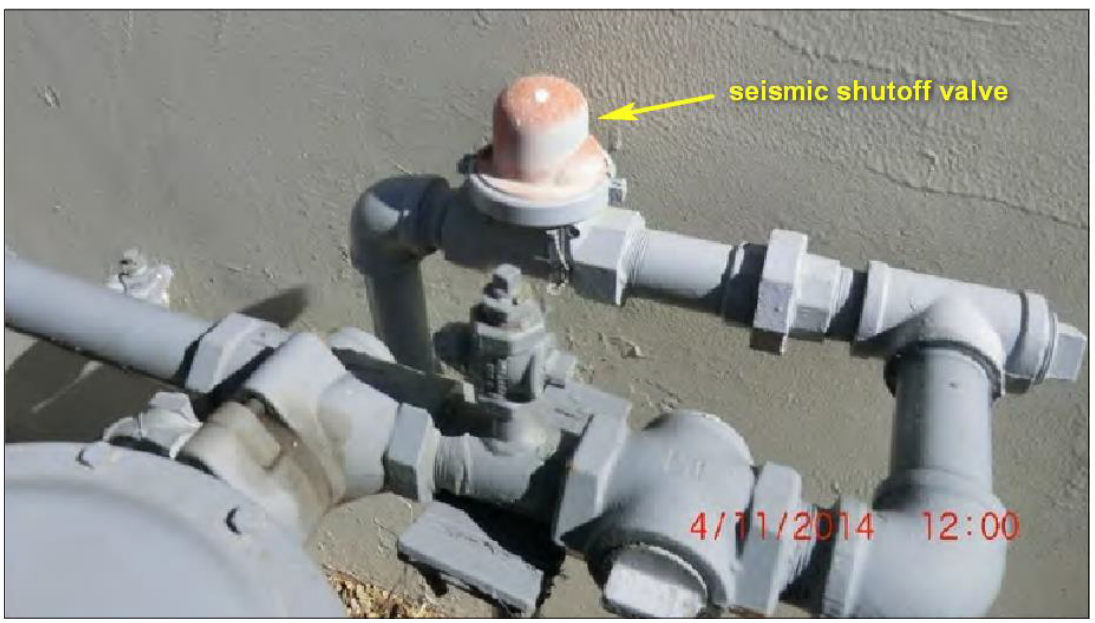

Figure 31. Photograph of an automatic gas shutoff valve installed after the meter on a gas-service line (photograph by Charles Scawthorn).

In regard to electricity, opportunities to reduce fire following earthquake are problematic. Electric power often fails in large earthquakes, owing to automatic system trips, as well as damage to the system. However, the power failure usually takes several seconds, during which power is a source of many ignitions. Certain electric appliances (such as those with heating elements) can still cause fires even after power is cut. Large-scale intentional curtailment of electric power would be problematic, because some communications systems and other essential equipment would not be useable.

Petroleum refineries and related facilities in the San Francisco Bay area are likely to sustain major fires in the HayWired scenario. The degree of earthquake preparedness of these facilities is generally unclear and may need to be reviewed.

\section{Conclusion}

That fire following earthquake is a significant problem in California is confirmed historically, by recent events, and by analysis. The $M_{\mathrm{w}} 7.0$ mainshock of the HayWired earthquake scenario is estimated to result in approximately 668 ignitions, such that in Alameda, Contra Costa, and Santa Clara Counties dozens to hundreds of large fires are likely to merge into numerous conflagrations destroying tens of city blocks, with several of these potentially merging into one or more super conflagrations, destroying hundreds of city blocks. The ultimate burned area is estimated to total 79 million square feet of residential and commercial building floor area, equivalent to more than 52,000 single-family dwellings, with property losses approaching $\$ 30$ billion. This loss is virtually fully insured and would be one of the largest single-loss events in the history of the insurance industry. Other economic impacts include the loss of perhaps $\$ 1$ billion in local tax revenues. A number of opportunities exist for mitigating fire following earthquake, including greatly enhancing the potential postearthquake supply of water for firefighting and the use of automated gas shut-off valves, or seismic shut-off meters, in densely built areas.

\section{References Cited}

Aagaard, B.T., Boatwright, J.L., Jones, J.L., MacDonald, Porter, K.A., Wein, A.M., 2017, HayWired scenario mainshock ground motions, chap. C of Detweiler, S.T., and Wein, A.M., eds., The HayWired earthquake scenario-Earthquake hazards: U.S. Geological Survey Scientific Investigations Report 2017-5013-A-H, 126 p., accessed November 16, 2017, at https://doi.org/10.3133/ sir20175013v1.

Anderson, D., Davidson, R.A., Himoto, K., and Scawthorn, C., 2016, Statistical modeling of fire occurrence using data from the Tohoku, Japan earthquake and tsunami: Risk Analysis, v. 36, no. 2, p. 378-395.

Association of Bay Area Governments, 2010, Taming natural disasters-Multi-jurisdictional local hazard mitigation plan for the San Francisco Bay area (2010 update of 2005 plan): Association of Bay Area Governments Resilience Program web page, accessed April 28, 2015, at http://resilience.abag.ca.gov/ wp-content/documents/ThePlan-Chapters-Intro.pdf.

Bay Area Water Supply and Conservation Agency, [n.d.], Member agency map: Bay Area Water Supply and Conservation Agency web page, accessed February 22, 2018, at http://bawsca.org/ members/map.

Bello, M., Cole, C., Knudsen, K.L., Turner, F., Parker, D., and Bott, J., 2006, San Francisco Bay area fire stationsSeismic risk assessment, in 100th Anniversary Earthquake Conference - Conference on Earthquake Engineering, 8th, San Francisco, Calif., April 18-22, 2006, Proceedings: Oakland, Calif., Earthquake Engineering Research Institute, paper no. 001662, $11 \mathrm{p}$.

California Department of Finance, 2014, E-1 population estimates for cities, counties, and the state-January 1, 2013 and 2014: California Department of Finance web page, accessed April 28, 2015, at http://www.dof.ca.gov/research/demographic/reports/ estimates/e-1/view.php. 
California Department of Transportation, 2014, Seismic retrofit program: California Department of Transportation web page, accessed April 28, 2015, at http://www.dot. ca.gov/hq/paffairs/about/retrofit.htm.

California Department of Water Resources, [n.d.], Water management planning tool: California Department of Water Resources website, accessed February 22, 2018, at https:// gis.water.ca.gov/app/boundaries/.

California Governor's Office of Emergency Services, 2013, California multi-hazard mitigation plan: California Governor's Office of Emergency Services, section 5.4, p. 250, accessed April 28, 2015, at http://www.caloes.ca.gov/ cal-oes-divisions/hazard-mitigation/hazard-mitigationplanning/state-hazard-mitigation-plan/.

California Governor's Office of Emergency Services, 2017, Regions: California Governor's Office of Emergency Services web page, accessed Dec 31, 2017, at http://www. caloes.ca.gov/cal-oes-divisions/fire-rescue/regions.

Datahub, [n.d.], California water district boundaries: Datahub web page, accessed February 22, 2018, at https://old. datahub.io/dataset/california-water-district-boundaries.

Davidson, R.A., 2009a, Generalized linear (mixed) models of post-earthquake ignitions: University of Buffalo, State University of New York, Multidisciplinary Center for Extreme Event Research, no. MCEER-09-0004, 124 p.

Davidson, R., 2009b, Modeling postearthquake fire ignitions using generalized linear (mixed) models: Journal of Infrastructure Systems, v. 15, p. 351-360.

Davidson, R.A., Kendra, J., Li, Sizheng, Long, L.C., McEntire, D.A., Scawthorn, C., and Kelly, J., 2012, San Bruno California, September 9, 2010 gas pipeline explosion and fire: Newark, Del., University of Delaware, Final Project Report no. 56, 201 p., accessed April 28, 2015, at http://udspace.udel.edu/handle/19716/11337.

Detweiler, S.T., and Wein, A.M., eds., 2017, The HayWired earthquake scenario-Earthquake hazards: U.S. Geological Survey Scientific Investigations Report 2017-5013-A-H, 126 p., accessed November 16, 2017, at https://doi. org/10.3133/sir20175013v1.

Ding, A., White, J.F., Ullman, P.W., and Fashokun, A.O., 2008, Evaluation of HAZUS-MH flood model with local data and other program: Natural Hazards Review, v. 9, no. 1, p. $20-28$.

East Bay Hills Fire Operations Review Group, 1992, The East Bay Hills Fire-Multi-agency review of the October 1991 fire in the Oakland/Berkeley Hills: California Office of Emergency Services, 74 p.
East Bay Municipal Utility District, 2011, Annex to 2010 Association of Bay Area Governments local hazard mitigation plan; taming natural disasters - East Bay Municipal Utility District: East Bay Municipal Utility District, 42 p., accessed April 28, 2015, at http://resilience.abag.ca.gov/wp-content/ documents/2010LHMP/EBMUD-Annex-2011.pdf.

East Bay Municipal Utility District, 2017, Water supply: East Bay Municipal Utility District web page, accessed November 16, 2017, at http://www.ebmud.com/water-and-drought/about-yourwater/water-supply/.

Federal Emergency Management Agency, 2003, Hazus multihazard loss estimation methodology, earthquake model, Hazus ${ }^{\circledR}-\mathrm{MH} 2.1$ technical manual: Federal Emergency Management Agency, Mitigation Division, 718 p. [Also available at https:// www.fema.gov/media-librarydata/20130726-1820-25045-6286/hzmh2_1_eq_tm.pdf.]

Hills Emergency Forum, 2005, Fires in the Oakland-Berkeley Hills: Hills Emergency Forum web page, accessed April 28, 2015, at http://www.hillsemergencyforum.org/docs/fire $\% 20$ history $\% 20$ eastbay $\% 20$ hills.pdf.

Hogan, Mark, 2014, The real costs of building housing: The Urbanist web page, accessed April 28, 2015, at http://www.spur. org/publications/article/2014-02-11/real-costs-building-housing.

Kawasumi, H., ed., 1968, General report on the Niigata Earthquake of 1964: Tokyo, Tokyo Electrical Engineering College Press, $648 \mathrm{p}$.

Lee, S., Davidson, R., Ohnishi, N., and Scawthorn, C., 2008, Fire following earthquake- Reviewing the state-of-the-art of modeling: Earthquake Spectra, v. 24, no. 4, p. 933-967.

Lund, L.V., and Schiff, A.J., 1992, TCLEE pipeline failure database: New York, Technical Council on Lifeline Earthquake Engineering, American Society of Civil Engineers.

National Board of Fire Underwriters, 1905, Report of National Board of Fire Underwriters by its Committee of Twenty on the City of San Francisco, Cal.: New York, 64 p.

National Board of Fire Underwriters, 1923 Report on the Berkeley, California conflagration of September 17, 1923: New York, National Board of Fire Underwriters, Committee on Fire Prevention and Engineering Standards, $9 \mathrm{p}$.

National Commission on Fire Prevention and Control, 1973, America burning - The report of the National Commission on Fire Prevention and Control: Washington, D.C., U.S. Government Printing Office, $191 \mathrm{p}$.

Routley, J.G., [n.d.], The East Bay Hills Fire, OaklandBerkeley, California: Federal Emergency Management Agency, U.S. Fire Administration, USFA-TR-060, 130 p., accessed November 16, 2017, at https://www.usfa.fema.gov/ downloads/pdf/publications/tr-060.pdf. 
San Francisco Chronicle, 2014, Huge San Francisco fire destroys six-story building: San Francisco Chronicle SFGATE website, accessed November 14, 2017, at http://www.sfgate. com/bayarea/article/Huge-San-Francisco-fire-destroys-sixstory-5308589.php.

San Jose State University, 2014, San Francisco Bay wind archives: San Jose State University WeatherSpark website, accessed October 21, 2014, at http://www.met.sjsu.edu/cgi-bin/wind/ new_windarchive.cgi?data $=$ obs;year $=2012 ;$ month $=4$; day $=18 ; \mathrm{h}$ our $=16$.

Scawthorn, C., 2000, ed., The Marmara, Turkey earthquake of August 17, 1999: University at Buffalo, State University of New York, Multidisciplinary Center for Earthquake Engineering Research Reconnaissance Report 00-0001, 169 p., accessed accessed April 28, 2015, at https://mceer.buffalo.edu/ pdf/report/00-0001.pdf.

Scawthorn, C., 2011a, Water supply in regard to fire following earthquake: Pacific Earthquake Engineering Research Center PEER Report 2011/08, 173 p., accessed accessed April 28, 2015, at http://peer.berkeley.edu/publications/peer_reports/ reports_2011/webPEER-2011-08-Scawthorn.pdf.

Scawthorn, C., 2011b, Fire following earthquake: Pacific Earthquake Engineering Research Center graphic handout, 4 p., accessed accessed April 28, 2015, at http://peer.berkeley. edu/publications/peer_reports/reports_2011/Fire Following Earthquake-online-view-layout-sm.pdf.

Scawthorn, C., Cowell, A.D., and Borden, F., 1998, Fire-related aspects of the Northridge Earthquake: National Institute of Standards and Technology Grant/Contract Report 98-743, $165 \mathrm{p}$.

Scawthorn, C., Eidinger, J.M., and Schiff, A.J., 2005, Fire following earthquake: Technical Council on Lifeline Earthquake Engineering Monograph no. 26, 345 p.

Scawthorn, C., and Khater M., 1992, Fire following earthquakeConflagration potential in the greater Los Angeles, San Francisco, Seattle and Memphis areas: EQE International, prepared for the Natural Disaster Coalition, Boston.

Scawthorn, C., and O'Rourke, T.D., 1989, Effects of ground failure on water supply and fire following earthquake-The 1906 San Francisco earthquake, in O'Rourke, T.D., and Hamada, M., eds., U.S.-Japan Workshop on Liquefaction, Large Ground Deformation and Their Effects on Lifelines, 2nd, September 26-29, 1989, Proceedings: Buffalo, N.Y., National Center for Earthquake Engineering Research, Technical Report 89-0032, p. 16-35.
Scawthorn, C., O’Rourke, T.D., and Blackburn, F.T., 2006, The 1906 San Francisco earthquake and fire-Enduring lessons for fire protection and water supply: Earthquake Spectra, v. 22, no. S2, p. 135-158.

Scawthorn, C., Yamada, Y., and Iemura, H., 1981, A model for urban post-earthquake fire hazard: Disasters, v. 5, no. 2, p. 125-132.

SPA Risk LLC, 2009, Enhancements in Hazus-MH, Fire following earthquake - Task 3, Updated Ignition Equation: SPA Risk LLC, 74 p.

SPA Risk LLC, 2014, 24 August 2014 South Napa Mw 6 Earthquake Reconnaissance Report: SPA Risk LLC, 63 p., accessed accessed April 28, 2015, at http://www.sparisk.com/ pubs/SPA-2014-Napa-Report.pdf.

U.S. Census Bureau, 2015, TIGER/line shapefiles: U.S. Census Bureau, accessed April 2015, at https://www.census.gov/geo/ maps-data/data/tiger-line.html.

U.S. Department of Transportation, 2015, National Pipeline Mapping System public viewer: National U.S. Department of Transportation website, accessed accessed April 28, 2015, at https://www.npms.phmsa.dot.gov/PublicViewer/.

U.S. Fire Administration, 2008, Residential structure and building fires: U.S. Fire Administration, Federal Emergency Management Agency, $84 \mathrm{p}$.

Van Anne, C., and Scawthorn, C., eds., 1994, The Loma Prieta, California, earthquake of October 17, 1989-Fire police transportation and hazardous materials, chap. C of Mileti, D.S., coord., Societal Response: U.S. Geological Survey Professional Paper 1553, 44 p., accessed April 28, 2015, at https://pubs.usgs. gov/pp/pp1553/.

WeatherSpark, 2014, The typical weather anywhere on Earth: WeatherSpark website, accessed October 21, 2014, at http:// www.weatherspark.com.

Wikipedia, 2017, October 2017 northern California wildfires: Wikipedia web page, accessed November 14, 2017, at https:// en.wikipedia.org/wiki/October_2017_Northern_California_ wildfires.

Witter, R.C., Knudsen, K.L., Sowers, J.M., Wentworth, C.M., Koehler, R.D., and Randolph, C.E., 2006, Maps of Quaternary deposits and liquefaction susceptibility in the central San Francisco Bay region, California, part 3-Description of mapping and liquefaction interpretation: U.S. Geological Survey Open-File Report 2006-1037, ver. 1.1., https://pubs. usgs.gov/of/2006/1037/. 



\title{
Chapter 0
}

\section{How Many Injuries Can Be Avoided in the HayWired Scenario Through Earthquake Early Warning and Drop, Cover, and Hold On?}

\author{
By Keith A. Porter ${ }^{1}$ and Jamie L. Jones ${ }^{2}$
}

\section{Abstract}

One of many potential benefits of earthquake early warning (EEW) is the reduction in injuries because people have more time to perform the self-protective series of actions called "drop, cover, and hold on" (DCHO). We offer an initial estimate of the potential benefit of EEW and DCHO in the HayWired earthquake scenario, both in terms of avoided injuries and the acceptable cost to avoid those injuries from the perspective of the U.S. Government. The HayWired scenario examines a hypothetical earthquake (mainshock) with a moment magnitude $\left(M_{\mathrm{w}}\right)$ of 7.0 occurring on April 18, 2018, at 4:18 p.m. on the Hayward Fault in the east bay part of California's San Francisco Bay area. Using estimates of EEW warning time in the HayWired scenario, new observations of the time required to DCHO, and Hazus-MH (Federal Emergency Management Agency, 2012) estimates of the number of nonfatal injuries in the scenario, we estimate that out of 18,000 estimated nonfatal injuries in the HayWired scenario, as many as 1,500 people who would otherwise be injured could complete the DCHO actions before the arrival of strong motion and avoid injury. The estimated value of these prevented injuries is approximately $\$ 300$ million. This is not the same as the probabilistic benefit of EEW and DCHO, because it is conditioned on the occurrence of a single earthquake among many whose occurrence is uncertain. However, it is a useful index of the potential benefit of EEW. The figures-1,500 avoided injuries and $\$ 300$ million value of statistical injuries avoided - represent upper bounds because we do not know how many people could realistically receive EEW and how effectively DCHO prevents injuries.

\section{Introduction}

The HayWired scenario examines a hypothetical earthquake (mainshock) with a moment magnitude $\left(M_{\mathrm{w}}\right)$ of 7.0 occurring on April 18, 2018, at 4:18 p.m. on the Hayward Fault in the east bay part of California's San Francisco Bay area. The hypothetical earthquake has its epicenter in Oakland, and strong ground shaking from the scenario causes a wide range of severe impacts throughout the greater bay region.

\section{Background}

Earthquake early warning (EEW) can provide several seconds advanced warning before the arrival of earthquake waves that cause strong ground motion. In that time, a person who receives the warning can take self-protective action. As of this writing, the American Red Cross, Earthquake Country Alliance, and others recommend a sequence of actions to protect oneself called "drop, cover, and hold on" (DCHO). To DCHO, a person drops to hands and knees on the floor, covers their head and neck with their arms, and if there is sturdy furniture such as a table nearby under which to take shelter, crawls there and holds on to the table legs to ensure that the cover does not slide away from the person. DCHO is also used as shorthand to cover a variety of additional advice for what to do during earthquake shaking in a variety of situations, such as outdoors, in a vehicle, and in a stadium. The Earthquake Country Alliance advises people to $\mathrm{DCHO}$ as a means to reduce the risk of injury, especially from falling objects (see, for example, https://earthquakecountry.org/step5/).

If DCHO reduces the risk of injury, then using EEW to get to cover sooner, before earthquake shaking arrives and causes items to fall, should further reduce injuries in earthquakes. To our knowledge no one has quantified the efficacy of DCHO; we do not know by how much DCHO reduces earthquake injury risk. We can establish an upper-bound estimate of its efficacy by assuming that DCHO prevents all earthquake injuries associated with falling, building contents, building nonstructural components, and actions such as jumping out of windows or attempting to catch falling objects.

${ }^{1}$ University of Colorado Boulder.

${ }^{2}$ U.S. Geological Survey. 


\section{Objectives}

Our objectives in this study are twofold. First, estimate the benefit of earthquake early warning in terms of the number of human injuries that could be avoided if the HayWired mainshock were to occur after the population of the San Francisco Bay region were all trained and drilled on DCHO and equipped with EEW. Second, estimate the economic value of the avoided injuries. We do not examine other applications of EEW such as stopping trains.

\section{Literature Review}

EEW has been in development since at least 1995, among its many goals is reducing deaths and injuries (see Anderson and others, 1995; Lee and others, 1996; or Gasparini and others, 2007). EEW has been implemented in Japan and is available there as a free app for Android and iOS devices, called Yurekuru Call (Sung, 2011). The U.S. Geological Survey (USGS), along with a coalition of university partners, is developing and testing an EEW system called ShakeAlert for the West Coast of the United States (Burkett and others, 2014).

If EEW can aid people in avoiding injuries, it is possible to assign an economic value to the avoided injuries. Since 1993, the U.S. Government has been required to demonstrate the cost effectiveness of new regulations, including those intended to enhance public safety (Clinton, 1993). To meet this requirement an acceptable cost to avoid statistical deaths and nonfatal injuries had to be established. "Statistical deaths and injuries" means deaths and injuries to unknown persons at some uncertain future date, as opposed to the value of a particular person's life or present or past injuries.

Different agencies of the U.S. Government assign these values differently but produce generally similar values. The U.S. Department of Transportation recently assigned a value of $\$ 9.1$ million per statistical fatality avoided in 2013 U.S. dollars (USD), lesser values for nonfatal injuries, and an inflation factor of 1.18 percent per year for years after 2013 (U.S. Department of Transportation, 2014). The degree of the nonfatal injuries is measured using the Abbreviated Injury Scale (AIS) of the Association for the Advancement of Automotive Medicine (Gennarelli and Wodzin, 2005).

In Natural Hazard Mitigation Saves-An Independent Study to Assess the Future Savings From Mitigation Activities (Multihazard Mitigation Council, 2005), Porter and colleagues employed Hazus-MH's (Federal Emergency Management Agency, 2012) estimates of deaths and injuries to estimate the cost effectiveness of natural-hazard mitigation, producing a value of $\$ 4$ saved for every $\$ 1$ invested by the Federal Emergency Management Agency (FEMA) on natural-hazard mitigation. To produce this value, the Hazus-MH 4-level injury severity scale was related to the 6-level scale of the AIS, using the definitions for each scale (Multihazard Mitigation Council, 2005).
The potential benefits of avoiding earthquake injuries are great. Porter and others (2006) show that the injuries experienced in the $M_{\mathrm{w}} 6.7$ January 17, 1994, Northridge earthquake in southern California had an economic value of \$2-3 billion in 2005 USD - that is, if all of the injuries in the 1994 Northridge earthquake could have been prevented, an expense of $\$ 2-3$ billion by the U.S. Government would have been justifiable. That work drew on Shoaf and others (1998), who offer statistics on the number, severity, and causes of injuries in several earthquakes, including the 1994 Northridge earthquake. They show that 55 percent of injuries in that earthquake were caused by nonstructural damage, 22 percent by the "physical force of the earthquake," 12 percent by behavior such as jumping out a window, 1 percent by "structural objects," and the 10 percent by other causes. These statistics can provide insight into the fraction of injuries that might realistically be prevented or avoided by DCHO. Johnston and others (2014) provide analogous statistics for the $M_{\mathrm{w}}$ 7.1 September 4, 2010, Darfield and $M_{\mathrm{w}} 6.3$ February 22, 2011, Christchurch, New Zealand, earthquakes.

Practicing DCHO is a key component of earthquake drills during annual ShakeOut exercises, which are held around the world. Practicing DCHO is the first item covered at ShakeOut. org (https://www.shakeout.org), which coordinates global ShakeOut registration and provides instructions and other resources. McBride and others (2014) evaluated the 2012 New Zealand ShakeOut and reported on the degree to which participants performed DCHO:

Over 60 percent of people seen by observers actively participated in drop, cover, and hold on. Of those who did not participate, disability and age (too young and too old) were reported to have been factors preventing participation.

McBride and others (2014) also reported that embarrassment played a role in some people not participating. Becker and others (2017) reported higher participation in DCHO in the 2015 New Zealand ShakeOut, with 65 percent of respondents indicating that everyone they saw was performing DCHO and approximately 35 percent of people responding "not everybody" or "no-one." The authors reported a 10-percent drop in people's reluctance to practice DCHO because of disability and suggest that messaging from the New Zealand Ministry of Civil Defence and Emergency Management may have helped in addressing concerns about how to perform DCHO with impaired mobility. It is also possible that experiencing the 2012 New Zealand ShakeOut may have helped people be less embarrassed about performing DCHO during the 2015 ShakeOut.

Lindell and others (2016) offer insight into what people do in actual earthquakes, having surveyed 257 people who experienced the 2011 Christchurch, New Zealand, earthquake and 332 people who experienced the 2011 Tohoku, Japan, earthquake. A considerable part of both groups of respondents reported their initial response to shaking was to freeze in place (38 percent of Christchurch respondents) rather than taking 
self-protective actions such as DCHO (only 17 percent of Christchurch respondents). However, it is noteworthy that as of 2011, New Zealand had not yet participated in a ShakeOut drill (which tends to promote training and practice of DCHO), so it is perhaps to be expected that few people completed DCHO. Lambie and others (2017) used closed-circuit television recordings to observe the reactions of 213 people during the 2011 Christchurch earthquake; none performed DCHO.

\section{Methodology}

The New Zealand and Tohoku experiences suggest that before ShakeOut drills became common, few people actually completed DCHO in an earthquake and that even during ShakeOut drills some people do not attempt to DCHO. An EEW system that recommends DCHO might increase DCHO participation in two ways - (1) by giving warning time so that people can complete DCHO before strong shaking begins (and while they still can do it) and (2) by reminding people what to do as part of the warning message. Suppose that training, EEW messaging, and other preparations were able to encourage action in an earthquake, such that nearly everyone would at least attempt DCHO. What might be the upper bound of benefit from combining DCHO and EEW, in terms of reduced injuries in an actual earthquake?

To estimate the number of avoided injuries, one can estimate the number of people who can complete DCHO actions after they receive an EEW message and before strong ground motion arrives at their location. That estimate requires an estimate of the time it takes people to complete $\mathrm{DCHO}$, which we calculated from a survey of more than 400 people who took online training and then timed themselves performing the actions. The estimate also requires one to estimate the number of people who would have been injured without EEW and DCHO. We estimated those quantities on a geographic basis using Hazus-MH. Finally, the estimate of avoided injuries requires an estimate of what fraction of injuries can be avoided by successfully completing DCHO. Estimating that quantity is problematic. It seems prudent to assume that $\mathrm{DCHO}$ cannot help much in the event of building collapse but that DCHO can prevent some large fraction of nonfatal injuries in the absence of collapse; we make a reasonable guess. Details of the methodology follow.

\section{Estimating Avoided Injuries}

Our goal is to produce an upper-bound estimate of how many fewer people would be nonfatally injured in the HayWired scenario if everyone in the San Francisco Bay region received EEW and had been well trained and drilled on DCHO. We refer to the reduction as the injury-prevention benefit from the combination of EEW and DCHO, or EEW+DCHO. We denote the benefit by $B$. We associate earthquake deaths entirely with structural collapse and assume that
DCHO would prevent few if any of them, so the EEW+DCHO benefit would be considered to accrue only from the reduction in nonfatal injuries from causes other than structural collapse. We estimate $B$ in any particular location $i$ as the product of three quantities:

- $I=$ number of nonfatal injuries under as-is conditions (without EEW),

- $F(t)=$ fraction of occupants who could in principle DCHO after receiving EEW and before arrival of strong motion $t$ seconds later, and

- $f=$ fraction of nonfatal injuries that could be avoided by DCHO.

Then the upper bound of avoided injuries in a particular earthquake can be estimated as:

$$
B=\sum_{i=1}^{N} I_{i} \times F\left(t_{i}\right) \times f,
$$

where $I_{i}$ denotes the number of nonfatal injuries estimated in geographic location $i$ (for example, a census tract or ZIP code) and $F\left(t_{i}\right)$ denotes the fraction of people in location $i$ who could take effective self-protective action within the available warning time $t_{i}$. The multiplicands can be estimated as follows $-I_{i}$ is estimated using Hazus-MH (Federal Emergency Management Agency, 2012), and $t_{i}$ is the warning time at location $i$ (the time between the EEW alert and arrival of $\mathrm{S}$ waves). The warning time calculations during a fault rupture are explained in appendix 2. Equation 2 estimates the warning time at location $i$ :

$$
t_{i}=\frac{R_{i}}{V}-t_{\mathrm{L}},
$$

where $R_{i}$ is hypocentral distance to location $i$ in kilometers, considering the 8-kilometer $(\mathrm{km})$ focal depth of the HayWired mainshock; $V$ is the shear-wave velocity in rock (3.4 kilometers per second, $\mathrm{km} / \mathrm{s}$ ); and $t_{\mathrm{L}}$ is latency time (from earthquake nucleation to transmission of the warning- 5 seconds, s). $F\left(t_{\mathrm{i}}\right)$ can be estimated as the cumulative distribution function of DCHO reaction time from a population survey evaluated at $t_{\mathrm{i}}$, the warning time for location $i$.

The fraction of nonfatal injuries that could be avoided by DCHO, $f$, can be estimated using data compiled from injuries suffered in the Northridge and possibly other earthquakes. Shoaf and others (1998) provide the necessary data- 55 percent of injuries result from nonstructural objects, 22 percent from earthquake force, and 12 percent from behavior. It seems reasonable that effective DCHO could prevent injuries from nonstructural objects such as a bookcase or television, by shielding the person from falling or sliding nonstructural objects. It also seems reasonable that $\mathrm{DCHO}$ could prevent injuries associated with earthquake force by having the person drop to the floor on hands and knees and therefore avoid being thrown by the force of the earthquake. Finally, DCHO is a behavior that substitutes for injurious ones such as jumping out of windows or trying to catch falling objects - two 
examples of behavior-related injuries in the Northridge earthquake. Summing these injuries, it seems DCHO could conceivably prevent $0.55+0.22+0.12=89$ percent of injuries, suggesting $f=0.89$. The remaining 11 percent of injuries in the Northridge earthquake were associated with structural objects ( 1 percent) and other causes (10 percent). Although some furnishings have supported structural objects in past earthquakes (for example, steel desks in a school building), it seems conservative to assume that this is not a general case, so we omit the 1 percent of injuries associated with structural objects from potential benefits of DCHO. Shoaf and others, (1998) provide no additional detail regarding the remaining 10 percent of injuries associated with other causes; we assume that DCHO would not prevent these either. We are aware of no research on the effectiveness of DCHO, so $f=0.89$ should be thought of as an upper bound on the number of nonfatal injuries that would in practice be avoided by DCHO. The figure $f=0.89$ with its two significant figures may give a false impression of precision. It is probably only meaningful to one significant figure, such as, $f=0.9$, but common engineering practice calls for carrying an extra significant figure to reduce cumulative rounding errors.

Note that Johnston and others (2014) categorize causes of injuries differently from Shoaf and others (1998) and lump together injuries that occurred during an earthquake and in its aftermath, such as helping others or injuries caused by glass. As a result, it is problematic to estimate $f$ using Johnston and others (2014) data. Depending on what one includes and excludes, one can estimate $f$ from these data to be between 69 percent and 99 percent. The range overlaps and therefore does not contradict the value derived using Shoaf and others, (1998).

\section{Estimating the Acceptable Cost to Avoid Injuries}

One can calculate the acceptable cost to avoid statistical injuries, $B_{2}$, as suggested in Multihazard Mitigation Council (2005) as follows:

$$
B_{2}=\sum_{j=1}^{3} B_{i} \times V_{j}
$$

where $B_{j}$ denotes the number of avoided injuries of severity $j$ and $V_{j}$ denotes the U.S. Government's acceptable cost to avoid a statistical injury of severity $j$. We take values of statistical injuries avoided from U.S. Department of Transportation (2014), inflate them to 2015 USD as instructed there, and map them to Hazus-MH injury severity levels using Multihazard Mitigation Council's (2005) table F-5 mapping 2. Table 1 presents those figures, rounded to two significant figures to avoid the appearance of excessive precision.

\section{Survey Design}

The University of Colorado Boulder developed a datacollection protocol to collect statistics about DCHO reaction time through a web-based survey instrument copied to
Table 1. Acceptable cost to avoid a statistical injury, calculated using Multihazard Mitigation Council (2005).

\begin{tabular}{|c|c|}
\hline Hazus injury severity ${ }^{1}$ & $\begin{array}{c}\text { Acceptable cost per avoided injury, in } \\
2015 \text { U.S. Dollars }{ }^{2}\end{array}$ \\
\hline $\begin{array}{l}\text { 1. Basic medical aid by } \\
\text { paraprofessionals }\end{array}$ & 28,000 \\
\hline $\begin{array}{l}\text { 2. More than } 1 \text { but not life } \\
\text { threatening }\end{array}$ & 660,000 \\
\hline $\begin{array}{l}\text { 3. Life threatening but not } \\
\text { immediately fatal }\end{array}$ & $3,700,000$ \\
\hline 4. Fatal & $9,400,000$ \\
\hline
\end{tabular}

appendix 1. The protocol was approved by the university's Institutional Review Board (IRB) on November 17, 2015. The survey instrument has six parts:

1. An introduction that explains the purpose of the survey, its procedures, risks, benefits, confidentiality, and consent to participate.

2. Training materials, text and brief YouTube videos, on how to DCHO.

3. Instructions on where and how to time oneself performing DCHO.

4. A question to determine the setting where the volunteer performed the exercise, in terms of Hazus-MH occupancy classification.

5. A series of questions to examine how well the training material worked.

6. Demographic questions.

In an initial trial study, volunteers were recruited through Twitter feeds and social media accounts. The initial study yielded only 65 responses, so the earlier sample was ignored and more than 500 participants were recruited through Qualtrics Panels, a paid service provided to the University of Colorado Boulder. Subsequent findings refer only to responses from Qualtrics Panels.

\section{Findings}

Because physical dexterity and proximity to protective furniture differs from person to person and by time of day, one should expect that people will take different amounts of time to complete DCHO. Survey results bear out that expectation.

\section{Distribution of DCHO Reaction Time}

Data on DCHO reaction times were collected using the web-based survey instrument shown in appendix 1 between December 18 and 23, 2015. As of this writing, we collected 
data from a large sample -525 people completed the survey out of 638 to whom the survey was sent, a response rate of 82 percent. We refer to these data as round-1 surveyed reaction times, in case future surveys are performed. Many of the data appear to reflect an incorrect understanding of when to stop counting or data-entry typographic errors-38 respondents reported times in excess of $20 \mathrm{~s}$, some as long as $200 \mathrm{~s}$. Omitting these 38 responses, the remaining 487 responses are shown in figure 1 along with a lognormal distribution fit to the data.

The nontechnical reader can interpret figure 1 as follows. The dashed, stairstep line represents the survey respondents' reaction time. For example, 10 percent of them were able to DCHO in $5 \mathrm{~s}$ or less (see how the dashed line passes through $x=5 \mathrm{~s}, y=0.10), 50$ percent in $9 \mathrm{~s}$ or less $(x=9 \mathrm{~s}, y=0.50)$, and 90 percent in $15 \mathrm{~s}$ or less $(x=15 \mathrm{~s}, y=0.90)$. The smooth S-shaped curve is a parametric distribution called the lognormal cumulative distribution function. It approximates the stairstep line with a more convenient mathematical equation. It is closely related to the familiar bell-shaped curve called the normal or Gaussian distribution. The lognormal cumulative distribution function has two variables that determine its shape. One of the variables, called the median, adjusts the $x$-value associated with the midpoint of the curve (the $x$-value associated with $y=0.50$ ). The other variable, called the standard deviation of the natural logarithm of the variable (or logarithmic standard deviation), adjusts the width of the S-shaped curve.

The reader should understand that lognormal may be the parametric probability distribution more commonly used than any other in earthquake engineering. Engineers use it for any of several reasons:

1. It often reasonably agrees with observations of realworld variables, as it does here.

2. Like many real-world variables, it can only take on a positive value and has a specifiable median and logarithmic standard deviation.

3. It assumes the least knowledge about the variable in question, conditioned on the value of the median and logarithmic standard deviation.

4. Tradition - engineers have used the lognormal at least since the 1980s to characterize earthquake damage to building components.

With the survey we can estimate that reaction time is approximately lognormally distributed with median $8.8 \mathrm{~s}$ and standard deviation of the natural logarithm equal to 0.40 , as shown in figure 1 . The lognormal appears to be a reasonable approximation of the sample data provided by the study participants according to a Lilliefors (1967) goodness-of-fit test.

Respondents were aged between 18 and 95, with a mean age of 35 . The majority of respondents ( 57 percent) were female, versus 50.8 percent in the general U.S. population in 2014 (U.S. Census, 2015). Most (69 percent) described their race or ethnicity as white/Caucasian (73.6 percent of the

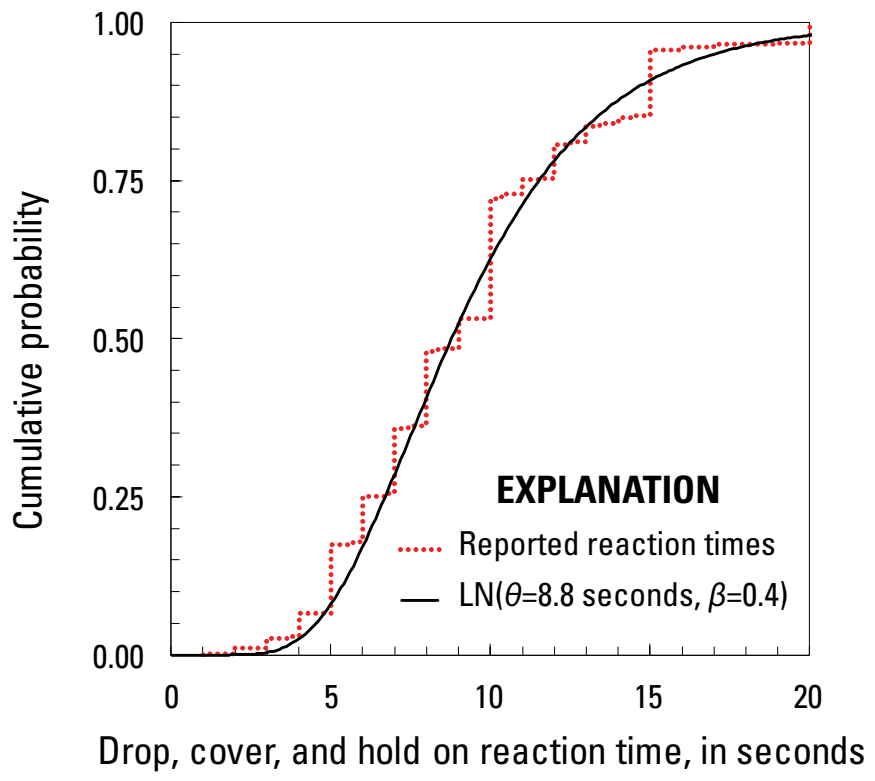

Figure 1. Graph of cumulative probability for "drop, cover, and hold on" ( $\mathrm{DCHO})$ reaction times. DCHO reaction times were collected from volunteers using the web-based survey instrument shown in appendix 1 . Red dotted line shows the distribution of reported reaction times for 487 respondents (38 respondents who reported DCHO times in excess of 20 seconds were omitted). Black curved line shows the lognormal distribution-LN, lognormal; $\theta$, median, $\beta$, standard deviation.

U.S. population), 13 percent described their race or ethnicity as African American (14 percent of the U.S. population), 10 percent described their race or ethnicity as Hispanic (17 percent of the U.S. population), 8 percent described their race or ethnicity as Asian (6 percent of the U.S. population), 3 percent described their race or ethnicity as Native American (2 percent of the U.S. population), 1 percent described their race or ethnicity as Pacific Islander (same as the U.S. population), and 4 percent described their race or ethnicity as other (respondents were allowed to select all that applied). The majority (56 percent) have at most some college education (U.S. population is 61 percent), 33 percent have a 2- or 4-year college degree (U.S. population is 28 percent), and 11 percent had a masters, professional, or doctoral degree (U.S. population is 10 percent) (U.S. population education attainment percentages from U.S. Census Bureau, 2015a). Respondents were slightly poorer than the U.S. population in general -53 percent report a combined household income less than $\$ 40,000$ per year (U.S. median household income is $\$ 53,657$ ) and 91 percent report a combined household income less than $\$ 110,000$ per year (90th percentile among the U.S. population is $\$ 155,000$ ) (U.S. general population household income data from U.S. Census Bureau, 2015b). 


\section{Calculation of Benefits}

We now apply the foregoing procedures to evaluate the benefits of the combination of EEW and DCHO in the HayWired scenario mainshock. Warning time $t_{i}$ of equation 2 is shown for the mainshock in figure 2. See appendix 2 of this chapter for the derivation of figure 2 .

We can now apply equations 1 and 3 . We compiled $I_{i}$ by census tract from the Hazus-MH (Federal Emergency Management Agency, 2012) analysis of the HayWired mainshock. We calculated $R_{i}$ at each census tract centroid, took $V=3.4 \mathrm{~km} / \mathrm{s}$ and $t_{L}$ as $5 \mathrm{~s}$, (as discussed in appendix 2), and idealized $F(t)$ as lognormally distributed with median reaction time equal to $8.8 \mathrm{~s}$ and logarithmic standard deviation equal to 0.40 , so that equation 4 now follows:

$$
F(t)=\Phi\left(\frac{\ln (t / 8.8 \mathrm{sec})}{0.40}\right) .
$$

The total number of nonfatal injuries from the HayWired scenario mainshock is estimated to be $18,130^{3}$; EEW could avoid as many as 1,468 of these, or 8 percent (table 2). Dollar values in table 2 are rounded to two significant figures. The data in table 2 suggests that if EEW were fully implemented and everyone in the San Francisco Bay region had been trained and drilled on DCHO before the HayWired mainshock occurred, as many as $\sim 1,500$ people who would otherwise be injured would have time to complete DCHO before the arrival of strong motion and avoid nonfatal injury. (Table 2 shows a calculated figure of 1,468 avoided injuries, but we use "about 1,500 " to avoid the appearance of excessive accuracy.) The acceptable cost to avoid those injuries is about $\$ 300$ million. Recall that the results in table 2 assume that completing DCHO effectively avoids 89 percent of injuries, which was acknowledged as an upper bound. The actual benefit would be lower in proportion to the ratio of actual nonfatal injuries avoided to the upper bound. Note also that some of the injuries shown in the first column would also be avoided by DCHO without EEW, because the Hazus injury model predates widespread training in DCHO. Perhaps DCHO would be less effective in the absence of EEW because people would be trying to take action during strong motion and would be injured before successfully completing the DCHO actions. We do not speculate on injuries avoided by DCHO without EEW.

EEW provides more advanced warning the farther the recipient is from the earthquake focus (fig. $3 A$ ), but injuries tend to be concentrated close to the focus. It is in the middle ground (where EEW provides at least some warning time but shaking is still strong enough to threaten life safety) that EEW combined with "drop, cover, and hold on" actions has the greatest potential to reduce injuries, as shown in figure $3 B$.

\section{Conclusions}

We do not know how effective DCHO is in preventing earthquake injuries, nor do we know how much time decisionmaking adds to DCHO reaction time. However, to begin to estimate the benefit of EEW and DCHO, we assume that training and drilling can reduce decision time to near zero relative to reaction time. We further neglect the benefit of DCHO without EEW and assume that DCHO before the arrival of strong motion can prevent almost all $(f=89$ percent) of nonfatal earthquake injuries. With all of these simplifying assumptions, we can estimate an upper bound to the benefit of the combination of EEW and DCHO. If everyone in the San Francisco Bay region were trained and drilled in DCHO and received EEW before the arrival of the HayWired scenario mainshock, the additional warning time provided by EEW would be sufficient for about 1,500 of 18,000 people who would otherwise be injured to take DCHO actions that successfully prevent their

Table 2. Upper-bound number and value of avoided injuries from earthquake early warning combined with "drop, cover, and hold on" actions in the San Francisco Bay region, California, in the hypothetical moment-magnitude-7.0 mainshock of the HayWired earthquake scenario.

\begin{tabular}{lcccc}
\hline \multicolumn{1}{c}{ Hazus injury severity } & Number of people injured & $\begin{array}{c}\text { Maximum number of } \\
\text { avoided injuries }\end{array}$ & $\begin{array}{c}\text { Acceptable cost per } \\
\text { avoided injury, in } \\
\text { 2015 U.S. Dollars }\end{array}$ & $\begin{array}{c}\text { Acceptable cost to avoid, } \\
\text { in millions of 2015 U.S. } \\
\text { Dollars }\end{array}$ \\
\hline $\begin{array}{l}\text { 1. Basic medical aid by } \\
\text { paraprofessionals }\end{array}$ & 14,081 & 1,216 & 28,000 & 34 \\
$\begin{array}{l}\text { 2. More than 1 but not life } \\
\text { threatening }\end{array}$ & 3,491 & 218 & 660,000 & 144 \\
$\begin{array}{l}\text { 3. Life threatening but not } \\
\text { immediately fatal }\end{array}$ & 558 & 34 & $3,700,000$ & 127 \\
$\begin{array}{l}\text { 4. Fatal } \\
\text { Total }\end{array}$ & 971 & 0 & $9,400,000$ & 0 \\
\hline
\end{tabular}

${ }^{1}$ Federal Emergency Management Agency (2012).

${ }^{2}$ U.S. Department of Transportation (2014).

${ }^{3}$ The Hazus-MH analysis estimated damages for shaking from the HayWired mainshock, as well as liquefaction, and these numbers were combined. The number differs from the 16,000 injuries reported in Seligson and others (this volume) for the mainshock in the context of the HayWired earthquake sequence, because only the shaking hazard data was consistently available across all earthquakes in the sequence. 


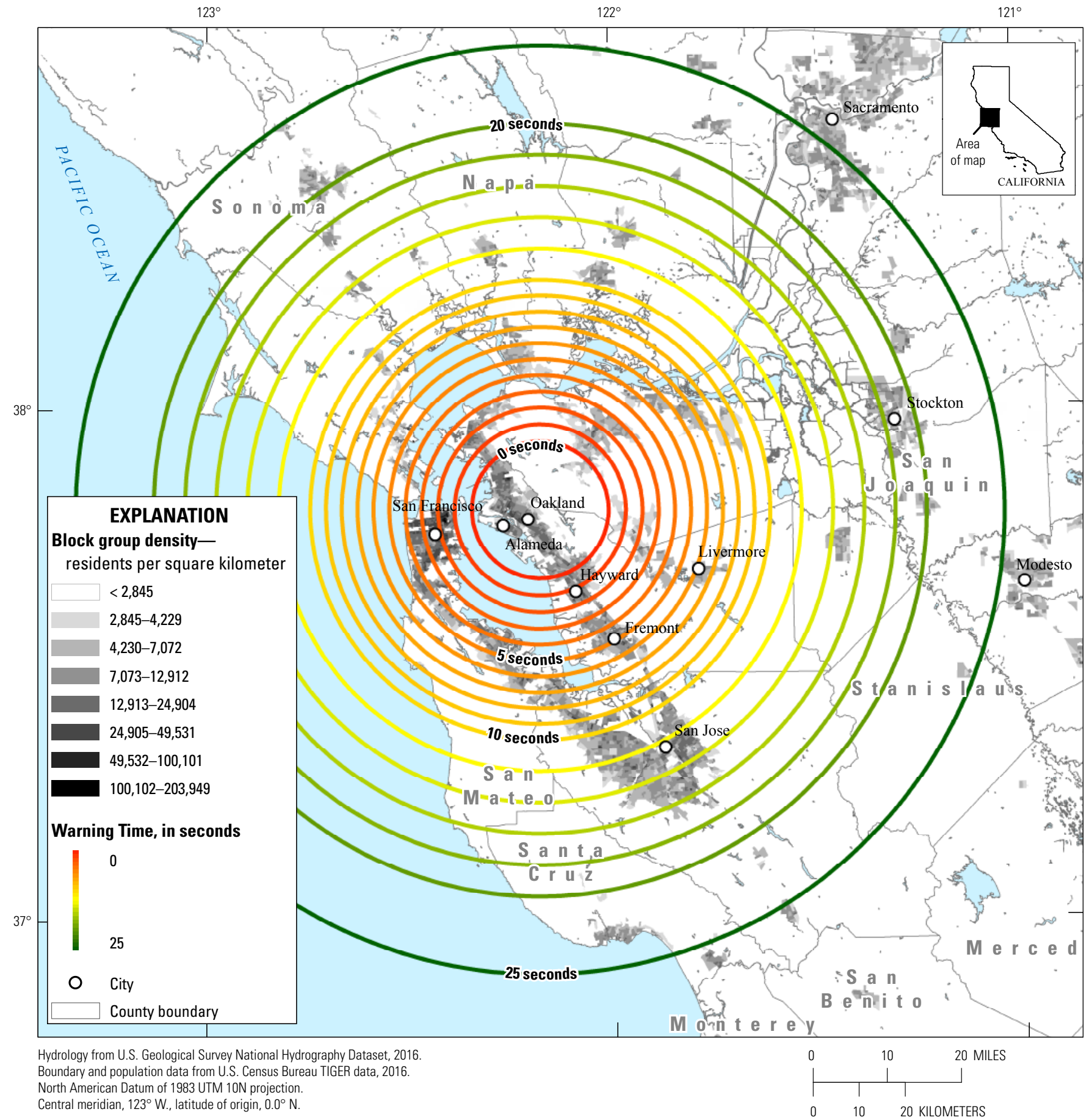

Figure 2. Map of the San Francisco Bay region, California, with contours of warning time ( $t_{i}$; see equation 2$)$ for the hypothetical moment-magnitude-7.0 mainshock of the HayWired earthquake scenario and block group density (residents per square kilometer). 


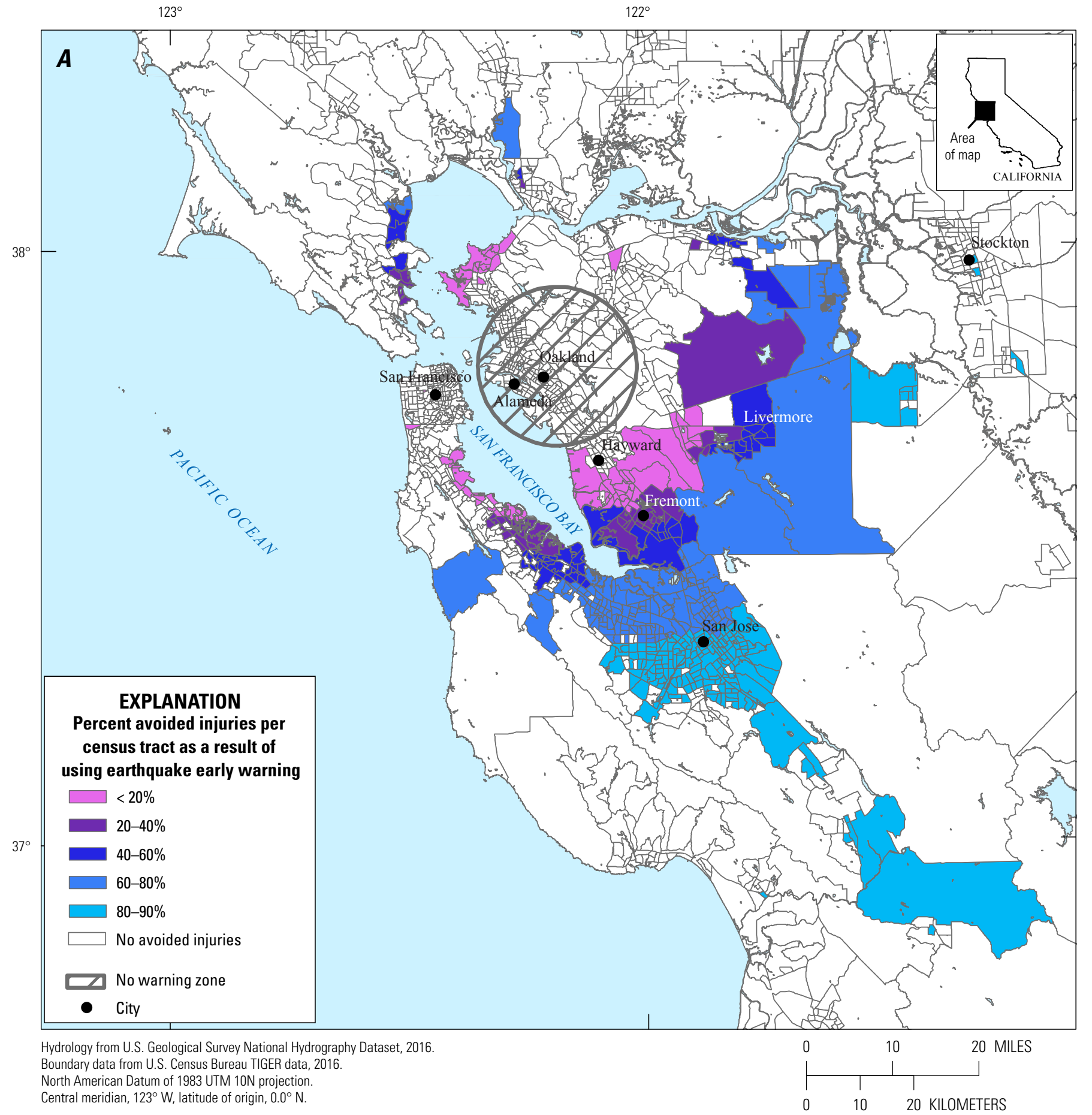

Figure 3. Maps of San Francisco Bay region, California, showing injuries potentially avoided because of earthquake early warning combined with "drop, cover, and hold on" actions in the hypothetical moment-magnitude-7.0 mainshock of the HayWired earthquake scenario. $A$, Fraction of injuries potentially avoided as a result of using earthquake early warning; $B$, upper bound number of injuries avoided by census tract as a result of using earthquake early warning. \%, percent. 


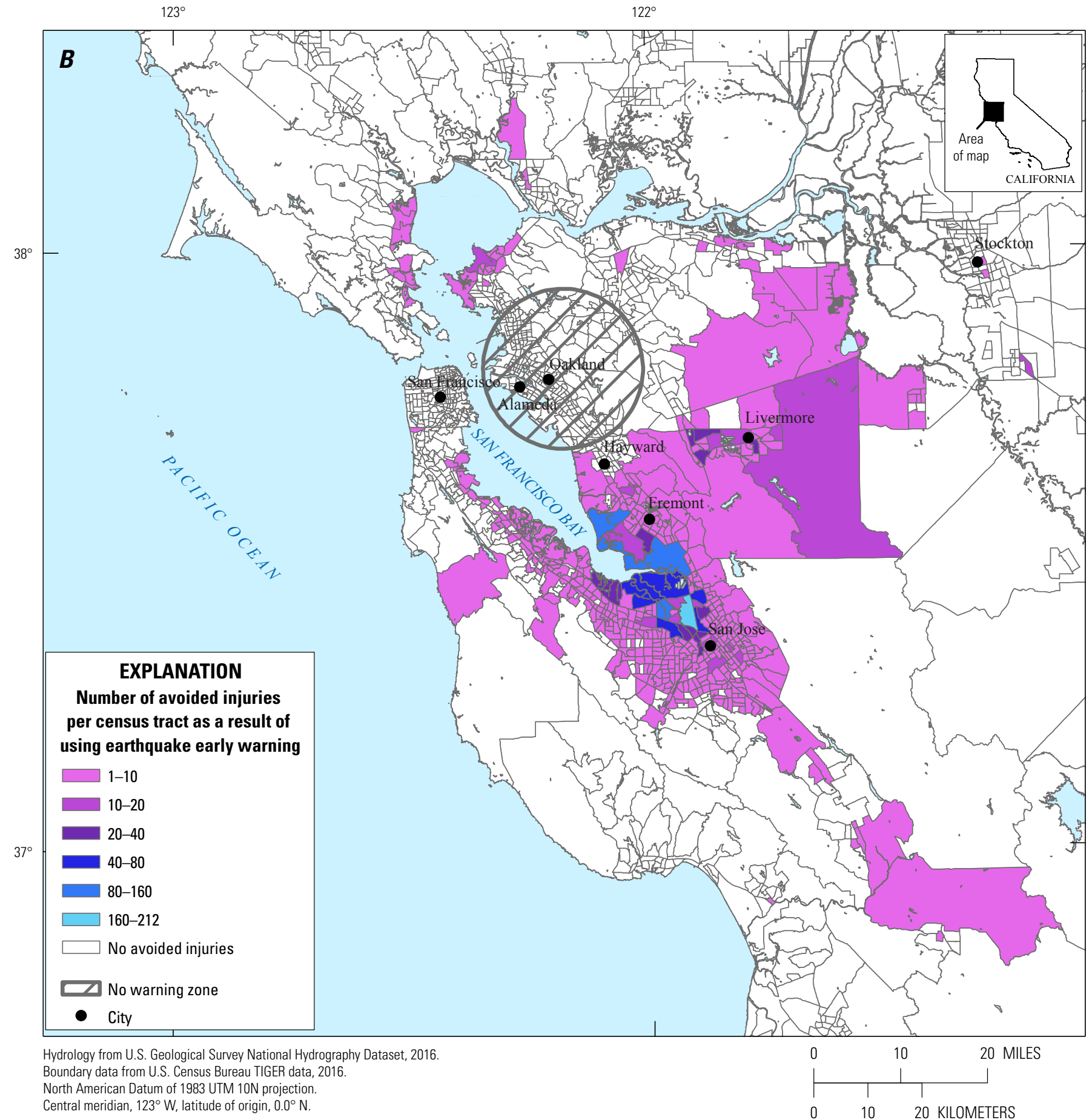

Figure 3.-Continued 
injury before the arrival of strong motion. The U.S. Government would value mitigation measures to avoid that number of nonfatal injuries at approximately $\$ 300$ million (2015 USD).

\section{Limitations and Research Needs}

The intent of this report is not to say that the probabilistic benefit of EEW and DCHO is $\$ 300$ million, for several reasons. That figure is an upper bound, not an expected value, and it is conditioned on the occurrence of a single earthquake, when in fact the future date of such an earthquake is uncertain, and there are many other possible earthquakes where EEW and DCHO would contribute to probabilistic benefit. However, the figures of 1,500 injuries and $\$ 300$ million are useful to understand the potential magnitude of the benefits of EEW and DCHO.

There does not appear to be any published research or other evidence on the effectiveness of DCHO to prevent injuries. For example, we do not know how many injuries related to nonstructural objects, earthquake force, or human behavior would actually be avoided by DCHO.

Other important, unanswered questions include the following - What fraction of fatal injuries could be avoided by DCHO? How much would reaction times differ in the real event as opposed to the calm setting of the survey? What fraction of injuries can be avoided without EEW, that is, if people DCHO when they begin to feel strong motion? How long after the initiation of strong motion do injuries occur? (Presumably the answer to this last question depends on the severity of motion.)

One can imagine laboratory experiments using human simulacra (crash-test dummies), finite-element analysis, and other means to explore these questions, but such experiments do not appear to have been carried out. According to a National Science Foundation (NSF) program officer, NSF does not appear to have a program to address earthquake-induced injuries (David Mendonca, NSF, written commun., December 8,2015 ), nor can we find record of a relevant program within the National Institutes of Health.

\section{References Cited}

Anderson, S., Kobara, S., Mathis, B., Rosing, D., and Shafrir, E., 1995, SYNERGIES - A vision of information products working together, in Miller, J., ed., Conference companion on human factors in computing systems: New York, Association for Computing Machinery, p. 423-424.
Becker, J.S., Coomer, M., Potter, S.H., McBride, S.K., Lambie, E., Johnston, D.M., Cheesman, B., Guard, J., and Walker, A., 2016, Evaluating New Zealand's ShakeOut national earthquake drills - A comparative analysis of the 2012 and 2015 events: Proceedings, 2016 New Zealand Society for Earthquake Engineering (NZSEE) Conference, Christchurch NZ, April 1-3, 2016.

Burkett, E.R., Given, D.G., and Jones, L.M., 2014, ShakeAlert-An earthquake early warning system for the United States West Coast: U.S. Geological Survey Fact Sheet 2014-3083, 4 p., accessed December 20, 2015, at https://doi.org/10.3133/fs20143083.

Clinton, W.J., 1993, Executive Order 12866 of September 30, 1993-Regulatory Planning and Review: Washington, D.C., Federal Register, v. 58, no. 190, accessed December 20, 2015, at http://www.archives.gov/federal_register/executive_orders/pdf/12866.pdf.

Federal Emergency Management Agency, 2012, Hazus multihazard loss estimation methodology, earthquake model, Hazus ${ }^{\circledR}-\mathrm{MH} 2.1$ technical manual: Federal Emergency Management Agency, Mitigation Division, accessed July 18, 2017, 718 p., at https://www.fema.gov/media-librarydata/20130726-1820-25045-6286/hzmh2_1_eq_tm.pdf.

Gennarelli, T.A., and Wodzin, E., eds., 2005, Abbreviated injury scale (AIS) 2005: Barrington, Ill., Association for the Advancement of Automotive Medicine, $68 \mathrm{p}$.

Gasparini, P., Manfredi, G., and Zschau, J., 2007, Earthquake early warning systems: Berlin, Springer, $350 \mathrm{p}$.

Johnston, D., Standring, S., Ronan, K., Lindell, M., Wilson, T., Cousins, J., Aldridge, E., Ardagh, M.W., Deely, J.M., Jensen, S., Kirsch, T., and Bissell, R., 2014, The 2010/2011 Canterbury earthquakes - Context and cause of injury: Natural Hazards, v. 73, no. 2, p. 627-637, accessed December 20, 2015, at https://doi.org/10.1007/s11069-014-1094-7.

Lee, W.H.K., Shin, T.C., and Teng, T.L., 1996, Design and implementation of earthquake early warning systems in Taiwan: 11th World Conference on Earthquake Engineering, Acapulco, Mexico, paper no. 2133, accessed December 20, 2015, at http://www.iitk.ac.in/nicee/wcee/article/11_2133. PDF.

Lilliefors, H.W., 1967, On the Kolmogorov-Smirnov test for normality with mean and variance unknown: Journal of the American Statistical Association, v. 62, no. 318, p. 399402, accessed December 20, 2015, at https://doi.org/10.108 0/01621459.1967.10482916. 
Lindell, M.K., Prater, C.S., Wu, H.C., Huang, S.-K., Johnston, D.M., Becker, J.S., and Shiroshita, H., 2016, Immediate behavioural responses to earthquakes in Christchurch, New Zealand, and Hitachi, Japan: Disasters, v. 40, no. 1, p. $85-111$.

McBride, S.K., Becker, J.M., Coomer, M.A., Tipler, K., and Johnston, D.M., 2014, New Zealand ShakeOut observation evaluation report-A summary of initial findings: GNS Science Report 2013/61, Institute of Geological and Nuclear Sciences Ltd, Lower Hutt, New Zealand, 39 p.

Multihazard Mitigation Council, 2005, Natural hazard mitigation saves - An independent study to assess the future savings from mitigation activities - vol. 1 and 2: Washington, D.C., National Institute of Building Sciences, 161 p., accessed December 20, 2015, at http://www.nibs. org $/$ ?page $=$ mmc_projects\#nhms.

Porter, K.A., Shoaf, K., and Seligson, H., 2006, Value of injuries in the Northridge earthquake: Earthquake Spectra, v. 22 , no. 2 , p. 555-563.

Shoaf, K.I., Sareen, H.R., Nguyen, L.H., and Bourque, L.B., 1998, Injuries as a result of California earthquakes in the past decade: Disasters, v. 22, no. 3, p. 218-235.
Sung, S.J., 2011, How can we use mobile apps for disaster communications in Taiwan-Problems and possible practice: 8th International Telecommunications Society (ITS) AsiaPacific Regional Conference, Taiwan, 26-28 June, 2011, accessed December 20, 2015, at https://www.econstor.eu/bits tream/10419/52323/1/67297973X.pdf.

U.S. Census Bureau, 2015a, Educational attainment in the United States-2014: U.S. Census Bureau web page, accessed January 4, 2016, at https://www.census.gov/data/ tables/2014/demo/educational-attainment/cps-detailed-tables. html.

U.S. Census Bureau, 2015b, Current population survey (CPS): U.S. Census Bureau web page, accessed January 4, 2016, at http://www.census.gov/hhes/www/cpstables/032015/hhinc/ hinc01 000.htm.

U.S. Census, 2015, QuickFacts-United States: U.S. Census Quick Facts website, accessed December 20, 2015, at https:// www.census.gov/quickfacts/.

U.S. Department of Transportation, 2014, Guidance on treatment of the economic value of a statistical life (VSL), in U.S. Department of Transportation Analyses-2014 adjustment: Washington, D.C., U.S. Department of Transportation, accessed November 30, 2015, at https://www.transportation. gov/sites/dot.gov/files/docs/VSL_Guidance_2014.pdf. 


\section{Appendix 1. Survey of DCHO Reaction Times}

The following survey instrument was successfully administered by the University of Colorado Boulder to study participants using the Qualtrics Panels service in December, 2015. The protocol was approved by the university's Institutional Review Board on November 17, 2015.

\section{University of Colorado} Boulder

How long does it take to drop, cover, and hold on?

Thanks for following the link to this project entitled Assessing Earthquake Early Warning (EEW) Self-Protection Reaction Time.

As a stakeholder in earthquake readiness, please participate in a study that will improve our understanding of personal protective actions for earthquake shaking and the potential value of warning messages about imminent earthquake shaking. By participating you may also improve your ability to protect yourself during earthquakes.

In this research, you will determine your reaction time to drop, cover, and hold on (DCHO). Participation will take approximately 10 minutes.

Procedures: You will be asked to 1) read brief written instructions and watch two short videos about how to drop, cover, and hold on; 2) time yourself performing the drop-cover-and-hold-on actions; 3 ) complete a questionnaire telling us how long it took to drop, cover, and hold on, where you started from, and assessing the effectiveness of the training. At your own option, you may bring a friend to time and videorecord you performing the drop-cover-and-hold-on exercise, and share the video with the researchers.

Risk: Participation in this study involves no risk to you.

Benefits: This information will help you to better understand how to drop, cover, and hold on, and it will help researchers understanding how much time people need to take appropriate self-protection action when alerted by earthquake early warning. 
Voluntary participation: Participation in this study is voluntary. There is no penalty if you choose not to participate.

Confidentiality: Your identity will be kept confidential and will not appear in any report. If you choose to provide an optional video recording, you will upload it to YouTube and only share the link with us. You will set the privacy. We recommend you set the privacy to "unlisted" so that only people who have the link can find and view the video. (If you leave the privacy set to "public," other people can view your video.) We will not download or store your YouTube video, nor will we present it to anyone. We will only view videos to spot check the efficacy of the training and your reaction time. You may delete your video from YouTube any time.

Questions: If you have any questions concerning participation in this study, now or in the future, contact Prof. Keith Porter, University of Colorado Boulder at keith.porter@colorado.edu. If you have questions about your rights as a research study participant, you can call the Institutional Review Board (IRB). The IRB is independent from the research team. You can contact the IRB if you have concerns or complaints that you do not want to talk to the study team about. The IRB phone number is (303) 735-3702, or email irbadmin@colorado.edu.

No participation by vulnerable populations: Members of the following vulnerable populations may not participate: children under 18 years old, people outside the United States, non-English speaking individuals, prisoners, pregnant women, and cognitively impaired or educationally disadvantaged individuals.

Consent to participate: I have read all of the above information about this research project and all my questions have been answered. By clicking "Agree to participate" I confirm that I am not a member of a vulnerable population and I consent to take part in the study.

I agree to participate. (The button will guide you through the study.)

I decline to participate. 
Thanks for agreeing to participate in this study of the time it takes to drop, cover, and hold on. Please read this training material, then watch the videos below.

\section{Drop, Cover, and Hold On when the earth shakes.}

[Image used in original survey instrument not shown]

Taking the proper actions, such as "Drop, Cover, and Hold On", can save lives and reduce the risk of injury. Everyone, everywhere, should learn and practice what to do during an earthquake, whether you're at home, work, school or traveling.

In MOST situations, you will reduce your chance of injury if you:

- DROP down onto your hands and knees (before the earthquakes knocks you down). This position protects you from falling but allows you to still move if necessary.

- COVER your head and neck (and your entire body if possible) under a sturdy table or desk. If there is no shelter nearby, only then should you get down near an interior wall (or next to low-lying furniture that won't fall on you), and cover your head and neck with your arms and hands.

- HOLD ON to your shelter (or to your head and neck) until the shaking stops. Be prepared to move with your shelter if the shaking shifts it around.

Official rescue teams, emergency preparedness experts, and others recommend "Drop, Cover, and Hold On" as the best way, in most situations, to protect yourself during earthquake shaking.

In general, it is important to think about what you will do to protect yourself wherever you are if an earthquake were to occur. What if you are driving, in a theater, in bed, at the beach, etc.? Read below for suggestions for these and other situations. 


\section{During earthquakes...}

The area near the exterior walls of a building is the most dangerous place to be. Windows, facades and architectural details are often the first parts of the building to collapse. To stay away from this danger zone, stay inside if you are inside and outside if you are outside.

Indoors: Drop, cover, and hold on. Drop to the floor, take cover under a sturdy desk or table, and hold on to it firmly. Be prepared to move with it until the shaking stops. If you are not near a desk or table, drop to the floor against the interior wall and protect your head and neck with your arms. Avoid exterior walls, windows, hanging objects, mirrors, tall furniture, large appliances, and kitchen cabinets with heavy objects or glass. Do not go outside!

[Image used in original survey instrument not shown]

In bed: If you are in bed, hold on and stay there, protecting your head with a pillow. You are less likely to be injured staying where you are. Broken glass on the floor has caused injury to those who have rolled to the floor or tried to get to doorways.

In a high-rise: Drop, cover, and hold on. Avoid windows and other hazards. Do not use elevators. Do not be surprised if sprinkler systems or fire alarms activate. 
Outdoors: Move to a clear area if you can safely do so; avoid power lines, trees, signs, buildings, vehicles, and other hazards.

Driving: Pull over to the side of the road, stop, and set the parking brake. Avoid overpasses, bridges, power lines, signs and other hazards. Stay inside the vehicle until the shaking is over. If a power line falls on the car, stay inside until a trained person removes the wire.

In a stadium or theater: Stay at your seat and protect your head and neck with your arms. Don't try to leave until the shaking is over. Then walk out slowly watching for anything that could fall in the aftershocks.

Near the shore: Drop, cover, and hold on until the shaking stops. Estimate how long the shaking lasts. If severe shaking lasts 20 seconds or more, immediately evacuate to high ground as a tsunami might have been generated by the earthquake. Move inland 3 kilometers (2 miles) or to land that is at least 30 meters (100 feet) above sea level immediately. Don't wait for officials to issue a warning. Walk quickly, rather than drive, to avoid traffic, debris and other hazards.

Below a dam: Dams can fail during a major earthquake. Catastrophic failure is unlikely, but if you live downstream from a dam, you should know flood-zone information and have prepared an evacuation plan.

Now, please watch these two videos, and then click "Next." Each video will open a new browser window or tab. When done, navigate back to this one.

\section{If you are near a study desk or table}

\section{If there is no sturdy desk or table.}


For the next step, either do it yourself or optionally bring a friend with a smartphone or a videocamera. Either way, bring a digital watch or a watch with a second hand to a place where you would commonly be on a weekday afternoon at 2 PM. Don't go any place where it will be dangerous or illegal to drop, cover, and hold on, either for you to do or for your friend to time and record you.

If you brought a friend, have the friend start a videorecording, hold the watch, and tell you "Ready set go."

The time starts when your friend says go, or if you didn't bring a friend, when you start to drop.

If you do not get under shelter, the time stops when you have covered your head and neck. If you did get under cover, the time stops when you have held on to the shelter.

How long did it take, from start to stop, in seconds? Please enter a number only. For example, if it took 10 seconds, enter the numbers 10 or 10.0 .

Which of the following best describes the setting where you timed yourself. Please mark only one answer.

\section{Residence}

Single family dwelling

Mobile home

Apartment or condominium

Hotel or motel

Group housing (military or college) or jail

Nursing home

Commercial establishment 
$\bigcirc$ Store

Warehouse

Shop or service station

Professional or technical services office

Bank or financial institution

Hospital

Medical office or clinic

Entertainment or recreation (for example, a restaurant or bar)

Theater

Parking lot or garage

Industrial facility

Heavy industry

$\bigcirc$ Light industry

Food, drugs, or chemical factory

Metals or minerals processing

High technology factory

Construction office

\section{Agriculture}

Agricultural facility, such as a farm or ranch

Religion or nonprofit

Church, mosque, synagogue, food pantry, or other nonprofit

\section{Government}

General services, such as a government office

Emergency response, such as a police or fire station

\section{Education}

School (pre-K to 12)

College or university, other than dormitory 
Optional: upload your video to Youtube, set the privacy to "unlisted," and paste the link to the video below. (Instructions on how to upload videos are here. A new browser window or tab will open. When done, navigate back to this one.)

Assessment of the instructional materials

The instructions I read and videos I viewed helped me realize the importance of taking appropriate self-protective actions in the event of strong shaking from an earthquake. (Please mark only one answer.)

$\begin{array}{cccc}\text { Strongly Disagree } & \text { Nisagree } & \text { Neither Agree nor } & \\ & \text { Disagree } & \text { Agree } & \text { Strongly Agree }\end{array}$

The instructions I read and videos I viewed made clear to me what to do if strong shaking occurs from an earthquake in most cases. (Please mark only one answer.) Neither Agree nor
Strongly Disagree Disagree
$\bigcirc$
O
Disagree
Agree
Strongly Agree

In the event of strong shaking from an earthquake, in most situations my selfprotective actions should be: (Please mark only one answer.)

\section{Find an area outside that is clear of power lines and trees and go there}

Drop to the floor, cover my head and neck under something sturdy, and hold on to the sturdy furniture or to my head and neck.

Find an evacuation route and drive to a place of safety as directed by emergency managers.

Take cover near an exterior wall that doesn't have any windows.

The instructions I read and videos I viewed made clear to me what to do if strong 
shaking from an earthquake occurs while I am in bed. (Please mark only one answer.)
Strongly Disagree
Disagree
Neither Agree nor
O

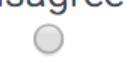
Disagree
Agree
Strongly Agree

In the event of strong shaking from an earthquake while I am in bed, my selfprotective actions should be: (Please mark only one answer.)

Find an area outside the building that is clear of power lines and trees and go there.

Drop out of bed to the floor, cover my head and neck under something sturdy, and hold on to the sturdy furniture or to my head and neck.

Stay in bed, hold on, and protect my head with a pillow.

Take cover near an exterior wall that doesn't have any windows.

The instructions I read and videos I viewed made clear to me what to do if strong shaking from an earthquake occurs while I am in a high-rise building. (Please mark only one answer.)

$\begin{array}{cccc}\text { Strongly Disagree } \quad \text { Disagree } & \text { Disagree } & \text { Agree } & \text { Strongly Agree }\end{array}$

In the event of strong shaking from an earthquake while I am in a high-rise building, my self-protective actions should be: (Please mark only one answer.)

Take the stairs to the first floor, get out of the building, and move to an area outside that is clear of power lines and trees.

Drop to the floor, cover my head and neck under something sturdy, and hold on to the sturdy furniture or to my head and neck.

Take the stairs to the first floor, get out of the building, and drive to a place of safety as directed by emergency managers.

Take cover near an exterior wall that doesn't have any windows. 
The instructions I read and videos I viewed made clear to me what to do if strong shaking from an earthquake occurs while I am outdoors. (Please mark only one answer.)
Strongly Disagree
Disagree
Neither Agree nor
Disagree
Agree
Strongly Agree

In the event of strong shaking from an earthquake while I am outdoors, my selfprotective actions should be: (Please mark only one answer.)

Find an area that is clear of power lines and trees and go there.

Find a building to go into and the drop to the floor, cover my head and neck under something sturdy, and hold on to the sturdy furniture or to my head and neck.

Find an evacuation route and drive to a place of safety as directed by emergency managers.

Stay where I am and drop to the ground, cover my head and neck, and hold onto a tree or some other sturdy object.

The instructions I read and videos I viewed made clear to me what to do if strong shaking from an earthquake occurs while I am driving. (Please mark only one answer.)
Strongly Disagree
Disagree
Neither Agree nor
O
Disagree
Agree
Strongly Agree

In the event of strong shaking from an earthquake while I am driving, my selfprotective actions should be: (Please mark only one answer.)

Find an area that is clear of power lines and trees and go there.

Pull over to the side of the road, stop, set the parking brake, and stay inside the vehicle.

Pull over to the side of the road, stop, and set the parking brake. Get out of the vehicle and drop to the ground, cover my head and neck, and hold on.

Find an evacuation route and drive to a place of safety as directed by emergency managers. 
The instructions I read and videos I viewed made clear to me what to do if strong shaking from an earthquake occurs while I am in a stadium or theater. (Please mark only one answer.)

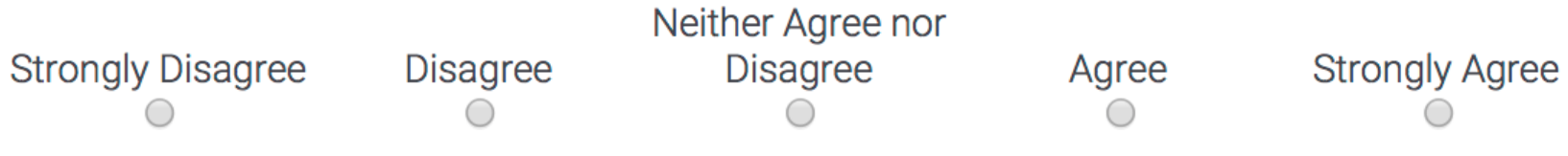

In the event of strong shaking from an earthquake while I am in a stadium or theater, my self-protective actions should be: (Please mark only one answer.)

Find an area outside that is clear of power lines and trees and go there.

Drop to the floor, cover my head and neck, and hold on to the seat or to my head and neck.

Find an evacuation route and drive to a place of safety as directed by emergency managers.

Stay in my seat and protect my head and neck with my arms.

The instructions I read and videos I viewed made clear to me what to do if an earthquake occurs while I am near the ocean shore. (Please mark only one answer.)

\begin{tabular}{|c|c|c|c|c|}
\hline Strongly Disagree & Disagree & $\begin{array}{l}\text { ither Agree nor } \\
\text { Disagree }\end{array}$ & Agree & Strongly Agree \\
\hline
\end{tabular}

In the event of strong shaking from an earthquake when I am near the ocean shore, my self-protective actions should be: (Please mark only one answer.)

Find an area that is clear of power lines and trees and go there.

Drop to the ground, cover my head and neck, and hold on to my neck and head until the shaking stops. Then evacuate to high ground.

Find an evacuation route and drive to a place of safety as directed by emergency managers.

Find a nearby building. Go inside and drop to the floor, cover my head and neck, and hold on to something sturdy. 
The instructions I read and videos I viewed made clear to me what to do if an earthquake occurs while I am downstream from a dam. (Please mark only one answer.)

Strongly Disagree

Disagree

Neither Agree nor

Disagree

Agree

Strongly Agree

In the event of strong shaking from an earthquake when I am downstream from a dam, my self-protective actions should be: (Please mark only one answer.)

Find an area outside the building that is clear of power lines and trees and go there.

Stay inside. Drop to the floor, cover my head and neck under something sturdy, and hold on to the sturdy furniture or to my head and neck.

Know the flood-zone information and proceed to evacuate the area if a warning to do so is issued.

Know of higher ground and proceed to the highest ground in the flood-zone area.

Based on the instructions I read and videos I saw, I am confident that I would take appropriate self-protective actions if strong shaking from an earthquake occurs. (Please mark only one answer.)

$\begin{array}{cccc}\text { Strongly Disagree } & \text { Disagree } & \text { Neither Agree nor } & \\ & \text { Disagree } & \text { Agree } & \text { Strongly Agree }\end{array}$

What if anything did you find particularly helpful in the written or video instructional materials?

What if anything do you believe would make the written or video instructional 
materials more helpful?

Demographic questions, to check how representative respondents are of the general population.

What year were you born?

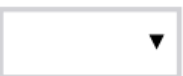

What is your gender?
Male
Female

Which of the following best describes your race or ethnicity? (Check all that apply.)
White/Caucasian
African American
Hispanic
Asian
Native American
Pacific Islander
Other

What is the highest level of education you have received?

Less than High School 
$\bigcirc$ High School / GED

Some College

2-year College Degree

4-year College Degree

Masters Degree

Doctoral Degree

$\bigcirc$ Professional Degree (JD, MD)

What is your combined household income?

under $\$ 20,000$

- 20,000-29,999

30,000-39,999

- 40,000-49,999

○ 50,000-59,999

- 60,000-69,999

○ 70,000-79,999

80,000-89,999

90,000-99,999

- $100,000-109,999$

- $110,000-119,999$

- $120,000-129,999$

- $130,000-139,999$

- $140,000-149,999$

- $150,000+$

You are done! Thank you for responding. If you have any other important comments, enter them here. Please be sure to press the "Next" button. 


\title{
Appendix 2. HayWired Mainshock Earthquake Early Warning Time Calculation
}

\author{
By Elizabeth S. Cochran, ${ }^{1}$ Anne M. Wein, ${ }^{1}$ Erin R. Burkett, ${ }^{1}$ Douglas D. Given, ${ }^{1}$ and Keith Porter ${ }^{2}$
}

We estimate the earthquake early warning (EEW) capabilities for the magnitude $(M) 7.0$ HayWired scenario mainshock based on the performance of the ShakeAlert (https:// www.shakealert.org) demonstration system during the $M 4.0$ Piedmont, California, earthquake on August 17, 2015. The Piedmont earthquake epicenter lies only 6 kilometers $(\mathrm{km})$ from the epicenter of the HayWired scenario mainshock. Therefore, it is a reasonable proxy for our purposes here, because the initial alert latency (the delay between earthquake origin time and the time at which the first alert is issued) is primarily dependent on the local station density. The latency between the earthquake initiation and the initial ShakeAlert alert time was 4.8 seconds (s) for the 2015 Piedmont earthquake. The alert latency includes (1) the time for the P-wave to reach the surface and travel to at least four seismic stations, (2) waveform data to be transmitted to the processing centers (generally $1 \mathrm{~s}$ or less for California Integrated Seismic Network, CISN, stations close to the Piedmont earthquake), and (3) computation of the magnitude and location of the earthquake. The $3 \mathrm{~km}$ difference in hypocentral depth between the Piedmont earthquake $(4.9 \mathrm{~km})$ and the HayWired scenario earthquake $(8 \mathrm{~km})$ would add approximately $0.5 \mathrm{~s}$ to the P-wave travel time to the Earth's surface - using an average speed of P-waves in California of 6 kilometers per second $(\mathrm{km} / \mathrm{s})$. Thus, we estimate that the initial alert time for the HayWired scenario mainshock would be approximately 5.3 $\mathrm{s}$ after the earthquake origin time - that is, after the rupture begins on the Hayward Fault.

For the purposes of this scenario, we make a series of simplifying assumptions. We assume the length of the waveform segments that were used for the estimation of the Piedmont earthquake magnitude are similar to those used for characterization of the HayWired scenario mainshock. For the Piedmont earthquake, the closest station is at a hypocentral distance of $6.2 \mathrm{~km}$, with a source-to-station P-wave travel time of about $1 \mathrm{~s}$. Assuming a network transmission latency of $1 \mathrm{~s}$, there was about $3 \mathrm{~s}$ of waveform available to analyze at this station before an alert was issued. In ShakeAlert, magnitude estimates can be made using waveform data from a single station. A source duration of about $3 \mathrm{~s}$ (as captured in the first $3 \mathrm{~s}$ of the $\mathrm{P}$ wave) would provide an initial magnitude estimate of at least M5.5 (for example, Meier and others, 2016). So, for the HayWired scenario mainshock, we estimate that an initial alert would be issued for a $M 5.5$ earthquake at $5.3 \mathrm{~s}$ after the earthquake origin and that the magnitude estimate would subsequently be updated as the rupture continued to grow into a $M 7.0$ earthquake.

ShakeAlert plans to distribute alerts to the public when the observed ground motions are consistent with an earthquake that is above a minimum magnitude (for example, $M>4.5$ ), and alerts will be sent to regions expected to experience ground shaking above a minimum predicted Modified Mercalli Intensity (MMI) (for example, MMI $\geq \mathrm{II})$. For the HayWired scenario, we assume that when the first alert is sent the initial estimated magnitude would be M5.5, and alerts would be issued to regions expected to experience MMI greater than or equal to II. This corresponds to a region inside of which users are expected to feel ground shaking, with or without resulting damage. Using a standard intensity relation (Atkinson and others, 2014) to calculate the initial alerting region, we find that for a M5.5 earthquake, the area that encompasses MMI II or larger ground shaking extends to approximately $250 \mathrm{~km}$.

We estimate the range of warning times for this initial alerting region from the time it takes for S-waves traveling at a velocity of $3.4 \mathrm{~km} / \mathrm{s}$ to travel distances between 0 and $250 \mathrm{~km}$, minus the alert latency time $(5.3 \mathrm{~s})$. At the time of the initial alert, issued $5.3 \mathrm{~s}$ after the earthquake origin time, S-waves would have traveled a hypocentral distance of $17 \mathrm{~km}$ (or $15 \mathrm{~km}$ epicentral distance). This circular region defined by a $15-\mathrm{km}$ radius around the epicenter defines a region of no warning for S-wave shaking. Note that we neglect the time it takes to distribute an alert to users. At epicentral distances greater than $15 \mathrm{~km}$, a user of the ShakeAlert system would receive an alert before the arrival of S-waves.

In the initial alert region, warning times range from no warning to more than $60 \mathrm{~s}$ of warning, assuming a constant S-wave velocity and no alert distribution latencies. This initial alert region encompasses the area that will eventually experience MMI III or greater shaking when the final magnitude (M7.0) is reached. Given that damage is unlikely to occur at shaking levels less than this, we do not extend this scenario through the entire rupture evolution. However, we expect that as the earthquake magnitude grows the alerting region will be also expanded in the seconds after the initial alert until the final scenario magnitude is reached. Assuming ShakeAlert algorithms correctly estimate the final earthquake magnitude of $M 7.0$, then the alerting region will extend to epicentral distances of about $575 \mathrm{~km}$. Here, we assume a point source that reflects the current capability of the ShakeAlert system, but a more realistic line source (finite rupture) EEW algorithm is currently under development for ShakeAlert and would result in a noncircular alert region.

\footnotetext{
${ }^{1}$ U.S. Geological Survey.

${ }^{2}$ University of Colorado Boulder.
} 
We note that earthquake-generated $\mathrm{P}$-waves tend to shake the ground vertically, whereas S-waves tend to shake the ground side-to-side, horizontally. P-waves tend to have smaller amplitudes than S-waves. Buildings, bridges, and other infrastructure tend to be stronger in resisting vertical motion than horizontal motion. For these reasons, the slower, later-arriving, horizontally shaking, and stronger S-waves tend to cause more damage to buildings, bridges, and other infrastructure than do the faster but weaker, vertically shaking P-waves. That is why, for EEW purposes, the warning time is typically measured between the alert time and the arrival of S-waves at a site. However, it is important to note that, particularly for sites close to the rupture, shaking from the P-wave can also be strong, and thus the time available to take action may be shorter (Meier, 2017; Minson and others, 2018). Also, warning times may be longer for cases where the shaking threshold is exceeded after S-wave arrival (Meier, 2017; Minson and others, 2018). The available warning time at a given location depends on a variety of factors, including (1) the time it takes for the rupture to grow (the final magnitudes of large earthquakes that rupture over a period of several to tens of seconds cannot be predicted in advance), (2) the magnitude and (or) shaking-intensity threshold for which an alert is generated, (3) the frequency at which alerts are updated (as the rupture evolves), (4) the time required to distribute alerts, and (5) how far the recipient of the warning is from the hypocenter (Minson and others, 2018).
Table 3 catalogs the shaking intensities and warning times that an EEW alert could provide until S-wave arrival for major cities affected by the hypothetical M7.0 HayWired rupture. Figure 4 shows the HayWired instrumental intensity map and contours of the warning time until S-wave arrival.

\section{References Cited}

Atkinson, G.M., Worden, B., and Wald, D.J., 2014, Intensity prediction equations for North America: Bulletin of the Seismological Society of America, v. 104, no. 6, p. 3084 3093, doi: 10.1785/0120140178.

Meier, M.-A., Heaton, T., and Clinton, J., 2016, Evidence for universal earthquake rupture initiation behavior: Geophysical Research Letters, v. 43, no. 15, p. 7991-7996, doi: 10.1002/2016GL070081.

Meier, M.-A., 2017, How "good" are real-time ground motion predictions from earthquake early warning systems: Journal of Geophysical Research — Solid Earth, v. 122, no. 7, p. 5561-5577, doi: 10.1002/2017JB014025.

Minson, S.E., Meier, M.-A., Baltay, A.S., Hanks, T.C., and Cochran, E.S., 2018, The limits of earthquake early warning-Timeliness of ground motion estimates: Science Advances, v. 4, no. 3, doi: 10.1126/sciadv.aaq0504.

Table 3. Estimated earthquake early warning times and shaking intensity at select locations in the San Francisco Bay region, California, for the hypothetical moment-magnitude-7.0 mainshock of the HayWired earthquake scenario.

\begin{tabular}{lllcccr}
\hline \multicolumn{1}{c}{ City } & Latitude & Longitude & $\begin{array}{c}\text { Epicentral dis- } \\
\text { tance, in miles }\end{array}$ & $\begin{array}{c}\text { Epicentral } \\
\text { distance, in } \\
\text { kilometers }\end{array}$ & $\begin{array}{c}\text { Warning time, in } \\
\text { seconds }\end{array}$ & Shaking intensity' \\
\hline Oakland & 37.80 & 122.27 & 5 & 8 & 0.0 & VIII \\
Berkeley & 37.87 & 122.27 & 7 & 11 & 0.0 & IX \\
Hayward & 37.67 & 122.08 & 11 & 17 & 0.7 & IX \\
San Francisco & 37.78 & 122.42 & 13 & 21 & 1.8 & VII \\
San Mateo & 37.55 & 122.31 & 19 & 30 & 4.3 & VII \\
Fremont & 37.55 & 122.99 & 21 & 33 & 5.2 & IX \\
Vallejo & 38.11 & 122.24 & 21 & 35 & 5.8 & VII \\
Redwood City & 37.48 & 122.24 & 23 & 36 & 6.0 & VII \\
San Rafael & 37.97 & 122.53 & 23 & 36 & 6.0 & VII \\
Livermore & 37.68 & 122.77 & 24 & 39 & 6.9 & VIII \\
San Jose & 37.34 & 121.89 & 36 & 58 & 12.4 & VIII \\
\hline
\end{tabular}

${ }^{1}$ Modified Mercalli Intensity. 
$123^{\circ}$

$122^{\circ}$

$121^{\circ}$

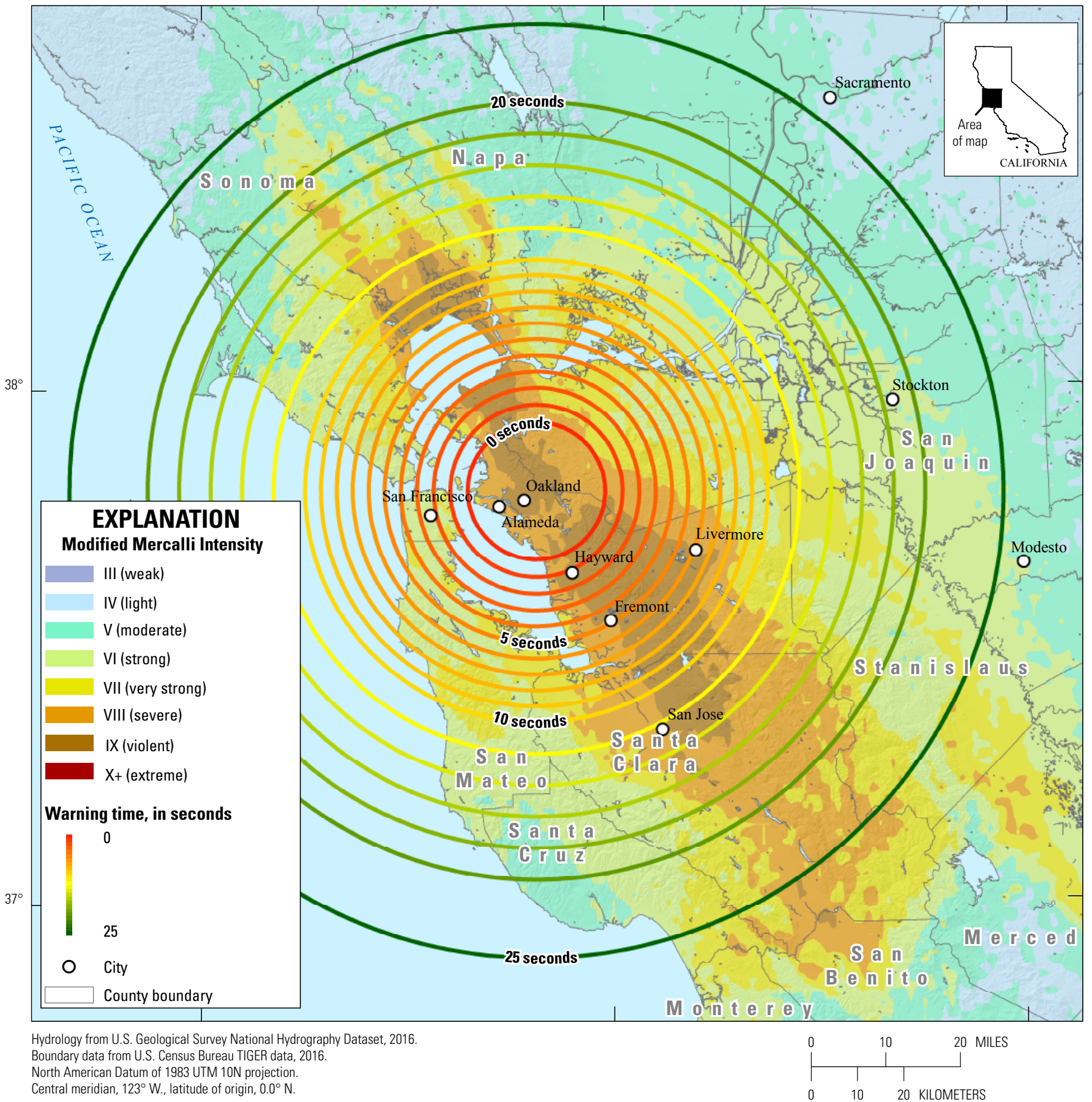

Figure 4. Map of the San Francisco Bay region, California, showing contours of estimated earthquake early warning times on a shaking intensity map (Modified Mercalli Intensity) for the hypothetical moment-magnitude-7.0 mainshock of the HayWired earthquake scenario on the Hayward Fault. For the scenario, the initial alerting region extends 250 kilometers from the earthquake epicenter, which is outside of the boundaries of the figure. Note that strong shaking can also occur at the time of the P-wave arrival, particularly close to the fault rupture, which would reduce available time for taking protective and risk-reduction actions. 

Menlo Park Publishing Service Center, California Manuscript approval date February 28, 2018

Edited by James W. Hendley II, Regan Austin, Scott Darling, Monica Erdman, Katherine Jacques, and Jessica Dyke

Design and layout by Cory Hurd and Vivian Nguyen 
옹

罗

毫

क

蛋

흥

害

含

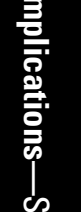

న.

爱

家

赵

릉.

향.

क

ग्ञ

7

응

G

$\frac{1}{1}$ 